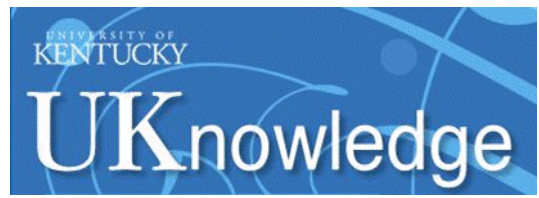

University of Kentucky UKnowledge

4-8-2019

\title{
Professional Responsibility: An Open-Source Casebook
}

Brian L. Frye

University of Kentucky, brianlfrye@uky.edu

Elizabeth Schiller

University of Richmond

Follow this and additional works at: https://uknowledge.uky.edu/lawfac_book

Part of the Legal Ethics and Professional Responsibility Commons, and the Legal Profession Commons 


\section{Professional Responsibility:}

\section{An Open-Source Casebook}

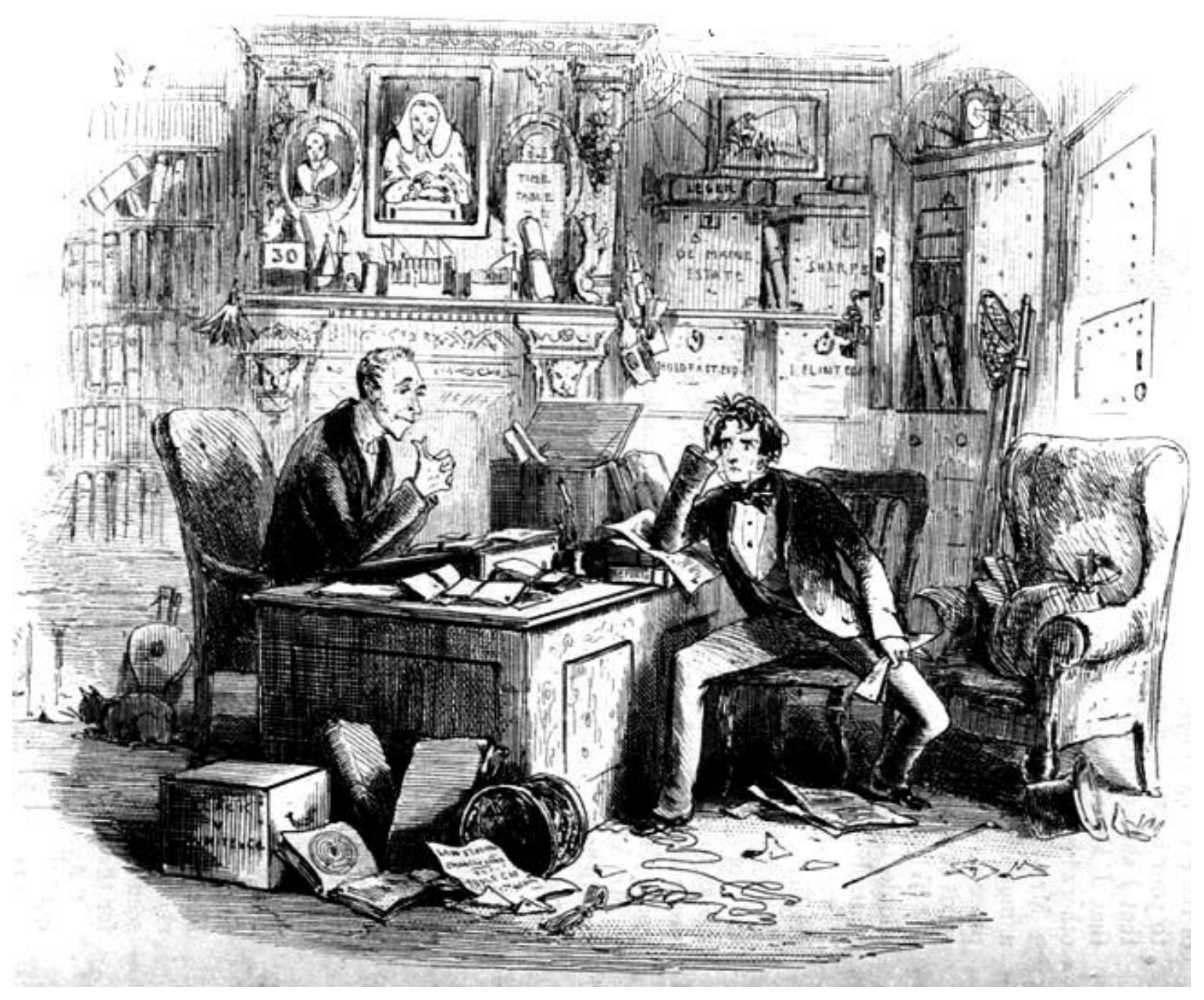

Brian L. Frye \& Elizabeth Schiller 
Cover:

Hablot Knight Brown or "Phiz"

Attorney and Client, Fortitute and Impatience (1853) 
It would be idle to assert that there is nothing of selfishness in the pursuit of a profession. But its ideal is not one of individual success in competitive acquisitive activity. And because ideals operate powerfully to shape action, professional activity, even at its worst, is restrained and guided by something better than the desire for money rewards. ${ }^{1}$

The function of the lawyer is to preserve a sceptical relativism in a society hell-bent for absolutes. The worse the society, the more law there will be. In Hell there will be nothing but law and due process will be meticulously observed. ${ }^{2}$

About half the practice of a decent lawyer consists of telling would-be clients that they are damned fools and should stop. ${ }^{3}$

We will not at present inquire whether the doctrine which is held on this subject by English lawyers be or be not agreeable to reason and morality; whether it be right that a man should, with a wig on his head, and a band round his neck, do for a guinea what, without those appendages, he would think it wicked and infamous to do for an empire; whether it be right that, not merely believing but knowing a statement to be true, he should do all that can be done by sophistry, by rhetoric, by solemn asseveration, by indignant exclamation, by gesture, by play of features, by terrifying one honest witness, by perplexing another, to cause a jury to think that statement false. ${ }^{4}$

Justice says ye? I tell ye Hogan's r-right whin he says: 'Justice is blind.' Blind she is, an' deef an' dumb an' has a wooden leg! Niver again will they dhraw me to a coort. I'll take th' rude justice iv a piece iv lead pipe without costs or th' r-right iv appeal. ${ }^{5}$

Lawyer - One who protects us against robbers by taking away the temptation. ${ }^{6}$

LAWYER, $n$. One skilled in circumvention of the law. ${ }^{7}$

The sad thing about lawyers is not that so many of them are stupid, but that so many of them are intelligent. The craft is a great devourer of good men; it sucks in and wastes almost as many as the monastic life consumed in the Middle Ages. There is something about it that is extraordinarily attractive to bright youngsters, especially in the United States. It not only offers the chance of very substantial rewards in money; it also holds out the temptation of a sort of public dignity, with political preferment thrown in for good measure. ${ }^{8}$

\footnotetext{
${ }^{1}$ Roscoe Pound, What is a Profession - the Rise of the Legal Profession in Antiquity, 19 Notre Dame L. Rev. 203 (1944).

${ }^{2}$ Grant Gilmore, The Ages of American Law 110 (1977).

${ }^{3}$ Philip C. Jessup, 1 Elihu Root 133 (1964).

${ }^{4}$ Thomas Babington Macaulay, Essay on Francis Bacon (1874).

5 Finley Peter Dunne, Mr. Dooley's Opinions 118 (1901).

${ }^{6}$ H.L. Mencken, A Mencken Chrestomathy (1949).

${ }^{7}$ Ambrose Bierce, The Cynic's Dictionary (1906).

${ }^{8}$ H.L. Mencken, Stewards of Nonsense, American Mercury 35 (Jan. 1928).
} 


\section{Preface}

Thank you for your interest in Professional Responsibility: An Open-Source Casebook. We hope that you find it useful and informative.

This is a free casebook. We believe that law students and others interested in the law should not have to pay the high prices that commercial publishers charge for casebooks. Many others agree, and have created free or low-cost casebooks covering many different areas of the law. Here are some examples:

- Barton Beebe, Trademark Law: An Open-Source Casebook

- James Boyle \& Jennifer Jenkins, Open Intellectual Property Casebook

- Stephen Clowney, James Grimmelmann, Michael Grynberg, Jeremy Sheff \& Rebecca Tushnet, Open Source Property: A Free Casebook

- James Grimmelmann, Internet Law: Cases and Problems

- James Grimmelmann, Patterns of Information Law: Intellectual Property Done Right

- Steve Semeraro, An Introduction to Property Law in the U.S.

- Jeffrey Litwak, Interstate Compact Law: Cases \& Materials

- Lydia Pallas Loren \& Joseph Scott Miller, Intellectual Property Law: Cases \& Materials

- John T. Parry, Cases and Problems in Civil Rights Litigation: State, Federal and International Perspectives

- Eric Goldman \& Rebecca Tushnet, $\underline{\text { Advertising \& Marketing Law: Cases \& Materials }}$

In addition, the Center for Computer-Assisted Legal Instruction (CALI) offers free casebooks in many different subjects, including:

- Bankruptcy Law and Practice

- Basic Income Tax

- Contract Doctrine, Theory \& Practice

- Corporate Income Tax

- The Ethics of Tax Lawyering

- First Amendment: Cases, Controversies, and Contexts

- Land Use

- The Law of Trusts

- Law of Wills

- Property

- Sales and Leases: A Problem-based Approach

- Selected Materials on the Law of Evidence

- Sources of American Law: An Introduction to Legal Research

- The Story of Contract Law

- Torts: Cases and Contexts

- U.S. Federal Income Taxation of Individuals

- Wetlands Law: A Course Source 
We noticed that there was no free and open-source casebook available for a professional responsibility class, so we decided to create one.

We wanted this casebook to be as easy to use and understand as possible. Accordingly, we included not only cases, but also the text of the rules and restatements, as well as concise explanations of the relevant law. Each chapter of the book addresses a different issue, in the following format. First, it clearly and concisely explains the relevant law governing that issue. Then provides the relevant text of any statutes, Model Rules, sections of the Restatement of the Law Governing Lawyers, or other sources, with a link to an open-source versions of the full text, when available. It provides one or more heavily edited cases intended to illustrate the application of the law at issue, with a link to an open-source version of the full text of the case. Each case is preceded by a brief summary of its facts, reasoning, and holding, and followed by questions intended to indicate subjects for further investigation or discussion. And finally, it includes citations to law review articles and other materials relevant to the law at issue, with links to open-source versions of those materials, when available.

This casebook covers a wide range of different subjects related to the professional responsibility of attorneys. While it is possible to cover all of this material in a three credit-hour course, you may wish to omit some subjects. You may also wish to supplement the materials in this casebook with additional materials. We encourage you to use this casebook in any way that you like.

This casebook is licensed "Creative Commons 0 / No Rights Reserved." That means that we explicitly disclaim any copyright claim in all of the original elements that we created in writing this casebook and have intentionally placed the casebook in the public domain. Because this casebook is in the public domain, you can use the materials in it in any way that you like, with or without attribution. Of course, the casebook contains many copyrighted elements that belong to other people and that we used pursuant to fair use. Those elements are still protected by copyright.

We hope that this free casebook helps show that it is possible to create teaching materials for legal education in an open-source format. And we hope it makes access to the law governing legal practice more accessible to law students, attorneys, and anyone interested in the regulation of the legal profession.

In closing, we would like to thank our research assistants Nicole Pottinger, Justin Cloyd, Mark Blankenship, Barrett Block, and Renee Wilson. We would also like to thank Cornelius Kearns, Brandon Magner, and Guy Hamilton-Smith for helpful comments.

\section{- Brian L. Frye \& Elizabeth Schiller}




\section{Table of Contents}

\section{Section 1: Introduction}

1.1: Introduction to Professional Responsibility

1.2: The History of the Legal Profession

Section 2: The Attorney-Client Relationship

2.1: Creating an Attorney-Client Relationship

2.2: Ending an Attorney-Client Relationship

2.3: The Attorney as Agent

2.4: The Client as Principal

2.5: Ex Parte Communications

2.6: Attorney's Fees

2.7: Financial Relationships with Clients

2.8: Organizations as Clients

2.9: Agents as Clients

Section 3: The Legal Duties of an Attorney

3.1: Fiduciary Duties

3.2: Legal Malpractice

3.3: Ineffective Assistance of Counsel

Section 4: Conflicts of Interest

4.1: Identifying Conflicts of Interest

4.2: Resolving Conflicts of Interest

4.3: Breach of the Duty of Loyalty

4.4: Current Client Conflicts of Interest

4.5: Former Client Conflicts on Interest

4.6: Associational Conflicts of Interest

4.7: Specific Conflicts of Interest

4.8: Personal Conflicts of Interest

\section{Section 5: Confidentiality}

5.1: The Duty of Confidentiality

5.2: Exceptions to the Duty of Confidentiality

5.3: The Attorney-Client Privilege

5.4: Applying the Attorney-Client Privilege

5.5: Corporate Privilege

5.6: The Work Product Doctrine

5.7: Exceptions to Privilege \& Work Product

\section{Section 6: Advocacy \& Conduct}

6.1: Frivolous Pleading

6.2: Improper Advocacy 
6.3: Attorney Misconduct

6.4: Client Perjury

6.5: Alternative Dispute Resolution

Section 7: The Regulation of the Legal Profession

7.1: Bar Admission

7.2: Advertising

7.3: Solicitation

7.4: Prosecutorial Misconduct

7.5: Judicial Recusal \& Misconduct

Section 8: Justifying the Rules of Professional Responsibility

8.1: Theories of Legal Ethics 


\section{Section 1: Introduction}

\section{1: Introduction to Professional Responsibility}

Our band could be your life. Real names'd be proof. ${ }^{9}$

Welcome to professional responsibility. Contrary to conventional wisdom among law students, this is one of the most important classes you will take in law school. It is not only the only class explicitly required by the American Bar Association ("ABA"), but also the subject of the Multistate Professional Responsibility Examination ("MPRE"), a test that the overwhelming majority of law school graduates must pass in order to become a member of their state bar association. $^{10}$

But that is the least of it. This class on professional responsibility will enable you to practice law consistent with the law governing lawyers and other professional obligations. And it will help you ensure that you are never the subject of a disciplinary action or sanction from the bar or the courts. In other words, this class could be your life, or at least your livelihood. Take it seriously, because the rules, principles, and obligations you learn about in this class will govern everything you do as an attorney.

\section{What is "Professional Responsibility"?}

Professional responsibility is the only class that the ABA explicitly requires law schools to provide in order to qualify for accreditation. Under the ABA's 2018-2019 Standards and Rules of Procedure for Approval of Law Schools, "A law school shall maintain a rigorous program of legal education that prepares its students, upon graduation, for admission to the bar and for effective, ethical, and responsible participation as members of the legal profession." Standard 301(a). Accordingly, "A law school shall establish learning outcomes that shall, at a minimum, include competency in the exercise of proper professional and ethical responsibilities to clients and the legal system, and other professional skills needed for competent and ethical participation as a member of the legal profession." Standard 302(c)\&(d). And in order to satisfy that requirement, "A law school shall offer a curriculum that requires each student to satisfactorily complete at least one course of at least two credit hours in professional responsibility that includes substantial instruction in rules of professional conduct, and the values and responsibilities of the legal profession and its members." Standard 303(a)(1).

However, law schools and law professors retain considerable discretion in how they teach professional responsibility. While the ABA accreditation standards provide that law schools must require a professional responsibility class, they do not specify what subjects the class must cover or how it should be taught. Unsurprisingly, law schools typically delegate those decisions

\footnotetext{
${ }_{9}^{9}$ Minutemen, History Lesson - Part II, Double Nickels on the Dime (1984).

${ }^{10}$ Wisconsin and Puerto Rico currently do not require the MPRE for bar membership. Connecticut and New Jersey currently accept successful completion of a law school course on professional responsibility in lieu of the MPRE.
} 
to law professors, who have adopted a wide range of different approaches. Some classes focus on the ABA's Model Rules of Professional Conduct and how courts use them to regulate attorneys. Other classes focus on the concept of legal ethics and the justification of the legal profession. And still other classes focus on how attorneys actually comply with rules of professional conduct in practice.

This casebook is designed for a class focused on the Model Rules of Professional Conduct and their practical application. Each chapter of the book addresses a different issue, in the following format. First, it clearly and concisely explains the relevant law governing that issue. Then provides the relevant text of any statutes, Model Rules, sections of the Restatement of the Law Governing Lawyers, or other sources, with a link to an open-source versions of the full text, when available. It provides one or more heavily edited cases intended to illustrate the application of the law at issue, with a link to an open-source version of the full text of the case. Each case is preceded by a brief summary of its facts, reasoning, and holding, and followed by questions intended to indicate subjects for further investigation or discussion. And finally, it includes citations to law review articles and other materials relevant to the law at issue, with links to open-source versions of those materials, when available.

\section{Legal Ethics v. The Regulation of Legal Practice}

Different lawyers think about professional responsibility in different ways, different law professors teach professional responsibility in different ways, and different legal scholars conceptualize professional responsibility in different ways. Some attorneys, professors, and scholars see professional responsibility as the practice of legal ethics. In other words, they believe that the rules of professional responsibility are expressions of ethical principles, and the legitimacy of those rules depends on the legitimacy of the ethical principles they express. But other attorneys, professors, and scholars see professional responsibility as merely the regulation of legal practice. In other words, they believe that the rules of professional responsibility are just the positive law governing attorneys.

\section{Legal Ethics}

Legal ethics can be either descriptive or normative. While both descriptive and normative legal ethics investigate the ethical values motivating the law of professional responsibility, they do so in very different ways, with fundamentally different goals. Descriptive legal ethics asks what the ethical values of law of professional responsibility are; normative legal ethics asks what they should be.

Descriptive legal ethics assumes that the statutes and rules governing the practice of law, as well as the cases interpreting and applying those statutes and rules, effectively express the ethical values of the legal profession. Accordingly, by studying the law of professional responsibility in action, one can identify the ethical values inherent in the law that motivate its articulation, interpretation, and application. 
Normative legal ethics asks whether the law of professional responsibility expresses a true moral theory. In other words, it starts with a moral theory, and asks whether the law of professional responsibility produces results consistent with that theory. Of course, different normative theories of legal ethics may adopt different moral theories. But they all assume that the purpose of the law of professional responsibility is to produce moral outcomes. Accordingly, the law of professional responsibility is justified if it expresses a true moral theory, and unjustified if it does not.

\section{The Regulation of Legal Practice}

This casebook focuses on the regulation of legal practice, not legal ethics. The primary purpose of this casebook is to help you better understand how the bar and the courts actually apply the statutes and rules governing the practice of law. While this casebook is not a study guide for the MPRE, it should help you better understand the questions on the MPRE and how to answer them correctly.

The various bar associations, often in conjunction with the courts, adopt disciplinary rules regulating legal practice. Some of those rules are mandatory, and define what attorneys must and must not do. Other rules are discretionary, and describe what attorneys may and may not do. And still other rules are aspirational, and explain what attorneys should and should not do.

When the courts consider a complaint against an attorney, they typically apply the disciplinary rules adopted by the bar association, in light of generally applicable legal principles. In other words, they ask not only whether the attorney violated the letter or spirit of the disciplinary rules, but also whether the rules at issue are valid and enforceable. However, a court may find that an attorney who has not violated the disciplinary rules has still violated some other legal duty.

Accordingly, this casebook focuses on describing the law of professional responsibility, explaining how it has been applied, and asking whether it was applied correctly. However, the law of professional responsibility differs from jurisdiction to jurisdiction. Sometimes those differences are minor, but other times they are fundamental. This casebook focuses of describing, explaining, and reflecting on the application of the most paradigmatic rules, as exemplified by the Model Rules of Professional Conduct and the Restatement of the Law Governing Lawyers.

Of course, studying an area of law inevitably provokes reflections on its purpose and justification. Even a casebook devoted to the study of the regulation of legal practice cannot avoid implicating questions of legal ethics. What values does the law of professional responsibility express? Are those values justified? What makes a rule of professional conduct justified or unjustified? What is the purpose of the law of professional responsibility? All of these ethical issues are implicit in the subject matter of this class. But they are not the subject matter of this casebook. Or at the very least, while this casebook may directly or indirectly raise those questions, it does not purport to answer them or take a position on how they should be answered. 
Model Rules of Professional Conduct: Preamble \& Scope

\section{Preamble: A Lawyer's Responsibilities}

1. A lawyer, as a member of the legal profession, is a representative of clients, an officer of the legal system and a public citizen having special responsibility for the quality of justice.

2. As a representative of clients, a lawyer performs various functions. As advisor, a lawyer provides a client with an informed understanding of the client's legal rights and obligations and explains their practical implications. As advocate, a lawyer zealously asserts the client's position under the rules of the adversary system. As negotiator, a lawyer seeks a result advantageous to the client but consistent with requirements of honest dealings with others. As an evaluator, a lawyer acts by examining a client's legal affairs and reporting about them to the client or to others.

3. In addition to these representational functions, a lawyer may serve as a third-party neutral, a nonrepresentational role helping the parties to resolve a dispute or other matter. Some of these Rules apply directly to lawyers who are or have served as thirdparty neutrals. In addition, there are Rules that apply to lawyers who are not active in the practice of law or to practicing lawyers even when they are acting in a nonprofessional capacity. For example, a lawyer who commits fraud in the conduct of a business is subject to discipline for engaging in conduct involving dishonesty, fraud, deceit or misrepresentation.

4. In all professional functions a lawyer should be competent, prompt and diligent. A lawyer should maintain communication with a client concerning the representation. A lawyer should keep in confidence information relating to representation of a client except so far as disclosure is required or permitted by the Rules of Professional Conduct or other law.

5. A lawyer's conduct should conform to the requirements of the law, both in professional service to clients and in the lawyer's business and personal affairs. A lawyer should use the law's procedures only for legitimate purposes and not to harass or intimidate others. A lawyer should demonstrate respect for the legal system and for those who serve it, including judges, other lawyers and public officials. While it is a lawyer's duty, when necessary, to challenge the rectitude of official action, it is also a lawyer's duty to uphold legal process.

6. As a public citizen, a lawyer should seek improvement of the law, access to the legal system, the administration of justice and the quality of service rendered by the legal profession. As a member of a learned profession, a lawyer should cultivate knowledge of the law beyond its use for clients, employ that knowledge in reform of the law and work to strengthen legal education. In addition, a lawyer should further the public's understanding of and confidence in the rule of law and the justice system because legal institutions in a constitutional democracy depend on popular participation and support to maintain their authority. A lawyer should be mindful of deficiencies in the administration of justice and of the fact that the poor, and sometimes persons who are not poor, cannot afford adequate legal assistance. Therefore, all lawyers should devote professional time 
and resources and use civic influence to ensure equal access to our system of justice for all those who because of economic or social barriers cannot afford or secure adequate legal counsel. A lawyer should aid the legal profession in pursuing these objectives and should help the bar regulate itself in the public interest.

7. Many of a lawyer's professional responsibilities are prescribed in the Rules of Professional Conduct, as well as substantive and procedural law. However, a lawyer is also guided by personal conscience and the approbation of professional peers. A lawyer should strive to attain the highest level of skill, to improve the law and the legal profession and to exemplify the legal profession's ideals of public service.

8. A lawyer's responsibilities as a representative of clients, an officer of the legal system and a public citizen are usually harmonious. Thus, when an opposing party is well represented, a lawyer can be a zealous advocate on behalf of a client and at the same time assume that justice is being done. So also, a lawyer can be sure that preserving client confidences ordinarily serves the public interest because people are more likely to seek legal advice, and thereby heed their legal obligations, when they know their communications will be private.

9. In the nature of law practice, however, conflicting responsibilities are encountered. Virtually all difficult ethical problems arise from conflict between a lawyer's responsibilities to clients, to the legal system and to the lawyer's own interest in remaining an ethical person while earning a satisfactory living. The Rules of Professional Conduct often prescribe terms for resolving such conflicts. Within the framework of these Rules, however, many difficult issues of professional discretion can arise. Such issues must be resolved through the exercise of sensitive professional and moral judgment guided by the basic principles underlying the Rules. These principles include the lawyer's obligation zealously to protect and pursue a client's legitimate interests, within the bounds of the law, while maintaining a professional, courteous and civil attitude toward all persons involved in the legal system.

10. The legal profession is largely self-governing. Although other professions also have been granted powers of self-government, the legal profession is unique in this respect because of the close relationship between the profession and the processes of government and law enforcement. This connection is manifested in the fact that ultimate authority over the legal profession is vested largely in the courts.

11. To the extent that lawyers meet the obligations of their professional calling, the occasion for government regulation is obviated. Self-regulation also helps maintain the legal profession's independence from government domination. An independent legal profession is an important force in preserving government under law, for abuse of legal authority is more readily challenged by a profession whose members are not dependent on government for the right to practice.

12. The legal profession's relative autonomy carries with it special responsibilities of selfgovernment. The profession has a responsibility to assure that its regulations are conceived in the public interest and not in furtherance of parochial or self-interested concerns of the bar. Every lawyer is responsible for observance of the Rules of Professional Conduct. A lawyer should also aid in securing their observance by other 
lawyers. Neglect of these responsibilities compromises the independence of the profession and the public interest which it serves.

13. Lawyers play a vital role in the preservation of society. The fulfillment of this role requires an understanding by lawyers of their relationship to our legal system. The Rules of Professional Conduct, when properly applied, serve to define that relationship.

\section{Scope}

14. The Rules of Professional Conduct are rules of reason. They should be interpreted with reference to the purposes of legal representation and of the law itself. Some of the Rules are imperatives, cast in the terms "shall" or "shall not." These define proper conduct for purposes of professional discipline. Others, generally cast in the term "may," are permissive and define areas under the Rules in which the lawyer has discretion to exercise professional judgment. No disciplinary action should be taken when the lawyer chooses not to act or acts within the bounds of such discretion. Other Rules define the nature of relationships between the lawyer and others. The Rules are thus partly obligatory and disciplinary and partly constitutive and descriptive in that they define a lawyer's professional role. Many of the Comments use the term "should." Comments do not add obligations to the Rules but provide guidance for practicing in compliance with the Rules.

15. The Rules presuppose a larger legal context shaping the lawyer's role. That context includes court rules and statutes relating to matters of licensure, laws defining specific obligations of lawyers and substantive and procedural law in general. The Comments are sometimes used to alert lawyers to their responsibilities under such other law.

16. Compliance with the Rules, as with all law in an open society, depends primarily upon understanding and voluntary compliance, secondarily upon reinforcement by peer and public opinion and finally, when necessary, upon enforcement through disciplinary proceedings. The Rules do not, however, exhaust the moral and ethical considerations that should inform a lawyer, for no worthwhile human activity can be completely defined by legal rules. The Rules simply provide a framework for the ethical practice of law.

17. Furthermore, for purposes of determining the lawyer's authority and responsibility, principles of substantive law external to these Rules determine whether a client-lawyer relationship exists. Most of the duties flowing from the client-lawyer relationship attach only after the client has requested the lawyer to render legal services and the lawyer has agreed to do so. But there are some duties, such as that of confidentiality, that attach when the lawyer agrees to consider whether a client-lawyer relationship shall be established. Whether a client-lawyer relationship exists for any specific purpose can depend on the circumstances and may be a question of fact.

18. Under various legal provisions, including constitutional, statutory and common law, the responsibilities of government lawyers may include authority concerning legal matters that ordinarily reposes in the client in private client-lawyer relationships. For example, a lawyer for a government agency may have authority on behalf of the government to decide upon settlement or whether to appeal from an adverse judgment. Such authority in various respects is generally vested in the attorney general and the state's attorney in 
state government, and their federal counterparts, and the same may be true of other government law officers. Also, lawyers under the supervision of these officers may be authorized to represent several government agencies in intragovernmental legal controversies in circumstances where a private lawyer could not represent multiple private clients. These Rules do not abrogate any such authority.

19. Failure to comply with an obligation or prohibition imposed by a Rule is a basis for invoking the disciplinary process. The Rules presuppose that disciplinary assessment of a lawyer's conduct will be made on the basis of the facts and circumstances as they existed at the time of the conduct in question and in recognition of the fact that a lawyer often has to act upon uncertain or incomplete evidence of the situation. Moreover, the Rules presuppose that whether or not discipline should be imposed for a violation, and the severity of a sanction, depend on all the circumstances, such as the willfulness and seriousness of the violation, extenuating factors and whether there have been previous violations.

20. Violation of a Rule should not itself give rise to a cause of action against a lawyer nor should it create any presumption in such a case that a legal duty has been breached. In addition, violation of a Rule does not necessarily warrant any other nondisciplinary remedy, such as disqualification of a lawyer in pending litigation. The Rules are designed to provide guidance to lawyers and to provide a structure for regulating conduct through disciplinary agencies. They are not designed to be a basis for civil liability. Furthermore, the purpose of the Rules can be subverted when they are invoked by opposing parties as procedural weapons. The fact that a Rule is a just basis for a lawyer's self-assessment, or for sanctioning a lawyer under the administration of a disciplinary authority, does not imply that an antagonist in a collateral proceeding or transaction has standing to seek enforcement of the Rule. Nevertheless, since the Rules do establish standards of conduct by lawyers, a lawyer's violation of a Rule may be evidence of breach of the applicable standard of conduct.

21. The Comment accompanying each Rule explains and illustrates the meaning and purpose of the Rule. The Preamble and this note on Scope provide general orientation. The Comments are intended as guides to interpretation, but the text of each Rule is authoritative.

\section{Questions:}

1. What are these two sections of the Model Rules intended to accomplish?

2. Does the Preamble seem to describe disciplinary rules, ethical rules, or both? What about the section on the scope of the Model Rules?

3. Does the Preamble suggest that the Model Rules provide ethical guidance for attorneys? What about the section on scope?

\section{The Duty of Zealous Representation}


The client never wants to be told he can't do what he wants to do; he wants to be told how to do it, and it is the lawyer's business to tell him how. ${ }^{11}$

If I had a million dollars, would you work for me? Well, I don't know my friend, I guess we'll have to wait and see. Would you do anything that I asked you to do? Yes, I would, if the money came through. $^{12}$

Perhaps the most fundamental duty of an attorney is the duty of "zealous representation." Attorneys must represent the interests of their clients to the best of their ability and to the extent permitted by the law. And attorneys must always advocate for their client's interests, to the exclusion of anyone else's interests, including their own. Specifically, attorneys must zealously represent their client's interests, even at their own expense.

But the duty of zealous representation can conflict with an attorney's other duties, especially an attorney's duties to the court. As members of the bar, attorneys are also officers of the court. Among other things, they owe the court a duty of candor. But sometimes an attorney's duty of zealous representation can conflict with the duty of candor. For example, the duty of zealous representation may require attorneys to avoid or minimize evidence that is detrimental to their clients. But the duty of candor may require attorneys to disclose that same evidence to the court.

Canon 7 of the ABA Model Code of Professional Responsibility (1980) stated that "a lawyer should represent a client zealously within the bounds of the law." Ethical Consideration 7-1 provided, "The duty of a lawyer, both to his client and to the legal system, is to represent his client zealously within the bounds of the law, which includes Disciplinary Rules and enforceable professional regulations." Among other things, Disciplinary Rule 7-101(A) provided, "A lawyer shall not intentionally fail to seek the lawful objectives of his client through reasonably available means permitted by law and the Disciplinary Rules."

When the ABA adopted the Model Rules of Professional Conduct in 1983, it did not use the term "zealous representation." Instead, Model Rule 1.3 provided, "A lawyer shall act with reasonable diligence and promptness in representing a client." However, Comment [1] observed:

A lawyer should pursue a matter on behalf of a client despite opposition, obstruction or personal inconvenience to the lawyer, and take whatever lawful and ethical measures are required to vindicate a client's cause or endeavor. A lawyer must also act with commitment and dedication to the interests of the client and with zeal in advocacy upon the client's behalf. A lawyer is not bound, however, to press for every advantage that might be realized for a client. For example, a lawyer may have authority to exercise professional discretion in determining the means by which a matter should be pursued.

\footnotetext{
${ }^{11}$ Robert T. Swaine, The Cravath Firm and Its Predecessors, 1819-1947, at 667 (1946) (quoting Elihu Root).

${ }^{12}$ Charles Manson, If I Had a Million Dollars, The Family Jams (1970/1997).
} 
The lawyer's duty to act with reasonable diligence does not require the use of offensive tactics or preclude the treating of all persons involved in the legal process with courtesy and respect.

Today, courts and scholars continue to refer to an attorney's "duty of zealous representation." What is the scope of that duty? What should it be? How should attorneys and courts balance the duty of zealous representation against an attorney's duties to the court and to society as a whole?

\section{Questions:}

1. After the terrorist attacks of September 11, 2001, President Bush asked the Office of Legal Counsel for its opinion on the legality of certain interrogation techniques. OLC produced several memoranda arguing that the techniques were legal under domestic and international law, which ultimately became known as the "torture memos." The torture memos were almost universally condemned by policymakers and legal scholars as both immoral and incorrect statements of the governing law. Should OLC have produced the memos? Was it a violation of the rules of professional conduct for OLC to make arguments based on inaccurate interpretations of the law. Was it a violation of legal ethics for OLC to make arguments in favor of the interrogation techniques? Would it have been a violation of legal ethics if those techniques were in fact legal? Would it have been a violation of the rules of professional conduct for OLC to produce memos presenting arguments both for and against the legality of the interrogation techniques?

Torres v. Donnelly, 554 F. 3d 322 (2d Cir. 2009)

Summary: Torres was charged with armed robbery. Anna Rodriguez, one of the victims, identified Torres when the police showed her a photo array and again when Torres's attorney Keefe showed her a photo array. In her trial testimony, Rodriguez stated that she did not identify Torres the "second time" the police showed her a photo array. Keefe realized that she was referring to the photo array he showed her, and informed the court that she had identified Torres. Torres was convicted, and filed a habeas petition, alleging ineffective assistance of counsel for failure to provide zealous representation. The court denied the petition, holding that Keefe's duty to correct false testimony did not conflict with his duty to provide zealous representation.

HALL, Circuit Judge:

Petitioner-Appellant Jesus Torres appeals from a judgment of the United States District Court for the Western District of New York denying his petition for a writ of habeas corpus. Following a jury trial, Torres was convicted of two counts of robbery in the first degree. On direct appeal, Torres raised an ineffective assistance of counsel claim. The Appellate Division dismissed his claim and unanimously affirmed his conviction. Here, Torres argues that he was denied effective assistance of counsel. 
The basis of Torres's habeas claim stems from his defense counsel's line of questioning during cross-examination of an identification witness, Anna Rodriguez, which inadvertently elicited testimony counsel personally knew to be inaccurate. Subsequently, to avoid becoming a witness himself and to comply with his ethical obligations to the court to correct false testimony, counsel agreed to stipulate that, contrary to Anna's testimony during cross-examination, Anna had identified Torres when counsel had shown her a photographic array prior to trial. Torres asserts that defense counsel Thomas Keefe's actions gave rise to an actual conflict of interest that so adversely affected his performance that it was unnecessary to demonstrate resulting prejudice. Torres also asserts that there is a reasonable possibility that, but for the errors of defense counsel, the outcome of his trial would have been different.

\section{BACKGROUND}

Torres was tried for the November 6, 1997 robberies of two grocery stores in Buffalo, New York. Torres does not contest his conviction for the first robbery of a store on Vermont Street. His habeas claim extends only to his conviction on the second robbery, which occurred on Hampshire Avenue. The robbery on Hampshire Avenue was witnessed by Olga Rodriguez, who was behind the counter, Olga's sister, Anna, and her niece, Lisalotte Rodriguez. Lisalotte was not called to testify as a trial witness.

At trial, Olga identified Torres as the robber and testified that she saw him clearly during the robbery. Olga also testified that her sister Anna had been unable to identify the defendant when shown a photo array by detectives. Defense counsel asked Olga, "In your presence, while you were in the store, did a detective with the Buffalo Police Department show a photo to your sister at any time?" Olga responded, "She did not identify. She was not paying too much attention that night of the robbery."

On cross-examination of Anna, defense counsel sought to build on Olga's testimony and elicit from Anna that she had been unable to identify the defendant in at least one photo array shown to her by police. In response to questioning from defense counsel and the trial court, Anna testified that she had identified the robber in the first photo array she was shown, but that she "couldn't identify the robber the second time around." Defense counsel then sought to determine the dates that the police had shown Anna the two photo arrays. Although Anna initially stated that the second photo array had been shown to her in January 1998, upon further questioning she indicated that it had occurred in June 1998, a fact which was clarified and confirmed by the trial court. According to Anna, she did not identify the robber when presented with this second array because she was "so nervous." When the date of the second photo array was confirmed by the court's questioning, however, Attorney Keefe realized that the photo array to which Anna was referring was the one that he had shown her in June or July 1998 as part of his preparation for trial and not one shown to her by police. He interjected and clarified to the court that he in fact had been in the store in June or July 1998 and presented a photo array to Anna. On redirect examination, Anna repeated that she did not identify Torres when Attorney Keefe 
showed her an array because she was nervous. Contrary to Anna's testimony, however, Attorney Keefe knew that Anna had identified Torres when he had shown her the photo array.

Later, in a colloquy outside the presence of the jury, the prosecutor argued that it was important to clarify to the jurors what Anna had told Attorney Keefe about the photo array. He asserted that by showing her the photo array, Keefe had essentially made himself a witness in the case. Upon questioning by the trial court, and because of Attorney Keefe's ethical obligation not to "knowingly use false evidence," Keefe ultimately informed the court that Anna had identified Torres when Keefe showed her the photo array in June or July 1998. Keefe explained that he had pursued his line of questioning under the mistaken belief that the police had shown Anna two sets of photo arrays on separate occasions.

To avoid the complications of defense counsel being called to the stand and possibly obtaining different counsel for Torres, the trial court suggested, and Attorney Keefe agreed to, the following stipulation, which the court then read to the jury:

Both parties are concerned that there may be confusion over Anna Rodriguez's testimony with regard to photo arrays. To clarify this issue over what photo array was shown to her, we, the attorneys, stipulate that on or about June or July of 1998, attorney Thomas Keefe showed her a photocopy of one of the arrays, and asked her if she could identify the robber. The witness did identify the robber as number 3.

After deliberations, the jury convicted Torres on both counts of robbery.

On direct appeal from the conviction, the Appellate Division affirmed Torres's conviction. As to counsel's cross-examination of Anna and resulting stipulation, it found that:

Defense counsel's stipulation advising the jury that a witness identified defendant in a photo array shown to her by defense counsel was not an egregious error that denied defendant effective assistance of counsel. Defense counsel reasonably believed that the witness had been shown two photo arrays by police; during cross examination the witness testified that she identified defendant in the first photo array but not in the second photo array. During the course of the witness's testimony, defense counsel realized the "second" photo array to which the witness referred was the photo array that he had shown the witness, and therefore the testimony of the witness that she did not identify defendant in that photo array was not true. Defense counsel could not "knowingly use false evidence" and thus was required to report the incorrect testimony to the court. Defense counsel's alternative to the stipulation was to testify as a witness, which would have required new counsel for defendant.

\section{DISCUSSION}

To establish that counsel's performance was constitutionally defective, a defendant must show that 'the lawyer's performance 'fell below an objective standard of reasonableness' and that 
'there is a reasonable probability that, but for counsel's unprofessional errors, the result of the proceedings would have been different."' Even if counsel's performance is found professionally unreasonable, "any deficiencies in counsel's performance must be prejudicial to the defense in order to constitute ineffective assistance under the Constitution." Therefore, the question becomes "whether there is a reasonable probability that, absent the errors, the factfinder would have had a reasonable doubt respecting guilt." In certain circumstances, however, prejudice may be presumed, and an individual inquiry regarding this factor is unnecessary. Similarly, the Supreme Court has recognized that when a criminal defendant claims that defense counsel was "burdened by an actual conflict of interest," this warrants a "limited presumption of prejudice." In these instances, the presumption of prejudice attaches "only if the defendant demonstrates that counsel 'actively represented conflicting interests' and that 'an actual conflict of interest adversely affected his lawyer's performance."'

Torres argues that the limited presumption is applicable to his case such that he is not required to demonstrate he was prejudiced by his counsel's performance. We disagree. Although Keefe had parallel duties to zealously represent his client and not to use false evidence, this did not create an actual conflict of interest. Though the presumption has been "unblinkingly" applied to "all kinds of alleged attorney ethical conflicts," it does not support this expansive application. The presumption was created to account for the "high probability of prejudice arising from multiple concurrent representation, and the difficulty of proving that prejudice." However, "not all attorney conflicts present comparable difficulties. Here, defense counsel's ethical obligation to correct the testimony he knew to be inaccurate does not present the difficulties and high probability of prejudice engendered by joint representation. At most, in this case defense counsel's earnest representation of his client was constrained by ethical guidelines applicable to every attorney appearing as trial counsel, to wit, that "in the representation of a client, a lawyer shall not knowingly use perjured or false evidence."

Accordingly, we hold that the tension between Keefe's parallel duties of (1) zealous representation and (2) candor to the court, which gives rise to his obligation to correct the record, did not create a conflict of interest of the sort identified in Sullivan. This holding "is consistent with the governance of trial conduct in what we have long called 'a search for truth."' Indeed, "an attorney's ethical duty to advance the interests of his client is limited by an equally solemn duty to comply with the law and standards of professional conduct; it specifically ensures that the client may not use false evidence."

We further find no actual conflict of interest inherent in counsel's decision to enter into the stipulation to correct the record. It is clear that several methods, such as calling as a witness the interpreter who was present when Attorney Keefe showed Anna the photo array, were available to accomplish this necessary task. Each of them, in order to correct the misstatement, would have yielded the same result.

\section{Questions:}


1. Could Keefe have relied on Rodriguez's testimony without violating his duty of candor to the court? What if the prosecutor did not notice the mistake? Would Keefe have a duty to disclose? Would it be a violation of the Model Rules if he did not disclose?

2. What are Keefe's ethical obligations under the circumstances? How should he balance his duty to Torres against his duty to the court?

\section{Further Reading:}

- David Luban \& W. Bradley Wendel, Philosophical Legal Ethics: An Affectionate History, 30 Geo. J.L. Ethics (2017).

- Robert W. Gordon, The Independence of Lawyers, 68 B.U. L. Rev. 1 (1988).

- Richard Wasserstrom, Lawyers as Professionals: Some Moral Issues, 5 Human Rights 1 (1975).

- William H. Simon, The Ideology of Advocacy: Procedural Justice and Professional Ethics, 1978 Wis. L. Rev. 29 (1978).

- Gerald J. Postema, Moral Responsibility in Professional Ethics, 55 N.Y.U. L. Rev. 63 (1980).

- Deborah L. Rhode, Ethical Perspectives on Legal Practice, 37 Stan. L. Rev. 589 (1985).

- Thomas L. Shaffer, On Being a Christian and a Lawyer: Law for the Innocent (1981).

- Charles Fried, The Lawyer as Friend: The Moral Foundations of the Lawyer-Client Relation, 85 Yale L.J. 1060 (1976).

- Monroe H. Freedman, Professional Responsibility of the Criminal Defense Lawyer: The Three Hardest Questions, 64 Mich. L. Rev. 1469 (1966).

- Judith Andre, Role Morality as a Complex Instance of Ordinary Morality, 28 Am. Phil. Q. 73 (1991).

- Monroe H. Freedman, A Critique of Philosophizing About Lawyers' Ethics, 25 Geo. J. Legal Ethics 91 (2012).

- Alice Woolley, The Lawyer as Advisor and the Practice of the Rule of Law, 47 UBC L. Rev. 743 (2014).

- Rebecca Roiphe, The Decline of Professionalism, 29 Geo. J. Legal Ethics 649 (2016). 


\section{2: A Brief History of the American Legal Profession}

\section{The Profession before the 1908 Ethics Rules}

The American legal profession was significantly unregulated for most of the eighteenth and nineteenth centuries. In fact, applying contemporary definitions in which a profession is selfregulating, it is not clear lawyers' work during this time was part of a unified legal profession at all. That's not to say lawyers did not play an important role in American society. Lawyers fulfilled not just one, but two equally important roles: as advocates for their clients and agents of the court. Before the organized American legal profession with formal rules, this dual-role model of lawyering shaped how lawyers thought about their professional responsibilities and standards for their conduct.

Many lawyers' everyday work primarily concerned advocating for the private interests of clients. Eighteenth and nineteenth century clients sought out lawyers for many of the same reasons people obtain lawyers today, including settling disputes over personal property, navigating commercial matters, and resolving all sorts of other conflicts between people. Although some of the events leading people to seek lawyer's assistance may seem familiar, the social, economic, and political conditions of the nineteenth century meant even this familiar role was anything but routine.

The time period between the American Revolution and the twentieth century was full of dramatic changes in the law, the work of lawyering, and the legal profession. The law itself became more voluminous and complex, beginning with post-Revolution efforts to create orderly state and federal governments. Industrialization sped up and increased the scope of economic of

\section{Lawrence Friedman's A History of American Law summarizes:}

What happened to American law in the nineteenth century, basically, was that it changed dramatically, fundamentally, to conform to the needs, wants, and pressures coming from the vast increase in the numbers of consumers of law. It is dangerous to sum up long periods and great movements in a sentence. But if colonial law had been, in the first place, colonial, and in the second place, paternal, emphasizing community, order, and the struggle against sin, then, gradually, a new set of attitudes developed, in which the primary function of law was not suppression and uniformity, but economic growth and services to its users.

Instrumentalist theories about law combined with a rapidly changing industrial society contributed to the idea that practicing judges, lawyers, and scholars could actively shape the world they worked in. Often this was in response to their work for the private interests of clients, although records of conversations among lawyers show continued concern for and attention to their public responsibilities as well.

\section{Question:}


- Is the dual-role model of lawyers' responsibilities useful for navigating professional ethical dilemmas? Based on what you know about lawyers' work, try to think of at least one scenario in which it would be helpful and one in which it might not be.

\section{American Bar Association's Ethics Rules}

The American Bar Association, founded in 1878, advanced its first attempt at a uniform standard of conduct for lawyers in 1908. The Canons of Professional Ethics were intended to be a general guide for lawyers, based on existing professional norms expressed in legal ethics scholarship and some state bar association literature. The ABA acknowledged the idealistic nature of the Canons, and did not intend for them to be enforceable. For an overview of the Canons, see the Preamble and the list of Canons, below, from the Final Committee Report on 1908 ABA Ethics Rules.

\section{Canons of Ethics}

\section{Preamble}

In America, where the stability of Courts and of all departments of government rests upon the approval of the people, it is peculiarly essential that the system for establishing and dispensing justice be developed to a high point of efficiency and so maintained that the public shall have absolute confidence in the integrity and impartiality of its administration. The future of the republic, to a great extent, depends upon our maintenance of justice pure and unsullied. It cannot be so maintained unless the conduct and the motives of the members of our profession are such as to merit the approval of all just men.

\section{The Canons of Ethics}

No code or set of rules can be framed, which will particularize all the duties of the lawyer in the varying phases of litigation or in all the relations of professional life. The following canons of ethics are adopted by the American Bar Association as a general guide, yet the enumeration of particular duties should not be construed as a denial of the existence of others equally imperative, though not specifically mentioned:

1. The Duty of the Lawyer to the Courts.

2. The Selection of Judges

3. Attempts to Exert Personal Influence on the Courts

4. When Counsel for an Indigent Prisoner.

5. The Defense or Prosecution of Those Accused of Crime.

6. Adverse Influences and Conflicting Interests.

7. Professional Colleagues and Conflicts of Opinion.

8. Advising Upon the Merits of a Client's Cause.

9. Negotiations with Opposite Party.

10. Acquiring Interest in Litigation.

11. Dealing with Trust Property.

12. Fixing the Amount of the Fee. 
13. Contingent Fees.

14. Suing a Client for a Fee.

15. How Far a Lawyer May Go in Supporting a Client's Cause.

16. Restraining Clients from Improprieties.

17. III Feeling and Personalities Between Advocates.

18. Treatment of Witnesses and Litigants.

19. Appearance of Lawyer as Witness for His Client.

20. Newspaper Discussion of Pending Litigation.

21. Punctuality and Expedition.

22. Candor and Fairness.

23. Attitude Toward Jury.

24. Right of Lawyers to Control the Incidents of the Trial.

25. Taking Technical Advantage of Opposite Counsel; Agreements with Him.

26. Professional Advocacy Other Than Before Courts.

27. Advertising, Direct or Indirect.

28. Stirring Up Litigation, Directly or Through Agents.

29. Upholding the Honor of the Profession.

30. Justifiable and Unjustifiable Litigations.

31. Responsibility for Litigation.

32. The Lawyer's Duty in Its Last Analysis.

\section{Questions:}

- Do you see evidence of dual-role model of lawyers' responsibilities in the Canons? Where?

- What does the adoption of the Canons tell us about the state of the profession in 1908 ?

Although the Canons were general statements of profession norms, they included some explanatory content. For example, see Canons 4, 17, and 29.

Canon 4 - When Counsel for an Indigent Prisoner. A lawyer assigned as counsel for an indigent prisoner ought not to ask to be excused for any trivial reason, and should always exert his best efforts in his behalf.

Canon 17- III Feeling and Personalities Between Advocates. Clients, not lawyers, are the litigants. Whatever may be the ill feeling existing between clients, it should not be allowed to influence counsel in their conduct and demeanor toward each other or toward suitors in the case. All personalities between counsel should be scrupulously avoided. In the trial of a cause it is indecent to allude to the personal history or the personal peculiarities and idiosyncrasies of counsel on the other side. Personal colloquies between counsel which cause delay and promote unseemly wrangling should also be carefully avoided.

Canon 29 - Upholding the Honor of the Profession. Lawyers should expose without fear or favor before the proper tribunals corrupt or dishonest conduct in the profession, and should accept 
without hesitation employment against a member of the Bar who has wronged his client. The counsel upon the trial of a cause in which perjury has been committed owe it to the profession and citing authorities. The lawyer should aid in guarding the Bar against admission to the profession of candidates unfit or unqualified because deficient in either moral character or education. He should strive at all times to uphold the honor and to maintain the dignity of the profession and to improve not only the law but the administration of justice.

\section{Questions:}

- Are the Canons useful for navigating professional ethical dilemmas?

- How helpful is the explanatory content? Does it answer all your questions about how to apply the Canons? Can you think of a situation in which lawyers might reasonably disagree about what conforming professional conduct might look like?

The ABA Canons of Professional Ethics were an important step towards professionalizing lawyers' work. While no longer in force, the Canons guided lawyers' professional standards for a sixty year period in which the modern profession emerged. Judicial opinions and state bars often referred to the text of and principles in the Canons. Attempts to apply the Canons revealed some challenges with moving from generalized principles to enforceable boundaries, prompting the ABA to work towards the Model Code of Professional Responsibility.

\section{Model Code of Professional Responsibility}

The ABA House of Delegates approved the Model Code of Professional Responsibility, a comprehensively revised set of rules, on August 12,1969 . The Model Code marked a significant shift from the Canons in its organization and scope. Where the Canons were idealistic and relied on external judgments to clarify conflicting priorities and refine broad goals, the Model Code contained three distinct but interrelated parts: canons, ethical considerations, and disciplinary rules. The canons stated the general rules which led to the ethical considerations and disciplinary rules. The ethical considerations were the aspirational principles. The disciplinary rules were mandatory statements about the minimum standards of conduct lawyers must adhere to in order to not face disciplinary action. Each canon might contain a dozen (or more!) ethical considerations and disciplinary rules.

For Example, explanatory content for Canon 6 includes six ethical considerations and two disciplinary rules.

CANON 6: A Lawyer Should Represent a Client Competently

\section{ETHICAL CONSIDERATIONS}

\section{EC 6-1}

Because of his vital role in the legal process, a lawyer should act with competence and proper care in representing clients. He should strive to become and remain proficient in his practice and should accept employment only in matters which he is or intends to become competent to handle. 
EC 6-2

A lawyer is aided in attaining and maintaining his competence by keeping abreast of current legal literature and developments, participating in continuing legal education programs, concentrating in particular areas of the law, and by utilizing other available means. He has the additional ethical obligation to assist in improving the legal profession, and he may do so by participating in bar activities intended to advance the quality and standards of members of the profession. Of particular importance is the careful training of his younger associates and the giving of sound guidance to all lawyers who consult him. In short, a lawyer should strive at all levels to aid the legal profession in advancing the highest possible standards of integrity and competence and to meet those standards himself.

\section{EC 6-3}

While the licensing of a lawyer is evidence that he has met the standards then prevailing for admission to the bar, a lawyer generally should not accept employment in any area of the law in which he is not qualified. However, he may accept such employment if in good faith he expects to become qualified through study and investigation, as long as such preparation would not result in unreasonable delay or expense to his client. Proper preparation and representation may require the association by the lawyer of professionals in other disciplines. A lawyer offered employment in a matter in which he is not and does not expect to become so qualified should either decline the employment or, with the consent of his client, accept the employment and associate a lawyer who is competent in the matter.

\section{EC 6-4}

Having undertaken representation, a lawyer should use proper care to safeguard the Interests of his client. If a lawyer has accepted employment in a matter beyond his competence but in which he expected to become competent, he should diligently undertake the work and study necessary to qualify himself. In addition to being qualified to handle a particular matter, his obligation to his client requires him to prepare adequately for and give appropriate attention to his legal work.

\section{EC 6-5}

A lawyer should have pride in his professional endeavors. His obligation to act competently calls for higher motivation than that arising from fear of civil liability or disciplinary penalty.

\section{EC 6-6}

A lawyer should not seek, by contract or other means, to limit his individual liability to his client for his malpractice. A lawyer who handles the affairs of his client properly has no need to attempt to limit his liability for his professional activities and one who does not handle the affairs of his client properly should not be permitted to do so. A lawyer who is a stockholder in or is associated with a professional legal corporation may, however, limit his liability for malpractice of his associates in the corporation, but only to the extent permitted by law. 
DR 6-101-Failing to Act Competently.

A. A lawyer shall not:

1. Handle a legal matter which he knows or should know that he is not competent to handle, without associating with him a lawyer who is competent to handle it.

2. Handle a legal matter without preparation adequate in the circumstances.

3. Neglect a legal matter entrusted to him.

DR 6-102-Limiting Liability to Client.

A. A lawyer shall not attempt to exonerate himself from or limit his liability to his client for his personal malpractice.

\section{Questions:}

- How useful is the Model Code for making decisions about professional conduct? Is the clarification between canons, ethical considerations, and disciplinary rules an improvement on the 1908 Canons?

- Is it necessary to have canons, ethical considerations, and disciplinary rules? Consider each statement's or rule's usefulness in lawyers' various roles and practice settings.

The Model Code, in various forms and versions, was the ABA's central document on professional responsibility from 1970 through 1981. While no longer in use, it's important to know about the Model Code. Many important cases decided during this time and some states' rules still contain references to and evidence of the influence of the Model Code.

\section{Model Rules of Professional Conduct}

The shift from idealistic Canons to boundary rules in the Model Code created the need for specificity the Model Code did not always address. To deal with this challenge, the ABA tasked a lawyer named Robert Kutak with chairing a commission to study the problem. The Kutak Commission focused on developing the minimum standards of conduct for lawyers into a series of black-letter rules. The resulting Model Rules, adopted in 1983, are the basis of the current Model Rules of Professional Conduct. The Model Rules have a regulatory structure, with a statement of minimum conduct and explanatory comments. The official comments are similar to other regulatory comments, in that they might content information about the reasoning behind a rule or examples to guide application. Like other model rules, the Model Rules of Professional Conduct are not themselves binding. They are designed to be examples a state may choose to adopt into law. For an example from the Model Rules, see the Rule 1:1 on Competence, below.

\section{Rule 1.1: Competence}

A lawyer shall provide competent representation to a client. Competent representation requires the legal knowledge, skill, thoroughness and preparation reasonably necessary for the representation. 
Comment:

Legal Knowledge and Skill

[1] In determining whether a lawyer employs the requisite knowledge and skill in a particular matter, relevant factors include the relative complexity and specialized nature of the matter, the lawyer's general experience, the lawyer's training and experience in the field in question, the preparation and study the lawyer is able to give the matter and whether it is feasible to refer the matter to, or associate or consult with, a lawyer of established competence in the field in question. In many instances, the required proficiency is that of a general practitioner. Expertise in a particular field of law may be required in some circumstances.

[2] A lawyer need not necessarily have special training or prior experience to handle legal problems of a type with which the lawyer is unfamiliar. A newly admitted lawyer can be as competent as a practitioner with long experience. Some important legal skills, such as the analysis of precedent, the evaluation of evidence and legal drafting, are required in all legal problems. Perhaps the most fundamental legal skill consists of determining what kind of legal problems a situation may involve, a skill that necessarily transcends any particular specialized knowledge. A lawyer can provide adequate representation in a wholly novel field through necessary study. Competent representation can also be provided through the association of a lawyer of established competence in the field in question.

[3] In an emergency a lawyer may give advice or assistance in a matter in which the lawyer does not have the skill ordinarily required where referral to or consultation or association with another lawyer would be impractical. Even in an emergency, however, assistance should be limited to that reasonably necessary in the circumstances, for illconsidered action under emergency conditions can jeopardize the client's interest.

[4] A lawyer may accept representation where the requisite level of competence can be achieved by reasonable preparation. This applies as well to a lawyer who is appointed as counsel for an unrepresented person. See also Rule 6.2.

Thoroughness and Preparation

[5] Competent handling of a particular matter includes inquiry into and analysis of the factual and legal elements of the problem, and use of methods and procedures meeting the standards of competent practitioners. It also includes adequate preparation. The required attention and preparation are determined in part by what is at stake; major litigation and complex transactions ordinarily require more extensive treatment than matters of lesser complexity and consequence. An agreement between the lawyer and 
the client regarding the scope of the representation may limit the matters for which the lawyer is responsible. See Rule 1.2(c).

Retaining or Contracting With Other Lawyers

[6] Before a lawyer retains or contracts with other lawyers outside the lawyer's own firm to provide or assist in the provision of legal services to a client, the lawyer should ordinarily obtain informed consent from the client and must reasonably believe that the other lawyers' services will contribute to the competent and ethical representation of the client. See also Rules 1.2 (allocation of authority), 1.4 (communication with client), 1.5(e) (fee sharing), 1.6 (confidentiality), and 5.5(a) (unauthorized practice of law). The reasonableness of the decision to retain or contract with other lawyers outside the lawyer's own firm will depend upon the circumstances, including the education, experience and reputation of the nonfirm lawyers; the nature of the services assigned to the nonfirm lawyers; and the legal protections, professional conduct rules, and ethical environments of the jurisdictions in which the services will be performed, particularly relating to confidential information.

[7] When lawyers from more than one law firm are providing legal services to the client on a particular matter, the lawyers ordinarily should consult with each other and the client about the scope of their respective representations and the allocation of responsibility among them. See Rule 1.2. When making allocations of responsibility in a matter pending before a tribunal, lawyers and parties may have additional obligations that are a matter of law beyond the scope of these Rules.

\section{Maintaining Competence}

[8] To maintain the requisite knowledge and skill, a lawyer should keep abreast of changes in the law and its practice, including the benefits and risks associated with relevant technology, engage in continuing study and education and comply with all continuing legal education requirements to which the lawyer is subject.

\section{Adoption of the Model Rules}

States adopted the structure of the model rules fairly quickly. Today, almost all states' disciplinary rules follow the numbering system of the Model Rules. The content of state rules varies, so it's important to follow the law of your jurisdiction. Since the Model Rules of Professional Conduct have been so influential, lawyers can look to these Model Rules just like they might look to other uniform laws or model acts.

\section{Questions:}


- In Rule 1.1 above, do the comments change your understanding of the rule? How? Do you have remaining questions about what the rule means or how it might work in application?

- Compare the usefulness of the Model Rules to the Model Code and the Canons. Consider the regulatory structure of the Model Rules, the distinction between ideals and boundaries, and the content in the examples above. 


\section{Section 2: The Attorney-Client Relationship}

\section{1: Creating an Attorney-Client Relationship}

The rest of life pales in significance, I'm looking for somebody with whom to dance. With whom to dance? With whom to dance? I'm looking for somebody with whom to dance. ${ }^{13}$

\section{Clients \& "Quasi-Clients"}

Ideally, the formation of an attorney-client relationship involves formalities like an engagement letter, a retainer agreement, and the payment of attorney's fees. But none of those formalities are necessary. An attorney-client relationship may be formed whenever a person asks an attorney for legal advice and the attorney provides it, so long as a reasonable person could believe that an attorney-client relationship existed.

I will refer to people an attorney intends to represent as "clients," and people an attorney does not intend to represent as "quasi-clients." An attorney has an "express attorney-client relationship" with clients and an "implied attorney-client relationship" with quasi-clients. But express and implied attorney-client relationships impose many of the same duties on an attorney.

\section{Restatement (Third) of the Law Governing Lawyers § 14 (2000)}

A relationship of client and lawyer arises when:

1. a person manifests to a lawyer the person's intent that the lawyer provide legal services for the person; and either

a. the lawyer manifests to the person consent to do so; or

b. the lawyer fails to manifest lack of consent to do so, and the lawyer knows or reasonably should know that the person reasonably relies on the lawyer to provide the services; or

2. a tribunal with power to do so appoints the lawyer to provide the services.

\section{The Duties of an Attorney}

Attorneys owe certain legal duties to their clients and quasi-clients, whether they have an express attorney-client relationship or an implied attorney-client relationship. Those duties are reflected in the Model Rules of Professional Conduct.

- Duty of Care: Attorneys have a duty to act with due diligence in pursuit of their client's interests. Model Rule 1.1.

${ }^{13}$ Stephin Merritt, The Magnetic Fields, With Whom to Dance?, Get Lost (1995). 
- Duty of Loyalty: Attorneys may not represent any party with an interest adverse to any of their clients, and must refrain from self-dealing. Model Rules $1.7 \& 1.8$.

- Duty of Impartiality: Attorneys must provide their clients with all of the information their clients need in order to make informed decisions. Model Rule 1.4. Attorneys must also "exercise independent professional judgment and render candid advice." Model Rule 2.1.

- Duty of Confidentiality: Attorneys must maintain in confidence all information obtained while representing their clients, and may not use any confidential client information in a way that could harm that client. Model Rule 1.6.

Togstad v. Vesely, Otto, Miller \& Keefe, 291 N.W.2d 686 (Minn. 1980)

Summary: John Togstad was paralyzed after surgery. His wife Joan Togstad met with attorney Jere Miller and asked him whether they had a viable medical malpractice action. Miller stated that he did not think his firm was interested, but he would consult with his partners. He did not charge Togstad or agree to represent her. He also did not inform her that he lacked experience in the area, encourage her to consult with another attorney, or warn her about the statute of limitations on medical malpractice actions. After the statute of limitations expired, the Togstads filed a legal malpractice action. The jury found that an attorney-client relationship existed and that Miller was negligent, and awarded damages to the Togstads. The Minnesota Supreme Court affirmed, holding that an attorney-client relationship existed because Miller provided legal advice and his advice was negligent.

This is an appeal by the defendants from a judgment of the Hennepin County District Court involving an action for legal malpractice. The jury found that the defendant attorney Jerre Miller was negligent and that, as a direct result of such negligence, plaintiff John Togstad sustained damages in the amount of $\$ 610,500$ and his wife, plaintiff Joan Togstad, in the amount of $\$ 39,000$. Defendants (Miller and his law firm) appeal to this court from the denial of their motion for judgment notwithstanding the verdict or, alternatively, for a new trial. We affirm.

In August 1971, John Togstad began to experience severe headaches and on August 16, 1971, was admitted to Methodist Hospital where tests disclosed that the headaches were caused by a large aneurysm on the left internal carotid artery. The attending physician, Dr. Paul Blake, a neurological surgeon, treated the problem by applying a Selverstone clamp to the left common carotid artery. The clamp was surgically implanted on August 27, 1971, in Togstad's neck to allow the gradual closure of the artery over a period of days.

The treatment was designed to eventually cut off the blood supply through the artery and thus relieve the pressure on the aneurism, allowing the aneurism to heal. It was anticipated that other arteries, as well as the brain's collateral or cross-arterial system would supply the required blood to the portion of the brain which would ordinarily have been provided by the left carotid artery. The greatest risk associated with this procedure is that the patient may become paralyzed if the brain does not receive an adequate flow of blood. In the event the supply of blood becomes so 
low as to endanger the health of the patient, the adjustable clamp can be opened to establish the proper blood circulation.

In the early morning hours of August 29, 1971, a nurse observed that Togstad was unable to speak or move. At the time, the clamp was one-half (50\%) closed. Upon discovering Togstad's condition, the nurse called a resident physician, who did not adjust the clamp. Dr. Blake was also immediately informed of Togstad's condition and arrived about an hour later, at which time he opened the clamp. Togstad is now severely paralyzed in his right arm and leg, and is unable to speak.

Plaintiffs' expert, Dr. Ward Woods, testified that Togstad's paralysis and loss of speech was due to a lack of blood supply to his brain. Dr. Woods stated that the inadequate blood flow resulted from the clamp being $50 \%$ closed and that the negligence of Dr. Blake and the hospital precluded the clamp's being opened in time to avoid permanent brain damage. Specifically, Dr. Woods claimed that Dr. Blake and the hospital were negligent for (1) failing to place the patient in the intensive care unit or to have a special nurse conduct certain neurological tests every half-hour; (2) failing to write adequate orders; (3) failing to open the clamp immediately upon discovering that the patient was unable to speak; and (4) the absence of personnel capable of opening the clamp.

Dr. Blake and defendants' expert witness, Dr. Shelly Chou, testified that Togstad's condition was caused by blood clots going up the carotid artery to the brain. They both alleged that the blood clots were not a result of the Selverstone clamp procedure. In addition, they stated that the clamp must be about $90 \%$ closed before there will be a slowing of the blood supply through the carotid artery to the brain. Thus, according to Drs. Blake and Chou, when the clamp is $50 \%$ closed there is no effect on the blood flow to the brain.

About 14 months after her husband's hospitalization began, plaintiff Joan Togstad met with attorney Jerre Miller regarding her husband's condition. Neither she nor her husband was personally acquainted with Miller or his law firm prior to that time. John Togstad's former work supervisor, Ted Bucholz, made the appointment and accompanied Mrs. Togstad to Miller's office. Bucholz was present when Mrs. Togstad and Miller discussed the case.

Mrs. Togstad had become suspicious of the circumstances surrounding her husband's tragic condition due to the conduct and statements of the hospital nurses shortly after the paralysis occurred. One nurse told Mrs. Togstad that she had checked Mr. Togstad at 2 a. m. and he was fine; that when she returned at 3 a. m., by mistake, to give him someone else's medication, he was unable to move or speak; and that if she hadn't accidentally entered the room no one would have discovered his condition until morning. Mrs. Togstad also noticed that the other nurses were upset and crying, and that Mr. Togstad's condition was a topic of conversation.

Mrs. Togstad testified that she told Miller "everything that happened at the hospital," including the nurses' statements and conduct which had raised a question in her mind. She stated that she "believed" she had told Miller "about the procedure and what was undertaken, what was 
done, and what happened." She brought no records with her. Miller took notes and asked questions during the meeting, which lasted 45 minutes to an hour. At its conclusion, according to Mrs. Togstad, Miller said that "he did not think we had a legal case, however, he was going to discuss this with his partner." She understood that if Miller changed his mind after talking to his partner, he would call her. Mrs. Togstad "gave it" a few days and, since she did not hear from Miller, decided "that they had come to the conclusion that there wasn't a case." No fee arrangements were discussed, no medical authorizations were requested, nor was Mrs. Togstad billed for the interview.

Mrs. Togstad denied that Miller had told her his firm did not have expertise in the medical malpractice field, urged her to see another attorney, or related to her that the statute of limitations for medical malpractice actions was two years. She did not consult another attorney until one year after she talked to Miller. Mrs. Togstad indicated that she did not confer with another attorney earlier because of her reliance on Miller's "legal advice" that they "did not have a case."

On cross-examination, Mrs. Togstad was asked whether she went to Miller's office "to see if he would take the case of her husband." She replied, "Well, I guess it was to go for legal advice, what to do, where shall we go from here? That is what we went for." Again in response to defense counsel's questions, Mrs. Togstad testified as follows:

Q And it was clear to you, was it not, that what was taking place was a preliminary discussion between a prospective client and lawyer as to whether or not they wanted to enter into an attorney-client relationship?

A I am not sure how to answer that. It was for legal advice as to what to do.

$\mathrm{Q}$ And Mr. Miller was discussing with you your problem and indicating whether he, as a lawyer, wished to take the case, isn't that true?

A Yes.

On re-direct examination, Mrs. Togstad acknowledged that when she left Miller's office she understood that she had been given a "qualified, quality legal opinion that she and her husband did not have a malpractice case."

Miller's testimony was different in some respects from that of Mrs. Togstad. Like Mrs. Togstad, Miller testified that Mr. Bucholz arranged and was present at the meeting, which lasted about 45 minutes. According to Miller, Mrs. Togstad described the hospital incident, including the conduct of the nurses. He asked her questions, to which she responded. Miller testified that "the only thing I told her after we had pretty much finished the conversation was that there was nothing related in her factual circumstances that told me that she had a case that our firm would be interested in undertaking."

Miller also claimed he related to Mrs. Togstad "that because of the grievous nature of the injuries sustained by her husband, that this was only my opinion and she was encouraged to ask another attorney if she wished for another opinion" and "she ought to do so promptly." He 
testified that he informed Mrs. Togstad that his firm "was not engaged as experts" in the area of medical malpractice, and that they associated with the Charles Hvass firm in cases of that nature. Miller stated that at the end of the conference he told Mrs. Togstad that he would consult with Charles Hvass and if Hvass's opinion differed from his, Miller would so inform her. Miller recollected that he called Hvass a "couple days" later and discussed the case with him. It was Miller's impression that Hvass thought there was no liability for malpractice in the case. Consequently, Miller did not communicate with Mrs. Togstad further.

On cross-examination, Miller testified as follows:

Q Now, so there is no misunderstanding, and I am reading from your deposition, you understood that she was consulting with you as a lawyer, isn't that correct?

A That's correct.

$Q$ That she was seeking legal advice from a professional attorney licensed to practice in this state and in this community?

A I think you and I did have another interpretation or use of the term "Advice." She was there to see whether or not she had a case and whether the firm would accept it.

$\mathrm{Q}$ We have two aspects; number one, your legal opinion concerning liability of a case for malpractice; number two, whether there was or wasn't liability, whether you would accept it, your firm, two separate elements, right?

A I would say so.

Q Were you asked on page 6 in the deposition, folio 14, "And you understood that she was seeking legal advice at the time that she was in your office, that is correct also, isn't it?" And did you give this answer, "I don't want to engage in semantics with you, but my impression was that she and Mr. Bucholz were asking my opinion after having related the incident that I referred to." The next question, "Your legal opinion?" Your answer, "Yes." Were those questions asked and were they given?

MR. COLLINS: Objection to this, Your Honor. It is not impeachment.

THE COURT: Overruled.

THE WITNESS: Yes, I gave those answers. Certainly, she was seeking my opinion as an attorney in the sense of whether or not there was a case that the firm would be interested in undertaking.

Kenneth Green, a Minneapolis attorney, was called as an expert by plaintiffs. He stated that in rendering legal advice regarding a claim of medical malpractice, the "minimum" an attorney should do would be to request medical authorizations from the client, review the hospital records, and consult with an expert in the field. John McNulty, a Minneapolis attorney, and Charles Hvass testified as experts on behalf of the defendants. McNulty stated that when an attorney is consulted as to whether he will take a case, the lawyer's only responsibility in refusing it is to so inform the party. He testified, however, that when a lawyer is asked his legal opinion on the merits of a medical malpractice claim, community standards require that the attorney check hospital records and consult with an expert before rendering his opinion. 
Hvass stated that he had no recollection of Miller's calling him in October 1972 relative to the Togstad matter. He testified that:

A When a person comes in to me about a medical malpractice action, based upon what the individual has told me, I have to make a decision as to whether or not there probably is or probably is not, based upon that information, medical malpractice. And if, in my judgment, based upon what the client has told me, there is not medical malpractice, I will so inform the client.

Hvass stated, however, that he would never render a "categorical" opinion. In addition, Hvass acknowledged that if he were consulted for a "legal opinion" regarding medical malpractice and 14 months had expired since the incident in question, "ordinary care and diligence" would require him to inform the party of the two-year statute of limitations applicable to that type of action.

This case was submitted to the jury by way of a special verdict form. The jury found that Dr. Blake and the hospital were negligent and that Dr. Blake's negligence (but not the hospital's) was a direct cause of the injuries sustained by John Togstad; that there was an attorney-client contractual relationship between Mrs. Togstad and Miller; that Miller was negligent in rendering advice regarding the possible claims of Mr. and Mrs. Togstad; that, but for Miller's negligence, plaintiffs would have been successful in the prosecution of a legal action against Dr. Blake; and that neither Mr. nor Mrs. Togstad was negligent in pursuing their claims against Dr. Blake. The jury awarded damages to Mr. Togstad of $\$ 610,500$ and to Mrs. Togstad of $\$ 39,000$.

In a legal malpractice action of the type involved here, four elements must be shown: (1) that an attorney-client relationship existed; (2) that defendant acted negligently or in breach of contract; (3) that such acts were the proximate cause of the plaintiffs' damages; (4) that but for defendant's conduct the plaintiffs would have been successful in the prosecution of their medical malpractice claim.

We believe it is unnecessary to decide whether a tort or contract theory is preferable for resolving the attorney-client relationship question raised by this appeal. The tort and contract analyses are very similar in a case such as the instant one, and we conclude that under either theory the evidence shows that a lawyer-client relationship is present here. The thrust of Mrs. Togstad's testimony is that she went to Miller for legal advice, was told there wasn't a case, and relied upon this advice in failing to pursue the claim for medical malpractice. In addition, according to Mrs. Togstad, Miller did not qualify his legal opinion by urging her to seek advice from another attorney, nor did Miller inform her that he lacked expertise in the medical malpractice area. Assuming this testimony is true, we believe a jury could properly find that Mrs. Togstad sought and received legal advice from Miller under circumstances which made it reasonably foreseeable to Miller that Mrs. Togstad would be injured if the advice were negligently given. Thus, under either a tort or contract analysis, there is sufficient evidence in the record to support the existence of an attorney-client relationship. 
Defendants argue that even if an attorney-client relationship was established the evidence fails to show that Miller acted negligently in assessing the merits of the Togstads' case. They appear to contend that, at most, Miller was guilty of an error in judgment which does not give rise to legal malpractice. However, this case does not involve a mere error of judgment. The gist of plaintiffs' claim is that Miller failed to perform the minimal research that an ordinarily prudent attorney would do before rendering legal advice in a case of this nature.

There is also sufficient evidence in the record establishing that, but for Miller's negligence, plaintiffs would have been successful in prosecuting their medical malpractice claim. Dr. Woods, in no uncertain terms, concluded that Mr. Togstad's injuries were caused by the medical malpractice of Dr. Blake. Defendants' expert testimony to the contrary was obviously not believed by the jury. Thus, the jury reasonably found that had plaintiff's medical malpractice action been properly brought, plaintiffs would have recovered.

Based on the foregoing, we hold that the jury's findings are adequately supported by the record. Accordingly we uphold the trial court's denial of defendants' motion for judgment notwithstanding the jury verdict.

\section{Questions:}

1. What was the basis for the Togstads' claim that Miller's actions formed an attorney-client relationship? How did Miller respond?

2. Why did the court hold that an attorney-client relationship existed between Miller and the Togstads? Do you think it was right?

3. How should Miller have responded in order to avoid creating an attorney-client relationship?

4. Why did the court hold that Miller was liable for negligence? Do you think it was right?

5. How should Miller have responded in order to avoid liability for negligence?

\section{Representation of an Organization}

When an attorney represents an entity, the attorney's client is the entity, not the entity's agents. In other words, when an attorney represents a corporation, limited liability company, partnership, or unincorporated association, the attorney's client is the organization, not the employees of the organization. Or to put it another way, the attorney has an attorney-client relationship with the organization, but does not necessarily have an attorney-client relationship with the employees of the organization. Specifically, the attorney has a duty to represent the organization, even when its interests diverge from the interests of its employees.

However, an attorney representing an organization must ensure that the employees of the organization understand that the attorney only represents the organization, and not its employees. In other words, the employees must understand that the organization's attorney is not their attorney, and that the organization's attorney has professional duties only to the organization. This can be difficult to explain, especially when employees identify their interests 
with those of the organization. But attorneys for organizations must clarify their legal relationship to the employees of those organizations, in order to avoid creating an attorney-client relationship.

\section{Model Rule 1.13: Organization as Client}

a. A lawyer employed or retained by an organization represents the organization acting through its duly authorized constituents.

b. If a lawyer for an organization knows that an officer, employee or other person associated with the organization is engaged in action, intends to act or refuses to act in a matter related to the representation that is a violation of a legal obligation to the organization, or a violation of law that reasonably might be imputed to the organization, and that is likely to result in substantial injury to the organization, then the lawyer shall proceed as is reasonably necessary in the best interest of the organization. Unless the lawyer reasonably believes that it is not necessary in the best interest of the organization to do so, the lawyer shall refer the matter to higher authority in the organization, including, if warranted by the circumstances to the highest authority that can act on behalf of the organization as determined by applicable law.

c. Except as provided in paragraph (d), if

1. despite the lawyer's efforts in accordance with paragraph (b) the highest authority that can act on behalf of the organization insists upon or fails to address in a timely and appropriate manner an action, or a refusal to act, that is clearly a violation of law, and

2. the lawyer reasonably believes that the violation is reasonably certain to result in substantial injury to the organization, then the lawyer may reveal information relating to the representation whether or not Rule 1.6 permits such disclosure, but only if and to the extent the lawyer reasonably believes necessary to prevent substantial injury to the organization.

d. Paragraph (c) shall not apply with respect to information relating to a lawyer's representation of an organization to investigate an alleged violation of law, or to defend the organization or an officer, employee or other constituent associated with the organization against a claim arising out of an alleged violation of law.

e. A lawyer who reasonably believes that he or she has been discharged because of the lawyer's actions taken pursuant to paragraphs (b) or (c), or who withdraws under circumstances that require or permit the lawyer to take action under either of those paragraphs, shall proceed as the lawyer reasonably believes necessary to assure that the organization's highest authority is informed of the lawyer's discharge or withdrawal.

f. In dealing with an organization's directors, officers, employees, members, shareholders or other constituents, a lawyer shall explain the identity of the client when the lawyer knows or reasonably should know that the organization's interests are adverse to those of the constituents with whom the lawyer is dealing.

g. A lawyer representing an organization may also represent any of its directors, officers, employees, members, shareholders or other constituents, subject to the provisions of Rule 1.7. If the organization's consent to the dual representation is required by Rule 1.7, 
the consent shall be given by an appropriate official of the organization other than the individual who is to be represented, or by the shareholders.

Ferranti Intern. PLC v. Clark, 767 F. Supp. 670 (E.D. Pa. 1991)

Summary: William Clark was general counsel of Ferranti and hired Hogan \& Hartson to represent the company in relation to a federal investigation. Hogan \& Hartson informed Ferranti's employees that they should consider retaining an attorney. During the investigation, Clark provided confidential information to Hogan \& Hartson. Eventually, Ferranti filed an action against Clark for breach of fiduciary duty and legal malpractice. Clark objected to Hogan \& Hartson's representation of Ferranti. The court dismissed Clark's objections, on the ground that he knew Hogan \& Hartson never represented him personally.

LUDWIG, District Judge.

Plaintiff sues for breach of fiduciary duty and professional malpractice and to rescind a $\$ 2.75$ million employee "settlement and release" agreement, which the complaint alleges was obtained by extortion. Defendant William A. Clark's motion to disqualify the firm of Hogan \& Hartson from representing plaintiff Ferranti International PLC in this action will be denied for the following reasons:

An attorney-client relationship, express or implied, did not exist between Hogan \& Hartson and William A. Clark when he was Ferranti International, Inc.'s vice president and general counsel.

In July, 1986 defendant Clark, himself an attorney, retained Hogan \& Hartson to represent plaintiff Ferranti International plc and its subsidiaries in regard to a government investigation of alleged wrongdoing on the part of their employees. He did so in his capacity as Ferranti International, Inc.'s vice president and general counsel. The need for representation was triggered by a federal grand jury subpoena served on plaintiff's subsidiary, the Marquardt Company. Thereafter, the investigation was widened with target letters and follow-up subpoenas to corporate employees of plaintiff and plaintiff's other subsidiaries.

Hogan \& Hartson did not represent the corporations' employees. Hogan \& Hartson attorneys repeatedly stated to the corporations' employees in defendant's presence that they should obtain separate counsel because of the potential conflict of interest between employer and employee. Defendant helped arrange for employees to be separately represented.

Any perception by defendant that he became a client or was a prospective client of Hogan \& Hartson as to his personal legal matters was unreasonable and without foundation. Defendant's position as general counsel and corporate officer excluded this law firm from acting as his personal attorney because of the self-evident interest conflict. Given the circumstances, the personal matters discussed did not involve an attorney-client relationship. 
The information given Hogan \& Hartson by defendant regarding plaintiff, its subsidiaries and employees was communicated by him in his capacity as Ferranti International, Inc.'s vice president and general counsel. Proof of defendant's knowledge of such information does not appear to require that a Hogan \& Hartson attorney testify as a witness.

Until shortly before the present disqualification motion was filed, February 28, 1991, defendant's sole objection to Hogan \& Hartson's representation of plaintiff in this action involved the possible calling of Hogan \& Hartson attorneys as plaintiff's witnesses. That was first noted by defendant's counsel as a potential problem in September, 1990. If either party intends to call a Hogan \& Hartson attorney as a witness, the court should be notified at least 60 days in advance of trial, and any issue thereby raised can be considered at that time.

Defendant's status as an attorney has contradictory facets. He selected Hogan \& Hartson to be plaintiff's counsel and subsequently worked with several of its attorneys in a confidential and apparently close relationship on behalf of plaintiff, the parent of his then employer. Having done so and formed such associations, he may understandably resent and find objectionable the turn of events in which he is now being sued not only by the same law firm but also on behalf of the client that he brought to that firm. However, these personal and business considerations do not necessitate disqualification on legal-ethical grounds.

This is not a case in which a layperson might have perceived or reasonably misperceived that his corporate employer's attorney was also representing him. As a general counsel, defendant must have keenly appreciated the distinction between the corporation and its employees as well as the employees' need for separate counsel. Defendant's assertion that the personal comments and observations exchanged between him and Hogan \& Hartson attorneys were in contemplation of, or resulted in, a personal attorney-client relationship is factitious and unconvincing.

Although it became a Hogan \& Hartson client through defendant, plaintiff has a cognizable interest in being permitted to continue to be represented by this firm. Moreover, disqualification-which is an increasingly frequent issue in the courts - may be the subject of tactical abuse. A party's choice of counsel should be set aside only where the circumstances legally require doing so.

Under the Rules of Professional Conduct and the cases, there is no legal basis on which to disqualify Hogan \& Hartson. An evidentiary hearing is unnecessary.

\section{Questions:}

1. Why did Clark object to Hogan \& Hartson representing Ferranti in its action action against him? Why did the court dismiss Clark's objections?

2. Clark was an attorney and general counsel for Ferranti. Would the court have reached the same conclusion if Clark were not an attorney? 
3. Should Ferranti be able to use confidential information provided to Hogan \& Hartson by Clark?

4. What should Clark have done differently?

\section{Prospective Clients}

People and organizations do not always choose to form an attorney-client relationship immediately. Sometimes, they consider forming an attorney-client relationship with multiple attorneys or firms before choosing one.

A "prospective client" is a person or organization that discusses the possibility of forming an attorney-client relationship with an attorney or firm. If an attorney or firm learns confidential information from a prospective client, the attorney or firm may be precluded from representing other parties in the same matter, if their interests are adverse to those of the prospective client.

Accordingly, attorneys should try to prevent prospective clients from disclosing confidential information, in order to avoid disqualification from representing adverse parties. And attorneys must determine whether potential clients have disclosed any confidential information, because it creates a duty of confidentiality.

\section{Model Rule 1.18: Client-Lawyer Relationship}

a. A person who consults with a lawyer about the possibility of forming a client-lawyer relationship with respect to a matter is a prospective client.

b. Even when no client-lawyer relationship ensues, a lawyer who has learned information from a prospective client shall not use or reveal that information, except as Rule 1.9 would permit with respect to information of a former client.

c. A lawyer subject to paragraph (b) shall not represent a client with interests materially adverse to those of a prospective client in the same or a substantially related matter if the lawyer received information from the prospective client that could be significantly harmful to that person in the matter, except as provided in paragraph (d). If a lawyer is disqualified from representation under this paragraph, no lawyer in a firm with which that lawyer is associated may knowingly undertake or continue representation in such a matter, except as provided in paragraph (d).

d. When the lawyer has received disqualifying information as defined in paragraph (c), representation is permissible if:

1. both the affected client and the prospective client have given informed consent, confirmed in writing, or:

2. the lawyer who received the information took reasonable measures to avoid exposure to more disqualifying information than was reasonably necessary to determine whether to represent the prospective client; and

i. the disqualified lawyer is timely screened from any participation in the matter and is apportioned no part of the fee therefrom; and

ii. written notice is promptly given to the prospective client. 


\section{Restatement (Third) of the Law Governing Lawyers § 15 (2000)}

1. When a person discusses with a lawyer the possibility of their forming a clientlawyer relationship for a matter and no such relationship ensues, the lawyer must:

a. not subsequently use or disclose confidential information learned in the consultation, except to the extent permitted with respect to confidential information of a client or former client as stated in $\S \S 61-67$;

b. protect the person's property in the lawyer's custody as stated in $\S \S 44-$ 46; and

c. use reasonable care to the extent the lawyer provides the person legal services.

2. A lawyer subject to Subsection (1) may not represent a client whose interests are materially adverse to those of a former prospective client in the same or a substantially related matter when the lawyer or another lawyer whose disqualification is imputed to the lawyer under $\S \S 123$ and 124 has received from the prospective client confidential information that could be significantly harmful to the prospective client in the matter, except that such a representation is permissible if:

a. (i) any personally prohibited lawyer takes reasonable steps to avoid exposure to confidential information other than information appropriate to determine whether to represent the prospective client, and (ii) such lawyer is screened as stated in $\S 124(2)(b)$ and (c); or

b. both the affected client and the prospective client give informed consent to the representation under the limitations and conditions provided in $\S$ 122.

Clark Capital Management Group, Inc. v. Annuity Investors Life Ins. Co., 149 F.Supp.2d 193 (E.D. Pa. 2001)

Summary: Clark filed a trademark infringement action against Annuity. Clark was represented by Woodcock Washburn Kurtz Mackiewicz \& Norris LLP and Annuity was represented by Donald E. Frechette of Edwards \& Angell LLP. Frechette contacted Thomas S. Biemer of Dilworth Paxson LLP as potential co-counsel. Frechette provided information about the action, and Biemer told Frechette that he would have to run a conflicts check. Frechette never formally retained Biemer. Eventually, Clark retained Stephen L. Friedman of Dilworth, and Annuity objected, on the ground that it was a former client of Dilworth in the same matter. The court held that Dilworth was not disqualified from representing Clark, but required it to screen Biemer from the action.

ANITA B. BRODY, District Judge. 
Defendant Annuity Investors Life Insurance Co. moves for the disqualification of Stephen L. Friedman and the firm Dilworth Paxson LLP as co-counsel for plaintiff Clark Capital Management Group. Friedman has submitted an opposition to this motion. I will deny the motion for disqualification.

\section{Factual Background}

On April 14, 2000, Clark Capital filed a complaint against Annuity alleging trademark infringement. Attorneys with the firm of Woodcock Washburn Kurtz Mackiewicz \& Norris LLP have represented Clark Capital from day one of this case. In the fall of 2000, Annuity retained Donald E. Frechette with the firm of Edwards \& Angell LLP.

Acting on Annuity's behalf, in the Fall of 2000, Frechette contacted by telephone Thomas S. Biemer, a partner at Dilworth, to inquire into Biemer's interest and availability to be retained as co-counsel for Annuity in the present action. Frechette submitted two sworn affidavits describing this communication. Frechette asserts in his first sworn affidavit that he spoke with Biemer by telephone on three occasions. He states that they first spoke on October 26, 2000 for approximately ten minutes. Frechette asserts that, during this conversation, he discussed with Biemer "the background facts of this case, the capabilities of opposing counsel, Mr. Biemer's firm's experience and familiarity with opposing counsel and the trial judge, the nature of Annuity's defenses, the relative merits of each party's case, and potential weaknesses in plaintiff's case." Frechette further states that he described how the case had been handled to date.

According to Frechette, he again spoke with Biemer by telephone on November 6, 2000, for approximately ten to fifteen minutes. He states that, in this conversation, Frechette provided Biemer with additional information relating to specific aspects of the case and Annuity's view of the strengths and weaknesses of these aspects. Frechette also recalls that they discussed one legal theory that might be employed in Annuity's defense. Frechette asserts that he spoke with Biemer for a third time on November 6, 2000, for three to four minutes about a matter of procedure and timing. Finally, Frechette asserts that he believed that any confidential information about the case, disclosed to Biemer during these several conversations, would be kept confidential.

Biemer submitted a sworn affidavit in response to Frechette's affidavit. Biemer states that he recalls the first two conversations described in Frechette's affidavit, but not the third conversation. Biemer agrees that the two attorneys discussed the nature of the case, plaintiff's counsel, and the court. He asserts, however, that he has no recollection that any confidential information was disclosed by Frechette. Biemer recalls only that Frechette informed him that Annuity was claiming the "usual affirmative defenses," which had already been pled and of public record. Biemer states in his affidavit that he has no recollection of any discussion of Annuity's perception of strengths and weaknesses in the case or of possible defense strategy. 
On June 12, 2001, when contacted by the court during a conference in this case in which Annuity first raised an objection to Friedman's participation in the case, Biemer stated over the telephone:

I don't recall, specifically, discussing the merits of the case, other than that it involved something that was named Navigator, it was a trademark case. I don't remember specifically discussing any affirmative defenses, but it's possible we did, I just don't recall, it was a while ago.

In addition, Biemer's affidavit states that he told Frechette during the first conversation that, before Dilworth could agree to represent Annuity, he would have to run a conflict check. Biemer avers that it was not until the second conversation that Frechette asked Biemer to run a conflict check, "if Dilworth was interested in serving as local counsel." Biemer also states that Frechette asked him to send Frechette any relevant information materials about Dilworth. Following the November 6, 2000 telephone conversation, Biemer had no further communications with Frechette about this case, and an offer of retention was never made.

Frechette's second affidavit was submitted in response to Biemer's affidavit. In this affidavit, Frechette asserts that the issue of a conflict search was not discussed during the telephone conversations. He states that Biemer mentioned a conflict check for the first time in a letter dated November 7, 2000. Frechette further states:

I certainly assumed that Attorney Biemer would not undertake a matter without performing a conflict check and, accordingly, felt no need to specifically inquire as to the matter further.

Annuity never retained Dilworth. On June 11, 2001, Friedman, a Dilworth attorney, entered an appearance on behalf of Clark Capital.

\section{Discussion}

Annuity asserts that these several telephone conversations between Frechette and Biemer rose to the level of an attorney-client relationship between Annuity and Biemer, such that Friedman is in violation of the Rules of Professional Conduct. This District has adopted the Pennsylvania Rules of Professional Conduct. These Rules provide that:

A lawyer who has formerly represented a client in a matter shall not thereafter:

(a) Represent another person in the same or substantially related matter in which that person's interests are materially adverse to the interests of the former client unless the former client consents after a full disclosure of the circumstances and consultation.

Rule of Professional Conduct 1.9. 
This prohibition disqualifies the lawyer's entire firm.

While lawyers are associated in a firm, none of them shall knowingly represent a client when any one of them practicing alone would be prohibited from doing so. Annuity argues that, because Frechette's telephone conversations with Biemer rose to the level of an attorney-client relationship, Annuity is a "former client" of Dilworth and, therefore, Friedman may not now represent the opposing party in this same matter.

To determine whether Friedman is in violation of these ethical rules, I must decide whether Annuity is a "former client" of Dilworth. In other words, did there previously exist an attorneyclient relationship between Annuity and Dilworth. "An attorney-client relationship is one of agency and arises only when the parties have given their consent, either express or implied, to its formation." Both parties agree that no formal attorney-client relationship existed between Annuity and Dilworth. "Where no express relationship exists, the intent to create an attorneyclient relationship can be implied from the conduct of the parties." The issue is whether an implied attorney-client relationship arose during the course of the several telephone conversations between Frechette and Biemer. Annuity asserts that an implied attorney-client relationship between Annuity and Biemer arose because, acting on Annuity's behalf, Frechette: (1) disclosed confidential information to Biemer, (2) with a reasonable belief that Biemer was acting in the capacity of attorney for Annuity throughout the course of the communication.

Based on the facts presented, I find that the several brief telephone conversations between Frechette and Biemer did not give rise to an implied attorney-client relationship between Annuity and Dilworth. Frechette asserts in his first sworn affidavit that he disclosed to Biemer confidential information related to Annuity's defenses and legal theories of the case. Biemer admits that it is possible such disclosures were made. However, Biemer contends that he has no recollection of disclosure of any confidential information.

Setting aside for the moment the question of whether confidential information was in fact disclosed, it is clear from the facts presented that Frechette could not have held a reasonable belief that Biemer was acting as an attorney for Annuity during the course of the communication. Frechette initiated the communication with Biemer to inquire into Biemer's interest and availability to be retained as co-counsel for Annuity in the present action. At no time during the communication did Frechette offer to retain Biemer as co-counsel and at no time during the communication did Biemer consent to representation of Annuity. To the contrary, it was evident from Frechette's request that Biemer send informational materials about the firm, that Frechette had not yet decided whether to retain Biemer as co-counsel. Frechette was reserving the right to make a decision after learning more about the firm.

Furthermore, it is evident that Frechette never conceived that Biemer was acting as Annuity's attorney during the communication, because Biemer had not yet run a conflict check. Frechette contests Biemer's assertion that Biemer raised the need to run a conflict check before consenting to representation during the telephone conversations. However, even if Biemer did not raise the need to run a conflict check, Frechette, equally knowledgeable of the ethical rules, 
was well aware that Biemer would not consent to representation of Annuity before running a conflict check. Frechette explicitly stated in his second sworn affidavit:

I certainly assumed that Attorney Biemer would not undertake a matter without performing a conflict check and, accordingly, felt no need to specifically inquire as to the matter further.

When Frechette first contacted Biemer on October 26, 2000, the telephone conversation during which Frechette asserts that he first disclosed confidential information to Biemer, Frechette could not have reasonably assumed that Biemer had already run a conflict check. By Frechette's own admission, therefore, it was unreasonable for Frechette to assume during that conversation that Biemer had consented to representation of Annuity. The duty to maintain confidences does not arise absent an attorney-client relationship. It follows that Frechette unreasonably assumed that Biemer would maintain the confidentiality of any information Frechette disclosed, despite Frechette's awareness that no attorney-client relationship had been established. Annuity is not a former client of Biemer and neither Friedman nor Dilworth are in violation of Pennsylvania Rule of Professional Conduct 1.9.

I must still address the concern that confidential information about the case may have been disclosed by Frechette, which potentially could be used to the detriment of Annuity if Friedman is permitted to serve as counsel to Clark Capital. "One of the inherent powers of the federal court is the admission and discipline of attorneys practicing before it." Therefore, when there is a risk that the underlying litigation may be tainted by participation of counsel, the court has the power to fashion an appropriate remedy.

In the event that confidential information was disclosed, I find that disqualification of Dilworth is an inappropriate remedy under the facts of this case, but rather that screening Biemer from the case will appropriately balance the interests of all parties. Biemer asserts that he has no recollection that any confidential information was disclosed to him about this case. Therefore, even if he did receive confidential information about the case, Biemer is not capable of relaying anything of substance to other Dilworth attorneys. Biemer also asserts in his affidavit that he has been screened from the matter from the moment Clark Capital contacted the firm. He states:

On approximately June 7, 2001, I learned that Dilworth was contacted by Clark Capital and asked to enter its appearance as counsel for Clark Capital. When I learned this, I relayed to one of the heads of Dilworth's litigation department, James Rogers, Esquire, the substance of my conversations with Mr. Frechette as outlined in this Affidavit. While we agreed that there was no conflict given the limited nature of these conversations, in an abundance of caution, it was decided that I would not be involved in any respect with this case and would not have any contact regarding the substance of the case with anyone working on the case for Dilworth. With the exception of my participation in the Conference Call before the Court on June 11, 2001 and the preparation of this Affidavit, I have not had any involvement in this case. Friedman substantiated Biemer's assertion 
on the record at the June 12, 2001 conference in this matter, stating that Biemer will have nothing to do with this case and that Friedman has had no conversations with Biemer about the case other than to inform Friedman of the brief communication between Biemer and Frechette.

I am not persuaded by Annuity's argument that disqualification of Dilworth is necessary to protect against the "mere appearance of an impropriety" and to maintain the integrity of the legal profession. While the ethical rules are designed, in part, to encourage attorney-client candor, attorneys that have already been retained in a matter and who are well versed in the perimeters of the attorney-client relationship, should be encouraged to take care with their client's confidences in the course of preliminary inquiries with potential co-counsel in another firm. Such inquiries should not form the basis for disqualification of an entire firm in situations, such as this, where it was clear to both parties that an attorney-client relationship was never established. Allowing Friedman to be retained by Clark Capital in this matter requires effective screening of only a single attorney out of approximately 100 attorneys at Dilworth. In light of this, the fact that Annuity is not a former client of Dilworth, and the minimal likelihood that Dilworth's involvement in this case would taint the pending litigation, I will deny Annuity's motion to disqualify Friedman and Dilworth. I will require that Dilworth continue to screen Biemer from any involvement in this case.

\section{Questions:}

1. What was the basis for Annuity's objection to Dilworth's representation of Clark?

2. If Frechette provided confidential information to Biemer, is screening him from the action a sufficient remedy?

3. Why shouldn't the court disqualify Dilworth from representing Clark in this action?

\section{Further Reading:}




\section{2: Ending an Attorney-Client Relationship}

This is the end, beautiful friend. This is the end, my only friend, the end. ${ }^{14}$

Take Me Baby, or Leave Me: Ending the Attorney-Client Relationship

Happy families are all alike; every unhappy family is unhappy in its own way. ${ }^{15}$

It is surprisingly easy to create an attorney-client relationship, and it can be surprisingly hard for an attorney to end one. In general, a client can end an attorney-client relationship at any time, for any reason, or for no reason at all. But attorneys cannot end an attorney-client relationship without good reason. Sometimes, attorneys must end an attorney-client relationship, and other times the rules of professional conduct prevent attorneys from ending an attorney-client relationship. In any case, attorneys may have duties to their clients that survive the attorneyclient relationship, especially the duty of confidentiality.

Sometimes, an attorney must end an attorney-client relationship. For example, an attorney cannot represent a client if the client fires the attorney, the attorney cannot effectively represent the client, the attorney has a conflict of interest, or representation would violate the rules of professional conduct.

Under certain circumstances, attorneys may choose to end an attorney-client relationship. But the ability of an attorney to end an attorney-client relationship is limited by the rules of professional conduct. Attorneys can end an attorney-client relationship only if they are permitted or required to end the relationship by the rules of professional conduct. They may be subject to discipline for ending an attorney-client relationship, even if it is permitted or required by the rules of professional conduct. And they may have duties to former clients that survive the attorneyclient relationship.

Before ending an attorney-client relationship, an attorney should determine whether good cause exists to end the relationship. If an attorney ends an attorney-client relationship without good cause, the attorney may be subject to discipline and liable to the client for malpractice or breach of fiduciary duty.

\section{Model Rule 1.16: Declining or Terminating Representation}

a. Except as stated in paragraph (c), a lawyer shall not represent a client or, where representation has commenced, shall withdraw from the representation of a client if:

1. the representation will result in violation of the rules of professional conduct or other law;

\footnotetext{
14 The Doors, The End (1967).

${ }^{15}$ Leo Tolstoy, Anna Karenina (1878).
} 
2. the lawyer's physical or mental condition materially impairs the lawyer's ability to represent the client; or

3. the lawyer is discharged.

b. Except as stated in paragraph (c), a lawyer may withdraw from representing a client if:

1. withdrawal can be accomplished without material adverse effect on the interests of the client;

2. the client persists in a course of action involving the lawyer's services that the lawyer reasonably believes is criminal or fraudulent;

3. the client has used the lawyer's services to perpetrate a crime or fraud;

4. the client insists upon taking action that the lawyer considers repugnant or with which the lawyer has a fundamental disagreement;

5. the client fails substantially to fulfill an obligation to the lawyer regarding the lawyer's services and has been given reasonable warning that the lawyer will withdraw unless the obligation is fulfilled;

6. the representation will result in an unreasonable financial burden on the lawyer or has been rendered unreasonably difficult by the client; or

7. other good cause for withdrawal exists.

c. A lawyer must comply with applicable law requiring notice to or permission of a tribunal when terminating a representation. When ordered to do so by a tribunal, a lawyer shall continue representation notwithstanding good cause for terminating the representation.

d. Upon termination of representation, a lawyer shall take steps to the extent reasonably practicable to protect a client's interests, such as giving reasonable notice to the client, allowing time for employment of other counsel, surrendering papers and property to which the client is entitled and refunding any advance payment of fee or expense that has not been earned or incurred. The lawyer may retain papers relating to the client to the extent permitted by other law.

\section{Restatement (Third) of the Law Governing Lawyers $\$ 31$ (2000): Termination of a Lawyer's Authority}

1. A lawyer must comply with applicable law requiring notice to or permission of a tribunal when terminating a representation and with an order of a tribunal requiring the representation to continue.

2. Subject to Subsection (1) and $\S 33$, a lawyer's actual authority to represent a client ends when:

a. the client discharges the lawyer;

b. the client dies or, in the case of a corporation or similar organization, loses its capacity to function as such;

c. the lawyer withdraws;

d. the lawyer dies or becomes physically or mentally incapable of providing representation, is disbarred or suspended from practicing law, or is ordered by a tribunal to cease representing a client; or

e. the representation ends as provided by contract or because the lawyer has completed the contemplated services. 
3. A lawyer's apparent authority to act for a client with respect to another person ends when the other person knows or should know of facts from which it can be reasonably inferred that the lawyer lacks actual authority, including knowledge of any event described in Subsection (2). Restatement (Third) of the Law Governing Lawyers $\S 32$ (2000): Discharge by a Client and
Withdrawal by a Lawyer

1. Subject to Subsection (5), a client may discharge a lawyer at any time.

2. Subject to Subsection (5), a lawyer may not represent a client or, where representation has commenced, must withdraw from the representation of a client if:

a. the representation will result in the lawyer's violating rules of professional conduct or other law;

b. the lawyer's physical or mental condition materially impairs the lawyer's ability to represent the client; or

c. the client discharges the lawyer.

3. Subject to Subsections (4) and (5), a lawyer may withdraw from representing a client if:

a. withdrawal can be accomplished without material adverse effect on the interests of the client;

b. the lawyer reasonably believes withdrawal is required in circumstances stated in Subsection (2);

c. the client gives informed consent;

d. the client persists in a course of action involving the lawyer's services that the lawyer reasonably believes is criminal, fraudulent, or in breach of the client's fiduciary duty;

e. the lawyer reasonably believes the client has used or threatens to use the lawyer's services to perpetrate a crime or fraud;

f. the client insists on taking action that the lawyer considers repugnant or imprudent;

g. the client fails to fulfill a substantial financial or other obligation to the lawyer regarding the lawyer's services and the lawyer has given the client reasonable warning that the lawyer will withdraw unless the client fulfills the obligation;

h. the representation has been rendered unreasonably difficult by the client or by the irreparable breakdown of the client-lawyer relationship; or

i. other good cause for withdrawal exists.

4. In the case of permissive withdrawal under Subsections (3)(f)-(i), a lawyer may not withdraw if the harm that withdrawal would cause significantly exceeds the harm to the lawyer or others in not withdrawing.

5. Notwithstanding Subsections (1)-(4), a lawyer must comply with applicable law requiring notice to or permission of a tribunal when terminating a representation and with a valid order of a tribunal requiring the representation to continue.

\section{You're Fired!: Discharge}


It's a sad situation, I must say, when someone wants to leave as bad as you want them to stay. $^{16}$

I don't feel bad about letting you go, I just feel sad about letting you know. ${ }^{17}$

Typically, clients can end the attorney-client relationship simply by firing their attorney. Under Model Rule 1.16(a)(3), "a lawyer shall not represent a client or . . . shall withdraw from the representation of a client if . . . the lawyer is discharged." And as Section 32(1) of the Restatement observes, "a client may discharge a lawyer at any time."

However, a client's ability to fire an attorney and end the attorney-client relationship is not absolute. Under some circumstances, a court may prohibit a client from firing an attorney, and order the attorney to continue representing the client. For example, a client typically cannot fire an attorney immediately before trial, because it could enable clients to improperly delay the proceedings.

Criminal defendants have a limited right to fire appointed counsel and receive alternative counsel. Criminal defendants also have a limited right to fire appointed counsel and represent themselves. Among other things, criminal defendant must express an "unequivocal" desire to represent themselves. In theory, this means that criminal defendants cannot fire appointed counsel only because they believe appointed counsel is bad.

When a client fires an attorney and hires a new attorney, the former attorney may have a claim against the former client. In a civil claim, the former attorney may recover the value of the services rendered.

\section{Demov, Morris, Levine \& Shein v. Glantz, 53 N.Y.2d 553 (N.Y. 1981)}

Summary: Respondent HGV Associates retained attorneys to retain possession of the premises of an amusement park to secure an advantageous condemnation award. HGV Associates signed a retainer agreement which provided that appellants (individual attorneys and a law firm) would prepare an application for a stay of eviction permitting the amusement park to reopen and would represent HVG in the condemnation proceeding. Appellants made clear they would not work unless they could also represent HGV in the condemnation proceeding. A representative of HGV fired appellant lawyers and law firm against the retainer agreement. Appellants argue fraud and breach of retainer agreement. The Appellate Division held the cause of action to be insufficient as a matter of law. The court noted that a cause of action will not be cognizable in the courts of this State when it is violative of strong public policy. The public policy of New York permits a client to terminate the attorney-client relationship freely at any time. The court held that when an attorney-client relationship deteriorates to the point where the

\footnotetext{
${ }^{16}$ Dolly Parton, When Someone Wants to Leave, Jolene (1974).

${ }^{17}$ Billy Bragg, A New England (1983).
} 
client loses faith in the attorney, the client should have the unbridled prerogative of termination.

WACHTLER, J.

The question on this appeal is whether an attorney may recover upon a cause of action against a former client for fraudulently inducing the attorney to enter into a retainer agreement. The Appellate Division held the cause of action is insufficient as a matter of law and we agree.

In 1972, the City of New York condemned a parcel of land in Queens owned by respondent HGV Associates upon which an amusement park was operated by respondent MHG Enterprises, Inc. Between 1972 and 1976, respondents retained several attorneys to undertake efforts to retain possession of the premises and secure the most advantageous condemnation award. Respondents remained in possession until May 28, 1976, when a Federal court ordered them to vacate the premises.

In June, 1976, respondent Glantz, the vice-president of MHG Enterprises, Inc., and a partner in HGV Associates, signed a retainer agreement which provided that appellants, individual attorneys, and a law firm, would prepare an application for a temporary stay of eviction permitting the amusement park to reopen and would represent respondents in the condemnation proceeding. Appellants were to be paid a fixed sum if the application to reopen was successful and their fee in the condemnation proceeding was dependent upon the amount eventually awarded to respondents. Appellants testified that they made it clear to Glantz that they would not work on the application to reopen unless they could also represent respondents in the condemnation proceeding. Glantz agreed to arrange to have appellants substituted as attorneys of record in the condemnation proceeding.

Appellants submitted the application to restore respondents to possession of the amusement park, which was denied. Thereafter, appellants were informed by respondents' attorney of record in the condemnation proceeding that Glantz had issued instructions not to forward the stipulation of substitution to appellants. Glantz then formally discharged appellants in writing and requested a bill for services rendered.

In October, 1976 appellants commenced an action against respondents for fraud, breach of the retainer agreement, and the reasonable value of legal services rendered. The cause of action for fraud was grounded upon the allegation that appellants were induced to enter the retainer agreement by respondents' promise to permit them to litigate the condemnation proceeding. Appellants also alleged that from the outset, respondents never intended to substitute appellants as attorneys of record in the condemnation proceedings unless and until the application to reopen was granted.

The trial court dismissed the claim for breach of contract, but upheld the cause of action for fraud. After trial a jury awarded appellants $\$ 34,000$ as the reasonable value of their services and $\$ 310,000$ as damages for fraud. The Appellate Division modified the judgment, on the law, by 
dismissing the cause of action sounding in fraud and otherwise affirmed the judgment insofar as is pertinent here.

The unique relationship between an attorney and client, founded in principle upon the elements of trust and confidence on the part of the client and of undivided loyalty and devotion on the part of the attorney, remains one of the most sensitive and confidential relationships in our society. A relationship built upon a high degree of trust and confidence is obviously more susceptible to destructive forces than are other less sensitive ones. It follows, then, that an attorney cannot represent a client effectively and to the full extent of his or her professional capability unless the client maintains the utmost trust and confidence in the attorney.

This philosophy engendered the development of the rule, now well rooted in our jurisprudence, that a client may at anytime, with or without cause, discharge an attorney in spite of a particularized retainer agreement between the parties. Moreover, we have held that since the client has the absolute right on public policy grounds to terminate the attorney-client relationship at any time without cause, it follows as a corollary that the client cannot be compelled to pay damages for exercising a right which is an implied condition of the contract, and the attorney discharged without cause is limited to recovering in quantum meruit the reasonable value of services rendered. In Martin v. Camp, we stated that the rule "is well calculated to promote public confidence in the members of an honorable profession whose relation to their clients is personal and confidential".

To be sure, a deliberate misrepresentation of present intent made for the purpose of inducing another to enter a contract will normally constitute actionable fraud if there is a reliance by the party to whom the misrepresentation was made. It is equally well established, however, that a cause of action will not be cognizable in the courts of this State when it is violative of strong public policy.

The public policy of New York which permits a client to terminate the attorney-client relationship freely at any time, notwithstanding the existence of a particularized retainer agreement between the parties, would be easily undermined if an attorney could hold a client liable for fraud on the theory that the client misrepresented his or her true intent when the retainer was executed. When an attorney-client relationship deteriorates to the point where the client loses faith in the attorney, the client should have the unbridled prerogative of termination. Any result which inhibits the exercise of this essential right is patently unsupportable.

Additionally, as a matter of law, the element of reliance essential to a cause of action for fraudulent misrepresentation of present intent cannot be established in this case. Given the rule that a client may discharge an attorney without cause at any time, it is evident that appellants could not rely upon Glantz's promise to substitute them as attorneys of record in the condemnation proceeding any more than they could rely upon continued representation in the event they had actually been substituted. Thus, an essential element of a claim of fraudulent misrepresentation is conspicuously absent. 
Appellants argue that the result reached today enables unscrupulous clients to defraud their attorneys with impunity. We do not agree. We have said that "the law does not permit the client to cheat his attorney." Permitting an attorney improperly discharged to recover the reasonable value of services rendered in quantum meruit, a principle inherently designed to prevent unjust enrichment, strikes the delicate balance between the need to deter clients from taking undue advantage of attorneys, on the one hand, and the public policy favoring the right of a client to terminate the attorney-client relationship without inhibition on the other.

\section{Questions:}

1. If a client fires an attorney for actual or perceived incompetence, should the attorney be able to recover in quantum meruit?

2. Many courts have held that a fired attorney may also recover a percentage of a contingent fee. "The outgoing attorney may elect to take compensation on the basis of a presently fixed dollar amount based upon quantum meruit for the reasonable value of services or, in lieu thereof, the outgoing attorney has the right to elect a contingent percentage fee based on the proportionate share of the work performed on the whole case." Lai Ling Cheng v. Modansky, 73 N.Y.2d 454 (1989). Do you agree with this conclusion?

\section{Woke Up New: Permissive Withdrawal}

I wish there was something you would do or say, to try and make me change my mind and stay. But we never did too much talking anyway. But don't think twice, it's all right. ${ }^{18}$

You can't open your mouth without telling a lie, but baby, you know how to say goodbye. ${ }^{19}$

On the morning when I woke up without you for the first time, I felt free and I felt lonely and I felt scared. ${ }^{20}$

While it is easy for clients to end an attorney-client relationship, it can be harder for attorneys. Model Rule 1.16(b) identifies several circumstances under which an attorney may end an attorney-client relationship.

Of course, attorneys can end attorney-client relationships at will, when it will not harm their clients. Model Rule 1.16(b)(1). But this exception is largely irrelevant, because clients typically abhor reluctant attorneys, and clients who suffer no harm rarely file malpractice actions. Clients who can afford another attorney say good riddance, and clients who cannot are harmed.

Attorneys can also end an attorney-client relationship if their client misbehaves. For example, attorneys can end an attorney-client relationship if their client uses their legal advice to break

\footnotetext{
${ }^{18}$ Bob Dylan, Don't Think Twice, It's Alright (1963).

${ }^{19}$ Stephin Merritt, How to Say Goodbye, 69 Love Songs (1999).

${ }^{20}$ The Mountain Goats, Woke Up New, Get Lonely (2006).
} 
the law. Attorneys can also end an attorney-client relationship based on irreconcilable differences of opinion. And attorneys can end an attorney-client relationship if their client cannot or will not pay for representation, or for any other "good reason." Model Rule 1.16(b)(2-7).

However, attorneys cannot simply end an attorney-client relationship and walk away. They must seek permission from the court, and cannot end an attorney-client relationship without the court's approval. If the court orders an attorney to continue representing a client, the attorney must comply, even if the attorney has good cause to withdraw. Model Rule 1.16(c). Typically, courts permit attorneys to withdraw only if they show that their client has retained other counsel or refuses representation. If the court permits withdrawal, the attorney must make a reasonable effort to protect the client's interests. Among other things, the attorney must provide reasonable notice of withdrawal to the client, transfer documents and property to the client, and refund any unearned payments or fees. However, the attorney may retain documents relating to the client, to the extent permitted by law.

\section{It's Not You, It's Me: Mandatory Withdrawal}

Are you out of love with me? Are you longing to be free? Do I drive you up a tree? Yeah! Oh, yeah! Do I drive you up the wall? Do you dread every phone call? Can you not stand me at all? Yeah! Oh, yeah! ${ }^{21}$

Under certain circumstances, attorneys must end an attorney-client relationship. Model Rule 1.16(a) provides that attorneys must withdraw if continued representation would cause a violation of the rules of professional conduct or some other law, their physical or mental condition materially impairs their ability to represent the client, or the client terminates representation.

Obviously, attorneys cannot represent clients seeking legal advice in furtherance of a criminal enterprise. For example, attorneys cannot provide legal advice that enables a client to commit or perpetuate fraud. However, attorneys are not required to withdraw from representation simply because their client suggests an improper or illegal action. Model Rule 1.16, Comment 2. On the contrary, they should counsel their client against such action, and withdraw only if their client insists on proceeding.

Attorneys also cannot represent a client if it would create a conflict of interest. If an attorney has previously represented a client with interests adverse to those of a potential or current client, the attorney must decline or withdraw from representation, unless the client can and does provide informed consent to representation. In some cases, a conflict of interest may preclude informed consent.

Attorneys must also withdraw from representation if their physical or mental state will materially impair their ability to represent their client. Obviously, attorneys who incur serious physical or

${ }^{21}$ Stephin Merritt, The Magnetic Fields, Yeah! Oh Yeah!, 69 Love Songs (1999). 
mental injuries may not be able to continue representing their clients. However, in some cases, they may be subject to discipline.

Whiting v. Lacara, 187 F. 3d 317 (2d Cir. 1999)

Summary: Lacara appeals from two orders denying Lacara's motion to withdraw as counsel for Whiting. Lacara asserted that appellee had failed to follow legal advice, was not focused on his legal rights, and demanded publicity against legal advice. Whiting said he would not be opposed to a court order relieving counsel. Lacara asserts permissive withdrawal. The court noted there are some instances in which an attorney representing a plaintiff in a civil case might have to withdraw even at the cost of significant interference with the trial court's management of its calendar. In reversing the decision of the lower court, this court noted that Whiting intends to dictate how his action is to be pursued. Whiting did not believe Lacara was the correct attorney for him. Based on the oral argument, the court determined Lacara's motion should be granted.

Garrett R. Lacara appeals from two orders of Judge Spatt denying Lacara's motions to withdraw as counsel for plaintiff-appellee Joseph M. Whiting. Although the record before Judge Spatt justified denial of the motions, amplification of Whiting's position at oral argument persuades us to reverse.

In July 1996, appellee, a former police officer, filed a civil rights action against Nassau County, the Incorporated Village of Old Brooksville, the Old Brooksville Police Department, other villages, and various individual defendants. The action was based on the termination of his employment as an officer. He sought $\$ 9,999,000$ in damages.

Appellee's initial counsel was Jeffrey T. Schwartz. In October 1996, Robert P. Biancavilla replaced Schwartz. A jury was selected in October 1997 but was discharged when Biancavilla withdrew from the case with appellee's consent.

Whiting retained Lacara in December 1997. In June 1998, the district court partially granted defendants' summary judgment motion and dismissed plaintiff's due process claims. The court scheduled the remaining claims, one free speech claim and two equal protection claims, for a jury trial on August 18, 1998. On July 20,1998, the district court denied appellee's motion to amend his complaint to add a breach of contract claim and another due process claim.

On August 6, 1998, Lacara moved to be relieved as counsel. In support, he offered an affidavit asserting that appellee "had failed to follow legal advice," that appellee "was not focused on his legal rights," and that appellee "demanded publicity against legal advice." Lacara also asserted that appellee had failed to keep adequate contact with his office, was "not sufficiently thinking clearly to be of assistance at the time of trial," and would "be of little or no help during trial." Furthermore, Lacara stated that appellee had "demanded that Lacara argue collateral issues which would not be allowed in evidence," demanded that Lacara continue to argue a due process claim already dismissed by the court, and drafted a Rule 68 Offer without Lacara's 
consent and demanded that he serve it on defendants. Finally, Lacara asserted that on July 30, 1998, Whiting had entered his office and, without permission, had "commenced to riffle Lacara's 'in box."' Lacara stated that he had to call 911 when Whiting had refused to leave the office. Lacara offered to provide further information to the court in camera. Whiting's responsive affidavit essentially denied Lacara's allegations. Whiting stated that he would not be opposed to an order relieving counsel upon the condition that Lacara's firm refund the legal fees paid by Whiting.

On August 13, Judge Spatt denied Lacara's motion to withdraw as counsel. Judge Spatt subsequently issued a written order giving the reasons for denying appellant's motion.

On August 13, 1998, Lacara filed a notice of appeal and moved for an emergency stay of the district court's order and to be relieved as appellee's attorney. We granted Lacara's motion for an emergency stay pending appeal but denied his request for relief on the merits at that time. At a status conference on September 23, 1998, the district court entertained another motion from Lacara to withdraw as counsel, which Judge Spatt again denied. Lacara filed a timely appeal, which was consolidated with the earlier appeal.

Judge Spatt denied Lacara's motion pursuant to Rule 1.4 of the Civil Rules of the United States District Court for the Southern and Eastern Districts of New York, which provides that:

an attorney who has appeared as attorney of record for a party may be relieved or displaced only by order of the court and may not withdraw from a case without leave of the court granted by order. Such an order may be granted only upon a showing by affidavit or otherwise of satisfactory reasons for withdrawal or displacement and the posture of the case, including its position, if any, on the calendar.

In addressing motions to withdraw as counsel, district courts have typically considered whether "the prosecution of the suit is likely to be disrupted by the withdrawal of counsel."

Considerations of judicial economy weigh heavily in favor of our giving district judges wide latitude in these situations, but there are some instances in which an attorney representing a plaintiff in a civil case might have to withdraw even at the cost of significant interference with the trial court's management of its calendar. For example, the Code of Professional Responsibility might mandate withdrawal where "the client is bringing the legal action merely for the purpose of harassing or maliciously injuring" the defendant. In such a situation, by denying a counsel's motion to withdraw, even on the eve of trial, a court would be forcing an attorney to violate ethical duties and possibly to be subject to sanctions.

Lacara does not claim that he faces mandatory withdrawal. Rather, he asserts three bases for "permissive withdrawal" under the Model Code: (i) Whiting "insists upon presenting a claim or defense that is not warranted under existing law and cannot be supported by good faith argument for an extension, modification, or reversal of existing law"; (ii) Whiting's "conduct has rendered it unreasonably difficult for Lacara to carry out employment effectively"; and (iii) 
Whiting has "deliberately disregarded an agreement or obligation to Lacara as to expenses or fees." Although the Model Code "was drafted solely for its use in disciplinary proceedings and cannot by itself serve as a basis for granting a motion to withdraw as counsel," we continue to believe that "the Model Code provides guidance for the court as to what constitutes "good cause' to grant leave to withdraw as counsel." However, a district court has wide latitude to deny a counsel's motion to withdraw, as here, on the eve of trial, where the Model Code merely permits withdrawal.

In the instant matter, we would be prepared to affirm if the papers alone were our only guide. Although Lacara has alleged a nonpayment of certain disputed fees, he has not done so with sufficient particularity to satisfy us that withdrawal was justified on the eve of trial. Moreover, there is nothing in the district court record to suggest error in that court's finding that "Whiting has been very cooperative and desirous of assisting his attorney in this litigation." To be sure, we are concerned by Lacara's allegation that appellee trespassed in his office and that appellant had to call 911 to get Whiting to leave. However, Whiting disputes Lacara's description of these events. Moreover, we strongly agree with the district court that, as the third attorney in this case, Lacara had ample notice that appellee was a difficult client.

Nevertheless, we reverse the denial of appellant's motion for withdrawal. Among Lacara's allegations are that Whiting insisted upon pressing claims already dismissed by the district court and calling witnesses Lacara deemed detrimental to his case. At oral argument, Whiting confirmed Lacara's contention that Whiting intends to dictate how his action is to be pursued. Whiting was asked by a member of the panel:

Are you under the impression that if we affirm Judge Spatt's ruling, you will be able to tell Mr. Lacara to make the arguments you want made in this case? That, if Mr. Lacara says, "That witness doesn't support your case," and you don't agree with that, are you under the impression that if we affirm Judge Spatt's ruling you'll be able to force him to call that witness?

To which Whiting replied, "Yes I am."

Moreover, in his statements at oral argument, Whiting made it clear that he was as interested in using the litigation to make public his allegations of corruption within the Brookville police department as in advancing his specific legal claims. For example, Whiting thought it relevant to inform us at oral argument that police officers in the department were guilty of "illegal drug use, acceptance of gratuities, and ongoing extramarital affairs while they were on duty." Appellee stated that he wanted to call an officer to testify that the officer could not "bring up anything criminal about the lieutenant, the two lieutenants, or the chief, which could get them in trouble or make the department look bad." Finally, Whiting made clear that he disagreed with Lacara about the handling of his case partly because Whiting suspects that Lacara wants to cover up corruption. Appellee stated: "For some strange reason, Mr. Lacara states that he doesn't want to put certain witnesses on the stand. The bottom line is he does not want to make waves and expose all of the corruption that's going on within this community." 
Also, at oral argument, appellee continued to bring up the already-dismissed due process claims. He asserted: "They found me guilty of something which was investigated by their department on two separate occasions and closed as unfounded on two separate occasions." We thus have good reason to conclude that Whiting will insist that Lacara pursue the already dismissed claims at trial.

Finally, appellee indicated that he might sue Lacara if not satisfied that Lacara provided representation as Whiting dictated. After admitting that he did not consider Lacara to be the "right attorney" for him in this case, Whiting asserted that he deemed Lacara "ineffective." The following exchange also occurred:

Question from Panel: If you think that Mr. Lacara is ineffective in representing you as you stand here now, doesn't Mr. Lacara face the prospect of a malpractice suit, by you, against him, if he continues in the case?

Appellee's Reply: Yes, I believe he absolutely does.

Question from Panel: Then, isn't that all the more reason to relieve him? So that what you say is ineffective and is in effect a distortion of the attorney-client relationship, doesn't continue?

Appellee's Reply: I believe I do have grounds to sue Mr. Lacara for misrepresentation ....

We believe that appellee's desire both to dictate legal strategies to his counsel and to sue counsel if those strategies are not followed places Lacara in so impossible a situation that he must be permitted to withdraw.

Attorneys have a duty to the court not to make "legal contentions unwarranted by existing law or by a nonfrivolous argument for the extension, modification, or reversal of existing law." We have determined that "an attorney who continues to represent a client despite the inherent conflict of interest in his so doing due to possible Rule 11 sanctions risks an ethical violation." In this case, appellee's belief that he can dictate to Lacara how to handle his case and sue him if Lacara declines to follow those dictates leaves Lacara in a position amounting to a functional conflict of interest. If required to continue to represent Whiting, Lacara will have to choose between exposure to a malpractice action or to potential Rule 11 or other sanctions. To be sure, such a malpractice action would have no merit. However, we have no doubt it would be actively pursued, and even frivolous malpractice claims can have substantial collateral consequences.

As previously noted, the interest of the district court in preventing counsel from withdrawing on the eve of trial is substantial. Moreover, we would normally be loath to allow an attorney to withdraw on the eve of trial when the attorney had as much notice as did Lacara that he was taking on a difficult client. However, the functional conflict of interest developed at oral argument causes us to conclude that the motion to withdraw should be granted. 
We therefore reverse and order the district court to grant appellant's motion to withdraw as counsel. We note that Lacara agreed in this court to waive all outstanding fees and to turn over all pertinent files to Whiting.

\section{Questions:}

1. Why did Lacara claim permissive withdrawal, rather than mandatory withdrawal?

2. Why did the district court deny Lacara's motion to withdraw? Why did the circuit court reverse?

3. How serious is the risk of Rule 11 sanctions? Is there a real conflict of interest?

4. Will Whiting be able to retain new counsel? If not, will he have to proceed pro se?

\section{Both Sides Now: Effective Withdrawal}

Sometimes an attorney-client relationship doesn't really end, but just fades away. Often, an attorney represents a client in a matter and the client has no need for further representation. For example, an attorney may represent a client in relation to a particular transaction or dispute, like the purchase of a home or an automobile accident. Ideally, the attorney and client will have formed an agreement, specifying the scope of representation, in which case the attorney-client relationship typically ends when the matter is concluded. But occasionally they may not, by accident or design. In that case, the attorney-client relationship still typically ends when the matter is concluded, although it may be less certain. Restatement (Third) of the Law Governing Lawyers $\S 31(2)(e)(2000)$.

In other cases, an attorney may have a long-term relationship with a client that gradually peters out over time. In that case, it may be hard to know whether and when the attorney-client relationship has ended. Worse, the attorney and client may disagree. An attorney may believe the relationship continues, only to be surprised when the client returns bills unpaid. And a client may believe the relationship continues, only to be surprised when the attorney ignores the client's affairs.

Generally, an attorney-client relationship continues to exist so long as a reasonable client would believe that it continues to exist. If an attorney wants to end an attorney-client relationship, the attorney should explicitly inform the client in writing that it has ended, and return any documents or property that belongs to the client. But attorneys are often reluctant to end long-term attorneyclient relationships, in the hope that the client will eventually return and provide more business. In that case, courts will ask whether a reasonable client would believe that an attorney-client relationship continued to exist under the circumstances.

\section{Forever \& a Day: Duties After Withdrawal}

Under Model Rule 1.16(d), an attorney who withdraws from representing a client has a duty to minimize any potential harm to the client. Among other things, the attorney must provide reasonable notice of withdrawal, return any documents or other property that belongs to the 
client, and refund any unearned fees or payments. However, some attorney work product may belong to the attorney, and some states permit attorneys to retain the client's property until the client pays any outstanding fees.

However, the attorney also has a permanent duty of confidentiality to former clients.

\section{Further Reading:}




\section{3: The Attorney as Agent}

The attorney-client relationship is a principal-agent relationship. The client is the principal and the attorney is the client's agent. But it is a unique form of principal-agent relationship, because the client's ability to control the attorney's exercise of agency is limited, and because the attorney has duties not only to the client, but also to the court and the public.

\section{Professional Relationships}

In this respect, the attorney-client relationship resembles other professional relations. In the doctor-patient relationship, patients decide whether to seek treatment, but doctors decide how to provide treatment. In the professor-student relationship, students decide whether to attend school, but professors decide what to teach. And in the priest-penitent relationship, priests have duties not only to the penitent, but also to God.

In an attorney-client relationship, the client decides the objectives, but the attorney decides the means. The client decides how much authority to delegate to the attorney, and retains the right to make all major decisions, but cannot dictate all of the attorney's actions. The attorney is entitled and required to exercise independent judgment about how to achieve the client's goals.

For example, in a contract negotiation, the client is entitled to decide the key terms, but the attorney must decide how to achieve them. In civil litigation, the client is entitled to decide whether to settle, but the attorney must decide whether to assert a particular claim or defense. And in criminal litigation, the client is entitled to decide whether to plead guilty, but the attorney must decide which witnesses to call and how to conduct cross-examination.

Moreover, in an attorney-client relationship, the attorney not only has a duty to protect the interests of the client, but also has a duty to protect the interests of the court and the public. An attorney is an agent of both the client and the court. In theory, while attorneys must pursue the interests of their clients, they also must not mislead the court, or allow their clients to lie to the court. Of course, in practice, this is often easier said than done.

\section{Attorneys as Agents}

As agents of their clients, attorneys often have the authority to act on behalf of their clients, but it may take the form of express, implied, or apparent authority.

- Express Authority: When an attorney acts pursuant to authority explicitly granted by the client. For example, clients can grant express authority to an attorney in an engagement letter or later instructions.

- Implied Authority: When an attorney acts pursuant to authority necessarily granted by the attorney-client relationship. For example, attorneys have implied authority to exercise discretion in implementing the instructions of their clients. 
- Apparent Authority: When an attorney acts pursuant to authority delegated by the client and an opposing party relies on the delegation, especially when the authority is normally reserved to the client. For example, if a client delegates the authority to approve a final settlement, and an opposing party relies on the delegation, the attorney may have apparent authority, even though the decision to approve a final settlement is normally reserved to the client.

When attorneys act pursuant to express, implied, or apparent authority, their actions bind their clients. But when attorneys act without authority, their actions are ultra vires, and may not be binding. Of course, when attorneys act without authority, they may also be liable for malpractice.

\section{Attorneys as Fiduciaries}

A friendship founded on business is better than a business founded on friendship. ${ }^{22}$

The attorney-client relationship is unusual because attorneys are fiduciaries of their clients. A fiduciary is a person who holds a legal duty of trust with another party, or "principal." A fiduciary duty is the highest standard of care. As Cardozo famously explained, a fiduciary "is held to something stricter than the morals of the marketplace. Not honesty alone, but the punctilio of an honor the most sensitive, is then the standard of behavior." Meinhard v. Salmon, 249 N.Y. 458 (1928). Accordingly, fiduciaries must act only for the sole benefit and interest of the principal, and must put the interests of the principal above their own interests.

As fiduciaries, attorneys have a legal duty to act only in the interests of their clients, and to put the interests of their clients above their own interests. Accordingly, attorneys may never form a relationship that would create a conflict of interest with a current or former client, without the client's informed consent.

\section{Model Rule 1.2: Scope of Representation \& Allocation of Authority Between Client \&} Lawyer

a. Subject to paragraphs (c) and (d), a lawyer shall abide by a client's decisions concerning the objectives of representation and, as required by Rule 1.4, shall consult with the client as to the means by which they are to be pursued. A lawyer may take such action on behalf of the client as is impliedly authorized to carry out the representation. A lawyer shall abide by a client's decision whether to settle a matter. In a criminal case, the lawyer shall abide by the client's decision, after consultation with the lawyer, as to a plea to be entered, whether to waive jury trial and whether the client will testify.

b. A lawyer's representation of a client, including representation by appointment, does not constitute an endorsement of the client's political, economic, social or moral views or activities.

\footnotetext{
22 John D. Rockefeller.
} 
c. A lawyer may limit the scope of the representation if the limitation is reasonable under the circumstances and the client gives informed consent.

d. A lawyer shall not counsel a client to engage, or assist a client, in conduct that the lawyer knows is criminal or fraudulent, but a lawyer may discuss the legal consequences of any proposed course of conduct with a client and may counsel or assist a client to make a good faith effort to determine the validity, scope, meaning or application of the law.

\section{Restatement (Third) of the Law Governing Lawyers, Introductory Note (2000)}

Traditionally, some lawyers considered that a client put affairs in the lawyer's hands, who then managed them as the lawyer thought would best advance the client's interests. So conducting the relationship can subordinate the client to the lawyer. The lawyer might not fully understand the client's best interests or might consciously or unconsciously pursue the lawyer's own interests. An opposite view of the client-lawyer relationship treats the lawyer as a servant of the client, who must do whatever the client wants limited only by the requirements of law. That view ignores the interest of the lawyer and of society that a lawyer practice responsibly and independently.

A middle view is that the client defines the goals of the representation and the lawyer implements them, but that each consults with the other. Except for certain matters reserved for client or lawyer to decide, the scope of the lawyer's authority is itself one of the subjects for consultation, with room for the client's wishes and the parties' contracts to modify the traditionally broad delegation of authority to the lawyer. This approach, accepted in this Restatement, permits a variety of allocations of authority.

\section{Restatement (Third) of the Law Governing Lawyers $\$ 20$ (2000)}

1. A lawyer must keep a client reasonably informed about the matter and must consult with a client to a reasonable extent concerning decisions to be made by the lawyer under $\S \S$ 21- 23.

2. A lawyer must promptly comply with a client's reasonable requests for information.

3. A lawyer must notify a client of decisions to be made by the client under $\S \$ 21-23$ and must explain a matter to the extent reasonably necessary to permit the client to make informed decisions regarding the representation.

\section{Restatement (Third) of the Law Governing Lawyers $\$ 21$ (2000)}

As between client and lawyer:

1. A client and lawyer may agree which of them will make specified decisions, subject to the requirements stated in $\S \S 18,19,22,23$, and other provisions of this Restatement. The agreement may be superseded by another valid agreement.

2. A client may instruct a lawyer during the representation, subject to the requirements stated in $\S \S 22,23$, and other provisions of this Restatement. 
3. Subject to Subsections (1) and (2) a lawyer may take any lawful measure within the scope of representation that is reasonably calculated to advance a client's objectives as defined by the client, consulting with the client as required by $\S 20$.

4. A client may ratify an act of a lawyer that was not previously authorized.

\section{L.F.S. Corp. v. Kennedy, 337 S.E.2d 209 (S.C. 1985)}

Summary: Kennedy represented L.F.S. in an action against the Town of Kershaw. Kennedy settled the action and L.F.S. accepted the settlement, but later objected to Kennedy settling without its consent. The court held that L.F.S. ratified Kennedy's actions by accepting the settlement.

\section{GREGORY, Justice:}

In this legal malpractice action, appellant L.F.S. Corporation appeals from the grant of respondents' motion for non-suit. We affirm.

Appellant raises numerous issues by twenty-four exceptions; however, we need only reach one issue which moots those remaining.

L.F.S. began planning a subdivision called Havenwood in 1964. In the early 1970 's, a dispute arose with the Town of Kershaw concerning the town's obligation to supply water to the subdivision under an alleged oral contract. Respondents were retained to represent the Corporation.

The gravamen of appellant's complaint is that respondents failed to follow instructions concerning settlement negotiations, and permitted summary judgment to be entered based on an unauthorized agreement. Notwithstanding respondents' alleged failure to follow instructions, the record clearly demonstrates L.F.S. subsequently ratified respondents' actions.

After entry of the disputed 1976 order, the town remitted $\$ 900.00$ in tap fees to the Corporation pursuant to the order. The check was accepted by the Corporation, and endorsed over to respondents to be applied against legal fees owned by the Corporation. Thereafter, one of the Corporation's directors wrote a letter to respondents seeking advice concerning enforcement of the order.

The events subsequent to the 1976 order clearly demonstrate L.F.S. ratified respondents' actions concerning entry of the order. The Corporation accepted financial benefit under the order, and sought to take advantage of the order. Acceptance of both benefits are clear, unequivocal acts of ratification.

\section{Questions:}

1. Did Kennedy have authority to agree to the settlement? 
2. If not, why did the court affirm the settlement?

Morris v. Ohio Cas. Ins. Co., 35 Ohio St. 3d 45 (Ohio 1988)

Summary: James Whitney represented an estate insured by Ohio Casualty Insurance, which issued settlement checks to Whitney, payable to the estate. Someone typographically endorsed the checks and deposited them in Whitney's office account. The court held that the endorsements were invalid, because Whitney lacked any authority to endorse the checks.

\section{DOUGLAS, J.}

The sole question posed for our consideration is whether an insurance carrier may be liable for conversion when the carrier authorizes its bank to pay a draft over a forged endorsement. We answer the question in the affirmative and, accordingly, uphold the decision of the court of appeals.

Initially, appellant asks this court to find that its payment to James Whitney, the attorney for the estate and guardianship, constituted payment to the estate and guardianship. Accordingly, appellant would have us hold that appellant's obligation to the estate and guardianship was discharged when appellant both delivered the drafts in question to the agent of the estate and the guardianship, and then authorized payment of such drafts to the same party. We decline to make such a finding in this case.

In essence, appellant asks this court to determine whether an attorney has the inherent power to endorse a settlement check on behalf of his client. If so, appellant would be discharged from its obligation to the estate and guardianship; if not, appellant's obligation remains unpaid and owing. We find both that an attorney has no inherent authority to endorse a settlement check in the name of his client, and that, on the basis of the record before us, attorney Whitney made no such endorsement in this case.

In Ohio, as elsewhere, "an attorney who is without special authorization has no implied or apparent authority, solely by virtue of his general retainer, to compromise and settle his client's claim or cause of action." Similarly, an attorney has no inherent authority to enter into a contract for the sale of real estate for his client. While this court has not previously addressed whether an attorney may endorse his client's name on a check or draft tendered to effect a settlement, numerous other courts have done so. The clear majority of these courts find that no such authority exists. Therefore, while we recognize that the decisions on this question are in conflict, we believe that the better rule is that an attorney possesses no inherent authority, arising solely from the attorney-client relationship, to endorse his client's name on a settlement check or draft. The authority to receive a negotiable instrument on behalf of a client does not imply the power to endorse it. 
Accordingly, we hold that an attorney, absent any express authority from his client, has no authority to endorse the client's name on a check or draft tendered to effect a settlement.

Further, contrary to appellant's contention that attorney Whitney properly endorsed and deposited the drafts into his escrow account, the only admissible evidence in the record, Whitney's affidavit, reflects that Whitney endorsed neither draft and that the drafts were deposited into one of Whitney's general office accounts. Further, even assuming that Whitney endorsed the drafts, an "unauthorized signature" includes both a forgery and a signature made by an agent exceeding his actual or apparent authority. Thus, given our finding that attorneys have no inherent authority to endorse their client's name to a settlement draft, and the undisputed fact that there was no apparent or actual authority vested in Whitney to endorse the drafts herein, Whitney's endorsements, had he made any, would be unauthorized and appellant's obligation to the estate and guardianship would remain in effect.

The endorsements at issue herein were typewritten and restrictive in character. While such endorsements may, at times, be valid, we find that the endorsements at issue herein were unauthorized and thus not valid to operate as the signature of either the administrator or the guardian, the payees thereon.

An "'unauthorized' signature or indorsement is one made without actual, implied, or apparent authority and includes a forgery." Further, an "unauthorized signature is wholly inoperative as that of the person whose name is signed unless he ratifies it or is precluded from denying it; but it operates as the signature of the unauthorized signer in favor of any person who in good faith pays the instrument or takes it for value." Thus, an unauthorized signature does not operate as the signature of the named payee and, accordingly, may not act to pass title to an instrument or relieve the drawer of his obligation to pay the payee.

In the instant case, appellees presented the sworn affidavits of attorney Whitney, Orin Morris and Tom Swope. These affidavits established that Whitney did not endorse the drafts at issue, and that Morris and Swope neither signed nor authorized anyone else to sign these drafts. Further, Morris and Swope are the only parties who possessed the authority to authorize an agent to sign on their behalf. Moreover, appellant has failed, through the use of any admissible evidence, to refute the statements contained in the affidavits. Accordingly, the endorsements appearing on the second and third drafts, No. X559281 and No. X559280, were unauthorized and the payment of the drafts, as endorsed, constituted a conversion.

Appellant authorized the payment of the drafts. Even though the appellant was the original drawer, appellant was also the drawee for purposes of liability.

We, therefore, affirm the judgment of the court of appeals and remand the cause to the trial court for determination of the currently pending claims.

\section{Questions:}


- Why did the insurance company pay the checks?

- Why did the court hold that payment was improper?

- What should the insurance company have done?

Makins v. District of Columbia, 861 A. 2d 590 (D.C. 2004)

Summary: John Harrison represented Brenda Makins in a discrimination action against the District of Columbia. Harrison attended a settlement conference, reached an agreement, left the room to call Makins, and finalized the agreement when he returned. But Makins later refused to sign the agreement, claiming that she had refused to settle without reinstatement. The District of Columbia tried to enforce the settlement agreement, but the court refused, holding that Harrison lacked apparent authority to accept the settlement offer.

NEBEKER, Senior Judge:

The United States Court of Appeals for the District of Columbia Circuit has certified the following question to this court:

Under District of Columbia law, is a client bound by a settlement agreement negotiated by her attorney when the client has not given the attorney actual authority to settle the case on those terms but has authorized the attorney to attend a settlement conference before a magistrate judge and to negotiate on her behalf and when the attorney leads the opposing party to believe that the client has agreed to those terms.

For reasons set forth below, we answer the question in the negative. In so doing, we confine our analysis to the undisputed facts and those recited in the certified question.

In November 1998, Brenda Makins, represented by John Harrison, Esquire, brought an action against the District of Columbia in the United States District Court for the District of Columbia claiming sex discrimination and retaliatory firing. Makins had been employed in the District's Department of Corrections from 1995 until her discharge in 1997. Her complaint sought reinstatement, compensatory damages, and attorney's fees.

In the summer of 2000, at a pre-trial conference, the district judge referred Makins' case to a magistrate judge "for settlement purposes only" and ordered the District to "have present at all settlement meetings an individual with full settlement authority." A similar admonition was absent as to Ms. Makins. A few days later, the magistrate ordered the "lead attorney(s) for the parties" to appear before him for a settlement conference; the order required that the "parties shall either attend the settlement conference or be available by telephone for the duration of the settlement conference."

When the conference took place, Makins was not present. After two and a half hours of negotiations, Harrison and the attorneys for the District reached an agreement. Makins would 
receive $\$ 99,000$ and have her personnel records amended from "discharged" to "resigned" (to preserve her retirement benefits if she were able to obtain other creditable employment). In return, Makins would dismiss her claims against the District. Mr. Harrison left the hearing room with cell phone in hand, apparently to call Ms. Makins. When he returned, the attorneys "shook hands" on the deal and later reduced it to writing. A few days later, when Harrison presented Makins with a copy for her signature, she refused to sign it. The District then filed a Motion to Enforce Settlement. Makins retained another attorney, and the court held an evidentiary hearing in which Harrison, Makins, and the lead attorney for the District testified.

The testimony of Makins and Harrison was at odds respecting whether Harrison had been given authority to settle absent a provision for her reinstatement to her job. The District Court, observing this "sharp conflict" in testimony, declined to resolve it. Instead, the court assumed arguendo that Harrison did not have actual authority to settle the case short of reinstatement. The court granted the District's motion to enforce the settlement on the alternative ground that Harrison had apparent authority to bind Makins to the agreement. The court saw "no justification for the District of Columbia not to reasonably believe that Mr. Harrison had the full confidence and authority of his client."

There is arguably some inconsistency as to the extent of authority required of an attorney in settlement negotiations. Indeed, a review of relevant case law and principles enunciated by the American Bar Association and the American Law Institute demonstrate some differences not only over the extent of authority, but also the appropriate definitions of authority. To the extent that there tends to be this inconsistency among the cases, it reflects, in part, a difference in the application or integration of agency law with legal ethics principles, the attorney-client relationship and policy considerations.

This dissonance may in part be seen as a result of the intersection of ethical guidelines and rules governing the client-lawyer relationship and the relationship of a principal to her agent in the context of settlement agreements. On the one hand, the District of Columbia Code of Professional Responsibility Ethical Consideration 7-7 provides that it is the exclusive authority of "the client to decide whether [s] he will accept a settlement offer." Similarly, District of Columbia Rule of Professional Conduct 1.2(a) provides that a "lawyer shall abide by a client's decision whether to accept an offer of settlement of a matter." On the other hand, "it is well established that settlement agreements are entitled to enforcement under general principles of contract law." Agency principles are applied to determine whether the attorney or agent had authority to bind his principal to the settlement contract. Of course, an attorney can settle his client's case if he or she has actual authority to do so. Agency principles also recognize the authority of the agent to bind the client based on the doctrine of apparent authority.

The Restatement (Second) of Agency $\S 8$ defines apparent authority as "the power to affect the legal relations of another person by transactions with third persons, professedly as an agent for the other, arising from and in accordance with the other's manifestations to such third persons." Thus, unlike actual authority, apparent authority does not depend upon any manifestation from the principal to her agent, but rather from the principal to the third party. This court has stated 
that apparent authority arises when a principal places an agent "in a position which causes a third person to reasonably believe the principal had consented to the exercise of authority the agent purports to hold. This falls short of an overt, affirmative representation by a principal." In such circumstances, an agent's representations need not expressly be authorized by his principal. The apparent authority of an agent arises when the principal places the agent in such a position as to mislead third persons into believing that the agent is clothed with the authority which in fact he does not possess. Apparent authority depends upon "the third-party's perception of the agent's authority." The third party's perception may be based upon "written or spoken words or any other conduct of the principal which, reasonably interpreted, causes the third person to believe that the principal consents to have the act done on her behalf by the person purporting to act for her."

We reiterate that apparent authority is an established doctrine in this court's jurisprudence, and that settlement agreements are enforceable under general contract principles. But because apparent authority depends upon the principal's manifestations to the third party, the issue before us is what conduct by a client in the settlement context is sufficient reasonably to cause a third person to believe that the attorney representing the client has full, final settlement authority, rather than something short of that. Whether an agent had apparent authority is a question of fact and the party asserting the existence of apparent authority must prove it. In determining whether the agent had apparent authority to bind the principal, "consideration should be given, inter alia, to the actual authority of the agent, the usual or normal conduct of the agent in the performance of his or her duties, previous dealings between the agent and the party asserting apparent authority, any declarations or representations allegedly made by the agent, and lastly, the customary practice of other agents similarly situated." We take as a given that a third party in the shoes of the District of Columbia would reasonably assume that Makins had authorized attorney Harrison (1) to attend the settlement conference, and (2) to negotiate on her behalf; neither Makins nor amicus contends otherwise. We hold, however, that absent further manifestations by Makins - not Harrison - which are not contained in the certified question, there was insufficient conduct by the client to support a reasonable belief by the District that Harrison had full and final authority to agree to the settlement terms.

As pointed out, in the District of Columbia the decision to settle belongs to the client, a fact confirmed by our decisions.

The RESTATEMENT (THIRD) further confirms the generally accepted distinction between the power to conduct negotiations and the power to end the dispute. Conducting settlement negotiations is properly in the attorney's domain: "in the absence of a contrary agreement or instruction, a lawyer normally has authority to initiate or engage in settlement discussions, although not to conclude them." Concluding those settlement negotiations, however, is strictly the client's prerogative: "the decision to settle is reserved to the client because a settlement definitively disposes of client rights."

These ethical principles are key to the issue before us, because they not only govern the attorney-client relationship, they inform the reasonable beliefs of any opposing party involved in 
litigation in the District of Columbia, as well as the reasonable beliefs of the opposing party's counsel, whose practice is itself subject to those ethical constraints. It is the knowledge of these ethical precepts that makes it unreasonable for the opposing party and its counsel to believe that, absent some further client manifestation, the client has delegated final settlement authority as a necessary condition of giving the attorney authority to conduct negotiations. And it is for this reason that opposing parties - especially when represented by counsel, as here - must bear the risk of unreasonable expectations about an attorney's ability to settle a case on the client's behalf. "When a lawyer purports to enter a settlement binding on the client but lacks authority to do so, the burden of inconvenience resulting if the client repudiates the unauthorized settlement is properly left with the opposing party, who should know that settlements are normally subject to approval by the client and who has received no manifested contrary indication from the client."

Applying these principles, we conclude that the two client manifestations contained in the certified question - sending the attorney to the court-ordered settlement conference and permitting the attorney to negotiate on the client's behalf — were insufficient to permit a reasonable belief by the District that Harrison had been delegated authority to conclude the settlement. Some additional manifestation by Makins was necessary to establish that she had given her attorney final settlement authority, a power that goes beyond the authority an attorney is generally understood to have. The District, in its briefs, points only to actions and representation of record by Harrison, not Makins, as support for the reasonableness of its belief. Thus, it asserts that "Mr. Harrison represented that Ms. Makins was available by telephone and that he would consult with her when appropriate"; that "Mr. Harrison spoke on his cell phone with plaintiff at least three times during the conference"; and that "at one point, Mr. Harrison left the room to phone plaintiff about the defendant's latest settlement proposal, and returned, phone in hand, to accept the proposal with one new condition regarding amendment of personnel forms." All of this information (including information purportedly about the client, Makins) was known to the District of Columbia only through representations made by Harrison, the attorney. As the Circuit Court stated in certifying the question to us: "Neither the District nor the magistrate ever heard from Makins, in person or by telephone. What the District derives from the telephone calls between Makins and Harrison amounts to nothing more than Harrison's representations of - and the District's educated guesses about - what was said in private between them, a disputed factual question the district court did not resolve." Harrison's conduct and representations about his own authority, in short, are not dispositive to whether Makins herself furnished the basis for a reasonable belief that he was authorized to conclude the settlement.

At the en banc argument, counsel for the District characterized the record as showing that Makins "sent" Harrison to the settlement conference, thus manifesting to the court and the District his apparent authority to settle her claim. But Makins had little choice, short of discharging Harrison, except to allow him to continue to represent her in the negotiations at the ordered conference. To execute a settlement agreement then and there is quite another matter. 
Since Ms. Makins, as principal, did not make any manifestation of authority to the District's attorneys, other than retaining Harrison, under the facts as certified in the question, a finding of apparent authority is precluded under the law of this jurisdiction. The District also presents several policy arguments supporting enforcement of settlement agreements on apparent authority grounds, none of which we find compelling. To be sure, settlement of disputes, both in trial courts and on appeal, is to be encouraged as sound public policy. However, we are not persuaded that the settlement process will be impeded simply by requiring some manifestation of the client's authorization to support a claim of apparent authority in these cases where the client challenges the authority of his attorney to settle the claim. In addition, "apparent authority is an equitable doctrine that places the loss on one whose manifestations to another have misled the latter." Our holding is consistent with this principle. Since Makins manifested nothing by words or conduct on which reliance could be placed (she merely continued to retain Harrison), our answer to the certified question is not erosive to that policy.

We answer the certified question in the negative.

\section{Question:}

- What kind of authority did the District of Columbia claim the attorney had? Why was it insufficient?

- What if Makins actually agreed to the settlement, but then had second thoughts

- What is the purpose of "apparent authority"? Under the standard adopted by the court, is it possible for an attorney to exercise apparent authority?

\section{Further Reading:}




\section{4: Client as Principal}

I planned each charted course, each careful step along the byway. And more, much more than this, I did it my way. ${ }^{23}$

\section{Decisions Reserved to Clients}

As the principal, the client has the sole authority to make certain important decisions about their legal representation. Model Rule 1.2(a) provides that an attorney must respect a client's decisions about the goals of representation and consult with the client about the means of achieving those goals. It also identifies particular decisions that are reserved to the client, specifically the decision whether to settle in a civil case, and the decisions how to plead, whether to waive jury trial, and whether to testify in a criminal case.

However, attorneys retain considerable discretion to make decisions about how to pursue representation, so long as those decisions are consistent with the client's decisions, and implicitly authorized by the client as necessary to representation. In other words, the client is entitled to specify the goals of representation, but not to control the attorney's every decision in pursuit of those goals.

\section{Rule 1.2: Scope of Representation \& Allocation of Authority Between Client \& Lawyer}

a. A lawyer shall abide by a client's decisions concerning the objectives of representation and shall consult with the client as to the means by which they are to be pursued. A lawyer may take such action on behalf of the client as is impliedly authorized to carry out the representation. A lawyer shall abide by a client's decision whether to settle a matter. In a criminal case, the lawyer shall abide by the client's decision, after consultation with the lawyer, as to a plea to be entered, whether to waive jury trial and whether the client will testify.

\section{Restatement (Third) of the Law Governing Lawyers $\$ 22$ (2000)}

1. As between client and lawyer, subject to Subsection (2) and $\S 23$, the following and comparable decisions are reserved to the client except when the client has validly authorized the lawyer to make the particular decision: whether and on what terms to settle a claim; how a criminal defendant should plead; whether a criminal defendant should waive jury trial; whether a criminal defendant should testify; and whether to appeal in a civil proceeding or criminal prosecution.

2. A client may not validly authorize a lawyer to make the decisions described in Subsection (1) when other law (such as criminal-procedure rules governing pleas, jurytrial waiver, and defendant testimony) requires the client's personal participation or approval.

\footnotetext{
${ }^{23}$ Paul Anka, My Way (1967).
} 
3. Regardless of any contrary contract with a lawyer, a client may revoke a lawyer's authority to make the decisions described in Subsection (1).

\section{Restatement (Third) of the Law Governing Lawyers § 23 (2000)}

As between client and lawyer, a lawyer retains authority that may not be overridden by a contract with or an instruction from the client:

1. to refuse to perform, counsel, or assist future or ongoing acts in the representation that the lawyer reasonably believes to be unlawful;

2. to make decisions or take actions in the representation that the lawyer reasonably believes to be required by law or an order of a tribunal.

Bronson v. Borst, 404 A. 2 d 960 (D.C. App. 1979)

Summary: Bronson hired Borst to be his attorney to help him recover money from a car accident. Borst negotiated a $\$ 6,000$ settlement, but Bronson clearly told him not to accept it. After multiple failed attempts at communication, including a letter suggesting that Bronson find a new attorney if he does not accept the settlement, Borst accepted the settlement a day before the statute of limitations ran without Bronson's permission. The Superior Court enforced the settlement through a declaratory judgment, agreeing with Borst's reasoning that if he did not accept the settlement Bronson would have lost all chance of recovery, and accepting the settlement was a reasonable and justified step in representing his client well. The Appellate Court reversed, stating that regardless of the good faith of the attorney, absent specific authority, an attorney cannot accept a settlement offer on behalf of a client, and a client is not bound by settlements accepted without his express consent.

KELLY, Associate Judge:

Eugene C. Bronson here appeals from an adverse decision in a declaratory judgment action filed against him to enforce a settlement agreement and for the payment of attorney's fees and costs, arguing that the trial court erred in holding that an attorney does not need specific authority to accept a settlement on behalf of his client. We reverse.

I

The material facts are largely undisputed. On May 1, 1972, appellant's automobile was struck by an automobile owned by Mattos, Inc. In order to pursue a claim for personal injuries caused by the accident, appellant retained appellee Borst under a general retainer agreement which provided only for the usual contingency basis of payment, i.e., Borst was to receive one-third of any judgment recovered.

Borst was able to negotiate a $\$ 6,000$ settlement of appellant's claim with Mattos' insurer, but when he informed appellant of the proposed agreement, appellant made it clear to Borst that he 
would not accept the offer of settlement. From then on relations between Borst and his client became strained. Bronson, who at the time resided outside the District, failed to respond to Borst's communications, which included a letter in which Borst suggested that if Bronson was unable to accept the settlement, he might wish to retain new counsel. On April 30, 1975, the day before the statute of limitations ran, Borst, on behalf of his client Bronson, accepted the settlement offer.

Borst thereafter filed suit in Superior Court for a declaratory judgment to enforce the settlement he had accepted and for payment therefrom of attorney's fees and costs. Under oath, at trial, Borst testified to the above facts and to his reasons for accepting the compromise. He said he felt that if he did not accept the settlement, Bronson would have lost all chance for recovery. Since he had received no direction from Bronson after the letter explaining why settlement was necessary and suggesting new counsel should Bronson wish to pursue the claim, Borst maintained that he had no alternative to the reasonable and justified step of accepting the settlement. Borst testified he felt that the claim was without merit since Bronson claimed a $100 \%$ disability resulting from a previous accident and therefore he could not hope to receive a jury award larger than the settlement offer. Borst also stated that Bronson was unwilling or unable to assume the responsibility of paying for expert witnesses and other court costs. The parties agreed that there existed no specific and explicit authority in Borst to accept a settlement offer to compromise appellant's claim.

Bronson conducted a vigorous, but inartful, cross-examination. Frequently the trial judge admonished Bronson that his questioning was argumentative and advised that he would have an opportunity later to take the stand and present his case. After Borst left the stand, however, the trial judge asked Bronson to present support in the law for his case. When Bronson completed his statement, the judge ruled for Borst without giving Bronson the opportunity to take the stand and testify under oath.

II

Appellant's first argument is that the trial court erred, as a matter of law, in holding that the settlement agreement at issue was binding on him. His analysis is that an attorney without express authority cannot accept for his client any settlement regardless of the merits of the client's case or the attractiveness of the settlement offer. That conclusion was stated succinctly in Ashley v. Atlas Mfg. Co. In Ashley, the court confronted a courtroom settlement to which counsel for both parties assented in open court. Although the court judged from the tenor of the agreement and the manner in which the attorney for defendant announced the agreement in the presence of the defendant that the attorney had specific authority to settle the case, the court noted that

as a matter of law it is true, strictly speaking, an attorney has no right, without special authority, to make a compromise for his client. 
Appellee argues that given the circumstances, his action in accepting the settlement in the face of his client's objections was reasonable and justified. He maintains that had he not so accepted the compromise offer, his client's claim would have been barred by the statute of limitations and his chances for recompense could have been lost forever. To file the suit as his client demanded, appellee contends, would have been a wholly futile and costly endeavor. Finally, appellee argues that his client was either ignorant of the high cost of litigation or was unwilling to bear the responsibility of making the expenditures; presumably the client expected his attorney to bear the expense of litigation.

In his brief to this court, appellee offers no support in the law for the above proposition. At trial, he relied on Mullen $v$. People's Drug Stores, for the proposition that "one who is represented by counsel is bound by his actions." Both Turner and Mullen, however, are inapposite to the issue here. In Turner, the court saddled the client with his attorney's negligence in not appearing to answer a complaint. In upholding a default judgment, the court noted that "one who comes into court through counsel of his own choice is bound by the actions of his counsel." In Mullen, the issue was whether a client is bound by the trial tactics of his attorney; specifically, the decision not to call a witness whose testimony would have gone to stipulated facts.

Whether to penalize a party for his counsel's failure to appear in court and whether to bind a client to his attorney's trial tactics present issues distinct from the issues here. In the two former situations, the inquiry concerns the execution by the attorney of the services that, by contract, he must perform for his client. In the instant case, we must analyze actions which counsel was neither duty bound nor authorized to perform.

We agree with appellant that regardless of the good faith of the attorney, absent specific authority, an attorney cannot accept a settlement offer on behalf of a client. Mr. Borst felt that he had no option but to accept the settlement offer for fear that the cause of action would be barred. Such a fear was unfounded. Mr. Bronson had made his stand clear; he wanted to pursue his claim. If Mr. Borst had ethical or financial reservations about continued representation of Mr. Bronson, he could have terminated the relationship well before the statute ran or he could have filed the suit and requested leave of the court to withdraw early in the litigation. Regardless of the options available to him, appellee chose one route that was, or should have been, foreclosed to him. Accordingly, we reverse the judgment of the trial court which purports to enforce the settlement agreement.

Finding that the trial court erred in its application of the law, we reverse the decision of the trial court and remand the cause for proceedings not inconsistent with this opinion.

\section{Questions:}

\section{Impaired Clients}

Attorneys often represent clients who have an impaired ability to make or express decisions. For example, attorneys often represent minors, who cannot make legally binding decisions. 
Attorneys may also represent people with physical impairments that affect their ability to express their decisions, or mental impairments that affect their ability to make decisions that are in their own best interests.

When an attorney represents a legally, physically, or mentally impaired client, the client remains the principal and is entitled to dignity and respect. Accordingly, the attorney must provide relevant information to the client, consult with the client, and pursue the client's wishes, whenever it is possible and in the client's best interests.

Sometimes, impaired clients have legal representatives empowered to make decisions on their behalf. In that case, the attorney must ordinarily obey the decisions of the legal representative. But the attorney must also inform the client about those decisions, and consult with the client whenever possible.

Regardless, the attorney must always put the client's interests first. If the attorney represents the impaired client directly, then the attorney has a fiduciary duty to the client, and must ensure that the legal representative's actions are in the client's best interests. If the attorney represents the legal representative, then the attorney has a fiduciary duty to the legal representative, but still must ensure that the legal representative respects its own fiduciary duty to the client. For example, if an attorney represents a client who is a minor, the attorney must obey the decisions of the client's guardian, but must also consult with the client, in order to determine the client's wishes, and ensure that the client's guardian does not violate its fiduciary duties. Likewise, if an attorney represents a comatose client, the attorney must obey the decisions of the client's guardian, but must also ensure that the guardian does not violate its fiduciary duties.

Sometimes, it is unclear whether a client is impaired. The client may be unable to communicate with the attorney, unable to make consistent decisions, unable to make good decisions, or unwilling to conform to social expectations. These are hard cases. If a direct attorney-client relationship is untenable, the attorney should seek the appointment of a legal representative. But if the attorney can represent the client directly, then the attorney must act in the client's best interests. This can create a conflict, if the attorney believes that the client's instructions are inconsistent with the client's best interests. Should the attorney obey the client?

\section{Rule 1.14: Client with Diminished Capacity}

a. When a client's capacity to make adequately considered decisions in connection with a representation is diminished, whether because of minority, mental impairment or for some other reason, the lawyer shall, as far as reasonably possible, maintain a normal client-lawyer relationship with the client.

b. When the lawyer reasonably believes that the client has diminished capacity, is at risk of substantial physical, financial or other harm unless action is taken and cannot adequately act in the client's own interest, the lawyer may take reasonably necessary protective action, including consulting with individuals or entities that have the ability to 
take action to protect the client and, in appropriate cases, seeking the appointment of a guardian ad litem, conservator or guardian.

c. Information relating to the representation of a client with diminished capacity is protected by Rule 1.6. When taking protective action pursuant to paragraph (b), the lawyer is impliedly authorized under Rule 1.6(a) to reveal information about the client, but only to the extent reasonably necessary to protect the client's interests.

\section{Restatement (Third) of the Law Governing Lawyers $§ 24$ (2000): A Client with Diminished Capacity}

1. When a client's capacity to make adequately considered decisions in connection with the representation is diminished, whether because of minority, physical illness, mental disability, or other cause, the lawyer must, as far as reasonably possible, maintain a normal client-lawyer relationship with the client and act in the best interests of the client as stated in Subsection (2).

2. A lawyer representing a client with diminished capacity as described in Subsection (1) and for whom no guardian or other representative is available to act, must, with respect to a matter within the scope of the representation, pursue the lawyer's reasonable view of the client's objectives or interests as the client would define them if able to make adequately considered decisions on the matter, even if the client expresses no wishes or gives contrary instructions.

3. If a client with diminished capacity as described in Subsection (1) has a guardian or other person legally entitled to act for the client, the client's lawyer must treat that person as entitled to act with respect to the client's interests in the matter, unless:

a. the lawyer represents the client in a matter against the interests of that person; or

b. that person instructs the lawyer to act in a manner that the lawyer knows will violate the person's legal duties toward the client.

4. A lawyer representing a client with diminished capacity as described in Subsection (1) may seek the appointment of a guardian or take other protective action within the scope of the representation when doing so is practical and will advance the client's objectives or interests, determined as stated in Subsection (2).

People v. Bolden, 99 Cal. App. 3d 375 (Cal. Ct. App. 1979)

Summary: Bolden was denied effective assistance of counsel when his counsel offered evidence of Bolden's incompetence although Bolden desired to be found competent. Two psychiatrists testified for the People saying Bolden wasn't competent because he was suffering delusions (thought the people he assaulted-his father and brother-were aliens from outer space). Bolden argues a section of the Penal Code that lets a judge who doubts the mental competence of the defendant ask the attorney's opinion of the defendant's competence violates the attorney-client privilege. The court found that an attorney's opinion about his client's competence does not reveal confidential information. The court held that Bolden's attorney provided effective assistance to his client. 
Samuel Othello Bolden, Jr., appeals the order finding him mentally incompetent to stand trial based upon a jury verdict of incompetence. Bolden contends he was denied due process by Penal Code section 1368 which requires his attorney to give an opinion of his client's competence, and was denied effective assistance of counsel when his counsel offered evidence of his incompetence although Bolden desired to be found competent.

Bolden was charged with robbery, two counts of assault with intent to murder, and two counts of assault with a deadly weapon. Criminal proceedings were suspended to determine if Bolden was competent to stand trial. The first jury trial on the issue of competence was declared a mistrial after the jury was unable to reach a verdict. New counsel was appointed for the retrial. Two psychiatrists testifying for the People said Bolden was not competent to stand trial, as he was suffering delusions. He believed the people he was charged with assaulting, his father and brother, were actually aliens from outer space who were inhabiting the bodies of his father and brother.

Out of the jury's presence Bolden's counsel explained to the court his client wanted to testify in his own behalf and wanted to be found competent to stand trial. While counsel felt he had a duty to pursue his client's desires, he also felt he had a duty to represent his client's best interests. He had been told by professional people a not-guilty-by-reason-of-insanity defense was available for his client. He felt he needed his client's cooperation to pursue this defense. Bolden's current mental state interfered with such cooperation. Counsel's solution to this dilemma was to place Bolden on the witness stand to testify to his competence, and then to offer his own psychiatric witness who testified Bolden was not competent to stand trial.

After 10 minutes of deliberation, the jury returned a verdict of not competent to stand trial. Bolden was committed to Patton State Hospital for treatment.

Penal Code section 1368 requires a judge who doubts the mental competence of the defendant to "inquire of the attorney for the defendant whether, in the opinion of the attorney, the defendant is mentally competent." Bolden contends this section violates the attorney-client privilege by requiring the attorney to reveal knowledge gained in the course of his relationship with his client.

This statute does not, however, require the disclosure of a confidential communication. "What the attorney observes of or hears from his client is not always privileged. It is apparent that some ingredient of disclosure or revelation is essential to the element of communication." Although an attorney's opinion of his client's competence may be principally drawn from confidential communications he has had with that client, merely giving the opinion does not reveal any protected information.

A "confidential communication" is defined as "information transmitted between a client and his lawyer in the course of that relationship and includes a legal opinion formed and the advice given by the lawyer." Bolden latches onto the words "legal opinion" and argues the opinion of competence is a legal opinion which is protected. The statute, however, uses "legal opinion" to 
specify one type of information protected. Substituting "legal opinion" for "information" in the statutory language, we see the type of legal opinion protected by the privilege is one "transmitted between a client and his lawyer," not one, as here, initially transmitted between the lawyer and the court.

Bolden contends even if the attorney's opinion of mental competence does not always reveal a confidential communication, in this case the psychiatrists who examined him based their opinions in part upon specific communications occurring between Bolden and his first counsel. Bolden cites us to only one place in the record where such communication is mentioned. There the psychiatrist testified Bolden's former attorney said Bolden believed the aliens inhabiting his father's body were from outer space. However, even assuming Bolden's former attorney improperly revealed privileged information to the psychiatrists, there was no prejudice to Bolden from the revelation as Bolden himself also told the psychiatrists, and testified in court, alien imposters had taken over the bodies of his family and others.

Bolden contends he was denied effective assistance of counsel, since he did not receive "the kind of legal assistance to be expected of a reasonably competent attorney acting as a conscientious, diligent advocate." No complaint is made about the skill of his attorney or the attorney's dedication to his client. Bolden's contention is the attorney was acting in what he felt was the best interest of his client rather than as an advocate of his client's position. By his attorney "siding" with the People in offering evidence of incompetence, Bolden contends, his desire to be found competent went unrepresented.

Diligent advocacy does not require an attorney to blindly follow every desire of his client. An attorney can ordinarily make binding waivers of many of his client's rights as to matters of trial tactics. When the attorney doubts the present sanity of his client, he may assume his client cannot act in his own best interests and may act even contrary to the express desires of his client. To do otherwise may cause prejudicial error.

Bolden's attorney provided effective assistance to his client.

\section{Questions:}

\section{Further Reading:}




\section{5: Ex Parte Communications}

I got something to say that might cause you pain. If I catch you talking to that boy again, I'm gonna let you down, and leave you flat, because I told you before, oh, you can't do that. ${ }^{24}$

Model Rule 4.2 prohibits attorneys from engaging in "ex parte" communications, or communications with a represented person without the consent of that person's attorney or the permission of the court.

In theory, the purpose of the prohibition on ex parte communications with represented persons is to help protect clients and ensure they receive the advice of counsel. As Model Rule 4.2, Comment [1] explains:

This Rule contributes to the proper functioning of the legal system by protecting a person who has chosen to be represented by a lawyer in a matter against possible overreaching by other lawyers who are participating in the matter, interference by those lawyers with the client-lawyer relationship and the uncounselled disclosure of information relating to the representation.

The prohibition on ex parte communications applies to all represented persons involved in a matter. Accordingly, it prohibits ex parte communications with not only represented persons who are adverse parties, but also represented persons who are co-parties or non-parties. And it applies to directed communications. In other words, an attorney cannot avoid the prohibition by instructing or advising a non-attorney to contact a represented person. Furthermore, the prohibition on ex parte communications is not waivable by the client, and it applies even if the client initiates the communication, requiring the attorney to immediately end the communication. Model Rule 4.2, Comment [2] \& [3].

The prohibition on ex parte communications with represented persons may also apply to the employees of represented organizations. Most courts have held that attorneys cannot engage in ex parte communications with employees of a represented organization who control the organization, acted on behalf of the organization in the matter, or make legal decisions for the organization. In other words, upper management and people directly involved in the matter are off-limits, but other employees are not. In particular, former employees are generally fair game.

Notably, Model Rule 4.2 does incorporate a mens rea requirement. Attorneys cannot be disciplined for engaging in an ex parte communication with a represented person unless they knew or should have known that the person was represented in relation to the matter. Model Rule 4.2, Comment [8].

And Model Rule 4.2 does not prohibit all ex parte communications. Nothing prevents an attorney from engaging in ex parte communications with a represented person about subjects unrelated

${ }^{24}$ The Beatles, You Can't Do That, A Hard Day's Night (1964). 
to the matter in which they are represented. And nothing prevents an attorney who is not representing anyone in relation to matter from engaging in ex parte communications with a represented party. In other words, attorneys may continue to pursue unrelated business, and clients may consult with outside counsel. Model Rule 4.2, Comment [4].

In addition, Model Rule 4.2 only applies to attorneys. Nothing prevents represented persons from engaging in ex parte communications with each other. And if represented persons choose to communicate with each other, their attorneys may provide them with advice. "Parties to a matter may communicate directly with each other, and a lawyer is not prohibited from advising a client concerning a communication that the client is legally entitled to make." Model Rule 4.2, Comment [4]. Indeed, attorneys can probably even advise their clients to engage in ex parte communications with represented parties.

\section{Rule 4.2: Communication with Person Represented by Counsel}

In representing a client, a lawyer shall not communicate about the subject of the representation with a person the lawyer knows to be represented by another lawyer in the matter, unless the lawyer has the consent of the other lawyer or is authorized to do so by law or a court order.

\section{Restatement (Third) of the Law Governing Lawyers § 99: A Represented Nonclient-The General Anti-Contact Rule}

1. A lawyer representing a client in a matter may not communicate about the subject of the representation with a nonclient whom the lawyer knows to be represented in the matter by another lawyer or with a representative of an organizational nonclient so represented as defined in $\S 100$, unless:

a. the communication is with a public officer or agency to the extent stated in $\S 101$;

b. the lawyer is a party and represents no other client in the matter;

c. the communication is authorized by law;

d. the communication reasonably responds to an emergency; or

e. the other lawyer consents.

2. Subsection (1) does not prohibit the lawyer from assisting the client in otherwise proper communication by the lawyer's client with a represented nonclient.

\section{Restatement (Third) of the Law Governing Lawyers § 100: Definition of a Represented Nonclient}

Within the meaning of $\S 99$, a represented nonclient includes:

1. a natural person represented by a lawyer; and:

2. a current employee or other agent of an organization represented by a lawyer:

a. if the employee or other agent supervises, directs, or regularly consults with the lawyer concerning the matter or if the agent has power to compromise or settle the matter; 
b. if the acts or omissions of the employee or other agent may be imputed to the organization for purposes of civil or criminal liability in the matter; or

c. if a statement of the employee or other agent, under applicable rules of evidence, would have the effect of binding the organization with respect to proof of the matter.

\section{Restatement (Third) of the Law Governing Lawyers § 101: A Represented Governmental Agency or Officer}

1. Unless otherwise provided by law (see $\S 99(1)(c)$ ) and except as provided in Subsection (2), the prohibition stated in $\S 99$ against contact with a represented nonclient does not apply to communications with employees of a represented governmental agency or with a governmental officer being represented in the officer's official capacity.

2. In negotiation or litigation by a lawyer of a specific claim of a client against a governmental agency or against a governmental officer in the officer's official capacity, the prohibition stated in $\S 99$ applies, except that the lawyer may contact any officer of the government if permitted by the agency or with respect to an issue of general policy.

In re Disciplinary Proceeding Against Haley, 126 P. 3d 1262 (Wash. 2006)

Summary: Haley is appealing the recommendation of a Disciplinary Board proceeding that Haley be subject to a 6 month suspension for violating Rule 4.2(a). Haley filed a lawsuit against a CEO of his former employer, Highland, acting pro se. Highland was represented by various attorneys. Haley sent a letter to Highland proposing a settlement. Highland's lawyer said the letter was a violation of Rule 4.2 and told Haley to not talk to Highland directly. Haley called Highland, appearing to tell him the legal status of his case and once again proposing settlement. This was an issue of first impression for the court and a split of among authorities. Haley argued that pro se lawyers should not be included in the scope of the rule because the lawyer has no client. The court held that a lawyer acting pro se is prohibited from contacting a party represented by counsel in the matter and applied the rule prospectively.

\section{OWENS, J.}

Attorney Jeffrey T. Haley appeals the recommendation of the Disciplinary Board of the Washington State Bar Association that Haley was subject to a six-month suspension for knowingly violating RPC 4.2(a), which provides that, "in representing a client, a lawyer shall not communicate with a party represented by another lawyer."

Although we hold that, under RPC 4.2(a), a lawyer acting pro se is prohibited from contacting a party represented by counsel in the matter, we apply our interpretation of RPC 4.2(a) prospectively only and dismiss the violation.

\section{FACTS}


In 1994, Haley filed a lawsuit against Carl Highland, the former chief executive officer of a defunct closely held corporation, Coresoft, of which Haley was formerly a shareholder and board member. Initially, Haley acted pro se in the matter but hired counsel when the case went to trial in November 1995. After the trial ended, Haley's counsel filed notice of withdrawal and Haley reverted to pro se status as to appeal and collection issues. Highland was represented by various attorneys at all times during this matter, and Haley knew that Highland was consistently represented by counsel.

The hearing officer and Board concluded that Haley's improper contact with a represented party arose out of two incidents. First, while Haley was acting pro se after the trial, he sent a letter to Highland and his wife proposing settlement. The letter was dated September 9, 1996, and stated in full as follows:

I am about to spend approximately $\$ 25,000$ on costs and attorneys fees for the appeal. If the appeal is successful, the personal earnings of both Ronda Hull and Carl Highland will be subject to garnishment to satisfy my judgment and the judgment now held by Carl Highland will be overruled. Also, the amount I am about the [sic] spend on costs and attorneys fees will be added to the judgment.

This is the last opportunity to settle the case before I spend the money on the appeal. This settlement offer will not be open after this week and may be withdrawn at any time if it is not promptly accepted. I am offering that all claims and judgments between the parties be releases [sic] with no payments. Please respond directly to me.

Highland forwarded the letter to his attorney who, in turn, suggested to Haley that the letter constituted a violation of RPC 4.2(a) and warned him not to have any further contact with Highland. Second, on January 31, 1997, Haley again contacted Highland, this time by telephone. Haley left the following voice message on Highland's phone:

Carl, this is Jeff Haley. I hope your attorneys have told you Jim Bates decided that your judgment against me is collectable only from my separate assets and I have none; they're all community assets. And, therefore, your judgment is uncollectable [sic]. And the chance for appeal of that determination by Jim Bates has run so you can't appeal it so that if the appeal proceeds my position can only improve and yours can only get worse and if you have nothing collectable there's no chance of ever getting anything collectable. It seems to me that we ought to settle this case and if we do so Monday there'll be an opportunity on Monday to do so if you're interested. Give me a call."

In his "Amended Findings of Fact and Conclusions of Law," the hearing officer stated that Haley's letter and phone message were "clearly prohibited" by RPC 4.2(a), but he acknowledged that there was some authority supporting Haley's position that attorneys acting pro se are not subject to the prohibition. Ultimately, in his "Additional Findings of Fact, Application of Standards, and Recommendation," the hearing officer determined that, "because 
of the specific language of RPC 4.2 (i.e., 'In representing a client') and because of the apparent absence of authority within the state of Washington on this specific issue, Mr. Haley could have harbored a sincere belief that contacts with a represented opposing party were not prohibited." Consequently, the hearing officer concluded that the violation was "negligent" and that the presumptive sanction was thus a reprimand.

Deleting the hearing officer's conclusion that Haley's violation was negligent, the Board substituted its contrary determination that "Haley's mental state was knowledge" and that the presumptive sanction was therefore a suspension. In doing so, the Board took note that Haley knew Highland was represented by counsel at all times and stated that a "reasonable reading of RPC 4.2 prohibits a lawyer, while representing himself or herself, from contacting a represented party." The Board also faulted Haley for not "taking time to determine whether his conduct was an ethical violation."

The hearing officer recommended that Haley be reprimanded for the violation. The Board recommended a six-month suspension.

Does RPC 4.2(a) prohibit a lawyer who is acting pro se from contacting a party who is represented by counsel? If so, should the rule be applied in the present case?

ANALYSIS

Applicability of RPC 4.2(a) to Lawyer Acting Pro Se. RPC 4.2(a) reads in full as follows:

In representing a client, a lawyer shall not communicate about the subject of the representation with a party the lawyer knows to be represented by another lawyer in the matter, unless the lawyer has the consent of the other lawyer or is authorized by law to do so.

The rule is virtually identical to model rule 4.2. While we have not formally adopted the commentary to the ABA Annotated Model Rules, we have noted that it "may be 'instructive in exploring the underlying policy of the rules."' As the comment to model rule 4.2 explains, the rule aims to protect those represented by counsel "against possible overreaching by other lawyers who are participating in the matter, interference by those lawyers with the client-lawyer relationship and the uncounselled disclosure of information relating to the representation." In Carmick, we acknowledged that "the rule's purpose is to prevent situations in which a represented party is taken advantage of by adverse counsel."

At issue in the present case is whether RPC 4.2(a) applies to lawyers acting pro se - or, more precisely, whether a lawyer who is representing himself or herself is, in the words of RPC 4.2(a), "representing a client." This court has not previously addressed this issue; nor has the WSBA issued an ethics opinion, formal or informal, on the question. Other jurisdictions that have considered the rule's applicability to lawyers acting pro se have generally concluded that the policies underlying the rule are better served by extending the restriction to lawyers acting pro se. 
Haley asks this court to take the contrary view and hold that the plain meaning of the word "client" in RPC 4.2(a) precludes application of the rule to a lawyer acting pro se. The word "client" is variously defined as "a person or entity that employs a professional for advice or help in that professional's line of work," and "a person who engages the professional advice or services of another." Thus, for the rule to apply to lawyers acting pro se, such lawyers would, in effect, be employing or engaging themselves for advice, help, or services. This, as Haley contends, suggests that lawyers who are acting pro se are excluded from the scope of the rule because such lawyers have no client.

In the alternative, Haley maintains that, even if RPC 4.2(a) were construed to restrict pro se lawyers from contacting represented parties, we should conclude that the rule as applied to him, a lawyer proceeding pro se, was unconstitutionally vague, violating his constitutional due process rights. Such a resolution finds support in Schaefer. There, the Nevada State Supreme Court relied on the principle that "a statute or rule is impermissibly vague if it "either forbids or requires the doing of an act in terms so vague that men of common intelligence must necessarily guess at its meaning and differ as to its application." The Schaefer court based its determination that Nevada's Supreme Court Rule 182, a rule identical to RPC 4.2(a), was unconstitutionally vague on "the absence of clear guidance" from the Nevada State Supreme Court and on "the existence of conflicting authority from other jurisdictions."

Both factors relied on in Schaefer are present here. First, as noted above, no prior opinion of this court has addressed the application of RPC 4.2(a) to lawyers proceeding pro se. Second, in late 1996 and early 1997 when Haley contacted Highland, authority permitting such contacts counterbalanced the prohibitions then existing from four jurisdictions. The comment to rule 2100 of the California RPCs, a rule identical to RPC 4.2(a) in all material respects, explicitly permits a lawyer proceeding pro se to contact a represented party:

The rule does not prohibit a lawyer who is also a party to a legal matter from directly or indirectly communicating on his or her own behalf with a represented party. Such a member has independent rights as a party which should not be abrogated because of his or her professional status. To prevent any possible abuse in such situations, the counsel for the opposing party may advise that party (1) about the risks and benefits of communications with a lawyer-party, and (2) not to accept or engage in communications with the lawyer-party.

Likewise, a comment to the restatement specifically provides that "a lawyer representing his or her own interests pro se may communicate with an opposing represented nonclient on the same basis as other principals."

Alongside these explicit statements permitting the questioned contact, other authorities supported a reasonable inference that our RPC 4.2(a) did not foreclose a pro se lawyer's communication with a represented opposing party. For example, the comparable rule in Oregon, DR 7-104(A)(1), put lawyers acting pro se squarely within the rule's ambit: 
(A) During the course of the lawyer's representation of a client, a lawyer shall not:

(1) Communicate or cause another to communicate with a person the lawyer knows to be represented by a lawyer. This prohibition includes a lawyer representing the lawyer's own interests.

The absence of an explicit prohibition in RPC 4.2(a) could have suggested that Washington's rule was narrower in scope than Oregon's and did not apply to lawyers acting pro se.

Additionally, the commentary to model rule 4.2 includes the statement that "parties to a matter may communicate directly with each other." Unlike the commentary to the restatement and to California's RPC 2-100, this comment does not pointedly refer to a lawyer-party acting pro se; consequently, the breadth of the statement permits an inference that all parties may communicate unreservedly with each other. Finally, the holding in Pinsky v. Statewide Grievance Committee, appears to call into question the policy concerns supporting the application of RPC 4.2(a) to lawyers acting pro se. In Pinsky, the Connecticut State Supreme Court concluded that a represented lawyer-party had not violated an identical version of RPC 4.2(a) when he directly contacted his landlord, who was also represented by counsel, during an eviction matter. The Pinsky court took note that "contact between litigants is specifically authorized by the comments under rule 4.2" and concluded that Pinsky was not "representing a client" as stated in the rule. The Pinsky court thus determined that communication between a represented lawyer-party and a represented nonlawyer party did not conflict with a key purpose of RPC 4.2(a) - the protection of a represented nonlawyer party from "possible overreaching by other lawyers who are participating in the matter." Because the Pinsky decision did not address why contacts from a lawyer acting pro se would pose a greater threat of overreaching than would contacts from a represented lawyer-party, Pinsky provides further equivocal authority on the application of RPC 4.2(a) to lawyers acting pro se.

In sum, consistent with the resolution of the same issue in Schaefer, we hold that a lawyer acting pro se is "representing a client" for purposes of RPC 4.2(a), but given the absence of a prior decision from this court, along with the presence of conflicting or equivocal authority from other jurisdictions and legal commentaries, we find the rule impermissibly vague as to its applicability to pro se attorneys and thus apply our interpretation of the rule prospectively only. We therefore dismiss the violation alleged in count 2. We need not reach Haley's alternative contention that the application of RPC 4.2(a) to his communications with Highland violated his free speech rights.

\section{CONCLUSION}

We hold that RPC 4.2(a) prohibits a lawyer who is representing his own interests in a matter from contacting another party whom he knows to be represented by counsel. However, because we conclude that RPC 4.2(a) was impermissibly vague as applied to Haley, we apply our interpretation of RPC 4.2(a) prospectively only and thus dismiss.

C.JOHNSON, BRIDGE, CHAMBERS, and J.M. JOHNSON, JJ, concur. 
MADSEN, J. (concurring).

I agree with part one of Justice Sanders' concurrence. This court currently has a new set of RPCs pending before it. Because I agree with the majority that the better policy is to include self-represented lawyers within the prohibition of RPC 4.2(a), I would revise that rule in conjunction with the review of the RPCs and avoid the issue of prospectivity.

SANDERS, J. (concurring).

The majority holds that self-represented lawyers are "representing a client" under RPC 4.2(a) and therefore may not contact a represented party. But it refrains from sanctioning Haley, implicitly holding that the scope of RPC 4.2(a) is ambiguous. I concur only in the result, because the majority incorrectly construes RPC 4.2(a). The plain language of RPC 4.2(a) exempts selfrepresented lawyers. And the rule of lenity requires strict and narrow construction of an ambiguous penal statute. We must apply RPC 4.2(a) prospectively just as we apply it today.

\section{THE PLAIN LANGUAGE OF RPC 4.2(A) PERMITS SELF-REPRESENTED LAWYERS TO CONTACT REPRESENTED PARTIES}

Court rules like the Code of Professional Responsibility "are subject to the same principles of construction as are statutes." Thus, when interpreting a rule we give "the words their ordinary meaning, reading the language as a whole and seeking to give effect to all of it." If the plain language of the rule is unambiguous, additional interpretation is unnecessary.

The plain language of RPC 4.2(a) unambiguously exempts self-represented lawyers. "In representing a client, a lawyer shall not communicate about the subject of the representation with a party the lawyer knows to be represented by another lawyer in the matter, unless the lawyer has the consent of the other lawyer or is authorized by law to do so." A "client" is "a person who consults or engages the services of a legal advisor," or a "person or entity that employs a professional for advice or help in that professional's line of work." In other words, a "client" is a third party who engages a lawyer. Because self-represented lawyers have no client, under RPC 4.2(a) they may contact a represented party.

The majority concedes that RPC 4.2(a) applies only when a lawyer is "representing a client" but nonetheless construes it to cover self-represented lawyers. Apparently, the majority concludes that self-represented lawyers are "employing or engaging themselves for advice, help, or services."

This ingenious bit of legal fiction illustrates the wisdom of avoiding interpretations "conceivable in the metaphysical sense" when the plain language of a statute "is both necessary and sufficient." Assuming that a self-represented lawyer represents a "client" certainly produces the majority's preferred outcome. Unfortunately, it does so only at the expense of coherence. Lawyers cannot retain themselves any more than pro se litigants can claim legal malpractice or 
ineffective assistance of counsel. Undoubtedly, wise lawyers follow their own counsel. But it is a neat trick indeed to advise oneself.

The majority's claim to follow an emerging majority rule is unavailing. Indeed, it cites decisions from six states concluding that self-represented lawyers are their own clients. But none offers any more convincing a rationale for this curious conclusion than the majority. Conclusory statements cannot substitute for legal reasoning, and another court's error cannot justify our own.

Likewise, the majority's reliance on the "purpose" of RPC 4.2(a) is misplaced. As the author of the court rules, we are "in a position to reveal the actual meaning which was sought to be conveyed." But in the interest of certainty and consistency, we approach them "as though they had been drafted by the Legislature." Whatever the purpose of RPC 4.2(a), it cannot extend to persons and actions its plain language excludes. We may not expand the scope of a rule by fiat. If we conclude that self-represented lawyers should not contact represented parties, we should simply rewrite the rule to clearly prohibit that conduct. Other states have already done so. Lawyers should not have to read slip opinions to divine their professional obligations.

\section{THE RULE OF LENITY REQUIRES A CONSTRUCTION OF RPC 4.2(A) EXEMPTING SELF-REPRESENTED LAWYERS}

Even assuming that the plain language of RPC 4.2(a) is somehow ambiguous, the rule of lenity requires a strict and narrow construction exempting self-represented lawyers. The rule of lenity is a venerable canon of statutory interpretation, requiring courts "to interpret ambiguous criminal statutes in the defendant's favor." While the Rules of Professional Conduct are only "quasicriminal," the rule of lenity applies to both criminal and quasi-criminal statutes. The deciding factor is the nature of the sanction imposed.

As a general rule, courts apply the rule of lenity to any statute imposing penal sanctions. "We are mindful of the maxim that penal statutes should be strictly construed." A statute is penal if it "can be punished by imprisonment and/or a fine" and remedial if it "provides for the remission of penalties and affords a remedy for the enforcement of rights and the redress of injuries."

The Rules of Professional Conduct are penal because they concern punishing an offender, not compensating a victim. Professional discipline "is punitive, unavoidably so, despite the fact that it is not designed for that purpose." While the "purpose of disciplining an attorney is not primarily to punish the wrongdoer," punishment is an important purpose - and a necessary consequence - of professional discipline.

Courts have long recognized that disbarment is "penal in its nature" and subject to the rule of lenity. The same holds for all other sanctions. "Because attorney suspension is a quasi-criminal punishment in character, any disciplinary rules used to impose this sanction on attorneys must be strictly construed resolving ambiguities in favor of the person charged." 
In his dissent, Chief Justice Alexander suggests that the Rules of Professional Conduct can tolerate a degree of vagueness. But RPC 4.2(a) is not vague. It is ambiguous. And the Rules of Professional Conduct certainly cannot tolerate ambiguity.

A statute is ambiguous if it "refers to $\mathrm{P}, \mathrm{P}$ can alternatively encompass either $\mathrm{a}$ or $\mathrm{b}$, and it is beyond dispute that the defendant did a" and vague if it "refers to X, but we cannot tell whether the disputed event is an X." No one disputes what Haley did: While representing himself, he contacted a represented party. The only question is whether the term "representing a client" encompasses self-represented lawyers, as well as lawyers representing third parties. And if the term "representing a client" is "susceptible to more than one reasonable meaning," it is ambiguous.

Courts routinely apply the rule of lenity to ambiguous statutes. And the rule of lenity is peculiarly appropriate to the Rules of Professional Conduct. We have recognized that "in a disciplinary proceeding, all doubts should be resolved in favor of the attorney." Because lawyers "are subject to professional discipline only for acts that are described as prohibited in an applicable lawyer code, statute, or rule of court," courts "should be circumspect in avoiding overbroad readings or resorting to standards other than those fairly encompassed within an applicable lawyer code." Application of the rule of lenity reflects that caution. It demands that we adopt the stricter, narrower construction, excluding self-represented lawyers.

\section{CONCLUSION}

The majority objects to the plain language of RPC 4.2(a) only because it believes that permitting self-represented lawyers to contact represented parties would violate the "purpose" of the rule. But the putative "spirit and intent" of a rule can trump only a "strained and unlikely" interpretation. And the plain language of RPC 4.2(a) is neither strained nor unlikely. It prohibits a lawyer representing a client - but not a self-represented lawyer — from contacting a represented party. As the majority concedes, several commentators and courts have found the plain language of essentially identical rules entirely unambiguous. We must not manufacture ambiguity and rely on legal fictions to arrive at a preferred result. Especially when we may simply write that result into law.

I therefore concur in result.

ALEXANDER, C.J. (dissenting).

I agree with the majority that RPC 4.2(a) prohibits lawyers who are representing themselves from communicating directly with opposing, represented parties unless they first obtain the consent of the parties' counsel. I disagree, however, with the majority's decision to limit application of this important rule to future violators. I know of no authority that supports imposition of a rule of professional conduct prospectively only. I believe, therefore, that this court should suspend Jeffrey Haley from the practice of law for his violation of RPC 4.2(a). The violation is especially egregious in light of Haley's claim that he "studied the rule" before directly 
contacting his opposing party, and in view of the fact that he contacted the party a second time after the party's lawyer warned him that doing so would violate RPC 4.2(a). Because the majority concludes that Haley should not be subjected to discipline for a violation of RPC 4.2(a), I dissent.

The majority correctly observes that among states considering the question with which we are here presented, the prevailing trend has been to apply RPC 4.2(a) to attorneys acting pro se, as was Haley, and not just to attorneys representing someone other than themselves. The majority acknowledges, additionally, that in late 1996 and early 1997, when Haley twice attempted to negotiate a settlement without going through the opposing party's lawyer, at least four jurisdictions already had concluded that RPC 4.2(a) prohibited such contacts. Yet none of the four jurisdictions mentioned by the majority applied the rule to pro se attorneys on a prospective basis only, as the majority does here. Rather, all four jurisdictions applied the rule to the facts before them, as this court should do. These four opinions, all cited by the majority, are sound and make it clear that at the time Haley engaged in the prohibited conduct, the weight of authority supported the disciplining of violators and did not even hint at the prospective-only application embraced by the majority in this case. In shielding Haley from application of RPC 4.2(a), the majority borrows from the reasoning of the Nevada Supreme Court in In re Discipline of Schaefer. There, the Nevada court declined to punish an attorney's violation of the Nevada equivalent of RPC 4.2(a) because of: (a) the "absence of clear guidance" from the court, and (b) "conflicting authority from other jurisdictions" as to whether the rule applied to pro se attorneys. In effect, the majority establishes a new test: if there is any doubt about how a rule will be construed, a violator will not be punished. That is a dangerous message to send.

Furthermore, whereas the Schaefer court relied on due process principles articulated by the United States Supreme Court in Connally in applying the Nevada rule prospectively, it is worth noting that this court has never drawn from Connally the proposition that discipline is inappropriate just because a rule is being interpreted for the first time. In fact, in Haley $v$. Medical Disciplinary Board, the only discipline case in which this court cited Connally, we affirmed sanctions against a physician for violating a statute prohibiting "moral turpitude" although we recognized "uncertainties associated with" the statutory language in question. Thus, this court has previously declined to interpret Connally in the way the Nevada court did in Schaefer and the majority does here - as if professional license holders have a due process right to avoid discipline simply because a court is newly construing the rule in question. Such an interpretation will have far-reaching impact, as many discipline cases that come before this court raise an issue of construction. In declining to sanction Haley for violating RPC 4.2(a), despite the fact that Haley had "studied" the rule and should have known that the prevailing construction prohibited his conduct, the majority suggests that questionable conduct will be tolerated as long as there is no prior Washington court decision exactly on point.

We must remember that our purpose in disciplining attorneys is to "protect the public and to preserve confidence in the legal system." In Curran, an attorney argued that he should not be punished for violating RLD 1.1(a) because, in forbidding actions that reflect "disregard for the rule of law," the rule was unconstitutionally vague. This court said, "We choose to give these 
words a narrowing construction. This law is not so vague as to be unconstitutional, given this limiting construction." We noted that "a statute will not be considered unconstitutionally vague just because it is difficult to determine whether certain marginal offenses are within the meaning of the language under attack." This court suspended the attorney, Curran, saying, "Standards may be used in lawyer disciplinary cases which would be impermissibly vague in other contexts." Just as we disciplined Curran there, despite uncertainty about the rule in question, so should Haley be disciplined for violating RPC 4.2(a) in order to "protect the public and to preserve confidence in the legal system."

Curran also weighs against the position taken by Justice Sanders in his concurring opinion that attorney discipline is a punishment scheme and therefore is subject to the rule of lenity - a criminal law doctrine. We said in that case, "The purposes of bar discipline do not precisely duplicate the purposes of the criminal law." More notably, we have said numerous times that "punishment is not a proper basis for discipline." In In re Disbarment of Beakley, we said:

Neither disbarment nor suspension is ordered for the purpose of punishment, but wholly for the protection of the public. When a matter such as this comes before the court, the question presented is not: What punishment should be inflicted on this man? The question presented to each of its judges is simply this: Can I, in view of what has been clearly shown as to this man's conduct, conscientiously participate in continuing to hold him out to the public as worthy of that confidence which a client is compelled to repose in his attorney?

Thus, this court has long rejected the notion that attorney discipline is penal, and the concurrence cannot point to any discipline case in which we have applied the rule of lenity to resolve ambiguity in the attorney's favor.

In sum, because the purpose of attorney discipline is to protect the public, it is our duty to enforce RPC 4.2(a) in this case. The majority provides no authority for applying RPC 4.2(a) to pro se attorneys prospectively only. I would apply the rule to Haley and suspend him for six months.

\section{Questions:}

1. What is the purpose of Model Rule 4.2 and its prohibition on attorneys engaging in ex parte communications with represented persons? Is it intended to protect clients or their attorneys?

2. Why don't the model rules prohibit clients from engaging in ex parte communications? Should ex parte communications between represented persons be encouraged, discouraged, or neither?

3. Haley retained counsel when the action at issue went to trial. If he had engaged in ex parte communications with Highland while represented by an attorney, would it have violated Model Rule 4.2? Should attorneys who are parties to an action and represented 
by counsel be permitted to engage in ex parte communications with represented persons? What if both parties are attorneys represented by counsel?

Niesig v. Team, 76 N.Y.2d 363 (N.Y. 1990)

Summary: Plaintiff was injured when he fell from a scaffolding at a building construction site, and is now suing his employer DeTrae. Plaintiff moved for his lawyer to be able to conduct ex parte interviews with employees of DeTrae that were present at the time of the accident. Plaintiff argued the employees were not managing or controlling employees and could therefore be interviewed. DeTrae argued the rule applies to all employees, citing Upjohn. The court reversed the lower court and held that an employee of a corporation is a "party" for the purpose of ex parte communications only if the employee's actions bind the corporation in the matter or the employee implements the advice of counsel.

KAYE, J.

Plaintiff in this personal injury litigation, wishing to have his counsel privately interview a corporate defendant's employees who witnessed the accident, puts before us a question that has generated wide interest: are the employees of a corporate party also considered "parties" under Disciplinary Rule 7-104(A)(1) of the Code of Professional Responsibility, which prohibits a lawyer from communicating directly with a "party" known to have counsel in the matter? The trial court and the Appellate Division both answered that an employee of a counseled corporate party in litigation is by definition also a "party" within the rule, and prohibited the interviews. For reasons of policy, we disagree.

As alleged in the complaint, plaintiff was injured when he fell from scaffolding at a building construction site. At the time of the accident he was employed by DeTrae Enterprises, Inc.; defendant J.M. Frederick was the general contractor, and defendant Team I the property owner. Plaintiff thereafter commenced a damages action against defendants, asserting two causes of action, and defendants brought a third-party action against DeTrae.

Plaintiff moved for permission to have his counsel conduct ex parte interviews of all DeTrae employees who were on the site at the time of the accident, arguing that these witnesses to the event were neither managerial nor controlling employees and could not therefore be considered "personal synonyms for DeTrae." DeTrae opposed the application, asserting that the disciplinary rule barred unapproved contact by plaintiff's lawyer with any of its employees. Supreme Court denied plaintiff's request, and the Appellate Division modified by limiting the ban to DeTrae's current employees.

The Appellate Division concluded, for theoretical as well as practical reasons, that current employees of a corporate defendant in litigation "are presumptively within the scope of the representation afforded by the attorneys who appeared in the litigation on behalf of that corporation." The court held that DeTrae's attorneys have an attorney-client relationship with 
every DeTrae employee connected with the subject of the litigation, and that the prohibition is necessitated by the practical difficulties of distinguishing between a corporation's control group and its other employees. The court further noted that the information sought from employee witnesses could instead be obtained through their depositions.

In the main we disagree with the Appellate Division's conclusions. However, because we agree with the holding that DR 7-104(A)(1) applies only to current employees, not to former employees, we modify rather than reverse its order, and grant plaintiff's motion to allow the interviews.

We begin our analysis by noting that what is at issue is a disciplinary rule, not a statute. In interpreting statutes, which are the enactments of a coequal branch of government and an expression of the public policy of this State, we are of course bound to implement the will of the Legislature; statutes are to be applied as they are written or interpreted to effectuate the legislative intention. The disciplinary rules have a different provenance and purpose. Approved by the New York State Bar Association and then enacted by the Appellate Divisions, the Code of Professional Responsibility is essentially the legal profession's document of self-governance, embodying principles of ethical conduct for attorneys as well as rules for professional discipline. While unquestionably important, and respected by the courts, the code does not have the force of law.

That distinction is particularly significant when a disciplinary rule is invoked in litigation, which in addition to matters of professional conduct by attorneys, implicates the interests of nonlawyers. In such instances, we are not constrained to read the rules literally or effectuate the intent of the drafters, but look to the rules as guidelines to be applied with due regard for the broad range of interests at stake. "When we agree that the Code applies in an equitable manner to a matter before us, we should not hesitate to enforce it with vigor. When we find an area of uncertainty, however, we must use our judicial process to make our own decision in the interests of justice to all concerned."

DR 7-104(A)(1), which can be traced to the American Bar Association Canons of 1908, fundamentally embodies principles of fairness. "The general thrust of the rule is to prevent situations in which a represented party may be taken advantage of by adverse counsel; the presence of the party's attorney theoretically neutralizes the contact." By preventing lawyers from deliberately dodging adversary counsel to reach — and exploit - the client alone, DR 7$104(A)(1)$ safeguards against clients making improvident settlements, ill-advised disclosures and unwarranted concessions.

There is little problem applying DR 7-104(A)(1) to individuals in civil cases. In that context, the meaning of "party" is ordinarily plain enough: it refers to the individuals, not to their agents and employees. The question, however, becomes more difficult when the parties are corporations as evidenced by a wealth of commentary, and controversy, on the issue. 
The difficulty is not in whether DR 7-104(A)(1) applies to corporations. It unquestionably covers corporate parties, who are as much served by the rule's fundamental principles of fairness as individual parties. But the rule does not define "party," and its reach in this context is unclear. In litigation only the entity, not its employee, is the actual named party; on the other hand, corporations act solely through natural persons, and unless some employees are also considered parties, corporations are effectively read out of the rule. The issue therefore distills to which corporate employees should be deemed parties for purposes of DR 7-104(A)(1), and that choice is one of policy. The broader the definition of "party" in the interests of fairness to the corporation, the greater the cost in terms of foreclosing vital informal access to facts.

The many courts, bar associations and commentators that have balanced the competing considerations have evolved various tests, each claiming some adherents, each with some imperfection. At one extreme is the blanket rule adopted by the Appellate Division and urged by defendants, and at the other is the "control group" test - both of which we reject. The first is too broad and the second too narrow.

Defendants' principal argument for the blanket rule — correlating the corporate "party" and all of its employees - rests on Upjohn v United States. As the Supreme Court recognized, a corporation's attorney-client privilege includes communications with low- and mid-level employees; defendants argue that the existence of an attorney-client privilege also signifies an attorney-client relationship for purposes of DR 7-104(A)(1).

Upjohn, however, addresses an entirely different subject, with policy objectives that have little relation to the question whether a corporate employee should be considered a "party" for purposes of the disciplinary rule. First, the privilege applies only to confidential communications with counsel, it does not immunize the underlying factual information - which is in issue here - from disclosure to an adversary. Second, the attorney-client privilege serves the societal objective of encouraging open communication between client and counsel, a benefit not present in denying informal access to factual information. Thus, a corporate employee who may be a "client" for purposes of the attorney-client privilege is not necessarily a "party" for purposes of DR 7-104(A)(1).

The single indisputable advantage of a blanket preclusion - as with every absolute rule - is that it is clear. No lawyer need ever risk disqualification or discipline because of uncertainty as to which employees are covered by the rule and which not. The problem, however, is that a ban of this nature exacts a high price in terms of other values, and is unnecessary to achieve the objectives of DR 7-104(A)(1).

Most significantly, the Appellate Division's blanket rule closes off avenues of informal discovery of information that may serve both the litigants and the entire justice system by uncovering relevant facts, thus promoting the expeditious resolution of disputes. Foreclosing all direct, informal interviews of employees of the corporate party unnecessarily sacrifices the longrecognized potential value of such sessions. "A lawyer talks to a witness to ascertain what, if any, information the witness may have relevant to his theory of the case, and to explore the 
witness' knowledge, memory and opinion - frequently in light of information counsel may have developed from other sources. This is part of an attorney's so-called work product." Costly formal depositions that may deter litigants with limited resources, or even somewhat less formal and costly interviews attended by adversary counsel, are no substitute for such off-the-record private efforts to learn and assemble, rather than perpetuate, information.

Nor, in our view, is it necessary to shield all employees from informal interviews in order to safeguard the corporation's interest. Informal encounters between a lawyer and an employeewitness are not - as a blanket ban assumes — invariably calculated to elicit unwitting admissions; they serve long-recognized values in the litigation process. Moreover, the corporate party has significant protection at hand. It has possession of its own information and unique access to its documents and employees; the corporation's lawyer thus has the earliest and best opportunity to gather the facts, to elicit information from employees, and to counsel and prepare them so that they will not make the feared improvident disclosures that engendered the rule.

We fully recognize that, as the Appellate Division observed, every rule short of the absolute poses practical difficulties as to where to draw the line, and leaves some uncertainty as to which employees fall on either side of it. Nonetheless, we conclude that the values served by permitting access to relevant information require that an effort be made to strike a balance, and that uncertainty can be minimized if not eliminated by a clear test that will become even clearer in practice.

We are not persuaded, however, that the "control group" test - defining "party" to include only the most senior management exercising substantial control over the corporation - achieves that goal. Unquestionably, that narrow (though still uncertain) definition of corporate "party" better serves the policy of promoting open access to relevant information. But that test gives insufficient regard to the principles motivating DR 7-104(A)(1), and wholly overlooks the fact that corporate employees other than senior management also can bind the corporation. The "control group" test all but "nullifies the benefits of the disciplinary rule to corporations." Given the practical and theoretical problems posed by the "control group" test, it is hardly surprising that few courts or bar associations have ever embraced it.

By the same token, we find unsatisfactory several of the proposed intermediate tests, because they give too little guidance, or otherwise seem unworkable. In this category are the case-bycase balancing test, and a test that defines "party" to mean corporate employees only when they are interviewed about matters within the scope of their employment.

The test that best balances the competing interests, and incorporates the most desirable elements of the other approaches, is one that defines "party" to include corporate employees whose acts or omissions in the matter under inquiry are binding on the corporation (in effect, the corporation's "alter egos") or imputed to the corporation for purposes of its liability, or employees implementing the advice of counsel. All other employees may be interviewed informally. 
Unlike a blanket ban or a "control group" test, this solution is specifically targeted at the problem addressed by DR 7-104(A)(1). The potential unfair advantage of extracting concessions and admissions from those who will bind the corporation is negated when employees with "speaking authority" for the corporation, and employees who are so closely identified with the interests of the corporate party as to be indistinguishable from it, are deemed "parties" for purposes of DR 7-104(A)(1). Concern for the protection of the attorney-client privilege prompts us also to include in the definition of "party" the corporate employees responsible for actually effectuating the advice of counsel in the matter.

In practical application, the test we adopt thus would prohibit direct communication by adversary counsel "with those officials, but only those, who have the legal power to bind the corporation in the matter or who are responsible for implementing the advice of the corporation's lawyer, or any member of the organization whose own interests are directly at stake in a representation." This test would permit direct access to all other employees, and specifically - as in the present case - it would clearly permit direct access to employees who were merely witnesses to an event for which the corporate employer is sued.

Apart from striking the correct balance, this test should also become relatively clear in application. It is rooted in developed concepts of the law of evidence and the law of agency, thereby minimizing the uncertainty facing lawyers about to embark on employee interviews. A similar test, moreover, is the one overwhelmingly adopted by courts and bar associations throughout the country, whose long practical experience persuades us that — in day-to-day operation - it is workable.

Finally, we note the particular contribution made by the various amici curiae in this case; by highlighting the diverse contexts in which the question may arise, their submissions have enlarged our comprehension of the broad potential impact of the issue presented. In so doing, however, they have also alerted us to the wisdom of flagging what is in any event implicit in our decisions - that they are limited by the facts before us and the questions put to us. Today's decision resolves the present controversy by allowing ex parte interviews with nonmanagerial witnesses employed by a corporate defendant; even in that limited context, we recognize that there are undoubtedly questions not raised by the parties that will yet have to be answered.

Defendants' assertions that ex parte interviews should not be permitted because of the dangers of overreaching, moreover, impel us to add the cautionary note that, while we have not been called upon to consider questions relating to the actual conduct of such interviews, it is of course assumed that attorneys would make their identity and interest known to interviewees and comport themselves ethically.

\section{Questions:}

\section{Further Reading:}


- John Leubsdorf, Communicating with Another Lawyer's Client: The Lawyer's Veto and the Client's Interests, 127 U. Pa. L. Rev. 683 (1979) 


\section{6: Attorney's Fees}

\section{Attorney's Fees}

If you've got the money, l've got the time. We'll go honky tonkin' and we'll have a time ... But if you run short of money, I'll run short of time. 'Cause you with no more money, honey, I've no more time. ${ }^{25}$

Attorneys can only charge a reasonable fee for their services. But the reasonableness of an attorney's fee depends on the circumstances. Main Street lawyers and Wall Street lawyers can and do charge very different fees for their services. And contingent fees necessarily reflect the risk of failure.

In theory, state bar associations are supposed to ensure that attorneys charge reasonable fees. But in practice, they are reluctant to question attorney's fee agreements. In fact, contract law may protect clients from excessive fees more effectively than the rules of professional responsibility.

\section{Model Rule 1.5: Fees}

a. A lawyer shall not make an agreement for, charge, or collect an unreasonable fee or an unreasonable amount for expenses. The factors to be considered in determining the reasonableness of a fee include the following:

1. the time and labor required, the novelty and difficulty of the questions involved, and the skill requisite to perform the legal service properly;

2. the likelihood, if apparent to the client, that the acceptance of the particular employment will preclude other employment by the lawyer;

3. the fee customarily charged in the locality for similar legal services;

4. the amount involved and the results obtained;

5. the time limitations imposed by the client or by the circumstances;

6. the nature and length of the professional relationship with the client;

7. the experience, reputation, and ability of the lawyer or lawyers performing the services; and

8. whether the fee is fixed or contingent.

b. The scope of the representation and the basis or rate of the fee and expenses for which the client will be responsible shall be communicated to the client, preferably in writing, before or within a reasonable time after commencing the representation, except when the lawyer will charge a regularly represented client on the same basis or rate. Any changes in the basis or rate of the fee or expenses shall also be communicated to the client.

c. A fee may be contingent on the outcome of the matter for which the service is rendered, except in a matter in which a contingent fee is prohibited by paragraph (d) or other law.

${ }^{25}$ Lefty Frizzell, If You've Got The Money I've Got The Time (1950). 
A contingent fee agreement shall be in a writing signed by the client and shall state the method by which the fee is to be determined, including the percentage or percentages that shall accrue to the lawyer in the event of settlement, trial or appeal; litigation and other expenses to be deducted from the recovery; and whether such expenses are to be deducted before or after the contingent fee is calculated. The agreement must clearly notify the client of any expenses for which the client will be liable whether or not the client is the prevailing party. Upon conclusion of a contingent fee matter, the lawyer shall provide the client with a written statement stating the outcome of the matter and, if there is a recovery, showing the remittance to the client and the method of its determination.

d. A lawyer shall not enter into an arrangement for, charge, or collect:

1. any fee in a domestic relations matter, the payment or amount of which is contingent upon the securing of a divorce or upon the amount of alimony or support, or property settlement in lieu thereof; or

2. a contingent fee for representing a defendant in a criminal case.

e. A division of a fee between lawyers who are not in the same firm may be made only if:

1. the division is in proportion to the services performed by each lawyer or each lawyer assumes joint responsibility for the representation;

2. the client agrees to the arrangement, including the share each lawyer will receive, and the agreement is confirmed in writing; and

3. the total fee is reasonable.

\section{Restatement (Third) of the Law Governing Lawyers § 34: Reasonable and Lawful Fees}

A lawyer may not charge a fee larger than is reasonable in the circumstances or that is prohibited by law.

\section{Restatement (Third) of the Law Governing Lawyers § 35: Contingent-Fee Arrangements}

1. A lawyer may contract with a client for a fee the size or payment of which is contingent on the outcome of a matter, unless the contract violates $\S 34$ or another provision of this Restatement or the size or payment of the fee is:

a. contingent on success in prosecuting or defending a criminal proceeding; or

b. contingent on a specified result in a divorce proceeding or a proceeding concerning custody of a child.

2. Unless the contract construed in the circumstances indicates otherwise, when a lawyer has contracted for a contingent fee, the lawyer is entitled to receive the specified fee only when and to the extent the client receives payment.

Matter of Cooperman, 633 N.E.2d 1069 (N.Y. 1994)

Summary: The Grievance Committee initiated a disciplinary proceeding against Cooperman for 15 violations of professional misconduct. Cooperman uses three separate agreements: the first is a written fee agreement to represent an individual in a criminal matter (a $\$ 15,000$ minimum fee). The second is a written agreement in 
connection with a probate proceeding (a $\$ 5,000$ minimum fee to act as counsel). The final agreement also involved a criminal matter (a $\$ 10,000$ minimum fee). The court found that an attorney using special non-refundable retainer fee agreements in advance of service and irrespective of whether any professional services are actually rendered violated the Code of Professional Responsibility because the agreements were a per se violation of New York public policy.

\section{BELLACOSA, J.}

The issue in this appeal is whether the appellant attorney violated the Code of Professional Responsibility by repeatedly using special nonrefundable retainer fee agreements with his clients. Essentially, such arrangements are marked by the payment of a nonrefundable fee for specific services, in advance and irrespective of whether any professional services are actually rendered. The local Grievance Committee twice warned the lawyer that he should not use these agreements. After a third complaint and completion of prescribed grievance proceedings, the Appellate Division suspended the lawyer from practice for two years. It held that the particular agreements were per se violative of public policy. We affirm the order of the Appellate Division.

\section{I.}

In 1990, the petitioner, Grievance Committee for the Tenth Judicial District, initiated a disciplinary proceeding charging attorney Cooperman with 15 specifications of professional misconduct. They relate to his use of three special nonrefundable retainer fee agreements.

The first five charges derive from a written fee agreement to represent an individual in a criminal matter. It states: "My minimum fee for appearing for you in this matter is Fifteen Thousand $(\$ 15,000.00)$ Dollars. This fee is not refundable for any reason whatsoever once I file a notice of appearance on your behalf." One month after the agreement, the lawyer was discharged by the client and refused to refund any portion of the fee. The client filed a formal complaint which the Grievance Committee forwarded to Cooperman for a response. Cooperman had already received a Letter of Caution not to use nonrefundable retainer agreements, and while this new complaint was pending, Cooperman was issued a second Letter of Caution admonishing him not to accept the kind of fee arrangement at issue here. He rejected the admonition, claiming the fee was nonrefundable.

Charges 6 through 10 refer to a written retainer agreement in connection with a probate proceeding. It states in pertinent part: "For the MINIMAL FEE and NON-REFUNDABLE amount of Five Thousand $(\$ 5,000.00)$ Dollars, I will act as your counsel." The agreement further provided: "This is the minimum fee no matter how much or how little work I do in this investigatory stage and will remain the minimum fee and not refundable even if you decide prior to my completion of the investigation that you wish to discontinue the use of my services for any reason whatsoever." The client discharged Cooperman, who refused to provide the client with an itemized bill of services rendered or refund any portion of the fee, citing the unconditional nonrefundable fee agreement. 
The last five charges relate to a fee agreement involving another criminal matter. It provides: "The MINIMUM FEE for Mr. Cooperman's representation to any extent whatsoever is Ten Thousand $(\$ 10,000.00)$ Dollars. The above amount is the MINIMUM FEE and will remain the minimum fee no matter how few court appearances are made. The minimum fee will remain the same even if Mr. Cooperman is discharged." Two days after execution of the fee agreement, the client discharged Cooperman and demanded a refund. As with the other clients, he demurred.

Cooperman's persistent refusals to refund any portion of the fees sparked at least three separate client complaints to the Grievance Committee. In each case, Cooperman answered the complaint but refused the Grievance Committee's suggestion for fee arbitration. Thereafter, the Grievance Committee sought authorization from the Appellate Division, Second Department, to initiate formal disciplinary proceedings against Cooperman. It tendered an array of arguments that these retainer agreements are unethical because, first, they violate the lawyer's obligation to "refund promptly any part of a fee paid in advance that has not been earned." Further, the agreements create "an impermissible chilling effect upon the client's inherent right upon public policy grounds to discharge the attorney at any time with or without cause." The petition also alleged that the fees charged by Cooperman were excessive, and that he wrongfully refused to refund unearned fees. Finally, it notes that denominating the fee payment as nonrefundable constitutes misrepresentation.

After an extensive hearing, the Referee made findings supporting violations on all 15 charges. On appropriate motion, the Appellate Division confirmed the Referee's report with respect to charges 2 through 5, 7 through 10, and 12 through 15. The Court disaffirmed the report as to charges 1,6 and 11, which alleged that the retainer agreements constituted deceit and misrepresentation. In sustaining the remaining charges, the Court held that these retainer agreements were unethical and unconscionable and "violative of an attorney's obligations under the Code of Professional Responsibility to refund unearned fees upon his or her discharge." The Court also concluded that Cooperman's fees were excessive. The Court suspended him from the practice of law for a period of two years but did not order restitution.

II.

Whether special nonrefundable retainer fee agreements are against public policy is a question we left open in Jacobson v. Sassower, a fee dispute case. We agree with the Appellate Division in this disciplinary matter that special nonrefundable retainer fee agreements clash with public policy and transgress provisions of the Code of Professional Responsibility, essentially because these fee agreements compromise the client's absolute right to terminate the unique fiduciary attorney-client relationship.

The particular analysis begins with a reflection on the nature of the attorney-client relationship. Sir Francis Bacon observed, "the greatest trust between people is the trust of giving counsel." This unique fiduciary reliance, stemming from people hiring attorneys to exercise professional judgment on a client's behalf - "giving counsel" — is imbued with ultimate trust and confidence. 
The attorney's obligations, therefore, transcend those prevailing in the commercial marketplace. The duty to deal fairly, honestly and with undivided loyalty superimposes onto the attorney-client relationship a set of special and unique duties, including maintaining confidentiality, avoiding conflicts of interest, operating competently, safeguarding client property and honoring the client's interests over the lawyer's. To the public and clients, few features could be more paramount than the fee - the costs of legal services. The Code of Professional Responsibility reflects this central ingredient by specifically mandating, without exception, that an attorney "shall not enter into an agreement for, charge, or collect an illegal or excessive fee," and upon withdrawal from employment "shall refund promptly any part of a fee paid in advance that has not been earned." Accordingly, attorney-client fee agreements are a matter of special concern to the courts and are enforceable and affected by lofty principles different from those applicable to commonplace commercial contracts.

Because the attorney-client relationship is recognized as so special and so sensitive in our society, its effectiveness, actually and perceptually, may be irreparably impaired by conduct which undermines the confidence of the particular client or the public in general. In recognition of this indispensable desideratum and as a precaution against the corrosive potentiality from failing to foster trust, public policy recognizes a client's right to terminate the attorney-client relationship at any time with or without cause. This principle was effectively enunciated in Martin v. Camp: "The contract under which an attorney is employed by a client has peculiar and distinctive features thus notwithstanding the fact that the employment of an attorney by a client is governed by the contract which the parties make the client with or without cause may terminate the contract at any time."

The unqualified right to terminate the attorney-client relationship at any time has been assiduously protected by the courts. An attorney, however, is not left without recourse for unfair terminations lacking cause. If a client exercises the right to discharge an attorney after some services are performed but prior to the completion of the services for which the fee was agreed upon, the discharged attorney is entitled to recover compensation from the client measured by the fair and reasonable value of the completed services. We have recognized that permitting a discharged attorney "to recover the reasonable value of services rendered in quantum meruit, a principle inherently designed to prevent unjust enrichment, strikes the delicate balance between the need to deter clients from taking undue advantage of attorneys, on the one hand, and the public policy favoring the right of a client to terminate the attorney-client relationship without inhibition on the other."

Correspondingly and by cogent logic and extension of the governing precepts, we hold that the use of a special nonrefundable retainer fee agreement clashes with public policy because it inappropriately compromises the right to sever the fiduciary services relationship with the lawyer. Special nonrefundable retainer fee agreements diminish the core of the fiduciary relationship by substantially altering and economically chilling the client's unbridled prerogative to walk away from the lawyer. To answer that the client can technically still terminate misses the reality of the economic coercion that pervades such matters. If special nonrefundable retainers are allowed to flourish, clients would be relegated to hostage status in an unwanted fiduciary 
relationship - an utter anomaly. Such circumstance would impose a penalty on a client for daring to invoke a hollow right to discharge. The established prerogative which, by operation of law and policy, is deemed not a breach of contract is thus weakened. Instead of becoming responsible for fair value of actual services rendered, the firing client would lose the entire "nonrefundable" fee, no matter what legal services, if any, were rendered. This would be a shameful, not honorable, professional denouement. Cooperman even acknowledges that the essential purpose of the nonrefundable retainer was to prevent clients from firing the lawyer, a purpose which, as demonstrated, directly contravenes the Code and this State's settled public policy in this regard.

Nevertheless, Cooperman contends that special nonrefundable retainer fee agreements should not be treated as per se violations unless they are pegged to a "clearly excessive" fee. The argument is unavailing because the reasonableness of a particular nonrefundable fee cannot rescue an agreement that impedes the client's absolute right to walk away from the attorney. The termination right and the right not to be charged excessive fees are not interdependent in this analysis and context. Cooperman's claim, in any event, reflects a misconception of the nature of the legal profession by turning on its head the axiom that the legal profession "is a learned profession, not a mere money-getting trade."

DR 2-110 (A) and (B) of the Code of Professional Responsibility add further instruction to our analysis and disposition:

Withdrawal from Employment

(A) In general.

(3) A lawyer who withdraws from employment shall refund promptly any part of a fee paid in advance that has not been earned.

(B) Mandatory withdrawal. A lawyer representing a client before a tribunal, with its permission if required by its rules, shall withdraw from employment, and a lawyer representing a client in other matters shall withdraw from employment, if:

(4) The lawyer is discharged by the client.

We believe that if an attorney is prohibited from keeping any part of a prepaid fee that has not been earned because of discharge by the client, it is reasonable to conclude also that an attorney may not negotiate and keep fees such as those at issue here. In each of Cooperman's retainer agreements, the Appellate Division found that the lawyer transgressed professional ethical norms. The fee arrangements expressed an absoluteness which deprived his clients of entitlement to any refund and, thus, conflicted with DR 2-110(A)(3).

Since we decide the precise issue in this case in a disciplinary context only, we imply no views with respect to the wider array of factors by which attorneys and clients may have fee dispute controversies resolved. Traditional criteria, including the factor of the actual amount of services rendered, will continue to govern those situations. Thus, while the special nonrefundable retainer agreement will be unenforceable and may subject an attorney to professional discipline, quantum meruit payment for services actually rendered will still be available and appropriate. 
Notably, too, the record in this case contradicts Cooperman's claim that he acted in "good faith." He urges us to conclude that he "complied with the limited legal precedents at the time." The conduct of attorneys is not measured by how close to the edge of thin ice they skate. The measure of an attorney's conduct is not how much clarity can be squeezed out of the strict letter of the law, but how much honor can be poured into the generous spirit of lawyer-client relationships. The "punctilio of an honor the most sensitive" must be the prevailing standard. Therefore, the review is not the reasonableness of the individual attorney's belief, but, rather, whether a "reasonable attorney, familiar with the Code and its ethical strictures, would have notice of what conduct is proscribed." Cooperman's level of knowledge, the admonitions to him and the course of conduct he audaciously chose do not measure up to this necessarily high professional template. He even acknowledged at his disciplinary hearing that he knew that "there were problems with the nonrefundability of retainers." Cooperman's case, therefore, constitutes a daring test of ethical principles, not good faith. He failed the test, and those charged with enforcing transcendent professional values, especially the Appellate Divisions, ought to be sustained in their efforts.

Our holding today makes the conduct of trading in special nonrefundable retainer fee agreements subject to appropriate professional discipline. Moreover, we intend no effect or disturbance with respect to other types of appropriate and ethical fee agreements. Minimum fee arrangements and general retainers that provide for fees, not laden with the nonrefundability impediment irrespective of any services, will continue to be valid and not subject in and of themselves to professional discipline.

The Court is also mindful of the arguments of some of the amici curiae concerned about sweeping sequelae from this case in the form of disciplinary complaints or investigations that may seek to unearth or examine into past conduct and to declare all sorts of unobjectionable, settled fee arrangements unethical. We are confident that the Appellate Divisions, in the highest tradition of their regulatory and adjudicatory roles, will exercise their unique disciplinary responsibility with prudence, so as not to overbroadly brand past individualized attorney fee arrangements as unethical, and will, instead, fairly assess the varieties of these practices, if presented, on an individualized basis. Therefore, we decline to render our ruling prospectively, as requested.

\section{Questions:}

1. Was the problem with Cooperman's fees that they were non-refundable, too high, or both? What if Cooperman had charged a non-refundable fee of $\$ 1000$ or $\$ 100$ ? What if Cooperman required a $\$ 10,000$ refundable retainer and a $\$ 5000$ engagement fee, paid at the end of representation?

2. What are "minimum fee arrangements and general retainers that provide for fees"? How are they different from Cooperman's non-refundable retainer fees?

3. Should attorneys be able to charge a flat fee for a service? What if the flat fee is the average fee for that service? What if it is less than the average fee? 
In the Matter of Fordham, 423 Mass. 481 (Mass. 1996)

Summary: Bar counsel alleges that Fordham charged a clearly excessive fee for defending Clark against a OUI and other charges. Hearing committee concluded that Fordham's fee was not substantially in excess of a reasonable fee and recommended against bar discipline. The Massachusetts Supreme Court reversed, holding that Fordham's fee was clearly excessive, given the nature of the representation, and issued a public reprimand.

\section{O'CONNOR, J.}

This is an appeal from the Board of Bar Overseers' dismissal of a petition for discipline filed by bar counsel against attorney Laurence S. Fordham. On March 11, 1992, bar counsel served Fordham with a petition for discipline alleging that Fordham had charged a clearly excessive fee for defending Timothy Clark in the District Court against a charge that he operated a motor vehicle while under the influence of intoxicating liquor (OUI) and against other related charges. Fordham moved that the board dismiss the petition and the board chair recommended that that be done. Bar counsel appealed from the chair's decision to the full board, and the board referred the matter to a hearing committee.

After five days of hearings, and with "serious reservations," the hearing committee concluded that Fordham's fee was not substantially in excess of a reasonable fee and that, therefore, the committee recommended against bar discipline. Bar counsel appealed from that determination to the board. By a vote of six to five, with one abstention, the board accepted the recommendation of the hearing committee and dismissed the petition for discipline. Bar counsel then filed in the Supreme Judicial Court for Suffolk County a claim of appeal from the board's action.

Fordham moved in the county court for a dismissal of bar counsel's appeal. A single justice denied Fordham's motion and reported the case to the full court. We conclude that the single justice correctly denied Fordham's motion to dismiss bar counsel's appeal. We conclude, also, that the board erred in dismissing bar counsel's petition for discipline. We direct a judgment ordering public censure be entered in the county court.

We summarize the hearing committee's findings. On March 4, 1989, the Acton police department arrested Timothy, then twenty-one years old, and charged him with OUI, operating a motor vehicle after suspension, speeding, and operating an unregistered motor vehicle. At the time of the arrest, the police discovered a partially full quart of vodka in the vehicle. After failing a field sobriety test, Timothy was taken to the Acton police station where he submitted to two breathalyzer tests which registered .10 and .12 respectively.

Subsequent to Timothy's arraignment, he and his father, Laurence Clark consulted with three lawyers, who offered to represent Timothy for fees between $\$ 3,000$ and $\$ 10,000$. Shortly after 
the arrest, Clark went to Fordham's home to service an alarm system which he had installed several years before. While there, Clark discussed Timothy's arrest with Fordham's wife who invited Clark to discuss the case with Fordham. Fordham then met with Clark and Timothy.

At this meeting, Timothy described the incidents leading to his arrest and the charges against him. Fordham, whom the hearing committee described as a "very experienced senior trial attorney with impressive credentials," told Clark and Timothy that he had never represented a client in a driving while under the influence case or in any criminal matter, and he had never tried a case in the District Court. The hearing committee found that "Fordham explained that although he lacked experience in this area, he was a knowledgeable and hard-working attorney and that he believed he could competently represent Timothy. Fordham described himself as 'efficient and economic in the use of his time."'

"Towards the end of the meeting, Fordham told the Clarks that he worked on a time charge basis and that he billed monthly. In other words, Fordham would calculate the amount of hours he and others in the firm worked on a matter each month and multiply it by the respective hourly rates. He also told the Clarks that he would engage others in his firm to prepare the case. Clark had indicated that he would pay Timothy's legal fees." After the meeting, Clark hired Fordham to represent Timothy.

According to the hearing committee's findings, Fordham filed four pretrial motions on Timothy's behalf, two of which were allowed. One motion, entitled "Motion in Limine to Suppress Results of Breathalyzer Tests," was based on the theory that, although two breathalyzer tests were exactly .02 apart, they were not "within" .02 of one another as the regulations require. The hearing committee characterized the motion and its rationale as "a creative, if not novel, approach to suppression of breathalyzer results." Although the original trial date was June 20, 1989, the trial, which was before a judge without jury, was held on October 10 and October 19, 1989. The judge found Timothy not guilty of driving while under the influence.

Fordham sent the following bills to Clark:

1. April 19, 1989, $\$ 3,250$ for services rendered in March, 1989.

2. May 15, 1989, $\$ 9,850$ for services rendered in April, 1989.

3. June 19, 1989, $\$ 3,950$ for services rendered in May, 1989.

4. July $13,1989, \$ 13,300$ for services rendered in June, 1989.

5. October $13,1989, \$ 35,022.25$ revised bill for services rendered from March 19 to June 30, 1989.

6. November 7, 1989, $\$ 15,000$ for services rendered from July 1, 1989 to October 19 , 1989."

The bills totaled $\$ 50,022.25$, reflecting 227 hours of billed time, 153 hours of which were expended by Fordham and seventy-four of which were his associates' time. Clark did not pay the first two bills when they became due and expressed to Fordham his concern about their amount. Clark paid Fordham $\$ 10,000$ on June 20,1989 . At that time, Fordham assured Clark 
that most of the work had been completed "other than taking the case to trial." Clark did not make any subsequent payments. Fordham requested Clark to sign a promissory note evidencing his debt to Fordham and, on October 7, 1989, Clark did so. In the October 13, 1989, bill, Fordham added a charge of $\$ 5,000$ as a "retroactive increase" in fees. On November 7 , 1989 , after the case was completed, Fordham sent Clark a bill for $\$ 15,000$.

Bar counsel and Fordham have stipulated that all the work billed by Fordham was actually done and that Fordham and his associates spent the time they claim to have spent. They also have stipulated that Fordham acted conscientiously, diligently, and in good faith in representing Timothy and in his billing in this case.

The board dismissed bar counsel's petition for discipline against Fordham because it determined, relying in large part on the findings and recommendations of the hearing committee, that Fordham's fee was not clearly excessive. Pursuant to S.J.C. Rule 3:07, DR 2106(B), "a fee is clearly excessive when, after a review of the facts, a lawyer of ordinary prudence, experienced in the area of the law involved, would be left with a definite and firm conviction that the fee is substantially in excess of a reasonable fee." The rule proceeds to list eight factors to be considered in ascertaining the reasonableness of the fee:

1. The time and labor required, the novelty and difficulty of the questions involved, and the skill requisite to perform the legal service properly.

2. The likelihood, if apparent to the client, that the acceptance of the particular employment will preclude other employment by the lawyer.

3. The fee customarily charged in the locality for similar legal services.

4. The amount involved and the results obtained.

5. The time limitations imposed by the client or by the circumstances.

6. The nature and length of the professional relationship with the client.

7. The experience, reputation, and ability of the lawyer or lawyers performing the services.

8. Whether the fee is fixed or contingent.

In concluding that Fordham did not charge a clearly excessive fee, the board adopted, with limited exception, the hearing committee's report. The board's and the hearing committee's reasons for dismissing the petition are as follows: Bar counsel and Fordham stipulated that Fordham acted conscientiously, diligently, and in good faith in his representation of the client and his billing on the case. Although Fordham lacked experience in criminal law, he is a "seasoned and well-respected civil lawyer." The more than 200 hours spent preparing the OUI case were necessary, "in part to educate Fordham in the relevant substantive law and court procedures," because he had never tried an OUI case or appeared in the District Court. The board noted that "although none of the experts who testified at the disciplinary hearing had ever heard of a fee in excess of $\$ 15,000$ for a first-offense OUI case, the hearing committee found that Clark had entered into the transaction with open eyes after interviewing other lawyers with more experience in such matters." The board also thought significant that Clark "later acquiesced, despite mild expressions of concern, in Fordham's billing practices." Moreover, the 
Clarks specifically instructed Fordham that they would not consider a guilty plea by Timothy. Rather they were interested only in pursuing the case to trial. Finally, Timothy obtained the result he sought: an acquittal.

Bar counsel contends that the board's decision to dismiss the petition for discipline is erroneous on three grounds: First, "the hearing committee and the Board committed error by analyzing only three of the factors set out in DR 2-106 (B) (1)-(8), and their findings with regard to these criteria do not support their conclusion that the fee in this case was not clearly excessive"; second, the board "misinterpreted DR 2-106's prohibition against charging a clearly excessive fee by reading into the rule a 'safe harbor' provision"; and third, "by allowing client acquiescence as a complete defense."

In reviewing the hearing committee's and the board's analysis of the various factors, as appearing in DR 2-106 (B), which are to be considered for a determination as to whether a fee is clearly excessive, we are mindful that, although not binding on this court, the findings and recommendations of the board are entitled to great weight. We are empowered, however, to review the board's findings and reach our own conclusion. In the instant case we are persuaded that the hearing committee's and the board's determinations that a clearly excessive fee was not charged are not warranted.

The first factor listed in DR 2-106(B) requires examining "the time and labor required, the novelty and difficulty of the questions involved, and the skill requisite to perform the legal service properly." Although the hearing committee determined that Fordham "spent a large number of hours on the matter, in essence learning from scratch what others already know," it "did not credit Bar Counsel's argument that Fordham violated DR 2-106 by spending too many hours." The hearing committee reasoned that even if the number of hours Fordham "spent were wholly out of proportion" to the number of hours that a lawyer with experience in the trying of OUI cases would require, the committee was not required to conclude that the fee based on time spent was "clearly excessive." It was enough, the hearing committee concluded, that Clark instructed Fordham to pursue the case to trial, Fordham did so zealously and, as stipulated, Fordham spent the hours he billed in good faith and diligence. We disagree.

Four witnesses testified before the hearing committee as experts on OUI cases. One of the experts, testifying on behalf of bar counsel, opined that "the amount of time spent in this case is clearly excessive." He testified that there were no unusual circumstances in the OUI charge against Timothy and that it was a "standard operating under the influence case." The witness did agree that Fordham's argument for suppression of the breathalyzer test results, which was successful, was novel and would have justified additional time and labor. He also acknowledged that the acquittal was a good result; even with the suppression of the breathalyzer tests, he testified, the chances of an acquittal would have been "not likely at a bench trial." The witness estimated that it would have been necessary, for thorough preparation of the case including the novel breathalyzer suppression argument, to have billed twenty to thirty hours for preparation, not including trial time. 
A second expert, testifying on behalf of bar counsel, expressed his belief that the issues presented in this case were not particularly difficult, nor novel, and that "the degree of skill required to defend a case such as this was not that high." He did recognize, however, that the theory that Fordham utilized to suppress the breathalyzer tests was impressive and one of which he had previously never heard. Nonetheless, the witness concluded that "clearly there is no way that he could justify these kind of hours to do this kind of work." He estimated that an OUI case involving these types of issues would require sixteen hours of trial preparation and approximately fifteen hours of trial time. He testified that he had once spent ninety hours in connection with an OUI charge against a client that had resulted in a plea. The witness explained, however, that that case had involved a second offense OUI and that it was a case of first impression, in 1987, concerning new breathalyzer equipment and comparative breathalyzer tests.

An expert called by Fordham testified that the facts of Timothy's case presented a challenge and that without the suppression of the breathalyzer test results it would have been "an almost impossible situation in terms of prevailing on the trier of fact." He further stated that, based on the particulars in Timothy's case, he believed that Fordham's hours were not excessive and, in fact, he, the witness, would have spent a comparable amount of time. The witness later admitted, however, that within the past five years, the OUI cases which he had brought to trial required no more than a total of forty billed hours, which encompassed all preparation and court appearances. He explained that, although he had not charged more than forty hours to prepare an OUI case, in comparison to Fordham's more than 200 expended hours, Fordham nonetheless had spent a reasonable number of hours on the case in light of the continuance and the subsequent need to reprepare, as well as the "very ingenious" breathalyzer suppression argument, and the Clarks' insistence on trial. In addition, the witness testified that, although the field sobriety test, breathalyzer tests, and the presence of a half-empty liquor bottle in the car placed Fordham at a serious disadvantage in being able to prevail on the OUI charge, those circumstances were not unusual and in fact agreed that they were "normal circumstances."

The fourth expert witness, called by Fordham, testified that she believed the case was "extremely tough" and that the breathalyzer suppression theory was novel. She testified that, although the time and labor consumed on the case was more than usual in defending an OUI charge, the hours were not excessive. They were not excessive, she explained, because the case was particularly difficult due to the "stakes and the evidence." She conceded, however, that legal issues in defending OUI charges are "pretty standard" and that the issues presented in this case were not unusual. Furthermore, the witness testified that challenging the breathalyzer test due to the .02 discrepancy was not unusual, but the theory on which Fordham proceeded was novel. Finally, she stated that she thought she may have known of one person who might have spent close to one hundred hours on a difficult OUI case; she was not sure; but she had never heard of a fee in excess of $\$ 10,000$ for a bench trial.

In considering whether a fee is "clearly excessive," the first factor to be considered pursuant to that rule is "the novelty and difficulty of the questions involved, and the skill requisite to perform the legal service properly." That standard is similar to the familiar standard of reasonableness 
traditionally applied in civil fee disputes. Based on the testimony of the four experts, the number of hours devoted to Timothy's OUI case by Fordham and his associates was substantially in excess of the hours that a prudent experienced lawyer would have spent. According to the evidence, the number of hours spent was several times the amount of time any of the witnesses had ever spent on a similar case. We are not unmindful of the novel and successful motion to suppress the breathalyzer test results, but that effort cannot justify a $\$ 50,000$ fee in a type of case in which the usual fee is less than one-third of that amount.

The board determined that "because Fordham had never tried an OUI case or appeared in the district court, Fordham spent over 200 hours preparing the case, in part to educate himself in the relevant substantive law and court procedures." Fordham's inexperience in criminal defense work and OUI cases in particular cannot justify the extraordinarily high fee. It cannot be that an inexperienced lawyer is entitled to charge three or four times as much as an experienced lawyer for the same service. A client "should not be expected to pay for the education of a lawyer when he spends excessive amounts of time on tasks which, with reasonable experience, become matters of routine." "While the licensing of a lawyer is evidence that he has met the standards then prevailing for admission to the bar, a lawyer generally should not accept employment in any area of the law in which he is not qualified. However, he may accept such employment if in good faith he expects to become qualified through study and investigation, as long as such preparation would not result in unreasonable delay or expense to his client." Although the ethical considerations set forth in the ABA Code of Professional Responsibility and Canons of Judicial Ethics are not binding, they nonetheless serve as a guiding principle.

The third factor to be considered in ascertaining the reasonableness of a fee is its comparability to "the fee customarily charged in the locality for similar legal services." The hearing committee made no finding as to the comparability of Fordham's fee with the fees customarily charged in the locality for similar services. However, one of bar counsel's expert witnesses testified that he had never heard of a fee in excess of $\$ 15,000$ to defend a first OUI charge, and the customary flat fee in an OUI case, including trial, "runs from $\$ 1,000$ to $\$ 7,500$." Bar counsel's other expert testified that he had never heard of a fee in excess of $\$ 10,000$ for a bench trial. In his view, the customary charge for a case similar to Timothy's would vary between $\$ 1,500$ and $\$ 5,000$. One of Fordham's experts testified that she considered a $\$ 40,000$ or $\$ 50,000$ fee for defending an OUI charge "unusual and certainly higher by far than any l've ever seen before." The witness had never charged a fee of more than $\$ 3,500$ for representing a client at a bench trial to defend a first offense OUI charge. She further testified that she believed an "average OUI in the bench session is two thousand dollars and sometimes less." Finally, that witness testified that she had "heard a rumor" that one attorney charged $\$ 10,000$ for a bench trial involving an OUI charge; this fee represented the highest fee of which she was aware. The other expert witness called by Fordham testified that he had heard of a $\$ 35,000$ fee for defending OUI charges, but he had never charged more than $\$ 12,000$ (less than twenty-five per cent of Fordham's fee).

Although finding that Fordham's fee was "much higher than the fee charged by many attorneys with more experience litigating driving under the influence cases," the hearing committee nevertheless determined that the fee charged by Fordham was not clearly excessive because 
Clark "went into the relationship with Fordham with open eyes," Fordham's fee fell within a "safe harbor," and Clark acquiesced in Fordham's fee by not strenuously objecting to his bills. The board accepted the hearing committee's analysis apart from the committee's reliance on the "safe harbor" rule.

The finding that Clark had entered into the fee agreement "with open eyes" was based on the finding that Clark hired Fordham after being fully apprised that he lacked any type of experience in defending an OUI charge and after interviewing other lawyers who were experts in defending OUI charges. Furthermore, the hearing committee and the board relied on testimony which revealed that the fee arrangement had been fully disclosed to Clark including the fact that Fordham "would have to become familiar with the law in that area." It is also significant, however, that the hearing committee found that "despite Fordham's disclaimers concerning his experience, Clark did not appear to have understood in any real sense the implications of choosing Fordham to represent Timothy. Fordham did not give Clark any estimate of the total expected fee or the number of $\$ 200$ hours that would be required." The express finding of the hearing committee that Clark "did not appear to have understood in any real sense the implications of choosing Fordham to represent Timothy" directly militates against the finding that Clark entered into the agreement "with open eyes."

That brings us to the hearing committee's finding that Fordham's fee fell within a "safe harbor." The hearing committee reasoned that as long as an agreement existed between a client and an attorney to bill a reasonable rate multiplied by the number of hours actually worked, the attorney's fee was within a "safe harbor" and thus protected from a challenge that the fee was clearly excessive. The board, however, in reviewing the hearing committee's decision, correctly rejected the notion "that a lawyer may always escape discipline with billings based on accurate time charges for work honestly performed."

The "safe harbor" formula would not be an appropriate rationale in this case because the amount of time Fordham spent to educate himself and represent Timothy was clearly excessive despite his good faith and diligence. Disciplinary Rule 2-106(B)'s mandate that "a fee is clearly excessive when, after a review of the facts, a lawyer of ordinary prudence, experienced in the area of the law involved, would be left with a definite and firm conviction that the fee is substantially in excess of a reasonable fee," creates explicitly an objective standard by which attorneys' fees are to be judged. We are not persuaded by Fordham's argument that "unless it can be shown that the 'excessive' work for which the attorney has charged goes beyond mere matters of professional judgment and can be proven, either directly or by reasonable inference, to have involved dishonesty, bad faith or overreaching of the client, no case for discipline has been established." Disciplinary Rule 2-106 plainly does not require an inquiry into whether the clearly excessive fee was charged to the client under fraudulent circumstances, and we shall not write such a meaning into the disciplinary rule.

Finally, bar counsel challenges the hearing committee's finding that "if Clark objected to the numbers of hours being spent by Fordham, he could have spoken up with some force when he began receiving bills." Bar counsel notes, and we agree, that "the test as stated in the DR 2- 
$106(A)$ is whether the fee 'charged' is clearly excessive, not whether the fee is accepted as valid or acquiesced in by the client." Therefore, we conclude that the hearing committee and the board erred in not concluding that Fordham's fee was clearly excessive.

Fordham argues that our imposition of discipline would offend his right to due process. A disciplinary sanction constitutes "a punishment or penalty" levied against the respondent, and therefore the respondent is entitled to procedural due process. Fordham contends that the bar and, therefore, he, have not been given fair notice through prior decisions of this court or the express language of DR 2-106 that discipline may be imposed for billing excessive hours that were nonetheless spent diligently and in good faith. It is true, as Fordham asserts, that there is a dearth of case law in the Commonwealth meting out discipline for an attorney's billing of a clearly excessive fee. There is, however, as we have noted above, case law which specifically addresses what constitutes an unreasonable attorney's fee employing virtually the identical factors contained within DR 2-106. More importantly, the general prohibition that "a lawyer shall not enter into an agreement for, charge, or collect an illegal or clearly excessive fee," is followed by eight specific, and clearly expressed, factors, to be evaluated by the standard of "a lawyer of ordinary prudence," in determining the propriety of the fee. In addition, nothing contained within the disciplinary rule nor within any pertinent case law indicates in any manner that a clearly excessive fee does not warrant discipline whenever the time spent during the representation was spent in good faith. The fact that this court has not previously had occasion to discipline an attorney in the circumstances of this case does not suggest that the imposition of discipline in this case offends due process. We reject Fordham's due process argument.

In charging a clearly excessive fee, Fordham departed substantially from the obligation of professional responsibility that he owed to his client. The ABA Model Standards for Imposing Lawyer Sanctions $\S 7.3$ endorses a public reprimand as the appropriate sanction for charging a clearly excessive fee. We deem such a sanction appropriate in this case. Accordingly, a judgment is to be entered in the county court imposing a public censure. The record in this case is to be unimpounded.

\section{Questions:}

1. Was the problem with Fordham's fee the rate he charged, the number of hours he billed, or both?

2. Why do other attorneys litigating similar cases bill so much less? Is it because cases of this kind should take less work or because their clients cannot spend any additional money?

3. What if Fordham's acquittal rate were substantially higher than other attorneys in the same practice area? Should he be able to charge a higher rate? How much higher?

4. What if Fordham estimated a fee of $\$ 50,000$ in advance, and billed only for work actually completed?

\section{Contingent Fees}


You never give me your money, you only give me your funny paper, and in the middle of negotiations, you break down. ${ }^{26}$

Typically, attorneys charge an hourly fee for their services, often billed in some fraction of an hour. But some attorneys charge a fixed fee for their services. Historically, the most prestigious law firms charged a fixed fee for their services, often refusing to provide an itemized list of the services they had provided. Today, detailed billing is the norm, with the exception of attorneys providing retail representation in routine matters, and appointed counsel for indigent defendants.

However, in some circumstances, attorneys and their clients will form a contingent fee agreement, under which both parties agree that the attorney is entitled to a certain percentage of any recovery, often $33 \%$. Contingent fee agreements are typically associated with personal injury actions, where the plaintiff often has a strong claim, but lacks the financial resources to pursue litigation. Under a contingent fee agreement, the attorney can fund the litigation, in exchange for a chance of a much larger recovery.

But contingent fee agreements can also make sense when a client wants to control an attorney's incentives. Under an hourly billing agreement, the attorney has an incentive to bill as many hours as possible, even as the additional work produces diminishing returns to the client. And under a fixed fee billing agreement, the attorney has an incentive to do as little work as possible. But under a contingent fee agreement, the attorney simply has an incentive to win.

Under Model Rule 1.5(c), contingency fee agreements cannot be unreasonable and must be in writing. In addition, contingent fees are prohibited in criminal law and family law actions. Attorneys cannot form a contingent fee agreement to be paid only if a criminal defendant is acquitted or receives some other favorable outcome. And attorneys typically cannot form a contingent fee agreement to receive compensation from the resolution of a domestic dispute.

Culpepper \& Carroll, PLLC v. Cole, 929 So. 2d 1224 (La. 2006)

Summary: Cole retained attorney Culpepper for a will contest. Cole requested one-third contingent fee and Culpepper agreed. Culpepper received a settlement offer and Cole refused to settle it. Cole terminated representation when Culpepper refused to file suit as a forced heir. Cole recovered nothing challenging the will by himself. Culpepper wanted $\$ 6,950$ plus legal interest as attorney's fees. Cole argued Culpepper did this on contingency basis, and that Culpepper quit the case. Court found that a contingent fee contract exists, but found that Culpepper is not entitled to recover attorneys fees because Cole did not obtain any recovery.

PER CURIAM.

${ }^{26}$ The Beatles, You Never Give Me Your Money, Abbey Road (1969). 
Connie Daniel Cole seeks review of a judgment of the court of appeal affirming an award of attorney's fees to his former counsel. For the reasons that follow, we reverse the judgment of the court of appeal.

\section{FACTS AND PROCEDURAL HISTORY}

Connie Daniel Cole retained attorney Bobby Culpepper of the law firm of Culpepper \& Carroll, PLLC to represent him in a contest of his mother's will. Mr. Cole requested that the firm handle the matter on a one-third contingent fee basis, and Mr. Culpepper agreed to do so. On September 20, 2000, Mr. Culpepper sent Mr. Cole a letter in which he confirmed that he would accept the representation on a contingent fee basis of one-third "of whatever additional property or money we can get for you."

After negotiation between Mr. Culpepper and counsel for the estate of Mr. Cole's mother, Mr. Cole was offered property worth $\$ 21,600.03$ over and above what he would have received under the terms of the decedent's will. Mr. Culpepper thought the compromise was reasonable and recommended to Mr. Cole that he accept the offer. However, Mr. Cole refused to settle his claim for that amount, believing he was entitled to a larger share of his mother's succession as a forced heir. When Mr. Culpepper refused to file suit in the matter, Mr. Cole terminated his representation. Mr. Cole then proceeded in proper person to challenge his mother's will, but he was unsuccessful and recovered nothing.

On April 12, 2004, Mr. Culpepper filed a "Petition on Open Account" on behalf of the Culpepper law firm. The suit was filed in Ruston City Court against Mr. Cole, seeking the sum of $\$ 6,950.01$, plus legal interest, together with $25 \%$ on the principal and interest as additional attorney's fees. Attached to the petition were Mr. Culpepper's invoice for attorney's fees and a demand letter to Mr. Cole seeking the payment of "the entire balance of $\$ 6,950.01$ that you owe Culpepper \& Carroll, PLLC."

Mr. Cole, appearing in proper person, answered the law firm's petition and denied that he owed any money. Mr. Cole explained in his answer that "Mr. Culpepper did this on a contingency fee basis," that Mr. Culpepper "quit the case," and that Mr. Cole paid court costs but Mr. Culpepper "would not go to court."

Following a trial on the merits, at which both parties testified, the city court rendered judgment in favor of the law firm, awarding the sum of $\$ 6,950.01$, plus legal interest from the date of judicial demand until paid, together with $25 \%$ on the principal and interest as additional attorney's fees, and costs. In oral reasons for judgment, the city court judge stated that a "contingency fee was present" based on the record, including the testimony in open court and the written admission in Mr. Cole's answer that there was a contingent fee arrangement. The court noted that "work was accomplished" by Mr. Culpepper and further noted that, according to the testimony, the settlement would have produced a better result than if the case had gone to trial on the issue of forced heirship. Thus, the court was satisfied that the law firm met its burden of proof. 
Mr. Cole appealed the city court's judgment, and in a 2-1 ruling, the court of appeal amended the judgment and affirmed. The majority agreed that a valid contingent fee contract existed between Mr. Cole and Mr. Culpepper, and found that by refusing to sign the "favorable settlement" negotiated by Mr. Culpepper before he was discharged, Mr. Cole was in effect depriving Mr. Culpepper of the contingent fee he had already earned. Accordingly, the court of appeal affirmed the award to Mr. Culpepper of \$6,950.01 in attorney's fees, plus legal interest. However, the court of appeal found that the money owing in this case does not derive from an open account, but rather from a contractual obligation in the form of a contingent fee agreement. Based on this reasoning, the court of appeal amended the trial court's judgment to delete the award to the law firm of $25 \%$ additional attorney's fees plus costs under the open account statute.

Judge Caraway dissented. He recognized that a contingent fee contract existed in this case, but found that because there was ultimately no recovery in the case, no fee was due to Mr. Culpepper. Judge Caraway further observed that to allow an attorney to collect a fee when the client rejects a settlement offer and later recovers nothing "ignores multiple and serious concerns embodied in the rules of professional conduct."

Upon Mr. Cole's application, we granted certiorari to review the correctness of the court of appeal's ruling.

\section{DISCUSSION}

As a threshold matter, we note the trial court made a finding of fact that a contingent fee contract existed between Mr. Cole and Mr. Culpepper. Based on our review of the record, we find no manifest error in this determination.

Having found a contingent fee contract exists, we now turn to the question of whether Mr. Culpepper is entitled to recover any attorney's fees under this contract. Pursuant to the parties' agreement, Mr. Culpepper is entitled to one-third "of whatever additional property or money" he obtained on behalf of Mr. Cole. It is undisputed that Mr. Cole recovered no additional property or money as a result of the litigation against his mother's estate. Because Mr. Cole obtained no recovery, it follows that $\mathrm{Mr}$. Culpepper is not entitled to any contingent fee.

Nonetheless, Mr. Culpepper urges us to find that his contingency should attach to the settlement offer he obtained on behalf of his client, even though his client refused to accept that offer. According to Mr. Culpepper, he did the work for which Mr. Cole retained him, and he is therefore entitled to one-third of the amount offered in settlement, notwithstanding Mr. Cole's rejection of the settlement offer.

With the benefit of hindsight, it would have been in Mr. Cole's best interest to accept the settlement offer obtained by Mr. Culpepper. However, it is clear that the decision to accept a settlement belongs to the client alone. Therefore, regardless of the wisdom of Mr. Cole's decision, his refusal to accept the settlement was binding on Mr. Culpepper. 
To allow Mr. Culpepper to recover a contingent fee under these circumstances would penalize Mr. Cole for exercising his right to reject the settlement. We find no statutory or jurisprudential support for such a proposition. Indeed, this court has rejected any interpretation of the Rules of Professional Conduct which would place restrictions on the client's fundamental right to control the case.

In summary, we find that Mr. Culpepper did not obtain any recovery on behalf of Mr. Cole. In the absence of a recovery, it follows that Mr. Culpepper cannot collect a contingent fee for his services. Accordingly, we must reverse the judgment of the court of appeal awarding a contingent fee to Mr. Culpepper.

\section{Questions:}

1. Why wasn't Culpepper entitled to compensation for the work he actually did for Cole?

2. Could the contingent fee agreement between Cole and Culpepper have included a clause requiring Cole to obtain Culpepper's consent before accepting or rejecting a settlement offer?

It's a bad business to be in. You don't get thanked and you don't get paid. It's a hard world to be in with, and to end with, and to think about leaving behind. ${ }^{27}$

${ }^{27}$ Liz Phair, Elvis, Be True, Girly-Sound (1991). 


\section{7: Financial Relationships with Clients}

\section{Client Trust Accounts}

Business? It's quite simple; it's other people's money. ${ }^{28}$

Oh, can somebody explain why things go on this way? I thought they were my friends. I can't believe it's me, I can't believe that I'm so green. Eyes down, round and round, let's all sit and watch the moneygoround. Everyone take a little bit here and a little bit there. ${ }^{29}$

When attorneys hold money or property in trust for their clients they must never commingle it with their own funds or property, on pain of sanction, typically suspension or disbarment. In other words, if a client deposits funds with an attorney, the attorney must place those funds in a trust account, and if a client deposits physical property, the attorney must also hold that property separately, typically in a safety deposit box. Commingling funds or property is a per se violation, with few exceptions, primarily in order to enable an attorney to pay any banking fees on a client's trust account.

State bar associations carefully monitor attorney trust accounts and punish any commingling of funds. Some state bar associations even randomly audit attorney trust accounts, looking for violations. State rules of professional conduct typically require attorneys to deposit client funds in an interest-bearing trust account. Many states require attorneys to deposit some or all of the interest generated by client trust accounts into a common fund. This Interest on Lawyers' Trust Accounts ("IOLTA") fund is used to provide legal services to indigent clients.

Attorneys may withdraw funds from a client's trust account in order to pay the client's attorney fees, as they are earned. The rule against commingling prohibits attorneys from using funds from a client trust account to pay business or personal expenses, and the attorney must return any funds remaining in a client's trust account to the client when the representation ends. When a client receives a settlement or award, the attorney must deposit the funds in the client's trust account, and then withdraw funds to pay the client's attorney fees and disburse to the client. Specifically, if the attorney and the client have a contingent fee agreement, the attorney must pay the client's contingent fee from the client trust account.

\section{Rule 1.15: Safekeeping Property}

a. A lawyer shall hold property of clients or third persons that is in a lawyer's possession in connection with a representation separate from the lawyer's own property. Funds shall be kept in a separate account maintained in the state where the lawyer's office is situated, or elsewhere with the consent of the client or third person. Other property shall be identified as such and appropriately safeguarded. Complete records of such account

\footnotetext{
${ }^{28}$ Alexandre Dumas.

${ }^{29}$ The Kinks, Moneygoround, Lola Versus Powerman and the Moneygoround (1970).
} 
funds and other property shall be kept by the lawyer and shall be preserved for a period of [five years] after termination of the representation.

b. A lawyer may deposit the lawyer's own funds in a client trust account for the sole purpose of paying bank service charges on that account, but only in an amount necessary for that purpose.

c. A lawyer shall deposit into a client trust account legal fees and expenses that have been paid in advance, to be withdrawn by the lawyer only as fees are earned or expenses incurred.

d. Upon receiving funds or other property in which a client or third person has an interest, a lawyer shall promptly notify the client or third person. Except as stated in this rule or otherwise permitted by law or by agreement with the client, a lawyer shall promptly deliver to the client or third person any funds or other property that the client or third person is entitled to receive and, upon request by the client or third person, shall promptly render a full accounting regarding such property.

e. When in the course of representation a lawyer is in possession of property in which two or more persons (one of whom may be the lawyer) claim interests, the property shall be kept separate by the lawyer until the dispute is resolved. The lawyer shall promptly distribute all portions of the property as to which the interests are not in dispute.

Neb. State Bar Ass'n v. Statmore, 352 N.W.2d 875 (Neb. 1984).

Summary: Statmore (Attorney) represented Kuzara for a 2nd offense DUI. Kuzara gave Statmore $\$ 500$ for representation. Statmore deposited the check, but it was returned twice by the bank due to insufficiency of funds. Without Statmore's knowledge, the bank deposited \$495. Statmore requested criminal prosecution to get paid. Kuzara hired a different attorney. Statmore got an addition \$540. Kuzara contacted Statmore about potential double payment and requested a reply, but Statmore did not reply. Statmore realized the double payment in February. Statmore acknowledged double payment but didn't have funds to reimburse. Statmore brought a $\$ 245$ check to pay Kuzara. Mistake did not relieve Statement of his professional duty regarding his client's funds.

\section{PER CURIAM.}

This is an original disciplinary proceeding by the Nebraska State Bar Association against Clay B. Statmore, an attorney admitted to practice in Nebraska. After a hearing before the Committee on Inquiry of the First Disciplinary District and a review by the Disciplinary Review Board, formal charges against Statmore have been filed in this court.

Statmore does not deny the charges. The charges allege violations of the following:

CANON 1. A Lawyer Should Assist in Maintaining the Integrity and Competence of the Legal Profession.

DR 1-102. Misconduct. 

A. A lawyer shall not:
1. Violate a Disciplinary Rule.
6. Engage in any other conduct that adversely reflects on his fitness to practice law.

CANON 9. A Lawyer Should Avoid Even the Appearance of Professional Impropriety. DR 9-102. Preserving Identity of Funds and Property of a Client.

\section{B. A lawyer shall:}

1. Promptly notify a client of the receipt of his funds, securities, or other properties.

4. Promptly pay or deliver to the client as requested by a client the funds, securities, or other properties in the possession of the lawyer which the client is entitled to receive. We review the evidence de novo to determine if discipline should be imposed and, if discipline is warranted, the nature of the discipline which is appropriate under the circumstances.

On April 15, 1982, Statmore undertook representation of Deborah A. Kuzara regarding a charge of driving while intoxicated, second offense. Kuzara, on June 2, gave Statmore her check for $\$ 500$ - the agreed fee for the representation. Statmore deposited Kuzara's June 2 check, which was returned twice by the bank due to insufficiency of Kuzara's account. Statmore contacted Kuzara and her father in New Jersey about the insufficient fund check.

On June 22 Kuzara issued another check (check A) for $\$ 500$, which Statmore deposited but which was returned to Statmore's Lincoln bank on account of Kuzara's insufficient funds. On June 30 Kuzara sent Statmore still another check (check B) in the amount of $\$ 540-\$ 500$ for Statmore's fee, plus $\$ 40$ for the check service charges regarding the other Kuzara checks. Check B was returned on account of insufficient funds. Unbeknown to Statmore, his bank had held check A and collected that check on July 9, 1982, with credit to Statmore's business account in the sum of $\$ 495$ ( $\$ 500$ less a $\$ 5$ service charge). Statmore again contacted Kuzara about the insufficient fund checks. At this time Statmore was still unaware that the bank had credited his account $\$ 495$ for check A on July 9 .

Statmore took check B to the Lancaster County attorney and requested criminal prosecution. Notified by the county attorney regarding prosecution on check B, Kuzara hired attorney George Thompson of Bellevue, Nebraska. Kuzara later delivered $\$ 540$ to the county attorney for check B. On November 12 the county attorney sent $\$ 540$ to Statmore regarding check B.

Kuzara contacted Statmore about the possibility of a double payment, that is, check A credited to Statmore on July 9 and the funds from the county attorney on November 12 regarding check B. Statmore asked for verification from Kuzara that there was in fact a double payment, and felt he was getting a "runaround" about the checks.

Attorney Thompson wrote Statmore on January 5, 1983, pointed out the double payment, and requested a reply. Statmore did not respond to Thompson's letter. Early in February, Statmore checked his deposit slips and saw that there indeed had been the "\$495 deposit" (check A) to his account on July 9. This was apparently Statmore's first verification of payment on check A. 
Thompson again wrote to Statmore on March 2 and demanded Kuzara's $\$ 495$ by return mail. Statmore never responded to that letter. By March 14 Statmore conclusively realized that he had received double payment from Kuzara. On March 16 Thompson telephoned Statmore, who then acknowledged the double payment and told Thompson he did not have the funds to reimburse Kuzara.

On May 23 Kuzara filed a complaint with the Counsel for Discipline of the Nebraska State Bar Association. Counsel for Discipline wrote Statmore as soon as Kuzara filed her complaint. Statmore paid Kuzara $\$ 250$ on June 28 and the same day wrote the Counsel for Discipline that he had "recently" paid Kuzara \$250. In his June 28 letter to the Counsel for Discipline, Statmore also mentioned that the "remaining $\$ 245$ should be repaid within the next fourteen days." Statmore paid nothing further until the day of the hearing before the Committee on Inquiry.

On the day of the hearing before the Committee on Inquiry, September 20, Statmore brought the Counsel for Discipline a check for $\$ 245$ to pay Kuzara, and stated he "didn't know who to send it to."

Statmore says he never reconciles his monthly bank statement and, therefore, had no knowledge that check $A$ had cleared and been credited to his account on July 9 . Such ignorance regarding check $A$ existed at the time Statmore received the money from the Lancaster County attorney regarding check B.

Throughout all the time in question, Statmore was having financial problems: failed to pay utilities (some of which were disconnected) and did not pay office rent (moved his office after delinquency in rent). Statmore implies that the somewhat chaotic office situation explains, if not excuses, the sorry state of affairs during his representation of Kuzara.

Implicit in the license to practice law is the requirement that the recipient of the license shall demean himself in a proper manner and shall refrain from practices which bring discredit upon the lawyer, the profession, and the courts.

Any violation of the ethical standards relating to the practice of law, or any conduct of an attorney which tends to bring reproach upon the courts or the legal profession, constitutes grounds for suspension or disbarment.

When the double payment occurred, Statmore held Kuzara's money, which he was not authorized to retain. Kuzara's conduct or mistake concerning payment of her checks did not relieve Statmore of his professional duty regarding his client's funds. Accurate accountability of a client's funds is the responsibility of the lawyer, not the client. Statmore's slipshod office management and careless bookkeeping prevented any semblance of the accurate accounting lawyers must maintain with respect to a client's funds. As a result of Statmore's poor management and failure to keep track of payment from Kuzara, there was a commingling of a client's money -an area of gravest concern of this court in reviewing claimed lawyer misconduct. The prohibition against commingling of funds is a salutary rule adopted 
to provide against the probability in some cases, the possibility in many cases, and the danger in all cases that such commingling will result in the loss of clients' money. Moral turpitude is not necessarily involved in the commingling of a client's money with an attorney's own money if the client's money is not endangered by such procedure and is always available to him. However, inherently there is danger in such practice for frequently unforeseen circumstances arise jeopardizing the safety of the client's funds, and as far as the client is concerned the result is the same whether his money is deliberately misappropriated by an attorney or is unintentionally lost by circumstances beyond the control of the attorney.

A lawyer's poor accounting procedures and sloppy office management are not excuses or mitigating circumstances in reference to commingled funds.

We realize that Statmore has repaid Kuzara the overpayment. However, a lawyer's restitution of a client's funds after being faced with legal accountability does not exonerate professional misconduct.

Among the major considerations in determining whether a lawyer should be disciplined is maintenance of the highest trust and confidence essential to the attorney-client relationship. As a profession, the bar continuously strives to build and safeguard such trust and confidence, but conduct such as before us in the present case weakens the efforts of the overwhelming majority of lawyers in Nebraska whose conduct meets, if not exceeds, the Code of Professional Responsibility.

To determine whether and to what extent discipline should be imposed, it is necessary that we consider the nature of the offense, the need for deterring others, the maintenance of the reputation of the bar as a whole, the protection of the public, the attitude of the offender generally, and his present or future fitness to continue in the practice of law.

Therefore, under the circumstances we find that a suspension is appropriate discipline for Statmore and that Statmore should be suspended from the practice of law for a period of 6 months. During such suspension, we sincerely suggest that Statmore reappraise the candor, fairness, and responsibility a lawyer owes to his client. We recommend that Statmore revise his accounting procedures and office management to prevent recurrence of any misconduct. Suspension of Statmore shall be effective September 1, 1984, and shall last for 6 months. Statmore shall make suitable arrangements that his clients' matters pending at and during his suspension shall be suitably protected.

\section{Questions:}

1. Was Statmore's commingling of Kuzara's funds with his own intentional? Was it reckless? Was Kuzara harmed, and if so, how? 
2. Was a 6 month suspension an appropriate sanction under the circumstances? How does it compare to the sanctions for other violations of the duty of care?

\section{Further Reading:}

- $\quad$ ABA Model Rules for Client Trust Account Records (2010).

\section{Equity as Compensation}

I've got the brains you've got the looks. Let's make lots of money. You've got the brawn l've got the brains. Let's make lots of money. ${ }^{30}$

Sometimes, attorneys agree to accept an equity interest in their client's property, in lieu of attorney fees. For example, an attorney representing a corporation may accept shares of the company rather than cash. This kind of agreement can benefit both the client and the attorney, especially if the client is cash-poor, but is a promising investment. The client receives legal advice with no upfront expense, and the attorney receives an investment potentially worth much more than the hourly fees. Moreover, the attorney has an incentive to provide the best possible advice, because it will increase the value of their investment.

But equity compensation is not limited to securities. An attorney may agree to represent a client in exchange for an equity interest in the client's real estate. Or a patent attorney may agree to prosecute a patent in exchange for an interest in the patent.

In any case, the Model Rules of Professional Conduct permits equity compensation, but only if the attorney complies with the requirements of Model Rule 1.8(a). Essentially, the attorney must disclose the terms of the agreement to the client, the attorney must advise the client to seek independent legal counsel, and the client must provide informed consent to the agreement, all of which must be in writing. In addition, the terms of the agreement must be substantively "fair and reasonable" to the client.

The concern is that the attorney's financial interest in the client's property could create a conflict of interest. In theory, both the client and the attorney want the property to increase in value. But in some cases, the attorney's interest in the property could compromise the impartiality of the attorney's advice, if a potential transaction would benefit the client, but harm the attorney's property interest.

\section{Model Rule 1.8: Current Clients: Specific Rules}

a. A lawyer shall not enter into a business transaction with a client or knowingly acquire an ownership, possessory, security or other pecuniary interest adverse to a client unless:

${ }^{30}$ Pet Shop Boys, Opportunities (Let's Make Lots of Money), Please (1986). 
1. the transaction and terms on which the lawyer acquires the interest are fair and reasonable to the client and are fully disclosed and transmitted in writing in a manner that can be reasonably understood by the client;

2. the client is advised in writing of the desirability of seeking and is given a reasonable opportunity to seek the advice of independent legal counsel on the transaction; and

3. the client gives informed consent, in a writing signed by the client, to the essential terms of the transaction and the lawyer's role in the transaction, including whether the lawyer is representing the client in the transaction.

\section{Committee on Prof. Ethics v. Mershon, 316 N.W.2d 895 (lowa 1982)}

Summary: Mershon did tax and property work for Miller. Mershon, Miller, and Schenk formed a corporation to turn land into a development property. Mershon gave the corporation a $\$ 6,250$ promissory note and received 200 shares of stock in exchange for his legal services. The project never happened due to lack of funding, and Miller died. Mershon expended $\$ 900$ in out of pocket expenses for the corporation (more than promissory note) but didn't intend to seek payment. Schenk wanted $1 / 2$ of the outstanding stock. Mershon violated the rules of professional responsibility because he and Miller had differing interests in the transaction. Mershon was reprimanded.

McCORMICK, Justice.

This case involves review of a Grievance Commission report recommending that respondent be reprimanded for alleged ethical violations arising from a business transaction with a client. We adopt the recommendation.

From our de novo review of the record, we find the facts as follows. Respondent is a Cedar Falls attorney. He began to do tax and property work for Leonard O. Miller, a farmer, in 1951. Miller owned 100 acres of farmland adjacent to a country club near the city. In 1969, when he was 68 , Miller became interested in developing the land for residential purposes. He employed a landscape architect and R. O. Schenk, of Schenk Engineering Company, to prepare a preliminary plat and market study.

When the preliminary work was completed, Miller brought Schenk to meet with respondent to discuss the project. Miller wished to proceed with the development but did not have sufficient funds to pay engineering costs. Schenk suggested that the three men form a corporation to which Miller would contribute the land, Schenk would contribute engineering services, and respondent would contribute legal services. They agreed the land was worth approximately $\$ 400$ an acre. Schenk estimated engineering costs at $\$ 400$ an acre, and he said legal costs were usually one half that amount.

After several conferences in early 1970, the three men formed a corporation, Union Township Development, Inc. Subsequently Miller conveyed the farmland to the corporation at a capitalized value of $\$ 12,500$ and received 400 shares of stock. Schenk gave the corporation a $\$ 12,500$ 
promissory note and also received 400 shares of stock. Respondent gave the corporation a $\$ 6,250$ promissory note and received 200 shares of stock. The promissory notes were interest free and due at the discretion of the corporation. They were to represent the services to be rendered by Schenk and respondent.

Development plans were premised on the corporation's ability to obtain financing on the security of the farmland. As it turned out, the corporation was unable to borrow money unless the three individuals would guarantee the obligation personally. They refused to do so, and financing was never obtained.

The trio met at least annually to discuss the development, but when Miller died on December 31,1978 , at the age of 77 , the project was still at a stalemate. Respondent believed the parties had an oral agreement that if development did not occur he and Schenk would relinquish their interests in the corporation to Miller. Three days after Miller's death, he transferred his stock to the corporation. He asked Schenk to do the same thing, but Schenk refused, denying any obligation to do so.

Respondent was nominated in Miller's will as executor of his estate. He served in that capacity until Miller's two daughters expressed dissatisfaction with his role in Miller's conveyance of the farmland to the corporation. He then resigned as executor. Consistent with his view, he showed Miller as owner of all corporate stock in the preliminary probate inventory. The farmland was appraised at $\$ 4,000$ an acre.

Although respondent had expended $\$ 900$ in out-of-pocket expenses for the corporation and performed legal services worth more than $\$ 6,000$, he did not intend to seek payment. Schenk, however, maintained at the time of the grievance hearing that he still owned one half of the outstanding stock of the corporation.

The determinative question in our review is whether this evidence establishes a violation of the principle in DR5-104(A), which provides:

A lawyer shall not enter into a business transaction with a client if they have differing interests therein and if the client expects the lawyer to exercise his professional judgment therein for the protection of the client, unless the client has consented after full disclosure.

In order to establish a violation of DR5-104(A) it is necessary to show that the lawyer and client had differing interests in the transaction, that the client expected the lawyer to exercise his professional judgment for the protection of the client, and that the client consented to the transaction without full disclosure.

The definitions section of the code of professional responsibility defines "differing interests": 
"Differing interests" include every interest that will adversely affect either the judgment or loyalty of a lawyer to a client, whether it be a conflicting, inconsistent, diverse, or other interest.

Miller and Mershon plainly had differing interests in at least two aspects of the transaction. One was the issue of giving respondent a present interest in the corporation in anticipation of future legal services. The fee agreement was made during the existence of the attorney-client relationship and thus was subject to the general principles governing attorney-client transactions. Because respondent's fee was tied to the amount of his stock in the corporation, he and Miller had differing interests concerning the extent of respondent's stock ownership. Another differing interest involved making respondent a debtor of the corporation to assure that the services would be performed. Because Miller's interest was aligned wholly with the corporation, he and respondent had differing interests with respect to respondent's promissory note.

No dispute exists that Miller relied on respondent to exercise his professional judgment to protect him. One respect in which respondent did so was in preparing a written agreement to assure that Miller was reimbursed from the first profits of the corporation for the preincorporation expenses of preliminary studies. This, however, was the only agreement of the parties that was reduced to writing.

The fighting issue before the Commission was whether respondent made full disclosure to Miller within the meaning of the Canon before Miller entered the transaction. If full disclosure means only that respondent made Miller fully aware of the nature and terms of the transaction, this requirement was satisfied. Nothing was hidden from Miller, and he was an active participant in the transaction. Full disclosure, however, means more than this.

Because of the fiduciary relationship which exists, the attorney

has the burden of showing that the transaction was in all respects fairly and equitably conducted; that he fully and faithfully discharged all his duties to his client, not only by refraining from any misrepresentation or concealment of any material fact, but by active diligence to see that his client was fully informed of the nature and effect of the transaction proposed and of his own rights and interests in the subject matter involved, and by seeing to it that his client either has independent advice in the matter or else receives from the attorney such advice as the latter would have been expected to give had the transaction been one between his client and a stranger.

Respondent acknowledges he did not suggest to Miller that he obtain independent advice. The record does not show he otherwise gave Miller the kind of advice Miller should have had if the transaction were with a stranger. Respondent let Schenk estimate the value of his legal services and thus the extent of respondent's stock ownership without any investigation to determine whether the estimate was accurate. Nor did he suggest to Miller that he make such investigation. If Schenk's estimate was generous, the effect may have been to chill respondent's 
scrutiny of the benchmark for the valuation, which was Schenk's valuation of his own services. Furthermore there was no discussion or investigation concerning the reasonableness or wisdom of tying respondent's fee for future services to a present twenty percent interest in the corporation. Respondent acknowledges that the arrangement was at least a technical violation.

Nothing was done to assure that Miller would get his farm back if either Schenk or respondent did not perform or if the development should not be undertaken. Nothing was done to protect Miller or his estate in the event of the death of any of the parties. The promissory notes could hardly have been on more favorable terms to the debtors. The record does not show whether Miller was informed of the difficulty the corporation might have in enforcing respondent's obligation. So far as the record shows, Miller was not told of any possible effect of respondent's differing interests on the exercise of his professional judgment.

The Commission found respondent is forthright and honest and gained no profit from the transaction. The record confirms this finding. As the Commission also found, however, a violation of DR5-104(A) was nevertheless established. Respondent had three alternatives when the Schenk proposal was first made. The safest and perhaps best course would have been to refuse to participate personally in the transaction. Alternatively, he could have recommended that Miller obtain independent advice. Finally, if Miller refused to seek independent advice or respondent did not recommend he do so, he could have made the least desirable choice. He could have attempted to meet the high standard of disclosure outlined in this opinion.

Having chosen to enter the transaction without recommending that Miller obtain independent advice, respondent was obliged to make full disclosure. Because the record does not show full disclosure was made before Miller consented to the transaction, a violation of DR5-104(A) has been established. This is true even though respondent did not act dishonestly or make a profit on the transaction.

In accordance with the Commission recommendation, we reprimand him for the violation.

\section{Questions:}

1. Did Mershon benefit at Miller's expense?

2. Why was Miller reprimanded? What should he have done to avoid a reprimand? Would it have changed the outcome?

3. Was Mershon's punishment sufficient under the circumstances?

\section{Litigation Finance}

Historically, "maintenance," "champerty," and "barratry" were illegal and tortious. ${ }^{31}$ Maintenance is litigation funding by a disinterested third party, champerty is litigation funding in exchange for

\footnotetext{
${ }^{31}$ Percy H. Winfield, History of Maintenance and Champerty, 35 L. Q. Rev. 50 (1919). In medieval England, maintenance and champerty were both prohibited by statute, and may also have been prohibited by the common law.
} 
a percentage of any recovery, and barratry is frivolous litigation. ${ }^{32}$ The prohibition was intended to prevent frivolous and abusive litigation. The concern was that nobles would abuse the courts to harass their enemies and extort settlements. ${ }^{33}$

Until recently, United States courts maintained the prohibition on maintenance and champerty. But people began to question the legitimacy of rules that prevented people from pursuing valid claims simply because they could not pay attorney's fees. First, courts began permitting contingent fee agreements, which are champerty, but limited to lawyers. And then they began permitting litigation finance agreements, which are champerty for everyone.

Contingent fee agreements are literally champerty, because an attorney agrees to fund litigation in exchange for a percentage of the recovery. And litigation finance agreements are champerty squared, because a third party agrees to fund litigation in exchange for a percentage of the recovery. But courts have held that both contingent fees and litigation finance are fine, because they enable people to pursue valid claims.

\section{Model Rule 1.8: Current Clients: Specific Rules}

e. A lawyer shall not provide financial assistance to a client in connection with pending or contemplated litigation, except that:

1. a lawyer may advance court costs and expenses of litigation, the repayment of which may be contingent on the outcome of the matter; and

2. a lawyer representing an indigent client may pay court costs and expenses of litigation on behalf of the client.

f. A lawyer shall not accept compensation for representing a client from one other than the client unless:

1. the client gives informed consent;

2. there is no interference with the lawyer's independence of professional judgment or with the client-lawyer relationship; and

3. information relating to representation of a client is protected.

\section{Model Rule 1.8: Current Clients: Specific Rules}

i. A lawyer shall not acquire a proprietary interest in the cause of action or subject matter of litigation the lawyer is conducting for a client, except that the lawyer may:

1. acquire a lien authorized by law to secure the lawyer's fee or expenses; and

2. contract with a client for a reasonable contingent fee in a civil case.

\section{Restatement (Third) of the Law Governing Lawyers § 36: Forbidden Client-Lawyer Financial Arrangements}

\footnotetext{
32 The word "champerty" derived from the Old French word "champart," which referred to a feudal lord's claim to a share of the produce of the land worked by a vassal. The word "barratry" derived from the Old French word "barater," which meant "to deceive."

33 In practice, the law prohibited champerty, and may have permitted maintenance without champerty.
} 
1. A lawyer may not acquire a proprietary interest in the cause of action or subject matter of litigation that the lawyer is conducting for a client, except that the lawyer may:

a. acquire a lien to secure the lawyer's fee or expenses; and

b. contract with a client for a contingent fee in a civil case except when prohibited.

2. A lawyer may not make or guarantee a loan to a client in connection with pending or contemplated litigation that the lawyer is conducting for the client, except that the lawyer may make or guarantee a loan covering court costs and expenses of litigation, the repayment of which to the lawyer may be contingent on the outcome of the matter.

3. A lawyer may not, before the lawyer ceases to represent a client, make an agreement giving the lawyer literary or media rights to a portrayal or account based in substantial part on information relating to the representation.

Saladini v. Righellis, 426 Mass. 231 (1997)

MARSHALL, J.

The plaintiff, Lisa Saladini, appeals from the decision of a judge in the Superior Court dismissing her complaint, sua sponte, on the ground that a written agreement she had with the defendant, George P. Righellis, was champertous and unenforceable. Saladini had sought a declaratory judgment establishing her rights under the agreement. We granted Saladini's application for direct appellate review to consider whether we should continue to enforce the doctrine. We rule that the common law doctrines of champerty, barratry, and maintenance no longer shall be recognized in Massachusetts. We reverse the judgment entered in the Superior Court and remand this case for further proceedings.

On September 23, 1992, Saladini and Righellis entered into a written agreement pursuant to which Saladini agreed to advance funds to Righellis to allow him to pursue potential legal claims he had arising out of his interest in real estate in Cambridge, known as Putnam Manor. In return, Righellis agreed that, if pursuit of his claims yielded any recovery, the first amount recovered would be used to reimburse Saladini, and that Saladini would, in addition, receive $50 \%$ of any net recovery remaining after payment of attorney's fees. Saladini, herself, had no interest in Putnam Manor.

Saladini thereafter advanced funds to Righellis that he used to retain an attorney under a contingent fee agreement to bring a lawsuit and to pursue his legal claims. At some point Righellis became dissatisfied with that attorney's representation and, with the concurrence of Saladini, hired a new lawyer, Robert Potters, to replace him. Righellis signed a new contingent fee agreement with Potters.

The original agreement between Saladini and Righellis did not anticipate retaining a second attorney to represent Righellis in the Putnam Manor lawsuit. Saladini maintains that to deal with 
this circumstance, she and Righellis agreed that each would pay one-half of the retainer required by Potters, each would pay one-half of the litigation disbursements, and that in all other respects the terms of their original agreement would remain in effect. No new or amended agreement was executed, but Saladini did pay one-half of the retainer to Potters and one-half of the litigation disbursements. All told, Saladini advanced a total of $\$ 19,229$ to Righellis.

At some point Righellis settled the Putnam Manor lawsuit, with the defendants in that case agreeing to pay him $\$ 130,000$. The first payment of $\$ 10,000$ was paid on or about November 2 , 1994, with the balance due on January 11, 1995. Neither Potters nor Righellis informed Saladini that a settlement had been reached, or that the first settlement funds had been received.

When Saladini became aware of the settlement, she filed suit, seeking to establish her rights under the agreement. She also sought, and a judge in the Superior Court granted, injunctive relief, enjoining Righellis and Potters from disbursing any of the settlement funds until her claims had been adjudicated.

In November, 1995, Righellis filed a motion for summary judgment that Saladini opposed. After reviewing the submissions of the parties, a judge in the Superior Court, sua sponte, invited both parties to submit memoranda on the issue whether the agreement between Saladini and Righellis was champertous. A hearing followed and, in September, 1996, another judge ruled that the agreement was champertous and unenforceable as against public policy. She ordered that Saladini's complaint be dismissed in its entirety. A judgment to that effect was entered on September 24, 1996. Saladini appealed. A judge granted Saladini's motion to continue the preliminary injunction pending her appeal.

II

Champerty has been described as the unlawful maintenance of a suit, where a person without an interest in it agrees to finance the suit, in whole or in part, in consideration for receiving a portion of the proceeds of the litigation. We described the doctrine as a "narrow and somewhat technical concept," a type of maintenance that occurs when a person engages in "officious intermeddling in a suit that no way belongs to one, by maintaining or assisting either party with money or otherwise, to prosecute or defend it."

The doctrine has a long and, in this country, checkered history. The ancient prohibition against champerty arose in feudal England. More recently the doctrine has been viewed as a check on frivolous or unnecessary litigation, or a mechanism to encourage the settlement of disputes without recourse to litigation. The extent to which courts, here, accepted the doctrine has varied. In some States, champerty was never adopted, or has been abandoned. In others, the doctrine was given narrow application. Massachusetts followed the common law prohibition against champerty, although we have never enforced the doctrine to the same extent as English 
courts. ${ }^{34}$ Nevertheless, under our own development of the doctrine we have little doubt that the agreement between Saladini and Righellis would be champertous were we to continue to recognize the offense. We no longer are inclined to do so.

We have long abandoned the view that litigation is suspect, and have recognized that agreements to purchase an interest in an action may actually foster resolution of a dispute. In more recent cases we have questioned whether the doctrine continues to serve any useful purpose. In Mclnerney, we noted that "the decline of champerty, maintenance, and barratry as offences is symptomatic of a fundamental change in society's view of litigation - from 'a social ill, which, like other disputes and quarrels, should be minimized' to 'a socially useful way to resolve disputes." In Christian v. Mooney, we declined to consider whether an agreement between a "bounty hunter in troubled titles" and other plaintiffs in a suit was champertous because that issue was not contested by the parties to the agreement - even though that plaintiff's repeated instigation of litigation regarding troubled real estate titles was the very conduct traditionally condemned as violative of the prohibition against champerty. Most recently, in Berman v. Linnane, we declined to strike down a contingent fee agreement that did not satisfy the requirements of S.J.C. Rule 3:05 as champertous, relying rather on "the public policy against the recovery of excessive fees" to limit the financial recovery by an attorney. We observed in that case that "at least as to lawyers, other principles fulfil whatever purpose champerty once had." These decisions all reflect the change in our attitude toward the financing of litigation.

We also no longer are persuaded that the champerty doctrine is needed to protect against the evils once feared: speculation in lawsuits, the bringing of frivolous lawsuits, or financial overreaching by a party of superior bargaining position. There are now other devices that more effectively accomplish these ends. Our rule governing contingent fees between attorneys and clients is based on the principle that an attorney's fee must be reasonable. We also recognize a public policy against the recovery of excessive fees. Additional devices include Mass. R. Civ. P. 11 , providing sanctions for misconduct, and G. L. c. $231, \S 6 \mathrm{~F}$, regulating the bringing of frivolous lawsuits. General Laws c. 93A, and the doctrines of unconscionability, duress, and good faith, establish standards of fair dealing between opposing parties. To the extent that we continue to have the concerns that the doctrine of champerty was thought to address, we conclude that it is better to do so directly, rather than attempting to mold an ancient doctrine to modern circumstances. ${ }^{35}$ As Justice Holmes, then a member of this court, said a century ago: "It

\footnotetext{
${ }^{34}$ For example, we consistently have held that it is not unlawful "to engage in the business of buying choses in action and enforcing them by suit if necessary," although under English common law assignments of choses in action are within the scope of champerty. We have not prohibited agreements otherwise champertous where the party has an independent interest in the suit. We also have recognized the validity of contingent fee arrangements with attorneys, which otherwise would be champertous.

${ }^{35}$ The doctrine of champerty may also be unworkable or have harsh results. Rather than punishing the owner of the legal claim who has entered into a champertous agreement, the doctrine bestows on him a windfall. In this case, for example, Righellis would be permitted to retain the full benefit of the positive result achieved in the Putnam Manor lawsuit, while he would not have to honor his obligations to Saladini, the person whose support made pursuit of the lawsuit possible. A defendant sued in a champerty-
} 
is revolting to have no better reason for a rule of law than that so it was laid down in the time of Henry IV. It is still more revolting if the grounds upon which it was laid down have vanished long since, and the rule simply persists from blind imitation of the past."

Other States that no longer recognize the doctrine of champerty have continued to scrutinize an agreement to finance a lawsuit with care. We shall do likewise. This means that if an agreement to finance a lawsuit is challenged, we will consider whether the fees charged are excessive or whether any recovery by a prevailing party is vitiated because of some impermissible overreaching by the financier. Judges also retain their inherent power to disapprove an attorney's fee that is unreasonable. We shall be guided in our analysis by a rule of what is fair and reasonable, looking to all of the circumstances at the time the arrangement is made to determine whether the agreement should be set aside or modified. In this case, for example, had the agreement been challenged, relevant factors might have included the respective bargaining position of the parties at the time the agreement was made, whether both parties were aware of the terms and consequences of the agreement, whether Righellis may have been unable to pursue the lawsuit at all without Saladini's funds, and whether the claim by Righellis that he will receive but $\$ 35,000$ of the total $\$ 130,000$ settlement award if Saladini prevails is unreasonable in the circumstances. We observe that before the judge raised the issue, Righellis had never challenged the validity of his agreement with Saladini. The record before us does not permit any conclusion regarding the reasonableness of the agreement between Righellis and Saladini on the one hand, or Righellis and Potters on the other. We see no reason why Righellis should be the beneficiary of any windfall, or why any adjustment to the financing arrangement — if appropriate at all — should be made solely at Saladini's expense. If pursued, those matters can be decided by the trial judge.

\section{Questions:}

1. On October 4, 2012, the website Gawker published a 2 minute excerpt from a 30 minute video of Terry Gene Bollea, better known as "Hulk Hogan," having sex with Heather Clem, the wife of Bollea's friend Bubba the Love Sponge Clem. Bollea claimed the video was made without his knowledge or consent, and filed an action against Gawker in Florida state court, alleging an assortment of tort claims. The jury ruled in favor of Bollea, awarding him \$115 million in compensatory damages and \$25 million in punitive damages. Gawker could not pay the judgment and filed for bankruptcy. After the trial, Peter Thiel disclosed that he had paid millions of dollars to finance Bollea's action, which he described as "one of my greater philanthropic things that I've done." Many people objected to Thiel's role in Bollea's action. Was it maintenance, champerty, or barratry? Should it have been prohibited?

2. In 2003, residents of Lago Agrio, Ecuador filed a class action against Chevron in an Ecuadorian court, alleging that its Lago Agrio oil field had polluted the environment. The plaintiffs were represented by the Ecuadorian lawyer Pablo Fajardo Mendoza and the American lawyer Steven Donziger, who obtained more than $\$ 32$ million in third-party 
litigation funding. The American documentary filmmaker Joe Berlinger documented the litigation and released the film Crude in 2009. In 2011, the Ecuadorian court ruled for the plaintiffs and ordered Chevron to pay $\$ 18$ billion in damages. Chevron's lawyers at Gibson, Dunn \& Crutcher LLP noticed that an early version of Crude had featured an ostensibly impartial environmental expert meeting with Donziger before the trial, and subpoenaed Berlinger's outtakes, which provided additional evidence of fraud and corruption. In 2014, the United States District Court for the Southern District of New York found that Donziger had used "corrupt means" in the Ecuadorian court and refused to enforce the verdict, and the Second Circuit affirmed. Both New York and the District of Columbia suspended Donziger from the practice of law. Was it improper for Donziger to obtain third-party litigation funding? Did the availability of funding create improper incentives? Are third-party litigation funders in a position to evaluate the legitimacy of the litigation they fund? Should they be?

\section{Further Reading:}

- Max Radin, Maintenance by Champerty, 24 Calif. L. Rev. 48 (1935)

- Jeremy Kidd, Modelling the Likely Effects of Litigation Financing, 47 Loy. Chi. L.J. 1239 (2016)

- Anthony J. Sebok, The Inauthentic Claim, 64 Vand. L. Rev. 61 (2011)

- Jonathan T. Molot, A Market in Litigation Risk, 76 U. Chi. L. Rev. 367 (2009)

- Maya Steinitz, Whose Claim is This, Anyway? Third-Party Litigation Funding, 95 Minn. L. Rev. 1268 (2011)

- Victoria Shannon Sahani, Reshaping Third Party Funding, 91 Tulane L. Rev. 405 (2017) 


\section{8: Organizations as Clients}

We live as we dream, alone. To crack the shell we mix with the others. ${ }^{36}$

You pull down the future with the one you love (I see no evil). ${ }^{37}$

When an attorney represents an organization, the attorney's client is typically the organization, and only the organization. An attorney may represent any kind of organization, irrespective of its form. Obviously, an attorney may represent an organization that is a legal entity, like a corporation or a limited liability company. But an attorney may also represent an organization that is not a legal entity, like a partnership or an unincorporated association. In all of these cases, the attorney may represent the organization without representing the constituents of the organization.

But an organization is a legal fiction that can act only through its agents. Accordingly, the attorney advises the organization by advising its agents, who make decisions on behalf of the organization, depending on their role in the organization. In other words, attorneys advise organizational clients by advising non-client agents, who make decisions that bind the organizational client.

Of course, the agents of an organizational client may consult with each other before making decisions for the organization. They may individually ask the attorney for advice about how to act on behalf of the organizational client. They may ask the attorney to advise them collectively about the organizational client's options. And they may ask the attorney for advice about the statements, decisions, and actions of other agents.

The attorney must provide legal advice to the agents of an organizational client, in their capacity as agents of that client. But the attorney must always remember that the client is the organization, not the organization's agent. When the attorney advises an agent, the attorney must provide advice for the benefit of the organization, not the agent. And the attorney must ensure that the agents observe their duties to the organization.

Specifically, an attorney representing an organizational client must ensure that its agents act consistently with the interests of the organization, rather than their own interests. If an agent of an organizational client acts or refuses to act in a way that violates a legal obligation to the organization, then the attorney must act to protect the interests of the organization. The attorney should generally report the concern to the management of the organization. In some cases, the attorney may even report confidential information or withdraw from representation, if it is necessary to protect the interests of the organization.

Model Rule 1.13: Organization as Client

a. A lawyer employed or retained by an organization represents the organization acting through its duly authorized constituents.

b. If a lawyer for an organization knows that an officer, employee or other person associated with the organization is engaged in action, intends to act or refuses to act in a

${ }^{36}$ Gang of Four, We Live as We Dream, Alone, Songs of the Free (1984).

${ }^{37}$ Television, See No Evil, Marquee Moon (1977). 
matter related to the representation that is a violation of a legal obligation to the organization, or a violation of law that reasonably might be imputed to the organization, and that is likely to result in substantial injury to the organization, then the lawyer shall proceed as is reasonably necessary in the best interest of the organization. Unless the lawyer reasonably believes that it is not necessary in the best interest of the organization to do so, the lawyer shall refer the matter to higher authority in the organization, including, if warranted by the circumstances to the highest authority that can act on behalf of the organization as determined by applicable law.

c. Except as provided in paragraph (d), if

1. despite the lawyer's efforts in accordance with paragraph (b) the highest authority that can act on behalf of the organization insists upon or fails to address in a timely and appropriate manner an action, or a refusal to act, that is clearly a violation of law, and

2. the lawyer reasonably believes that the violation is reasonably certain to result in substantial injury to the organization, then the lawyer may reveal information relating to the representation whether or not Rule 1.6 permits such disclosure, but only if and to the extent the lawyer reasonably believes necessary to prevent substantial injury to the organization.

d. Paragraph (c) shall not apply with respect to information relating to a lawyer's representation of an organization to investigate an alleged violation of law, or to defend the organization or an officer, employee or other constituent associated with the organization against a claim arising out of an alleged violation of law.

e. A lawyer who reasonably believes that he or she has been discharged because of the lawyer's actions taken pursuant to paragraphs (b) or (c), or who withdraws under circumstances that require or permit the lawyer to take action under either of those paragraphs, shall proceed as the lawyer reasonably believes necessary to assure that the organization's highest authority is informed of the lawyer's discharge or withdrawal.

f. In dealing with an organization's directors, officers, employees, members, shareholders or other constituents, a lawyer shall explain the identity of the client when the lawyer knows or reasonably should know that the organization's interests are adverse to those of the constituents with whom the lawyer is dealing.

g. A lawyer representing an organization may also represent any of its directors, officers, employees, members, shareholders or other constituents, subject to the provisions of Rule 1.7. If the organization's consent to the dual representation is required by Rule 1.7, the consent shall be given by an appropriate official of the organization other than the individual who is to be represented, or by the shareholders.

\section{Restatement (Third) of the Law Governing Lawyers § 96: Representing an Organization as Client}

1. When a lawyer is employed or retained to represent an organization:

a. the lawyer represents the interests of the organization as defined by its responsible agents acting pursuant to the organization's decision-making procedures; and 
b. subject to Subsection (2), the lawyer must follow instructions in the representation.

2. If a lawyer representing an organization knows of circumstances indicating that a constituent of the organization has engaged in action or intends to act in a way that violates a legal obligation to the organization that will likely cause substantial injury to it, or that reasonably can be foreseen to be imputable to the organization and likely to result in substantial injury to it, the lawyer must proceed in what the lawyer reasonably believes to be the best interests of the organization.

3. In the circumstances described in Subsection (2), the lawyer may, in circumstances warranting such steps, ask the constituent to reconsider the matter, recommend that a second legal opinion be sought, and seek review by appropriate supervisory authority within the organization, including referring the matter to the highest authority that can act in behalf of the organization.

In the Matter of Silva, 636 A.2d 316 (R.I. 1994)

Summary: Attorney Daniel Silva represented both Medcon Mortgage Corporation and Suncoast Savings and Loan. Medcon was owned by Silva's friend Edward Medeiros. Silva learned that Medeiros was illegally diverting funds and advised him to stop, but did not advise Suncoast, because Medeiros claimed attorney-client privilege. The Disciplinary Board found that Silva violated the rules of professional conduct, and the Supreme Court agreed, holding that Silva should have reported Medeiros's fraud and withdrawn from representing Medcon and Suncoast.

\section{PER CURIAM.}

The respondent, Daniel J. Silva, appeared before this court on December 2, 1993, pursuant to an order to show cause why discipline should not be imposed. The Disciplinary Board conducted an evidentiary hearing and received legal memoranda from the respondent and disciplinary counsel. The board has filed with us its decision and a concurring opinion signed by three members of the board.

The board found that Silva violated several provisions of the Rules of Professional Conduct when he failed to report a diversion of mortgage funds by his long-time friend Edward Medeiros. Silva served as counsel to Medeiros's mortgage company, Medcon Mortgage Corporation, and Suncoast Savings and Loan of Hollywood, Florida. In his capacity as closing attorney for Suncoast, Silva received wire transfers of mortgage proceeds in his client account. Upon receipt of the wire transfers from Suncoast, Silva simply turned the proceeds over to Medeiros and/or MEDCON for disbursement. In the fall of 1990 Silva learned that Medeiros had diverted funds from a closing funded by Suncoast in which Silva acted as closing attorney. The diverted funds were designated to pay off a preexisting mortgage on the property. Silva advised Medeiros that his conduct was criminal. Silva did not notify Suncoast of the diversion of funds, nor did he inform the title insurance company, which had issued a title policy that did not except the prior mortgage from coverage, that the prior mortgage had not been discharged. Silva testified that 
Medeiros forbade him to do so on the basis of Medeiros's assertion of the attorney/client privilege on behalf of both MEDCON and himself personally.

In December 1990 Silva received a wire transfer from Suncoast for another closing with MEDCON. Notwithstanding his knowledge of the previous diversion of funds by Medeiros, Silva did not disburse the funds in accordance with the terms listed on the closing sheet; instead, he turned the proceeds over to MEDCON. Silva kept $\$ 100$ of the proceeds as his fee for serving as a conduit of the funds. Medeiros converted those funds to his own use, and was subsequently convicted and imprisoned. The respondent was never charged with committing a criminal act.

The respondent's position before the board and this court is that he was prohibited from disclosing Medeiros's defalcation by the provisions of Rule 1.6 of the Rules of Professional Conduct. Respondent also took the position that he had no obligation to protect Suncoast's interests. We do not agree with either of his contentions.

On the basis of the record before us, we believe that Silva had an obligation to both MEDCON and Suncoast to ensure that the transactions in which he acted as attorney and/or agent were carried out with fair dealing and good faith. We further believe that Silva had an obligation to report Medeiros's overt act of diverting the funds as soon as he learned of it. In addition Silva should have withdrawn from representing both MEDCON and Suncoast as soon as he discovered Medeiros's fraud.

Although we consider Silva's failure to act appropriately and to make the requisite disclosures serious breaches of his ethical obligation, we find no evidence that Silva's actions were motivated by personal gain. Rather, he appears to have had a genuine belief that Medeiros's assertion of the attorney/client privilege and the requirements of Rule 1.6 prohibited the disclosure we now say was required.

Silva did not appear to appreciate and understand to whom he owed the duty of confidentiality. It is apparent from this record, however, that he was counsel to the corporate entity MEDCON, and therefore, it was to MEDCON he owed the duty of confidentiality. Silva's dealings with Medeiros did not establish the attorney/client relationship that would trigger the application of the prohibitions against disclosure encompassed in Rule 1.6. Therefore, Silva's obligations to both Suncoast and MEDCON required him to disclose Medeiros's overt criminal act of conversion of the funds.

This court concurs with the findings of the disciplinary board that Silva exercised very poor judgment and that he engaged in serious misconduct. We are constrained however to depart from the board's recommendation for sanction. We believe that Rule 1.6 has created a great deal of confusion among the members of the Rhode Island Bar. We therefore censure Silva for his failure to fulfill his ethical obligations to the parties to these transactions. The court's issuance of this sanction rather than the three-month suspension of Silva's license is due in part to the absence of any motive for personal gain and Silva's ten years at the bar without a disciplinary complaint. The court's position on the appropriate level of sanction, however, would 
be more severe were it not for the apparent confusion in the mind of this attorney concerning whom he represented and the silence of Rule 1.6 on that question.

\section{Questions:}

1. Medeiros owned Medcon. How could Silva have reported to Medcon?

2. Could Silva have reasonably believed that he represented Medeiros?

3. Did the court impose an appropriate punishment?

\section{Representing a Corporation}

\section{Brennan v. Ruffner, 640 So. 2d 143 (Fla. 1994)}

Summary: In 1976, Dr. Brennan and Dr. Martell formed a professional association. Attorney Charles Ruffner prepared the shareholders agreement. When Dr. Mirmelli joined the association in 1982, Ruffner revised the agreement, which provided for the involuntary termination of any shareholder by majority vote. All of the shareholders agreed. In 1989, Martell and Mirmelli voted to terminate Brennan. Among other things, Brennan filed a malpractice action against Ruffner. The trial court granted summary judgment to Ruffner, and the appellate court affirmed, holding that Ruffner represented the corporation, not Brennan.

PARIENTE, Judge.

We affirm a final summary judgment entered in favor of a lawyer and against a disgruntled minority shareholder of a closely held corporation. We find that an attorney/client relationship did not exist between the individual shareholder and the attorney representing the corporation. Consequently, there is no basis for a legal malpractice action. We further reject the other theories of liability asserted by appellant.

In 1976, appellant, Robert J. Brennan, M.D., along with a Dr. Martell, employed appellee, Charles L. Ruffner, Esq., to incorporate their medical practice as a professional association. In connection with the incorporation, the lawyer prepared a shareholder's agreement. In 1982, a third doctor, Dr. Mirmelli, joined the corporation, and each doctor became a one-third shareholder in the new firm. The lawyer, who was corporate counsel since 1976, was requested to draft a new shareholder's agreement. After approximately 8 months of negotiation, the shareholders executed a new shareholder's agreement. The new agreement included a provision for the involuntary termination of any shareholder by a majority vote of the two other shareholders. It is undisputed that Dr. Brennan was aware of this provision at the time he signed the documents and that he signed the agreement upon reassurances from Dr. Mirmelli that he would not join with Dr. Martell in using the provision against Dr. Brennan.

However, despite the assurances, in 1989 Dr. Martell and Dr. Mirmelli involuntarily terminated Dr. Brennan as a shareholder and employee of the corporation. Dr. Brennan instituted a lawsuit 
against Dr. Martell and Dr. Mirmelli claiming breach of contract and fraud in the inducement. The verified complaint in that lawsuit specifically alleged that Dr. Brennan was not represented by counsel in the negotiation of the shareholder's agreement. That lawsuit was settled. Dr. Brennan then filed this suit for legal malpractice, breach of contract, breach of fiduciary duty and breach of contract as a third party beneficiary. In contradiction to the sworn allegations of the first lawsuit, Dr. Brennan alleged in this complaint that the lawyer represented him individually, as well as the corporation, in the preparation and drafting of the agreement. The lawyer denied undertaking the representation of Dr. Brennan individually.

In a legal malpractice action, a plaintiff must prove three elements: the attorney's employment, the attorney's neglect of a reasonable duty and that such negligence resulted in and was the proximate cause of loss to the plaintiff. Florida courts have uniformly limited attorney's liability for negligence in the performance of their professional duties to clients with whom they share privity of contract.

The material undisputed facts in this case support a legal conclusion that there was no privity of contract between Dr. Brennan and the corporation's lawyer. It is undisputed that the lawyer was representing the corporation. The issue raised by Dr. Brennan's complaint was whether the lawyer was also representing him individually. While Dr. Brennan made the initial contact with the lawyer, there is no evidence in the record to create a credible issue of fact that the lawyer ever represented Dr. Brennan individually. Dr. Brennan's sworn complaint against the other doctors, which preceded the legal malpractice action against the lawyer, states he was unrepresented by counsel in the negotiation of the shareholder's agreement.

Dr. Brennan argues that a separate duty to him as a shareholder arose by virtue of the lawyer's representation of the closely held corporation. Although never squarely decided in this state, we hold that where an attorney represents a closely held corporation, the attorney is not in privity with and therefore owes no separate duty of diligence and care to an individual shareholder absent special circumstances or an agreement to also represent the shareholder individually. While there is no specific ethical prohibition in Florida against dual representation of the corporation and the shareholder if the attorney is convinced that a conflict does not exist, an attorney representing a corporation does not become the attorney for the individual stockholders merely because the attorney's actions on behalf of the corporation may also benefit the stockholders. The duty of an attorney for the corporation is first and foremost to the corporation, even though legal advice rendered to the corporation may affect the shareholders. Cases in other jurisdictions have similarly held.

We reject the notion that the lawyer in this case could be held liable to one of the minority shareholders for a breach of fiduciary duty. In any closely held corporation, there will be an inherent conflict between the potential rights of the minority shareholder and the rights of the corporation in a shareholder's agreement concerning termination. At the time this agreement was drafted, any one of the three shareholders could have ended up becoming the minority shareholder. While Dr. Brennan claimed in the complaint that the lawyer had a duty to advise him of a conflict of interest and never advised him of a potential conflict, the facts in the record 
do not support that contention. Dr. Brennan testified in deposition that he simply did not recall any conversations. However, the accountant for the corporation specifically remembered a conversation where the lawyer told the doctors collectively that he represented only the corporation in the drafting of the shareholder agreement. Absent some evidence that the corporation's lawyer conspired or acted with the two shareholders to insert provisions that would work to the detriment of the third shareholder; that the corporation's lawyer concealed his representation of another individual shareholder; or that the attorney agreed to the dual representation, there is no breach of fiduciary duty established in this case.

Finally, even assuming arguendo that a duty existed based on an attorney/client relationship, a third party beneficiary theory or a breach of fiduciary relationship, we simply do not find any factual dispute concerning the issue of proximate cause. It is undisputed that Dr. Brennan was aware of the provisions in the agreement and chose to take his chances upon being reassured by Dr. Mirmelli that he would never use the provisions against Dr. Brennan.

\section{Questions:}

1. Why did the court hold that Ruffner represented the corporation, rather than Brennan? What if Brennan were a majority shareholder of the corporation?

2. Did Ruffner provide Brennan with legal advice? If so, did Ruffner provide negligent legal advice?

3. Did Ruffner represent any of the doctors?

4. Did Ruffner represent anyone?

\section{Representing a Partnership}

Mursau Corp. v. Florida Penn Oil \& Gas, Inc., 638 F. Supp. 259 (W.D. Pa. 1986)

Summary: Thomas Murray owned Mursau Corporation, which purchased a limited partnership in Florida-Penn Oil and Gas, Inc., in a deal managed by Goldberg \& Snodgrass. Mursau filed a breach of fiduciary duty action against G\&S, but the district court granted summary judgment to G\&S, because it found no attorney-client relationship or evidence of fraud.

COHILL, Chief Judge.

Presently before us are Motions for Summary Judgment filed on behalf of each Defendant. Having held oral argument and having reviewed the affidavits, depositions, briefs and other exhibits filed, we find no genuine issue as to any material fact. Consequently, we will grant these motions.

Facts 
Plaintiff, Mursau Corporation, through its President and majority stockholder, Thomas $\mathrm{H}$. Murray, Esquire, purchased a limited partnership interest in Defendant Florida-Penn Oil \& Gas, Inc.'s 1981-102 Drilling Program. Defendant Christian E. Carlsen is the President of Fla-Penn and Defendant David Graham is a stockholder of Fla-Penn. Defendant Goldberg \& Snodgrass, a law firm in which individual Defendants Lee H. Goldberg and Stewart R. Snodgrass are partners, was retained by Fla-Penn to structure the 102 program and prepare a tax opinion letter with regard to that program.

Mursau's acquisition of the limited partnership interest in the 102 program came about as a result of Murray contacting Goldberg in early October, 1981. Murray was interested in the 102 program as a tax shelter for Mursau. Since Mursau's fiscal year ended on October 31, Murray wanted to close the deal on or before October 30 , in order to secure tax advantages for Mursau in 1981.

At his initial meeting with G\&S, Murray was given a copy of a Private Placement Memorandum for an earlier Fla-Penn oil and gas partnership, the 101 program. He was told that the PPM for the 102 program would be materially similar but that the costs would be reduced proportionally according to the lesser number of wells to be drilled under the 102 program. The 101 program drilled 10 wells; the 102 program would drill only 4. Murray reviewed the PPM for the 101 program with independent counsel, then signed a commitment letter for the 102 program.

On October 29, 1981, Murray received a copy of the PPM for the 102 program which was in fact materially similar to the PPM for the 101 program. At the closing on October 30, 1981, Murray refused to tender a check on behalf of Mursau unless he was granted check-signing authority for the partnership, a demand clearly in conflict with the limited partnership agreement already signed by Murray. Murray wanted that authority so that, after closing, he could dispute the payment of certain costs provided for in the PPM, including a finder's commission to the group securing the limited partners participation. As indicated by his notes comparing the costs under the 101 and 102 program, Murray was fully aware of the $\$ 49,600$ finder's commission prior to the time set for closing.

Although Murray initially walked out of the closing because of the refusal of Fla-Penn to acquiesce in his demands, he returned after a conversation with Snodgrass outside on the sidewalk. Fla-Penn never acceded to Murray's demands. After the closing, Fla-Penn paid G\&S $\$ 20,000$ for legal fees and $\$ 49,600$ as a finder's commission. Murray became aware of these payments sometime in December of 1981.

In the complaint, Murray essentially alleges breach of fiduciary duty arising out of an attorneyclient relationship between Mursau and G\&S and Goldberg and Snodgrass individually.

The Defendants maintain that the 102 PPM as well as the 101 PPM, on which the 102 was modeled, disclose all material information. Both PPMs disclose the payment of legal fees to G\&S and the finder's commission; both disclose the potential conflict of interest of G\&S as 
counsel for the partnership and the general partner. Both advise prospective limited partners to consult independent counsel.

In order to recover for a breach of fiduciary duty by an attorney, the plaintiff has a threshold burden of showing existence of an attorney-client relationship. The intent to create an attorneyclient relation can be implied from the conduct of the parties where no express relationship exists.

Although the relationship of attorney and client may be implied from the conduct of the parties, such conduct must evidence an offer or request by the client for legal services and an acceptance of the offer by the attorney. It is clear that an attorney client relationship exists only with the consent of both parties.

As noted above, G\&S's representation of the partnership and general partner was disclosed to Plaintiff, and Plaintiff was advised to obtain independent counsel. Murray admits that he did retain legal counsel who, on behalf of Mursau, met with G\&S about the 102 plan. Murray received a bill and remitted payment to his independent counsel for legal services.

In contrast, Plaintiff paid no fees to G\&S. As stated in the 102 PPM, the partnership paid G\&S for adapting the 101 PPM for use in the 102 plan and for preparing the tax opinion letter to accompany the 102 PPM. The legal fees paid to G\&S by the partnership did not include any amount for services rendered to the Plaintiff. Plaintiff concedes that the only legal advice he received from G\&S concerned the tax aspects of the 102 plan. We conclude that the legal advice on the tax consequences of the 102 plan was a service provided to and paid for by the partnership as part of its efforts to secure a limited partner for its venture.

Since we see no evidence from which we can imply an offer or request for services by Plaintiff, nor an acceptance of any such request by G\&S, we must conclude that no attorney-client relationship was formed between Mursau, the limited partnership, and G\&S. G\&S did have an attorney-client relationship with the partnership and probably the general partner who organized the venture. Although Mursau indirectly benefited by receiving the services $G \& S$ performed on behalf of the partnership to enable the partnership to attract a limited partner, it never requested, nor did it receive, other legal advice or services from G\&S.

Even were we to find evidence from which an attorney-client relationship between G\&S and Mursau could be inferred, as discussed above, we see no facts indicating any fraud or other breach tending to violate such a relationship.

Viewing the facts presented in a light most favorable to Mursau, the nonmoving party, we believe Defendants have met their burden of showing the absence of any genuine issue of material fact and are entitled to summary judgment.

\section{Questions:}


1. Did Mursau have any attorney-client relationship with G\&S?

2. Did Mursau pay G\&S for legal services?

3. Why did the court conclude that Mursau had no attorney-client relationship with G\&S in relation to this matter? 


\section{9: Agents as Clients}

There's nothing wrong with having aspirations, nothing wrong with walking tall. But if misfortune deals the consequences, sooner or later, friend, you've got to fall. ${ }^{38}$

In theory, an attorney who represents an organization represents only the organization, and does not represent the organization's agents. However, organizations can act only through their agents, and when attorneys represent organizations, they do so by providing legal advice to the organization's agents, who made decisions on behalf of the organization. Attorneys must convince the organization's agents to hire them. Attorneys must convince the organization's agents to follow their advice. And attorneys must obey the decisions of the organization's agents. It is easy for attorneys representing an organization to see its agents as their clients, rather than the organization itself.

But that is a terrible mistake. When attorneys represent organizations, they must never treat its agents as their clients. They must always represent the interests of the organization, and only the organization. Attorneys representing an organization must always act in the best interest of the organization, and they must ensure that its agents also act in the best interests of the organization. And if the interests of the organization conflict with the interests of its agents, the attorney must always pursue the interests of the organization.

Usually, the interests of an organization and its agents coincide, and the agents pursue the interests of the organization to the best of their ability. But that is not always the case.

Sometimes, the interests of an organization and its agents diverge, and the agents pursue their own interests, at the expense of the organization.

Attorneys representing organizations must always be vigilant to ensure that the organization's interests are aligned with the interests of its agents, and that its agents are acting in the organization's interests, rather than their own. For example, if an agent wants to make a transaction on behalf of the organization that will benefit the agent at the organization's expense, the attorney must object. Likewise, if the agent wants to disclose confidential information about the organization that will benefit the agent, but harm the organization, the attorney must object.

\section{Agents as Quasi-Clients}

Attorneys representing an organization must always be careful to ensure that its agents do not become quasi-clients. If an attorney is retained by an organization, then the attorney has an express attorney-client relationship with the organization. But in order to represent an organization, an attorney must provide legal advice to its agents, who will act on the organization's behalf. Accordingly, the attorney must only provide legal advice relating to the interests of the organization, and must not provide legal advice relating to the interests of its

${ }^{38}$ Hüsker Dü, Friend, You've Got to Fall, Warehouse: Songs and Stories (1987). 
agents. In fact, attorneys representing an organization should explicitly inform its agents that they represent the organization, and not its agents. And they should advise the organization's agents to seek outside counsel, if their interests may diverge from the interests of the organization.

In theory, an attorney representing an organization who wants to interview an agent of the organization can prevent the agent from becoming a client by explicitly warning the agent that the attorney represents the organization, and does not represent the agent. This warning is often called an "Upjohn warning" or "corporate Miranda warning," because its purpose is to inform agents of their right to remain silent. After all, an organization cannot force its agents to testify against themselves. But it can fire them, if they refuse to participate in an investigation.

If an attorney representing an organization provides legal advice to an agent of that organization, then the agent may become a quasi-client of the attorney. That is awkward, because it can create a conflict of interest.

\section{American Bar Association White Collar Crime Committee Working Group Model "Upjohn Warning" or "Corporate Miranda" Warning}

I am a lawyer for Corporation A. I represent only Corporation A, and I do not represent you personally.

I am conducting this interview to gather facts in order to provide legal advice for Corporation A. This interview is part of an investigation to determine the facts and circumstances of $\mathrm{X}$ in order to advise Corporation $\mathrm{A}$ how best to proceed.

Your communications with me are protected by the attorney-client privilege. But the attorney-client privilege belongs solely to Corporation A, not you. That means Corporation $A$ alone may elect to waive the attorney-client privilege and reveal our discussion to third parties. Corporation $A$ alone may decide to waive the privilege and disclose this discussion to such third parties as federal or state agencies, at its sole discretion, and without notifying you.

In order for this discussion to be subject to the privilege, it must be kept in confidence. In other words, with the exception of your own attorney, you may not disclose the substance of this interview to any third party, including other employees or anyone outside of the company. You may discuss the facts of what happened but you may not discuss this discussion.

Do you have any questions?

Are you willing to proceed?

\section{Questions:}


1. Does this model warning adequately explain that the attorney represents the organization and not its agents?

2. If you were an attorney representing an organization, would you have any concerns about this warning?

3. If you received this warning, would you answer any questions? Would you give candid answers? Would you obtain outside counsel? What if you were unaware of the subject matter of the inquiry?

In re Grand Jury Subpoena: Under Seal, 415 F. 3d 334 (4th Cir. 2005)

Summary: AOL started an internal investigation re: its relationship with PurchasePro. AOL retained Wilmer, Cutler \& Pickering to assist in the investigation. AOL general counsel told its employees that were interviewed that the GC represented the company, but could represent them if there was no conflict of interest. GC also told the employees that they could retain personal counsel at company expense. The SEC began to investigate AOL's relationship with PurchasePro. One employee, Wakeford, was deposed by SEC and believed the attorneys represented both them and the company. Others, John Doe \#1, \#2, that were deposed sought independent counsel. The court denied Wakeford's motion to quash because it found that attorney-client privilege in the subpoenaed documents belonged only to AOL.

WILSON, District Judge.

This is an appeal by three former employees of AOL Time Warner from the decision of the district court denying their motions to quash a grand jury subpoena for documents related to an internal investigation by AOL. Appellants in the district court that the subpoenaed documents were protected by the attorney-client privilege. Because the district court concluded that the privilege was AOL's alone and because AOL had expressly waived its privilege, the court denied the appellants' motion. We affirm.

I.

In March of 2001, AOL began an internal investigation into its relationship with PurchasePro, Inc. AOL retained the law firm of Wilmer, Cutler \& Pickering to assist in the investigation. Over the next several months, AOL's general counsel and counsel from Wilmer Cutler interviewed appellants, AOL employees Kent Wakeford, John Doe 1, and John Doe 2.

The investigating attorneys interviewed Wakeford, a manager in the company's Business Affairs division, on six occasions. At their third interview, and the first one in which Wilmer Cutler attorneys were present, Randall Boe, AOL's General Counsel, informed Wakeford, "We represent the company. These conversations are privileged, but the privilege belongs to the company and the company decides whether to waive it. If there is a conflict, the attorney-client privilege belongs to the company." Memoranda from that meeting also indicate that the 
attorneys explained to Wakeford that they represented AOL but that they "could" represent him as well, "as long as no conflict appeared." The attorneys interviewed Wakeford again three days later and, at the beginning of the interview, reiterated that they represented $\mathrm{AOL}$, that the privilege belonged to $\mathrm{AOL}$, and that Wakeford could retain personal counsel at company expense.

The investigating attorneys interviewed John Doe 1 three times. Before the first interview, Boe told him, "We represent the company. These conversations are privileged, but the privilege belongs to the company and the company decides whether to waive it. You are free to consult with your own lawyer at any time." Memoranda from that interview indicate that the attorneys also told him, "We can represent you until such time as there appears to be a conflict of interest, but the attorney-client privilege belongs to $\mathrm{AOL}$ and $\mathrm{AOL}$ can decide whether to keep it or waive it." At the end of the interview, John Doe 1 asked if he needed personal counsel. A Wilmer Cutler attorney responded that he did not recommend it, but that he would tell the company not to be concerned if Doe retained counsel.

AOL's attorneys interviewed John Doe 2 twice and followed essentially the same protocol they had followed with the other appellants. They noted, "We represent AOL, and can represent you too if there is not a conflict." In addition, the attorneys told him that, "the attorney-client privilege is AOL's and AOL can choose to waive it."

In November, 2001, the Securities and Exchange Commission began to investigate AOL's relationship with PurchasePro. In December 2001, AOL and Wakeford, through counsel, entered into an oral "common interest agreement," which they memorialized in writing in January 2002. The attorneys acknowledged that, "representation of their respective clients raised issues of common interest to their respective clients and that the sharing of certain documents, information, and communications with clients" would be mutually beneficial. As a result, the attorneys agreed to share access to information relating to their representation of Wakeford and AOL, noting that "the oral or written disclosure of Common Interest Materials would not diminish in any way the confidentiality of such Materials and would not constitute a waiver of any applicable privilege."

Wakeford testified before the SEC on February 14, 2002, represented by his personal counsel. Laura Jehl, AOL's general counsel, and F. Whitten Peters of Williams \& Connolly, whom AOL had retained in November 2001 in connection with the PurchasePro investigation, were also present, and both stated that they represented Wakeford "for purposes of the deposition." During the deposition, the SEC investigators questioned Wakeford about his discussions with AOL's attorneys. When Wakeford's attorney asserted the attorney-client privilege, the SEC investigators followed up with several questions to determine whether the privilege was applicable to the investigating attorneys' March-June 2001 interviews with Wakeford. Wakeford told them he believed, at the time of the interviews, that the investigating attorneys represented him and the company. 
John Doe 1 testified before the SEC on February 27, 2002, represented by personal counsel. No representatives of $\mathrm{AOL}$ were present. When SEC investigators questioned Doe about the March-June 2001 internal investigation, his counsel asserted that the information was protected and directed Doe not to answer any questions about the internal investigation "in respect to the company's privilege." He stated that Doe's response could be considered a waiver of the privilege and that, "if the AOL lawyers were present, they could make a judgment, with respect to the company's privilege, about whether or not the answer would constitute a waiver."

On February 26, 2004, a grand jury in the Eastern District of Virginia issued a subpoena commanding $\mathrm{AOL}$ to provide "written memoranda and other written records reflecting interviews conducted by attorneys for AOL" of the appellants between March 15 and June 30, 2001. While $\mathrm{AOL}$ agreed to waive the attorney-client privilege and produce the subpoenaed documents, counsel for the appellants moved to quash the subpoena on the grounds that each appellant had an individual attorney-client relationship with the investigating attorneys, that his interviews were individually privileged, and that he had not waived the privilege. Wakeford also claimed that the information he disclosed to the investigating attorneys was privileged under the common interest doctrine.

The district court denied John Doe 1's and John Doe 2's motions because it found they failed to prove they were clients of the investigating attorneys who interviewed them. The court based its conclusion on its findings that: (1) the investigating attorneys told them that they represented the company; (2) the investigating attorneys told them, "we can represent you," which is distinct from "we do represent you"; (3) they could not show that the investigating attorneys agreed to represent them; and (4) the investigating attorneys told them that the attorney-client privilege belonged to the company and the company could choose to waive it.

The court initially granted Wakeford's motion to quash because it found that his communications with the investigating attorneys were privileged under the common interest agreement between counsel for Wakeford and counsel for AOL. Following a motion for reconsideration, the court reversed its earlier ruling and held that the subpoenaed documents relating to Wakeford's interviews were not privileged because it found that Wakeford's common interest agreement with AOL postdated the March-June 2001 interviews. In addition, the court held that Wakeford failed to prove that he was a client of the investigating attorneys at the time the interviews took place. The court based its conclusion on its findings that: (1) none of the investigating attorneys understood that Wakeford was seeking personal legal advice; (2) the investigating attorneys did not provide any personal legal advice to him; and (3) the investigating attorneys believed they represented $\mathrm{AOL}$ and not Wakeford. This appeal followed.

II.

Appellants argue that because they believed that the investigating attorneys who conducted the interviews were representing them personally, their communications are privileged. However, we agree with the district court that essential touchstones for the formation of an attorney-client relationship between the investigating attorneys and the appellants were missing at the time of 
the interviews. There is no evidence of an objectively reasonable, mutual understanding that the appellants were seeking legal advice from the investigating attorneys or that the investigating attorneys were rendering personal legal advice. Nor, in light of the investigating attorneys' disclosure that they represented AOL and that the privilege and the right to waive it were AOL's alone, do we find investigating counsel's hypothetical pronouncement that they could represent appellants sufficient to establish the reasonable understanding that they were representing appellants. Accordingly, we find no fault with the district court's opinion that no individual attorney-client privilege attached to the appellants' communications with AOL's attorneys.

"The attorney-client privilege is the oldest of the privileges for confidential communications known to the common law." "When the privilege applies, it affords confidential communications between lawyer and client complete protection from disclosure." Because its application interferes with "the truth seeking mission of the legal process," however, we must narrowly construe the privilege, and recognize it "only to the very limited extent that excluding relevant evidence has a public good transcending the normally predominant principle of utilizing all rational means for ascertaining the truth." Accordingly, the privilege applies only to "confidential disclosures by a client to an attorney made in order to obtain legal assistance." The burden is on the proponent of the attorney-client privilege to demonstrate its applicability."

The person seeking to invoke the attorney-client privilege must prove that he is a client or that he affirmatively sought to become a client. "The professional relationship hinges upon the client's belief that he is consulting a lawyer in that capacity and his manifested intention to seek professional legal advice." An individual's subjective belief that he is represented is not alone sufficient to create an attorney-client relationship. Rather, the putative client must show that his subjective belief that an attorney-client relationship existed was reasonable under the circumstances.

With these precepts in mind, we conclude that appellants could not have reasonably believed that the investigating attorneys represented them personally during the time frame covered by the subpoena. First, there is no evidence that the investigating attorneys told the appellants that they represented them, nor is there evidence that the appellants asked the investigating attorneys to represent them. To the contrary, there is evidence that the investigating attorneys relayed to Wakeford the company's offer to retain personal counsel for him at the company's expense, and that they told John Doe 1 that he was free to retain personal counsel. Second, there is no evidence that the appellants ever sought personal legal advice from the investigating attorneys, nor is there any evidence that the investigating attorneys rendered personal legal advice. Third, when the appellants spoke with the investigating attorneys, they were fully apprised that the information they were giving could be disclosed at the company's discretion. Under these circumstances, appellants could not have reasonably believed that the investigating attorneys represented them personally. Therefore, the district court's finding that appellants had no attorney-client relationship with the investigating attorneys is not clearly erroneous. 
The appellants argue that the phrase "we can represent you as long as no conflict appears," manifested an agreement by the investigating attorneys to represent them. They claim that, "it is hard to imagine a more straightforward assurance of an attorney-client relationship than 'we can represent you." We disagree. As the district court noted, "we can represent you" is distinct from "we do represent you." If there was any evidence that the investigating attorneys had said, "we do represent you," then the outcome of this appeal might be different. Furthermore, the statement actually made, "we can represent you," must be interpreted within the context of the entire warning. The investigating attorneys' statements to the appellants, read in their entirety, demonstrate that the attorneys' loyalty was to the company. That loyalty was never implicitly or explicitly divided. In addition to noting at the outset that they had been retained to represent $\mathrm{AOL}$, the investigating attorneys warned the appellants that the content of their communications during the interview "belonged" to AOL. This protocol put the appellants on notice that, while their communications with the attorneys were considered confidential, the company could choose to reveal the content of those communications at any time, without the appellants' consent.

We note, however, that our opinion should not be read as an implicit acceptance of the watereddown "Upjohn warnings" the investigating attorneys gave the appellants. It is a potential legal and ethical mine field. Had the investigating attorneys, in fact, entered into an attorney-client relationship with appellants, as their statements to the appellants professed they could, they would not have been free to waive the appellants' privilege when a conflict arose. It should have seemed obvious that they could not have jettisoned one client in favor of another. Rather, they would have had to withdraw from all representation and to maintain all confidences. Indeed, the court would be hard pressed to identify how investigating counsel could robustly investigate and report to management or the board of directors of a publicly-traded corporation with the necessary candor if counsel were constrained by ethical obligations to individual employees. However, because we agree with the district court that the appellants never entered into an attorney-client relationship with the investigating attorneys, they averted these troubling issues.

\section{Questions:}

1. Why did the court hold that no attorney-client relationship existed? Do you agree with its conclusion?

2. What information should an attorney representing an organization be required to provide to the agents of that organization in order to ensure that the agents understand that the attorney represents the organization, and does not represent them?

3. Does it make sense for attorneys representing an organization to say they can represent an agent of the organization unless there is a conflict?

United States v. Stein, 463 F. Supp. 2d 459 (S.D.N.Y. 2006)

Summary: Warley was a partner at KPMG. She was questioned in course of IRS investigation by attorneys hired by KPMG. The firm waived its attorney-client privilege and gave the government documents that described attorney's communication with 
Warley. Warley says the attorneys were representing her and KPMG and her attorneyclient privilege was compromised by the actions of KPMG and the evidence should be suppressed. Evidence suggests there was no Upjohn warning. Warley's showing of her subjective belief that the attorneys represented her is insufficient to meet her burden of proving privilege. Thus, the court denied Warley's motion for relief from the government's alleged violation of her attorney-client privilege.

KAPLAN, District Judge.

Defendant Carol Warley was a partner in KPMG LLP, one of the world's largest accounting firms. She was questioned in the course of an IRS investigation by attorneys hired by KPMG. When that investigation gave way to a threatened indictment of KPMG, the firm, in an effort to curry favor with prosecutors and avoid prosecution, waived its attorney-client privilege and gave the government documents embodying the substance of the attorneys' communications with Ms. Warley. Warley contends that the attorneys were representing her as well as KPMG, that her attorney-client privilege was compromised by the actions of the government and KPMG, and that the evidence should be suppressed. She thus raises a troublesome question that arises whenever an employee of a business organization consults with counsel retained by the entity about matters involving both the employee and the entity - when does the lawyer represent the employee as well as the entity?

This problem could be avoided if counsel in these situations routinely made clear to employees that they represent the employer alone and that the employee has no attorney-client privilege with respect to his or her communications with employer-retained counsel. Indeed, the Second Circuit advised that they do so years before the communications here in question. But there is no evidence that the attorneys who spoke to Ms. Warley followed that course.

\section{Facts}

Ms. Warley was a partner of KPMG at all relevant times. In 2003, the IRS was investigating KPMG's tax shelter activities, including some in which clients of Warley had participated. In the course of the investigation, Warley communicated with KPMG's in-house counsel and with two law firms retained by KPMG, Kronish Lieb Weiner \& Hellman LLP and King \& Spalding LLP. Warley does not recall having been told that the attorneys represented only KPMG or that any privilege belonged solely to the firm and could be waived by the firm without her consent.

In September 2004, in circumstances that have been discussed elsewhere, KPMG waived its attorney-client privilege for communications relating to the IRS summons. It gave the government documents relating to these communications, and the government apparently intends to use them in prosecuting Warley and others. The government argues that KPMG's waiver was sufficient to allow it to obtain the documents and disputes Warley's claim of privilege. 
Warley identifies two sets of allegedly privileged communications relating to which the government has documents. First, Warley was interviewed by attorneys from Kronish and King \& Spalding on two occasions in August 2003. The government is in possession of a memorandum of these interviews prepared by a Kronish attorney as well as his handwritten notes. In addition, it has listed as a trial witness one of the Kronish attorneys present at these interviews.

The second allegedly privileged communication is an email exchange in January and February of 2003 between Warley and Steven Gremminger, an in-house attorney for KPMG, relating to the tax strategies under investigation. The government has a copy of this email string.

Both parties point to the substance of the communications to support their respective claims that privilege did or did not attach. Warley further relies upon KPMG's 2003 partnership agreement, which provided that "the General Counsel shall act on behalf of all Members, except where a dispute arises between an individual Member and the Firm." Finally, Warley alleges that counsel retained by KPMG jointly represented KPMG and her personally in two lawsuits prior to the events at issue here.

\section{Discussion}

\section{A. Scope of Privilege}

The question whether employee communications with counsel retained by the employer about matters relating to the employment are privileged vis-a-vis the employee - in other words, whether the employee has a personal attorney-client privilege that only the employee may waive - is troublesome because competing interests are at play.

On the one hand, an employee, like any other agent, owes the employer a duty to disclose to the employer any information pertinent to the employment. This includes an obligation "to assist the employer's counsel in the investigation and defense of matters pertaining to the employer's business." Moreover, an employer has a substantial interest in retaining freedom of action to respond to investigations and other legal threats, an interest borne of the desire to remain in business and of duties to other constituents of the entity. Allowing individual employees to assert personal attorney-client privilege over communications with the employer's counsel could frustrate an employer's ability to act in its own self interest, perhaps to the detriment of other employees, stockholders, or partners.

Nevertheless, there are weighty considerations on the other side of the scale. Once a government investigation begins, the interests of employees and of the entity may diverge. Indeed, that may be true in other circumstances in which employees communicate with employer counsel. Employees often are unaware of the potential personal consequences of cooperating with lawyers hired by their employers. Even more troublesome, they may cooperate with employer-retained counsel in the belief that their communications are protected by a 
personal privilege, sometimes as a result of a misapprehension of the law and occasionally perhaps as a result of deception, inadvertent or otherwise.

Courts have wrestled with this problem for some time now. In the absence of evidence that the employee was deceived by the employer as to the existence of a personal attorney-client relationship or as to a personal right to control the disclosure of privileged materials, circuits have employed different standards to determine when personal privilege attaches. Some have looked at whether the individual reasonably believed that there was a personal attorney-client relationship, although the Second Circuit has rejected this approach. Others have focused on whether the individual expressly requested personal advice or representation. In In re Bevill, Bresler \& Schulman Asset Management Corp., the Third Circuit enunciated a five-part test that has been adopted by at least two other circuits

First, the individual claiming personal privilege must show they approached counsel for the purpose of seeking legal advice. Second, they must demonstrate that when they approached counsel they made it clear that they were seeking legal advice in their individual rather than in their representative capacities. Third, they must demonstrate that the counsel saw fit to communicate with them in their individual capacities, knowing that a possible conflict could arise. Fourth, they must prove that their conversations with counsel were confidential. And, fifth, they must show that the substance of their conversations with counsel did not concern matters within the company or the general affairs of the company.

Our circuit addressed the issue in United States v. International Brotherhood of Teamsters. The Teamsters court first noted that courts typically have said that the attorney-client privilege for an employee's communication with corporate counsel about corporate matters belongs to the corporation, not the individual employee. Nevertheless, it said, courts have found a personal privilege where the individual met "certain requirements." It quoted the Third Circuit's Bevill test as one such example and noted that other courts have required the employee "make it clear to corporate counsel that he seeks legal advice on personal matters." Drawing upon all of these sources, the Circuit concluded that the individual before it lacked any personal privilege with respect to the communications at issue because he "neither sought nor received legal advice from his employer's counsel on personal matters."

Teamsters' holding thus rests on the scope of "personal matters." But the meaning of that phrase has not been developed. Do "personal matters" involve solely the individual, with no impact on the entity's interests whatsoever? Or may they encompass matters that implicate both the individual and the entity? Although the facts of Teamsters suggest that the Circuit might have contemplated the former view, it did not expressly address the question.

Some guidance may be gained from circuits that have addressed this issue in the context of the fifth Bevill factor, which requires that the communication "not concern matters within the company or the general affairs of the company." The Tenth Circuit concluded that this factor 
only precludes an officer from asserting an individual attorney client privilege when the communication concerns the corporation's rights and responsibilities. However, if the communication between a corporate officer and corporate counsel specifically focuses upon the individual officer's personal rights and liabilities, then the fifth prong of Bevill can be satisfied even though the general subject matter of the conversation pertains to matters within the general affairs of the company. For example, a corporate officer's discussion with his corporation's counsel may still be protected by a personal, individual attorney-client privilege when the conversation specifically concerns the officer's personal liability for jail time based on conduct interrelated with corporate affairs.

The First Circuit adopted the Tenth Circuit's interpretation and discussed its application where communications involving the individual's liabilities "do not appear to be distinguishable" from those concerning the entity's interests. Acknowledging that both the employee and the entity could have an attorney-client relationship with the attorney with respect to such a communication, but noting also the fiduciary duty owed by a corporate officer to the corporation, the First Circuit concluded that "a corporation may unilaterally waive the attorney-client privilege with respect to any communications made by a corporate officer in his corporate capacity, notwithstanding the existence of an individual attorney-client relationship between him and the corporation's counsel." Thus, under the First Circuit formulation, individual privilege may be asserted successfully only when "communications regarding individual acts and liabilities are segregable from discussions about the corporation." To hold otherwise, the court reasoned, "would open the door to a claim of jointly held privilege in virtually every corporate communication with counsel."

The Tenth and First Circuits thus have argued persuasively that communications implicating personal liability for acts within the scope of an individual's employment may be protected by individual attorney-client privilege, at least in some circumstances. It is an open question whether such communications involve "personal matters" within the meaning of Teamsters. But it is unnecessary to resolve that issue here. As discussed below, and particularly in light of the fact that the burden of proof lies with the party asserting privilege, Warley fails to meet any standard.

\section{B. Warley's Claims}

To begin with, there is no evidence that Warley was deceived by KPMG or its attorneys about the nature of her relationship with counsel. Although she claims to have "understood that counsel were representing her personally as a partner in the firm," her subjective belief alone does not support a conclusion that KPMG's acts were responsible for that belief. Accordingly, the analysis of her claims rests on whether the communications involved "personal matters."

Warley's communications with counsel were about events and conduct within the scope of her work as a partner at KPMG, thus clearly implicating KPMG's interest in responding to the IRS investigation. The events and conduct, however, also implicated Warley's personal interests and liabilities, as is amply evidenced by her status as a defendant in this case. Warley's 
communications thus present the difficult circumstance where both the individual's and the entity's interests are involved.

As discussed above, the scope of "personal matters" under Teamsters is unclear. Under a narrow reading, the fact that the communications implicated KPMG's interests alone would require that Warley's claim of privilege be rejected. Even under the approach adopted by the First and Tenth Circuits, however, Warley could not prevail on a privilege claim absent a showing that communications implicated her interests alone and were segregable from those involving KPMG's interests. Nothing in the allegedly privileged documents or the affidavits submitted with this motion indicates that the communications focused on her personal interests alone. The Court therefore need not determine the parameters of "personal matters," as Warley's disclosures would not come within even a broad view of the term.

Warley nevertheless argues that her communications were privileged vis-a-vis herself because (1) the KPMG partnership agreement provides that "the General Counsel shall act on behalf of all Members, except where a dispute arises between an individual Member and the Firm," and (2) counsel retained by KPMG represented both Warley and the firm in litigation on two occasions prior to the communications here at issue. But these contentions are not persuasive.

To begin with, the occasions on which Warley and KPMG were jointly represented occurred in circumstances in which Warley was a witness, not a party, to the litigation. The Court is not persuaded that representation of an employee by employer-retained counsel where the employee's role is that of a witness in a lawsuit against the employer could give rise to a reasonable expectation on the part of the employee that all communications she might have with employer-retained counsel, even a long time thereafter, were made in the context of an individual attorney-client relationship.

Nor has Warley offered any evidence that she in fact subjectively relied either upon the language in the partnership agreement or the previous litigation experience in concluding that Kronish, King \& Spalding, or Gremminger was representing her individually.

Conclusion

In the end, Warley's showings amount merely to a claim of her subjective belief which, without more, is insufficient to meet her burden of proving privilege. For the foregoing reasons, Warley's motion for relief from the government's alleged violation of her attorney-client privilege is denied.

\section{Questions:}

1. Did Warley believe KPMG's attorneys represented her personally? If so, why was she wrong. Did anyone tell her that KPMG's attorneys were not representing her personally?

2. Why does Warley want to claim that the documents at issue are protected by the attorney-client privilege? Why can't she make a privilege claims? Could KPMG have made a privilege claim over the same information? 
3. Should Warley have a malpractice claim against KPMG's attorneys?

\section{Further Reading:}

- Grace M. Giesel, Upjohn Warnings, the Attorney-Client Privilege, and Principles of Lawyer Ethics: Achieving Harmony, 65 U. Miami L. Rev. 109 (2010)

- Ashish S. Joshi, Corporate Miranda: Clarifying Lawyers' Loyalty During an Internal Investigation, American Bar Association (2009) 


\section{Section 3: The Legal Duties of an Attorney}

\section{1: Fiduciary Duties}

Attorneys are fiduciaries of their clients. As fiduciaries, they have certain legal duties to their clients, which include:

- The Duty of Care: Ordinary care under the circumstances.

- The Duty of Loyalty: Absolute loyalty.

- The Duty of Impartiality: Absolute candor.

- The Duty of Confidentiality: Absolute confidentiality.

The duties of care, loyalty, impartiality, and confidentiality attach whenever an attorney-client relationship begins and may continue after an attorney-client relationship ends. Accordingly, attorneys may owe duties to both current and former clients, which may affect an attorney's ability to continue representing those clients or to represent new clients.

\section{The Duty of Care}

Attorneys must exercise reasonable care when representing their clients. Typically, courts expect attorneys to use the degree of care expected of an ordinary attorney in similar circumstances. In other words, the duty of care imposed on an attorney is a duty of professional care, reflecting the expectations of both the client and other attorneys. An attorney who fails to exercise reasonable care is negligent, and may be liable in tort for malpractice. Attorneys may have a duty of care to both current and former clients, and any negligent act in relation to representation of a client may create a malpractice claim.

In order to prove a malpractice claim for a breach of the duty of care, the plaintiff must show that a duty of care existed, the attorney breached the duty of care, and the breach caused a harm to the plaintiff. Of course, a duty of care exists only if an attorney-client relationship exists. So the first element of a malpractice claim for negligence is proving the existence of an attorney-client relationship.

\section{The Duty of Loyalty}

Attorneys are fiduciaries of their clients because clients justifiably vest confidence, good faith, reliance, and trust in their attorneys. Accordingly, attorneys have a fiduciary duty to maintain an undivided loyalty to their clients at all times. Attorneys must ensure that their duties to their clients never conflict with their own financial interests, the interests of another client, or any other interest that would affect their ability to provide competent and diligent representation.

Under the duty of loyalty, attorneys cannot represent anyone with an interest adverse to one of their clients, because it would create a conflict of interest. If that interest becomes an issue, the attorney's loyalty would be divided between the two clients. Obviously, an attorney cannot 
represent two parties with interests directly adverse to each other, like opposing parties in litigation, because the conflict of interest is fundamental and unavoidable. MR 1.7, cmt. [8]. But the restriction imposed by the duty of loyalty applies more broadly. Any adverse or potentially adverse interest may create a conflict of interest, even if that interest is not yet at issue.

\section{The Duty of Impartiality}

As fiduciaries of their clients, attorneys have a duty to provide candid and impartial advice. In order to satisfy the duty of impartiality, attorneys must be able to exercise their independent professional judgment, without any conflicts of interest. If a client's interests are adverse or potentially adverse to the attorney's interests or the interests of another client, a conflict of interest exists that will compromise the attorney's impartiality. Under those circumstances, attorneys will have an incentive to provide advice that benefits themselves or their other clients, and withhold advice that does not. Even if the client is not harmed by the advice itself, the client is harmed by not receiving candid and impartial advice reflecting the full range of available options.

For example, if an attorney represents a client in a contract negotiation, and the outcome of the negotiation could affect the interests of another client, a conflict of interest exists, because the attorney has an incentive to provide advice that will benefit the other client and withhold advice that will harm the other client. Even if the advice benefits both clients, the client receiving the advice is harmed by not receiving candid and impartial advice. Likewise, if an attorney both represents and has a financial interest in a corporation, a conflict of interests exists, because the attorney has an incentive to provide advice that will benefit the attorney's investment and withhold advice that will not, depriving the client of the full range of options.

\section{Model Rule 2.1: Advisor}

In representing a client, a lawyer shall exercise independent professional judgment and render candid advice. In rendering advice, a lawyer may refer not only to law but to other considerations such as moral, economic, social and political factors, that may be relevant to the client's situation.

\section{The Duty of Confidentiality}

As fiduciaries of their clients, attorneys also have a duty to maintain the confidentiality of private information disclosed to them by their clients. Under the duty of confidentiality, attorneys must never disclose confidential client information to a third party not bound by the duty of confidentiality or use confidential client information to benefit themselves or another client. Clients are entitled to confide in their attorney, secure in the knowledge that the confidential information they disclose cannot be used against them.

If a client's interests are adverse or potentially adverse to the attorney's interests or the interests of another client, a conflict of interests exists that will compromise the attorney's ability to 
maintain confidentiality. Under those circumstances, attorneys have an incentive to use the confidential information for their own benefit or the benefit of their other client. Even if the client is not harmed by the use of the confidential information, the client is harmed by the betrayal of trust.

\section{Model Rule 1.6: Confidentiality of Information}

a. A lawyer shall not reveal information relating to the representation of a client unless the client gives informed consent, the disclosure is impliedly authorized in order to carry out the representation or the disclosure is permitted.

\section{Limitations on the Duties of an Attorney}

While the absolute duties of loyalty, impartiality, and confidentiality are the quintessence of professional responsibility, they are necessarily observed in the breach. Taken literally, they would inevitably preclude attorneys from ever representing more than one client. It is always possible that the interests of a potential client will conflict with those of a current client. It is always possible that advice given to one client will affect the interests of another client. And it is always possible that confidential information disclosed by one client will be relevant to another. In practice, the duties of an attorney must yield to the practical realities of representation.

Accordingly, the duties of attorneys are shaped by the rights of clients, attorneys, and the bar. Clients are entitled to hire the attorney of their choice, and may consent to representation, despite a formal conflict. Attorneys are entitled to represent more than one client, so long as they disclose any conflicts and the client consents. And the bar is entitled to prevent parties from using conflicts strategically to disqualify opposing counsel.

In other words, clients may provide informed consent to certain conflicts of interest. Attorneys may represent clients with conflicts of interests under certain circumstances, so long as the clients provide informed consent. And under certain circumstances, the bar may even permit attorneys to represent parties with conflicting interests without consent.

However, attorneys must always observe the duty of care. An attorney who fails to exercise reasonable care under the circumstances is negligent and potentially liable for malpractice, even if the client consents.

Ishmael v. Millington, 241 Cal. App. 2d 520 (Cal. Ct. App. 1966)

Summary: Earl F. Anders and Roberta Ishmael were married and owned a trucking company. Eventually, they decided to divorce. Under California law, Ishmael was entitled to $50 \%$ of the marital assets. Attorney Robert Millington had previously represented Anders and his company. Anders asked Millington to represent Ishmael. He agreed, and prepared a settlement agreement that Ishmael signed. Ishmael was entitled to $\$ 41,250$, but under the agreement she received $\$ 8,807$. Ishmael filed a malpractice action, and 
the trial court granted Millington's motion for summary judgment. The appellate court reversed, holding that a jury could have found that Millington breached his duty of care.

FRIEDMAN, J.

This is a legal malpractice action in which the plaintiff-client appeals from a summary judgment granted the defendant-attorney. The factual narrative will possess heightened significance against a backdrop of general doctrine:

Actionable legal malpractice is compounded of the same basic elements as other kinds of actionable negligence: duty, breach of duty, proximate cause, damage. Touching the first element, duty, the general rule is that "the attorney, by accepting employment to give legal advice or to render other legal services, impliedly agrees to use such skill, prudence, and diligence as lawyers of ordinary skill and capacity commonly possess and exercise in the performance of the tasks which they undertake."

In this case the defense is that the client sought no advice from the attorney and was given none; by the client's express admission, she did not rely on the attorney, thus, that her alleged damage was not proximately caused by the attorney's cause of action.

The facts are presented by summary judgment affidavits, which include extracts from depositions. There is no significant conflict in the evidence. Roberta Ishmael, the plaintiff, was formerly married to Earl F. Anders. The couple had three children. They lived in Gridley, where Mr. Anders was a partner in a family trucking business. Domestic difficulties resulted in a separation, and Mrs. Anders moved to Sacramento where she secured employment. She and her husband agreed upon a divorce and property settlement. She knew that she was entitled to one-half the marital property.

Mr. Anders called upon defendant Robert Millington, a Gridley attorney who had for some time represented him and his trucking firm. Mr. Millington advised Anders that if he could establish adulterous conduct by Mrs. Anders, he might be awarded more than one-half the community property. For one reason or another there was a decision that the wife rather than the husband would apply for divorce. At Anders' request Mr. Millington agreed to act as the wife's attorney, to prepare the necessary papers and to file a divorce action for her. He drew up a complaint and a property settlement agreement and handed these documents to Mr. Anders, who took them to Sacramento and had his wife sign them. She knew that Mr. Millington had represented her husband in the past. Faulty recall prevents ascertainment whether Mrs. Anders ever met personally with the attorney before the papers were drawn. She did not discuss the property settlement agreement with the attorney before she signed it. Mr. Millington believed the divorce and property settlement arrangements were "cut and dried" between the husband and wife; he "assumed that she knew what she was doing;" he believed that she was actually getting half the property but made no effort to confirm that belief. 
In her deposition the former Mrs. Anders testified that in signing the complaint and property settlement agreement she relied solely on her husband and did not rely on the attorney. Later, when so instructed, she traveled to the courthouse at Oroville, where she and her corroborating witness met Mr. Millington. He escorted her through a routine ex parte hearing which resulted in an interlocutory divorce decree and judicial approval of the property settlement.

According to her complaint, the former Mrs. Anders discovered that in return for a settlement of $\$ 8,807$ she had surrendered her right to community assets totaling $\$ 82,500$. Ascribing her loss to the attorney's negligent failure to make inquiries as to the true worth of the community property, she seeks damages equivalent to the difference between what she received and onehalf the asserted value of the community.

By the very act of undertaking to represent Mrs. Anders in an uncontested divorce suit, Mr. Millington assumed a duty of care toward her, whatever its degree. Described in terms traditionally applicable to the attorney-client relationship, the degree of care exacted by that duty was that of a figurative lawyer of ordinary skill and capacity in the performance of like tasks.

The degree of care is related to the specific situation in which the defendant found himself. The standard is that of ordinary care under the circumstances of the particular case. A lawyer owes undivided loyalty to his client. Minimum standards of professional ethics usually permit him to represent dual interests where full consent and full disclosure occur. The loyalty he owes one client cannot consume that owed to the other. Most descriptions of professional conduct prohibit his undertaking to represent conflicting interests at all; or demand that he terminate the threeway relationship when adversity of interest appears. Occasional statements sanction informed representation of divergent interests in "exceptional" situations. Even those statements demand complete disclosure of all facts and circumstances which, in the attorney's honest judgment, may influence his client's choice, holding the attorney civilly liable for loss caused by lack of disclosure.

Divorces are frequently uncontested; the parties may make their financial arrangements peaceably and honestly; vestigial chivalry may impel them to display the wife as the injured plaintiff; the husband may then seek out and pay an attorney to escort the wife through the formalities of adjudication. We describe these facts of life without necessarily approving them. Even in that situation the attorney's professional obligations do not permit his descent to the level of a scrivener. The edge of danger gleams if the attorney has previously represented the husband. A husband and wife at the brink of division of their marital assets have an obvious divergence of interests. Representing the wife in an arm's length divorce, an attorney of ordinary professional skill would demand some verification of the husband's financial statement; or, at the minimum, inform the wife that the husband's statement was unconfirmed, that wives may be cheated, that prudence called for investigation and verification. Deprived of such disclosure, the wife cannot make a free and intelligent choice. Representing both spouses in an uncontested divorce situation (whatever the ethical implications), the attorney's professional obligations demand no less. He may not set a shallow limit on the depth to which he will represent the wife. 
The general standard of professional care is appropriate to the garden variety situation, where the attorney represents only one of several parties or interests. It falls short of adequate description where the attorney's professional relationship extends to two clients with divergent or conflicting interests in the same subject matter. A more specific statement of the same rule is needed to guide the fact trier to the law's demands when the attorney attempts dual representation. In short, an attorney representing two parties with divergent interests must disclose all facts and circumstances which, in the judgment of a lawyer of ordinary skill and capacity, are necessary to enable his client to make free and intelligent decisions regarding the subject matter of the representation.

In view of the degree of care imposed by law on an attorney in defendant's position, a fact trier might reasonably find him negligent in failing to disclose to plaintiff the limited representation she was receiving and in failing to point to the possibility of independent legal advice. The question of breach was thus a triable issue which could not be resolved on a summary judgment motion.

Legal malpractice may consist of a negligent failure to act. The attorney's negligence, whether consisting of active conduct or a failure to act, need not be the sole cause of the client's loss. Here the attorney is charged not with erroneous advice, but with failure to advise, failure to investigate, failure to disclose. The wife's reliance on her husband's alleged misrepresentations is not at all inconsistent with the claim that her loss was the result of the attorney's negligent failure. A jury might find that the husband's misrepresentations were a realizable likelihood which made the attorney's inaction negligent, thus forming a concurrent (and not superseding) cause of harm. Causation was a jury question which could not be resolved as a matter of law.

Contributory negligence on plaintiff's part was specially pleaded and, if established, would bar malpractice recovery. Plaintiff, as she testified, relied on her husband's list of assets; apparently did not trouble to investigate or even to inquire whether she was getting her share of property; was seemingly content to let her husband take charge; accepted his attorney for the limited purpose of piloting her through the divorce formalities. A court, however, cannot say that reasonable jurors would inevitably characterize her conduct as contributory negligence. That issue was a triable issue of fact.

Thus, notwithstanding the lack of conflict in the evidence, the summary judgment rests on the determination of issues reserved for decision by a fact trier and which could not be resolved as a matter of law. Since triable issues of fact existed, the motion should have been denied.

\section{Questions:}

1. Did Anders assert a violation of the duty of care, the duty of loyalty, or both?

2. Did Anders show a violation of the duty of care, the duty of loyalty, or both?

3. Could Anders have prevailed on a violation of either the duty of care or the duty of loyalty? 


\section{The Appearance of Impropriety}

Let this, my young Readers, be your constant Maxim, That no Man can be good enough to enable him to neglect the Rules of Prudence; nor will Virtue herself look beautiful, unless she be bedecked with the outward Ornaments of Decency and Decorum. ${ }^{39}$

The ABA has long held that judges should avoid "the appearance of impropriety." When the ABA adopted the Canons of Judicial Ethics in 1924, Canon 4 held that judges should avoid "the appearance of impropriety." When it adopted the Code of Judicial Conduct in 1972, Canon 2 held that a judge should avoid "the appearance of impropriety in all his actions." When it adopted the Model Code of Judicial Conduct in 1990, Canon 2A maintained the appearance of impropriety standard, holding that "the test for the appearance of impropriety is whether the conduct would create in reasonable minds a perception that the judge's ability to carry out judicial responsibilities with integrity, impartiality and competence is impaired." And Rule 1.2 of the revised Model Rules of Judicial Conduct retains the same standard.

But lawyers have resisted applying the appearance of impropriety standard to themselves. When the ABA adopted the Model Code of Professional Responsibility in 1969, it included the appearance of impropriety standard only as an "ethical consideration," rather than a "disciplinary rule," making it aspirational, rather than mandatory. And when the ABA adopted the Model Rules of Professional Conduct in 1983, it eliminated the appearance of impropriety standard entirely.

\section{Model Code of Professional Responsibility \\ Canon 9: A Lawyer Should Avoid Even the Appearance of Professional Impropriety Ethical Consideration 9-2}

Public confidence in law and lawyers may be eroded by irresponsible or improper conduct of a lawyer. On occasion, ethical conduct of a lawyer may appear to laymen to be unethical. In order to avoid misunderstandings and hence to maintain confidence, a lawyer should fully and promptly inform his client of material developments in the matters being handled for the client. While a lawyer should guard against otherwise proper conduct that has a tendency to diminish public confidence in the legal system or in the legal profession, his duty to clients or to the public should never be subordinate merely because the full discharge of his obligation may be misunderstood or may tend to subject him or the legal profession to criticism. When explicit ethical guidance does not exist, a lawyer should determine his conduct by acting in a manner that promotes public confidence in the integrity and efficiency of the legal system and the legal profession.

\section{Restatement (Third) of the Law Governing Lawyers §121(c)(iv): The perspective for determining conflict of interest}

${ }^{39}$ Henry Fielding, The History of Tom Jones, A Foundling (1749). 
This Section employs an objective standard by which to assess the adverseness, materiality, and substantiality of the risk of the effect on representation. The standard of this Section is not the "appearance of impropriety" standard formerly used by some courts to define the scope of impermissible conflicts. That standard could prohibit not only conflicts as defined in this Section, but also situations that might appear improper to an uninformed observer or even an interested party.

The propriety of the lawyer's action should be determined based only on facts and circumstances that the lawyer knew or should have known at the time of undertaking or continuing a representation. It should not be evaluated in light of information that became known only later and that could not reasonably have been anticipated.

The standard of this Section allows consideration in a given situation of the social value of the lawyer's behavior alleged to constitute the conflict. For example, a lawyer's statement about a matter of public importance might conflict with a client's objectives, but the public importance of free expression is a factor to be considered in limiting the possible reach of the relevant conflicts rule.

Whether there is adverseness, materiality, and substantiality in a given circumstance is often dependent on specific circumstances that are ambiguous and the subject of conflicting evidence. Accordingly, there are necessarily circumstances in which the lawyer's avoidance of a representation is permissible but not obligatory. A lawyer also would be justified in withdrawing from some representations in circumstances in which it would be improper to disqualify the lawyer or the lawyer's firm.

\section{Model Code of Judicial Conduct: Canon 1}

Rule 1.2: Promoting Confidence in the Judiciary

A judge shall act at all times in a manner that promotes public confidence in the independence, integrity, and impartiality of the judiciary, and shall avoid impropriety and the appearance of impropriety.

\section{Rule 1.2, Comment 5}

The test for appearance of impropriety is whether the conduct would create in reasonable minds a perception that the judge violated this Code or engaged in other conduct that reflects adversely on the judge's honesty, impartiality, temperament, or fitness to serve as a judge.

Bd. Of. Ed. Of. NY City v. Nyquist, 590 F. 2d 1241 (2d Cir. 1979)

Summary: The Board of Education of the City of New York used separate seniority lists when deciding layoffs of male and female Health and Physical Education teachers (HPETs). The Commissioner of Education held that using separate lists was illegal, but 
the Department of Health, Education, and Welfare (HEW) disagreed, arguing that merging the lists would violate Title IX by disproportionately affecting women. The BoE filed a declaratory judgment action against three male and three female HPETs. The male HPETs were represented by James R. Sandner of New York State United Teachers (NYSUT). The female HPETs filed a motion to disqualify Sandner, on the ground that their union dues helped pay for his services. The district court granted the motion, but the Second Circuit reversed, holding that no conflict of interest existed, and that any appearance of impropriety was insufficient to require disqualification.

\section{Before FEINBERG, MANSFIELD and SMITH, Circuit Judges.}

\section{FEINBERG, Circuit Judge:}

This unusual case presents difficult questions regarding the appropriate role of federal courts when called upon by disqualification motions to evaluate the conduct of attorneys who appear before them. Three male Health and Physical Education teachers (HPETs) in the New York City school system appeal from an order of the United States District Court for the Southern District of New York, Morris E. Lasker, J., disqualifying their counsel upon the motion of three female HPETs. Appellant male teachers claim that the order was an abuse of discretion because it disregarded their constitutional rights, and was without any sound basis. For reasons set forth below, we hold that the motion to disqualify should have been denied, and we therefore reverse the order of the district court.

The contending parties on appeal - the male and female HPETs - are all defendants in this declaratory judgment action brought by the Board of Education of the City of New York and the Chancellor of the City School District. In February 1977, these plaintiffs found themselves in the middle of apparently contradictory positions held by the Commissioner of Education of the State of New York and the office of Civil Rights of the Department of Health, Education and Welfare (HEW). In a case involving one of these appellants, the State Commissioner had ruled that the use of separate seniority lists for male and female HPETs for the purpose of layoffs was illegal. Shortly thereafter, HEW initially indicated to the Board that HEW took exactly the contrary view, that merger of the lists would violate Title IX. Caught in this apparent dilemma, plaintiffs provisionally merged the seniority lists of male and female HPETs and commenced this action for a declaratory judgment in which all concerned parties would be present. The complaint named as defendants HEW and its Secretary, the New York State Commissioner of Education, the State Division of Human Rights, three named male HPETs, individually and as representatives of all male HPETs, and three named female HPETs, individually and as representatives of all female HPETs. The male and female defendants have asserted counterclaims and cross-claims. The relief sought by plaintiffs is a judgment declaring that the provisional policy of merging the seniority lists, effective February 1, 1977 but not retroactively, is lawful. 
The two classes of defendants are the actual contending parties in this litigation. The male HPETs allege that maintaining separate seniority lists for male and female HPETs is illegal and that:

all defendant male Health and Physical Education teachers who were laid off on or after September 1, 1975, are entitled to reinstatement with back pay and all other retroactive benefits incident to their positions to the date of their layoff if less senior female teachers were retained at that time or at any time thereafter.

The female HPETs allege that their seniority status perpetuates past discriminatory practices of plaintiffs and that if the provisional merged seniority list is used for layoff purposes "it will result in the layoff of at least six times as many female HPETs as male HPETs." The stakes in the lawsuit are obviously high.

The male HPETs are represented in this action by James R. Sandner, Esq., who is also General Counsel of New York State United Teachers (NYSUT). That organization is an unincorporated membership association of approximately 180,000 teachers, librarians, guidance counsellors and other school related employees of the almost 800 school districts in New York State. We are told that in each of the school districts there is a separate local union, which is the exclusive bargaining representative for employees in that unit. The majority of these individual unions have chosen to affiliate themselves with NYSUT, but the latter does not collectively bargain for any public employees. It does, however, provide a number of services to its members, including a legal service program under the direction and control of Mr. Sandner. Both the male and female HPETs are represented in collective bargaining by the American Federation of Teachers (AFT), to whom they pay dues. A portion of the dues paid to the AFT is remitted to NYSUT, which, at least in part, apparently finances the legal service program.

Under the program, NYSUT's members may apply to obtain legal representation free of charge. Mr. Sandner and his staff may take an applicant's case when, in their judgment, the claim is both job-related and meritorious. It is through this procedure that the male defendants retained Mr. Sandner as their attorney. NYSUT itself, however, has taken no position on the merits or on any other issue in this litigation.

The female HPETs moved to disqualify Mr. Sandner as counsel for the male HPETs or, in the alternative, to require NYSUT to furnish counsel for the female teachers. Judge Lasker concluded that "the female teachers are paying, in part, for their opponents' legal expenses." This violated "at least the spirit, if not the letter, of Canon 9 of the Code of Professional Responsibility that 'A lawyer should avoid even the appearance of impropriety."' Accordingly, the judge granted the motion and this appeal by the male HPETs followed.

We begin the discussion by noting that, curiously, the power of the federal courts to disqualify attorneys in litigation pending before them has long been assumed without discussion, and attention has focused on identifying the circumstances in which exercise of the power is appropriate. Our reading of the cases in this circuit suggests that we have utilized the power of 
trial judges to disqualify counsel where necessary to preserve the integrity of the adversary process in actions before them. In other words, with rare exceptions disqualification has been ordered only in essentially two kinds of cases: (1) where an attorney's conflict of interests in violation of Canons 5 and 9 of the Code of Professional Responsibility undermines the court's confidence in the vigor of the attorney's representation of his client, or more commonly (2) where the attorney is at least potentially in a position to use privileged information concerning the other side through prior representation, for example, in violation of Canons 4 and 9, thus giving his present client an unfair advantage. In such cases, we note Chief Judge Kaufman's oft-quoted admonition that,

When dealing with ethical principles, we cannot paint with broad strokes. The lines are fine and must be so marked. Guideposts can be established when virgin ground is being explored, and the conclusion in a particular case can be reached only after a painstaking analysis of the facts and precise application of precedent.

But in other kinds of cases, we have shown considerable reluctance to disqualify attorneys despite misgivings about the attorney's conduct. This reluctance probably derives from the fact that disqualification has an immediate adverse effect on the client by separating him from counsel of his choice, and that disqualification motions are often interposed for tactical reasons. And even when made in the best of faith, such motions inevitably cause delay. For example, this lawsuit has been at a standstill now for close to a year.

Weighing the needs of efficient judicial administration against the potential advantage of immediate preventive measures, we believe that unless an attorney's conduct tends to "taint the underlying trial" by disturbing the balance of the presentations in one of the two ways indicated above, courts should be quite hesitant to disqualify an attorney. Given the availability of both federal and state comprehensive disciplinary machinery, there is usually no need to deal with all other kinds of ethical violations in the very litigation in which they surface.

With these thoughts in mind, we turn to the ethical problems presented by the instant appeal. The district court disqualified Mr. Sandner because a "layman's faith would be severely troubled" by the fact that "the female teachers are paying, in part, for their opponents' legal expenses." There is no claim, however, that Mr. Sandner feels any sense of loyalty to the women that would undermine his representation of the men. Nor is there evidence that his representation of the men is anything less than vigorous. There is also no claim that the men have gained an unfair advantage through any access to privileged information about the women. Were there any such problem, the women would not be asking, and the district judge would not have ordered, as an alternative to disqualification of Mr. Sandner, that NYSUT pay their attorney's fees. Thus, in no real sense can Mr. Sandner's representation of the men be said to taint the trial.

We agree that there is at least some possibility that Mr. Sandner's representation of the men has the appearance of impropriety, because of the large number of union members involved and the public importance of the civil rights issue at the heart of the dispute. But in any event, 
we think that disqualification was inappropriate. We believe that when there is no claim that the trial will be tainted, appearance of impropriety is simply too slender a reed on which to rest a disqualification order except in the rarest cases. This is particularly true where, as in this case, the appearance of impropriety is not very clear. We note that while on one hand there is an element of unfairness to the women, on the other it seems probable that if NYSUT were to take a position on the merits of this litigation, Mr. Sandner's representation of the men would apparently be within the protection of the "fair representation" cases. This means that the question whether Mr. Sandner's conduct is unethical could be a very close one. Since disqualification entails immediate disruption of the litigation, it is better to relegate any questions about Mr. Sandner's conduct to other appropriate proceedings. In addition to the possibility of grievance proceedings and an internal union attack on the legal plan, it may be that judicial construction of the plan, in an appropriate lawsuit, could provide some relief for the women.

We therefore reverse the order of the district court disqualifying counsel, and remand for continuation of the action.

\section{Questions:}

1. Who does Sandner represent? Does he represent the female members of the teachers union? Does he have any duties to the plaintiffs in this action?

2. Why might someone be concerned about an appearance of impropriety under these circumstances? Why did the court find that any appearance of impropriety did not prevent Sandner from representing the male teachers?

3. Do you agree with the court's conclusion? Would you feel differently if the male teachers were paying for their own representation? Would you feel differently if the union provided representation for the female teachers?

In re Disciplinary Proc. Against Sanders, 145 P. 3d 1208 (Wa. 2006)

Summary: Justice Sanders of the Washington Supreme Court visited the Special Commitment Center on McNeil Island, which houses people civilly committed as sexually violent predators. During the visit, Sanders accepted documents from inmates and asked them about volitional control, among other things. The Attorney General of Washington filed a complaint against Sanders with the Washington Commission on Judicial Conduct. After an investigation and a hearing, the Commission found that Sanders violated Canon 1 by failing to enforce high standards of judicial conduct and also violated Canon 2(A) by failing to promote public confidence in the integrity and impartiality of the judiciary. Sanders appealed and the court affirmed.

\section{GROSSE, J.}

A visit by a judicial officer to a special facility for sexually violent predators is not in itself inappropriate conduct under the Code of Judicial Conduct. However, conversations with the residents of the facility concerning the reasons for their confinement, particularly when one or 
more of these residents has a matter or matters pending before the court on which the judge sits, can violate the Code of Judicial Conduct. By asking questions of inmates who were litigants or should have been recognized as potential litigants on issues currently pending before the court, Justice Richard B. Sanders violated the Code of Judicial Conduct. His conduct created an appearance of partiality as a result of ex parte contact.

The Washington Commission on Judicial Conduct received a complaint on March 18, 2003, regarding Justice Sanders' conduct while visiting the Special Commitment Center (SCC) on McNeil Island. The Commission conducted an independent investigation of the allegations, determined that sufficient evidence existed to support the complaint, and sent a Statement of Allegations to Justice Sanders on October 8, 2003. In April 2004, the Commission determined that probable cause existed to believe that Justice Sanders violated Canons 1, 2(A) and 3(A)(4) of the Code of Judicial Conduct. After a fact-finding hearing, the Commission issued its decision holding that Justice Sanders violated Canons 1 and 2(A), but did not violate Canon 3(A)(4). The Commission found that Justice Sanders' conduct violated Canon 1 by failing to enforce high standards of judicial conduct and also violated Canon 2(A) by failing to promote public confidence in the integrity and impartiality of the judiciary. The Commission imposed the sanction of admonishment. Under Discipline Rules for Judges 3, Justice Sanders filed a notice of contest.

Justice Sanders embarked on a tour of the SCC despite warnings from his colleagues on the Supreme Court about potential ex parte contact with litigants. During the tour of this facility, Justice Sanders accepted documents on two separate occasions from the inmates. Moreover, in meetings with the residents, some of whom had cases pending before the court, he directly asked them about the issue of volitional control.

At the time of the visit, the Supreme Court was in the process of deciding In re Detention of Thorell. Drafts of both a majority opinion and a dissent by Justice Sanders were circulating among the justices at the Supreme Court. Thorell was a seminal case in which separate actions by six petitioners were combined, including at least one of the SCC residents with whom Justice Sanders met. A pivotal issue before the Supreme Court in Thorell was volitional control. The court was weighing whether the "fact finder must determine that the person facing commitment as a sexually violent predator (SVP) has serious difficulty controlling behavior and, if so, whether this determination must be a separate finding based upon a jury instruction." Thus, the factual record was before the court in each of the consolidated six cases.

The Commission held, and we agree, that the record established through clear, cogent, and convincing evidence that Justice Sanders violated Canons 1 and 2(A). In support of that holding, the findings reference two of the three letters from resident Andre Brigham Young inviting the justices to visit McNeil Island. Those letters indicate that the residents were looking for something more than just a tour of the facility. In fact, Young suggested that others (opposing counsel and defense attorneys) should be asked to attend to avoid "the appearance of partiality." The letters in and of themselves should have given sufficient notice to Justice Sanders that this visit had the potential of being more than an institutional tour. Additional 
warning flags were also raised by three justices who expressed concerns about the visit and potential problems. Moreover, a simple computer check would have revealed that Rickey Calhoun and Andre Brigham Young, two people mentioned in the prior communication with Justice Sanders, had cases pending before the Supreme Court. When Justice Sanders met with the residents in small groups, he warned the residents that he could not hear their particular case issues. However, these warnings were followed by specific questions asking the residents about their confinement and what they thought of volitional control.

The Commission justifiably found that Justice Sanders, with full awareness of the potential for situations that could conflict with the Code of Judicial Conduct, embarked on the tour and met with litigants who had pending cases before the court. Further, by raising such critical issues as volitional control with these litigants, Justice Sanders created a situation that clearly violated both the letter and the spirit of the canons and created serious concern for both counsel and fellow jurists about the appearance of partiality.

Justice Sanders claims that a violation of Canons 1 and 2(A) cannot be found without a concomitant violation of a proscribed act or canon and thus the Commission's failure to find a direct violation of Canon 3(A)(4) precludes it from finding a violation of the other canons. We disagree.

In our view, Turco is dispositive. There, the court found that the judge's act of striking his wife in public had a sufficient nexus to the judicial role, particularly when the judge heard domestic violence cases. If extrajudicial tortious conduct can provide a nexus to the judicial role, then a fortiori, judicial conduct can provide a basis for a violation of Canons 1 and 2(A). In the instant case, Justice Sanders' actions were not simply undertaken as a private citizen, but rather within the context of his judicial duties. Our conclusion is underscored by the decision in In re Disciplinary Proceeding Against Ritchie. In that case, Judge John G. Ritchie argued that Canons 1 and 2(A) of the Code of Judicial Conduct, together with the statute regulating the behavior, were too vague to give him adequate notice of the prohibited behavior. In denying the claim, the court stated:

It is true the conduct pursuant to which he was disciplined is not clearly proscribed by RCW 3.58.040, insofar as the statute does not expressly prohibit judges from combining business and pleasure trips, and does not define "reasonable traveling expenses" or "business of the court".

Judge Ritchie's vagueness challenge is ultimately immaterial, however, because he was not disciplined for violating the statute. Rather, he was censured for violating Canons 1 and 2(A) of the Code of Judicial Conduct which hold judges to a higher standard of integrity and require avoiding even the appearance of impropriety.

As noted in the Commission's decision, there are a number of facts in this case that, when taken together, clearly demonstrate that a predictable appearance of partiality could be foreseen. 
Where a judge's decisions are tainted by even a mere suspicion of partiality, the effect on the public's confidence can be debilitating. The canons of judicial conduct should be viewed in broad fashion, and judges should err on the side of caution. Under Canon 3(D)(1), "judges should disqualify themselves in a proceeding in which their impartiality might reasonably be questioned." In Sherman, the court found that where a trial judge "may have inadvertently obtained information critical to a central issue on remand, a reasonable person might question his impartiality." The court set the test for determining impartiality:

In deciding recusal matters, actual prejudice is not the standard. The Commission recognizes that where a trial judge's decisions are tainted by even a mere suspicion of partiality, the effect on the public's confidence in our judicial system can be debilitating. The test for determining whether the judge's impartiality might reasonably be questioned is an objective test that assumes that "a reasonable person knows and understands all the facts."

This court in In re Disciplinary Proceeding Against Sanders noted that the interest of the State in maintaining and enforcing high standards of judicial conduct under the auspices of Canon 1 is a compelling one. In Sanders, this court balanced that interest against Justice Sanders' First Amendment rights and found that an independent basis for finding a violation of Canon 1 under those circumstances was not possible. Justice Sanders argues that the language in Canon 1 is hortatory and therefore cannot stand as an independent basis for a violation of the Code of Judicial Conduct. In the instant case, Canon 1 sets the conceptual framework under which Canon 2(A) operates. Canon 2(A) provides the more specific restraint, to wit: "Judges should act at all times in a manner that promotes public confidence in the integrity and impartiality of the judiciary." Under the circumstances of this case, Canon 1 taken in conjunction with Canon 2(A) provides a sufficiently specific basis to find a violation of the Code of Judicial Conduct. Here, it was clear that there was a substantial basis and expectation that Justice Sanders would be in contact with possible litigants who had pending litigation before the court and that this contact would be viewed as improper. We concur with the Commission's finding that it was clearly reasonable to question the impartiality of the justice under the circumstances of this case.

\section{Questions:}

1. Why did the court hold that visiting the Special Commitment Facility did not create an appearance of impropriety, but speaking to a resident of the facility did?

2. Would it create an appearance of impropriety for a judge to visit a prison? What if the judge spoke to an inmate?

3. Would it create an appearance of impropriety for a judge to speak with a person who had a pending civil action?

\section{Further Reading:}


- Peter W. Morgan, The Appearance of Propriety: Ethics Reform and the Blifil Paradoxes, 44 Stan. L. Rev. 593 (1992)

- W. Bradley Wendel, Impartiality in Judicial Ethics: A Jurisprudential Analysis, 22 Notre Dame J.L. Ethics \& Pub. Pol'y 305 (2008)

- Ronald D. Rotunda, Judicial Ethics, the Appearance of Impropriety, and the Proposed New ABA Judicial Code, 34 Hofstra Law Review 1337 (2006) 


\section{2: Malpractice}

Attorneys may be liable for malpractice if they violate any of their fiduciary duties of care, loyalty, impartiality, or confidentiality. However, the standard for liability may differ depending on the duty at issue. Attorneys may be liable for a violation of the duty of care only if they are negligent. But they may be liable for any violation of the duties of loyalty, impartiality, and confidentiality.

Under the duty of care, attorneys must always exercise reasonable care under the circumstances. Attorneys are professionals, so the professional standard of care applies. In other words, an attorney must exercise the standard of care that an ordinary attorney would exercise under similar circumstances. If an attorney breaches the duty of care, then the attorney is negligent, and may be liable in tort for malpractice.

By contrast, under the duties of loyalty, impartiality, and confidentiality, attorneys must always avoid conflicts of interest, provide candid advice, and protect confidential information. Any violation of these duties is a tort, irrespective of negligence. In effect, they are analogous to strict liability torts.

\section{The Elements of the Tort of Legal Malpractice}

Legal malpractice is a tort, with the same basic elements as any other tort claim: duty, breach, causation, and damages. An attorney has a duty only if an attorney-client relationship exists. Accordingly, the plaintiff in an action claiming legal malpractice must prove:

1. Existence of an attorney-client relationship

2. Breach of a legal duty

3. Factual causation of harm

4. Proximate causation of harm

5. Actual damages

\section{Legal Duty}

Attorneys owe legal duties to their clients, but do not owe legal duties to non-clients. Accordingly, the threshold question in a malpractice action is whether the plaintiff is a client to whom the attorney owes legal duties.

Marker v. Greenberg, 313 N.W.2d 4 (Minn. 1981)

Summary: Theodore Marker hired attorney Robert Greenberg for estate planning services. Among other things, Greenberg prepared deeds conveying real estate to Marker and his son as joint tenants. When Marker died, the real estate was subject to estate tax. Marker's son sued Greenberg for malpractice, alleging that if the real estate had been conveyed as tenants in common, it would not have been subject to estate tax. The trial court granted Greenberg's motion for summary judgment and the appeals court 
affirmed, holding that Marker's son lacked an attorney-client relationship with Greenberg, and could not bring a malpractice action as a beneficiary of the estate because he received the property.

SCOTT, Justice.

This is an appeal from an order of the Hennepin County District Court in a legal malpractice action brought by the surviving joint tenant against the attorney who drafted the deed. By that order the trial court granted respondent Robert Greenberg's motion for summary judgment on the grounds that plaintiff could not bring the action absent an attorney-client relationship and that the six-year statute of limitations barred the action since the statutory period began to run in 1973 when the alleged negligence occurred. We affirm.

For purposes of this appeal, the facts are uncontested. Appellant's father, Theodore Marker, retained respondent, an attorney, for estate planning services. In December 1972 respondent prepared a will for appellant's father. In August 1973, on behalf of appellant's father, respondent drafted deeds which conveyed certain real estate to appellant's father and appellant as joint tenants.

Appellant's father died on December 24, 1977. Because the real estate in question was held by appellant and his father as joint tenants, its entire value, $\$ 120,000$, was included in the decedent's gross estate for tax purposes.

Appellant asserts that, if he and his father had held the real estate as tenants in common, $\$ 20,858.18$ in federal and state taxes would have been saved. Appellant commenced this action to recover the amount of the additional estate taxes, claiming the loss resulted from respondent's negligence in not having the real estate conveyed into tenancy in common.

Appellant was never a client of respondent. Appellant does not allege that he was a beneficiary of his father's estate with respect to this property, but that he was a surviving joint tenant.

The trial court granted summary judgment in favor of the respondent and dismissed the complaint. Therefore, the issue arises as to whether a surviving joint tenant has a cause of action for malpractice against the attorney who drafted the joint tenancy deeds when the surviving joint tenant was never a client of the attorney.

The general rule in legal malpractice is that an attorney is liable for professional negligence only to a person with whom the attorney has an attorney-client relationship and not, in the absence of special circumstances such as fraud or improper motive, to anyone else. Courts have recognized exceptions, however, where strict privity is not required. Exceptions are frequently found in cases involving drafting or executing a will.

Many courts have followed the lead of the California Supreme Court, which declared in Lucas v. Hamm, that an intended beneficiary may bring an action for legal malpractice against the 
decedent's attorney where the attorney's negligent act caused the named beneficiary to lose the intended bequest.

The relaxation of the strict privity requirement is very limited, however. Especially in probate proceedings, this stringent restriction is a necessity to prevent a myriad of causes of action. The will cases listed above which follow Lucas $\mathrm{v}$. Hamm are all situations in which the attorney by his actions produced an instrument that failed to carry out the testamentary intent of the testator, either by faulty drafting or by improper attestation. The cases extending the attorney's duty to non-clients are limited to a narrow range of factual situations in which the client's sole purpose in retaining an attorney is to benefit directly some third party. As stated by the lowa Supreme Court in Brody v. Ruby, "It is clear, however, that the third party, in order to proceed successfully in a legal malpractice action, must be a direct and intended beneficiary of the lawyer's services."

In determining the extent of an attorney's duty to a non-client, courts frequently consider the factors expressed by the Lucas court:

The determination whether in a specific case the defendant will be held liable to a third person not in privity is a matter of policy and involves the balancing of various factors, among which are the extent to which the transaction was intended to affect the plaintiff, the foreseeability of harm to him, the degree of certainty that the plaintiff suffered injury, the closeness of the connection between the defendant's conduct and the injury, and the policy of preventing future harm.

Applying these factors to the deed drafted by respondent for appellant's father reveals that the respondent owed no duty to appellant. This is not a case where the property did not pass to the intended recipient upon the death of the testator. The deed was effective at the time it was recorded in 1973. There was no invalidity in the deed. Appellant does not allege that the disposition of the property was contrary to the intent of his father. The benefit which Theodore Marker wished to give to his son was the joint ownership of the property, and this was accomplished by the documents.

The facts of Bucquet $v$. Livingston, to which appellant compares his situation, are distinguishable. In Bucquet, the beneficiaries of an inter vivos trust alleged professional negligence by the defendant attorney in drafting the trust agreement. The complaint alleged that the attorney was employed to plan the settlor's estate and to carry out his intent that the nonmarital half of the trust principal would ultimately pass to the beneficiaries free of estate taxes after his wife's death. Because the attorney negligently included a general power of appointment in the instrument, additional taxes were imposed which reduced the corpus of the trust passing to the beneficiaries. In that case the express purpose of the trust was minimization of taxes. No such purpose is alleged in the instant case. In Bucquet the desired savings in taxes failed because of the faulty drafting by the attorney. In the present case, there is no allegation that the deed as drafted failed to accomplish the objective of the client as expressed to the respondent. 
The facts of the instant case are more similar to those of Hiemstra v. Huston. In that case the court recognized the exception established in earlier California cases holding an attorney liable to an intended beneficiary for defects in drafting of a will. The court nevertheless held that the complaint failed to state a cause of action in the allegations that under a will drafted by the defendant attorneys the plaintiff son received a smaller bequest than he would have received under an earlier will of testator. The court noted that plaintiff did not assert any legal deficiency in the will, nor did plaintiff assert either as a conclusion or by allegation of ultimate facts that the will failed to reflect the intent of the testator. The court concluded that if plaintiff was deprived of a substantial part of his father's estate, it was the result not of any negligence on the part of the defendant attorneys but of the testator's intention as expressed in the valid document.

In the case before us, the objective of the deed was to transfer ownership of the real estate to joint tenancy between the father and the son. The complaint alleges no invalidity in the documents and no conflict of the result with decedent's intentions. The estate taxes that were due at Theodore Marker's death were the natural result of the form of ownership chosen by the decedent and not the result of any negligence by respondent. In this case summary judgment was proper. We therefore need not discuss the disputed application of the statute of limitations.

\section{Questions:}

1. Why didn't Marker have an attorney-client relationship with Greenberg?

2. Was Greenberg negligent? Would Marker's father have had a malpractice action against Greenberg?

3. Who is the real party in interest: Marker or his father's estate? Why did Marker's father choose joint tenancy rather than tenancy in common? What outcome was Marker's father trying to accomplish? Did Greenberg help him achieve that outcome? All else being equal, do you think Marker's father would have wanted to minimize the tax?

\section{Breach of Duty}

If an attorney-client relationship exists, then the attorney owes certain legal duties to the client. In order to prevail in a malpractice action, the plaintiff must prove that the attorney breached one of those legal duties. However, different duties have different liability standards. For example, the duty of care requires attorneys to exercise reasonable care under the circumstances. But the duty of loyalty requires absolute loyalty.

Equitania Ins. v. Slone \& Garrett, 191 S.W.3d 552 (Ky. 2006)

Summary: Attorney Laurel Garrett represented Vimont in an effort to prevent Pavenstedt from gaining control of Equitania Insurance. Vimont filed a malpractice claim against Garrett, alleging that she provided unsound advice. The trial court instructed the jury that attorneys are not liable for errors of judgment, and the jury found for Garrett. The Supreme Court reversed, holding that attorneys must exercise ordinary care under the circumstances. 
WINTERSHEIMER, Justice.

This appeal is from an opinion of the Court of Appeals which affirmed a judgment of the circuit court based on a summary judgment/jury verdict that rejected the claim of the Equitania Insurance Company and its Vimont shareholder group for legal malpractice against Garrett and her law firm.

The major issues are whether the proper standard for proving liability in a legal malpractice case was followed and whether the instructions given by the trial judge to the jury regarding specific factual issues violated the rule in favor of barebones jury instructions.

Two groups of shareholders, the Vimont group, composed of four of the shareholders, and the Pavenstedt group, composed of a group of shareholders led by Johann Pavenstedt began to vie for control of Equitania, an insurance company which provided insurance for horse owners. After the Vimont group bought out the Pavenstedt group, the company continued to decline in its efforts to return a profit. Vimont eventually entered an agreement to sell the book of business to Markel Insurance Company. That deal was closed in January 1995. In March of that year, the Vimont group filed a civil action in circuit court, seeking to rescind the agreement between them and the Pavenstedt group. That case was assigned to Fayette Circuit Judge Gary Payne. A judgment was rendered against the Vimont group and it was upheld by the Court of Appeals in an unpublished opinion.

Laurel Garrett and the law firm of Slone \& Garrett represented the Vimont group in its attempt to gain control of the company prior to Vimont buying the shares of Pavenstedt. As a result of that representation, Vimont filed a civil action against Garrett in circuit court in February of 1997, alleging legal malpractice by Garrett in connection with her representation. That case was assigned to Fayette Circuit Judge John R. Adams and it is the principal subject of this appeal. Judge Adams ruled against Vimont and the Court of Appeals upheld that decision. This appeal followed.

This case is a complex legal malpractice claim brought by Vimont against Garrett alleging that she negligently advised them during the midst of the shareholder dispute. They claim that Garrett negligently failed to properly advise them as to how to retain control of the corporation; that the methods she advised violated the insurance code; violated a fiduciary duty to shareholders; was unethical, and was substantially more expensive. The circuit judge granted Garrett a partial summary judgment based on his interpretation of the contract which was different from the interpretation made by the circuit judge in the earlier civil case. The other portion of the claim was resolved in favor of Garrett by a jury verdict. The Court of Appeals upheld the decision of the circuit court, and this Court granted discretionary review.

\section{Jury Instructions}


Correct instructions are absolutely essential to an accurate jury verdict. The fundamental function of instructions is to tell the jury what it must believe from the evidence in order to resolve each dispositive factual issue in favor of the party who has the burden of proof on that issue.

We should note it is well recognized that the function of instructions is only to state what the jury must believe from the evidence. There should not be an abundance of detail but the jury instructions should provide only the "bare bones" of the question for the jury. The bare bones may then be fleshed out by counsel during closing argument.

The jury instructions given by the trial court over the objection by Vimont were not an accurate statement of the law regarding legal malpractice in Kentucky. Vimont objected to the instructions and tendered instructions of their own which were not used. The instructions given follow:

Instruction No. 2: It was the duty of Defendant, Laurel Garrett, in undertaking the legal representation of the plaintiffs, to possess to an ordinary extent the technical knowledge commonly possessed in her profession, to exercise that degree of care and skill which an ordinary, reasonably competent lawyer would exercise under the same or similar circumstances. Provided, however, a lawyer cannot be held responsible for errors in judgment or for advising a course of action even if that course of action ultimately proves to be unsuccessful.

The given instructions were incorrect for several reasons. It was properly preserved because there was an objection to Instruction No. 2 in the submitted instructions.

Kentucky law does not provide for an exception for attorney liability for errors in judgment. A case relied on by the Court of Appeals, Daugherty v. Runner, stated that misjudgment of the law will generally not render a lawyer liable. However, Daugherty did not state that a lawyer can never be held liable for an error in judgment. The tendered instructions did not advise the jury that it had to be an error of law which precluded liability, nor did it inform the jury that there are circumstances in which misjudgment of the law could be a basis for liability. There can be many circumstances in which lawyers can commit errors of judgment which deviate from the standard of care. Whether an error of judgment is legal malpractice is a question of fact for the jury.

Vimont offered an expert, Manning Warren, to evaluate the methods undertaken by Garrett to assist the company in its shareholders dispute. Specifically, Warren testified that Garrett should have pursued an administrative process with the Department of Insurance to join the Vimont group to the Pavenstedt agreement which, if successful, would have resulted in the shareholders maintaining control of Equitania and would have resolved the issue. This would have avoided a prolonged battle with Pavenstedt and would have avoided spending over two million dollars by buying the stock. They also would have avoided the issues with the Department of Insurance regarding change of control as a result of their purchase. It was their conclusion that Garrett committed ongoing malpractice by failing to advise them of change of control issues. Warren further testified that it was a deviation to fail to pursue this option. 
However, it is apparently undisputed that the Department of Insurance would not have approved a Pavenstedt sale even if it had been properly submitted.

Kentucky should not allow lawyers to avoid liability for committing errors in judgment which the average reasonably prudent lawyer would not commit. Any avoidance of liability should only be allowed for errors of judgment made in absolute good faith.

Here, Garrett failed to plead or present evidence regarding her alleged errors in judgment so as to justify her decision. The error in judgment instruction indirectly required the jury to define and understand abstract legal principles. The jury could not have reasonably understood the distinction between errors in judgment and legal malpractice. It is of interest to note that the instruction provided by Vimont in this case is similar to the instructions provided in Daugherty.

The proper jury instruction must follow a form similar to that in Palmore:

It was the duty of Defendant in undertaking the legal representation of Plaintiff to exercise the degree of care and skill expected of a reasonably competent lawyer acting under similar circumstances. If you are satisfied from the evidence that Defendant failed to comply with this duty and that such failure was a substantial factor causing the loss, you will find for Plaintiff; otherwise you will find for Defendant.

This instruction form contains the elements prescribed in Daugherty without requiring the jury to understand abstract legal principles. The jury is able to determine from the evidence whether there was a breach of duty and whether that breach caused the loss.

Consequently, under the circumstances regarding the instructions, this matter is reversed and remanded. The decisions of the Court of Appeals and the trial court are reversed and this matter is remanded to the trial court for a jury determination as to all factual issues.

\section{Questions:}

1. Why was Garrett's advice unsound? What was her defense?

2. How should juries evaluate malpractice claims alleging violations of the duty of care? What is the correct standard of liability?

\section{Causation of Harm}

Clients can recover for malpractice only if their attorney's negligence was both the "factual" or "but for" cause and proximate cause of a legally cognizable harm. An attorney who is negligent but causes no harm is not liable for malpractice.

Courts typically apply the "suit within a suit" or "trial within a trial" doctrine to legal malpractice actions. Under this doctrine, the factfinder must determine not only how the attorney's breach of duty affected the action, but also how the action would have ended without the breach of duty. 
In other words, the client must prove that the attorney's breach of duty caused a foreseeably worse outcome.

Accordingly, an attorney is not liable for malpractice if the client's injury was inevitable. For example, an attorney who negligently fails to file an action with no chance of success is not liable for negligence. But what if the action had a small chance of success? And what if the action had no chance of success, but still had settlement value?

In an action for transactional malpractice, the client must prove that the attorney's breach of duty caused a worse outcome than non-breach would have caused. For example, the client could show that alternative actions would have produced a better result.

The client must also prove that the attorney's negligence was the proximate cause of the injury. In other words, the plaintiff must provide that a reasonable attorney under the circumstances would have foreseen the injury.

In theory, causation is a straightforward concept. Attorneys are liable for malpractice only if their actions caused a harm that they could have foreseen. But in practice, causation of harm and foreseeability can be difficult to determine in the face of diverse probabilities and uncertain counterfactuals.

For example, consider the following scenarios:

- The attorney advises the client not to accept a $\$ 10,000$ settlement for a $\$ 100,000$ damages claim, and the jury rules for the defendant.

- The attorney advises the client not to accept a $\$ 10,000$ settlement for a $\$ 100,000$ damages claim, and the judge grants the defendant's motion for summary judgment.

- The attorney advises the client not to accept a $\$ 10,000$ settlement for a $\$ 100,000$ damages claim, and the judge grants the defendant's motion to dismiss.

- Before discovery, the attorney advises the client not to accept a $\$ 10,000$ settlement for a $\$ 100,000$ damages claim before discovery. After discovery, the client accepts a $\$ 5,000$ settlement.

- The attorney advises the client to accept a $\$ 10,000$ settlement for a $\$ 100,000$ damages claim, and the client later obtains a $\$ 50,000$ settlement.

- The attorney advises the client to accept a $\$ 10,000$ settlement for a $\$ 100,000$ damages claim. The client accepts the settlement, but could have obtained a $\$ 20,000$ settlement.

In each of these circumstances, has the attorney caused a foreseeable harm?

Daugherty v. Runner, 581 S.W.2d 12 (Ky. Ct. App. 1978)

Summary: Lula Daugherty Roach died in the hospital after a car accident. Runner represented Roach's estate, and filed an action against the other driver, but not against the hospital. The estate eventually hired another attorney to file a medical malpractice 
action, but it was barred by the statute of limitations. The estate filed a malpractice action against Runner for failing to file a medical malpractice action. The jury found for Runner, but also held that the estate would have recovered $\$ 146 \mathrm{k}$ in a medical malpractice action. The court of appeals affirmed, holding that Runner did not necessarily violate the duty of care.

HAYES, Judge.

This appeal is from a judgment entered pursuant to a jury verdict which exonerated the appellee, an attorney, from the charges of legal malpractice. The charges of the legal malpractice claim arose from a medical malpractice cause of action on behalf of the deceased, Lula Daugherty Roach. This type of action is commonly referred to as a "suit within a suit." The basis for the legal malpractice claim is that appellee Runner, while representing the deceased Roach for injuries sustained in an automobile accident, failed to pursue a medical malpractice claim by the estate of Roach against the hospital where Roach was treated for her injuries after her accident and against the doctors who treated her, until her claim was barred by the statute of limitations.

The jury found for Runner on the legal malpractice claim and additionally found that the appellant would have recovered on the medical malpractice case, if suit had been timely filed, in the amount of $\$ 146,123.75$. Both parties appealed.

The appellant contends that the trial court erred in submitting the issue of Runner's negligence to the jury and in failing to instruct the jury properly.

Appellee's cross-appeal is of a protective nature wherein it is contended that if we reverse the trial court based on appellant's assignments of error, then appellee believes the jury verdict awarding appellant $\$ 146,123.75$ on his medical malpractice claim is erroneous because of improperly admitted evidence.

We will not reach the claim of appellee on cross-appeal since we affirm the judgment of the lower court.

On February 22, 1972, Mrs. Roach and her husband Russell were involved in an automobile accident near Richmond, Kentucky. After receiving emergency medical treatment in Richmond, Mrs. Roach was transferred to St. Joseph Hospital in Lexington, Kentucky. She was admitted on February 22, 1972, under the care of an orthopedic doctor, George Gumbert, Jr. Mrs. Roach died in the hospital on March 17, 1972. The official cause of death listed on the certificate of death was bronchial pneumonia due to, or as a consequence of, generalized peritonitis and bacterial endocarditis. On the date of Mrs. Roach's death, her husband Russell, individually and as executor of the estate of Mrs. Roach, entered into a contract with attorney Runner to the effect that Runner was to "institute a claim for damages against any and all responsible parties as a result of injuries received upon the 22nd day of February, 1972." The contract was a standard contract approved by the Louisville Bar Association. 
A later contract, dated July 28, 1973, was entered into between James Russell Roach and another attorney, whereby this "second attorney" was to represent Roach, individually and as administrator of the estate of Lula Roach, in the medical malpractice claim. James Russell Roach was a nonresident, so the present appellant, Byrd E. Daugherty, was appointed ancillary administrator.

Suit was filed on August 1, 1973, in Fayette Circuit Court on behalf of Daugherty by his present attorney, against St. Joseph Hospital and others based on the medical malpractice claim. The trial court in that case granted a summary judgment against Daugherty and the estate of Lula Roach because the suit was not filed within the period of limitations.

Runner testified he was not hired to represent the estate of Lula Roach on a medical malpractice claim; made an investigation of the facts surrounding the auto accident; filed suit on same in Federal Court for the Eastern District of Kentucky at Lexington against the driver of the other auto in the accident, and never suspected the possibility of a medical malpractice claim.

Appellant contends it is what Runner did not do that makes him liable for malpractice. It is asserted he did not examine the hospital records until after the statute of limitations had run on any medical malpractice claim, and that he never advised his client that he did not handle medical malpractice cases. There was also testimony on behalf of appellant that Russell Roach, who had died prior to the trial, had telephoned Runner in January, 1973, inquiring of Runner the status of any medical malpractice investigation Runner was conducting. Runner denied ever having such a conversation. It is uncontradicted, however, that appellant hired the "second attorney" on March 15, 1973, to represent him in the medical malpractice claim against St. Joseph Hospital and others.

The Fayette Circuit Court had determined that the statute of limitations began to run on the medical malpractice claim "on March 17, 1972, and certainly no later than July 20, 1972, when the record of the decedent's treatment was fully complete." From the evidence in the record and the legal briefs filed on behalf of the parties, it is unclear why the second attorney, who accepted a retainer fee, did not file the medical malpractice claim within the period of time permitted by the statute and case law of this Commonwealth.

The appellant contends that the trial court erred in (1) submitting the question of the attorney's negligence to the jury; (2) allowing an expert opinion to be presented to the jury based upon improper evidence; and, (3) in failing to instruct the jury that the fact that other hired counsel might have been able to toll the statute of limitations was no defense to appellee Runner.

The standard of care is generally composed of two elements - care and skill. The first has to do with care and diligence which the attorney must exercise. The second is concerned with the minimum degree of skill and knowledge which the attorney must display. 
In determining whether that degree of care and skill exercised by the attorney in a given case meets the requirements of the standard of care aforementioned, the attorney's act, or failure to act, is judged by the degree of its departure from the quality of professional conduct customarily provided by members of the legal profession.

As it would be in negligence cases generally, the question of whether the conduct of the attorney meets the standard of care test is one for the trier of the facts to determine.

Having determined that the standard of care an attorney owes his client is not that of a "reasonable man" under the circumstances, but is that care and skill as men of the legal profession commonly, or ordinarily, possess and exercise under the circumstances, and having determined that this is generally a question for the trier of the facts, we look now at the facts of the instant case.

The appellant Daugherty contends the trial court erred in submitting the negligence of appellee Runner to the jury. He in effect is saying he, Daugherty, was entitled to a directed verdict on this point because Runner was negligent as a matter of law.

Appellant was required to prove in the legal malpractice suit (1) that Runner was employed by appellant; (2) that he neglected his duty to exercise the ordinary care of a reasonably competent attorney acting in the same or similar circumstances; and (3) that such negligence resulted in and was the substantially contributing factor in the loss to the client.

The appellant has presented two theories in support of his argument that he was entitled to a directed verdict on the question of Runner's negligence. The first is that Runner was retained to bring all possible legal actions resulting from the injuries and death of Mrs. Roach, including a medical malpractice action, if appropriate, and that he failed to carry out this duty. This argument is clearly without merit. The written contract between the parties recited that Runner was retained "to institute a claim for damages against any and all responsible parties, as a result of injuries received upon the 22 day of February, 1972." While there was some testimony about a conversation with Runner regarding a medical malpractice action, the evidence was disputed on that matter, and the question of whether Runner had any duty to handle any medical malpractice case was certainly one for the jury.

Appellant's second theory in support of his directed verdict argument seems to be that even if Runner was not employed specifically to pursue a medical malpractice action, that he nevertheless had a duty to obtain and examine the medical records of the patient, to investigate the treatment procedures administered to her, and to inform his client that there may have been some question about the medical care and treatment she received, but that he did not handle medical malpractice. Appellee's contention on this issue is simply that Mr. Runner was not retained under the contract to handle a medical malpractice case, and he therefore had no duties in that regard. 
We are not ready to hold that Mr. Runner had absolutely no duties to his client with regard to a medical malpractice action simply because the written contract did not specifically mention a malpractice suit. To do so would require the client, presumably a layman who is unskilled in the law, to recognize for himself all potential legal remedies. An attorney cannot completely disregard matters coming to his attention which should reasonably put him on notice that his client may have legal problems or remedies that are not precisely or totally within the scope of the task being performed by the attorney.

On the other hand, we certainly cannot say that Mr. Runner was neglectful as a matter of law. There was considerable testimony concerning Runner's negligence, or lack of it. There was expert testimony from two attorneys, one for each side.

Runner's testimony, in summary, was that he was hired to represent the Roaches only for the injuries Mrs. Roach sustained as a result of the automobile collision of February 22nd. He testified that he did not handle medical malpractice claims because he was not competent to do so. He had never processed one. He testified that the fact Mrs. Roach entered the hospital with, according to the hospital admission report, multiple contusions and abrasions, a fractured nose, fractured right shoulder and a compressed fracture of the spine, and that she died in the hospital some thirty (30) days later, did not arouse his suspicion of a medical malpractice claim. He did not review the hospital records until he filed the wrongful death action on behalf of Mrs. Roach in Federal Court in Lexington, Kentucky, on June 9, 1972. Runner's law associate, who actually reviewed the medical records on June 9, 1972, testified the records were incomplete as there was no autopsy report in the medical records on June 9th.

Runner further testified that no one representing the deceased Mrs. Roach ever called to his attention the possibility of a medical malpractice claim until the "second attorney" previously mentioned contacted him some few days before the statute of limitations ran on the medical malpractice claim. Runner's testimony was that he told this other attorney to "go ahead" with the medical malpractice claim.

Appellant offered proof that Runner was contacted by members of Mrs. Roach's family concerning the medical malpractice case long before the statute ran. They were concerned with what Runner was doing about the medical malpractice case. The appellant produced expert testimony from a local lawyer to the effect that Runner's failure to inquire into the cause of death of Mrs. Roach and his failure to review the medical records was not consistent with good legal practice and, in fact, was a substantial departure therefrom.

The other important testimony was that the Roach family, including Daugherty, a brother of Mrs. Roach, had discussed, among themselves, the medical malpractice case as early as December, 1972. They had in fact contacted two attorneys in Lexington, who declined the case. They were aware of the statute of limitations.

The family then proceeded to northern Kentucky, where on March 15, 1973, they employed the "second attorney" to represent the estate in the medical malpractice case. He filed no complaint. 
Some time after July 28,1973 , he turned the case over to the appellant's current attorney, who on August 1, 1973, filed a medical malpractice claim in Fayette Circuit Court which was subsequently dismissed as barred by the statute of limitations.

Under these circumstances the question of whether Runner had exercised the degree of care and skill expected of a reasonably competent attorney was a question for the jury to decide. This is true especially in light of the fact that there was disputed testimony concerning whether the possibility of a medical malpractice action had been discussed with Runner.

The issue of Runner's negligence was submitted to the jury under the following instructions:

4. It was the duty of the defendant, E. Michael Runner, Attorney at Law, in undertaking the legal representation of the Estate of Lula Daugherty Roach, to exercise that degree of care and skill expected of a reasonably competent lawyer acting in the same or similar circumstances about which you have heard evidence, and this general duty, included the following specific duties:

(A) Not to undertake representation in a legal matter in which he knew or should have known he was not competent without associating with himself a lawyer that was competent to handle it;

(B) Not to undertake representation in a legal matter without preparation adequate in the circumstances.

5. The Jury will answer the following interrogatory: Do you believe from the evidence that the defendant, E. Michael Runner, failed in one or more of the duties imposed upon him by instruction number 4, and such failure was the substantial factor in the Estate of Lula Daugherty Roach not recovering the award set out in instruction number 3 and incorporated in Verdict $A$ ?

Nine of the jurors answered the question in the negative. While we may have found differently had we sat as jurors in this case, we believe there is sufficient evidence to support this jury's verdict, and we therefore will not disturb it. Based upon the conflicting evidence, we fail to see how Runner was negligent as a matter of law.

We note that the trial court's instruction mistakenly required the jury to find that Runner's breach of duty, if any, was "the" substantial factor in the plaintiff's failure to recover. The instruction should have read, "a" substantial factor. However, the trial court was not made aware of the error by objection, and it has not been raised on appeal, nor could it be. For this reason we are not able to review the question. In any event, it does not appear to be so substantial as to have caused the plaintiff any prejudice.

In conclusion, we would add that we do agree somewhat with a statement appellant makes in his well-written brief. Appellant states thusly: 
Perhaps the issue that is involved in this case is far beyond the instant action, and must be laid at the doors of the Bar as a whole and more specifically, appellee. Maybe we, as a profession, have not discharged our responsibility to inform the public as a whole, and more specifically, Mr. Roach, that we specialize and limit our practice. However, in the end result, the effect on the client is the same; the public expects, and has the right to demand, that their legal affairs will be approached with expertise and initiative and anything short of that is a violation of the trust and confidence reposed in a member of our profession.

To that, we would simply repeat that all the evidence in this case was submitted to a jury of twelve citizens of this community, nine of whom found for the attorney. Even though we may have found differently had we sat as jurors in this case, we cannot disturb their verdict, as it was sufficiently supported by the evidence.

\section{Questions:}

1. What was the harm to Roach's estate? Could Runner have prevented that harm? Could anyone else have prevented the harm?

2. What was the error in the jury instructions? Do you agree with the court's conclusion that the error was not prejudicial?

TIG Ins. v. Giffin Winning Cohen \& Bodewes, 444 F. 3d 587 (7th Cir. 2006)

Summary: Giffin Winning represented Illinois State University in a gender discrimination action, and failed to produce three gender equity studies to Joel Bellows, attorney for the plaintiffs. Soon afterward, TIG and Latham \& Watkins took over ISU's defense. Soon afterward, Gorrell gave Bellows the studies and claimed they were based on a nonexistent database. Bellows moved to sanction Giffin Winning and ISU for not producing the database, and TIG paid Latham \& Watkins $\$ 1.2$ million to defend ISU. The action ultimately settled, and TIG filed a malpractice action against Giffin Winning for failing to produce the studies. The district court dismissed the action, and the circuit court affirmed, holding that TIG failed to allege proximate cause because the injury was not foreseeable.

EVANS, Circuit Judge.

TIG Insurance Company appeals the dismissal of its malpractice case against the Giffin Winning law firm and one of its attorneys, Carol Hansen Posegate.

To explain the malpractice claim we must reach back to the underlying lawsuit, in which Giffin Winning, at least for a time, represented Illinois State University (ISU) in a class-action, genderdiscrimination lawsuit brought by several female professors. In the suit, the plaintiffs contended that they were being paid less than male professors and that ISU retaliated against female professors who complained about the discrimination. Their attorney was Joel Bellows. TIG was 
ISU's liability insurer at the time and it paid the attorney fees which are at the heart of the present malpractice action; TIG, in turn, was reimbursed by its reinsurers.

The malpractice alleged in the present case arose out of discovery problems in the case. The major problem involved Giffin Winning's failure to produce three documents called gender equity studies (two of which are at issue here) in their response to a discovery request. The response was signed in October 1996. A month later the case was stayed. Soon thereafter, the law firm of Latham \& Watkins filed an appearance on behalf of ISU and essentially took control of ISU's defense, though Giffin Winning remained of record. Latham had an attorney-client relationship with ISU's insurer TIG. Giffin Winning did not.

The facts show that Giffin Winning received two gender equity studies from ISU in 1994 — while the Varner case was still pending before the Equal Employment Opportunity Commission. Two years later, when the law firm received the second request for documents, the subject of the October 1996 response at issue here, they routed the request to William Gorrell, the former executive director for Information Systems and the head of the Planning Policy department at ISU. He did not at that time forward the studies to Giffin Winning for production and the law firm did not produce them on its own. On this point, Judge Mihm later said that Gorrell was the one who "dropped the ball entirely."

During the stay in the case, Bellows talked with Gorrell, who by then was no longer employed by ISU and had his own lawsuit pending against the school for wrongful termination. He independently provided Bellows with the gender equity studies. He also executed an affidavit detailing particulars of a "planning policy database" on which he said the studies were based.

Once the stay was lifted, Bellows confronted Latham with the studies. (The Latham firm was now representing ISU). Bellows demanded that ISU turn over the database on which he alleged the studies were based. Apparently thinking the best defense is a good offense, Latham's first response apparently was to point fingers, saying Bellows had also not adequately complied with discovery requests. Also at this time, Latham began preparing a motion to disqualify Bellows for improperly soliciting privileged information from Gorrell.

For his part, Bellows filed a motion for sanctions against both ISU and Giffin Winning, in part based on the failure to produce the gender equity studies. As relevant here, Bellows' contention in his motion for sanctions was not simply that the studies were not produced. After all, he now had the studies. Rather, he claimed that the gender equity studies were not produced because of a conspiracy to hide the "Planning Policy database." To have produced the studies, he argued, "would have alerted the Varner plaintiffs to the existence of the databases."

We now arrive at the essence of the case - the pivotal facts about the database. At a 4-day hearing on the pending motions, Gorrell testified that the database contained variables relevant to the issue of gender equity and was maintained in a format which enabled a user to prepare comparative studies. He testified that the gender equity studies were prepared from this database. He said he had done one of the studies himself, though he also said he had never 
personally accessed the database. The actual data processing, he said, was done by his research assistant, Anna Wells, and her preparation of the data for his 1994 study would have taken her no more than a day or two using the database:

Q How long did it take Anna Wells to compile the information for the 1994 study? A It could be done in a day or two.

That apparently was news to Wells. She testified that she did not use any database in compiling the data.

Q Ms. Wells, when you collected the information reflected in these tables, was there a single source that you could go to to collect all the information reflected in the tables? A No.

Q Was there a single database maintained by the Planning Policy department that contained all of the information reflected in these tables?

A No.

She used hard copy (probably the same 279 banker boxes of material which had, in fact, been produced to Bellows), and it took her "a few weeks, several weeks" to locate the information and format it for use. Why? Because, as Judge Mihm found, there was no database and never had been:

I don't believe that the plaintiffs have ever established the existence of the kind of database that I thought was being alleged here, that there was some button at ISU that could be punched that would involve a print-out of all this information. That clearly is not true. The nonexistence of the database - which Bellows said there was an alleged conspiracy to hide - is not seriously contested.

Nevertheless, Judge Mihm sanctioned Giffin Winning \$10,000 for discovery lapses, a sanction which was later vacated. Judge Mihm, however, wisely denied Bellows' request for a default judgment based on the failure to produce the gender equity studies. He remarked that "I don't believe it was appropriate - but even if I had ordered that, I think that would have been reversed on appeal." In addition, although he denied Latham's motion to disqualify Bellows because of his contact with Gorrell, Judge Mihm sanctioned Bellows $\$ 10,000$ as well. Ultimately, the case was settled; mercifully, we think.

We now get to the present malpractice action that TIG filed against Giffin Winning in which the damages TIG alleges are the attorney fees it paid Latham to defend against the sanction motion - a whopping $\$ 1.2$ million, give or take, for the work of 27 attorneys and various paralegals. It seems that when Latham said it took the motion seriously, it meant it. As we said, TIG paid the bill and was subsequently reimbursed by its reinsurers.

The elements of a legal malpractice action in Illinois are well-settled. They are: "(1) the existence of an attorney-client relationship that establishes a duty on the part of the attorney; (2) 
a negligent act or omission constituting a breach of that duty; (3) proximate cause; and (4) damages." A legal malpractice case is similar to any other negligence claim, and traditional principles apply. Proximate cause describes two distinct requirements - cause in fact and legal cause. Cause in fact exists only if the defendant's conduct was a "material element and a substantial factor in bringing about the injury." Legal cause, on the other hand, is largely a question of foreseeability. The relevant inquiry is whether "the injury is of a type that a reasonable person would see as a likely result of his or her conduct." The occurrence must have been "reasonably" foreseeable: "Not what actually happened, but what the reasonably prudent person would then have foreseen as likely to happen, is the key to the question of reasonableness."

This is not the same as (but, in this case, necessarily a bit difficult to distinguish from) a determination as to whether the fees themselves are reasonable. For purposes of proximate cause, if the fees do not reflect work reasonably, foreseeably related to the negligence alleged in the case, it does not matter that in some other sense they might be "reasonable." We draw this distinction in response to TIG's argument, that because the fees were paid, they are prima facie reasonable. In this situation, we find the argument breathtaking, say nothing of irrelevant.

Proximate cause is the issue on which this case falters. Having said that, we recognize that the Illinois courts indicate that proximate cause should ordinarily be decided not as a matter or law, but by a trier of fact. However, in a situation in which it is clear as a matter of law that the injury could not have been foreseeable, Illinois courts have upheld summary judgment on the issue. The situation before us is such a case.

The fundamental negligence allegedly committed by Giffin Winning was a failure to produce documents - especially gender equity studies - pursuant to a discovery request. The attorneys had routed the request to Gorrell, who was at that point still employed by ISU. He did not forward the studies to the attorneys. However, the attorneys had copies of the studies, which they also failed to produce. This is a clear breakdown of the discovery process, which we infer was not going at all smoothly on either side of this case.

In this all-too-common situation, the question for us is whether it would be reasonably foreseeable that a failure to produce these documents would result in the injury alleged here. Could the attorneys foresee that Gorrell, who failed to produce the documents when they turned the request over to him, would then, after he became disgruntled with ISU, independently provide the documents to Bellows? Beyond that, would reasonable people foresee that Gorrell would mislead Bellows about a database which did not exist? Would reasonable people then think that, upon hearing Gorrell's story, Bellows' first impulse would be to move for sanctions including default judgment in the case? Would reasonable people foresee that, next, a large law firm, apparently thinking of Judge Mihm as a bit trigger-happy, would jump into high gear out of fear of default judgment and launch an army of 27 attorneys, plus paralegals, to defend against the possibility that Judge Mihm might grant default judgment on the basis of an alleged conspiracy to hide something which does not exist? In other words, was the Latham response to a failure to produce documents and the resulting injury foreseeable? 
We think it was not as a matter of law. Our point can be illustrated by a very different sort of negligence action. In Abrams, the city failed to send an ambulance for a woman, Abrams (of course), who was in labor. A friend, who then drove her to the hospital, ran a red light and collided with a car driven by a drug-and-alcohol-impaired driver with a suspended license. Abrams was seriously injured and spent 2 weeks in a coma; sadly, her baby died. The court found, however, that as a matter of law there was no proximate cause. The city could not have foreseen the situation that unfolded. Perhaps a bit callously, the court remarked that "millions of women in labor make it safely to the hospital each year by private transportation."

It is also true - though less tragically so - that countless failures to produce documents occur in the federal courts every year. That is not a good thing. But we are not at a point at which it is foreseeable that such a failure will spawn a million-dollar bill for attorney fees. If it were, litigation would become more of a blood sport than it already is. Lawyers would be even more obsessive about irrelevant and tedious details. No good could come of it.

There is, in fact, nothing which distinguishes the failure to produce in this case with countless others. Judge Mihm himself made this point in response to Bellows' argument that this was the worst discovery abuse he had ever seen. Judge Mihm said:

But you said in your 34 years of practice this was the most shocking thing you had ever seen in terms of this discovery issue. I wonder what kind of practice you've had if that's the case because, boy, in the scheme of things, I've seen things 50 times worse than this.

What is foreseeable as a result of a failure to produce documents is the reasonable procedure set out in Civil Rule of Civil Procedure 37, which provides for sanctions only after other reasonable efforts to work out disagreements fail. It may be that, as Judge Mihm also said, that did not happen enough in this case. But ISU and Giffin Winning could hardly be expected to foresee all this trouble over a phantom database. Why would they? It was ISU's alleged database and Giffin Winning was representing ISU at the time. They knew of no database; they were hiding no database; there was no database. For Giffin Winning's carelessness in failing to produce documents (which Bellows had in his possession), the sanction of $\$ 10,000$ might well have been sustained on appeal. But as a matter of law, the injury alleged here was not reasonably foreseeable.

\section{Questions:}

1. What was TIG's injury? Did Giffin Winning's negligence cause that injury?

2. Why did the court hold that TIG's injury was not reasonably foreseeable? Was TIG'S injury a reasonably foreseeable risk?

\section{Damages}


The plaintiff in a legal malpractice action can only recover actual damages, and can only recover damages that were reasonably foreseeable by the defendant. As a consequence, the plaintiff must prove the amount of damages, and cannot recover speculative damages.

Kituskie v. Corbman, 714 A. 2d 1027 (Pa. 1998)

Summary: Kituskie was injured by Trapp in a car accident while on vacation in California. He returned home to Pennsylvania and hired attorney Corbman to represent him in a tort action. Corbman negligently failed to file an action within California's two-year statute of limitations, and advised Kituskie to file a legal malpractice action. Trapp's insurance policy had a $\$ 25,000$ maximum, but the jury awarded Kituskie $\$ 2.3$ million in damages against Corbman. The appellate court vacated the judgment and remanded, holding that the jury must consider the collectability of damages, and that the defendant bears the burden of proof that damages are not collectable. The Supreme Court affirmed.

\section{CASTILLE, Justice.}

This Court granted allocatur in this matter in order to address two issues. The first issue is whether the collectibility of damages in an underlying action is relevant to and, therefore, admissible in a legal malpractice action. The second issue is, if collectibility of damages should be considered, which party bears the burden of proving collectibility. Because we find that collectibility of damages in the underlying action should be considered in a legal malpractice action and that the defendant/attorney bears the burden of proof, we affirm the order of the Superior Court and remand for further proceedings consistent with this opinion.

The facts relevant to this appeal are not in dispute. Leo J. Kituskie is a Pennsylvania resident who is a practicing periodontist. On September 3,1989, Kituskie was injured in a two-car automobile accident during his vacation in San Jose, California. The traffic collision report for the accident stated that a vehicle being driven by Evan Mark Trapp crossed a highway on-ramp into the path of Kituskie's automobile after it struck a curb and a cyclone fence. The traffic collision report also indicated that Trapp was driving while intoxicated and that his vehicle was being operated at the time of the accident at a high rate of speed. After the accident, Kituskie returned to the Philadelphia area in order to begin treatment for his injuries. As a result of this automobile accident, Kituskie avers that he suffers from a degenerative and arthritic back condition which makes it difficult for him to work full-time as a periodontist.

On September 9, 1989, Kituskie retained Scott K. Corbman, Esquire, to pursue his claim against Trapp for the personal injuries he sustained in the accident. Corbman is an attorney licensed to practice law in the Commonwealth of Pennsylvania and is a principal/shareholder in the law firm of Garfinkle, Corbman, Greenberg and Jurikson, P.C.

Corbman proceeded to obtain Kituskie's medical reports. After reviewing the medical reports, Corbman made a claim on Kituskie's behalf against Trapp's insurance carrier, California State 
Automobile Association ("CSAA"). During settlement negotiations with CSAA, Corbman learned that Trapp's insurance policy had a limit of $\$ 25,000$.

On September 17, 1990, more than one year after the accident, Corbman discovered that the California statute of limitations for injuries such as those suffered by Kituskie was only one year as opposed to the two-year statute of limitations in Pennsylvania. CSAA ultimately informed Corbman that it would not make a settlement offer to Kituskie because the one-year statute of limitations had passed without Corbman instituting a formal legal action. As soon as Corbman learned this information, Corbman met with Kituskie and informed him that his claim had been terminated because no suit was filed or settlement reached within the one-year statute of limitations period. During this meeting, Corbman advised Kituskie to seek the services of another attorney in order to assert a legal malpractice claim against Corbman and the Garfinkle firm.

On August 28, 1991, Kituskie, represented by new counsel, filed a legal malpractice claim against Corbman and the Garfinkle law firm in the Montgomery County Court of Common Pleas. Immediately prior to jury selection, counsel for each side filed motions in limine requesting that each side be precluded from presenting expert testimony on the issue of CSAA possibly settling the matter within the policy limits of Trapp's policy. Neither of these motions dealt directly with the issue of whether the jury in this legal malpractice action could consider Kituskie's ability to collect on an underlying judgment against Trapp. However, the trial court, realizing that its resolution of whether collectibility of damages in an underlying case could be an issue at trial, withheld its disposition of the two motions in limine. On January 6, 1995, prior to commencing the trial in this matter, the trial court decided that collectibility of damages in an underlying case was not relevant to a legal malpractice claim in Pennsylvania. Thus, the trial court granted both motions in limine.

Following a trial on the matter, on January 11, 1995, a jury found that Corbman and the Garfinkle firm were liable to Kituskie for legal malpractice in the amount of $\$ 2,300,000$. Corbman and the Garfinkle firm appealed to the Superior Court. The Superior Court, in a published opinion, vacated the judgment and remanded for further proceedings because it held that the collectibility of damages in an underlying case should be considered in a legal malpractice action. The Superior Court also held that the attorney being sued for legal malpractice bore the burden of proving as a defense in the form of mitigation of damages that the potential underlying case which formed the basis of the legal malpractice award would have been uncollectible. This Court granted allocatur in order to decide whether collectibility should be part of a legal malpractice action and, if so, which party bears the burden of proof as to that issue.

In order to establish a claim of legal malpractice, a plaintiff/aggrieved client must demonstrate three basic elements:

1) employment of the attorney or other basis for a duty;

2) the failure of the attorney to exercise ordinary skill and knowledge; and

3 ) that such negligence was the proximate cause of damage to the plaintiff. 
An essential element to this cause of action is proof of actual loss rather than a breach of a professional duty causing only nominal damages, speculative harm or the threat of future harm. Damages are considered remote or speculative only if there is uncertainty concerning the identification of the existence of damages rather than the ability to precisely calculate the amount or value of damages. In essence, a legal malpractice action in Pennsylvania requires the plaintiff to prove that he had a viable cause of action against the party he wished to sue in the underlying case and that the attorney he hired was negligent in prosecuting or defending that underlying case (often referred to as proving a "case within a case").

A review of case law in the Commonwealth shows that the issue of whether collectibility of damages in an underlying case should also be a part of a legal malpractice action is one of first impression. Other jurisdictions, however, have addressed this issue and have held that collectibility of damages should also be considered in a legal malpractice action.

Like these other jurisdictions, this Court believes that collectibility of damages in the underlying action should also be part of the analysis in a legal malpractice action. We do so because we recognize that a legal malpractice action is distinctly different from any other type of lawsuit brought in the Commonwealth. A legal malpractice action is different because, as described above, a plaintiff must prove a case within a case since he must initially establish by a preponderance of the evidence that he would have recovered a judgment in the underlying action (here, the underlying action would have involved Kituskie's lawsuit against Trapp). It is only after the plaintiff proves he would have recovered a judgment in the underlying action that the plaintiff can then proceed with proof that the attorney he engaged to prosecute or defend the underlying action was negligent in the handling of the underlying action and that negligence was the proximate cause of the plaintiff's loss since it prevented the plaintiff from being properly compensated for his loss. However, this Court has held that the plaintiff in a legal action should only be compensated for his actual losses. Actual losses in a legal malpractice action are measured by the judgment the plaintiff lost in the underlying action and the attorney who negligently handled the underlying action is the party held responsible for the lost judgment. However, as noted by the Superior Court, "it would be inequitable for the plaintiff to be able to obtain a judgment against the attorney which is greater than the judgment that the plaintiff could have collected from the third party; the plaintiff would be receiving a windfall at the attorney's expense." Thus, we now hold that collectibility of damages in the underlying case is a matter which should be considered in legal malpractice actions.

Because this Court has concluded that collectibility of damages is an issue which should be considered in legal malpractice actions, we now must decide who bears the burden of proof. While other jurisdictions considering the issue of collectibility of damages have unanimously concluded that collectibility is a part of a legal malpractice action, they have been split on which party in the legal malpractice action bears the burden of proof. A majority of courts in other jurisdictions have placed the burden of proving collectibility on the plaintiff because it is viewed as being closely related to the issue of proximate cause, a burden which clearly the plaintiff bears as part of his prima facie case. In doing so, these courts place the burden on the plaintiff 
because a plaintiff can prove that the attorney's malfeasance was the proximate cause of his loss only if he demonstrates that he would have succeeded on the underlying action and that he would have succeeded in collecting on the resulting judgment.

A minority of courts in other jurisdictions, however, have rejected the majority's line of reasoning and placed the burden of proving non-collectibility on the defendant/attorney. These courts have recognized that the plaintiff must prove a case within a case. These minority of courts, however, do not believe that it logically follows from the case within a case burden of proof that the plaintiff must also prove that the damages in the underlying case would have been collectible. Instead, these courts believe that the burden of proof in a legal malpractice action only requires the plaintiff to prove a loss of judgment on a valid claim. To require the plaintiff to also prove collectibility of damages would result in placing an unfair burden on the plaintiff where the plaintiff's legal malpractice action is often brought years after the initial accident causing his injuries solely because the defendant/lawyer failed to act in a timely and competent manner. Thus, the minority of courts believe that it is more logical and fair to treat collectibility as an affirmative defense which the defendant/attorney must plead and prove in order to avoid or mitigate the consequences of that attorney's negligent acts. Moreover, this minority has criticized the majority position because it ignores the possibility of settlement between the plaintiff and the underlying tortfeasor and also overlooks that the passage of time itself can be a militating factor either for or against collectibility of the underlying case.

After considering both positions, this Court finds the reasoning of the minority position to be more persuasive. Thus, we adopt the minority position and hold that a defendant/lawyer in a legal malpractice action should plead and prove the affirmative defense that the underlying case was not collectible by a preponderance of the evidence.

Accordingly, for the reasons expressed above, we find that the Superior Court correctly held that collectibility of damages in an underlying case is a matter which must be considered in a legal malpractice action and that the defendant/lawyer bears the burden of proving that the underlying case which formed the basis of the damages award in a legal malpractice action would not have been fully collectible. Therefore, the order of the Superior Court is affirmed and the matter remanded for further proceedings.

\section{Questions:}

1. Why did the court hold that Kituskie could only recover collectable damages? Why couldn't he recover all of his damages?

2. Why did the court hold that Corbman bore the burden of proving that damages were not collectable? Will it be hard for Corbman to prove the damages were not collectable, under the circumstances? 


\section{3: Ineffective Assistance of Counsel}

\section{Ineffective Assistance of Counsel}

The Sixth Amendment and the Due Process clause guarantee criminal defendants the right to the effective assistance of counsel. In Gideon v. Wainwright, 372 U.S. 335 (1963), the Supreme Court held that indigent criminal defendants are entitled to appointed counsel in all felony cases. And in Strickland v. Washington, 466 U.S. 668 (1984), it held that appointed counsel must provide a competent defense. If a criminal defendant receives ineffective assistance of counsel, then any conviction is unconstitutional and void. However, courts evaluating ineffective assistance of counsel claims are "highly deferential" to the decisions of appointed counsel, and will provide relief only if counsel's decisions are both unreasonable and prejudicial. Accordingly, ineffective assistance of counsel claims are difficult to prove, unless counsel provided no defense at all or had a conflict of interest.

\section{U.S. Const. Amend. 6}

In all criminal prosecutions, the accused shall enjoy the right to a speedy and public trial, by an impartial jury of the state and district wherein the crime shall have been committed, which district shall have been previously ascertained by law, and to be informed of the nature and cause of the accusation; to be confronted with the witnesses against him; to have compulsory process for obtaining witnesses in his favor, and to have the assistance of counsel for his defense.

\section{Strickland v. Washington, 466 U.S. 668 (1984)}

The Supreme Court established the rules governing ineffective assistance of counsel claims in criminal cases in the landmark case Strickland $v$. Washington. In Strickland, the Court held that due process and the Counsel Clause of the Sixth Amendment guarantees all criminal defendants the right to the effective assistance of counsel. "The benchmark for judging any claim of ineffectiveness must be whether counsel's conduct so undermined the proper functioning of the adversarial process that the trial cannot be relied on as having produced a just result."

In order to prove a claim for ineffective assistance of counsel, a criminal defendant must show that counsel violated the duty of care or loyalty, and that the violation prejudiced the defendant. "First, the defendant must show that counsel's performance was deficient. This requires showing that counsel made errors so serious that counsel was not functioning as the 'counsel' guaranteed the defendant by the Sixth Amendment. Second, the defendant must show that the deficient performance prejudiced the defense. This requires showing that counsel's errors were so serious as to deprive the defendant of a fair trial, a trial whose result is reliable."

The evaluation of counsel's performance must be "highly deferential" and "judge the reasonableness of counsel's challenged conduct on the facts of the particular case, viewed as 
of the time of counsel's conduct." Accordingly, the defendant "must identify the acts or omissions of counsel that are alleged not to have been the result of reasonable professional judgment" and "the court must then determine whether, in light of all the circumstances, the identified acts or omissions were outside the wide range of professionally competent assistance."

In addition, the defendant must show that counsel's unreasonable conduct was prejudicial. "Any deficiencies in counsel's performance must be prejudicial to the defense in order to constitute ineffective assistance under the Constitution." There is a legal presumption of prejudice if the defendant was actually or constructively denied the assistance of counsel, the government interfered with representation, or counsel had a conflict of interest that adversely affected performance. But if counsel violated the duty of care, the defendant must show that counsel's unreasonable conduct was actually prejudicial. "The defendant must show that there is a reasonable probability that, but for counsel's unprofessional errors, the result of the proceeding would have been different."

Knowles v. Mirzayance, 556 U.S. 111 (2009)

Summary: Mirzayance confessed to killing his cousin, and pleaded both not guilty and not guilty by reason of insanity. During the guilt phase of the trial, the jury rejected evidence of insanity and convicted Mirzayance of first-degree murder. On the advice of counsel, Mirzayance withdrew his insanity plea, because his parents effectively refused to testify, and there was no other new evidence. On state and federal habeas, Mirzayance argued that counsel's advice to withdraw his insanity plea was ineffective assistance of counsel, because he had no other defense. The district court granted habeas, because Mirzayance had "nothing to lose" by an insanity defense, and the circuit court affirmed. The Supreme Court reversed, holding that the insanity defense had no "reasonable probability" of success.

Justice THOMAS delivered the opinion of the Court.

In this case, respondent Alexandre Mirzayance claimed ineffective assistance of counsel because his attorney recommended withdrawing his insanity defense. The California courts rejected this claim on state postconviction review. We must decide whether this decision was contrary to or an unreasonable application of clearly established federal law. We hold that it was not. Mirzayance failed to establish that his counsel's performance was ineffective.

Mirzayance confessed that he stabbed his 19-year-old cousin nine times with a hunting knife and then shot her four times. At trial, he entered pleas of not guilty and not guilty by reason of insanity (NGI). Under California law, when both of these pleas are entered, the court must hold a bifurcated trial, with guilt determined during the first phase and the viability of the defendant's $\mathrm{NGI}$ plea during the second. During the guilt phase of Mirzayance's trial, he sought to avoid a 
conviction for first-degree murder by obtaining a verdict on the lesser included offense of second-degree murder. To that end, he presented medical testimony that he was insane at the time of the crime and was, therefore, incapable of the premeditation or deliberation necessary for a first-degree murder conviction. The jury nevertheless convicted Mirzayance of first-degree murder.

The trial judge set the NGI phase to begin the day after the conviction was entered but, on the advice of counsel, Mirzayance abandoned his NGI plea before it commenced. He would have borne the burden of proving his insanity during the NGI phase to the same jury that had just convicted him of first-degree murder. Counsel had planned to meet that burden by presenting medical testimony similar to that presented in the guilt phase, including evidence that Mirzayance was insane and incapable of premeditating or deliberating. Because the jury rejected similar evidence at the guilt phase (where the State bore the burden of proof), counsel believed a defense verdict at the NGI phase (where the burden was on the defendant) was unlikely. He planned, though, to have Mirzayance's parents testify and thus provide an emotional account of Mirzayance's struggles with mental illness to supplement the medical evidence of insanity. But on the morning that the NGI phase was set to begin, Mirzayance's parents refused to testify. After consulting with co-counsel, counsel advised Mirzayance that he should withdraw the NGI plea. Mirzayance accepted the advice.

After he was sentenced, Mirzayance challenged his conviction in state postconviction proceedings. Among other allegations, he claimed that counsel's recommendation to withdraw the NGI plea constituted ineffective assistance of counsel under Strickland. The California trial court denied the petition, and the California Court of Appeal affirmed without offering any reason for its rejection of this particular ineffective-assistance claim. Mirzayance then filed an application for federal habeas relief, which the District Court denied without an evidentiary hearing. The Court of Appeals reversed the District Court and ordered an evidentiary hearing on counsel's recommendation to withdraw the NGI plea. During that evidentiary hearing, a Magistrate Judge made factual findings that the District Court later adopted.

According to the Magistrate Judge, counsel's strategy for the two-part trial was to seek a second-degree murder verdict in the first stage and to seek an NGI verdict in the second stage. This strategy faltered when the jury instead convicted Mirzayance of first-degree murder. In the circumstances of this case, the medical evidence that Mirzayance planned to adduce at the NGI phase essentially would have duplicated evidence that the jury had necessarily rejected in the guilt phase. First-degree murder in California includes any killing that is "willful, deliberate, and premeditated." To prove NGI, a defendant must show that he was incapable of knowing or understanding the nature of his act or of distinguishing right from wrong at the time of the offense. Highlighting this potential contradiction, the trial judge instructed the jury during the guilt phase that "the word 'deliberate,"' as required for a first-degree murder conviction, "means formed or arrived at or determined upon as a result of careful thought and weighing of considerations for and against the proposed course of action." 
When the jury found Mirzayance guilty of first-degree murder, counsel doubted the likelihood of prevailing on the $\mathrm{NGI}$ claim. According to the Magistrate Judge:

The defense suspected that a jury's finding, beyond a reasonable doubt, that Mirzayance had "deliberated" and "premeditated" his killing of the victim as a practical matter would cripple Mirzayance's chances of convincing the jury later, during the sanity phase, that Mirzayance nevertheless "was incapable of knowing or understanding the nature and quality of his act and of distinguishing right from wrong at the time of the commission of the offense."

Any remaining chance of securing an NGI verdict now depended (in counsel's view) on presenting some "emotional impact" testimony by Mirzayance's parents, which counsel had viewed as key even if the defense had secured a second-degree murder verdict at the guilt phase.

But, as the Magistrate Judge found, on the morning that the NGI phase was set to begin, Mirzayance's parents effectively refused to testify:

The parents at least expressed clear reluctance to testify, which, in context, conveyed the same sense as a refusal.

Although the parties disputed this point, the parents' later actions supported the Magistrate Judge's finding that the parents' reluctance to testify amounted to refusal:

Corroborating the Court's finding that Mirzayance's parents indicated a strong disinclination to testify at the NGI phase are the facts that (1) they did not testify later at his sentencing hearing, and (2) the reason for their choosing not to do so is that it would have been "too emotional" for them. If weeks after the guilty verdict and the withdrawal of their son's NGI plea, Mirzayance's parents' emotions still prevented them from testifying at the sentencing hearing, then surely those emotional obstacles to their testifying in the NGI phase would have been at least as potent, and probably more so.

The Magistrate Judge found that counsel made a carefully reasoned decision not to go forward with the NGI plea:

Counsel carefully weighed his options before making his decision final; he did not make it rashly. Counsel's strategy at the NGI phase depended entirely on the heartfelt participation of Mirzayance's parents as witnesses. Moreover, counsel knew that, although he had experts lined up to testify, their testimony had significant weaknesses. Counsel's NGI-phase strategy became impossible to attempt once Mirzayance's parents expressed their reluctance to testify. All counsel was left with were four experts, all of whom reached a conclusion - that Mirzayance did not premeditate and deliberate his crime - that the same jury about to hear the NGI evidence already had rejected under a beyond-a-reasonable-doubt standard of proof. The experts were subject to other 
impeachment as well. Counsel discussed the situation with his experienced co-counsel who concurred in counsel's proposal that he recommend to Mirzayance the withdrawal of the NGI plea.

Based on these factual findings, the Magistrate Judge stated that, in his view, counsel's performance was not deficient.

Despite this determination, the Magistrate Judge concluded that the court was bound by the Court of Appeals' remand order to determine only whether "there were tactical reasons for abandoning the insanity defense." Even though the Magistrate Judge thought that counsel was reasonable in recommending that a very weak claim be dropped, the Magistrate Judge understood the remand order to mean that counsel's performance was deficient if withdrawing the NGI plea would achieve no tactical advantage. The Magistrate Judge found that "Mirzayance had nothing to lose" by going forward with the NGI phase of the trial, and thus held, under the remand order, that counsel's performance was deficient. As to prejudice, the Magistrate Judge concluded the court was similarly bound by the remand order because the Court of Appeals described the NGI defense as remaining "viable and strong." Accordingly, the Magistrate Judge found prejudice and recommended granting the writ of habeas corpus. The District Court accepted this recommendation and granted the writ.

The Court of Appeals affirmed. It first stated that the lower court had misunderstood its remand order, which it described as requiring an examination of "counsel's reason for abandoning the insanity defense," rather than as mandating that the District Court must find deficient performance if it found counsel had "nothing to lose" by pursuing the insanity defense. Nonetheless, the Court of Appeals affirmed the finding of deficient performance. According to the court, Mirzayance's "parents did not refuse, but merely expressed reluctance to testify." And because they may have been willing, "competent counsel would have attempted to persuade them to testify, which counsel here admits he did not." The Court of Appeals also "disagreed that counsel's decision was carefully weighed and not made rashly."

Furthermore, even though it had suggested that the District Court unnecessarily evaluated counsel's strategy under a "nothing to lose" standard, the Court of Appeals affirmed the District Court in large part because Mirzayance's "counsel did not make a true tactical choice" based on its view that counsel had nothing to gain by dropping the NGI defense. The court held that "reasonably effective assistance would put on the only defense available, especially in a case such as this where there was significant potential for success." The Court of Appeals also found prejudice because, in its view, "if counsel had pursued the insanity phase of the trial, there is a reasonable probability that the jury would have found Mirzayance insane."

We granted the petition for writ of certiorari.

Even if Mirzayance's ineffective-assistance-of-counsel claim were eligible for de novo review, it would still fail. Strickland requires a defendant to establish deficient performance and prejudice. Mirzayance can establish neither. 
Mirzayance has not shown "that counsel's representation fell below an objective standard of reasonableness."

The proper measure of attorney performance remains simply reasonableness under prevailing professional norms. Judicial scrutiny of counsel's performance must be highly deferential, and a court must indulge a strong presumption that counsel's conduct falls within the wide range of reasonable professional assistance. Strategic choices made after thorough investigation of law and facts relevant to plausible options are virtually unchallengeable.

Here, Mirzayance has not shown that his counsel violated these standards. Rather, his counsel merely recommended the withdrawal of what he reasonably believed was a claim doomed to fail. The jury had already rejected medical testimony about Mirzayance's mental state in the guilt phase, during which the State carried its burden of proving guilt beyond a reasonable doubt. The Magistrate Judge explained this point:

All counsel was left with were four experts, all of whom reached a conclusion - that Mirzayance did not premeditate and deliberate his crime - that the same jury about to hear the NGI evidence already had rejected under a beyond-a-reasonable-doubt standard of proof. The experts were subject to other impeachment as well.

In fact, the Magistrate Judge found that counsel "convincingly detailed ways in which the experts could have been impeached, for overlooking or minimizing facts which showcased Mirzayance's clearly goal-directed behavior."

In the NGI phase, the burden would have switched to Mirzayance to prove insanity by a preponderance of the evidence. Mirzayance's counsel reasonably believed that there was almost no chance that the same jury would have reached a different result when considering similar evidence, especially with Mirzayance bearing the burden of proof. Furthermore, counsel knew he would have had to present this defense without the benefit of the parents' testimony, which he believed to be his strongest evidence. Counsel reasonably concluded that this defense was almost certain to lose.

The Court of Appeals took the position that the situation was not quite so dire because the parents "merely expressed reluctance to testify." It explained that "competent counsel would have attempted to persuade them to testify." But that holding is in tension with the Magistrate Judge's findings and applies a more demanding standard than Strickland prescribes. The Magistrate Judge noted that the parents "conveyed the same sense as a refusal." Indeed, the Magistrate Judge found that the parents "did not testify later at Mirzayance's sentencing hearing" because it "would have been 'too emotional' for them." Competence does not require an attorney to browbeat a reluctant witness into testifying, especially when the facts suggest that no amount of persuasion would have succeeded. Counsel's acceptance of the parents' 
"conveyance of a refusal" does not rise to the high bar for deficient performance set by Strickland.

Mirzayance's failure to show ineffective assistance of counsel is confirmed by the Magistrate Judge's finding that "counsel carefully weighed his options before making his decision final; he did not make it rashly." The Magistrate Judge explained all of the factors that counsel considered - many of which are discussed above — and noted that counsel "discussed the situation with his experienced co-counsel" before making it. In making this finding, the Magistrate Judge identified counsel's decision as essentially an informed decision "made after thorough investigation of law and facts relevant to plausible options." As we stated in Strickland, such a decision is "virtually unchallengeable."

Without even referring to the Magistrate Judge's finding, the Court of Appeals "disagreed that counsel's decision was carefully weighed and not made rashly." In its view, "counsel acted on his subjective feelings of hopelessness without even considering the potential benefit to be gained in persisting with the plea." But courts of appeals may not set aside a district court's factual findings unless those findings are clearly erroneous. Here, the Court of Appeals failed even to mention the clearly-erroneous standard, let alone apply it, before effectively overturning the lower court's factual findings related to counsel's behavior.

In light of the Magistrate Judge's factual findings, the state court's rejection of Mirzayance's ineffective-assistance-of-counsel claim was consistent with Strickland. The Court of Appeals insisted, however, that "'reasonably effective assistance' required here that counsel assert the only defense available." But we are aware of no "prevailing professional norms" that prevent counsel from recommending that a plea be withdrawn when it is almost certain to lose. And in this case, counsel did not give up "the only defense available." Counsel put on a defense to firstdegree murder during the guilt phase. Counsel also defended his client at the sentencing phase. The law does not require counsel to raise every available nonfrivolous defense. Counsel also is not required to have a tactical reason - above and beyond a reasonable appraisal of a claim's dismal prospects for success - for recommending that a weak claim be dropped altogether. Mirzayance has thus failed to demonstrate that his counsel's performance was deficient.

In addition, Mirzayance has not demonstrated that he suffered prejudice from his counsel's performance. To establish prejudice, "the defendant must show that there is a reasonable probability that, but for counsel's unprofessional errors, the result of the proceeding would have been different. A reasonable probability is a probability sufficient to undermine confidence in the outcome." To prevail on his ineffective-assistance claim, Mirzayance must show, therefore, that there is a "reasonable probability" that he would have prevailed on his insanity defense had he pursued it. This Mirzayance cannot do. It was highly improbable that a jury, which had just rejected testimony about Mirzayance's mental condition when the State bore the burden of proof, would have reached a different result when Mirzayance presented similar evidence at the NGI phase. 
Mirzayance has not shown that the state court's conclusion that there was no ineffective assistance of counsel "was contrary to, or involved an unreasonable application of, clearly established Federal law." In fact, he has not shown ineffective assistance at all. The judgment of the Court of Appeals is reversed, and the case is remanded with instructions to deny the petition.

\section{Questions:}

1. Did Mirzayance's insanity plea have any chance of success? Was there any reason to withdraw it?

2. Could Mirzayance's attorney have had a tactical reason for advising him to withdraw his insanity plea?

\section{Lee v. United States, 137 S. Ct. 1958 (2017)}

Summary: Jae Lee was a lawful permanent resident of the United States, who was indicted for an "aggravated felony." Lee pleaded guilty on the advice of his attorney, who assured him that he would not be deported. In fact, Lee was subject to mandatory deportation. Lee filed a motion to vacate his conviction and sentence based on ineffective assistance of counsel, arguing that he would not have pleaded guilty if he had known it would mean mandatory deportation. The district court denied relief, because Lee would "almost certainly" have been found guilty and deported anyway, and the circuit court affirmed. The Supreme Court reversed, holding that the attorney's incompetence deprived Lee of a chance of avoiding deportation.

Chief Justice ROBERTS delivered the opinion of the Court.

Petitioner Jae Lee was indicted on one count of possessing ecstasy with intent to distribute. Although he has lived in this country for most of his life, Lee is not a United States citizen, and he feared that a criminal conviction might affect his status as a lawful permanent resident. His attorney assured him there was nothing to worry about - the Government would not deport him if he pleaded guilty. So Lee, who had no real defense to the charge, opted to accept a plea that carried a lesser prison sentence than he would have faced at trial.

Lee's attorney was wrong: The conviction meant that Lee was subject to mandatory deportation from this country. Lee seeks to vacate his conviction on the ground that, in accepting the plea, he received ineffective assistance of counsel in violation of the Sixth Amendment. Everyone agrees that Lee received objectively unreasonable representation. The question presented is whether he can show he was prejudiced as a result. 
Jae Lee moved to the United States from South Korea in 1982. He was 13 at the time. His parents settled the family in New York City, where they opened a small coffee shop. After graduating from a business high school in Manhattan, Lee set out on his own to Memphis, Tennessee, where he started working at a restaurant. After three years, Lee decided to try his hand at running a business. With some assistance from his family, Lee opened the Mandarin Palace Chinese Restaurant in a Memphis suburb. The Mandarin was a success, and Lee eventually opened a second restaurant nearby. In the 35 years he has spent in the country, Lee has never returned to South Korea. He did not become a United States citizen, living instead as a lawful permanent resident.

At the same time he was running his lawful businesses, Lee also engaged in some illegitimate activity. In 2008, a confidential informant told federal officials that Lee had sold the informant approximately 200 ecstasy pills and two ounces of hydroponic marijuana over the course of eight years. The officials obtained a search warrant for Lee's house, where they found 88 ecstasy pills, three Valium tablets, $\$ 32,432$ in cash, and a loaded rifle. Lee admitted that the drugs were his and that he had given ecstasy to his friends.

A grand jury indicted Lee on one count of possessing ecstasy with intent to distribute. Lee retained an attorney and entered into plea discussions with the Government. The attorney advised Lee that going to trial was "very risky" and that, if he pleaded guilty, he would receive a lighter sentence than he would if convicted at trial. Lee informed his attorney of his noncitizen status and repeatedly asked him whether he would face deportation as a result of the criminal proceedings. The attorney told Lee that he would not be deported as a result of pleading guilty. Based on that assurance, Lee accepted the plea and the District Court sentenced him to a year and a day in prison, though it deferred commencement of Lee's sentence for two months so that Lee could manage his restaurants over the holiday season.

Lee quickly learned, however, that a prison term was not the only consequence of his plea. Lee had pleaded guilty to what qualifies as an "aggravated felony" under the Immigration and Nationality Act, and a noncitizen convicted of such an offense is subject to mandatory deportation. Upon learning that he would be deported after serving his sentence, Lee filed a motion to vacate his conviction and sentence, arguing that his attorney had provided constitutionally ineffective assistance.

At an evidentiary hearing on Lee's motion, both Lee and his plea-stage counsel testified that "deportation was the determinative issue in Lee's decision whether to accept the plea." In fact, Lee explained, his attorney became "pretty upset because every time something comes up I always ask about immigration status," and the lawyer "always said why are you worrying about something that you don't need to worry about." According to Lee, the lawyer assured him that if deportation was not in the plea agreement, "the government cannot deport you." Lee's attorney testified that he thought Lee's case was a "bad case to try" because Lee's defense to the charge was weak. The attorney nonetheless acknowledged that if he had known Lee would be deported upon pleading guilty, he would have advised him to go to trial. Based on the hearing 
testimony, a Magistrate Judge recommended that Lee's plea be set aside and his conviction vacated because he had received ineffective assistance of counsel.

The District Court, however, denied relief. Applying our two-part test for ineffective assistance claims from Strickland $v$. Washington, the District Court concluded that Lee's counsel had performed deficiently by giving improper advice about the deportation consequences of the plea. But, "in light of the overwhelming evidence of Lee's guilt," Lee "would have almost certainly" been found guilty and received "a significantly longer prison sentence, and subsequent deportation," had he gone to trial. Lee therefore could not show he was prejudiced by his attorney's erroneous advice. Viewing its resolution of the issue as debatable among jurists of reason, the District Court granted a certificate of appealability.

The Court of Appeals for the Sixth Circuit affirmed the denial of relief. On appeal, the Government conceded that the performance of Lee's attorney had been deficient. To establish that he was prejudiced by that deficient performance, the court explained, Lee was required to show "a reasonable probability that, but for counsel's errors, he would not have pleaded guilty and would have insisted on going to trial." Lee had "no bona fide defense, not even a weak one," so he "stood to gain nothing from going to trial but more prison time." Relying on Circuit precedent holding that "no rational defendant charged with a deportable offense and facing overwhelming evidence of guilt would proceed to trial rather than take a plea deal with a shorter prison sentence," the Court of Appeals concluded that Lee could not show prejudice. We granted certiorari.

The Sixth Amendment guarantees a defendant the effective assistance of counsel at "critical stages of a criminal proceeding," including when he enters a guilty plea. To demonstrate that counsel was constitutionally ineffective, a defendant must show that counsel's representation "fell below an objective standard of reasonableness" and that he was prejudiced as a result. The first requirement is not at issue in today's case: The Government concedes that Lee's pleastage counsel provided inadequate representation when he assured Lee that he would not be deported if he pleaded guilty. The question is whether Lee can show he was prejudiced by that erroneous advice.

\section{A}

A claim of ineffective assistance of counsel will often involve a claim of attorney error "during the course of a legal proceeding" - for example, that counsel failed to raise an objection at trial or to present an argument on appeal. A defendant raising such a claim can demonstrate prejudice by showing "a reasonable probability that, but for counsel's unprofessional errors, the result of the proceeding would have been different."

But in this case counsel's "deficient performance arguably led not to a judicial proceeding of disputed reliability, but rather to the forfeiture of a proceeding itself." When a defendant alleges 
his counsel's deficient performance led him to accept a guilty plea rather than go to trial, we do not ask whether, had he gone to trial, the result of that trial "would have been different" than the result of the plea bargain. That is because, while we ordinarily "apply a strong presumption of reliability to judicial proceedings," "we cannot accord" any such presumption "to judicial proceedings that never took place."

We instead consider whether the defendant was prejudiced by the "denial of the entire judicial proceeding to which he had a right." When a defendant claims that his counsel's deficient performance deprived him of a trial by causing him to accept a plea, the defendant can show prejudice by demonstrating a "reasonable probability that, but for counsel's errors, he would not have pleaded guilty and would have insisted on going to trial."

The dissent contends that a defendant must also show that he would have been better off going to trial. That is true when the defendant's decision about going to trial turns on his prospects of success and those are affected by the attorney's error - for instance, where a defendant alleges that his lawyer should have but did not seek to suppress an improperly obtained confession.

Not all errors, however, are of that sort. Here Lee knew, correctly, that his prospects of acquittal at trial were grim, and his attorney's error had nothing to do with that. The error was instead one that affected Lee's understanding of the consequences of pleading guilty. The Court confronted precisely this kind of error in Hill. Rather than asking how a hypothetical trial would have played out absent the error, the Court considered whether there was an adequate showing that the defendant, properly advised, would have opted to go to trial. The Court rejected the defendant's claim because he had "alleged no special circumstances that might support the conclusion that he placed particular emphasis on his parole eligibility in deciding whether or not to plead guilty."

Lee, on the other hand, argues he can establish prejudice under Hill because he never would have accepted a guilty plea had he known that he would be deported as a result. Lee insists he would have gambled on trial, risking more jail time for whatever small chance there might be of an acquittal that would let him remain in the United States. The Government responds that, since Lee had no viable defense at trial, he would almost certainly have lost and found himself still subject to deportation, with a lengthier prison sentence to boot. Lee, the Government contends, cannot show prejudice from accepting a plea where his only hope at trial was that something unexpected and unpredictable might occur that would lead to an acquittal.

\section{B}

The Government asks that we, like the Court of Appeals below, adopt a per se rule that a defendant with no viable defense cannot show prejudice from the denial of his right to trial. As a general matter, it makes sense that a defendant who has no realistic defense to a charge supported by sufficient evidence will be unable to carry his burden of showing prejudice from accepting a guilty plea. But in elevating this general proposition to a per se rule, the Government makes two errors. First, it forgets that categorical rules are ill suited to an inquiry 
that we have emphasized demands a "case-by-case examination" of the "totality of the evidence." And, more fundamentally, the Government overlooks that the inquiry we prescribed in Hill v. Lockhart focuses on a defendant's decisionmaking, which may not turn solely on the likelihood of conviction after trial.

A defendant without any viable defense will be highly likely to lose at trial. And a defendant facing such long odds will rarely be able to show prejudice from accepting a guilty plea that offers him a better resolution than would be likely after trial. But that is not because the prejudice inquiry in this context looks to the probability of a conviction for its own sake. It is instead because defendants obviously weigh their prospects at trial in deciding whether to accept a plea. Where a defendant has no plausible chance of an acquittal at trial, it is highly likely that he will accept a plea if the Government offers one.

But common sense (not to mention our precedent) recognizes that there is more to consider than simply the likelihood of success at trial. The decision whether to plead guilty also involves assessing the respective consequences of a conviction after trial and by plea. When those consequences are, from the defendant's perspective, similarly dire, even the smallest chance of success at trial may look attractive. For example, a defendant with no realistic defense to a charge carrying a 20-year sentence may nevertheless choose trial, if the prosecution's plea offer is 18 years. Here Lee alleges that avoiding deportation was the determinative factor for him; deportation after some time in prison was not meaningfully different from deportation after somewhat less time. He says he accordingly would have rejected any plea leading to deportation - even if it shaved off prison time - in favor of throwing a "Hail Mary" at trial.

The Government urges that, in such circumstances, the possibility of an acquittal after trial is "irrelevant to the prejudice inquiry," pointing to our statement in Strickland that "a defendant has no entitlement to the luck of a lawless decisionmaker." That statement, however, was made in the context of discussing the presumption of reliability we apply to judicial proceedings. As we have explained, that presumption has no place where, as here, a defendant was deprived of a proceeding altogether. In a presumptively reliable proceeding, "the possibility of arbitrariness, whimsy, caprice, 'nullification,' and the like" must by definition be ignored. But where we are instead asking what an individual defendant would have done, the possibility of even a highly improbable result may be pertinent to the extent it would have affected his decisionmaking.

C

"Surmounting Strickland's high bar is never an easy task," and the strong societal interest in finality has "special force with respect to convictions based on guilty pleas." Courts should not upset a plea solely because of post hoc assertions from a defendant about how he would have pleaded but for his attorney's deficiencies. Judges should instead look to contemporaneous evidence to substantiate a defendant's expressed preferences.

In the unusual circumstances of this case, we conclude that Lee has adequately demonstrated a reasonable probability that he would have rejected the plea had he known that it would lead to 
mandatory deportation. There is no question that "deportation was the determinative issue in Lee's decision whether to accept the plea deal." Lee asked his attorney repeatedly whether there was any risk of deportation from the proceedings, and both Lee and his attorney testified at the evidentiary hearing below that Lee would have gone to trial if he had known about the deportation consequences.

Lee demonstrated as much at his plea colloquy: When the judge warned him that a conviction "could result in your being deported," and asked "does that at all affect your decision about whether you want to plead guilty or not," Lee answered "Yes, Your Honor." When the judge inquired "how does it affect your decision," Lee responded "I don't understand," and turned to his attorney for advice. Only when Lee's counsel assured him that the judge's statement was a "standard warning" was Lee willing to proceed to plead guilty.

There is no reason to doubt the paramount importance Lee placed on avoiding deportation. Deportation is always "a particularly severe penalty," and we have "recognized that "preserving the client's right to remain in the United States may be more important to the client than any potential jail sentence." At the time of his plea, Lee had lived in the United States for nearly three decades, had established two businesses in Tennessee, and was the only family member in the United States who could care for his elderly parents - both naturalized American citizens. In contrast to these strong connections to the United States, there is no indication that he had any ties to South Korea; he had never returned there since leaving as a child.

The Government argues, however, that a defendant "must convince the court that a decision to reject the plea bargain would have been rational under the circumstances." The Government contends that Lee cannot make that showing because he was going to be deported either way; going to trial would only result in a longer sentence before that inevitable consequence.

We cannot agree that it would be irrational for a defendant in Lee's position to reject the plea offer in favor of trial. But for his attorney's incompetence, Lee would have known that accepting the plea agreement would certainly lead to deportation. Going to trial? Almost certainly. If deportation were the "determinative issue" for an individual in plea discussions, as it was for Lee; if that individual had strong connections to this country and no other, as did Lee; and if the consequences of taking a chance at trial were not markedly harsher than pleading, as in this case, that "almost" could make all the difference. Balanced against holding on to some chance of avoiding deportation was a year or two more of prison time. Not everyone in Lee's position would make the choice to reject the plea. But we cannot say it would be irrational to do so.

Lee's claim that he would not have accepted a plea had he known it would lead to deportation is backed by substantial and uncontroverted evidence. Accordingly we conclude Lee has demonstrated a "reasonable probability that, but for his counsel's errors, he would not have pleaded guilty and would have insisted on going to trial."

Justice THOMAS, with whom Justice ALITO joins except for Part I, dissenting. 
The Court today holds that a defendant can undo a guilty plea, well after sentencing and in the face of overwhelming evidence of guilt, because he would have chosen to pursue a defense at trial with no reasonable chance of success if his attorney had properly advised him of the immigration consequences of his plea. Neither the Sixth Amendment nor this Court's precedents support that conclusion. I respectfully dissent.

The Court and both of the parties agree that the prejudice inquiry in this context is governed by Strickland $v$. Washington. The Court in Strickland held that a defendant may establish a claim of ineffective assistance of counsel by showing that his "counsel's representation fell below an objective standard of reasonableness" and, as relevant here, that the representation prejudiced the defendant by "actually having an adverse effect on the defense."

To establish prejudice under Strickland, a defendant must show a "reasonable probability that, but for counsel's unprofessional errors, the result of the proceeding would have been different." Strickland made clear that the "result of the proceeding" refers to the outcome of the defendant's criminal prosecution as a whole. It defined "reasonable probability" as "a probability sufficient to undermine confidence in the outcome." And it explained that "an error by counsel does not warrant setting aside the judgment of a criminal proceeding if the error had no effect on the judgment."

The parties agree that this inquiry assumes an "objective" decisionmaker. That conclusion also follows directly from Strickland. According to Strickland, the "assessment of the likelihood of a result more favorable to the defendant must exclude the possibility of arbitrariness, whimsy, caprice, 'nullification,' and the like." It does not depend on subjective factors such as "the idiosyncrasies of the particular decisionmaker," including the decisionmaker's "unusual propensities toward harshness or leniency." These factors are flatly "irrelevant to the prejudice inquiry." In other words, "a defendant has no entitlement to the luck of a lawless decisionmaker." Ibid. Instead, "the assessment of prejudice should proceed on the assumption that the decisionmaker is reasonably, conscientiously, and impartially applying the standards that govern the decision."

When the Court extended the right to effective counsel to the plea stage, it held that "the same two-part standard" from Strickland applies. To be sure, the Court said - and the majority today emphasizes - that a defendant asserting an ineffectiveness claim at the plea stage "must show that there is a reasonable probability that, but for counsel's errors, he would not have pleaded guilty and would have insisted on going to trial." But that requirement merely reflects the reality that a defendant cannot show that the outcome of his case would have been different if he would have accepted his current plea anyway. In other words, the defendant's ability to show that he would have gone to trial is necessary, but not sufficient, to establish prejudice.

The Hill Court went on to explain that Strickland's two-part test applies the same way in the plea context as in other contexts. In particular, the "assessment" will primarily turn on "a prediction whether," in the absence of counsel's error, "the evidence" of the defendant's innocence or guilt "likely would have changed the outcome" of the proceeding. Thus, a defendant cannot show 
prejudice where it is "inconceivable" not only that he would have gone to trial, but also "that if he had done so he either would have been acquitted or, if convicted, would nevertheless have been given a shorter sentence than he actually received." In sum, the proper inquiry requires a defendant to show both that he would have rejected his plea and gone to trial and that he would likely have obtained a more favorable result in the end.

To the extent Hill was ambiguous about the standard, our precedents applying it confirm this interpretation. In Premo v. Moore, the Court emphasized that "strict adherence to the Strickland standard" is "essential" when reviewing claims about attorney error "at the plea bargain stage." In that case, the defendant argued that his counsel was constitutionally ineffective because he had failed to seek suppression of his confession before he pleaded no contest. In analyzing the prejudice issue, the Court did not focus solely on whether the suppression hearing would have turned out differently, or whether the defendant would have chosen to go to trial. It focused as well on the weight of the evidence against the defendant and the fact that he likely would not have obtained a more favorable result at trial, regardless of whether he succeeded at the suppression hearing.

The Court in Missouri v. Frye, took a similar approach. In that case, the Court extended Hill to hold that counsel could be constitutionally ineffective for failing to communicate a plea deal to a defendant. The Court emphasized that, in addition to showing a reasonable probability that the defendant "would have accepted the earlier plea offer," it is also "necessary" to show a "reasonable probability that the end result of the criminal process would have been more favorable by reason of a plea to a lesser charge or a sentence of less prison time." In short, the Court did not focus solely on whether the defendant would have accepted the plea. It instead required the defendant to show that the ultimate outcome would have been different.

Finally, the Court's decision in Lafler v. Cooper is to the same effect. In that case, the Court concluded that counsel may be constitutionally ineffective by causing a defendant to reject a plea deal he should have accepted. The Court again emphasized that the prejudice inquiry requires a showing that the criminal prosecution would ultimately have ended differently for the defendant - not merely that the defendant would have accepted the deal. The Court stated that the defendant in those circumstances "must show" a reasonable probability that "the conviction or sentence, or both, under the offer's terms would have been less severe than under the judgment and sentence that in fact were imposed."

These precedents are consistent with our cases governing the right to effective assistance of counsel in other contexts. This Court has held that the right to effective counsel applies to all "critical stages of the criminal proceedings." Those stages include not only "the entry of a guilty plea," but also "arraignments, postindictment interrogation, and postindictment lineups." In those circumstances, the Court has not held that the prejudice inquiry focuses on whether that stage of the proceeding would have ended differently. It instead has made clear that the prejudice inquiry is the same as in Strickland, which requires a defendant to establish that he would have been better off in the end had his counsel not erred. 
The majority misapplies this Court's precedents when it concludes that a defendant may establish prejudice by showing only that "he would not have pleaded guilty and would have insisted on going to trial," without showing that "the result of that trial would have been different than the result of the plea bargain." In reaching this conclusion, the Court relies almost exclusively on the single line from Hill that "the defendant must show that there is a reasonable probability that, but for counsel's errors, he would not have pleaded guilty and would have insisted on going to trial." For the reasons explained above, that sentence prescribes the threshold showing a defendant must make to establish Strickland prejudice where a defendant has accepted a guilty plea. In Hill, the Court concluded that the defendant had not made that showing, so it rejected his claim. The Court did not, however, further hold that a defendant can establish prejudice by making that showing alone.

The majority also relies on a case that arises in a completely different context, Roe v. FloresOrtega. There, the Court considered a defendant's claim that his attorney failed to file a notice of appeal. The Court observed that the lawyer's failure to file the notice of appeal "arguably led not to a judicial proceeding of disputed reliability," but instead to "the forfeiture of a proceeding itself." The Court today observes that petitioner's guilty plea meant that he did not go to trial. Because that trial "never took place," the Court reasons, we cannot "apply a strong presumption of reliability" to it. And because the presumption of reliability does not apply, we may not depend on Strickland's statement "that a defendant has no entitlement to the luck of a lawless decisionmaker." This point is key to the majority's conclusion that petitioner would have chosen to gamble on a trial even though he had no viable defense.

The majority's analysis, however, is directly contrary to Hill, which instructed a court undertaking a prejudice analysis to apply a presumption of reliability to the hypothetical trial that would have occurred had the defendant not pleaded guilty. After explaining that a court should engage in a predictive inquiry about the likelihood of a defendant securing a better result at trial, the Court said: "As we explained in Strickland $v$. Washington, these predictions of the outcome at a possible trial, where necessary, should be made objectively, without regard for the "idiosyncrasies of the particular decisionmaker."' That quote comes from the same paragraph in Strickland as the discussion about the presumption of reliability that attaches to the trial. In other words, Hill instructs that the prejudice inquiry must presume that the foregone trial would have been reliable.

The majority responds that Hill made statements about presuming a reliable trial only in "discussing how courts should analyze predictions of the outcome at a possible trial," which "will not always be necessary." I agree that such an inquiry is not always necessary - it is not necessary where, as in Hill, the defendant cannot show at the threshold that he would have rejected his plea and chosen to go to trial. But that caveat says nothing about the application of the presumption of reliability when a defendant can make that threshold showing. 
In any event, the Court in Hill recognized that guilty pleas are themselves generally reliable. Guilty pleas "rarely" give rise to the "concern that unfair procedures may have resulted in the conviction of an innocent defendant." That is because "a counseled plea of guilty is an admission of factual guilt so reliable that, where voluntary and intelligent, it quite validly removes the issue of factual guilt from the case." Guilty pleas, like completed trials, are therefore entitled to the protections against collateral attack that the Strickland prejudice standard affords.

Finally, the majority does not dispute that the prejudice inquiry in Frye and Lafler focused on whether the defendant established a reasonable probability of a different outcome. The majority instead distinguishes those cases on the ground that they involved a defendant who did not accept a guilty plea. According to the majority, those cases "articulated a different way to show prejudice, suited to the context of pleas not accepted." But the Court in Frye and Lafler (and Hill, for that matter) did not purport to establish a "different" test for prejudice. To the contrary, the Court repeatedly stated that it was applying the "same two-part standard" from Strickland.

The majority today abandons any pretense of applying Strickland to claims of ineffective assistance of counsel that arise at the plea stage. It instead concludes that one standard applies when a defendant goes to trial (Strickland); another standard applies when a defendant accepts a plea (Hill); and yet another standard applies when counsel does not apprise the defendant of an available plea or when the defendant rejects a plea (Frye and Lafler). That approach leaves little doubt that the Court has "opened a whole new field of constitutionalized criminal procedure" - "plea-bargaining law" - despite its repeated assurances that it has been applying the same Strickland standard all along. In my view, we should take the Court's precedents at their word and conclude that "an error by counsel does not warrant setting aside the judgment of a criminal proceeding if the error had no effect on the judgment."

III

Applying the ordinary Strickland standard in this case, I do not think a defendant in petitioner's circumstances could show a reasonable probability that the result of his criminal proceeding would have been different had he not pleaded guilty. Petitioner does not dispute that he possessed large quantities of illegal drugs or that the Government had secured a witness who had purchased the drugs directly from him. In light of this "overwhelming evidence of guilt," the Court of Appeals concluded that petitioner had "no bona fide defense, not even a weak one." His only chance of succeeding would have been to "throw a 'Hail Mary' at trial." As I have explained, however, the Court in Strickland expressly foreclosed relying on the possibility of a "Hail Mary" to establish prejudice. Strickland made clear that the prejudice assessment should "proceed on the assumption that the decisionmaker is reasonably, conscientiously, and impartially applying the standards that govern the decision."

In the face of overwhelming evidence of guilt and in the absence of a bona fide defense, a reasonable court or jury applying the law to the facts of this case would find the defendant guilty. There is no reasonable probability of any other verdict. A defendant in petitioner's shoes, therefore, would have suffered the same deportation consequences regardless of whether he 
accepted a plea or went to trial. He is thus plainly better off for having accepted his plea: had he gone to trial, he not only would have faced the same deportation consequences, he also likely would have received a higher prison sentence. Finding that petitioner has established prejudice in these circumstances turns Strickland on its head.

\section{IV}

The Court's decision today will have pernicious consequences for the criminal justice system. This Court has shown special solicitude for the plea process, which brings "stability" and "certainty" to "the criminal justice system." The Court has warned that "the prospect of collateral challenges" threatens to undermine these important values. And we have explained that "prosecutors must have assurance that a plea will not be undone years later," lest they "forgo plea bargains that would benefit defendants," which would be "a result favorable to no one."

The Court today provides no assurance that plea deals negotiated in good faith with guilty defendants will remain final. For one thing, the Court's artificially cabined standard for prejudice in the plea context is likely to generate a high volume of challenges to existing and future plea agreements. Under the majority's standard, defendants bringing these challenges will bear a relatively low burden to show prejudice. Whereas a defendant asserting an ordinary claim of ineffective assistance of counsel must prove that the ultimate outcome of his case would have been different, the Court today holds that a defendant who pleaded guilty need show only that he would have rejected his plea and gone to trial. This standard does not appear to be particularly demanding, as even a defendant who has only the "smallest chance of success at trial" - relying on nothing more than a "Hail Mary" - may be able to satisfy it. For another, the Court does not limit its holding to immigration consequences. Under its rule, so long as a defendant alleges that his counsel omitted or misadvised him on a piece of information during the plea process that he considered of "paramount importance," he could allege a plausible claim of ineffective assistance of counsel.

In addition to undermining finality, the Court's rule will impose significant costs on courts and prosecutors. Under the Court's standard, a challenge to a guilty plea will be a highly factintensive, defendant-specific undertaking. Petitioner suggests that each claim will "at least" require a "hearing to get the facts on the table." Given that more than 90 percent of criminal convictions are the result of guilty pleas, the burden of holding evidentiary hearings on these claims could be significant. In circumstances where a defendant has admitted his guilt, the evidence against him is overwhelming, and he has no bona fide defense strategy, I see no justification for imposing these costs.

\section{Questions:}

1. Does an ineffective assistance of counsel claim more closely resemble a breach of the duty of care or a breach of the duty of loyalty?

2. Is there a difference between a lawyer making a bad decision and a lawyer providing inaccurate advice? Should there be? 
3. Should courts apply the "case within a case" doctrine to ineffective assistance of counsel claims?

4. The dissent argues that guilty pleas are reliable. But scholarship suggests that they are not. Should this affect the analysis of ineffective assistance of counsel claims in relation to plea bargains?

\section{Malpractice in Criminal Cases}

Criminal defense attorneys who provide negligent representation may also be liable to their clients in tort for malpractice. However, most courts have adopted a different standard for evaluating malpractice claims in civil and criminal representation, holding that criminal defendants can recover for malpractice only if they prove "actual innocence." In other words, where civil clients only have to prove that they would have won in order to recover in a legal malpractice action, criminal clients have to prove that they were entitled to win on the merits.

Ang v. Martin, 114 P. 3d 637 (Wash. 2005)

Summary: Jessy and Editha Ang provided medical services to the State of Washington, and were indicted for social security fraud, among other things. The Angs hired attorneys Richard Hansen and Michael G. Martin, who advised them to accept a plea bargain. After accepting the plea bargain, the Angs hired attorney Monte Hester, who advised them to withdraw it. Eventually, the Angs were acquitted. The Angs filed a legal malpractice action against Hansen and Martin. The trial court instructed the jury that the Angs could recover only if they proved "actual innocence," and the jury found they did not. The Angs appealed, arguing that acquittal is actual innocence, but the Court of Appeals and Supreme Court affirmed.

OWENS, J.

We are asked to determine whether plaintiffs in a malpractice action against their former criminal defense attorneys were properly required to prove by a preponderance of the evidence that they were actually innocent of the underlying criminal charges. The Court of Appeals concluded that, as an element of their negligence claim, plaintiffs were required "to prove innocence in fact and not merely to present evidence of the government's inability to prove guilt." We affirm the Court of Appeals.

\section{FACTS}

Psychiatrist Jessy Ang and his wife Editha jointly owned Evergreen Medical Panel, Inc., a company that provided the Washington State Department of Labor and Industries with independent medical examinations of injured workers. As a result of Dr. Ang's contact with a target of a governmental task force investigating social security fraud, Dr. Ang himself became a person of interest. In February 1994, the task force executed a search warrant on Dr. Ang's office and seized copies of two sets of signed tax returns that reported conflicting amounts of 
income. The Angs were arrested in April 1996, following the execution of a search warrant at their residence. A year later, the Angs were indicted on 18 criminal counts, including conspiracy to defraud the United States, bank and tax fraud, and filing false statements.

The Angs retained defendants Richard Hansen and Michael G. Martin for flat fees of $\$ 225,000$ and $\$ 100,000$, respectively. Attorneys Hansen and Martin engaged in a round of plea negotiations prior to trial, but the Angs rejected the plea bargain. The case proceeded to a jury trial before Judge Tanner in federal district court in December 1997. On the fifth day of trial, just prior to the conclusion of the government's case, Hansen and Martin recommended that the Angs accept another proffered plea, one that the Angs viewed as the least attractive of any agreement previously presented. After Dr. Ang was allegedly told that Mrs. Ang could face sexual assault in prison, the Angs agreed to plead guilty to two of the 18 counts.

The Angs then engaged attorney Monte Hester to review the plea discussions and provide a second opinion. Hester concluded that the government had not met its burden of proof and that the plea agreement provided the Angs with no material benefit. Retaining Hester and Keith A. MacFie to represent them, the Angs successfully moved to withdraw the pleas, which Judge Tanner had never formally accepted. In September 1999, the matter again proceeded to trial before Judge Tanner, with the Angs waiving their right to a jury. Although the government offered another plea bargain prior to trial, one requiring no plea on Dr. Ang's part, a misdemeanor or felony for Mrs. Ang, and a $\$ 500,000$ fine, the Angs rejected the plea and were acquitted on all 18 counts.

The Angs, along with Evergreen Medical, filed the present legal malpractice action against Hansen and Martin in May 2000 in Pierce County Superior Court. The complaint stated claims for legal malpractice and for violations of the Washington Consumer Protection Act. The trial court denied the defendants' motion for summary judgment, and a jury trial began in November 2001. The trial court instructed the jury that the Angs had to prove by a preponderance of the evidence that they were innocent of the underlying criminal charges. On January 11, 2002, responding to the initial two questions on a special verdict form, the jury found that the Angs had not "proven by a preponderance of the evidence they were innocent of all the criminal charges against them." As to the verdict form's third question, asking whether "any of the defendants had been negligent," the jury made a finding of negligence against Martin only.

The plaintiffs appealed, but the Court of Appeals affirmed. This court granted the plaintiffs' petition for review.

\section{ISSUES}

Where a legal malpractice suit stems from the representation of clients in a criminal prosecution, must plaintiffs who were acquitted of the criminal charges prove their actual innocence of the crimes, or does their acquittal satisfy the innocence element of their malpractice action? 
Essential Elements of Legal Malpractice Claims against Criminal Defense Counsel. A plaintiff claiming negligent representation by an attorney in a civil matter bears the burden of proving four elements by a preponderance of the evidence:

(1) The existence of an attorney-client relationship which gives rise to a duty of care on the part of the attorney to the client; (2) an act or omission by the attorney in breach of the duty of care; (3) damage to the client; and (4) proximate causation between the attorney's breach of the duty and the damage incurred.

The fourth element, proximate causation, includes "cause in fact and legal causation." Cause in fact, or "but for" causation, refers to "the physical connection between an act and an injury." In a legal malpractice trial, the "trier of fact will be asked to decide what a reasonable jury or fact finder in the underlying trial or 'trial within the trial' would have done but for the attorney's negligence." Legal causation, however, presents a question of law: "It involves a determination of whether liability should attach as a matter of law given the existence of cause in fact." To determine whether the cause in fact of a plaintiff's harm should also be deemed the legal cause of that harm, a court may consider, among other things, the public policy implications of holding the defendant liable. In "criminal malpractice" suits, two elements related to proximate causation have been added. In Falkner v. Foshaug, the Court of Appeals "concluded that postconviction relief is a prerequisite to maintaining a criminal malpractice suit and proof of innocence is an additional element a criminal defendant/malpractice plaintiff must prove to prevail at trial in his legal malpractice action."

The trial court in the present case thus instructed the jury as follows on the elements of the Angs criminal malpractice claims:

To prove their legal malpractice claims, the plaintiffs bear the burden of proving by a preponderance of the evidence each of the following:

First, that there is an attorney-client relationship giving rise to a duty owed by a defendant to a plaintiff;

Second, that plaintiffs have obtained a successful challenge to their convictions based on their attorneys failure to adequately defend them;

Third, that plaintiff was innocent of the crimes charged;

Fourth, that there is an act of omission by a defendant that breached the duty of care of an attorney;

Fifth, that a plaintiff was damaged; and

Sixth, that a breach of duty by a defendant is a proximate cause of a plaintiff's damages.

The Angs assigned error to this instruction, contending that their undisputed acquittal of the criminal charges met not only the additional element of postconviction relief but also the innocence requirement. 
By successfully withdrawing their guilty pleas and receiving an acquittal on all charges, the Angs unquestionably received the equivalent of postconviction relief, but contrary to their contention, they did not thereby satisfy the innocence requirement. The Angs mistakenly claim that they were simply required to prove legal innocence, not actual innocence." Legal guilt or innocence is that determination made by the trier of fact in a criminal trial," whereas "actual guilt is intended to refer to a determination in a civil trial, by a preponderance of the evidence, that the defendant engaged in the conduct he was accused of in the prior criminal proceeding." But the Falkner court referred explicitly to the "actual innocence requirement" and at no point equated the innocence requirement with legal innocence. Plainly, a requirement of legal innocence would have been redundant alongside the additional, unchallenged requirement of postconviction relief and would have necessitated a confusing overlay of standards of proof, requiring the malpractice jury to consider whether the Angs had proved by a preponderance of the evidence that they would not have been found guilty beyond a reasonable doubt in the underlying criminal trial.

Moreover, proving actual innocence, not simply legal innocence, is essential to proving proximate causation, both cause in fact and legal causation. Unless criminal malpractice plaintiffs can prove by a preponderance of the evidence their actual innocence of the charges, their own bad acts, not the alleged negligence of defense counsel, should be regarded as the cause in fact of their harm. Likewise, if criminal malpractice plaintiffs cannot prove their actual innocence under the civil standard, they will be unable to establish, in light of significant public policy considerations, that the alleged negligence of their defense counsel was the legal cause of their harm. Summarizing the policy concerns, the Falkner court observed that, "requiring a defendant to prove by a preponderance of the evidence that he is innocent of the charges against him will prohibit criminals from benefiting from their own bad acts, maintain respect for our criminal justice systems procedural protections, remove the harmful chilling effect on the defense bar, prevent suits from criminals who may be guilty, but could have gotten a better deal, and prevent a flood of nuisance litigation."

In the alternative, the Angs argue that, if a plaintiff's actual guilt or innocence has any place in a criminal malpractice suit, the issue should be raised as an affirmative defense, not as an element of the plaintiffs cause of action. The Angs find support in Shaw II, the only decision adopting the actual innocence requirement and shifting to the criminal malpractice defendant "the burden of proof by a preponderance of the evidence as to the actual guilt of the plaintiff." As respondent Martin explained, however, "the criminal defendant/malpractice plaintiff is in a far better position to bear the burden of establishing innocence," since, unlike his defense attorney, he "knows if he is actually innocent," "was, presumably, present or involved in the underlying events which led to the criminal charges," "has unlimited access to the information about his own acts necessary to prove innocence," "would know what, if any, inculpatory facts he withheld from his lawyer," and would have the "opportunity to accept a plea, potentially an Alford plea which could preserve his malpractice claim, before all facts and witness testimony have been developed or are known to his or her attorney." We find this practical analysis persuasive and thus decline to adopt the minority position of Shaw II. 
In sum, we conclude that the Angs were properly required to prove by a preponderance of the evidence that they were actually innocent of the underlying criminal charges. We therefore affirm the Court of Appeals.

\section{CONCLUSION}

We conclude that, as plaintiffs in a criminal malpractice action, the Angs were properly required to prove by a preponderance of the evidence that they were actually innocent of the underlying criminal charges. We find no persuasive reasons for this court to follow the minority position and shift the burden to the defendant attorneys to prove that their former clients were actually guilty of the charged crimes.

C. JOHNSON, MADSEN, BRIDGE and FAIRHURST, JJ., concur.

\section{SANDERS, J. (dissenting).}

I dissent because the malpractice standard for criminal cases should be the same as civil. There is no reason to invite malpractice in criminal cases by heightening the plaintiff's burden to prove postconviction relief and actual innocence. In every situation a client should rightfully expect competent legal representation.

We have clearly stated the standard for legal malpractice:

To establish a claim for legal malpractice, a plaintiff must prove the following elements: (1) The existence of an attorney-client relationship which gives rise to a duty of care on the part of the attorney to the client; (2) an act or omission by the attorney in breach of the duty of care; (3) damage to the client; and (4) proximate causation between the attorney's breach of the duty and the damage incurred.

This rule does not suggest the additional requirements the majority adds to cases of criminal malpractice, namely, postconviction relief and proof of actual innocence. I see no reason to add them.

The majority cites a Court of Appeals case, Falkner v. Foshaug, to support additional elements. The Court of Appeals opinion Falkner is not binding authority, nor is case law from other jurisdictions upon which Falkner is based. Nor am I persuaded by its logic. Attorneys who negligently represent their clients should be responsible for any harm that results from the misconduct. It does not matter if the subject matter of the case is civil or criminal. Forcing criminal defendants to prove actual innocence does not serve any purpose except to frustrate the client's right to competent representation.

Citing a "public policy" present in the minds of the individuals in the majority, the majority argues the defendant's acts should be viewed as the cause of any harm unless he demonstrates his 
innocence. However, our constitution sets the "public policy" which entitles criminal defendants to adequate representation. I prefer that policy as my guide.

The issue is causation. Under our precedent, cause in fact is determined by the jury as a question of fact. Cause in fact is a minimum threshold that asks but for the lawyer's negligence would the client have been harmed. In other words, would the result be different if the lawyer had used reasonable care?

Legal causation is a subsequent inquiry, asking as a matter of law whether liability should attach. The majority argues a criminal defendant should not profit from his crimes, and hence the defense attorney should not be liable for his negligence unless the defendant first proves his own innocence. I disagree. The criminal defendant is equally entitled to competent representation, and the negligent attorney should take responsibility for his malpractice. The majority's rule simply invites malpractice since the defense attorney knows he is held to a lower standard. Proving innocence is impossible since a negative cannot be proved.

Here the Angs's defense attorneys, Michael Martin and Richard Hansen, recommended a particular plea agreement. The Angs initially agreed but later withdrew the plea on recommendation from new counsel and were acquitted on all charges at a subsequent trial. They sued their former defense attorneys and a jury found that Martin alone was negligent even though it found the Angs had not proved their innocence by a preponderance of the evidence. Since the latter consideration should be irrelevant, Martin should bear the responsibility for his negligence. I would reverse as to Martin, and remand for a trial on damages.

ALEXANDER, C.J. (concurring in dissent).

I agree with Justice Sanders that the trial court erred in instructing the jury that Jessy and Editha Ang had to prove that they were actually innocent of the crime charged in order to prevail in their legal malpractice claim against attorneys Richard Hansen and Michael Martin. For that reason, we should reverse the Court of Appeals and remand to the trial court for a new trial on the Angs' claim against Martin.

I write separately because, in my view, we should not stop with a determination that the trial court erred but should go further to indicate that the defendant attorney may raise the issue of the plaintiff's actual guilt in the criminal case as an affirmative defense. That was the position taken by the Supreme Court of Alaska in a similar case, Shaw v. Department of Administration. There, the court said that because plaintiffs in such actions must already bear the burden of proving that they have obtained postconviction relief from their criminal convictions, they should not have to prove their "actual innocence." The court went on to indicate, however, that the defendant may raise the issue of the plaintiff's "actual guilt" as an affirmative defense and seek to establish it by a preponderance of the evidence. Although the Alaska court did not engage in an extensive discussion of its reasons for placing the burden on the defendant to establish this affirmative defense, it did indicate that putting the burden there is consistent with the requirement that defendants establish traditional affirmative defenses that look to plaintiffs' 
actions such as contributory/comparative negligence and assumption of the risk. The Alaska rule makes perfect sense to me for that reason and for the additional reason that it is consonant with the traditional notion that one is presumed innocent until proven guilty beyond a reasonable doubt. Furthermore, shifting the burden to the defendant relieves the plaintiff of the almost impossible burden of proving innocence while at the same time addressing the policy concern noted by the majority, that criminals should not benefit from "their own bad acts."

IRELAND, J. Pro Tem., concurs.

CHAMBERS, J. (concurring in dissent).

I concur in Justice Sanders' dissent but write separately to express my indignation that this court, based upon the policy of protecting lawyers, would carve out a special protection for criminal defense attorneys whose acts of professional negligence are harmful to their clients. Under this logic, it is not enough for the injured client to prove actual harm from the attorney's failure to meet professional standards; the injured client must also prove that her hands were always clean. Under this logic, why not give immunity to accountants for professional negligence unless the accountant's client can prove he or she never understated income or requested an unavailable deduction, even when the accountants' bad acts caused actual harm to their clients or society? Surely tax dodgers should not profit from their misdeeds. Under this logic, why not give immunity to health care providers who harm their patients unless the patient can prove perfect good health but for the negligence of the provider? Surely the unhealthy should not profit from their illness.

But this logic ignores the fact that professionals owe a duty to the sick as well as the healthy; to the scrupulously honest business woman as well as the one looking for the angle; to the guilty as well as the innocent. Those of us caught in the grip of the law are always entitled to competent legal representation whether or not we are totally innocent. The heart of the criminal defense lawyer's job is often not to prove absolute innocence; the irreducible core of the job is to make the state prove its case and make the best case for the defendant possible. Often the sole issue is the level of culpability and the sanction to be imposed upon the client. The government may seek multiple counts where a single count is appropriate, seek charges of a higher degree than the evidence supports, or seek a sentence disproportionate to the offense. The negligence of her lawyer may cost her client her fortune, her liberty, or her life. The "actual innocence" requirement is impractical and harmful in the area of criminal malpractice law; it creates an almost impossible burden and provides almost absolute immunity to criminal defense lawyers.

The most troubling aspect of the actual innocence requirement announced by the majority lies with its origin. It is based upon a policy to protect lawyers from lawsuits. Tort actions are maintained for a variety of reasons, including the deterrence of wrongful conduct. As a matter of basic policy, accountability, compensation, and deterrence of wrongful conduct should trump protecting lawyers from lawsuits. 
Second, while it may be true that a majority of courts that have reached the issue require the plaintiff to establish actual innocence, the numbers do not appear to be great. Only Missouri, New York, Massachusetts, Alaska, Pennsylvania, California, New Hampshire, Nebraska, Illinois, Florida, and Wisconsin require either proof of actual innocence or that the conviction was set aside on postconviction relief. This is hardly a national consensus.

This court should protect the public from lawyers' misdeeds, not the other way around. A plaintiff who is not categorically innocent seeking compensation under ordinary principles of tort law faces no light burden. Such a guilty plaintiff must prove a duty, a breach of that duty, injuries proximately caused by the breach, and the amount of his damages. I see no reason to provide additional protections for lawyers.

\section{Questions:}

1. Is the "actual innocence" requirement imposed by the court similar to the "case within a case" doctrine? Does it requirement a criminal defendant to prove more?

2. Should a criminal defendant be required to prove actual innocence in order to show malpractice? Can a criminal defense lawyer provide negligent representation to a guilty client?

3. The majority is concerned about the possibility of criminals "benefiting from their own bad acts." What is the benefit in question?

4. Criminal defense attorneys are often appointed counsel. Should that affect the standard of care? Should it affect the standard for evaluating whether they have provided negligent representation? Should the standard for malpractice differ depending on whether the client is paying for representation? 


\section{Section 4: Conflicts of Interest}

\section{1: Identifying Conflicts of Interest}

I can't believe you had a life before me. I can't believe they let you run around free, just putting your body wherever it seemed like a good idea. ${ }^{40}$

\section{What is a Conflict of Interest?}

Attorneys must always watch for and avoid "conflicts of interest." A conflict of interest exists whenever an attorney may have to choose between the interests of a client and some other interest. Under the fiduciary duty of loyalty, attorneys must always put the interests of their clients before any other interests, including their own. Accordingly, a conflict of interest exists whenever the interests of a client differ from the interests of another client, the attorney, or a third party with a relationship to the attorney.

Broadly speaking, there are four categories of conflicts of interest, e.g. conflicts between the interests of a client and:

1. the lawyer's own interests

2. the lawyer's duties to another client

3. the lawyer's duties to a former client

4. the lawyer's duties to a third person.

The conflict of interest rules are intended to ensure that attorneys observe the duty of loyalty, by preventing them from representing clients with competing interests.

However, the term "conflict of interest" is hard to define with any precision, because the concept of a conflict of interest is both procedural and substantive, reflecting the intersection of formal rules and normative values. Not every formal conflict of interest presents a real conflict of interest. Some conflicts are trivial, and do not create a substantial concern. Others are merely speculative, and do not require analysis.

Formally, a conflict of interests exists whenever an attorney's legal duties to a client actually or potentially conflict with the interests of the attorney, another actual or potential client, or a third party to whom the attorney has a legal duty. But substantively, perhaps not every formal conflict of interest should necessarily qualify as an actual conflict of interest. Many are trivial, and many more will never materialize. If a formal conflict does not present a substantive conflict, is it really a conflict at all?

Ultimately, the definition of a conflict of interest depends on the purpose of the conflicts rules. If the purpose of the rules is to protect clients from their attorneys, then perhaps the rules should

${ }^{40}$ Liz Phair, Jealousy, Whip-Smart (1994). 
be interpreted and applied literally, in order to ensure that unscrupulous attorneys cannot avoid regulation. But if the purpose of the rules is to govern a business relationship between clients and their attorneys, then perhaps the rules should be interpreted and applied more flexibly, in order to help parties reach a mutually agreeable outcome.

\section{ABA Canons of Professional Ethics: Canon 6 (1908)}

It is the duty of the lawyer at the time of retainer to disclose to the client all the circumstances of his relations to the parties, and any interest in or connection with the controversy, which might influence the client in the selection of counsel.

It is unprofessional to represent conflicting interests, except by express consent of all concerned given after a full disclosure of the facts. Within the meaning of this canon, a lawyer represents conflicting interests when, on behalf of one client, it is his duty to contend for that which duty to another client requires him to oppose.

The obligation to represent the client with undivided fidelity forbids also the subsequent acceptance of retainers or employment from others in matters adversely affecting any interest of the client with respect to which confidence has been reposed.

\section{ABA Model Code of Professional Responsibility (1980)}

Canon 5: A Lawyer Should Exercise Independent Professional Judgment on Behalf of a Client

The professional judgment of a lawyer should be exercised, within the bounds of the law, solely for the benefit of his client and free of compromising influences and loyalties. Neither his personal interests, the interests of other clients, nor the desires of third persons should be permitted to dilute his loyalty to his client.

\section{Model Rule 1.7: Conflict of Interest: Current Clients}

a. Except as provided in paragraph (b), a lawyer shall not represent a client if the representation involves a concurrent conflict of interest. A concurrent conflict of interest exists if:

1. the representation of one client will be directly adverse to another client; or

2. there is a significant risk that the representation of one or more clients will be materially limited by the lawyer's responsibilities to another client, a former client or a third person or by a personal interest of the lawyer.

b. Notwithstanding the existence of a concurrent conflict of interest under paragraph (a), a lawyer may represent a client if:

1. the lawyer reasonably believes that the lawyer will be able to provide competent and diligent representation to each affected client;

2. the representation is not prohibited by law; 
3. the representation does not involve the assertion of a claim by one client against another client represented by the lawyer in the same litigation or other proceeding before a tribunal; and

4. each affected client gives informed consent, confirmed in writing.

\title{
Restatement (Third) of the Law Governing Lawyers $\S 121:$ The Basic Prohibition of Conflicts of Interest
}

A conflict of interest is involved if there is a substantial risk that the lawyer's representation of the client would be materially and adversely affected by the lawyer's own interests or by the lawyer's duties to another current client, a former client, or a third person.

\section{Glueck v. Jonathan Logan, Inc., 653 F. 2d 746 (2d Cir. 1981)}

\begin{abstract}
Summary: Jonathan Logan, Inc. fired Charles Glueck, who hired Phillips Nizer to represent him in a wrongful termination action. Logan filed a motion to disqualify Phillips Nizer because the firm represented the Apparel Manufacturers Association, Inc., a membership organization that includes one of Logan's divisions. The district court granted the motion, because the relationship between Phillips Nizer and Logan resembled an attorney-client relationship, and the subject matter of Glueck's action was "substantially related" to Phillips Nizer's representation of the Association. The circuit court affirmed, because representing both Glueck and the Association would create a "realistic risk" of Phillips Nizer breaching its duty of loyalty.
\end{abstract}

NEWMAN, Circuit Judge:

The issue on this appeal is whether in the circumstances of this case a law firm that represents an incorporated trade association may represent an individual client in a suit against a corporation one division of which is a member of the association. The District Court for the Southern District of New York ruled that the firm must be disqualified. We conclude that Judge Conner applied the correct standards of law and reached a result well within his discretion, and we therefore affirm.

The appellant, Charles Glueck, formerly employed as an executive of appellee Jonathan Logan, Inc., brought this suit against Logan, alleging that he was discharged in breach of his employment contract. Logan promptly moved to disqualify Glueck's law firm, Phillips, Nizer, Benjamin, Krim \& Ballon. The motion was based on the following undisputed facts. Phillips Nizer represents the Apparel Manufacturers Association, Inc., a not-for-profit incorporated trade association of dress manufacturers with more than 100 members. The sole function of the Association is to negotiate multi-employer collective bargaining agreements on behalf of its members with employees represented by the International Ladies Garment Workers' Union. One of the Association's members is R \& K Originals, a division of Logan. The division's president, Manny Eagle, is executive vice-president of the Association and a member of the 
Association's negotiating committee. Eagle has had occasion to meet with lawyers from Phillips Nizer and discuss labor matters with them. On these facts, Judge Conner granted appellee's motion to disqualify Phillips Nizer from representing Glueck in his suit against Logan. From that ruling, Glueck appeals.

Recognizing the serious impact of attorney disqualification on the client's right to select counsel of his choice, we have indicated that such relief should ordinarily be granted only when a violation of the Canons of the Code of Professional Responsibility poses a significant risk of trial taint. That risk is encountered when an attorney represents one client in a suit against another client, in violation of Canon 5 , or might benefit a client in a lawsuit by using confidential information about an adverse party obtained through prior representation of that party, in violation of Canon 4. Mindful of our standards, the parties have joined issue on whether Logan is a client of Phillips Nizer by virtue of the firm's representation of the Association. Glueck contends that members of an incorporated trade association are not clients of the association's lawyer and emphasizes that the retainer agreement between Phillips Nizer and the Association explicitly negates the firm's representation of the Association's members. Logan responds that the members of an incorporated association are the clients of the association's lawyer and argues that Phillips Nizer's retainer agreement only assures it the right to charge separate fees for legal work done specifically for an Association member.

We share Judge Conner's view that the issue is not whether Phillips Nizer's relationship to Logan is in all respects that of attorney and client, but whether there exist sufficient aspects of an attorney-client relationship "for purposes of triggering inquiry into the potential conflict involved in Phillips Nizer's role as plaintiff's counsel in this action." ${ }^{41}$ Having concluded that such inquiry should be made, Judge Conner then applied the strict standards that ordinarily prohibit representation of adverse interests, and determined that, in view of the relationship between the subject of Glueck's lawsuit and the nature of the services rendered by Phillips Nizer to the Association and its members, Phillips Nizer had not demonstrated "that there will be no actual or apparent conflict in loyalties or diminution in the vigor of its representation."

We reach the same conclusion, but analyze the issue in a slightly different way. We do not believe the strict standards are inevitably invoked whenever a law firm brings suit against a member of an association that the firm represents. If they were, many lawyers would be needlessly disqualified because the standards of Canon 5 impose upon counsel who seeks to avoid disqualification a burden so heavy that it will rarely be met. That burden is properly imposed when a lawyer undertakes to represent two adverse parties, both of which are his clients in the traditional sense. But when an adverse party is only a vicarious client by virtue of membership in an association, the risks against which Canon 5 guards will not inevitably arise. A law firm that represents the American Bar Association need not decline to represent a client injured by an automobile driven by a member of the ABA. Moreover, if Canon 5 were applicable to all suits against association members, there would be a temptation to water down the strict standards of Canon 5 and find them met more easily than in cases where the adverse parties

\footnotetext{
${ }^{41}$ We have previously held the standards of Canon 5 to be applicable even though the interests adverse to those of a law firm's client are not those of another client in the traditional sense.
} 
are really clients of the same lawyer. In this case, Judge Conner, after finding Canon 5 applicable, applied what amounted to a "substantial relationship" test, and concluded that the subject of Glueck's lawsuit was substantially related to Phillips Nizer's representation of the Association. However, "the 'substantial relationship' test does not set a sufficiently high standard by which the necessity for disqualification under Canon 5 should be determined." We think the standards of Canon 5 should be strict. We also believe those standards should apply to suits against association members only when the risks against which Canon 5 protects are likely to arise.

This approach leads us to use the "substantial relationship" test in determining when Canon 5 should be applied to suits brought by an association's law firm against an association member. Disqualification will ordinarily be required whenever the subject matter of a suit is sufficiently related to the scope of the matters on which a firm represents an association as to create a realistic risk either that the plaintiff will not be represented with vigor or that unfair advantage will be taken of the defendant. Moreover, although our concern is with the risk of tainting a trial, once that risk appears, it is appropriate to assess the risk that prosecution of a plaintiff's lawsuit by an association's law firm will inhibit the free flow of information from the defendant to the firm that is necessary for the firm's proper representation of the association.

Though structured in a slightly different framework, ${ }^{42}$ Judge Conner's findings fully justify disqualification under the approach we have outlined. Judge Conner relied upon the risk that the issue of whether Logan had cause to terminate Glueck might well arise in the course of collective bargaining discussions conducted by Phillips Nizer for the Association. He also noted the risk that in preparing for collective bargaining sessions, the law firm might learn of Logan's policies or past practices bearing on the subject of Glueck's termination. These risks demonstrate the requisite relationship between Glueck's lawsuit and the subject matter of Phillips Nizer's representation of the Association. Because of that relationship, the strict standards apply, ${ }^{43}$ and we agree with Judge Conner that appellant has not sustained the heavy burden of demonstrating that, under those standards, disqualification can be avoided. The entry of an order of disqualification was well within the proper exercise of discretion by the District Court. ${ }^{44}$ The order is affirmed.

\footnotetext{
42 Judge Conner, in effect, used the "substantial relationship" test to determine whether Phillips Nizer had met its burden under Canon 5; we use the test to determine whether Canon 5 is applicable.

${ }^{43}$ We reject the appellant's contention that the result reached by Judge Conner is foreclosed by Board of Education v. Nyquist. That decision concerned a lawyer who represented male teachers in litigation adverse to the interests of female teachers, under circumstances where the lawyer was supplied to the male teachers pursuant to a legal service program supported in part by the union dues of both the male and female teachers. A disqualification order was reversed for lack of any risk that the lawyer's loyalty to his male clients would be diminished or that he might gain unfair advantage through access to any privileged information from the female teachers.

${ }^{44}$ We reject, as did Judge Conner, the appellant's contention that disqualification should not occur because Logan's division, $\mathrm{R} \& \mathrm{~K}$ Originals, is a member of the Association, rather than Logan itself. The risks identified by Judge Conner are sufficient to warrant disqualification even though only Logan's division is a member of the Association. Nor do we accept the contention that it will be unduly burdensome for law firms that represent trade associations to inform themselves of the corporate identity of those members of an association that are constituent parts of a non-member corporation.
} 


\section{Questions:}

1. Why did Phillips Nizer have a conflict of interest?

2. Why did the district court disqualify Phillips Nizer? Why did the circuit court disqualify Phillips Nizer? How did their reasoning differ, if at all?

3. The court distinguishes this case from Board of Education v. Nyquist. Do you find that distinction convincing?

4. If the Association kicked out Logan, would Phillips Nizer still have a conflict of interest or be disqualified?
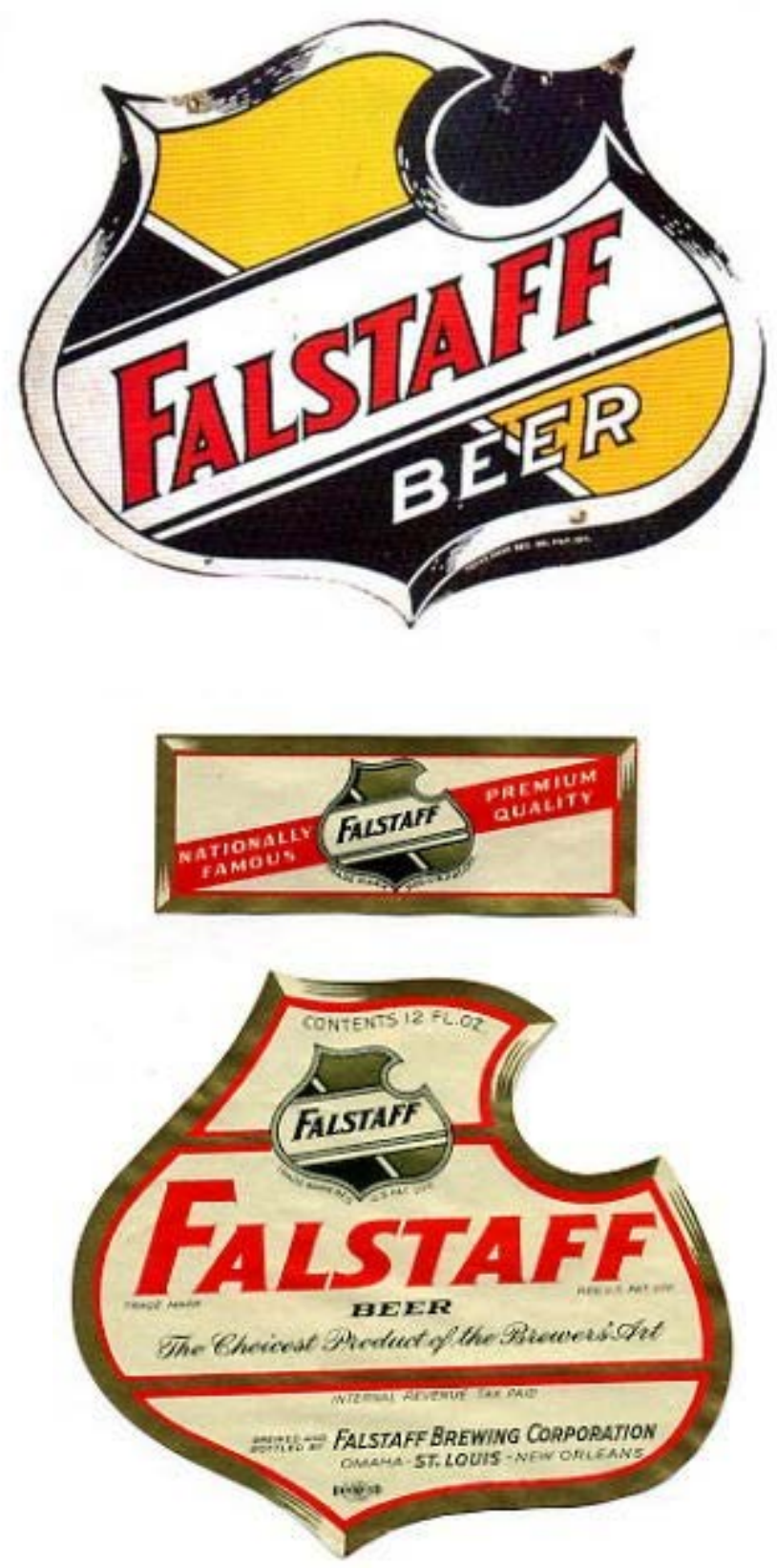
Gutting v. Falstaff Brewing Corp., 710 F. 2d 1309 (8th Cir. 1983)

Summary: Ferdinand Gutting was the president of Falstaff Brewing, which gave him a life insurance policy, payable unless he was discharged for proper cause. Paul Kalmanovitz bought Falstaff and fired Gutting, and when Gutting died, Falstaff refused to pay his life insurance benefits. Virginia Gutting filed a breach of contract claim, and hired attorney James $\mathrm{S}$. McClellan to represent her. Falstaff filed a motion to disqualify McClellan, on the ground that he had previously represented Falstaff. McClellan withdrew, and Gutting hired Harry B. Wilson. But Wilson also withdrew after identifying a conflict of interest, and Gutting hired David G. Dempsey. In the meantime. Falstaff filed a motion for summary judgment, arguing that Gutting had admitted all of the facts alleged in its complaint by failing to timely answer its request for admissions. The district court granted the motion, but the circuit court reversed, holding that the district court should have considered the disqualification of Gutting's counsel.

LAY, Chief Judge.

Virginia M. Gutting appeals from an order of the district court entering summary judgment in favor of Falstaff Brewing Corporation and denying her motion for summary judgment. Gutting's primary argument on this appeal is based on the claim that the district court erred in denying her motion for leave to file answers out of time to Falstaff's request for admissions and in ordering the matters set forth in the request deemed admitted. Because we conclude that the district court erred by not allowing Gutting to file late answers to the request for admissions, we reverse and remand.

Virginia Gutting is the widow of Ferdinand (Ferd) J. Gutting, former member of the Board of Directors and President of Falstaff. In 1972 Falstaff established an insurance plan for certain key employees. Pursuant to this plan, in January 1973, Ferdinand Gutting entered into a written agreement with Falstaff entitled Employee's Death Benefit Agreement. The purpose of the agreement was to provide for Falstaff's payment of a death benefit to Virginia Gutting, Ferd Gutting's designated payee. Falstaff purchased three life insurance policies on Ferd Gutting's life to secure this obligation. The agreement provided that all benefits would be forfeited if (1) the life insurance policies were contested successfully by the insurance company; (2) the employee left Falstaff's employment voluntarily, subject to certain vesting provisions; or (3) the employee was discharged "for proper cause."

In early 1975, Paul Kalmanovitz purchased voting control of Falstaff and became Chairman of the Board. Subsequently, for reasons in dispute in this lawsuit, Ferd Gutting's employment with Falstaff was terminated and the Board of Directors voted to deny Ferd Gutting all benefits because his termination was for cause. Ferd Gutting died in December 1980. Falstaff has refused to pay the amounts due to Virginia Gutting pursuant to the terms of the Employee's Death Benefit Agreement and she brought suit to recover the proceeds. Throughout this litigation Falstaff has asserted as an affirmative defense that Ferd Gutting was terminated for 
cause and thus forfeited all benefits due his beneficiary under the agreement. Virginia Gutting claims the termination was not for "proper cause" as that term is defined in the agreement.

Procedural History.

Virginia Gutting filed a complaint on July 8, 1981, through her attorney James S. McClellan. On September 30, 1981, Falstaff filed a motion to disqualify McClellan because he formerly had been a member of Falstaff's Board of Directors and outside general counsel to Falstaff. Falstaff asserted that McClellan had material, firsthand knowledge of events relevant to Falstaff's defense and that McClellan would likely be called as a witness. While the motion to disqualify was pending, on October 13, 1981, Falstaff filed its request for admissions, first interrogatories, and request for production of documents. ${ }^{45}$ Thereafter, the district court held a conference at which McClellan indicated he would withdraw voluntarily. On December 4, 1981, McClellan formally withdrew.

On December 11, 1981, Harry B. Wilson entered his appearance on behalf of Gutting. On January 4, 7, and 8, 1982, Falstaff served notices of 15 depositions to begin on February 8 in Providence, Rhode Island, and to continue throughout February and early March around the country. On January 7 counsel for Falstaff, Steven P. Sanders, sent a letter to Harry Wilson concerning the failure to respond to the request for admissions and asking for the answers. Wilson and Sanders discussed the request over the telephone several days later and Sanders agreed to wait an indefinite period of time.

According to an affidavit filed by Wilson he began to prepare for the upcoming depositions and to draft responses to discovery requests on January 29,1982 . Wilson further swore that on January 30 he concluded his firm had a serious conflict of interest because some of the scheduled deponents were current clients of the firm. These clients had on-going litigation matters with Falstaff. Wilson researched the nature of the conflict, discussed it with lead counsel in the case, and called Sanders on February 6, 1982, to inform him of the conflict of interest. On February 8 Wilson appeared before the district court and requested leave to withdraw. The motion evidently was pending throughout February and the scheduled depositions for February were postponed.

\footnotetext{
${ }^{45}$ Falstaff's request for admissions strategically concerned the major contested factual issue in the case of whether Ferd Gutting had been discharged for cause. The request stated in full:

1. Admit that the life insurance program set forth and discussed in your complaint allowed Falstaff to terminate all life insurance benefits with respect to any employee whose employment was terminated "for cause."

2. Admit that if "cause" existed for the termination by Falstaff of Ferd Gutting's employment, Falstaff had the right to terminate all life insurance benefits otherwise available to Ferd Gutting and his heirs and beneficiaries.

3. Admit that Ferd Gutting was told by Falstaff at the time of the termination of his employment by Falstaff that he was being discharged from his employment "for cause."

4. Admit that Ferd Gutting was discharged from his employment with Falstaff "for cause."
} 
Falstaff alleges that on February 27, 1982, Wilson again telephoned Sanders to advise him that the depositions scheduled for the following week would have to be canceled. Sanders refused, in part due to a March 15 trial setting, and both parties appeared in court on March 1. Wilson sought a protective order asking the court to postpone the March 2 and 3 depositions because of his conflict of interest. The court indicated the depositions would not be delayed unless new counsel for Gutting entered an appearance. Later the same day, Gutting's third attorney, David G. Dempsey, entered his appearance and the depositions were postponed one day. The court granted Wilson leave to withdraw and continued the trial setting until June 7, 1982.

On April 9, 1982, Dempsey filed several motions on behalf of Gutting, including a motion for leave to file answers to the request for admissions out of time. On the same date, Falstaff filed a motion for summary judgment on the theory that all fact issues in the case had been admitted by Gutting's failure to make a timely response to the request. On April 21, the court denied Gutting's motion for leave to file the answers and delayed ruling on Falstaff's summary judgment motion. The case was still scheduled to proceed to trial on June 7,1982 , and Falstaff chose to proceed with 11 scheduled discovery depositions. On May 28, 1982, the district court granted Falstaff's summary judgment motion. The court ruled there was no genuine issue of material fact that the death benefits had been properly withheld under the terms of the agreement because the matter of Ferd Gutting's termination for cause had been deemed admitted.

\section{Discussion}

\section{Conflicts of Interest of Gutting's Counsel.}

Gutting contends that the late responses should have been allowed because Falstaff's motion to disqualify McClellan and Wilson's withdrawal due to his conflict of interest rendered her without effective representation. The conflicts of interest experienced by McClellan and Wilson disrupted their professional duties to take actions best suited to furthering Gutting's interests. Once the conflicts became apparent, each attorney became unable to exercise his independent professional judgment. Gutting seems to be arguing that she should not be penalized because of her attorney's "inability" to take actions on her behalf. We agree that her counsels' conflicts of interest should have been considered by the district court.

The rules of professional responsibility that prohibit an attorney from representing differing interests are designed to protect the client from the attorney's potential abuses. It would appear to us that the purpose of such rules would be best furthered if an attorney discovering a conflict of interest took no action that may be inimical to the client's interests. The existence of a conflict, if not actually tolling the time period for answering discovery requests, should at least be a factor when evaluating the reasons for an untimely response.

In the instant case, Falstaff first filed the motion to disqualify McClellan and then filed the request for admissions barely two weeks later. Falstaff could not expect Gutting to answer the request during the pendency of the motion to disqualify her attorney. Indeed, once McClellan 
agreed to withdraw, Falstaff agreed to wait for a response until a new attorney had entered an appearance and had an opportunity to review the file. Wilson entered an appearance on December 11, 1981; his appearance was formally accepted on December 17. Sanders, counsel for Falstaff, concedes that he advised Wilson the extension of time for a response was good for a reasonable period of time. In early January 1982 Sanders and Wilson again informally agreed that the time for answering the requests could be extended a little while longer. Falstaff admits that it would have accepted the answers through the end of January and perhaps during the first few days of February. In the affidavit of Wilson, he swears that he discovered a possible conflict of interest on January 30,1982, as he was preparing responses to the discovery requests. He notified Sanders of the conflict of interest on February 6 and requested leave to withdraw on February 8. At the time Wilson discovered the existence of the conflict, Falstaff concedes that answers to the request still would have been accepted. It was sometime after January 30 that Falstaff began to consider the matters in the request admitted.

Falstaff contends that regardless of Wilson's conflict of interest he could have responded to the request for admissions. Wilson's conflict related only to certain upcoming depositions and did not affect his ability to answer the request. We disagree. As we read the conflict-of-interest 1 'rules, any actions taken by Wilson may have appeared to be inimical to Gutting's interests. Wilson could not have responded to the request as long as he was hindered by a conflict of interest in any aspect of his representation. ${ }^{46}$

We do not mean to imply disapproval of the district court's use of discovery sanctions in appropriate cases. An attorney's conflict of interest and his or her resulting inability to act must be distinguished from the situation in which the attorney's failure to act was inexcusable. In Mrs. Gutting's case it would be inequitable to deem the requests admitted and penalize her because of her attorney's compliance with the rules of professional responsibility.

We reverse the judgment of the district court and remand for further proceedings with directions that the district court set a reasonable time period in which to allow Gutting to file answers to the request for admissions.

\section{Questions:}

1. What is the purpose of the conflict of interest rules? Who are they intended to protect? Who do they actually protect?

2. Should Gutting's attorneys have been disqualified? What if she consented to the conflict?

\section{Further Listening:}

\footnotetext{
${ }^{46}$ We do not know why it took Wilson one week to inform Sanders of the conflict and another three weeks to withdraw formally from the case and have Mr. Dempsey enter his appearance. Falstaff complains of this time lag because it was required to cancel several depositions. Given the pending deposition schedule and trial setting, an expeditious substitution of counsel would have been appropriate. Nevertheless, our analysis of the conflict-of-interest problem remains the same.
} 
- Jill I. Gross, Professional Responsibility: Client Conflicts of Interest, Law to Fact: The Law School Podcast (March 19, 2019). 


\section{2: Resolving Conflicts of Interest}

I saw the future in a dream last night. Somebody's gonna get hurt, somebody's gonna get hurt. I hope it's not me, but I suspect it's going to have to be. ${ }^{47}$

While conflicts of interest implicate the duty of loyalty, they do not necessarily preclude representation or require withdrawal from representation. Some conflicts of interest cannot be resolved. For example, an attorney cannot represent both the plaintiff and the defendant in an action, and typically cannot represent any parties with actual or potential claims against each other. But many conflicts of interest can be resolved, if the attorney can represent the client without breaching the duty of loyalty, and the client provides informed consent to representation despite the conflict.

\section{Waiver of Conflicts of Interest}

In order to resolve a conflict of interest problem, attorneys should apply the four-step process outlined in Model Rule 1.7, comment [2]:

1. clearly identify the client or clients;

2. determine whether a conflict of interest exists;

3. decide whether the representation may be undertaken despite the existence of a conflict, i.e., whether the conflict is consentable; and

4. if so, consult with the clients affected and obtain their informed consent, confirmed in writing.

This process provides a framework for identifying, evaluating, and resolving conflicts of interest. Essentially, it requires an attorney to ask: 1) whether an attorney-client relationship exists; 2) whether the attorney's legal duties to a client conflict with the interests of the attorney, another current or former client, or a third-party to whom the lawyer owes a legal duty; 3 ) whether representation is legally permissible and practically possible under the circumstances; and 4) whether the client is adequately informed of the nature and potential consequences of the conflict, and has consented to representation in writing, despite the conflict. However, each of those steps requires an exercise of judgment on the part of the attorney.

\section{Identifying Clients}

A "client" is any party with whom an attorney has an attorney-client relationship of any kind. The conflict of interest rules apply to both clients and quasi-clients. As a consequence, a party may be a client for the purpose of the conflict of interest rules even if the attorney did not intend to form an attorney-client relationship. For example, a party that disclosed confidential information to an attorney in the course of seeking representation may be a client for the purpose of the conflict of interest rules, even if the party never hired the attorney. The agents or employees of a

47 The Mountain Goats, Black Pear Tree (2008). 
client organization may be clients, if they reasonably believe the attorney has agreed to represent them personally or have provided confidential information pertaining to their own circumstances. And a subsidiary of a client organization may also be a client, if the attorney effectively represents the subsidiary as well as the parent.

\section{Identifying Conflicts of Interest}

A "conflict of interest" exists if an attorney's fiduciary duties to a client conflict with the interests of the attorney, another current or former client, or a third-party to whom the attorney owes a legal duty. In other words, if the interests of the attorney, another current or former client, or third-party could provide an incentive for the attorney not to observe those legal duties to the client, then a conflict of interest exists. If the attorney could benefit from putting another interest ahead of the client's interests, providing less than candid and impartial advice, or using confidential information provided by the client, then a conflict of interest exists, whether or not the attorney ever has or would violate the fiduciary duties of loyalty, impartiality, and confidentiality.

Notably, a conflict of interest does not require actual harm to the client, only potential harm. There is no such thing as a "potential conflict of interest." A conflict of interest exists as soon as the potential for harm is created, whether or not the harm ever materializes. The risk of harm to the client's interests creates the conflict of interest, so the question is not whether a conflict exists, but how serious a conflict it presents. In some cases, the risk of harm may be too small to create a meaningful conflict, or an attorney's legal duties may themselves prevent the conflict from arising. But the conflict still exists, it simply is not a material conflict that requires an attorney to decline or withdraw from representation.

The paradigmatic conflict of interest exists when an attorney represents directly adverse parties, or one client litigating a claim against another. Notably, a conflict of interest exists whenever clients are directly adverse in any action, even if the attorney represents neither client in that action. Of course, co-defendants and co-plaintiffs may be directly adverse, because crossclaims and third-party claims create direct adversity. And potential claims may also create direct adversity, even if they are never filed. Accordingly, attorneys should be wary whenever they represent clients on the opposite sides of any transaction. Any potential adversity may create a conflict of interest.

Of course, a conflict of interest may exist without direct adversity. If an attorney represents two clients with opposing interests, it may "materially limit" the attorney's ability to represent both clients, because it may create an incentive for the attorney to compromise those interests. If dual representation could affect the attorney's decisions, then a conflict of interest exists.

Conflicts of interest can arise unexpectedly, as a client's interests may change over time. Accordingly, a conflicts analysis can never be a "one and done" practice. Attorneys must always be vigilant to identify and resolve conflicts of interest whenever they arise. 
However, a conflict of interest may or may not be material. A conflict of interest is material if it creates a substantial risk of providing an incentive for an attorney to violate a fiduciary duty to a client. But by extension, a conflict of interest is no material if it does not create such a risk. Attorneys must obtain the informed consent of their client in order to resolve a material conflict of interest. But attorneys need not obtain informed consent in order to resolve an immaterial conflict of interest, because no actual conflict exists. Of course, it can be difficult to determine whether a conflict is material, and immaterial conflicts have an unfortunate tendency to become material.

\section{Waivable Conflicts of Interest}

If a material conflict of interest exists, then the attorney must determine whether it is waivable. Some conflicts are waivable, but others are not. Specifically, a conflict is waivable only if it does not make representation prohibited or impossible under the circumstances. For example, some attorneys, typically former government employees, are prohibited by law from representing certain clients, so that is a conflict of interest that cannot be waived. Likewise, courts have uniformly held that attorneys cannot represent parties to an action with claims against each other, so that is also a conflict of interest that cannot be waived. However, many courts have held that attorneys can represent directly adverse clients, so long as the attorney does not represent both clients in the same matter, and both clients provide informed consent, so that is a conflict of interest that may be waived.

\section{Informed Consent}

If a waivable conflict of interest exists, then the attorney must obtain informed consent to the conflict from the client or clients. For example, if an attorney's interests conflict with a client's interests, then the attorney must obtain informed consent from the client. If a client's interests conflict with another client's interests, then the attorney must obtain informed consent from both clients. And if a client's interests conflict with a third party's interests, then the attorney must obtain informed consent from the client.

Sometimes, obtaining informed consent is easy. For example, a formal conflict of interest may not create a real conflict of interest, and the client may readily consent. Indeed, some clients may even see some formal conflicts of interest as advantages, rather than liabilities. One person's "conflict of interest" may be another person's "investment in the outcome."

But other times, obtaining informed consent may be difficult or impossible. A former client may well resent their former attorney representing an adversary and withhold consent. And a quasiclient may be even more likely to harbor misgivings. In those circumstances, even a relatively trivial conflict of interest may become an insuperable barrier to representation.

\section{Rule 1.7: Conflict of Interest: Current Clients}


a. Except as provided in paragraph (b), a lawyer shall not represent a client if the representation involves a concurrent conflict of interest. A concurrent conflict of interest exists if:

1. the representation of one client will be directly adverse to another client; or

2. there is a significant risk that the representation of one or more clients will be materially limited by the lawyer's responsibilities to another client, a former client or a third person or by a personal interest of the lawyer.

b. Notwithstanding the existence of a concurrent conflict of interest under paragraph (a), a lawyer may represent a client if:

1. the lawyer reasonably believes that the lawyer will be able to provide competent and diligent representation to each affected client;

2. the representation is not prohibited by law;

3. the representation does not involve the assertion of a claim by one client against another client represented by the lawyer in the same litigation or other proceeding before a tribunal; and

4. each affected client gives informed consent, confirmed in writing.

\section{Restatement (Third) of the Law Governing Lawyers § 122: Client Consent to a Conflict of Interest}

1. A lawyer may represent a client notwithstanding a conflict of interest prohibited by $\S 121$ if each affected client or former client gives informed consent to the lawyer's representation. Informed consent requires that the client or former client have reasonably adequate information about the material risks of such representation to that client or former client.

2. Notwithstanding the informed consent of each affected client or former client, a lawyer may not represent a client if:

a. the representation is prohibited by law;

b. one client will assert a claim against the other in the same litigation; or

c. in the circumstances, it is not reasonably likely that the lawyer will be able to provide adequate representation to one or more of the clients.

\section{Obtaining Informed Consent to a Conflict of Interest}

An attorney may represent a client despite a conflict of interest only if the attorney obtains informed consent to the conflict from the client, ideally in writing. In order to obtain informed consent, the attorney must provide the client with adequate disclosure of the conflict. Specifically, the attorney must disclose any and all competing interests that could create a conflict. And the attorney must explain the nature of every conflict and how they could affect the attorney's representation of the client, including the attorney's fiduciary duties of loyalty, impartiality, and confidentiality. In addition, attorneys should, and often must, obtain informed consent to any conflicts before commencing representation, and typically cannot obtain valid informed consent when terminating representation. 


\section{Restatement (Third) of the Law Governing Lawyers § 122(c)(i): The Requirement of Informed Consent-Adequate Information}

Informed consent requires that each affected client be aware of the material respects in which the representation could have adverse effects on the interests of that client. The information required depends on the nature of the conflict and the nature of the risks of the conflicted representation. The client must be aware of information reasonably adequate to make an informed decision.

Information relevant to particular kinds of conflicts is considered in several of the Sections hereafter. In a multiple-client situation, the information normally should address the interests of the lawyer and other client giving rise to the conflict; contingent, optional, and tactical considerations and alternative courses of action that would be foreclosed or made less readily available by the conflict; the effect of the representation or the process of obtaining other clients' informed consent upon confidential information of the client; any material reservations that a disinterested lawyer might reasonably harbor about the arrangement if such a lawyer were representing only the client being advised; and the consequences and effects of a future withdrawal of consent by any client, including, if relevant, the fact that the lawyer would withdraw from representing all clients. Where the conflict arises solely because a proposed representation will be adverse to an existing client in an unrelated matter, knowledge of the general nature and scope of the work being performed for each client normally suffices to enable the clients to decide whether or not to consent.

When the consent relates to a former-client conflict, it is necessary that the former client be aware that the consent will allow the former lawyer to proceed adversely to the former client. Beyond that, the former client must have adequate information about the implications (if not readily apparent) of the adverse representation, the fact that the lawyer possesses the former client's confidential information, the measures that the former lawyer might undertake to protect against unwarranted disclosures, and the right of the former client to refuse consent. The former client will often be independently represented by counsel. If so, communication with the former client ordinarily must be through successor counsel.

The lawyer is responsible for assuring that each client has the necessary information. A lawyer who does not personally inform the client assumes the risk that the client is inadequately informed and that the consent is invalid. A lawyer's failure to inform the clients might also bear on the motives and good faith of the lawyer. On the other hand, clients differ as to their sophistication and experience, and situations differ in terms of their complexity and the subtlety of the conflicts presented. The requirements of this Section are satisfied if the client already knows the necessary information or learns it from other sources. A client independently represented-for example by inside legal counsel or by other outside counsel—will need less information about the consequences of a conflict but nevertheless may have need of information adequate to reveal its scope 
and severity. When several lawyers represent the same client, responsibility to make disclosure and obtain informed consent may be delegated to one or more of the lawyers who appears reasonably capable of providing adequate information.

Disclosing information about one client or prospective client to another is precluded if information necessary to be conveyed is confidential. The affected clients may consent to disclosure, but it also might be possible for the lawyer to explain the nature of undisclosed information in a manner that nonetheless provides an adequate basis for informed consent. If means of adequate disclosure are unavailable, consent to the conflict may not be obtained.

The requirement of consent generally requires an affirmative response by each client. Ambiguities in a client's purported expression of consent should be construed against the lawyer seeking the protection of the consent. In general, a lawyer may not assume consent from a client's silent acquiescence. However, consent may be inferred from active participation in a representation by a client who has reasonably adequate information about the material risks of the representation after a lawyer's request for consent. Even in the absence of consent, a tribunal applying remedies such as disqualification will apply concepts of estoppel and waiver when an objecting party has either induced reasonable reliance on the absence of objection or delayed an unreasonable period of time in making objection.

Effective client consent to one conflict is not necessarily effective with respect to other conflicts or other matters. A client's informed consent to simultaneous representation of another client in the same matter despite a conflict of interest does not constitute consent to the lawyer's later representation of the other client in a manner that would violate the former-client conflict rule.

\section{NuStar Farms, LLC v. Zylstra, 880 N.W.2d 478 (lowa 2016)}

Summary: Between 2002 and 2014, attorney Larry Stoller represented Robert and Marcia Zylstra in several different matters. In 2007, Stoller and the Zylstras discussed a manure easement agreement with NuStar Farms. In 2014, Stoller began representing NuStar, which had a dispute with the Zylstras over a deed. Soon afterward, Stoller ended his representation of the Zylstras and filed an action against them for NuStar. The Zylstras retained attorney John Sandy, who filed a motion to disqualify Stoller. The trial court denied the motion, but the lowa Supreme Court reversed, holding that Stoller had a conflict of interest and the Zylstras did not consent.

ZAGER, Justice.

In this interlocutory appeal, we are asked to decide whether an attorney should be disqualified from representing one party in a lawsuit, either because his representation of the two parties was concurrent or because he had previously represented the opposing party in a similar 
matter. The district court concluded that the attorney need not be disqualified. For the reasons stated below, we conclude that the district court did not abuse its discretion in concluding that the prior attorney-client relationship failed the "substantial relationship" test. However, we conclude that the attorney did have a concurrent conflict of interest. Therefore, we find the district court abused its discretion in not disqualifying the attorney.

\section{Background Facts and Proceedings.}

Attorney Larry Stoller began representing Robert and Marcia Zylstra in 2002. Stoller represented them in a number of legal matters between 2002 and 2014, including financial issues, business acquisitions, and real estate transactions. Although the Zylstras were represented by Stoller on a number of occasions, they also used the services of other attorneys throughout this time period. At issue for the purposes of this case are a meeting in January 2007 and a small claims case ending in 2014.

On January 24, 2007, Robert met with Stoller to discuss estate planning and manure easement agreements. At the time of the meeting, the Zylstras were shareholders in Sibley Dairy, LLP. During this meeting, Robert showed Stoller a multipage document containing multiple manure easement agreements that the Zylstras intended to enter into with NuStar Farms, LLC. The parties disagree as to the extent of Stoller's involvement during this meeting regarding the manure easement agreements. Stoller asserts that he only briefly glanced at the easement agreements and then advised Robert that he should seek the advice of another attorney. Although Stoller acknowledges he made notations on the first page of the document, he argues that the notations do not indicate he read the entirety of the multipage manure easement agreements. Robert asserts that he asked Stoller to review the manure easement agreements and provide advice. Robert further alleges that Stoller examined the agreements during the meeting and advised him to go ahead and complete and sign them.

The record reflects that Stoller made notations on the documents. However, Stoller claims the notations were made at Robert's request to help Robert remember what to discuss with one of the attorneys that Stoller suggested Robert contact. Both parties agree that Stoller suggested Robert find an attorney with more experience in the area of manure easements. Stoller sent a follow-up email to Robert with two attorney references who he thought could assist the Zylstras with the easements. The email also confirmed that Robert asked Stoller to look at the easements and that Stoller "briefly looked at them." Further, Stoller wrote, "The changes you were talking about should be run by the other attorney and I suggest that if approved they be included in the easements. I would also think that some permit would be necessary." The record also reflects that during this conference they discussed estate planning matters. This is confirmed in the follow-up email and Stoller's office notes of the conference. Stoller billed the Zylstras for 1.20 hours and described the meeting as, "Conference with Robert on manure easement; review easements and agreement." There is nothing in the record to indicate that Stoller represented the Zylstras when they executed the manure easement agreements with NuStar or that he had any further involvement in the sale of Sibley Dairy. 
Stoller continued to represent the Zylstras in a number of other legal matters between 2007 and 2014. In December 2013, Stoller began representing the Zylstras in a small claims matter. The case was submitted to the small claims court on February 10, 2014, but the court did not issue its ruling until May 30. Stoller began representing NuStar in early May in an action regarding Ioan covenants. Also in early May, Stoller began contacting the Zylstras on behalf of NuStar. At least part of these contacts involved the Zylstras' failure to provide NuStar with a deed to property involving ingress. Stoller acknowledges that he contacted Robert about the Zylstras' need to sign the deed. On May 13, Stoller sent the Zylstras an email that stated it was the third time he had contacted them about the deed to ingress property sold by the Zylstras to NuStar. Stoller wrote in the email,

I must now put you on formal notice that if the signed deed is not received by my office by the close of business on Wednesday, May 14, 2014, that I will need to pursue the appropriate remedies for specific performance and damages on behalf of Nustar.

Stoller also wrote in his email, "I have tried to remain neutral in those matters and advised both parties that I could represent neither."

In this same email, Stoller informed the Zylstras that he would no longer be representing them in any future matters. Robert acknowledges that he understood the May 13 email as a severance of the attorney-client relationship. Stoller emailed the Zylstras again on May 14, expressing disappointment that the Zylstras were not going to sign the deed. Stoller also reminded Robert of his prior financial situation and how Stoller had helped him in the past.

By May 15, the Zylstras had retained John Sandy to represent them in their dealings with NuStar. In Sandy's correspondence to Stoller that same day, he alerted Stoller that the Zylstras found his representation of NuStar to be a conflict of interest based on his prior legal representation and counsel provided to the Zylstras. Sandy specifically requested that Stoller cease further representation of NuStar when those interests conflicted with the Zylstras.

On June 5 , Stoller sent the Zylstras a letter notifying them of the judge's ruling in the small claims case and informing them that he believed the decision was appealable. Stoller further notified the Zylstras of their rights to appeal and the deadlines associated with such an appeal. Stoller wrote he would be willing to file an appeal on their behalf and included information about his retainer and billing rate. Stoller also advised the Zylstras that if they chose to have another attorney represent them on the appeal he would release their file to that attorney.

On July 9, Stoller filed a multicount petition on behalf of NuStar against the Zylstras. The petition alleged the Zylstras agreed to sell NuStar a parcel in farmland in 2008, but they failed to tender the requisite deed. One count of the petition also alleged the Zylstras did not abide by certain terms contained in the manure easement agreements. In response, the Zylstras filed a preanswer motion to dismiss based on statute of limitations grounds. They also filed a motion seeking to disqualify Stoller as the attorney for NuStar based on a conflict of interest. 
On August 8, the district court held a hearing, and the parties argued both the motion to dismiss and the motion to disqualify Stoller. On October 14, the district court denied both motions. On November 10, the Zylstras filed an application for interlocutory appeal seeking review of the district court's denial of their motion to disqualify Stoller. We granted the application for interlocutory appeal on December 5.

Analysis

The right of a party to choose his or her own attorney is important, but it must be balanced against the need to maintain "the highest ethical standards" that will preserve the public's trust in the bar and in the integrity of the court system. A court must necessarily balance these two competing interests when determining whether to disqualify an attorney. In doing so, the court "must also be vigilant to thwart any misuse of a motion to disqualify for strategic reasons." When we evaluate motions to disqualify an attorney, we use our lowa Rules of Professional Conduct as the starting point.

Rule 32:1.7 covers concurrent conflicts of interest and states in pertinent part,

(a) Except as provided in paragraph (b), a lawyer shall not represent a client if the representation involves a concurrent conflict of interest. A concurrent conflict of interest exists if:

(1) the representation of one client will be directly adverse to another client; or

(2) there is significant risk that the representation of one or more clients will be materially limited by the lawyer's responsibilities to another client, a former client, or a third person by a personal interest of the lawyer.

The rule goes on to state that a lawyer may continue with the representation of a client if certain stipulations are met, one of which is that each client gives informed, written consent.

The Zylstras allege that Stoller's representation of NuStar was a concurrent conflict of interest with his representation of them. They argue that he began the action on behalf of NuStar in early May, while knowing that the representation would be adverse to the Zylstras because it involved a deed between the two parties. Further, Stoller began contacting the Zylstras on behalf of NuStar before the May 13 email officially terminating his attorney-client relationship with the Zylstras on the small claims case. Stoller responds that there was no concurrent conflict of interest because he did not file the action on behalf of NuStar against the Zylstras until after the May 13 email terminating the attorney-client relationship. In the alternative, the Zylstras argue that Stoller's June 5 email indicates that he was continuing to represent them in the small claims matter until the court issued its ruling. Even thereafter, Stoller advised the Zylstras there was a basis to appeal the judgment, the time for perfecting such an appeal, and his willingness to continue representing them in the appeal. Stoller contends that it was his duty to inform the Zylstras, as his former clients, of the outcome of the small claims hearing and the time limits for appeal. He further contends that, although he said he would be willing to represent the Zylstras 
on the appeal, he was also recommending they find alternate representation and thus was only informing them of their options if they chose to go forward with an appeal.

Before we turn to an analysis of whether a concurrent conflict of interest exists, we must address two questions: when the attorney-client relationship between the Zylstras and Stoller ended, and when the attorney-client relationship between NuStar and Stoller began. The first question we may dispose of easily. Generally, a lawyer's representation of a client extends until the time period for motions or appeals expires in a civil action. However, both the attorney and the client may terminate the relationship prior to this natural ending. Both Stoller and the Zylstras agree that the attorney-client relationship was terminated with the May 13 email. Further, while Stoller did offer to represent the Zylstras on the appeal, the Zylstras did not actually appeal the small claims case and did not solicit Stoller's services on any other legal matters. We find that the attorney-client relationship between Stoller and the Zylstras ended with the May 13 email.

The next question we must address is when the attorney-client relationship between Stoller and NuStar began. The attorney-client relationship is governed by general contract principles. It may be either express, such as when representation is based on a written agreement, or implied by the conduct of the parties. There are three elements that must be met to find that an attorneyclient relationship has been established:

(1) a person sought advice or assistance from an attorney, (2) the advice or assistance sought pertained to matters within the attorney's professional competence, and (3) the attorney expressly or impliedly agreed to give or actually gave the desired advice or assistance.

The relationship between Stoller and NuStar clearly meets this test. NuStar sought advice from Stoller at least beginning in early May about the action that required a deed from the Zylstras. The advice they sought from Stoller pertained to matters within his professional ability. Stoller has practiced law for a number of years and across a number of areas. Last, Stoller both agreed to give and actually gave NuStar advice and assistance. On NuStar's behalf, Stoller began contacting the Zylstras regarding the deed that NuStar was demanding. We find that the attorney-client relationship between NuStar and Stoller began, at the latest, in early May. This is also confirmed by Stoller's correspondence with the Zylstras on May 13 in which he asserts that it was the third time he had contacted them in regard to the deed. We now turn to a discussion of whether this attorney-client relationship involved a concurrent conflict of interest that violates rule $32: 1.7$.

There are two ways for a concurrent conflict of interest to exist under rule $32: 1.7$. The first is if "the representation of one client will be directly adverse to another client." The second is if "there is a significant risk that the representation will be materially limited by the lawyer's responsibilities to another client, a former client, or a third person." We may find a concurrent conflict of interest under either situation. 
We have acknowledged that rule 32:1.7(a) "applies where directly adverse representation will take place, as when one current client is about to file suit against another current client." The comments to the rule expand on what a "directly adverse" action may be:

Loyalty to a current client prohibits undertaking representation directly adverse to that client without that client's informed consent. Thus, absent consent, a lawyer may not act as an advocate in one matter against a person the lawyer represents in some other matter, even when the matters are wholly unrelated.

Stoller acknowledged in a letter to the lowa Supreme Court Attorney Disciplinary Board that he began the representation of NuStar in early May and that the Zylstras were aware of his representation of NuStar. It is unclear from the record at what point Stoller realized the action would include the deed that NuStar wanted the Zylstras to sign. However, by the time Stoller sent the May 13 email, he was already contemplating taking action against the Zylstras on behalf of NuStar. The email stated,

I must now put you on formal notice that if the signed deed is not received by my office by the close of business on Wednesday, May 14, 2014, that I will need to pursue the appropriate remedies for specific performance and damages on behalf of Nustar.

In this email, Stoller clearly demonstrates the intent to pursue a future, adverse action against the Zylstras on behalf of NuStar. Although Stoller terminated the attorney-client relationship with the Zylstras in the same email, the intent to pursue legal action unless the Zylstras complied with NuStar's request to sign the deed arose before the email was sent - which is precisely why the demand or "formal notice" language is included. We find that Stoller's representation of NuStar was a directly adverse concurrent conflict of interest. Because Stoller did not properly obtain consent from the Zylstras to represent NuStar, his actions fall squarely within the guidance of the comments that "absent consent, a lawyer may not act as an advocate in one matter against a person the lawyer represents in some other matter, even when the matters are wholly unrelated." Thus, we find Stoller should be disqualified from representing NuStar in the action against the Zylstras. Because the district court applied the law in error, we find that it abused its discretion in concluding that Stoller should not be disqualified.

Rule 32:1.9(a) - Duties to Former Clients

Stoller argues that, even though there was a concurrent conflict of interest in the past, the conflict no longer exists because he severed the attorney-client relationship, and therefore he can continue to represent NuStar in the current action against the Zylstras. Rule 32:1.9(a) concerns a lawyer's duties to former clients. In pertinent part, it provides,

A lawyer who has formerly represented a client in a matter shall not thereafter represent another person in the same or a substantially related matter in which that person's interests are materially adverse to the interests of the former client unless the former client gives informed consent, confirmed in writing. 
The comments expand on what makes a matter "substantially related" for purposes of the rule. A matter is substantially related if it involves the same transaction or legal dispute. If there is "a substantial risk that confidential factual information as would normally have been obtained in the prior representation would materially advance the client's position in the subsequent matter," then the matter is substantially related.

We consider three factors when we determine whether a substantial relationship exists:

(1) the nature and scope of the prior representation; (2) the nature of the present lawsuit; and (3) whether the client might have disclosed a confidence to his or her attorney in the prior representation which could be relevant to the present action.

Under the first factor, we must consider the scope - if any - of Stoller's representation of the Zylstras in regard to the manure easement agreements. There is no question that Stoller and Robert met to discuss the agreements and that Stoller was aware the Zylstras intended to enter into the agreements with NuStar. During the meeting, Robert showed Stoller the easement agreements. Stoller acknowledges that he looked at the first page and made some notations, though he contends the notations were made at Robert's request so Robert would know what he needed to discuss with another attorney. Stoller further claims that he did not read the entirety of the agreements. During the meeting, Stoller advised Robert to find another attorney to help him with the agreements because it was not an area of the law Stoller was familiar with. He gave Robert the names of two attorneys to contact.

Stoller sent an email to Robert following the meeting that summarized their discussion about the easement agreements. The email stated that Robert asked Stoller to look at the easements and that he "briefly looked at them." Stoller also wrote, "The changes you were talking about should be run by the other attorney and I suggest that if approved they be included in the easements. I would also think that some permit would be necessary." This reflects at least some level of advice given to Robert by Stoller. However, this is in stark contrast to our previous cases where we have found an attorney was extensively involved in prior representation.

In Doe, we found an attorney was highly involved in a client's prior representation when he had met with the clients, had telephone conversations with the clients, appeared as their attorney, and signed pleadings on their behalf. In Marks, we found that the attorney violated rule 32:1.9(a) when he represented a client in a foreclosure action and later represented his own wife in the sale of property to that same former client. We found that the attorney's representation of the client and his wife were substantially related because he had obtained information about the client's property during the foreclosure action. In comparison to our prior cases, we cannot say that the scope of Stoller's representation of the Zylstras regarding the manure easement agreements was in any way significant.

The second factor we consider is the nature of the present lawsuit between the Zylstras and NuStar. In the original petition that Stoller filed on behalf of NuStar, he included six counts. All of 
the counts except one deal with a real estate contract between NuStar and the Zylstras. Stoller did not participate in the real estate contract on behalf of the Zylstras. Count IV alleges a breach of the manure easement agreements between NuStar and the Zylstras. Although the majority of the counts do not relate to the manure easement agreements that Stoller had knowledge of, at least one part of the current lawsuit does relate to the prior scope of Stoller's representation.

The final factor we consider is "whether the client might have disclosed a confidence to his or her attorney in the prior representation which could be relevant to the present action." The meeting between Robert and Stoller to discuss the manure easement agreements was brief. The parties only superficially discussed the substance of the agreements and Stoller specifically suggested that Robert seek other competent agricultural law counsel to review the agreements before signing them. The email from Stoller does note that the two discussed whether permits were required or whether Robert should change anything in the agreements. However, nothing from this meeting indicates that Robert disclosed anything in confidence about the agreements to Stoller that would affect the current lawsuit between the Zylstras and NuStar.

We do not find that a substantial relationship exists sufficient to disqualify Stoller under rule 32:1.9(a). We therefore find that the district court did not abuse its discretion in holding that Stoller could not be disqualified under the substantial relationship test.

\section{Conclusion}

We find that the district court did not abuse its discretion in concluding that any prior relationship between Stoller and Zylstra in regard to the manure easement agreements failed the substantial relationship test. However, we find that Stoller did have a concurrent conflict of interest. Therefore, we conclude that the district court abused its discretion in not disqualifying Stoller from representing NuStar in the action. On remand, the district court should enter an order disqualifying Stoller from further representation of NuStar in this lawsuit.

\section{Questions:}

1. Why did the court hold that a conflict of interest prevented Stoller from representing NuStar in this action? Do you think that a substantial conflict of interest existed?

2. Why didn't the Zylstras want Stoller to represent NuStar in the action against them? 


\section{3: Breach of the Duty of Loyalty}

Don't look so surprised. You've been telling me lies. True confessions. ${ }^{48}$

Your depths made a pressure that punctured my works and all your fluids couldn't tolerate the force of my thirst. I love the place where we shared our tiny grace, but just because it's real don't mean it's gonna work. ${ }^{49}$

Attorneys have a fiduciary duty of loyalty to their clients. And attorneys who breach that duty of loyalty may be liable for malpractice. Typically, attorneys breach their duty of loyalty by ignoring or concealing a conflict of interest. A conflict of interest reflects an incentive to breach the duty of loyalty. And attorneys who act on that incentive have probably committed malpractice.

\section{The Scope of the Duty of Loyalty}

While attorneys owe their clients both a duty of care and a duty of loyalty, the duties are not the same. The duty of care requires reasonable care under the circumstances, but the duty of loyalty is an absolute duty. In other words, attorneys must always be vigilant for conflicts of interest. And if a conflict arises, attorneys must either resolve the conflict or withdraw from representation.

Moguls of Aspen, Inc. v. Faegre \& Benson, 956 P. 2d 618 (Colo. App. 1997)

Summary: While representing Moguls of Aspen in a dispute with its landlord, Faegre \& Benson provided inaccurate legal advice, which caused Moguls of Aspen to lose its lease and go out of business. Moguls of Aspen sued Faegre \& Benson for malpractice, but the trial court refused to instruct the jury on its claim for breach of the duty of loyalty, finding that the facts did not support the claim. The court of appeals affirmed, finding that Moguls of Aspen presented evidence of negligence, but did not present evidence of a conflict of interest.

Opinion by Judge CRISWELL.

Plaintiffs, Moguls of Aspen, Inc. (MOA) and Mogul Shop, Inc. (MSI), appeal from the judgment entered upon a jury verdict in favor of defendants, Faegre \& Benson, a law firm, and Christian Onsager, one of its members. We affirm.

Plaintiffs are two corporations wholly owned by Nancy Snell. MOA leased commercial space and subleased it to MSI, which operated a retail ski apparel shop on the premises.

\footnotetext{
48 The Undertones, True Confessions (1979).

49 The Blow, True Affection, Paper Television (2006).
} 
Plaintiffs first contacted the defendant law firm as a result of a dispute between them and the lessor of the commercial space concerning the amount of rent owed. After receiving notice from the lessor that they were in default on their lease, plaintiffs' real estate attorney contacted the law firm to discuss the possibility of filing a Chapter 11 bankruptcy petition.

A meeting was held with two attorneys of the law firm on June 25,1991 . Plaintiffs brought both the written lease and the lessor's notice of default to the meeting. At trial, their evidence sought to establish that an attorney-client relationship was established at this meeting. According to plaintiffs, while the plain language of the lease stated that the lessor could terminate the lease ten days after serving the notice of default, defendants did not advise them of this fact, nor did they disclose the legal effect of taking no immediate action to preserve the lease.

Plaintiffs asserted that, after this initial meeting, defendants performed no further work on plaintiffs' behalf until August 7, 1991. At trial, plaintiff's experts testified that these acts and omissions by defendants constituted professional negligence, as well as breaches of their fiduciary duties to act with "due diligence" and "in the client's best interest."

On August 7, 1991, after the lessor had served a demand for payment or possession on them, plaintiffs again contacted one of the attorneys who had been present at the June 25,1991 , meeting. This attorney told plaintiffs that he was too busy to handle the matter, and he referred it to defendant Onsager. Onsager informed plaintiffs that the lessor could not obtain possession of the premises unless an additional three-day notice was served upon them. This advice was admittedly inaccurate.

On August 22, 1991, the lessor terminated plaintiffs' lease. As a result, plaintiffs ceased doing business.

The original complaint in this case was filed a few days before the statute of limitations expired. At that time, because MSI, the owner of the business, was subject to a Chapter 7 bankruptcy proceeding and its trustee had elected not to pursue a legal malpractice claim against defendants, MSI was not made a party to the action. Nancy Snell was an original plaintiff. However, before trial, the trial court dismissed all of Snell's individual claims, concluding that there was no evidence to support a reasonable inference that Snell, the individual, as distinguished from the two wholly-owned corporations, had an attorney-client relationship with defendants.

Nevertheless, the court allowed the complaint to be amended to add MSI as a plaintiff. It also concluded that, because the claims that Snell had attempted to state were substantially the same as the claims now asserted by MSI, the latter claims would relate back to the date that Snell filed the initial complaint. Hence, it held that MSI's claim was not time-barred.

During the course of the later trial, the court submitted the claim of professional malpractice to the jury. It refused, however, to instruct upon any separate claim based upon an alleged 
violation of fiduciary duty. The jury rejected the claim submitted to it, and the court entered judgment upon that verdict.

MOA and MSI appeal from that judgment, asserting that the court erred in refusing to instruct the jurors with respect to their claim that defendants had violated certain fiduciary duties that defendants owed to them. We disagree.

The court here instructed the jurors upon the alleged professional malpractice of defendants consistent with the standard instruction. In accordance with this instruction, the jurors were required to determine whether defendants acted in a reasonably prudent manner, as measured against the acts or omissions of a reasonably careful attorney under the same or similar circumstances.

Plaintiffs tendered an instruction which set forth the elements of a claim based upon the violation of a fiduciary duty. In addition, they tendered an instruction describing the fiduciary duties that plaintiffs asserted defendants had violated. This instruction would have told the jurors that defendants owed the following duties to plaintiffs (none of the terms of which were further defined or described):

A duty to their client to employ that degree of knowledge, skill and judgment ordinarily possessed by members of the legal profession in carrying out the services for their client.

A duty to their client to act with due diligence in the affairs of their client.

A duty to their client to provide accurate information to their client regarding the status of legal matters intrusted to them.

A duty to their client of undivided loyalty and should exercise independent judgment on behalf of their client.

A duty to their client to the highest degree of fairness and good faith.

A duty to their client of full disclosure.

The trial court, however, determined that the evidence would support no claim beyond one based upon defendants' alleged negligence and lack of due diligence, the claim for which was adequately covered in the other elemental instruction. Hence, it refused to instruct the jurors as plaintiffs requested. We conclude that such refusal was proper.

Plaintiffs assert that each of the duties described in their tendered instructions was violated because: (1) plaintiffs were not advised at the initial meeting as to the procedure pursuant to which the lease could be terminated or the effect of such termination upon the effectiveness of any later bankruptcy proceedings; (2) defendants failed adequately to investigate plaintiffs' circumstances and failed to formulate a plan of action on their behalves from the initial meeting until plaintiffs contacted defendants again in August; and (3) on this latter date, the attorney who initially consulted with plaintiffs asserted that he was too busy with other matters to provide any further services and referred them to defendant Onsager. 
All of these allegations, while serious, do not implicate defendants actions except in a negligence or malpractice context. There is no allegation or evidence that defendants' acts or omissions, if any, resulted from an improper motive, a conflict of interest, or any other consideration beyond carelessness and lack of attention.

Under such circumstances, other courts have concluded that a claim for breach of a fiduciary duty is duplicative of a claim for professional malpractice and that only the latter claim should be the subject of adjudication. As stated in Calhoun v. Rane:

A fiduciary relationship exists as a matter of law between an attorney and his client. Thus, in effect any alleged malpractice by an attorney also evidences a simultaneous breach of trust; however, that does not mean every cause of action for professional negligence also sets forth a separate and independent cause of action for breach of fiduciary duty. In the present case, we find that the client has not pleaded a cause of action for breach of fiduciary duty distinct from the alleged malpractice case still pending in the trial court. A duplicative count may be properly dismissed.

No Colorado appellate court has yet addressed this issue with respect to the alleged breach of a fiduciary duty resulting from a lawyer's malpractice. There have been several instances in which a trial court has allowed both types of claims to be passed upon by a jury. But, the question whether, under the particular factual circumstances, the claims were duplicative was not addressed. In Bailey v. Allstate Insurance Co., the issue presented was whether the damages awarded under each of the two claims were duplicative, not whether the claims themselves were separate.

Nevertheless, previous Colorado decisions with respect to claims asserted against members of the medical profession are consistent with the analysis adopted by other courts as to claims asserted against lawyers.

Further, each of the duties referred to in plaintiffs' tendered instructions, insofar as the evidence would implicate any of them, is stated in absolute terms, i.e., duty "to provide accurate information." Yet, where, as here, it is the attorney's lack of due diligence and negligence that is the basis for the claim, the duty is not an absolute one. Rather, as the court properly instructed the jurors, the duty is to act with that care and diligence with which a reasonably careful attorney would act under the same or similar circumstances.

We agree with plaintiffs that some duties owed by attorneys may be absolute. The duty of "undivided loyalty" may be one. However, contrary to plaintiffs' assertions, here, the evidence does not implicate such a duty; the violations of duty alleged here were grounded upon the lawyers' alleged negligence and lack of due diligence.

We recognize that circumstances may exist in which a lawyer may be guilty both of malpractice and of other violations of his or her fiduciary obligations. If a claimed fiduciary violation is separate and independent from any alleged negligence, separate claims may well be properly 
asserted. This, however, is not such a case. And, the trial court properly recognized that it was not.

\section{Questions:}

1. Why did Moguls of Aspen fail to state a claim for breach of the duty of loyalty? What additional allegations would have stated a claim for breach of the duty of loyalty?

2. How does the duty of care differ from the duty of loyalty? Is it possible to negligently breach the duty of loyalty?

\section{Breach of the Duty of Loyalty}

David Welch Co. v. Erskine \& Tulley, 203 Cal. App. 3d 884 (Cal. App. 1988)

Summary: David Welch Company was a collection agency. In 1972, Erksine \& Tulley and Michael Carroll began providing legal representation to Welch. Among other things, they assisted Welch in collecting debts for employee-benefit trust funds from delinquent employers. In 1980, E\&T and Welch ended their attorney-client relationship. Soon afterward, E\&T began submitting proposals to collect debts for Welch's clients, without Welch's consent. Welch filed an action for breach of fiduciary duty and the trial court found for Welch. The appeals court affirmed, holding that E\&T's duty of loyalty to Welch required it to obtain informed consent before submitting proposals to Welch's clients.

\section{CHANNELL, J.}

Following a court trial, defendants Erskine \& Tulley (E\&T) and Michael Carroll appeal from a judgment entered against them and in favor of David Welch Co. (Welch). The trial court held that E\&T, a law corporation, and Attorney Carroll had breached their fiduciary duty towards Welch, their former client, and had received a benefit of $\$ 350,000$, which defendants were deemed to hold in constructive trust for Welch. Defendants were ordered to disgorge that benefit to Welch. Welch cross-appeals from that portion of the judgment providing that its recovery shall be only from those defendants, and only in the amount of $\$ 350,000$.

This controversy arises from the fact that after E\&T and Welch terminated their attorney-client relationship in December 1980, E\&T gradually acquired the collection business activities formerly performed by Welch in behalf of several employee benefit trust funds. The basic issue in the trial court was whether, in doing so, the law firm or any of its attorneys breached a fiduciary duty towards their former client.

\section{FACTS}

Welch is a licensed collection agency which, over several years, developed a highly profitable specialty in collecting delinquent employer contributions owed to 35 or more employee-benefit trust funds. From 1972 to 1980, E\&T acted as counsel for Welch, with Attorney Carroll doing 
most of the work for them in the later years. Before undertaking the representation of Welch, neither E\&T nor Carroll had experience in collection agency work for trust funds.

The evidence was in conflict as to how defendants acquired their knowledge for conducting this type of collection activity. Defendants presented evidence indicating that, from a legal standpoint, it was like any other collection work, and that no specialized knowledge or expertise was required. Welch presented evidence that the E\&T attorneys were specially trained by the owner, David Welch, on these matters; they were entrusted with complete access to information about Welch's confidential and profitable business techniques; and they were introduced by Welch as its attorneys to the trustees of the various trust funds. All of the information so provided was intended by Welch to be confidential.

When collecting a debt, Welch had the trust fund assign legal title to it, with the trust fund retaining equitable title. If its own collection efforts proved unsuccessful, Welch had E\&T file suit in Welch's name as assignee of the trust fund. Before turning a case over to its counsel, Welch would carry out its own collection efforts, investigate the financial status of the delinquent employer, and prepare a case file which included all of the background documents, suggestions for handling the matter, and a draft complaint ready for filing in court.

Because collecting for trust funds was so profitable, David Welch organized his business in a manner designed to preserve the confidentiality of its procedures. He separated the trust fund activity from his other collection activities, used only his most trusted employees, physically located the activity on a separate floor of his office, and took other steps to minimize dissemination of information and to protect against someone within his firm from breaking away and starting a competitive business.

In late 1979, the collection agency was sold, and Welch was taken over by Philip W. Coyle. In 1980, Welch stopped referring collection matters to E\&T. The parties thereafter agreed to terminate their relationship, effective after December 31, 1980. At approximately the same time, notices were sent by Coyle to Welch's trust fund clients indicating that Welch soon would be increasing its fees for those clients for the first time since 1968.

In mid-1981, the Sheet Metal Workers Trust severed its relationship with Welch, and transferred its collection business to E\&T. At the time, Welch viewed this as an isolated incident. During 1982 and early 1983, several more trust funds did likewise. The evidence indicates that E\&T did not solicit these particular clients, but instead responded to inquiries from each trust fund requesting a proposal. On the other hand, there was no evidence that E\&T disclosed to Welch, its former client, that it was submitting these proposals, nor that E\&T sought to secure Welch's consent to take over these accounts. In each instance, Welch learned it had lost its account from someone other than E\&T, usually in the form of a letter from the trust fund announcing as a fait accompli that their business was being transferred to E\&T. 
By the time Welch filed its complaint against E\&T in February 1983, the law firm had obtained the collection accounts of at least 10 of Welch's former trust fund clients, with annual billings approximating $\$ 156,715$.

\section{DISCUSSION}

\section{A. Breach of Fiduciary Duty}

Defendants' first set of contentions relates to whether substantial evidence supports the trial court's findings that they breached their fiduciary duty towards Welch. With respect to a cause of action alleging breach of a fiduciary duty, the existence of the duty is a question of law. "The relation between attorney and client is a fiduciary relation of the very highest character, and binds the attorney to most conscientious fidelity - uberrima fides."

There is no dispute that a fiduciary duty did exist in this case. The issue is whether defendants breached that duty towards Welch, which is a question of fact. As in other claims of lack of evidence, the question is "whether there is any substantial evidence contradicted or uncontradicted which will support the finding of fact."

Defendants' initial contention concerning this issue is that the trial court erred in finding a breach of fiduciary duty based on alleged violations of rules 4-101 and 5-101 of the Rules of Professional Conduct. Before trial, defendants had successfully moved for summary judgment as to the first cause of action, which had alleged that a violation of the rules, as a matter of law, provided a basis for civil liability. Nevertheless, these rules, together with statutes and general principles relating to other fiduciary relationships, all help define the duty component of the fiduciary duty which the attorney owes to his or her client.

In their argument, defendants cite rules 4-101 and 5-101 and then proceed to argue why their conduct neither fits within one of those rules nor otherwise constitutes a breach of a fiduciary duty. Defendants repeatedly suggest that the trial court concluded that their "mere acceptance of legal work from plaintiff's former clients" constituted such a breach. But more than that is required to establish a breach, and more than that was proven.

For example, the trial court found that defendants "breached their fiduciary duty owed to plaintiff by accepting employment adverse to plaintiff without plaintiff's informed and written consent relating to a matter in reference to which defendants had obtained confidential information by reason of or in the course of their employment by plaintiff."

This finding was patterned after rule 4-101, a rule which on its face applies to former as well as present clients. The primary purpose of that rule is to protect the confidential relationship which exists between attorney and client. It has been said that an attorney may not "at any time use against his former client knowledge or information acquired by virtue of the previous relationship." The actual use or misuse of confidential information is not determinative; it is the 
possibility of the breach of confidence which controls. This duty to protect confidential information continues even after the formal relationship ends.

Although neither party is able to cite a case involving a fact pattern analogous to this one, rule 4-101 seems to apply literally to this case. The typical case falling within the rule arises in the context of legal representation of a client whose interests are adverse to another client or former client of the attorney. But "adverse" also connotes being "opposed to one's interest" or "unfavorable." The acquisition by an attorney of business clientele of a former client operates to the economic advantage of the attorney and unfavorably upon the former client. Concerning access to confidential information, David Welch testified as to his company's efforts to maintain the confidentiality of this portion of Welch's business, including its fees schedules, its methods of operation, and other information. Nevertheless, all of this information was shared with defendants. Finally, defendants accepted the new employment without first notifying or in any way seeking the informed consent of Welch before submitting its proposals to the various trust funds.

The trial court further found that "defendants breached their fiduciary duty owed to plaintiff by knowingly acquiring a pecuniary interest adverse to plaintiff without first obtaining plaintiff's informed written consent." This finding highlights what we consider to be a critical factor in finding a breach of duty in this case, namely, the fact that defendants, who previously had been privy to Welch's confidential information, in no way informed Welch that they were preparing proposals designed to undercut Welch's business relationships.

We agree with defendants that the various trust funds were free to send their business to any entity they chose, as absent a contract to that effect, they were under no continuing duty to continue business with Welch. Similarly, any law firm, other than E\&T, was free to make proposals at the request of those trust funds in an effort to obtain their business, as E\&T did in this case. But, due to the preexisting attorney-client relationship during which defendants were in a position to and did obtain confidential information about Welch's business, these defendants had a higher duty, which was to refrain from acquiring any pecuniary interest involving collection work for these trust funds unless they first notified and obtained the informed consent of Welch to submit their business proposals. As they did not do so, the trial court properly found that they had breached their fiduciary duty towards Welch.

\section{Questions:}

1. Why was it a breach of the duty of loyalty for E\&T to submit proposals to Welch's clients without Welch's consent? What if Welch unreasonably refused consent?

2. Why did it matter that Welch allegedly shared confidential information with E\&T? If Welch had not shared confidential information with E\&T, would it still have been a breach of the duty of loyalty for E\&T to submit proposals to Welch's clients without Welch's consent?

3. When E\&T provided collection services to Welch's former clients, did it create an attorney-client relationship? Does it matter for the purpose of the duty of loyalty? 
4. After the attorney-client relationship between E\&T and Welch ended, could E\&T compete with Welch for business without Welch's consent? Are there circumstances where it could and circumstances where it couldn't?

\section{Remedies for the Breach of the Duty of Loyalty}

Maxwell v. Gallagher, 709 A. 2d 100 (DC App. 1998)

Summary: Gallagher \& Co., Real Estate, Inc. was a closely-held corporation. In 1987, Maxwell \& Bear provided legal advice to Gallagher and its owners in connection with the division of ownership shares in the corporation. In the transaction, 11 of the 100 shares in the corporation were transferred to Maxwell \& Bear, which filed a declaratory judgment action to claim its shares. The corporation and its owners counterclaimed, seeking recission of the transfer for breach of fiduciary duty. The trial court found that the transaction created a conflict of interest that Maxwell \& Bear did not resolve, causing a breach of the duty of loyalty, and ordered recission. The trial court found no actual damages, but awarded $\$ 75,000$ in punitive damages to the plaintiffs. The appellate court affirmed the recission, but reversed the punitive damages award, because the trial court found no actual damages.

\section{FARRELL, Associate Judge:}

This appeal from a judgment and award of damages for breach of fiduciary duty requires us, inter alia, to consider once again the relationship between compensatory (or actual) and punitive damages. Because the trial judge as factfinder expressly found that the appellees (counterclaimants) had not proven a basis for an award of actual damages, we hold that the judge's award of punitive damages was impermissible. We reverse that award but otherwise affirm the judgment.

I.

Plaintiff James S. Maxwell sought a declaratory judgment in Superior Court confirming the right of the law firm Maxwell \& Bear to retain its ownership of eleven shares of stock in Gallagher \& Co., Real Estate, Inc., of which Maxwell and Robert H. Bear had been directors and Maxwell an officer. The remaining owners of the corporation, Eugene J. Gallagher and Daniel J. O'Lone, as well as the corporation, answered and filed a counterclaim adding Bear as a counter-defendant. They sought rescission of the stock transfer to Maxwell \& Bear primarily on grounds of breach of fiduciary duty by the firm in providing legal representation to the corporation and the other owners. Following a bench trial, Judge Mitchell-Rankin issued an exhaustive written order and opinion concluding that Maxwell and Bear each had furnished legal representation to the corporation and Messrs. Gallagher and O'Lone during the relevant times and had breached their resultant fiduciary duty by placing their personal interest in controlling the corporation ahead of the interests of the clients. The judge ordered rescission of the stock held by Maxwell 
\& Bear, awarded $\$ 1$ in nominal damages to the appellees after finding no support for an award of actual damages, and ordered Maxwell and Bear to pay $\$ 75,000$ in punitive damages.

II.

The trial judge found that Maxwell \& Bear undertook to represent the corporation and its principals at meetings in December 1987 and January 1988 during which the division of ownership shares in the closely-held corporation was negotiated and agreed upon, resulting in the allocation of eleven of the one hundred shares to the law firm of Maxwell \& Bear. The judge further found that Maxwell undertook the representation "under circumstances where the interest between the members including Maxwell \& Bear and the corporate client were not compatible, and under circumstances where the law firm fostered and exploited the divergence." In particular, the stock division, including "the equity interest solicited and obtained by the law firm was not consummated to facilitate the best interest of the corporation, but only to satisfy the demands of individual members and the law firm." Moreover, from the beginning of the attorneyclient relationship, Maxwell had never disclosed to, or discussed with, the other principals the possible conflicts of interest that relationship entailed. By engaging in this course of "double dealing" designed to insure themselves effective control of the corporation, the judge found that Maxwell and Bear breached fundamental attorney-client obligations as reflected in multiple provisions of the District of Columbia Code of Professional Responsibility.

On appeal, Maxwell and Bear primarily dispute the trial judge's finding that they undertook legal representation of the other principals in connection with the division of the stock. They concede that they represented Gallagher, O'Lone, and Pollard on other matters (indeed, they so stipulated at trial), but argue that when it came to the pivotal meetings at which the stock division was negotiated, all present knew that Maxwell and Bear "were there for their own business reasons."

Significant first is that Maxwell and Bear do not deny that they purported to represent the corporation with regard to the stock division. They contend that "there is no evidence to support any finding that the attorneys ever undertook any professional responsibility in connection with the issuance of the stock other than to the corporation." Yet in that admitted capacity, they concede that they owed a fiduciary duty, and the trial judge expressly found that they had placed their private interest in securing control of the corporation above the interests of the corporate client.

Moreover, there is ample record support for the judge's finding that the law firm purported to represent the other principals at the stock division meetings. Those meetings took place against the background of a course of dealing starting in 1984 during which Maxwell and Bear played the "dual/multiple roles" of business associates and legal counsel to Gallagher, including when jointly forming a predecessor company in 1986. As a later illustration, the judge found that Gallagher "sought and received legal advice from Mr. Maxwell as to the most appropriate time to resolve Mr. Pollard's interest in the company," an important issue because Pollard faced collateral legal (and potential criminal) liability at the time he joined the corporation. Indeed, the 
December 18, 1997 meeting at which the stock division became the paramount subject was originally called by Maxwell, at Gallagher's request, to discuss a real estate commission dispute the company had had with another real estate firm, "a matter in which Maxwell \& Bear served as legal counsel for Messrs. Gallagher, Pollard, and O'Lone." According to testimony by O'Lone, Maxwell expressly justified the law firm's demanded percentage ownership as payment for the ongoing representation it was providing to and on behalf of the company and its principals. In short, we find no reason to disturb the finding of a legal relationship between Maxwell \& Bear and the others extending through the stock division and beyond.

Nor will we disturb the finding that appellants breached the duties imposed by that relationship by failing to disclose the business advantages they sought which "might affect the firm's legal judgment vis-a-vis Mr. Gallagher" and by acting repeatedly to effectuate their own interests at the expense of the other principals.

The relation of attorney and client is one of the highest trust and confidence, and demands the utmost good faith on the part of the attorney. This relation is not only highly confidential, but presents so many opportunities for the reaping of special benefits at the expense of the client by an attorney so disposed, that courts will closely scrutinize any transaction in which the attorney has assumed a position antagonistic to his client. In thus "scrutinizing" the relationship at hand, the trial judge found ample reason, as do we, to conclude that

the law firm acted in complete disregard of the interests of the corporate client and $\mathrm{Mr}$. Gallagher. The law firm made no disclosures to any client, obtained no informed consents from any client, and sought by its disregard of its ethical and fiduciary duties to its corporate client to benefit itself.

We therefore sustain the judge's rescission of the stock transfer "as the tangible product of the breaches of fiduciary duty."

III.

Although the trial judge ordered cancellation of the stock transfer, she also found "no record evidence of any meaningful evaluation of the stock" at the time it was divided. Nor did the appellees present at trial any evidence of the dollar value of the stock. This exemplified what the trial judge found to be a complete failure of the appellees to present proof of loss from the breach of duty for which compensatory damages could be awarded. Maxwell and Bear argue that, in the absence of such proof, it was error for the trial judge to award punitive damages. We are constrained to agree. Despite some uncertainty in our decisions over the years, the principle we derive from them is that, before punitive damages may be awarded, there must be a basis in the record for an award of actual damages, even if nominal. Since the trial judge expressly found no such basis in the record of this case, punitive damages will not lie.

A. 
In her original opinion, the judge denied the counterclaim "with respect to compensatory damages, in the absence of proof of the same," but awarded $\$ 75,000$ in punitive damages for the breach of fiduciary duty. The appellees then moved to amend the judgment "solely for the court to make an express finding that they are entitled to compensatory damages in at least a nominal amount." The judge modified her order by awarding appellees "nominal damages in the amount of $\$ 1.00$," but she made explicit that this was not an award for actual damages because the appellees had shown no basis for such compensation. The judge distinguished between proof of "injury" and "evidence of any loss occasioned by" the injury. Referring to her original finding that "the harm caused to the corporation as a client and to Mr. Gallagher as a client by the law firm's cavalier and self-interested approach to its ethical and fiduciary duties is amply demonstrated by the facts in this case," she continued:

Although this Court does agree there is ample justification for a finding of injury as provided in the original order, it does not concur with appellees that they are entitled to compensatory damages. The reason is simple: they have failed to produce evidence of any loss occasioned by Maxwell's and Bear's conduct for which they should be compensated. Having proven only breach of fiduciary duty, and hence injury, appellees are entitled only to a nominal damage award but are not equally entitled to a corresponding compensatory damage award.

The judge thus awarded nominal damages of $\$ 1.00$ as what she believed to be the requiredand sufficient—-predicate for punitive damages to a "plaintiff whose legal right has been technically violated but has proved no real damage." In a word, the breach of fiduciary duty without more supplied the basis for the punitive damage award.

B.

First of all, we reject the appellees' assertion that the trial judge found actual damages but was merely unable to quantify them-the $\$ 1.00$ in nominal damages being a proxy for that indeterminate but actual loss. The appellees alleged only economic damages, something not inherently impossible to quantify if they had been proven. More importantly, the judge took pains to state repeatedly that the appellees had "failed to produce evidence of any loss"- hence any compensable damage-resulting from the breach of fiduciary duty. We therefore must decide whether the award of punitive damages was permissible without proof that actual damages were warranted.

We think the essence of our case law is this: A plaintiff must prove a basis for actual damages to justify the imposition of punitive damages. The amount of such damages may be nominal, stemming from the difficulty of quantifying them or from some other cause. But without proof of at least nominal actual damages, punitive damages may not be awarded.

Our most recent statement of this rule was in Ayala v. Washington. There we said: 
Under the law of the District of Columbia, although there must be a basis for compensatory damages before punitive damages will be considered, a plaintiff need not prove anything more than nominal actual damages to justify the imposition of punitive damages.

In awarding punitive damages despite the absence of a basis for actual damages, the trial judge relied partly on the following passage from Brown v. Coates:

Once it has been shown that one trained and experienced holds himself out to the public as worthy to be trusted for hire to perform services for others, and those so invited do place their trust and confidence, and that trust is intentionally and consciously disregarded, and exploited for unwarranted gain, community protection, as well as that of the victim, warrants the imposition of punitive damages.

The cogency of this reasoning is indisputable but Brown does not bear upon the issue presented here of the necessity vel non of proof of actual damages before punitive damages may be awarded. We hold that, because the trial judge expressly found that appellees had proven no actual damages, punitive damages could not be awarded.

\section{Questions:}

1. Why did the court find that Maxwell \& Bear violated its duty of loyalty? How could Maxwell \& Bear have avoided violating its duty of loyalty?

2. Did Maxwell \& Bear owe a duty of loyalty to the corporation or to the owners of the corporation? Could Maxwell \& Bear represent all of the owners of the corporation?

3. Why did the court find no actual damages? Was it right?

\section{Further Reading:}

- Lisa G. Lerman, Lying to Clients, 138 U. Pa. L. Rev. 659 (1990) 


\section{4: Current Client Conflicts of Interest}

I'll never leave him down though I might mess around. It's only 'cause I need some affection. So I creep, yeah, just creepin' on. On the down low, 'cept nobody is supposed to know. So I creep yeah, 'cause he doesn't know what I do, and no attention goes to show. ${ }^{50}$

Attorneys have fiduciary duties of care, loyalty, impartiality, and confidentiality to both the clients they intend to represent and the quasi-clients they do not. Sometimes, it is unclear whether a conflict of interest implicates the duty of care or the duty of loyalty.

Typically, attorneys have more than one client at a time. Whenever they contemplate forming a new attorney-client relationship, they must determine whether it would create a conflict of interest with one of their existing clients. And they must always be attentive to the possibility that conflicts of interest will arise between different clients.

In case a conflict of interest exists with respect to a new client, or arises with respect to an existing client, attorneys must obtain informed consent from all of their clients affected by the conflict, or withdraw from representation.

Weil, Gotshal \& Manges, LLP v. Fashion Boutique of Short Hills, Inc., 10 A.D.3d 267 (NY App. Div. 2004)

Summary: Weil, Gotshal \& Manges represented Fashion Boutique in an action against Fendi, but also represented Prada, which acquired Fendi. When Weil filed an action against Fashion Boutique for unpaid legal fees, Fashion Boutique counterclaimed against Weil for malpractice and breach of fiduciary duty, because it failed to investigate or introduce relevant testimony. The trial court dismissed the malpractice claims, but not the fiduciary duty claims. The appellate court reversed, reinstating the malpractice claim and dismissing the fiduciary duty claim as redundant.

This action for $\$ 2.7$ million in unpaid legal fees arose out of the representation, commencing in 1993, of counterclaim plaintiff Fashion Boutique of Short Hills, Inc. and its principals by counterclaim defendant law firm and two of its partners. Fashion Boutique alleges that, while representing it against Fendi in an action in federal court, Prada, which had acquired a controlling interest in Fendi in October 1999, retained the law firm. The federal action was based on alleged disparaging remarks by Fendi, a competing Fifth Avenue boutique, and its parent Fendi, which led to the destruction of Fashion Boutique's retail business, thereby violating the Lanham Act and New York State law prohibiting product disparagement. The law firm represented Fashion Boutique through extensive pretrial discovery, a summary judgment motion resulting in the dismissal of the Lanham Act claim and a July 2000 jury trial, which resulted in the award of $\$ 35,000$ in compensatory damages and $\$ 75,000$ in punitive damages in favor of Fashion Boutique. Earlier, in March 2000, the Fendi defendants had made a settlement

50 TLC, Creep, CrazySexyCool (1994). 
offer of $\$ 1.4$ million, which, although recommended by the law firm, was rejected by Fashion Boutique. The law firm was granted leave to withdraw in September 2000. In December 2002, the United States Court of Appeals for the Second Circuit affirmed the dismissal of the Lanham Act claim.

The law firm thereafter commenced this action for unpaid legal fees; Fashion Boutique answered and asserted counterclaims for legal malpractice and breach of fiduciary duty, seeking $\$ 15,555,537$ in damages, based on two principal allegations. It alleged that the two law firm partners "disregarded their fiduciary obligation and breached their duty of undivided loyalty to Fashion Boutique" by agreeing in late 1999 to represent Prada and thereby creating an "irresolvable conflict of interest." It also alleges that, as a result of this conflict, the law firm did not use adequately the testimony of a witness, Caroline Clarke, a former Fendi officer, who, it is claimed, could supply "critical elements" of proof relevant to the dismissed Lanham Act claim. According to Fashion Boutique, Ms. Clarke, in an October 6, 1999 e-mail, told one of the defendant law firm partners that she could testify about hundreds of incidents in which Fendi employees made disparaging remarks about Fashion Boutique and that she knew of a "continued policy of disparagement" against Fashion Boutique. In a prior February 1994 deposition, Ms. Clarke denied personal knowledge of any Fendi policy to disparage the quality of Fashion Boutique merchandise. Notwithstanding, Fashion Boutique claimed that the law firm failed to appreciate the significance of the "new evidence" contained in the e-mail and to use Ms. Clarke's testimony more effectively to reinstate the Lanham Act claim and prove the remaining claims at trial. Fashion Boutique also alleged that the law firm failed to alert the trial judge to claimed threats against Ms. Clarke at the time of trial and that, because of its divided loyalty, in the face of these threats, the law firm, in effect, abandoned her as a witness; that after the dismissal of the Lanham Act claim, it improvidently advised Fashion Boutique to agree to a stipulated judgment and take an immediate appeal; and that it failed to conduct adequate crossexamination of Fendi witnesses and to submit certain financial records to the jury on the punitive damages issue.

The law firm moved to dismiss the counterclaims, arguing that no conflict of interest exists since the product disparagement action is completely unrelated to the trademark enforcement issues in certain "gray goods" litigation in which the law firm was advising Prada. The law firm also argued that, even if a conflict of interest case had been properly pleaded, Fashion Boutique cannot establish the element of loss causation. The motion court granted the motion in part and denied it in part, dismissing the second counterclaim for legal malpractice but sustaining the first counterclaim for breach of fiduciary duty. In so ruling, the motion court rejected the probative value of Clarke's October 1999 e-mail, the focal point of Fashion Boutique's counterclaims, finding, "Nothing in the E-mail would have altered the federal courts' conclusion, upon which dismissal of the Lanham Act claim was based, that Fendi's actions did not constitute 'advertising or promotion' within the meaning of the Lanham Act." Similarly, as to Fashion Boutique's common-law product disparagement claims, the motion court found that the documentary evidence "refutes Fashion Boutique's contention that, but for the counterclaim-defendants' failure to properly utilize Clarke as a witness, Fashion Boutique would have obtained a substantially greater award of damages on its claims under New York State law." The court also 
rejected the claim that "Clarke was unable to testify fully and freely at trial, because Fendi was subjecting her to an alleged campaign of threats and intimidation." The court noted that the federal trial court examined Clarke at a hearing outside the jury's presence to consider the effect of the purported threats on her testimony, at the conclusion of which the court concluded: "I have listened to a very distraught woman who has addressed subjects which are irrelevant to this lawsuit." The motion court rejected each of the criticisms of the way in which the law firm conducted the trial, finding that they constitute "simply dissatisfaction with strategic choices." Despite this finding, the court sustained the breach of fiduciary duty counterclaim, holding that even if the law firm may not have had an actual conflict of interest it might not have been "sensitive to forces that might operate upon it subtly in a manner likely to diminish the quality of its work." The same documentary evidence that refuted legal malpractice, the court held, "does not utterly refute" the allegations that the law firm's "failure to make better use of Clarke's testimony, and delay in advising the federal trial court of the purported campaign of intimidation against Clarke until after she had already given her trial testimony, substantially contributed to the failure to achieve a better result in the Fendi action." We reverse.

Fashion Boutique's theory of liability, common to both the legal malpractice and breach of fiduciary duty counterclaims, is that during the latter part of the law firm's representation of Fashion it labored under a conflict of interest that was at such an extent that it compromised the law firm's level of advocacy and contributed to a trial outcome less favorable than would otherwise have been achieved. In dismissing the legal malpractice counterclaim, the motion court reviewed a record consisting of 17 different exhibits, ranging from pleadings to transcripts of arguments to testimony, both at trial and in depositions, as well as an e-mail, on the basis of which it made factual findings in support of its decision. The testimonial portion of that submission, alone, ran to more than 700 pages. Such a review, culminating in factual findings, would be most unusual even if this motion had been converted, which it was not, to one for summary judgment. The law firm argued that the 500 pages of exhibits constituted documentary evidence. In opposing the motion, Fashion Boutique relied on the detailed factual allegations of its counterclaims and whether reasonable inferences could be drawn therefrom. A court is obliged to accept the complaint's factual allegations as true, according to plaintiff the benefit of every possible favorable inference, and determining "only whether the facts as alleged fit within any cognizable legal theory. Dismissal is warranted only if the documentary evidence submitted conclusively establishes a defense to the asserted claims as a matter of law." The motion court clearly departed from this standard. Disregarding the allegations of the counterclaims and the possible inferences to be drawn therefrom, it reviewed evidence, including deposition and trial testimony and a three-page e-mail narrative, described by its author, Ms. Clarke, as an "overview" of the areas of interest as to which she could offer testimony, and made factual findings. In considering such evidence, the court went far beyond what the Legislature intended. The submissions here are of a type that "do not meet the requirement of conclusively establishing the defense as a matter of law." For instance, the motion court disregarded the fact that Ms. Clarke's e-mail was only an overview of her testimony and viewed it as the whole of her testimony. Nor did the court take into account the many ways Ms. Clarke indicated she could testify with personal knowledge about Fendi's campaign of disparagement. On this record, we find that the legal malpractice counterclaim's allegation that but for the law firm's failure, due to 
its debilitating conflict of interest, to make proper use of Ms. Clarke's testimony, the Fashion Boutique case against Fendi would have had a more favorable result, was not conclusively controverted. Thus, the legal malpractice counterclaim should be reinstated.

As to the claim for breach of fiduciary duty, we have consistently held that such a claim, premised on the same facts and seeking the identical relief sought in the legal malpractice cause of action, is redundant and should be dismissed.

We take this occasion to note that the court erred in holding that the "but for" standard of causation, applicable to a legal malpractice claim, does not apply to the claim for breach of fiduciary duty. Instead, it applied the less rigorous "substantial factor" causative standard. We have never differentiated between the standard of causation requested for a claim of legal malpractice and one for breach of fiduciary duty in the context of attorney liability. The claims are coextensive. Under New York law, to establish the elements of proximate cause and actual damages, where the injury is the value of the claim lost, the client must meet the "case within a case" requirement, demonstrating that "but for" the attorney's conduct the client would have prevailed in the underlying matter or would not have sustained any ascertainable damages. The cases relied upon by Fashion Boutique did not involve a former client's breach of fiduciary claim against his attorneys, but rather a typical commercial dispute as to the fiduciary obligation owed by a lawyer to his former partners when departing to join another firm.

\section{Questions:}

1. Why did Fashion Boutique think Weil committed malpractice? Why did Fashion Boutique think Weil breached its fiduciary duty?

2. How did the trial court analyze those claims? Why did the appellate court reverse?

3. What is the difference between a malpractice claim and a breach of fiduciary duty claim? Are they redundant? Which kind of claim did Fashion Boutique have, if either?

\section{Prospective Informed Consent}

Obtaining a client's informed consent to a conflict of interest after it arises can be difficult. After all, it may not be in the client's interest to consent to the conflict. Accordingly, many lawyers ask new clients to provide informed consent to conflicts that may arise in the course of representation.

Should clients be able to provide informed consent to potential future conflicts? When should prospective consent be permitted? Are there circumstances in which it should not be permitted? How should courts determine whether prospective consent was sufficiently informed to be effective?

Model Rule 1.7, Comment [22] 
Whether a lawyer may properly request a client to waive conflicts that might arise in the future is subject to the test of paragraph (b). The effectiveness of such waivers is generally determined by the extent to which the client reasonably understands the material risks that the waiver entails. The more comprehensive the explanation of the types of future representations that might arise and the actual and reasonably foreseeable adverse consequences of those representations, the greater the likelihood that the client will have the requisite understanding. Thus, if the client agrees to consent to a particular type of conflict with which the client is already familiar, then the consent ordinarily will be effective with regard to that type of conflict. If the consent is general and open-ended, then the consent ordinarily will be ineffective, because it is not reasonably likely that the client will have understood the material risks involved. On the other hand, if the client is an experienced user of the legal services involved and is reasonably informed regarding the risk that a conflict may arise, such consent is more likely to be effective, particularly if, e.g., the client is independently represented by other counsel in giving consent and the consent is limited to future conflicts unrelated to the subject of the representation. In any case, advance consent cannot be effective if the circumstances that materialize in the future are such as would make the conflict nonconsentable under paragraph (b).

Visa USA, Inc. v. First Data Corp., 241 F. Supp. 2d 1100 (N.D. Ca. 2003)

Summary: Heller Ehrman White \& McAuliffe represented Visa. First Data asked Heller to represent it in a patent infringement action, and Heller agreed, if First Data consented to Heller's representation of Visa in any future disputes. Soon afterward, Visa sued First Data, represented by Heller. First Data filed a motion to disqualify Heller. The court denied the motion because First Data knowingly consented to the conflict and Heller protected First Data's confidentiality.

HAMILTON, District Judge.

Plaintiff Visa sued defendant First Data in April 2002 for trademark infringement, dilution, and various breach of contract claims. First Data has contracted with Visa to process financial transactions on Visa's behalf. First Data has recently launched a new business initiative, which will allow First Data to bypass Visa's regulations on the processing of certain Visa-related transactions. Visa claims these private arrangements violate its contractual and trademark rights.

Visa is represented in this matter by the law firm of Heller Ehrman White \& McAuliffe's San Francisco office. In March 2001, before this lawsuit was filed, First Data was sued in an unrelated patent infringement action currently pending in the District of Delaware. First Data sought to retain Heller's Silicon Valley office as counsel in the Delaware action. After running a conflicts check, Heller informed First Data that it had a long-standing relationship with Visa. While Heller did not see any conflicts between the two parties at that time, Heller could not represent First Data in the patent infringement case unless First Data agreed to permit Heller to 
represent Visa in any future disputes, "including litigation," that might arise between First Data and Visa. First Data consented to those terms, which were memorialized in an engagement letter between Heller and First Data. The relevant portion of the letter states:

Our engagement by you is also understood as entailing your consent to our representation of our other present or future clients in "transactions," including litigation in which we have not been engaged to represent you and in which you have other counsel, and in which one of our other clients would be adverse to you in matters unrelated to those that we are handling for you. In this regard, we discussed Heller's past and on-going representation of Visa in matters which are not currently adverse to First Data. Moreover, as we discussed, we are not aware of any current adversity between Visa and First Data. Given the nature of our relationship with Visa, however, we discussed the need for the firm to preserve its ability to represent Visa on matters which may arise in the future including matters adverse to First Data, provided that we would only undertake such representation of Visa under circumstances in which we do not possess confidential information of yours relating to the transaction, and we would staff such a project with one or more attorneys who are not engaged in your representation. In such circumstances, the attorneys in the two matters would be subject to an ethical wall, screening them from communicating with each other regarding their respective engagements. We understand that you do consent to our representation of Visa and our other clients under those circumstances.

After First Data agreed to the waiver, Visa also agreed to Heller's dual representation.

A few months later, in July 2001, First Data publicly announced its intention to launch its new private arrangement plan, and in the beginning of 2002, First Data officially notified Visa. Visa then sued First Data. First Data in response threatened antitrust counterclaims against Visa, and then began settlement discussions. Almost four months after the complaint was filed, and shortly after settlement talks broke down, First Data informed Visa in August 2002 that it intended to move to disqualify Heller as counsel for Visa in this matter.

First Data claims that when it signed the waiver letter, it was not adequately informed of the possibility that its patent counsel could sue it for millions of dollars in damages and raise claims disparaging First Data and attacking the very core of its business. First Data contends that under the California Rules of Professional Conduct, Heller at a minimum was required to reaffirm First Data's prospective consent when the actual conflict between Visa and First Data arose. First Data has also indicated that it believes that Heller's patent lawyers have access to confidential information from First Data that Visa could use against First Data in this action.

Heller and Visa argue that First Data was fully informed about the situation and agreed to allow Heller to represent Visa in future litigation against First Data. Heller and Visa argue that the California Rules of Professional Conduct and other ethical rules expressly permit prospective written consent to a conflict waiver, and that no rules require Heller to obtain a second consent 
to continue in their representation of Visa. Heller also indicates that it has put an ethical wall in place that adequately protects First Data's confidential information.

\section{DISCUSSION}

\section{A. Motion to Disqualify Counsel-Legal Standards}

The Northern District of California has adopted the California Rules of Professional Conduct, and attorneys practicing in this court are required to adhere to those standards, as articulated in the rules and any court decisions interpreting them. The right to disqualify counsel is within the discretion of the trial court as an exercise of its inherent powers.

Motions to disqualify counsel are strongly disfavored. Thus, such requests "should be subjected to particularly strict judicial scrutiny."

In reviewing a motion to disqualify counsel, the district court must make "a reasoned judgment and comply with the legal principles and policies appropriate to the particular matter at issue." The district court is permitted to resolve disputed factual issues in deciding a motion for disqualification and must make findings supported by substantial evidence.

\section{B. Simultaneous Representation of Adverse Clients and Written Waivers}

\section{Conflict Waiver Letters}

First Data claims that Heller has violated Cal. Rule of Prof. Conduct 3-310(C)(3), which states:

A member of the California State Bar shall not, without the informed written consent of each client:

(3) represent a client in a matter and at the same time in a separate matter accept as a client a person or entity whose interest in the first matter is adverse to the client in the first matter.

First Data argues that this rule automatically disqualifies Heller from representing both Visa and First Data, even though First Data's patent litigation is unrelated to this action.

When evaluating whether a law firm may concurrently represent two clients, even on unrelated matters, it is presumed that the duty of loyalty has been breached and counsel is automatically disqualified. But, as Visa and Heller note, the presumption may be rebutted and a law firm may nonetheless simultaneously represent two adverse clients if full disclosure of the situation is made to both clients and both agree in writing to waive the conflict. Here, it is undisputed that Heller and First Data executed a conflict waiver letter. Thus, Heller is not automatically disqualified from representing both Visa and First Data. 


\section{Prospective Waivers}

First Data next argues that Heller's use of a prospective waiver, which purported to waive all future conflicts between Visa and First Data, was improper without, at minimum, a second disclosure and waiver once the situation between Visa and First Data ripened into an actual conflict. Visa and Heller argue that the prospective waiver signed by First Data was proper and fully informed, and thus no second waiver was required.

An advance waiver of potential future conflicts, such as the one executed by First Data and Heller, is permitted under California law, even if the waiver does not specifically state the exact nature of the future conflict. The only inquiry that need be made is whether the waiver was fully informed. In some circumstances, a second waiver will be warranted, but only if the attorney believes that the first waiver was insufficiently informed. There is no case law requiring a second disclosure in all circumstances for an advance waiver to be valid.

\section{Fully Informed Waiver}

A second waiver by First Data in a nonrelated litigation would only be required if the waiver letter insufficiently disclosed the nature of the conflict that subsequently arose between Visa and First Data. Thus, to prevail on this motion, First Data must show that it was not fully informed about the consequences of its conflicts waiver when it signed the waiver letter. To show full disclosure, Heller must demonstrate that it "communicated information reasonably sufficient to permit the client to appreciate the significance of the matter in question."

An evaluation of whether full disclosure was made and the client made an informed waiver "is obviously a fact-specific inquiry." Factors that may be examined include the breadth of the waiver, the temporal scope of the waiver (whether it waived a current conflict or whether it was intended to waive all conflicts in the future), the quality of the conflicts discussion between the attorney and the client, the specificity of the waiver, the nature of the actual conflict (whether the attorney sought to represent both clients in the same dispute or in unrelated disputes), the sophistication of the client, and the interests of justice. In evaluating all these factors, there is substantial evidence showing that Heller made a full and reasonable disclosure to First Data and First Data knowingly waived any conflicts concerning Heller's ongoing representation of Visa.

\section{a. Heller Fully Disclosed the Conflict to First Data.}

Most significantly, the waiver letter itself demonstrates that Heller fully explained to First Data the nature of the conflict waiver at issue. When First Data first approached Heller to represent it in the patent litigation, Heller explained to First Data that, even though there were no present conflicts between Visa and First Data, there was a significant risk of future adversity because Visa and First Data were major competitors in the processing side of the credit card business. Heller thus informed First Data that it would not be able to take the matter unless First Data would waive any conflicts that might arise out of Heller's ongoing work for Visa in matters up to 
and including possible future litigation. This understanding was confirmed in the written waiver letter.

Our engagement by you is also understood as entailing your consent to our representation of our other present or future clients in "transactions," including litigation in which we have not been engaged to represent you and in which you have other counsel, and in which one of our other clients would be adverse to you in matters unrelated to those that we are handling for you. In this regard, we discussed Heller's past and on-going representation of Visa U.S.A. and Visa International in matters which are not currently adverse to First Data. Moreover, as we discussed, we are not aware of any current adversity between Visa and First Data. Given the nature of our relationship with Visa, however, we discussed the need for the firm to preserve its ability to represent Visa on matters which may arise in the future including matters adverse to First Data, provided that we would only undertake such representation of Visa under circumstances in which we do not possess confidential information of yours relating to the transaction.

The letter identifies the adverse client, Visa, and discloses as fully as possible the nature of any potential conflict that could arise between the two parties. The letter also clearly states that the waiver contemplates Heller's representation of Visa against First Data in matters "including litigation." First Data was given ample information concerning the conflict in question that it was asked to waive, reviewed this information, and then agreed to the waiver. First Data has failed to demonstrate that it was not fully and reasonably informed when it signed the waiver letter.

The cases where law firms have been disqualified for insufficient disclosures involve situations much more egregious than the facts presented here. For instance, in Image, Kodak successfully disqualified Coudert Brothers, Image's attorneys, from representing Image in that action because Coudert had also represented Kodak in unrelated corporate matters. Kodak produced evidence that Coudert had deliberately misrepresented the scope of their representation of Image to Kodak by downplaying their actual conflict. Specifically, Coudert failed to mention to Kodak's business people that they would be arguing against Kodak before the U.S. Supreme Court in a landmark antitrust case that had been litigated for six years. They also failed to disclose any of this information to Kodak's in-house counsel, and failed to obtain a written consent. After weighing these factors, the court determined that this could not constitute full disclosure and ordered Coudert disqualified.

Here, in contrast, Heller notified First Data's director of intellectual property and division general counsel of the potential for a future conflict, fully discussed the nature of that conflict, and informed First Data that Heller would be unable to represent First Data unless the conflict was waived. The facts and law do not support a finding that First Data was not given sufficient information to understand the scope of its waiver.

\section{b. Knowing Consent}


There is also substantial evidence in the record that First Data was aware of this potential conflict with Visa and Heller when it signed the waiver letter, and thus First Data knowingly waived that conflict in order to have Heller to represent it in the patent litigation. First Data in its Answer stated that it had been contemplating its new private arrangement initiative and had given preliminary notice to Visa about it "as early as 1999." In 2000, First Data had also indicated that Visa's business plans concerning private arrangements raised antitrust concerns for the payment-card industry in amicus papers and motions to intervene in the Department of Justice antitrust litigation against Visa.

First Data does not deny that it first began contemplating this arrangement in 1999 or that it foresaw antitrust concerns in 2000 over Visa's position on private arrangements. Instead, First Data argues that it did not realize that Heller would represent Visa in those matters and had assumed that Heller would, at most, represent Visa against First Data on incidental matters such as implementation and enforcement of payment processor rules. First Data admits that it is "unlikely" that such matters would result in litigation with Visa.

This is not credible. Heller informed First Data that it represented Visa in large-scale commercial litigation, and that due to the nature of the potential conflicts between the two parties, Heller would not be able to represent First Data at all without a broad prospective waiver. First Data had also submitted briefs in high-profile antitrust litigation in which Heller was representing Visa, and where First Data had threatened Visa with further antitrust claims. First Data knew that Heller was Visa's counsel on major matters that could potentially involve First Data. Given this information, First Data could not have believed that Heller would be uninvolved in any major litigation that could potentially arise between Visa and First Data, or that Visa would have restricted itself to hiring Heller solely for relatively minor regulatory disputes between the two parties.

First Data contended on reply and at the hearing that even if it did know in 2001 when it signed the waiver letter that Visa and First Data could potentially be involved in high-stakes litigation over First Data's private arrangement initiative, First Data had no duty to recognize that conflict on its own. First Data argues that it was instead Visa and Heller's duty to inform First Data of these risks, citing State Farm. In State Farm, though, the law firm in question had made no disclosure to the junior client, and then argued that because the two clients were aware of the conflict when the junior client hired the law firm, they had implicitly consented to a conflict waiver. The court found that the attorneys were still required to disclose the conflict and obtain explicit consent from the clients in that circumstance. State Farm requires only that the attorneys disclose conflicts to clients. Here, those requirements were met when Heller disclosed the existence of the potential Visa conflict before forming an attorney-client relationship with First Data and obtained a written conflict waiver agreement. No case law allows First Data to ignore its own additional knowledge concerning the nature of the potential conflict when deciding whether to waive.

c. First Data is a Sophisticated User of Legal Services 
In determining whether First Data gave informed consent in the waiver letter, the court may also properly consider First Data's level of experience with legal services.

First Data is a Fortune 500 company with over $\$ 6$ billion in annual revenues. It is a knowledgeable and sophisticated user of legal services. It has a legal department of about fifty attorneys and routinely hires top-tier national law firms such as Bingham McCutchen, Heller, and Sidley Austin to handle its complex corporate transactions and litigation matters. First Data can and should be expected to understand the full extent of what it waived when it signed Heller's explicit waiver letter.

\section{Ethical Walls}

It is undisputed that Heller immediately put an intra-firm ethical wall in place when Visa sued First Data, which barred contact between the Heller attorneys representing First Data and the Heller attorneys representing Visa. First Data argues that the institution of an ethical wall is insufficient to repair Heller's breach of its duty of loyalty, and that Heller has breached its duty of confidentiality to First Data by its dual representation of Visa and First Data.

Heller conceded at oral argument that if it had breached its duty of loyalty to First Data through its dual representation of Visa and First Data, an ethical wall would not be sufficient to cure the breach. But Heller did not breach its duty of loyalty to First Data by agreeing to represent Visa in this matter after receiving a valid prospective conflict waiver from First Data. Heller thus is not claiming that the ethical wall is necessary to protect Heller's duty of loyalty to First Data.

Rather, Heller instituted the ethical wall to protect Heller's duty of confidentiality to its client First Data. First Data states that it has shared information concerning its finances and its general business plan to its patent lawyers, and argues that such information is presumed imputed to all Heller attorneys. Heller can rebut that presumption by "showing that effective screening procedures were implemented to prevent the passing of information between the tainted lawyers and other members of the firm." Because First Data makes no showing in its papers beyond the presumption of shared confidentiality in support of its allegations, and because Heller has demonstrated that it immediately put an ethical wall in place as soon as Heller was retained as Visa's counsel in this action, there has been no breach of the duty of confidentiality here.

\section{Questions:}

1. Why did First Data think that Heller had a conflict of interest? Why did the court disagree?

2. Should a client be able to consent to being sued by their attorney?

3. How did Heller avoid creating a conflict of interest? How did the duty of loyalty and the duty of confidentiality create different problems?

\section{Conflicts of Law}


When courts decide whether a conflict of interest exists and how to evaluate it, they must also decide what law to apply. For state courts, the choice of law question is relatively easy. They must apply the state law governing lawyers, although they may refer to federal law and general principles in interpreting the state law.

But for federal courts, the choice of law question is more complicated. They are necessarily reviewing the actions of attorneys who are members of a state bar and subject to state rules. But they also have their own bar and may consider national rules and principles.

Accordingly, federal courts must decide whether to apply state or national law in determining whether a conflict of interest exists, and how to evaluate any conflicts of interest they find.

In re Dresser Industries, Inc., 972 F. 2d 540 (5th Cir. 1992)

Summary: Susman Godfrey represented Dresser Industries in several actions, but also represented the plaintiffs in the Drill Bits class action, and informed Dresser of a potential conflict. Dresser declined to seek new counsel, but moved to disqualify Susman Godfrey when it became a defendant in Drill Bits. The district court denied the motion, based on Texas law, but the circuit court reversed, based on the Model Rules.

\section{E. GRADY JOLLY, Circuit Judge:}

In this petition for a writ of mandamus, we determine whether a law firm may sue its own client, which it concurrently represents in other matters. In a word, no; and most certainly not here, where the motivation appears only to be the law firm's self-interest. ${ }^{51}$ We therefore grant the writ, directing the district judge to disqualify counsel.

I

The material facts are undisputed. This petition arises from a consolidated class action antitrust suit brought against manufacturers of oil well drill bits.

Dresser Industries, Inc., is now a defendant in Drill Bits, charged - by its own lawyers — with conspiring to fix the prices of drill bits and with fraudulently concealing its conduct. Stephen D. Susman, with his firm, Susman Godfrey, is lead counsel for the plaintiff's committee. As lead counsel, Susman signed the amended complaint that levied these charges against Dresser, his firm's own client.

Susman Godfrey concurrently represents Dresser in two pending lawsuits. CPS International, Inc. v. Dresser Industries, Inc., is the third suit brought by CPS International, a company that

\footnotetext{
51 "Bits was going to be a case that was going to be active, big, protracted, the first price fixing case that's come along in Houston in a long time. I had made somewhat of a reputation in that area, and I guess it's kind of painful not to be able to play in the game anymore." Deposition of Stephen D. Susman.
} 
claims Dresser forced it out of the compressor market in Saudi Arabia. CPS International initially sued Dresser for antitrust violations and tortious interference with a contract. The antitrust claim has been dismissed, but the tort claim is scheduled for trial. Susman Godfrey has represented Dresser throughout these actions, which commenced in 1985. During its defense of Dresser, Susman Godfrey lawyers have had relatively unfettered access to data concerning Dresser's management, organization, finances, and accounting practices. Susman Godfrey's lawyers have engaged in privileged communications with Dresser's in-house counsel and officers in choosing antitrust defenses and other litigation strategies. Susman Godfrey has also, since 1990, represented Dresser in Cullen Center, Inc. v. W.R. Gray Co., a case involving asbestos in a Dresser building, which is now set for trial in Texas state court.

On October 24 and November 24, 1991, Susman Godfrey lawyers wrote Dresser informing it that Stephen Susman chaired the plaintiffs' committee in Drill Bits, that Dresser might be made a Drill Bits defendant, and that, if Dresser replaced Susman Godfrey, the firm would assist in the transition to new counsel. Dresser chose not to dismiss Susman Godfrey in CPS and Cullen Center.

Dresser was joined as a defendant in Drill Bits on December 2, 1991. Dresser moved to disqualify Susman as plaintiffs' counsel on December 13. Both Dresser and Susman Godfrey submitted affidavits and depositions to the district court, which, after a hearing, issued a detailed opinion denying the motion.

The district court noted that Southern District local rule 4B provides that the code of professional responsibility for lawyers practicing in that district is the Code of Responsibility of the State Bar of Texas. Although the court further noted that other district courts look to other codes in deciding motions to disqualify, nevertheless, it concluded that "Dresser's motion to disqualify Susman Godfrey is governed wholly by the Texas Disciplinary Rules of Professional Conduct." The court then focused on Texas Disciplinary Rule 1.06, which provides:

(b) Except to the extent permitted in paragraph (c), a lawyer shall not represent a person if the representation of that person:

(1) involves a substantially related matter in which that person's interests are materially and directly adverse to the interests of another client of the lawyer or the lawyer's firm; or

(2) reasonably appears to be or become adversely limited by the lawyer's or law firm's responsibilities to another client or to a third person or by the lawyer's or law firm's own interests.

(c) A lawyer may represent a client in the circumstances described in (b) if:

(1) the lawyer reasonably believes the representation of each client will not be materially affected; and

(2) each affected or potentially affected client consents to such representation after full disclosure. 
The district court described the Drill Bits complaint as a civil antitrust case, thus somewhat softening Dresser's description of it as an action for fraud or criminal conduct. The court held, "as a matter of law, that there exists no relationship, legal or factual, between the Cullen Center case and the Drill Bits litigation," and that no similarity between Drill Bits and the CPS suits was material. The court concluded that "Godfrey's representation of the plaintiffs in the Drill Bits litigation does not reasonably appear to be or become adversely limited by Susman Godfrey's responsibilities to Dresser in the CPS and Cullen Center cases," and accordingly denied the motion to disqualify. Finally, the court denied permissive interlocutory appeal.

In evaluating a motion to disqualify, we interpret the controlling ethical norms governing professional conduct as we would any other source of law. When the facts are undisputed, district courts enjoy no particular advantage over appellate courts in formulating ethical rules to govern motions to disqualify. Thus, in the event an appropriate standard for disqualification is based on a state's disciplinary rules, a court of appeals should consider the district court's interpretation of the state disciplinary rules as an interpretation of law, subject essentially to de novo consideration.

III

The district court clearly erred in holding that its local rules, and thus the Texas rules, which it adopted, are the "sole" authority governing a motion to disqualify. Motions to disqualify are substantive motions affecting the rights of the parties and are determined by applying standards developed under federal law.

The district court's authority to promulgate local rules is derived from 28 U.S.C. $\S 2071$, which allows the courts only to adopt "rules for the conduct of their business." Thus, although the district court should determine rules for the conduct of attorneys for the purpose of identifying conduct subject to sanctions, its local rules alone cannot regulate the parties' rights to counsel of their choice.

\section{IV}

We apply specific tests to motions to disqualify counsel in circumstances governed by statute or the Constitution. When presented with a motion to disqualify counsel in a more generic civil case, however, we consider the motion governed by the ethical rules announced by the national profession in the light of the public interest and the litigants' rights. Our source for the standards of the profession has been the canons of ethics developed by the American Bar Association. We have applied particularly the requirement of canon 5 that a lawyer exercise "independent professional judgment on behalf of the client" and the admonition of canon 9 that lawyers should "avoid even the appearance of impropriety." 
Our most far-reaching application of the national standards of attorney conduct to an attorney's obligation to avoid conflicts of interest is Woods v. Covington County Bank. We held in Woods that standards such as the ABA canons are useful guides but are not controlling in adjudicating such motions. The considerations we relied upon in Woods were whether a conflict has (1) the appearance of impropriety in general, or (2) a possibility that a specific impropriety will occur, and (3) the likelihood of public suspicion from the impropriety outweighs any social interests which will be served by the lawyer's continued participation in the case.

We applied the Woods standard to a conflict that arose when an attorney brought a suit against a former client in Brennan's Inc. v. Brennan's Restaurant, Inc. In Brennan's, the plaintiffs moved to have the court disqualify the attorney for the defendants because, prior to the litigation, the attorney had jointly represented both parties. We affirmed the disqualification of the attorney, holding that an attorney could not sue a former client in a matter substantially related to the representation of a former client. Similarly, in Wilson P. Abraham Construction Corp. v. Armco Steel Corp., we held that the court should bar an attorney from suing the co-defendant of a former client if the co-defendants and their attorneys exchanged information.

In Woods, Wilson Abraham, and Brennan's, we applied national norms of attorney conduct to a conflict arising after the attorney's prior representation had been concluded. Now, however, we are confronted with our first case arising out of concurrent representation, in which the attorney sues a client whom he represents on another pending matter. We thus consider the problem of concurrent representation under our framework in Woods as tailored to apply to the facts arising from concurrent representation.

We turn, then, to the current national standards of legal ethics to first consider whether this dual representation amounts to impropriety. Neither the ABA Model Rules of Professional Conduct nor the Code of Professional Responsibility allows an attorney to bring a suit against a client without its consent. This position is also taken by the American Law Institute in its drafts of the Restatement of the Law Governing Lawyers.

Unquestionably, the national standards of attorney conduct forbid a lawyer from bringing a suit against a current client without the consent of both clients. Susman's conduct violates all of these standards - unless excused or justified under exceptional circumstances not present here.

Exceptional circumstances may sometimes mean that what is ordinarily a clear impropriety will not, always and inevitably, determine a conflicts case. Within the framework we announced in Woods, Susman, for example, might have been able to continue his dual representation if he could have shown some social interest to be served by his representation that would outweigh the public perception of his impropriety. ${ }^{52}$ Susman, however, can present no such reason. There

\footnotetext{
${ }^{52}$ We found above that the Texas rules of discipline do not control a motion to disqualify in federal court. We are mindful, however, that the Texas rules' allowance of some concurrent representation is based, in part, on a concern that concurrent representation may be necessary either to prevent a large company, such as Dresser, from monopolizing the lawyers of an area or to assure that certain classes of unpopular
} 
is no suggestion that other lawyers could not ably perform his offices for the plaintiffs, nor is there any basis for a suggestion of any societal or professional interest to be served. This fact suggests a rule of thumb for use in future motions for disqualification based on concurrent representation: However a lawyer's motives may be clothed, if the sole reason for suing his own client is the lawyer's self-interest, disqualification should be granted.

\section{$\mathrm{V}$}

We find, therefore, that Dresser's right to the grant of its motion to disqualify counsel is clear and indisputable. We further find that the district court clearly and indisputably abused its discretion in failing to grant the motion. We have thus granted the petition and have issued the writ of mandamus, directing the United States District Court for the Southern District of Texas to enter an order disqualifying Stephen D. Susman and Susman Godfrey from continuing as counsel to the plaintiffs.

\section{Questions:}

1. Why did the circuit court think a conflict of interest existed? Why did the court think Dresser did not or could not provide consent?

2. Should the court have applied the Texas rule or the model rule?

clients receive representation. Although we do not now reach the matter, our consideration of social benefit to offset the appearance of impropriety might allow such a representation if the balance clearly and unequivocally favored allowing such representation to further the ends of justice.

We believe, moreover, that the Texas rules are drawn to allow concurrent representation as the exception and not the rule. Even if the Texas rules had applied, no special circumstances being present here, Texas rule 1.06's prohibition of representation of potentially adverse interests would have barred the representation. 


\section{5: Former Client Conflicts of Interest}

It's harder to be friends than lovers, and you shouldn't try to mix the two. 'Cause if you do it and you're still unhappy, then you know that the problem is you. ${ }^{53}$

Attorneys have fiduciary duties not only to their current clients, but also to their former clients. While some of an attorney's fiduciary duties apply only to current clients, other duties survive the attorney-client relationship. For example, the duty of care typically applies only to current clients, although an attorney may also have a duty of care not to negligently harm the interests of former clients. The duty of loyalty applies primarily to current clients, but also applies to former clients in certain circumstances. And the duty of confidentiality applies with equal force to both current and former clients.

\section{Rule 1.9: Duties to Former Clients}

a. A lawyer who has formerly represented a client in a matter shall not thereafter represent another person in the same or a substantially related matter in which that person's interests are materially adverse to the interests of the former client unless the former client gives informed consent, confirmed in writing.

b. A lawyer shall not knowingly represent a person in the same or a substantially related matter in which a firm with which the lawyer formerly was associated had previously represented a client

1. whose interests are materially adverse to that person; and

2. about whom the lawyer had acquired information protected by Rules 1.6 and 1.9 (c) that is material to the matter; unless the former client gives informed consent, confirmed in writing.

c. A lawyer who has formerly represented a client in a matter or whose present or former firm has formerly represented a client in a matter shall not thereafter:

1. use information relating to the representation to the disadvantage of the former client except as these Rules would permit or require with respect to a client, or when the information has become generally known; or

2. reveal information relating to the representation except as these Rules would permit or require with respect to a client.

\section{Rule 1.9 Duties To Former Clients, Comment [2]}

The scope of a "matter" for purposes of this Rule depends on the facts of a particular situation or transaction. The lawyer's involvement in a matter can also be a question of degree. When a lawyer has been directly involved in a specific transaction, subsequent representation of other clients with materially adverse interests in that transaction clearly is prohibited. On the other hand, a lawyer who recurrently handled a type of problem for a former client is not precluded from later representing another client in a factually distinct problem of that type even though the

${ }^{53}$ Liz Phair, Divorce Song, Exile in Guyville (1993). 
subsequent representation involves a position adverse to the prior client. Similar considerations can apply to the reassignment of military lawyers between defense and prosecution functions within the same military jurisdictions. The underlying question is whether the lawyer was so involved in the matter that the subsequent representation can be justly regarded as a changing of sides in the matter in question.

\section{Rule 1.9 Duties To Former Clients, Comment [3]}

Matters are "substantially related" for purposes of this Rule if they involve the same transaction or legal dispute or if there otherwise is a substantial risk that confidential factual information as would normally have been obtained in the prior representation would materially advance the client's position in the subsequent matter. For example, a lawyer who has represented a businessperson and learned extensive private financial information about that person may not then represent that person's spouse in seeking a divorce. Similarly, a lawyer who has previously represented a client in securing environmental permits to build a shopping center would be precluded from representing neighbors seeking to oppose rezoning of the property on the basis of environmental considerations; however, the lawyer would not be precluded, on the grounds of substantial relationship, from defending a tenant of the completed shopping center in resisting eviction for nonpayment of rent. Information that has been disclosed to the public or to other parties adverse to the former client ordinarily will not be disqualifying. Information acquired in a prior representation may have been rendered obsolete by the passage of time, a circumstance that may be relevant in determining whether two representations are substantially related. In the case of an organizational client, general knowledge of the client's policies and practices ordinarily will not preclude a subsequent representation; on the other hand, knowledge of specific facts gained in a prior representation that are relevant to the matter in question ordinarily will preclude such a representation. A former client is not required to reveal the confidential information learned by the lawyer in order to establish a substantial risk that the lawyer has confidential information to use in the subsequent matter. A conclusion about the possession of such information may be based on the nature of the services the lawyer provided the former client and information that would in ordinary practice be learned by a lawyer providing such services.

\section{Wilson P. Abraham Const. v. Armco Steel Corp., 559 F. 2d 250 (5th Cir. 1977)}

Summary: Stephen D. Susman represented Whitlow Steel in a Texas federal antitrust conspiracy action. Armco, Ceco, and Laclede were Whitlow's co-defendants in that action, and were also the defendants in a Louisiana federal antitrust conspiracy action. Ultimately, they pleaded to all of the charges. William E. Wright filed a civil action against Whitlow, Armco, Ceco, and Laclede in Texas, on behalf of Wilson P. Abraham Construction. And then Wright filed an action against Armco, Ceco, and Laclede in Louisiana, and hired Susman as co-counsel. Defendant's in the Louisiana action filed a motion to disqualify Susman because he represented Whitlow in the antitrust conspiracy action. The district court denied the motion, and the circuit court vacated and remanded for the district court to determine whether Susman received confidential information. 
This is an appeal from an order of the district court denying the defendants' motion to disqualify counsel for plaintiff. Though the appeal is not from a final judgment in the traditional sense, we take jurisdiction of it as a collateral matter severable from the underlying suit, and too important to be denied review at this time.

This dispute centers around exactly what relationship cocounsel for the plaintiff, a Mr. Stephen D. Susman, had with the various defendants in this suit in a prior legal matter. The factual background which leads up to this current dispute is somewhat detailed and complicated. It begins in 1972 when Mr. Susman was associated with the firm of Fulbright and Jaworski in Houston, Texas. At that time, he undertook to represent Whitlow Steel Company, Inc., an independent rebar fabricator in Houston. This representation was in connection with a Federal Grand Jury investigation of the rebar steel industry in Texas. In August 1973, charges of antitrust violations were levied against Whitlow, Armco Steel Corp., The Ceco Corp., and Laclede Steel Company. Armco, Ceco, and Laclede are the defendants in the present action before this court. As counsel for Whitlow, Mr. Susman met on more than one occasion with the representatives of Armco, Ceco, and Laclede. At these meetings some efforts allegedly were made to develop a cooperative defense. Exactly what information was exchanged, and the importance of that information, is hotly disputed. Mr. Susman contends that the meetings were disorganized and nothing of substance was ever discussed. The defendants contend that documents were in fact discussed and disseminated, grand jury witness lists were prepared, and reports were given as to exactly what testimony was being presented before the grand jury by the various witnesses. The gist of the defendants' argument is that Mr. Susman was privy to a substantial amount of confidential information. Mr. Susman flatly denies this.

At the same time of the grand jury investigation of the Texas steel industry, a separate grand jury investigation of the Louisiana steel industry was underway. In April 1974, four mills (including Armco, Ceco, and Laclede), an independent fabricator, and five individuals were indicted for "bid rigging." All defendants except one pled nolo contendere to the Louisiana indictment. After Armco, Ceco, and Laclede were sentenced in Louisiana, they filed motions to dismiss the Texas indictment. They argued that because of the close relationship of the Texas case to the Louisiana case, the double jeopardy clause prevented further prosecution. The Texas district court refused to rule on the defendants' motion at that time saying that the motion presented such a close factual question that it could not be ruled on until the court heard all the evidence at trial. This ruling prompted the defendants to enter pleas in order to avoid trial.

The final fact which needs to be brought out to fully understand the controversy before this Court is that some time after the Texas grand jury investigation, a civil suit was filed in Texas against Whitlow and the defendants in this suit. The counsel for the plaintiff in that suit was a Mr. William E. Wright. That civil suit is still pending, but at the time it was filed Mr. Susman was still counsel for Whitlow. Mr. Susman, however, denies that anything of substance was done in connection with the defense of that case where he represented Whitlow. 
We are now in a position to set forth exactly what the present controversy involves. The plaintiff in the present suit, Wilson P. Abraham Construction Corporation, has filed a civil suit in Louisiana based primarily upon some facts which led to the Louisiana indictments. Counsel for the plaintiff in this suit is William E. Wright, the same person who had been counsel for another party in the Texas civil suit in which Mr. Susman represented Whitlow Steel Company. The defendants allege that the complaint in this case is virtually identical to the Texas complaint in which they were also party defendants. In any event, Mr. Wright has sought to engage Mr. Susman as co-counsel in this case. The defendants are challenging this alleging basically that Mr. Susman has a conflict of interest because of his previous relationship with them when he represented Whitlow Steel Company.

The law in this Circuit is fairly straightforward. This Court has recently reaffirmed with regards to attorney disqualification that a former client seeking to disqualify an attorney who appears on behalf of his adversary, need only to show that the matters embraced within the pending suit are substantially related to the matters or cause of action wherein the attorney previously represented him. This rule rests upon the presumption that confidences potentially damaging to the client have been disclosed to the attorney during the former period of representation. The Court may not even inquire as to whether such disclosures were in fact made or whether the attorney in fact is likely to use the damaging disclosures to the detriment of his former client. The inquiry is limited solely to whether the matters of the present suit are substantially related to matters of the prior representation, and this is because this Court recognizes that in order to aid the frank exchange between attorney and client, it is necessary to preclude even a possibility that information given in confidence by a former client will ever be used without that client's consent. The law in this Circuit is, of course, little more than a reinforcement of the Code of Professional Responsibility, Ethical Considerations, and Disciplinary Rules, promulgated by the American Bar Association and adopted by the Supreme Court of Louisiana effective July 1 , 1970.

The case before us, however, presents somewhat of a twist to the usual attorney-client controversy. It is not a former client of Mr. Susman who seeks to disqualify him, but rather codefendants of a former client. The defendants here contend that in a case alleging conspiracy, such as the case at bar, the defendants have a right to consult together about the case, and that all information derived by any of the counsel from such consultation is necessarily privileged. The defendants persuasively argue that in a joint defense of a conspiracy charge, the counsel of each defendant is, in effect, the counsel of all for the purposes of invoking the attorney-client privilege in order to shield mutually shared confidences. We agree, and hold that when information is exchanged between various co-defendants and their attorneys that this exchange is not made for the purpose of allowing unlimited publication and use, but rather, the exchange is made for the limited purpose of assisting in their common cause. In such a situation, an attorney who is the recipient of such information breaches his fiduciary duty if he later, in his representation of another client, is able to use this information to the detriment of one of the codefendants. Just as an attorney would not be allowed to proceed against his former client in a cause of action substantially related to the matters in which he previously represented that client, an attorney should also not be allowed to proceed against a co-defendant of a former 
client wherein the subject matter of the present controversy is substantially related to the matters in which the attorney was previously involved, and wherein confidential exchanges of information took place between the various co-defendants in preparation of a joint defense.

Having stated the bare facts of this rather complicated dispute, and having set forth the law, we unfortunately are unable to presently resolve the controversy. Exactly what information was exchanged between Mr. Susman when he represented Whitlow Steel Company and worked with counsel for the various defendants is greatly contested. Here there is no presumption that confidential information was exchanged as there was no direct attorney-client relationship. Mr. Susman should not be disqualified unless the trial court should determine that Mr. Susman was actually privy to confidential information. The parties also have a completely different version as to the similarity of the Texas grand jury investigation and the Louisiana investigation, and whether or not these investigations are substantially related to the present case.

Under these circumstances it is impossible for us to resolve this matter without some specific factual findings by the trial judge as to the content of the information which was exchanged and whether or not the present controversy is substantially related to the prior one. Nowhere in our search of the record were we able to find any findings made by the trial judge before he denied the defendants' motion to disqualify Mr. Susman. Consequently, we set aside the district court order denying the defendants' motion for disqualification and remand for the entry of formal findings of fact and conclusions of law dealing with these issues.

Doe v. A Corporation, 709 F. 2d 1043 (5th Cir. 1983)

Summary: Attorney John Doe was in-house counsel to A Corporation. Among other things, Doe advised A on its employee benefits. In 1980, Doe quit and filed an ERISA class action against $A$, alleging multiple claims, and seeking to represent a class of plaintiffs with similar claims. A filed a motion to dismiss Doe's action, and Doe withdrew as class counsel. The district court granted summary judgment to $A$, because Doe had received confidential information about $A$. The circuit court held that Doe could not represent the class or serve as class representative, because it would violate his duty of confidentiality to A. But it held that Doe could pursue his own claim against $A$.

ALVIN B. RUBIN, Circuit Judge:

A lawyer employed as house counsel for a corporation rendered legal advice concerning employee benefits to the corporation and to the administrators of its benefit plan. After he resigned from employment with the corporation, he sued for benefits allegedly due him under the corporation's pension and life insurance plans. He also sought to represent a class of other employees allegedly entitled to those benefits. We affirm the district court's judgment holding that he is barred by his ethical obligations as a lawyer from prosecuting such litigation as the class representative of other employees. However, we hold that he may prosecute an action in his own behalf and reverse that part of the judgment dismissing his personal claims. 
I.

The plaintiff, who is identified as John Doe, ${ }^{54}$ was employed in the legal department of A Corporation from 1975 to 1980. In his professional capacity as a lawyer, he consulted with and advised both A Corporation and the administrators of its Benefit Plan concerning legal questions about employee benefits, including those arising in the course of the administration of the Benefit Plan and those involving A Corporation's group life insurance policy and other benefits. He made daily decisions concerning the rights of individual employees and the acceptability of their beneficiary designations, gave the plan administrators legal advice, and worked with other lawyers in drafting plan provisions. These duties continued until Doe was transferred to $A$ Corporation's litigation section in April 1979. He resigned in March 1980.

Eleven months later Doe filed suit against A Corporation and $X$ Insurance Company, asserting a claim arising under the Employee Retirement Income Security Act of 1974, as well as pendent claims arising under state law. Doe alleged that $X$ Insurance Company had issued a group policy insuring the lives of A Corporation's employees. He alleged that premiums were paid on a contributory basis, partly by A Corporation and partly by its employees. As a result of its favorable experience, Doe claimed, X Insurance Company had paid dividends to A Corporation, which A Corporation retained without disclosing their receipt to its employees or to "the appropriate federal and state agencies." Doe also contended that he was improperly denied conversion of his policy to a "comparable term life" policy upon termination of his employment and was offered only the right to convert to whole life insurance. Doe conceded that, as part of his legal duties for A Corporation, he had advised the corporation whether it had a duty to disclose its receipt of dividends to plan participants.

In a separate suit against $A$ Corporation and its Benefit Plan, Doe contended that his pension benefits should have been vested when he resigned. This claim was based on a provision in the plan, required by ERISA, vesting plan benefits in an employee who has been employed for five years. Doe had completed four years and 1600 hours of employment and argued that this was legally sufficient for vesting under the plan and the applicable federal statute.

Doe signed the pleadings in each suit as co-counsel. In each he sought, in addition to prosecuting his own claim, to appear as representative of a class of employees having like claims. In each he sought broad relief for the members of the class, including equitable relief and damages, a "special award" for himself of one-third of any recovery, and an attorney's fee for himself and his co-counsel based on a percentage of the class recovery.

\footnotetext{
${ }^{54}$ To prevent identification of the company and the possible disclosure of confidential information concerning its affairs, the district court granted the defendant corporation's motion to seal the record; require the suit to be prosecuted without revealing the name of either the lawyer or the corporation; and enjoin Doe and his co-counsel from pursuing any actions arising out of the facts on which his suits were based, communicating with other persons to induce them to bring a similar action, and disclosing or using any information Doe gained during his employment by the corporation.
} 
A Corporation filed a motion to dismiss, to enjoin Doe and his co-counsel from prosecuting the suit, and to seal the record on the ground that Doe was barred from initiating a lawsuit because its prosecution would result in his violating the attorney-client privilege and in his disclosing confidential information. Benefit Plan, represented by the same counsel as A Corporation, joined in the motion. Doe withdrew as co-counsel for the class but continued to assert his right to appear both as an individual plaintiff and as a representative of the plaintiff class.

The district court treated the motion as one for summary judgment. It granted the motion, holding that Doe was disqualified to sue either A Corporation or Benefit Plan because they were his former clients. Relying on an irrebuttable presumption that the substantial relationship between Doe's duties for A Corporation and the issues in the suit would lead Doe to use his former clients' confidential information to their detriment in prosecuting the action, the court dismissed both suits with prejudice to Doe but without prejudice to a suit by any present or future employee of A Corporation.

A client is usually entitled to counsel of his choice. But the lawyer may be forbidden by ethical strictures to accept tendered employment. Because Doe has now withdrawn as counsel, we must go beyond the question whether he would be barred from acting as a lawyer for others whose interests conflict with those of his former client and consider how those ethical standards constrain his conduct in representing others as class representative, albeit not lawyer, and in asserting his own claims.

II.

The attorney-client privilege is evidentiary. A client may invoke it to prevent his lawyer from revealing communications made in confidence to the lawyer while acting in the capacity of professional legal adviser for the purpose of obtaining legal advice. However, during the course of representing a client, a lawyer may receive information that is not shielded by the privilege but is considered confidential by the client. He may, for example, receive information from some source other than the client or information imparted for a purpose other than obtaining legal advice.

Some of the information Doe acquired about A Corporation's affairs was protected by the attorney-client privilege. However, he apparently gained other information that was not privileged. For example, he apparently saw letters and other documents that originated with $X$ Insurance Company and received and answered questions from other A Corporation employees about their rights.

The Code of Professional Responsibility seeks to safeguard both the attorney-client privilege and other confidential information by restricting a lawyer's ability to accept employment that would threaten disclosure of either. Canon 4 deals directly with the matter: "A Lawyer Should Preserve the Confidences and Secrets of a Client." But other principles are also applicable, for Canon 9 states, "A Lawyer Should Avoid Even the Appearance of Professional Impropriety." 
These provisions protect not only against disclosure of privileged communications but also against the revelation of confidential information that is not privileged.

Ethical Consideration 4-4 states: "The attorney-client privilege is more limited than the ethical obligation of a lawyer to guard the confidences and secrets of his client. This ethical precept, unlike the evidentiary privilege, exists without regard to the nature or source of information or the fact that others share the knowledge." The ethical duty extends to shielding the confidentiality of all information acquired in the course of representing a client, preventing the use of any such knowledge to the client's disadvantage. "The use of the word 'information' in these Ethical Considerations as opposed to 'confidence' or 'secret' is particularly revealing of the drafters' intent to protect all knowledge acquired from a client without regard to whether someone else may be privy to it."

Adherence to Canon 4 requires that a lawyer be disqualified from representing a party to litigation if the adversary party can show that matters in the pending suit are substantially related to matters in which the attorney previously represented the adversary. A substantial relationship between issues in a lawsuit and a lawyer's earlier work for an adversary may also serve as the basis for disqualification under Canon 9.

If a lawyer seeks to act adversely to his former client in a matter that might involve disclosure of information acquired during the prior employment, the former client need not prove that the lawyer has used or is likely to use such information in order to disqualify the lawyer representing the party suing him. There is a conclusive and irrebuttable presumption that permitting the lawyer who has switched loyalties to represent the adversary of a former client in substantially related litigation will lead to disclosure and misuse of confidential information obtained during the previous representation.

The applicability of Canon 9 turns on whether the moving party has shown that there is a reasonable possibility of the occurrence of some specifically identifiable improper conduct and whether the likelihood of public suspicion outweighs the social interest in the lawyer's continued participation in the case.

If Doe were still attempting to represent the class as its lawyer, he would have a patent conflict of interest.

It must be remembered that the attorney in such situations as this does not have the shelter enjoyed by a defendant whose adversary must meet a burden of proof. Where conflict of interest or abuse of professional confidence is asserted, the right of an attorney freely to practice his profession must, in the public interest, give way in cases of doubt.

The standard of ethical conduct not only disqualifies Doe from representing a class as lawyer but also bars him from disclosing information he received from A Corporation to some other lawyer. A lawyer is not merely a panderer who is to do for a client anything that the client would 
like to do himself had he but the lawyer's knowledge. As a member of a profession that enjoys the exclusive license to engage in the practice of law, he is required to deny requests that would violate the ethical tenets of his profession even at the sacrifice of self-interest.

The responsibilities of a class representative are not identical to those of the lawyer for the class. The class representative need not be a member of the bar and is not subject to the profession's ethical constraints. But a representative owes duties to the class that require him to exert the utmost diligence on behalf of all of its members. To allow Doe to act as class representative would create a tension between his obligation as representative to do all he can to vindicate the rights of the class members and his personal ethical duty to protect $A$ Corporation's secrets. A lawyer may not, simply by assuming a new identity, escape the strictures that would govern his conduct were he representing the class as counsel. Doe contends that he must be permitted to represent the class because he has yet another identity as a fiduciary for Benefit Plan and his fellow employees of A Corporation. Although the attorneyclient privilege may be inapplicable when either the lawyer or the client stands in a fiduciary relationship to the party seeking disclosure, Doe simply was not such a fiduciary. He was a lawyer for and representative of A's corporate interest.

If there are meritorious causes of action against A Corporation, someone other than Doe can and must file the suit as class representative just as someone other than he must act as class counsel. Obviously, Doe may not divulge information that would enable another to volunteer as class representative. If no other class member ever learns of the claim, it may go forever unvindicated. The lawyer's duty to his client creates the possibility that his silence will permit valid claims to lie unasserted.

III.

The assertion of ethical barriers to Doe's attempt to vindicate his personal claims creates a conflict with another fundamental policy: the availability of a legal forum for the adjudication of rights. The Supreme Court has recognized that, in some circumstances, access to courts is protected by the due process clause. While the principle does not give any broad "right" of access to federal court, the courtroom door should not lightly be barred to a person who has a tenable legal claim.

The conflict between protection of the client's need for confidentiality and the lawyer's opportunity to assert claims against that client cannot be resolved on the basis that one enjoys universal primacy over the other. The Code makes confidentiality the general principle but recognizes exceptions to the prohibition against divulging even a client's secrets. Thus, a lawyer may reveal confidential information and secrets when it is necessary for him to do so to prevent the client from committing a crime, to collect a fee, or to defend himself against an accusation of wrongful conduct. The rationale for the last of these exceptions is: "It would be a manifest injustice to allow the client to take advantage of the rule of exclusion as to professional confidence to the prejudice of his attorney, or that it should be carried to the extent of depriving the attorney of the means of obtaining or defending his own rights." 
In none of the cases relied upon by A Corporation has a lawyer been prohibited from asserting a personal cause of action. In Richardson v. Hamilton International Corp., the plaintiff was an attorney who held stock in the defendant corporation. He had represented the corporation in his private practice before filing the lawsuit. He filed a shareholder's derivative action as a class action. The court disqualified him from appearing as a lawyer in the action and prohibited him from maintaining the suit while recognizing that another shareholder could maintain the action. Because a derivative suit is brought on behalf of the corporation, not the suing individual, the lawyer was not seeking to assert a cause of action to vindicate his personal rights.

Meyerhofer v. Empire Fire \& Marine Insurance Co. contains language arguably to the contrary. The court affirmed a district court decision "to the extent that the orders appealed from prohibit the attorney from acting as a party or as an attorney for a party." Yet the court had earlier in its opinion stated: "The attorney never sought to 'prosecute litigation,' either as a party or as counsel for a plaintiff party."

The distinction between what is forbidden to the lawyer appearing as an attorney-at-law and what is permitted an individual who is a lawyer but asserts only his personal rights was drawn in Hull v. Celanese. The court affirmed the disqualification of a law firm seeking to represent a potential intervenor in a sex discrimination suit. The intervenor was herself a lawyer and an employee of the defendant; she had worked on the defense of the sex discrimination suit in which she sought to intervene. The court made clear that: "This decision should not be read to imply that the lawyer cannot pursue her claim of employment discrimination based on sex."

In an attempt to demonstrate that Doe has been guilty of unethical conduct that should be added to the balance against him, A Corporation has brought to our attention material of record indicating impropriety. Before filing suit, Doe threatened A Corporation with litigation on behalf of a purported class if it did not meet demands that included the payment to him of a "contingent attorney fee" of $10 \%$ of a fund he described as "millions of dollars." From his actions thereafter, something other than a disinterested effort to vindicate the rights of a group of wronged employees might be inferred. When he filed suit, he did not seek only redress for his own claims and for those members of the classes he wished to represent: in the suit involving the group insurance, he demanded payment to himself, personally, of a "special award" of one-third of the "class" recovery, which he asserted to be in the "millions," as well as treble damages, and he sought "at least $\$ 300,000$ " as personal recompense in the suit against the Benefit Plan. In addition, he signed the complaints as co-counsel, and sought to be awarded an attorneys' fee in both actions, the fee in the group insurance suit to be based on a "percentage" of the "class" recovery. If, indeed, it develops after the facts are fully explored that Doe attempted either to blackmail or to mulct the corporation, we do not condone that conduct. If he has violated the Code of Professional Responsibility, disciplinary charges should be brought against him. The district court did not, however, dismiss Doe's personal claim because of his misconduct. The district judge granted summary judgment on the basis that Doe's prior representation of $A$ Corporation was a per se bar. A lawyer, however, does not forfeit his rights simply because to 
prove them he must utilize confidential information. Nor does the client gain the right to cheat the lawyer by imparting confidences to him.

The sole interest A Corporation can assert, other than defeating Doe's claim, is preservation of confidentiality for the secrets Doe learned while in its employment. The corporation's interest in confidentiality, however, can be at least partially protected by anonymity. There is no social interest in allowing the corporation to conceal wrongdoing, if in fact any has occurred. Nor is there any social interest in allowing it to deny Doe pension rights or insurance benefits if they are legally due him. But that would be the effect of our refusing to allow Doe to prosecute his individual lawsuit.

IV.

Doe, in turn, seeks to disqualify counsel for the defendants on the basis that they represent both A Corporation and the Benefit Plan, whose interests are allegedly conflicting. He relies on Disciplinary Rule 5-105(B), which provides: "A lawyer shall not continue multiple employment if the exercise of his independent professional judgment in behalf of a client will be or is likely to be adversely affected by his representation of another client, or if it would be likely to involve him in representing differing interests, except to the extent permitted under DR 5-105(C)."

Counsel representing both A Corporation and Benefit Plan assert that they have made a full disclosure to their respective clients and that both have consented to the joint representation, waiving any possible claim of conflict of interest which may arise. A potential or even real conflict of interest may, of course, be waived, even in criminal cases. At the moment, A Corporation and Benefit Plan share an important common interest in seeking to prevent misuse of their confidences by their former lawyer and employee. While their interests may at some time diverge, it is for them, once fully informed, to determine whether their lawyer can be faithful to both of their interests.

Accordingly, we AFFIRM as much of the judgment as dismisses the class action claims in both suits without prejudice, places the case records under seal, and enjoins Doe and co-counsel from communicating with other persons to induce them to file suit and from disclosing any confidential information Doe gained during his employment by A Corporation. We REVERSE the judgment insofar as it dismisses Doe's personal claim with prejudice and REMAND for further proceedings consistent with this opinion. Each party shall bear its own costs. 

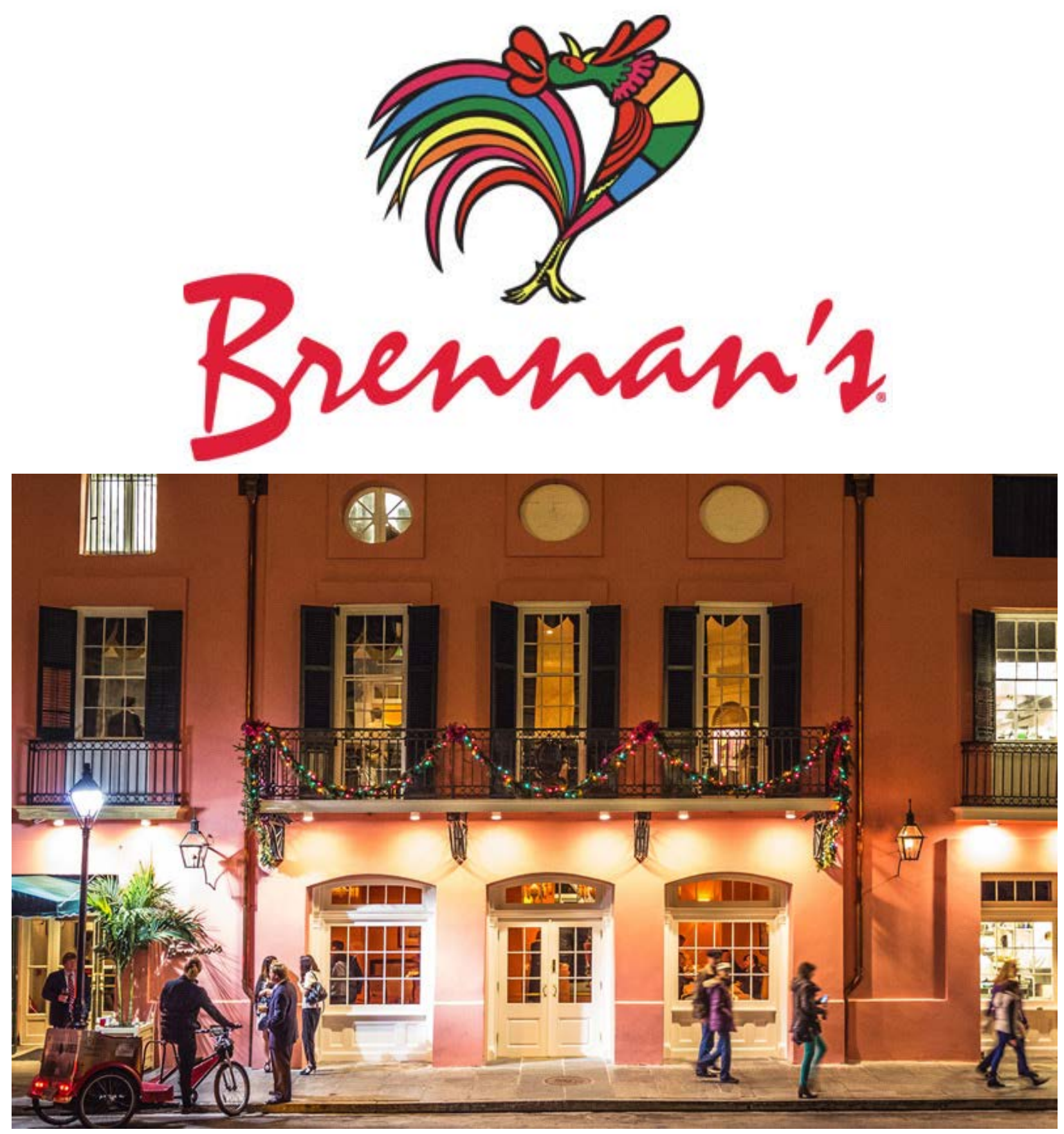

Brennan's, Inc. v. Brennan's Restaurants, Inc., 590 F. 2d 168 (5th Cir. 1979)

Summary: The Brennan family owned Brennan's, Inc. in New Orleans and Brennan's Restaurants, Inc., which operated other restaurants. Edward F. Wegmann was general counsel for all of the family businesses, and helped them register trademarks. After a dispute, the family divided the enterprise, but did not determine rights to the trademarks. Brennan's Restaurants filed a trademark infringement action against Brennan's, which hired Wegmann to represent it. Wegmann hired Arnold Sprung, a trademark specialist, as co-counsel. Brennan's Restaurants filed a motion to disqualify Wegmann and Sprung, 
which the district court grant. The circuit court affirmed the disqualification of Wegmann, based on the appearance of impropriety, but vacated and remanded the disqualification of Sprung, to determine whether he actually learned any confidential information from Wegmann.

\section{TJOFLAT, Circuit Judge:}

This is an action for trademark infringement and unfair competition. This appeal, however, concerns the disqualification of attorneys. The district court barred the appellants' attorneys from further representing them on grounds of conflict of interest. The correctness of this order is the only issue before us.

I

The underlying dispute in this case arises out of the business affairs of the Brennan family of New Orleans, Louisiana, who have been in the restaurant business for many years. All of the corporate parties are owned and closely held by various members of the Brennan family. Appellee Brennan's, Inc., the plaintiff below, owns and operates Brennan's restaurant at 417 Royal Street in New Orleans. The corporate appellants own and operate other restaurants in Louisiana, Texas, and Georgia. There has been no trial as yet, but a review of the facts leading to the present suit, as disclosed by the pleadings and affidavits, is necessary to a decision of this appeal. For convenience, the parties will be referred to in the capacities in which they appear in the court below.

Prior to 1974, all the members of the Brennan family were stockholders and directors of plaintiff, and some of them were stockholders and directors of the corporate defendants. All the corporations were independent legal entities in the sense that none held any of the stock of another, but they were all owned by members of the Brennan family and had interlocking boards of directors. In 1971, Edward F. Wegmann became general counsel for the family businesses, and his retainer was paid pro rata by all the corporations. He continued this joint representation until November 1973.

As part of his services, Mr. Wegmann, in close cooperation with trademark counsel in Washington, D.C., prosecuted applications for the federal registration of three service marks: "Brennan's," "Breakfast at Brennan's," and a distinctive rooster design. A registration for the rooster design was issued in February 1972, but the applications for the other two marks were initially denied on the ground that they were primarily a surname. On the advice of Washington trademark counsel, Mr. Wegmann collected data supporting a demonstration that the marks had acquired a secondary meaning, and the applications were amended to include this material. Registrations were subsequently issued in plaintiff's name in March 1973. These registered service marks are the subject of this lawsuit.

Later in 1973 a dispute developed within the Brennan family over the operation and management of the family businesses. This dispute was resolved in November 1974 by dividing 
the corporations' stock between the two opposing family groups. Plaintiff became $100 \%$ owned by one group and the corporate defendants became $100 \%$ owned by the second group, composed of the individual defendants. Mr. Wegmann elected to continue to represent defendants and severed his connections with plaintiff and its shareholders.

At no time during the negotiations which culminated in the November 1974 settlement was there any discussion of who would have the right to use the registered service marks. Both sides claimed ownership of the marks and continued to use them after the settlement. Attempts to negotiate a license or concurrent registration were unsuccessful. Plaintiff filed this suit for trademark infringement and unfair competition on May 21, 1976. In their answer and counterclaim defendants alleged that the marks were registered in plaintiff's name for convenience only, and, "in truth and actuality, the applications were filed and the registrations issued for the benefit and ownership of all of the Brennan family restaurants, including the corporate defendants." Defendants also alleged that the marks and registrations are invalid.

Upon the filing of this suit, Mr. Wegmann, on behalf of the defendants, retained the services of Arnold Sprung, a New York patent and trademark attorney, to assist him in the defense of the case. On October 22, 1976, plaintiff moved for the disqualification of both attorneys: Mr. Wegmann on the ground that his present representation was at odds with the interests of plaintiff, his former client, and Mr. Sprung by imputation of Mr. Wegmann's conflict. After a hearing, the district court granted the motion. It found that the subject matter of the present suit is substantially related to matters in which Mr. Wegmann formerly represented plaintiff, and to allow him now to represent an interest adverse to his former client creates the appearance of impropriety. It also found that "the close working relationship which has been shown to exist between Mr. Wegmann and Mr. Sprung creates a significant likelihood that Mr. Sprung would have had access to or been informed of confidential disclosures made to Mr. Wegmann by his former client."

II

We first consider the disqualification of Mr. Wegmann.

Defendants argue that the district court failed to consider that in his prior representation of plaintiff, Mr. Wegmann also represented defendants. This fact of joint representation is crucial, they assert, since no confidences can arise as between joint clients. Hence, the argument goes, Mr. Wegmann violates no ethical duty in his present representation.

We have not addressed this precise question before. In Wilson P. Abraham Construction Corp. v. Armco Steel Corp., we reaffirmed the standard that "a former client seeking to disqualify an attorney who appears on behalf of his adversary, need only to show that the matters embraced within the pending suit are substantially related to the matters or cause of action wherein the attorney previously represented him," but we acknowledged that "this rule rests upon the presumption that confidences potentially damaging to the client have been disclosed to the attorney during the former period of representation." Defendants contend that this presumption 
cannot apply in this case. This argument, in our view, interprets too narrowly an attorney's duty to "preserve the confidences and secrets of a client." The fundamental flaw in defendants' position is a confusion of the attorney-client evidentiary privilege with the ethical duty to preserve a client's confidences. Assuming the prior representation was joint, defendants are quite correct that neither of the parties to this suit can assert the attorney-client privilege against the other as to matters comprehended by that joint representation. But the ethical duty is broader than the evidentiary privilege: "This ethical precept, unlike the evidentiary privilege, exists without regard to the nature or source of information or the fact that others share the knowledge." "A lawyer should not use information acquired in the course of the representation of a client to the disadvantage of the client." The use of the word "information" in these Ethical Considerations as opposed to "confidence" or "secret" is particularly revealing of the drafters' intent to protect all knowledge acquired from a client, since the latter two are defined terms. Information so acquired is sheltered from use by the attorney against his client by virtue of the existence of the attorney-client relationship. This is true without regard to whether someone else may be privy to it. The obligation of an attorney not to misuse information acquired in the course of representation serves to vindicate the trust and reliance that clients place in their attorneys. A client would feel wronged if an opponent prevailed against him with the aid of an attorney who formerly represented the client in the same matter. As the court recognized in E.F. Hutton \& Co. $v$. Brown, this would undermine public confidence in the legal system as a means for adjudicating disputes. We recognize that this concern implicates the principle embodied in Canon 9 that attorneys "should avoid even the appearance of professional impropriety." We have said that under this canon there must be a showing of a reasonable possibility that some specifically identifiable impropriety in fact occurred and that the likelihood of public suspicion must be weighed against the interest in retaining counsel of one's choice. The conflict of interest is readily apparent here, however, and we think that the balance weighs in favor of disqualification. The need to safeguard the attorney-client relationship is not diminished by the fact that the prior representation was joint with the attorney's present client. Since the district court's findings of prior representation and substantial relationship are not disputed, we affirm the disqualification of Mr. Wegmann.

Whether Mr. Sprung should be disqualified presents a more difficult case. He has never had an attorney-client relationship with plaintiff; the district court disqualified him by imputation of Mr. Wegmann's conflict. Up to this point we have accepted, for the sake of argument, defendants' assertion that they were formerly joint clients with plaintiff of Mr. Wegmann. There is no dispute that plaintiff and defendants were previously represented by Mr. Wegmann simultaneously, but plaintiff maintains that, at least with respect to the registration of the service marks, Mr. Wegmann was representing plaintiff alone. The district court made no findings on the issue. Because we think that the disqualification of Mr. Sprung may turn on this fact and others not found by the court below, we vacate that part of the court's order relating to Mr. Sprung and remand the cause for further proceedings. For the guidance of the court on remand, we set forth our view of the applicable ethical standards. 
If the court finds that Mr. Wegmann previously represented plaintiff and defendants jointly, we can see no reason why Mr. Sprung should be disqualified. As between joint clients there can be no "confidences" or "secrets" unless one client manifests a contrary intent. Thus, Mr. Sprung could not have learned anything from Mr. Wegmann that defendants did not already know or have a right to know. Plaintiff argues that this permits the defendants indirectly to gain the benefit of Mr. Wegmann's services when they could not do so directly. If the representation was joint, however, defendants possess no information as to which plaintiff could have had any expectation of privacy in relation to the defendants. The only remaining ground for disqualification then would be an appearance of impropriety. In Part II of this opinion, we decided there is such an appearance when an attorney represents an interest adverse to that of a former client in a matter substantially related to the subject of the prior representation. Mr. Sprung has never been plaintiff's counsel, however; he is only the cocounsel of one who was. We are enjoined not to give Canon 9 an overly broad application and to maintain "a reasonable balance between the need to ensure ethical conduct on the part of lawyers and other social interests, which include the litigant's right to freely chosen counsel." In the case of Mr. Sprung, we think the balance weighs against disqualification. Assuming that Mr. Wegmann's prior retainer was joint, plaintiff has suffered no actual prejudice from communications between Mr. Wegmann and Mr. Sprung. There is a possibility that Mr. Sprung has obtained informally information that he would otherwise have had to seek through discovery. The Second Circuit has indicated that circumvention of the discovery rules is grounds for automatic disqualification. This seems to us an overly rigid approach. In a disqualification case, it is well to remember that "in deciding questions of professional ethics men of good will often differ in their conclusions." As the Second Circuit itself has said:

When dealing with ethical principles, we cannot paint with broad strokes. The lines are fine and must be so marked. Guideposts can be established when virgin ground is being explored, and the conclusion in a particular case can be reached only after painstaking analysis of the facts and precise application of precedent.

Under the peculiar facts of this case, we do not think there would be such an appearance of impropriety in Mr. Sprung's continued representation of defendants as to warrant his disqualification.

If the district court finds that Mr. Wegmann did not previously represent these parties jointly, it does not necessarily follow that Mr. Sprung should be disqualified. The courts have abjured a per se approach to the disqualification of cocounsel of disqualified counsel. In the absence of an attorney-client relationship between Mr. Sprung and plaintiff, a presumption of disclosure of confidences is inappropriate. Mr. Sprung should not be disqualified unless he has learned from Mr. Wegmann information the plaintiff had intended not be disclosed to the defendants.

Marcum v. Scorsone, 457 S.W.3d 710 (Ky. 2015)

Summary: Appellants Marcum, Conway, Foster Northrop, and Cheney sought a writ of prohibition in the Court of Appeals to bar enforcement of an order disqualifying their 
lawyers, the firm Miller, Griffin \& Marks, PSC (MGM), in a shareholder-derivative suit brought by Paul R. Plante, Jr., where the order was granted based on a finding of an "appearance of impropriety." The court held that MGM's representation of two shareholders and officers of the company while advising the company's board of directors did not create an actual conflict of interest. Moreover, the mere appearance of any resulting impropriety was not sufficient to merit MGM's disqualification.

OPINION OF THE COURT BY Justice, NOBLE.

Appellants, Frank D. Marcum, James D. Conway, Foster Northrop, and Mark Cheney, sought a writ of prohibition in the Court of Appeals to bar enforcement of an order disqualifying their lawyers, the firm Miller, Griffin, \& Marks, PSC (MGM), in a shareholder-derivative suit brought by the Real Party in Interest, Paul R. Plante, Jr., where the order was granted based on a finding of an "appearance of impropriety." The Court of Appeals denied the writ, concluding that one of the prerequisites for a writ, specifically a showing of irreparable harm, had not been made. This Court concludes that the Appellants have adequately shown the prerequisites for the availability of a writ and that the trial court applied an incorrect legal standard ("an appearance of impropriety") in disqualifying the firm. Moreover, disqualification was improper under the correct standard (a showing of actual conflict), at least based on the current record and findings of the trial court. Thus, this Court reverses and remands for entry of the requested writ.

\section{Background}

The shareholder-derivative suit underlying this writ action gives an excellent corporate representation of the infamous "Gordian knot." The Real Party in Interest (Plante) and the Appellants (Marcum, Conway, Northrop and Cheney), along with Bill Seanor, began their journey as the shareholders of Arthrodynamic Technologies Animal Health Division, Inc. (ADT), a Kentucky corporation that sells veterinary products. Originally, Marcum and Conway each owned $37.5 \%$ of the shares; Cheney owned $10 \%$; and Northrop, Plante, and Seanor each owned $5 \%$. All six shareholders were originally on the board of directors. Over time, disputes among the shareholders led to changes in the officers and membership of the corporate board.

In late 2010, Plante and Seanor seized control of the board, apparently having convinced a majority of the directors that Marcum and Conway had acted improperly, and caused Marcum and Conway to be removed from the board. Plante and Seanor were installed as the secretary and president respectively. In February 2011, Conway and Marcum, holding a total of $75 \%$ of the shares of ADT, returned to the board, though Plante and Seanor remained in their role as officers.

In March 2011, a majority of the board caused the corporation to file a lawsuit against Marcum and Conway in Fayette Circuit Court alleging breach of fiduciary duties, misappropriation of corporate funds, and other claims. The suit was later transferred to Woodford Circuit Court. 
Miller, Griffin and Marks (MGM) represented Marcum and Conway individually in that action through the services of Thomas Miller.

On August 29, 2011, Bioniche Animal Health USA, Inc., which had been ADT's manufacturer, filed suit against ADT in federal court over a contract dispute. ADT was defended in the litigation by Stites Harbison PLLC, a Kentucky law firm, and Sutherland Asbill \& Brennan LLP, a firm headquartered in Atlanta.

In October and November 2011, there was some shaking up of the board's membership related to Marcum's claimed purchase of shares owned by Northrop, Cheney, and Conway. Northrop tendered his resignation from the board, which was accepted at an October board meeting. In October, Cheney also executed a resignation letter, addressed to Seanor as president, but the letter was never delivered and was instead held by Marcum's counsel. Upon acceptance of Northrop's resignation, Bob Watson was named to the board in his stead. On October 31, 2011, a board meeting was held at which Seanor was removed as president and replaced by Marcum, Cheney was made vice-president, Seanor was made secretary, and Watson was made Treasurer.

At the board meetings in October and November 2011, MGM attorneys were present, recorded minutes, and participated in discussions with the board members. Before the November meeting, Marcum, acting as president, sent letters to the litigation firms asking that they take no further action in the Bioniche litigation. At the November 2011 meeting, MGM advised the directors to settle with Bioniche. Plante was a director at the time, and he objected to the settlement. Three of the four Appellants (Marcum, Cheney, and Conway) were also on the board at that time, however, and they, along with Watson, voted in favor of settling. Though the record does not disclose the exact timing, it appears that the lawsuit by ADT against Marcum and Conway was also discussed at these meetings, and it was dismissed soon after.

That, however, means that the suit by ADT against Marcum and Conway overlapped with the Bioniche litigation against ADT. Both were ongoing actions as of the October and November 2011 board meetings. As a result, MGM represented the two individuals, Marcum and Conway, in an action brought by ADT, at the board's behest, at the same time that the firm was advising the board in some capacity about the Bioniche suit.

On January 3, 2012, the underlying shareholder derivative action was filed by Plante and Seanor (who has since settled his claim) in Fayette Circuit Court. The original complaint named only two of ADT's directors, Marcum and Conway, as defendants. On April 18, 2012, Northrop came back on the board, replacing Watson. After some discovery, the complaint was amended to also name Cheney and Northrop as defendants. The suit alleges, among other things, that the Appellants had violated various provisions of ADT's shareholder agreement with respect to sales of stock. MGM was retained to represent Appellants as they defended against this claim. Another law firm, Stoll Keenon Ogden, represents ADT, which was included in the suit as a nominal party on whose behalf Plante has brought the suit. 
On June 18, 2012, Plante moved to disqualify MGM as the counsel for the Appellants, alleging that because MGM had represented the board, including Plante, in giving advice on the Bioniche litigation, and because MGM had represented Marcum and Conway individually in ADT's suit against them in Woodford County, MGM's participation in the underlying shareholder action created a conflict of interest or at least an appearance of impropriety sufficient to require MGM's disqualification. In other words, because MGM represented Marcum and Conway against ADT (of which Plante was a board member) in the Woodford County suit, and then represented the board in the Bioniche suit (by advising the board), MGM effectively acted as counsel both against the board and for the board. By extension, Plante, as a shareholder, argued that MGM had taken a position against him and represented him at the same time.

In January 2013, Marcum, Conway, Cheney, and Northrop met, acting as a quorum of the board. They adopted a resolution stating that there was no conflict of interest in MGM's representation of them "with respect to ADT," and purporting to waive any conflict that might exist.

Briefing and arguments regarding this motion and other matters occurred for some period of time. (The exact scope of these proceedings is not clear because a writ action does not contain the entire record of an underlying lawsuit.) Eventually, however, the motion was submitted for decision, and the trial court ruled in Plante's favor, granting his motion to disqualify MGM from representing the Appellants. The court specifically found that "during the course of MGM's representation of Conway and Marcum in the lawsuit filed against them by ADT, MGM also provided legal advice to the board of directors of ADT in a separate lawsuit with Bioniche."

But then the trial court specifically found, in the next two sentences, that it was making "no finding on whether Miller and MGM provided legal advice in their capacity as representative of Conway and Marcum or with the intent to represent ADT in settlement negotiations with Bioniche," and "no finding as to any actual impropriety on the part of Miller and MGM." (Emphasis added.) The court then said that it was difficult to see how Plante, as a part owner of the corporation ADT, could perceive that he got "utmost advocacy" when MGM represented "both the corporation in advising about Bioniche and individuals adverse to the corporation in the suit against Conway and Marcum." The court then concluded that disqualification of MGM was required based on "the appearance of impropriety" under Lovell v. Winchester.

The Appellants filed a writ action at the Court of Appeals. The court denied the writ because they had not shown irreparable injury, one of the usual prerequisites for issuance of such a writ.

The case is appealed to this Court as a matter of right.

\section{Analysis}

In disqualifying MGM, the trial judge, to his credit, was simply following precedent, namely, Lovell $v$. Winchester. He justified the disqualification because he saw an appearance of impropriety. He was bound by this Court's decision to apply that standard. 
But this Court is not so bound, except by the force of stare decisis. And this Court has concluded that disqualification based on an appearance of impropriety is inappropriate under the existing Rules of Professional Conduct. It is telling that the appearance-of-impropriety standard does not appear in those rules, except in commentary condemning its use and noting that it has been deleted from the rules. Although this Court has previously upheld the use of that standard in deciding lawyer disqualification questions, the standard must now be rejected. Disqualification under that standard is "little more than a question of subjective judgment by the former client." In essence, all the former client has to do is claim discomfort with the subsequent representation to create the appearance that something untoward is going on and thus that there is an appearance of impropriety. Moreover, "since 'impropriety' is undefined, the term 'appearance of impropriety' is question-begging." Even if impropriety is the same as an actual conflict, there should be something more substantive than just a possible conflict before disqualification takes place.

The simple fact is that disqualification is easier to achieve under the appearance-of-impropriety standard. While that is appropriate for judicial recusal questions, because there is a heightened concern about public confidence in the judiciary, that concern is less pressing when dealing with the private lawyer-client relationship. If anything, use of such a low standard in that context creates a "greater likelihood of public suspicion of both the bar and the judiciary" and "would ultimately be self-defeating," because it creates the impression that courts are ruling based on appearances rather than facts. Before a lawyer is disqualified based on a relationship with a former client or existing clients, the complaining party should be required to show an actual conflict, not just a vague and possibly deceiving appearance of impropriety. And that conflict should be established with facts, not just vague assertions of discomfort with the representation.

There is no doubt that personal choice of representation is based on a litigant's belief in the competency of chosen counsel, and the confidence placed in counsel. Even though all practicing lawyers are presumed to be competent, common sense dictates that not all lawyers share the same degree of competence. Otherwise, clients would not care who their lawyers were, and there would be little competition among lawyers for business. A litigant has the reasonable expectation that he will have the best representation he can and is willing to afford, and taking his chosen counsel away based on an "appearance" alone creates the belief that the court is arbitrary or capricious. That undermines faith in the judicial process, which, in turn, clearly affects the orderly administration of justice negatively in general and, in that specific case, irreparably. On the other hand, specific findings of an actual conflict refute arbitrariness, and promote faith in the fairness of the proceeding.

Lovell applied a standard that is no longer a part of the Rules of Professional Conduct and is simply inadequate to preserve the interests involved when a conflict of interest is alleged. To the extent that Lovell and other cases have approved the appearance-of-impropriety standard, they are overruled. Instead, in deciding disqualification questions, trial courts should apply the standard that is currently in the Rules of Professional Conduct, which at this time requires a showing of an actual conflict of interest. 
To resolve that question, the trial court must hold an evidentiary hearing. And before disqualifying counsel, the court must find that an actual conflict exists, and state on the record what that conflict is. To the extent that the trial judge did not do this, consideration of a specialcases writ is appropriate in this case. Thus, a writ is available as a remedy.

Moreover, this Court concludes that the writ should issue. In many ways, the trial court in this case complied with what we require today for disqualification of counsel. The trial court ordered briefing on the disqualification issue, and conducted multiple hearings. The court heard evidence and did not rely merely on allegations in motions and pleadings. And, as noted above, the trial court applied the standard previously approved by this Court.

But, also as noted above, that standard is no longer appropriate under the Rules of Professional Conduct. A mere appearance of impropriety, as found by the trial court in this case, cannot support disqualification of counsel. Such an extreme remedy must be based on an actual conflict of interest. And the trial court's order specifically stated it was not finding an actual impropriety, that is, an actual conflict.

Although the Court's order stated that MGM had represented ADT at the same time that it represented individuals adverse to $A D T$, that does not, by itself, support disqualification in the shareholder-derivative suit. First, it is not entirely clear that MGM actually represented the corporation when providing advice on whether to settle the Bioniche litigation. In fact, the trial court's order specifically states that it "makes no findings on whether Miller and MGM provided legal advice in their capacity as representatives of Conway and Marcum or with the intent to represent ADT in settlement negotiations with Bioniche." And ADT, as a corporate entity, had been represented by other counsel in that litigation. Although Plante has argued that MGM represented the corporation, whether that was actually the case is less than clear. Thus, the concern that MGM may have been both for and against ADT at the same time may be unfounded. At the very least, there are insufficient findings in the trial court's order to show an actual conflict.

Second, even if there was an actual conflict when MGM advised the board about the Bioniche litigation, while also representing Marcum and Conway against ADT, that conflict only extended to the Bioniche litigation. Once that case settled, and the Marcum-Conway case was dismissed, there was no longer a conflict stemming from the simultaneous representation-and certainly not one that extends to the derivative suit underlying this action.

For that reason, this Court concludes the trial court's disqualification order was improper under the standard articulated today. A writ of prohibition barring its enforcement is the appropriate remedy.

This is not to say, however, that Plante cannot show a sufficient conflict to have MGM disqualified once this case returns to the trial court. It is possible that by advising the board, of which Plante was a member, about the Bioniche litigation, MGM was representing Plante. Since 
the allegedly improper resolution of the Bioniche litigation is part of the underlying derivative suit, among other things, it is possible that MGM may have an actual conflict under Rule of Professional Conduct 1.9, which governs duties to former clients. There has also been some suggestion that MGM now represents the entire board, including Plante, in the derivative action, although only the Appellants appear to have been named as defendants. If MGM is representing the entire board, that could give rise to a conflict with an existing client under Rule 1.7.

But the focus in the trial court appears not to have been these possible conflicts, but the conflict that previously existed in the Bioniche litigation itself. Regardless, the trial court's order does not have findings sufficient to show such a conflict based on duties to former clients, and this Court cannot make such findings, especially based on the limited record in a writ action. If the issue is raised again in the trial court, it will be necessary to establish exactly who represents and has represented whom, and when the representation occurred before the conflict issues can be resolved. It will also be necessary to establish the precise relationship of the parties to each other and in what capacities they have sued or been sued.

\section{Conclusion}

The Court concludes that review of the disqualification order in this case is available through the special-cases exception for writs. Further, this Court concludes the trial court applied a disqualification standard that is no longer appropriate under the Rules of Professional Conduct, and that the trial court's factual findings are insufficient to allow disqualification under the proper standard of a showing of actual conflict. For those reasons, a writ of prohibition barring enforcement of the trial court's order is appropriate at this time, even though the issue of disqualification may be revisited in the trial court. The Court of Appeals' decision to deny the writ is therefore reversed, and this matter is remanded to that court to issue the writ. 


\section{6: Associational Conflicts of Interest}

When attorneys are associated with each other in a partnership, firm, or similar organization, a conflict of interest affecting one of the associated attorneys may be imputed to the other attorneys who are members of the association. For example, associated attorneys typically may not represent clients with adverse interests, just like individual attorneys may not represent clients with adverse interests. Associated attorneys may not represent new clients whose interests are adverse to the interests of a client of an associated attorney. And if the clients of an associated attorney develop adverse interests, the attorneys may be required to withdraw from representation.

Of course, conflicts of interest do not necessarily preclude representation. The clients of associated attorneys may provide informed consent to representation despite the conflict, just like the clients of individual attorneys.

Often, the clients of associated attorneys have conflicts of interest relating to the duty of confidentiality. If the conflict in question can be resolved by informed consent, associated attorneys often can avoid violating the duty of confidentiality by adopting screening procedures that prevent attorneys representing one client from accessing confidential information provided by the other client.

\section{Rule 1.10: Imputation of Conflicts of Interest: General Rule}

a. While lawyers are associated in a firm, none of them shall knowingly represent a client when any one of them practicing alone would be prohibited from doing so by Rules 1.7 or 1.9 , unless

1. the prohibition is based on a personal interest of the disqualified lawyer and does not present a significant risk of materially limiting the representation of the client by the remaining lawyers in the firm; or

2. the prohibition is based upon Rule 1.9(a) or (b) and arises out of the disqualified lawyer's association with a prior firm, and

i. the disqualified lawyer is timely screened from any participation in the matter and is apportioned no part of the fee therefrom;

ii. written notice is promptly given to any affected former client to enable the former client to ascertain compliance with the provisions of this Rule, which shall include a description of the screening procedures employed; a statement of the firm's and of the screened lawyer's compliance with these Rules; a statement that review may be available before a tribunal; and an agreement by the firm to respond promptly to any written inquiries or objections by the former client about the screening procedures; and

iii. certifications of compliance with these Rules and with the screening procedures are provided to the former client by the screened lawyer and by a partner of the firm, at reasonable intervals upon the former client's written request and upon termination of the screening procedures. 
b. When a lawyer has terminated an association with a firm, the firm is not prohibited from thereafter representing a person with interests materially adverse to those of a client represented by the formerly associated lawyer and not currently represented by the firm, unless:

1. the matter is the same or substantially related to that in which the formerly associated lawyer represented the client; and

2. any lawyer remaining in the firm has information protected by Rules 1.6 and 1.9 (c) that is material to the matter.

c. A disqualification prescribed by this rule may be waived by the affected client under the conditions stated in Rule 1.7.

d. The disqualification of lawyers associated in a firm with former or current government lawyers is governed by Rule 1.11 .

\section{Rule 1.10 Imputation of Conflicts of Interest: General Rule, Comment [1]}

For purposes of the Rules of Professional Conduct, the term "firm" denotes lawyers in a law partnership, professional corporation, sole proprietorship or other association authorized to practice law; or lawyers employed in a legal services organization or the legal department of a corporation or other organization.

\section{Rule 1.10 Imputation of Conflicts of Interest: General Rule, Comment [2]}

The rule of imputed disqualification stated in paragraph (a) gives effect to the principle of loyalty to the client as it applies to lawyers who practice in a law firm. Such situations can be considered from the premise that a firm of lawyers is essentially one lawyer for purposes of the rules governing loyalty to the client, or from the premise that each lawyer is vicariously bound by the obligation of loyalty owed by each lawyer with whom the lawyer is associated. Paragraph (a)(1) operates only among the lawyers currently associated in a firm.

\section{Restatement (Third) of the Law Governing Lawyers § 123 (2000): Imputation of a Conflict of Interest to an Affiliated Lawyer}

Unless all affected clients consent to the representation under the limitations and conditions provided in $\S 122$ or unless imputation hereunder is removed as provided in $\S 124$, the restrictions upon a lawyer imposed by §§ 125- 135 also restrict other affiliated lawyers who:

1. are associated with that lawyer in rendering legal services to others through a law partnership, professional corporation, sole proprietorship, or similar association;

2. are employed with that lawyer by an organization to render legal services either to that organization or to others to advance the interests or objectives of the organization; or

3. share office facilities without reasonably adequate measures to protect confidential client information so that it will not be available to other lawyers in the shared office.

Restatement (Third) of the Law Governing Lawyers § 124 (2000): Removing Imputation 
1. Imputation specified in $\S 123$ does not restrict an affiliated lawyer when the affiliation between the affiliated lawyer and the personally prohibited lawyer that required the imputation has been terminated, and no material confidential information of the client, relevant to the matter, has been communicated by the personally prohibited lawyer to the affiliated lawyer or that lawyer's firm.

2. Imputation specified in $\S 123$ does not restrict an affiliated lawyer with respect to a former-client conflict under $\S 132$, when there is no substantial risk that confidential information of the former client will be used with material adverse effect on the former client because:

a. any confidential client information communicated to the personally prohibited lawyer is unlikely to be significant in the subsequent matter;

b. the personally prohibited lawyer is subject to screening measures adequate to eliminate participation by that lawyer in the representation; and

c. timely and adequate notice of the screening has been provided to all affected clients.

3. Imputation specified in $\S 123$ does not restrict a lawyer affiliated with a former government lawyer with respect to a conflict under $\S 133$ if:

a. the personally prohibited lawyer is subject to screening measures adequate to eliminate involvement by that lawyer in the representation; and

b. timely and adequate notice of the screening has been provided to the appropriate government agency and to affected clients.

Cinema 5, Ltd. v. Cinerama, Inc., 528 F. 2d 1384 (2d Cir. 1976)

Summary: Attorney Manly Fleischmann was a partner in Jaeckle, Fleischmann and Mugel of Buffalo and in Webster, Sheffield, Fleischmann, Hitchcock and Brookfield of New York City. Cinerama distributed movies and operated movie theaters. Cinerama hired Fleischmann and Jaeckle to defend it in an antitrust action in upstate New York. Then, Cinema 5 hired Webster to represent it in an antitrust action in New York City. Cinerama filed a motion to disqualify Webster because Fleischmann was a partner. Fleischmann responded that the actions were not substantially related. The district court granted the motion, and the circuit court affirmed.

Before MOORE, FEINBERG and VAN GRAAFEILAND, Circuit Judges.

VAN GRAAFEILAND, Circuit Judge:

This appeal from an order granting defendants' motion to disqualify plaintiff's counsel presents a somewhat unusual set of facts. Counsel has been disqualified from further representation of plaintiff because a partner in this New York City law firm is also a partner in a Buffalo firm which is presently representing the defendant Cinerama, Inc. in other litigation of a somewhat similar nature. Although we agree with the district court that there was no actual wrongdoing and intend no criticism of the lawyers involved, we find no abuse of the district court's discretion, and so affirm. 
There is little or no dispute as to the facts, most of them having been stipulated. Attorney Manly Fleischmann is a partner in Jaeckle, Fleischmann and Mugel of Buffalo and in Webster, Sheffield, Fleischmann, Hitchcock and Brookfield of New York City. He divides his time between the two offices. Cinerama is a distributor of motion pictures and the operator of several large theater chains. In January 1972 the Jaeckle firm was retained to represent Cinerama and several other defendants in an action brought in the United States District Court for the Western District of New York. Plaintiffs in that suit are local upstate theater operators who allege antitrust violations resulting from discriminatory and monopolistic licensing and distribution of motion pictures in the Rochester area. A similar action involving allegedly illegal distribution in the Buffalo area was commenced in March 1974, and the Jaeckle office represents the interests of Cinerama in this action also. Both suits are presently pending in the Western District.

The instant action, brought in the Southern District of New York in August 1974, alleges a conspiracy among the defendants to acquire control of plaintiff corporation through stock acquisitions, with the intention of creating a monopoly and restraining competition in New York City's first-run motion picture theater market. Judge Brieant found that there was sufficient relationship between the two law firms and the two controversies to inhibit future confidential communications between Cinerama and its attorneys and that disqualification was required to avoid even the appearance of professional impropriety.

Appellant's counsel strongly dispute these findings. They say that they should not be disqualified unless the relationship between the controversies is substantial, and they contend there is nothing substantial in the relationship between an upstate New York conspiracy to deprive local theater operators of access to films and an attempted corporate take-over in New York City.

The "substantial relationship" test is indeed the one that we have customarily applied in determining whether a lawyer may accept employment against a former client. However, in this case, suit is not against a former client, but an existing one. One firm in which attorney Fleischmann is a partner is suing an actively represented client of another firm in which attorney Fleischmann is a partner. The propriety of this conduct must be measured not so much against the similarities in litigation, as against the duty of undivided loyalty which an attorney owes to each of his clients.

A lawyer's duty to his client is that of a fiduciary or trustee. When Cinerama retained Mr. Fleischmann as its attorney in the Western District litigation, it was entitled to feel that at least until that litigation was at an end, it had his undivided loyalty as its advocate and champion, and could rely upon his "undivided allegiance and faithful, devoted service." Because "no man can serve two masters," Matthew 6:24, it had the right to expect also that he would "accept no retainer to do anything that might be adverse to his client's interests." Needless to say, when Mr. Fleischmann and his New York City partners undertook to represent Cinema 5, Ltd., they owed it the same fiduciary duty of undivided loyalty and allegiance. 
Ethical Considerations 5-1 and 5-14 of the American Bar Association's Code of Professional Responsibility provide that the professional judgment of a lawyer must be exercised solely for the benefit of his client, free of compromising influences and loyalties, and this precludes his acceptance of employment that will adversely affect his judgment or dilute his loyalty. The Code has been adopted by the New York State Bar Association, and its canons are recognized by both Federal and State Courts as appropriate guidelines for the professional conduct of New York lawyers.

Under the Code, the lawyer who would sue his own client, asserting in justification the lack of "substantial relationship" between the litigation and the work he has undertaken to perform for that client, is leaning on a slender reed indeed. Putting it as mildly as we can, we think it would be questionable conduct for an attorney to participate in any lawsuit against his own client without the knowledge and consent of all concerned. This appears to be the opinion of the foremost writers in the field, and it is the holding of the New York courts. In Matter of Kelly, New York's highest court said that "with rare and conditional exceptions, the lawyer may not place himself in a position where a conflicting interest may, even inadvertently, affect, or give the appearance of affecting, the obligations of the professional relationship." Nor is New York alone in this view. In Grievance Committee v. Rottner, Connecticut's highest court held that the maintenance of public confidence in the bar requires an attorney to decline employment adverse to his client, even though the nature of such employment is wholly unrelated to that of his existing representation.

Whether such adverse representation, without more, requires disqualification in every case, is a matter we need not now decide. We do hold, however, that the "substantial relationship" test does not set a sufficiently high standard by which the necessity for disqualification should be determined. That test may properly be applied only where the representation of a former client has been terminated and the parameters of such relationship have been fixed. Where the relationship is a continuing one, adverse representation is prima facie improper, and the attorney must be prepared to show, at the very least, that there will be no actual or apparent conflict in loyalties or diminution in the vigor of his representation. We think that appellants have failed to meet this heavy burden and that, so long as Mr. Fleischmann and his Buffalo partners continue to represent Cinerama, he and his New York City partners should not represent Cinema 5, Ltd. in this litigation.

Because he is a partner in the Jaeckle firm, Mr. Fleischmann owes the duty of undivided loyalty to that firm's client, Cinerama. Because he is a partner in the Webster firm, he owes the same duty to Cinema 5, Ltd. It can hardly be disputed that there is at least the appearance of impropriety where half his time is spent with partners who are defending Cinerama in multimillion dollar litigation, while the other half is spent with partners who are suing Cinerama in a lawsuit of equal substance. ${ }^{55}$

\footnotetext{
${ }^{55}$ Mr. Fleischmann's personal participation in the Buffalo litigation was minimal, and we are confident that he would make every effort to disassociate himself from both lawsuits and would not divulge any information that came to him concerning either. However, we cannot impart this same confidence to the public by court order.
} 
Because "an attorney must avoid not only the fact, but even the appearance, of representing conflicting interests," this requires his disqualification. Moreover, because of the peculiarly close relationship existing among legal partners, if Mr. Fleischmann is disqualified, his partners at the Webster firm are disqualified as well.

Nothing that we have heretofore said is intended as criticism of the character and professional integrity of Mr. Fleischmann and his partners. We are convinced that the dual representation came about inadvertently and unknowingly, and we are in complete accord with Judge Brieant's finding that there has been no actual wrongdoing. Furthermore, the record shows that after learning of the conflict which had developed, the Jaeckle firm, through Mr. Fleischmann, offered to withdraw its representation of Cinerama in the Western District actions. However, that offer was not accepted, and Mr. Fleischmann continued, albeit reluctantly, to have one foot in each camp.

Under the circumstances, Judge Brieant's order of disqualification cannot be construed as an abuse of his discretion. We therefore affirm.

\section{Questions:}

1. Why did the court grant Cinerama's motion to disqualify Fleischmann? Did it identify a conflict of interest? Was Fleischmann working on the action against Cinerama?

2. Why did Cinerama file a motion to disqualify Webster? Should Cinema 5's preferences matter under the circumstances?

\section{Borden v. Borden, 277 A. 2d 89 (D.C. App. 1971)}

Summary: Helen Borden filed a complaint to divorce her husband, George, on the ground of adultery. Helen was represented by an attorney from the Neighborhood Legal Services Program (NLSP). Helen's attorney moved for assignment of counsel to represent George. The trial court ordered attorney David S. Raycroft, who works for NLSP, to represent George. Both attorneys from NLSP filed a motion to set aside the trial court's order since both attorneys were employed by NLSP and the order created a conflict of interest under the Code of Professional Responsibility. The trial court denied the motion because no economic conflict existed. The appellate court reversed, because the NLSP functions as a firm and there is an inherent conflict of interest that public policy concerns do not override.

KERN, Associate Judge:

The issue presented by this appeal is whether it was error for the trial judge sitting in the Domestic Relations Branch of the District of Columbia Court of General Sessions to refuse to vacate his order assigning an attorney employed by the Neighborhood Legal Services Program (NLSP) to represent the defendant in this action, when the plaintiff was already represented by an NLSP lawyer. 
On September 22, 1969, appellant Helen Borden filled a complaint seeking a divorce from appellee George Borden on the ground of adultery. On April 2, 1970, appellant, represented by an attorney from NLSP and proceeding in forma pauperis, moved for assignment of counsel to represent appellee. The trial court ordered David S. Raycroft, an attorney employed by the NLSP, to enter an appearance on behalf of and represent appellee. On June 8, 1970, appellant's attorney, joined by appellee's attorney, filed a motion to set aside the trial court's order of appointment of counsel on the ground that since both attorneys in the case were employed by the NLSP the order created a conflict of interest under the Code of Professional Responsibility, and the divorce ultimately obtained could be invalid due to alleged collusion.

On June 9, 1970, the trial judge denied the motion to set aside his appointment of counsel, relying specifically on his order in another case, McGee v. McGee, which stated, inter alia:

Since, therefore, no economic conflict exists, no corporate interests is in any way involved and no legal partnership as such has been disclosed it would appear that in fact and objectively speaking there is no conflict of interest.

Mrs. Borden appeals from this order of denial.

While the trial court's refusal to set aside his order of appointment is not final in the sense of disposing of the case on its merits, it does have "a final and irreparable effect upon the rights of the parties" and is therefore appealable. The effect of the trial court's order is to force the parties to go to trial represented by attorneys who practice law within the same organization, which appears on its face to constitute a conflict of interest, and who have stated upon the record their inability to represent the cause of their clients and remain faithful to the Code of Professional Responsibility. In addition, the parties have ground for concern that the final decree in the case on the merits could be subject to the subsequent charge of collusion and its validity thus put in question. We think that the administration of justice would best be served by recognizing the cloud which the order of appointment of counsel has put upon the present proceedings and by treating the order as final for the purpose of review.

Turning to the merits of the assignment of counsel order, it is axiomatic that members of the same law firm may not represent adverse parties. Corporation Counsel concedes this but takes the position that:

NLSP cannot be analogized to the typical law firm for purposes of application of the conflict-of-interest concept NLSP's activities more logically fall within the group legal services concept.

It argues that under N.A.A.C.P. v. Button, the constitutional right being asserted must be balanced on the scale of public interest against the alleged professional impropriety. When this is done, in the instant case, so the argument goes, the right and need of the poor to have legal representation in domestic relations matters is paramount to the allegedly remote possibility of a 
conflict of interest growing out of the representation of both parties by NLSP attorneys. It is pointed out that since NLSP attorneys receive no compensation from their clients there can be no economic conflict of interest, as would be the case if they were practicing in the same law firm.

We are not persuaded that the possibility of conflict of interest which appellee's attorney proffered as his reason for wishing to withdraw from participation in this case is remote. While the NLSP is not a law firm it is a group of attorneys practicing law together in an organizational structure much like a law firm. It has a Board of Directors and an Executive Director who are analogous to a firm's managing partners. It has one attorney in each of its branch offices whose responsibility is to supervise the junior attorneys, much like a firm's senior partner working with his associates. All NLSP attorneys participate in office meetings and receive intra-office communications on substantive law, litigation techniques and tactics and office policy. Lawyers who practice their profession side-by-side, literally and figuratively, are subject to subtle influences that may well affect their professional judgment and loyalty to their clients, even though they are not faced with the more easily recognized economic conflict of interest. In addition, the appointment of attorneys who work together presents an impression scarcely consistent with the bar's efforts to maintain public confidence in the law and lawyers.

Also we fail to find in this case the extraordinary circumstances present in N.A.A.C.P. v. Button, where legal representation to vindicate constitutional rights of a group of citizens was simply unavailable except in the form of group legal services which the State contended amounted to barratry, maintenance and champerty. With all deference to the trial court's efforts to date to assure full representation of all who seek access to the Domestic Relations Court we are not persuaded that the supply of attorneys available in the District of Columbia has been exhausted so that NLSP attorneys must now represent both sides of a divorce action.

Finally, we are reluctant to approve any action in the matter of professional ethics which distinguishes between attorneys who are in private practice and attorneys who are not. In the first place, Congress has expressly recognized that "anti-poverty lawyers" are to be governed by the traditional standards of the profession. The ABA has held that legal aid attorneys have a "primary obligation of loyalty" to their clients and are required "to act in accordance with the Code of Professional Responsibility." Other jurisdictions have specifically barred anti-poverty lawyers from representing adverse parties in domestic relations litigation because such representation falls afoul of the Canons. We are reluctant ever to make an exception from the professional norm for attorneys employed by the government or others who provide legal representation without compensation from the client because then we might encourage a misapprehension that the special nature of such representation justifies departure from the profession's standards. We should avoid always any action that would give the appearance that government attorneys are "legal Hessians" hired "to do a job" rather than attorneys at law. On the other hand, we should expect always from these attorneys uncompromising adherence to the profession's established standards. 
We conclude that it was error for the trial court to refuse to vacate its assignment of an NLSP attorney to represent appellee in the trial of appellant's divorce action which was being presented by another NLSP attorney and that this case must be remanded for appointment of new counsel for appellee.

\section{Questions:}

1. What was the conflict of interest?

2. Why did NLSP's corporate counsel argue against the motion?

3. What public policy concerns did the court say were not sufficient to override the inherent conflict of interest?

4. Did the court's ruling harm or benefit NLSP's mission to provide legal services to the poor?

People ex rel. Dept. of Corporations v. SpeeDee Oil Change Systems, Inc., 20 Cal. 4th 1135 (Cal. 1999)

Summary: Attorney Eliot G. Disner was "of counsel" to Shapiro, Rosenfeld \& Close. Attorney Geordan Goebel represented SpeeDee Oil Change Systems. Goebel consulted with Shapiro about an antitrust action SpeeDee had filed against Mobil Oil, and then associated Shapiro with the action as counsel. Cohon and Gardner represented Mobil in the SpeeDee action. Cohon consulted with Disner about the SpeeDee action, and planned to retain him as a consultant. But when Cohon and Gardner learned that Shapiro was representing SpeeDee, they filed a motion to disqualify the firm, because of its association with Disner. The trial court denied the motion, and the intermediate appellate court affirmed, because Disner did not provide any confidential information to Shapiro. The California Supreme Court reversed, because Disner represented adversaries in the same litigation.

CHIN, J.

When a conflict of interest requires an attorney's disqualification from a matter, the disqualification normally extends vicariously to the attorney's entire law firm. This rule safeguards clients' legitimate expectations that their attorneys will protect client confidences. Here, we decide whether the same rule should apply when a party unknowingly consults an attorney "of counsel" to the law firm representing the party's adversary in the subject of the consultation.

Mobil Oil Corporation consulted Attorney Eliot G. Disner, who was of counsel to Shapiro, Rosenfeld \& Close. Mobil was a defendant in a complaint in intervention by respondents Gary and Annette Burch et al., Southern California franchisees of SpeeDee Oil Change Systems, Inc. While Mobil was consulting Disner, respondents associated the Shapiro firm as counsel of record in their action against Mobil. Mobil moved to disqualify the Shapiro firm 
upon learning of its association, arguing that Disner had a conflict of interest that required its vicarious disqualification.

The trial court denied Mobil's motion. The court found no basis for a presumption that Disner disclosed confidences to the Shapiro firm, notwithstanding Disner's relationship with the firm. The Court of Appeal affirmed, concluding that substantial evidence existed for implied findings that Disner's relationship with the Shapiro firm was not "close, personal, continuous, and regular" and that Disner conveyed no confidential information to the firm. We granted Mobil's petition for review.

We adopt the prevailing rule concerning "of counsel" conflicts of interest and reverse the judgment of the Court of Appeal. For attorneys in the same firm to represent adverse parties in the same litigation is so patently improper that the rule of disqualification is a per se or "automatic" one. Conflicting representations that would disqualify all of a law firm's attorneys are not more acceptable when an attorney of counsel to the firm creates the conflict. Clients, and the public, should expect confidentiality and loyalty from attorneys who effectively declare they practice law in a close, personal, and continuing association. These legitimate expectations would be frustrated if a firm could represent one party in litigation while an attorney of counsel to the firm represented an adversary in the same case.

\section{FACTUAL AND PROCEDURAL BACKGROUND}

Attorney Geordan Goebel, a sole practitioner, had represented respondents since 1994. Because of the action's scope, he decided to associate a law firm as attorneys of record to help him prosecute respondents' claims. Goebel approached the Shapiro firm because of its expertise in franchise law and met with Mitchell Shapiro on June 22, 1996. Around this time, the Shapiro firm's letterhead listed 14 attorneys' names, with 4 more attorneys listed as of counsel to the firm, all at the same office address. Among those identified as of counsel to the firm was Eliot G. Disner, an attorney who had substantial experience with antitrust issues.

Over the next few weeks, Goebel developed a "good working relationship" with the Shapiro firm. On July 10, he signed a notice associating the Shapiro firm as counsel of record for respondents. Mitchell Shapiro signed the notice for the Shapiro firm on July 12. The notice of association of counsel was served by mail on July 15, 1996, and filed with the court the following day.

The law firm of Cohon and Gardner represented Mobil in the SpeeDee Oil action. Early in July 1996, Jeffrey Cohon, an associate with Cohon and Gardner, spoke to Attorney Steven Hecht about contacting Disner concerning the case. Hecht knew both Cohon and Disner personally. To facilitate an initial check for conflicts, Cohon told Hecht the name of the case and the principal attorneys involved. Hecht spoke with Disner later that week. Hecht asked 
Disner if he knew of the case involving SpeeDee Oil and Mobil. When Disner said he did not, Hecht asked him to call Jeffrey Cohon.

Disner and Cohon spoke by telephone on July 11 or 12 . When Cohon returned Disner's call, the receptionist answered the telephone, "Shapiro, Rosenfeld and Close." Cohon's call was put through to Disner, who confirmed he had spoken with Hecht and had not heard of the SpeeDee Oil case or the attorneys involved in it. In a conversation Cohon believed was confidential, he and Disner discussed the case's substantive allegations, its procedural status, and Mobil's theories. They arranged a meeting for July 16.

On July 16, 1996, Cohon and Gardner Attorneys Bennett Cohon, Jeffrey Cohon, and Steven Gardner met with Disner to discuss his assisting with Mobil's representation. They spoke for one to two hours over lunch. Gardner received a copy of Disner's resume, which—like Disner's business card—prominently featured the Shapiro firm's name and address.

Gardner briefed Disner on the case and Mobil's position. The matters disclosed to Disner included "the background of the case, Mobil's theories in the case, Mobil's discovery strategy and an analysis of the procedural and substantive issues which had arisen to date and [were] likely to arise in the future, the state of the case, experts, and consultants, and specific factual issues." The Cohon and Gardner attorneys considered the information disclosed to Disner to be confidential and attorney work product.

According to Gardner's and Jeffrey Cohon's declarations, when the meeting ended, Gardner and Disner agreed to prepare a document formally retaining Disner as a consultant. Disner did not directly contradict the Cohon and Gardner attorneys' statements. His declaration stated that at the end of the meeting, the Cohon and Gardner attorneys "expressed interest" in using his services, although they did not know "exactly" how they intended to do so.

Gardner further declared that Disner agreed to check some statutes and case law that applied to a few of the issues they discussed. He stated that he and Disner spoke again later in the afternoon of July 16, and Disner conveyed the results of his review of those issues. No declaration contradicted Gardner's account of those discussions.

The next day, July 17, Gardner received the notice of the Shapiro firm's association as counsel for respondents. Consequently, that same day the Cohon and Gardner firm informed Disner that Mobil would not be using his services. Gardner immediately faxed a letter to the Shapiro firm, Disner, and Goebel, stating that Mobil objected to the Shapiro firm's participation in the case on behalf of respondents. Gardner's letter asserted the Shapiro firm had an ethical conflict because of Cohon and Gardner's conversations with and disclosures to Disner concerning the case. The Shapiro firm responded with a letter 
faxed the next day, contending there was no basis for the firm's disqualification. The response stated that the Shapiro firm had already associated as counsel for respondents when Disner met with the Cohon and Gardner attorneys. The response also stated that Disner was of counsel to the Shapiro firm and not an associate, partner, or shareholder.

Four days later, on July 22, 1996, Mobil filed an ex parte application for an order shortening time for a motion to disqualify the Shapiro firm. Mobil's motion was set for hearing on July 24,1996 . The moving and opposing papers included declarations and exhibits setting out the facts related above. In addition, Disner's declaration stated he had not "discussed the merits of the SpeeDee Oil action with any attorney or other employee" of the Shapiro firm. $\mathrm{He}$ also said he customarily reviewed possible conflicts of interest with the firm before associating with them on cases. Disner and the Shapiro firm did not discuss a potential conflict in this instance because neither had asked the other to associate for the SpeeDee Oil case. Similarly, Mitchell Shapiro declared that he had "not discussed this action" with Disner and did not know "what was discussed between" Disner and the Cohon and Gardner attorneys.

The Shapiro firm's declarations submitted in opposition to Mobil's motion provided additional details of the firm's relationship with Disner. Disner's declaration stated: "Although I am designated as 'Of Counsel' to SRC [the Shapiro firm], I have a separate law practice from SRC. I have my own clients, whom I bill separately from SRC. I pay rent to SRC for office space. I have my own staff whom I pay for their services. I do not share in any profits of SRC, nor do I incur any liabilities on behalf of SRC. In those few cases (perhaps 3-4 per year) on which I associate with SRC, which is strictly determined on a case-by-case basis, if I use any attorney from SRC to perform services, I pay SRC a percentage of that attorney[s] usual hourly rate for the time spent working on my clients' cases. Similarly, if SRC uses my services on any cases, it pays me a percentage of my usual hourly fee for services rendered."

The trial court denied Mobil's motion to disqualify the Shapiro firm. The court decided the matter based on the written submissions, stating: "There is no basis on which to presume that Eliot Disner, Esq., who is of counsel to the Shapiro firm, imparted any confidential information to the firm, as concerns this case. Disner and the Shapiro firm were initially unaware of each other's involvement in this case and Disner was not retained by MOBIL nor is he presently involved in this case."

Court of Appeal affirmed the trial court's order, applying an abuse of discretion standard of review. The court viewed the matter as one involving conflicting evidence and inferences on the actual nature of the particular "of counsel" relationship in question: "We agree that if the Shapiro firm simultaneously represented both Mobil and the respondents in this litigation, it would be subject to automatic disqualification. And we assume for purposes of discussion that by performing legal research for Mobil, Mr. Disner represented it. However, the trial 
court impliedly concluded Mr. Disner practiced law separate and apart from [the Shapiro firm] except on those few annual occasions when Mr. Disner or [the Shapiro firm] associated the other on a particular case.... [There] was probative and persuasive evidence of a 'close, personal, continuous, and regular' professional affinity which characterizes the 'of counsel' relationship.... However, there was conflicting evidence which indicated there was in reality no 'close, personal, continuous, and regular' relationship.... Simply stated, the evidence concerning the relationship was in conflict and the trial judge resolved that dispute in favor of one side. Furthermore, even if a concern for client confidentiality arose on the facts of this case, substantial evidence established Mr. Disner did not impart any confidential information to [the Shapiro firm]. Therefore, we find no abuse of discretion."

\section{DISCUSSION}

This case requires us to resolve two distinct questions. First, were Disner's contacts and discussions with the Cohon and Gardner attorneys such that he represented Mobil for purposes of a conflict of interest analysis? Second, if so, should any conflict of interest be imputed to the law firm to which he was of counsel so as to require its disqualification? To answer these questions, we first review the principles involved when one party seeks to disqualify its opponent's counsel, beginning with the appropriate standard of appellate review.

\section{DISQUALIFICATION PRINCIPLES}

A motion to disqualify a party's counsel may implicate several important interests. Consequently, judges must examine these motions carefully to ensure that literalism does not deny the parties substantial justice. Depending on the circumstances, a disqualification motion may involve such considerations as a client's right to chosen counsel, an attorney's interest in representing a client, the financial burden on a client to replace disqualified counsel, and the possibility that tactical abuse underlies the disqualification motion. Nevertheless, determining whether a conflict of interest requires disqualification involves more than just the interests of the parties.

A trial court's authority to disqualify an attorney derives from the power inherent in every court "[t]o control in furtherance of justice, the conduct of its ministerial officers, and of all other persons in any manner connected with a judicial proceeding before it, in every matter pertaining thereto." Ultimately, disqualification motions involve a conflict between the clients' right to counsel of their choice and the need to maintain ethical standards of professional responsibility. The paramount concern must be to preserve public trust in the scrupulous administration of justice and the integrity of the bar. The important right to counsel of one's choice must yield to ethical considerations that affect the fundamental principles of our judicial process. 
Protecting the confidentiality of communications between attorney and client is fundamental to our legal system. The attorney-client privilege is a hallmark of our jurisprudence that furthers the public policy of ensuring "'the right of every person to freely and fully confer and confide in one having knowledge of the law, and skilled in its practice, in order that the former may have adequate advice and a proper defense.' [Citation.]" To this end, a basic obligation of every attorney is "[t]o maintain inviolate the confidence, and at every peril to himself or herself to preserve the secrets, of his or her client."

To protect the confidentiality of the attorney-client relationship, the State Bar Rules of Professional Conduct prohibits attorneys from accepting, without the client's informed written consent, "employment adverse to the client or former client where, by reason of the representation of the client or former client, the [attorney] has obtained confidential information material to the employment." Where an attorney successively represents clients with adverse interests, and where the subjects of the two representations are substantially related, the need to protect the first client's confidential information requires that the attorney be disqualified from the second representation. For the same reason, a presumption that an attorney has access to privileged and confidential matters relevant to a subsequent representation extends the attorney's disqualification vicariously to the attorney's entire firm.

A related but distinct fundamental value of our legal system is the attorney's obligation of loyalty. Attorneys have a duty to maintain undivided loyalty to their clients to avoid undermining public confidence in the legal profession and the judicial process. The effective functioning of the fiduciary relationship between attorney and client depends on the client's trust and confidence in counsel. The courts will protect clients' legitimate expectations of loyalty to preserve this essential basis for trust and security in the attorney-client relationship. Therefore, if an attorney—or more likely a law firm—simultaneously represents clients who have conflicting interests, a more stringent per se rule of disqualification applies. With few exceptions, disqualification follows automatically, regardless of whether the simultaneous representations have anything in common or present any risk that confidences obtained in one matter would be used in the other.

The most egregious conflict of interest is representation of clients whose interests are directly adverse in the same litigation. Such patently improper dual representation suggests to the clients - and to the public at large - that the attorney is completely indifferent to the duty of loyalty and the duty to preserve confidences. However, the attorney's actual intention and motives are immaterial, and the rule of automatic disqualification applies. "The rule is designed not alone to prevent the dishonest practitioner from fraudulent conduct," but also to keep honest attorneys from having to choose between conflicting duties, or being tempted to reconcile conflicting interests, rather than fully pursuing their clients' rights. The loyalty the attorney owes one client cannot be allowed to compromise the duty owed another. 
Here, any concerns about compromised attorney loyalty must take into account the limited period during which the Shapiro firm represented respondents and Disner was engaged in communications with Mobil's counsel. Mobil effectively ended the risk of divided loyalty by promptly terminating Disner's services. However, the concern for client confidences, like the attorney's duty to preserve those confidences, continues after the attorney's services end. Therefore, we examine the relationship between Disner and Mobil, conducted through Mobil's counsel, to determine whether Disner should be deemed to have represented Mobil for purposes of a conflict of interest analysis.

\section{CONSULTATION AND REPRESENTATION}

In considering whether an attorney-client relationship has reached a point where the attorney can be subject to disqualification for a conflict of interest, we begin with the relationship's early stages, as noted in Beery v. State Bar: "The fiduciary relationship existing between lawyer and client extends to preliminary consultations by a prospective client with a view to retention of the lawyer, although actual employment does not result. When a party seeking legal advice consults an attorney at law and secures that advice, the relation of attorney and client is established prima facie. The absence of an agreement with respect to the fee to be charged does not prevent the relationship from arising."

The primary concern is whether and to what extent the attorney acquired confidential information. That question is not necessarily answered by the amount of time involved. "Even the briefest conversation between a lawyer and a client can result in the disclosure of confidences." Consequently, a formal retainer agreement is not required before attorneys acquire fiduciary obligations of loyalty and confidentiality, which begin when attorney-client discussions proceed beyond initial or peripheral contacts. An attorney represents a clientfor purposes of a conflict of interest analysis-when the attorney knowingly obtains material confidential information from the client and renders legal advice or services as a result.

The initial discussions between Disner and the Cohon and Gardner attorneys involved substantial amounts of material confidential information. Moreover, Disner did not receive the information about Mobil's case theories, strategy, and analyses from a lay person who might or might not be knowledgeable about which matters were significant. Instead, after receiving the background information on the case, Disner participated in an extended briefing with the attorneys conducting Mobil's defense against respondents' claims. Obviously, communications of that kind are likely to involve an efficient transfer of material confidential information and attorney work product.

The record here shows without contradiction that Disner received material confidential information concerning respondents' claims against Mobil. In his first telephone conversation with one of Mobil's attorneys, Disner discussed the substantive allegations, 
the procedural status, and Mobil's theories of the case. During their luncheon meeting, Mobil's attorneys again briefed Disner on Mobil's theories and on its attorneys' discovery strategy, analyses of the issues, and assessment of the state of the case. Moreover, he acted on some of that information and provided Mobil's attorneys with the results of his own research. Although Disner stated that he did not discuss "the merits" of the case with attorneys or employees of the Shapiro firm, the firm's declarations fail to establish that Mobil's confidences were unavailable to its adversaries' attorneys, or that effective screening procedures secured those confidences from disclosure.

Therefore, the undisputed facts established that, for purposes of a conflict of interest analysis, Disner represented Mobil. Consequently, Disner and the firm to which he was of counsel, the Shapiro firm, represented opposing parties in the same litigation. The potential for a breach of the duty of confidentiality, whether inadvertent or otherwise, is apparent. The record provides no basis for considering whether an ethical screen, or other means of protecting Mobil's confidences, could serve the same prophylactic purpose as disqualification. We turn, then, to the reasons for applying the rule of disqualification to attorneys of counsel to a firm.

\section{IMPUTED DISQUALIFICATION AND "OF COUNSEL” ATTORNEYS}

As amicus curiae, the State Bar of California, observes, "The 'of counsel' designation has, over the years, come to mean a variety of things in jurisdictions across the nation." Attorneys who are of counsel to a firm may be permanent full-time practitioners who for various reasons are not on the traditional career path towards partnership in the firm. Of counsel attorneys also may be part-time affiliates of a firm who have other personal or professional commitments, or they may be potential partners brought into a firm for a probationary period.

The minimum requirements for designating an attorney in California as being of counsel to a firm are found among the standards for communications that presumptively violate the prohibition against false or deceptive communications: "A 'communication' which states or implies that a member or law firm is 'of counsel' to another lawyer or a law firm unless the former has a relationship with the latter (other than as a partner or associate, or officer or shareholder pursuant to Business and Professions Code sections 6160-6172) which is close, personal, continuous, and regular."

We agree with the State Bar's view that the essence of the relationship between a firm and an attorney of counsel to the firm "is the closeness of the 'counsel' they share on client matters. Members of the public are encouraged to consult with those sharing an 'of counsel' relationship with the expectation that the counselling resources of both are fully available to clients." The same view was reflected in the Bar Association of San Francisco's Formal Opinion No. 1985-1: "[A] firm which lists an attorney as 'of counsel' on its letterhead, shingle 
or listing is making an affirmative representation to its clients that the services of that attorney are available to clients of the firm."

As noted earlier, the need to protect client confidences can cause one attorney's conflict of interest disqualification to be imputed to other attorneys in the same firm. When attorneys presumptively share access to privileged and confidential matters because they practice together in a firm, the disqualification of one attorney extends vicariously to the entire firm. The vicarious disqualification rule recognizes the everyday reality that attorneys, working together and practicing law in a professional association, share each other's, and their clients', confidential information. The expectation that attorneys associated together will share confidences is reflected in the American Bar Association Model Rules of Professional Conduct, rule 1.6, comment [8]: "Lawyers in a firm may, in the course of the firm's practice, disclose to each other information relating to a client of the firm, unless the client has instructed that particular information be confined to specified lawyers."

The close, personal, continuous, and regular relationship between a law firm and the attorneys affiliated with it as of counsel contains many of the same elements that justify the rule of vicarious disqualification applied to partners, associates, and members. An of counsel attorney, particularly one frequently in the firm's offices or in contact with the firm's attorneys, may be consulted on a variety of matters without being formally identified as cocounsel. This close, fluid, and continuing relationship, with its attendant exchanges of information, advice, and opinions, properly makes the of counsel attorney subject to the conflict imputation rule, regardless of whether that attorney has any financial stake in a particular matter.

We find persuasive amicus curiae the State Bar of California's conclusion in its 1993 ethics opinion on the subject: "[T]o the extent the relationship between a principal member [of the State Bar] or law firm and another member or law firm is sufficiently 'close, personal, regular and continuous,' such that one is held out to the public as 'of counsel' for the other, the principal and 'of counsel' relationship must be considered a single, de facto firm for purposes of rule 3-310. Accordingly, if the 'of counsel' is precluded from a representation by reason of rule 3-310 of the California Rules of Professional Conduct, the principal is presumptively precluded as well, and vice-versa." The American Bar Association Committee on Ethics and Professional Responsibility reached the same conclusion in its Formal Opinion No. 90-357: "There can be no doubt that an of counsel lawyer (or firm) is 'associated in' and has an 'association with' the firm (or firms) to which the lawyer is of counsel, for purposes of both the general imputation of disqualification ... and the imputation of disqualification resulting from former government service.... Similarly, the of counsel lawyer is 'affiliated' with the firm and its individual lawyers for purposes of the general attribution of disqualifications under DR 5-105(d) of the Model Code." Notwithstanding the variations to be expected across the nation on any point of law, the prevailing view is that 
for purposes of disqualification, the of counsel attorney is considered to be affiliated with a firm so that the disqualification of one from representation must be imputed to the other.

In order to designate themselves as of counsel, attorneys must have close, personal, continuous, and regular relationships with their affiliated firms. Consequently, the attorneys brought together in these relationships frequently will have occasion to share client confidences in the course of exchanging advice and performing legal services for those clients. The fundamental nature of the relationship makes a presumption of shared confidences as appropriate for the of counsel attorney as it is for partners, associates, and members of law firms. From the clients' and the public's perspective, the of counsel attorney can hardly be distinguished from other attorneys who may be more closely tied to a firm financially. As a result, the need to preserve confidentiality and public confidence in the integrity of the legal profession and judicial process require that of counsel attorneys be regarded as the same as partners, associates, and members of law firms for conflict of interest issues.

In this case, the of counsel attorney obtained confidential information and provided legal services to Mobil. For conflict of interest purposes, the attorney's involvement went beyond initial or peripheral contacts and rose to the level for which fiduciary duties of confidentiality and loyalty properly can be imposed. This development meant that Disner and the Shapiro firm represented adversaries in the same litigation, with the concomitant potential for a breach of the duty of confidentiality.

Disner's conflict of interest must be imputed to the Shapiro firm because of the public designation of their relationship. Consequently, Disner's conflict of interest must inevitably lead to the Shapiro firm's vicarious disqualification from representing respondents to assure the preservation of Mobil's confidences and the integrity of the judicial process.

\section{Questions:}

1. Why did the Supreme Court hold that the Shapiro firm was disqualified from representing SpeeDee?

2. How could the Shapiro firm have avoided disqualification?

3. Could adopting "firewall" have enabled the Shapiro firm to represent SpeeDee?

\section{Kala v. Aluminum Smelting \& Refining Company, Inc., 81 Ohio St. 3d 1 (1998)}

Summary: Attorney Pearson and the Spangenberg law firm represented Kala in an action against his former employer, Aluminum Smelting. During Kala's appeal, Pearson left Spangenberg and joined the Duvin firm, which represented Aluminum Smelting in the same action. Kala filed a motion to disqualify Duvin, which the Ohio Supreme Court granted despite Duvin's efforts to firewall Pearson, because of the strong appearance of impropriety. 


\section{LUNDBERG STRATTON, J.}

The issue before the court is whether a law firm should be automatically disqualified from representing a party when an attorney leaves his or her former employment with a firm representing a party and joins the law firm representing the opposing party, or whether that law firm may overcome any presumption of shared confidences by instituting effective screening mechanisms. Although this issue has been dealt with in many other jurisdictions, this is a case of first impression for Ohio. To fairly decide this issue, we must consider the Disciplinary Rules and Ethical Considerations in the Ohio Code of Professional Responsibility, competing public policy interests, and the guidance provided by federal case law.

\section{ETHICAL PRINCIPLES}

A fundamental principle in the attorney-client relationship is that the attorney shall maintain the confidentiality of any information learned during the attorney-client relationship. A client must have the utmost confidence in his or her attorney if the client is to feel free to divulge all matters related to the case to his or her attorney.

The obligation of an attorney to preserve the confidences and secrets of the client continues even after the termination of the attorney's employment.

In addition, an attorney should avoid even the appearance of impropriety. Because of the importance of these ethical principles, it is the court's duty to safeguard the preservation of the attorney-client relationship. In doing so, a court helps to maintain public confidence in the legal profession and assists in protecting the integrity of the judicial proceeding.

When an attorney leaves his or her former employment and becomes employed by a firm representing an opposing party, a presumption arises that the attorney takes with him or her any confidences gained in the former relationship and shares those confidences with the new firm. This is known as the presumption of shared confidences. Some courts have held that such a change of employment results in an irrebuttable presumption of shared confidences that necessitates the disqualification of the attorney (primary disqualification) and the entire new firm (imputed disqualification).

\section{CLIENT'S RIGHT TO CHOOSE COUNSEL}

Balanced against the former client's interest in preventing a breach of confidence is the public policy interest in permitting the opposing party's continued representation by counsel of his or her choice. Disqualification interferes with a client's right to choose counsel.

"Disqualification, as a prophylactic device for protecting the attorney-client relationship, is a drastic measure which courts should hesitate to impose except when absolutely necessary. A 
disqualification of counsel, while protecting the attorney-client relationship, also serves to destroy a relationship by depriving a party of representation of their own choosing."

This issue has become increasingly important as the practice of law has changed. A review of the historical development of disqualification issues reveals the early conflicts created by the clash of the above principles.

\section{HISTORY OF MOTIONS TO DISQUALIFY}

Many of the early disqualification cases arose out of charges of conflict of interest where government attorneys left the public service and went into private practice. Early courts struggled with the need to fashion a rule that would preserve the confidences of the government client yet not discourage able attorneys from entering public service through fear of being locked forever into government service, unable to change positions.

"If past employment in government results in the disqualification of future employers from representing some of their long-term clients, it seems clearly possible that government attorneys will be regarded as 'Typhoid Marys.' Many talented lawyers, in turn, may be unwilling to spend a period in government service, if that service makes them unattractive or risky for large law firms to hire."

As more and more private attorneys also began changing firms, motions to disqualify under the irrebuttable presumption of shared confidences increased, and inequities and abuses also began to surface. While some of these motions to disqualify were legitimate and necessary, such motions were also often misused to harass an opponent, disrupt the opponent's case, or to gain a tactical advantage, and therefore were viewed with increasing caution.

As a result, several federal cases began fashioning a way to deal with the competing interests caused by increased mobility of attorneys and the rise of motions to disqualify. The Court of Appeals for the Sixth Circuit in Manning summed up the changing practice of law as follows:

Perhaps these motions have become more numerous simply because the changing nature of the manner in which legal services are delivered may present a greater number of potential conflicts. Certainly, the advent of law firms employing hundreds of lawyers engaging in a plethora of specialties contrasts starkly with the former preponderance of single practitioners and small firms engaging in only a few practice specialties. In addition, lawyers seem to be moving more freely from one association to another, and law firm mergers have become commonplace. At the same time that the potential for conflicts of interest has increased as the result of these phenomena, the availability of competent legal specialists has been concentrated under fewer roofs.

Consequently, these new realities must be at the core of the balancing of interests necessarily undertaken when courts consider motions for vicarious disqualification of counsel. 
As a result of the changing legal profession, federal courts and the ABA Model Rules of Professional Conduct began allowing the use of various mechanisms to isolate an attorney who had transferred employment. Although originally applied only to government attorneys, these mechanisms have now been extended to situations involving transfers of private counsel as well.

\section{DEVELOPMENT OF STANDARDS FOR DISQUALIFICATION}

Several federal courts in addressing both primary and imputed disqualification have devised a three-part test to determine whether disqualification is proper when one attorney leaves a firm and joins another firm representing an opposing party. We believe this test adequately covers many different scenarios and will give the courts of Ohio guidance on disqualification issues.

First, a court must determine whether a substantial relationship exists between prior and present representations. If there is no substantial relationship, then no ethical problem exists. For example, when an attorney had represented a client in a trademark infringement case, the Court of Appeals for the Sixth Circuit denied disqualification in a later unrelated civil RICO case.

Second, if a substantial relationship is found between the current matter and the prior matter, the court must examine whether the attorney shared in the confidences and representation of the prior matter. There is a presumption that such confidences would also be shared among members of the prior firm, but that presumption may be rebutted.

In Freeman, the Court of Appeals for the Seventh Circuit, in setting the rules on primary disqualification, instructed the trial court that it could "rely on any of a number of factors, among them being the size of the law firm, the area of specialization of the attorney, the attorney's position in the firm, and the demeanor and credibility of witnesses at the evidentiary hearing."

If the presumption of shared confidences within the prior firm is rebutted by such evidence, then there is again no need for primary disqualification, as there are no confidences to be shared. However, if that presumption is not rebutted, and the attorney does or is presumed to possess client confidences, primary disqualification results, and a presumption of shared confidences arises between the attorney and the members of the attorney's new firm. The issue then is whether a presumption of shared confidences will also disqualify the entire new firm (imputed disqualification). Kala implies that this presumption should be irrebuttable and that once an attorney, particularly one as involved in the case as Pearson was, moves to opposing counsel's firm, no steps can be taken to restore confidence so as to overcome the appearance of impropriety; the entire firm must be disqualified.

Some courts have taken this approach. New Jersey has refused to adopt the rebuttablepresumption approach, finding that there is no way to overcome the appearance of impropriety in a "side-switching attorney" case. Cardona, 942 F.Supp. at 976-977. The New Jersey courts 
cite the impossibility of proving when a breach has been made, as those lawyers within the new firm are least likely to divulge such information. Judge Orlofsky in Cardona explained:

"At the heart of every 'side-switching attorney' case is the suspicion that by changing sides, the attorney has breached a duty of fidelity and loyalty to a former client, a client who had freely shared with the attorney secrets and confidences with the expectation that they would be disclosed to no one else. It is for this reason that the 'appearance of impropriety doctrine' was adopted to protect the public, our profession, and those it serves. In short, this much maligned doctrine exists to engender, protect and preserve the trust and confidence of clients."

On the other hand, with the realities of modern-day practice, as discussed in the Manning case, such a hard-and-fast rule works an unfair hardship also. Ultimately, one must have faith in the integrity of members of the legal profession to honor their professional oath to uphold the Code of Professional Responsibility, safeguarded by the precautions required to rebut the presumption of shared confidences. If used properly, the process of screening attorneys who possess client confidences from other members of a firm can preserve those confidences while avoiding the use of the motion to disqualify as a device to gain a tactical advantage. Therefore, we believe that the fairer rule in balancing the interests of the parties and the public is to allow the presumption of shared confidences with members of the new firm to be rebutted.

Thus, the third part of the test on disqualification is whether the presumption of shared confidences with the new firm has been rebutted by evidence that a "Chinese wall" has been erected so as to preserve the confidences of the client. ${ }^{56}$ The Chinese wall is the specific institutional screening mechanisms that will prevent the flow of confidential information from the quarantined attorney to other members of the law firm.

Factors to be considered in deciding whether an effective screen has been created are whether the law firm is sufficiently large and whether the structural divisions of the firm are sufficiently separate so as to minimize contact between the quarantined attorney and the others, the likelihood of contact between the quarantined attorney and the specific attorneys responsible for the current representation, the existence of safeguards or procedures which prevent the quarantined attorney from access to relevant files or other information relevant to the present litigation, prohibited access to files and other information on the case, locked case files with keys distributed to a select few, secret codes necessary to access pertinent information on electronic hardware, instructions given to all members of a new firm regarding the ban on exchange of information, and the prohibition of the sharing of fees derived from such litigation.

\footnotetext{
56 "Chinese wall" has become the legal term to describe a "procedure which permits an attorney involved in an earlier adverse role to be screened from other attorneys in the firm so as to prevent disqualification of the entire law firm simply because one member of firm previously represented a client who is now an adversary of the client currently represented by the firm." Black's Law Dictionary (6 Ed.Rev.1990) 240. This term refers historically to the Great Wall of China, which served ancient Chinese emperors as a barrier to invasion. Ironically, however, the Great Wall of China was of limited military value. The concept is also referred to in cases and commentary as "screening devices," "ethical screens," or "institutional mechanisms for screening." [Editor's note: Screening procedures are now typically called "firewalls."]
} 
A very strict standard of proof must be applied to the rebuttal of this presumption of shared confidences, however, and any doubts as to the existence of an asserted conflict of interest must be resolved in favor of disqualification in order to dispel any appearance of impropriety.

Some courts have held that unrebutted affidavits attesting to a Chinese wall are sufficient to prevent disqualification. However, we reject such a bright-line test, as the court should maintain discretion to weigh issues of credibility. The court should be free to assess the reputation of an attorney and law firm for integrity and honesty. The court should also be free to balance the appearance of impropriety against the protections of a Chinese wall. For example, suppose a sole practitioner representing a plaintiff switches sides to a five-person defense firm representing the opposing party, leaving his former client to seek new counsel. The appearance of impropriety in such a fact pattern may be impossible to overcome.

If applied properly, screening mechanisms to insulate a quarantined attorney from the rest of the firm can protect client confidences while allowing for attorney mobility and the right of a client to choose counsel.

\section{ADDITIONAL FACTORS TO CONSIDER IN MOTIONS TO DISQUALIFY}

In addition to the screening devices, there are other important factors to be considered by the trial court. First, the screening devices must be employed as soon as the disqualifying event occurs. Very few cases address how early the disqualifying event occurs. In the Manning case, a conflict arose with the attorney's former firm only after the attorney, with the former client's knowledge, had moved to an uninvolved law firm. In Cromley, the attorney and the new firm agreed that "absolutely nothing of a substantive nature regarding the instant lawsuit would occur until decisions were made and the clients were made aware of them." Other cases reviewed have been silent as to the issue of when screening procedures were timely employed, although all cases agree that the screens must be in place when the attorney joins the firm. Instituting screens after a motion to disqualify is too late. Accordingly, a court must weigh the timeliness of the screening devices.

A second factor to consider is the hardship that a client would incur in obtaining new counsel if a motion to disqualify is granted. Hardship may be more of an issue if a conflict arose after a transfer. However, hardship may not carry much weight in a "side-switching" case. Ironically, where an attorney switches sides and joins an opposing counsel's firm, the attorney has de facto deprived his or her first client of the attorney of that client's choice, namely himself or herself. If the attorney has been lead counsel, other counsel in the firm must spend time and effort to take over the lead. If no one remaining in the prior firm is able to handle the matter, or if the attorney was a sole practitioner, the former client must seek out new counsel and incur the burden and expense created by the switch. In this scenario, the departing attorney has created a competing hardship for his or her former client, and the claim by the new firm of hardship created by its own doing in accepting the new attorney into the firm may no longer be persuasive. These are matters that should be left to the trier of fact to weigh. 
In addition, a law firm contemplating hiring counsel who had been directly involved on the opposing side also has a duty to disclose to its own client that such a hiring may place the firm in conflict and could result in disqualification. The law firm may have to subordinate its desire to augment its staff against its duties to its client and avoid placing the firm's interests above the client's interests.

Finally, the court should hold an evidentiary hearing on a motion to disqualify and must issue findings of fact if requested based on the evidence presented. Because a request for disqualification implies a charge of unethical conduct, the challenged firm must be given an opportunity to defend not only its relationship with the client, but also its good name, reputation and ethical standards. In Analytica, the Court of Appeals for the Seventh Circuit summarized the situation as follows:

An attorney's and/or a law firm's most valuable asset is their professional reputation for competence, and above all honesty and integrity, which should not be jeopardized in a summary type of disqualification proceeding of this nature. As court proceedings are matters of public record, a news media report concerning a summary disqualification order, based on a scant record of this type, can do irreparable harm to an attorney's or law firm's professional reputation. We must recognize that the great majority of lawyers, as officers of the court, do conduct themselves well within the bounds of the Code of Professional Responsibility.

\section{THE REBUTTABLE-PRESUMPTION TEST FOR MOTIONS TO DISQUALIFY}

In conclusion, we hold that in ruling on a motion for disqualification of either an individual (primary disqualification) or the entire firm (imputed disqualification) when an attorney has left a law firm and joined a firm representing the opposing party, a court must hold an evidentiary hearing and issue findings of fact using a three-part analysis:

(1) Is there a substantial relationship between the matter at issue and the matter of the former firm's prior representation;

(2) If there is a substantial relationship between these matters, is the presumption of shared confidences within the former firm rebutted by evidence that the attorney had no personal contact with or knowledge of the related matter; and

(3) If the attorney did have personal contact with or knowledge of the related matter, did the new law firm erect adequate and timely screens to rebut a presumption of shared confidences with the new firm so as to avoid imputed disqualification?

\section{APPLICATION OF TEST TO THIS CASE}

Under the facts of this case, Pearson clearly met the substantial-relationship test and possessed client confidences, as he was the lead attorney on Kala's lawsuit. Thus, the first two parts of the test require disqualification of Pearson and raise a presumption in favor of 
disqualification of Duvin. No one disputes that Pearson, himself, cannot work further on the case.

Therefore, we must determine whether the entire firm should be disqualified under the third part of the analysis, imputed disqualification. The appellate court took evidence in the form of affidavits but denied the parties oral argument. The appellate order consisted of the following findings:

"Motion by appellant to disqualify counsel for defendants/appellees is granted. Appellee's new counsel shall file a notice of appearance on or before May 31, 1996."

Therefore, we must examine the record we have before us, which consists of exhibits and affidavits filed while the parties were briefing the disqualification question in the court of appeals.

Kala retained Pearson and the Spangenberg firm in 1993 as his attorneys. From 1993 through 1995, Kala trusted Pearson, relied upon him as his attorney, and disclosed all matters pertaining to his case involving his former employer, Aluminum Smelting. Pearson proceeded to file an appeal after the directed verdict and apparently even participated in a settlement conference with the Eighth District Court of Appeals on November 13, 1995. On January 8, 1996, Pearson obtained a continuance to file Kala's appellate brief. On January 22, 1996, Pearson left the Spangenberg firm and joined the Duvin firm, which was representing Aluminum Smelting and had been throughout the prior proceedings with Kala. The only conclusion that can be reached from the record is that Pearson was negotiating with Duvin while still actively representing Kala without disclosing to Kala his negotiations.

The appearance of impropriety is so strong that nothing that the Duvin firm could have done would have had any effect on Kala's perception that his personal attorney had abandoned him with all of his shared confidences and joined the firm representing his adversary while the case was still pending. No steps of any kind could possibly replace the trust and confidence that Kala had in his attorney or in the legal system if such representation is permitted. This is the classic "side-switching attorney" case.

We find that under this set of egregious facts, the appearance of impropriety was so great that the attempts made by Duvin to erect a Chinese wall were insufficient to overcome the appearance of impropriety. Accordingly, we affirm the disqualification ruling of the court of appeals. 


\section{7: Specific Conflicts of Interest}

I was gambling in havana, I took a little risk. Send lawyers, guns, and money, Dad, get me out of this, hiyah! ${ }^{57}$

Under the Model Rules of Professional Conduct, special rules govern the attorney-client relationship in specific circumstances, and define obligations imposed by the attorney's fiduciary duties. As discussed in Class 9, attorneys may engage in financial transactions with their clients only if transaction is fair and reasonable to the client, and the attorney obtains the client's informed consent to the transaction in writing. But Rule 1.8 also imposes other specific obligations on attorneys in relations to other potential agreements and transactions with their clients. For example, it requires attorneys to obtain informed consent before using confidential client information to the detriment of the client, and limits the ability of attorneys to receive gifts from or makes loans to their clients.

\section{Rule 1.8: Current Clients: Specific Rules}

a. A lawyer shall not enter into a business transaction with a client or knowingly acquire an ownership, possessory, security or other pecuniary interest adverse to a client unless:

1. the transaction and terms on which the lawyer acquires the interest are fair and reasonable to the client and are fully disclosed and transmitted in writing in a manner that can be reasonably understood by the client;

2. the client is advised in writing of the desirability of seeking and is given a reasonable opportunity to seek the advice of independent legal counsel on the transaction; and

3. the client gives informed consent, in a writing signed by the client, to the essential terms of the transaction and the lawyer's role in the transaction, including whether the lawyer is representing the client in the transaction.

b. A lawyer shall not use information relating to representation of a client to the disadvantage of the client unless the client gives informed consent, except as permitted or required by these Rules.

c. A lawyer shall not solicit any substantial gift from a client, including a testamentary gift, or prepare on behalf of a client an instrument giving the lawyer or a person related to the lawyer any substantial gift unless the lawyer or other recipient of the gift is related to the client. For purposes of this paragraph, related persons include a spouse, child, grandchild, parent, grandparent or other relative or individual with whom the lawyer or the client maintains a close, familial relationship.

d. Prior to the conclusion of representation of a client, a lawyer shall not make or negotiate an agreement giving the lawyer literary or media rights to a portrayal or account based in substantial part on information relating to the representation.

e. A lawyer shall not provide financial assistance to a client in connection with pending or contemplated litigation, except that:

${ }^{57}$ Warren Zevon, Lawyers, Guns and Money, Excitable Boy (1978). 
1. a lawyer may advance court costs and expenses of litigation, the repayment of which may be contingent on the outcome of the matter; and

2. a lawyer representing an indigent client may pay court costs and expenses of litigation on behalf of the client.

f. A lawyer shall not accept compensation for representing a client from one other than the client unless:

1. the client gives informed consent;

2. there is no interference with the lawyer's independence of professional judgment or with the client-lawyer relationship; and

3. information relating to representation of a client is protected as required by Rule 1.6.

g. A lawyer who represents two or more clients shall not participate in making an aggregate settlement of the claims of or against the clients, or in a criminal case an aggregated agreement as to guilty or nolo contendere pleas, unless each client gives informed consent, in a writing signed by the client. The lawyer's disclosure shall include the existence and nature of all the claims or pleas involved and of the participation of each person in the settlement.

h. A lawyer shall not:

1. make an agreement prospectively limiting the lawyer's liability to a client for malpractice unless the client is independently represented in making the agreement; or

2. settle a claim or potential claim for such liability with an unrepresented client or former client unless that person is advised in writing of the desirability of seeking and is given a reasonable opportunity to seek the advice of independent legal counsel in connection therewith.

\section{Loans to Clients}

In its majestic equality, the law forbids rich and poor alike to sleep under bridges, beg in the streets and steal loaves of bread. ${ }^{58}$

In re Morse, 748 S.E.2d 921 (Ga. 2013)

Summary: Attorney Jack Morse lent a client $\$ 1,400$ to avoid foreclosure and possible jail time for his violation probation. Even though his client repaid the loan in full, Morse admitted that this was a violation of Model Rule 1.8(e). Accordingly, the Supreme Court of Georgia imposed a voluntary reprimand on Morse.

\section{PER CURIAM.}

This disciplinary matter is before the Court on a Petition for Voluntary Discipline filed by Respondent Jack O. Morse (State Bar No. 525800) pursuant to Bar Rule 4-227(b)(2) before a

\footnotetext{
${ }^{58}$ Anatole France, The Red Lily (1894).
} 
formal complaint was issued. In his petition, Morse admits violating Rule 1.8(e) of the Georgia Rules of Professional Conduct set forth in Bar Rule 4-102(d). Although such a violation is punishable by public reprimand, Morse requests the imposition of a Review Panel reprimand. The State Bar has no objection.

Morse, who has been a member of the State Bar since 1972, admits that while representing a client in a personal injury claim, he lent the client $\$ 1,400$ for the client's use in avoiding foreclosure and possible jail time for his violation of probation. Although the client repaid the loan in full, Morse admits that he violated Rule 1.8(e). He asserts that while he has had three instances of prior discipline (having received a 90-day suspension in 1996, and Review Panel reprimands in both 1993 and 1998 - one of which was for similar misconduct), he has had no disciplinary matters for an extended period of time. He further asserts that since 1998, he has shown a strong regard for the professional standards of conduct and asks that this Court consider, in mitigation, his cooperative attitude with disciplinary authorities and the fact that the violation occurred as a result of him attempting to assist the client, a longtime acquaintance.

Under these specific circumstances, we agree that imposition of a Review Panel reprimand is an appropriate sanction. Accordingly, we accept Morse's petition for voluntary discipline and hereby order that Morse receive a Review Panel reprimand in accordance with Bar Rules 4102(b)(4) and 4-220(b) for his admitted violation of Rule 1.8(e).

Petition for voluntary discipline accepted. Review Panel reprimand.

All the Justices concur.

BLACKWELL, Justice, concurring.

I concur fully in the opinion of the Court, but I write separately to remind our readers that a lawyer providing financial assistance to a litigation client is not always a violation of Rule 1.8(e). With two exceptions, Rule 1.8(e) provides that "a lawyer shall not provide financial assistance to a client in connection with pending or contemplated litigation." By its plain terms, the Rule only prohibits the provision of financial assistance to a litigation client to the extent of some "connection" between the financial assistance on the one hand, and the litigation or representation on the other. Absent such a "connection," a lawyer may provide financial assistance to a litigation client without running afoul of Rule 1.8(e).

This understanding not only is required by the plain terms of the Rule, but it also is perfectly consistent with the three purposes of Rule 1.8(e). First, Rule 1.8(e) is intended to preserve the loyalty and independence that the lawyer owes to the client, loyalty and independence that might be compromised if the lawyer obtained "too great a financial stake in the litigation." Second, the Rule is intended to "prevent clients from selecting a lawyer based on improper factors," considering that "unregulated lending to clients might generate unseemly bidding wars for cases." Third, the Rule is intended to restrain the pernicious practices of barratry, maintenance, and champerty. As I see it, financial assistance to an existing client that has no 
connection whatsoever with the litigation or representation of the client does not offend any of the policies that the Rule is intended to promote.

This case is a little troubling to me because it appears from the record that Morse has been a friend of his client for a long time, such that he might have provided financial assistance to his client independent of the attorney-client relationship or the litigation, and indeed, even in the absence of an attorney-client relationship or litigation. Lawyers can be generous, and it is not uncommon for lawyers to help out their kin, their friends, and their neighbors. Nevertheless, Morse has unequivocally admitted a violation of Rule 1.8(e), and as such, he has implicitly admitted a connection between the financial assistance he provided and the litigation in which he represented his client. For that reason, I am content to join the Court in accepting his petition for voluntary discipline, and I am satisfied with the discipline that the Court has seen fit to impose. I am authorized to state that Justice Hunstein joins in this concurrence.

\section{State ex rel. Oklahoma Bar Ass'n v. Smolen, 17 P.3d 456 (Okla. 2000)}

Summary: The Oklahoma Bar Association brought an action against attorney Donald E. Smolen who made a loan to his client for living expenses in violation of Model Rule 1.8. Smolen challenged this action on the grounds that Model Rule 1.8 violated the equal protection clause of the Fourteenth Amendment because it treats similarly situated classes of litigants differently: those who need advances for living expenses and those who need advances for litigation costs. Accordingly, the Oklahoma Supreme Court applied the rational basis test to determine that this disparate treatment was rationally related to legitimate goal of protecting clients and maintaining integrity of the Bar. Therefore, the Court imposed a 60 day suspension on Smolen.

\section{OVERVIEW}

Complainant, the Oklahoma Bar Association, alleged one count of misconduct warranting discipline against respondent attorney, Donald E. Smolen (Respondent). The complaint alleged that Respondent had violated rule 1.8(e) of the Oklahoma Rules of Professional Conduct (ORPC), Okla. Stat. tit. 5, ch. 1, app. 3-A (1991) (prohibition against providing financial assistance to a client in connection with pending or contemplated litigation). Respondent received a public reprimand in 1992 for loaning money to clients. In an unpublished reprimand issued in 1987, the respondent received an eight-month suspension from the practice of law. The 1987 suspension was imposed for violations of DR 1-102(A)(3) ("engaging in illegal conduct involving moral turpitude"), DR 1-102(A)(4) (engaging "in conduct involving dishonesty, fraud, deceit, or misrepresentation"), DR 9-102(B) (failing to preserve the "identity of funds and property of a client"), and rule 1.3 of the Rules Governing Disciplinary Proceedings (acting in a manner "contrary to prescribed standards of conduct").

In the present matter, the parties have stipulated to the facts and recommended discipline. The Professional Responsibility Tribunal (PRT) accepted the stipulations of fact, found that Respondent had violated rule 1.8(e), and recommended Respondent be publicly censured. 


\section{FACTS}

During Respondent's representation of Mr. Miles in a case before the Workers' Compensation Court, Respondent loaned Mr. Miles \$1,200. The check to Mr. Miles recited that the money was for travel expenses. Respondent admitted that the true purpose of the loan was for living expenses because Mr. Miles' home had been destroyed by fire. Without the loan, Mr. Miles indicated he would have to move to Indiana and would be unable to continue his medical treatment or make court appearances. At the time of the loan, Mr. Miles was receiving temporary total disability benefits of $\$ 426.00$ a week from which Respondent's attorney fee was subtracted. Mr. Miles received $\$ 384.00$ a week before loan payments.

Respondent's loan to Mr. Miles was interest free and without penalty or cost other than the amount of the principal. Mr. Miles was to repay the loan at $\$ 100.00$ a week from his temporary total disability benefits. Mr. Miles made three $\$ 100.00$ payments on the loan. One of the payments was returned to Mr. Miles resulting in his paying only $\$ 200.00$ on the loan. Respondent agreed to forego further repayment until final settlement of the Workers' Compensation case.

When Mr. Miles became involved in other legal matters, he sought an attorney to handle the additional matters together with the workers' compensation claim. After learning of Mr. Miles search for a new attorney, Respondent terminated the attorney-client relationship with Mr. Miles. Thereafter, Mr. Miles hired Mr. Elias to represent him. During mediation over a fee dispute between Mr. Miles and Mr. Elias, the Tulsa County Bar Association learned of Respondent's loan and reported Respondent's conduct to the Oklahoma Bar Association.

Respondent admits the loan to Mr. Miles is not an isolated incident. He testified that he had consulted lawyers whose opinions are well respected in legal ethics, and it was their belief that Respondent's conduct would not violate rule 1.8(e). Respondent admits that his actions violate the express language of rule 1.8(e). However, Respondent submits that he has not violated the intent of rule $1.8(\mathrm{e})$, and that rule $1.8(\mathrm{e})$ unconstitutionally treats clients who need humanitarian loans differently than clients who receive advances of litigation expenses and court costs.

\section{ANALYSIS}

Rule 1.8(e) of the ORPC under which Respondent was disciplined in 1992 for giving financial assistance to clients, provided:

While representing a client in connection with contemplated or pending litigation, a lawyer shall not advance or guarantee financial assistance to a client, except that a lawyer may advance or guarantee the expenses of litigation, including court costs, expenses of investigation, expenses of medical examination, and costs of obtaining and presenting evidence, provided the client remains ultimately liable for such expenses. 
Based on the Model Rules adopted by the American Bar Association, rule 1.8(e) was amended in 1993 to provide:

A lawyer shall not provide financial assistance to a client in connection with pending or contemplated litigation, except that a lawyer may advance court costs and expenses of litigation, the repayment of which may be contingent on the outcome of the matter.

The primary change under the Model Rules is that the repayment of litigation expenses and court costs may be contingent on the outcome of the case. Both the 1992 and 1993 versions of rule 1.8(e) unambiguously prohibit a lawyer from advancing living expenses to clients. In this case, Respondent advanced funds for living expenses to be repaid from the client's worker's compensation benefits, an action admittedly prohibited by rule 1.8(e).

Most authorities prohibit a lawyer from providing financial assistance to clients for living expenses during representation. In 1991, a draft of a provision of the Restatement of Law would have allowed a lawyer to make or guarantee a loan to a client "if the loan was needed to enable the client to withstand delay in litigation that otherwise might unjustly induce the client to settle or dismiss a case because of financial hardship rather than on the merits." However, in 1996 the American Law Institute Council decided the rule was ill-advised, and, in 1998, the provision was removed. The final draft of the Restatement would not allow a lawyer to make or guarantee a loan to a client except for litigation expenses and court costs. Rule 1.8(e) of the American Bar Association's Model Rules of Professional Conduct adopted in 1983 prohibits a lawyer from advancing funds to a client for living expenses. A proposal to allow lawyers to advance clients funds for living expenses was rejected by the American Bar Association House of Delegates.

Twenty-nine states have adopted the current version of ABA Model Rule 1.8(e) which allows repayment of litigation costs to be contingent on the outcome of the case but forbids advances for living expenses. Fourteen other states follow the ABA Model Code of Professional Responsibility, adopted in 1969, or a version of the Model Rules or Model Code that requires the client remain liable for litigation expenses and court costs and prohibits advances for living expenses. Only eight states explicitly allow lawyers to advance or guarantee loans to clients for living expenses: Alabama, California, Louisiana, Minnesota, Mississippi, Montana, North Dakota, and Texas.

Only one state has refused to discipline a lawyer for advancing funds to clients for living expenses during representation. The Louisiana State Supreme Court stated that advancing money to an indigent client for necessary living expenses during representation did not violate the Louisiana rules of legal ethics. Even though the court questioned the constitutionality of the rule, the court based its conclusion on a finding that the conduct did not violate the rule's intent. The lawyer was disciplined for making advances which were not based on the client's needs. In The Alaska Supreme Court held the rule did not unconstitutionally deny or interfere with the client's access to the courts. Further, no court has invalidated rule 1.8(e) based on a constitutional infirmity. 
We have has previously disciplined lawyers for providing financial assistance to clients for purposes other than litigation expenses and court costs. Several other courts addressing the question have also imposed discipline on lawyers for like conduct. The Mississippi Supreme Court expressed its concern that allowing a lawyer to advance funds to a client for living expenses would "generate unseemly bidding wars for cases and inevitably lead to further denigration of our civil justice system."

\section{A. INTENT OF THE RULE}

Respondent admits violating rule 1.8(e) but argues that he should not be disciplined because he did not violate the intent of the rule. What Respondent in reality requests is that we adopt an exception to the rule that allows attorneys to make loans to clients for necessary living expenses after the attorney-client relationship is established.

The rule against attorneys providing financial assistance to clients for living expenses is based on the common-law prohibitions against practice of champerty and maintenance. The evils associated with champerty and maintenance intended to be prevented by rule 1.8(e)'s prohibition are: (1) clients selecting a lawyer based on improper factors, and (2) conflicts of interest, including compromising a lawyer's independent judgment in the case and creating the potentially conflicting roles of the lawyer as both lawyer and creditor with divergent interests.

Respondent argues that he advanced the funds only after the attorney-client relationship was established with repayment to be made from benefits which had already been awarded, and the loan was for humanitarian purposes. Thus, he posits that the evils of champerty and maintenance are absent here and that he should not be disciplined because he did not violate the intent of the rule. We reject this argument as have most other states. First, Mr. Miles' workers' compensation claim had not been completely resolved. He was receiving only temporary benefits at the time Respondent made the loan, and, at least, a potential settlement regarding permanent disability remained pending. Second, it would be unrealistic to conclude that even if Respondent does not publicize that he makes loans to clients for living expenses, potential clients would not learn of Respondent's practice from existing and past clients. Thus, potential clients may base their decision to retain Respondent on improper inducements. The fact that the loan was for humanitarian purposes may be a mitigating factor. Nonetheless, Respondent violated rule 1.8(e).

Given that the Restatement and the ABA have rejected the same exception tendered by Respondent and an overwhelming number of courts have also declined to adopt Respondent's proposed exception, we also decline to make the ad hoc exception to rule 1.8(e) advocated by Respondent. We are not unsympathetic to the plight of litigants. However, because of the potential ethical problems which can arise from a lawyer advancing clients money for living expenses, the explicit prohibition against such conduct in the Oklahoma Rules of Professional Conduct, we believe Respondent should be disciplined. 


\section{B. CONSTITUTIONALITY}

Respondent asserts that rule 1.8(e) is invalid because it does not treat similarly situated classes of litigants equally. The Fourteenth Amendment to the United States Constitution provides: "No State shall make or enforce any law which shall deny to any person within its jurisdiction the equal protection of the laws." This same prohibition is present in article 2, section 7 of the Oklahoma Constitution. The two classes of clients proposed by Respondent are those who need advances for living expenses and those who need advances for litigation costs.

The deferential rational basis test is applied in constitutional challenges based on the equal protection clause when the classification is not based upon an inherently suspect characteristic or jeopardizes a fundamental right. The divergent treatment must have only "some relevance to the purpose for which the classification is made." Respondent does not argue that the classification is based on an inherently suspect characteristic or that a fundamental right is jeopardized. Thus, Respondent's challenge is analyzed under the rational basis test.

Assuming for purposes of argument that the two classes posed by Respondent are similarly situated, rule 1.8(e)'s disparate treatment of advances for litigation expenses and court costs and advances for all other expenses is based on legitimate goals and reflects the differences in living expenses and litigation expenses and court costs. First, litigation expenses and court costs are directly related to the actual litigation. Living and other expenses are not. Second, litigation expenses and court costs are within a lawyer's expertise. Other expenses of clients are not considered part of a lawyer's expertise. Third, it is a lawyer's duty to advise his client on which litigation expenses and court costs are necessary for the litigation. It is not generally the lawyer's duty to advise his clients as to what other expenses are necessary. Fourth, a lawyer generally pays the litigation expenses and costs directly to the provider. In the case of other expenses, the lawyer generally would give the money to the client, and there would be no guarantee that the money would be utilized for the loan's intended purpose.

We agree with the drafters of the Restatement and the ABA Model Rules that a rule allowing lawyers to make loans to clients for reasons other that advancing litigation expenses and court costs is ill-advised. Because of the potentially inherent abuses in allowing lawyers to make loans to clients for reasons other than litigation expenses and court costs, the divergent treatment is rationally related to a legitimate goal of protecting clients and maintaining the integrity of the Bar. Respondent has failed to show that rule 1.8(e) is unconstitutional.

\section{APPROPRIATE DISCIPLINE}

Respondent has been previously disciplined by this Court, once in 1987 and again in 1992. In 1992, Respondent was publicly censured for the same misconduct with which he is presently charged. He admits that the current loan is not an isolated incident. One of the purposes of discipline is "deterrence of like behavior by both the respondent and other members of the bar." This Court is not bound by the stipulated discipline of the parties. Because Respondent was previously disciplined in 1987 for violations of ethical standards, was publicly censured in 1992 
for the same misconduct for which he is being disciplined in this matter, and has admitted that the current violation is not an isolated incident, we deem the appropriate discipline is a sixty-day suspension.

\section{Fixed-Fee Agreements}

American Ins. Ass'n v. Kentucky Bar Ass'n, 917 S.W.2d 568 (Ky. 1996)

Summary: The American Insurance Association and other insurance associations sought review of Court of Advisory Ethics Opinion prohibiting any lawyer from entering into contract with an insurer to do all of the insurer's defense work for a set fee. The Supreme Court held that such set fee arrangements are prohibited, because under rule 1.8(f)(2), it interferes with the exercise of the attorney's independent professional judgment. Instead, "the insurance company must hire members of the private bar to undertake representation of their insured."

STUMBO, Justice.

In this consolidated action, Complainants - American Insurance Association, National Association of Independent Insurers, and State Farm Mutual Automobile Insurance Company and State Farm Fire and Casualty Company - timely filed a motion seeking review by this Court of Advisory Ethics Opinion E-368 which was issued by the Board of Governors of Respondent, Kentucky Bar Association, and which appeared in the Fall 1994 issue of Kentucky Bench \& Bar. In addition, State Farm requests that this Court review that portion of Unauthorized Practice of Law Opinion U-36 which proscribes the use, by insurance companies, of salaried attorneys to provide defense services under the insurers' policies of insurance.

After carefully evaluating the opinions at issue, and the briefs filed and arguments advanced by both Complainants and Respondent, we hereby approve and adopt E-368 as written, and choose not to disturb U-36.

At issue in this action is the following question presented in E-368:

(1) May a lawyer enter into a contract with a liability insurer in which the lawyer or his firm agrees to do all of the insurer's defense work for a set fee?

The Board of Governors answered "no" to this question, and stated that the arrangement at issue would violate Kentucky Rules of Professional Conduct 1.7(b)[1] and 1.8(f)(2)[2], stating therein "to some extent the lawyer becomes the insurer; and the lawyer stands to gain by limiting the services rendered to the client." The Board, indicating that the lawyer's duty to the insured client was a function of the attorney-client relationship and not governed by or limited by the terms of the insurance contract, expressed concern that this set fee arrangement would result in the loss of control of the insured client vis-a-vis actions taken by counsel in the course of representation. The Board also noted that the insurer would take on a dual role in such a 
situation, in that "the insurer wants to continue to promise the insured a defense in the contract of insurance, while limiting the extent of its undertaking in a side contract between the insured's lawyer and the insurer to which the insured is not a party." The Board characterized the circumstance presented in E-368 as but the latest issue to arise from attempts by insurers to cut costs. One such cost-cutting measure, referenced in the "Background" section of E-368 and more fully discussed in U-36, involved the practice of insurers to attempt to provide defense services directly through salaried attorney employees - a practice, the Board concluded, that "is not permitted in Kentucky, for in addition to the obvious conflicts of interest that would be presented by such an arrangement, the practice would violate the law governing unauthorized practice."

More specifically, this issue was addressed in U-36 through the following question:

May an insurance company employ in-house counsel (salaried employees) to represent their insured after a lawsuit has been filed?

This question was answered in the negative. The opinion relied upon both Canon 3 of the ABA Code of Professional Responsibility, which governs the areas of unauthorized practice of law, and SCR 3.020, which defines the practice of law in Kentucky and recognizes that "nothing herein shall prevent any natural person not holding himself out as a practicing attorney from drawing any instrument to which he is a party without consideration unto himself therefor." The opinion also cited to long-standing Kentucky case law which proscribes a corporation from being licensed to practice a learned profession, such as law. Ethical rules and legal precedent were merged in the opinion to reach the conclusion that in the typical action on an insurance contract, the insured, and not the insurer, was the party-defendant, and that, therefore, "the insurance company must hire members of the private bar to undertake representation of their insured."

Complainants contend that not only did the Board paint with too broad a brush in applying U-36 to E-368, but, that the former opinion, of itself, represents only a minority view of the interpretation of the ABA Code of Professional Responsibility, and is, in fact, antithetical to the precedent which attempts to follow the intent of the Code. Complainants seek support from the ethics opinions and case law of other jurisdictions which allow house counsel to provide insurance defense services. Additionally, State Farm asserts that Gardner v. North Carolina State Bar, which is referenced in E-368 and which this Complainant terms "the sole court decision holding that the use of claim litigation counsel constitutes the unauthorized practice of law," lacks substance. State Farm points out that this decision has been rejected by every court to consider it.

In its attack upon U-36, State Farm goes so far as to characterize the opinion as "inconsistent with law and logic." The "law," to which State Farm refers, appears to be contained in those decisions of other jurisdictions which allow insurers to provide insurance defense services through salaried attorney employees. Such precedent, as State Farm explains, is based upon "the identity or community of financial interest between the insured and insurer in defending the claim and because of the insurer's contractual obligation to defend the insured at the insurer's 
expense." The "logic," to which this Complainant refers, appears to lie within this rubric of "community of interest." For example, State Farm indicates that it is contradictory for U-36 to require the insurer to hire outside counsel to represent the insured once a complaint has been filed, and yet to allow an insurer's employees, including attorneys, to take actions necessary to protect the interests of both the insurer and its insured prior to the filing of a complaint, as this latter activity is "inextricably intertwined with any defense of the insured." State Farm also asserts that as the prohibition against the unauthorized practice of law is designed to protect the public "from the incompetent, the untrained and the unscrupulous in the practice of law," who could be more competent, trained and scrupulous therein than claims litigation counsel employed by insurance companies who, because their practice is concentrated in automobile and premises liability law, are able to specialize and become more proficient in the disposition of such matters. State Farm implies that the legal system as a whole would benefit from such house counsel, in that, as the compensation of these attorneys is not tied to billable hours, they may be apt to dispose of these cases more quickly.

Notwithstanding the trends of other jurisdictions, any alleged nonsensical application of the prohibition against the unauthorized practice of law, and the untapped resource of "competent, trained and scrupulous" in-house insurance defense counsel as pipe cleaners for a clogged legal system, we do not feel that U-36 deserves review. The age-old adage of "if it ain't broke, don't fix it" seems appropriate in disposing of Complainants' argument herein, especially in light of the fact that $U-36$ first surfaced nearly fifteen years ago and there is now no compelling reason to overrule the more than fifty years of legal precedent which recognizes the principles outlined in that opinion. "There is scarcely any judicial dissent from the proposition that a corporation cannot lawfully engage in the practice of law." Moreover, "a corporation cannot obtain license to practice law, since it is wholly incapable of acquiring the educational qualifications necessary to obtain such license, nor can it possess in its corporate name the necessary moral character required therefor." Nothing has changed since the rendering of Kendall and Hobson, or since the adoption of U-36, to assuage the moral dilemmas and ethical concerns connected to the unauthorized practice of law. In fact, no situation is more illustrative of the inherent pitfalls and conflicts therein than that in which house counsel defends the insured while remaining on the payroll of the insurer. "No man can serve two masters," regardless here of either any perceived "community of interest," or Complainants' Pollyanna postulate that house counsel will continue to provide undivided loyalty to the insured. Complainants' pleas for logic are unpersuasive, as we are inclined to view U-36 in the way in which Respondent characterizes the opinion - as a prophylactic measure, not unlike the imputed disqualification rules. See Rule 1.10. As such, we believe that U-36 logically discerns when house counsel would fall into that precarious position between employee of insurer and advocate of insured, and, thus, logically prevents the occurrence of such a happening, and its onerous fallout.

Moreover, we are unswayed by Complainants' reliance on the practices of other jurisdictions and what amounts to an "everyone else is doing it, why can't we" argument. In State Farm Mut. Auto. Ins. Co. v. Reeder, the task of this Court was to evaluate our state's Unfair Claims Settlement Practices Act to determine if a third-party claimant injured by an insurance company's violation of that statute could maintain a private right of action for damages. In our 
decision, we were unaffected by the "substantial split in authority among other states as to whether individuals can maintain an action under their respective state laws." In determining that such a cause of action did exist in the Commonwealth, we concluded that "whether other states permit private individuals to maintain claims is based upon their particular statutory system and is of no consequence here. Our decision must be based on the language of the Kentucky law." Likewise, the Kentucky Rules of Professional Conduct and the means by which this state oversees the conduct of its attorneys are personal to Kentucky. "The right to prescribe such rules as are necessary to qualify, regulate, and control attorneys as officers of the court is a right of self-preservation." That other jurisdictions govern the practice of law differently, or even allow for the unauthorized practice of law, is of no concern to us in this matter.

As for E-368, Complainants assert that there is no language within our Rules of Professional Conduct which prevents an attorney and an insurer from entering into an agreement whereby the attorney agrees to perform all of the insurer's defense work for a set fee. In support, Complainants analogize the set fee to other alternative billing methods - such as retainers and contingency fees - and argue that there exists no real difference between these latter, more accepted arrangements, and the set fee. Moreover, American and National contend that if any type of fee arrangement is to be viewed as suspect, it is the hourly-based fee, which, these Complainants argue, is vulnerable to "padding," and even creates a conflict of interest wherein the client has incentive to control costs by controlling counsel. The necessity to be free to exercise independent judgment in order that the attorney may adequately represent the insured is not, according to Complainants, jeopardized by the set fee arrangement, as the form of compensation is not as significant a factor in evaluating the propriety of the attorney-client relationship as, for example, whether or not the attorney has a personal interest in the outcome of the litigation. American and National assert that the high standards of ethical conduct with which attorneys must comply do not mandate a per se prohibition on set fee arrangements as such "a blanket prohibition is overbroad and does nothing to protect the integrity of the profession." Likewise, State Farm maintains that these ethical standards, which include counsel's implied duty of loyalty, mandate zealous representation of the insured, even if the set fee has been exhausted. Complainants remind us that not only does this Court have the power to defend the attorney-client relationship, but that, should this relationship break down and the insured incur damage, the insured would most likely have a cause of action against the attorney or the insurer or both.

Taking these latter propositions first, we agree that this Court does indeed have the power to protect the attorney-client relationship, and is, herein, exercising such power by adopting E-368 as written. Moreover, we do not take comfort, as Complainants do, in knowing that the insured, aggrieved by inadequate representation occasioned by the set fee arrangement, could proceed against the attorney and/or the insurer. Such recourse requires that the insured first suffer a harm, a circumstance which cannot be reconciled with this Court's view that the interest of the insured is to be protected. We also do not agree with Complainants' contention that the form of compensation has little relevance in examining the attorney-client relationship. To the contrary, a set fee arrangement enables the insurer to constrain counsel for the insured by, in effect, limiting the defense budget - a practice that Respondent cautioned, in E-331, could create 
ethical problems similar to those herein. We agree with Respondent that the pressures exerted by the insurer through the set fee interferes with the exercise of the attorney's independent professional judgment, in contravention of Rule 1.8(f)(2). The set fee arrangement also clashes with Rule 1.7(b) in that it creates a situation whereby the attorney has an interest in the outcome of the action which conflicts with the duties owed to the client: quite simply, in easy cases, counsel will take a financial windfall; in difficult cases, counsel will take a financial loss. Finally, Complainants' rationale that other, more commonly used and less restricted billing methods are not as bad as, just as bad as, or worse, than the set fee does not influence us in our review of E-368.

Complainants maintain that set fee arrangements do not create impermissible conflicts of interest between the insurance defense attorney and the insured. In support, Complainants again take solace with our Rules of Professional Conduct and contend that ethical constraints do not allow for the scope of representation to be dependent upon the fee counsel is to be paid. Additionally, Allstate and National retreat to the abstract and assert that potential conflicts of interest are everywhere, and not just confined to set fee arrangements. These Complainants argue that there is no rational basis which would support a conclusion that one form of employment is more likely to generate conflicts than another, especially after considering that there is no guarantee that the attorney stands to substantially profit from a set fee arrangement. Moreover, State Farm contends that the potential for conflict is very often lacking, because in general, the interests of the insurer and the insured are aligned. According to State Farm, only when the coverage is in dispute is there any real conflict between these parties.

We dispose of these arguments by first stressing that the mere appearance of impropriety is just as egregious as any actual or real conflict. Therefore, E-368, in the same manner as U-36, acts as a prophylactic device to eliminate the potential for a conflict of interest or the compromise of an attorney's ethical and professional duties. Furthermore, we do not wear the blinders that Complainants apparently have in place, for we view the situation surrounding the set fee agreement as ripe with potential conflicts. Respondent was able to cite to nineteen such conflicts, including representation of the insured which becomes more complex than anticipated, resulting in financial hardship for the attorney; policy and/or coverage defenses asserted by the insurer against the insured; and disagreement between the insured and the insurer with regard to settlement negotiations. Moreover, we do not believe that in most instances the interests of the insured and the insurer are alike, but are more apt to agree with Respondent's contention that while the insured and the insurer may share some common interests, the two parties are subject to complete divergence at any time. Inherent in all of these potential conflicts is the fear that the entity paying the attorney, the insurer, and not the one to whom the attorney is obligated to defend, the insured, is controlling the legal representation.

Finally, Complainants attack the case law and ethics opinions upon which E-368 is founded. In particular, State Farm contends that E-368 cites to decisions which have either been overruled, are inapposite as silent on the ethical issues addressed in E-368, or lack a basis in law and precedent. Complainants also attack E-368 as overbroad and lacking any factual predicate. In arguing that a reasoned, fact-based analysis is required in order to evaluate potential conflicts of 
interest, State Farm relies on the commentary to the Kentucky Rules of Professional Conduct, which states, in part: "A possible conflict does not itself preclude the representation. The critical questions are the likelihood that a conflict will eventuate and, if it does, whether it will materially interfere with the lawyer's independent professional judgment." Additionally, Allstate and National contend that the Board adopted the wrong version of E-368, in that a revised draft of the opinion better articulates the ethical standard which should apply to counsel involved in set fee arrangements. These Complainants note that the ethics opinions referenced in E-368 such as E-331 and E-340 - bear out the assertion that blanket prohibitions are unnecessary where sufficient reliance is placed upon counsel's ability to comply with the ethical obligations owed to the client, including the requirement that counsel act in the best interest of the client.

First, we believe that the ethics opinions and case law cited in E-368 are on point, and defer to our previous discussion on the inapplicability of the decisions of other jurisdictions to Kentucky's own governance of professional responsibility. Moreover, we are convinced by Respondent's assertion that few of the other jurisdictions to which Complainants cite have conducted any meaningful analysis of the issues presented, nor do these jurisdictions share our state's aversion to the practice of law by corporations. For example, Respondent distinguishes the Tennessee opinion of Youngblood, from the North Carolina opinion of Gardner, by noting that Tennessee does not proscribe a corporation from practicing law for the public, whereas North Carolina does prohibit this practice, as does Kentucky. Finally, notwithstanding the language of other ethics opinions issued by Respondent, or Complainants' argument regarding the alleged inadequacy of the language of the ethics opinion at issue, we find, as discussed above, that the language of E-368 is complete and articulate, and hold that the opinion clearly presents its stated purpose and rationale.

For the foregoing reasons, we approve E-368 as written, and do not disturb U-36.

In re State Grand Jury Investigation, 983 A.2d 1097 (N.J. 2009)

Summary: In a grand jury proceeding investigating an employer for fraud, the state moved to disqualify the counsel of the employees on the grounds that the employer had selected the counsel and was paying them. The Supreme Court held that the employees' counsel was not required to be disqualified under RPC 1.7(a) or 1.8(f) because the counsel had no present relationship to the employer, were barred from disclosing any information to the employer, and were to be paid unless the court granted the employer leave to discontinue payment.

Justice RIVERA-SOTO delivered the opinion of the Court.

Confronted with a grand jury inquiry that commanded the testimony of several of its employees, an employer elected to provide and pay for counsel to those employees for purposes of that investigation. Fearing that having individual employees/grand jury witnesses represented by counsel retained and compensated by the putative target of the grand jury inquiry violated several of the Rules of Professional Conduct, the State moved to disqualify those counsel. The 
trial court denied that application, limited the amount of information to be transmitted by such counsel to the employer, and, further, imposed restrictions both on the ability of the employer to discontinue paying the fees of counsel for the employees as well as on the ability of those counsel to discontinue representing the subpoenaed employees.

Regardless of the setting-whether administrative, criminal or civil, either as part of an investigation, during grand jury proceedings, or before, during and after trial-whether an attorney may be compensated for his services by someone other than his client is governed in large measure by RPC 1.8(f) and, to a lesser extent, RPC 1.7(a) and RPC 5.4(c). The overarching Rule, which purposely is written in the negative, forbids a lawyer from "accepting compensation for representing a client from one other than the client unless three factors coalesce: (1) the client gives informed consent; (2) there is no interference with the lawyer's independence of professional judgment or with the lawyer-client relationship; and (3) information relating to representation of a client is protected" as provided in the RPCs. A straightforward application of RPCs 1.7(a), 1.8(f) and 5.4(c) requires that we affirm the order of the trial court.

I.

The operative facts on which this appeal arise are readily stated. The State commenced a grand jury investigation into whether a corporate contractor had submitted fraudulent invoices for services purportedly rendered to a county government. That inquiry focused primarily on the contractor and three of its employees. In response, the company arranged for counsel for its employees. The company entered into four separate retainer agreements with four separate lawyers, three of whom were assigned to represent, respectively, the three specific employees noted, and the fourth was retained to represent "all non-target current and former employees of the company in connection with the current state grand jury investigation."

The retainer agreements with each of the four lawyers, however, shared common characteristics and were, in all substantive and material respects, indistinguishable. A typical retainer agreement provided (1) that the company "will be ultimately responsible to the law firm for all reasonable and necessary legal fees and expenses incurred in this matter"; (2) that the "undertaking by the company is made with the express understanding that the sole professional obligation of the law firm will be to the named employee"; (3) that the "law firm is not required to disclose any legal strategy, theory, plan of action, or the like, to the company"; (4) that "payment of legal fees by the company to the law firm in no way depends upon any such disclosure"; (5) that "no professional relationship will arise between the company and the law firm as a result of the rendering of legal services by the law firm or the payment of legal fees and expenses by the company"; (6) that "the reimbursement of legal fees and expenses is neither conditioned upon nor dependent upon the law firm's cooperation with the company or any other party"; (7) that while "detailed invoices will be provided to the represented employee, to preserve the attorney/client privilege, only summary invoices will be submitted to the company"; and (8) that the company would be responsible to pay those invoices "upon receipt." 
Based on the company's retention of separate counsel for each of three employees identified by the State, the company wrote to each such employee, informing them that:

As you know, the New Jersey Attorney General's office served the company with a Grand Jury subpoena seeking various billing and payroll records related to the company's contract with the specified county government. The company has been fully cooperative with the State's investigation.

Recently the Attorney General's office has begun interviewing some of our employees at the identified project. Given your position with the company and involvement in this project, and based upon the advice of our attorneys in New Jersey, we believe it would be prudent to retain separate counsel to represent you personally in connection with the State's investigation. Accordingly, the company has retained a specially retained lawyer to represent you in connection with the State's investigation. You do not have to use that specially retained lawyer as your attorney. You are free to hire your own attorney, at your own costs.

You should not interpret this decision to mean that the company believes there to have been any illegal activity in this matter on the part of any company employee. Rather, it is based upon the recognition that your personal rights may conflict with the interests of the company. While the company agrees to pay for your legal representation in this matter, please understand that it has no obligation to do so and may stop paying those legal fees and costs at any time, should it believe it appropriate to do so.

Your specially retained lawyer may be reached at [ $\_$] His firm address is: [ $\left[\_\right.$. Please expect your specially retained lawyer to contact you directly to arrange a convenient time to meet and discuss this matter. Please feel free to contact me directly or speak with the company's local counsel if you have any questions regarding this matter.

Very truly yours, /s/ Senior Vice President and General Counsel

The company also announced to all other employees that the company had retained a lawyerfree of charge to the employees-with whom those employees could consult and who was available to represent those employees in respect of the grand jury inquiry.

In time, two of the four lawyers retained by the company to represent its employees were subpoenaed to appear before the grand jury; they declined to appear, and the State later withdrew those subpoenas. The State then notified the company that it, along with several unnamed employees, had been designated as targets of the grand jury's investigation, and later served grand jury subpoenas for the company's records in respect of the retention of counsel for its employees. The company complied with that subpoena by producing responsive but nonprivileged documents. 
The State moved before the Superior Court to disqualify the counsel retained by the company to represent its employees "from further participation in this matter, pursuant to RPC 1.7, RPC 1.8 and RPC 1.10." In response, each of the employees to whom the company had provided counsel to date-the three identified "target" employees and two additional "nontarget" employees-submitted certifications asserting that none of them could afford to retain separate counsel, and that each was satisfied with and wished to remain with their then counsel.

The trial court noted at the outset that it "viewed the company's conduct as one that is certainly to be appreciated." Addressing the caliber of the lawyers retained by the company for its employees, the trial court explained that "as a major corporation, the company didn't go out and hire some low-level attorney. They went out and hired competent, knowledgeable, respected attorneys." Focusing on the application of the Rules of Professional Conduct to the State's motion for disqualification, the court first observed that RPC 1.5 "talks about fees being reasonable and that is not an issue before the Court." Moving on to the application of RPC 1.6, which addresses the confidentiality of information between a lawyer and his client, the trial court remarked that the retained lawyers had provided certifications and sample redacted bills. Agreeing that the procedure employed was proper, the trial court emphasized that "the only thing that I would require going forward is that all of the bills sent to the company be redacted and that no specific information be detailed in the billing."

Turning to RPC 1.7, the general conflict of interest rule, the trial court concluded that, "at least at this point, there's been no demonstration that there is even a conflict and even if there were, these employees have the right to waive that conflict." It also declared itself "satisfied that there has been informed consent given by all of the employees by way of what they have put in the certifications." It concluded that

The Court finds nothing improper about the attorneys that have been retained by the company. In fact, the Court would go further and say that the company acted responsibly, quite frankly, and with corporate policy and, quite frankly, having been advised of the reputation of these attorneys. And clearly the understanding between the company and these attorneys was spelled out in not only the retainer agreements, but in previous letters before all this was signed.

It added, however, some restrictions: "that the company and the individual attorneys, prior to ending any relationship for payment, would have to make application to the Court," and that counsel were to "redact the billings to cure any notion that the State may have that somehow the billings will reveal significant aspects of the grand jury investigation."

The trial court entered an order that denied the State's motion to disqualify counsel. More specifically, it

FURTHER ORDERED that before the company may cease paying any of the attorney's legal fees and costs, the company shall provide notice to the Court and all parties, and 
the Court shall conduct a hearing on the issue of whether the company may cease paying such legal fees and costs; and

IT IS FURTHER ORDERED that before any of the attorneys may withdraw from this case based upon the refusal of the company to pay the attorney's legal fees and costs, such attorney shall provide notice to the Court and all parties, and the Court shall conduct a hearing on the issue of the attorney's request to withdraw; and

IT IS FURTHER ORDERED that the attorneys henceforth shall submit to the company legal bills either in summary form or with all detailed information redacted therefrom.

The State sought leave to appeal that determination and, in an unpublished order, the Appellate Division denied that application. It then moved before this Court, seeking leave to appeal the trial court's order and other ancillary relief. Those motions were granted. We also granted leave to the Association of Criminal Defense Lawyers of New Jersey to appear as amicus curiae. For the reasons that follow, we affirm the order of the trial court.

II.

According to the State, a per se conflict of interest arises whenever, as here, two facts contemporaneously appear: a target in a grand jury investigation unilaterally selects and retains a lawyer to represent potential witnesses against it, and the lawyer relies on the target for payment of legal fees. In the State's view, that arrangement will split the attorney's loyalty and will discourage the lawyer from counseling the client to cooperate with the State, even when cooperation might be in the client's best interest. It asserts that the perceived effect of allowing a target to select and pay for counsel for the witnesses against it is to irreparably taint the proceedings. The State also claims that such a conflict cannot be waived and that, even if it could be waived, a waiver could only be demonstrated through the live testimony of the witnesses, and not, as was done here, via certifications.

The lawyers whose disqualification is sought counter that RPC 1.8(f) clearly contemplates an employer designated as a grand jury "target" providing and paying for separate counsel for its employees during that grand jury inquiry. They reject the State's claim that, in the criminal law setting, the better rule is the imposition of a per se conflict. Finally, they assert that, even if a potential conflict of interest exists, it has been effectively waived. Amicus ACDL-NJ repeats those arguments.

The company echoes the arguments advanced both by the lawyers whose disqualification is sought and by amicus, and further asserts that, under the laws of its place of incorporation, it has an obligation to provide counsel to its employees, noting that, absent counsel provided by and paid for by the company, most of its employees would be unable to afford a lawyer.

III. 
A.

Our evaluation of an actual or apparent conflict does not take place in a vacuum, but is, instead, highly fact specific. In that respect, the Court's attention is directed to something more than a fanciful possibility. To warrant disqualification in this setting, the asserted conflict must have some reasonable basis.

The State asserts that a target of a grand jury inquiry providing and paying for the lawyers who will represent the target's employees before the very grand jury considering the target's culpability creates an insoluble conflict not subject to waiver. Although the State's arguments possess considerable initial appeal, in light of modern changes in the manner in which attorneyclient relationships are to be viewed, we are constrained to disagree.

No doubt, it long has been the law of this State that it is "improper for the attorney for an employee to have accepted the organization's promise to pay his bill, for such an arrangement has the inherent risk of dividing an attorney's loyalty between his client and his client's employer who will pay for the services." In those instances, we have concluded that "a conflict of interest inheres in every such situation," one that cannot be waived "when the subject matter is crime and when the public interest in the disclosure of criminal activities might thereby be hindered." Reasoning that "an attorney must realize that the employer who agrees to pay him is motivated by the expectation that he will be protected," we have concluded that

It is inherently wrong to represent both the employer and the employee if the employee's interest may, and the public interest will, be advanced by the employee's disclosure of his employer's criminal conduct. For the same reasons, it is also inherently wrong for an attorney who represents only the employee to accept a promise to pay from one whose criminal liability may turn on the employee's testimony.

See also Wood v. Georgia, 450 U.S. 261, 268-69 (1981) (emphasizing that "courts and commentators have recognized the inherent dangers that arise when a criminal defendant is represented by a lawyer hired and paid by a third party, particularly when the third party is the operator of the alleged criminal enterprise. One risk is that the lawyer will prevent his client from obtaining leniency by preventing the client from offering testimony against his former employer or from taking other actions contrary to the employer's interest").

B.

That said, effective September 10, 1984, New Jersey replaced its then extant Canons of Professional Ethics and Disciplinary Rules with the more modern Rules of Professional Conduct. Among these was RPC 1.8(f), which then provided that

A lawyer shall not accept compensation for representing a client from one other than the client unless: (1) the client consents after consultation; (2) there is no interference with the lawyer's independence of professional judgment or with the lawyer-client relationship 
and (3) information relating to representation of a client is protected as required by RPC 1.6 .

Thereafter, starting in 2001 and continuing for almost two years, New Jersey engaged in a "review of the existing Rules of Professional Conduct in light of the work of the American Bar Association's Commission on Evaluation of the Rules of Professional Conduct." This process culminated in yet another round of modifications to the Rules of Professional Conduct. In respect of RPC 1.8(f), however, only minor changes were made; it now provides in full as follows:

A lawyer shall not accept compensation for representing a client from one other than the client unless:

(1) the client gives informed consent;

(2) there is no interference with the lawyer's independence of professional judgment or with the lawyer-client relationship; and

(3) information relating to representation of a client is protected as required by RPC 1.6.

C.

However, RPC 1.8(f) does not exist in a vacuum: two other RPCs directly touch on the question presented. First, RPC 1.7(a) forbids a lawyer from representing a client "if the representation involves a concurrent conflict of interest." That RPC recognizes "a concurrent conflict of interest if: there is a significant risk that the representation of one or more clients will be materially limited by the lawyer's responsibilities to a third person or by a personal interest of the lawyer." Second, RPC 5.4(c) provides that "a lawyer shall not permit a person who recommends, employs, or pays the lawyer to render legal services for another to direct or regulate the lawyer's professional judgment in rendering such legal services."

Our task, then, is to harmonize RPCs $1.7(\mathrm{a})(2), 1.8(\mathrm{f})$ and $5.4(\mathrm{c})$ seemingly overlapping mandates so as to give proper guidance on whether, and under what circumstances, a lawyer may represent a client when the fees and costs incurred are being paid by another.

D.

The starting point for analysis must be the RPC that most specifically addresses the question of when a lawyer can represent a client while being paid by another: RPC 1.8(f). That RPC makes clear that three factors must coalesce in order to allow a lawyer paid by a third party to represent a client: the client must give informed consent; the lawyer's independent professional judgment and the lawyer-client relationship must be maintained sacrosanct; and no improper disclosures relating or referring to the representation can be made. However, the considerations that animate RPC 1.7(a)(2) — that there be no concurrent conflict of interest-and RPC 5.4(c)that no third party may influence the lawyer's professional judgment - also are relevant and must be addressed. 
A synthesis of RPCs 1.7(a)(2), 1.8(f) and 5.4(c) yields a salutary, yet practical principle: a lawyer may represent a client but accept payment, directly or indirectly, from a third party provided each of the six conditions is satisfied. Those conditions are:

(1) The informed consent of the client is secured. In this regard, "'informed consent' is defined as the agreement by a person to a proposed course of conduct after the lawyer has communicated adequate information and explanation about the material risks of and reasonably available alternatives to the proposed course of conduct."

(2) The third-party payer is prohibited from, in any way, directing, regulating or interfering with the lawyer's professional judgment in representing his client.

(3) There cannot be any current attorney-client relationship between the lawyer and the third-party payer.

(4) The lawyer is prohibited from communicating with the third-party payer concerning the substance of the representation of his client. The breadth of this prohibition includes, but is not limited to, the careful and conscientious redaction of all detail from any billings submitted to the third-party payer.

(5) The third-party payer shall process and pay all such invoices within the regular course of its business, consistent with manner, speed and frequency it pays its own counsel.

(6) Once a third-party payer commits to pay for the representation of another, the thirdparty payer shall not be relieved of its continuing obligations to pay without leave of court brought on prior written notice to the lawyer and the client. In such an application, the third-party payer shall bear the burden of proving that its obligation to continue to pay for the representation should cease; the fact that the lawyer and the client have elected to pursue a course of conduct deemed in the client's best interests but disadvantageous to the third-party payer shall not be sufficient reason to discontinue the third-party payer's continuing obligation of payment. If a third-party payer fails to pay an employee's legal fees and expenses when due, the employee shall have the right, via a summary action, for an order to show cause why the third-party payer should not be ordered to pay those fees and expenses.

\section{E.}

We now apply this principle, and its conditions, to the case on appeal.

Informed consent. Each of the letters from the company to the individual employees provided that the employee "did not have to use the assigned counsel as your attorney. You are free to hire your own attorney, at your own costs." As conceded by counsel for the company during oral argument, that "take-it-or-leave-it" approach, on its face, does not satisfy the requirement that 
the employee's acceptance of counsel be based on informed consent. Therefore, presumptively, the retention of counsel here does not comply with RPC 1.8(f)(1). However, as acknowledged by the trial court, each of the employees certified that he was satisfied with the assigned counsel and wished to remain as that counsel's client. Therefore, we conclude that the arrangement approved by the trial court below is satisfactory, albeit with the caveat that, in the future, no such limitations on the choice of counsel should be communicated or imposed on the employee/client save for reasonable limitations on fees and expenses.

Interference with the lawyer's professional judgment. As clearly set forth in the separate retention letters between the lawyers and the company, each of the lawyers explained that "the sole professional obligation of the law firm will be to the assigned client." For the avoidance of future doubt, such retention letters should clearly and conspicuously note that nothing in the representation shall limit the lawyer's responsibilities to the client, as provided in RPC 1.8(f)(2), and that the third-party payer shall not, in any way, seek to "direct or regulate the lawyer's professional judgment in rendering such legal services." RPC 5.4(c).

Current representation. The record is clear that none of the lawyers selected to represent the individual employees had any current relationship with the company, and that "no professional relationship will arise between the company and the law firm as a result of the rendering of legal services by the assigned lawyer or the payment of legal fees and expenses by the company." Those facts, standing alone, constitute a sufficient showing in favor of permitting this representation. Again, as an aid in future matters, the retention letters should clearly spell out that the lawyer does not have a professional relationship with the third-party payer.

Prohibited communications. Each of the retention letters made clear that the lawyer "is not required to disclose any legal strategy, theory, plan of action, or the like, to the company and payment of legal fees by the company to the law firm in no way depends upon any such disclosure." In this respect, the better practice is to affirmatively state that the lawyer will not disclose any part of the substance of the representation of the client to the third-party payer. Consistent with that representation, all billings from the lawyer to the third-party payer must have any detail information redacted, simply stating the sum due for services rendered and the sum due for expenses incurred. Because these latter conditions were imposed by the trial court, the retention letters, as modified by the trial court, clearly comply with the requirements we have imposed.

Prompt and continued payment. Once an employer commits to paying the legal fees and expenses of its employees, it scrupulously must honor that commitment. Also, if the employer wishes to discontinue paying the legal fees and expenses of one or more of its employees, it may only do so by leave of court granted. Because this condition also was imposed by the trial court and was agreed to by all parties, the arrangements at issue are satisfactory.

In sum, through the combined product of the good faith of an employer, the diligence of competent counsel and the exercise of a trial court's supervisory authority, the net result of the company's retention and payment of counsel for its employees complies with the Rules of 
Professional Conduct. For these reasons, the trial court properly denied the State's motion to disqualify counsel.

IV.

The order of the Law Division denying the State's motion to disqualify the counsel retained to represent the company's employees before the grand jury is affirmed. 


\section{8: Personal Conflicts of Interest}

Way out in Reno, Nevada, where romance blooms and fades, a great Philadelphia lawyer was in love with a Hollywood maid. Come, love, and we'll go ramblin', down where the lights are so bright. I'll win you a divorce from your husband, and we can get married tonight. ${ }^{59}$

Am I the only one who hears the screams and the strangled cries of lawyers in love? ${ }^{60}$

Do I look like l'm asking for it? ${ }^{61}$

It's harder to be friends than lovers, and you shouldn't try to mix the two. Cause if you do it and you're still unhappy, then you know that the problem is you. ${ }^{62}$

\section{Model Rule 1.8: Current Clients: Specific Rules}

(j) A lawyer shall not have sexual relations with a client unless a consensual sexual relationship existed between them when the client-lawyer relationship commenced.

\section{Model Rule 1.8, Comments [17]-[19]: Client-Lawyer Sexual Relationships}

[17] The relationship between lawyer and client is a fiduciary one in which the lawyer occupies the highest position of trust and confidence. The relationship is almost always unequal; thus, a sexual relationship between lawyer and client can involve unfair exploitation of the lawyer's fiduciary role, in violation of the lawyer's basic ethical obligation not to use the trust of the client to the client's disadvantage. In addition, such a relationship presents a significant danger that, because of the lawyer's emotional involvement, the lawyer will be unable to represent the client without impairment of the exercise of independent professional judgment. Moreover, a blurred line between the professional and personal relationships may make it difficult to predict to what extent client confidences will be protected by the attorney-client evidentiary privilege, since client confidences are protected by privilege only when they are imparted in the context of the client-lawyer relationship. Because of the significant danger of harm to client interests and because the client's own emotional involvement renders it unlikely that the client could give adequate informed consent, this Rule prohibits the lawyer from having sexual relations with a client regardless of whether the relationship is consensual and regardless of the absence of prejudice to the client.

[18] Sexual relationships that predate the client-lawyer relationship are not prohibited. Issues relating to the exploitation of the fiduciary relationship and client dependency are

\footnotetext{
${ }^{59}$ Woody Guthrie, Philadelphia Lawyer (1937).

60 Jackson Browne, Lawyers in Love (1983)

${ }^{61}$ Chia Pet, Hey Baby (1992).

${ }^{62}$ Liz Phair, Divorce Song, Exile in Guyville (1993).
} 
diminished when the sexual relationship existed prior to the commencement of the client-lawyer relationship. However, before proceeding with the representation in these circumstances, the lawyer should consider whether the lawyer's ability to represent the client will be materially limited by the relationship. See Rule 1.7(a)(2).

[19] When the client is an organization, paragraph (j) of this Rule prohibits a lawyer for the organization (whether inside counsel or outside counsel) from having a sexual relationship with a constituent of the organization who supervises, directs or regularly consults with that lawyer concerning the organization's legal matters.

\section{Walter v. Stuart, 67 P.3d 1042 (Utah 2003)}

Summary: Attorney Alan Stewart represented client Beth Walter in a divorce proceeding. Stewart told Walter that he was divorced, and they began a personal relationship, which soon became sexual. Eventually, Walter learned that Stewart was actually married and ended the relationship. Walter filed an action against Stewart, alleging breach of fiduciary duty. The trial court granted Stewart's motion for summary judgment, but the Supreme Court reversed, finding that issues of fact existed.

This case arises out of an attorney-client relationship, which turned sexually intimate, between one-time client Beth Walter and her former attorney Alan Stewart. Following her discovery that Stewart was married, Walter filed claims against Stewart for breach of fiduciary duty, fraud, intentional infliction of emotional distress, reckless misconduct, breach of contract, and battery. Upon Stewart's motion, the trial court entered summary judgment against Walter on all of her claims. Walter now appeals. We reverse in part, affirm in part, and remand.

\section{BACKGROUND}

In June of 1998, Walter retained Stewart as her attorney in a divorce action. Through that representation, Stewart learned that Walter was in a "fragile emotional state and had personal self esteem issues," including a "doubt in her ability to have a successful relationship." Walter decided to relocate to Maryland. In the first part of April of 1999, Walter phoned Stewart several times, anxious that her divorce be finalized so she could move.

During his representation of Walter, Stewart became "very flirtatious, often commenting regarding Walter's personal appearance and grooming." In April of 1999, Stewart began to call Walter daily and, on April 15, took her on a lunch date. Following the lunch date Stewart asked Walter, "If you move to Maryland, how are we supposed to have a relationship?" Walter then "decided to postpone the move to see where Stewart's 'relationship' with her would head."

Through the first part of May, Stewart continued to tell Walter "that he was waiting to hear from her husband's lawyer to finalize the divorce." On May 12, after personally contacting her exhusband and the trial court, Walter learned that her divorce had actually been finalized on April 
26.

The divorce decree required Walter to pay her ex-husband an amount of money. On May 13, Walter asked Stewart about paying the judgment. Stewart told her "to hold off on payment to see if her ex-husband would pursue collection and further advised her that if her ex-husband tried to collect on the amount due, she could make arrangements to pay before a judgment was levied against her." Walter took Stewart's advice and did not make the payment. Also upon finalization of her divorce, Walter desired to resume the use of her maiden name and asked Stewart "why her name change was not reflected in the divorce decree." He told her that she could take the decree to the Department of Social Security to have her name changed, which she did.

Stewart and Walter continued to see each other on a personal basis, and on June 5, 1999, Stewart kissed Walter, tried to undress her, and said that he wanted to "make love." Upon Walter's questioning, Stewart told her that he was a divorced father of four children. The two did not engage in sexual relations that day but did become sexually intimate on July 22, 1999. "On that night as they discussed sleeping together, Walter told Stewart that she would only do so if they were going to have an exclusive-monogamous relationship, a condition with which Stewart readily concurred and agreed to."

During their personal relationship, Stewart took Walter on numerous dates in public as well as on business trips. He never wore a wedding ring. He displayed on his desk an engraved clock that Walter gave him, and wore clothing she gave him. The two also spoke of getting married.

In August of 1999, Walter received an order to show cause for her failure to pay her ex-husband what she owed him under the divorce decree. Walter contacted Stewart, and he said that he would take care of the matter and declined her offer to pay for his services. He then made payment arrangements with the attorney for Walter's ex-husband, and the show-cause hearing was canceled. "For his services rendered and as a token of appreciation, Walter bought Stewart a $\$ 100$ fountain pen."

In October of 1999, Walter considered breaking off her relationship with Stewart. However, when she expressed those feelings to him, he "told her that he loved her, that he wouldn't accept her breaking up with him and that he would 'stalk her and wait for her in the parking garage at work."' They continued to see each other, exchanged Christmas gifts, and spent much of New Years Day 2000 together. Although their dates became less frequent in 2000, Stewart continued to express a commitment to their relationship.

In September of 2000, while pursuing an unrelated international adoption, Walter was told by the Immigration and Naturalization Service that she had illegally resumed use of her maiden name since a name change was not included in her divorce decree. Walter contacted Stewart, who told her that she would need to petition the court to amend the divorce decree. Because Walter's ex-husband would not cooperate in the action, she "retained Stewart's services once more to petition the court for a name change and paid him the sum of $\$ 350.00$." 
The hearing on Walter's name change was held on November 2, 2000. "Following the hearing, Stewart escorted Walter to her car. When they got to the car he grabbed her around the waist and asked her to have sex with him." "Because of the on again-off again nature of Stewart's relationship with her during the latter half of 2000 , Walter became curious regarding his marital status." In a phone conversation on November 12, Stewart told Walter that he and his wife were back together and that he had not been divorced, but only separated. After their phone conversation, Stewart went to Walter's home and told her that "he reconciled with his wife to be with his children, that he was under discipline by his church for a previous affair, and that he had been living with his mother." Stewart nevertheless expressed a desire to keep in contact.

Over the next four days, Stewart called Walter "approximately four times a day," and, on November 16, took her out to lunch. On the evening of November 16, Walter called Stewart's wife and learned that Stewart had been married for twenty years, had never separated from his wife, had not been disciplined by his church for a previous affair, and that he had not lived with his mother at any time during his affair with Walter. Shortly after Walter's conversation with Stewart's wife, Stewart called Walter and told her that she had ruined his life and then hung up. The two have not spoken since.

Walter filed a complaint against Stewart. Her complaint includes claims for breach of fiduciary duty, fraud, intentional infliction of emotional distress, reckless misconduct, breach of contract, and battery. Stewart moved for summary judgment on all of Walter's claims. The trial court granted Stewart's motion in its entirety, stating simply that Walter's battery claims were barred by the statute of limitations and that Walter "failed to support by Affidavit facts sufficient to support" her other claims. She now appeals.

\section{ANALYSIS}

\section{Breach of Fiduciary Duty}

"Actions for breach of fiduciary duty are grounded on the fundamental principle that attorneys must be completely loyal to their clients and must never use their position of trust to take advantage of client confidences for themselves or for other parties. In all relationships with clients, attorneys are required to exercise impeccable honesty, fair dealing, and fidelity." Indeed, due to their "professional responsibility and the confidence and trust" that their clients "legitimately repose" in them, attorneys "must adhere to a high standard of honesty, integrity, and good faith in dealing with" their clients. Attorneys are "not permitted to take advantage of their position or superior knowledge to impose upon clients; nor to conceal facts or law, nor in any way deceive clients without being held responsible therefor."

"The essential elements of legal malpractice based on breach of fiduciary duty include the following: (1) an attorney-client relationship; (2) breach of the attorney's fiduciary duty to the client; (3) causation, both actual and proximate; and (4) damages suffered by the client." 
It is undisputed that an attorney-client relationship existed between Stewart and Walter through at least April of 1999. In May, Walter sought advice from Stewart regarding a sum of money she owed her ex-husband under the divorce decree. Stewart "advised Walter to hold off on payment to see if her ex-husband would pursue collection and further advised Walter that if her exhusband tried to collect on the amount due, she could make arrangements to pay before a judgment was levied against her." This evidence, when viewed in the light most favorable to Walter, indicates that both Stewart and Walter anticipated further representation of her in the divorce action. It is undisputed that Stewart later represented Walter on an order to show cause, which came about because of the advice he gave her regarding payment of the judgment. He represented her again in a name change hearing. Therefore, viewing the facts in a light most favorable to Walter, an attorney-client relationship existed between the parties at all relevant times.

As to a breach of the duty owed Walter, the facts viewed in a light most favorable to her indicate that Stewart took advantage of information he gained during his representation of her to initiate first a dating relationship and then a sexually intimate relationship with Walter. He also misrepresented his marital status and the state of her legal affairs for his own interests. Stewart's conduct can be reasonably construed as taking advantage of a client's fiduciary trust through deception. Walter has thus stated facts sufficient to place the element of breach of duty into dispute.

Walter states damages that she claims were caused, actually and proximately, by Stewart's conduct. The reason for the dissolution of the parties' relationship, as well as the timing of that dissolution relative to the damages Walter alleges, raise a reasonable inference supporting both actual and proximate causation. "Causation is an issue of fact, and we refuse to take it from the jury if there is any evidence upon which a reasonable jury could infer causation." We cannot, therefore, rule against Walter as a matter of law on this element.

Stewart contends that "emotional injury, unaccompanied by a tangible manifestation of that injury," is not recoverable in a claim for breach of fiduciary duty. Walter, however, has alleged the following damages arising from Stewart's breach of duty: emotional pain, a need for mental health counseling, physical pain, medical bills, loss of employment, and a need for sexual therapy.

Because none of the elements of breach of fiduciary duty can be resolved against Walter as a matter of law, we reverse the grant of summary judgment on this claim.

\section{Questions:}

City Bar Ass'n v. Williamson, 117 Ohio St. 3d 399 (Ohio 2008)

Summary: Attorney Karl Williamson represented a female client in a domestic-violence action pending in Fairfield Municipal Court. He began to represent her, and eventually 
she and her two children moved in with him. When she and her husband reconciled after five months, she and her two children moved out. Resultantly, Williamson withdrew from representation. The Supreme Court held that Williamson's relationship with his client violated the professional rule and warranted indefinite suspension.

Respondent, Karl E. Williamson has been admitted to the practice of law in Ohio since 1990. The Board of Commissioners on Grievances and Discipline now recommends that we indefinitely suspend respondent's license to practice based on findings that he became intimately involved with a client after agreeing to represent her. On review, we agree that respondent committed professional misconduct as found by the board and that an indefinite suspension is appropriate.

Relator, Butler County Bar Association, charged respondent with two counts of misconduct, the first relating to respondent's affair with his client and the second for his failure to appear in response to relator's investigative subpoenas. Attempts to serve the complaint by certified mail were unsuccessful and the mail was unclaimed, and relator served the Clerk of the Supreme Court. A master commissioner appointed by the board heard the case, made findings of fact and conclusions of law, and recommended an indefinite suspension. The board adopted the master commissioner's findings of misconduct and recommended sanction.

\section{Misconduct}

\section{Count One}

In May 2004, respondent agreed to represent a female client in proceedings to terminate her marriage before the Butler County Common Pleas Court. He also agreed to help her through a domestic-violence action pending in Fairfield Municipal Court. The client paid respondent \$500 toward a requested $\$ 1,000$ fee.

Respondent began dating his client shortly after she hired him. Their relationship became intimate in the end of May 2004, after the client paid the $\$ 500$ and respondent had appeared at a preliminary hearing in the domestic-violence case against her husband. By mid-June 2004, respondent had allowed the client and her two children to move in with him. The client and her children continued to reside with respondent until October 2004, when the client and her husband reconciled.

In a letter to his client dated May 27, 2004, respondent claimed to be withdrawing as her lawyer in the divorce or dissolution proceedings. Afterward, he began denying their attorney-client relationship in correspondence to the lawyer representing her husband, although he continued to assist her in secret. As part of his plan to hide their affair, respondent also directed his client not to refer to him in public as her lawyer and promised to have another attorney, one of his colleagues, "sign off" on any required papers. The colleague later testified in a deposition that respondent never consulted him about the client. 
By engaging in an affair with his client and continuing to represent her, respondent risked his client's legal and personal interests for his own advantage. As we said in Disciplinary Counsel v. Sturgeon, "a lawyer who attempts to engage in a sexual relationship with a client puts the lawyer's own personal feelings ahead of the objectivity that must be the hallmark of any successful attorney-client relationship." Respondent thereby violated DR 1-102(A)(5) (prohibiting a lawyer from engaging in conduct that is prejudicial to the administration of justice), 1-102(A)(6) (prohibiting a lawyer from engaging in conduct that adversely reflects on the lawyer's fitness to practice law), and 2-110(B)(2) (requiring a lawyer to withdraw from representation when the lawyer knows or it is obvious that his or her continued employment will violate a Disciplinary Rule). Moreover, by lying to conceal the relationship, respondent violated DR 1-102(A)(4) (prohibiting a lawyer from engaging in conduct involving fraud, deceit, dishonesty, or misrepresentation).

\section{Count Two}

The client and her husband filed grievances against respondent. In investigating their claims, relator subpoenaed respondent to appear twice, once in November 2005 and again in February 2006. Respondent did not comply with either subpoena. He thereby violated Gov.Bar R. V(4)(G) (requiring a lawyer to cooperate in an investigation of misconduct).

\section{Sanction}

"We have consistently disapproved of lawyers engaging in sexual conduct with clients where the sexual relationship arises from and occurs during the attorney-client relationship. A lawyer's sexual involvement with a client has warranted a range of disciplinary measures depending on the relative impropriety of the situation, including actual suspension from the practice of law." Moreover, a lawyer's failure to cooperate in a disciplinary investigation, in and of itself, may warrant an actual suspension from practice.

To determine the appropriate sanction, however, we must also weigh the aggravating and mitigating factors of respondent's case.

We accept the board's findings regarding aggravating factors. Respondent attempted to mislead relator by reporting during the investigation that his client was actually represented by independent counsel. He also changed the date of the letter purporting to terminate his professional relationship with his client so that it appeared to coincide with a date after his last appearance in court on her behalf. Moreover, respondent's license to practice has been under suspension since December 5,2005 , for his failure to properly register as an attorney. No mitigating evidence dissuades us from imposing the recommended indefinite suspension.

Respondent is therefore indefinitely suspended from the practice of law in Ohio.

\section{Questions:}


Cleveland Metro. Bar Assn. v. Paris, 148 Ohio St. 3d 55 (Ohio 2016)

Summary: The Bar association alleged that attorney Tasso Paris made unwelcome sexual advance toward a female client and failed to appear at her criminal-sentencing hearing for DUI. At several client meetings he referred to her as his beautiful red haired Irish girl--which he thought relevant given her DUI coincided with St. Patrick's day. The client's fiancee was apparently present for all but one of these meetings. He also asked his client to go out with him several times and invited her to his house to join him in his hot tub on more than one occasion. She discussed this with her fiancee, ultimately agreeing she would go out with Paris just to ensure he represented her effectively. But she could not bring herself to do so. After this, Paris failed to appear at her sentencing hearing. His client then reported him. The Court compared his conduct to other similar cases and resultantly would be suspended from the practice of law for six months if he failed to pay restitution to the client's fiancee.

Respondent, Tasso Paris of Cleveland, Ohio was admitted to the practice of law in Ohio in 1987.

In a January 2015 complaint, relator, Cleveland Metropolitan Bar Association, alleged that Paris violated multiple Rules of Professional Conduct by making unwelcome sexual advances toward a female client and failing to appear at her criminal-sentencing hearing.

The parties entered into stipulations of fact, misconduct, and aggravating and mitigating factors and jointly recommended that Paris be suspended from the practice of law for six months, all stayed on the condition that he engage in no further misconduct. A panel of the Board of Professional Conduct conducted a hearing at which it admitted stipulations submitted by the parties and heard testimony from Paris and the affected client. The panel largely adopted the stipulations but, noting that Paris's testimony contradicted some of those stipulations, also found that he failed to understand and acknowledge the wrongful nature of his conduct. The panel therefore rejected the sanction suggested by the parties and recommended that Paris serve a six-month actual suspension from the practice of law in Ohio. The board adopted the panel's report in its entirety.

Paris objects to the board's finding of an additional aggravating factor to which the parties had not stipulated. He also argues that given the parties' comprehensive stipulations and the limited nature of the testimony before the panel, this court should reject the sanction recommended by the panel and adopt the stipulated sanction of the parties. We adopt the board's findings of fact and misconduct but sustain Paris's objections and suspend him from the practice of law in Ohio for six months, all stayed on conditions.

Misconduct

Following an automobile accident that occurred on March 17, 2013, a woman hired Paris to defend her in the Cleveland Municipal Court against charges of driving under the influence and 
driving under suspension, and her fiancé paid him $\$ 1,000$. Paris stipulated that he referred to her as his "beautiful Irish girl" but testified that he had referred to her as "a red haired Irish girl, coming out of an Irish bar, in Cleveland, Ohio, on March 17th" only in the context of explaining that no one was going to believe her claim that she had had only one drink before her St.

Patrick's Day automobile accident. Paris also stipulated that during the course of his representation, he asked his client to go out with him several times and invited her to his house to join him in his hot tub on more than one occasion. Although he never denied the truth of that stipulation, he also testified that the client's fiancé was present at all but one of their meetings.

Paris stipulated that his client was afraid to do anything about his conduct out of fear that it would affect his representation. The client testified that his conduct made her uncomfortable but that she never told him that she would not go out with him. Instead, she attempted to avoid the issue by saying, "We'll see" or "We will talk about it." The client and her fiancé discussed her concerns on several occasions and agreed that she would just go out with Paris so that he would do a better job representing her, but she could not bring herself to go through with it. She testified that as the case dragged on, however, she would have done "whatever he wanted" to get it resolved.

On August 6, 2013, the client pleaded guilty to driving while under suspension and failure to maintain reasonable control of her vehicle and was ordered to appear at a later date for sentencing. Paris stipulated that he not only failed to attend the sentencing hearing but that he also failed to notify the client of his absence and to request that another attorney attend the hearing on his behalf. At the panel hearing, Paris acknowledged that stipulation and confirmed its truth. He testified, however, that he had asked his father to attend the client's sentencing hearing and that upon returning to the office after the hearing, his father reported that the case had been "sent to another judge." Paris's father was not called as a witness, but he represented Paris before the panel. During his closing argument, he stated that he attended the sentencing hearing at Paris's request. But the parties had stipulated - and the client's testimony confirmed - that when the judge asked her whether she was represented by counsel, she responded that Paris had failed to appear and that she did not expect him to because "he's been doing nothing but trying to get in my pants."

Based on the client's statement, the judge vacated the client's plea and recused herself from the case. The case was reassigned, and a public defender was appointed to represent the client. The client ultimately pleaded guilty to operating an unsafe vehicle and was fined $\$ 200$. She later filed a grievance against Paris.

The board adopted the parties' stipulations and agreed that Paris's conduct violated Prof.Cond.R. 1.3 (requiring a lawyer to act with reasonable diligence in representing a client) and 1.8(j) (prohibiting a lawyer from soliciting or engaging in sexual activity with a client unless a consensual sexual relationship existed prior to the lawyer-client relationship).

Recommended Sanction 
When imposing sanctions for attorney misconduct, we consider several relevant factors, including the ethical duties that the lawyer violated, relevant aggravating and mitigating circumstances, and the sanctions imposed in similar cases.

The board adopted the parties' stipulation that Paris has no prior disciplinary record and cooperated with relator's investigation. It also noted that Paris did not present evidence of any other mitigating factors.

In addition to adopting the parties' stipulated aggravating factors - that Paris acted with a selfish motive and engaged in multiple offenses - the board found that Paris's conduct harmed a vulnerable client. The board also found that Paris did not understand or accept the wrongful nature of his conduct based on testimony in which he (1) asked why the client referred a female friend to him after terminating his representation if he was "hitting on" her, (2) stated that the client's fiancé was present during all but one of their meetings, (3) claimed that he merely referred to the client as a "red haired Irish girl" - and only when explaining that no one was going to believe her claim that she had had only one drink before her St. Patrick's Day automobile accident, and (4) claimed that his father had attended the client's sentencing hearing. While noting that relator offered no evidence that Paris engaged in a pattern of misconduct, the board also commented that "there is likewise no evidence to assure the panel that it was an isolated event that is unlikely to reoccur."

The parties jointly recommend that Paris be suspended for six months but that the suspension be stayed in its entirety on the condition that he engage in no further misconduct. In support of that sanction, the parties cited Disciplinary Counsel v. Hubbell (imposing a conditionally stayed six-month suspension on an attorney who attempted to initiate a romantic relationship with a client whom he represented, pro bono, in a custody dispute), and Disciplinary Counsel v. Quatman (imposing a conditionally stayed one-year suspension on an attorney who put his hands on a client's breasts for several seconds and told her that they were "very nice").

Noting the increasing frequency of cases involving repeated and unwelcome solicitation of clients for sexual activity, the board, however, urges us to hold that in the absence of significant mitigating factors, this court will impose an actual suspension on attorneys who have engaged in such conduct - as we do in cases involving attorneys who have engaged in a material misrepresentation to a court or have engaged in a pattern of dishonesty with a client.

In accordance with this suggested presumption and in light of Paris's repeated and unwelcome solicitation of his client, his failure to appear for her sentencing hearing after she rebuffed his advances, his failure to acknowledge the wrongful nature of his conduct, and the absence of additional mitigating evidence, the board recommends that we suspend Paris from the practice of law for six months with no stay.

Paris's Objections 
In his objections to the board's report and recommendation, Paris urges us to reject the board's finding of the additional aggravating factor that Paris failed to accept the wrongful nature of his conduct. He also challenges the board's recommended sanction and urges us to adopt the parties' stipulated sanction of a fully stayed six-month suspension.

We agree that Paris did not plainly acknowledge the wrongful nature of his conduct or make a particularly strong showing of remorse at the panel hearing. But we also note that despite the intention of the parties to submit the case entirely upon their stipulations, the panel sought to hear testimony not only from Paris but also from the grievant. This created some confusion regarding the scope of the evidence to be presented at the hearing. It also resulted in the inadvertent admission of testimony that touched upon stipulated issues. Although relator and the panel chairperson expressed that it was their intention to rely on the stipulations rather than the testimony in those instances, there is a possibility that some of Paris's contradictory testimony was offered to rebut portions of the grievant's testimony on those stipulated issues. Therefore, in the interest of fairness, we decline to adopt additional aggravating factors based on that testimony. Moreover, in light of Paris's nearly 30 years of practice with no disciplinary record prior to this incident, we are inclined to agree that there is some evidence that his behavior in this matter is an isolated incident.

We have consistently disapproved of the conduct of lawyers who have solicited or engaged in sexual activity with their clients even before the adoption of Prof.Cond.R. 1.8(j), and depending on the relative impropriety of the situation, we have imposed a wide range of disciplinary measures for such conduct. We have publicly reprimanded attorneys who have commenced consensual sexual relationships with their clients that have not compromised the clients' interests. On the other end of the spectrum, we have disbarred an attorney who solicited sex from clients in exchange for a reduced legal fee, made inappropriate sexual comments to clients, touched them in a sexual manner, exposed himself to a client, and lied repeatedly during the disciplinary process.

In between those two extremes, we typically impose term suspensions with all or part of the suspension stayed, depending on the severity of the misconduct and the applicable aggravating and mitigating factors.

We by no means condone Paris's conduct in this matter, but on the stipulated facts before us, we find that his actions are most comparable to cases in which we have imposed fully stayed suspensions. Therefore, we sustain Paris's objection to the board's recommended sanction and find that a six-month suspension, stayed on conditions, is the appropriate sanction for his misconduct.

Accordingly, Tasso Paris is suspended from the practice of law for six months, with the entire suspension stayed on the conditions that he make full restitution of $\$ 1,000$ to the affected client and engage in no further misconduct. If Paris fails to comply with the conditions of the stay, the stay will be lifted and he will serve the full six-month suspension. Costs are taxed to Paris. 
KENNEDY, J., concurring.

I agree with the majority that a six-month suspension, stayed on conditions, is the appropriate sanction for the misconduct of respondent, Tasso Paris. The majority opinion tacitly rejects the board's request that we adopt a new presumption that in the absence of significant mitigating factors, the court will impose an actual suspension for the repeated and unwelcome solicitation of vulnerable clients for sexual activity. The dissenting opinion argues in favor of adopting this presumption. I write separately to squarely address whether it is this court's role to create a new presumption in favor of an actual suspension in lieu of our deeply rooted process of determining the appropriate sanction in each individual case.

Gov. Bar R. V(13) imposes a duty on the Board of Professional Conduct to examine the unique facts and circumstances of each disciplinary case, the aggravating and mitigating factors applicable to the individual attorney, and his or her life circumstances in order to determine the appropriate sanction for that particular attorney. Therefore, the establishment of a presumption of an actual suspension would be antithetical to our rules.

In 1995, this court established a presumption of an actual suspension in cases with misconduct involving dishonesty, fraud, deceit, or misrepresentation, absent mitigating factors justifying a stay. A majority of the court in Fowerbaugh reasoned that a presumption was warranted for conduct by an attorney involving deception, falsehood, or fraud because "such conduct strikes at the very core of a lawyer's relationship with the court and with the client. Respect for our profession is diminished with every deceitful act of a lawyer."

In my view, however, deception and fraud are not the only types of misconduct that strike at the core of a lawyer's relationship with the court and with the client. Instead, every act of misconduct does so and diminishes the honor and nobility of our great profession. But to echo the views expressed in Justice Resnick's separate opinion in Fowerbaugh:

It is the responsibility of this court to give guidance as to what conduct constitutes a violation of the Disciplinary Rules. It is not the province of this court to use syllabus law to mandate a particular sanction once a violation has been found. The sanction in each individual's case should be determined based upon the unique facts and circumstances of that case.

Without question, inappropriate sexual conduct by an attorney toward his or her client undermines the attorney-client relationship and diminishes respect for our profession. However, if we were to adopt a presumption of an actual suspension for this category of misconduct based on the reasoning advanced by the majority in Fowerbaugh, why not extend this approach and establish a similar presumption for any and all cases involving violations that undermine the attorney-client relationship and diminish respect for our profession? Adoption of the proposed presumption in this case would move us closer to a reality in which the "exception swallows the rule." 
Gov.Bar R. V(2)(A) provides that "except as otherwise expressly provided in rules adopted by the Supreme Court, all grievances involving alleged misconduct by attorneys shall be brought, conducted, and disposed of in accordance with the provisions of this rule." This provision applies to all of Gov. Bar R. V, including Gov. Bar R. V(13). Presuming an actual suspension would fundamentally transform our well-established individualized process of attorney discipline into a formulaic "one size fits all" system. This philosophical shift should be carried out, if ever, only pursuant to this court's longstanding rulemaking process, not through judicial fiat. It is for the members of the legal community - guided by the principle that the primary purpose of the disciplinary process is not to punish the offender but to "protect the public against members of the bar who are unworthy of the trust and confidence essential to the relationship of attorney and client" - to debate whether it would be appropriate to establish a presumption of an actual suspension.

Accordingly, I respectfully concur.

LANZINGER, J., dissenting.

This court has been asked to consider establishing a presumption that in the absence of significant mitigating factors, we will impose an actual suspension on attorneys who engage in the repeated and unwelcome solicitation of vulnerable clients for sexual activity. We already presume that an actual suspension will be the sanction for behavior involving dishonesty, fraud, deceit, or misrepresentation, unless mitigating factors justify a stay. I believe that the same type of sanction should be imposed upon respondents like Tasso Paris, especially because it appears that cases of this type are increasing.

In my view, this court should do more than merely express disapproval of the attorney's actions by imposing a stayed suspension. The extent of the mitigation is that he has no previous discipline and has cooperated with the investigation. On the other hand, he stipulated that he acted with a selfish motive and engaged in multiple offenses. In addition, the board found that he did not understand or accept the wrongful nature of his actions and so failed to show that his misconduct was unlikely to recur. Most importantly, the client was harmed when Paris did not appear for her sentencing, conduct that she attributed to her rebuffing his sexual advances.

I respectfully dissent from the court's judgment with respect to the sanction in this case. I would adopt the recommendation of both the panel and the board and would suspend Paris from the practice of law for a period of six months.

O'CONNOR, C.J., and O'NEILL, J., concur in the foregoing opinion.

\section{Questions:}

Disciplinary Counsel v. Engler, 110 Ohio St. 3d 138 (Ohio 2006) 
Summary: Attorney Engler had two sexual encounters with a 28-year-old female divorce client. The client relationship began in June 2004 when Engler credited her bill for a $\$ 400$ painting of hers. In August she and her husband agreed to dissolve their marriage. In September, Engler and his client met at a restaurant to discuss the dissolution process and afterwards they had consensual sexual relations. Seven to ten days later, they did it again at Engler's home. Engler informed his client that they could no longer have a personal relationship until her case was over and she was no longer his client. Engler did some more work for his client but was dismissed in October. He reimbursed his client for all she had paid and returned her painting. Because of several mitigating factors including he had no prior record, he made restitution, he was cooperative in the disciplinary proceedings, and had a good reputation, the Court imposed nothing more than a public reprimand.

Respondent, David Lee Engler of Boardman, Ohio was admitted to the practice of law in Ohio in 1985.

On October 10, 2005, relator, Disciplinary Counsel, charged respondent with violating the Code of Professional Responsibility by engaging in a sexual relationship with a client. A panel of the Board of Commissioners on Grievances and Discipline heard the cause on the parties' consentto-discipline agreement, filed pursuant to Section 11 of the Rules and Regulations Governing Procedure on Complaints and Hearings Before the Board of Commissioners on Grievances and Discipline. The panel accepted the parties' agreement and made corresponding findings of misconduct and a recommendation, which the board adopted.

\section{Misconduct}

The parties stipulated that respondent had two sexual encounters with a divorce client and had thereby violated DR 1-102(A)(6) (prohibiting conduct that adversely reflects on a lawyer's fitness to practice law) and 5-101(A)(1) (prohibiting a lawyer from accepting employment if the exercise of professional judgment on behalf of a client will be or reasonably may be affected by the lawyer's personal interests). The parties also agreed that respondent's misconduct warranted a public reprimand.

Respondent has a law practice under the name of Engler \& Associates. On June 29, 2004, a 28-year-old female client consulted respondent about ending her marriage. During their discussions, respondent learned that the client was an artist and had sold some of her paintings. He indicated an interest in possibly purchasing her work, and sometime later, the client brought paintings to respondent's office. Respondent offered to buy some of the paintings by crediting the client for $\$ 400$ toward his $\$ 1,000$ fee. The client agreed to trade the paintings and paid the balance of respondent's $\$ 600$ legal fee.

The client expected her husband to agree to dissolve their marriage, and in late August 2004, respondent sent a separation agreement to the husband for review. On September 8, 2004, 
respondent met his client at a restaurant to discuss the dissolution process. Afterward, respondent and the client went to his house and engaged in consensual sexual relations.

Approximately seven to ten days later, the client visited respondent at home again, and the couple again had consensual sex. Respondent subsequently told his client that he could not continue to have a personal relationship with her until her case had ended and she was no longer his client. About the same time, respondent wrote a memo to the client's file indicating he had told the client he could not have a personal relationship with her and that the client had agreed.

In late September 2004, an attorney representing the husband sent respondent proposed changes to the dissolution agreement. Early in October 2004, respondent met with his client in the presence of his assistant to review the changes and then wrote to the other lawyer regarding those changes.

In a telephone conversation on October 12, 2004, respondent again told his client that he could not continue their personal relationship while he was representing her. The next day, the client sent a letter of dismissal to respondent. Respondent promptly replied with a letter indicating that he had completed his work in her case. Respondent enclosed a final invoice and a check reimbursing the client for the remaining balance of her paid fees. Later, respondent also returned the paintings that he had accepted from his client in partial payment of his fees.

Recommended Sanction

In recommending a sanction for respondent's misconduct, the board weighed the mitigating and aggravating factors of his case.

The parties stipulated to the mitigating factors that (1) respondent had no prior disciplinary record, (2) he had made timely good-faith efforts at restitution, (3) he made a full and free disclosure of information and was cooperative in the disciplinary proceedings, and (4) he had a good reputation in the legal community apart from the underlying misconduct. According to the parties, respondent on his own initiative had also received instruction on ethics and practice management from a former president of the Mahoning County Bar Association. In addition, the board found that respondent had acknowledged his wrongdoing in this isolated incident of misconduct.

Adopting the panel's report, the board recommended that respondent receive a public reprimand for his misconduct.

\section{Review}

We agree that respondent violated DR 1-102(A)(6) and 5-101(A)(1), as found by the board. Moreover, we generally impose a public reprimand when a sexual relationship develops during 
an attorney-client relationship if the affair is legal and consensual and has not compromised client interests. Therefore, we find the recommended sanction appropriate.

Respondent is therefore publicly reprimanded for his violations of DR 1-102(A)(6) and 5101(A)(1).

\section{Disciplinary Counsel v. Hines, 133 Ohio St. 3d 166 (Ohio 2012)}

Summary: Attorney Dean Hines agreed to represent a client in an ongoing domesticrelations dispute with her ex-husband. Hines invited her to dinner and assured her a personal relationship would not pose a conflict of interest; after a second dinner the next evening, they had sex. His client testified she was afraid to resist Hines' advances because she needed his legal assistance. In the months that followed Hines hired her as his bookkeeper, leased her a car, helped with her mortgage and utility payments, and travelled together to Austria, Arizona, and South Carolina, and let her and her children live with him while she recuperated from surgery. Eventually, the relationship fell apart and Hines called 911 for a domestic violence incident. He fired the client the next day-the same time at which she received an adverse ruling she could only object to within 11 days. Considering some aggravating factors, including the client's sensitivity and Hines downplaying of his wrongdoing, the Court imposed a six month suspension.

Respondent, Dean Edward Hines of Centerville, Ohio was admitted to the practice of law in Ohio in 1994. On October 11, 2010, relator, disciplinary counsel, filed a complaint alleging that Hines had engaged in an inappropriate relationship with a client and violated Prof.Cond.R. 1.8(j) and $8.4(\mathrm{~h})$.

The parties stipulated to Hines's misconduct. Upon the parties' stipulations, the Board of Commissioners on Grievances and Discipline accepted the parties' joint recommendation that we publicly reprimand Hines. However, we did not accept the recommendation and remanded the case for further proceedings.

On October 14, 2011, the Board of Commissioners on Grievances and Discipline issued a second report and recommended a 12-month suspension of Hines's law license, with six months stayed.

\section{Misconduct}

In early 2009, Hines agreed to represent a new client in an ongoing domestic-relations dispute with the client's ex-husband. On March 16, 2009, after several appointments and a pretrial conference, Hines invited the client to dinner, where he discussed his interest in dating her. Hines assured the client that a personal relationship between the two would not pose a conflict of interest with respect to their attorney-client relationship. After another dinner the next evening, Hines and the client became sexually intimate. Describing her feelings at this time, the 
client later testified that she was overwhelmed by Hines's advances and that she was afraid to resist him when she needed his legal assistance.

In the months that followed, Hines continued to represent the client in the domestic dispute while continuing their romantic relationship. Hines hired the client to work as a bookkeeper at his law firm, leased a car for her use, and contributed to her mortgage and utility payments. They traveled together to Austria, Arizona, and South Carolina, and when the client underwent surgery requiring a lengthy recovery period, Hines moved the client and her children into his home.

The relationship fell apart in November 2009. On November 9, 2009, Hines called 9-1-1 to report a domestic dispute with the client. He filed charges of aggravated menacing and domestic violence and obtained a temporary protection order barring any contact with Hines. The charges were eventually dropped.

The day after their altercation, Hines fired the client. A few days later, he mailed a letter simultaneously notifying her of an adverse ruling in the underlying domestic case and of the end of their attorney-client relationship.

When Hines mailed the letter, 11 days remained in which the client could protect her legal rights by objecting to the magistrate's ruling. Hines must have known about the client's vulnerability; during their relationship, she had faced financial troubles and a serious physical illness requiring surgery, not to mention the legal issues for which she had sought Hines's help. Yet Hines did not seek leave for an extension of this deadline, refer the client to another attorney, or otherwise assist the client in protecting her rights. Instead, he left a vulnerable client without legal representation or assistance at a critical time in her case, and he did so through an accusatory letter that blamed the client for the adverse decision.

Although he left the client without counsel to protect her rights, Hines continued to make overtures to her. He repeatedly e-mailed her and sent her text messages. As a practical matter, these overtures encouraged the client to violate the temporary protection order. She did not accept that invitation, even after Hines's promises that he would not report her to police if she responded.

The parties have stipulated that Hines's conduct violated Prof.Cond.R. 1.8(j), which generally prohibits sexual activity between attorneys and their clients, and Prof.Cond.R. 8.4(h), which bars behavior that reflects adversely on the fitness of a lawyer to practice law. We adopt the board's findings of fact and misconduct.

\section{Sanction}

The parties stipulated to the absence of aggravating factors. However, the Board of Commissioners on Grievances and Discipline identified several aggravating factors pertaining to Hines's misconduct: (1) he "knew from the outset that his conduct violated the Ohio Rules of 
Professional Conduct but he nevertheless acted with a clearly selfish motive," (2) he "has attempted to excuse or minimize that conduct rather than acknowledge that it was wrong," and (3) the client "was a vulnerable person and has been harmed as a result of" Hines's misconduct. Hines objects to these findings. We overrule the objections and adopt the findings of aggravating factors.

The parties stipulated to the following mitigating factors: (1) Hines has no prior disciplinary record, (2) Hines cooperated with the investigation of his misconduct, and (3) as evidenced by several letters of support, Hines enjoys a positive reputation in the legal community.

Disciplinary counsel suggests a six-month suspension, with all six months stayed. Hines suggests a public reprimand or a stayed suspension of no more than six months. The Board of Commissioners on Grievances and Discipline recommends that we suspend Hines from the practice of law for 12 months, with the final six months stayed.

In the past, we have imposed public reprimands on attorneys who engaged in improper consensual relationships with their clients, when the relationships did not compromise the clients' interests. But this is not a simple case of mutual consent; Hines used his position of power to initiate and pursue an intimate relationship with a vulnerable client who was afraid to resist. Furthermore, Hines's conduct in leaving the client without legal assistance at a critical juncture in her case threatened her interests. A public reprimand is not enough.

Nor do we find Hines's misdeeds comparable to those of attorneys whom we have suspended. Hines's conduct involved only one client, he has not engaged in any deception to hide the misconduct, and he has cooperated with the disciplinary process.

The appropriate penalty in cases like these is often a stayed suspension, which reflects the hope that the misconduct is limited to one occurrence and the reality that its recurrence would necessitate serious consequences.

Like Hines, the attorney in Burkholder pursued an improper relationship with a vulnerable domestic-relations client. Burkholder made numerous advances to the client until she fired him. However, Burkholder had no prior disciplinary violations, and he cooperated throughout the disciplinary process. We imposed a six-month, stayed suspension of Burkholder's license to practice law.

We imposed the same penalty in Disciplinary Counsel $v$. Siewert. The attorney in Siewert engaged in a consensual but improper relationship with a domestic-relations client. Unlike Hines, Siewert had a record of prior discipline; however, we noted as mitigating factors Siewert's struggles with depression and his efforts to correct his personal problems.

We find Burkholder and Siewert instructive. Like the attorneys in those cases, Hines made a serious mistake and abused the position of trust conferred upon attorneys, but the limited nature 
of his misconduct and his cooperative approach to the investigation give us reason to believe that Hines will conduct himself appropriately in the future.

Accordingly, we suspend Hines from the practice of law for six months, and we stay the suspension on the condition that Hines engage in no further misconduct. Costs are taxed to Hines. 


\section{Section 5: Confidentiality}

\section{1: The Duty of Confidentiality}

I don't know where you heard it. Don't know who's spreading it round. All I know is, I'm clean as a whistle, baby. I didn't utter a sound. I never said nothing. ${ }^{63}$

Attorneys have a fiduciary duty of confidentiality to their clients. The duty of confidentiality provides that attorneys may not disclose confidential information provided to them by their clients, unless their clients consent to disclosure, or an exception to the duty of confidentiality permits disclosure. The duty of confidentiality applies to both current and former clients. Clients disclose confidential information to their attorneys in order to obtain legal advice. Generally, clients are entitled to assume that their attorney has a duty to maintain the confidentiality of any information disclosed in private. However, the duty of confidentiality does not apply to information that is "generally known" to the public.

The duty of confidentiality is broader in scope than the attorney-client privilege and the work product doctrine. Information that is not privileged or protected from disclosure as attorney work product may still be protected by the duty of confidentiality. Attorneys may not disclose confidential information about their clients without informed consent, unless one of the exceptions to confidentiality applies. Accordingly, the duty of confidentiality provides less protection to confidential client information than the attorney-client privilege or the work product doctrine, which may preclude the disclosure of confidential information when the duty of confidentiality alone would not.

\section{Model Rule 1.6: Confidentiality of Information}

a. A lawyer shall not reveal information relating to the representation of a client unless the client gives informed consent, the disclosure is impliedly authorized in order to carry out the representation or the disclosure is permitted by paragraph (b).

b. A lawyer may reveal information relating to the representation of a client to the extent the lawyer reasonably believes necessary:

1. to prevent reasonably certain death or substantial bodily harm;

2. to prevent the client from committing a crime or fraud that is reasonably certain to result in substantial injury to the financial interests or property of another and in furtherance of which the client has used or is using the lawyer's services;

3. to prevent, mitigate or rectify substantial injury to the financial interests or property of another that is reasonably certain to result or has resulted from the client's commission of a crime or fraud in furtherance of which the client has used the lawyer's services;

4. to secure legal advice about the lawyer's compliance with these Rules;

${ }^{63}$ Liz Phair, Never Said, Exile in Guyville (1993). 
5. to establish a claim or defense on behalf of the lawyer in a controversy between the lawyer and the client, to establish a defense to a criminal charge or civil claim against the lawyer based upon conduct in which the client was involved, or to respond to allegations in any proceeding concerning the lawyer's representation of the client;

6. to comply with other law or a court order; or

7. to detect and resolve conflicts of interest arising from the lawyer's change of employment or from changes in the composition or ownership of a firm, but only if the revealed information would not compromise the attorney-client privilege or otherwise prejudice the client.

c. A lawyer shall make reasonable efforts to prevent the inadvertent or unauthorized disclosure of, or unauthorized access to, information relating to the representation of a client.

\section{Model Rule 1.6: Confidentiality of Information, Comment [2]}

A fundamental principle in the client-lawyer relationship is that, in the absence of the client's informed consent, the lawyer must not reveal information relating to the representation. This contributes to the trust that is the hallmark of the client-lawyer relationship. The client is thereby encouraged to seek legal assistance and to communicate fully and frankly with the lawyer even as to embarrassing or legally damaging subject matter. The lawyer needs this information to represent the client effectively and, if necessary, to advise the client to refrain from wrongful conduct. Almost without exception, clients come to lawyers in order to determine their rights and what is, in the complex of laws and regulations, deemed to be legal and correct. Based upon experience, lawyers know that almost all clients follow the advice given, and the law is upheld.

\section{Restatement (Third) of the Law Governing Lawyers $\$ 59$ (2000): Definition of "Confidential Client Information"}

Confidential client information consists of information relating to representation of a client, other than information that is generally known.

\section{Restatement (Third) of the Law Governing Lawyers $\$ 59$ (2000): Comment b, Kinds of confidential client information}

A client's approach to a lawyer for legal assistance implies that the client trusts the lawyer to advance and protect the interests of the client. The resulting duty of loyalty is the predicate of the duty of confidentiality. The information that a lawyer is obliged to protect and safeguard is called confidential client information in this Restatement.

This definition covers all information relating to representation of a client, whether in oral, documentary, electronic, photographic, or other forms. It covers information gathered 
from any source, including sources such as third persons whose communications are not protected by the attorney-client privilege. It includes work product that the lawyer develops in representing the client, such as the lawyer's notes to a personal file, whether or not the information is immune from discovery as lawyer work product. It includes information acquired by a lawyer in all client-lawyer relationships, including functioning as inside or outside legal counsel, government or private-practice lawyer, counselor or litigator, advocate or intermediary. It applies whether or not the client paid a fee, and whether a lawyer learns the information personally or through an agent, for example information acquired by a lawyer's partners or associate lawyers or by an investigator, paralegal, or secretary. Information acquired by an agent is protected even if it was not thereafter communicated to the lawyer, such as material acquired by an investigator and kept in the investigator's files.

The definition includes information that becomes known by others, so long as the information does not become generally known. The fact that information falls outside the attorney-client privilege or work-product immunity does not determine its confidentiality under this Section.

A lawyer may learn information relevant to representation of a client in the course of representing another client, from casual reading or in other accidental ways. In the course of representation, a lawyer may learn confidential information about the client that is not necessary for the representation but which is of a personal or proprietary nature or other character such that the client evidently would not wish it disclosed. Such information is confidential under this Section.

\section{Restatement (Third) of the Law Governing Lawyers $\$ 60$ (2000): A Lawyer's Duty to Safeguard Confidential Client Information}

1. Except as provided in $\S \S 61-67$, during and after representation of a client:

a. the lawyer may not use or disclose confidential client information as defined in $\S$ 59 if there is a reasonable prospect that doing so will adversely affect a material interest of the client or if the client has instructed the lawyer not to use or disclose such information;

b. the lawyer must take steps reasonable in the circumstances to protect confidential client information against impermissible use or disclosure by the lawyer's associates or agents that may adversely affect a material interest of the client or otherwise than as instructed by the client.

2. Except as stated in $\S 62$, a lawyer who uses confidential information of a client for the lawyer's pecuniary gain other than in the practice of law must account to the client for any profits made.

\section{Confidential \& Privileged Information}

In re Advisory Opinion No. 544 of NJ Sup. Court, 511 A. 2d 609 (N.J. 1986) 
Summary: The Community Health Law Project represented indigent and disabled clients in New Jersey. Organizations providing funding requested client-identifying information, but the Law Project provided only anonymized information. Some of the funders objected, and the Advisory Committee on Professional Ethics found that disclosure would not violate client confidence. The Law Project appealed, and the court held that the attorney-client privilege and duty of confidentiality precluded the Law Project from disclosing identifying information about its clients without informed consent or a reasonable regulatory obligation.

We are called to consider in this case the application of attorney-client protections to the relationship between a public legal services organization and the individuals whom it assists. The issue posed is whether certain information relating to the clients of a legal services organization, which provides legal assistance to mentally impaired or disabled and indigent persons, may be disclosed to the private and governmental entities that provide funds to the organization, without violating the protections of confidentiality accorded attorney-client communications and relationships.

The legal services organization resisting such disclosure is the Community Health Law Project. It is a non-profit organization providing legal services to indigent, mentally disabled and retarded persons in Essex, Mercer, Union, and Camden counties. Its legal services are funded by private and public sources. Various contracts with the funding entities obligate the Law Project to make periodic reports relating to the services provided, including in some instances information about the individual clients served.

Under the funding plans of several community mental health centers, identifying, descriptive information, such as a client's name, address, and date of birth, have been sought by the entities providing funds. The Law Project has chosen not to reveal the identity of individual clients by furnishing such information. Rather, it has attempted to accommodate these requests by providing data that have been aggregated and by disclosing information on individual clients only to the extent and in a manner that the revelation would not serve to identify the clients directly or indirectly. However, several funding entities expressed their dissatisfaction with the generalized nature of the information received from the Law Project and have insisted upon obtaining individual client-identifying information.

In the face of these more particularized demands, the Law Project has taken the position that such identifying information is or may be protected from disclosure under the strictures governing the professional conduct of lawyers. However, confronted by this genuine ethical dilemma, the Law Project sought guidance from the Advisory Committee on Professional Ethics in January 1984 to ensure that disclosure would not violate any ethical precepts.

In Opinion No. 544, the ACPE ruled that the disclosure of the information requested by private and public funding entities does not violate the confidences of the Law Project's clients and that the information requested would not violate client secrets or confidences within the meaning of 
then-applicable ethics standards. The Law Project then filed a petition with this Court to review the determination of the ACPE, which was originally denied. A motion for reconsideration of the denial was then granted by this Court.

We must initially consider the applicability of the attorney-client privilege to the relationships that exist between the Law Project and its clientele. The Law Project, as we have noted, is an organization that provides legal services to a particular class of persons, consisting of indigent, mentally-retarded, or disabled individuals. These persons are in need of legal assistance but cannot otherwise afford to retain an attorney and hence turn to the Law Project for legal help. The Law Project engages licensed attorneys of the State, who furnish legal advice and counselling to the individuals eligible for such services.

As licensed attorneys, the Law Project's lawyers are subject in every respect to the rules governing the professional conduct of lawyers. Accordingly, lawyers employed by governmental or public interest organizations are bound by the same ethical mandates of the Supreme Court's Rules of Professional Conduct, as well as other standards governing the professional activities of licensed attorneys.

Further, the persons who receive the legal services of the Law Project through its individual staff attorney are "clients." A client, in the context of the attorney-client privilege, is a person who "consults a lawyer for the purpose of retaining the lawyer or securing legal service or advice from him in his professional capacity." Consequently, it is not questioned that there exists between the Law Project and its attorneys who render legal services and the persons who receive those services an attorney-client relationship to which the attorney-client privilege fully applies.

It is also beyond question that indigent, needy, or otherwise eligible clients, assisted by attorneys without fees, are entitled to the same protections as clients who retain private counsel. Because the status of clients in every sense is ascribed to these persons, we must accordingly consider in this case the extent of these client-protections, particularly as to matters falling within the ambit of the attorney-client privilege.

The major focus of the attorney-client privilege has historically and traditionally been upon the communications that occur or information that is exchanged between an attorney and his or her client relating to the special attorney-client relationship. The attorney-client privilege is recognized as one of "the oldest of the privileges for confidential communications." While the attorney-client privilege has evolved and changed in terms of its emphasis and applications, the primary justification and dominant rationale for the privilege has come to be the encouragement of free and full disclosure of information from the client to the attorney. This has led to the recognition that the privilege belongs to the client, rather than the attorney.

The extent of the protection accorded communications and other information arising in the course of any attorney-client relationship is governed by the attorney-client privilege as well as several ethics standards. The attorney-client privilege itself, while rooted in the common law, 
has acquired a basis in both statute and rule. This codification provides that communications between a lawyer and his or her client in the course of that relationship and in professional confidence are privileged; a client has a privilege (a) to refuse to disclose any such communication, and (b) to prevent his or her lawyer from disclosing it. While in a sense the privilege belongs to the client, the lawyer is obligated to claim the privilege unless otherwise instructed by the client or the client's representative.

The scope of the attorney-client privilege or protections is also subject to ethics rules governing attorney conduct. In this case, the ACPE determined the issue posed by the Law Project under the former Disciplinary Rules. It applied Disciplinary Rule 4-101(A), entitled "Preservation of Confidences and Secrets of a Client." Under this rule, confidences are defined as information protected by the attorney-client privilege under applicable law. Ibid. The rule also deals with "secrets," which are defined as other information gained in the professional relationship that the client has requested be held inviolate or the disclosure of which would be embarrassing or detrimental to the client.

The Disciplinary Rules have been superseded by the Rules of Professional Conduct. The relevant rule now provides that a lawyer shall not reveal information relating to representation of a client unless the client consents after consultation except for disclosures that are impliedly authorized in order to carry out the representation. In comparison to the provisions of the former Disciplinary Rule, this Rule expands the scope of protected information to include all information relating to the representation, regardless of the source or whether the client has requested it be kept confidential or whether disclosure of the information would be embarrassing or detrimental to the client. Thus, the definition of confidential information under Rules of Professional Conduct 1.6(a) is broader and more inclusive than that of Disciplinary Rule 4-101(A).

The ethics rules generally forbid disclosure of client information, without the client's consent, unless one of the exceptions to the rule is available. Disclosure of client information is permissible if the client consents after consultation. In this case no one urges the possible applicability of this provision dealing with consent. In situations such as this where the clients receiving legal services are indigent as well as mentally impaired or disabled, they may not be able to appreciate the nature or importance of their own interests or their ability to resist or decline consent or disclosure.

The appropriate analysis must therefore focus upon whether the revelation of client information to someone other than the lawyer amounts to the impermissible disclosure of a privileged communication or a secret or information relating to the relationship. That inquiry is here particularized in terms of whether certain information that identifies the disabled and indigent persons receiving legal services from a legal services project may be disclosed to funding sources without violating the attorney-client privilege as defined by both statute and the Court's ethics strictures governing professional conduct.

Arguably "information gained in the course of an attorney-client relationship," as provided under the former Disciplinary Rule 4-101(A), might not include information that consists of only the 
identity of the client. The thrust of this definitional standard appears to be directed to information in the nature of communications. While a client's identity per se might not be necessarily considered a privileged communication as such, in some instances disclosure of identity may indirectly reveal other information about the client. Hence, depending upon the nature of such additional or collateral information that is revealed by the disclosure of a client's identity, the need for confidentiality could appropriately cloak even identity. In this case, for example, disclosure of the identity of clients of the Law Project would be tantamount to the revelation of the mental and financial status of the individuals, as well as the fact that he or she has a legal problem that required the services of an attorney.

Furthermore, under the former Disciplinary Rules, it would appear that matters such as the identification or address of a client could still be considered to be a "secret" entitled to nondisclosure. In Fellerman v. Bradley, an attorney refused to disclose the address of his client, thereby thwarting the enforcement of a divorce judgment against the client. The Court concluded that this information could be considered a confidence or in the nature of a protected secret covered by the attorney-client privilege and the Disciplinary Rule, holding nonetheless that, in the circumstances, the fraud exception to the privilege applied to preclude nondisclosure of the client's address.

The dilemma posed by requests for client-identity information has been addressed by the American Bar Association Committee on Professional Ethics and various state advisory committees. In an opinion issued in 1969, the Committee ruled that a legal services office could allow the accounting office to examine its intake and disposition forms provided all identifying data were deleted. Similarly, in 1974, the Committee determined that a legal services organization could reveal client information to its Board of Directors if anonymity was preserved, the information was reasonably required by the board for a legitimate purpose, and the client expressed an informed consent.

The Board of Professional Responsibility of the Supreme Court of Tennessee reached a similar result. It determined that a client's name, address, zip code, sex, race, age, social security number, phone number, source of referral, and the dates representation began were all secrets within the meaning of Disciplinary Rule 4-101 and could not be disclosed to funding sources unless the client consented.

We are persuaded by the soundness of these opinions. Also highly relevant to our analysis is the fact that client information that serves to identify the client would clearly be protected under the current Rules of Professional Conduct, RPC 1.6. As noted, this rule accords confidentiality to any information relating to the representation of a client. Manifestly this would include a client's identity.

Accordingly, we hold that under current standards governing attorney conduct, client-identity may not be disclosed to any private or public funding agency in the absence of appropriate consent or other legal justification. In so ruling, we determine that a client's identity constitutes information relating to the representation of a client under the current Rules of Professional 
Conduct and a secret entitled to non-disclosure, if not a protected confidential communication, under the attorney-client privilege and former Disciplinary Rule 4-101(A), which was relied upon by the ACPE in this case.

It is further suggested that even though this information might otherwise be subject to a privilege against disclosure, there may be a legal justification that would allow such disclosure.

Disclosure of such information is permissible because, it is contended, the information sought is required to be furnished by law. The Division of Mental Health and Hospitals has promulgated regulations requiring reporting for all agencies receiving financial assistance through the Division, to aid in monitoring compliance and for program planning and development. Also, under N.J.A.C. 10:37-6.84 information such as client services and fiscal reports are to be submitted to the Division. Further, the Divisions of Mental Health and Hospitals and Developmental Disabilities and the various county mental health agencies are required to maintain the confidentiality of any client information it receives from the Law Project. It is contended that the reporting of information is needed to comply with these regulations and that this would not constitute either impermissible disclosure or public disclosure of client information violative of applicable ethics restrictions.

Under the Rules of Professional Conduct a lawyer may reveal such information to the extent the lawyer reasonably believes necessary to comply with the law. However, the regulations promulgated by the Division that provide for reporting as related to the persons assisted by the Law Project do not specifically require client-identifying information. Moreover, there is no legal requirement that client-identifying information be disclosed to private funding agencies. In the absence of such requirements, we may not infer that this client-identifying information is necessary to be disclosed as a matter of law. Hence, it may remain privileged under the Rules of Professional Conduct.

This result, we point out, would not be different under the former ethics rules. In Fellerman $v$. Bradley, the compliance-with-law exception of Disciplinary Rule 4-101(C)(3), was deemed to prohibit disclosure of attorney-client information except in a situation in which the client was attempting through non-disclosure to evade an order of a court. We expressed the view that the policies underlying the privilege would not be advanced by allowing the client through his attorney to perpetrate a fraud on the court or to thwart justice by consenting to and subsequently ignoring a judgment of the court by refusing to disclose the client's address.

We acknowledge that if by statute or valid rule or regulation information concerning the identity of clients of a legal services organization were clearly required to be reported for legitimate governmental purposes, the analysis and result could well be different. A different conclusion as to the propriety of disclosure might also obtain in the event private funding sources sought client information under enforceable rules or regulations. It can reasonably be assumed that in such a context, the welfare and interests of clients would remain a paramount concern and that the disclosure occasioned by such necessary reporting would be attended by suitable protections reflecting needs for confidentiality and privacy. 
II.

We conclude that client-identifying data with respect to persons receiving legal assistance through the Law Project constitute matters clearly covered by the Rules of Professional Conduct as "information relating to representation." Such material is also covered under the attorneyclient privilege and the former Disciplinary Rule as information in the nature of client secrets that could be embarrassing or detrimental to the client if revealed. Under these strictures we are satisfied that it would be improper to reveal such information to either public or private funding sources in the absence of valid consent or reasonable rules clearly requiring such disclosure for legitimate purposes.

Accordingly, we reverse Opinion No. 544.

\section{Questions:}

1. Why did the court hold that the Law Project could not produce identifying information?

2. What is the difference between confidential information and privileged information? When can an attorney disclose confidential information? When can an attorney disclose privileged information?

3. When should attorneys address the disclosure of confidential information, if their clients cannot provide informed consent?

\section{“Generally Known” Information}

The duty of confidentiality prevents attorneys from using information about their current or former clients only if the information is "confidential." Accordingly, the duty of confidentiality does not apply to information that is "generally known." Of course, whether information is "generally known" may be unclear.

\section{Restatement (Third) of the Law Governing Lawyers $\$ 59$ (2000): Comment d, Generally Known Information}

The "generally known" standard of this Section is the standard of ABA Model Rules of Professional Conduct, Rule 1.9(b), which is not further elaborated upon in its Comment. The ABA Model Code of Professional Responsibility (1969) included in DR 4-101(A) all information, without regard to its public or private nature, within its definition of "confidences and secrets." ABA Model Rule 1.9(b), on the other hand, excepts from its requirement of confidentiality information that "has become generally known." No similar exception is contained, however, in the general-purpose analog to ABA Model Rule 1.9(b), ABA Model Rule 1.8(b) Commentators have differed over the wisdom of the ABA Model Rule approach. Case law is sparse, but extant authority agrees with the position taken in the Section and Comment. 
The law generally provides that a client communication cannot become public and still remain protected by the attorney-client privilege. The general law of agency also permits a former agent to compete with a former principal so long as the agent employs only information about the principal that is "a matter of general knowledge." The scant case authority is divided on the question whether the definition of confidential client information includes publicly available information.

The position taken in the Section and Comment-that "generally known" information is not part of the definition of confidential client information for either present or past clients-adheres to ABA Model Rule 1.9(b). The absence of a similarly limiting provision in ABA Model Rule 1.8(b), which applies to ongoing representations, is not inconsistent. Any such lawyer use would be impermissible on the broad ground that a lawyer may not use even publicly known information to the detriment of a current client, whether to further a personal interest of the lawyer or to further the interest of another client. Revealing client information adversely in a way that is gratuitous or negligent would violate the duty to take all reasonably available steps to advance the client's lawful objectives.

Dougherty v. Pepper Hamilton LLP, 133 A. 3d 792 (Pa. Super. Ct. 2016)

Summary: Pepper Hamilton LLP represented John J. Dougherty in a federal grand jury investigation, which included a search of his house. The search warrant affidavit was filed under seal, but the FBI later attached it to an unrelated public document by accident. When Dougherty ran for public office, the Philadelphia Inquirer published several articles stating that he had committed crimes. Daugherty filed a defamation action against the Inquirer, which hired Pepper Hamilton. When Pepper Hamilton threatened to submit the affidavit and other information, Daugherty filed a motion to disqualify, as well as a malpractice action. The trial court granted the Inquirer's motion for summary judgment, but the appellate court reversed, holding that the affidavit was still "confidential," despite being attached to a public document, because it was not "generally known."

\section{OPINION BY SHOGAN, J.:}

Appellant, John J. Dougherty, appeals from the order granting summary judgment in favor of Pepper Hamilton LLP and its attorneys Amy B. Ginensky, Michael E. Baughman, Peter M. Smith, and Raphael Cunniff, in this civil action alleging breach of fiduciary duty and breach of contract. For the reasons that follow, we reverse and remand for further proceedings.

We summarize the protracted history of this case as follows. On October 30, 2003, Appellant retained Pepper Hamilton to represent him in relation to a federal matter involving a grand jury subpoena he received. Although Appellant was not the target of the grand jury investigation, an FBI Affidavit was filed to secure a search of Appellant's residence. Appellant has alleged that he provided Pepper Hamilton unfettered access to documents during the firm's representation of 
Appellant. Also, counsel from Pepper Hamilton was present during the execution of the search warrant at Appellant's home in November of 2006.

Initially, the FBI Affidavit securing the search warrant was under seal, but, somehow, the FBI Affidavit inadvertently became attached to a document presented in an unrelated criminal matter involving an unrelated person named "Donald Dougherty, Jr." According to Appellant, on January 30, 2008, the federal government filed a response to Donald Dougherty Jr.'s motion to suppress evidence, which was entered as Document No. 27 on the federal criminal docket for the prosecution of Donald Dougherty, Jr. This filing was allegedly made under "restricted status." 64 Document No. 27 referenced, as Exhibit "A," a copy of an affidavit by an FBI agent in support of the issuance of a search warrant for Donald Dougherty, Jr.'s premises. However, the affidavit that was attached to Document No. 27 as Exhibit "A" was actually the FBI Affidavit in support of the search of Appellant's premises.

At least some of the documents in Donald Dougherty Jr.'s case were filed under seal and, thus, not accessible to the public. Subsequently, however, in April of 2008, certain documents in Donald Dougherty Jr.'s case were unsealed by Judge Robreno of the United States District Court for the Eastern District of Pennsylvania. More specifically, Judge Robreno's April 11, 2008 order authorized the eastern district Clerk of Court to lift the seal on Documents 31, 32, 48 and 38. Appellant alleges that Document No. 27 was also, albeit mistakenly, removed from "restrictive status" around this time.

When Appellant was running for a vacant seat in the Pennsylvania Senate in April of 2008, the Philadelphia Inquirer published several articles about Appellant. The articles implied that Appellant had engaged in criminal conduct in the past and was likely to do so again if elected to the Pennsylvania Senate. In March of 2009, Appellant initiated a defamation suit against the Inquirer in state court. In 2011, Pepper Hamilton assumed representation of the defense for the Inquirer in the defamation suit filed by Appellant. In 2012, Pepper Hamilton informed the trial court that the defense of the defamation action would rely on information relating to the federal investigation in which Pepper Hamilton had previously represented Appellant. In 2013, Appellant moved to have Pepper Hamilton removed as defense counsel in his defamation action against the Inquirer. The trial court denied the motion to disqualify Pepper Hamilton. On appeal this Court reversed the decision of the trial court and remanded the matter for the entry of an order barring Pepper Hamilton and its attorneys from representing the Inquirer.

On December 10, 2012, while Pepper Hamilton and its attorneys were still representing the Inquirer, the firm filed a motion for summary judgment in the defamation suit and included in the attached exhibits a copy of the FBI Affidavit. On December 12, 2012, the Inquirer then published a front-page article, which included detailed references to the FBI Affidavit.

\footnotetext{
${ }^{64}$ Documents filed on the federal court's PACER system are publicly available for a fee to those who have registered for and received a PACER account. However, in his memorandum of law in support of his response to Pepper Hamilton's motion for summary judgment, Appellant asserts that a document on "restricted status" is unavailable to anyone but the court and the parties.
} 
On February 11, 2013, Appellant initiated the instant action by filing a complaint against Appellees alleging breach of fiduciary duty and breach of contract. Appellant alleged that, in representing the Inquirer in the defamation suit, Pepper Hamilton acted against the interests of Appellant, its former client. The trial court has summarized the subsequent procedural history of this case as follows:

Appellees filed Preliminary Objections on April 3, 2013. These Preliminary Objections were overruled by this Court by Order dated June 18, 2013. An Answer was filed by Appellees on July 8, 2013. On May 27, 2014, after some discovery was conducted and a Revised Case Management Order entered, Appellees filed a Motion for Summary Judgment. An Answer in response to the Motion for Summary Judgment was filed by Appellant on June 27, 2014. A Reply in Support of the Motion for Summary Judgment was filed by Appellees on July 2, 2014. A Supplemental Memorandum in Support of the Motion for Summary Judgment was filed by Appellees on July 25, 2014, and a Supplemental Memorandum in Opposition was filed by Appellant on July 29, 2014. By Order dated July 29, 2014, and entered on the docket on July 30, 2014, Summary Judgment was granted.

This timely appeal followed.

Appellant presents the following issues for our review:

A. Whether the Trial Court erred in granting Appellees' motion for summary judgment on the mistaken basis that, because Pepper's breach of fiduciary duty was also a violation of the Pennsylvania Rules of Professional Conduct, Appellant cannot assert a claim against Pepper as a matter of law.

B. Whether the Trial Court erred in holding that Appellees were entitled to summary judgment because, although they used information against Appellant that is substantially related to their former representation of him, that information is publicly available and thus cannot form the basis of a disloyalty claim.

C. Whether the Trial Court prematurely granted Appellees motion for summary judgment where the parties had exchanged limited written discovery and taken no depositions.

Each of Appellant's issues challenges the propriety of the trial court's determination granting summary judgment.

A legal malpractice claim based on breach of contract, "involves (1) the existence of a contract, (2) a breach of a duty imposed by the contract, and (3) damages." With respect to a legal malpractice claim based on breach of contract, this Court has stated the following:

The attorney's liability must be assessed under the terms of the contract. Thus, if the attorney agrees to provide her best efforts and fails to do so, an action in assumpsit will accrue. An attorney who agrees for a fee to represent a client is by implication agreeing 
to provide that client with professional services consistent with those expected of the profession at large.

With respect to a breach of fiduciary duty claim, "a confidential relationship and the resulting fiduciary duty may attach wherever one occupies toward another such a position of advisor or counsellor as reasonably to inspire confidence that he will act in good faith for the other's interest." The leading case in Pennsylvania discussing breach of a fiduciary duty by an attorney with regard to a conflict of interest is Maritrans GP Inc. v. Pepper, Hamilton \& Scheetz. In Maritrans, our Supreme Court upheld the trial court's issuance of a preliminary injunction preventing Pepper Hamilton from representing its former clients' competitors. The Court found that a cause of action for breach of a fiduciary duty against a law firm was actionable where the firm acquired confidential information during the course of its representation. In discussing actionability for breach of a fiduciary duty, our Supreme Court reiterated the following longstanding principles:

Activity is actionable if it constitutes breach of a duty imposed by statute or by common law. Our common law imposes on attorneys the status of fiduciaries vis a vis their clients; that is, attorneys are bound, at law, to perform their fiduciary duties properly. Failure to so perform gives rise to a cause of action. It is "actionable."

At common law, an attorney owes a fiduciary duty to his client; such duty demands undivided loyalty and prohibits the attorney from engaging in conflicts of interest, and breach of such duty is actionable.

The Maritrans Court highlighted that Pepper Hamilton "was furnished with substantial confidential commercial information" and "came to know the complete inner-workings of the company along with Maritrans' longterm objectives, and competitive strategies." As explained by the Court, adherence to a fiduciary duty "ensures that clients will feel secure that everything they discuss with counsel will be kept in confidence" and that Pepper Hamilton "had a duty to administer properly their responsibilities to respect the confidences of Maritrans." It further explained that the rationale behind this policy is to prevent an attorney from taking "undue advantage of the confidential communications of such client."

In reaching its determination, the Court in Maritrans emphasized the confidential information that Pepper Hamilton garnered during the course of its representations.

Pennsylvania Rule of Professional Conduct 1.9 further addresses attorney duties to former clients and provides, in relevant part, as follows:

(a) A lawyer who has formerly represented a client in a matter shall not thereafter represent another person in the same or a substantially related matter in which that person's interests are materially adverse to the interests of the former client unless the former client gives informed consent. 
(c) A lawyer who has formerly represented a client in a matter or whose present or former firm has formerly represented a client in a matter shall not thereafter:

(1) use information relating to the representation to the disadvantage of the former client except as these Rules would permit or require with respect to a client, or when the information has become generally known; or

(2) reveal information relating to the representation except as these Rules would permit or require with respect to a client.

The explanatory comment to Rule $1.9(\mathrm{c})$ offers the following pertinent insight:

[8] Paragraph (c) provides that information acquired by the lawyer in the course of representing a client may not subsequently be used or revealed by the lawyer to the disadvantage of the client. However, the fact that a lawyer has once served a client does not preclude the lawyer from using generally known information about that client when later representing another client.

In addition, section 59 of the Restatement (Third) of the Law Governing Lawyers defines the term "Confidential Client Information" as "Confidential client information consists of information relating to representation of a client, other than information that is generally known." Comment $b$ to the above definition explains that "the definition includes information that becomes known by others, so long as the information does not become generally known." Furthermore, comment $d$ states the following:

d. Generally known information. Confidential client information does not include information that is generally known. Such information may be employed by a lawyer who possesses it in permissibly representing other clients and in other contexts where there is a specific justification for doing so. Information might be generally known at the time it is conveyed to the lawyer or might become generally known thereafter. At the same time, the fact that information has become known to some others does not deprive it of protection if it has not become generally known in the relevant sector of the public.

Whether information is generally known depends on all circumstances relevant in obtaining the information. Information contained in books or records in public libraries, public-record depositaries such as government offices, or in publicly accessible electronic-data storage is generally known if the particular information is obtainable through publicly available indexes and similar methods of access. Information is not generally known when a person interested in knowing the information could obtain it only by means of special knowledge or substantial difficulty or expense. Special knowledge includes information about the whereabouts or identity of a person or other source from which the information can be acquired, if those facts are not themselves generally known.

A lawyer may not justify adverse use or disclosure of client information simply because the information has become known to third persons, if it is not otherwise generally 
known. Moreover, if a current client specifically requests that information of any kind not be used or disclosed in ways otherwise permissible, the lawyer must either honor that request or withdraw from the representation.

We further observe that there is no Pennsylvania case law directly on point. However, as the Supreme Court of Ohio aptly stated in Akron Bar Association v. Holder, "An attorney is not free to disclose embarrassing or harmful features of a client's life just because they are documented in public records or the attorney learned of them in some other way." Likewise, in Lawyer Disciplinary Board v. McGraw, the Supreme Court of West Virginia observed that "the ethical duty of confidentiality is not nullified by the fact that the information is part of a public record or by the fact that someone else is privy to it."

Here, the trial court concluded that because the FBI Affidavit was inadvertently appended to a document in an unrelated criminal matter, the information contained therein was public. Specifically, the trial court stated that "the fact that the FBI Affidavit in question was publicly available for many years precludes a determination that the receipt of the improperly filed FBI Affidavit through a breach by Appellees of the attorney-client relationship and duty of fidelity is actionable."

Our review of the record, in the light most favorable to Appellant as the non-moving party, reflects that the trial court erred in granting summary judgment in this case. Indeed, this case presents genuine issues of fact. The record reveals that the FBI Affidavit in question became part of another criminal matter through inadvertence. Even accepting that the FBI Affidavit was publicly available through PACER prior to December 10, 2012, we are left to ponder whether the FBI Affidavit was actually "generally known." All that is acknowledged at this point in the proceedings is that the FBI Affidavit was inadvertently appended to a document in a case that did not involve Appellant as a party. Therefore, it appears that such document was not "indexed" under Appellant's name and that a person interested in the FBI Affidavit "could obtain it only by means of special knowledge." Furthermore, it is unknown exactly how and when the FBI Affidavit came into the possession of the Inquirer and eventually became the subject of an article in the Inquirer during Pepper Hamilton's representation of the Inquirer. Whether Pepper Hamilton committed a breach of its duties to Appellant depends on the answers to these questions. Thus, these questions are sufficient to establish genuine issues of material fact regarding Pepper Hamilton's conduct. Contrary to the trial court's conclusion, in the event that the FBI Affidavit was not generally known information, it appears that Pepper Hamilton breached its duty to Appellant as a former client and such breach was actionable. Accordingly, we reverse the order granting summary judgment.

\section{Questions:}

1. Why did the court hold that the information about Daugherty was protected by the duty of confidentiality, even though it was publicly available?

2. How well-known does information have to be before it becomes "generally known"? Why didn't the Inquirer's articles make the information at issue "generally known"? 
Matter of Tennant, 392 P. 3d 143 (Mont. 2017)

Summary: Attorney David G. Tennant was the subject of a disciplinary complaint based on his representation of Richard and Debbie Harshman. When the Harshmans did not pay Tennant's bill, he filed an attorney's lien on their property and purchased it at the Sheriff's sale. The Harshmans filed a complaint against Tennant with the Office of Disciplinary Counsel, claiming that Tennant improperly used confidential client information to their detriment. The Commission on Practice found no violation of the duty of confidentiality, but the Montana Supreme Court reversed, because the information was not "generally known."

Justice Beth Baker delivered the Opinion and Order of the Court.

These consolidated proceedings include two formal disciplinary complaints filed against Montana attorney David G. Tennant. The complaints, which arise from Tennant's debt collection practices against clients and former clients, will be referenced in this Opinion and Order as the Ray complaint and the Harshman complaint.

\section{BACKGROUND}

Tennant represented Richard and Debbie Harshman in an action for eviction of tenants from, and possession of, real property in Hungry Horse, Montana. The Harshmans obtained a default judgment against their tenants for damages to the property, including attorney fees of $\$ 3,063.54$. When he was unable to collect the attorney fees through execution on the tenants and the Harshmans did not pay their bill to Tennant's firm, Tennant filed an attorney's lien on the property. He later filed a complaint against the Harshmans alleging breach of contract, account stated, and foreclosure of the attorney's lien, in which action he was granted a default judgment of $\$ 8,148.68$. Tennant assigned the judgment to a collection agency, which obtained a writ of execution on the Harshmans' property. A sheriff's sale was held, at which the collection agency was the successful bidder. The Harshmans later redeemed their property.

Both Ray and the Harshmans filed complaints against Tennant with the Office of Disciplinary Counsel, and ODC filed formal disciplinary complaints in both matters. On August 31, 2016, Tennant filed conditional admissions and an affidavit of consent to discipline in these consolidated proceedings, pursuant to Rule 26, Montana Rules for Lawyer Disciplinary Enforcement. ODC objected to Tennant's conditional admissions. On October 20, 2016, the Commission on Practice held a hearing on the complaints and to consider Tennant's conditional admissions. Tennant was present with counsel and testified on his own behalf.

On January 5, 2017, the Commission submitted to this Court its Findings of Fact, Conclusions of Law, and Recommendation for Discipline. The Commission rejected Tennant's conditional admissions. The Commission concluded that ODC failed to carry its burden of proving by clear and convincing evidence any MRPC violations alleged in the Harshman complaint. 
The Commission recommends that, as a result of his violations of the Montana Rules of Professional Conduct, Tennant be disciplined by public censure by this Court. The Commission recommends that, in the future, Tennant be required to provide to clients and former clients copies of any attorney's liens he or his firm files against them. In addition, the Commission recommends that, for a period of three years, Tennant be required to provide to ODC copies of any attorney's liens filed by him or his firm, copies of all complaints filed by him or his firm and served against former clients for unpaid fees, and copies of judgments or assignments of judgments obtained by him or his firm against former clients.

ODC has filed written objections to the Commission's findings, conclusions, and recommendation, and Tennant has filed a response.

\section{DISCUSSION}

ODC argues that the Commission erred in concluding that it failed to prove violation of Rule 1.9, MRPC, in relation to the Harshmans. Rule 1.9(c) provides:

A lawyer who has formerly represented a client in a matter or whose present or former firm has formerly represented a client in a matter shall not thereafter:

(1) use information relating to the representation to the disadvantage of the former client except as these Rules would permit or require with respect to a client, or when the information has become generally known.

ODC alleged Tennant violated this Rule when he bid on the Harshmans' Hungry Horse property at the sheriff's sale, because Tennant's knowledge of the property derived from his representation of the Harshmans. The Commission determined that because Tennant could have found out that the Harshmans owned property in Hungry Horse via public record and then foreclosed his fee lien and bid at the sheriff's sale, no violation of Rule 1.9 occurred.

As ODC emphasizes, Rule 1.9's language requires that, in order for the attorney to be free from the prohibition against using representation-related information to the disadvantage of a former client, the information at issue must be "generally known."

Whether information is generally known depends on all circumstances relevant in obtaining the information. Information contained in books or records in public libraries, public-record depositories such as government offices, or in publicly accessible electronic-data storage is generally known if the particular information is obtainable through publicly available indexes and similar methods of access. Information is not generally known when a person interested in knowing the information could obtain it only by means of special knowledge or substantial difficulty or expense. 
A lawyer may not justify adverse use or disclosure of client information simply because the information has become known to third persons, if it is not otherwise generally known.

Some courts have applied a strict definition of "generally known" in the context of a Rule 1.9 analysis. That the information at issue is generally available does not suffice; the information must be within the basic understanding and knowledge of the public. "The client's privilege in confidential information disclosed to his attorney is not nullified by the fact that the circumstances to be disclosed are part of a public record, or that there are other available sources for such information, or by the fact that the lawyer received the same information from other sources."

In this case, although it would have been possible for Tennant to discover the existence of the Harshmans' property through searches of public records, he undisputedly learned of the property as part of his representation of the Harshmans. Tennant used that information to the Harshmans' disadvantage. We will not interpret the "generally known" provision of Rule 1.9(c) to allow Tennant to take advantage of his former clients by retroactively relying on public records of their information for self-dealing. The Commission erred in concluding that Tennant did not violate Rule 1.9, MRPC.

ODC further claims that, absent the Harshmans' redemption of their property, Tennant would have exceeded his fee claim and lien by receiving a windfall from the sheriff's sale of upwards of $\$ 80,000$ - his former clients' equity in their property. ODC submits that this is a clear violation of Rule 1.9(c), MRPC. However, the Harshmans did redeem their property, and ODC's assumptions do not satisfy its burden of proof.

\section{Sanctions}

Finally, ODC argues that the Commission's recommended sanctions are inadequate given Tennant's unethical conduct and will not deter the same type of conduct by other Montana attorneys. ODC had recommended that Tennant be suspended from the practice of law for at least seven months and that he be required to retake and pass the Multistate Professional Responsibility Exam.

We have concluded that ODC established one ethical violation in addition to those recognized by the Commission. However, that violation ultimately did not harm Tennant's clients - the Harshmans redeemed their property. Further, the additional violation does not undermine the Commission's overall conclusions on the evidence presented, and on this record we are not inclined to deviate from the discipline recommended by the Commission.

\section{Questions:}

1. A Sheriff's sale is a public event. Why did the court hold that the duty of confidentiality protected this information about the Harshmans? 
2. What would have happened if someone other than Tennant had purchased the Harshmans' property?

Stanley A. Kaplan, The Case of the Unwanted Will, 65 ABA J. 484 (1979)

John Smith and his wife Mary go to a lawyer who has handled some minor legal matters for John to make their wills prior to going on a trip abroad.

John tells his lawyer what disposition he and his wife desire to make of their estates, and the lawyer prepares separate wills for them to sign prior to their departure. After John has signed his will, the lawyer suggests to John that he would like to be alone with Mary before she signs. John withdraws to another office. The lawyer asks Mary if the will is as she would have made it had her husband not been present at the conference and if the will were to be secret from her husband.

She says no, that the will as drawn contains several provisions that are contrary to her wishes, and that she would change if her husband were not to know the ultimate disposition of her estate. However, she says that she would not be willing to precipitate the domestic discord and confrontation that would occur if her husband were to learn that she had drawn a will contrary to his wishes and in accordance with her own desires.

Mary asks the lawyer if he will write one page of her will to provide that certain persons benefiting by her will as drawn will be replaced by certain other persons. The lawyer states that under the circumstances he does not think that he can in fairness represent her in making these changes but suggests that she go ahead and sign this will and then, as soon as possible, go to some other lawyer and have her will rewritten in accordance with her true wishes.

The departure time for the trip comes on Mary before she is able to make arrangements to have her will rewritten. John and Mary are involved in an airplane accident and both are killed while on the trip. Their son, Tom, who is named as executor in each of their wills, comes to the lawyer who drew the wills and asks him to represent him as executor in connection with probating the wills and distributing the estate.

What are the ethical problems the lawyer faces in connection with probate and distribution in accordance with the wills as drawn? Did the lawyer have any obligation to speak to Mary separately, as he did, about her will? When the lawyer learned from Mary that she had other wishes that were being suppressed, what were his obligations? What, if anything, should the lawyer have done and, did not do after learning Mary's true wishes? Do Mary's true but unfulfilled wishes concerning the revision of her will have any legal effect? Does the lawyer have any right or obligation to disclose what Mary told him about her testamentary desires?

\section{Comments from George W. Overton}


The first question to be asked in all problems involving professional responsibility or ethics is "Who is the client?" Not "Who brought Mary to my office?" Not even "Who is paying my bill?" And emphatically not "Whose anger will cost me the most business?" In facts given, John probably presumes that the lawyer is his and that he is the lawyer's client, and that's all that need be said. The lawyer probably accepted this notion without clarification.

The problem is that in the drafting of Mary's will Mary is the client, no matter who pays the bill and no matter what chain of events brought Mary to the lawyer's office. The first issue that has to be disposed of is: Can the lawyer continue to serve Mary in the preparation of any will other than the one first drafted? Can he do so without John's knowledge? I suggest that he cannot.

The lawyer must explain to Mary her three alternatives:

1. To execute the will, and she and the lawyer remain silent unless questioned. Presumably this won't work, because the lawyer, if questioned by John, cannot lie to him, although I do not believe the lawyer has a duty to volunteer any information. It is enough that he says, in response to a question, either "John, I cannot answer your question" or "Mary did not execute the will I drafted" and the lawyer should refuse to answer further questions.

2. To execute the will as drafted, hoping to replace it soon. In this case he must explain to Mary that it is unquestionably her will, until revoked, and that even if all their conversation were reproduced in court, it would not affect the validity of the will, since it could easily be proved that she had testamentary capacity, and contemporaneous inconsistent statements are admissable only as to capacity.

3. To have a new will drawn (or a new insertion) but let the lawyer tell John: "Mary changed her will." The lawyer need not say more to John.

If, as we presuppose in 2, the lawyer explains to Mary her alternatives and the conclusiveness of the execution of the will, he is out of trouble at the time of execution.

However, he should reflect, for the future, on how to avoid this awkward box. First of all, the custom of separating spouses at execution of wills, although not uncommon, is an anachronism, based on the notion that one spouse, presumably the husband, could coerce the other into an unintended result? or someone could so claim. The time to elicit separate responses is at the first meeting or immediately there after. Probably a letter, following the first meeting, could state something like the following:

"I will proceed as instructed to draft both your wills, on the assumption that each of you has given me your wishes. If there is anything on this subject that either of you wishes to discuss this subject with me separately, please let me know and I will then decide if I can go further."

As stated above, in preparing Mary's will the lawyer can only be Mary's lawyer, but has he made this clear to John? Has he been guilty of any implied communication to John inducing John to execute a will based on John's presuppositions of Mary's will that is misleading or false? In the 
technical sense, he has not. If John wanted his will to be conditioned on certain dispositions by Mary, legal mechanisms existed (conditional bequests, or mutual wills, or a joint will) to effectuate those purposes. But the lawyer has undoubtedly not outlined these alternatives.

On the other hand, it should not be said that there is an inherent conflict of interest in representing both husband and wife in estate planning. Obviously, most couples would be appalled at the notion of having to pay two lawyers' fees for this service. What is necessary is that the lawyer identify the possibility of disagreements at the earliest possible stage.

After Mary's death the lawyer's responsibility is to file the will and assist, as necessary, in its probate. For the reasons stated, Mary's inconsistent comments made at the time of execution are relevant only to the issue of capacity, and I do not see that the lawyer has a duty to anyone to raise that issue if he has no doubts on that score.

The intricate ramifications of the ethical problem emerge, however, if the question of capacity is raised. Let us suppose that her will excluded some heir by intestacy who attacks the will on this ground. Probably in this event the lawyer should inform Tom of the facts, and Tom can decide as the personal representative of Mary whether to attempt to assert privilege as to the testimony involved. He is not likely to succeed in that endeavor. I cannot see that the lawyer has any duty to Mary's heirs at law to volunteer any information.

\section{Comments from John C. Williams}

The problems the lawyer faces concerning John and Mary and their wills are essentially problems involving the interests of multiple clients. The special problems are these:

1. How do the general principles of multiple representation apply to estate planning work for a married couple?

2. When a lawyer represents two clients on a common project, what are his responsibilities in preserving the confidences of one client from the other?

3. When a lawyer who represents two clients learns that their interests are in fact conflicting, what does the lawyer do about it, particularly in a case in which the conflict is known to one of the clients but not the other?

Surprisingly, neither the Code of Professional Responsibility nor published opinions of the American Bar Association Committee on Ethics and Professional Responsibility nor Drinker offers much guidance, yet the second two questions presumably arise frequently in the practice of, say, a lawyer who represents codefendants in criminal cases or coplaintiffs in personal injury cases.

Who is the client? That's the first question. There may be lawyers who suppose that the husband and wife have such a community of interest or that the wife is so subservient to her husband that they are, collectively, one client. Mr. Bumble would advise that if the lawyer 
supposes that, the lawyer is "a ass - a idiot" and probably a bachelor. Clearly, both must be considered clients.

As was suggested in the first "Legal Ethics Forum," there are many good, perhaps compelling, reasons to avoid bringing multiple lawyers into an amicable situation. Expense may be a prohibitive factor, and one must consider the risk that multiple lawyers will create problems where none existed. These considerations are important enough when the clients are two business partners. They are even more important when the clients are a happily married husband and wife whose interest in the continuity and development of their marital relationship may be more important than the outcome of a particularly legal negotiation.

Most married couples probably never consider consulting separate lawyers for the preparation of their wills. They assume that their mutual interests will be served by working co-operatively toward a co-ordinated estate plan and by confiding in one another in seeking to understand and reconcile what differences may exist between them.

This assumption is so prevalent, on behalf of both clients and lawyers, that in most cases the "multiple representation" problem is never discussed. Ethical Consideration 5-16 requires that before a lawyer may represent multiple clients, he should explain fully to each client the implications of the common representation and should accept or continue employment only if the clients consent. I believe this is rarely done when the clients are husband and wife who retain a lawyer for the preparation of wills. In my judgment it is unnecessary for a lawyer formally to seek an express consent to multiple representation when the clients are a married couple who want wills drawn, unless the lawyer knows of special circumstances that lead to the belief that there is a substantial conflict of interests. An informed consent may properly be inferred from the circumstances.

Problems such as those presented by this case might have been avoided, however, if at the initial interview with John and Mary the lawyer had probed for possible conflicts. This is especially important in cases in which the likelihood is great that the interests of the husband and wife may be conflicting, such as in a marriage that is in the process of disintegration, in a second marriage in which there are children by the spouses' prior marriages, or in other cases in which the natural objects of the bounty of the husband and wife are not identical.

Finally, one should recognize that women are taking an increasingly active voice in the conduct of their personal business. A "liberated woman" may feel that sharing a lawyer with her husband enhances neither her personal dignity nor the marital relationship. She may prefer independent representation and be prepared to pay for it.

Confidentiality with multiple clients. Disciplinary Rule 4-101 directs that a lawyer shall not knowingly reveal a confidence or secret of a client during or after the termination of the professional relationship. In a multiple representation case the difficulty is determining what constitutes a client's "confidence." When John, Mary, and the lawyer meet together face to face, what Mary tells the lawyer is not a confidence, so far as John is concerned. But what if Mary 
meets privately with the lawyer, or telephones or writes him? There is an implied understanding, when two or more clients retain a lawyer for work on a common project, that the lawyer is free to disclose to all of his clients his communications with each of them.

It was a mistake for the lawyer to ask to meet privately with Mary before she signed her will. By doing so, he invited Mary to speak "confidentially" with him and opened the door to the dilemma that confronted him when Mary told him that she was dissatisfied with her will.

If, after the lawyer met with John and Mary jointly, he had no reason to be concerned as to lack of testamentary capacity on Mary's part or undue influence or duress by John, the private meeting with Mary was a mistake. If he had these concerns, he should have resolved them by withdrawing from employment.

The execution of Mary's will. The lawyer was correct in refusing to cooperate with Mary in making a secret change in her will. As E.C. 5-14 states, "maintaining the independence of professional judgment required of a lawyer precludes his acceptance or continuation of employment that will adversely affect his judgment on behalf of or dilute his loyalty to a client. This problem arises whenever a lawyer is asked to represent two or more clients who may have differing interests."

Though a husband and wife do not agree completely on the provisions of their wills, a lawyer may prepare wills for both, but only if there is an informed consent. That prerequisite is missing here. The consent given by implication at the initial meeting was vitiated when Mary sought to make a change of which John was not informed.

The root of the conflict is Mary's problem. She doesn't like the will that was discussed in her husband's presence, but she doesn't want to disclose to him her dissatisfaction with it. This dilemma is Mary's and she should decide what to do about it. The lawyer, by meeting privately with Mary, has permitted her to transfer the problem to him.

I agree that the lawyer should have presented alternatives to Mary and required her to make the choice. I disagree that it would be proper for the lawyer to draw a revised will for Mary on the condition that he be permitted to tell John simply that "Mary changed her will." This is not the full disclosure that the canons require.

Validity of Mary's will. Mary's will is valid as signed. She understood the provisions of the will and the significance of signing it. To my knowledge, there is no authority for refusing to probate or for reforming a will on the basis of statements made by the testator at the time of signing that he or she was not entirely satisfied with its provisions.

Most lawyers with extensive experience in writing wills have clients who never sign a will without protesting that it is not final - perhaps they feel that acceptance of the will somehow involves an acceptance of death. The courts properly attach no significance to these statements. There is 
no evidence that Mary did not understand what she was doing or of lack of capacity, undue influence, or duress. The will should be probated as written.

The lawyer's dilemma. After Mary advised the lawyer that she was dissatisfied with the will and intended to change it, did the lawyer have further responsibilities? In the circumstances it is clear that Mary considered her statements to the lawyer confidential, and the lawyer led her to believe that they would be so treated. If the lawyer discloses to John what Mary has told him about her intentions, he is revealing a client's confidence.

On the other hand, if by silence the lawyer permits John to leave the office with the false impression that Mary has signed the will she discussed in John's presence, the lawyer may be seen to have conspired with Mary to defraud John. By doing this, the lawyer has permitted Mary's desires to dilute his loyalty to John.

There is no easy way out for the lawyer. D.R. 5-105 requires that a lawyer shall not continue employment if it would be likely to involve him in representing differing interests, unless it is obvious that he can adequately represent the interest of each and if each consents, after full disclosure. It is strange that the authorities offer little guidance as to what the lawyer must do when multiple representation is no longer proper. There is some authority for the proposition that the lawyer may continue to represent the client with the most seniority. The better view would seem to be that when the interests of clients diverge and become antagonistic, their lawyer must be absolutely impartial, which, unless they both or all desire him to represent them both or all, usually means that he may represent none.

In most cases the conflict between clients will have become apparent to everyone. Here John does not know that the conflict exists. The lawyer may not disclose Mary's confidences to John, but he must disclose to both John and Mary that they have differing interests and that he may no longer represent either of them in connection with their estate planning. This will alert John to the fact that something is amiss, with out directly breaching Mary's confidence. This, in my judgment, is the least bad solution.

Postdeath disclosure. Mary's statements to the lawyer about her dissatisfaction with the will were confidences not to be disclosed during her lifetime. It is well established, however, that after the testator's death the attorney is at liberty to disclose all that affects the execution and tenor of a will. If the lawyer were subpoenaed, he would be obliged to testify concerning these matters, but Mary's statements about her will would not be material in any suit to challenge it. Thus, even though the privilege expires on her death, the lawyer should not be required to testify.

\section{Further Reading:}

- Thomas Shaffer, The Legal Ethics of Radical Individualism, 65 Tex. L. Rev. 963 (1987)

- Teresa Stanton Collett, The Ethics of Intergenerational Representation, 62 Fordham L. Rev. 1453 (1994) 
- Alysa Christmas Rollock, Professional Responsibility and Organization of the Family Business: The Lawyer as Intermediary, 73 Ind. L.J. 567 (1998)

- Russell G. Pearce, Family Values and Legal Ethics: Competing Approaches to Conflicts in Representing Spouses, 62 Fordham L. Rev. 1253 (1994) 


\section{2: Exceptions to the Duty of Confidentiality}

Tell me at least six things you may or may not consider personal. l'm not talking about jet ski accidents, rather truly things you'd never thought you'd tell. ${ }^{65}$

This very secret you're trying to conceal, is the very same one you're dying to reveal. ${ }^{66}$

\section{Exceptions to the Professional Duty of Confidentiality}

There are many state variations in the scope of the duty of confidentiality. As a result, a practicing lawyer should be particularly attentive to local law. The lawyer should be attentive to the distinction between a permission to disclose and a requirement to disclose. This distinction is indicated by the use of "may" or "shall" in the language. Remember that the ethical duty of confidentiality covers a broader range of information than the privilege. The ethical duty also covers the use of information to the disadvantage of a client, a prospective client, or a former client.

The third-party doctrine (the presence of a nonprivileged third person) does not necessarily destroy an attorney's duty of confidentiality. Confidential information remains confidential even if it is known to others, unless the information becomes generally known.

There are eight exceptions to the Duty of Confidentiality: client's consent, dispute concerning attorney's conduct, disclosure to obtain legal ethics advice, disclosure required by law or court order, disclosure to prevent death or substantial bodily harm, disclosure to prevent or mitigate substantial financial harm, and disclosure to detect and resolve conflicts of interest.

\section{a. Client's Informed Consent}

Model Rule 1.6 implicitly says that an attorney may reveal or use confidential information if the client gives informed consent. "Informed consent" means that the client agrees to a proposed course of action after the lawyer has adequately explained the risks and reasonable alternatives.

Model Rule 1.6(a)

Model Rule 1.0(e)

\section{Restatement (Third) of the Law Governing Lawyers § 62 (2000): Using or Disclosing Information with Client Consent}

\footnotetext{
65 The Blow, Jet Ski Accidents.

${ }^{66}$ Ronald Eldon Sexsmith, Secret Heart, Ron Sexsmith (1995).
} 
A lawyer may use or disclose confidential client information when the client consents after being adequately informed concerning the use or disclosure.

\section{b. Implied Authority}

An attorney has implied authority from the client to use or disclose confidential information when appropriate to carry out the representation, unless the client gives specific instructions to the contrary.

\section{Restatement (Third) of the Law Governing Lawyers $§ 61$ (2000): Using or Disclosing Information to Advance Client Interests}

A lawyer may use or disclose confidential client information when the lawyer reasonably believes that doing so will advance the interests of the client in the representation.

\section{c. Dispute Concerning Attorney's Conduct}

An attorney may reveal a client's confidential information to the extent necessary to protect the attorney's interests in a dispute that involves the conduct of the attorney. An attorney wishing to use this exception should reveal only what is necessary, attempt to limit the disclosure to those who need to know it, and obtain protective orders or take other steps to minimize the risk of unnecessary harm to the client.

\section{d. Disclosure to Obtain Legal Ethics Advice}

A lawyer may disclose enough of the client's confidential information as is necessary to obtain legal ethics advice for the lawyer.

\section{e. Disclosure Required by Law or Court Order}

ABA Model Rule 1.6(b)(6) permits a lawyer to reveal her client's confidential information to the extent that she is required to do so by law or court order.

\section{Restatement (Third) of the Law Governing Lawyers § 63 (2000): Using or Disclosing Information When Required by Law}

A lawyer may use or disclose confidential client information when required by law, after the lawyer takes reasonably appropriate steps to assert that the information is privileged or otherwise protected against disclosure.

\section{f. Disclosure to Prevent Death or Substantial Bodily Harm}


ABA Model Rule 1.6(b)(1) permits a lawyer to reveal the client's confidential information to the extent that the lawyer reasonably believes necessary to prevent reasonably certain death or substantial bodily harm. This exception applies to death or bodily harm whatever the cause; it does not need to be caused by the client, and the cause need not be a criminal act. It also does not need to be imminent, just reasonably certain.

The exception also gives the lawyer discretion to disclose the confidential information-- it does not require disclosure. Some states may require disclosure if they have not accepted the Model Rules.

\section{Restatement (Third) of the Law Governing Lawyers § 66 (2000): Using or Disclosing Information to Prevent Death or Serious Bodily Harm}

(1) A lawyer may use or disclose confidential client information when the lawyer reasonably believes that its use or disclosure is necessary to prevent reasonably certain death or serious bodily harm to a person.

(2) Before using or disclosing information under this Section, the lawyer must, if feasible, make a good-faith effort to persuade the client not to act. If the client or another person has already acted, the lawyer must, if feasible, advise the client to warn the victim or to take other action to prevent the harm and advise the client of the lawyer's ability to use or disclose information as provided in this Section and the consequences thereof. (3) A lawyer who takes action or decides not to take action permitted under this Section is not, solely by reason of such action or inaction, subject to professional discipline, liable for damages to the lawyer's client or any third person, or barred from recovery against a client or third person.

\section{g. Disclosure to Prevent or Mitigate Substantial Financial Harm}

The Model Rules permit a lawyer to reveal the client's confidential information to the extent necessary to prevent the client from committing a crime or fraud that is reasonably certain to result in substantial financial harm to someone if the client is using or has used the lawyer's services in the matter. The exception also applies if the client has already acted, and the lawyer's disclosure can prevent or mitigate the consequent financial harm.

\section{Restatement (Third) of the Law Governing Lawyers $\S 67$ (2000): Using or Disclosing Information to Prevent, Rectify, or Mitigate Substantial Financial Loss}

(1) A lawyer may use or disclose confidential client information when the lawyer reasonably believes that its use or disclosure is necessary to prevent a crime or fraud, and:

(a) the crime or fraud threatens substantial financial loss;

(b) the loss has not yet occurred; 
(c) the lawyer's client intends to commit the crime or fraud either personally or through a third person; and

(d) the client has employed or is employing the lawyer's services in the matter in which the crime or fraud is committed.

(2) If a crime or fraud described in Subsection (1) has already occurred, a lawyer may use or disclose confidential client information when the lawyer reasonably believes its use or disclosure is necessary to prevent, rectify, or mitigate the loss.

(3) Before using or disclosing information under this Section, the lawyer must, if feasible, make a good-faith effort to persuade the client not to act. If the client or another person has already acted, the lawyer must, if feasible, advise the client to warn the victim or to take other action to prevent, rectify, or mitigate the loss. The lawyer must, if feasible, also advise the client of the lawyer's ability to use or disclose information as provided in this Section and the consequences thereof.

(4) A lawyer who takes action or decides not to take action permitted under this Section is not, solely by reason of such action or inaction, subject to professional discipline, liable for damages to the lawyer's client or any third person, or barred from recovery against a client or third person.

\section{h. Disclosure to Detect and Resolve Conflicts of Interest}

Lawyers may disclose limited client information, such as client names and a summary of general issues, when a lawyer changes firms, when two firms merge, or when a law practice is being purchased. This is allowed in order to detect and resolve conflicts of interest. This exception is subject to four conditions:

1. The disclosure may be made only after substantive discussions regarding the new relationship have occurred

2. The disclosure must be limited to the minimum necessary to detect any conflicts of interest

3. The disclosed information must not compromise the attorney-client privilege or otherwise prejudice the clients; and

4. The disclosed information may be used only to the extent necessary to detect and resolve any conflicts of interest

\section{i. Protecting Confidential Information}

A lawyer must make reasonable efforts to protect a client's confidential information from inadvertent or unauthorized disclosure by the lawyer and those under the lawyer's supervision, and from unauthorized access by third parties. The reasonableness of the lawyer's efforts is determined by considering such factors as the sensitivity of the client's information, the cost of additional safeguards, and the difficulty of implementing the safeguards.

Model Rule of Professional Conduct 1.6: Confidentiality of Information, Comment [3] 
The principle of client-lawyer confidentiality is given effect by related bodies of law: the attorneyclient privilege, the work product doctrine and the rule of confidentiality established in professional ethics. The attorney-client privilege and work product doctrine apply in judicial and other proceedings in which a lawyer may be called as a witness or otherwise required to produce evidence concerning a client. The rule of client-lawyer confidentiality applies in situations other than those where evidence is sought from the lawyer through compulsion of law. The confidentiality rule, for example, applies not only to matters communicated in confidence by the client but also to all information relating to the representation, whatever its source. A lawyer may not disclose such information except as authorized or required by the Rules of Professional Conduct or other law.

\section{United States v. Franklin, 598 F. 2d 954 (5th Cir. 1979)}

Summary: Attorney Robert Senor represented Morton Franklin in relation to various criminal charges. Senor offered confidential client information to the government in an unsuccessful attempt to obtain more lenient treatment. Franklin filed a motion to dismiss his indictment, on the ground that Senor improperly disclosed confidential information. The district court denied the motion, and the circuit court affirmed, because Senor disclosed the information in order to benefit Franklin, among other things.

\section{PER CURIAM:}

Appealing his false loan application and obstruction of justice convictions, defendant contends that the indictment should have been dismissed because it was based on information obtained by the Government from his attorney. Concluding that the facts of this case do not support the relief requested, we affirm.

Defendant was charged with assisting in the submission of a materially false statement to a federally insured bank to obtain financing for a gun smuggling operation and with obstructing justice by preventing an investigation into these financial arrangements.

\section{DISMISSAL OF INDICTMENT}

Prior to trial, defendant moved to dismiss the indictment on the ground that the Government had improperly obtained information from his attorney, Robert Senor. Senor had contacted Government agents for the purpose of arranging leniency for the defendant on a marijuana charge. Without detailing the evidence in relation to these contacts and the information revealed to the Government by Senor, it appears from the record that defendant cannot prevail under any theory presented.

In Weatherford v. Bursey, the Supreme Court held it fatal to a conviction for the Government to obtain defense strategy from an attorney only where there was "a realistic possibility of injury to defendant or benefit to the State." 
Senor testified he had discussed defense strategy with his friend Edward Ragen, a Supervisory Customs Air Officer. Since Ragen did not communicate this information to his superiors and was not officially assigned to this case, and the Government did not purposely infiltrate the defense camp, there was no realistic possibility of harm to defendant or benefit to the Government. Senor's statement to Zisk that Franklin maintained his innocence cannot be regarded as a disclosure of the defense strategy.

Defendant further contends that the Government had made Senor its undercover agent. Although the affidavit for warrants to search codefendants' premises and automobiles had listed Senor as a "confidential source" and contained information relayed by Senor, the facts do not support the contention here made.

Acting on defendant's behalf in seeking to barter information for leniency on the marijuana charge, defendant's attorney initiated the contact. It appeared to the Government that he was acting with the approval of his client in his client's best interests. Throughout these communications Senor insisted that his client was innocent of any wrongdoing in the gun smuggling operation and only wished to exchange information incriminating others for leniency. This case is thus fundamentally different from Messelt $v$. Alabama, in which an "utter perversion of the attorney-client relationship" resulted from the defense attorney's effort to gain leverage for the payment of his fee by suggesting to the prosecution that his client be charged with more serious offenses, and his proposal to his client that they participate together in a drug scheme.

The Government's response to Senor's efforts was restrained and proper. The Government agent, Philip Zisk, told Senor he was not interested in bargaining and already had access to information about the smuggling operation. Although Zisk did list Senor as a source of information in the application for the search warrants, he testified that the information on which the affidavit was based came primarily from undercover officers, that Senor was only one of four sources, and that the information provided by him was merely cumulative. Defendant had no interest in the property searched, was without standing to challenge the validity of the search, and did not attempt to do so. Senor thus was not, as claimed, a confidential agent in the service of the Government.

Basically, Senor communicated three items of information to Zisk: (1) defendant's role in arranging the financing of what he thought was to be a legitimate gun operation; (2) trips to Cleveland by a codefendant to secure financing; and (3) details concerning Franklin's later discovery of gun smuggling. That Senor communicated information given by his client to the Government does not taint his conviction for several reasons. First, the information was available to the Government from other sources and not based on Senor's communications. Second, the information did not incriminate defendant. Third, the information was communicated voluntarily as an inducement to a plea bargain. Fourth, at a later meeting defendant himself communicated substantially the same information to the Government through Senor, thereby waiving any privilege he may have had and ratifying Senor's communication, if he had not in fact approved it from the outset. Fifth, neither the information communicated by Senor nor the fact the communication took place was introduced at trial. 
The only evidence introduced at the trial that implicated defendant and which related to Senor's communication was a codefendant's diary seized during the search. Even assuming that evidence was obtained by the Government in an illegal manner, the proper remedy would be suppression, not dismissal of the prosecution. Suppression was not sought. In any event, the evidence had minimal impact.

Therefore, the district court did not err in denying the motion to dismiss the indictment.

\section{Questions:}

1. Why did Franklin think he was entitled to relief?

2. Did Senor violate his duty of confidentiality to Franklin by disclosing the information at issue?

3. Did disclosure of the information materially impact Franklin's trial? Should it matter?

In re Original Grand Jury Investigation, 89 Ohio St. 3d 544 (Ohio 2000)

Summary: An attorney represented a client in relation to grand jury investigation. The attorney received a letter written by the client that disclosed a possible crime. The attorney asked the court how to proceed, and ultimately orally disclosed the contents of the letter, without disclosing the letter itself. The Ohio Supreme Court held that the letter was a client "secret," but that disclosure was required in order to prevent a crime.

FRANCIS E. SWEENEY, SR., J.

The issue presented in this case is whether an attorney can be compelled to disclose to the grand jury a letter written by a client and discovered by an investigator that contains evidence of a possible crime or whether the Ohio Code of Professional Responsibility prohibits such disclosure.

At the outset, we understand that appellant was faced with an ethical dilemma and had the difficult decision of determining how to respond to the competing challenges of maintaining client confidentiality and preserving the safety concerns of the public. We appreciate that appellant confronted the problem head-on by first asking the Secretary of the Board of Commissioners on Grievances and Discipline of the Supreme Court for advice on whether he had an obligation to report a possible crime and then by heeding that advice by reporting the matter to the court and cooperating with the police. Nevertheless, for the reasons that follow, we find that appellant must comply with the grand jury subpoena and relinquish the letter in question.

The concept of client confidentiality, including the attorney's ethical obligations concerning confidentiality, is embodied in DR 4-101. DR 4-101(A) defines the terms "confidence" and "secret" as follows: 
"Confidence" refers to information protected by the attorney-client privilege under applicable law and "secret" refers to other information gained in the professional relationship that the client has requested to be held inviolate or the disclosure of which would be embarrassing or would be likely detrimental to the client.

DR 4-101(B) states, "Except when permitted under DR 4-101(C), a lawyer shall not knowingly reveal a confidence or secret of a client."

We must first determine whether the letter sought falls within the definition of a client "secret." Unlike "confidence," which is limited to information an attorney obtains directly from his or her client, the term "secret" is defined in broad terms. Therefore, a client secret includes information obtained from third-party sources, including "information obtained by a lawyer from witnesses, by personal investigation, or by an investigation of an agent of the lawyer, disclosure of which would be embarrassing or harmful to the client."

The court of appeals found that the letter was not a secret because it was not information gained in the professional relationship. Instead, the court said that the letter was simply physical evidence, which needed to be disclosed to the authorities. Even though the letter does constitute physical evidence of a possible crime, it also contains information detrimental to appellant. Thus, we find that the letter falls within the definition of a client "secret," since it was obtained in the professional attorney-client relationship, by appellant's agent (the investigator), and since it contains detrimental information detailing a possible crime committed by appellant's former client.

Although the letter is a client secret, this does not necessarily mean that disclosure of the letter is absolutely prohibited. An attorney may disclose a client secret if one of the four listed exceptions in DR 4-101(C) applies.

Appellant concedes that DR 4-101(C)(3) permits him to "reveal the intention of his client to commit a crime and the information necessary to prevent the crime. ${ }^{n 67}$ Nevertheless, appellant contends that this provision is narrow in its scope and permits him to orally disclose the information contained in the letter, but does not permit him to disclose the physical evidence (the letter). Therefore, appellant maintains that DR 4-101(C)(3) did not permit him to reveal more than he did when he orally disclosed the intention of his former client to commit a crime and prevented a crime from occurring.

We agree with appellant that he was authorized by DR 4-101(C)(3) when he chose to reveal the intent of his client to commit a crime, and, actually, went beyond what DR 4-101(C)(3) allows by reading the entire letter to the trial court and police. However, the fact that he revealed this

\footnotetext{
${ }^{67}$ Appellant points out that this provision is written in permissive terms, since it states that a lawyer "may" reveal the client's intent to commit a crime. We acknowledge that DR 4-101(C)(3) is permissive. Nevertheless, this has no bearing on the outcome in this case, since appellant concedes that he already disclosed the relevant information to the authorities.
} 
information does not answer the question whether he is obligated to produce the letter itself. Thus, the question that remains is whether appellant is required to relinquish the letter itself and present it to the grand jury. We find that the exception found in DR 4-102(C)(2) governs disposition of this issue.

DR 4-101(C)(2) provides that an attorney may reveal "confidences or secrets when permitted under Disciplinary Rules or required by law or court order." Although the language contained in DR 4-101(C)(2), like that of DR 4-101(C)(3), is written in permissive terms, courts have interpreted provisions similar to DR 4-101(C)(2) in such a manner as to require disclosure. The exception of DR 4-101(C)(2) for disclosures required by law has been construed so that "the effect of other rules compels disclosures." Consequently, if a lawyer is "required by law" to disclose information to the authorities, "these legal obligations create 'forced' exceptions to confidentiality." Under these circumstances, a lawyer's duty "not to use or disclose confidential client information is superseded when the law specifically requires such use or disclosure."

The exception of DR 4-101(C)(2) for disclosures required by law has been applied in the context of mandating that attorneys relinquish evidence and instrumentalities of crime to lawenforcement agencies. Thus, the rule has emerged that, despite any confidentiality concerns, a criminal defense attorney must produce real evidence obtained from his or her client or from a third-party source, regardless of whether the evidence is mere evidence of a client's crime, or is a fruit or instrumentality of a crime. In either event, the physical evidence must be turned over to the proper authorities. In essence, the confidentiality rules do not give an attorney the right to withhold evidence.

Appellant contends, however, that there are strong policy reasons against mandating disclosure. Appellant believes that mandatory disclosure will discourage attorneys from reporting possible threats made by their clients and will therefore run contrary to the intent of the code, which is to prevent crimes from occurring. Appellant cites the Massachusetts decision of Purcell v. Dist. Atty. for Suffolk Dist., which highlights these concerns.

In Purcell, an attorney informed police about his client's intention to commit arson. The trial court ordered the attorney to testify about the conversation he had with his client concerning his client's intention to commit this crime, and the state defended the order on the basis of the crime-fraud exception to the attorney-client privilege. The Massachusetts Supreme Court vacated the trial court's order and held that the attorney did not have to testify against his client. In so holding, the court noted:

We must be cautious in permitting the use of client communications that a lawyer has revealed only because of a threat to others. Lawyers will be reluctant to come forward if they know that the information that they disclose may lead to adverse consequences to their clients. A practice of the use of such disclosures might prompt a lawyer to warn a client in advance that the disclosure of certain information may not be held in confidence, thereby chilling free discourse between lawyer and client and reducing the prospect that the lawyer will learn of a serious threat to the well-being of others. 
Although these may be valid concerns, we find that the Purcell decision is distinguishable from the instant case, and that the policy reasons cited in Purcell have less validity here. Purcell involved direct communications between an attorney and client. The issue in that case was whether the attorney was required to testify against his client. In this case, the attorney-client privilege is not at issue. Nor is appellant being asked to testify against his former client. Instead, the instant case revolves around whether a physical piece of evidence must be relinquished to the grand jury. While we recognize the importance of maintaining a client's confidences and secrets and understand that an attorney may have concerns in turning over incriminating evidence against his or her client, we do not believe that these concerns should override the public interest in maintaining public safety and promoting the administration of justice by prosecuting individuals for their alleged criminal activity.

Since the letter sought in this case contains evidence of a possible crime, we find that the letter must be turned over to the grand jury. Accordingly, we hold that where an attorney receives physical evidence from a third party relating to a possible crime committed by his or her client, the attorney is obligated to relinquish that evidence to law-enforcement authorities and must comply with a subpoena issued to that effect.

Other provisions of the code support our holding that appellant must relinquish the letter to the grand jury. DR 7-109(A) provides, "A lawyer shall not suppress any evidence that he or his client has a legal obligation to reveal or produce." Furthermore, DR 7-102(A)(3) provides, "In his representation of a client, a lawyer shall not conceal or knowingly fail to disclose that which he is required by law to reveal." Reading these rules together, we believe that under the facts presented in this case, appellant has a legal obligation to turn the letter over to the grand jury.

We agree with the court of appeals that the sanction imposed against appellant stemming from the contempt proceedings should be vacated, given that appellant challenged the subpoena on confidentiality grounds in good faith. Under these circumstances, we do not believe appellant should be punished and held in contempt. The finding of contempt is vacated on condition that appellant comply with the subpoena. Accordingly, we affirm the judgment of the court of appeals and order appellant to relinquish the letter in question to the grand jury.

PFEIFER, J., concurring in part and dissenting in part.

I agree with the majority that the letter is a client secret and that Helmick was authorized to reveal the intent of his client to commit a crime. DR 4-101(C)(3). Revealing "the information necessary to prevent the crime" should have concluded the matter. Unfortunately, the trial court and now a majority of this court chose to read DR 4-101(C)(2) liberally. That reading of the exception swallows the rule of DR 4-101(B)(1), which states that a lawyer "shall not knowingly reveal a confidence or secret of his client," and declares open season on defense attorney files.

The majority relies on cases from other jurisdictions in which attorneys were required to turn over to the proper authorities the fruits and instrumentalities, including a gun, of crime. Those 
cases are not similar factually to this case. Purcell is, and we should have taken a similarly cautious approach. Otherwise, "lawyers will be reluctant to come forward if they know that the information that they disclose may lead to adverse consequences to their clients, thereby chilling free discourse between lawyer and client and reducing the prospect that the lawyer will learn of a serious threat to the well-being of others."

Helmick acted the way all attorneys with an ethical dilemma should: he sought out competent counsel and followed the advice given. He acted in a manner designed to prevent the commission of a crime, which is what the $(C)(3)$ exception to DR 4-101 is all about.

Today's opinion will likely have two unfortunate results. First, overzealous prosecutors will be more likely to engage in fishing expeditions. Second, attorneys and their clients will be less likely to discuss potential crimes, which will decrease the likelihood that the crimes can be prevented. I concur in part and dissent in part.

\section{Questions:}

1. Why did the appellate court and the Ohio Supreme Court disagree about whether the letter was "confidential information" for the purpose of the duty of confidentiality?

2. Why did the court find that the attorney could disclose the contents of the letter? Do you agree?

3. What is the difference between disclosing the information necessary to prevent a crime from occurring and disclosing confidential information?

McClure v. Thompson, 323 F.3d 1233 (9th Cir. 2003)

Summary: Robert McClure was arrested for the murder of Carol Jones and the disappearance of her two children. Attorney Christopher Mecca represented McClure. In the course of representation, McClure told Mecca the location of the children. Mecca disclosed that information to the police, who found their bodies. McClure was convicted for three murders. He filed a habeas petition, alleging that Mecca improperly disclosed confidential information. The district court denied the petition, and the Ninth Circuit affirmed, holding that McClure had not provided informed consent to disclosure, but Mecca reasonably believed disclosure could save the children.

WILLIAM W. FLETCHER, Circuit Judge:

Oregon state prisoner Robert A. McClure appeals the district court's denial of his habeas corpus petition challenging his jury trial conviction for three aggravated murders. McClure's original defense attorney, Christopher Mecca, placed an anonymous telephone call to law enforcement officials directing them to the locations of what turned out to be the bodies of two children whom McClure was ultimately convicted of killing. The district court rejected McClure's arguments that the disclosure constituted ineffective assistance of counsel, holding there was no breach of the duty of confidentiality and no actual conflict of interest. We affirm. 


\section{Background}

\section{A. Offense, Arrest and Conviction}

On Tuesday, April 24, 1984, the body of Carol Jones was found in her home in Grants Pass, Oregon. She had been struck numerous times on the head, arms and hands with a blunt object. A gun cabinet in the home had been forced open and a .44 caliber revolver was missing. Two of Jones' children - Michael, age 14, and Tanya, age 10 - were also missing. The fingerprints of Robert McClure, a friend of Jones, were found in the blood in the home. On Saturday, April 28, McClure was arrested in connection with the death of Carol Jones and the disappearance of the children.

That same day, McClure's mother contacted attorney Christopher Mecca and asked him to represent her son. As discussed in more detail below, sometime in the next three days, under circumstances described differently by McClure and Mecca, McClure revealed to Mecca the separate remote locations where the children could be found. On Tuesday, May 1, Mecca, armed with a map produced during his conversations with McClure, arranged for his secretary to place an anonymous phone call to a sheriff's department telephone number belonging to a law enforcement officer with whom Mecca had met earlier.

Later that day and the following day, sheriff's deputies located the children's bodies, which were in locations more than 60 miles apart. The children had each died from a single gunshot wound to the head. Mecca then withdrew from representation. On May 3, McClure was indicted for the murders of Carol Jones and her children. At trial, the prosecution produced extensive evidence that stemmed from the discovery of the children's bodies and introduced testimony regarding the anonymous phone call. McClure was found guilty of all three murders and was sentenced to three consecutive life sentences with 30-year minimums. On direct appeal, his conviction was affirmed without opinion.

\section{B. Disclosure of the Children's Whereabouts}

The parties agree that Mecca and McClure met at the jail and spoke on the telephone on a number of occasions between April 28 and May 1. However, the substance of the conversations between McClure and Mecca are the subject of significant dispute.

Mecca recorded his account in notes that he wrote immediately after the children's bodies were discovered. Mecca also gave deposition testimony for McClure's state post conviction proceeding, submitted an affidavit prior to McClure's federal habeas proceeding, and gave testimony at the federal district court evidentiary hearing in the habeas proceeding. In his notes, Mecca wrote that McClure had initially claimed that he was "being framed" for the murder, but that he was nervous about his fingerprints being in the house. He had asked Mecca to help him remove some other potential evidence, which Mecca declined to do. 
According to the notes, on the Sunday night after McClure's Saturday arrest, Mecca received a "frantic phone call" from McClure's sister, who was convinced that McClure had murdered Jones, but had reason to believe that the children were alive and perhaps "tied up or bound someplace." In response, Mecca set up a meeting with McClure, his sister and his mother at the jail, at which McClure's sister "directly confronted McClure and begged him to divulge information about the whereabouts of the kids." McClure and his sister discussed how McClure sometimes did "crazy things" when he was using drugs, but McClure strongly maintained his innocence as to Carol Jones' murder and the children's disappearance.

According to his notes, when Mecca next spoke with McClure on Monday, McClure was less adamant in his denial. Mecca described how, when they met on Monday afternoon, McClure began to tell him of his "sexual hallucinations and fantasies" involving young girls and about "other situations that happened in the past involving things he would do while under the influence of drugs." "It was at that time," Mecca wrote, "when I realized in my own mind that he had committed the crime and the problem regarding the children intensified." Mecca wrote that he "was extremely agitated over the fact that these children might still be alive."

After a Monday night visit to the crime scene, Mecca returned to the jail to speak with McClure again, at which time he "peeled off most of the outer layers of McClure and realized that there was no doubt in my mind that he had killed Carol Jones." McClure told Mecca he wanted to see a psychiatrist, then launched into "bizarre ramblings." "Each time as I would try to leave," Mecca recalled in his notes, "McClure would spew out other information, bits about the children, and he would do it in the form of a fantasy." Mecca wrote that he "wanted to learn from him what happened to those children." He told McClure "that we all have hiding places, that we all know when we go hiking or driving or something, we all remember certain back roads and remote places," and that McClure "related to me one place where a body might be" and then "described where the other body would be located." Mecca wrote that he "wasn't going to push him for anything more," but "when I tried to leave, he said, and he said it tentatively, "would you like me to draw you a map and just give you an idea?' and I said 'Yes' and he did." Mecca recorded that "at that time, I felt in my own mind the children were dead, but, of course, I wasn't sure."

Very late on Monday evening, McClure telephoned Mecca at home and said, "I know who did it." Mecca recorded in his notes that the next morning he went to meet with McClure, and asked him about this statement. McClure told Mecca that "Satan killed Carol." When Mecca asked, "What about the kids?" McClure replied, "Jesus saved the kids." Mecca wrote in his notes that this statement "hit me so abruptly, I immediately assumed that if Jesus saved the kids, that the kids are alive." Mecca wrote that he "kind of felt that McClure was talking about a sexual thing, but, in any event, I wasn't sure."

Mecca's notes indicate that on Monday, before McClure made the "Jesus saved the kids" comment, and again on Tuesday, immediately after the meeting at which he made that comment, Mecca had conversations with fellow lawyers, seeking advice regarding "the dilemma that he faced." After the second of these conversations, which took place Tuesday morning, Mecca arranged for a noon meeting with the undersheriff and the prosecutor. At the meeting, he 
"mentioned to them that I may have information which would be of interest to the State" and attempted to negotiate a plea. When the prosecutor responded that there would be no deal, Mecca recorded in his notes, "I had made up my mind then that I had to do the correct thing. The only option I had, as far as I was concerned, was to disclose the whereabouts of the bodies." (Recall that by the time Mecca wrote these notes, he had learned that the children were dead.) A law enforcement official testified in a federal court deposition that, after both the state bar association and the attorney general "recommended that it would be unwise for Mr. Mecca to provide us information," Mecca "indicated that, even though there might be sanctions, that he still was wanting to provide information that he had regarding the children." Mecca stated that when he spoke with McClure's sister and mother, they were adamant that he do whatever he could to locate the children, and that "they were still under the impression that one or both of the children were alive, or at least there was a chance they were alive."

Mecca then returned to the jail Tuesday afternoon and, according to his notes, "advised McClure that if there was any possibility that these children were alive, we were obligated to disclose that information in order to prevent, if possible, the occurrence of what could be the elevation of an assault to a murder, for instance. I further indicated that if he really requested psychiatric help, to help him deal with his problem, that this perhaps was the first step." "In any event," Mecca recorded in his notes, "he consented." "I arranged to have the information released anonymously to the Sheriff's Department with directions to the bodies." He noted that there was "no provable way to connect" McClure to the information, "but I think it's rather obvious from those in the know, who the information came from."

In the deposition conducted in conjunction with McClure's state habeas proceeding, Mecca gave a similar account of the events surrounding disclosure of the locations of the children. He emphasized that "it all happened relatively quickly" and that there was a public "hysteria about these kids, whether the kids were dead, whether the kids were alive." Mecca reiterated that much of the later conversations with McClure consisted of hypotheticals and fantasies - "like he was playing a game with me" — but that it was clear that McClure wanted to tell him where the children were. Mecca stated in his deposition that "the condition of the children was never discussed," but that the insistence by McClure's mother and sister that McClure wouldn't hurt the children put him "in this mode of thinking these kids might be alive someplace."

Mecca testified in his deposition that he thought that if the children were alive, it might relieve McClure of additional murder charges, but that the children were his main concern. When asked if he was "primarily concerned with the children's welfare or with Mr. McClure's welfare" at the time he disclosed the location of the bodies, Mecca replied, "At that point I was concerned with the children's welfare." When asked if he explained to McClure that "if they were in fact dead, that revealing the location of the bodies would lead to evidence which could implicate Mr. McClure in their murders," Mecca answered: "No. I don't think I had the presence of mind to sit down and analyze every single detail and go over with him, 'Geez, you know, if they are really dead, why don't you tell me." However, he testified, "McClure knew I thought there was a chance those kids were alive." 
Mecca testified in the deposition that the plan to place the anonymous telephone call was his, but that McClure knew that he planned to do it, and that, in his late-night call, McClure had made clear that he "absolutely wanted to disclose where those kids were." When asked, "Did he give you permission to reveal this information?" Mecca responded, "Oh, yes."

In a 1999 affidavit submitted in conjunction with McClure's federal habeas proceeding, Mecca gave an additional statement regarding McClure's consent: "Mr. McClure did not orally or expressly consent to the disclosure. I inferred consent from the circumstances, specifically, the fact that Mr. McClure called me at home on several occasions with the request that I see him at the jail, and the fact that he drew a map of the location of the bodies of the victim in his own handwriting and gave me the map."

In addition to reviewing Mecca's notes, his state-court deposition testimony, and his federalcourt affidavit, the federal district court heard testimony from Mecca at an evidentiary hearing. In this testimony, Mecca emphasized that he generally takes a low-keyed approach to questioning his clients. He also emphasized that McClure was "fully engaged in his defense" and "was running the show." Every time they met or conversed, he said, it was at McClure's request. He said that he and McClure "discussed at various times various methods of what I was going to do with this information." Mecca testified that McClure never expressly said that he consented to the disclosure, and that Mecca never asked for such consent. He confirmed his earlier testimony that he inferred consent, and added for the first time that this inference was based on McClure's nodding, saying "okay," and otherwise manifesting assent. He said this was what he had meant when he had written in his notes that McClure consented. Mecca also reiterated that he never told McClure of the legal risks involved in disclosing the children's locations.

Mecca testified that after the Monday conversation with McClure, "the conclusion I came to was that, without telling me, he told me he had killed three people." But he stated that he did not confirm that conclusion by directly asking McClure if it was the case. Instead, he said, he emphasized to McClure that if there was a chance the children were alive, they needed to save them, and in response McClure "never said they were dead." After the "Jesus saved the kids" comment on Tuesday, Mecca testified, "I allowed myself to believe that these kids might somehow be alive." When asked on cross examination whether, at the time he decided to make the anonymous call, he thought there was "a strong possibility the kids still may be alive," Mecca responded that he "felt that it was a possibility. I wouldn't say a strong possibility." One of the reasons he felt this possibility existed, he said, was that his "client had not indicated anything differently." He testified that the possibility of saving his client from additional murder charges "was something that was going through his mind" during his decisionmaking. He noted that the weather at that time of year was "warm" and "pleasant," and that if the children had been left in the woods it was possible that the weather would not have contributed to their death.

McClure disagreed with Mecca's account of the events leading up to the anonymous call. In testimony in both the state and federal district court proceedings, he repeatedly insisted that he did not give Mecca permission to disclose any information and that he was reassured that everything he told Mecca would remain confidential. He said Mecca pressured him into 
disclosing information by setting up the meeting with his sister and mother, and then disseminated that information to his detriment without his knowledge or consent.

McClure testified that Mecca never asked him directly if the children were alive or dead, but that the hypothetical conversations that they had were about where Mecca might find dead "bodies," not live "children." He said his disclosure of those locations was his way of admitting to having killed them. He testified that Mecca never told him that he intended to make an anonymous telephone call.

\section{Discussion}

McClure's single claim is that habeas relief is appropriate because he received ineffective assistance of counsel under the Sixth Amendment. He asserts three independent grounds on which ineffectiveness could be found. The first two are based on alleged breaches of Mecca's professional duty to maintain client confidentiality. McClure argues that this duty was breached both by a failure to obtain informed consent prior to the disclosure of confidential information and by a failure to inquire thoroughly before concluding that disclosure was necessary to prevent the deaths of the children. The third ground is that the primacy of Mecca's concern for the victims constituted a conflict of interest that rendered Mecca's counsel constitutionally ineffective.

The Duty of Confidentiality

McClure contends that Mecca's disclosure of McClure's confidential statements about the location of the children violated McClure's Sixth Amendment right to effective assistance of counsel. ABA Model Rule of Professional Conduct 1.6 sets forth a widely recognized duty of confidentiality: "A lawyer shall not reveal information relating to representation of a client." Our legal system is premised on the strict adherence to this principle of confidentiality, and "the Supreme Court has long held attorneys to stringent standards of loyalty and fairness with respect to their clients." There are few professional relationships "involving a higher trust and confidence than that of attorney and client," and "few more anxiously guarded by the law, or governed by sterner principles of morality and justice."

As critical as this confidential relationship is to our system of justice, the duty to refrain from disclosing information relating to the representation of a client is not absolute. The ABA Model Rule provides a list of well-established exceptions to the general principle of confidentiality, two of which are pertinent to the present case. First, a lawyer may reveal confidential information if "the client consents after consultation." Second, "a lawyer may reveal such information to the extent the lawyer reasonably believes necessary to prevent the client from committing a criminal act that the lawyer believes is likely to result in imminent death or substantial bodily harm." The relevant provisions of the Oregon Code of Professional Responsibility echo both the general principle of confidentiality and these particular exceptions. 
The duty of an attorney to keep his or her client's confidences in all but a handful of carefully defined circumstances is so deeply ingrained in our legal system and so uniformly acknowledged as a critical component of reasonable representation by counsel that departure from this rule "makes out a deprivation of the Sixth Amendment right to counsel." With this uncontested premise as our starting point, we examine whether the circumstances surrounding Mecca's revelation of a confidential client communication excused his disclosure, such that his performance could have been found by the state court and the district court to be constitutionally adequate. Specifically, we look to see if Mecca's client "consented after consultation" or if Mecca "reasonably believed the revelation was necessary to prevent the client from committing a criminal act that Mecca believed was likely to result in imminent death or substantial bodily harm." We conclude that the first of these exceptions does not apply to justify Mecca's behavior, but that the second does.

\section{Consent After Consultation}

McClure argues that Mecca rendered constitutionally ineffective assistance because he breached his duty of confidentiality by not obtaining McClure's informed consent before disclosure. The professional standard that allows disclosure of confidential communications when "the client consents after consultation" has two distinct parts: consent by the client, and consultation by the counsel. Our required deference to both the state court's factual findings and the district court's credibility determination leads us to hold that the first of these elements was met. However, despite this deference, we hold that the second element was not met.

\section{a. Consent}

The state court made the following finding: "Trial counsel received petitioner's permission to anonymously disclose the whereabouts of the children to the authorities." AEDPA demands that this finding of consent be presumed correct and accepted as true unless McClure rebuts the presumption with clear and convincing evidence to the contrary. The district court, whose credibility determinations are given great weight, and whose findings of fact are reviewed only for clear error, explicitly accepted that finding, and stated that it did "not find credible petitioner's assertion that he did not consent to the disclosure of the information contained in the map." It found that McClure "voluntarily drew the map and gave it to Mecca," and that, even in the absence of the words "I consent," Mecca could infer consent from the circumstances and from McClure's conduct. It stated that it found Mecca's testimony "entirely credible and corroborated by his contemporaneous notes which state specifically that petitioner consented to the disclosure."

There is evidence in the record to cast doubt on these consent findings - indeed, enough evidence that if we were sitting as trier of fact, we might find that McClure did not give consent. McClure repeatedly denied that he consented, and certainly would have had good reason not to consent. The state court determination that McClure had consented was made before Mecca clarified that the consent was implied and not express. Moreover, it was based on Mecca's unconditional affirmative response, in his state-court deposition, to the question of whether 
permission to reveal the information was granted. Only later, in the federal habeas proceeding, did it come to light that Mecca had merely inferred McClure's consent.

Further, Mecca's account of the circumstances from which he inferred McClure's consent changed over the years. His initial account stated that he inferred consent from the fact that McClure called him at home, drew the map, and gave it to him. It is a significant leap to infer McClure's consent to disclose the map to law enforcement authorities from the fact that McClure gave the map to Mecca. Virtually all clients provide information to their attorneys, but they do so assuming that the attorneys will not breach their duty of confidentiality. Further, Mecca's behavior at the time of the disclosure suggested that he thought he lacked the kind of informed consent that would give him the legal authority to act.

However, the findings reached by the state and district courts are not so "implausible" particularly in light of the district court's credibility determinations - that they produce a "definite and firm conviction that a mistake has been committed." The district court believed Mecca's account at the evidentiary hearing, disbelieved McClure's, and found the discrepancies in Mecca's testimony to be "minor." Because there are "two permissible views of the evidence, the factfinder's choice between them cannot be clearly erroneous." We therefore hold that McClure gave his consent to the disclosure.

\section{b. Consultation}

However, the mere fact of consent is not sufficient to excuse what would otherwise be a breach of the duty of confidentiality. Consent must also be informed. That is, the client can provide valid consent only if there has been appropriate "consultation" with his or her attorney. Mecca's consultation with McClure regarding his consent to disclosure was addressed in the state court and district court findings. Both courts found that Mecca did not advise McClure about the potential harmful consequences of disclosure. The state court found that "before petitioner authorized trial counsel to reveal the childrens' locations to authorities, trial counsel did not advise petitioner that if authorities located the children, he could be further implicated in the criminal activity and the evidence against him would be stronger." The district court found that "Mecca admits that he did not advise petitioner of all potential adverse consequences."

Emphasizing that McClure was "fully engaged" in his defense and that he was told that the obligation to disclose the children's location arose only if the children were alive, the district court held that "under the circumstances, Mecca's failure to advise petitioner of all possible adverse consequences was not unreasonable." We believe this holding is inconsistent with the consultation requirement because it does not attach sufficient importance to the role that an attorney's advice plays in the attorney-client relationship. It is not enough, as the district court suggests, that McClure "did not dissuade Mecca from his intentions" to share the map with authorities. The onus is not on the client to perceive the legal risks himself and then to dissuade his attorney from a particular course of action. The district court's statement that Mecca was relieved of his duty to counsel his client because "common sense dictated that petitioner understood the consequences of his actions" fails to acknowledge the seriousness of those 
consequences and the importance of good counsel regarding them. Even in cases in which the negative ramifications seem obvious - for example, when criminal defendants opt for selfrepresentation - we require that a criminal defendant's decision be made on the basis of legal guidance and with full cautionary explanation. We disagree with the district court's conclusion that this case was so exceptional that the attorney's basic consultation duties did not apply. It is precisely because the stakes were so high that Mecca had an obligation to consult carefully with his client. In the absence of some other exception to the duty of confidentiality, his failure to obtain informed consent would demonstrate constitutionally deficient performance under the Sixth Amendment.

\section{Prevention of Further Criminal Acts}

The State contends that, even if Mecca did not have informed consent, his revelation of client confidences did not amount to ineffective assistance of counsel because he reasonably believed that disclosing the location of the children was necessary in order to prevent further criminal acts. That is, Mecca reasonably believed that revealing the children's locations could have prevented the escalation of kidnapping to murder. This is not a traditional "prevention of further criminal acts" case, because all of the affirmative criminal acts performed by McClure had been completed at the time Mecca made his disclosure. Mecca was thus acting to prevent an earlier criminal act from being transformed by the passage of time into a more serious criminal offense. Nonetheless, we believe that where an attorney's or a client's omission to act could result in "imminent death or substantial bodily harm" constituting a separate and more severe crime from the one already committed, the exception to the duty of confidentiality may be triggered.

This exception, however, requires that an attorney reveal confidences only to the extent that he "reasonably believes necessary to prevent" those criminal acts and imminent harms. In assessing the effectiveness of McClure's counsel in light of this standard, the first step is to determine what a constitutionally effective counsel should be required to do before making a disclosure. That is, we must determine what basis the attorney had for believing that the precondition to disclosure was present, and how much investigation he or she must have undertaken before it was "reasonable" to "believe it necessary" to make the disclosure to prevent the harm. The second step is to apply that standard to the facts surrounding Mecca's decision to disclose.

There is remarkably little case law addressing the first analytical step. Citing cases dealing with a separate confidentiality exception allowing attorneys to reveal intended perjury on the part of their clients, McClure argues that a lawyer must have a "firm factual basis" before adopting a belief of impending criminal conduct. However, we are not persuaded that the perjury cases provide the proper standard.

McClure is correct that our inquiry must acknowledge the importance of the confidential attorney-client relationship and the gravity of the harm that results from an unwarranted breach of that duty. However, the standard applied in the professional responsibility code asks only if 
the attorney "reasonably believes" disclosure is necessary to prevent the crime. Further, the Strickland standard likewise focuses on "whether counsel's assistance was reasonable considering all the circumstances." Accordingly, we hold that the guiding rule for purposes of the exception for preventing criminal acts is objective reasonableness in light of the surrounding circumstances.

Reasonableness of belief may be strongly connected to adequacy of investigation or sufficiency of inquiry in the face of uncertainty. Significantly, as indicated above, Strickland explicitly imposes a duty on counsel "to make reasonable investigations or to make a reasonable decision that makes particular investigations unnecessary." In any ineffectiveness of counsel case, "a particular decision not to investigate must be directly assessed for reasonableness in all the circumstances, applying a heavy measure of deference to counsel's judgments." Thus, in determining whether Mecca's disclosure of confidential client information constituted ineffective assistance of counsel, we must examine whether Mecca "reasonably believed" that the precondition for disclosure existed and whether, in coming to that belief, Mecca conducted a reasonable investigation and inquiry.

The parties vigorously debate both the reasonableness of Mecca's belief that the children were alive and the reasonableness of his level of investigation and inquiry on that point. McClure argues that any conclusion that Mecca had a reasonable belief is unsupported because Mecca himself indicated that he harbored doubts as to the children's state, and yet failed to inquire further. He points to evidence in the record that Mecca, at least at some stages of his representation of McClure, did not believe the children were alive-or that he, at the least, suspected that they were dead. It is indisputable that this evidence exists, and that most of this evidence is contained in statements by Mecca himself, whom the district court found "highly credible." Mecca's notes state that, after McClure drew the map, Mecca "felt in my own mind that the children were dead, but, of course, I wasn't sure." He testified in the district court evidentiary hearing that the conclusion he came to was that, "without telling me, McClure had told me he had killed three people." And he stated in this same testimony that, at the time he had his secretary place the anonymous call, he thought there was a "possibility," but not a "strong possibility," that the children were alive.

McClure argues that the statement Mecca says abruptly changed his mind about the status of the children - McClure's comment that "Jesus saved the kids" - was so vague and ambiguous that it was not a sufficient basis for a "reasonable belief" that disclosure was necessary. Despite Mecca's acknowledgment that this comment led him only to "assume" that McClure was saying the children were alive, Mecca never directly asked a question that could have confirmed or refuted that assumption. Mecca repeatedly testified that he never squarely asked about the condition of the children or whether McClure had killed them. Accordingly, McClure argues, any finding that Mecca believed the children were alive is not sufficient to establish effective assistance of counsel, because Mecca's failure to engage in a reasonable level of investigation and inquiry rendered that belief unreasonable. 
Given the implicit factual findings of the state court, and the explicit factual findings of the district court, which are at least plausible in light of the record viewed in its entirety, we disagree. The ultimate question of the reasonableness of Mecca's belief is a question of law, which we review de novo. In answering that question, however, we look to the facts and circumstances of the case, and as to these facts, we give great deference to the findings of the state court and the district court.

The district court made a number of specific findings regarding the factual basis for Mecca's belief that the children were alive. It found that only McClure knew the true facts and that he deliberately withheld them, leading Mecca to believe the children were alive. It found that McClure controlled the flow of information, and that when Mecca informed McClure that he had an obligation to disclose the children's whereabouts if there were a chance they were alive, McClure did not tell him they were dead. It specifically rejected McClure's assertion that Mecca in fact believed that the children were dead or that he lacked information that they were alive, noting that at the time there was no evidence, other than their disappearance and the passage of time, that they had been injured or killed.

The district court also made specific factual findings regarding the nature of Mecca's investigation and inquiry. It found that "Mecca attempted to discern whether the children were alive" and "that Mecca investigated to the best of his ability under extremely difficult circumstances." McClure argues that these findings are clearly erroneous, and that "arguments that Mr. McClure was manipulative and difficult are essentially irrelevant to the lawyer's obligations." But Strickland holds otherwise. The Strickland Court emphasized that "the reasonableness of counsel's actions may be determined or substantially influenced by the defendant's own statements or actions." More specifically, it held that "what investigation decisions are reasonable depends critically" on the "information supplied by the defendant."

This is a close case, even after we give the required deference to the state and district courts. The choices made by McClure's counsel give us significant pause, and, were we deciding this case as an original matter, we might decide it differently. But we take as true the district court's specific factual findings as to what transpired - including what McClure said and did, and what actions Mecca took and why he took them - and we conclude that Mecca made the disclosure "reasonably believing it was necessary to prevent the client from committing a criminal act that Mecca believed was likely to result in imminent death or substantial bodily harm." Mecca therefore did not violate the duty of confidentiality in a manner that rendered his assistance constitutionally ineffective.

Conclusion

For the foregoing reasons, we conclude that McClure did not receive constitutionally ineffective assistance of counsel. Accordingly, the district court's denial of McClure's petition for writ of habeas corpus is affirmed.

\section{Questions:}


1. Do you agree with the court's conclusion that McClure did not provide informed consent to disclosure?

2. Do you agree with the court's conclusion that Mecca reasonably believed that disclosure could save the children?

3. Should Mecca have disclosed the information under the circumstances? Should Mecca have consulted with McClure about disclosure? 


\section{3: The Attorney-Client Privilege}

Nobody knows, nobody sees. Nobody knows, but me. ${ }^{68}$

The "attorney-client privilege" is an evidentiary privilege that protects certain confidential communications between attorneys and their clients. Attorneys have a fiduciary duty of confidentiality that prohibits them from disclosing any confidential client information unless their client consents or they are required to disclose by law. The attorney-client privilege resembles the duty of confidentiality, but provides broader protection for particular kinds of confidential communications.

Specifically, the attorney-client privilege applies to confidential attorney-client communications for the purpose of obtaining legal advice. All confidential client information is protected by the duty of confidentiality, but only confidential attorney-client communications for the purpose of obtaining legal advice are protected by the attorney-client privilege.

The attorney-client privilege provides broader protection than the duty of confidentiality. The government can require the disclosure of confidential client information in circumstances where it could not require the disclosure of privileged attorney-client communications. In fact, the government can rarely require the disclosure of privileged information, and courts interpret the exceptions to attorney-client privilege quite narrowly. But they also interpret the scope of the attorney-client privilege quite strictly. The attorney-client privilege is quite strong, when it applies. But it only applies to certain kinds of communications, and it is easy to lose.

To begin with, the attorney-client privilege only protects confidential attorney-client communications. In other words, if a third-party receives the communication, then it is not privileged, although it may still be confidential. So, if anyone other than the attorney and the client participate in the communication, then it is not privileged.

Moreover, the attorney-client privilege only covers communications for the purpose of obtaining legal advice. If an attorney-client communication does not concern legal advice, then it is not privileged, even if it is confidential. The attorney-client privilege does not cover business advice, or other non-legal advice.

In addition, the attorney-client privilege is easily destroyed. Like the duty of confidentiality, the attorney-client privilege belongs to the client, not the attorney. Accordingly, only the client can waive the privilege, not the attorney. But the client waives the privilege by disclosing privileged information to a third-party, whether or not the client intended to waive the privilege. By contrast, information remains "confidential" until it is "generally known."

${ }^{68}$ Danny Dill \& Marijohn Wilkin, Long Black Veil (1959). 
Attorneys should emphasize to their clients the fragility of the attorney-client privilege. Clients should know that any disclosure to a third-party destroys the privilege, regardless of the context. Some courts have even held that inadvertent disclosure destroys the privilege.

\section{Identifying Privileged Information}

The definition of communications protected by the attorney-client privilege may differ slightly from jurisdiction to jurisdiction. However, as a general rule, information is protected by the attorney-client privilege only if:

1. An attorney-client relationship existed when the communication occurred;

2. The information was confidential and not shared with any third-parties; and

3. The information was communicated for the purpose of obtaining legal advice.

So, the attorney-client privilege only applies to communications made in the context of an attorney-client relationship. Of course, the privilege applies whether the attorney-client relationship is express or implied. But if no attorney-client relationship had formed or the attorney-client relationship had ended when the communication occurred, then the information is not privileged, although it may still be protected by the duty of confidentiality.

In addition, the attorney-client privilege only applies to information that is absolutely confidential. If the information is disclosed to any third-parties, it is not privileged, although it may still be protected by the duty of confidentiality. This limitation applies to third-parties who participate in the initial communication as well as third-parties who receive the communication after the fact. If a lawyer with whom the client lacks an attorney-client relationship receives the information, then it is not privileged. And if a non-lawyer who is not part of the attorney-client relationship receives the information, then it is not privileged. Notably, the "joint-defense privilege" or "common defense rule" provides that joint defendants can share certain confidential information under certain circumstances, without destroying the privilege.

Finally, the attorney-client privilege only protects information communicated for the purpose of obtaining legal advice. Confidential communication between attorneys and clients for the purpose of obtaining non-legal advice are not privileged, although they may be protected by the duty of confidentiality. Attorneys often provide non-legal advice to their clients, especially when those lawyers are employees of companies. Such non-legal advice is not protected by the attorney client privilege.

The attorney-client privilege belongs to the client, not the attorney. Accordingly, only the client can waive the privilege. And clients can waive the privilege either intentionally or unintentionally. Attorneys should explicitly inform their clients that sharing privileged information with any thirdparty will destroy the privilege, and discourage their clients from sharing any privileged information without consultation. 
Sometimes, attorneys or clients inadvertently disclose privileged information to third-parties. Different courts treat such disclosures differently. Some courts hold that accidental disclosure does not destroy the privilege, and that the recipient of the information must return or destroy it, and may not use it. Other courts hold that accidental disclosure does destroy the privilege. In those courts, an attorney may accidentally destroy the privilege, even though the attorney lacks the authority to waive the privilege.

While the attorney-client privilege is quite strong, when it applies, there are certain exceptions to the privilege.

There are a number of exceptions to the attorney-client privilege. Chief among them is the "crime-fraud exception," which provides that the privilege does not protect attorney-client communications made for the purpose of committing or furthering a crime, fraud, or tort. However, the exception applies only if the crime, fraud, or tort actually occurs. For example, confidential communications between clients and attorneys for the purpose of determining whether an action is a crime, fraud, or tort are protected by the privilege, so long as the crime, fraud, or tort in questions is not actually committed.

\section{The Purpose Attorney-Client Privilege}




\title{
WANTED BY THE NEW YORK STATE POLICE FPR MURDER \\ (WARRANT ISSUED)
}
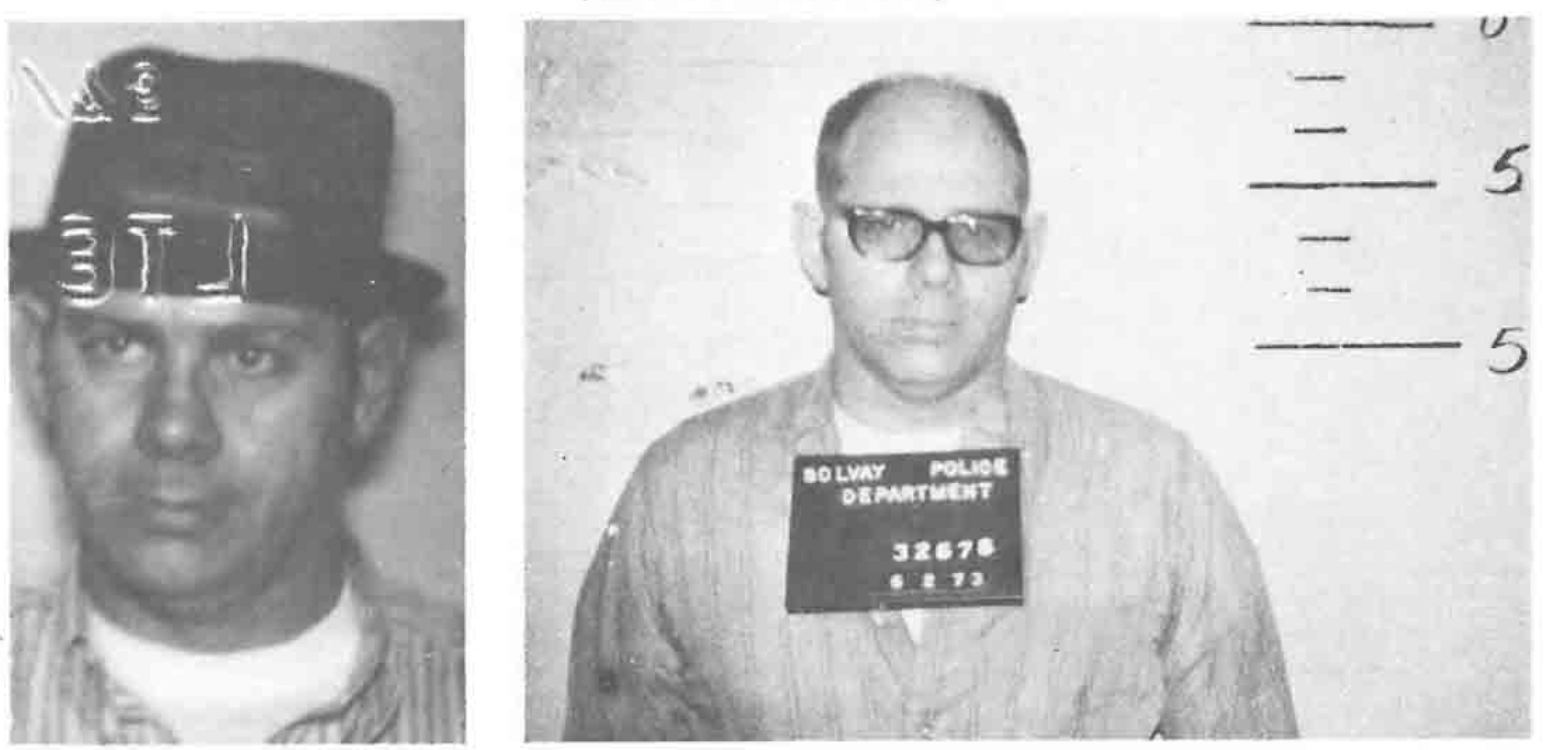

ROBERT FRANCIS GARROW, SR.

Description. white - male - 38 - DOB - March 4, 1936 - 5-11/1/2 - 215 - well built - very museular - brown halr (bald on top) - blue eyes - ("Foster Grant" type) glasses Varied Density "adjust to Ilght" - brown framesslight speech impediment - tattoo "Mom and Dad" and a heart on left forearm - sear index finger right hand - tip of thumb left hand - large scar ( 48 stitches) inside left thigh - small scar left eyebrow to bridge of nose - full upper and partial lower dentures - Habit of Always wearing a Hat and Behng Clean Shaven) .

When last seen was wearing forest green workpants and medium blue long-sleeved sport shirt. (Aug. 2, 1973.) Residence: III Berwyn Avenue, Syracuse, N. Y. - has relatives in Witherbee - Port Henry and Mineville (Essex County) and Schenectady, N. Y.

Has extensive record for Rape and various sex crimes usually involving females under the age of 16 - Burglary Grand Larceny - Attempted Robbery. DCI - 566621X - FBI - $121770 \mathrm{C}$

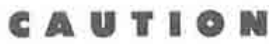 \\ SUBJECT IS EXTREMELY DAMGEROUS}

Is known to be armed with a $30-30$ cal. Olin lever-action rifle, unknown quantity of ammunition and a knlfe of unknown description.

\author{
ANY INFORMATION CONTACT: NEW YORK STATE POLICE \\ Troop B \\ Westport, New York \\ Telephone: 518- 546-7611 or 962-8235 \\ $873-2111$ or $585-6200$ \\ or ANY STATE POLICE STATION
}

People v. Belge, 83 Misc. 2d 186 (NY County Court 1975) 
Summary: Robert F. Garrow, Jr. was charged with murder and represented by Frank H. Armani and Francis R. Belge, who presented an insanity defense. In the course of representation, Garrow disclosed three other murders to his attorneys. Based on information provided by Garrow, Belge discovered the body of one of the victims, but did not disclose it to the police until the trial.

Ormand N. Gale, J.

In the summer of 1973 Robert F. Garrow, Jr., stood charged in Hamilton County with the crime of murder. The defendant was assigned two attorneys, Frank H. Armani and Francis R. Belge. A defense of insanity had been interposed by counsel for Mr. Garrow. During the course of the discussions between Garrow and his two counsel, three other murders were admitted by Garrow, one being in Onondaga County. On or about September of 1973 Mr. Belge conducted his own investigation based upon what his client had told him and with the assistance of a friend the location of the body of Alicia Hauck was found in Oakwood Cemetery in Syracuse. Mr. Belge personally inspected the body and was satisfied, presumably, that this was the Alicia Hauck that his client had told him that he murdered.

This discovery was not disclosed to the authorities, but became public during the trial of Mr. Garrow in June of 1974, when to affirmatively establish the defense of insanity, these three other murders were brought before the jury by the defense in the Hamilton County trial. Public indignation reached the fever pitch, statements were made by the District Attorney of Onondaga County relative to the situation and he caused the Grand Jury of Onondaga County, then sitting, to conduct a thorough investigation. As a result of this investigation Frank Armani was no-billed by the Grand Jury but Indictment No. 75-55 was returned as against Francis R. Belge, Esq., accusing him of having violated subdivision 1 of section 4200 of the Public Health Law, which, in essence, requires that a decent burial be accorded the dead, and section 4143 of the Public Health Law, which, in essence, requires anyone knowing of the death of a person without medical attendance, to report the same to the proper authorities. Defense counsel moves for a dismissal of the indictment on the grounds that a confidential, privileged communication existed between him and Mr. Garrow, which should excuse the attorney from making full disclosure to the authorities.

The National Association of Criminal Defense Lawyers, as amicus curiae, succintly state the issue in the following language: If this indictment stands, "The attorney-client privilege will be effectively destroyed. No defendant will be able to freely discuss the facts of his case with his attorney. No attorney will be able to listen to those facts without being faced with the Hobson's choice of violating the law or violating his professional code of Ethics."

Initially in England the practice of law was not recognized as a profession, and certainly some people are skeptics today. However, the practice of learned and capable men appearing before the court on behalf of a friend or an acquaintance became more and more demanding. Consequently, the King granted a privilege to certain of these men to engage in such practice. 
There had to be rules governing their duties. These came to be known as "Canons." The King has, in this country, been substituted by a democracy, but the "Canons" are with us today, having been honed and refined over the years to meet the changes of time. Most are constantly being studied and revamped by the American Bar Association and by the bar associations of the various States. While they are, for the most part, general by definition, they can be brought to bear in a particular situation. Among those is the following, cited in United States v. Funk: "Confidential communications between an attorney and his client are privileged from disclosure as a rule of necessity in the administration of justice."

In the most recent issue of the New York State Bar Journal there is an article by Jack B. Weinstein, entitled "Educating Ethical Lawyers." In a subcaption to this article is the following language which is pertinent: "The most difficult ethical dilemmas result from the frequent conflicts between the obligation to one's client and those to the legal system and to society. It is in this area that legal education has its greatest responsibility, and can have its greatest effects." In the course of his article Mr. Weinstein states that there are three major types of pressure facing a practicing lawyer. He uses the following language to describe these: "First, there are those that originate in the attorney's search for his own wellbeing. Second, pressures arise from the attorney's obligation to his client. Third, the lawyer has certain obligations to the courts, the legal system, and society in general."

Our system of criminal justice is an adversary system and the interests of the State are not absolute, or even paramount. "The dignity of the individual is respected to the point that even when the citizen is known by the state to have committed a heinous offense, the individual is nevertheless accorded such rights as counsel, trial by jury, due process, and the privilege against self incrimination."

A trial is in part a search for truth, but it is only partly a search for truth. The mantle of innocence is flung over the defendant to such an extent that he is safeguarded by rules of evidence which frequently keep out absolute truth, much to the chagrin of juries. Nevertheless, this has been a part of our system since our laws were taken from the laws of England and over these many years has been found to best protect a balance between the rights of the individual and the rights of society.

The concept of the right to counsel has again been with us for a long time, but since the decision of Gideon v. Wainwright, it has been extended more and more so that at the present time a defendant is entitled to have counsel at a parole hearing or a probation violation hearing.

The effectiveness of counsel is only as great as the confidentiality of its client-attorney relationship. If the lawyer cannot get all the facts about the case, he can only give his client half of a defense. This, of necessity, involves the client telling his attorney everything remotely connected with the crime.

Apparently, in the instant case, after analyzing all the evidence, and after hearing of the bizarre episodes in the life of their client, they decided that the only possibility of salvation was in a 
defense of insanity. For the client to disclose not only everything about this particular crime but also everything about other crimes which might have a bearing upon his defense, requires the strictest confidence in, and on the part of, the attorney.

When the facts of the other homicides became public, as a result of the defendant's testimony to substantiate his claim of insanity, "Members of the public were shocked at the apparent callousness of these lawyers, whose conduct was seen as typifying the unhealthy lack of concern of most lawyers with the public interest and with simple decency." A hue and cry went up from the press and other news media suggesting that the attorneys should be found guilty of such crimes as obstruction of justice or becoming an accomplice after the fact. From a layman's standpoint, this certainly was a logical conclusion. However, the Constitution of the United States of America attempts to preserve the dignity of the individual and to do that guarantees him the services of an attorney who will bring to the Bar and to the Bench every conceivable protection from the inroads of the State against such rights as are vested in the Constitution for one accused of crime. Among those substantial constitutional rights is that a defendant does not have to incriminate himself. His attorneys were bound to uphold that concept and maintain what has been called a sacred trust of confidentiality.

The following language from the brief of the amicus curiae further points up the statements just made: "The client's Fifth Amendment rights cannot be violated by his attorney. There is no viable distinction between the personal papers and criminal evidence in the hands or mind of the client. Because the discovery of the body of Alicia Hauck would have presented 'a significant link in a chain of evidence tending to establish his guilt,' Garrow was constitutionally exempt from any statutory requirement to disclose the location of the body. And Attorney Belge, as Garrow's attorney, was not only equally exempt, but under a positive stricture precluding such disclosure. Garrow, although constitutionally privileged against a requirement of compulsory disclosure, was free to make such a revelation if he chose to do so. Attorney Belge was affirmatively required to withhold disclosure. The criminal defendant's self-incrimination rights become completely nugatory if compulsory disclosure can be exacted through his attorney."

In the recent and landmark case of United States $v$. Nixon the court stated: "the constitutional need for production of relevant evidence in a criminal proceeding is specific and neutral to the fair adjudication of a particular criminal case in the administration of justice. Without access to specific facts a criminal prosecution may be totally frustrated." In the case at bar we must weigh the importance of the general privilege of confidentiality in the performance of the defendant's duties as an attorney, against the inroads of such a privilege on the fair administration of criminal justice as well as the heart tearing that went on in the victim's family by reason of their uncertainty as to the whereabouts of Alicia Hauck. In this type situation the court must balance the rights of the individual against the rights of society as a whole. There is no question but Attorney Belge's failure to bring to the attention of the authorities the whereabouts of Alicia Hauck when he first verified it, prevented bringing Garrow to the immediate bar of justice for this particular murder. This was in a sense, obstruction of justice. This duty, I am sure, loomed large in the mind of Attorney Belge. However, against this was the Fifth Amendment right of his client, 
Garrow, not to incriminate himself. If the Grand Jury had returned an indictment charging Mr. Belge with obstruction of justice under a proper statute, the work of this court would have been much more difficult than it is.

There must always be a conflict between the obstruction of the administration of criminal justice and the preservation of the right against self incrimination which permeates the mind of the attorney as the alter ego of his client. But that is not the situation before this court. We have the Fifth Amendment right, derived from the Constitution, on the one hand, as against the trivia of a pseudo-criminal statute on the other, which has seldom been brought into play. Clearly the latter is completely out of focus when placed alongside the client-attorney privilege. An examination of the Grand Jury testimony sheds little light on their reasoning. The testimony of Mr. Armani added nothing new to the facts as already presented to the Grand Jury. He and Mr. Belge were cocounsel. Both were answerable to the Canons of professional ethics. The Grand Jury chose to indict one and not the other. It appears as if that body were grasping at straws.

It is the decision of this court that Francis R. Belge conducted himself as an officer of the court with all the zeal at his command to protect the constitutional rights of his client. Both on the grounds of a privileged communication and in the interests of justice the indictment is dismissed.

\section{Questions:}

1. You may find this video about the People v. Belge case interesting.

2. Why did the court hold that the attorney-client privilege superseded the criminal law requiring Belge to disclose the location of the victim's body? Do you agree?

3. What if Garrow had not been convicted of any other crime? Would the attorney-client privilege have prevented Belge from disclosing the location of the victim's body indefinitely?

4. What if Belge had reason to believe the victim was still alive? Would the privilege have prevented him from disclosing the victim's location?

\section{The Scope of the Attorney-Client Privilege}

Colton v. United States, 306 F. 2d 633 (2d Cir. 1962)

Summary: Attorney Edward E. Colton represented Herbert and Mercedes Matter in relation to their taxes. The IRS began an investigation of the Matters, and asked Colton to provide testimony and relevant documents. Colton refused, citing the attorney-client privilege. The district court ordered Colton to answer certain questions and produce certain documents, and the circuit court affirmed, holding that those questions and documents were not privileged.

LUMBARD, Chief Judge. 
These appeals raise questions concerning the propriety of a virtually complete refusal by tax counsel, primarily on the ground of the attorney-client privilege, to answer questions and produce files at an examination conducted by special agents of the Internal Revenue Service concerning the tax liability of a client. We hold that it was proper to require counsel to answer questions concerning the years during which they performed legal services and the general nature of the services. We also affirm the order requiring counsel to produce certain documents or files and to answer relevant questions concerning the nature of papers in their possession.

At some time prior to July 29, 1960, the Internal Revenue Service began an investigation into the tax liabilities of Herbert Matter and his wife, Mercedes, apparently with a view to possible criminal prosecution. On July 29, 1960, the Service served identical summonses upon Edward E. Colton, an attorney, and Lillian Kaltman, an attorney associated with Mr. Colton, directing them to appear in New York City before special agent Anton Kurtzuk on August 9, 1960 to give testimony and to bring with them and produce "retained copies of income tax returns, workpapers, correspondence files, memoranda and all other data relating to the preparation and the filing of Federal Income Tax Returns for or on the behalf of the Matters covering and including the years 1951 through 1958." The appellants state, and the government does not deny, that special agent Kurtzuk informed Miss Kaltman that "he wished to question the attorneys about the reasons which the taxpayers gave their counsel for filing certain tax returns late"; an affidavit submitted by agent Kurtzuk below states the primary purpose of the investigation in similar language. The Service later consented to the adjournment of the return date of the summonses to September 21, 1960.

On September 20,1960, the appellants obtained from the district court an order requiring the government to show cause why the summonses should not be quashed or modified and staying compliance. The appellants stated that "the subject matter of Mr. Kurtzuk's proposed inquiry would so flagrantly induce a violation of their duty to the taxpayers arising out of the relationship of attorney and client that this petition was deemed necessary by the petitioners." Pending the hearing of the petition, the appellants entered into a stipulation with the government that the above quoted portion of the summonses be amended to add the phrase "except for such portions of said testimony and production that are within the attorney-client privilege." Pursuant to further terms of the stipulation the appellants appeared to testify on November 23, 1960; the stipulation provided that if the appearance was not accepted by the Service as adequate compliance with the summonses, then the petition to quash should proceed for hearing in the district court.

At the November 23 hearing, Mr. Colton and Miss Kaltman testified only that the Matters were clients of their firm, refusing to give any substantial information as to the firm's role, if any, in preparing the tax returns in question. They had with them records of the firm pertaining to the Matters, but refused to turn them over to the agents for examination without the consent of the Matters. Virtually all of the questions asked by the agents were objected to on the basis of the attorney-client privilege. Dissatisfied with the results of the hearing, the government caused the appellants' pending motion to quash to come on for hearing in the district court, on February 28 , 
1961. Judge Dawson denied the motion and vacated the stay without opinion, and Mr. Colton and Miss Kaltman filed their notice of appeal to this court.

Apparently the Internal Revenue Service requested Colton to return for further questioning and he refused. The Service on March 7, 1961 served on Colton alone a new summons in substance identical to the earlier ones as modified by the stipulation. Colton again appeared on March 24, 1961, in response to this second summons, but gave the Service no more satisfaction than he had at his first appearance, again declining on the basis of the attorneyclient privilege to answer certain questions concerning tax work his firm might have done for the Matters.

Colton now offers to answer by affidavit thirteen of the questions he objected to at the March 24, 1961 hearing, and the government has accepted the offer, making the appeal moot insofar as these questions are concerned. The remaining questions, all of which were objected to as infringing upon the attorney-client privilege, may be grouped under two general headings: those inquiring into the date and nature of the services performed by the Colton firm for the Matters, and those relating to the files of the firm which the Service sought to have Mr. Colton turn over to it.

Those questions which pertain to the date and general nature of the legal services performed by the Colton firm for the Matters should be answered as they do not call for any confidential communication. The question numbered 16 in the Internal Revenue Service's transcript of the hearing, although ambiguous, ${ }^{69}$ appears to inquire whether in 1951 the firm performed any services for the Matters other than the preparation of income tax returns. (Colton now agrees to answer the preceding question, which asked whether or not the firm had prepared, or caused to be prepared, a 1951 tax return.) Question 18 asked Colton to state the nature of the services he admitted to having rendered the Matters in the years prior to 1951. In directing Colton to answer this question, Judge Metzner limited the required information to "general responses, such as 'litigation,' 'drafting of documents,' 'tax advice' and the like," thus excluding inquiry into specific details; since the government does not here contest this interpretation, the question remains so limited for our purposes. Questions 52 and 54 inquire whether the firm performed any legal services for the Matters during 1954, 1955, 1956 and 1957. Question 55 asks whether the firm received "any remunerations" for legal services during those four years. Finally, Question 80 asks, "Did you or any member of your firm cause to have prepared a 1953 income tax return for or on behalf of Herbert and Mercedes Matter in 1954?"

This court has accepted, and few if any lawyers would quarrel with, Dean Wigmore's statement of the basic principle underlying the attorney-client privilege:

In order to promote freedom of consultation of legal advisers by clients, the apprehension of compelled disclosure by the legal advisers must be removed; hence the law must prohibit such disclosure except on the client's consent.

\footnotetext{
69 16. Q. Did you or any member of your firm perform any services, other than the preparation of income tax returns for the year 1951 for Herbert and/or Mercedes Matter?
} 
It cannot be seriously argued that this policy justifies any member of the bar from refusing to testify as to all transactions he may have had with any person whom he chooses to designate a "client." Thus, according to Judge Wyzanski's much quoted formulation, it must be shown that:

(1) the asserted holder of the privilege is or sought to become a client; (2) the person to whom the communication was made (a) is a member of the bar of a court, or his subordinate and (b) in connection with this communication is acting as a lawyer; (3) the communication relates to a fact of which the attorney was informed (a) by his client (b) without the presence of strangers (c) for the purpose of securing primarily either (i) an opinion on law or (ii) legal services or (iii) assistance in some legal proceeding, and not (d) for the purpose of committing a crime or tort; and (4) the privilege has been (a) claimed and (b) not waived by the client.

There can, of course, be no question that the giving of tax advice and the preparation of tax returns - which unquestionably constituted a very substantial part of the legal services rendered the Matters by the Colton firm - are basically matters sufficiently within the professional competence of an attorney to make them prima facie subject to the attorney-client privilege. But, although the word "communications" must be broadly interpreted in this context, the authorities are clear that the privilege extends essentially only to the substance of matters communicated to an attorney in professional confidence. Thus the identity of a client, or the fact that a given individual has become a client are matters which an attorney normally may not refuse to disclose, even though the fact of having retained counsel may be used as evidence against the client. To be sure, there may be circumstances under which the identification of a client may amount to the prejudicial disclosure of a confidential communication, as where the substance of a disclosure has already been revealed but not its source.

We find, however, no such special circumstances in the case at bar. Nor was the permissible inquiry in this regard ended when Colton stated that the Matters were his clients and had been for some time. The principle that permits inquiry into the existence of a professional relationship obviously also permits questioning as to the years during which the relationship has continued. Thus, under the accepted doctrine, there was no basis for Colton's refusal to answer Questions 52 and 54.

For similar reasons there was no basis for Colton's refusal to state, in answer to Question 55, whether he had received any remuneration from the Matters for legal services rendered during the years 1954 through 1957. Although no question as to the relevancy of the matters inquired into is before us, we note that the government states that this question is relevant to a determination whether the attorney-client relationship actually existed, as well as to the propriety of deductions for legal fees taken by the taxpayers in their returns for those years. Such matters are surely relevant, and - in the absence of allegations as to special circumstances - we see no reason why an attorney should be any less subject to questioning about fees received from a taxpayer than should any other person who has dealt with the taxpayer. There is no further encroachment here upon any confidential relationship than there is in questioning about the 
existence or date of the relationship. All these matters are quite separate and apart from the substance of anything that the client may have revealed to the attorney.

Moreover, a determination whether Colton rendered legal services to the Matters in a given year is proper as a basis for obtaining further unprivileged information from him. Not all communications between an attorney and his client are privileged. Particularly in the case of an attorney preparing a tax return (as the questioning agent attempted to establish Colton did for the Matters), a good deal of information transmitted to an attorney by a client is not intended to be confidential, but rather is given for transmittal by the attorney to others - for example, for inclusion in the tax return. Such information is, of course, not privileged.

It was also proper for agent Kurtzuk, in Questions 16 and 18, to inquire into the nature of the "legal services" rendered by Colton. Attorneys frequently give to their clients business or other advice which, at least insofar as it can be separated from their essentially professional legal services, gives rise to no privilege whatever. Indeed, Colton admitted at the Service hearing that he sometimes gave "a little investment advice" to his clients. Because Colton's work for the Matters - both legal and non-legal - may thus have involved unprivileged communications with them, it is proper for the Service in its search for unprivileged matters not only to inquire into the years during which he rendered "legal services" but also to explore, as it does in Questions 16 and 18, to some extent the nature of the services rendered. These questions are appropriate to a determination of what, if any, areas may be inquired into further and what is protected by the attorney-client privilege. Judge Metzner excluded detailed inquiry into the work done. Although it would be inappropriate for us to speculate regarding those questions which might properly be asked in this area, we note that some restriction may be necessary to protect the privilege and that none of the possible responses called for by Question 18 as now limited would reveal anything which could be regarded as a communication within the meaning of the privilege doctrine. Nor do we find anything in Question 80 which calls for the revelation of any communication by the Matters.

2. The remaining questions, which pertain to documents and files, can be subdivided into two categories. The colloquy relating to Questions $22,73,74$ and 75 reflects Colton's total refusal, on grounds of the attorney-client privilege, to produce "retained copies of income tax returns, workpapers, correspondence, memoranda and all other data pertaining to the preparation and filing of the returns in question" and the fact that before and after the first hearing before the Service the firm had returned some of these papers to the Matters. The remaining questions inquire into the general nature of the papers presently or formerly in the firm's possession.

Judge Metzner ordered Colton to answer this last group of questions concerning the nature of the papers, and held that the privilege did not justify a blanket refusal to produce those documents and files still in the firm's possession. He did not require Colton to make any efforts to recapture any papers no longer in the firm's possession, and the government makes no contention here that he should have. The judge apparently also held, and in any event the government now concedes, that the privilege is still available to Colton to the extent of permitting him to withhold any particular confidential papers which were "specifically prepared 
by the client for the purpose of consultation with his attorney" and any of the firm's memoranda and worksheets "to the extent of any unpublished expression made by an attorney therein of confidences which had passed between him and his clients."

It is self-evident that individual documents and files may still be withheld insofar as they thus are or report confidential communications between Colton and his clients, the Matters. Documentary evidence of confidential communications is necessarily privileged as much as testimonial evidence. Moreover, if a proper showing is made, Colton will be able to raise the Matters' privilege against self-incrimination as a basis for refusing to produce any independently preexisting records or other documents turned over to the firm by the Matters if the Matters could have refused to produce them under that privilege.

Clearly Colton's blanket refusal on the grounds of the attorney-client privilege to produce anything was unjustified. As we have noted, the attorney-client privilege protects only those papers prepared by the client for the purpose of confidential communication to the attorney or by the attorney to record confidential communications, and Colton has not made the necessary showing that the papers he refused to produce are of such nature.

Insofar as the papers include pre-existing documents and financial records not prepared by the Matters for the purpose of communicating with their lawyers in confidence, their contents have acquired no special protection from the simple fact of being turned over to an attorney. It is only if the client could have refused to produce such papers that the attorney may do so when they have passed into his possession. Any other rule would permit a person to prevent disclosure of any of his papers by the simple expedient of keeping them in the possession of his attorney.

Appellant admits in his brief that statements, correspondence, and documents received from third parties are not protected by the attorney-client privilege, and the principle is obvious. He argues, however, that in any event such papers are wholly unavailable to the government under the "work product" rule which the Supreme Court in Hickman v. Taylor held justified an attorney's refusal to permit discovery in a civil case of statements obtained by him from prospective witnesses. We need not reach the government's contention that the work-product rule is inapplicable to such administrative investigations as that conducted by the Internal Revenue Service here, because Colton has made no suggestion that any of the papers involved were collected or prepared in anticipation of litigation, as must be shown to justify invocation of this rule.

Because Colton was unjustified in his blanket refusal to produce all of his firm's papers concerning the Matters, it was, of course, appropriate for agent Kurtzuk to question him at the hearing concerning the nature of the papers in order to determine which of them were and which were not privileged. All of the remaining questions are relevant to the government's proper attempt to uncover papers not protected under the attorney-client privilege. Questions 23, 25 and 76 have the identical purpose of trying to find out whether the firm's files contain documents received from or correspondence with third parties. We have already noted that papers received from third parties are unprivileged and no theory has been presented on which 
communications from an attorney to a third party are privileged. Question 65 inquires whether the firm's "papers contained retained copies of Herbert and Mercedes Matter's income tax returns" for the relevant years. Such copies would be unprivileged as not confidential because by definition they contain no information that was not intended to be given to the Internal Revenue Service. None of these questions call for any information which could possibly reveal protected communications. Thus these questions must be answered and the materials they refer to must be produced.

\section{Questions:}

1. Why did the court find information relating to the date and general nature of the legal services provided by Colton to the Matters was not privileged? Do you agree?

2. Why did the court found that the identity of a client is not privileged? Do you agree?

3. Why did the court find that pre-existing documents provided to Colton were not privileged? Could the government draw incriminating inferences from the fact the Matters provided those documents to Colton? Should that matter for the purpose of the attorney-client privilege?

\section{Confidentiality \& Privilege}

X Corp. v. Doe, 805 F. Supp. 1298 (E.D. Va. 1992)

ELLIS, District Judge.

Few problems are as vexing as determining what evidence justifies a lawyer's disclosure of a client's confidential information and documents, which the lawyer believes reflect an ongoing or future crime or fraud. This case presents precisely this problem. Plaintiff, X Corp. brings this suit, in part, to prevent defendant, John Doe, X Corp.'s former in-house counsel, from disclosing $X$ Corp.'s confidential information and documents retained by Doe following his discharge from $X$ Corp. X Corp. also seeks return of the documents. In support of the relief sought, X Corp. cites the attorney-client privilege, the parties' confidentiality agreement, and the lawyer's general duty to preserve a client's confidences. For his part, Doe claims that the documents in issue disclose ongoing civil and criminal frauds perpetrated by $\mathrm{X}$ Corp. against the federal government. As such, according to Doe, the documents fall within the public policy crime-fraud exception to the attorney-client privilege and to any general or contractual duty of confidentiality.

The matter is before the Court on X Corp.'s motion for a preliminary injunction. For the reasons stated here, the motion is granted in part and denied in part.

\section{Facts}

X Corp. hired Doe in March 1989 as a member of its in-house legal staff based in Northern California. Formerly an Associate Deputy Attorney General of the United States and Chief of Staff to the Attorney General, Doe was a member of the bar of the state of Pennsylvania. When 
he was hired, Doe executed an "Employment, Invention and Confidential Information Agreement," in which he expressly agreed (i) to return to X Corp. all records obtained during, or in connection with, his employment and (ii) to preserve X Corp.'s confidential information. Thereafter, in the course of his employment, Doe regularly received confidential information from X Corp. management and its employees in order to provide legal opinions and advice. During approximately two years with X Corp., Doe apparently excelled; his professional performance was regarded as excellent. Eventually he was promoted to Group Counsel with primary responsibility worldwide for X Corp.'s compliance with numerous government regulations and antitrust laws.

In November 1990, Doe was transferred from X Corp.'s California office to Virginia as X Corp.'s only United States-based lawyer outside California. The parties sharply dispute the reason for the transfer. In X Corp.'s view, the transfer occurred because Doe failed the California bar examination. Doe, on the other hand, asserts that he initiated the transfer to escape California's high cost of living and because he and his wife wanted to live closer to their relatives in Virginia. Doe also contends that X Corp. negotiated with him to retain his services because he was "an important contributor and asset" and because X Corp. wanted to locate a regulatory and antitrust attorney near Washington, D.C.

X Corp. terminated Doe's employment effective February 28, 1992, providing him with thirty-one weeks severance pay. The reason for Doe's discharge is as hotly disputed as the reason for the transfer. X Corp. claims Doe was laid-off as part of a company-wide reduction in force involving over 700 employees. Doe counters, however, that he was unlawfully fired in retaliation for actions X Corp. believed he was taking in furtherance of a possible qui tam suit. On leaving X Corp.'s employ, Doe took with him copies of certain documents and files, leaving the originals with $X$ Corp. Doe claims these documents reveal that $X$ Corp. is defrauding the federal government, in violation of the False Claims Act.

X Corp.'s complaint asserts breach of the Confidentiality Agreement. X Corp. claims that filing this action was necessary to prevent disclosure of $X$ Corp.'s confidential information in the event Doe filed his draft complaint on the public record. That circumstance never materialized.

Following oral argument, the Court took the matter under advisement. Doe, by counsel, agreed to refrain from further disclosures of X Corp.'s claimed confidential information until the Court's ruling.

Analysis

Without doubt, this litigation presents "grave or serious questions," questions involving difficult and troubling ethical issues arising in the context of attorney-client confidentiality. Few questions are graver or more serious in the practice of law than determining what evidence of crime or fraud justifies a lawyer's disclosure of his client's confidential information. Moreover, allegations of attorney misconduct, or even potential misconduct, engender significant and serious questions of professional conduct critical to the client, to the accused attorney, and to the bar as 
a whole. Such allegations, regardless of their veracity, erode the already fragile public confidence in the legal profession and in the administration of justice. And it is undeniable that our legal system cannot function effectively unless the public has confidence in the integrity and competence of the system and its participants. Thus, it is paramount that lawyers understand and abide by settled and accepted norms of professional conduct. But even settled and accepted norms frequently provide inadequate or ambiguous guidance in the face of specific factual circumstances. So it is here.

This litigation focuses on two professional standards of attorney confidentiality - (i) the evidentiary attorney-client privilege and (ii) the broader ethical duty of confidentiality — and their application to the specific facts presented. Understanding the distinction between these two standards is essential to the matter at bar. For that reason, it is worth describing them here in some detail.

The first of these standards, the evidentiary attorney-client privilege, is quite familiar, and the principles associated with it are well-settled. This evidentiary privilege applies to disclosures of certain types of confidences communicated between client and attorney during the course of the attorney's representation of the client. To prevent such disclosures, the client, through counsel or otherwise, may invoke the privilege. The purpose of the attorney-client privilege is to encourage full and frank communication between attorneys and their clients and thereby promote broader public interests in the observance of law and administration of justice. The privilege recognizes that sound legal advice or advocacy serves public ends and that such advice or advocacy depends upon the lawyer's being fully informed by the client.

Nevertheless, because it "impedes the full and free discovery of the truth," and is "in derogation of the public's 'right to every man's evidence," the attorney-client privilege is not "favored" by federal courts. Accordingly, the privilege is narrowly construed to apply only to those situations in which the party invoking the privilege consulted an attorney for the purpose of securing a legal opinion or services and in connection with that consultation communicated information intended to be kept confidential.

The evidentiary attorney-client privilege, while more familiar, is not the lawyer's only duty of confidentiality to a client. Too often unrecognized is the broader ethical duty of an attorney to preserve a client's confidences and secrets that may fall outside the attorney-client privilege. The leading case discussing this ethical duty is the Fifth Circuit's decision in Brennan's Inc. $v$. Brennan's Restaurants, Inc. There, defendants took the position that the attorney-client privilege barred an attorney from further representation of a former joint client. The Fifth Circuit disagreed, noting that "the fundamental flaw in defendants' position is a confusion of the attorney-client evidentiary privilege with the ethical duty to preserve a client's confidences." The panel held that although a former joint client could not assert the attorney-client privilege as to matters encompassed by the former joint representation because confidences cannot arise between joint clients, a broader ethical duty protects joint clients. In this regard, the court stated: 
Information acquired from a client is sheltered from use by the attorney against his client by virtue of the existence of the attorney-client relationship. This is true without regard to whether someone else may be privy to it. The obligation of an attorney not to misuse information acquired in the course of representation serves to vindicate the trust and reliance that client's place in their attorneys. A client would feel wronged if an opponent prevailed against him with the aid of an attorney who formerly represented the client in the same matter this would undermine public confidence in the legal system as a means for adjudicating disputes.

As the Fifth Circuit sensibly recognized in Brennan's, attorney confidentiality is essential to sustaining public confidence in the legal profession and the legal system. Clients therefore have a right to enforce that confidentiality, absent specific circumstances abrogating that right. Of course, an attorney's duty to his client is limited by his duty to comply with the law and the standards of professional conduct.

Consistent with most jurisdictions, Virginia recognizes a broad duty of confidentiality in Canon 4 of the Virginia Code of Professional Responsibility, which states: "A Lawyer Should Preserve the Confidences and Secrets of a Client." The corresponding Disciplinary Rules provide in relevant part:

DR4-101. Preservation of Confidences and Secrets of a Client. - (A) "Confidence" refers to information protected by the attorney-client privilege under applicable law, and "secret" refers to other information gained in the professional relationship that the client has requested be held inviolate or the disclosure of which would be embarrassing or would be likely to be detrimental to the client.

(B) Except as provided by DR 4-101(C) and (D), a lawyer shall not knowingly:

(1) Reveal a confidence or secret of his client.

(2) Use a confidence or secret of his client to the disadvantage of the client.

(3) Use a confidence or secret of his client for the advantage of himself or a third person, unless the client consents after full disclosure.

Thus, mandatory Disciplinary Rule 4-101 defines two categories of protected information: (i) a narrow category of "confidences," comprising information protected by the attorney-client privilege, and (ii) a broader category of "secrets," encompassing "other information gained in the professional relationship that the client has requested be held inviolate or the disclosure of which would be embarrassing or would be likely to be detrimental to the client." In distinguishing between these two categories, Virginia has manifest its intention to protect from disclosure a range of communications broader than that protected by the attorney-client privilege. Confidentiality of both categories of information must be maintained. Yet the duty of confidentiality imposed by the Virginia Code of Professional Responsibility is not absolute. A lawyer may reveal confidences and secrets in specific circumstances. 
Yet despite its similar purpose, DR 4-101(C)(3) "clearly establishes" standard imposes a heavier burden on the party seeking disclosure than the prima facie standard of the crime-fraud exception to the attorney-client privilege. In other words, matters subject to the attorney-client privilege seem to be less stringently protected from disclosure than matters subject to the ethical privilege. This, at first blush, seems puzzling, indeed paradoxical, for one would think that the attorney-client privilege deserves the greater protection. On reflection, however, the two different standards make sense given that they apply in different contexts. Succinctly put, the evidentiary attorney-client privilege arises only where disclosures are sought to be compelled in some litigation context, whereas the broader ethical duty arises in the context of voluntary or uncompelled disclosures, typically outside a litigation context. More particularly, the attorneyclient privilege is an evidentiary privilege applicable where someone seeks to compel an attorney or his client to reveal communications between lawyer and client made for the purpose of securing a legal opinion or legal services and intended to be kept confidential. Thus, the privilege arises in the context of litigation and is therefore subject to discipline of the adversary process and the safeguard of judicial scrutiny, if the affected client invokes the privilege and the opposing party seeks to overcome it. Significantly, however, the evidentiary attorney-client privilege does not control where disclosures occur, or potential disclosures are contemplated, in circumstances involving uncompelled disclosure and no judicial scrutiny. In such circumstances, the ethical duty - with its appropriately higher standard of protection against unwarranted disclosure of suspected fraudulent activities - governs.

Given this, in proving its claim that Doe is obligated to maintain its confidences pursuant to the ethical duty, X Corp. bears the initial burden of establishing that the duty exists and that the disputed communications are subject to it. To do so, $X$ Corp. must show, inter alia, that the communications sought to be protected are "confidences" or "secrets" within the meaning of Virginia Code of Professional Responsibility DR4-101(A). If X Corp. carries this burden and establishes that Doe is ethically bound not to disclose this material, the burden then shifts to Doe.

\section{Conclusion}

In sum, the Court concludes that plaintiff's motion for preliminary injunction should be granted in part and denied in part. Specifically, an appropriately tailored preliminary injunction will issue with respect to disclosure of $\mathrm{X}$ Corp.'s claimed confidential information and documents.

\section{Questions:}

1. How is the duty of confidentiality different from the attorney-client privilege?

2. Why did the court hold that the information at issue is covered by the duty of confidentiality, rather than the attorney-client privilege? 


\section{4: Applying the Attorney-Client Privilege}

Pay no mind to what they say, it doesn't matter anyway, our lips are sealed. ${ }^{70}$

The fiduciary duty of confidentiality protects confidential communications between attorneys and their clients, as described in the Model Rules of Professional Conduct. The attorney-client privilege also protects certain confidential communications between attorneys and their clients, but it is not described by the Model Rules of Professional Conduct. In contrast to the duty of confidentiality, which imposes a fiduciary duty on attorneys, the attorney-client privilege is a common law doctrine that creates an evidentiary privilege for certain confidential attorney-client communications, specifically communications for the purpose of obtaining or providing legal advice.

The attorney-client privilege was created by the courts, and its scope is defined by the courts. Accordingly, the attorney-client privilege differs from jurisdiction to jurisdiction. However, the Restatement of the Law Governing Lawyer describes the paradigmatic form of the attorneyclient privilege.

\section{Federal Rule of Evidence 501: Privilege in General}

The common law - as interpreted by United States courts in the light of reason and experience governs a claim of privilege unless any of the following provides otherwise:

- the United States Constitution;

- a federal statute; or

- rules prescribed by the Supreme Court.

But in a civil case, state law governs privilege regarding a claim or defense for which state law supplies the rule of decision.

\section{Restatement (Third) of the Law Governing Lawyers § 68 (2000): Attorney-Client Privilege}

Except as otherwise provided in this Restatement, the attorney-client privilege may be invoked with respect to:

1. a communication

2. made between privileged persons

3. in confidence

4. for the purpose of obtaining or providing legal assistance for the client.

Restatement (Third) of the Law Governing Lawyers § 69 (2000): “Communication"

${ }^{70}$ The Go-Gos, Our Lips Are Sealed, Beauty and the Beat (1981). 
A communication within the meaning of $\S 68$ is any expression through which a privileged person, as defined in $\S 70$, undertakes to convey information to another privileged person and any document or other record revealing such an expression.

\section{Restatement (Third) of the Law Governing Lawyers § 70 (2000): "Privileged Persons"}

Privileged persons within the meaning of $\S 68$ are the client (including a prospective client), the client's lawyer, agents of either who facilitate communications between them, and agents of the lawyer who facilitate the representation.

\section{Restatement (Third) of the Law Governing Lawyers § 71 (2000): "In Confidence"}

A communication is in confidence within the meaning of $\S 68$ if, at the time and in the circumstances of the communication, the communicating person reasonably believes that no one will learn the contents of the communication except a privileged person as defined in $\S 70$ or another person with whom communications are protected under a similar privilege.

\section{Restatement (Third) of the Law Governing Lawyers $\S 72$ (2000): Legal Assistance as the Object of a Privileged Communication}

A communication is made for the purpose of obtaining or providing legal assistance within the meaning of $\S 68$ if it is made to or to assist a person:

1. who is a lawyer or who the client or prospective client reasonably believes to be a lawyer; and

2. whom the client or prospective client consults for the purpose of obtaining legal assistance.

\section{Who is a "Privileged Person"?}

\section{State v. Spell, 399 So. 2d 551 (La. 1981)}

Summary: Jenkins, an inmate of the prison, worked at the law library. Defendant argues that Jenkins was acting as an attorney when the inculpatory statements were made. Jenkins wasn't an attorney and didn't hold himself out as a lawyer. Defendant knew Jenkins was not an attorney and voluntarily gave information to Jenkins. The communication is not subject to the attorney-client privilege.

JASPER E. JONES, Justice Ad Hoc.

Thomas Rhuel Spell was charged by grand jury indictment with the crime of second degree murder of Ricky Mire. On December 20, 1979 defendant was convicted before a jury of twelve by a vote of eleven to one. The defendant was sentenced to life imprisonment without eligibility for parole, probation, or suspension of sentence for forty years. 
Defendant appealed his conviction. While the case was pending on appeal, defendant filed a motion for new trial based upon a contention that he had discovered new evidence which, if it had been introduced at trial, would probably have changed the verdict of guilty. The defendant's new trial motion contended that the new evidence could not have been discovered by him before or during the trial. This court remanded the case to the trial court for a hearing on defendant's motion for a new trial.

Following a hearing on the new trial motion the trial court denied the new trial. The case is now before this court on the merits of the appeal which were not considered before the remand.

The evidence at trial reflected the following facts:

On November 12, 1975, at about 4:00 p. m., Anthony Broussard was driving his car in the south part of Crowley, La. in the Parish of Acadia when he was stopped by defendant. Defendant asked Broussard to take him for a ride, and Broussard agreed to the request. Shortly after Broussard and defendant commenced their ride they observed Ricky Mire walking down the street. Defendant had Broussard stop and defendant went and talked to Mire. Mire returned to Broussard's car with defendant and got into the car with Broussard and defendant.

At defendant's direction Broussard drove to an isolated area in Crowley near a dried-up drainage canal and stopped. Mire and defendant got out of the car, and while Mire was standing near the front of the vehicle, defendant secured the car keys from Broussard, opened the trunk of the car and removed from it a tire tool. Mire and defendant then walked out of sight in the direction of the drainage ditch. Defendant carried the tire tool with him as he left the vehicle. Soon after defendant and Mire disappeared from view Broussard got out of the car and went in search of them and found them a short distance away, apparently over the drainage ditch levee. Broussard observed defendant push Mire who was in front of him. Broussard then returned to his car. After the elapse of about ten minutes defendant returned to Broussard's vehicle without Mire and advised Broussard not to ask any questions and to return him to his car which he had left at the point where he had entered Broussard's vehicle.

Broussard did not see the tire tool in defendant's hands when he returned to the car, but he heard defendant drop it upon the floor. When the pair arrived back at defendant's car, defendant got out of Broussard's car and the tire tool was not left in Broussard's vehicle. Broussard did not see defendant take the tire tool out of his car.

At about 5:00 p. m. that afternoon, three horseback riders found Mire in the drainage ditch apparently unconscious with his head and face covered with blood. There was a lot of blood on the ground near Mire. They notified the sheriff's office who obtained an ambulance and carried Mire to a Crowley hospital where his head was bandaged in the emergency room. The parish coroner arrived at 6:30 p. m. and observed that Mire was in a critical condition and ordered his immediate transfer to a Lafayette hospital where Mire died at 9:35 p. m. that night. 
Mire's body was returned to Crowley and examined by the parish coroner who testified he died from several head injuries that appeared to have been caused by a blunt instrument with a sharp end.

\section{ASSIGNMENT OF ERROR}

Defendant contends that the trial judge erred in admitting over his objection the testimony of Ronald Jenkins that defendant had told him he had killed the victim. Defendant contends that these inculpatory statements were made to Jenkins in confidence and were therefore inadmissible. Jenkins, an inmate of the prison, was assigned to the law library to help other prisoners with their legal problems by writing letters, preparing pleadings, and otherwise giving them whatever advice he could. Defendant contends that the information was a privileged communication because Jenkins was acting as an attorney in the law library at the Dixon Correctional Institute when the inculpatory statements were made to him by defendant. Defendant cites no authority for his contention.

Jenkins was not an attorney and did not hold himself out as a lawyer. Defendant knew that Jenkins was a fellow inmate in the prison and was not an attorney. He voluntarily gave the information to Jenkins. The communication is not subject to the attorney-client privilege. In the case of State $v$. Lassai, the court rejected the contention that a communication given by the defendant to a counselor at a drug abuse center was privileged where communications to certified social workers are classified as privileged communication. The court there said:

Nor does the record disclose a privilege which would prevent the evidentiary use of an admission by defendant to the director of counseling at the Euterpe Center; it was not shown that she was a social worker, and for that reason R.S. 37:2714 is not applicable. Privileges are narrowly construed, and will not be extended to the counselor solely because she was "in the same position" as a physician or social worker.

Defendant's inculpatory statements to Jenkins were not subject to any privilege.

\section{Questions:}

1. What if Jenkins had been an imprisoned attorney?

2. Can Jenkins effectively provide legal advice to the prisoners if their communications with him are not privileged?

Jones v. US, 828 A. 2d 169 (DC App. 2003)

Summary: The police contacted Stacy Jones about the murder of Darcie Silver, and asked for a DNA sample. Jones called his girlfriend, Tina Ducharme, an attorney employed by the federal government, and asked her for advice. Later, Jones was arrested and charged with murder. Ducharme testified at the trial. Jones argued that 
their telephone conversation was protected by the attorney-client privilege. The trial court disagreed, and the appellate court affirmed.

TERRY, Associate Judge:

After a jury trial, appellant was convicted of first-degree burglary, first-degree sexual abuse, firstdegree felony murder, and second-degree murder. On appeal he contends that the trial court erred when it ruled that the attorney-client privilege did not require the exclusion of testimony about a conversation that appellant had with his girlfriend (at the time), who was an attorney employed by the federal government. We affirm on the merits, and remand for the sole purpose of vacating a redundant conviction.

On Saturday, March 23, 1996, at about 10:00 a.m., Metropolitan Police officers found Darcie Silver dead in her apartment after they received a call from her concerned co-workers reporting that she had failed to show up for work. The medical examiner determined that the cause of death was asphyxia by strangulation; other injuries indicated that she might also have been smothered. In addition, there were burns around her genital area; pieces of burned newspaper were found in the vicinity of her crotch. A vaginal swab revealed the presence of male deoxyribonucleic acid (DNA). In addition, investigators found semen stains on Ms. Silver's nightgown and on a denim jacket recovered from her apartment. The DNA evidence was later matched to appellant through testing by the FBI.

A police investigation revealed that on Friday evening, March 22, Ms. Silver had dinner with a co-worker from her job at Bread \& Circus, a supermarket in the Georgetown area of the city. She returned to her apartment at approximately 10:00 p.m. and spoke to her father on the telephone from 10:47 p.m. on Friday until 12:03 a.m. on Saturday.

Two neighbors in Ms. Silver's apartment building heard a knocking at the front door of the building at about 2:30 a.m. on Saturday. One of the neighbors looked out a window and saw a "stocky" man with a fair to medium complexion at the door. This description was similar to that of appellant, who is a weightlifter and bodybuilder. Both neighbors heard the man respond to the building intercom using the name "Darcie." They then heard him say that he had locked himself out of his apartment and needed to borrow a telephone. The intercom made a buzzing noise, which unlocked the front door, and the man walked upstairs to the area of Ms. Silver's apartment. About fifteen minutes later, one neighbor heard a "crash" coming from Silver's apartment, and the other heard a loud "thump."

Appellant's primary argument on appeal is that the court erred when it ruled that the attorneyclient privilege did not attach to a conversation that he had with his girlfriend at the time, Tina Ducharme, who was also a lawyer. 
After Darcie Silver was murdered, the police interviewed several employees, including appellant, at the Bread \& Circus store where Ms. Silver worked. The police requested hair and blood samples from appellant, but he declined to give them. He told the police that his girlfriend was a lawyer and that he "wanted to talk to her first and he even invited them to come to his house to talk to them if they wanted to, but only in her company." Later appellant called his girl friend, Tina Ducharme, a lawyer who worked for the federal government. At the time, she was away on business in San Diego. Appellant left a message at her hotel there, and she returned his call some time thereafter.

During their telephone conversation, appellant told Ms. Ducharme about the police interview at Bread \& Circus. Defense counsel moved to exclude any testimony from Ms. Ducharme about that conversation. At a pre-trial hearing on the motion, Ms. Ducharme testified that appellant "told me that the police had been by his work and had questioned him and several other people who used to work with Darcie and had asked for blood samples from several individuals." Ms. Ducharme's response to appellant's concern was that "obviously he didn't have to provide the police with a sample if they didn't have a warrant." She also asked him, however, "why he wouldn't, since it would clear the air. Obviously he didn't have anything to do with it or didn't have anything to be concerned about. I didn't understand why he wouldn't just go ahead and do it." Appellant also told her that "he had been in Darcie's apartment before, and he questioned whether or not some fingerprints of his would be remaining in the apartment," particularly on some drinking glasses. Ms. Ducharme replied with the "common sense advice" that "probably Darcie had washed her glasses in the intervening amount of time." Finally, appellant asked "what if he had gone to the bathroom and left some sperm in there?" Ms. Ducharme laughed and commented that "unless he was masturbating in her bathroom, I really didn't think that would be a concern." Ms. Ducharme testified that appellant never said anything about her representing him in a criminal matter, nor did she intend to advise appellant as a lawyer, adding, "I wasn't qualified to advise anyone on criminal matters." Appellant, in fact, had never asked her to perform any legal work on his behalf. Besides, she said, she was barred by a regulation from representing any private individual "either criminally or civilly" because she was a government lawyer. Further, she believed the conversation was a typical call between boyfriend and girlfriend: "when either of us had a problem, we would call the other person to ask their advice or tell them about it."

Appellant's account of the conversation was different. He stated that he telephoned Ms. Ducharme because he "wanted to know what kind of position I would be putting myself in by giving hair and blood samples." Appellant said that he called her "because she's an attorney" and that he "was seeking legal advice." He testified, "I never thought she could be subpoenaed or anything because she was an attorney." On the basis of his prior experience with other attorneys, appellant believed their conversation would remain confidential.

At the close of the hearing, the court ruled that the conversation was not protected by the attorney-client privilege. Accepting Ms. Ducharme's version of the conversation as credible, the court found appellant's testimony incredible because he "kept switching around on the witness 
stand as if he was waiting on which way to go." In addition, the court ruled that the only thing Ms. Ducharme "said as a lawyer" was that appellant did not have to give the police hair and blood samples, which he had already elected not to do. Otherwise, said the court, the types of questions appellant asked Ms. Ducharme were "what if" questions that were more scientific than legal:

They were questions about-they're scientific questions. And she wasn't a criminal lawyer to begin with. What if I used a glass, would the fingerprints still be there? Not a legal question. What if I went to the bathroom, would I have semen there? That's not a legal question. None of these were legal questions. The only legal question in this thing he already knew the answer to.

As a result, the court refused to allow appellant to invoke the attorney-client privilege, and Ms. Ducharme's testimony about the telephone conversation was later introduced into evidence at trial.

In the case at bar, the court heard testimony about the nature and substance of the conversation between appellant and his one-time girl friend, Ms. Ducharme. It made a credibility determination about the contents of the conversation and a factual finding that Ms. Ducharme was not acting as an attorney, but as a friend. On this record we see no reason to depart from our usual standard of review for factual findings by a trial court; i.e., we must uphold that court's determination of the facts unless it is "plainly wrong or without evidence to support it." In particular, a trial court's "findings of fact relevant to the essential elements of a claim of attorneyclient privilege will not be overturned unless clearly erroneous." This standard of review places a heavy burden on appellant. Because appellant has not shown that the trial court's factual findings were clearly erroneous or, in the words of our statute, "plainly wrong," we uphold the court's rejection of his claim of privilege.

The attorney-client privilege is the oldest of the established privileges for confidential communications. Its main purpose is to encourage full and frank communication between attorneys and their clients. Nevertheless, courts construe the attorney-client privilege narrowly to protect only those purposes which it serves. Thus the privilege applies only in the following circumstances:

(1) where legal advice of any kind is sought (2) from a professional legal advisor in his capacity as such, (3) the communications relating to that purpose, (4) made in confidence (5) by the client, (6) are at his instance permanently protected (7) from disclosure by himself or by the legal adviser, (8) except the protection be waived.

The burden of proving that the attorney-client privilege shields a particular communication from disclosure rests with the party asserting the privilege. This means that the party asserting the privilege must clearly show that the communication was made "in a professional legal capacity." "In general, American decisions agree that the privilege applies if one of the significant purposes of a client in communicating with a lawyer is that of obtaining legal assistance." 
Whether a purpose is significantly that of obtaining legal assistance or is for a nonlegal purpose depends upon the circumstances, including the extent to which the person performs legal and nonlegal work, the nature of the communication in question, and whether or not the person had previously provided legal assistance relating to the same matter.

In the case of someone seeking advice from a friend who is also a lawyer, the lawyer-friend must be giving advice as a lawyer and not as a friend in order for the privilege to attach. The nature of the relationship is a factual question for the trial court to decide.

Finally, the relationship between attorney and client hinges on the client's intention to seek legal advice and his belief that he is consulting an attorney. In this case the government argues that the conversation in question was not privileged because Ms. Ducharme was not a criminal lawyer; because, as a government employee, she was barred by a regulation from representing appellant_or any other individual_-in a private capacity; and because she believed that she was speaking to appellant as his girlfriend and not as a lawyer. ${ }^{71}$ These arguments fall short, however, because the intent of the person seeking advice is assessed from that person's viewpoint, not that of the attorney. The issue ultimately is what appellant believed when he was seeking advice and whether his belief about the confidentiality of the conversation was reasonable. Thus Ms. Ducharme's understanding of the conversation and of why appellant had called her is relevant only to whether appellant reasonably believed he was consulting her as an attorney, with the protections that such a relationship provides.

Guided by these principles, we agree with the trial court that appellant failed to make the clear showing necessary to establish that his conversation with Ms. Ducharme was within the protection of the attorney-client privilege. We note that the trial court found appellant's testimony incredible, in part, because he appeared to have tailored his testimony to fit the legal standard for the privilege, which counsel and the court had discussed in front of him during the hearing. The court said to defense counsel:

It's the court's observation that appellant is very bright. And I was especially fond of his answer to counsel's last question about whether he heard me. Then counsel and I had this legal discussion, at which time your client then answered the question, he didn't understand the concept. It's as if we helped him answer the question, the two of us.

In addition, the court ruled that the questions appellant asked Ms. Ducharme were not "legal" questions. The court noted that appellant knew his rights when he refused to provide blood and hair samples to the police. According to Ms. Ducharme, whose testimony the court expressly credited, appellant did not inquire about his right not to give samples without a warrant, but

\footnotetext{
${ }^{71}$ During the evidentiary hearing, defense counsel attempted to impeach Ms. Ducharme with her grand jury testimony. Before the grand jury, Ms. Ducharme initially testified that she gave appellant advice "as a lawyer," but then stated a few moments later that appellant had called her "as his girlfriend." The trial court presumably considered this discrepancy but nevertheless found Ms. Ducharme credible.
} 
instead asked "scientific" questions about whether or not his fingerprints might remain on a glass or whether his semen and hair might be discovered in the bathroom.

While such concerns about "bad facts" might fall within the privilege if they were expressed in a communication within a clearly established attorney-client relationship, we conclude, like the trial court, that appellant failed to establish that, as a matter of fact, such a relationship existed between him and Ms. Ducharme. We see no reason to upset the court's conclusion, which rested largely on its determination that Ms. Ducharme was credible and that appellant was not. We find no error in that determination. ${ }^{72}$

\section{Questions:}

1. Why did the court hold that the communications at issue were not protected by the attorney-client privilege?

2. If Jones had been speaking to hired or appointed counsel, would the communications at issue have been protected by the attorney-client privilege?

\section{What is a "Communication"?}

In re Grand Jury Proceedings, 791 F. 2d 663 (8th Cir. 1986)

BRIGHT, Senior Circuit Judge.

Janet Cheetham appeals from the district court's denial of her motion to quash a subpoena requiring her testimony before a grand jury investigating one of her clients. We affirm.

\section{BACKGROUND.}

A grand jury is investigating John Doe on suspicion of bank and credit card fraud. As part of its investigation, the grand jury seeks photographs and handwriting exemplars of Doe for comparison with signatures used on the fraudulent documents.

The Immigration and Naturalization Service has produced documents purporting to bear the signatures and photograph of Doe. These documents also bear the signature of Cheetham attesting that she prepared the documents. Cheetham represented Doe in INS matters unrelated to the grand jury proceedings, and does not represent Doe in the grand jury investigation.

The grand jury subpoenaed Cheetham to testify regarding the authenticity of Doe's signatures and photograph on the INS documents. Cheetham brought a motion to quash before the

\footnotetext{
72 The government argues that even if there was error in the admission of the conversation, the error was harmless because the case against appellant was strong, noting in particular the DNA evidence and the testimony of the two neighbors. Given our conclusion that the conversation between appellant and Ms. Ducharme was not protected by the attorney-client privilege, we need not reach this issue.
} 
magistrate, which was denied. She appealed to the district court, which also denied her motion and ordered her to testify. ${ }^{73}$ Cheetham brings this appeal, contending that the district court erred in concluding that her testimony would not be protected by the attorney-client privilege, and in not requiring the Government to prove the need for her testimony through affidavit.

\section{DISCUSSION.}

The common law rule of attorney-client privilege ${ }^{74}$ extends only to confidential communications from a client to his or her attorney. Confidential communications encompass that information communicated on the understanding that it would not be revealed to others, and to matters constituting protected attorney work product. The identity of one's client usually falls outside the scope of the attorney-client privilege. Moreover, matters existing in the public eye, such as a person's appearance and handwriting, are generally not confidential communications because they were not exposed on the assumption that others would not learn of them. Indeed, in this case, Doe voluntarily revealed his signatures and photograph to the INS.

Cheetham contends that the attorney-client privilege should apply here because the information sought might tend to incriminate her client. She argues that any information gained by an attorney in her relationship with a client is privileged if exposure of the information might become a link in a chain of evidence connecting her client with a crime. Cheetham asserts that she gained the information sought by the grand jury during her legal relationship with Doe, and that her testimony could provide the necessary link between Doe and the fraudulent scheme.

We disagree. It is true that certain information ordinarily outside the privilege may become privileged if, by revealing the information, the attorney would necessarily disclose confidential communications. Nonprivileged information is not suddenly transformed into confidential communications, however, whenever it becomes relevant to a criminal investigation or prosecution of a client. We conclude that the information sought by the grand jury does not constitute confidential communications protected by the attorney-client privilege.

\section{When is a Communication "In Confidence"?}

${ }^{73}$ Cheetham was ordered to answer these specific questions:

1. Do you know John Doe?

2. When did you first meet him?

3. How many times have you met with him in person?

4. Would you recognize him if you saw him again?

5. Did you (or someone from your office) prepare Exhibits 1-5 [the INS documents] at his request?

6. Is the photograph on Exhibits 1 and 2 a true likeness of John Doe?

7. Did you witness John Doe sign his name on Exhibits 1-5?

8. If not, do you know who, if anyone, witnessed the signature?

${ }^{74}$ Cheetham seeks to invoke the Texas statutory attorney-client privilege as controlling in this action. The "Texas Rule" provides that "an attorney shall not disclose any other facts which came into knowledge of such attorney by reason of such relationship." However, questions of privilege are governed by the common law as interpreted by federal courts in the absence of a relevant Supreme Court rule, federal statute, or constitutional provision. We therefore apply the common law rule in this action, and not the Texas Rule. 
Hofmann v. Conder, 712 P. 2d 216 (Utah 1985)

\section{PER CURIAM.}

This matter comes before the Court in an extraordinary proceeding to prohibit the district court from compelling petitioner's hospital nurse to testify about statements she overheard petitioner make to his attorney. The trial court made no findings of fact, although it prepared a memorandum decision. It appears from that decision that the controlling issue on which the trial court decided the matter was a legal one, namely, the standard determining when the presence of a third party during communications between a lawyer and client results in a waiver of the attorney-client privilege. We hold that the trial court erred in deciding that the attorney-client privilege applies only if the presence of a third person, who overhears a confidential communication, is "necessary for urgent or life-saving procedures." The proper standard is whether the third person's presence is reasonably necessary under the circumstances.

The record establishes that the presence of petitioner's hospital nurse was reasonably necessary under the circumstances. The threshold question of whether the communication was intended to be confidential was not ruled on by the trial court, or at least the judge's decision gives us no indication of his having made any factual findings on that question. Although there are ambiguities in the record, the totality of the circumstances surrounding petitioner's communications to his attorney require the inference that the communication was intended to be confidential and within the protection of the statutory privilege. Immediately before the communication, petitioner had requested the presence of his attorney, he had stated that he would not make a statement to the police that night, and he had acquiesced in the request of his attorney that the police and hospital security personnel not only leave the room but also go far enough away to be out of earshot. Given his helpless physical condition and the intensive nature of the hospital care he had been receiving throughout the evening and during this incident, we cannot infer that petitioner intended his communications to his attorney to be public. Since the presence of the hospital nurse was reasonably necessary under all the circumstances, the privilege was not waived because of that presence.

The order of the trial court is vacated, and this matter is remanded for the entry of a protective order preventing the disclosure by the witness of confidential communications overheard by her.

ZIMMERMAN, Justice (dissenting).

I agree that Judge Conder applied the wrong standard in concluding that the presence of the nurse made the attorney-client privilege unavailable. A third person's presence should not avoid an otherwise available privilege if the third person's presence is reasonably necessary under the 
circumstances. The evidence indicates that the nurse's presence was reasonably necessary for Hofmann's well-being. ${ }^{75}$

I disagree with the result reached by the Court, however, and would uphold the ruling below, because I conclude that petitioner has not met the threshold requirement for claiming an attorney-client privilege - petitioner has failed to establish that the communication between the client and the attorney was intended by the client to be confidential. "The mere fact that the relationship of attorney and client exists between two individuals does not ipso facto make all communications between them confidential. The circumstances must indicate whether by implication the communication was of a sort intended to be confidential." I think the Court slights this inquiry. By failing to carefully consider the question of the client's intent, courts may shield from scrutiny communications that the privilege was not created to protect.

There is evidence in the record sufficient to establish that the attorney thought the communication was at least private and perhaps confidential. However, I find the record very sparse on the question of the client's intention. Although the client was available to give an affidavit in support of his claim of privilege, the record is strangely devoid of direct evidence as to the client's state of mind at the time of the communication. As for the facts and circumstances in the record that constitute indirect evidence of his intent, I find them ambiguous at best. All persons must give evidence, unless they establish a recognized justification for refusing to do so. Petitioner has the burden of establishing that the communication was privileged. On the present state of the record, I conclude that petitioner has not carried this burden. Therefore, I would uphold the trial court's refusal to find the communication privileged.

\section{Communication for the Purpose of Legal Advice}

In the Matter of a Grand Jury Investigation, 453 Mass. 453 (Mass. 2009)

SPINA, J.

This case requires us to decide whether the attorney-client privilege applies where a client leaves messages on his counsel's telephone answering machine threatening to harm others and the attorney discloses those communications in order to protect those threatened.

The salient facts are not in dispute. Attorney John Doe was representing Michael Moe, a father, in a care and protection proceeding in the Juvenile Court. On November 8, 2007, two days after an adverse ruling by a Juvenile Court judge, Moe left six messages on Attorney Doe's answering machine between 1:08 A.M. and 1:24 A.M. Moe indicated that he knew where the judge lived and that she had two children. In the fourth message, a voice that Attorney Doe

\footnotetext{
${ }^{75} \mathrm{I}$ also conclude that the privilege is not lost if a third person whose presence is not otherwise justified overhears a confidential attorney-client communication without the client's knowledge, so long as reasonable precautions were taken to protect against overhearing. However, because the nurse's presence was justified, the reasonableness of the precautions taken to exclude third parties has no bearing on the question before us.
} 
recognized as Moe's wife stated that she and Moe were going to "raise some hell." In the fifth message, Moe stated that "some people need to be exterminated with prejudice." Attorney Doe subsequently erased the messages from the answering machine.

During the following week, Attorney Doe observed that Moe had become "more and more angry," and on November 13, 2007, he filed a motion to withdraw as Moe's counsel, which was subsequently allowed. Concerned for the safety of the judge and her family, he disclosed the substance of the messages to the judge.

On November 21, 2007, Attorney Doe was interviewed by a State trooper regarding the substance of the messages, but declined to sign a written statement.

A District Court complaint alleging threats to commit a crime and intimidation of a witness subsequently issued against Moe. The Commonwealth then initiated grand jury proceedings and filed a motion to summons Attorney Doe before the grand jury. That motion was allowed. On December 21, 2007, Attorney Doe, citing the attorney-client privilege, moved to quash the summons. A judge in the Superior Court denied Attorney Doe's motion, reasoning that Attorney Doe and Moe had not carried their burden of demonstrating that the attorney-client privilege applied "because they failed to show that the messages were left in an attempt to obtain legal services." Attorney Doe filed a motion to reconsider, requesting, inter alia, an evidentiary hearing. The motion was denied. The Commonwealth and Attorney Doe submitted a joint request to report the decision to the Appeals Court. The Superior Court judge reported the case, and we transferred the case here on our own motion.

Neither party disputes that Attorney Doe could, consistent with rule 1.6, disclose the substance of Moe's messages. Rule 1.6 provides, in pertinent part:

(a) A lawyer shall not reveal confidential information relating to representation of a client unless the client consents after consultation, except for disclosures that are impliedly authorized in order to carry out the representation, and except as stated in paragraph (b).

(b) A lawyer may reveal, and to the extent required by Rule 3.3, Rule 4.1 (b), or Rule 8.3 must reveal, such information: (1) to prevent the commission of a criminal or fraudulent act that the lawyer reasonably believes is likely to result in death or substantial bodily harm."

While nothing in rule 1.6 (b) required Attorney Doe to disclose Moe's communications to the judge or police, he had discretion to do so. However, the ethical permissibility of Attorney Doe's disclosure does not resolve the distinct issue presented here: whether Attorney Doe can be compelled to testify before the grand jury.

Evidentiary privileges "are exceptions to the general duty imposed on all people to testify." We accept such privileges "only to the very limited extent that permitting a refusal to testify or excluding relevant evidence has a public good transcending the normally predominant principle 
of utilizing all rational means for ascertaining truth." The attorney-client privilege "is founded upon the necessity, in the interest and administration of justice, of the aid of persons having knowledge of the law and skilled in its practice, which assistance can only be safely and readily availed of when free from the consequences or the apprehension of disclosure." A party asserting the privilege must show that (1) the communications were received from the client in furtherance of the rendition of legal services; (2) the communications were made in confidence; and (3) the privilege has not been waived.

The Commonwealth contends that the attorney-client privilege does not apply because Moe's communications were not made "for the purpose of facilitating the rendition of legal services." In making this argument, the Commonwealth implicitly asks us to reconsider a portion of our discussion in the Purcell case.

In Purcell, the client was discharged as a maintenance man at the apartment building in which his apartment was located and had received an order to vacate his apartment. During consultation with an attorney, the client stated an intent to burn the apartment building. The attorney disclosed these communications to police and criminal charges were brought against the client. When the prosecutor subpoenaed the attorney to testify at trial, the attorney filed a motion to quash, which was denied. The central issue in that case was whether the crime-fraud exception to the attorney-client privilege applied. We concluded that the communications would not fall within the crime-fraud exception unless the district attorney could establish facts by a preponderance of the evidence showing that the client's communication sought assistance in or furtherance of future criminal conduct.

Recognizing that whether the attorney-client privilege applied at all was open on remand, we also considered whether a communication of an intention to commit a crime, if not within the crime-fraud exception, could be considered a communication for the purposes of facilitating the rendition of legal services. We held that a "statement of an intention to commit a crime made in the course of seeking legal advice is protected by the privilege, unless the crime-fraud exception applies." We reasoned that a gap between the crime-fraud exception and the applicability of the privilege "would make no sense," because the attorney-client privilege was premised on the benefits of unimpeded communication between attorney and client, and noted that "an informed lawyer may be able to dissuade the client from improper future conduct and, if not, under the ethical rules may elect in the public interest to make a limited disclosure of the client's threatened conduct."

The limited disclosure adverted to in the Purcell case occurred here. Concerned for the safety of the judge, her family, and a social worker, Attorney Doe disclosed Moe's communications to the judge and law enforcement authorities to protect them from harm.

We discern no reason to depart from the Purcell decision, and hold that Moe's communications were made in furtherance of the rendition of legal services and thus protected by the attorneyclient privilege. The Commonwealth's argument to the contrary essentially raises an issue of germaneness. Scholars, commentators, and courts have formulated a number of tests for 
determining the germaneness of a client's communication. However, none of these formulations appears to give clients breathing room to express frustration and dissatisfaction with the legal system and its participants. The expression of such sentiments is a not uncommon incident of the attorney-client relationship, particularly in an adversarial context, and may serve as a springboard for further discussion regarding a client's legal options. If a lawyer suspects that the client intends to act on an expressed intent to commit a crime, the lawyer may attempt to dissuade the client from such action, and failing that, may make a limited disclosure to protect the likely targets. Requiring the privilege to yield for purposes of a criminal prosecution not only would hamper attorney-client discourse, but also would discourage lawyers from exercising their discretion to make such disclosures, as occurred here, and thereby frustrate the beneficial public purpose underpinning the discretionary disclosure provision of rule 1.6. Furthermore, any test to ascertain the germaneness of an ostensibly threatening communication on a case-bycase basis would make the privilege's applicability uncertain, rendering the privilege "little better than no privilege." Warning clients that communications deemed irrelevant to the matter for which they have retained counsel will not be protected not only may discourage clients from disclosing germane information, but also may disincline clients to share their intentions to engage in criminal behavior. In the latter circumstance, a lawyer's ability to aid in the administration of justice by dissuading a client from engaging in such behavior is impaired. The lawyer also may never receive the very information necessary for him or her to determine whether to make a limited disclosure to prevent the harm contemplated by the client.

In sum, we reaffirm that a client's communications to his lawyer threatening harm are privileged unless the crime-fraud exception applies. Because the Commonwealth does not assert that Moe's communications come within the crime-fraud exception, they were privileged. The order denying Attorney Doe's motion to quash is hereby vacated and the case is remanded to the Superior Court for further proceedings consistent with this opinion.

Keating v. McCahill, Civil Action No. 11-518 (E.D. Pa. 2012)

Summary: Equisoft hired Keating as a management consultant. Soon afterward, Keating quit Equisoft and joined Capgemini. Equisoft hired Synnott, a Canadian lawyer, to provide legal advice. After consultation with Synnott, Equisoft sent a letter to Capgemini making certain demands. After receiving the letter, Capgemini fired Keating, who filed a tort action against Equisoft, asserting several claims. During discovery, Equisoft produced certain documents, as well as a privilege log listing relevant documents not produced. Keating filed a motion to compel those documents. The court found that some of the documents were protected by the attorney-client privilege or the work product doctrine, and others were not.

GENE E.K. PRATTER, District Judge.

Plaintiff Daniel Keating has objected to Defendants Equisoft, Inc., Thomas McCahill, and Luis Romero's assertion of attorney-client privilege and work product protection over certain documents in the Defendants' privilege log. The parties have submitted twenty-five documents 
— twenty-four produced with redactions and one withheld in full — to the Court for an in camera review to determine whether the communications at issue are shielded from disclosure by the attorney-client privilege and/or the work product doctrine.

For the reasons that follow, the Court finds that the twenty-four redacted documents may remain redacted as presented to the Court, but Equisoft shall produce the one unproduced document in redacted form as more fully set forth below.

\section{FACTUAL BACKGROUND}

Mr. Keating, a management consultant in the software industry, alleges that in late November 2009, his consulting business, the Keating Consulting Group, Inc., entered into a three month consulting services contract with Equisoft, Inc. The consulting services contract was terminable at-will by either party with 30 days written notice. Mr. Keating also entered into a NonSolicitation Agreement, a Confidentiality Agreement, and an Intellectual Property Agreement with Equisoft, Inc.

Approximately halfway through the term of the consulting agreement, Mr. Keating was offered and accepted a position with Capgemini Financial Services USA, Inc. and entered an employment agreement with Capgemini on January 14, 2010. The next day, Mr. Keating traveled to Equisoft's Pennsylvania offices to give Mr. McCahill, Equisoft, Inc.'s Life Insurance Division President, the required 30 days notice pursuant to the contract. On January 21, 2010, Mr. Keating began working for Capgemini.

In the immediate wake of Mr. Keating giving his notice, Mr. McCahill and certain members of Equisoft's senior management convened to address the issues posed by Mr. Keating's resignation. These individuals included the Equisoft CEO Mr. Romero, Equisoft Vice President and COO Steeve Michaud, and then-Equisoft General Manager for Philadelphia Operations William O'Donnell. Equisoft hired Bernard Synnott, a Canadian attorney to advise senior management on issues relating to Mr. Keating's resignation. Mr. Michaud was responsible for communicating with Mr. Synnott on behalf of Equisoft, and "relayed questions, information, comments, and advice from Mr. Synnott to senior management, and conveyed questions, information and comments from the senior management to Mr. Synnott."

From January 18, 2010 to February 8, 2010, Messrs. Michaud, O’Donnell, and Romero activity assisted Mr. Synnott in formulating strategy and drafting a demand letter to effectuate that strategy. On February 8, 2010, Mr. Synnott sent the final version of this demand letter to Mr. Keating and Capgemini representatives threatening litigation if Mr. Keating continued to work for Capgemini. Three weeks after he began his new job, on February 16, 2010, Mr. Keating was terminated by Capgemini.

In September 2010, Mr. Synnott received a letter from Mr. Keating's attorney, Heather Sussman, Esq., threatening to commence litigation if Equisoft did not comply with various demands. For the remainder of September 2010, Messrs. Michaud, O'Donnell, and Romero 
assisted Mr. Synnott in evaluating Ms. Sussman's demand letter and drafting a response, which was sent on September 24, 2010.

On January 25, 2011, Mr. Keating filed this lawsuit, asserting that his termination from Capgemini was the result of Equisoft's unlawful actions. He claims tortious interference with his contractual relationship with Capgemini and his prospective economic advantage, defamation via slander and libel, intentional infliction of emotional distress, and prima facie tort.

After Mr. Keating served his initial document requests, the Defendants provided Mr. Keating with a privilege log. On October 17, 2011, one week after Equisoft provided Mr. Keating with their privilege log, Mr. Keating filed a motion to compel requesting that Equisoft produce every document on its privilege log not already produced because (1) Mr. Synnott, a foreign attorney, is not "a member of the bar of a court" as, Mr. Keating claims, is necessary for the attorneyclient privilege to apply, (2) the attorney-client privilege cannot apply where the challenged communications do not include a lawyer as a sender or a recipient, and (3) the work product doctrine cannot apply where the documents at issue were not prepared by an attorney or his representative.

Since the filing of that motion - which was mooted by Order of the Court - the parties have reduced the universe of documents in dispute from 253 to 25. Twenty-four of these disputed documents have been produced in redacted form, and one document has been withheld in its entirety. These 25 documents have been submitted to the Court for an in camera review to determine whether the attorney-client privilege and/or the work product doctrine shields them from disclosure. Along with the documents submitted for judicial review, Equisoft submitted affidavits from Mr. Synnott, Mr. Romero, Mr. O’Donnell, and Mr. Michaud in support of its assertion of privilege and work product protection.

\section{LEGAL STANDARDS}

\section{A. Attorney-Client Privilege}

Federal courts sitting in diversity, as in this case, apply the law of the host state to determine privilege. Thus, Pennsylvania law governs the privilege issues in this case. In order for the attorney-client privilege to apply in Pennsylvania, the following conditions must be met: "(1) the asserted holder of the privilege is or sought to become a client; (2) the person to whom the communication was made is a member of the bar of a court, or his subordinate; (3) the communication relates to a fact of which the attorney was informed by his client, without the presence of strangers, for the purpose of securing either an opinion of law, legal services or assistance in a legal matter, and not for the purposes of committing a crime or tort; and (4) the privilege has been claimed and is not waived by the client." Here, only the second and third elements are in dispute.

The Pennsylvania rule that the lawyer must be "a member of the bar of a court" does not limit the privilege to members of the Pennsylvania bar. Rather, "the privilege applies to 
communications to a person whom the client reasonably believes to be a lawyer. Thus, a lawyer admitted to practice in another jurisdiction or a lawyer admitted to practice in a foreign nation is a lawyer for the purposes of the privilege."

The attorney-client privilege protects the communications themselves, not the underlying facts. The privilege may cover documents that "while not involving employees assisting counsel, still reflect confidential communications between client and counsel or subordinates of counsel for the purposes of either (1) providing legal services or (2) providing information to counsel to secure legal services. The privilege applies to both corporations and natural persons. The "scope of an individual's employment is highly relevant to the question of maintenance of confidentiality," and "the privilege is waived if the communications are disclosed to employees who did not need access to them."

However, "a document need not be authored or addressed to an attorney in order to be properly withheld on attorney-client privilege grounds." Where a corporate client is involved, "privileged communications may be shared by non-attorney employees in order to relay information requested by attorneys." "Documents subject to the privilege may be transmitted between nonattorneys so that the corporation may be properly informed of legal advice and act appropriately." "Drafts of documents prepared by counsel or circulated to counsel for comments on legal issues are considered privileged if they were prepared or circulated for the purpose of giving or obtaining legal advice and contain information or comments not included in the final version."

Because the privilege obstructs the truth-finding process, it should be "applied only where necessary to achieve its purpose." And because the privilege promotes the "dissemination of sound legal advice," it applies only where the advice is legal in nature, and not where the lawyer provides non-legal business advice. Thus, "the party asserting the privilege bears the burden of proving that it applies to the communications at issue" and "Federal Rule of Evidence 501 requires the federal courts, in determining the nature and scope of an evidentiary privilege, to engage in the sort of case-by-case analysis that is central to common-law adjudication."

\section{B. Work Product Doctrine}

Federal Rule of Civil Procedure 26(b)(3) outlines work product protection in diversity cases. In order to come within the qualified immunity from discovery created by Rule 26(b)(3) three tests must be satisfied. The material must be: (1) "documents and tangible things;" (2) "prepared in anticipation of litigation or for trial;" and (3) "by or for another party or by or for that other party's representative."

"Work-product immunity protects only documents and tangible things prepared in anticipation of litigation or for trial, such as memoranda, letters, and e-mails."

Documents are prepared in anticipation of litigation when "in light of the nature of the document and the factual situation in the particular case, the document can be fairly said to have been 
prepared or obtained because of the prospect of litigation." The preparer's anticipation of litigation must be objectively reasonable. Generally, a reasonable anticipation of litigation requires existence of an identifiable specific claim or impending litigation at the time the materials were prepared.

As Rule 26(b)(3) makes clear, the materials themselves need not be prepared by a lawyer or a lawyer's representative to qualify for work product protection. Rather, "the focus of the rule seems to be on whether the work was done in anticipation of litigation by the person preparing the work." Indeed, the fact that the documents sought for discovery do not include legal advice is, "as a matter of law, irrelevant provided they were prepared in anticipation of litigation."

A party claiming work product protection bears the initial burden of showing that the materials in question were prepared in anticipation of litigation. A party seeking disclosure of documents claimed as work product must demonstrate substantial need for the materials in the preparation of his case and is unable without undue hardship to obtain the substantial equivalent of the materials by other means.

\section{DISCUSSION}

Seven documents contain all of the redacted material at issue, as the redacted material in the other eighteen documents is fully duplicated within these seven. Equisoft argues that attorneyclient privilege and the work product doctrine shield each of these documents from disclosure. Accordingly, the Court will analyze each of these documents in turn.

\section{A. Document 96}

Document 96 is a February 2010 string of e-mails between Mr. Michaud and Mr. O'Donnell regarding the February 8, 2010 demand letter. ${ }^{76}$ Equisoft produced the document to Mr. Keating but redacted two e-mails in the chain: a February 6, 2010 e-mail from Mr. Michaud to Mr. O'Donnell, and Mr. O'Donnell's February 7, 2010 response.

\footnotetext{
${ }^{76}$ Neither Mr. Michaud nor Mr. O'Donnell are attorneys, and they are the only individuals copied on either of the redacted e-mails or any e-mails in the string. Unless otherwise indicated, the same is true for the other documents in question. However, each of the individuals in the senior management of the Company, as well as Mr. Synnott, have affirmed that Mr. Michaud "was responsible for communicating with Mr. Synnott on behalf of the company," and "often relayed questions, information, comments, and advice" from Mr. Synnott to the control group. Because a document "need not be authored or addressed to an attorney in order to be properly withheld on attorney-client privilege grounds," provided it "reflects confidential communications between client and counsel for the purposes of (1) providing legal services or (2) providing information to counsel to secure legal services," the absence of an attorney copied on the e-mails in question does not necessarily defeat the assertion of the attorney client privilege. Also, as noted above, the Court is not persuaded that simply because Mr. Synnott is admitted to practice law only in foreign jurisdictions that he is not "a member of the bar of a court" for the purposes of the attorneyclient privilege and the work product doctrine. Therefore, the Court will treat Mr. Synnott as an attorney (which he, indeed, is) for the purposes of this analysis.
} 
Mr. Michaud attests that the material redacted from his February 6, 2010 e-mail is "advice that he received from Mr. Synnott regarding the demand letters" to be sent to Mr. Keating and Capgemini. After careful in camera review of the redacted e-mail, the Court concludes that Mr. Michaud's e-mail relayed Mr. Synnott's legal advice and strategy regarding the demand letters to Mr. O'Donnell, and, accordingly, is privileged and may remain withheld except as redacted. To require disclosure of this e-mail would reveal client communications and legal advice from counsel.

Mr. O'Donnell affirms that his February 7, 2010 e-mail "consists of his opinion regarding the legal advice from Mr. Synnott that Mr. Michaud relayed to him regarding the demand letters." He further asserts generally, that he "often conveyed questions, information, and comments, to Mr. Michaud with the understanding that he would relay them to Mr. Synnott."

Unlike Mr. Michaud's e-mail, the Court does not conclude that Mr. O'Donnell's e-mail is a privileged communication. As an initial matter, without the disclosure of the underlying communication from Mr. Synnott via Mr. Michaud, Mr. O'Donnell's e-mail does not contain any confidential information and does not divulge any legal advice from Mr. Synnott. Rather, it merely indicates Mr. O'Donnell's agreement with the redacted advice of counsel communicated to him via Mr. Michaud. Additionally, although Mr. O'Donnell has indicated in a general sense that he had the "understanding" that Mr. Michaud would relay all of his comments to Mr. Synnott relating to Mr. Keating in the month of September, Equisoft has not offered evidence that this particular communication was made for the purpose of securing either an opinion of law, legal services, or assistance in a legal matter.

Nevertheless, the work product doctrine shields Mr. O'Donnell's e-mail from disclosure. Although it does not qualify as "core or opinion work product that encompasses the mental impressions, conclusions, opinion, or legal theories of an attorney or other representative of a party concerning the litigation which is generally afforded near absolute protection from discovery," Mr. O'Donnell's e-mail most certainly qualifies as a document prepared by a party "because of" or in anticipation of litigation. Moreover, Mr. Keating has made no claim of substantial need or undue hardship that would justify disclosure notwithstanding the work product claim.

Accordingly, the Court finds that protection attaches to Mr. Michaud's February 6, 2010 e-mail, and that the work product doctrine shields Mr. O'Donnell's February 7, 2010 e-mail from disclosure.

\section{B. Document 202}

Document 202 is a September 2010 string of e-mails between Mr. Michaud and Mr. O'Donnell regarding revisions to a draft of Equisoft's September 2010 letter. Equisoft produced the document to Mr. Keating but redacted two e-mails in the chain: a September 15, 2010 e-mail from Mr. Michaud to Mr. O'Donnell, and Mr. O'Donnell's September 15, 2010 response. 
Mr. Michaud attests that his e-mail "discloses requests that Mr. Romero and he made to Mr. Synnott regarding Ms. Sussman's demand letter and Mr. Synnott's response thereto." Based upon the text of the e-mail, the Court discerns no particular "requests" Mr. Romero and Mr. Michaud made of Mr. Synnott. The redacted portion of Mr. Michaud's e-mail merely reflects Mr. Michaud's opinion about whether the draft letter incorporates his and Mr. Romero's communications to counsel. The e-mail does not divulge the communications themselves. Accordingly, the Court concludes that the redacted portion of Mr. Michaud's e-mail is not shielded by the attorney-client privilege.

However, the work product doctrine does shield Mr. Michaud's e-mail from disclosure because it is a document prepared by a party in anticipation of litigation, and Mr. Keating has made no claim of substantial need or undue hardship that would justify disclosure.

Regarding Mr. O'Donnell's redacted response, Mr. O'Donnell affirms that the redacted portion of his e-mail "consists of his comments regarding a draft that he reviewed of Mr. Synnott's response to Ms. Sussman's demand letter," and that his intent was for Mr. Michaud to relay some or all of his comments to Mr. Synnott."

Here, Mr. O'Donnell's statement that he intended for "some or all" of his comments to be relayed to Mr. Synnott is unhelpful in the Court's review because it offers no specifics as to which of his comments he intended for Mr. Michaud to forward to Mr. Synnott. However, the text of the redacted e-mail and the other e-mails on the chain make clear that Mr. O'Donnell intended his comments to be forwarded to Mr. Synnott. Indeed, in a 12:10 p.m. e-mail on September 15, 2010 in the chain, Mr. Michaud indicated to Mr. O'Donnell his intention "to give Mr. Synnott their feedback later today." Mr. O'Donnell's e-mail, a mere five hours later, was clearly sent with the intention that it be sent along to Mr. Synnott.

However, even if the attorney-client privilege does not apply to Mr. O'Donnell's e-mail, the work product doctrine protects the redacted portion of Mr. Michaud's e-mail from disclosure because it is a document prepared by a party in anticipation of litigation. Once again, Mr. Keating has made no claim of substantial need or undue hardship that would justify disclosure.

Accordingly, the Court finds that the privilege attaches to the redacted portions of both Mr. Michaud's and Mr. O'Donnell's e-mails.

\section{Document 207}

Document 207 is a September 2010 string of e-mails between Mr. Michaud and Mr. O'Donnell with an attached draft letter from Mr. Synnott to Mr. Keating's attorney. Equisoft produced the document to Mr. Keating but redacted a portion of Mr. Michaud's 11:39 a.m. e-mail on September 17, 2010, and the entirety of the attachment

Mr. Michaud attests that the redacted portion of his September 17, 2010 e-mail is "advice he received from Mr. Synnott regarding the timing of his response to Ms. Sussman's demand 
letter," and that, consistent with his responsibilities, he relayed this information from Mr. Synnott to the other senior management, in this case, Mr. O'Donnell. After careful in camera review of the redacted portion of the e-mail, the Court concludes that Mr. Michaud's e-mail relayed Mr. Synnott's legal advice and strategy to Mr. O'Donnell regarding the demand letters. Accordingly, the document is privileged and may remain redacted.

Turning to the attached draft letter, Mr. O'Donnell affirms that it "consists of his proposed revisions to a draft that he reviewed of Mr. Synnott's response to Ms. Sussman's demand letter," and that "his intent was for Mr. Michaud to relay some or all of his revisions to Mr. Synnott."

First, the draft letter authored by Mr. Synnott is protected by the attorney-client privilege as "drafts of documents prepared by counsel are considered privileged if they were prepared or circulated for the purpose of giving or obtaining legal advice and contain information or comments not included in the final version." Here, the draft document contains both information and comments not contained in the final version.

Second, Mr. O'Donnell's proposed revisions to the attached letter were clearly intended to be communicated to Mr. Synnott through Mr. Michaud for the purpose of securing either an opinion of law, legal services or assistance in the legal matter. Although Mr. O'Donnell's statement that he intended for "some or all" of his comments to be relayed to Mr. Synnott is unhelpful in the Court's review, that is of no moment. Accordingly, the Court concludes that Mr. O'Donnell's proposed revisions to Mr. Synnott's draft are protected by the attorney-client privilege.

Third, the attached letter as a whole is shielded from disclosure by the work product doctrine. The attachment was a draft document prepared by counsel in reasonable anticipation of litigation. That the draft was sent to Mr. O'Donnell through Mr. Michaud does not remove it from the protection of the work product doctrine. Regardless, Mr. Keating has not established a substantial need for the materials to prepare his case or undue hardship in obtaining the substantial equivalent of the materials by other means.

Accordingly, the Court finds that the privilege attaches to Mr. Michaud's e-mail, and both the attorney-client privilege and the work product doctrine shields the attachment from disclosure.

D. Document 215

Document 215 is a September 2010 string of e-mails between Mr. Michaud and Mr. O'Donnell regarding revisions to a draft of Equisoft's September 2010 letter responding to Mr. Keating's attorney. The document includes eight e-mails, four of which contain redactions.

Mr. Michaud's 11:39 a.m. e-mail on September 17, 2010 is a duplicate of the redacted e-mail in Document 207. Accordingly, the Court concludes that this e-mail is privileged and may remain redacted for the same reasons as described above. 
Mr. O'Donnell affirms that the redacted portion of his 10:04 a.m. e-mail on September 20, 2010 "consists of his comments regarding a draft that he reviewed of Mr. Synnott's response to Ms. Sussman's demand letter," and that "his intent was for Mr. Michaud to relay some or all of this information to Mr. Synnott."

After careful in camera review of the redacted portions of Mr. O'Donnell's e-mail, the Court cannot conclude that Mr. O'Donnell's 10:04 a.m. e-mail is shielded from disclosure by the attorney-client privilege. As discussed above, Mr. O'Donnell's statement that he intended for "some or all" of his comments to be relayed to Mr. Synnott is unhelpful in the Court's review. The text of the e-mail and the chain as a whole does not indicate that Mr. O'Donnell intended Mr. Michaud to communicate his comments to Mr. Synnott for the purpose of securing either an opinion of law, legal services or assistance in a legal matter. If anything, as indicated by the unredacted portion of the e-mail, Mr. O'Donnell is soliciting a response from Mr. Michaud, as he noted, "Let me know what you think." Thus, this communication is not protected by the attorneyclient privilege.

Mr. Michaud attests that the redacted portion of his 10:11 a.m. e-mail on September 20, 2010 "consists of his opinion regarding Mr. O'Donnell's comments on and proposed revisions to a draft of Mr. Synnott's response to Ms. Sussman's demand letter." The redactions also "consist of his opinion regarding litigation threatened by Ms. Sussman in her demand letter and the effect Mr. Synnott's would have on that threatened litigation."

Upon careful in camera review of Mr. Michaud" e-mail, the Court is not persuaded that the redacted portions of Mr. Michaud's e-mail are shielded from disclosure by the attorney-client privilege. The redactions merely reflect Mr. Michaud's own opinion about Mr. O'Donnell's comments, and there is no evidence that Mr. Michaud intended this opinion to be communicated to Mr. Synnott. Also, the redacted portion does not divulge any communications between counsel and client. The Court is not persuaded that when one non-lawyer (Mr. Michaud) gives his opinion to a second non-lawyer (Mr. O'Donnell) about the second non-lawyer's comments about a lawyer's draft document, that the communication is protected under the attorney-client privilege. Accordingly, the Court concludes that the redacted portion of Mr. Michaud's e-mail is not protected by the attorney-client privilege.

Finally, Mr. O'Donnell attests that the redacted portion of his 10:15 a.m. e-mail on September 20, 2010 "consists of his opinion regarding the litigation threatened by Ms. Sussman in her demand letter and the effect Mr. Synnott's response would have on that threatened litigation," and that "his intent was for Mr. Michaud to relay some or all of this information to Mr. Synnott."

Once again, Mr. O'Donnell's statement that he intended for "some or all" of his comments to be relayed to Mr. Synnott is unhelpful in the Court's review. Likewise, it does not appear from the text of his e-mail or the other e-mails on the chain that Mr. O'Donnell intended for the redacted portion of the communication to be communicated to Mr. Synnott for the purpose of securing either an opinion of law, legal services or assistance in a legal matter. Accordingly, the Court 
concludes that the redacted portion of Mr. Michaud's e-mail is not protected by the attorneyclient privilege.

Even though the attorney-client privilege does not apply to the redacted portions of these communications, the work product doctrine shields the redacted portions of this e-mail chain from disclosure. The redacted statements were committed to documents and were prepared by a party in anticipation of litigation. Mr. Keating has made no claim of substantial need or undue hardship that would justify disclosure.

\section{E. Document 226}

Document 226 is a September 2010 string of e-mails between Mr. Michaud and Mr. O'Donnell regarding revisions to a draft of Equisoft's September 2010 letter responding to Mr. Keating's attorney. The document includes eight e-mails, six of which contain redactions.

Mr. Michaud attests that his two redacted e-mails to Mr. O'Donnell on the e-mail string "consist of his opinion about Mr. O'Donnell's comments on a draft of Mr. Synnott's response to Mr. Sussman's demand letter." Mr. O'Donnell affirms that his three redacted e-mails to Mr. Michaud and one redacted e-mail to himself on the e-mail string "consist of his comments regarding a draft that I reviewed of Mr. Synnott's response to Mr. Sussman's demand letter," and that his "intent was for Mr. Michaud to relay some or all of his comments to Mr. Synnott."

The redacted information in Mr. O'Donnell's September 21, 2010 e-mails at 10:16 a.m., (2) 10:21 a.m., and (3) 10:21:49 a.m. contain substantive revisions to Mr. Synnott's draft letter and were clearly intended to be communicated to Mr. Synnott through Mr. Michaud for the purpose of securing either an opinion of law, legal services, or assistance in the legal matter. Indeed, in Mr. Michaud's 8:49 p.m. e-mail of the previous day, he included a revised version of the letter he sent to Mr. Synnott, and told Mr. O'Donnell that the lawyer "will call me to discuss the changes." Also, after providing all of his substantive changes, Mr. O'Donnell asked Mr. Michaud to "call him after he talks with the lawyer." Accordingly, in light of the factual background and the content of the letters, it seems that Mr. O'Donnell intended the redacted portion of these e-mails to be communicated to Mr. Synnott for the purpose of obtaining legal advice. Thus, the Court concludes that these three e-mails are protected by the attorney-client privilege.

The Court does not find, however, that the remaining redacted material in the e-mail string is protected by the attorney-client privilege. Regarding the redacted material in Mr. Michaud's September 21, 2010 e-mails at 10:49 a.m. and 1:31 p.m., as with Mr. Michaud's 10:11 a.m. email on September 20, 2010 from Document 215, the Court is not persuaded that Mr. Michaud providing his opinion to Mr. O'Donnell about Mr. O'Donnell's comments about a lawyer's draft document is protected under the attorney-client privilege. This is especially true, where, as here, the Court cannot discern what "opinion" about Mr. O'Donnell's comments, if any, Mr. Michaud is communicating. Mr. Michaud's two e-mails in this string do not divulge anything about Mr. Synnott's underlying communications in the draft letter, or anything about Mr. O'Donnell's 
comments about the letter. Accordingly, the Court concludes that the redacted portions of Mr. Michaud's e-mails are not shielded by the attorney-client privilege.

However, the work product doctrine does shield the redacted portions of Mr. Michaud's e-mails from disclosure. The redacted statements clearly qualify as a document prepared by a party in anticipation of litigation. Mr. Keating has made no claim of substantial need or undue hardship that would justify disclosure.

Finally, the redacted information in Mr. O'Donnell's 10:53 a.m. e-mail on September 21, 2010 is not protected from disclosure by the attorney-client privilege because there is no indication that he intended his redacted statements to be communicated to Mr. Synnott and the statement does not request an opinion of law, legal services, or assistance in a legal matter. However, this document is entitled in work product protection for the same reasons as Mr. Michaud's e-mails.

Accordingly, the Court finds that the attorney-client privilege and/or the work product doctrine shields the redacted portions of these documents from disclosure.

\section{F. Document 240}

Document 240 is a September 2010 string of e-mails between or among Mr. Michaud, Mr. O'Donnell, and Mr. Synnott regarding revisions to Equisoft's September 2010 draft letter to Mr. Keating's attorney. Equisoft produced the document to Mr. Keating but redacted Mr. Synnott's 10:30 a.m. e-mail on September 22, 2010 to Mr. Michaud, and Mr. Michaud's 12:15 p.m. e-mail to Mr. O'Donnell.

Mr. Michaud has affirmed that Mr. Synnott's letter to him "consists of Mr. Synnott's comments regarding a draft of his response to Ms. Sussman's demand letter," and his e-mail to Mr. O'Donnell "consists of his comments regarding that draft of Mr. Synnott's letter and the timing of the sending of the final version."

Mr. Synnott's e-mail to Mr. Michaud is protected by the attorney-client privilege because it is a communication from an attorney to a client "relating to a fact of which the attorney was informed by his client for the purpose of securing either an opinion of law, legal services or assistance in a legal matter."

The redacted portion of Mr. Michaud's e-mail to Mr. O'Donnell is not protected by the attorney client privilege, however, because, as noted above, the personal opinion or comments from a non-lawyer to another non-lawyer about communications from a lawyer are not protected under the attorney client privilege. Rather, only the communications to or from the attorney are protected. Accordingly, Mr. Michaud's e-mail is not shielded from disclosure by the attorneyclient privilege.

However, the work product doctrine does shield the redacted portions of Mr. Michaud's e-mail from disclosure. The redacted statements are contained in a document prepared by a party in 
anticipation of litigation. Mr. Keating has made no claim of substantial need or undue hardship that would justify disclosure.

Accordingly, the Court finds that the privilege attaches to Mr. Synnott's e-mail, and the work product doctrine shields Mr. Michaud's e-mail from disclosure.

\section{G. Document 253}

Document 253 is a November 17, 2010 Executive Summary presented to the Equisoft Board of Directors, the last paragraph of which reports on Ms. Sussman's September 2, 2010 demand letter and provides Mr. Synnott's assessment regarding the probability of litigation. Equisoft has withheld the entire document - the final paragraph on work product and attorney-client privilege grounds and the rest because it is irrelevant to the subject lawsuit.

As an initial matter, the Court agrees that all but the last paragraph of this document is completely irrelevant to the subject lawsuit. Accordingly, it need not be disclosed.

With respect to the one relevant paragraph of the document, Mr. Michaud asserts that "along with Mr. Romero and Equisoft Finance Director Aurora Ciugulan," he prepared the document for Equisoft's seven board of directors, Equisoft's Chief Information Officer Nicolas Ledoux, Equisoft Lead Architect Stephane Boutros, and Equisoft VP for Financial Products Jonathan Georges. Mr. Michaud asserts that "the final paragraph recounts Mr. Synnott's assessment of the probability of Mr. Keating commencing litigation against Equisoft."

The evidence submitted to the Court is insufficient to establish that the attorney-client privilege protects this document from disclosure. First, Mr. Michaud and Mr. Romero have attested that beyond the named individuals, they are "not aware of any further distribution of the document." Indeed, Equisoft has not and cannot argue that Document 253 was seen only by the individuals discussed above. Regardless, even if the document was limited to these individuals, many of them were outside the group of senior management who Equisoft has indicated was responsible for making strategic decisions related to the legal issues involving Mr. Keating.

Moreover, contrary to Mr. Michaud's assertions, only the final sentence of the Executive Summary - rather than the final paragraph — recounts Mr. Synnott's assessment of the probability of Mr. Keating commencing litigation against Equisoft. The remainder of the paragraph merely recounts underlying facts that are not shielded by the attorney-client privilege. Nothing in the Executive Summary or in any of the supporting affidavits suggests that Mr. Synnott drafted these underlying facts. In fact, Mr. Michaud attested that he, not Mr. Synnott, prepared the final paragraph of the document. Only the last sentence offers any assessment by Mr. Synnott of the probability of litigation. Accordingly, the Court cannot conclude that Document 253 is fully shielded from disclosure by the attorney-client privilege.

Nor can the Court conclude that the work product doctrine shields this document from disclosure. Mr. Michaud asserts that "he prepared the final paragraph because of potential 
litigation with Mr. Keating," but a document "falls within the scope of the work-product doctrine only if it was prepared primarily in anticipation of future litigation." "Documents created in the ordinary course of business, even if useful in subsequent litigation, are not protected by the work-product doctrine." Here, the Court cannot conclude that the executive summary was prepared primarily in anticipation of litigation. To the contrary, the purpose of the document was to update the board of directors on various issues facing the company, including the demand letter sent by Mr. Keating.

Accordingly, the Court finds that the last paragraph of Document 253 must be disclosed, but the remainder of the document may remain redacted on the basis of attorney-client privilege.

\section{CONCLUSION}

In light of the foregoing, the twenty-four documents that Equisoft has redacted on the basis of attorney client privilege and/or the work product doctrine may remain redacted as presented to the Court in Equisoft's March 23, 2012 submission, but Equisoft shall produce Document 253 in redacted form as discussed above. 


\section{5: Corporate Privilege}

When an attorney represents an organization, the default position of the law is that the client is the organization, and not its agents. However, an attorney representing an organization can form an attorney-client relationship with one or more agents of the organization, in addition to or instead of the organization itself, by explicit agreement. For example, an attorney could represent a particular agent of the organization, or a component of the organization, like its board of directors.

When an attorney-client relationship exists between an attorney and an organization, the attorney-client privilege may protect communications between the attorney and the organization. As a practical matter, the privilege may protect communications between the attorney and certain agents of the organization. Courts must determine whether the privilege applies to communications with particular agents and about particular subjects.

When an attorney represents an organization, the attorney-client privilege belongs to the organization, not its agents. Accordingly, only the organization can waive the privilege. While an agent of the organization must effectuate the waiver, agents may waive the privilege only for the benefit of the organization, not for their own personal benefit or the benefit of any third-party. In addition, the organization may waive the privilege without the consent of the agent or agents who participated in the communication.

Of course, the agents of an organization may form an attorney-client relationship with their own attorney, in which case their communications with their attorney may also be protected by the attorney-client privilege. But the agents of an organization may not personally claim the privilege in relation to communications they made as agents of the organization.

While the attorney-client privilege may protect communications between an attorney representing an organization and the agents of that organization, it does not necessarily protect all such communications, only those for the purpose of providing legal advice. And it does not necessarily protect communications with all agents. A small minority of states apply the "control group" test, which provides that the privilege only protects communications with the management of the organization. But most states and the federal courts apply the "Upjohn" test adopted by the Supreme Court, under which the privilege can protect communications with any agent, so long as the communication was for the purpose of providing legal advice, including the collection of information for the purpose of providing legal advice.

\section{The “Upjohn” Test for Corporate Privilege}

Upjohn Co. v. United States, 449 U.S. 383 (1981)

Summary: The Supreme Court held that the attorney-client privilege applies to an organization's attorney's communications with its agents: 1) when a communication is made to the organization's counsel that is acting in their capacity as counsel (and not as 
business consultants, for example); 2) at the direction of management for the purpose of securing legal advice from counsel; 3) concerning a subject within the scope of employment; and 4) when the agent knows that the purpose of the communication is for the organization to procure legal advice.

JUSTICE REHNQUIST delivered the opinion of the Court.

We granted certiorari in this case to address important questions concerning the scope of the attorney-client privilege in the corporate context and the applicability of the work-product doctrine in proceedings to enforce tax summonses. With respect to the privilege question the parties and various amici have described our task as one of choosing between two "tests" which have gained adherents in the courts of appeals. We are acutely aware, however, that we sit to decide concrete cases and not abstract propositions of law. We decline to lay down a broad rule or series of rules to govern all conceivable future questions in this area, even were we able to do so. We can and do, however, conclude that the attorney-client privilege protects the communications involved in this case from compelled disclosure and that the work-product doctrine does apply in tax summons enforcement proceedings.

Petitioner Upjohn Co. manufactures and sells pharmaceuticals here and abroad. In January 1976 independent accountants conducting an audit of one of Upjohn's foreign subsidiaries discovered that the subsidiary made payments to or for the benefit of foreign government officials in order to secure government business. The accountants so informed petitioner Mr. Gerard Thomas, Upjohn's Vice President, Secretary, and General Counsel. Thomas is a member of the Michigan and New York Bars, and has been Upjohn's General Counsel for 20 years. He consulted with outside counsel and R. T. Parfet, Jr., Upjohn's Chairman of the Board. It was decided that the company would conduct an internal investigation of what were termed "questionable payments." As part of this investigation the attorneys prepared a letter containing a questionnaire which was sent to "All Foreign General and Area Managers" over the Chairman's signature. The letter began by noting recent disclosures that several American companies made "possibly illegal" payments to foreign government officials and emphasized that the management needed full information concerning any such payments made by Upjohn. The letter indicated that the Chairman had asked Thomas, identified as "the company's General Counsel," "to conduct an investigation for the purpose of determining the nature and magnitude of any payments made by the Upjohn Company or any of its subsidiaries to any employee or official of a foreign government." The questionnaire sought detailed information concerning such payments. Managers were instructed to treat the investigation as "highly confidential" and not to discuss it with anyone other than Upjohn employees who might be helpful in providing the requested information. Responses were to be sent directly to Thomas. Thomas and outside counsel also interviewed the recipients of the questionnaire and some 33 other Upjohn officers or employees as part of the investigation. 
On March 26, 1976, the company voluntarily submitted a preliminary report to the Securities and Exchange Commission on Form 8-K disclosing certain questionable payments. A copy of the report was simultaneously submitted to the Internal Revenue Service, which immediately began an investigation to determine the tax consequences of the payments. Special agents conducting the investigation were given lists by Upjohn of all those interviewed and all who had responded to the questionnaire. On November 23, 1976, the Service issued a summons demanding production of:

All files relative to the investigation conducted under the supervision of Gerard Thomas to identify payments to employees of foreign governments and any political contributions made by the Upjohn Company or any of its affiliates since January 1,1971 and to determine whether any funds of the Upjohn Company had been improperly accounted for on the corporate books during the same period.

The records should include but not be limited to written questionnaires sent to managers of the Upjohn Company's foreign affiliates, and memorandums or notes of the interviews conducted in the United States and abroad with officers and employees of the Upjohn Company and its subsidiaries.

The company declined to produce the documents specified in the second paragraph on the grounds that they were protected from disclosure by the attorney-client privilege and constituted the work product of attorneys prepared in anticipation of litigation. On August 31, 1977, the United States filed a petition seeking enforcement of the summons in the United States District Court for the Western District of Michigan. That court adopted the recommendation of a Magistrate who concluded that the summons should be enforced. Petitioners appealed to the Court of Appeals for the Sixth Circuit which rejected the Magistrate's finding of a waiver of the attorney-client privilege, but agreed that the privilege did not apply "to the extent that the communications were made by officers and agents not responsible for directing Upjohn's actions in response to legal advice for the simple reason that the communications were not the 'client's." The court reasoned that accepting petitioners' claim for a broader application of the privilege would encourage upper-echelon management to ignore unpleasant facts and create too broad a "zone of silence." Noting that Upjohn's counsel had interviewed officials such as the Chairman and President, the Court of Appeals remanded to the District Court so that a determination of who was within the "control group" could be made. In a concluding footnote the court stated that the work-product doctrine "is not applicable to administrative summonses."

Federal Rule of Evidence 501 provides that "the privilege of a witness shall be governed by the principles of the common law as they may be interpreted by the courts of the United States in light of reason and experience." The attorney-client privilege is the oldest of the privileges for confidential communications known to the common law. Its purpose is to encourage full and frank communication between attorneys and their clients and thereby promote broader public interests in the observance of law and administration of justice. The privilege recognizes that 
sound legal advice or advocacy serves public ends and that such advice or advocacy depends upon the lawyer's being fully informed by the client. "The lawyer-client privilege rests on the need for the advocate and counselor to know all that relates to the client's reasons for seeking representation if the professional mission is to be carried out." The purpose of the privilege is "to encourage clients to make full disclosure to their attorneys." This rationale for the privilege has long been recognized by the Court. Admittedly complications in the application of the privilege arise when the client is a corporation, which in theory is an artificial creature of the law, and not an individual; but this Court has assumed that the privilege applies when the client is a corporation, and the Government does not contest the general proposition.

The Court of Appeals, however, considered the application of the privilege in the corporate context to present a "different problem," since the client was an inanimate entity and "only the senior management, guiding and integrating the several operations, can be said to possess an identity analogous to the corporation as a whole."

Such a view, we think, overlooks the fact that the privilege exists to protect not only the giving of professional advice to those who can act on it but also the giving of information to the lawyer to enable him to give sound and informed advice. The first step in the resolution of any legal problem is ascertaining the factual background and sifting through the facts with an eye to the legally relevant. See ABA Code of Professional Responsibility, Ethical Consideration 4-1:
A lawyer should be fully informed of all the facts of the matter he is handling in order for his client to obtain the full advantage of our legal system. It is for the lawyer in the exercise of his independent professional judgment to separate the relevant and important from the irrelevant and unimportant. The observance of the ethical obligation of a lawyer to hold inviolate the confidences and secrets of his client not only facilitates the full development of facts essential to proper representation of the client but also encourages laymen to seek early legal assistance.

In the case of the individual client the provider of information and the person who acts on the lawyer's advice are one and the same. In the corporate context, however, it will frequently be employees beyond the control group as defined by the court below-"officers and agents responsible for directing the company's actions in response to legal advice" - who will possess the information needed by the corporation's lawyers. Middle-level-and indeed lower-levelemployees can, by actions within the scope of their employment, embroil the corporation in serious legal difficulties, and it is only natural that these employees would have the relevant information needed by corporate counsel if he is adequately to advise the client with respect to such actual or potential difficulties.

In a corporation, it may be necessary to glean information relevant to a legal problem from middle management or non-management personnel as well as from top executives. The attorney dealing with a complex legal problem "is thus faced with a 'Hobson's choice'. If he interviews employees not having 'the very highest authority', their communications to him will not be privileged. If, on the other hand, he interviews only 
those employees with 'the very highest authority', he may find it extremely difficult, if not impossible, to determine what happened."

The control group test adopted by the court below thus frustrates the very purpose of the privilege by discouraging the communication of relevant information by employees of the client to attorneys seeking to render legal advice to the client corporation. The attorney's advice will also frequently be more significant to noncontrol group members than to those who officially sanction the advice, and the control group test makes it more difficult to convey full and frank legal advice to the employees who will put into effect the client corporation's policy.

The narrow scope given the attorney-client privilege by the court below not only makes it difficult for corporate attorneys to formulate sound advice when their client is faced with a specific legal problem but also threatens to limit the valuable efforts of corporate counsel to ensure their client's compliance with the law. In light of the vast and complicated array of regulatory legislation confronting the modern corporation, corporations, unlike most individuals, "constantly go to lawyers to find out how to obey the law," particularly since compliance with the law in this area is hardly an instinctive matter. The test adopted by the court below is difficult to apply in practice, though no abstractly formulated and unvarying "test" will necessarily enable courts to decide questions such as this with mathematical precision. But if the purpose of the attorneyclient privilege is to be served, the attorney and client must be able to predict with some degree of certainty whether particular discussions will be protected. An uncertain privilege, or one which purports to be certain but results in widely varying applications by the courts, is little better than no privilege at all. The very terms of the test adopted by the court below suggest the unpredictability of its application. The test restricts the availability of the privilege to those officers who play a "substantial role" in deciding and directing a corporation's legal response. Disparate decisions in cases applying this test illustrate its unpredictability.

The communications at issue were made by Upjohn employees to counsel for Upjohn acting as such, at the direction of corporate superiors in order to secure legal advice from counsel. As the Magistrate found, "Mr. Thomas consulted with the Chairman of the Board and outside counsel and thereafter conducted a factual investigation to determine the nature and extent of the questionable payments and to be in a position to give legal advice to the company with respect to the payments." Information, not available from upper-echelon management, was needed to supply a basis for legal advice concerning compliance with securities and tax laws, foreign laws, currency regulations, duties to shareholders, and potential litigation in each of these areas. The communications concerned matters within the scope of the employees' corporate duties, and the employees themselves were sufficiently aware that they were being questioned in order that the corporation could obtain legal advice. The questionnaire identified Thomas as "the company's General Counsel" and referred in its opening sentence to the possible illegality of payments such as the ones on which information was sought. A statement of policy accompanying the questionnaire clearly indicated the legal implications of the investigation. The policy statement was issued "in order that there be no uncertainty in the future as to the policy with respect to the practices which are the subject of this investigation." It began "Upjohn will comply with all laws and regulations," and stated that commissions or payments "will not be 
used as a subterfuge for bribes or illegal payments" and that all payments must be "proper and legal." Any future agreements with foreign distributors or agents were to be approved "by a company attorney" and any questions concerning the policy were to be referred "to the company's General Counsel." This statement was issued to Upjohn employees worldwide, so that even those interviewees not receiving a questionnaire were aware of the legal implications of the interviews. Pursuant to explicit instructions from the Chairman of the Board, the communications were considered "highly confidential" when made, and have been kept confidential by the company. Consistent with the underlying purposes of the attorney-client privilege, these communications must be protected against compelled disclosure.

The Court of Appeals declined to extend the attorney-client privilege beyond the limits of the control group test for fear that doing so would entail severe burdens on discovery and create a broad "zone of silence" over corporate affairs. Application of the attorney-client privilege to communications such as those involved here, however, puts the adversary in no worse position than if the communications had never taken place. The privilege only protects disclosure of communications; it does not protect disclosure of the underlying facts by those who communicated with the attorney:

The protection of the privilege extends only to communications and not to facts. A fact is one thing and a communication concerning that fact is an entirely different thing. The client cannot be compelled to answer the question, "What did you say or write to the attorney?" but may not refuse to disclose any relevant fact within his knowledge merely because he incorporated a statement of such fact into his communications to his attorney.

Here the Government was free to question the employees who communicated with Thomas and outside counsel. Upjohn has provided the IRS with a list of such employees, and the IRS has already interviewed some 25 of them. While it would probably be more convenient for the Government to secure the results of petitioner's internal investigation by simply subpoenaing the questionnaires and notes taken by petitioner's attorneys, such considerations of convenience do not overcome the policies served by the attorney-client privilege. As Justice Jackson noted in his concurring opinion in Hickman v. Taylor: "Discovery was hardly intended to enable a learned profession to perform its functions on wits borrowed from the adversary."

Needless to say, we decide only the case before us, and do not undertake to draft a set of rules which should govern challenges to investigatory subpoenas. Any such approach would violate the spirit of Federal Rule of Evidence 501. While such a "case-by-case" basis may to some slight extent undermine desirable certainty in the boundaries of the attorney-client privilege, it obeys the spirit of the Rules. At the same time we conclude that the narrow "control group test" sanctioned by the Court of Appeals in this case cannot, consistent with "the principles of the common law as interpreted in the light of reason and experience," govern the development of the law in this area.

\section{Questions:}


1. Which agents of an organization can be parties to privileged communications?

2. When is a communication with an agent of an organization not privileged?

3. Is the Upjohn test for corporate privilege too narrow, too broad, or just right?

Matter of Bevill, Bresler \& Schulman Asset Manag., 805 F. 2d 120 (3d Cir. 1986)

\section{Summary:}

SEITZ, Circuit Judge.

This appeal arises out of two related proceedings currently before the district court: the Chapter 11 reorganization of Bevill, Bresler \& Schulman Asset Management Corporation (AMC) and the liquidation of Bevill, Bresler \& Schulman, Inc. (BBS) under the Security Investor Protection Act (SIPA). Intervenors John D. Rooney and Robert L. Bevill, two principals of the corporations, appeal the order of the district court directing Gilbert Schulman, president of AMC, and Hellring, Lindeman, Goldstein, Siegal \& Greenberg, counsel for BBS, to respond to questions posed in depositions by the trustees for AMC and BBS. The order permits the trustees to discover the substance of certain meetings that took place between the law firm and the principals of the corporations before the Chapter 11 petition was filed. Because Rooney and Bevill allege that the district court's order violates their attorney-client privilege, we have jurisdiction.

I.

We turn first to the facts as narrated by the district court. Gilbert Schulman first became aware that AMC was in financial difficulties on March 19, 1985, when Robert Bevill telephoned him in Greece. After talking again with Bevill on the following day, Schulman flew back to the United States. According to Schulman, he was unable to obtain any information about AMC until he consulted with Hellring, Lindeman on March 25, 1985.

Between March 25, 1985 and April 7, 1985, Schulman met with Hellring, Lindeman almost daily. Other principals of BBS and AMC, including Bevill and Rooney, were present at some of these meetings.

When Schulman first met with Hellring, Lindeman, he explained that he was seeking both personal and corporate legal advice. In his deposition, he testified that with regard to the March 26th meeting:

I stated to Mr. Hellring and Mr. Goldstein that I had arranged for Mr. Bevill to come down and meet them and at that point I had said to them that "Possibly you will represent me, possibly you will represent Mr. Bevill and me, possibly you will represent the firms," but I was definitely seeking personal legal advice at that time. 
On March 31, 1985, Hellring, Lindeman was retained to represent BBS. In addition, it continued to consider whether it would represent the principals of BBS. On April 4, 1985, Hellring, Lindeman informed the principals that they should obtain separate counsel.

On April 7, 1985, AMC filed a petition for bankruptcy under Chapter 11 of the Bankruptcy Code. A trustee was subsequently appointed by the district court. On April 8, the SEC filed a civil complaint in the district court alleging fraud against AMC, BBS, and the principals of the corporations, including appellants. In addition, the SEC began a criminal investigation, and there is currently a grand jury investigation into the affairs of the two corporations. On May 8 , the district court placed BBS under a SIPA receivership and the SIPA trustee commenced a liquidation proceeding.

On May 13, 1985, the counsel for the AMC trustee began to depose Schulman. By the consent of the parties, this deposition was conducted as a joint proceeding in the AMC Chapter 11 proceeding, the BBS SIPA liquidation, and the SEC proceeding. The AMC trustee sought to depose Schulman as to the substantive communications between Hellring, Lindeman and the principals, and indicated that the trustee had waived AMC's attorney-client privilege. Schulman's counsel instructed Schulman not to answer the questions. Counsel for the other principals also instructed Schulman not to respond, asserting the existence of a joint defense privilege.

On May 21, 1985, the deposition of Schulman resumed, and the AMC trustee began questioning Schulman about the circumstances surrounding the meetings with counsel, including the dates of the meetings, who was present, and whether the discussions involved personal or corporate matters. Once again, counsel for the other principals objected on the grounds of a joint defense privilege.

The AMC and BBS trustees and the SEC subsequently filed motions with the district court for an order directing the principals and Hellring Lindeman to respond to a series of questions as to the circumstances surrounding the meetings. In opposition to these motions, Rooney filed an unsworn affirmation with the district court stating that he met with counsel for personal advice and with the expectation that the communications would be confidential. He further stated that he would not have met with counsel without the assurance of confidentiality.

After a hearing, the district court ordered Bevill, Rooney, Schulman, Robert Levine, another principal, and Hellring, Lindeman to answer written interrogatories about the scope of counsel's representation. Bevill and Rooney refused to answer the interrogatories on the ground of the fifth amendment. Schulman stated that he attended all meetings except the March 31st meeting for the purpose of securing personal legal advice. Levine concurred in this statement, and also stated that the participants in the meetings were engaged in a joint defense effort. Schulman, however, has asserted in a letter to the BBS trustee from his counsel that he was never part of a joint defense.

Hellring, Lindeman confirmed in their answers to the interrogatories that the principals had sought both personal and corporate legal advice at the meetings that occurred from March 25th 
through April 4th. In a letter to the BBS trustee, it further explained its understanding of its representation:

Our firm was initially consulted on Monday, March 25, 1985. On that date and during the week of March 25, 1985 we were consulted by officials of Bevill, Bresler \& Schulman, Inc. on a confidential and privileged basis for the purpose of personal representation as well as corporate representation of Bevill, Bresler \& Schulman, Inc. and other companies.

We were not retained until Sunday, March 31, 1985 on which date we agreed to represent Bevill, Bresler \& Schulman, the broker/dealer and its affiliated broker/dealer companies and to consider further the matter of representation for the individuals and other corporations.

During the next few days we continued to be consulted by officials of Bevill, Bresler \& Schulman, Inc. on a confidential and privileged basis for purposes of personal representation and to consider the need therefor.

Within a few days of March 31, 1985 we advised each individual official to retain separate and individual counsel.

The trustees, relying on their waiver of the corporations' attorney-client privileges, moved for an order directing Schulman and Hellring, Lindeman to testify about the substance of the meetings insofar as they related to the affairs of the two corporations and Schulman's activities as a director or officer of the corporations. Bevill and Rooney opposed the motions based on their attorney-client privileges and a joint defense privilege.

After hearing argument from counsel on the trustees' motions, the district court, in an oral opinion, granted the motions in part. The court held that a corporate officer must satisfy the following test to assert a personal claim of attorney-client privilege as to communications with corporate counsel:

First, they must show they approached counsel for the purpose of seeking legal advice. Second, they must demonstrate that when they approached counsel they made it clear that they were seeking legal advice in their individual rather than in their representative capacities. Third, they must demonstrate that the counsel saw fit to communicate with them in their individual capacities, knowing that a possible conflict could arise. Fourth, they must prove that their conversations with counsel were confidential. And, fifth, they must show that the substance of their conversations with counsel did not concern matters within the company or the general affairs of the company.

The court rejected Rooney's claim that he consulted with counsel for the sole or primary purpose of securing personal legal advice, finding such a claim unsupported by the evidence. It then turned to the principals' contention that the corporate communications were 
indistinguishable from those that related to their personal legal problems, and that, therefore, all communications are privileged. The court agreed with Bevill and Rooney insofar as the trustees sought to obtain information about meetings prior to March 31st when Hellring, Lindeman agreed to represent BBS. The court thus held that these communications were privileged. The trustees do not appeal this ruling.

It, however, rejected the appellants claim of a blanket privilege for those meetings that occurred after March 31st. It found that once Hellring, Lindeman agreed to represent BBS, it was to BBS that the lawyers owed any duty. Further, based on counsel's knowledge of BBS and AMC when the bankruptcy petition was filed, the court found that "it is obvious that immediately after March 31,1985 , Hellring, Lindeman turned its attention to the affairs of its corporate clients." Finally, the court stated that the only personal advice that had been identified was that relating to separate representation.

The court also rejected Bevill's and Rooney's claim of a joint defense privilege, finding that they did not bear their burden of showing that a joint defense in fact existed.

The district court ordered Hellring, Lindeman to testify as to all communications about the corporations and the roles and functions of the officers that took place after the law firm agreed to represent BBS. It further held that no questions could be asked concerning separate representation or the officers' potential personal liabilities, unless the communications also related to the business and assets of the corporations or the roles of the principals in the corporations. Finally, the court stated that Hellring, Lindeman could submit any communications it was doubtful about to the court for in camera inspection. This appeal followed.

II.

Bevill and Rooney claim that the district court's order directing disclosure of the substantive communications with counsel between March 31st and April 4th violates their attorney-client privilege. In addition, Bevill claims that such disclosure is barred by the joint defense privilege.

Privileges in federal court are "governed by the principles of common law as they may be interpreted in light of reason and experience." Whether there is a valid claim of privilege is decided on a case-by-case basis. Although the applicability of a privilege is a factual question, determining the scope of a privilege is a question of law, subject to plenary review.

\section{A.}

The purpose of the attorney-client privilege "is to encourage full and frank communication between attorneys and their clients and thereby promote broader public interests in observance of the law and administration of justice." This privilege applies to corporations as well as individuals. As the Supreme Court has recognized, however, "the administration of the privilege in the case of corporations presents special problems. As an inanimate entity, a corporation must act through agents." 
In this case, we address the relationship between a corporation's waiver of its privilege and the individual directors' assertion of a claim of personal attorney-client privilege with respect to counsel consulted on both a personal and corporate basis after the counsel has been retained by the corporation. The parties agree that the trustees had the power to waive the corporations' attorney-client privilege regarding prebankruptcy communications with counsel. They also agree that the directors or officers may have an individual attorney-client privilege apart from those of the corporations. The dispute centers on whether the individuals' assertion of an attorney-client privilege can prevent the disclosure of corporate communications with corporate counsel when the corporation's privilege has been waived.

As we understand appellants' position, they claim that the district court erred as a matter of law in holding that communications related to their role as corporate officers were not privileged. They contend that because their personal legal problems were inextricably intertwined with those of the corporation, disclosure of discussions of corporate matters would eviscerate their personal privileges. They therefore assert that a blanket privilege should be applied to all communications with counsel between March 31st and April 4th.

The appellants' argument, however, does not pay sufficient attention to the fact that under existing law, any privilege that exists as to a corporate officer's role and functions within a corporation belongs to the corporation, not the officer. Because a corporation can act only through its agents, a corporation's privilege consists of communications by corporate officials about corporate matters and their actions in the corporation. A corporate official thus may not prevent a corporation from waiving its privilege arising from discussions with corporate counsel about corporate matters.

The two decisions cited by appellants, In re Citibank v. Andros and Diversified Industries, Inc. v. Meredith, do not support their position that they may assert their personal privilege over the corporation's waiver with regard to corporate matters. Rather, these two cases simply recognize that an individual officer may have an individual claim of attorney-client privilege with regard to communications with corporate counsel.

Moreover, we find that appellants' position is contrary to the public policies identified by the Supreme Court. The Weintraub Court found that permitting a bankrupt corporations' management to assert the corporation's privilege against the bankruptcy trustee would defeat the Bankruptcy Code's goal of uncovering insider fraud. To provide a blanket privilege regarding all discussions of corporate matters on the basis of an assertion of personal privileges by the officers would prevent the trustee from investigating possible misconduct by the officers and permit the officers to "use the privilege as a shield against the trustee's efforts."

The test adopted by the district court does not invade the personal privilege of the officers because they do not have an attorney-client privilege with regard to communications made in their role as corporate officials. Moreover, the district court has not precluded the possibility that appellants may assert their personal privilege as to matters not related to their role as officers of 
the corporation. First, the order directs that no questions could be asked regarding the need for separate representation. Second, the court allowed for the possibility that appellants could demonstrate that some of the communications after March 31st were personal and protected communications relating to the principals' personal liabilities, except insofar as they were related to their role as corporate officers. Finally, the district court held that it would review in camera any communication over which there was a question whether it was personal or corporate in nature.

In light of the foregoing analysis, we find that that the district court's order properly defined the extent to which the principals were entitled to bar discovery of communications with counsel based on their individual attorney-client privileges.

\section{Questions:}

1. Under the commonly used Bevill standard, agents of an organization seeking to prove either a joint or separate attorney-client relationship with the organization's attorney must establish that: 1) the employee approached the corporation's attorney for legal advice; 2) the employee made it clear that the request had to do with matters that arose in his or her individual capacity; 3) the attorney understood this request and advised on the matter even though there was a potential for conflict; 4) these communications were confidential; and 5) the subject matter of the communication did not concern a more general corporate matter. How frequently do you think agents will be able to satisfy these criteria?

\section{The "Need to Know" Standard}

\section{Summary:}

FTC v. GlaxoSmithKline, 294 F. 3d 141 (D.C. Cir. 2002)

GINSBURG, Chief Judge:

In the course of investigating whether a manufacturer of drugs listed its patents properly in the compilation maintained by the Food and Drug Administration, the Federal Trade Commission issued a subpoena directing the company to produce documents relating to a particular drug. When the company resisted, claiming the attorney-client privilege shields the documents, the Commission repaired to the district court, which enforced the subpoena. We reverse the decision of the district court because the court both relied upon an argument to which the company had no opportunity to respond and ruled erroneously that, by failing to keep confidential the contents of the documents, the company had waived the attorney-client privilege.

I. Background 
GlaxoSmithKline manufactures paroxteine hydrochloride hemihydrate under the brand name Paxil, the annual sales of which in the United States exceed \$1 billion. Several companies have applied to the Food and Drug Administration for permission to sell generic versions of Paxil when GSK's patents expire. The Federal Trade Commission is investigating whether GSK, in an attempt to prevent or delay competition from generic versions of Paxil, has abused the process for listing its patents in the FDA's compilation of "Approved Drug Products with Therapeutic Evaluations."

The Commission issued a subpoena directing GSK to produce two types of documents. First, the Commission sought all documents concerning Paxil that the United States District Court for the Northern District of Illinois had directed GSK to disclose when GSK had sued two manufacturers of generic pharmaceuticals for infringement of its patents - the so-called Chicago documents. Second, the Commission wanted all "documents related to the manufacturing and marketing of Paxil, the listing and use of any patents regarding Paxil, and any filings with the FDA regarding Paxil." GSK and the Commission resolved their differences over the inclusion or exclusion of thousands of documents, but because GSK declined to produce hundreds of others - primarily on the ground that they were shielded by the attorneyclient privilege - the Commission petitioned the district court to enforce the subpoena.

The parties then agreed upon a procedure for presenting their positions to the district court. First, each would submit its contentions about the Chicago documents. If the court compelled GSK to produce those documents, then the parties would contest the second category of documents as follows. The Commission would "identify for GSK every responsive (and allegedly privileged) document that the Commission sought to have produced and the reason(s) why each privilege claim was invalid." GSK would then either produce the document or list it in a "privilege log identifying any documents as to which it continued to assert privilege." Accordingly, only after the Commission had informed GSK of its objections to the Company's claims of privilege would the parties seek judicial resolution. At that final stage the court would either call for oral argument or resolve summarily "any issues submitted to it in connection with the FTC's enforcement petition."

The district court did enforce the subpoena with respect to the Chicago documents. The parties then resolved through negotiation their disputes about the disclosure of hundreds more documents, leaving unresolved the status of only 91 . GSK asserted that all 91 documents were protected by the attorney-client privilege and that 34 of them were protected also by the privilege for attorney work product. The Commission told GSK it considered the assertions of privilege invalid for two reasons: (1) GSK had forfeited its claim to confidentiality by disseminating all 91 documents widely both within GSK and to consultants and other thirdparties; and (2) the decision in Apotex estopped GSK from asserting that the 34 documents were attorney work product, that is, were prepared in anticipation of litigation. In response to these objections, GSK compiled a privilege log describing each of the 91 documents, and the parties presented their arguments to the district court. 
In its opening brief to the district court, the Commission raised the two objections it had previously presented to GSK. The Commission also introduced in that brief a new argument: Regardless whether Apotex foreclosed the Company's claim of attorney work product, GSK's privilege log "failed to provide facts demonstrating that the documents were created in anticipation of litigation." When GSK objected that the Commission had not made this argument during pre-motion negotiations, the Commission withdrew the argument. It explained in a Stipulation approved by the district court that it had "inadvertently failed to provide GSK with the agreed advance notice regarding the grounds for challenging the documents."

GSK submitted its responsive brief to the district court and attached thereto the Company's privilege log and the affidavit of Charles Kinzig, GSK's Vice President and Director of Corporate Intellectual Property. For each document, the log described the contents; listed the author, intended recipients, and date of creation; and noted whether the author or intended recipients were attorneys. A supplement to the log indicated the title or titles of each person therein named who was not an attorney. The Kinzig Declaration stated that the documents had been disseminated to various "teams" of company employees and contractors, and explained the duties of each team. According to Kinzig, all the teams were "involved in seeking or giving legal advice and/or gathering and recording information in anticipation of or preparation for litigation." The Kinzig Declaration states also that every employee and contractor named in the privilege log was "bound not to disclose confidential information to persons outside GSK" without receiving permission from a high-ranking official of the Company.

The Commission then filed a reply brief in which it made yet another argument for the first time: The attorney-client privilege does not shield the documents because they contain no confidential information.

The district court ordered GSK to produce the 91 documents. The court rejected GSK's claims of attorney-client privilege on the grounds that (1) "GSK had not sustained its burden of demonstrating that the relevant documents were distributed on a 'need to know' basis or to employees that were 'authorized to speak or act' for GSK," and (2) the Company had "failed to provide sufficient evidence that the information contained therein is confidential." The court rejected GSK's claims of attorney work product for the reason withdrawn by the Commission, namely, that "GSK failed to set forth objective facts that support the corporation's assertion that the relevant documents were created in anticipation of litigation." Having determined that "even if GSK is not precluded from asserting the privilege for attorney work product, it has failed to satisfy its burden of showing the applicability of the doctrine to the relevant documents," the district court found it unnecessary to resolve whether the decision in Apotex estopped GSK from claiming otherwise. GSK sought and we granted a stay pending appeal.

\section{Analysis}

GSK contends the district court erred both by rejecting its claims of privilege based upon arguments the Commission did not raise properly and by misapplying the standard for determining whether a corporation has kept confidential the contents of a communication. The 
Commission defends the decision of the district court and argues that GSK is collaterally estopped in any event, by reason of the Apotex litigation, from claiming the 34 documents are attorney work product.

The district court held that GSK failed to establish either of two prerequisites for recognition of the attorney-client privilege - that the documents contain confidential information and that they have been kept confidential. As the Company points out, during the parties' negotiations the Commission did not dispute that the documents contain confidential information. The Commission did not even raise the argument in its opening brief before the district court, waiting instead until its reply brief and thereby depriving GSK of any opportunity to respond.

The Commission had agreed, pursuant to the Scheduling Stipulation approved by the district court, to inform GSK of its reasons for disputing the Company's claims of privilege before asking the court for a ruling. The Commission therefore was bound not to put before the district court any objection not first raised with its adversary. Accordingly, the district court abused its discretion when it ruled against GSK based upon an argument that was raised not only in violation of the Scheduling Stipulation but so belatedly that the Company had no chance to respond to it.

The question that remains is whether the district court erred in ruling that GSK failed to satisfy the second prerequisite for attorney-client privilege - that the documents have been kept confidential. GSK contends that this issue, too, was raised in a manner that deprived the Company of an opportunity to respond. We think not. The Commission took the position in its negotiations with GSK that the Company had lost its claim of privilege by disseminating the documents widely. This argument put the Company on notice that it needed to establish it had kept the documents confidential. The Commission renewed the point in its opening brief to the district court thus: "In view of the breadth of distribution and GSK's failure to carry its burden of establishing that each and every recipient had a demonstrable 'need to know,' GSK's assertions of attorney-client privilege must fail." And the Company joined this argument on the merits before the district court. Having defended as sufficient the evidence it submitted to the district court on this point, GSK may not now claim it was unfairly surprised by the argument.

Although the district court was correct to entertain the Commission's second argument, it erred in resolving the legal issue. The applicable standard is, as the district court recognized, whether the "the documents were distributed on a 'need to know' basis or to employees that were 'authorized to speak or act' for the company." The Company's privilege log and the affidavit of Charles Kinzig establish that GSK circulated the documents in question only to specifically named employees and contractors, most of whom were attorneys or managers and all of whom "needed to provide input to the legal department and/or receive the legal advice and strategies formulated by counsel." The affidavit also states that each intended recipient was bound by corporate policy or, in the case of the contractors, by a separate understanding, to keep confidential the contents of the documents. The Company's submission thus leads ineluctably to the conclusion that no document was "disseminated beyond those persons who, because of the corporate structure, needed to know its contents." 
The district court faulted GSK for not having explained "why any, let alone all, of the employees received copies of certain documents," and the Commission likewise claims on brief that GSK should have shown why each individual in possession of a confidential document "needed the information therein to carry out his/her work." These demands are overreaching. The Company's burden is to show that it limited its dissemination of the documents in keeping with their asserted confidentiality, not to justify each determination that a particular employee should have access to the information therein. Not only would that task be Herculean - especially when the sender and the recipient are no longer with the Company - but it is wholly unnecessary. After all, when a corporation provides a confidential document to certain specified employees or contractors with the admonition not to disseminate further its contents and the contents of the documents are related generally to the employees' corporate duties, absent evidence to the contrary we may reasonably infer that the information was deemed necessary for the employees' or contractors' work. We do not presume, therefore, that any business would include in a restricted circulation list a person with no reason to have access to the confidential document - that is, one who has no "need to know."

Moreover, we can imagine no useful purpose in having a court review the business judgment of each corporate official who deemed it necessary or desirable for a particular employee or contractor to have access to a corporate secret. It suffices instead that the corporation limited dissemination to specific individuals whose corporate duties relate generally to the contents of the documents. As we have seen in this case, the privilege log and the Kinzig Declaration together establish that GSK did just that, and the Company thereby demonstrated its entitlement to the attorney-client privilege. The FTC has proffered nothing to the contrary.

Our conclusion that the documents are protected by the attorney-client privilege extends also to those communications that GSK shared with its public relations and government affairs consultants. The Kinzig affidavit notes that GSK's corporate counsel "worked with these consultants in the same manner as they did with full-time employees; indeed, the consultants acted as part of a team with full-time employees regarding their particular assignments" and, as a result, the consultants "became integral members of the team assigned to deal with issues that were completely intertwined with GSK's litigation and legal strategies." In these circumstances, "there is no reason to distinguish between a person on the corporation's payroll and a consultant hired by the corporation if each acts for the corporation and possesses the information needed by attorneys in rendering legal advice."

\section{Questions:}

1. Why does it matter for the attorney-client privilege whether an agent of an organization "needed to know" about a communication?

2. How demanding is the "need to know" standard?

3. When does an agent of an organization fail to satisfy the "need to know" standard?

\section{Independent Contractors}


Steinfeld v. IMS Health Inc., No. 10 Civ. 3301 (S.D.N.Y. 2011)

PAUL E. DAVISON, Magistrate Judge.

By letter dated October 31, 2011, Plaintiff seeks an order compelling Defendant to produce certain documents containing communications shared between attorneys for Defendant and a compensation consulting firm and its principal, Steven Root. Defendant's offer to produce the documents at issue for in camera inspection was accepted and that material has been reviewed.

IMS retained Root as an independent equity compensation consultant. ${ }^{77}$ He advises IMS directors and counsel on matters involving the company's executive compensation and benefits plans and disclosure obligations. On this basis, Defendant contends that the communications shared between counsel for IMS and Root are protected by the attorney-client privilege. Defendant relies upon the theory announced by the Eighth Circuit in In re Bieter Co., and which a small number of district courts within this circuit have recognized. Under this authority, the privilege is extended in certain narrow instances to protect "communications between a corporation's attorney and outside agents or consultants to the corporation who act as the functional equivalent of a corporate employee." Defendant specifically argues that Root was the functional equivalent of an IMS employee because he "contributed to the rendering of legal advice in communications with the client's outside counsel," was "necessary to such communications," and "possessed information needed by IMS counsel in order to render legal advice" to their client.

Generally, the presence of third parties waives entitlement to the attorney-client privilege. While, as discussed below, certain exceptions apply, courts should be cautious when expanding the privilege's application. The party asserting entitlement to the privilege bears the burden of proof.

Because the cases relied upon by counsel in this matter are extremely fact-specific, I first discuss Bieter and other cases applying its functional equivalence test.

In Bieter, a two-man partnership formed for purposes of developing farm land. A third-party real estate consultant was retained who worked out of the company's office for several years. The consultant's primary duty was to secure tenants for the development project. He also worked directly with architects, other consultants, and attorneys on matters related to the project and its ensuing litigation. He appeared on behalf of the company at public hearings and was viewed by the public as a representative of the company. Accordingly, the court determined that "there was no principled basis to distinguish the consultant's role from that of an employee, and his involvement in the subject matter of the litigation makes him precisely the sort of person with whom a lawyer would wish to confer confidentially in order to understand the company's reasons for seeking representation."

\footnotetext{
${ }^{77}$ Although Root is an attorney, Defendant acknowledges that IMS retained him as a compensation consultant and not as a legal advisor.
} 
In In re Copper Market Antitrust Litigation, a Japanese corporation retained a public relations firm as an independent consultant after a corporate executive disclosed information which prompted government investigations and litigation. The corporation had no experience with, or other employees who could deal with, public relations communications in the English-speaking, Western media. The PR firm issued press statements on behalf of the corporation and otherwise communicated with the Western press as an agent of the corporation. In the course of preparing and making its communications and statements, the firm consulted with the corporation's in-house and outside counsel. The firm also had the authority to make independent decisions on the corporation's behalf with respect to public relations matters. Accordingly, the court determined that the firm was the functional equivalent of a corporate employee.

In Twentieth Century Fox Film Corporation v. Marvel Enterprises, a studio contracted with individuals as independent contractors to perform movie production services. The film produced became the subject of ensuing litigation. The court held that the contractors were the functional equivalent of employees because "the sporadic nature of employment in the motion picture industry dictates the use of independent contractors over employees."

In In re Adelphia Communications Corporation, an independent credit counseling firm was retained as an independent contractor. An employee of the contractor worked full-time at the corporation for three years. He held substantial responsibility with respect to the corporation's relations with another company. He also became the primary contact person between the corporation and the other company, and was given authority to make decisions and to speak on behalf of the corporation. In addition, the employee of the contractor sought legal advice from the corporation's counsel as part of his job duties. Accordingly, the court held that this individual was "the functional equivalent of a corporate employee."

In American Manufacturers Mutual Insurance Company v. Payton Lane Nursing Home, an independent construction management contractor was retained by a company for purposes of overseeing the daily operations of a construction project. The company itself did not send its own employees to the construction site, nor did it employ staff with construction experience. The contractor was given authority to speak for, and to make decisions on behalf of, the company relating to the construction project. This included negotiating with contractors and pursuing payments. The contractor also sought legal advice from the company's attorney regarding the construction project. Accordingly, the court held that the contractor served as the company's "eyes and ears" and was therefore the functional equivalent of an employee.

In contrast, in Export-Import Bank of the United States v. Asia Pulp and Paper Company, a Singapore corporation retained an independent financial consultant to help the corporation restructure its debt. The corporation did not have employees of its own with experience in restructuring. The consultant negotiated on behalf of the corporation and communicated the corporation's positions to creditors. Although the corporation provided the consultant with office space in its building, the office was not used. Additionally, the court determined that the 
consultant did not spend a sufficient amount of his time working with corporation. Accordingly, the court held that the party asserting entitlement to the attorney-client privilege failed to meet its burden to show that the consultant was "so fully integrated into the corporation's hierarchy as to be a de facto employee."

In this case, Defendant has failed to meet its burden to show that Root is the functional equivalent of an IMS employee. First, there is no indication that IMS uses independent contractors instead of employees because its business is sporadic. Second, there is no evidence that Root has ever appeared on behalf of IMS, corresponded with third parties as a representative of IMS, or has been viewed by others as an employee of IMS. In camera review of the documents at issue reveals that Root frequently signed his emails as the managing director of his consulting firm and submitted memoranda on his own firm's letterhead.

Third, Defendant offers nothing to suggest that Root was so physically present that he functioned as a de facto employee. For example, there is nothing to indicate that Root has ever maintained an office at IMS or otherwise spent a substantial amount of his time interacting with, and working on behalf of, the corporation.

Fourth, Defendant offers nothing to show that IMS lacked the internal resources necessary for an employee to perform Root's services. Indeed, as in camera review tends to confirm. Root participated as part of a "team" of IMS employees and outside counsel.

Fifth, the evidence presented does not reveal that Root exercises any measure of independent decision-making authority within this team. Instead, it appears that Root's role was to provide suggestions, comments, and (non-legal) advice.

Finally, Defendant has failed to show that Root has ever sought out legal advice from IMS's attorneys as part of his work with the corporation. Rather, the communications reviewed indicate that it was Root who offered advice and suggestions to counsel and the team in general.

Root's status vis-a-vis Defendant is simply distinguishable from the situations in those cases that have followed Bieter. Root is not, therefore, the functional equivalent of an IMS employee. ${ }^{78}$ Accordingly, Plaintiffs request to compel production Is GRANTED. Defendant is directed to produce to Plaintiff the documents shared with Mr. Root or his firm no later than December 16, 2011.

\section{Former Employees}

\footnotetext{
${ }^{78}$ To the extent Defendant separately argues the privilege applies because Root acted as an agent of IMS who had information necessary for counsel to render legal advice to IMS, Defendant has similarly failed to meet its burden of proof. An attorney's communications with a third party will be privileged "if the third party's role is limited to helping a lawyer give effective advice by explaining concepts to the lawyer." Here, Root's role was simply more expansive than this. He did not explain unfamiliar concepts to counsel, but instead provided the "team" with suggestions and advice on what actions may be undertaken. Such communications are not privileged.
} 
US v. Merck-Medco Managed Care, LLC, 340 F. Supp. 2d 554 (E.D. Pa. 2004)

SCUDERI, United States Magistrate Judge.

After consideration of a Motion to Compel Testimony From Susan Elliott filed by the United States Government, the Response of Defendants, Merck-Medco Managed Care, LLC, Plaintiffs Reply, and Medco Defendants' Sur-Reply, it is hereby ORDERED that the Motion is GRANTED, as follows:

In the instant motion, Plaintiffs seek to compel additional testimony from Susan Elliott, a former employee of Medco Defendants. Plaintiffs deposed Ms. Elliott on July 28, 2004, at which time she testified that she did not have her own attorney, and that she was not represented by counsel for Medco Defendants. Counsel for Medco Defendants confirmed that they did not represent Ms. Elliott. Nevertheless, counsel for Medco Defendants asserted the attorney-client privilege and instructed Ms. Elliott not to answer any questions concerning communications between Medco Defendants and Ms. Elliott in preparation for her deposition, or concerning communications that occurred during breaks in her deposition. Ms. Elliott complied with all instructions not to answer such questions.

Statements made under oath by Ms. Elliott at her deposition clearly differed from statements she previously made regarding certain activities which are material to this case. As a result, Plaintiffs seek additional testimony from Ms. Elliott regarding four (4) specific categories of questions:

a. Statements made by Medco Defendants' counsel to Ms. Elliott regarding the nature of the case;

b. Statements made by Ms. Elliott to Medco Defendants' counsel regarding her conversations with Government investigators;

c. Descriptions and/or summaries of witness testimony provided to Ms. Elliott by counsel for Medco Defendants; and

d. Conversations between counsel for Medco Defendants and Ms. Elliott while she was under oath during the deposition.

Plaintiffs argue that they are entitled to question Ms. Elliott on these topics because her communications with corporate counsel had the potential to "affect, influence or change" Ms. Elliott's testimony.

Medco Defendants oppose the current motion, arguing that all of the communications at issue between Ms. Elliott and counsel for Medco Defendants are protected by the attorney-client privilege because the privilege should be applied in the same way for former employees as for current employees.

In Upjohn Co. v. United States, the Supreme Court held that a corporation's attorneys' conversations with current corporate employees could be covered by the attorney-client 
privilege. The privilege applies when the conversations: (1) were made to the corporate counsel, acting as such; (2) were made at the direction of corporate supervisors for the purpose of securing legal advice from counsel; (3) concerned matters within the scope of the employees' corporate duties; and (4) the employees were sufficiently aware that they were being questioned in order that the corporation could obtain legal advice. In a concurring opinion, Chief Justice Berger opined that the attorney-client privilege should be extended to protect communications between corporate counsel and former employees. Nevertheless, the Supreme Court in Upjohn left open the question of whether communications between corporate counsel and former employees were included within the privilege.

As noted by the parties, the Third Circuit has not addressed the question left open by the Supreme Court in Upjohn. Moreover, although this Court has acknowledged that the Upjohn privilege may apply to former employees as well as current employees, that case is factually distinguishable and did not specifically address whether corporate counsel's communications with a former employee are privileged as to the four discrete topics at issue in the instant motion.

Fortunately, other federal courts have addressed the present issue under similar circumstances. In Infosystems, Inc. v. Ceridian Corp., the District Court for the Eastern District of Michigan extended the privilege over former employees, but limited it to communications which themselves were privileged and which occurred during the employment relationship. The Court explained that the willingness of former employees to provide information is generally unrelated to directions from former corporate superiors and, therefore, "counsel's communications with a former employee of the client corporation generally should be treated no differently from communications with any other third-party fact witness." In City of New York v. Coastal Oil New York, Inc., the District Court for the Southern District of New York confronted the same issue presented here, namely, whether plaintiffs' counsel should be permitted to question a former employee of the defendant corporation about conversations he had with corporate defense counsel in preparation for his deposition, as well as conversations that may have occurred during a recess in the deposition. The Court concluded that, because corporate counsel did not represent the former employee and there was no evidence that the conversations occurred for the purpose of legal advice, the record did not contain any basis for an assertion of the attorneyclient privilege. In so holding, the District Court in Coastal Oil explicitly followed the reasoning of Peralta.

In Peralta, the District Court for the District of Connecticut rejected a defendant corporation's attempt to utilize the attorney-client privilege to block all questions about communications between corporate counsel and a former employee. Instead, the court limited the privilege to communications that either: (1) concerned knowledge obtained or conduct that occurred during the course of the former employee's employment; or (2) related to communications which were themselves privileged and which occurred during the employment relationship. Importantly, the court specified that the attorney-client privilege would not apply in certain specific circumstances, such as to information given by corporate counsel to the former employee regarding the testimony of other witnesses, or to discussions between the former employee and 
corporate counsel during breaks in a deposition. These are virtually the same circumstances present here. Moreover, the court in Peralta explained that allowing limited discovery regarding such communications was particularly necessary "given their potential to influence a witness to conform or adjust her testimony to such information, consciously or unconsciously." The identical concern is present here.

The Court is persuaded by the reasoning set forth in the aforementioned cases, as well as both the reasoning and the practical solutions set forth by the District Courts in Peralta and Coastal Oil. The Court is aware of potential difficulties in separating facts developed during litigation, which are not privileged pursuant to the aforementioned case law, and facts known by the employee as a result of her employment, which likely would be privileged. However, as the court in Peralta made clear, the line to be drawn is not difficult: if the communication sought to be elicited relates to Ms. Elliott's conduct or knowledge during her employment with Medco Defendants, or if it concerns conversations with corporate counsel that occurred during her employment, the communication is privileged; if not, the attorney-client privilege does not apply.

As a result of the foregoing - and because it is apparent that the communications between Ms. Elliott and Medco Defendants' may have influenced her testimony - Plaintiffs' motion is granted. However, Plaintiffs may obtain additional testimony from Ms. Elliott only regarding the four specific avenues of inquiry previously discussed, and in a manner consistent with the limitations set forth above.

\section{Questions:}




\section{6: The Work Product Doctrine}

Let's make some plans 'cause they can't go wrong. Getting there may be times three maybe not. To loosen your lips and you're talking rubbish. To loosen your whole mistaken tenfold. ${ }^{79}$

Andy said a lot of things, I stored them all away in my head. Sometimes, when I can't decide what I should do, I think, "What would Andy have said?" He'd probably say, "You think too much, that's 'cause there's work that you don't want to do." It's work. The most important thing is work. $^{80}$

The "Work Product Doctrine" is an evidentiary privilege providing that attorneys ordinarily cannot be required to produce documents they created in the course of preparing for litigation. It applies to the notes, records, and other documents created by attorneys in gathering information in preparation for litigation and in the course of preparing litigation documents.

The work product doctrine differs from the attorney-client privilege in several respects. First, it applies to different subject matter. The attorney-client privilege applies to confidential communications with clients for the purpose of providing legal advice, but the work product doctrine applies to certain documents created by attorneys, whether or not those documents are communicated to the client. Second, it belongs to a different party. The attorney-client privilege belongs to the client, so the client is the only person who can waive the privilege, but the work product doctrine belongs to the attorney. Third, it is not as strong. The attorney-client privilege is sacrosanct and abrogated only if abused, but the work product doctrine can give way to necessity.

Notably, the work product doctrine may cover any documents created by or for an attorney in anticipation of litigation. This requirement is generally interpreted liberally. A document is created "in anticipation of litigation" if litigation is conceivable, even if no actual litigation has commenced. In addition, the document need not be created by an attorney. A document created for an attorney in anticipation of litigation may be protected by the work product doctrine.

However, while the protection provided by the work product doctrine is broader than the protection provided by the attorney-client privilege, it is also weaker. Unlike the attorney-client privilege, the work product doctrine can be overcome by a showing of necessity. Specifically, courts distinguish between "fact" and "opinion" work product. Fact work product is factual documents created in anticipation of litigation, and opinion work product is documents that reflect the mental impressions, conclusions, opinions or legal theories of an attorney. Fact work product is discoverable if the opposing party can show a substantial need for the document, and it cannot obtain the relevant information by other means, without undue hardship. But opinion work product generally is not discoverable, unless one of the exceptions to the attorney-client privilege applies.

\footnotetext{
${ }^{79}$ Close Lobsters, Let's Make Some Plans, What Is There To Smile About (1988).

${ }^{80}$ Lou Reed \& John Cale, Work, Songs for Drella (1990).
} 
For example, if an attorney records an interview with a non-client witness and takes notes, the recording and notes will be protected by the work product doctrine, but not the attorney-client privilege. Under the work product doctrine, neither the recording nor the notes would normally be discoverable, as opposing counsel can interview the witness independently. But if the witness is unavailable, then opposing counsel may be entitled to limited discovery, to the extent necessary to obtain material information. Typically, the interview would be discoverable because it is fact work product, but the attorney's notes would not be discoverable because they are opinion work product. If fact work product and opinion work product are combined in the same document, then the opinion work product would be redacted before the document is produced.

\section{Federal Rule of Civil Procedure 26: General Provisions Governing Discovery}

b. Discovery Scope and Limits.

3. Trial Preparation: Materials.

A. Documents and Tangible Things. Ordinarily, a party may not discover documents and tangible things that are prepared in anticipation of litigation or for trial by or for another party or its representative (including the other party's attorney, consultant, surety, indemnitor, insurer, or agent). But, subject to Rule 26(b)(4), those materials may be discovered if:

i. $\quad$ they are otherwise discoverable under Rule 26(b)(1); and

ii. the party shows that it has substantial need for the materials to prepare its case and cannot, without undue hardship, obtain their substantial equivalent by other means.

B. Protection Against Disclosure. If the court orders discovery of those materials, it must protect against disclosure of the mental impressions, conclusions, opinions, or legal theories of a party's attorney or other representative concerning the litigation.

C. Previous Statement. Any party or other person may, on request and without the required showing, obtain the person's own previous statement about the action or its subject matter. If the request is refused, the person may move for a court order, and Rule 37(a)(5) applies to the award of expenses. A previous statement is either:

i. a written statement that the person has signed or otherwise adopted or approved; or

ii. a contemporaneous stenographic, mechanical, electrical, or other recording-or a transcription of it-that recites substantially verbatim the person's oral statement. 


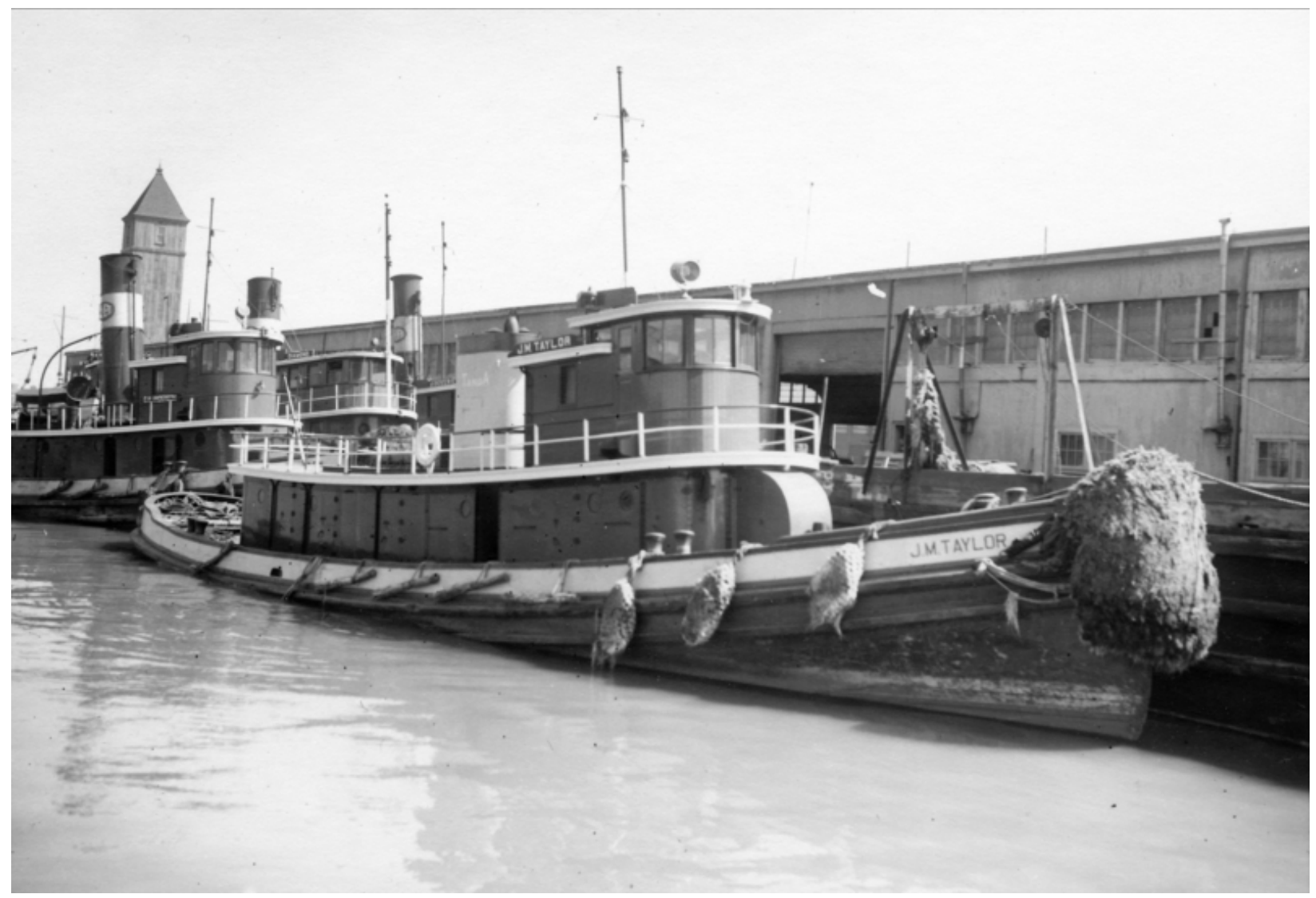

The J.M. Taylor, Philadelphia, Pa. ( 1940)

Hickman v. Taylor, 329 U.S. 495 (1947)

Summary: A tugboat sank and five crewmen died. The owners and insurers were represented by Fortenbaugh, who interviewed the surviving crewmen and memorialized the interviews. The estates of the dead crewmen filed wrongful death actions against the owners, all of which settled but one. Plaintiff's counsel asked Fortenbaugh to produce any information related to the interviews. Fortenbaugh refused, the district court ordered him to produce the information, and the circuit court reversed, under the work product doctrine. The Supreme Court affirmed, holding that work product is discoverable only with a sufficient showing of necessity.

MR. JUSTICE MURPHY delivered the opinion of the Court.

This case presents an important problem under the Federal Rules of Civil Procedure as to the extent to which a party may inquire into oral and written statements of witnesses, or other information, secured by an adverse party's counsel in the course of preparation for possible litigation after a claim has arisen. Examination into a person's files and records, including those resulting from the professional activities of an attorney, must be judged with care. It is not without reason that various safeguards have been established to preclude unwarranted excursions into the privacy of a man's work. At the same time, public policy supports reasonable 
and necessary inquiries. Properly to balance these competing interests is a delicate and difficult task.

On February 7, 1943, the tug "J.M. Taylor" sank while engaged in helping to tow a car float of the Baltimore \& Ohio Railroad across the Delaware River at Philadelphia. The accident was apparently unusual in nature, the cause of it still being unknown. Five of the nine crew members were drowned. Three days later the tug owners and the underwriters employed a law firm, of which respondent Fortenbaugh is a member, to defend them against potential suits by representatives of the deceased crew members and to sue the railroad for damages to the tug.

A public hearing was held on March 4, 1943, before the United States Steamboat Inspectors, at which the four survivors were examined. This testimony was recorded and made available to all interested parties. Shortly thereafter, Fortenbaugh privately interviewed the survivors and took statements from them with an eye toward the anticipated litigation; the survivors signed these statements on March 29. Fortenbaugh also interviewed other persons believed to have some information relating to the accident and in some cases he made memoranda of what they told him. At the time when Fortenbaugh secured the statements of the survivors, representatives of two of the deceased crew members had been in communication with him. Ultimately claims were presented by representatives of all five of the deceased; four of the claims, however, were settled without litigation. The fifth claimant, petitioner herein, brought suit in a federal court under the Jones Act on November 26, 1943, naming as defendants the two tug owners, individually and as partners, and the railroad.

One year later, petitioner filed 39 interrogatories directed to the tug owners. The 38th interrogatory read: "State whether any statements of the members of the crews of the Tugs 'J.M. Taylor' and 'Philadelphia' or of any other vessel were taken in connection with the towing of the car float and the sinking of the Tug 'John M. Taylor.' Attach hereto exact copies of all such statements if in writing, and if oral, set forth in detail the exact provisions of any such oral statements or reports."

Supplemental interrogatories asked whether any oral or written statements, records, reports or other memoranda had been made concerning any matter relative to the towing operation, the sinking of the tug, the salvaging and repair of the tug, and the death of the deceased. If the answer was in the affirmative, the tug owners were then requested to set forth the nature of all such records, reports, statements or other memoranda.

The tug owners, through Fortenbaugh, answered all of the interrogatories except No. 38 and the supplemental ones just described. While admitting that statements of the survivors had been taken, they declined to summarize or set forth the contents. They did so on the ground that such requests called "for privileged matter obtained in preparation for litigation" and constituted "an attempt to obtain indirectly counsel's private files." It was claimed that answering these requests "would involve practically turning over not only the complete files, but also the telephone records and, almost, the thoughts of counsel." 
In connection with the hearing on these objections, Fortenbaugh made a written statement and gave an informal oral deposition explaining the circumstances under which he had taken the statements. But he was not expressly asked in the deposition to produce the statements. The District Court for the Eastern District of Pennsylvania, sitting en banc, held that the requested matters were not privileged. The court then decreed that the tug owners and Fortenbaugh, as counsel and agent for the tug owners, forthwith "answer Plaintiff's 38th interrogatory and supplementary interrogatories; produce all written statements of witnesses obtained by Mr. Fortenbaugh, as counsel and agent for Defendants; state in substance any fact concerning this case which Defendants learned through oral statements made by witnesses to Mr. Fortenbaugh whether or not included in his private memoranda and produce Mr. Fortenbaugh's memoranda containing statements of fact by witnesses or to submit these memoranda to the Court for determination of those portions which should be revealed to Plaintiff." Upon their refusal, the court adjudged them in contempt and ordered them imprisoned until they complied.

The Third Circuit Court of Appeals, also sitting en banc, reversed the judgment of the District Court. It held that the information here sought was part of the "work product of the lawyer" and hence privileged from discovery under the Federal Rules of Civil Procedure. The importance of the problem, which has engendered a great divergence of views among district courts, led us to grant certiorari.

The pre-trial deposition-discovery mechanism established by Rules 26 to 37 is one of the most significant innovations of the Federal Rules of Civil Procedure. Under the prior federal practice, the pre-trial functions of notice-giving, issue-formulation and fact-revelation were performed primarily and inadequately by the pleadings. Inquiry into the issues and the facts before trial was narrowly confined and was often cumbersome in method. The new rules, however, restrict the pleadings to the task of general notice-giving and invest the deposition-discovery process with a vital role in the preparation for trial. The various instruments of discovery now serve (1) as a device, along with the pre-trial hearing under Rule 16, to narrow and clarify the basic issues between the parties, and (2) as a device for ascertaining the facts, or information as to the existence or whereabouts of facts, relative to those issues. Thus civil trials in the federal courts no longer need be carried on in the dark. The way is now clear, consistent with recognized privileges, for the parties to obtain the fullest possible knowledge of the issues and facts before trial.

In urging that he has a right to inquire into the materials secured and prepared by Fortenbaugh, petitioner emphasizes that the deposition-discovery portions of the Federal Rules of Civil Procedure are designed to enable the parties to discover the true facts and to compel their disclosure wherever they may be found. It is said that inquiry may be made under these rules, epitomized by Rule 26, as to any relevant matter which is not privileged; and since the discovery provisions are to be applied as broadly and liberally as possible, the privilege limitation must be restricted to its narrowest bounds. On the premise that the attorney-client privilege is the one involved in this case, petitioner argues that it must be strictly confined to confidential communications made by a client to his attorney. And since the materials here in issue were 
secured by Fortenbaugh from third persons rather than from his clients, the tug owners, the conclusion is reached that these materials are proper subjects for discovery under Rule 26.

As additional support for this result, petitioner claims that to prohibit discovery under these circumstances would give a corporate defendant a tremendous advantage in a suit by an individual plaintiff. Thus in a suit by an injured employee against a railroad or in a suit by an insured person against an insurance company the corporate defendant could pull a dark veil of secrecy over all the pertinent facts it can collect after the claim arises merely on the assertion that such facts were gathered by its large staff of attorneys and claim agents. At the same time, the individual plaintiff, who often has direct knowledge of the matter in issue and has no counsel until some time after his claim arises could be compelled to disclose all the intimate details of his case. By endowing with immunity from disclosure all that a lawyer discovers in the course of his duties, it is said, the rights of individual litigants in such cases are drained of vitality and the lawsuit becomes more of a battle of deception than a search for truth.

But framing the problem in terms of assisting individual plaintiffs in their suits against corporate defendants is unsatisfactory. Discovery concededly may work to the disadvantage as well as to the advantage of individual plaintiffs. Discovery, in other words, is not a one-way proposition. It is available in all types of cases at the behest of any party, individual or corporate, plaintiff or defendant. The problem thus far transcends the situation confronting this petitioner. And we must view that problem in light of the limitless situations where the particular kind of discovery sought by petitioner might be used.

We agree, of course, that the deposition-discovery rules are to be accorded a broad and liberal treatment. No longer can the time-honored cry of "fishing expedition" serve to preclude a party from inquiring into the facts underlying his opponent's case. Mutual knowledge of all the relevant facts gathered by both parties is essential to proper litigation. To that end, either party may compel the other to disgorge whatever facts he has in his possession. The deposition-discovery procedure simply advances the stage at which the disclosure can be compelled from the time of trial to the period preceding it, thus reducing the possibility of surprise. But discovery, like all matters of procedure, has ultimate and necessary boundaries. As indicated by Rules 30 (b) and (d) and 31(d), limitations inevitably arise when it can be shown that the examination is being conducted in bad faith or in such a manner as to annoy, embarrass or oppress the person subject to the inquiry. And as Rule 26(b) provides, further limitations come into existence when the inquiry touches upon the irrelevant or encroaches upon the recognized domains of privilege.

We also agree that the memoranda, statements and mental impressions in issue in this case fall outside the scope of the attorney-client privilege and hence are not protected from discovery on that basis. It is unnecessary here to delineate the content and scope of that privilege as recognized in the federal courts. For present purposes, it suffices to note that the protective cloak of this privilege does not extend to information which an attorney secures from a witness while acting for his client in anticipation of litigation. Nor does this privilege concern the memoranda, briefs, communications and other writings prepared by counsel for his own use in 
prosecuting his client's case; and it is equally unrelated to writings which reflect an attorney's mental impressions, conclusions, opinions or legal theories.

But the impropriety of invoking that privilege does not provide an answer to the problem before us. Petitioner has made more than an ordinary request for relevant, non-privileged facts in the possession of his adversaries or their counsel. He has sought discovery as of right of oral and written statements of witnesses whose identity is well known and whose availability to petitioner appears unimpaired. He has sought production of these matters after making the most searching inquiries of his opponents as to the circumstances surrounding the fatal accident, which inquiries were sworn to have been answered to the best of their information and belief. Interrogatories were directed toward all the events prior to, during and subsequent to the sinking of the tug. Full and honest answers to such broad inquiries would necessarily have included all pertinent information gleaned by Fortenbaugh through his interviews with the witnesses. Petitioner makes no suggestion, and we cannot assume, that the tug owners or Fortenbaugh were incomplete or dishonest in the framing of their answers. In addition, petitioner was free to examine the public testimony of the witnesses taken before the United States Steamboat Inspectors. We are thus dealing with an attempt to secure the production of written statements and mental impressions contained in the files and the mind of the attorney Fortenbaugh without any showing of necessity or any indication or claim that denial of such production would unduly prejudice the preparation of petitioner's case or cause him any hardship or injustice. For aught that appears, the essence of what petitioner seeks either has been revealed to him already through the interrogatories or is readily available to him direct from the witnesses for the asking.

The District Court, after hearing objections to petitioner's request, commanded Fortenbaugh to produce all written statements of witnesses and to state in substance any facts learned through oral statements of witnesses to him. Fortenbaugh was to submit any memoranda he had made of the oral statements so that the court might determine what portions should be revealed to petitioner. All of this was ordered without any showing by petitioner, or any requirement that he make a proper showing, of the necessity for the production of any of this material or any demonstration that denial of production would cause hardship or injustice. The court simply ordered production on the theory that the facts sought were material and were not privileged as constituting attorney-client communications.

In our opinion, neither Rule 26 nor any other rule dealing with discovery contemplates production under such circumstances. That is not because the subject matter is privileged or irrelevant, as those concepts are used in these rules. ${ }^{81}$ Here is simply an attempt, without

${ }^{81}$ The English courts have developed the concept of privilege to include all documents prepared by or for counsel with a view to litigation. "All documents which are called into existence for the purpose - but not necessarily the sole purpose - of assisting the deponent or his legal advisers in any actual or anticipated litigation are privileged from production. Thus all proofs, briefs, draft pleadings, etc., are privileged; but not counsel's indorsement on the outside of his brief, nor any deposition or notes of evidence given publicly party bona fide for the use of his solicitor for the purposes of the action, whether in fact so used or not. Reports by a company's servant, if made in the ordinary course of routine, are not privileged, even though it is desirable that the solicitor should have them and they are subsequently sent to him; but if the solicitor 
purported necessity or justification, to secure written statements, private memoranda and personal recollections prepared or formed by an adverse party's counsel in the course of his legal duties. As such, it falls outside the arena of discovery and contravenes the public policy underlying the orderly prosecution and defense of legal claims. Not even the most liberal of discovery theories can justify unwarranted inquiries into the files and the mental impressions of an attorney.

Historically, a lawyer is an officer of the court and is bound to work for the advancement of justice while faithfully protecting the rightful interests of his clients. In performing his various duties, however, it is essential that a lawyer work with a certain degree of privacy, free from unnecessary intrusion by opposing parties and their counsel. Proper preparation of a client's case demands that he assemble information, sift what he considers to be the relevant from the irrelevant facts, prepare his legal theories and plan his strategy without undue and needless interference. That is the historical and the necessary way in which lawyers act within the framework of our system of jurisprudence to promote justice and to protect their clients' interests. This work is reflected, of course, in interviews, statements, memoranda, correspondence, briefs, mental impressions, personal beliefs, and countless other tangible and intangible ways - aptly though roughly termed by the Circuit Court of Appeals in this case as the "work product of the lawyer." Were such materials open to opposing counsel on mere demand, much of what is now put down in writing would remain unwritten. An attorney's thoughts, heretofore inviolate, would not be his own. Inefficiency, unfairness and sharp practices would inevitably develop in the giving of legal advice and in the preparation of cases for trial. The effect on the legal profession would be demoralizing. And the interests of the clients and the cause of justice would be poorly served.

We do not mean to say that all written materials obtained or prepared by an adversary's counsel with an eye toward litigation are necessarily free from discovery in all cases. Where relevant and non-privileged facts remain hidden in an attorney's file and where production of those facts is essential to the preparation of one's case, discovery may properly be had. Such written statements and documents might, under certain circumstances, be admissible in evidence or give clues as to the existence or location of relevant facts. Or they might be useful for purposes of impeachment or corroboration. And production might be justified where the witnesses are no longer available or can be reached only with difficulty. Were production of written statements and documents to be precluded under such circumstances, the liberal ideals of the depositiondiscovery portions of the Federal Rules of Civil Procedure would be stripped of much of their meaning. But the general policy against invading the privacy of an attorney's course of preparation is so well recognized and so essential to an orderly working of our system of legal procedure that a burden rests on the one who would invade that privacy to establish adequate reasons to justify production through a subpoena or court order. That burden, we believe, is necessarily implicit in the rules as now constituted.

has requested that such documents shall always be prepared for his use and this was one of the reasons why they were prepared, they need not be disclosed." 
Rule 30(b), as presently written, gives the trial judge the requisite discretion to make a judgment as to whether discovery should be allowed as to written statements secured from witnesses. But in the instant case there was no room for that discretion to operate in favor of the petitioner. No attempt was made to establish any reason why Fortenbaugh should be forced to produce the written statements. There was only a naked, general demand for these materials as of right and a finding by the District Court that no recognizable privilege was involved. That was insufficient to justify discovery under these circumstances and the court should have sustained the refusal of the tug owners and Fortenbaugh to produce.

But as to oral statements made by witnesses to Fortenbaugh, whether presently in the form of his mental impressions or memoranda, we do not believe that any showing of necessity can be made under the circumstances of this case so as to justify production. Under ordinary conditions, forcing an attorney to repeat or write out all that witnesses have told him and to deliver the account to his adversary gives rise to grave dangers of inaccuracy and untrustworthiness. No legitimate purpose is served by such production. The practice forces the attorney to testify as to what he remembers or what he saw fit to write down regarding witnesses' remarks. Such testimony could not qualify as evidence; and to use it for impeachment or corroborative purposes would make the attorney much less an officer of the court and much more an ordinary witness. The standards of the profession would thereby suffer.

Denial of production of this nature does not mean that any material, non-privileged facts can be hidden from the petitioner in this case. He need not be unduly hindered in the preparation of his case, in the discovery of facts or in his anticipation of his opponents' position. Searching interrogatories directed to Fortenbaugh and the tug owners, production of written documents and statements upon a proper showing and direct interviews with the witnesses themselves all serve to reveal the facts in Fortenbaugh's possession to the fullest possible extent consistent with public policy. Petitioner's counsel frankly admits that he wants the oral statements only to help prepare himself to examine witnesses and to make sure that he has overlooked nothing. That is insufficient under the circumstances to permit him an exception to the policy underlying the privacy of Fortenbaugh's professional activities. If there should be a rare situation justifying production of these matters, petitioner's case is not of that type.

We fully appreciate the wide-spread controversy among the members of the legal profession over the problem raised by this case. It is a problem that rests on what has been one of the most hazy frontiers of the discovery process. But until some rule or statute definitely prescribes otherwise, we are not justified in permitting discovery in a situation of this nature as a matter of unqualified right. When Rule 26 and the other discovery rules were adopted, this Court and the members of the bar in general certainly did not believe or contemplate that all the files and mental processes of lawyers were thereby opened to the free scrutiny of their adversaries. And we refuse to interpret the rules at this time so as to reach so harsh and unwarranted a result.

We therefore affirm the judgment of the Circuit Court of Appeals.

MR. JUSTICE JACKSON, concurring. 
The narrow question in this case concerns only one of thirty-nine interrogatories which defendants and their counsel refused to answer. As there was persistence in refusal after the court ordered them to answer it, counsel and clients were committed to jail by the district court until they should purge themselves of contempt.

The interrogatory asked whether statements were taken from the crews of the tugs involved in the accident, or of any other vessel, and demanded "Attach hereto exact copies of all such statements if in writing, and if oral, set forth in detail the exact provisions of any such oral statements or reports." The question is simply whether such a demand is authorized by the rules relating to various aspects of "discovery."

The primary effect of the practice advocated here would be on the legal profession itself. But it too often is overlooked that the lawyer and the law office are indispensable parts of our administration of justice. Law-abiding people can go nowhere else to learn the ever changing and constantly multiplying rules by which they must behave and to obtain redress for their wrongs. The welfare and tone of the legal profession is therefore of prime consequence to society, which would feel the consequences of such a practice as petitioner urges secondarily but certainly.

"Discovery" is one of the working tools of the legal profession. It traces back to the equity bill of discovery in English Chancery practice and seems to have had a forerunner in Continental practice. Since 1848 when the draftsmen of New York's Code of Procedure recognized the importance of a better system of discovery the impetus to extend and expand discovery, as well as the opposition to it, has come from within the Bar itself. It happens in this case that it is the plaintiff's attorney who demands such unprecedented latitude of discovery and, strangely enough, amicus briefs in his support have been filed by several labor unions representing plaintiffs as a class. It is the history of the movement for broader discovery, however, that in actual experience the chief opposition to its extension has come from lawyers who specialize in representing plaintiffs, because defendants have made liberal use of it to force plaintiffs to disclose their cases in advance. Discovery is a two-edged sword and we cannot decide this problem on any doctrine of extending help to one class of litigants.

It seems clear and long has been recognized that discovery should provide a party access to anything that is evidence in his case. It seems equally clear that discovery should not nullify the privilege of confidential communication between attorney and client. But those principles give us no real assistance here because what is being sought is neither evidence nor is it a privileged communication between attorney and client.

To consider first the most extreme aspect of the requirement in litigation here, we find it calls upon counsel, if he has had any conversations with any of the crews of the vessels in question or of any other, to "set forth in detail the exact provision of any such oral statements or reports." Thus the demand is not for the production of a transcript in existence but calls for the creation of a written statement not in being. But the statement by counsel of what a witness told him is not 
evidence when written. Plaintiff could not introduce it to prove his case. What, then, is the purpose sought to be served by demanding this of adverse counsel?

Counsel for the petitioner candidly said on argument that he wanted this information to help prepare himself to examine witnesses, to make sure he overlooked nothing. He bases his claim to it in his brief on the view that the Rules were to do away with the old situation where a law suit developed into "a battle of wits between counsel." But a common law trial is and always should be an adversary proceeding. Discovery was hardly intended to enable a learned profession to perform its functions either without wits or on wits borrowed from the adversary.

The real purpose and the probable effect of the practice ordered by the district court would be to put trials on a level even lower than a "battle of wits." I can conceive of no practice more demoralizing to the Bar than to require a lawyer to write out and deliver to his adversary an account of what witnesses have told him. Even if his recollection were perfect, the statement would be his language, permeated with his inferences. Every one who has tried it knows that it is almost impossible so fairly to record the expressions and emphasis of a witness that when he testifies in the environment of the court and under the influence of the leading question there will not be departures in some respects. Whenever the testimony of the witness would differ from the "exact" statement the lawyer had delivered, the lawyer's statement would be whipped out to impeach the witness. Counsel producing his adversary's "inexact" statement could lose nothing by saying, "Here is a contradiction, gentlemen of the jury. I do not know whether it is my adversary or his witness who is not telling the truth, but one is not." Of course, if this practice were adopted, that scene would be repeated over and over again. The lawyer who delivers such statements often would find himself branded a deceiver afraid to take the stand to support his own version of the witness's conversation with him, or else he will have to go on the stand to defend his own credibility - perhaps against that of his chief witness, or possibly even his client.

Every lawyer dislikes to take the witness stand and will do so only for grave reasons. This is partly because it is not his role; he is almost invariably a poor witness. But he steps out of professional character to do it. He regrets it; the profession discourages it. But the practice advocated here is one which would force him to be a witness, not as to what he has seen or done but as to other witnesses' stories, and not because he wants to do so but in self-defense.

And what is the lawyer to do who has interviewed one whom he believes to be a biased, lying or hostile witness to get his unfavorable statements and know what to meet? He must record and deliver such statements even though he would not vouch for the credibility of the witness by calling him. Perhaps the other side would not want to call him either, but the attorney is open to the charge of suppressing evidence at the trial if he fails to call such a hostile witness even though he never regarded him as reliable or truthful.

Having been supplied the names of the witnesses, petitioner's lawyer gives no reason why he cannot interview them himself. If an employee-witness refuses to tell his story, he, too, may be examined under the Rules. He may be compelled on discovery, as fully as on the trial, to 
disclose his version of the facts. But that is his own disclosure - it can be used to impeach him if he contradicts it and such a deposition is not useful to promote an unseemly disagreement between the witness and the counsel in the case.

It is true that the literal language of the Rules would admit of an interpretation that would sustain the district court's order. So the literal language of the Act of Congress which makes "any writing or record made as a memorandum or record of any occurrence, or event" admissible as evidence, would have allowed the railroad company to put its engineer's accident statements in evidence. But all such procedural measures have a background of custom and practice which was assumed by those who wrote and should be by those who apply them. We reviewed the background of the Act and the consequences on the trial of negligence cases of allowing railroads and others to put in their statements and thus to shield the crew from crossexamination. We said, "Such a major change which opens wide the door to avoidance of crossexamination should not be left to implication." We pointed out that there, as here, the "several hundred years of history behind the Act indicate the nature of the reforms which it was designed to effect." We refused to apply it beyond that point. We should follow the same course of reasoning here. Certainly nothing in the tradition or practice of discovery up to the time of these Rules would have suggested that they would authorize such a practice as here proposed.

The question remains as to signed statements or those written by witnesses. Such statements are not evidence for the defendant. Nor should I think they ordinarily could be evidence for the plaintiff. But such a statement might be useful for impeachment of the witness who signed it, if he is called and if he departs from the statement. There might be circumstances, too, where impossibility or difficulty of access to the witness or his refusal to respond to requests for information or other facts would show that the interests of justice require that such statements be made available. Production of such statements are governed by Rule 34 and on "showing good cause therefor" the court may order their inspection, copying or photographing. No such application has here been made; the demand is made on the basis of right, not on showing of cause.

I agree to the affirmance of the judgment of the Circuit Court of Appeals which reversed the district court.

\section{Questions:}

1. Why did the Supreme Court find that the work product doctrine is justified?

2. How does the justification for the work product doctrine differ from the justification for the attorney-client privilege?

3. How does the protection provided by the work product doctrine differ from the protection provided by the attorney-client privilege?

4. Why didn't plaintiff's counsel make a sufficient showing of necessity in this case? 


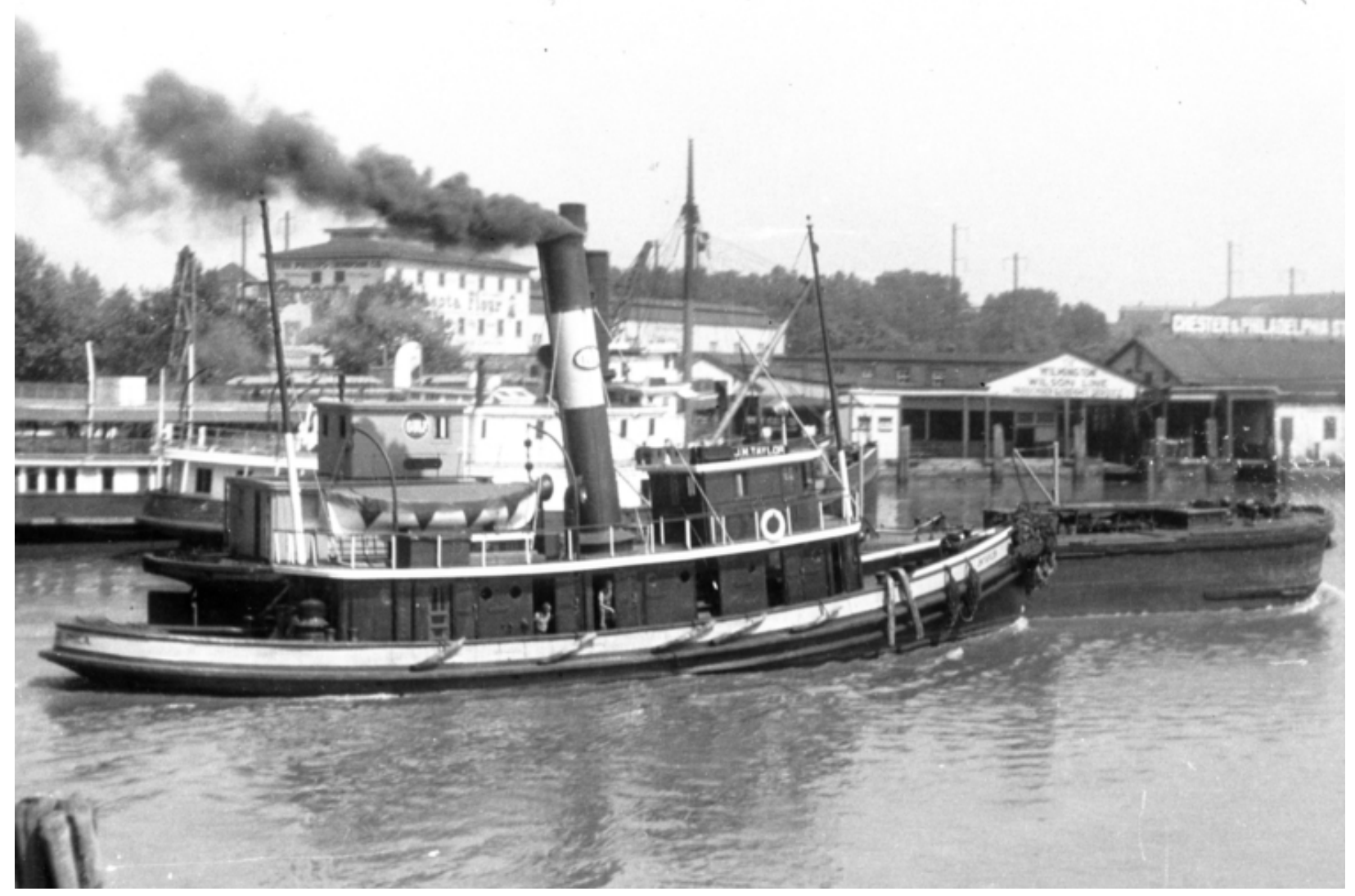

The J.M. Taylor, Philadelphia, Pa. ( 1940)

Upjohn Co. v. United States, 449 U.S. 383 (1981)

Summary: The Supreme Court held that notes and memoranda generated by Upjohn's attorneys that were not protected by the attorney-client privilege could still be protected by the work product doctrine. Specifically, it found that necessity alone was not enough to require production of opinion work product.

Our decision that the communications by Upjohn employees to counsel are covered by the attorney-client privilege disposes of the case so far as the responses to the questionnaires and any notes reflecting responses to interview questions are concerned. The summons reaches further, however, and Thomas has testified that his notes and memoranda of interviews go beyond recording responses to his questions. To the extent that the material subject to the summons is not protected by the attorney-client privilege as disclosing communications between an employee and counsel, we must reach the ruling by the Court of Appeals that the work-product doctrine does not apply. 
While conceding the applicability of the work-product doctrine, the Government asserts that it has made a sufficient showing of necessity to overcome its protections. The Magistrate apparently so found. The Government relies on the following language in Hickman:

We do not mean to say that all written materials obtained or prepared by an adversary's counsel with an eye toward litigation are necessarily free from discovery in all cases. Where relevant and nonprivileged facts remain hidden in an attorney's file and where production of those facts is essential to the preparation of one's case, discovery may properly be had. And production might be justified where the witnesses are no longer available or can be reached only with difficulty.

The Government stresses that interviewees are scattered across the globe and that Upjohn has forbidden its employees to answer questions it considers irrelevant. The above-quoted language from Hickman, however, did not apply to "oral statements made by witnesses whether presently in the form of the attorney's mental impressions or memoranda." As to such material the Court did "not believe that any showing of necessity can be made under the circumstances of this case so as to justify production. If there should be a rare situation justifying production of these matters, petitioner's case is not of that type." Forcing an attorney to disclose notes and memoranda of witnesses' oral statements is particularly disfavored because it tends to reveal the attorney's mental processes.

Rule 26 accords special protection to work product revealing the attorney's mental processes. The Rule permits disclosure of documents and tangible things constituting attorney work product upon a showing of substantial need and inability to obtain the equivalent without undue hardship. This was the standard applied by the Magistrate. Rule 26 goes on, however, to state that "in ordering discovery of such materials when the required showing has been made, the court shall protect against disclosure of the mental impressions, conclusions, opinions or legal theories of an attorney or other representative of a party concerning the litigation." Although this language does not specifically refer to memoranda based on oral statements of witnesses, the Hickman court stressed the danger that compelled disclosure of such memoranda would reveal the attorney's mental processes. It is clear that this is the sort of material the draftsmen of the Rule had in mind as deserving special protection.

Based on the foregoing, some courts have concluded that no showing of necessity can overcome protection of work product which is based on oral statements from witnesses. Those courts declining to adopt an absolute rule have nonetheless recognized that such material is entitled to special protection.

We do not decide the issue at this time. It is clear that the Magistrate applied the wrong standard when he concluded that the Government had made a sufficient showing of necessity to overcome the protections of the work-product doctrine. The Magistrate applied the "substantial need" and "without undue hardship" standard articulated in the first part of Rule 26(b)(3). The notes and memoranda sought by the Government here, however, are work product based on oral statements. If they reveal communications, they are, in this case, 
protected by the attorney-client privilege. To the extent they do not reveal communications, they reveal the attorneys' mental processes in evaluating the communications. As Rule 26 and Hickman make clear, such work product cannot be disclosed simply on a showing of substantial need and inability to obtain the equivalent without undue hardship.

While we are not prepared at this juncture to say that such material is always protected by the work-product rule, we think a far stronger showing of necessity and unavailability by other means than was made by the Government or applied by the Magistrate in this case would be necessary to compel disclosure. Since the Court of Appeals thought that the work-product protection was never applicable in an enforcement proceeding such as this, and since the Magistrate whose recommendations the District Court adopted applied too lenient a standard of protection, we think the best procedure with respect to this aspect of the case would be to reverse the judgment of the Court of Appeals for the Sixth Circuit and remand the case to it for such further proceedings in connection with the work-product claim as are consistent with this opinion.

\section{Questions:}

1. How does the Court distinguish between fact work product and opinion work product?

2. Why is the standard for discovery of fact work product lower than the standard for opinion work product?

3. Should opinion work product ever be discoverable? What if it is inextricable from fact work product?

4. How would discoverability of fact or opinion work product affect the incentives of attorneys?

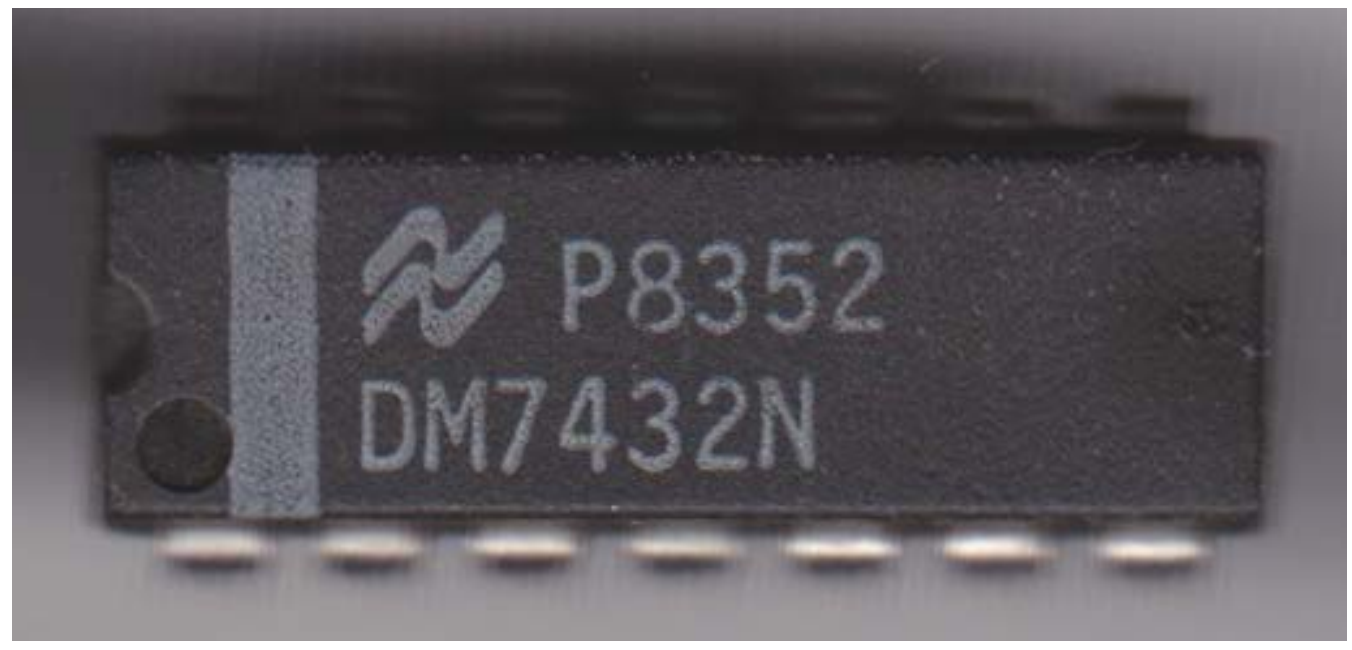

National Semiconductor DM7432N Quad 2-Input OR Gates

Sporck v. Peil, 759 F. 2d 312 (3d Cir. 1985)

Summary: Peil filed an action against Sporck and Sprague, alleging that they conspired to inflate the value of National Semiconductor stock. Among other things, defendants 
produced more than 100,000 documents. Counsel for defendants showed Sporck documents while preparing him for a deposition. Plaintiff asked Sporck to identify all of the documents he reviewed in preparation for the deposition. Sporck refused, the district court ordered production, and the circuit court reversed, holding that the attorney's choice of which documents to show Sporck was opinion work product.

JAMES HUNTER, III, Circuit Judge.

This case arises on a Petition for Writ of Mandamus involving a discovery dispute between the parties to a securities fraud class action suit. The underlying action involves an allegation by plaintiff-respondent Raymond K. Peil that defendant National Semiconductor Corporation, defendant-petitioner Charles F. Sporck, NSC's president, and defendant Peter J. Sprague, NSC's chairman, conspired to inflate artificially the value of NSC stock, in order to enable Sporck and Sprague to sell their own shares at the inflated level. The wrongful conduct alleged includes various misrepresentations and nondisclosures of material facts during an eight-month period continuing from July 1, 1976, until March 1, 1977.

During pretrial discovery, attorneys for Peil served numerous sets of combined interrogatory and document requests on defendants. In response, defendants produced hundreds of thousands of documents, from which Peil's attorneys selected more than 100,000 for copying. There is no allegation in this case that defendants have improperly concealed or refused to produce requested documents.

The issue presently before this court arose on May 16, 1983, at the deposition of defendantpetitioner Sporck. Prior to the deposition, counsel for defendants had prepared Sporck for his expected week-long deposition by showing him an unknown quantity of the numerous documents produced by defendants in response to plaintiff's discovery requests. Defense counsel selected and compiled these documents in a folder in Philadelphia, and transported them to California solely for the deposition. According to defense counsel, the selected documents represented, as a group, counsel's legal opinion as to the evidence relevant both to the allegations in the case and the possible legal defenses. It is conceded that none of the individual documents, in their redacted form, contained work product of defense counsel.

At the inception of the Sporck deposition, Peil's attorney asked: "Mr. Sporck, in preparation for this deposition, did you have occasion to examine any documents?" Sporck answered affirmatively, and Peil's attorney first orally, and then by written motion pursuant to Federal Rule of Civil Procedure 34, requested identification and production of "all documents examined, reviewed or referred to by Charles E. Sporck in preparation for the session of his deposition commencing May 16, 1983." Defense counsel refused to identify the documents, arguing first that all the documents had previously been produced, and second, that the select grouping of the documents was attorney work product protected from discovery by Federal Rule of Civil Procedure 26(b)(3). Defense counsel agreed, however, to allow Peil's counsel to ask Sporck about his reliance on individual documents in the context of specific factual questions, and Sporck's deposition continued on this basis. 
Peil filed a motion to compel identification and production of the selected documents, on the ground that all documents used in preparing a witness for a deposition are properly discoverable under Federal Rule of Evidence 612. Judge John B. Hannum granted Peil's motion, and ordered that defendant produce or identify all documents reviewed by Sporck in preparation for his deposition. Upon petitioner's motion for reconsideration, Judge Hannum reaffirmed his order, holding that although the select grouping of documents constituted attorney work product, it was not "opinion" work product entitled to absolute protection, and that the principles behind Federal Rule of Evidence 612 supported Peil's claim to identification of the documents. Sporck now asks this court to issue a writ of mandamus directing the trial court to vacate both orders.

The threshold issue in this case is whether the selection process of defense counsel in grouping certain documents together out of the thousands produced in this litigation is work product entitled to protection under Federal Rule of Civil Procedure 26(b)(3) and the principles of Hickman v. Taylor. Petitioner concedes that the individual documents that comprise the grouping are not attorney work product, but argues that the selection process itself represents defense counsel's mental impressions and legal opinions as to how the evidence in the documents relates to the issues and defenses in the litigation. Because identification of the documents as a group will reveal defense counsel's selection process, and thus his mental impressions, petitioner argues that identification of the documents as a group must be prevented to protect defense counsel's work product. We agree.

The work product doctrine had its modern genesis in the seminal opinion in Hickman v. Taylor. In Hickman, the Court rejected "an attempt, without purported necessity or justification, to secure written statements, private memoranda and personal recollections prepared or formed by an adverse party's counsel in the course of his legal duties." Preserving the privacy of preparation that is essential to the attorney's adversary role is the central justification for the work product doctrine. Without this zone of privacy:

Much of what is now put down in writing would remain unwritten. An attorney's thoughts, heretofore inviolate, would not be his own. Inefficiency, unfairness and sharp practices would inevitably develop in the giving of legal advice and in the preparation of cases for trial. The effect on the legal profession would be demoralizing. And the interests of the clients and the cause of justice would be poorly served.

The work product doctrine as articulated in Hickman has been partially codified in Federal Rule of Civil Procedure 26(b)(3). That rule conditions the production of "documents and tangible things" prepared in anticipation of litigation by or for an opposing party on the moving party's showing of substantial need and undue hardship. Even where such a showing is made, however, the trial court, in ordering the production of such materials, "shall protect against disclosure of the mental impressions, conclusions, opinions, or legal theories of an attorney or other representative of a party concerning the litigation." Thus, Rule 26(b)(3) recognizes the distinction between "ordinary" and "opinion" work product first articulated by the Supreme Court. 
Opinion work product includes such items as an attorney's legal strategy, his intended lines of proof, his evaluation of the strengths and weaknesses of his case, and the inferences he draws from interviews of witnesses. Such material is accorded an almost absolute protection from discovery because any slight factual content that such items may have is generally outweighed by the adversary system's interest in maintaining the privacy of an attorney's thought processes and in ensuring that each side relies on its own wit in preparing their respective cases.

We believe that the selection and compilation of documents by counsel in this case in preparation for pretrial discovery falls within the highly-protected category of opinion work product. As the court succinctly stated in James Julian, Inc. v. Raytheon Co.:

In selecting and ordering a few documents out of thousands counsel could not help but reveal important aspects of his understanding of the case. Indeed, in a case such as this, involving extensive document discovery, the process of selection and distillation is often more critical than pure legal research. There can be no doubt that at least in the first instance the binders were entitled to protection as work product.

Further, in selecting the documents that he thought relevant to Sporck's deposition, defense counsel engaged in proper and necessary preparation of his client's case. As the Supreme Court noted in Hickman:

Proper preparation of a client's case demands that he assemble information, sift what he considers to be the relevant from the irrelevant facts, prepare his legal theories and plan his strategy without undue and needless interference. That is the historical and the necessary way in which lawyers act within the framework of our system of jurisprudence to promote justice and to protect their client's interest.

In the instant case, without the protection that the work product doctrine accords his preparation, defense counsel may have foregone a sifting of the documents, or at the very least chosen not to show the documents to petitioner. As a result, petitioner may not have been as well-prepared for his deposition, and neither plaintiff nor defendant would have realized the full benefit of a well-prepared deponent's testimony. For these reasons, Rule 26(b)(3) placed an obligation on the trial court to protect against unjustified disclosure of defense counsel's selection process.

This conclusion, however, does not end the issue. Respondent argues, and the trial court agreed, that operation of Federal Rule of Evidence 612 removed any protection that defense counsel's selection process would ordinarily enjoy. Because we find that Federal Rule of Evidence 612 does not apply to the facts of this case, we disagree.

Federal Rule of Evidence 612 provides in relevant part: 
If a witness uses a writing to refresh his memory for the purpose of testifying, (2) before testifying, if the court in its discretion determines it is necessary in the interest of justice, an adverse party is entitled to have the writing produced at the hearing, to inspect it, to cross-examine the witness thereon, and to introduce in evidence those portions which relate to the testimony of the witness.

This rule is applicable to depositions and deposition testimony. Although applicable to depositions, Rule 612 is a rule of evidence, and not a rule of discovery. Its sole purpose is evidentiary in function - "to promote the search of credibility and memory."

By its very language, Rule 612 requires that a party meet three conditions before it may obtain documents used by a witness prior to testifying: 1) the witness must use the writing to refresh his memory; 2) the witness must use the writing for the purpose of testifying; and 3) the court must determine that production is necessary in the interests of justice. The first requirement is consistent with the purposes of the rule, for if the witness is not using the document to refresh his memory, that document has no relevance to any attempt to test the credibility and memory of the witness.

The second requirement - that the witness use the document for the purpose of testifying was designed "to safeguard against using the rule as a pretext for wholesale exploration of an opposing party's files and to insure that access is limited only to those writings which may fairly be said in part to have an impact upon the testimony of the witness." As with the first requirement, the second requirement recognizes that the document is of little utility for impeachment and cross-examination without a showing that the document actually influenced the witness' testimony. Finally, the third requirement codifies the Supreme Court's holding in Goldman v. United States, that even though a witness may review notes prior to testifying, a trial court should exercise discretion to guard against "fishing expeditions among a multitude of papers which a witness may have used in preparing for trial."

In the case before us, the apparent conflict between the protected status of defense counsel's document selection process under Rule 26(b)(3) and the asserted need, for cross-examination purposes, of the identification of the documents actually selected resulted from the failure to establish the first two requirements under Rule 612. In seeking identification of all documents reviewed by petitioner prior to asking petitioner any questions concerning the subject matter of the deposition, respondent's counsel failed to establish either that petitioner relied on any documents in giving his testimony, or that those documents influenced his testimony. Without first eliciting the testimony, there existed no basis for asking petitioner the source of that testimony. We conclude, therefore, that deposing counsel failed to lay a proper foundation under Rule 612 for production of the documents selected by counsel.

Indeed, if respondent's counsel had first elicited specific testimony from petitioner, and then questioned petitioner as to which, if any, documents informed that testimony, the work product petitioner seeks to protect - counsel's opinion of the strengths and weaknesses of the case as represented by the group identification of documents selected by counsel - would not have 
been implicated. Rather, because identification of such documents would relate to specific substantive areas raised by respondent's counsel, respondent would receive only those documents which deposing counsel, through his own work product, was incisive enough to recognize and question petitioner on. The fear that counsel for petitioner's work product would be revealed would thus become groundless.

Rule 612, therefore, when properly applied, does not conflict with the protection of attorney work product of the type involved in this case. Because the trial court did not properly condition its application of Rule 612 on a showing that petitioner relied upon the requested documents for his testimony and that those documents impacted on his testimony, the court committed legal error. This error became prejudicial when it implicated work product of petitioner's counsel. Proper application of Rule 612 should never implicate an attorney's selection, in preparation for a witness' deposition, of a group of documents that he believes critical to a case. Instead, identification of such documents under Rule 612 should only result from opposing counsel's own selection of relevant areas of questioning, and from the witness' subsequent admission that his answers to those specific areas of questioning were informed by documents he had reviewed. In such a case, deposing counsel would discover the documents through his own wit, and not through the wit of his adversary.

We conclude, therefore, that the trial court committed clear error of law in ordering the identification of the documents selected by counsel. Because we are confident that the district court will proceed in accordance with our opinion without formal issuance of the writ, we will remand to the district court.

SEITZ, Circuit Judge, dissenting.

The majority approves in effect the use of the work product doctrine to prevent an identification of documents reviewed by a witness in preparation for his deposition. I dissent because I am convinced that such a ruling is an impermissible expansion of the work product doctrine at the expense of legitimate discovery.

The plaintiffs-respondents sought in the district court the discovery of relevant objective facts: the identities of the documents that the deponent reviewed prior to testifying. These facts are not, in themselves, the opinion or thought processes of an attorney. Nor were the contents of the documents, all of which had already been produced by the defendants, created by defendants' attorney in anticipation of litigation.

Yet, the defendant-petitioner claims that the mere identification of the documents examined prior to his deposition would reveal his attorney's litigation strategy. Presumably, the petitioner's argument must be that if the respondents knew which documents were reviewed, they could, upon examination of the documents identified, draw conclusions as to why each document was chosen. 
The problem with the petitioner's theory is that it assumes that one can extrapolate backwards from the results of a selection process to determine the reason a document was selected for review by the deponent. There are many reasons for showing a document or selected portions of a document to a witness. The most that can be said from the fact that the witness looked at a document is that someone thought that the document, or some portion of the document, might be useful for the preparation of the witness for his deposition. This is a far cry from the disclosure of the a lawyer's opinion work product. Even assuming that the documents were selected by the petitioner's attorney, the subject matter is so undifferentiated that its potential for invasion of work product is miniscule at best.

Every act by a litigant or his attorney gives rise to similar vague inferences. For example, a typical interrogatory from a leading treatise would permit questions of the following form: "Identify each writing which relates or refers directly or indirectly to a transaction in question." It cannot seriously be contended that an answer is not required because it would reveal the fact that the attorney thought that certain documents were relevant to the transaction.

Moreover, in order to claim the shield of opinion work product, it must be established that it is the attorney's thought processes that are revealed. The respondents' request did not require the identification of the person who selected the documents. The only disclosed connection to the petitioner's attorney in our situation is that the petitioner gratuitously volunteered the fact that his attorney selected the documents. To permit this volunteered information to provide a necessary link to attorney's thought processes, as the majority has done, is to permit the petitioner to cloak the non-work product aspects of the information sought with work product protection. Certainly an attorney cannot cloak a document under the mantle of work product by simply reviewing it. It is difficult to see how an attorney or his witness may insulate the discoverable fact that the witness reviewed a particular document by volunteering that the attorney selected the document for deposition preparation purposes.

Finally, the petitioner contends that the information sought was "fact" work product, and that the respondents have made an insufficient showing of need to require its production. Assuming without deciding that the information sought was fact work product, I would not decide this issue on a petition for a writ of mandamus. To reach this issue would require us to review a decision committed to the discretion of the district court, and such decisions do not constitute "clear and indisputable" legal error. Further, revelation of fact work product does not constitute the same sort of irreparable harm that would come from the revelation of opinion work product.

Because I find no disclosure of the attorney's work product that would provide a basis for granting the writ, I would not reach the issue of whether a proper foundation had been established for the requested information under Federal Rule of Evidence 612 or the provision covering relevant evidence found in Federal Rule of Civil Procedure 26(b)(1). Decisions on such matters are not independently reviewable on a petition seeking the extraordinary remedy of mandamus. 
Based on the record presented by the petitioner, I fail to see how any conclusions may be drawn as to what his attorney may or may not have thought about this litigation. The mere identification of documents used to prepare a witness for his deposition does not convey any meaningful information of the type entitled to protection under the work product doctrine. I would deny the petition.

\section{Questions:}

1. Why did the majority hold that the attorney's choice of which documents to show Sporck in preparation for the deposition was opinion work product?

2. Why did the dissent argue that it was not work product at all?

\section{United States v. Deloitte LLP, 610 F. 3d 129 (D.C. Cir. 2010)}

Summary: Dow Chemicals filed an action disputing a tax adjustment. Among other things, the IRS subpoenaed documents from Deloitte \& Touche, Dow's auditor. Deloitte refused to produce three documents, under the work product doctrine. The district court denied the IRS's motion to compel, finding that the documents were created in anticipation of litigation and reflected attorney thoughts, and therefore were protected by the work product doctrine. The circuit court vacated in part and affirmed in part, holding that the district court lacked sufficient information to determine whether some of the documents were work product, but did not abuse its discretion with respect to other documents.

\section{SENTELLE, Chief Judge:}

The United States appeals from a district court order denying its motion to compel Dow Chemical Company's independent auditor, Deloitte \& Touche USA, LLP, to produce three documents in connection with ongoing tax litigation between Dow and the government. The district court ruled that all three documents were protected from discovery under the workproduct doctrine. On appeal, the government contends that one of the documents is not work product because it was prepared by Deloitte during the audit process. In addition, while it concedes that the other two documents are work product, it argues that Dow waived workproduct protection when it disclosed them to Deloitte. We vacate the district court's decision that the document prepared by Deloitte is work product and remand for in camera review to determine whether it is entirely work product. With respect to the other two documents, we affirm the district court's decision that Dow did not waive work-product protection when it disclosed them to Deloitte.

\section{Background}

This discovery dispute arises from ongoing tax litigation in the U.S. District Court for the Middle District of Louisiana. The litigation concerns the tax treatment of two partnerships owned by Dow Chemical Company and two of its wholly-owned subsidiaries. The first of these 
partnerships was Chemtech I; it was succeeded by Chemtech II. In 2005, Dow filed a civil suit challenging IRS adjustments to partnership returns filed by Chemtech I and Chemtech II. During discovery, the government subpoenaed documents from Dow's independent auditor, Deloitte \& Touche USA, LLP. Since the subpoena sought production in Washington, D.C., it issued from the U.S. District Court for the District of Columbia. Deloitte produced a number of documents, but refused to produce three documents Dow identified as attorney work product. In response, the government filed a motion to compel production.

The three disputed documents are described in Dow's privilege log and in a declaration by William Curry, Dow's Director of Taxes. The first document is a 1993 draft memorandum prepared by Deloitte that summarizes a meeting between Dow employees, Dow's outside counsel, and Deloitte employees about the possibility of litigation over the Chemtech I partnership, and the necessity of accounting for such a possibility in an ongoing audit. This meeting took place after Dow informed Deloitte about the likelihood of litigation over the Chemtech I transaction. The second is a 1998 memorandum and flow chart prepared by two Dow employees - an accountant and an in-house attorney. The third is a 2005 tax opinion prepared by Dow's outside counsel. Curry's declaration explains that the second and third documents were disclosed to Deloitte so that it could "review the adequacy of Dow's contingency reserves for the Chemtech transactions. According to Curry, Deloitte "compelled Dow's production of these documents by informing the company that access to these documents was required in order to provide Dow with an unqualified audit opinion for its public financial statements." The privilege log describes the subject matter of these documents as "tax issues related to the Chemtech partnership" and states that each one is a "document prepared in anticipation of litigation." We will refer to the first document, which was prepared by Deloitte, as the "Deloitte Memorandum," and the second and third documents, which were created by Dow, as the "Dow Documents."

The district court denied the government's motion to compel without reviewing the disputed documents in camera. It concluded that the Deloitte Memorandum was work product because it was "prepared because of the prospect of litigation with the IRS over the tax treatment of Chemtech." The court further concluded that, although the document was created by Deloitte, it was nonetheless Dow's work product because "its contents record the thoughts of Dow's counsel regarding the prospect of litigation." In addition, the court rejected the government's contention that Dow had waived work-product protection for the three documents. The court acknowledged that disclosing work product to a third party can waive protection if that disclosure is "inconsistent with the maintenance of secrecy from the disclosing party's adversary," but concluded that Dow's disclosure to Deloitte was not inconsistent with maintaining secrecy because (1) Deloitte was not a potential adversary and (2) nothing suggested that it was unreasonable for Dow to expect Deloitte to maintain confidentiality. The government appeals this ruling, and Dow has intervened to assert work-product protection.

\section{Analysis}


The government contends that the Deloitte Memorandum is not attorney work product. Alternatively, it argues that even if the Deloitte Memorandum is work product, Dow waived workproduct protection when it orally disclosed the information recorded therein to Deloitte. Turning to the Dow Documents, the government concedes they are attorney work product, but argues that Dow waived work-product protection when it gave them to Deloitte.

\section{A. The Work-Product Doctrine}

The Supreme Court established the work-product doctrine in Hickman v. Taylor, which held that an attorney's notes recording his interviews with witnesses to the litigation-prompting incident were protected from discovery. The Court recognized that to prepare for litigation, an attorney must "assemble information, sift what he considers to be the relevant from the irrelevant facts, prepare his legal theories and plan his strategy without undue and needless interference." This preparation "is reflected in interviews, statements, memoranda, correspondence, briefs, mental impressions, personal beliefs, and countless other tangible and intangible ways." The Court reasoned that giving opposing counsel access to such work product would cause significant problems:

Much of what is now put down in writing would remain unwritten. An attorney's thoughts, heretofore inviolate, would not be his own. Inefficiency, unfairness and sharp practices would inevitably develop in the giving of legal advice and in the preparation of cases for trial. The effect on the legal profession would be demoralizing. And the interests of the clients and the cause of justice would be poorly served.

Consequently, the Court concluded that attorney work product is protected from discovery unless "the one who would invade that privacy" carries the burden of "establishing adequate reasons to justify production through a subpoena or court order."

The work-product doctrine announced in Hickman was subsequently partially codified in Federal Rule of Civil Procedure 26(b)(3), which states:

(A) Documents and Tangible Things. Ordinarily, a party may not discover documents and tangible things that are prepared in anticipation of litigation or for trial by or for another party or its representative (including the other party's attorney, consultant, surety, indemnitor, insurer, or agent).

Rule 26(b)(3) allows a court to order disclosure when the requesting party can show a "substantial need" for the material and an inability to procure equivalent information "without undue hardship." When a court orders disclosure under this exception, however, it must still "protect against disclosure of the mental impressions, conclusions, opinions, or legal theories of a party's attorney or other representative concerning the litigation." This type of work product, which is often described as opinion work product, "is virtually undiscoverable."

\section{B. The Deloitte Memorandum}


The government makes two categorical arguments that the Deloitte Memorandum cannot be work product. First, it argues that the Deloitte Memorandum cannot be work product because it was created by Deloitte, not Dow or its representative. Second, it argues that the Deloitte Memorandum cannot be work product because it was generated as part of the routine audit process, not in anticipation of litigation. If either argument is correct, the Deloitte Memorandum cannot be work product, regardless of its contents. We reject both arguments, but nevertheless conclude that the district court lacked sufficient information to determine that the entire Deloitte Memorandum is work product.

1

The government first contends that Dow cannot claim work-product protection for the Deloitte Memorandum because it was prepared by Deloitte. Rule 26(b)(3) only protects "documents and tangible things that are prepared by or for another party or its representative." Given this language, the government argues that the Deloitte Memorandum is not work product because Deloitte is not Dow's representative. It relies principally on United States v. Arthur Young \& Co., in which the Supreme Court refused to recognize an accountant work-product privilege. In Arthur Young, the Court contrasted the role of an attorney with that of an accountant, explaining that an attorney is "a loyal representative whose duty it is to present the client's case in the most favorable possible light," whereas an independent certified public accountant has a "public responsibility" and "owes ultimate allegiance to the corporation's creditors and stockholders, as well as to the investing public." In the government's view, Arthur Young demonstrates that Deloitte cannot be Dow's representative, which in turn means that the Deloitte Memorandum cannot be work product under the plain language of Rule 26(b)(3). Dow counters that the "representative" for purposes of Rule 26(b)(3) is its counsel, whose thoughts and opinions are recorded in the document. In addition, it argues that the Deloitte Memorandum is work product because it contains the same type of opinion work product that is found in the Dow Documents, which the government concedes are work product.

Even if the government is correct in asserting that the Deloitte Memorandum falls outside the definition given by Rule 26(b)(3), this does not conclusively establish that it is not work product. The government mistakenly assumes that Rule 26(b)(3) provides an exhaustive definition of what constitutes work product. On the contrary, Rule 26(b)(3) only partially codifies the workproduct doctrine announced in Hickman. Rule 26(b)(3) addresses only "documents and tangible things," but Hickman's definition of work product extends to "intangible" things. Moreover, in Hickman, the Court explained that the attorney's "mental impressions" were protected from discovery, so that he could not be forced to "repeat or write out" that information in discovery. Thus Hickman provides work-product protection for intangible work product independent of Rule 26(b)(3).

The government focuses on Deloitte's role in creating the document and on its relationship to Dow. Under Hickman, however, the question is not who created the document or how they are related to the party asserting work-product protection, but whether the document contains work 
product - the thoughts and opinions of counsel developed in anticipation of litigation. The district court found that the memorandum records those thoughts, even though Deloitte and not Dow or its attorney committed them to paper. The work product privilege does not depend on whether the thoughts and opinions were communicated orally or in writing, but on whether they were prepared in anticipation of litigation. Thus Deloitte's preparation of the document does not exclude the possibility that it contains Dow's work product.

\section{2}

The government next contends that the Deloitte Memorandum cannot be work product because it was generated during an annual audit, not prepared in anticipation of litigation. The courts are not unanimous on the proper test for determining whether a document was prepared "in anticipation of litigation." Under the test adopted by most circuits, the question is whether the document was created "because of" the anticipated litigation. The Fifth Circuit, however, requires that anticipation of litigation be the "primary motivating purpose" behind the document's creation.

Like most circuits, we apply the "because of" test, asking "whether, in light of the nature of the document and the factual situation in the particular case, the document can fairly be said to have been prepared or obtained because of the prospect of litigation." In addition, while this standard addresses a "document," it applies equally to work product in other forms. Thus for the Deloitte Memorandum, the question is whether it records information prepared by Dow or its representatives because of the prospect of litigation.

In the government's view, the Deloitte Memorandum was prepared not "because of the prospect of litigation," but as part of the routine audit process. The government asserts that a document's function, not its content, determines whether it is work product. For this proposition the government relies on Delaney, Migdail \& Young, Chartered v. IRS. In Delaney, a law firm sought to obtain under the Freedom of Information Act memoranda and supporting documents relating to the government's legal analysis of an Internal Revenue Service program concerning the use of statistical sampling in auditing large accounts. In that case it was the IRS that asserted work-product protection. The court held that the documents were work product because they "advised the agency of the types of legal challenges likely to be mounted against a proposed program, potential defenses available to the agency, and the likely outcome." In its reasoning, the court noted that a previous work-product decision had identified "the function of the documents as the critical issue." The government seizes on this language, arguing that the Deloitte Memorandum is not work product because its function was to facilitate Deloitte's audit, not to prepare Dow for litigation.

We think the government misreads Delaney. While Delaney used the term "function," it was not considering any distinction between function and content in determining whether a document constituted work product. On the contrary, the court evaluated the function of the IRS documents at issue by examining their contents. It contrasted the documents at issue in the Coastal States case, which were like "an agency manual, fleshing out the meaning of the statute 
it was authorized to enforce," with the documents at issue in Delaney, which were memoranda describing potential legal challenges, possible defenses, and likely outcomes. Delaney does not support the proposition that we should look solely to a document's function divorced from its contents in determining its status as work product.

In short, a document can contain protected work-product material even though it serves multiple purposes, so long as the protected material was prepared because of the prospect of litigation.

Rejecting the government's categorical arguments establishes only that the Deloitte Memorandum may be protected work product under the law; we must now determine whether it is. On examination of the record, we conclude that the district court did not have a sufficient evidentiary foundation for its holding that the memorandum was purely work product. According to the record, the document was created during Deloitte's preparation of an audit report which in Deloitte's view required consideration of potential litigation. The meeting generating the document included both Deloitte and Dow employees, as well as Dow's outside counsel. The document itself was prepared by a third party. While none of this negates the possibility of workproduct privilege, it could make it likely that the document includes other information that is not work product. According to Dow's privilege log and the Curry declaration, the memorandum does contain thoughts and analyses by legal counsel, but this does not rule out or even render unlikely the possibility that it also includes other facts, other thoughts, other analyses by nonattorneys which may not be so intertwined with the legal analysis as to warrant protection under the work-product doctrine. We will therefore remand this question to the district court for the purpose of independently assessing whether the document was entirely work product, or whether a partial or redacted version of the document could have been disclosed. Accordingly, we vacate the district court's decision that the Deloitte Memorandum was work product and remand so that the district court can examine the document in camera to determine whether it is entirely work product.

\section{The Dow Documents}

Although the government concedes that the Dow Documents are work product, it contends that Dow waived work-product protection by disclosing them to Deloitte. To the best of our knowledge, no circuit has addressed whether disclosing work product to an independent auditor constitutes waiver. Among the district courts that have addressed this issue, most have found no waiver.

While voluntary disclosure waives the attorney-client privilege, it does not necessarily waive work-product protection. The attorney-client privilege and the work-product doctrine serve different purposes: the former protects the attorney-client relationship by safeguarding confidential communications, whereas the latter promotes the adversary process by insulating an attorney's litigation preparation from discovery. Voluntary disclosure waives the attorneyclient privilege because it is inconsistent with the confidential attorney-client relationship. 
Voluntary disclosure does not necessarily waive work-product protection, however, because it does not necessarily undercut the adversary process. Nevertheless, disclosing work product to a third party can waive protection if "such disclosure, under the circumstances, is inconsistent with the maintenance of secrecy from the disclosing party's adversary." Under this standard, the voluntary disclosure of attorney work product to an adversary or a conduit to an adversary waives work-product protection for that material.

Applying this standard, the government contends that Dow has waived work-product protection for the Dow Documents because Deloitte is (1) a potential adversary and (2) a conduit to other adversaries. We reject both contentions and conclude that Dow has not waived the protection.

The government contends that Deloitte is a potential adversary of Dow because disputes sometimes arise between independent auditors and their clients and because independent auditors have the power to issue opinions that adversely affect their clients. Neither argument demonstrates that Deloitte is a potential adversary for purposes of waiver analysis. First, as an independent auditor, Deloitte cannot be Dow's adversary. Even the threat of litigation between an independent auditor and its client can compromise the auditor's independence and necessitate withdrawal. Further, Deloitte's power to issue an adverse opinion, while significant, does not make it the sort of litigation adversary contemplated by the waiver standard. Similarly, "any tension between an auditor and a corporation that arises from an auditor's need to scrutinize and investigate a corporation's records and book-keeping practices simply is not the equivalent of an adversarial relationship contemplated by the work product doctrine." Second, the possibility of a future dispute between Deloitte and Dow does not render Deloitte a potential adversary for the present purpose. If it did, any voluntary disclosure would constitute waiver. Yet the work-product doctrine allows disclosures as long as they do not undercut the adversary process.

Here, the question is not whether Deloitte could be Dow's adversary in any conceivable future litigation, but whether Deloitte could be Dow's adversary in the sort of litigation the Dow Documents address. We conclude that the answer must be no. In preparing the Dow Documents, Dow anticipated a dispute with the IRS, not a dispute with Deloitte. The documents, which concern the tax implications of the Chemtech partnerships, would not likely be relevant in any dispute Dow might have with Deloitte. Thus Deloitte cannot be considered a potential adversary with respect to the Dow Documents.

2

The government also asserts that Deloitte is a conduit to Dow's adversaries. It claims the district court failed to address this question, but this ignores the district court's explicit statement that "no evidence suggests that it was unreasonable for Dow to expect Deloitte USA to maintain confidentiality." Like the district court, we conclude that Deloitte is not a conduit to Dow's adversaries. 
Our prior decisions applying the "maintenance of secrecy" standard, while fact-intensive, have generally made two discrete inquiries in assessing whether disclosure constitutes waiver. First, we have considered whether the disclosing party has engaged in self-interested selective disclosure by revealing its work product to some adversaries but not to others. Such conduct militates in favor of waiver, for it is "inconsistent and unfair to allow parties to select according to their own self-interest to which adversaries they will allow access to the materials."

Second, we have examined whether the disclosing party had a reasonable basis for believing that the recipient would keep the disclosed material confidential. A reasonable expectation of confidentiality may derive from common litigation interests between the disclosing party and the recipient. "The existence of common interests between transferor and transferee is relevant to deciding whether the disclosure is consistent with the nature of the work product privilege." This is true because when common litigation interests are present, "the transferee is not at all likely to disclose the work product material to the adversary." Alternately, a reasonable expectation of confidentiality may be rooted in a confidentiality agreement or similar arrangement between the disclosing party and the recipient. Nevertheless, a confidentiality agreement must be relatively strong and sufficiently unqualified to avoid waiver. In Williams, for example, we concluded that the government's assurance that it would maintain confidentiality "to the extent possible" was not sufficiently strong or sufficiently unqualified to prevent the government from disclosing the information to a criminal defendant under Brady v. Maryland. Likewise, we have determined that a mere promise to give the disclosing party notice before releasing documents does not support a reasonable expectation of confidentiality.

The selective disclosure inquiry is straightforward. Selective disclosure involves disclosing work product to at least one adversary. As we have explained, Deloitte is not an adversary, so Dow's disclosure to Deloitte was not selective disclosure. The "reasonable expectation of confidentiality" inquiry is more complicated. As to common interests, Dow and Deloitte do not have common litigation interests in the Dow Documents - Dow has a litigation interest in the documents because of its interest in the Chemtech partnerships, but Deloitte has no similar interest in the documents. Absent common interests, the question is whether a confidentiality agreement or similar assurance gave Dow a reasonable expectation that Deloitte would keep its work product confidential.

We conclude that Dow had a reasonable expectation of confidentiality because Deloitte, as an independent auditor, has an obligation to refrain from disclosing confidential client information. Rule 301 of the American Institute of Certified Public Accountants Code of Professional Conduct provides: "A member in public practice shall not disclose any confidential client information without the specific consent of the client." William Curry's declaration explains that "Dow furnished these documents to Deloitte with the expectation that Deloitte would retain the confidentiality of the two documents." Given the obligation imposed by Rule 301, we think this expectation was reasonable. 
The government responds that this is a "qualified assurance' that does not suffice to prevent waiver because Rule 301 also explains that it "shall not be construed to affect in any way the member's obligation to comply with a validly issued and enforceable subpoena or summons." But an assertion of work-product protection challenges the enforceability of a subpoena with respect to those materials. Thus Deloitte could refuse to produce the documents, thereby allowing Dow to intervene and assert work-product protection, without violating its obligation to comply with enforceable subpoenas. Indeed, this is exactly what Deloitte did. Accordingly, this caveat does not significantly diminish the reasonableness of Dow's expectation of confidentiality.

The government also attempts to bolster its waiver argument by identifying instances in which an independent auditor might disclose information obtained from a company whose finances it audits. For example, it asserts that Deloitte could make Dow disclose its confidential tax analysis in footnotes to its public financial statements. Likewise, Deloitte could testify about confidential information obtained from Dow in proceedings brought by the SEC or private parties. Or Deloitte might report illegal acts it detects during its audit. Finally, the government returns to Arthur Young, arguing that as an independent auditor, Deloitte is a "public watchdog" whose ultimate allegiance is to Dow's creditors, stockholders, and the investing public - all potential adversaries of Dow. In sum, the government contends that Dow could not reasonably expect confidentiality from Deloitte after giving it the Dow Documents, given the myriad ways Deloitte could reveal that information.

Of course Deloitte might disclose some information relevant to Dow's finances. But the government has neither pointed to any regulatory provision nor posited any specific circumstance under which Deloitte would be required to disclose attorney work product like that contained in the Dow Documents. An independent auditor can fulfill its duties and render an opinion concerning a company's public financial statements without revealing every piece of information it reviews during the audit process. In short, Deloitte's independent auditor obligations do not make it a conduit to Dow's adversaries.

Likewise, the government's reliance on Arthur Young is misplaced. In Arthur Young, the Court considered whether accountant work-product should be granted the same protection attorney work product receives. The government quotes the Court's statement that "To insulate from disclosure a certified public accountant's interpretations of the client's financial statements would be to ignore the significance of the accountant's role as a disinterested analyst charged with public obligations." All well and good. In this case, however, the government attempts to discover not an independent auditor's "interpretations of the client's financial statements," which Arthur Young would permit, but an attorney's thoughts and opinions developed in anticipation of litigation, which the work-product doctrine forbids.

Furthermore, we are mindful that independent auditors have significant leverage over the companies whose finances they audit. An auditor can essentially compel disclosure by refusing to provide an unqualified opinion otherwise. Finding waiver based on such disclosures could well encourage the sort of "inefficiency, unfairness and sharp practices" that Hickman sought to 
avoid. For example, it might discourage companies from seeking legal advice and candidly disclosing that information to independent auditors. Moreover, the government has not proffered any good reason for wanting the Dow Documents other than its desire to know what Dow's counsel thought about the Chemtech partnerships. Granting discovery under these circumstances would undercut the adversary process and let the government litigate "on wits borrowed from the adversary," We conclude that the district court applied the correct legal standard and acted within its discretion in determining that Dow had not waived work-product protection. Consequently, we affirm the district court's decision denying the government's motion to compel with respect to the Dow Documents.

\section{Questions:}

1. Why did the court hold that a document disclosed to a third-party can be protected by the work product doctrine? Do you agree with its conclusion?

2. When would a document disclosed to a third-party not be protected by the work product doctrine?

\section{Further Reading:}

- Sean Grammel, Comment, Protecting Search Terms as Opinion Work Product: Applying the Work Product Doctrine to Electronic Discovery, 161 U. Pa. L. Rev. 2063 (2013)

- Sherman L. Cohn, The Work-Product Doctrine: Protection, Not Privilege, 71 Geo. L.J. 917 (1984)

- Vivian K. Yamaguchi, Discovery and the Work Product Doctrine, 11 Loy. U. Chi. L. J. 863 (1980) 


\section{7: Exceptions to Privilege \& Work Product}

Hush hush, keep it down now, voices carry. ${ }^{82}$

Listen, do you want to know a secret? Do you promise not to tell? Closer. Let me whisper in your ear, say the words you long to hear. ${ }^{83}$

While the attorney-client privilege and work product doctrine provide strong protection against discovery of the communications and documents they protect, they are both subject to waiver and other exceptions.

The attorney-client privilege belongs to the client, and can be waived by the client. Obviously, a client can intentionally waive the attorney-client privilege. But it less clear whether a client can unintentionally waive the attorney-client privilege, and if so, when an unintentional waiver will be effective. And it is even less clear whether an attorney or third-party can unintentionally waive the attorney-client privilege.

Typically, a client's intentional disclosure of a privileged communication to an non-privileged third-party constitutes a waiver of the attorney-client privilege, even if the client didn't intend to waive the privilege. But what if the client unintentionally disclosed the communication? For example, what if the client misplaced a copy of a privileged communication and a non-privileged third-party found it? Or what if the client disclosed a privileged communication to a nonprivileged third-party, under the mistaken belief that the third-party was privileged?

In theory, an attorney cannot waive the attorney-client privilege. But it is unclear whether communications intentionally or unintentionally disclosed to a third-party by an attorney retain the privilege. For example, what if an attorney inadvertently produces a privileged document? Or what if an attorney intentionally discloses a privileged communication to the public? Likewise, it is unclear whether communications obtained and disclosed by a third-party retain the privilege.

In most jurisdictions, inadvertent disclosure does not necessarily destroy the privilege. Specifically, if an attorney inadvertently produces a privileged document, opposing counsel must return or destroy the document, and may not read or otherwise use the document. And even an intentional disclosure by an attorney will not necessarily destroy the privilege. But in some jurisdictions, inadvertent disclosure may destroy the privilege. And if a privileged communication becomes generally known, at some point the privilege is probably constructively waived, irrespective of how the waiver occurred.

In addition, the attorney-client privilege and work product doctrine are subject to the crime-fraud exception, which provides that communications and documents in furtherance of a crime or

82 'Til Tuesday, Voices Carry, Voices Carry (1985).
83 The Beatles, Do You Want to Know a Secret, Please Please Me (1963). 
fraud are not protected. The privilege applies to confidential attorney-client communications about a crime or fraud that has already occurred, in order to enable clients to obtain candid legal advice. But the privilege does not apply to communications in furtherance of a future crime or fraud.

The work product doctrine may be subject to an even broader exception for "attorney misconduct," which provides that documents are not protected if they are the product of improper behavior on the part of the attorney.

\section{Federal Rule of Civil Procedure Rule 26(b): Duty to Disclose}

5. Claiming Privilege or Protecting Trial-Preparation Materials.

A. Information Withheld. When a party withholds information otherwise discoverable by claiming that the information is privileged or subject to protection as trialpreparation material, the party must:

i. expressly make the claim; and

ii. describe the nature of the documents, communications, or tangible things not produced or disclosed-and do so in a manner that, without revealing information itself privileged or protected, will enable other parties to assess the claim.

B. Information Produced. If information produced in discovery is subject to a claim of privilege or of protection as trial-preparation material, the party making the claim may notify any party that received the information of the claim and the basis for it. After being notified, a party must promptly return, sequester, or destroy the specified information and any copies it has; must not use or disclose the information until the claim is resolved; must take reasonable steps to retrieve the information if the party disclosed it before being notified; and may promptly present the information to the court under seal for a determination of the claim. The producing party must preserve the information until the claim is resolved.

Federal Rule of Evidence 502: Attorney-Client Privilege and Work Product; Limitations on Waiver

The following provisions apply, in the circumstances set out, to disclosure of a communication or information covered by the attorney-client privilege or work-product protection.

a. Disclosure Made in a Federal Proceeding or to a Federal Office or Agency; Scope of a Waiver. When the disclosure is made in a federal proceeding or to a federal office or agency and waives the attorney-client privilege or work-product protection, the waiver extends to an undisclosed communication or information in a federal or state proceeding only if:

1. the waiver is intentional;

2. the disclosed and undisclosed communications or information concern the same subject matter; and 
3. they ought in fairness to be considered together.

b. Inadvertent Disclosure. When made in a federal proceeding or to a federal office or agency, the disclosure does not operate as a waiver in a federal or state proceeding if:

1. the disclosure is inadvertent;

2. the holder of the privilege or protection took reasonable steps to prevent disclosure; and

3. the holder promptly took reasonable steps to rectify the error, including (if applicable) following Federal Rule of Civil Procedure 26(b)(5)(B).

c. Disclosure Made in a State Proceeding. When the disclosure is made in a state proceeding and is not the subject of a state-court order concerning waiver, the disclosure does not operate as a waiver in a federal proceeding if the disclosure:

1. would not be a waiver under this rule if it had been made in a federal proceeding; or

2. is not a waiver under the law of the state where the disclosure occurred.

d. Controlling Effect of a Court Order. A federal court may order that the privilege or protection is not waived by disclosure connected with the litigation pending before the court - in which event the disclosure is also not a waiver in any other federal or state proceeding.

e. Controlling Effect of a Party Agreement. An agreement on the effect of disclosure in a federal proceeding is binding only on the parties to the agreement, unless it is incorporated into a court order.

f. Controlling Effect of This Rule. Notwithstanding Rules 101 and 1101, this rule applies to state proceedings and to federal court-annexed and federal court-mandated arbitration proceedings, in the circumstances set out in the rule. And notwithstanding Rule 501, this rule applies even if state law provides the rule of decision.

g. Definitions. In this rule:

1. "attorney-client privilege" means the protection that applicable law provides for confidential attorney-client communications; and

2. "work-product protection" means the protection that applicable law provides for tangible material (or its intangible equivalent) prepared in anticipation of litigation or for trial.

\section{Inadvertent Waiver}

In re Sealed Case, 877 F. 2d 976 (D.C. Cir. 1989)

Summary: The IRS investigated a company for tax evasion and subpoenaed documents relevant to the investigation. The company refused to produce certain documents, claiming attorney-client privilege. The government conceded that the attorney-client privilege applied to the documents, but argued that it had been waived. The district court found that the privilege was waived with respect to all of the documents, because they were disclosed to third-parties. The circuit court found that the privilege had been waived for some of the documents, but possibly not all of them. 
SILBERMAN, Circuit Judge:

The appellant, "Company," appeals from a contempt order of the district court. Company refused to comply with a grand jury subpoena insofar as it was directed to six documents that Company claimed were covered by attorney-client privilege. The district court held the privilege was waived as to all six documents. We agree that there was at least a partial waiver of the privilege, but we remand for the district court to further consider of the scope of the waiver.

I.

Appellant is a government contractor performing work for the Defense Department on a costplus basis. Company and its former chief executive officer are under a grand jury investigation into the possibility of Company's tax evasion as well as a possible conspiracy to defraud the United States. It is thought CEO may have engineered a scheme whereby he received secret rebates (undeclared personal income to him) from subcontractors while the amounts rebated were included on Company's books as payments to the subcontractors and thus business expenses.

The grand jury issued a subpoena in June 1988 to Company seeking production of documents relating to certain adjusting entries made to Company's books in the latter part of 1987. Company produced the documents sought, except for six it claimed were protected by the attorney-client privilege. Three of these documents contain notes taken by Company's former vice president for finance at meetings with attorneys from a law firm retained by Company. The other three are memoranda from that vice president to Company's chief accounting officer transmitting the law firm's legal advice to amend the corporate books to reflect that certain amounts previously reported on its books - and to the IRS - as business expenses be shown as nondeductible income payments to CEO.

The government moved to compel production of all six documents, arguing that the privilege was waived since the documents presumably contained only information that had been or would eventually be reported to the IRS. The district court granted the order, concluding "whatever attorney-client privilege that may have attached to the documents was waived by the filing (or the intention to file) of required forms to the IRS." Company refused to comply, was held in contempt, and thereafter brought an appeal.

While the appeal was pending, the government learned that one of the memoranda in question had already been disclosed, in January 1988, by the CAO to the Defense Contract Audit Agency during a routine audit of the contractor's travel expenses. The government sought and gained a remand to permit the district court to consider this additional ground for the government's claim of waiver. Appellant claimed on remand that the disclosure of the one document to the DCAA had been inadvertent ("a bureaucratic error") and offered to prove that through the testimony of its $\mathrm{CAO}$, but only if his testimony were limited to that issue and his Fifth Amendment privilege were not waived. The district court rejected the proffer, reiterated its prior finding that if the privilege existed, it had been waived because the information in the documents 
was to be publicly reported, and further found that the disclosure of the one document "was a voluntary intentional disclosure" which "constituted a further waiver of the attorney-client privilege not only with respect to the particular document but also as to all related communications." The district court believed that had the disclosure to DCAA been inadvertent rather than intentional, it would have constituted a waiver (if that were the sole grounds for finding a waiver) only with respect to that document and not the other five.

Prior to the remand hearing it was further revealed that the vice president had entered into a personal immunity agreement with the government in October 1987 and, at that time, given all six of the documents to the government without Company's authorization. From that, we infer the government continues to seek the documents through subpoena because it is uncertain as to the use that can be made of the copies voluntarily turned over by the vice president. The government asserts that the attorney handling the grand jury proceedings has not been given access to the documents. Nevertheless, Company urged the district court, in the exercise of its supervisory power over grand jury proceedings, to conduct an evidentiary hearing to determine whether the government had engaged in misconduct, which Company apparently thought might justify quashing the subpoena. The district court declined to do so and Company appeals that determination as well.

II.

The government does not dispute that all six documents fall within Company's attorney-client privilege. It is not argued, for instance, that the memoranda from the vice president to the CAO, communicating the advice given by counsel and directing the adjusting entries be made in accordance with that advice, are outside the privilege. Nor is it claimed that the conversation between the corporate officers and the law firm were not intended to be confidential so that the privilege never attached. Instead, the government relies on two grounds for concluding Company waived the privilege for all six documents.

The government first claims that because the documents provide background "detail" supporting the adjusting bookkeeping entries that have been reported to the IRS, Company has waived its privilege in the documents. The government relies on several cases that have addressed the status of the attorney-client privilege in cases involving disclosure of financial information to the IRS or other third parties. In United States v. Cote, the Eighth Circuit held that the act of filing amended IRS returns waived any attorney-client privilege in an attorney-supervised accountant's workpapers, which contained information later transcribed onto the returns. But the Court remanded to the district court to determine whether any of the workpapers contained "unpublished expressions" not part of the data revealed on the tax returns. The Court also recognized that in tax cases, waiver typically is not an issue, because "the privilege is said not to attach to information which the taxpayer intends his attorney to report in the contents of a tax return."

In that vein, United States $v$. (Under Seal) held that the privilege did not cover documents, including communications between two attorneys relating to a proposed tax ruling for a client, 
and material supplied by the client concerning commercial transactions upon which the proposed tax ruling would be based. These documents, according to the court, either did not reveal client communications or were not meant to be confidential. The court thus applied its previous holding in In re Grand Jury Proceedings that "if a client communicates information to his attorney with the understanding that the information will be revealed to others, that information, as well as the details underlying the data which was to be published, will not enjoy the privilege." Apparently recognizing the aphorism that "God is in the details," the court explained in a footnote:

The details underlying the published data are the communications relating the data, the document, if any, to be published containing the data, all preliminary drafts of the document, and any attorney's notes containing material necessary to the preparation of the documents. Copies of other documents, the contents of which were necessary to the preparation of the published document, will also lose the privilege. But if any of the nonprivileged documents contain client communications not directly related to the published data, those communications, if otherwise privileged, must be removed by the reviewing court before the document may be produced.

Although these cases seem to conflate two theories - waiver of an existing privilege and absence of an intent to maintain confidentiality in the first place - we think under either theory the IRS cases are inapposite; the government much too facilely claims that the six documents are merely "details" underlying past or future returns. To be sure, virtually all the material in the documents reflects adjusting entries in Company's books, which have been or will be reported to the IRS. ${ }^{84}$ But the crucial significance of the documents - and the apparent reason the government wishes to present them to the grand jury — is that they suggest Company made the adjusting entries on the advice of counsel (after the investigation commenced).

The raison d'etre of the hallowed attorney-client privilege is the protection of a client's communications to counsel so that persons, including organizations, will be induced to consult counsel when needed. The attorney's communications (his advice) to the client must also be protected, because otherwise it is rather easy to deduce the client's communications to counsel. The documents sought in this case reveal directly the attorney's confidential advice, and their disclosure thereby invades the core of the privilege; it permits an inference to be drawn as to the nature of the client's communications with its lawyers, and, perhaps, as to their motivation (e.g., guilty knowledge) for consulting counsel as well.

Even the very existence of an attorney-client relationship, not normally protected, is privileged in the rare case when a "strong possibility exists that disclosure of the information would implicate the client in the very matter for which legal advice was sought in the first case." We therefore do not think that any portion of the six documents revealing that the adjusting entries were made on the advice of counsel would be disclosable under the government's primary theory of waiver.

\footnotetext{
${ }^{84}$ If the information has not yet been disclosed, it is hard to think of Company's action as a waiver. Rather, data that Company intends to report is never privileged in the first place.
} 
Alternatively, however, the government relies on a waiver caused by the disclosure of one memo to a DCAA auditor, and we think the government is, in this respect, on firmer ground. It will be recalled that Company does not dispute the disclosure but denies its voluntariness, claiming it was inadvertent - "a bureaucratic error." The district court found otherwise, but we do not think it matters whether the waiver is labeled "voluntary" or "inadvertent" and thus do not find it necessary to consider appellant's claim that the CAO should have been permitted to offer limited testimony on this issue only.

Although the attorney-client privilege is of ancient lineage and continuing importance, the confidentiality of communications covered by the privilege must be jealously guarded by the holder of the privilege lest it be waived. The courts will grant no greater protection to those who assert the privilege than their own precautions warrant. We therefore agree with those courts which have held that the privilege is lost "even if the disclosure is inadvertent."

Even assuming Company's disclosure was due to "bureaucratic error," which we take to be a euphemism that necessarily implies human error, that unfortunate lapse simply reveals that someone in the company and thereby Company itself (since it can only act through its employees) was careless with the confidentiality of its privileged communications. Normally the amount of care taken to ensure confidentiality reflects the importance of that confidentiality to the holder of the privilege. To hold, as we do, that an inadvertent disclosure will waive the privilege imposes a self-governing restraint on the freedom with which organizations such as corporations, unions, and the like label documents related to communications with counsel as privileged. To readily do so creates a greater risk of "inadvertent" disclosure by someone and thereby the danger that the "waiver" will extend to all related matters, perhaps causing grave injury to the organization. But that is as it should be. Otherwise, there is a temptation to seek artificially to expand the content of privileged matter. In other words, if a client wishes to preserve the privilege, it must treat the confidentiality of attorney-client communications like jewels - if not crown jewels. Short of court-compelled disclosure or other equally extraordinary circumstances, ${ }^{85}$ we will not distinguish between various degrees of "voluntariness" in waivers of the attorney-client privilege.

Our conclusion that Company's disclosure of the one memorandum constitutes a waiver still leaves a question as to the scope of the waiver. Appellant would confine the waiver to the one document, but, as we have previously said, a waiver of the privilege in an attorney-client communication extends "to all other communications relating to the same subject matter." Since such determinations properly depend heavily on the factual context in which the privilege is asserted, we will not disturb a district court's decision as to the question unless it can be shown the court abused its discretion. In this case, although the district court extended the waiver to all six documents, it did not fully explain why the communications were related. Of course, all six including the notes of the meeting - stemmed from the same consultation Company had with its law firm. But the "subject matter" of the waiver could, nevertheless, be defined in a number of different ways. Did the district court mean, for instance, to define the "subject matter" as all

\footnotetext{
${ }^{85}$ We do not face here any claim that the information was acquired by a third party despite all possible precautions, in which case there might be no waiver at all.
} 
communications "relating" to the adjustment entries, which — as suggested at oral argument would permit the individual lawyers and corporate officers present at the meeting to be called before the grand jury to describe their discussions, or perhaps even other communications between Company and its counsel? Or, alternatively, was the waiver limited to those intraCompany communications revealing that Company's accounting adjustments were made upon the advice of counsel, in which case is it not clear whether the actual notes of the meeting must be disclosed? Given the potential implications of a broad definition of the subject matter of Company's waiver, we think it appropriate to remand to the district court for further consideration of that issue.

\section{Further Reading:}

- Shawn T. Gaither, The Attorney-Client Privilege: An Analysis of Involuntary Waiver, 48 Clev. St. L. Rev. 311 (2000)

\section{The Crime-Fraud Exception}

\section{Clark v. United States, 289 U.S. 1 (1933)}

MR. JUSTICE CARDOZO delivered the opinion of the Court.

There is a privilege protecting communications between attorney and client. The privilege takes flight if the relation is abused. A client who consults an attorney for advice that will serve him in the commission of a fraud will have no help from the law. He must let the truth be told. There are early cases apparently to the effect that a mere charge of illegality, not supported by any evidence, will set the confidences free. But this conception of the privilege is without support in later rulings. "It is obvious that it would be absurd to say that the privilege could be got rid of merely by making a charge of fraud." To drive the privilege away, there must be "something to give colour to the charge;" there must be "prima facie evidence that it has some foundation in fact." When that evidence is supplied, the seal of secrecy is broken. Nor does the loss of the privilege depend upon the showing of a conspiracy, upon proof that client and attorney are involved in equal guilt. The attorney may be innocent, and still the guilty client must let the truth come out. 


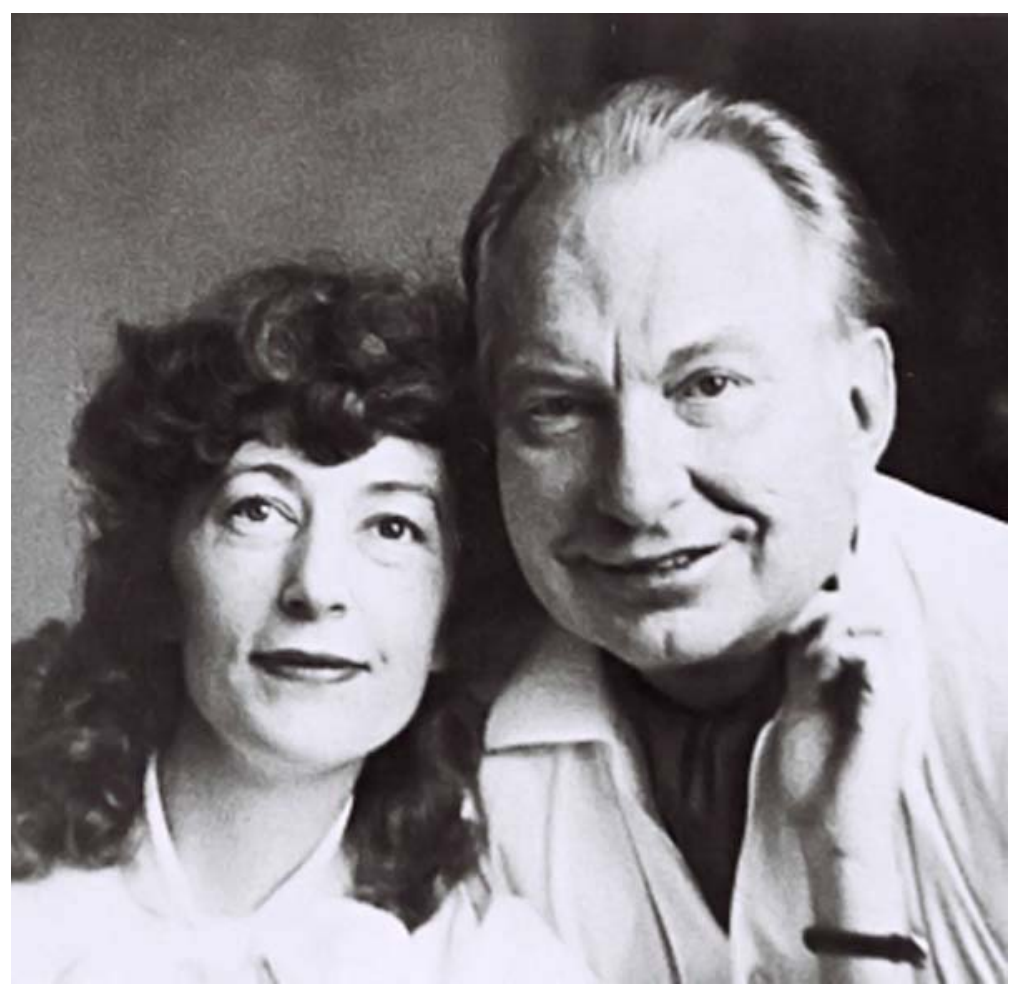

Mary Sue \& L. Ron Hubbard ( 1970)

United States v. Zolin, 491 U.S. 554 (1989)

Summary: In a case against the Church of Scientology (Church), the IRS sought to introduce into evidence tape recordings of meetings between representatives of the Church and its attorney. The IRS claimed that the tapes fell within the crime-fraud exception to the attorneyclient privilege and asked the district court to listen to the tapes in camera to determine if the privilege applied. The IRS attempted to provide the court with partial transcripts of the tape recordings that it acquired from a confidential source so that the court could make its determination. The district court refused to listen to the tapes and the court of appeals affirmed by categorically refusing to listen to the tapes or read the transcripts. The IRS appealed.

JUSTICE BLACKMUN delivered the opinion of the Court.

This case arises out of the efforts of the Criminal Investigation Division of the Internal Revenue Service to investigate the tax returns of L. Ron Hubbard, founder of the Church of Scientology for the calendar years 1979 through 1983. We granted certiorari to consider two issues that have divided the Courts of Appeals. The first is whether, when a district court enforces an IRS summons, the court may condition its enforcement order by placing restrictions on the disclosure of the summoned information. The Court of Appeals in this case upheld the restrictions. We affirm its judgment on that issue by an equally divided Court.

The second issue concerns the testimonial privilege for attorney-client communications and, more particularly, the generally recognized exception to that privilege for communications in 
furtherance of future illegal conduct - the so-called "crime-fraud" exception. The specific question presented is whether the applicability of the crime-fraud exception must be established by "independent evidence" (i.e., without reference to the content of the contested communications themselves), or, alternatively, whether the applicability of that exception can be resolved by an in camera inspection of the allegedly privileged material. We reject the "independent evidence" approach and hold that the district court, under circumstances we explore below, and at the behest of the party opposing the claim of privilege, may conduct an in camera review of the materials in question. Because the Court of Appeals considered only "independent evidence," we vacate its judgment on this issue and remand the case for further proceedings.

In the course of its investigation, the IRS sought access to 51 documents that had been filed with the Clerk of the Los Angeles County Superior Court in connection with a case entitled Church of Scientology of California v. Armstrong. The Armstrong litigation involved, among other things, a charge by the Church that one of its former members, Gerald Armstrong, had obtained by unlawful means documentary materials relating to Church activities, including two tapes. Some of the documents sought by the IRS had been filed under seal.

The IRS, by its Special Agent Steven Petersell, served a summons upon the Clerk on October 24,1984 , demanding that he produce the 51 documents. The tapes were among those listed. On November 21, IRS agents were permitted to inspect and copy some of the summoned materials, including the tapes.

On November 27, the Church and Mary Sue Hubbard, who had intervened in Armstrong, secured a temporary restraining order from the United States District Court for the Central District of California. The order required the IRS to file with the District Court all materials acquired on November 21 and all reproductions and notes related thereto, pending disposition of the intervenors' motion for a preliminary injunction to bar IRS use of these materials. By order dated December 10, the District Court returned to the IRS all materials except the tapes and the IRS' notes reflecting their contents.

On January 18, 1985, the IRS filed in the District Court a petition to enforce its summons. In addition to the tapes, the IRS sought 12 sealed documents the Clerk had refused to produce in response to the IRS summons. The Church and Mary Sue Hubbard intervened to oppose production of the tapes and the sealed documents. Respondents claimed that IRS was not seeking the documents in good faith, and objected on grounds of lack of relevance and attorney-client privilege.

Respondents asserted the privilege as a bar to disclosure of the tapes. The IRS argued, among other things, however, that the tapes fell within the crime-fraud exception to the attorney-client privilege, and urged the District Court to listen to the tapes in the course of making its privilege determination. In addition, the IRS submitted to the court two declarations by Agent Petersell. In 
the first, Petersell stated his grounds for believing that the tapes were relevant to the investigation. In the second, Petersell offered a description of the tapes' contents, based on information he received during several interviews. Appended to this declaration - over respondents' objection - were partial transcripts of the tapes, which the IRS lawfully had obtained from a confidential source. ${ }^{86}$ In subsequent briefing, the IRS reiterated its request that the District Court listen to the tapes in camera before making its privilege ruling.

After oral argument and an evidentiary hearing, the District Court rejected respondents' claim of bad faith. The court ordered production of 5 of the 12 documents and specified: "The documents delivered hereunder shall not be delivered to any other government agency by the IRS unless criminal tax prosecution is sought or an Order of Court is obtained."

Turning to the tapes, the District Court ruled that respondents had demonstrated that they contain confidential attorney-client communications, that the privilege had not been waived, and that 'the 'fraud-crime' exception to the attorney-client privilege does not apply. The quoted excerpts tend to show or admit past fraud but there is no clear indication that future fraud or crime is being planned." On this basis, the court held that the Clerk "need not produce its copy of the tapes pursuant to the summons." The District Court denied the IRS' motion for reconsideration, rejecting the IRS' renewed request that the court listen to the tapes in toto. "While this was at one time discussed with counsel, thereafter Mr. Petersell's declaration was submitted, and no one suggested that this was an inadequate basis on which to determine the attorney-client privilege question."

Respondents appealed to the Court of Appeals for the Ninth Circuit, and the IRS crossappealed on two relevant grounds. First, the IRS claimed that the District Court abused its discretion by placing conditions on the IRS' future use of the subpoenaed information. The Court of Appeals disagreed, holding: "A district court may, when appropriate, condition enforcement of a summons on the IRS' agreeing to abide by disclosure restrictions."

Second, the IRS contended that the District Court erred in rejecting the application of the crimefraud exception to the tapes. In particular, the IRS argued that the District Court incorrectly held that the IRS had abandoned its request for in camera review of the tapes, and that the court should have listened to the tapes before ruling that the crime-fraud exception was inapplicable. Respondents contended, in contrast, that the District Court erred in the opposite direction: they argued that it was error for the court to rely on the partial transcripts, because "in this Circuit, a party cannot rely on the communications themselves - whether by listening to the tapes or

\footnotetext{
${ }^{86}$ The IRS denied that the transcripts were made using tapes obtained from the Superior Court or from any other illicit source. Agent Petersell declared: "The partial transcripts were not prepared by the United States from the tapes in the custody of the Superior Court for Los Angeles County, California, nor from copies of the tape now in the custody of the Clerk of this Court. The transcripts were obtained from a confidential source by another Special Agent prior to the issuance of this summons. The source was not a party to Church of Scientology v. Armstrong, nor an attorney for any party in that proceeding." As the District Court made no finding of illegality, we assume for present purposes that the transcripts were legally obtained.
} 
reviewing excerpts or transcripts of them - to bear its burden to invoke the exception but must bear the burden by independent evidence."

The panel of the Court of Appeals agreed with respondents that, under Shewfelt, "the Government's evidence of crime or fraud must come from sources independent of the attorneyclient communications recorded on the tapes," thereby implicitly holding that even if the IRS had properly preserved its demand for in camera review, the District Court would have been without power to grant it. The Court of Appeals then reviewed "the Government's independent evidence." That review appears to have excluded the partial transcripts, and thus the Court of Appeals implicitly agreed with respondents that it was improper for the District Court to have considered even the partial transcripts. On the basis of its review of the "independent evidence," the Court of Appeals affirmed the District Court's determination that the IRS had failed to establish the applicability of the crime-fraud exception.

This Court is evenly divided with respect to the issue of the power of a district court to place restrictions upon the dissemination by the IRS of information obtained through a $\S 7604$ subpoena-enforcement action. We therefore affirm the judgment of the Court of Appeals insofar as it upheld the District Court's conditional-enforcement order.

Questions of privilege that arise in the course of the adjudication of federal rights are "governed by the principles of the common law as they may be interpreted by the courts of the United States in the light of reason and experience." We have recognized the attorney-client privilege under federal law, as "the oldest of the privileges for confidential communications known to the common law." Although the underlying rationale for the privilege has changed over time, courts long have viewed its central concern as one "to encourage full and frank communication between attorneys and their clients and thereby promote broader public interests in the observance of law and administration of justice." That purpose, of course, requires that clients be free to "make full disclosure to their attorneys" of past wrongdoings, in order that the client may obtain "the aid of persons having knowledge of the law and skilled in its practice."

The attorney-client privilege is not without its costs. "Since the privilege has the effect of withholding relevant information from the factfinder, it applies only where necessary to achieve its purpose." The attorney-client privilege must necessarily protect the confidences of wrongdoers, but the reason for that protection - the centrality of open client and attorney communication to the proper functioning of our adversary system of justice - "ceases to operate at a certain point, namely, where the desired advice refers not to prior wrongdoing, but to future wrongdoing." It is the purpose of the crime-fraud exception to the attorney-client privilege to assure that the "seal of secrecy," between lawyer and client does not extend to communications "made for the purpose of getting advice for the commission of a fraud" or crime. 
The District Court and the Court of Appeals found that the tapes at issue in this case recorded attorney-client communications and that the privilege had not been waived when the tapes were inadvertently given to Armstrong. These findings are not at issue here. Thus, the remaining obstacle to respondents' successful assertion of the privilege is the Government's contention that the recorded attorney-client communications were made in furtherance of a future crime or fraud.

A variety of questions may arise when a party raises the crime-fraud exception. The parties to this case have not been in complete agreement as to which of these questions are presented here. In an effort to clarify the matter, we observe, first, that we need not decide the quantum of proof necessary ultimately to establish the applicability of the crime-fraud exception. Rather, we are concerned here with the type of evidence that may be used to make that ultimate showing. Within that general area of inquiry, the initial question in this case is whether a district court, at the request of the party opposing the privilege, may review the allegedly privileged communications in camera to determine whether the crime-fraud exception applies. If such in camera review is permitted, the second question we must consider is whether some threshold evidentiary showing is needed before the district court may undertake the requested review. Finally, if a threshold showing is required, we must consider the type of evidence the opposing party may use to meet it: i.e., in this case, whether the partial transcripts the IRS possessed may be used for that purpose.

\section{A}

We consider first the question whether a district court may ever honor the request of the party opposing the privilege to conduct an in camera review of allegedly privileged communications to determine whether those communications fall within the crime-fraud exception. We conclude that no express provision of the Federal Rules of Evidence bars such use of in camera review, and that it would be unwise to prohibit it in all instances as a matter of federal common law.

At first blush, two provisions of the Federal Rules of Evidence would appear to be relevant. Rule 104(a) provides: "Preliminary questions concerning the qualification of a person to be a witness, the existence of a privilege, or the admissibility of evidence shall be determined by the court. In making its determination it is not bound by the rules of evidence except those with respect to privileges." Rule 1101(c) provides: "The rule with respect to privileges applies at all stages of all actions, cases, and proceedings." Taken together, these Rules might be read to establish that in a summons-enforcement proceeding, attorney-client communications cannot be considered by the district court in making its crime-fraud ruling: to do otherwise, under this view, would be to make the crime-fraud determination without due regard to the existence of the privilege.

Even those scholars who support this reading of Rule 104(a) acknowledge that it leads to an absurd result. 
Because the judge must honor claims of privilege made during his preliminary fact determinations, many exceptions to the rules of privilege will become "dead letters," since the preliminary facts that give rise to these exceptions can never be proved. For example, an exception to the attorney-client privilege provides that there is no privilege if the communication was made to enable anyone to commit a crime or fraud. There is virtually no way in which the exception can ever be proved, save by compelling disclosure of the contents of the communication; Rule 104(a) provides that this cannot be done.

We find this Draconian interpretation of Rule 104(a) inconsistent with the Rule's plain language. The Rule does not provide by its terms that all materials as to which a "claim of privilege" is made must be excluded from consideration. In that critical respect, the language of Rule 104(a) is markedly different from the comparable California evidence rule, which provides that "the presiding officer may not require disclosure of information claimed to be privileged under this division in order to rule on the claim of privilege." There is no reason to read Rule 104(a) as if its text were identical to that of the California rule.

Nor does it make sense to us to assume, as respondents have throughout this litigation, that once the attorney-client nature of the contested communications is established, those communications must be treated as presumptively privileged for evidentiary purposes until the privilege is "defeated" or "stripped away" by proof that the communications took place in the course of planning future crime or fraud. Although some language in Clark might be read as supporting this view, respondents acknowledged at oral argument that no prior holding of this Court requires the imposition of a strict progression of proof in crime-fraud cases.

We see no basis for holding that the tapes in this case must be deemed privileged under Rule 104(a) while the question of crime or fraud remains open. Indeed, respondents concede that "if the proponent of the privilege is able to sustain its burden only by submitting the communications to the court" for in camera review, the court is not required to avert its eyes (or close its ears) once it concludes that the communication would be privileged, if the court found the crime-fraud exception inapplicable. Rather, respondents acknowledge that the court may "then consider the same communications to determine if the opponent of the privilege has established that the crime-fraud exception applies." Were the tapes truly deemed privileged under Rule 104(a) at the moment the trial court concludes they contain potentially privileged attorney-client communications, district courts would be required to draw precisely the counterintuitive distinction that respondents wisely reject. We thus shall not adopt a reading of Rule 104(a) that would treat the contested communications as "privileged" for purposes of the Rule, and we shall not interpret Rule 104(a) as categorically prohibiting the party opposing the privilege on crime-fraud grounds from relying on the results of an in camera review of the communications. 
Having determined that Rule 104(a) does not prohibit the in camera review sought by the IRS, we must address the question as a matter of the federal common law of privileges. We conclude that a complete prohibition against opponents' use of in camera review to establish the applicability of the crime-fraud exception is inconsistent with the policies underlying the privilege.

We begin our analysis by recognizing that disclosure of allegedly privileged materials to the district court for purposes of determining the merits of a claim of privilege does not have the legal effect of terminating the privilege. Indeed, this Court has approved the practice of requiring parties who seek to avoid disclosure of documents to make the documents available for in camera inspection, and the practice is well established in the federal courts. Respondents do not dispute this point: they acknowledge that they would have been free to request in camera review to establish the fact that the tapes involved attorney-client communications, had they been unable to muster independent evidence to serve that purpose.

Once it is clear that in camera review does not destroy the privileged nature of the contested communications, the question of the propriety of that review turns on whether the policies underlying the privilege and its exceptions are better fostered by permitting such review or by prohibiting it. In our view, the costs of imposing an absolute bar to consideration of the communications in camera for purpose of establishing the crime-fraud exception are intolerably high.

"No matter how light the burden of proof which confronts the party claiming the exception, there are many blatant abuses of privilege which cannot be substantiated by extrinsic evidence. This is particularly true of situations in which an alleged illegal proposal is made in the context of a relationship which has an apparent legitimate end." A per se rule that the communications in question may never be considered creates, we feel, too great an impediment to the proper functioning of the adversary process. This view is consistent with current trends in the law.

\section{B}

We turn to the question whether in camera review at the behest of the party asserting the crimefraud exception is always permissible, or, in contrast, whether the party seeking in camera review must make some threshold showing that such review is appropriate. In addressing this question, we attend to the detrimental effect, if any, of in camera review on the policies underlying the privilege and on the orderly administration of justice in our courts. We conclude that some such showing must be made.

Our endorsement of the practice of testing proponents' privilege claims through in camera review of the allegedly privileged documents has not been without reservation. This Court noted that "examination of the evidence, even by the judge alone, in chambers" might in some cases "jeopardize the security which the privilege is meant to protect." Analogizing to claims of Fifth Amendment privilege, it observed more generally: "Too much judicial inquiry into the claim of 
privilege would force disclosure of the thing the privilege was meant to protect, while a complete abandonment of judicial control would lead to intolerable abuses."

The Court recognized that some compromise must be reached. In Reynolds, it declined to "go so far as to say that the court may automatically require a complete disclosure to the judge before the claim of privilege will be accepted in any case." We think that much the same result is in order here.

A blanket rule allowing in camera review as a tool for determining the applicability of the crimefraud exception, as Reynolds suggests, would place the policy of protecting open and legitimate disclosure between attorneys and clients at undue risk. There is also reason to be concerned about the possible due process implications of routine use of in camera proceedings. Finally, we cannot ignore the burdens in camera review places upon the district courts, which may well be required to evaluate large evidentiary records without open adversarial guidance by the parties.

There is no reason to permit opponents of the privilege to engage in groundless fishing expeditions, with the district courts as their unwitting (and perhaps unwilling) agents. Courts of Appeals have suggested that in camera review is available to evaluate claims of crime or fraud only "when justified" or "in appropriate cases." Indeed, the Government conceded at oral argument (albeit reluctantly) that a district court would be mistaken if it reviewed documents in camera solely because "the government begged it" to do so, "with no reason to suspect crime or fraud." We agree.

In fashioning a standard for determining when in camera review is appropriate, we begin with the observation that "in camera inspection is a smaller intrusion upon the confidentiality of the attorney-client relationship than is public disclosure." We therefore conclude that a lesser evidentiary showing is needed to trigger in camera review than is required ultimately to overcome the privilege. Ibid. The threshold we set, in other words, need not be a stringent one.

We think that the following standard strikes the correct balance. Before engaging in in camera review to determine the applicability of the crime-fraud exception, "the judge should require a showing of a factual basis adequate to support a good faith belief by a reasonable person" that in camera review of the materials may reveal evidence to establish the claim that the crimefraud exception applies.

Once that showing is made, the decision whether to engage in in camera review rests in the sound discretion of the district court. The court should make that decision in light of the facts and circumstances of the particular case, including, among other things, the volume of materials the district court has been asked to review, the relative importance to the case of the alleged privileged information, and the likelihood that the evidence produced through in camera review, together with other available evidence then before the court, will establish that the crime-fraud exception does apply. The district court is also free to defer its in camera review if it concludes that additional evidence in support of the crime-fraud exception may be available that is not 
allegedly privileged, and that production of the additional evidence will not unduly disrupt or delay the proceedings.

\section{C}

The question remains as to what kind of evidence a district court may consider in determining whether it has the discretion to undertake an in camera review of an allegedly privileged communication at the behest of the party opposing the privilege. Here, the issue is whether the partial transcripts may be used by the IRS in support of its request for in camera review of the tapes.

The answer to that question, in the first instance, must be found in Rule 104(a), which establishes that materials that have been determined to be privileged may not be considered in making the preliminary determination of the existence of a privilege. Neither the District Court nor the Court of Appeals made factual findings as to the privileged nature of the partial transcripts, so we cannot determine on this record whether Rule 104(a) would bar their consideration.

Assuming for the moment, however, that no rule of privilege bars the IRS's use of the partial transcripts, we fail to see what purpose would be served by excluding the transcripts from the District Court's consideration. There can be little doubt that partial transcripts, or other evidence directly but incompletely reflecting the content of the contested communications, generally will be strong evidence of the subject matter of the communications themselves. Permitting district courts to consider this type of evidence would aid them substantially in rapidly and reliably determining whether in camera review is appropriate.

Respondents suggest only one serious countervailing consideration. In their view, a rule that would allow an opponent of the privilege to rely on such material would encourage litigants to elicit confidential information from disaffected employees or others who have access to the information. We think that deterring the aggressive pursuit of relevant information from thirdparty sources is not sufficiently central to the policies of the attorney-client privilege to require us to adopt the exclusionary rule urged by respondents. We conclude that the party opposing the privilege may use any nonprivileged evidence in support of its request for in camera review, even if its evidence is not "independent" of the contested communications as the Court of Appeals uses that term. ${ }^{87}$

\footnotetext{
${ }^{87}$ In addition, we conclude that evidence that is not "independent" of the contents of allegedly privileged communications - like the partial transcripts in this case - may be used not only in the pursuit of in camera review, but also may provide the evidentiary basis for the ultimate showing that the crime-fraud exception applies. We see little to distinguish these two uses: in both circumstances, if the evidence has not itself been determined to be privileged, its exclusion does not serve the policies which underlie the attorney-client privilege.
} 
In sum, we conclude that a rigid independent evidence requirement does not comport with "reason and experience," and we decline to adopt it as part of the developing federal common law of evidentiary privileges. We hold that in camera review may be used to determine whether allegedly privileged attorney-client communications fall within the crime-fraud exception. We further hold, however, that before a district court may engage in in camera review at the request of the party opposing the privilege, that party must present evidence sufficient to support a reasonable belief that in camera review may yield evidence that establishes the exception's applicability. Finally, we hold that the threshold showing to obtain in camera review may be met by using any relevant evidence, lawfully obtained, that has not been adjudicated to be privileged.

Because the Court of Appeals employed a rigid independent-evidence requirement which categorically excluded the partial transcripts and the tapes themselves from consideration, we vacate its judgment on this issue and remand the case for further proceedings consistent with this opinion. On remand, the Court of Appeals should consider whether the District Court's refusal to listen to the tapes in toto was justified by the manner in which the IRS presented and preserved its request for in camera review. In the event the Court of Appeals holds that the IRS's demand for review was properly preserved, the Court of Appeals should then determine, or remand the case to the District Court to determine in the first instance, whether the IRS has presented a sufficient evidentiary basis for in camera review, and whether, if so, it is appropriate for the District Court, in its discretion, to grant such review. 


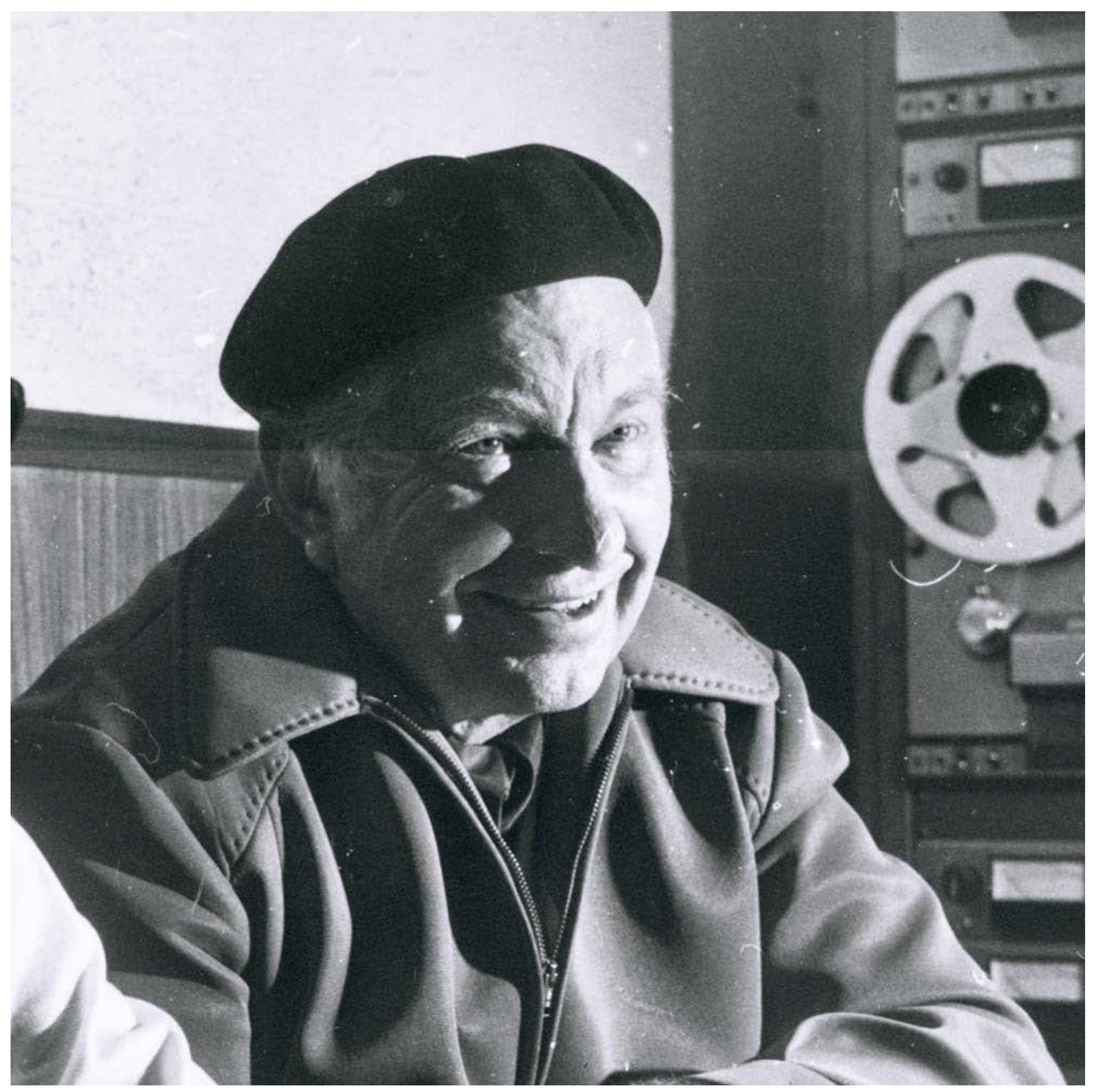

L. Ron Hubbard with audiotape recorders

Blumenthal v. Kimber Mfg., 265 Conn. 1 (2003)

Summary: The Attorney General of Connecticut opened an antitrust investigation and sent Kimber a subpoena. While Kimber produced some documents, it refused to produce one email. Exceptions to the attorney-client privilege should be made only when the reason for disclosure outweighs the potential chilling of essential communications. The burden of proof is on the party seeking to pierce the privilege.

The crime fraud exception applies only after a determination by the trial court "that there is probable cause to believe that a crime or fraud has been attempted or committed and that the communication was in furtherance thereof." Probable cause requires that a 
prudent person have a reasonable basis to suspect the perpetration or attempted perpetration of a crime or fraud and that the communication was in furtherance thereof.

Katz, J.

The petitioner, Richard Blumenthal, the attorney general of the state of Connecticut, appeals from the decision of the trial court denying his application for an order requiring the respondents, Kimber Manufacturing, Inc., a firearms manufacturer with its principal place of business in Yonkers, New York, and Leslie Edelman, Kimber's president, to comply with the petitioner's discovery request for a certain document sent from one Kimber employee to an attorney and three other Kimber employees. The petitioner contends that the trial court improperly determined that: (1) the communication was protected by the attorney-client privilege; and (2) the communication was not otherwise subject to disclosure under the crime-fraud exception to that privilege. We conclude that the trial court properly determined that the document was protected by the attorney-client privilege and that the petitioner did not meet his burden of establishing that the crime-fraud exception applies to exclude the document from protection under the privilege. Accordingly, we affirm the decision of the trial court.

The record discloses the following relevant facts. On March 17, 2000, Smith and Wesson Corporation (Smith \& Wesson), a firearms manufacturer located in Springfield, Massachusetts, entered into an agreement with representatives of various federal, state and local governmental agencies (agreement). The agreement was an attempt to settle both pending and threatened litigation by these governmental agencies against various firearms manufacturers. The agreement required Smith \& Wesson, as well as all other potential signatories to the agreement, to engage in certain practices, opposed by most of the firearms industry, regarding the manufacturing, sale and marketing of firearms. At the time of the proceeding before the trial court, Smith \& Wesson was the only firearms manufacturer to have signed the agreement.

On May 2, 2000, based on his suspicion of the respondents' participation in a retaliatory economic boycott against Smith \& Wesson, the petitioner issued to the respondents interrogatories and a subpoena duces tecum, pursuant to the petitioner's investigatory authority under General Statutes $\S 35-42$, seeking documents "as to any matter relevant to any alleged violation of the Connecticut Antitrust Act"; and specifically any documents related to Smith \& Wesson. On May 31, 2000, the respondents submitted responses, and thereafter submitted supplemental responses on July 20 and December 28, 2000. Unsatisfied with the respondents' disclosure, on March 20, 2001, the petitioner filed with the trial court an application for compliance. Thereafter, the respondents submitted five additional supplemental responses, leading to a total disclosure of approximately 577 pages of documents. After negotiation between the parties as to outstanding documents sought, the hearing on the petitioner's application for compliance was reduced to one issue - a claim of attorney-client privilege on a document sent via electronic mail (e-mail) by Dwight Van Brunt, a Kimber employee, to Edelman, Denis Schusterman, another Kimber employee, and Jerry S. Goldman, an attorney in private practice. ${ }^{[3]}$ The e-mail also was copied to Ryan Busse, another Kimber employee. The e- 
mail expressly referred to the Smith \& Wesson agreement, and the firearms industry's initial reaction to it.

In response to a joint motion for entry of consent order, the trial court directed the respondents to submit the e-mail to the court for an in camera determination of the privilege issue. The parties submitted to the court a joint stipulation of facts, setting forth the factual and procedural background of the matter. At a hearing on the consent order, following a joint request, the trial court sealed the record.

Goldman, one of the parties to whom the e-mail had been sent, appeared as counsel on behalf of the respondents. Goldman represented to the court that, because the agreement arose out of a series of lawsuits that all named John Doe as a defendant in the complaints, potential firearms manufacturer defendants, like Kimber, needed to evaluate the agreement and the firearms industry's reaction to the agreement in order to plan an effective legal strategy of their own. Goldman also provided the court with the corporate titles of each of the e-mail recipients, which identified them as senior Kimber officers. Goldman contended that, because the reactions of others in the firearms industry to the agreement - such as whether to sign similar agreements or litigate - would inform Kimber's legal decision making, Kimber's management needed to keep track of these developments and communicate them to him, as Kimber's counsel.

The petitioner contended that the e-mail was not subject to the attorney-client privilege because it was not marked as confidential and did not request legal advice; rather, according to the petitioner, the subject matter of the e-mail concerned ongoing business developments. The petitioner also contended that the respondents had presented no evidence that litigation had been filed or even threatened against Kimber, nor any evidence of the existence of "John Doe" defendants in such litigation. The petitioner further claimed that, because reference to the e-mail itself did not indicate that it satisfied the requirements of the attorney-client privilege, and because the respondents did not produce any evidence beyond the e-mail and the stipulated facts, the respondents had failed to satisfy their burden of proof to invoke the privilege.

Furthermore, the petitioner argued that, even if the trial court were to infer that the e-mail had been a request for legal advice, and therefore privileged, it would be subject to disclosure under the crime-fraud exception to the privilege.

On September 10, 2001, the same day as the consent order hearing, the trial court issued an order stating that the e-mail was subject to a valid claim of attorney-client privilege. On January 30,2002 , in response to the petitioner's motion for articulation, the trial court issued a memorandum of decision setting forth the reasons for its decision. Specifically, the trial court set forth and applied the four part test that we articulated in Shew $v$. Freedom of Information Commission, for determining whether the attorney-client privilege applies to protect communications between corporate employees and attorneys retained by the corporation. The court determined that, under the test, the e-mail qualified for protection from disclosure.

Additionally, the court concluded that the crime-fraud exception did not apply because the email "is a patent update of firearms litigation developments and does not advocate any criminal or illegal activity." This appeal followed. 
We turn to the petitioner's claim that, even if we were to assume that the privilege generally applied, the trial court improperly determined that the e-mail was not subject to disclosure under the crime-fraud exception to the attorney-client privilege. Specifically, the petitioner contends that other documents submitted as exhibits to the trial court provide probable cause to believe that the respondents engaged in an unlawful boycott of Smith \& Wesson and that the e-mail was in direct furtherance of the boycott. We conclude that the trial court properly concluded that the e-mail did not fall under the crime-fraud exception.

As an initial matter, we note that "exceptions to the attorney-client privilege should be made only when the reason for disclosure outweighs the potential chilling of essential communications." The crime-fraud exception to the attorney-client privilege, therefore, is a limited one, and the burden of proof is on the party seeking to pierce the privilege. We also recognize, however, "that since the attorney-client privilege has the effect of withholding relevant information from the factfinder, it applies only where necessary to achieve its purpose." In Olson v. Accessory Controls \& Equipment Corp., we set forth the proper inquiry for determining when the crime-fraud exception extinguishes the attorney-client privilege. The exception applies only after a determination by the trial court "that there is probable cause to believe that a crime or fraud has been attempted or committed and that the communication was in furtherance thereof."

Probable cause "requires that a prudent person have a reasonable basis to suspect the perpetration or attempted perpetration of a crime or fraud, and that the communication was in furtherance thereof." "The appropriate inquiry under the probable cause standard targets the client's intent in obtaining legal advice; only if there is probable cause to believe that the client intended to perpetrate a crime or fraud does the exception properly come to bear." We have explained that, "without reference to intent, the attorney-client privilege would be pierced whenever probable cause could be made that an illegal act occurred after the client conferred with an attorney - even if the consultation was part of a good-faith attempt to follow the law. Good-faith consultations with attorneys by clients who are uncertain about the legal implications of a proposed course of action however are entitled to the protection of the privilege, even if that action should later be held improper."

We note that, in the present case, the trial court did not determine specifically whether the petitioner had met this probable cause requirement. Even if we were to assume, however, that there was probable cause to believe that the respondents had committed or intended to commit a crime by engaging in an economic boycott in violation of antitrust law, we nevertheless conclude that the petitioner failed to meet his burden of proof.

In addition to probable cause, the crime-fraud exception is limited by a second requirement that the communication sought in discovery was made in furtherance of that unlawful act. "The crime-fraud exception does not apply simply because privileged communications would provide 
an adversary with evidence of a crime or fraud. Mere relevance is insufficient; there must be a showing that the communications at issue were made with an intent to further an unlawful act."

Our analysis as to the "in furtherance" requirement is informed largely by our reasoning in part I of this opinion. As we previously stated, the trial court reasonably could have found that the email concerned matters involving the agreement by a major firearms manufacturer seeking to avoid litigation, and how that agreement, along with the litigation that gave rise to it, similarly might affect the respondents. Moreover, the e-mail reveals nothing that suggests an intent to break the law. Indeed, we agree with the trial court's determination that the critical statements at issue are "not words of advocacy, but, rather, statements of fact or impression." Furthermore, to the extent that the e-mail refers to any action, it is the actions of others, and not of the respondents; it neither advocates that Kimber take any action of its own, nor that others take a particular action. The evidence does not support a conclusion that the respondents sent the email with the intent to further a fraud or crime. Rather, as the trial court reasonably concluded, it was intended to keep Goldman informed so that he could provide them with sound legal advice. Accordingly, the injury that would inure to the relationship of Kimber and its attorneys by disclosure of the e-mail is greater than the benefit that would be gained by its disclosure to the petitioner.

Therefore, we conclude that the trial court properly concluded that the e-mail is not subject to disclosure under the crime-fraud exception to the attorney-client privilege.

\section{Attorney Misconduct \& the Work Product Doctrine}

Moody v. Internal Revenue Service, 654 F. 2d 795 (D.C. Cir. 1981)

WALD, Circuit Judge:

This action is an appeal from a judgment of the district court upholding the Internal Revenue Service's refusal to disclose documents pertinent to appellant's Freedom of Information Act requests. Appellant Shearn Moody, Jr. filed three requests pursuant to the FOIA, asking for the release of all records in the IRS's possession regarding Moody, several business and charitable entities in which he had interests, and "Project Southwest." The IRS released many documents pertinent to these requests, but withheld approximately 150 documents or portions of documents. After an in camera examination of a sample of thirty-five of the challenged withholdings, the district court upheld the IRS's claims of exemptions with respect to all except portions of four documents.

The appellant promptly challenged every aspect of the trial court's decision, seeking before this court both reversal of the findings of applicability of FOIA exemptions to particular documents and a remand on the issues of segregability and the propriety of an award of attorney's fees. The bulk of appellant's arguments on appeal were explicitly, and we feel correctly, dealt with in the district court's admirably comprehensive nineteen page opinion. However, we find two 
issues deserve additional consideration, and remand the case to the district court for this purpose.

\section{DOCUMENT 19 AND THE WORK PRODUCT EXEMPTION}

Exemption 5 of the FOIA permits non-disclosure of:

Inter-agency or intra-agency memorandums or letters which would not be available by law to a party other than an agency in litigation with the agency.

Among the civil litigation privileges incorporated into the FOIA by this section is the attorney work product privilege.

The work product privilege, "distinct from and broader than the attorney-client privilege," exempts from discovery documents prepared by an attorney in contemplation of litigation. Document 19, which the trial court held non-disclosable as attorney work product, seems to fall within this class. It details a meeting held between an IRS lawyer and the federal district judge presiding over the receivership of W. L. Moody \& Sons, Banker, regarding the enforcement of a summons served on E. O. Buck, the bank's receiver. Prepared as a memorandum to the file by the participating IRS attorney, Document 19 predates by two days the filing of a petition to enforce the summons.

Appellant contends, however, that the work product doctrine does not cover Document 19 because it is the fruit of impermissible legal conduct. According to appellant, the purposeful exclusion of opposing counsel from the meeting violated the court's rules and the American Bar Association's ethical standards. Moody argues that it would be a perversion of the work product doctrine, designed "to encourage effective legal representation within the framework of the adversary system," to allow it to be used to "cover up" activities destructive of that system.

We agree that, at least in some circumstances, a lawyer's unprofessional behavior may vitiate the work product privilege. We therefore remand this case to the district court so that it may determine in the first instance whether such circumstances exist in this case, and more fundamentally, whether the actions of the IRS attorney in fact violated professional standards.

The work product privilege creates a zone of privacy within which a lawyer can prepare his case free of adversarial scrutiny. From its inception, however, the courts have stressed that the privilege is "not to protect any interest of the attorney, who is no more entitled to privacy or protection than any other person, but to protect the adversary trial process itself." Some protection of lawyers' "heretofore inviolate" thoughts was deemed necessary to avoid an incentive to develop "unfair and sharp practices for the giving of legal advice and in the preparation of cases for trial," as the development of such practices would "poorly serve the interests of the clients and the cause of justice." 
It would indeed be perverse, as appellant contends, to allow a lawyer to claim an evidentiary privilege to prevent disclosure of work product generated by those very activities the privilege was meant to prevent. Non-disclosure would then ${ }^{88}$ provide an incentive for, rather than against, the disfavored practices. The integrity of the adversary process is not furthered by protecting a lawyer who steps outside his role as "an officer of the court working for the advancement of justice while faithfully protecting the rightful interests of his clients." An attorney should not be able to exploit the privilege for ends outside of and antithetical to the adversary system any more than a client who attempts to use the privilege to advance criminal or fraudulent ends.

However, the conclusion that an attorney has no right to object to the disclosure of work product made possible by his misconduct does not necessarily mean that the work product privilege is inapplicable to such documents. Unlike the attorney-client privilege, which exists solely for the benefit of the client, and can be asserted and waived exclusively by him, the work product privilege creates a legally protectable interest in non-disclosure in two parties: lawyer and client. Just as "an invasion of the attorney's necessary privacy may not be justified by the misfortune of representing a fraudulent client," the client's interest in preventing disclosures about his case may survive the misfortune of his representation by an unscrupulous attorney. A court must look to all the circumstances of the case, including the availability of alternate disciplinary procedures, ${ }^{89}$ to decide whether the policy favoring disclosure outweighs the client's legitimate interest ${ }^{90}$ in secrecy. No court should order disclosure under the FOIA or in discovery if the disclosure would traumatize the adversary process more than the underlying legal misbehavior.

We have attempted to outline in our footnotes to this opinion some of the factors we would take into consideration when balancing the policy favoring disclosure against that favoring continued secrecy. However, each case obviously presents new permutations and combinations of fact patterns, all of which must be taken into account when reaching a decision. For this reason, the trial court, which is both familiar with the case and in a position to gather any evidence deemed necessary to a reasoned decision, is best equipped to weigh the balance.

\footnotetext{
${ }^{88}$ We stress that in this case, appellee has admitted engaging in the conduct which forms the basis of the charge of unprofessional conduct. We are therefore not dealing with a situation where disclosure is sought for the purpose of determining whether such misbehavior has in fact occurred. The latter case involves an entirely different problem - an exception which threatens to swallow the rule - than is presented in this case.

${ }^{89}$ Lawyers, of course, are always subject to disciplinary proceedings, if not criminal or civil malpractice sanctions, for malfeasance in the conduct of their legal affairs. Thus, disclosure is not the sole available remedy for a breach of a professional duty, and may in fact bear so little relationship to the underlying breach as to be inappropriate as a remedy. In this case, of course, if a violation of legal standards occurred, it lay in the attorney's exclusion of the opposing party and his counsel from a meeting; disclosure of what went on at that meeting to that opponent, the appellant in this FOIA action, would therefore seem an appropriate remedy.

${ }^{90}$ A client's interest in non-disclosure would be illegitimate, of course, if he knowingly instigated or participated in the conduct which constituted the breach of duty. In some cases, the extent to which a client should be allowed to benefit from unprofessionally obtained information may also be questioned; such benefits, in some cases, may not be deemed a "legitimate" secrecy interest.
} 
We therefore remand this case for reconsideration of the withholdings from Document 19 in light of our Neufeld decision, for an evaluation of the attorney's conduct and, if it is found in violation of professional standards, a determination of whether his breach of professional standards vitiated the work product privilege otherwise attributable to Document 19. If the documents released as a result of the proceedings on remand are sufficient for a court to conclude appellant substantially prevailed in his FOIA action, he will then become eligible for an award of attorney's fees.

Haigh v. Matsushita Elec. Corp. of America, 676 F. Supp. 1332 (E.D. Va. 1987)

SPENCER, District Judge.

Plaintiff Richard Haigh, a Virginia citizen, was employed by defendant Matsushita Electric Corporation of America from October 17, 1974 through January 27, 1987. He is fifty-seven years old, and is Jewish. Plaintiff Norma Haigh, a Virginia citizen, is Haigh's wife.

Defendant Panasonic is a Delaware corporation.

The Second Amended Complaint, which is currently before the Court, is sixty-eight pages long, and contains a plethora of allegations. In brief, Haigh states that he was a salesman for Panasonic who handled the accounts of Best Products and Circuit City. Haigh claims that during his tenure business with these two outfits skyrocketed. In December 1986, Haigh was told that the Best Products and Circuit City accounts were being taken away from him and given to defendant Weber. Haigh also claims he was told his salary would be cut, along with his earnable bonuses. Additionally, he was told that he would be reassigned from his Richmond, Virginia location to the Panasonic accounts in western Virginia. Haigh claims he argued that the reassignment was unlawful, and requested to be told the legitimate business reason for the action. In response, defendants Willner and Adamyk allegedly proposed that the Richmond accounts of Thalhimers, Miller \& Rhoads, Robert's Leasing, and Dominion Pottery be added to Haigh's new territory. Haigh also asserts that these two defendants sought a complete release for all of Panasonic's actions to date.

In due course, by letter dated January 27, 1987, Haigh stated that his reassignment was unacceptable, and claimed that Panasonic had constructively terminated his employment. Since that time, Haigh claims to have vigorously sought employment without success.

Defendants move for an order compelling discovery of certain tape recordings, and awarding expenses in connection thereto. The facts underlying the motion are as follows. Defendants made the usual request for production of documents in August 1987. Subsequently, during Haigh's deposition on October 21, 1987, he admitted that he had taped conversations with fiftyeight individuals. The tapes were made without the knowledge of these individuals, at Haigh's own initiative, and absent directives from Haigh's attorneys. Upon learning of their existence, defendants asked for the tapes. Plaintiffs turned over three tapes, which contained 
conversations with named defendants. Plaintiffs also surrendered a list of the names of the individuals who were on the recordings.

Defendants now seek the production of all the recordings. Plaintiffs argue that the tapes come within the work product privilege in that they were prepared in anticipation of litigation. Specifically, plaintiffs state that Haigh consulted legal counsel in December 1986, evidently fearing that defendants were trying to push him out of the company. Haigh considered himself constructively terminated in late January 1987. On March 12, 1987, he filed an EEOC complaint. He states that between February 1987 and October 1987, he made the tape recordings. He delivered the cassette tapes to counsel for the plaintiffs within a day or two following each conversation, and the contents of such tapes were reviewed by counsel and used by counsel to prepare the Complaint and discovery requests.

This matter came before the Court on defendants' November 2, 1987 motion. The motion was briefed by the parties, and oral argument was held on November 13, 1987, at which time the Court directed counsel to submit additional memoranda addressed to the question whether the work product privilege had been vitiated. The parties have filed their memoranda, and the motion is now ripe for decision. Although several issues are raised by the parties, only two need to be addressed by this Court.

Issue I - Are the tapes protected by the work product privilege?

Issue II - If the answer to the question in Issue I is yes, is the privilege vitiated in this case?

Issue I

Federal Rule of Civil Procedure 26(b)(3) addresses the work product privilege. Basically, in order for the privilege to be applicable, the material must be (1) documents or tangible things, (2) prepared in anticipation of litigation or for trial, and (3) prepared by or for another party or by or for that other party's representative. Additionally, the question whether the material was prepared in anticipation of litigation does not turn on whether a suit had already been filed.

In arguing that the work product privilege does not apply here, defendants make the following statement: "The tapes were made by a party to this action and apparently do not contain the thoughts and impressions of plaintiff's counsel, who was not involved in the conversations, and, therefore, cannot be considered attorneys' work product under the most liberal interpretation of that doctrine."

Defendants are living in the past, and are presenting a pre-1970 argument. "The 1970 amendment to Fed. R. Civ. P. 26 extends the work product protection to documents and things prepared for litigation or trial by or for the adverse party himself or his agent. Prior to the amendment some cases have held that documents of this kind were not within the immunity."

Moreover, in an identical situation, the United States District Court for the Southern District of New York held that a party's surreptitiously obtained tape recordings are protected under Fed. 
R. Civ. P. 26(b)(3), assuming that the statements were obtained and recorded in anticipation of litigation or in preparation for trial.

Based upon the facts and arguments as now appearing before the Court, the Court is of the opinion that the work product privilege would apply to the tape recordings, and production would be denied unless the Court became convinced that defendants had a substantial need for the recordings and were unable to obtain their equivalent without undue hardship.

Issue II

The Court need not delve into questions of "substantial need," "undue hardship," or "substantial equivalent." The Court holds that the work product privilege has, in this case, been vitiated.

In recent years, courts have come to recognize that "in some circumstances, a lawyer's unprofessional behavior may vitiate the work product privilege."

The Moody opinion was discussed by the Eleventh Circuit in Parrott v. Wilson. There, plaintiff's attorney had clandestinely taped telephone conversations with two witnesses. Defendants moved to compel production of the recordings, and plaintiff objected on the ground that the tapes were work product under Fed. R. Civ. P. 26(b)(3). It is helpful to quote in length from that opinion.

The Moody court reasoned that the purpose of the work product privilege is to protect the integrity of the adversary process; therefore, it would be improper to allow an attorney to exploit the privilege for ends that are antithetical to that process. In the instant case, the record clearly demonstrates that counsel for the appellant clandestinely recorded conversations with witnesses. While this practice violates no law, the Code of Professional Conduct imposes a higher standard than mere legality. The American Bar Association's Committee on Ethics and Professional Responsibility has ruled that the recording of conversations of witnesses without their consent is unethical.

We are mindful of the client's interest in protecting against the disclosure of work product. However, we are unable to say that the disclosure in this case "traumatized the adversary process more than the underlying legal misbehavior." The only discernible effect of the disclosure was that the depositions of Sharp and Godfrey commenced with the playing of the taped conversations. We thus hold that whatever work product privilege might have existed was vitiated by counsel's clandestine recording of conversations with witnesses.

Carrying the question a step further, one court has recognized the potential difficulties of the situation in which an attorney directs his client to engage in behavior that would be improper for the attorney. It is apparent to this Court that such a course of action on the part of an attorney would clearly be improper. 
In the instant situation, counsel for plaintiffs did not direct Haigh to undertake the clandestine recordings. As represented to this Court, he clearly initiated such conduct on his own, and he, of course, is not bound by the ethical strictures which bind his counsel.

This does not end the question, however. The Court is troubled by language contained in plaintiff's memorandum in response to the motion to compel.

Haigh began a concerted effort to interview persons throughout the United States who may have relevant information relating to his legal claims. Between February 1987 and October 1987, Haigh has telephoned approximately fifty-eight such persons and, in most instances, tape recorded the conversations. The cassette tapes were delivered to counsel for the plaintiffs within a day or two following each such conversation and the contents of such tapes reviewed by counsel. In many instances, the information obtained during such telephone conversations was used by plaintiffs' counsel to prepare the initial complaint, the first amended and restated complaint, and the second amended and restated complaint filed in this action. Counsel also used such information to prepare other discovery requests.

While counsel did not tell Haigh to initiate or continue taping conversations, the old adage "actions speak louder than words" comes to mind. Indeed, Haigh and his attorneys fell into a pattern of conduct whereby Haigh would tape conversations and almost immediately turn the tapes over to counsel for their use. This pattern of conduct continued over a period of approximately nine months, and included the taping of fifty-eight conversations.

The Court would not be so troubled if it were faced with the situation where a party, in his exuberance over pending litigation, pursued such a course of conduct and delivered a handful of tapes to his counsel. In that situation, the lawyer's conduct could fairly be described as simple acquiescence in the situation created by the client's exuberance. There is a point, however, where acquiescence ceases to be passive and noncommittal, and becomes active encouragement and affirmative support. There is, and can be, no bright line to determine when this point is reached. Instead, the circumstances of each case must be viewed in their totality in an attempt to get a fix on that point. Here, the Court is certain that that point has been crossed. As such, the Court holds that the work product privilege has been vitiated.

The ruling today should not be taken as an indictment of counsel's ethics or professionalism. To be sure, the law on this point is in an infant, perhaps even fetal, state. The Court in no way assumes or believes that counsel's intent was to run afoul of ethical strictures.

Additionally, it should be noted that this ruling may be interpreted by some as punishment for Haigh's retention of counsel. Indeed, if Haigh were proceeding pro se, the privilege would not be vitiated. However, an attorney's clients may not reap the benefits of the attorney's expertise in a vacuum-like state. Rather, the client must realize that the attorney is bound by a Code of Professional Responsibility, and, when he retains the attorney, he also retains the responsibilities imposed on that attorney. 


\section{Questions:}

\section{Further Reading:}

- G. Michael Halfenger, The Attorney Misconduct Exception to the Work Product Doctrine, 58 U. Chi. L. Rev. 1079 (1991)

- David J. Fried, Too High a Price for Truth: The Exception to the Attorney-Client Privilege for Contemplated Crimes and Frauds, 64 N.C. L. Rev. 443 (1986)

- Michele DeStefano Beardslee, Taking the Business Out of Work Product, 79 Fordham L. Rev. 1869 (2011) 


\section{Section 6: Advocacy \& Conduct}

\section{1: Frivolous Pleadings}

Meaningless, who dare to say it wasn't meaningless? Shout from the rooftops and address the press. Ha ha ha it was totally meaningless. ${ }^{91}$

While courts have always prohibited "frivolous" litigation, they have also struggled to define it. In theory, frivolous litigation consists of a pleading or motion that a competent attorney would know has no legitimate basis in fact or law. But of course, it is often hard to know whether a legal claim is legitimate or has a chance of success. Sometimes, courts change their minds, and sometimes, juries are unpredictable. Frivolity is often in the eye of the beholder.

The Supreme Court has revised the procedural rules governing frivolous litigation many times, and adopted different approaches to identifying and dissuading frivolous litigation at different points in time. The notes of the Advisory Committee on the Federal Rules of Civil Procedure seem to reflect both frustration with frivolous litigation and uncertainty how to prevent it. For example, the 1983 notes observe, "Experience shows that in practice Rule 11 has not been effective in deterring abuses." They accompanied revisions that encouraged the imposition of sanctions. And the 1993 notes observe, "Experience shows that in practice Rule 11 has not been effective in deterring abuses." They accompanied revisions that discouraged the imposition of sanctions.

Under the current version of Rule 11, a party may file a motion for sanctions only after serving the draft motion on opposing counsel and giving them time to respond. While courts may impose sanctions under Rule 11 sua sponte, the Rule implicitly discourages sanctions and encourages dispute resolution.

\section{Federal Rule of Civil Procedure 11: Signing Pleadings, Motions, and Other Papers;} Representations to the Court; Sanctions

a. Signature. Every pleading, written motion, and other paper must be signed by at least one attorney of record in the attorney's name-or by a party personally if the party is unrepresented. The paper must state the signer's address, e-mail address, and telephone number. Unless a rule or statute specifically states otherwise, a pleading need not be verified or accompanied by an affidavit. The court must strike an unsigned paper unless the omission is promptly corrected after being called to the attorney's or party's attention.

b. Representations to the Court. By presenting to the court a pleading, written motion, or other paper-whether by signing, filing, submitting, or later advocating it-an attorney or unrepresented party certifies that to the best of the person's knowledge, information, and belief, formed after an inquiry reasonable under the circumstances:

91 The Magnetic Fields, Meaningless, 69 Love Songs (1999). 
1. it is not being presented for any improper purpose, such as to harass, cause unnecessary delay, or needlessly increase the cost of litigation;

2. the claims, defenses, and other legal contentions are warranted by existing law or by a nonfrivolous argument for extending, modifying, or reversing existing law or for establishing new law;

3. the factual contentions have evidentiary support or, if specifically so identified, will likely have evidentiary support after a reasonable opportunity for further investigation or discovery; and

4. the denials of factual contentions are warranted on the evidence or, if specifically so identified, are reasonably based on belief or a lack of information.

c. Sanctions.

1. In General. If, after notice and a reasonable opportunity to respond, the court determines that Rule 11(b) has been violated, the court may impose an appropriate sanction on any attorney, law firm, or party that violated the rule or is responsible for the violation. Absent exceptional circumstances, a law firm must be held jointly responsible for a violation committed by its partner, associate, or employee.

2. Motion for Sanctions. A motion for sanctions must be made separately from any other motion and must describe the specific conduct that allegedly violates Rule 11(b). The motion must be served under Rule 5, but it must not be filed or be presented to the court if the challenged paper, claim, defense, contention, or denial is withdrawn or appropriately corrected within 21 days after service or within another time the court sets. If warranted, the court may award to the prevailing party the reasonable expenses, including attorney's fees, incurred for the motion.

3. On the Court's Initiative. On its own, the court may order an attorney, law firm, or party to show cause why conduct specifically described in the order has not violated Rule 11(b).

4. Nature of a Sanction. A sanction imposed under this rule must be limited to what suffices to deter repetition of the conduct or comparable conduct by others similarly situated. The sanction may include nonmonetary directives; an order to pay a penalty into court; or, if imposed on motion and warranted for effective deterrence, an order directing payment to the movant of part or all of the reasonable attorney's fees and other expenses directly resulting from the violation.

5. Limitations on Monetary Sanctions. The court must not impose a monetary sanction:

A. against a represented party for violating Rule 11(b)(2); or

B. on its own, unless it issued the show-cause order under Rule 11(c)(3) before voluntary dismissal or settlement of the claims made by or against the party that is, or whose attorneys are, to be sanctioned.

6. Requirements for an Order. An order imposing a sanction must describe the sanctioned conduct and explain the basis for the sanction. 
d. Inapplicability to Discovery. This rule does not apply to disclosures and discovery requests, responses, objections, and motions under Rules 26 through 37.

\section{Further Reading:}

- Georgene Vairo, Rule 11 and the Profession, 67 Fordham L. Rev. 589 (1998)

- Julia K. Cowles, Rule 11 of the Federal Rules of Civil Procedure and the Duty to Withdraw a Baseless Pleading, 56 Fordham L. Rev. 697 (1988)

- Suja A. Thomas, Frivolous Cases, 59 DePaul L. Rev. 633 (2010)

- Charles Yablon, Hindsight, Regret, and Safe Harbors in Rule 11 Litigation, 37 Loy. L.A. L. Rev. 599 (2004)

- $\quad$ Robert G. Bone, Modeling Frivolous Suits, 145 U. Pa. L. Rev. 519 (1997)

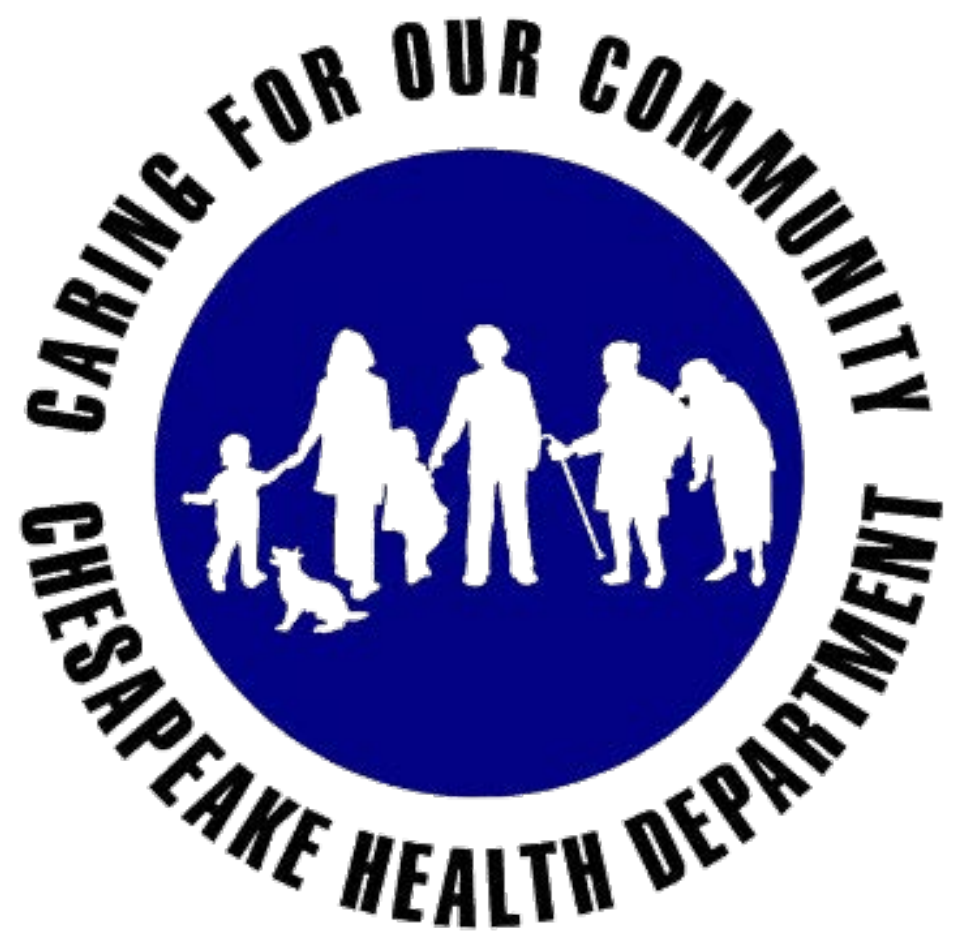

Simpson v. Welch, 900 F. 2d 33 (4th Cir. 1990)

Summary: Simpson filed an employment discrimination action against the Chesapeake Health Department, but failed to respond to subsequent motions or to appear at the hearing, so the district court dismissed the complaint and granted the defendant's motion for fees and costs under Rule 11. The circuit court reversed, because Rule 11 only covers frivolous pleadings, not the failure to respond to motions or pleadings.

PER CURIAM: 
The questions presented are whether the district court properly dismissed plaintiff's complaint and whether the court properly awarded sanctions pursuant to Rule 11 of the Federal Rules of Civil Procedure. We hold that the dismissal was proper, but that Rule 11 does not provide authority for the sanctions imposed in this case.

Appellant is a black employee at the Chesapeake Health Department in Chesapeake, Virginia. After receiving "Right to Sue" letters from the Equal Employment Opportunity Commission, she filed this employment discrimination suit on February 16, 1989. The individual appellees, the present and former directors of the Department, filed a motion to dismiss on March 13, 1989. The City of Chesapeake filed a motion for summary judgment on March 20, 1989.

An initial pretrial conference was held on April 3, 1989, at which all counsel were present. At the conference, an April 17, 1989 deadline was established for appellant to file responses to the motions to dismiss and for summary judgment, and a hearing on these motions was scheduled for May 2, 1989. Appellant failed to oppose these motions, and appellees moved for judgment on the pleadings. After appellant's counsel also failed to appear at the May 2, 1989 hearing, the district court granted appellees' motions and dismissed the complaint.

The court concluded that the Department and its employees were agents of the state, not the City. Therefore, the court granted the City's motion for summary judgment and held that the Eleventh Amendment barred appellant's claims for damages and other relief. The Court also held that all of appellant's claims should be dismissed under Rule 12(b)(6) for failure to state a claim upon which relief can be granted. Appellant's "vague and conclusory" allegations were insufficient to satisfy the notice pleading requirements of the Federal Rules of Civil Procedure. In the alternative, the court held that "plaintiff's continued failure to follow the rules and orders of this Court or even to appear in Court as required justifies dismissal under Rule 41 (b)."

Appellees moved for an award of attorneys' fees and costs, and appellant moved under Rule 60(b) for relief from the order of dismissal. The district court denied the Rule 60(b) motion, finding no excuse for appellant's counsel's neglect in failing to respond to appellees' motions to dismiss and for summary judgment. The court extended the deadline for appellant to oppose appellees' motion for attorneys' fees and costs, but appellant again failed to file any opposition. Thus, on July 13, 1989, the district court granted appellees' motion for attorneys' fees and costs.

II

The allegations in appellant's complaint are insufficient to state a claim upon which relief can be granted. Appellant alleges that she was "required to work in places and under conditions where prejudice and bias exist," but her complaint nowhere alleges any specific oppressive conditions or expressions of "prejudice and bias." She alleges that she was "denied opportunities to be promoted," but never indicates the positions for which she applied. She asserts that she was 
"treated poorly on the job and harassed," but described no specific incidents of improper treatment or of harassment. As the district court stated:

The Complaint contains no factual allegations whatsoever to support these charges. The plaintiff has set forth no specific incidents of discrimination, no details of promotions to which she was entitled but which she did not receive, no explanation of the forms that any alleged harassment took, no specifics regarding her claims of disparate treatment of blacks and whites. The Complaint alleges religious discrimination but fails even to state what plaintiff's religious affiliation is, let alone how it has been the basis of any discriminatory acts. In short, the Complaint fails to allege sufficient facts to state a claim of racial or religious discrimination.

Appellant's conclusory allegations of discrimination and harassment do not state a claim upon which relief can be granted. The district court properly dismissed appellant's complaint in its entirety.

In the alternative, the district court did not abuse its discretion when it dismissed appellant's complaint for failure to comply with court orders. Appellant failed to oppose appellees' motions to dismiss and for summary judgment, even after the district court extended the time to respond, and appellant's counsel failed to appear at the May 2, 1989 hearing. The district court acted within its discretion when it dismissed the complaint under Rule 41(b).

III

Although appellees moved for attorneys' fees and costs under Rules 11 and 54(d) of the Federal Rules of Civil Procedure and under 42 U.S.C. $\S 1988$, the district court's order awarding fees and costs mentions only Rule 11. Rule 11 states:

Every pleading, motion, and other paper of a party represented by an attorney shall be signed by at least one attorney of record in the attorney's individual name. The signature of an attorney or party constitutes a certificate by the signer that the signer has read the pleading, motion, or other paper; that to the best of the signer's knowledge, information, and belief formed after reasonable inquiry, it is well grounded in fact and is warranted by existing law or a good faith argument for the extension, modification, or reversal of existing law, and that it is not interposed for any improper purpose, such as to harass or to cause unnecessary delay or needless increase in the cost of litigation. If a pleading, motion, or other paper is signed in violation of this rule, the court, upon motion or upon its own initiative, shall impose upon the person who signed it, a represented party, or both, an appropriate sanction, which may include an order to pay to the other party or parties the amount of the reasonable expenses incurred because of the filing of the pleading, motion, or other paper, including a reasonable attorney's fee.

The rule imposes "a duty to conduct a pre-filing examination of both the facts and the law before instituting legal process." The rule does not purport to be a means for district courts to sanction 
conduct in the course of a lawsuit, such as failure to comply with court orders, that does not involve the signing of pleadings, motions, or other papers.

The district court faulted appellant for filing a suit in which the "weight of existing law" favored appellees, but the court admitted that there was a legal basis for appellant's Title VII claims. The court justified its sanction under Rule 11 by noting that appellant had failed to oppose the motions to dismiss and for summary judgment and that the complaint set forth only vague and conclusory allegations. But this does not establish that there was not a factual and legal basis for appellant's claim under Title VII. It merely establishes that appellant's counsel failed to comply with court orders and filed an inartfully pled complaint. Even a vague and conclusory complaint may be "well grounded in fact and warranted by existing law or a good faith argument for the extension, modification, or reversal of existing law." Indeed, if Rule 11 permitted sanctions merely on the basis of inartful pleading, rather than for a failure to investigate the legal and factual basis for that pleading, Rule 12(e) motions for a more definite statement would be virtually unheard of. The fact that appellant's complaint was vague and conclusory does not justify sanctions under Rule 11.

The district court also awarded attorneys' fees and costs because of appellant's counsel's "blatant disregard" for the local rules of the district court and for "his lackadaisical attitude in failing to respond to defendants' Motion for Award of Attorneys' Fees." Because the order awarding fees and costs does not indicate any other source of authority, we must presume that the district court awarded fees on this ground pursuant to Rule 11. Again, Rule 11 is inapplicable. Rule 16(f) specifically provides for sanctions "if a party or party's attorney fails to obey a scheduling or pretrial order, or if no appearance is made on behalf of a party at a scheduling or pretrial conference." In contrast, Rule 11, by its own terms, can never be the basis for sanctions for failure to file certain papers. Thus, although appellant's counsel's conduct in the course of this lawsuit fully justified sanctions, Rule 11 is an inappropriate vehicle for the imposition of such sanctions. Because appellees' motion for attorneys' fees and costs rested on a number of grounds and because the district court appeared to rely only on Rule 11, the award of fees and costs must be vacated and the issue remanded to the district court for consideration of alternative bases for such an award.

\section{IV}

The district court properly dismissed appellant's complaint for failure to state a claim upon which relief could be granted and for failure to comply with court orders. Although the district court had ample grounds under Rule 16(f) for imposing sanctions on appellant's counsel, Rule 11 does not provide authority for sanctions in this case.

\section{Questions:}

1. Should the circuit court have read Rule 11 this narrowly?

2. If sanctions were permitted on a basis other than Rule 11, why didn't the circuit court affirm on alternative grounds? 
3. Should plaintiff's failure to respond be sanctionable? What about defendant's failure to respond?

In re Sargent, 136 F. 3d 349 (4th Cir. 1998)

Summary: Cox filed a complaint alleging that Saunders and others violated his constitutional rights by subjecting him to harmful prison conditions. The district court dismissed all but one of Cox's claims, and informed him that the Prison Litigation Reform Act precluded prisoners who filed three frivolous complaints from filing any additional complaints, unless they were in danger of imminent harm. Assistant Attorney General Sargent filed a motion for summary judgment, arguing that Cox's complaint was frivolous. The district court dismissed and then reinstated Cox's complaint, at his request. The district court also imposed Rule 11 sanctions on Sargent for misrepresenting the PLRA and enjoined application of the PLRA to Cox. The circuit court reversed, holding that Sargent's motion for summary judgment did not violate Rule 11 and that precluding application of the PLRA to Cox was not an appropriate remedy for the alleged misconduct.

WILKINS, Circuit Judge:

Pamela A. Sargent, an Assistant Attorney General for the Commonwealth of Virginia, appeals a sanction imposed pursuant to Federal Rule of Civil Procedure 11 enjoining application of the Prison Litigation Reform Act to inmate Richard Cox in any civil action in the United States District Court for the Western District of Virginia. We reverse.

I.

Cox, a Virginia prisoner, filed an action against Warden Lonnie Saunders and other prison officials, alleging that they had violated his constitutional rights by, inter alia, intentionally subjecting him to harmful prison conditions. The prison officials filed a motion to dismiss Cox's action, which was granted except as to one claim. Soon afterward, the district court issued a notice informing Cox of the passage and practical effects of the PLRA. The court correctly explained that under the PLRA

A prisoner may not bring a civil action without prepayment of the appropriate filing fee if the prisoner has, on three or more prior occasions, brought an action or appeal in a federal court that was dismissed as frivolous, as malicious, or for failure to state a claim upon which relief may be granted, unless the prisoner is under imminent danger of serious physical injury.

Shortly thereafter, Sargent filed a motion for summary judgment on behalf of the prison officials. In the penultimate paragraph of the accompanying memorandum, she asserted: 
Cox has already had two cases dismissed for being frivolous or for failure to state a claim. Pursuant to the newly enacted Prison Litigation Reform Act, Cox will forfeit the right to file future cases if a third case is found to be frivolous, malicious or fails to state a claim upon which relief can be granted. The prison officials submit that this is that third case and that an Order should be entered dismissing the case with prejudice, awarding them costs and attorney's fees, and barring Cox from future filings.

Approximately one week later, Cox requested that his action be dismissed without prejudice, and the district court granted the dismissal. Thereafter, however, the district court granted Cox's motion to reinstate the action. In ruling on that motion, the district court found that Sargent's contentions were "a blatant misrepresentation of the content of that provision and its application to this case" because a portion of Cox's complaint had already survived a motion to dismiss. The district court also noted that Sargent had misstated the law regarding the filing of future cases because $\S 1915(\mathrm{~g})$ of the PLRA provides that an inmate who has three qualifying dismissed cases is not barred from all future filings but only from filing actions in forma pauperis when he does not face an imminent danger of serious physical injury. The district court directed Sargent to show cause why the memorandum in support of the motion for summary judgment did not violate Federal Rule of Civil Procedure 11(b). After receiving Sargent's response, the district court determined that sanctions were warranted and enjoined application of $\S 1915(\mathrm{~g})$ to Cox until further order of the court.

II.

Sargent first argues that the sanction should be reversed because the district court abused its discretion in finding that the legal contentions contained in the memorandum in support of the motion for summary judgment violated Rule 11. We agree.

The provisions of Rule 11 dictate that in presenting a motion to a court, an attorney represents that the "legal contentions therein are warranted by existing law or by a nonfrivolous argument for the extension, modification, or reversal of existing law or the establishment of new law." An assertion of law violates Rule 11(b)(2) when, applying a standard of objective reasonableness, it can be said that "a reasonable attorney in like circumstances could not have believed his actions to be legally justified." A legal contention is unjustified when "a reasonable attorney would recognize it as frivolous." Put differently, a legal position violates Rule 11 if it "has absolutely no chance of success under the existing precedent."

Here, the district court first took issue with Sargent's contention that the earlier dismissal of some of the claims in Cox's present lawsuit should be considered his third strike for the purpose of $\S 1915(\mathrm{~g})$. However, ten of the eleven claims in Cox's complaint had been dismissed for failure to state a claim upon which relief could be granted, and it was well within the bounds of fair adversarial argument for the Government to suggest that the remaining claim must also be dismissed as frivolous, causing the three-strike rule to apply. If the latter occurred, Cox's underlying suit could indeed constitute the third strike against him. We cannot say that the position had no chance of success under existing law. 
The district court next found fault with Sargent's representation that pursuant to § 1915(g) a third dismissal for frivolity, malice, or failure to state a claim would bar Cox from future filings. Assuredly, Sargent's legal contention was not a complete explanation of the consequences of a third strike. But, the consequences of a third strike in all future cases were not put into issue by the motion. And, Sargent explains that the statement was meant to convey only that Cox would be barred from filing cases pursuant to $\S 1915$ - the statute at issue — which addresses only in forma pauperis filings. Thus, although Sargent's statement of the consequences of obtaining a third strike perhaps was not completely thorough, it can plausibly be read as a mere shorthand reference to the statute and was not unwarranted under the circumstances. Accordingly, we find the decision of the district court to sanction Sargent under Rule 11 constituted an abuse of discretion.

III.

Sargent also maintains that even if her conduct warranted sanctions, the district court abused its discretion in choosing the particular sanction imposed. "A sanction imposed for violation of Rule 11 shall be limited to what is sufficient to deter repetition" of the objectionable conduct. This court has made "clear that the primary purpose of Rule 11 is to deter future litigation abuse." Other objectives advanced by the imposition of a sanction are remediation of the harm caused by the Rule 11 violation, for example by compensating the victim for attorney's fees expended in responding to the frivolous claim; punishment of the person or entity responsible for the violation; and enhancement of judicial administration.

With these purposes in mind, we conclude that the district court abused its discretion in ruling that the sanction imposed was limited to what was sufficient to deter Sargent's conduct. The finding by the district court that Sargent violated Rule 11 by advancing an unsupported legal assertion essentially amounts to a public reprimand that, in and of itself, should be a significant deterrent to future violations. And, there is no serious suggestion that further sanction was necessary to curb future abuses by Sargent. Further, Cox was in no way prejudiced by Sargent's legal assertion. Assuming that Cox moved to dismiss his action based upon Sargent's legal representations, the district court permitted reinstatement of the action upon Cox's request. Thus, the imposition of any sanction was unnecessary for purposes of remediating harm caused by the Rule 11 violation. Moreover, assuming that Cox was prejudiced in some way by Sargent's statements, the sanction imposed by the district court failed to provide remediation because it had no potential to alleviate any type of harm that Cox could have suffered in the present litigation. Indeed, we can envision no circumstances in which such a sanction would be appropriate to remediate harm to a victim of a Rule 11 violation. Finally, there is no suggestion that an injunction on application of $\S 1915(\mathrm{~g})$ to Cox was necessary to punish Sargent or to enhance judicial administration. For that matter, it is difficult to say that the sanction adversely impacted Sargent in the least. And, we fail to appreciate how the suspension of a statute specifically designed to reduce the amount of frivolous prisoner litigation could be thought to enhance the administration of justice. Accordingly, we conclude that the district court 
abused its discretion in choosing a sanction to impose upon Sargent even if her conduct had violated Rule 11.

\section{Questions:}

1. When should an argument in a pleading be sanctionable under Rule 11?

2. Should prosecutors and other government lawyers be held to a different standard than private attorneys or pro se litigants?

3. What is the appropriate sanction for a Rule 11 violation?

\section{The Duty of Reasonable Investigation}

Cleveland Demolition Co., Inc. v. Azcon Scrap Corp., 827 F. 2d 984 (4th Cir. 1987)

Summary: Paul Haddad represented himself as the President of Cleveland Demolition and sold scrap material to Azcon Scrap. But when Azcon tried to collect the scrap, Cleveland refused to provide it, arguing that Haddad was not its President and that he was not authorized to sell the scrap. Azcon filed a breach of contract action against Cleveland. At trial, Azcon Vice-President Richard Spine testified that he had requested a verbal Dun \& Bradstreet report on Cleveland that listed Haddad as President. A later, printed report listed Haddad as President, and the district court granted summary judgment to Azcon. Cleveland filed a motion to vacate, arguing that Spine perjured himself, because Dun \& Bradstreet had no record of a verbal report. The district court dismissed the motion and imposed Rule 11 sanctions on Cleveland, finding that its claims lacked a factual basis, and the circuit court affirmed.

WILKINSON, Circuit Judge:

Cleveland Demolition seeks to set aside an earlier jury verdict for Azcon Scrap on the basis that Azcon's trial attorney conspired with a witness to present perjured testimony. The only evidence of this alleged conspiracy, however, is an evidentiary conflict between the witness's testimony and statements made by a different party in a subsequent lawsuit. This routine evidentiary conflict does not justify an action for fraud on the court or the serious allegations of attorney misconduct leveled in this case. We therefore affirm the district court's decision to grant summary judgment for Azcon and to impose Rule 11 sanctions on Cleveland and its attorneys.

I.

In 1983, Cleveland Demolition demolished a power plant for an electric company in West Virginia, leaving Cleveland with several tons of scrap material. In June 1983, Paul Haddad, who represented himself as the president of Cleveland, contacted Richard Spine, a vice-president of Azcon Scrap, to inquire whether Azcon was interested in buying the scrap. After inspecting the site and negotiating over terms, Spine and Haddad signed a contract on July 14 th. When an Azcon crew arrived at the demolition site, however, it was prevented from removing the scrap by 
Cleveland employees, who informed them that Haddad was not the president of Cleveland and had no authority to sign the contract with Azcon. Azcon sued Cleveland for breach of contract.

A crucial issue at trial was whether Haddad had apparent authority to sell the scrap for Cleveland Demolition. Azcon presented a great deal of evidence to justify its belief that Haddad was the president of Cleveland. For example, Cleveland employees at the scrap site had treated Haddad as if he were the president and a representative of the electric company had told Spine that Haddad was the president of Cleveland. Haddad also testified that Phillip Schwab, the owner of Cleveland, had asked him to act as president in dealing with the West Virginia electric company because a different Schwab company had defaulted on an earlier contract with the same power company.

During the trial, Spine testified that on July 5th, before signing the contract with Haddad, he requested a verbal Dun \& Bradstreet report on Cleveland Demolition from Azcon's Chicago office. According to Spine, Azcon's Chicago office reported that Haddad was listed as the president of Cleveland Demolition. After learning that Haddad was not the actual president, Azcon requested a print-out of the Dun \& Bradstreet report. This report, dated August 2nd and introduced at trial, indicated that Haddad was the president of Cleveland. Based on this evidence, the jury returned a $\$ 500,000$ verdict for Azcon. This court affirmed in an unpublished opinion, concluding that "sufficient evidence exists to support the jury's finding that Paul Haddad was acting as an agent of Cleveland Demolition."

Cleveland now claims that the earlier verdict should be vacated because Spine deliberately lied when he testified that he requested a Dun \& Bradstreet report on July 5 th. To support this charge of perjury, Cleveland claims that Spine's pretrial deposition, in contrast to his specific trial testimony, was ambiguous and did not clearly reveal that he requested a July report. Moreover, Cleveland notes that Dun \& Bradstreet has no internal record of a request by Azcon for information on July 5 th. Cleveland concludes that Spine lied about the July request to help Azcon's case.

Cleveland does not stop at alleging perjury by Spine. It claims that Azcon's trial attorney, Lawrence Demase, conspired with Spine to present this perjured testimony. In an attempt to prove Demase's involvement, Cleveland notes that he prepared two affidavits for Spine, but neither affidavit mentioned a July 5th request for a Dun \& Bradstreet report. Nonetheless, Demase questioned Spine about the July 5th report at the trial and used this testimony in his opening and closing statements. Cleveland cites as further evidence of Demase's participation his acknowledgement that he and Spine reviewed Spine's deposition statements and concluded that they did not completely reflect what Spine had intended to say. Finally, Cleveland claims that Demase should have known that Spine did not request a report on July 5 th because Dun \& Bradstreet has no record of this request.

In sum, Cleveland believes that Spine must have perjured himself because his deposition is unclear and his trial testimony conflicts with Dun \& Bradstreet's records. Cleveland concludes that Demase must have actively participated in this perjury because he was Azcon's trial 
attorney. Relying on such conclusory allegations, Cleveland brought this independent action to set aside the earlier verdict, claiming that it was obtained by a fraud on the court. The district court granted Azcon's motion for summary judgment, finding that there was "no evidence here that either Spine gave false testimony or that Demase participated." The district court noted that Cleveland had produced no "smoking gun", nor even so much as a "singed paperclip." Because Cleveland's attorneys did not adequately investigate the factual or legal basis for this lawsuit, the district court also assessed attorney fees and costs under Rule 11.

II.

A verdict may be set aside for fraud on the court if an attorney and a witness have conspired to present perjured testimony. The only evidence that Spine committed perjury, however, is the conflict between his trial testimony and Dun \& Bradstreet's version of the July 5th report; the only evidence of Demase's involvement is that he was Azcon's trial attorney. This meager evidence falls woefully short of proving a fraud on the court. More importantly, if a losing party could attack a verdict whenever two witnesses disagreed and an attorney was involved, no verdict would be final. The district court properly granted summary judgment for Azcon.

District courts may entertain an independent action in equity to set aside a judgment for fraud on the court. Fraud on the court is a serious allegation, however, involving "corruption of the judicial process itself." A verdict will be vacated only in the "most egregious cases in which the integrity of the court and its ability to function impartially is directly impinged." Although perjury by a witness will not suffice, the "involvement of an attorney, as an officer of the court, in a scheme to suborn perjury should certainly be considered fraud on the court." Thus, if Spine deliberately lied and Demase participated in the fraud, the earlier verdict for Azcon should be set aside.

According to Cleveland, Spine must have committed perjury because his deposition is vague and Dun \& Bradstreet has no record of a July 5th request. Cleveland, however, overestimates the ambiguity of the deposition. Although not a model of clarity, Spine's deposition does state that he requested a verbal Dun \& Bradstreet report when the Azcon employees inspected the demolition site, which was in late June or early July. The deposition also shows that Spine claimed that Azcon's Chicago office reported that Haddad was listed as the president on the Dun \& Bradstreet report. The deposition is not inconsistent with Spine's subsequent testimony; the trial testimony is simply more specific.

The lack of a Dun \& Bradstreet record also fails to show that Spine committed perjury. Cleveland did not learn that there was no record until it sued Dun \& Bradstreet for negligently informing Azcon that Haddad was the president. Thus, the statements by Dun \& Bradstreet employees that they have no internal record actually amount to nothing more than unverified, exculpatory claims by an interested party. This evidence does not show that Spine never requested a report from the Chicago office or that Spine deliberately lied on the stand. It simply shows that Spine and Dun \& Bradstreet disagree over whether Azcon made a request on July 5th. Although Cleveland could certainly have used this evidence to impeach Spine during the 
initial trial, it cannot use this routine evidentiary conflict to support an action for fraud on the court.

Cleveland has produced even less evidence of Demase's involvement in this alleged conspiracy. Demase acted only as Azcon's trial attorney, performing such typical activities as preparing affidavits and questioning witnesses. Cleveland apparently argues for a virtually automatic rule that, whenever a witness lies on the stand, his attorney must have known about and actively participated in the perjury. In addition to being unjustified, this rule would allow parties to circumvent the Rule 60(b)(3) one-year time limitation on motions to set aside a judgment for fraud or misrepresentation. Losing parties could transform a perjury case into an action for fraud on the court simply by alleging that an attorney was present.

In essence, Cleveland asks this court to vacate the earlier verdict because Spine's testimony conflicts with the Dun \& Bradstreet statements and Demase participated in the trial. Not only does this argument fail to establish any evidence of a fraud on the court, but it seriously undermines the principle of finality. If a routine evidentiary dispute, which occurs in virtually all trials, could justify an action for fraud on the court, then any losing party could bring an independent action to set aside the verdict, forcing extended proceedings in almost every case. Because Rule 60(b) imposes no time limit on these independent actions, they could be brought at any time. Thus, under Cleveland's version of the doctrine, no verdict would ever be final until a second proceeding was held to determine if there was a fraud on the court.

Rather than unravel the finality of judgments through the abuse of Rule $60(\mathrm{~b})$, we adhere to the well-established rule that evidentiary conflicts must be resolved during the initial trial. Cleveland should have been aware of the conflict between Spine's testimony and Dun \& Bradstreet's records; Spine's deposition was specific enough to put Cleveland on notice. Having failed to depose Dun \& Bradstreet in time for the trial, Cleveland cannot avoid the verdict by leveling a charge of fraud on the court. Because Cleveland has produced no evidence of a conspiracy between Spine and Demase, Azcon was entitled to summary judgment.

III.

After granting summary judgment, the district court imposed Rule 11 sanctions on Cleveland and its attorneys for filing this action. A decision to impose sanctions will be reversed only for an abuse of discretion. Because Cleveland did not conduct a reasonable investigation of the factual and legal basis for this claim, we think the district court acted well within its discretion in imposing sanctions.

When an attorney signs a complaint, he certifies that "to the best of his knowledge, information, and belief formed after reasonable inquiry, the complaint is well grounded in fact and is warranted by existing law." Under this rule, Cleveland's attorneys were required to investigate the factual and legal basis for the claim before filing this lawsuit. The 1972 amendments underscored this duty by eliminating the subjective "good faith" harbor and requiring an attorney to conduct an objectively reasonable investigation. If an attorney signs a complaint without 
undertaking the necessary investigation, Rule 11 provides that the district court "shall" impose sanctions.

The district court found that Cleveland did not conduct a reasonable factual or legal investigation. We agree. Although Cleveland discovered a conflict between the Spine and Dun \& Bradstreet versions, this discovery should have been only the beginning of the inquiry into whether Spine committed perjury. Rather than continuing its investigation, however, Cleveland was apparently satisfied with a few interviews with a Dun \& Bradstreet employee.

A complaint of this nature has a potentially devastating impact upon professional reputations. Even if Cleveland had found evidence of perjury, it had an obligation to investigate whether attorney Demase was involved. Cleveland's inquiry never produced any evidence that Demase participated in Spine's alleged perjury. As the district court noted, "this part of Cleveland's case has always been nothing more than speculative and conclusory." Instead of conducting a reasonable factual investigation, Cleveland apparently chose to build its case on the unsupported assumption that Spine must have been lying and that Demase must have been participating. This speculative basis for a Rule 60(b) action alleging attorney misconduct of the most serious nature does not satisfy Rule 11 standards.

Cleveland also failed to conduct a reasonable legal investigation to determine if the complaint was "warranted by existing law." Cleveland limited its inquiry to a brief reading of Rule 60, a portion of American Jurisprudence, a Federal Procedure Guide, and Hazel-Atlas Glass Co. v. Hartford-Empire Co. (1944). If Cleveland had conducted even a minimal investigation into Fourth Circuit precedent, it would have discovered Great Coastal Express v. International Brotherhood of Teamsters. Although Great Coastal suggests that a conspiracy by a witness and an attorney to commit perjury will amount to a fraud on the court, the case specifically notes that other sanctions exist to punish perjury and that "perjury or fabricated evidence are not grounds for relief as a fraud on the court." Thus, even if Cleveland had evidence of perjury by Spine, it was still required to show that Demase participated. Because Cleveland had absolutely no evidence of involvement by Demase, a quick reading of Great Coastal would have revealed that Cleveland's complaint had "absolutely no chance of success under the existing precedent."

In sum, Rule 11 "explicitly and unambiguously imposes an affirmative duty on each attorney to conduct a reasonable inquiry into the validity of a pleading before it is signed." The Rule does not seek to stifle the exuberant spirit of skilled advocacy or to require that a claim be proven before a complaint can be filed. The Rule attempts to discourage the needless filing of groundless lawsuits. To fulfill his duty, an attorney must investigate the facts, examine the law, and then decide whether the complaint is justified. Cleveland failed to discharge this duty; it conducted only a minimal factual inquiry and a cursory legal investigation. The district court properly imposed sanctions.

In determining the specific amount of the sanctions, the district court reduced Azcon's legal fees by $10 \%$, finding that the case was slightly over-lawyered and did not require a trial. The hourly fees of several attorneys were lowered to reflect the prevailing local rate, while the fees of 
attorneys from out of state were reduced by $10 \%$ because they failed to provide the district court with sufficient information about their professional backgrounds. These adjustments are consistent with the twelve factors listed in Barber v. Kimbrell's, Inc., and we therefore affirm the amount of the award in this case.

\section{Questions:}

1. What was the basis for Cleveland's claim that Spine perjured himself?

2. What investigation should Cleveland have done before filing its motion to vacate?

3. Is it possible that Spine did not request a verbal report from Dun \& Bradstreet? Does it matter?

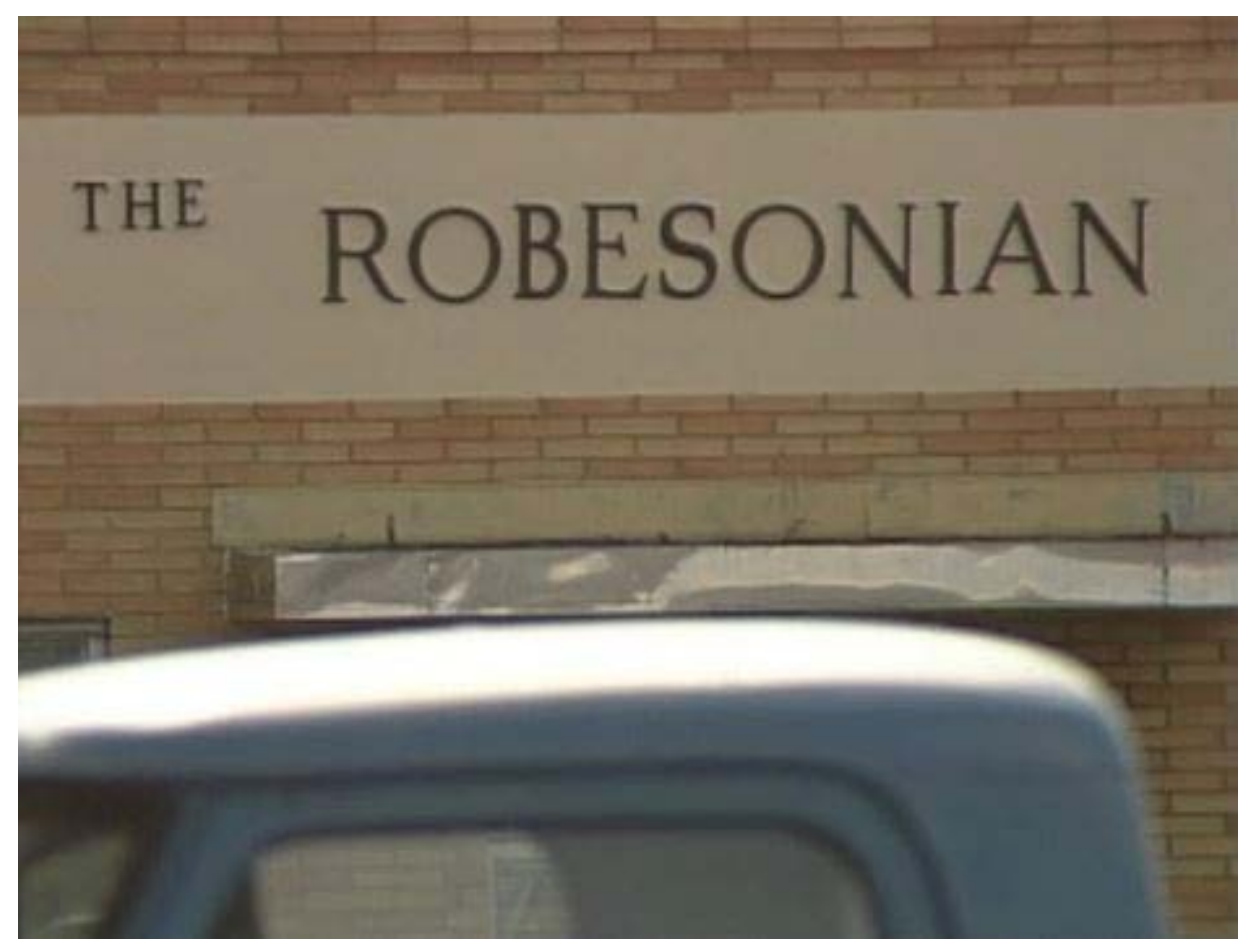




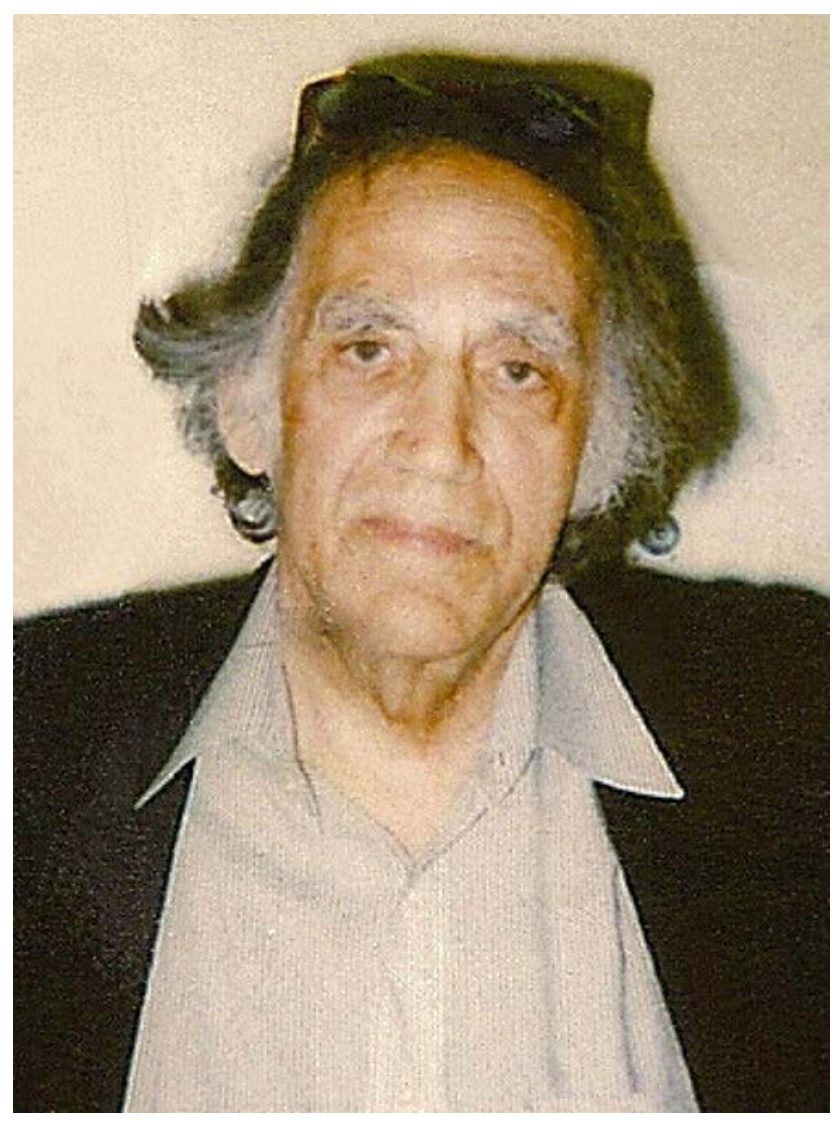

William Kunstler (1989)

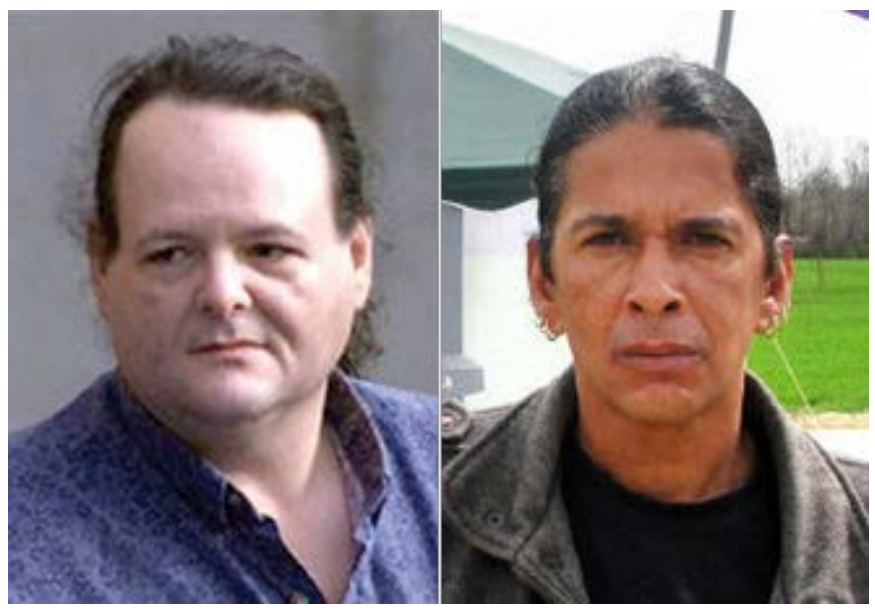

Eddie Hatcher \& Timothy Jacobs

In re Kunstler, 914 F. 2d 505 (4th Cir. 1990)

Summary: Eddie Hatcher and Timothy Jacobs hijacked the offices of the Robeson, North Carolina newspaper The Robesonian and took its employees hostage. They eventually surrendered, in exchange for a promise that the governor would investigate their claims of government corruption. The federal government prosecuted Hatcher and 
Jacobs, but they were acquitted. Then, North Carolina prosecuted Hatcher and Jacobs. Barry Nakell, Lewis Pitts, and William Kunstler filed a § 1983 against the Governor of North Carolina and other state officials, for improper prosecution. The district court dismissed the action and imposed Rule 11 sanctions on Nakell, Pitts, and Kunstler. The circuit court affirmed, but remanded for reconsideration of the sanctions.

CHAPMAN, Circuit Judge:

Three attorneys appeal the award of Rule 11 sanctions against them in the amount of $\$ 122,834$.28. Appellants were sanctioned following the dismissal of a 42 U.S.C. $\S 1983$ action, in which they represented certain plaintiffs seeking monetary damages and injunctive relief from the Governor of North Carolina, a number of North Carolina district attorneys, a sheriff, certain State Bureau of Investigation officers, the State Attorney General and others for an allegedly improper state criminal prosecution and harassment. We affirm in part, vacate in part, and remand with instructions.

The appellant attorneys are Barry Nakell, a professor at the University of North Carolina School of Law; Lewis Pitts, Director of the Christic Institute South, a public interest law firm in Carrboro, North Carolina; and William Kunstler, a nationally known civil rights attorney. The § 1983 action was connected with the appellants' earlier representation of two American Indians, Eddie Hatcher and Timothy Jacobs, in a federal criminal case.

On February 1, 1988, Hatcher and Jacobs staged an armed takeover of The Robesonian, a local newspaper in Robeson County, North Carolina. Hatcher and Jacobs held twenty hostages and charged the State District Attorney and the Sheriff's Office with corruption and criminal misconduct. Hatcher and Jacobs surrendered to federal authorities in exchange for a promise that a Governor's Task Force would investigate their complaints. The Task Force ultimately announced that it had found no evidence to support Hatcher's and Jacobs' charges.

Hatcher and Jacobs were acquitted of federal criminal charges on October 14, 1988, but North Carolina District Attorney Joe Freeman Britt announced that Hatcher and Jacobs might face state indictments. Soon after that announcement, Hatcher began a petition drive seeking to have Hubert and Kevin Stone removed from the Sheriff's Office. The Robeson Defense Committee, which had supported Hatcher in his federal trial, supported the petition drive. In November 1988, newspaper reports indicated that the State Bureau of Investigation was investigating whether there had been a conspiracy in the takeover of The Robesonian.

Appellants Barry Nakell and Lewis Pitts contacted the Attorney General's office to express their concern that $\mathrm{SBI}$ agents would intimidate citizens who were working with Hatcher in the petition drive. The Attorney General responded that no action would be taken by his office because he did not believe that the SBI was engaged in any abuse of process. Attorney Nakell alleges that the Deputy Attorney General orally admitted that the decision was political. 
Attorney Pitts volunteered legal assistance to anyone on the Robeson Defense Committee subjected to harassment because of their participation in the petition drive. Appellants allege that six members of the Defense Committee contacted Attorneys Pitts and Nakell with claims of harassment by SBI agents and the Sheriff's Department, primarily involving surveillance and questioning.

On December 6, 1988, Hatcher and Jacobs were indicted on state charges. After the indictment, Jacobs fought extradition from New York. Hatcher was in federal custody in California.

By late December 1988, appellants contend that they believed that Jacobs' extradition, the pending state prosecutions, and an alleged pattern of activity by the District Attorney and his staff, members of the Sheriff's Department, and the SBI raised constitutional concerns which could only be resolved by a civil suit, because public officials were unresponsive. Appellants contend that they also believed that there was an illegal campaign to split Jacobs from Hatcher, and to interfere with Jacobs' right to counsel by persuading him to hire local counsel.

Attorneys Pitts and Nakell contend that they initially refrained from filing the complaint in hopes of enhancing Jacobs' plea bargaining opportunities, but Mr. Nakell filed the complaint on January 31,1989 , the eve of the one-year anniversary of the armed takeover of The Robesonian, and he called a press conference to announce the filing. An amended complaint, signed by all three appellants, was filed on March 16, 1989.

The suit named eight plaintiffs, including various members of the Robeson Defense Committee, and Jacobs and Hatcher. The thirty-page amended complaint names nineteen defendants, including two district attorneys and members of their staffs, five SBI agents, the SBI Director, the Sheriff of Robeson County and five Deputy Sheriffs, the Attorney General of North Carolina, and the Governor of North Carolina. The complaint alleges First Amendment and Sixth Amendment violations concerning an alleged campaign of intimidation of political activity, and efforts to induce Jacobs to testify against Hatcher. All defendants were sued in their official and individual capacities, except the Governor, who was named only in his official capacity in a count seeking an injunction against extradition. The complaint also sought injunctions against the pending state criminal prosecutions, and against the defendants' harassment and interference with the attorney-client relationship established by Jacobs. The complaint sought damages against all individually named defendants and Robeson County.

After the case was filed, appellants sought expedited discovery to depose defendant SBI agent Bowman, who was the case agent in the state's pending criminal action against Jacobs and Hatcher. The defendants moved for a protective order claiming that discovery was improperly sought to obtain information concerning the state criminal proceedings, which plaintiffs could not otherwise obtain. The district court did not rule on this motion prior to the dismissal of the case. In late March 1989, Jacobs, having failed in resisting extradition, was returned to North Carolina. In April, Jacobs agreed to a plea bargain. Appellants contend that a variety of events 
then caused them to reevaluate the viability of their civil suit, and to conclude that dismissal was appropriate.

On April 20, Mr. Nakell called Joan Byers, a Special Deputy Attorney General, seeking defendants' approval to a stipulated dismissal under Rule 41(a)(1)(ii). Byers would not stipulate to a dismissal under Rule 41(a)(1), but authorized appellants to state that defendants did not object to a dismissal under Rule 41(a)(2). Appellants proceeded under Rule 41(a)(2), and the order dismissing the case was entered on May 2, 1989.

On June 13, 1989, the state defendants filed their Rule 11 motion, and the county defendants filed a similar motion for sanctions on July 5. On August 8, appellants responded to the Rule 11 motions and requested an evidentiary hearing. On September 5, appellants filed a Rule 11 motion seeking sanctions against the appellees. On September 8, the court heard arguments of counsel and shortly thereafter requested submissions by defendants' counsel of their fees and expenses. On September 29, the district court imposed Rule 11 sanctions upon appellants, and dismissed appellants' Rule 11 motion. Sanctions against appellants included full fees and costs of $\$ 92,834.28$ and $\$ 10,000$ additional sanctions against each appellant based upon the baseless claims which appellants had taken care to publicize. We affirm the district court's findings that appellants violated all three prongs of Rule 11, but vacate and remand for reconsideration of the appropriate sanction.

\section{SANCTIONS AFTER DISMISSAL}

Initially, we must determine whether the defendants' failure to notify the plaintiffs or the court prior to dismissal that defendants intended to file a Rule 11 motion should have precluded consideration of the Rule 11 motion. Appellants cite Barr Labs., Inc. v. Abbott Labs., where the Second Circuit affirmed the denial of a Rule 11 motion filed after a stipulated dismissal under Rule 41(a)(1)(ii). There, the defendant's attorney did not indicate an intention to seek Rule 11 sanctions prior to dismissal and implied in a letter to plaintiff's counsel, prior to the dismissal, that sanctions would not be sought if the case were voluntarily dismissed. The Barr court enunciated a rule "prohibiting a motion for Rule 11 sanctions after the execution of a stipulation of dismissal without a reservation of the right to move for such relief."

The present case is different from Barr because it does not involve a stipulated dismissal, which requires opposing counsel to sign the dismissal order. We have a dismissal under Rule 41(a)(2), which does not require a stipulation by the defendants. No court has adopted a rule prohibiting a motion for Rule 11 sanctions after a dismissal with prejudice under Rule 41(a)(2). In addition, unlike Barr, there is no evidence that defendants indicated that they would not pursue Rule 11 sanctions. We decline to extend Barr to dismissals under Rule 41(a)(2).

Appellants also argue that since Rule 41(a)(2) specifies that dismissal is subject to such "terms and conditions as the court deems proper," the potential for Rule 11 sanctions should be stated 
by a defendant as a condition to a dismissal. We disagree. Rule 41(a)(2) does not require the defendant or a court to indicate the possibility of Rule 11 sanctions as a "term or condition" of a plaintiff's dismissal. Recently, in Cooter \& Gell v. Hartmarx Corp., the Supreme Court hypothesized that even a Rule 11 sanction which prohibited refiling a complaint dismissed without prejudice under Rule 41(a)(1) would not be a "term or condition" placed upon the dismissal. Waiver of a Rule 11 motion may not be a condition to dismissal because a decision not to dismiss may not prevent the imposition of sanctions for an improvidently filed complaint. "As the 'violation of Rule 11 is complete when the paper is filed,' a voluntary dismissal does not expunge the Rule 11 violation."

There may be circumstances under which Rule 11 sanctions should not be granted after the voluntary dismissal of a case, i.e., a defendant has indicated an intent not to pursue sanctions, or the motion is filed an inordinately long time after the dismissal. "Although Rule 11 does not establish a deadline for the imposition of sanctions, the Advisory Committee did not contemplate there would be a lengthy delay prior to their imposition." However, these considerations are equitable, and must be resolved on a case by case analysis. The party seeking sanctions may avoid such problems by notifying his opponent and the court of his intention to pursue sanctions at the earliest possible date.

As the Supreme Court has recently confirmed, there is no jurisdictional bar to the imposition of sanctions after a voluntary dismissal.

In order to comply with Rule 11 's requirement that a court "shall" impose sanctions "if a pleading, motion, or other paper is signed in violation of this rule," a court must have the authority to consider whether there has been a violation of the signing requirement regardless of the dismissal of the underlying action.

"The only time limitation in filing Rule 11 arises out of equitable considerations." The defendants filed their motion six weeks after the Rule 41(a)(2) dismissal, the appellants were not prejudiced by appellees' delay in filing, and the district court's consideration of the motion was proper.

\section{VIOLATIONS OF RULE 11}

Rule 11 states, in relevant part:

The signature of an attorney or party constitutes a certificate by the signer that the signer has read the pleading, motion, or other paper; that to the best of the signer's knowledge, information, and belief formed after reasonable inquiry it is well grounded in fact and is warranted by existing law or a good faith argument for the extension, modification, or reversal of existing law, and that it is not interposed for any improper purpose, such as to harass or to cause unnecessary delay or needless increase in the cost of litigation. If a pleading, motion, or other paper is signed in violation of this rule, the court, upon motion or upon its own initiative, shall impose upon the person who signed it, a represented party, or both, an appropriate sanction, which may include an order to pay to the other 
party or parties the amount of the reasonable expenses incurred because of the filing of the pleading, motion, or other paper, including a reasonable attorney's fee.

The district court found that the three appellants violated all three prongs of Rule 11 by failing to make a reasonable inquiry to determine that the complaint stood well grounded in fact and warranted by existing law, and by filing the complaint for an improper purpose. We review all aspects of the district court's Rule 11 determinations under an abuse-of-discretion standard.

\section{A. Mr. Kunstler's Liability}

Before reviewing the specific violations of Rule 11 found by the district court, we note that Mr. Kunstler's affidavit states that he "did not actively participate in the instant litigation, relying on Prof. Barry Nakell, who was on the scene, to prepare and file it." The district court stated that "in light of the serious allegations in the complaint, Mr. Kunstler's total reliance on other counsel is itself a violation of Rule 11." This finding is supported by a recent pronouncement of the Supreme Court. Mr. Kunstler's reliance on others was indeed an improper delegation of his responsibility under Rule 11 to certify that the pleading filed over his name was well grounded in fact and in law.

The signing attorney cannot leave it to some trusted subordinate, or to one of his partners, to satisfy himself that the filed paper is factually and legally responsible; by signing he represents not merely the fact that it is so, but also the fact that he personally has applied his own judgment.

"The purpose of Rule 11 as a whole is to bring home to the individual signer his personal, nondelegable responsibility." Having failed in his responsibility, Mr. Kunstler may not now be heard to protest that he does not share in any violations of Rule 11 which are evident on the face of the complaint.

\section{B. Well Grounded in Fact}

The district court based sanctions in part on a violation of the first prong of Rule 11 - finding that the complaint was not well grounded in fact. An objective test is used "to determine the reasonableness of a lawyer's prefiling investigation." "Blind reliance on the client is seldom a sufficient inquiry." Mr. Nakell and Mr. Pitts have argued that they had "an intimate knowledge of the county and its people; factors which made them professionally capable of assimilating and weighing the facts gathered prior to filing the civil suit." In light of that knowledge, the factual inaccuracies in the complaint are even more egregious.

The district court noted numerous misstatements of fact, such as the assertion that the district attorney "serves as the criminal prosecution arm of Defendant Robeson County and as such makes policy in police investigation and criminal prosecution matters for Defendant Robeson County." In fact, the District Attorney is an officer of the state, not an agent nor an employee of the county. Contrary to the complaint, defendants Britt, Townsend, and Sampson, and the 
District Attorney's staff, are state officers, not agents or employees of Robeson County. The complaint alleges that District Attorney Britt refused and failed to discipline, train and supervise the Sheriff's deputies "under their control and supervision." District Attorneys possess no such power or responsibility.

Appellants acknowledge some errors, but contend they are "isolated" and thus do not warrant sanctions. We do not agree with this characterization. The errors pervade the complaint and concern information which either was or should have been known to appellants. The errors provide a false foundation for appellants' allegation of a county-wide "conspiracy," and are central to the complaint. Appellants also suggest that, under Pembaur v. Cincinnati (1986), state officials can sometimes establish county policy for purposes of $\S 1983$ liability. Unlike Pembaur, there is no provision of North Carolina law which suggests that the state officials in this case either could or did act to establish county policy.

Other causes of action were founded on allegations which utterly lacked any basis in fact. For example, the complaint alleged that the Governor, the Attorney General and District Attorney entered into a "no state prosecution" agreement, and this agreement was breached when the state prosecution commenced. The district court found that prior to filing their complaint, appellants

had access to the transcript of the negotiations leading to the hostage release agreement as well as a copy of the written agreement. Nothing in the agreement or in any of the negotiations, suggests an agreement that Hatcher and Jacobs would not face North Carolina charges, and none of the negotiators had the authority to so agree.

Moreover, North Carolina law does not grant the Governor or the State Attorney General the power to bind the state not to prosecute. Neither the Attorney General nor District Attorney Britt played any role in the hostage negotiations, but appellants now argue that unspecified evidence, obtainable through discovery, "could show" that a no prosecution agreement was made. While a lawyer may rely on discovery to reveal additional facts to support claims which are well grounded in fact, Rule 11 sanctions are appropriate when a lawyer attempts to use discovery to support outrageous and frivolous claims for which there is no factual support. Unsubstantiated claims such as these constitute an abuse of the judicial process for which Rule 11 sanctions were designed.

Appellants appear to have relied entirely upon discovery in the hope of finding some factual support for many of their claims. In their Memorandum and Opposition to Defendants' Motion for a Protective Order, appellants wrote:

Plaintiffs anticipate that as a result of deposing SBI defendant Bowman they will be in a position to apply to the Court for temporary injunctive relief and make the showing required by Rule 65(b) of the Federal Rules of Civil Procedure. 
Appellants requested a temporary restraining order in their complaint. Rule 65(b) makes clear that a temporary restraining order may be granted only if

it clearly appears from specific facts shown by affidavit or by the verified complaint that immediate and irreparable injury, loss, or damage will result to the applicant before the adverse party or his attorney can be heard in opposition.

Rule 65(b) does not authorize counsel to request relief and then search through discovery for facts to support the relief already requested. The rule requires that "specific facts" be "shown" to the court with the request for relief. We agree with the district court that the appellants' request for relief and their indication that they were not "in a position to make the showing required by Rule 65(b)" without later discovery indicates an unacceptable level of pre-filing investigation.

We affirm the district court's findings that many of the allegations against state and local officials "have nothing to do with this case and are factually unsubstantiated." Allegations which suggest that the Sheriff is engaged in drug trafficking and that a black inmate died while in the Sheriff's custody are irrelevant. These allegations involve no injury to the plaintiffs, and the report of drug trafficking by the Sheriff's Office is wholly unsupported in fact. Appellants protest that these allegations were represented in the complaint only as beliefs of their clients, but this does not make them relevant to the complaint or less scandalous in nature. While irrelevant allegations, standing alone, may not be cause for Rule 11 sanctions, the existence of numerous irrelevant, unsubstantiated, and sensational allegations is an appropriate factor for a district court to consider in determining whether the pleading as a whole lacks adequate factual foundation.

In this case, the complaint was filled with irrelevant allegations not tied to specific injuries to plaintiffs, i.e., general allegations of abusive behavior against blacks and Indians, and allegations that Robeson County is beleaguered by poverty, illiteracy, and violence. There was little basis for the allegation that Britt, Townsend, Thornburg and Morgan conspired to appoint Townsend as District Attorney and to use SBI agents as political police to discredit the Republican candidate, and that allegation was again irrelevant. Hatcher and Jacobs had been indicted prior to Townsend's appointment, and none of the other candidates for District Attorney suggested that they would not continue the prosecution. Appellants' arguments as to the relevance of such allegations are tangential at best and often strain credulity.

Although Mr. Nakell and Mr. Pitts filed lengthy affidavits detailing their factual inquiry, such affidavits do not provide factual or legal support for the inaccuracies noted by the district court. The number of hours allegedly spent by counsel in prefiling investigation does not dissuade us from affirming the district court's findings of Rule 11 violations. Given the adequate time to prepare and hours allegedly spent in preparation of the complaint, appellants have presented no excuse for the many clear factual errors in this pleading.

Appellants have argued that, despite the lack of pre-filing foundation for their claims, it was appropriate to include the claims because support for them could only be obtained through discovery. In Kraemer v. Grant County, the court held that sanctions were not warranted where 
an attorney relied on client information to support a cause of action based on a theory of conspiracy, even though additional facts were needed to prove the claim. "If discovery is necessary to establish a claim, then it is not unreasonable to file a complaint so as to obtain the right to conduct that discovery." Despite this sweeping statement, there were in Kraemer a number of factors cautioning against sanctions which are not present here. In Kraemer, the attorney was a recent law school graduate, and had hired a private investigator to look into his client's allegations. The investigator's report did not discredit any part of the client's story and the prospective defendants refused to cooperate with the investigator. Only a single portion of the complaint - that dealing with the proof of state action — was ultimately found to be without support.

In the present case, appellants are experienced attorneys with both the time and the means to conduct a responsible factual investigation. The complaint contains myriad inaccuracies rather than a single error. Many of the factual inaccuracies could have been discovered by the most cursory investigation. The irrelevances are inexcusable considering the attorneys' experience. Indeed, it is remarkable that so many errors could have been undetected by appellants. The number of claims without factual foundation warrants sanctions, whether the errors stem from incompetency or wilful misconduct.

The need for discovery to complete the factual basis for alleged claims is not an excuse to allege claims with no factual basis. While we do not disagree with the result obtained in Kraemer, we find that it is not applicable to the present case. A lawyer is an officer of the court, and he should never file a lawsuit without confidence that it has a reasonable basis in fact and is well grounded in law. For the purposes of Rule 11, the factual inquiry necessary to file a complaint is generally satisfied if all of the information which can be obtained prior to suit supports the allegations made, even though further facts must be obtained through discovery to finally prove the claim. However, a complaint containing allegations unsupported by any information obtained prior to filing, or allegations based on information which minimal factual inquiry would disprove, will subject the author to sanctions.

\section{Well Grounded In Law}

The district court found that the complaint was not well grounded in law. We agree. Appellants contend that the strength of the legal basis of the complaint is demonstrated by their opponent's lengthy response to them, and the approval of a civil rights attorney, who reviewed and approved of, but did not sign, the complaint. The length of an opponent's response to a complaint does not validate the otherwise insubstantial claims therein, because a lengthy response may reveal less the merit of particular claims than the number of valid defenses to them. An opponent may have employed "scorched earth" tactics in composing a response far beyond what is required to oppose frivolous claims. Nor is the Rule 11 standard of whether a "reasonable attorney in like circumstances would believe his actions to be factually and legally justified" satisfied merely by having another attorney review a complaint. The reviewing attorney may be unfamiliar with the true facts of the case, the factual and legal investigation conducted, or the law relevant to the complaint. 
The district court enumerated several substantial claims without legal foundation. The court found no factual or legal basis for the double jeopardy claim to the state prosecution of Hatcher and Jacobs following the federal prosecution, because a subsequent prosecution by a different sovereign plainly does not constitute double jeopardy. Although a "tool of the same authorities" exception is possible in some circumstances, that exception may only be established by proof that State officials had little or no independent volition in their proceedings. In this case, however, the complaint alleged that the state officials instituted and controlled the state proceeding, which precludes the establishment of that exception. The district court also considered a quotation attributed to Mr. Pitts in a newspaper article that the state charges did not constitute double jeopardy. Although we caution the court against relying too heavily on press reports, we do not fault the district court for considering the statement.

The district court found without legal foundation the plaintiffs' claim that Hatcher's Fifth Amendment rights were damaged when the state tried to extract testimony from Jacobs. Fifth Amendment protection is personal to the individual whose testimony is being compelled and appellants as experienced attorneys should have been well aware of this. Appellants make no attempt to explain away this glaring blunder.

Appellants sought to enjoin state criminal proceedings, but the district court found that the Younger $v$. Harris abstention doctrine clearly barred such relief. The court also found that Hatcher and Jacobs could have presented their federal constitutional claims to the state court. We agree that plaintiffs had no factual basis for claiming that the state prosecution was brought in bad faith, or without a reasonable expectation of conviction, because Hatcher and Jacobs had never denied taking hostages. Although appellants cite an Eighth Circuit case which suggests that the Younger abstention doctrine does not apply if "a prosecution was brought in retaliation for or to discourage the exercise of constitutional rights 'regardless of whether valid convictions conceivably could be obtained," that proposition has been rejected by this court. In Suggs $v$. Brannon, we upheld the use of the Younger abstention doctrine when plaintiffs claimed that their prosecution under obscenity laws chilled their First Amendment rights.

The district court also noted "serious standing problems with many of the plaintiffs' claims." For example, on the claim that the prosecution chilled Hatcher and Jacobs' First Amendment expression, the complaint presented no facts showing specific harm or threat of harm. Appellants respond that they did show concrete and specific harm insofar as plaintiffs' participation in the petition drive was curtailed. However, Hatcher and Jacob's participation was not curtailed, and the district court's observation on their standing problem with respect to that claim is valid.

We therefore affirm the court's findings that the complaint on the whole was not well grounded in law.

D. Improper Purpose 
Sanctions could have been imposed for the violations already discussed, but the district court also based the award of sanctions on appellants' improper purpose in filing the complaint. The type and number of Rule 11 violations are considered in determining the appropriate sanction, and it was proper for the district court to consider appellants' purpose. Although the district court first discussed "improper purpose" under Rule 11, whether or not a pleading has a foundation in fact or is well grounded in law will often influence the determination of the signer's purpose, and we suggest that a district court should consider the first two prongs of Rule 11 before making a determination of improper purpose.

Appellants argue that the district court's conclusions as to their purpose are clearly erroneous, because there is no evidence in the record to support the court's findings, or the findings are based on factual conclusions which were contested by affidavit. The district court concluded that sanctions would be appropriate based on the improper purpose of the lawsuit "even if the complaint had a proper legal and factual basis." Since we have affirmed the court's findings that the complaint in the instant case was not well grounded in law or in fact, we need not decide whether a complaint which is well grounded in law and in fact can be sanctioned solely on the basis that it was filed for an improper purpose. Rather, we look only to whether the court abused its discretion in finding that the complaint was filed for an improper purpose.

Rule 11 defines the term "improper purpose" to include factors "such as to harass or to cause unnecessary delay or needless increase in the costs of litigation." The factors mentioned in the rule are not exclusive. If a complaint is not filed to vindicate rights in court, its purpose must be improper. However, if a complaint is filed to vindicate rights in court, and also for some other purpose, a court should not sanction counsel for an intention that the court does not approve, so long as the added purpose is not undertaken in bad faith and is not so excessive as to eliminate a proper purpose. Thus, the purpose to vindicate rights in court must be central and sincere. Filing of excessive motions may sometimes constitute "harassment" under the rule even if the motions are well grounded. Likewise, filing a motion or pleading without a sincere intent to pursue it will garner sanctions.

We have previously stated that in order to determine "improper purpose," a district court must judge the conduct of counsel under an objective standard of reasonableness rather than assessing subjective intent. This test was derived from Zaldivar v. City of Los Angeles, where it was stated that "harrassment under Rule 11 focuses upon the improper purpose of the signer, objectively tested, rather than the consequences of the signer's act, subjectively viewed by the signer's opponent." In other words, it is not enough that the injured party subjectively believes that a lawsuit was brought to harass, or to focus negative publicity on the injured party; instead, such improper purposes must be derived from the motive of the signer in pursuing the suit. An opponent in a lawsuit, particularly a defendant, will nearly always subjectively feel that the lawsuit was brought for less than proper purposes; plaintiffs and defendants are not often on congenial terms at the time a suit is brought. However, a court must ignore evidence of the injured party's subjective beliefs and look for more objective evidence of the signer's purpose. 
There is some paradox involved in this analysis, because it is appropriate to consider the signer's subjective beliefs to determine the signer's purpose in filing suit, if such beliefs are revealed through an admission that the signer knew that the motion or pleading was baseless but filed it nonetheless. This evidence may be said to be "objective" in the sense that it can be viewed by a court without fear of misinterpretation; it does not involve difficult determinations of credibility. Circumstantial facts surrounding the filing may also be considered as evidence of the signer's purpose. Repeated filings, the outrageous nature of the claims made, or a signer's experience in a particular area of law, under which baseless claims have been made, are all appropriate indicators of an improper purpose.

The district court concluded that plaintiffs' counsel never intended to litigate this $\S 1983$ action and that counsel filed it for publicity, to embarrass state and county officials, to use as leverage in criminal proceedings, to obtain discovery for use in criminal proceedings, and to intimidate those involved in the prosecution of Hatcher and Jacobs.

The court drew its conclusions without the aid of an evidentiary hearing, but relied upon the evidence before it. The court's first conclusion, that counsel never intended to litigate the action, is the one which most clearly supports sanctions based on a finding of improper purpose. The fact that so many allegations in the complaint lacked a basis in law or in fact strongly supports the court's finding of improper purpose. The existence of baseless allegations does not alone require a finding of improper purpose, because inexperience or incompetence may have caused their inclusion in a pleading, rather than or in addition to willfulness or deliberate choice. However, in this case counsel are clearly not inexperienced, and the number and magnitude of claims without foundation suggests that incompetence is not the cause for such allegations in the complaint. This court is left with the conclusion, drawn by the district court, that counsel wilfully included the baseless claims. If counsel wilfully files a baseless complaint, a court may properly infer that it was filed either for purposes of harassment, or some purpose other than to vindicate rights through the judicial process. We therefore affirm the district court's finding that appellants violated the improper purpose prong of Rule 11.

In addition to relying upon the complaint itself, the district court inferred an improper purpose from the timing of the filing of the complaint, on the eve of the anniversary of the takeover of The Robesonian, and some time after the alleged constitutional violations began. The court also viewed with suspicion the timing and nature of the dismissal of the complaint, which occurred after Jacobs lost his extradition fight in the criminal case, and before any significant discovery might have given notice to the plaintiffs that their claims were not valid. The district court dismissed as incredible appellants' explanations for dismissal, which contended that many of the claims had become moot through a series of events. The district court found it "absurd" to think that the wide-spread conspiracy involving high-level state and public officials had suddenly become unimportant by May 2, 1989. The court noted that the basis of the complaint - the breach of the alleged no-prosecution agreement - still existed even after Hatcher's and Jacobs' guilty pleas to the state charges. The court stated that the double jeopardy claims, damage claims, and other requests for equitable relief, if ever valid, did not cease being valid. In 
finding improper purpose, the district court was also influenced by the outrageous nature of the claims made.

The affidavits submitted by counsel strongly disputed the court's conclusions as to the timing of the filing and of the dismissal of the suit, and claimed that no improper motive influenced the timing of events. As to the decision to dismiss, appellants argued that it was based solely on financial considerations and the necessity of devoting professional resources elsewhere. Appellants argue that many equitable claims had become moot, and that the prospect for damages on the remaining claims did not warrant the expense of continuing the suit. However, the district court's determination that these explanations are not reasonable or believable, in light of all of the evidence surrounding the filing of the complaint and the frivolous nature of the allegations made, is not clearly erroneous.

The district court noted other evidence which suggested that appellants' purpose in filing the complaint was not to vindicate plaintiffs' rights, such as appellants sending a copy of the complaint to the state judge who likely would have tried Hatcher and Jacobs in the criminal case. The court also noted a quotation reported by the media, in which Mr. Pitts allegedly suggested that the suit was dropped after the Attorney General's office showed strong opposition to the suit. The court further considered an affidavit by New York attorney Neal Rose concerning Mr. Pitts' alleged admission that the suit was commenced as leverage and lacked a factual basis, although that affidavit was contradicted by an affidavit by attorney Alan Rosenthal. In light of other evidence which supports the court's finding of improper purpose, we cannot say that it was an abuse of discretion for the court to consider these matters as additional support, even though determinations of credibility are best made after an evidentiary hearing.

In concluding that appellants had never intended to litigate their suit, the district court also concluded that circumstances surrounding the case, when viewed as a whole, supported the conclusion that appellants' primary motives in filing the complaint were to gain publicity, to embarrass state and county officials, to gain leverage in criminal proceedings, to obtain discovery for use in criminal proceedings, and to intimidate those involved in the prosecution of Hatcher and Jacobs. At least some of these motives would not warrant sanctions under the improper purpose portion of Rule 11, if appellants' central purpose in bringing suit had been to vindicate rights of the plaintiffs. Holding a press conference to announce a lawsuit, while perhaps in poor taste, is not grounds for a Rule 11 sanction, nor is a subjective hope by a plaintiff that a lawsuit will embarrass or upset a defendant, so long as there is evidence that a plaintiff's central purpose in filing a complaint was to vindicate rights through the judicial process. In this case, however, there was no proper purpose for appellants' filing of the suit, and the district court's consideration of other possible motives for the suit based on the evidence available was proper.

We have affirmed the district court's conclusion that sanctions were warranted based on the improper purpose prong of Rule 11 because it is not clearly erroneous and is supported by facts such as the baseless allegations made, appellants' legal experience, and the cumulative nature of the evidence. However, we urge district courts to exercise special caution when evaluating a 
signer's purpose under Rule 11. When there are issues of credibility, disputed questions of fact, and rational explanations of purpose given, an evidentiary hearing may well be necessary to resolve the issues. This is particularly true when large sanctions are being considered on the ground of improper purpose as well as failure to comply with the first two prongs of Rule 11 . We do not find that the court erred in failing to hold an evidentiary hearing in this case, because the cumulative nature of the evidence, as well as our earlier findings on the frivolousness of the allegations made in the complaint and the lack of a legal or factual basis, convinces us that the court's finding of improper purpose is not clearly erroneous and would not have been altered by an evidentiary hearing.

\section{DUE PROCESS}

Appellants argue that the district court should not have found a violation of the "improper purpose" prong of Rule 11 without holding an evidentiary hearing. We disagree. Due process does not require an evidentiary hearing before sanctions are imposed, even when sanctions are imposed in part under the improper purpose prong of Rule 11. The Advisory Committee Note on Rule 11, indicates that satellite litigation over sanctions and separate hearings should be limited to the extent possible. "The court must to the extent possible limit the scope of the sanction proceedings to the record."

In determining whether and to what extent a hearing is required prior to the imposition of sanctions, we are guided by the Advisory Committee Note to Rule 11 and the reasoning of Donaldson v. Clark:

The Advisory Committee Note indicates some of the matters to be considered: (1) the circumstances in general; (2) the type and severity of the sanction under consideration; and (3) the judge's participation in the proceedings, the judge's knowledge of the facts, and whether there is need for further inquiry. The Advisory Committee Note observes that "in many situations the judge's participation in the proceedings provides him with full knowledge of the relevant facts and little further inquiry will be necessary."

When an attorney has failed to present necessary factual support for claims despite several opportunities to do so, for example, further hearing on the sanctions issue may well be not only unnecessary but also a waste of judicial resources. On the other hand, when a court is asked to resolve an issue of credibility or to determine whether a good faith argument can be made for the legal position taken, the risk of an erroneous imposition of sanctions under limited procedures and the probable value of additional hearing are likely to be greater. Prior opportunities to respond to Rule 11 charges will also influence the extent to which further hearing is necessary.

As mentioned by the Advisory Committee, the type and severity of the sanction are necessary elements in the calculus. The more serious the possible sanction both in absolute size and in relation to actual expenditures, the more process that will be due. 
Even if an evidentiary hearing is not required in every "improper purpose" case, appellants argue that such hearing was required in this case. Although the number of credibility determinations which the court made without an evidentiary hearing should have suggested to the court that an evidentiary hearing would have been of value, we affirm the court's findings that appellants violated all three prongs of Rule 11 because the findings are not clearly erroneous even excluding some evidence of "improper motive" which appellants contested.

The district judge's participation in the proceedings was adequate to give him full knowledge of the relevant facts without the necessity of an evidentiary hearing. The district court had before it the pleadings, the summary judgment motions of the state defendants and the 12(b) motion of the county defendants. We also find that counsel were given an adequate opportunity to contest the court's determinations that Rule 11 was violated. The district court allowed appellants to submit affidavits, and voluminous written legal arguments. The district judge also heard oral argument. We find that due process requirements were satisfied by the opportunities appellants were given to respond to the charges that their complaint violated Rule 11.

However, although we find that counsel had an adequate opportunity to contest the court's finding that Rule 11 was violated, we find that appellants were not given an adequate opportunity to respond to the type and amount of sanction imposed, particularly in light of the large monetary sanction. Appellants were given no opportunity to contest the fee statements submitted, and the amount of the sanction was largely the result of those statements. Under the facts of this case, particularly the amount of the sanction, due process requires that appellants have some opportunity to contest the amount of the sanction imposed. We therefore vacate the sanction imposed. As discussed below, we vacate the type and amount of sanction chosen by the district court for certain additional reasons. On remand, under the guidelines set forth below the appellants will be given an appropriate opportunity to respond to the type and the amount of the sanction.

\section{AMOUNT OF SANCTION}

\section{A. Attorney Fees Portion}

Rule 11 requires that "an appropriate sanction" be imposed upon those who violate its requirements. Appellants argue that the amount of sanctions was inappropriate, in part because the district court used the Rule to shift fees and compensate the defendants, rather than to deter improper litigation. We agree and vacate the amount of the monetary sanction.

We have previously held that the least severe sanction adequate to serve the purposes of Rule 11 should be imposed. It is clear that Rule 11 should not blindly be used to shift fees. In this instance, it appears that the district court erred in assuming that "the first purpose of sanctions under Rule 11 is to compensate the offended parties." In establishing the amount of the sanction, the district court improperly focused on providing "compensatory sanctions." The amount of expense borne by opposing counsel in combatting frivolous claims may well be an appropriate factor for a district court to consider in determining whether a monetary sanction 
should issue and if so, in what amount. However, it is clear that the primary, or "first" purpose of Rule 11 is to deter future litigation abuse. A district court can and should bear in mind that other purposes of the rule include compensating the victims of the Rule 11 violation, as well as punishing present litigation abuse, streamlining court dockets and facilitating court management. But the amount of a monetary sanction should always reflect the primary purpose of deterrence.

When a monetary award is issued, a district court should explain the basis for the sanction so a reviewing court may have a basis to determine whether the chosen sanction is appropriate. A district court should consider the four factors recently enumerated by the Tenth Circuit in White v. General Motors Corp.: (1) the reasonableness of the opposing party's attorney's fees; (2) the minimum to deter; (3) the ability to pay; and (4) factors related to the severity of the Rule 11 violation.

1) Reasonableness (lodestar) calculation. Because the sanction is generally to pay the opposing party's "reasonable expenses including a reasonable attorney's fee," incurred because of the improper behavior, determination of this amount is the usual first step. The plain language of the rule requires that the court independently analyze the reasonableness of the requested fees and expenses. The injured party has a duty to mitigate costs by not overstaffing, overresearching or overdiscovering clearly meritless claims. In evaluating the reasonableness of the fee request, the district court should consider that the very frivolousness of the claim is what justifies the sanctions.

Attorney time which is attributed to responding to the media, or to claims within a pleading which do not merit sanctions, should be excluded from consideration. Only attorney time which is in response to that which has been sanctioned should be evaluated. In this case, it is appropriate for the court to consider on remand whether the large amount of time devoted to the pursuit of sanctions was warranted, and whether the injured parties failed to mitigate their costs by delaying their pursuit of sanctions until after the dismissal. It would also be appropriate for the district court to reduce the amount of any fees awarded based on appellees' failure to give earlier notice to appellants that their conduct warranted Rule 11 sanctions. While the analysis of the reasonableness of costs may call for fairly detailed affidavits, this requirement is not intended to require evidentiary hearings.

Although amici curiae for appellants argue that sanctions based in whole or in part on attorney's fees require the same procedures of discovery, briefing, and argument allowed in attorney's fees cases, we have already stated that sanctions, unlike attorney's fees, are not primarily intended to compensate the prevailing party. Because the purposes of sanctions differ from those of attorney's fees, the amount of process due the offending party differs.

The determination of the type or amount of the sanction imposed comes only after the offending party has had an opportunity to defend against the imposition of any sanction. Presumably, a party's interest in the kind and amount of a sanction is of less import than his or her interest in the decision to impose any sanction. As stated, a district court is required to choose the least 
severe sanction adequate to accomplish the purpose of Rule 11. Thus, a monetary sanction should never be based solely on the amount of attorney's fees claimed by the injured party, even where a court determines that the amount of the sanction should equal the fees claimed by the injured party. As we have previously stated, "reasonable" attorney's fees in the context of Rule 11 "does not necessarily mean actual expenses and attorney's fees." Because the amount of a monetary sanction is not based solely on any claimed amount of attorney's fees, but rather on all of the factors listed herein, the risk of an erroneous calculation based on fee statements is less troublesome in the context of a Rule 11 sanction than in attorney's fees cases. We also bear in mind the interest in avoiding additional hearings for purposes of calculating the amount of fees in the context of Rule 11. Given these considerations, we hold that a sanctioned party is not entitled to an evidentiary hearing or to all of the procedural safeguards available in the context of attorney's fees actions. Instead, a district court may permit a sanctioned party to respond to an opposing party's fee statements in its discretion. Of course, such discretion must be exercised with proper considerations of due process. Where a court determines that a large monetary sanction should issue, and the amount is heavily influenced by an injured party's fee statements, as was the case here, the court should permit the sanctioned party to examine and contest the injured party's fee statements as an aid to the court's own independent analysis of the reasonableness of the claimed fees.

2) Minimum to deter. As we have already stated, the primary purpose of sanctions is to deter attorney and litigant misconduct, not to compensate the opposing party for its costs in defending a frivolous suit. It is particularly inappropriate to use sanctions as a means of driving certain attorneys out of practice. Such decisions are properly made by those charged with handling attorney disbarment and are generally accompanied by specific due process provisions to protect the rights of the attorney in question. The amount of sanctions is appropriate only when it is the "minimum that will serve to adequately deter the undesirable behavior." Thus, the limit of any sanction award should be that amount reasonably necessary to deter the wrongdoer.

A district court must constantly bear in mind the limited purposes of Rule 11, particularly in a case such as this, where a court may disagree with aspects of counsel's conduct which fall outside of the scope of Rule 11. Of course, a court must also constantly bear in mind that the rule is not to chill the bringing of facially valid lawsuits, or a lawyer's creativity in introducing novel theories of recovery.

3. Ability to pay. The offender's ability to pay must also be considered, not because it affects the egregiousness of the violation, but because the purpose of monetary sanctions is to deter attorney and litigant misconduct. Because of their deterrent purpose, Rule 11 sanctions are analogous to punitive damages. It is hornbook law that the financial condition of the offender is an appropriate consideration in the determination of punitive damages. Inability to pay what the court would otherwise regard as an appropriate sanction should be treated as reasonably akin to an affirmative defense, with the burden upon the parties being sanctioned to come forward with evidence of their financial status. 
Although the burden is upon the parties being sanctioned to come forward with evidence of their financial status, a monetary sanction imposed without any consideration of ability to pay would constitute an abuse of discretion. A court should refrain from imposing a monetary award so great that it will bankrupt the offending parties or force them from the future practice of law. Generally, the smaller the amount of the monetary sanction imposed, the greater the likelihood that a court's consideration of the ability to pay will not want for lack of the formal submission of evidence on a sanctioned party's financial status. When the monetary sanction is large, however, the parties should generally be given the opportunity to submit affidavits on their financial status, or to submit such other evidence as the court's discretion permits. In this case, the amount of the monetary sanction originally imposed was substantial, and the parties should have been afforded the opportunity to submit evidence on the issue of whether the amount imposed was so great as to unfairly restrict their access to the courts or to otherwise curtail their ability to practice law or to cause them great financial distress.

4. Other factors. In addition, the court may consider factors such as the offending party's history, experience, and ability, the severity of the violation, the degree to which malice or bad faith contributed to the violation, the risk of chilling the type of litigation involved, and other factors as deemed appropriate in individual circumstances.

In this case, it is appropriate for the court to consider counsel's vast experience, the outrageous and scandalous nature of the claims made, and the improper purpose of the lawsuit. A court might also increase a sanction if one attorney has been previously sanctioned, because such conduct might indicate that the previous sanction was not enough to deter the repetition of the offense.

In addition to the four factors just stated, a district court must sometimes consider whether joint and several liability is appropriate, such as where sanctions are to be imposed against both a client and his counsel. In this case, joint and several liability among attorneys, who each signed a complaint in violation of Rule 11, was not inappropriate. Each attorney has a duty to ensure that the pleading he has signed comports with Rule 11. Issues of individual culpability do not arise where each sanctioned party has committed the same Rule 11 violations.

\section{B. Additional Sanctions}

In addition to imposing sanctions in the amount of attorney's fees claimed by the defendants, the district court imposed sanctions in the amount of $\$ 10,000$ upon each appellant based on his conduct in wilfully filing outrageous claims and appellants' "pains to publicize the allegations through the media." We believe this sanction was error. Rule 11 does not confine courts to any maximum monetary sanction, nor does it even require courts to restrict themselves to monetary penalties. However, Rule 11 must be accorded its plain meaning. The text of the Rule clearly pertains only to a "pleading, motion, or other paper." Rule 11 does not encompass all conduct within judicial proceedings, and it clearly does not reach conduct outside of the judicial process. In this case, it appears the court imposed sanctions in part based on appellants' publication of 
their baseless claims through the media. While such publication may not be actionable as libel or slander, and is reprehensible, Rule 11 was clearly not designed to encompass such conduct.

\section{CONCLUSION}

In sum, we affirm the findings of the district court which led to the imposition of Rule 11 sanctions in this case against plaintiffs' attorneys. However, we vacate the sanction imposed, because it was based on improper considerations and the size of the sanction required the district court to allow sanctioned counsel an opportunity to respond, at least to the fee statements on which the sanction was based. On remand, the district court should consider the factors which we have adopted prior to determining the sanction which should be imposed.

\section{Questions:}

1. Do you agree with the district court's conclusion that Nakell, Pitts, and Kunstler violated Rule 11? Do you find Kunstler's defense compelling?

2. Should courts impose Rule 11 sanctions on attorneys representing clients pro bono? Should they be more reluctant to impose sanctions? 
571

CORRESPONDENCE REGULATIONS

No. 1 -- Only 2 letters each week, not to exceed 2 sheets letter-size $81 / 2 \times 11$ " and written on one side only. and if ruled paper, do not write between lines. Your complete name must be signed at the close of your letter. Clippings, stamps, letters from other people, stationery or cash must not be enclosed in your letters.

No. 2 -- All letters must be addressed in the complete prison name of the inmate. Cell number, where applicable, and prison number must be placed in lower left corner of envelope, with your complete name and address in the upper left corner.

No. 3 -- Do not send any packages without a Package Permit. Unauthorized packages will be destroyed.

No. 4 -- Letters must be written in English only.

the publisher. No. 6 -- Money must be sent in the form of Postal Money Orders only, in the inmate's complete prison name direct from the
No. 6
and prison number.

INSTITUTION CELL NUMBER

NAME NUMBER

In The Supreme Court of The United states washing tor D.C.

clarence Earl Gideon?

petitioner I petition for awrit VS.

of Certiores-i Directed

H.G. Cuchresjy, as To The Supreme Court Directors Divisions $\{$ state of florida. of corrections state No. -890 Misc. of Florida CuT. Thill 1031

To. The Honorable Ear- / Warrens, Enremefount Justice of the United states

Comes now the petitioner; Clarence Farl Gideon, a citizen of the United states of America, in proper person, and appearing as his own counsel. Who petitions this Honorable Count for a Writ of Certiorari directed to The supreme court of the state of Florida. To review the order -and Judgeament of the count below demy ing 7 he petitioner a writ of theseus Corpus.

Petitioner submits that 7 he supreme Count of the united states has the authority end jurisdiction to review the final Judgerent of the supreme court of The state of floridethe highest court of the state Virdersec. 344 (B) Ti. te 28 U.S.C.A. and Bend use the "hue outraces clause " of th m Electronic copy available at: https://ssm.com/abstract $=3367936$ 


\section{DIVISION OF CORRECTIONS \\ CORRESPONDENCE REGULATIONS}

MAIL WILL NOT DE DELIVERED WHICH DOES NOT CONFORM WITH THESERULES

No. 1 -- Only 2 letters each week, not to exceed 2 sheets letter-size $81 / 2 \times 11^{\prime \prime}$ and written on one side only, and if ruled paper, do not write between lines. Your complete name must be signed at the close of your letter. Clippings, stamps, letters from other people, stationery or cash must not be enclosed in your letters.

No. 2 - All letters must be addressed in the complete prison name of the inmate. Cell number, where appl1cable, and prison number must be placed in lower left corner of envelope, with your complete name and address in the upper left corner.

No. 3 -- Do not send any packages without a Package Permit. Unauthorized packages will be destroyed.

No. 4 -- Letters must be written in English only.

No, 5 -- Books, magazines, pamphlets, and newspapers of reputable character will be delivered only if mailed direct from the publisher.

No. 6 ._ Money must be sent in the form of Postal Money ordersonly, in the inmate's complete prison name and prison number.

INSTITUTION

CELL NUMBER

NAME

NUMBER

fourterenth admendment of the constitution and the fifth and sixth articales of the Bill ofjerigh has been violeted. Fin Furthermiore the ofecisidn of the court. be low denying the petitioner a W -itox Habeus Corpus is a/su inconsistentand adverseto-its own previuus decisidos inperalled cases.

ATTached hereto, andmiade ajoertax this petition is a true copy of the petition for a Writ of Habeus Corpus as presented To the thorida su,oreme Courti Petitione asts this Honorable cuurt to cosider The same arqumients and authorities cited inthe,betitions for Writof thbeus corpws beforde the Florida supreme Court, In consideretion of this, pet, tion for a Wirt of Ces-7iojerí.

The suprenne Court of Florida dienox Write, any opinion, Orderof that coust denying petition for Writ of Habeus Coppus dated Octobes-30,1961, are

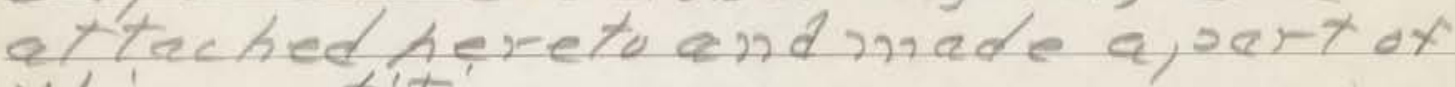
this petitivit.

petitioner, contends thet he bas beern deprived of due process of law Habeus $(a) p u s, p e t i t i e n$ alleging that $+h-1$ Eléctronic copy availabte at: https: $/ /$ ssrn.comabstract $=3367936$ 


\section{DIVISION OF CORRECTIONS \\ CORRESPONDENCE REGULATIONS}

MAIL WILL NOT BE DELIVERED WHICH DOES NOT CONFORM WITH THESE RULES

No, 1 -- Only 2 letters each week, not to exceed 2 sheets letter-size $81 / 2 \times 11 "$ and written on one side only, and if ruled paper, do not write between lines. Your complete name must be signed at the close of your letter. Clippings, stamps, letters from other people, stationery or cash must not be enclosed in your letters.

No. 2 -- All lelters must be addressed in the complete prison name of the inmate. Cell number, where applicable, and prison number must be placed in lower left corner of envelope, with your complete name and address in the

upper left corner.

No. 3 - Do not send any packages without a Packa
No. 4 -- Letters must be written in English only.

No. 5 -- Books, magazines, pamphlets, and newspapers of reputable character will be dellvered only if mailed direct from the publisher.

No. 6 -- Money must be sent in the form of Postal Money Orders only, in the inmate's complete prison name and prison number.

INSTITUTION

CELL NUMBER

NAME

NUMBER

fiederal guestion of substance, in a way notin accord with the appliceble decisions of thi's Homorable court. When at the tinne of the petitiness trid. Heast the lower court for the aid of coursel. The court refused $7 / h$ is aid Petitioner Fold the court that this court had made decisian to the effect that all citizens Tried for a felony erime chould have aid of counsel. The lower Count iquored this, slea.

$$
\text { petitioner al leges thatpins to }
$$

petitioners convictions, and sentence for Breationg and En,tening wilh the mitent To conmit petty knreenp. he had requestad aid af counsel, mat at the time af his conviction and sentences petitionen was wilhout aid of counsel. Thet the cuont refused and did not a,ppoint counsel, and that he was $127 \mathrm{capable}$ arequately of math ing his rwn de fense. In consequence of whichis was made to stand tral, Made a Prima Facia show ing of deniel of dueprocessof law. Cu.s.6.A. Const Anrend, 14 ) Willien $V_{1} K a$ isen Ws. state ofinissouri 65 CT. 363 Counsel nurst be assigned to the accused if he $\angle 5$, 20 ble to e $227,0 / 0 \mathrm{f}$ Electronic copy available at: https://ssrn.com/abstract=3367936 
574

DIVISION OF CORRECTIONS CORRESPONDENCE REGULATIONS

No. 1 -- Only 2 letters each week, not to exceed 2 sheets letter-size $81 / 2 \times 11^{\text {" }}$ and written on one side only. and if ruled paper, do not write between lines. Your complete name must be signed at the close of your letter. Clippings, stamps, letters from other people, stationery or cash must not be enclosed in your letters.

No. 2 -- All letters must be addressed in the complete prison name of the inmate. Cell number, where applycable, and prison number must be placed in lower left corner of envelope, with your complete name and address in the upper left corner.

No. 3 -- Do not send any packages without a Package Permit. Unauthorized packages will be destroyed.

No. 4 -- Letters must be written in English only.
No. 5 -- Books, magazines, pamphlets,

the publisher. No. 6 -- Money must be sent in the form of Postal Money Ordersonly, in the inmate's complete prison name and prison number.

INSTITUTION CELL NUMBER

NAME NUMBER

one, and's incapable adequately of mating his own defense

Tompkins is state missouri 65 et $3>0$

on the sid June $146 / A$. b. your Petitioner was ares ted for foresaid crime and convicted for sene, petitioner recieve Trial andsentenree without aid of counsel, your petitioner was deprived 'Due process of law'

Petitioner was deprived endue process of lew in The cuortionidence in the lower -court did not show that a crime of Breaking and Entering with thereat To commit petty, Latency had beer committed. Youi-petítioner was compelled to mealie his own defense, he was in capable adequately of making his swndefense pet, \&, on er did not plead mol contentlen But that is what his trial amounted To.

Electronic copy available at: https://ssrn.com/abstract=3367936 
575

DIVISION OF CORREcTIONS
CORRESPONDENCE REGULATIONS

No. 1 -- Only 2 letters each week, not to exceed 2 sheets letter-size $81 / 2 \times 11^{\prime \prime}$ and written on one side only. and if ruled paper, do not write between lines. Your complete name must be signed at the close of your letter. Clippings, stamps, letters from other people, stationery or cash must not be enclosed in your letters.

No. 2 -. All letters must be addressed in the complete prison name of the inmate. Cell number, where applicable, and prison number must be placed in lower left corner of envelope, with your complete name and address in the upper left corner.

No. 3 - Do not send any packages without a Package Permit. Unauthorized packages will be destroyed,

No. 4 - Letters must be written in English only.

the publisher. direct from the publisher.
No. 6 -. Money must be sent in the form of Postal Money Orders only, in the inmate's complete prison name and prison number.

INSTITUTION CELL NUMBER

NAME NUMBER

Wherefore the premises considered it is respect fully contented that the decision of the count below was in error and the case should be review by this court, accosdmglf the writ prepared and, orated for should be is sue.

IT is respect fully sub mitred

Clarence Earl Gideon P. $0, B \Delta x 221$

stateof Florida) Reiford Florida evil of unions sr

Petitionenclarence Farl Gideon, personally appear ing before me and being duly sworn. Affirms, that The foregoing petition and the feats set forth in the petition are correct and true

Swords and subscribed before ne this 5 th. day of fan 1962

Penance CDergen Notation $B / 1<$

Electronic copy available at: https://ssrn.com/abstract=3367936 


\section{Pro Se Litigants}

Typically, courts exempt pro se litigants from the requirements of Rule 11. While many pro se complaints are frivolous, some pro se complaints are meritorious, and some have even caused dramatic changes in the law. For example, in 1962, Clarence Earl Gideon filed a handwritten pro se petition for certiorari alleging that Florida had violated his civil rights by denying him legal representation. The Supreme Court granted his petition and held in Gideon v. Wainwright, 372 U.S. 335 (1963) that the Sixth Amendment guarantees criminal defendants the right to representation.

By contrast, Jonathan Lee Riches filed more than 2600 complaints while he was incarcerated at the Federal Medical Center in Lexington, Kentucky, none of which were successful. His complaints alleged improbable harms and requested unusual forms of relief. For example, Riches filed a complaint alleging, inter alia, tort claims against Michael Vick for stealing his dogs and using them for dogfighting, then selling the dogs and using the proceeds to purchase missiles from Iran. Among other things, Riches asked the court to order Vick "to stop physically hurting my feelings and dashing my hopes." Eventually, the court prohibited Riches from filing any more complaints in forma pauperis, meaning that he would have to pay filing fees.

\section{Questions:}

1. How should courts evaluate pro se filings?

2. Should courts apply Rule 11 to pro se plaintiffs? 
577

IN THE UNITED STATES DISTRICT COURT Hodson(R) EASTERN DISTRICT OF VIRGINIA RICHMOND DIVISION

Jonathan Lee Riches?

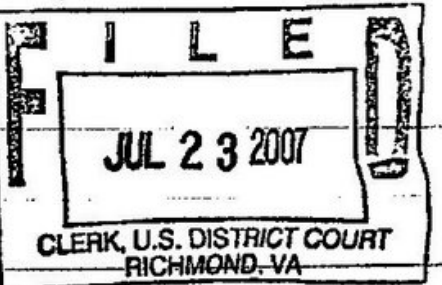
Plaintiff

CIULLAction No:

vs.

$$
3: 020 v 434
$$

MichaeL VICK,

DEFENDANT

COMPLAINT

"THEFT AND ABUSE OF MY ANIMALS"

"FRO TEMPORARY RESTRAINING ORDER"

This Suit is a Givens action and civil Rights violation by

The Constitution a Laws of the United States; and Federal

Tort claims inflicted by that include, but not limited to:

Injury to wildlife, conspiracy, illegaldogfightiogr extortion,

Racketeering, gam 6 ling; copy riant infringement, Identib

the ft, fraud, threats to commit violent acts, Brutality, tax

Fraud.

Comes Now the Plaint ff Jonathan Lee Riches ow prose, Moues this. Honorable Court to issue an order for DEFEnDANT MICHAEL VICK to glue a response. Also Moves this honorable Court to issue a TRO TEMPORAry Restraining order ag VICK from any further contact with PLaintiff. As D SI II claiming that his Federal and State Constitutional R

sing

STAFFATTORNE

Electronic copy available at: https://ssrn.com/abstract=3367936 
578

Violated under the $1^{\text {st }}, 2 n d, 4^{\text {th }}, 5^{\text {th }}, 6^{\text {th }}, 8^{\text {th }}$ and $14^{\text {th }}$ amendment of the Constitution. For relief. Plarifte seek's $63,000,000,000,00$ Billion dollars backed by guldand s, Leer

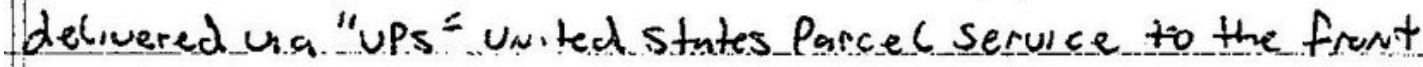
gates of Fol will amsburg, sackers S.C. Collected from Defendant MICHAEL NICK.

1

MICHAEL VICK is a Quarterback fur the Atlanta Falcons. ON Apr .L 20 th 2007 Mr. Nick Stole two white mixed Pit Bul dogs from my residence in Holiday florida, and used them fur dog fighting throughout the Richmond Area. MR wick damaged my RFID Chips in my days collars so I will not be 9.6 le to track them. These 2 dogs were used for fighting on Apr. $L 23^{\text {nd }}, 2 x^{\text {th }}$, and $26^{\text {th }}$ 2007. ON Apo $28^{\text {th }}$, MR. UICK Sod My dog 300 EBAY. Auction, and usech the proceeds to purchase missiles from the Iran Gourmont.

2

MICHAEC UICK CONtinued to harass me oN May $4^{\text {th }}$, $20096 \mathrm{y}$ Stealing my Identity from my coat. My Identity was used to open New store account cards to petsmart and doggie ware house to purchase food fur MR. v eck's illegal dog fighting operation

MICHAEC. VICK violated $\frac{3}{-m y}$ copyright Laws 6 y using my Copy right Name on his personal football outfit and casual -clothing without paying me for use this conspiracy started Jer $10^{\text {th }}, 2001$ until the day -this Suit was written. MR. Jack uses my name to sell tr shirts, Jownthw lee Riches mugs, Mr Riches tats.

Electronic copy available at: https://ssrn.com/abstract=3367936 
579

4

ON Feb $10^{\text {th }}$ 2007 MICHAEL U2 ak plead Aluengence to AC-qaeda MICHAEC UICK Subjected me to microwave resting MICHAEL UICK Used dias in School 2 ones

MECHAEL VICK is in the business of illegal steroids.

Plaintiff prays this court to give him relief on these 2 saves

Qhaintff prays this court will issue a rempomiry Restraining order Aguish MECHAEL WICk so he cav do conger sell my fopynghted Materials, MICHAEC UICK cant stent anymore of my animals (dogs) for dog fighting. MICHAEC Grok litas te stop Physically hurting My feelings and dashing my hopes.

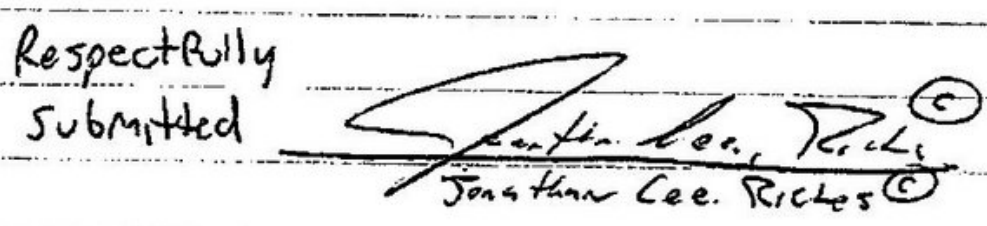

Jonathan Lee. Riches

$\$ 40948-018$

Fol williams burg

Poo. Bu $\times 340$

Satters,sc 29590

DUE To Restridions on typewriters. this suit was Hand written

Electronic copy available at: https://ssrn.com/abstract=3367936 


\section{2: Improper Advocacy}

Here's the last toast of the evening, here's to those who still believe. All the losers will be winners, all the givers shall receive. Here's to trouble-free tomorrows, may your sorrows all be small. Here's to the losers, bless them all. ${ }^{92}$

The head on my shoulders is sorta loose, and I ain't got the sense God gave a goose. Lord, I ain't crazy, but I'm a nut. ${ }^{93}$

Federal Rule of Civil Procedure 11 prohibits frivolous pleadings. But Model Rule of Professional Conduct 3.1 goes farther, prohibiting frivolous argument and abusive litigation tactics as well. In other words, under Rule 3.1, litigants must not only ensure that their pleadings are meritorious, but also that their litigation tactics are reasonable. Unsurprisingly, this rule is enforced almost entirely in the breach. Courts are reluctant to sanction attorneys for improper tactics, and when they do, the sanctions are often reversed as improperly imposed.

Nevertheless, good attorneys realize that the court is always watching. And they know that judges tend to reward good behavior and punish bad behavior. Sometimes, those rewards and punishments are explicit. But more often they are implicit, and come in the form of motions granted or denied.

\section{Model Rule of Professional Conduct 3.1: Meritorious Claims \& Contentions}

A lawyer shall not bring or defend a proceeding, or assert or controvert an issue therein, unless there is a basis in law and fact for doing so that is not frivolous, which includes a good faith argument for an extension, modification or reversal of existing law. A lawyer for the defendant in a criminal proceeding, or the respondent in a proceeding that could result in incarceration, may nevertheless so defend the proceeding as to require that every element of the case be established.

\section{Model Rule of Professional Conduct 3.1: Meritorious Claims \& Contentions, Comments} [1]-[3]

1. The advocate has a duty to use legal procedure for the fullest benefit of the client's cause, but also a duty not to abuse legal procedure. The law, both procedural and substantive, establishes the limits within which an advocate may proceed. However, the law is not always clear and never is static. Accordingly, in determining the proper scope of advocacy, account must be taken of the law's ambiguities and potential for change.

2. The filing of an action or defense or similar action taken for a client is not frivolous merely because the facts have not first been fully substantiated or because the lawyer

\footnotetext{
92 Robert Wells \& Jack Segal, Here's to the Losers (1963).

${ }^{93}$ Leroy Pullins, I'm a Nut (1966).
} 
expects to develop vital evidence only by discovery. What is required of lawyers, however, is that they inform themselves about the facts of their clients' cases and the applicable law and determine that they can make good faith arguments in support of their clients' positions. Such action is not frivolous even though the lawyer believes that the client's position ultimately will not prevail. The action is frivolous, however, if the lawyer is unable either to make a good faith argument on the merits of the action taken or to support the action taken by a good faith argument for an extension, modification or reversal of existing law.

3. The lawyer's obligations under this Rule are subordinate to federal or state constitutional law that entitles a defendant in a criminal matter to the assistance of counsel in presenting a claim or contention that otherwise would be prohibited by this Rule.

Model Code of Professional Responsibility, Canon 7: A Lawyer Should Represent a Client Zealously Within the Bounds of the Law (1969)

EC 7-1 The duty of a lawyer, both to his client1 and to the legal system, is to represent his client zealously within the bounds of the law, which includes Disciplinary Rules and enforceable professional regulations. The professional responsibility of a lawyer derives from his membership in a profession which has the duty of assisting members of the public to secure and protect available legal rights and benefits. In our government of laws and not of men, each member of our society is entitled to have his conduct judged and regulated in accordance with the law; to seek any lawful objective through legally permissible means; and to present for adjudication any lawful claim, issue, or defense.

EC 7-2 The bounds of the law in a given case are often difficult to ascertain. The language of legislative enactments and judicial opinions may be uncertain as applied to varying factual situations. The limits and specific meaning of apparently relevant law may be made doubtful by changing or developing constitutional interpretations, inadequately expressed statutes or judicial opinions, and changing public and judicial attitudes. Certainty of law ranges from well-settled rules through areas of conflicting authority to areas without precedent.

EC 7-3 Where the bounds of law are uncertain, the action of a lawyer may depend on whether he is serving as advocate or adviser. A lawyer may serve simultaneously as both advocate and adviser, but the two roles are essentially different. In asserting a position on behalf of his client, an advocate for the most part deals with past conduct and must take the facts as he finds them. By contrast, a lawyer serving as adviser primarily assists his client in determining the course of future conduct and relationships. While serving as advocate, a lawyer should resolve in favor of his client doubts as to the bounds of the law. In serving a client as adviser, a lawyer in appropriate circumstances should give his professional opinion as to what the ultimate decisions of the courts would likely be as to the applicable law.

Duty of the Lawyer to a Client 
EC 7-4 The advocate may urge any permissible construction of the law favorable to his client, without regard to his professional opinion as to the likelihood that the construction will ultimately prevail. His conduct is within the bounds of the law, and therefore permissible, if the position taken is supported by the law or is supportable by a good faith argument for an extension, modification, or reversal of the law. However, a lawyer is not justified in asserting a position in litigation that is frivolous.

EC 7-5 A lawyer as adviser furthers the interest of his client by giving his professional opinion as to what he believes would likely be the ultimate decision of the courts on the matter at hand and by informing his client of the practical effect of such decision. He may continue in the representation of his client even though his client has elected to pursue a course of conduct contrary to the advice of the lawyer so long as he does not thereby knowingly assist the client to engage in illegal conduct or to take a frivolous legal position. A lawyer should never encourage or aid his client to commit criminal acts or counsel his client on how to violate the law and avoid punishment therefor.

In re Snyder, 472 U.S. 634 (1985)

Summary: Snyder objected to the United States District Court for the District of North Dakota's treatment of attorneys representing indigent criminal defendants, and refused to apologize for the tone of his objection. The Chief Judge of the district court suspended Snyder for one year for disrespecting the court and the circuit court affirmed. The Supreme Court reversed, holding that Snyder's conduct was not sanctionable.

CHIEF JUSTICE BURGER delivered the opinion of the Court.

We granted certiorari to review the judgment of the Court of Appeals suspending petitioner from practice in all courts of the Eighth Circuit for six months.

In March 1983, petitioner Robert Snyder was appointed by the Federal District Court for the District of North Dakota to represent a defendant under the Criminal Justice Act. After petitioner completed the assignment, he submitted a claim for $\$ 1,898.55$ for services and expenses. The claim was reduced by the District Court of $\$ 1,796.05$.

Under the Criminal Justice Act, the Chief Judge of the Court of Appeals was required to review and approve expenditures for compensation in excess of $\$ 1,000$. Chief Judge Lay found the claim insufficiently documented, and he returned it with a request for additional information. Because of technical problems with his computer software, petitioner could not readily provide the information in the form requested by the Chief Judge. He did, however, file a supplemental application. 
The secretary of the Chief Judge of the Circuit again returned the application, stating that the proffered documentation was unacceptable. Petitioner then discussed the matter with Helen Monteith, the District Court Judge's secretary, who suggested he write a letter expressing his view. Petitioner then wrote the letter that led to this case. The letter, addressed to Ms. Monteith, read in part:

In the first place, I am appalled by the amount of money which the federal court pays for indigent criminal defense work. The reason that so few attorneys in Bismarck accept this work is for that exact reason. We have, up to this point, still accepted the indigent appointments, because of a duty to our profession, and the fact that nobody else will do it.

Now, however, not only are we paid an amount of money which does not even cover our overhead, but we have to go through extreme gymnastics even to receive the puny amounts which the federal courts authorize for this work. We have sent you everything we have concerning our representation, and I am not sending you anything else. You can take it or leave it.

Further, I am extremely disgusted by the treatment of us by the Eighth Circuit in this case, and you are instructed to remove my name from the list of attorneys who will accept criminal indigent defense work. I have simply had it.

Thank you for your time and attention.

The District Court Judge viewed this letter as one seeking changes in the process for providing fees, and discussed these concerns with petitioner. The District Court Judge then forwarded the letter to the Chief Judge of the Circuit. The Chief Judge in turn wrote to the District Judge, stating that he considered petitioner's letter:

totally disrespectful to the federal courts and to the judicial system. It demonstrates a total lack of respect for the legal process and the courts.

The Chief Judge expressed concern both about petitioner's failure to "follow the guidelines and refusal to cooperate with the court," and questioned whether, "in view of the letter" petitioner was "worthy of practicing law in the federal courts on any matter." He stated his intention to issue an order to show cause why petitioner should not be suspended from practicing in any federal court in the Circuit for a period of one year. Subsequently, the Chief Judge wrote to the District Court again, stating that if petitioner apologized the matter would be dropped. At this time, the Chief Judge approved a reduced fee for petitioner's work of $\$ 1,000$ plus expenses of $\$ 23.25$.

After talking with petitioner, the District Court Judge responded to the Chief Judge as follows: 
He sees his letter as an expression of an honest opinion, and an exercise of his right of freedom of speech. I, of course, see it as a youthful and exuberant expression of annoyance which has now risen to the level of a cause.

He has decided not to apologize, although he assured me he did not intend the letter as you interpreted it.

The Chief Judge then issued an order for petitioner to show cause why he should not be suspended for his "refusal to carry out his obligations as a practicing lawyer and officer of the court" because of his refusal to accept assignments under the Criminal Justice Act. Nowhere in the order was there any reference to any disrespect in petitioner's letter of October 6, 1983.

Petitioner requested a hearing on the show cause order. In his response to the order, petitioner focused exclusively on whether he was required to represent indigents under the Criminal Justice Act. He contended that the Act did not compel lawyers to represent indigents, and he noted that many of the lawyers in his District had declined to serve. He also informed the court that prior to his withdrawal from the Criminal Justice Act panel, he and his two partners had taken 15 percent of all the Criminal Justice Act cases in their district.

At the hearing, the Court of Appeals focused on whether petitioner's letter of October 6, 1983, was disrespectful, an issue not mentioned in the show cause order. At one point, Judge Arnold asked: "I am asking you, sir, if you are prepared to apologize to the court for the tone of your letter?" Petitioner answered: "That is not the basis that I am being brought forth before the court today." When the issue again arose, petitioner protested: "But, it seems to me we're getting far afield here. The question is, can I be suspended from this court for my request to be removed from the panel of attorneys."

Petitioner was again offered an opportunity to apologize for his letter, but he declined. At the conclusion of the hearing, the Chief Judge stated:

I want to make it clear to Mr. Snyder what it is the court is allowing you ten days lapse here, a period for you to consider. One is, that, assuming there is a general requirement for all competent lawyers to do pro bono work that you stand willing and ready to perform such work and will comply with the guidelines of the statute. And secondly, to reconsider your position as Judge Arnold has requested, concerning the tone of your letter of October 6.

Following the hearing, petitioner wrote a letter to the court, agreeing to "enthusiastically obey the mandates" of any new plan for the implementation of the Criminal Justice Act in North Dakota, and to "make every good faith effort possible" to comply with the court's guidelines regarding compensation under the Act. Petitioner's letter, however, made no mention of the October 6, 1983, letter.

The Chief Judge then wrote to Snyder, stating among other things: 
The court expressed its opinion at the time of the oral hearing that interrelated with our concern and the issuance of the order to show cause was the disrespect that you displayed to the court by way of your letter addressed to Helen Montieth, Judge Van Sickle's secretary, of October 6,1983 . The court expressly asked if you would be willing to apologize for the tone of the letter and the disrespect displayed. You serve as an officer of the court and, as such, the Canons of Ethics require every lawyer to maintain a respect for the court as an institution.

Before circulating your letter of February 23, I would appreciate your response to Judge Arnold's specific request, and the court's request, for you to apologize for the letter that you wrote.

Please let me hear from you by return mail. I am confident that if such a letter is forthcoming that the court will dissolve the order.

Petitioner responded to the Chief Judge:

I cannot, and will never, in justice to my conscience, apologize for what I consider to be telling the truth, albeit in harsh terms.

It is unfortunate that the respective positions in the proceeding have so hardened. However, I consider this to be a matter of principle, and if one stands on a principle, one must be willing to accept the consequences.

After receipt of this letter, petitioner was suspended from the practice of law in the federal courts in the Eighth Circuit for six months. The opinion stated that petitioner "contumaciously refused to retract his previous remarks or apologize to the court." It continued:

Petitioner's refusal to show continuing respect for the court and his refusal to demonstrate a sincere retraction of his admittedly "harsh" statements are sufficient to demonstrate to this court that he is not presently fit to practice law in the federal courts. All courts depend on the highest level of integrity and respect not only from the judiciary but from the lawyers who serve in the court as well. Without public display of respect for the judicial branch of government as an institution by lawyers, the law cannot survive. Without hesitation we find Snyder's disrespectful statements as to this court's administration of CJA contumacious conduct. We deem this unfortunate.

We find that Robert Snyder shall be suspended from the practice of law in the federal courts of the Eighth Circuit for a period of six months; thereafter, Snyder should make application to both this court and the federal district court of North Dakota to be readmitted. 
The opinion specifically stated that petitioner's offer to serve in Criminal Justice Act cases in the future if the panel was equitably structured had "considerable merit."

Petitioner moved for rehearing en banc. In support of his motion, he presented an affidavit from the District Judge's secretary - the addressee of the October 6 letter - stating that she had encouraged him to send the letter. He also submitted an affidavit from the District Judge, which read in part:

I did not view the letter as one of disrespect for the Court, but rather one of somewhat frustrated lawyer hoping that his comments might be viewed as a basis for some changes in the process.

Mr. Snyder has appeared before me on a number of occasions and has always competently represented his client, and has shown the highest respect to the court system and to me.

The petition for rehearing en banc was denied. An opinion for the en banc court stated:

The gravamen of the situation is that Snyder in his letter of October 6, 1983 became harsh and disrespectful to the Court. It is one thing for a lawyer to complain factually to the Court, it is another for counsel to be disrespectful in doing so.

Snyder states that his letter is not disrespectful. We disagree. In our view, the letter speaks for itself.

The en banc court opinion stayed the order of suspension for 10 days, but provided that the stay would be lifted if petitioner failed to apologize. He did not apologize, and the order of suspension took effect.

We granted certiorari. We reverse.

II

A

Petitioner challenges his suspension from practice on the grounds (a) that his October 6, 1983, letter to the District Judge's secretary was protected by the First Amendment, (b) that he was denied due process with respect to the notice of the charge on which he was suspended, and (c) that his challenged letter was not disrespectful or contemptuous. We avoid constitutional issues when resolution of such issues is not necessary for disposition of a case. Accordingly, we consider first whether petitioner's conduct and expressions warranted his suspension from practice; if they did not, there is no occasion to reach petitioner's constitutional claims. 
Courts have long recognized an inherent authority to suspend or disbar lawyers. This inherent power derives from the lawyer's role as an officer of the court which granted admission. The standard for disciplining attorneys practicing before the courts of appeals is set forth in Federal Rule of Appellate Procedure 46:

(b) Suspension or Disbarment. When it is shown to the court that any member of its bar has been suspended or disbarred from practice in any other court of record, or has been guilty of conduct unbecoming a member of the bar of the court, he will be subject to suspension or disbarment by the court. The member shall be afforded an opportunity to show good cause, within such time as the court shall prescribe, why he should not be suspended or disbarred. Upon his response to the rule to show cause, and after hearing, if requested, or upon expiration of the time prescribed for a response if no response is made, the court shall enter an appropriate order.

The phrase "conduct unbecoming a member of the bar" must be read in light of the "complex code of behavior" to which attorneys are subject. Essentially, this reflects the burdens inherent in the attorney's dual obligations to clients and to the system of justice. Justice Cardozo once observed:

Membership in the bar is a privilege burdened with conditions. An attorney is received into that ancient fellowship for something more than private gain. He becomes an officer of the court, and, like the court itself, an instrument or agency to advance the ends of justice.

As an officer of the court, a member of the bar enjoys singular powers that others do not possess; by virtue of admission, members of the bar share a kind of monopoly granted only to lawyers. Admission creates a license not only to advise and counsel clients but also to appear in court and try cases; as an officer of the court, a lawyer can cause persons to drop their private affairs and be called as witnesses in court, and for depositions and other pretrial processes that, while subject to the ultimate control of the court, may be conducted outside courtrooms. The license granted by the court requires members of the bar to conduct themselves in a manner compatible with the role of courts in the administration of justice.

Read in light of the traditional duties imposed on an attorney, it is clear that "conduct unbecoming a member of the bar" is conduct contrary to professional standards that shows an unfitness to discharge continuing obligations to clients or the courts, or conduct inimical to the administration of justice. More specific guidance is provided by case law, applicable court rules, and "the lore of the profession," as embodied in codes of professional conduct.

Apparently relying on an attorney's obligation to avoid conduct that is "prejudicial to the administration of justice," the Court of Appeals held that the letter of October 6, 1983, and an unspecified "refusal to show continuing respect for the court" demonstrated that petitioner was 
"not presently fit to practice law in the federal courts." Its holding was predicated on a specific finding that petitioner's "disrespectful statements in his letter of October 6, 1983 as to this court's administration of the CJA constituted contumacious conduct."

We must examine the record in light of Rule 46 to determine whether the Court of Appeals' action is supported by the evidence. In the letter, petitioner declined to submit further documentation in support of his fee request, refused to accept further assignments under the Criminal Justice Act, and criticized the administration of the Act. Petitioner's refusal to submit further documentation in support of his fee request could afford a basis for declining to award a fee; however, the submission of adequate documentation was only a prerequisite to the collection of his fee, not an affirmative obligation required by his duties to a client or the court. Nor, as the Court of Appeals ultimately concluded, was petitioner legally obligated under the terms of the local plan to accept Criminal Justice Act cases.

We do not consider a lawyer's criticism of the administration of the Act or criticism of inequities in assignments under the Act as cause for discipline or suspension. The letter was addressed to a court employee charged with administrative responsibilities, and concerned a practical matter in the administration of the Act. The Court of Appeals acknowledged that petitioner brought to light concerns about the administration of the plan that had "merit," and the court instituted a study of the administration of the Criminal Justice Act as a result of petitioner's complaint. Officers of the court may appropriately express criticism on such matters.

The record indicates the Court of Appeals was concerned about the tone of the letter; petitioner concedes that the tone of his letter was "harsh," and, indeed it can be read as illmannered. All persons involved in the judicial process - judges, litigants, witnesses, and court officers - owe a duty of courtesy to all other participants. The necessity for civility in the inherently contentious setting of the adversary process suggests that members of the bar cast criticisms of the system in a professional and civil tone. However, even assuming that the letter exhibited an unlawyerlike rudeness, a single incident of rudeness or lack of professional courtesy - in this context - does not support a finding of contemptuous or contumacious conduct, or a finding that a lawyer is "not presently fit to practice law in the federal courts." Nor does it rise to the level of "conduct unbecoming a member of the bar" warranting suspension from practice.

\section{Questions:}

1. Why did the district court sanction Snyder? Why did the circuit court affirm? And why did the Supreme Court reverse?

2. When should courts be able to sanction attorneys for disrespectful behavior? When should the discretion of the court be limited? 


\section{COURT REINSTATES ANGRY LAWYER, 33}

\author{
Justices Say His Complaint on \\ Getting Fee From U.S. Did \\ Not Merit Suspension
}

BY LINDA GREENHOUSE Spedil to The New York Times
WASHINGTON, June 24 - It was a fight over principle and pride between a 33-year-old lawyer from Bismarck,
N.D., and the United States Court of Appeals for the Eighth Circuit.

The lawyer complained, in blunt terms, about the effort required to ge: reimbursed for representing poor defendants in the Federal courts. The court called him disrespectful and de manded a retraction and apology. His refusal to provide either one cost him the right to practice law in the Federa court or seven Midale Western states. Thed tered its own brand of frontier justice. The court ruled, 8 too, that the court of Appeals hover yer's complaints. Chief Justice Warre . Burger administration, even when expressed yer-like rudeness" " cannot form the yer-ike rudeness, cannot form the

As one of the most unusual cases to come before the Court in the term now drawing to a close, the dispute betwom the lawyer, Robert J. Snyder, and the Eighth Circuit has been something of a cause celebre in the legal profession. Lawyers often rail, although not quite as publicly as Mr. Snyder did, apainst the power of judges to control their des tinies, and many of Mr. Snyder's colleagues adopted him as a David fight ing their battle against Goliath.

\section{Ohio Bar Files Brief}

The Ohio State Bar Association filed a brief on behalf of the lawyer, who practices in partnerstip with two classDakota Law School. His case was featured in The A.B.A. Journal, the monthly magazine of the American Bar Association. The seven biggest law Supreme Court appeal without charge. "Boy, it feels real good," Mr. Snyder said in a telephone interview today. "It's been a long fight, and it looked blesk."

Mr. Snyder's problems began two years ago, when he submitted a bill for representing an indigent criminal defendant in Federal District Court in tice Act, lawyers were paid $\$ 30$ an hour tor such work, a fee that Congress dou bled in amending the act last October. He requested payment of $\$ 1,898.55$. Donald P. Lay, Chief Judge of the Eighth Circuit, which includes the Dakotas and five other states, rejected the claim as inadequately documented. Mr. Snyder then wrote to the secretary of the judge who had presided over the treme gymnaștics" required "even to

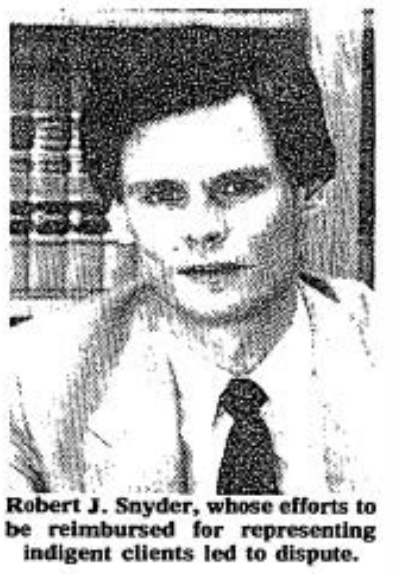

receive the puny amounts which the Federal courts authorize for this work." His letter continued

"I am not sending you anything else. You can take it or leave it. Further, 1 am extremely disgusted by the treatment of us by the Eighth Circuit in this case, and you are instructed to remove my name from the list of attorneys who will accept criminal indigent defense work. I have simply had it.

The district judge took no offense at the letter, but Judge Lay did. He cut Mr. Snyder's fee to $\$ 1,000$ and told the district judge to warn the lawyer that he faced a ono-year suspension unless he apologized for the letter. Mr. Snyder refused, and he was summoned to a hearing before a panel of the appeals court, where he declined once again to apologize.

After the hearing, Judge Lay wrote to him and asked for an apology "by return mail."

Mr. Synder replied that he could not in good conscience "apologize for what I consider to be telling the truth, albeit in harsh terms. The Eighth Circuit en suspended him for six months. Mr. Snyder was about six weeks into his suspension before Associate Justice Harry A. Blackmun granted a stay cide cide the case. Justice Blackmun, himmell a former Eighth Circuit judge who court, did not vote in the case. Chit dustice nure in the case.

Chief Justice Burger's opinion, In re that while ". all persons involved in the judicial process - jud , litigants, witnesses, and court officers awes, duty of courtesy to all other participants," Mr. Snyder's behavior had not demonstrated that he was unfit te prac tice in the Federal courts. "We do not consider a lawyer"s criticism of the ad ministration of the act " the Chief Jus tice said, "as cause for discipline or suspension Officers of the court may appropriately express criticism on such matters.."

Judge Lay, in a telephone intervieg oday from his chambers in St. Paul, said: "I still feel very strongly that a lawyer should not be disrespectful to the court." But "the decision doesn't wother me at all," he said. "It's another case among many."

Gadda v. Ashcroft, 377 F. 3d 934 (9th Cir. 2004) 
Summary: The California Bar disbarred Gadda for incompetence, based on his failure to provide competent legal representation to clients in immigration court. The Ninth Circuit also disbarred Gadda, based on the California Bar's decision. Gadda objected to his disbarment by the 9th Circuit, arguing that the California Bar lacked authority to discipline him for incompetent representation in immigration court. The 9th Circuit disagreed, holding that both the California Bar and the 9th Circuit had the authority to discipline him.

BEEZER, Circuit Judge.

On July 30, 2001, the California State Bar Court found that Miguel Gadda, Esq. repeatedly failed to perform legal services competently. It placed Gadda on involuntary inactive status and recommended that Gadda be disbarred.

This opinion and order relate to two federal proceedings resulting from the State Bar Court's recommendation. In the first, Gadda appeals an order of the United States District Court for the Northern District of California, which denies Gadda's motion to preliminarily enjoin the Board of Immigration Appeals decision to suspend him from practice based on his suspension by the State Bar Court. Gadda asserts that the State Bar Court cannot affect his right to practice before the BIA. The other proceeding is a disciplinary action initiated by this court after we received notice of Gadda's suspension from practice by the State Bar Court.

Gadda argues that any reciprocal discipline imposed by the BIA or by this court based on the State Bar Court's suspension order is invalid because the Supreme Court of California lacked jurisdiction to discipline him. He claims that federal law preempts the states' authority to regulate attorneys, like him, who practice only in the administration of immigration law and in the federal courts, but not in the state courts. Because both of these proceedings involve the same underlying preemption issue, we consolidate them for opinion purposes only.

We conclude that federal law does not preempt the Supreme Court of California's authority to suspend or disbar attorneys admitted to practice in California state courts. The Supreme Court of California's discipline orders may serve as the basis for reciprocal disbarment actions by both the BIA and this court.

We disbar Gadda from the practice of law before the United States Court of Appeals for the Ninth Circuit.

।

Gadda was admitted to the California State Bar in 1975. Thereafter, he was admitted to practice law and became a member of the bar of the United States District Court for the Northern District of California, the United States Court of Appeals for the Ninth Circuit, and the Supreme Court of the United States. He was also admitted to practice before the Board of Immigration Appeals 
and was authorized to appear for clients before the BIA and in all Immigration Courts throughout the United States.

\section{A. California State Court Disciplinary Proceedings}

On August 26, 2002, the Review Department of the California State Bar Court affirmed the State Bar Court's decision recommending Gadda's disbarment and placing him on involuntary inactive status. On January 22, 2003, the Supreme Court of California ordered that Gadda be disbarred from the practice of law in California, effective February 21, 2003.

The Review Department's opinion surveyed Gadda's history of federal immigration practice, concluding that "disbarment is warranted under the circumstances for the protection of the public, the courts, and the legal profession." The Review Department cited seventeen acts of misconduct extending over six years and involving eight federal immigration client matters and one client trust account matter. This misconduct included Gadda's failure to appear at scheduled court conferences and to keep clients apprised of the proceedings and relevant court dates. Five of Gadda's clients were ordered deported in absentia and at least six courts found Gadda to have provided ineffective assistance. The Review Department concluded that Gadda failed "to perform legal services competently, demonstrated indifference toward rectification of or atonement for the consequences of his misconduct, and significantly harmed clients." The Review Department determined that aggravating factors, including prior discipline for similar misconduct in 1990, outweighed any mitigating factors Gadda presented.

We incorporate by reference that portion of the Review Board's opinion which inventories Gadda's incompetence between 1994 and 1999. Of the eight federal immigration client matters which the Review Board describes, that of the Saba family is especially egregious.

The four minor Saba children applied for political asylum. After the INS denied their application, the children retained Gadda to represent them. Gadda advised the children to withdraw their asylum claim; the Immigration Judge ordered that they voluntarily depart from the United States.

Thereafter, the children's parents became naturalized citizens. The children were eligible for priority consideration of their application for adjustment of status to legal residency or citizenship based on their parents' naturalization. However, as a result of Gadda's neglect and incompetence, the children were deprived of an adjustment of their immigration status, and ultimately were placed in deportation proceedings.

Gadda moved for a stay of the children's deportation. In the course of a hearing on that motion, Gadda left the Saba family unrepresented before an immigration officer. Gadda also directed the children to sign a statement promising they would voluntarily depart once the stay expired. The immigration court granted the stay but the children did not depart as promised. Gadda assured the children that he was appealing the earlier BIA decision. 
Because Gadda negligently allowed the time for an appeal from the BIA to this court to lapse, he was forced to seek habeas corpus relief before the district court. Gadda directed William Gardner, an attorney Gadda employed on a contract basis but did not supervise, to file the habeas petition. Before Gardner filed the habeas petition, the IJ ordered the Saba children to be deported on account of their refusal to depart voluntarily at the expiration of the stay. Gadda once again advised the children not to comply with the court's order.

Gardner subsequently filed the habeas petition and the district court ordered a hearing. The district court made a sua sponte finding of ineffective assistance by Gadda and remanded the matter to the immigration court to reopen the deportation hearing. By the time the case was heard, two of the Saba children were no longer minors. Gadda has not refunded the $\$ 3,000$ the Saba children paid him.

Regarding the Saba matter, the Review Department agreed with the State Bar that Gadda "recklessly and repeatedly failed to perform legal services" and "failed to refund unearned fees promptly upon termination." Specifically, the Review Department found Gadda's performance incompetent in the following ways:

(1) by leaving the children alone, unrepresented, in the middle of a hearing before an immigration officer and advising them to sign a voluntary departure form; (2) by failing to advise the Saba children to depart on or before the deadline; (2) by failing to timely move to reopen deportation proceedings; (4) by failing to file a petition for review with the Ninth Circuit; (5) by failing to file for adjustment of status after Mrs. Saba became a naturalized citizen and instead filing for adjustment of status on the children's last day to depart voluntarily, approximately three months later; and (6) by failing to supervise Gardner in filing a petition for writ of habeas corpus.

\section{B. Gadda v. Ashcroft - appeal from BIA disciplinary proceedings}

Based on the State Bar Court's order, on October 2, 2001, the BIA suspended Gadda from practice before the BIA, the Immigration Courts, and the Department of Homeland Security. Gadda unsuccessfully sought a preliminary injunction of the BIA's action in the district court. Gadda appealed the denial of the preliminary injunction to this court. We deferred submission pending the outcome of disciplinary proceedings before the BIA.

Meanwhile, the Office of General Counsel for the Executive Office for Immigration Review initiated disciplinary proceedings and an adjudicatory official suspended Gadda indefinitely from practice on August 22, 2002. On July 8, 2003, the BIA dismissed Gadda's appeal and ordered him expelled from practice before the BIA, the Immigration Courts, and the DHS.

\section{Ninth Circuit Disciplinary Proceedings}

On May 29, 2002, we ordered Gadda to resign from the Ninth Circuit's bar or show cause why he should not be suspended or disbarred based on the California State Bar Court's order 
placing him on involuntary inactive status and recommending that he be disbarred. Gadda responded and we referred the case to the Appellate Commissioner. On September 25, 2002, the Appellate Commissioner stayed the disciplinary proceedings pending a decision by the Supreme Court of California on the State Bar Court's recommendation or a decision by us.

Following the Supreme Court of California's January 22, 2003 order disbarring Gadda, the Appellate Commissioner again ordered Gadda to resign from the bar of the United States Court of Appeals for the Ninth Circuit or show cause why he should not be suspended or disbarred. Gadda requested a stay, claiming that the Supreme Court of California's disbarment order was not final and that we should first resolve Gadda v. Ashcroft.

The Appellate Commissioner conducted a hearing on March 27, 2003 and filed a report and recommendation on May 22, 2003. The Appellate Commissioner recommends that Gadda be disbarred from the practice of law before the United States Court of Appeals for the Ninth Circuit.

II

"Membership in the bar is a privilege burdened with conditions. An attorney is received into that ancient fellowship for something more than private gain. He becomes an officer of the court, and, like the court itself, an instrument or agency to advance the ends of justice." We have both statutory and inherent power to suspend or disbar an attorney who has been admitted to this court's bar.

Federal Rule of Appellate Procedure 46 regulates attorney conduct, including admission to the bar of the Ninth Circuit and the conditions for suspension and disbarment. FRAP 46 provides that a member of this court's bar is subject to suspension or disbarment if the member either (1) "has been suspended or disbarred from practice in any other court"; or (2) "is guilty of conduct unbecoming a member of the court's bar."

\section{A. Reciprocal Discipline}

In this case, Gadda's suspension and disbarment from the practice of law in California forms the basis for his disbarment from the BIA and this court.

\section{B. Conduct Unbecoming}

Even if the California courts had not acted to disbar Gadda, we have independent authority to suspend or disbar him from practice. Conduct unbecoming a member of the bar of the Ninth Circuit is sufficient cause for disbarment. Unlike some of our sister circuits, the Ninth Circuit has not adopted local rules elaborating on FRAP 46's "conduct unbecoming" standard. The Supreme Court has held that "conduct unbecoming" is conduct "contrary to professional standards that show an unfitness to discharge continuing obligations to clients or courts, or 
conduct inimical to the administration of justice." We have consistently found conduct unbecoming where an attorney failed to prosecute an appeal with due diligence.

Because we have jurisdiction over appeals from the immigration courts, the quality of the practice by attorneys appearing before the immigration courts is crucial to our ability to administer justice and function effectively. The quality of our review is heavily dependent on the record established in administrative immigration hearings, which in turn is dependent on the competence of the attorneys creating that record. Gadda's incompetence impedes our operations and endangers the rights of his clients.

In the course of one immigration matter, for example, Gadda neglected to introduce crucial documents relating to changed country conditions. Although his client was in possession of such documents, Gadda failed to have the documents translated and offered as evidence. In that same matter, the Review Department found that Gadda failed to elicit persuasive testimony in support of his client's contention of fear of future persecution. Gadda currently represents petitioners in approximately 50 matters pending before this court. We hold that conduct such as his before the immigration courts is sufficient to constitute "conduct unbecoming" a member of the bar of this court.

\section{Inherent Power}

We hold that we also have inherent authority respecting the suspension and disbarment of attorneys who perform incompetently in federal immigration proceedings. This power derives from an attorney's role as an officer of the court which granted the attorney admission to the bar; it is necessary to maintain the respectability and harmony of the bar, as well as to protect the public. We exercise this power with restraint and discretion.

"The behavior for which an attorney is disciplined pursuant to our inherent power must have some nexus with the conduct of the litigation before the court." Such a connection exists in the context of immigration proceedings because, as noted above, we have jurisdiction over appeals from the immigration courts and rely on the records established in those courts.

III

It is ORDERED that Miguel Gadda, Esq. should be and hereby is disbarred from the practice of law before the United States Court of Appeals for the Ninth Circuit and his name shall be stricken from the roll of attorneys.

\section{Questions:}

1. When should the courts discipline attorneys like Gadda? What kind of discipline should they impose?

2. Why was Gadda disbarred? Is it possible that he provided some of his clients with competent representation? 
Dollars and Dreams: Immigrants as Prey

Rivlin, Gary

New York Times (1923-Current file); Jun 11, 2006; ProQuest Historical Newspapers: The New York Times pg. B1
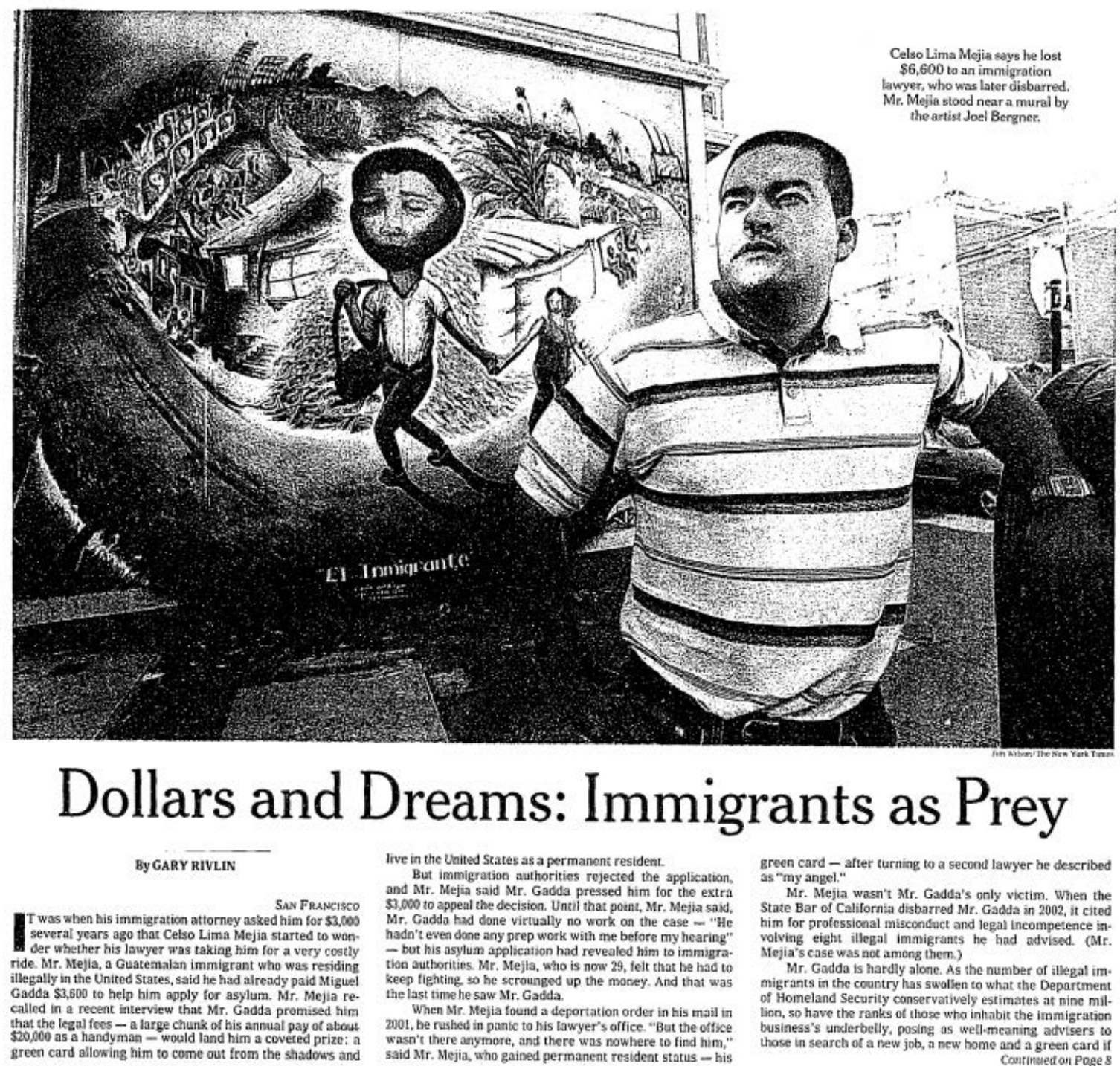
Iive in the United States as a permanent resident. and Mr. Mejia said Mr. Gaddas rejected the application. $\$ 3,000$ to appeal the decision. Until that point, Mr. Mejia said, $\mathrm{Mr}$. Gadda had done vittually no work on the case - "He hadn't even dane any prep work with me before my hearing" - but his asylum applicarion had revealed him to immigra ton authorities. Mr. Mejla, who is now 29 , felt that he had to keep fighting so he scrounged up the money. And that was When he saw Mr. Gadda.
When Mr. Mejia found a deportation order in his mail in wasn't there anymore, anis there wer's office, "But the ofrice said Mr. Mejia, who gained permanent resident status - his

\begin{abstract}
green card - after turning to a second lawyer he described
Mr. Mejia wasn't Mr. Gadda's only victim. When the him for profossional disbarred Mr. Gadda in 2002, it cited volving eight illegal immigrants he had advised. (Mr. (ejia's case was not among them.)

Mr. Gadda is hardly alone. As the number of allegal immigrants in the country has swolien to what the Department of Homeland Security canservatively estimates at nine millinn, so have the ranks of those who inhabit the immigration business's underbelly. posing as well-meaning advisers to Conrmeded on Poge 8
\end{abstract}

Avista Management vs. Wausau Underwriters Insurance Co. (M.D. FI. 2006)

This matter comes before the Court on Plaintiff's Motion to designate location of a Rule 30(b)(6) deposition. Upon consideration of the Motion ñ the latest in a series of Gordian knots that the parties have been unable to untangle without enlisting the assistance of the federal courts $\tilde{n}$ it is

ORDERED that said Motion is DENIED. Instead, the Court will fashion a new form of alternative dispute resolution, to wit: at 4:00 P.M. on Friday, June 30, 2006, counsel shall convene at a neutral site agreeable to both parties. If counsel cannot agree on a neutral site, they shall meet on the front steps of the Sam M. Gibbons U.S. Courthouse, 801 North Florida Ave., Tampa, 
Florida 33602. Each lawyer shall be entitled to be accompanied by one paralegal who shall act as an attendant and witness. At that time and location, counsel shall engage in one (1) game of "rock, paper, scissors." The winner of this engagement shall be entitled to select the location for the 30(b)(6) deposition to be held somewhere in Hillsborough County during the period July 1112 , 2006. If either party disputes the outcome of this engagement, an appeal may be filed and a hearing will be held at 8:30 A.M. on Friday, July 7, 2006 before the undersigned in Courtroom 3, George C. Young United States Courthouse and Federal Building, 80 North Hughey Avenue, Orlando, Florida 32801.

Jan Pudlow, 'Rock, paper, scissors' order garners worldwide attention, Florida Bar News (July 1, 2006)

Dutifully following a playful, but pointed, federal court order, Tampa lawyers David Pettinato, of the Merlin Law Group, and D. Lee Craig, of Butler Pappas, will meet June 20 and engage in one game of "rock, paper, scissors" to solve a dispute in the midst of heated litigation.

"We will do it quickly, humbly, and go on about our business," said a contrite Pettinato, who is amazed about "getting bombarded from news media from all over the country."

CNN, ABC, The Wall Street Journal, and The New York Times, to name a few.

Make that international news, as London's The Guardian also did its version of the everybody'stalking-about-it June 6 order issued by U.S. Middle District Judge Gregory Presnell, who was a member of The Florida Bar Board of Governors from 1989-93.

At issue was the childlike squabbling between the attorneys in Avista Management, Inc., vs. Wausau Underwriters Insurance Co., in litigation over an insurance settlement stemming from 2004's Hurricane Charley.

Even though the sparring lawyers' offices are only four floors apart in the same building at 777 S. Harbor Island Blvd. in Tampa, they could not agree on where to hold a deposition. Craig, representing Wausau, wanted to question a witness in his office. Pettinato, representing Avista, was not willing to let Craig have the home-court advantage, and insisted on a neutral setting of a court reporter's office down the street.

When they took the matter to the court, Presnell let them have it, fed up with "the latest series of Gordian knots that the parties have been unable to untangle without enlisting the assistance of the federal courts."

In what the judge called "a new form of alternative dispute resolution," Presnell ordered that each attorney will be "accompanied by one paralegal who shall act as an attendant and witness," and "the winner of this engagement shall be entitled to select the location for the 30 (b)(6) deposition to be held somewhere in Hillsborough County during the period July 11-12, 
2006. If either party disputes the outcome of this engagement, an appeal may be filed and a hearing will be held at 8:30 a.m. on Friday, July 7 , before the undersigned in Courtroom 3."

That creative order compelled St. Petersburg Times columnist Sue Carlton to nominate Presnell for "Jurist of the Year."

\section{NO NEED FOR AN APPEAL}

On June 8, Pettinato said that he and Craig have resolved the issue. Pettinato said both sides agreed to play rock, paper, scissors, at "an undisclosed location." Whoever wins will get to hold the deposition in his office.

"We want to do it out of respect for the judge's order," said Pettinato, who added, "I have to say I am a little disappointed that we couldn't resolve our differences without this court order. But it provided us with an eye-opener to resolve our differences in a more amicable way. Since the hurricanes, we have been having huge battles trying to get insurance companies to pay... . If you get a little too passionate advocating for your client, it helps to rethink your strategy."

The matter has been zinging across the state, around the country, and across the ocean, on news Web sites, lawyers' e-mails, and law blogs.

Orlando lawyer Lynn James Hinson, who called Presnell an excellent lawyer and judge, posted this comment on The Wall Street Journal's Law Blog: "Many lawyers act like they are in kindergarten, and this order treats them appropriately."

Craig, who did not return the News ' request for an interview, may be at a disadvantage. Pettinato has a kindergartner in the house, as the father of a 5-year-old and 9-year-old.

"I play it all the time with them. I can't say I'm an expert, but I know the rules," Pettinato said. "Now, my 5-year-old keeps throwing her hand out, saying, 'Dad, let's practice."”

Pettinato said his kids have advised him to open with rock, which he thought was apropos "because my case is solid as a rock."

But Matti Leshem, co-commissioner of the USA Rock Paper Scissors League, told The New York Times, "I guarantee you right now that both lawyers will open with paper. Lawyers open with paper 67 percent of the time, because they deal with so much paper."

Leshem agreed to officiate, saying, "What I don't want is some rogue element of rock-paperscissors coming down from the bench. When the law takes rock-paper-scissors into its own hands, mayhem can occur."

While Pettinato said he has greatest respect for the judge and "got the message," he is willing to laugh at himself, "or else l'll grow despondent." 
Taking it somewhat seriously is the World Rock Paper Scissors Society.

"This is a landmark case of how RPS should be used to keep the wheels of justice moving forward when dealing with lawyer engaging in posturing tactics," Doug Walker, managing director of the World RPS Society, told the News.

"Although we take issue with RPS being labeled as a 'new' form of dispute resolution, we understand it is not commonly used in courtrooms and applaud Judge Presnell's wisdom in the matter."

Noting that Rock, Paper, Scissors dates back to at least the 18th century in Japan, it was used to settle an auction-house dispute in April when "an $\$ 18$ million art portfolio was acquired by Christie's due to a cleverly executed throw of paper," over Sotheby's rock.

The World Rock Paper Scissors Society, Walker said, plans to invite Judge Presnell to attend the International Rock Paper Scissors Championships in Toronto on September 30, as "chief consultant to Head Referee Brad Fox."

No word yet on whether the judge will accept the invitation.

\section{Questions:}

1. Why did the court order Pettinato and Craig to resolve their dispute via a game of Roshambo?

2. Was the judge's decision justified and appropriate under the circumstances?

Auto-Owners Ins. Co. v. Summit Park Townhome, 886 F. 3d 863 (10th Cir. 2018)

Summary: Harris and Pettinato represented Summit Park in an action against AutoOwners. Summit Park was damaged by hail, but the parties disagreed about the amount of damage. The district court ordered them both to obtain independent appraisals. Harris and Pettinato retained Keys as their appraiser, but did not disclose their previous relationship with him. When the district court learned that Keys was not impartial, it sanctioned Harris and Pettinato. They appealed, but the circuit court affirmed.

BACHARACH, Circuit Judge.

Mr. William Harris and Mr. David Pettinato are two attorneys who represented Summit Park Townhome Association. While representing Summit Park against its insurer, the two attorneys were sanctioned for failing to disclose information. In this appeal, the attorneys challenge the sanctions based on five arguments:

1. The district court lacked authority to require the disclosure requirements. 
2. The attorneys did not violate the court's disclosure requirements.

3. The district court awarded attorneys' fees beyond the scope of an earlier sanctions order.

4. The district court's award of attorneys' fees resulted in a deprivation of due process.

5. The amount of attorneys' fees awarded was unreasonable.

We affirm. Regardless of whether the district court had authority to require the disclosures, the attorneys were obligated to comply. They did not, and the district court acted reasonably in issuing sanctions, determining the scope of the sanctions, and calculating the amount of the sanctions.

I. Mr. Harris and Mr. Pettinato were sanctioned for failing to comply with the disclosure order.

This appeal grew out of an insurance dispute. Summit Park sustained hail damage and filed a claim with its insurer, Auto-Owners Insurance Company. The parties agreed that damage had occurred but disagreed on the dollar amount of the damage. Auto-Owners sued for a declaratory judgment to decide the value.

Summit Park retained Mr. Harris and Mr. Pettinato, who successfully moved to compel an appraisal based on the insurance policy. In the event of an appraisal, the insurance policy required:

Each party will select a competent and impartial appraiser. The two appraisers will select an umpire. If they cannot agree, either may request that selection be made by a judge of a court having jurisdiction. The appraisers will state separately the value of the property and amount of loss. If they fail to agree, they will submit their differences to the umpire. A decision agreed to by any two will be binding.

Based on continuing disputes between the parties, Auto-Owners asked the district court to resolve these disputes by ordering an "appraisal agreement." The court did so and ordered disclosure of facts potentially bearing on the appraisers' impartiality:

An individual who has a known, direct, and material interest in the outcome of the appraisal proceeding or a known, existing, and substantial relationship with a party may not serve as an appraiser. Each appraiser must, after making a reasonable inquiry, disclose to all parties and any other appraiser any known facts that a reasonable person would consider likely to affect his or her impartiality, including (a) a financial or personal interest in the outcome of the appraisal; and (b) a current or previous relationship with any of the parties (including their counsel or representatives) or with any of the participants in the appraisal proceeding. Each appraiser shall have a continuing obligation to disclose to the parties and to any other appraiser any facts that he or she learns after accepting appointment that a reasonable person would consider likely to affect his or her impartiality. 
The court warned: "Notice is given that, if the court finds that the parties and/or their counsel have not complied with this order, the court will impose sanctions against the parties and/or their counsel pursuant to the court's inherent authority."

Before the court imposed these requirements, Summit Park selected Mr. George Keys as its appraiser. This selection led Auto-Owners to express doubt about Mr. Keys's impartiality. But Auto-Owners did not object to Mr. Keys or move to compel further disclosures.

Mr. Keys and the court-appointed umpire agreed on an appraisal award of over $\$ 10$ million, which was $47 \%$ higher than Summit Park's own public adjuster had determined. Auto-Owners then launched an investigation, which culminated in an objection to Mr. Keys. In the objection, Auto-Owners argued that Mr. Keys was not impartial and that Summit Park had failed to disclose evidence bearing on his impartiality. The district court credited these arguments, disqualifying Mr. Keys and vacating the appraisal award.

With vacatur of the appraisal award, Auto-Owners moved for sanctions against Mr. Harris and Mr. Pettinato, seeking attorneys' fees and expenses based on violation of the disclosure order. The district court granted the motion, assessing sanctions against Mr. Harris and Mr. Pettinato for $\$ 354,350.65$ in attorneys' fees and expenses.

II. Mr. Harris and Mr. Pettinato were bound by the court's disclosure order.

Mr. Harris and Mr. Pettinato challenge the district court's authority to enter the disclosure order. But even if the court had exceeded its authority, Mr. Harris and Mr. Pettinato would still have needed to comply with the disclosure order. If the two attorneys believed that the order had been unauthorized, they could have sought reconsideration or a writ; but they could not violate the order.

There is "impressive authority for the proposition that an order issued by a court with jurisdiction over the subject matter and person must be obeyed by the parties until it is reversed by orderly and proper proceedings." The parties agree that the district court had jurisdiction over the subject matter and parties; thus, the attorneys and parties bore an obligation to comply in the absence of an appellate challenge. In light of the duty to comply, violation of the order could trigger sanctions.

Regardless of whether the district court had authority to issue the disclosure order, Mr. Harris and Mr. Pettinato:

- bore an obligation to comply in the absence of an appellate challenge and

- could be sanctioned for noncompliance.

III. Mr. Harris and Mr. Pettinato violated the disclosure order. 
The district court concluded that the two attorneys had violated the disclosure order. Challenging this conclusion, Mr. Harris and Mr. Pettinato make two arguments:

1. The district court misinterpreted the term "impartial."

2. Mr. Harris and Mr. Pettinato disclosed sufficient information about Mr. Keys.

Both arguments fail.

B. Mr. Harris and Mr. Pettinato failed to disclose information specified in the disclosure order.

The district court required disclosure of:

- the appraiser's "financial or personal interest in the outcome of the appraisal,"

- Any "current or previous relationship" between the appraiser and Summit Park's counsel, and

- any other facts subsequently learned that "a reasonable person would consider likely to affect" the appraiser's impartiality.

1. Mr. Harris and Mr. Pettinato did not disclose the extent of their relationships with Mr. Keys. Regardless of whether the district court had correctly defined "impartial," the disclosure order itself was clear in what was required. For example, the order expressly required disclosure of the attorneys' current or previous relationships with the appraiser. The failure to disclose this information constituted a sanctionable violation regardless of the court's interpretation of the word "impartial."

The district court could reasonably find that the two attorneys had failed to disclose the extent of their relationships with Mr. Keys. For example, the attorneys failed to disclose that

- other attorneys in their law firm (the Merlin Law Group) had worked with Mr. Keys on appraisals for at least 33 clients,

- Merlin attorneys had represented Mr. Keys on various matters for over a decade,

- Merlin's founder and Mr. Keys had co-founded a Florida lobbying operation, whose "number one goal was to protect policyholders and the public adjusting profession," and

- Merlin attorneys had served as the incorporator and registered agent for one of Mr. Keys's companies.

Mr. Harris and Mr. Pettinato argue that their disclosures were sufficient. They made two disclosures:

1. "Mr. Keys does not have any significant prior business relationship with Merlin, Summit Park, or C3 Group. Mr. Keys has acted as a public adjuster and/or appraiser on behalf of policyholders that Merlin has represented in the past, however, this obviously does not affect his ability to act as an appraiser in this matter." 
2. "Mr. Keys has acted as a public adjuster and/or appraiser on behalf of policyholders that Merlin has represented in the past. Mr. Keys has no financial interest in the claim, and has no previous relationship with the policyholder in this matter."

In addition, Mr. Keys disclosed:

I do not have a material interest in the outcome of the Award and have never acted either for or against Summit Park Townhome Association. My fee agreement is based upon hourly rates plus expenses. I do not have any substantial business relationship or financial interest in Merlin. There have been cases where both Merlin and Keys Claims Consultants acted for the same insured but under separate contracts.

Mr. Harris and Mr. Pettinato make two defenses of their disclosures:

1. They disclosed enough information about Mr. Keys's impartiality.

2. Mr. Harris and Mr. Pettinato lacked personal knowledge about the undisclosed facts.

These arguments fail.

First, the district court acted within its discretion in concluding that Mr. Harris and Mr. Pettinato had failed to disclose the extent of their relationships with Mr. Keys. The two attorneys disclosed only that Mr. Keys had worked as an appraiser on behalf of Merlin's clients, and Mr. Keys stated that he lacked a substantial business relationship with Merlin. The district court could reasonably find that these disclosures had failed to provide meaningful information about the extent of the relationships between the two attorneys and Mr. Keys.

Second, Mr. Harris and Mr. Pettinato cannot avoid sanctions based on their asserted lack of knowledge about Mr. Keys's contacts with other Merlin attorneys. Mr. Harris and Mr. Pettinato knew about some of the contacts, as reflected in Mr. Pettinato's description of his firm's connection with Mr. Keys: "Both Mr. Keys and his staff have assisted me as well as my firm in resolving an untold number of large multi-million dollar losses to an amicable resolution and settlement to the policyholders' benefit and satisfaction." In addition, however, Mr. Harris and Mr. Pettinato bore an obligation to make "a reasonable inquiry." In light of this obligation, Mr. Harris and Mr. Pettinato could not profess ignorance while failing to inquire about contacts with other Merlin attorneys.

In these circumstances, the district court acted within its discretion in finding a failure to disclose the extent of the relationships between the two attorneys and Mr. Keys.

2. Mr. Harris and Mr. Pettinato distort the effect of the district court's definition of "impartial."

The district court required disclosure not only of the appraiser's relationship with counsel but also of known facts that a reasonable person would consider likely to affect the appraiser's 
impartiality. This part of the disclosure requirement was tied to the court's definition of the term "impartial."

Mr. Harris and Mr. Pettinato focus on the court's definition of "impartial," arguing that it was wrong and that the court failed to adequately inform Mr. Harris and Mr. Pettinato of the scope of their obligations. But in the disclosure order itself, the court stated what it meant by "impartial": "An individual who has a known, direct, and material interest in the outcome of the appraisal proceeding or a known, existing, and substantial relationship with a party may not serve as an appraiser." Because the court stated precisely what it meant by "impartial," Mr. Harris and Mr. Pettinato knew what was required. And as we have discussed, Mr. Harris and Mr. Pettinato could not disobey the order even if the court had based the disclosure requirements on a misguided definition of "impartial."

3. The district court reasonably found a violation of the disclosure order tied to this test of "impartial."

Based on this definition, the district court required disclosure of any facts that a reasonable person would view as likely to affect the appraiser's impartiality. Mr. Harris and Mr. Pettinato argue that evidence of an appraiser's advocacy was unlikely to affect the appraiser's impartiality. For the sake of argument, let's assume that Mr. Harris and Mr. Pettinato are right. Still, the district court could reasonably view Mr. Keys's undisclosed prior statements as likely to affect his impartiality based on a known, direct, and material interest in the outcome.

For example, in a presentation to a group of public adjusters in Florida, Mr. Keys taught participants how to "harvest the claim money" from an insurer during an appraisal. And one of Mr. Keys's companies maintains a website stating: "Our purpose is simple: To shift the balance of power from the insurer to the policy holder." The district court could reasonably view these undisclosed statements as proof of a material interest in an outcome favoring the policyholder over the insured.

Evidence also suggests that Mr. Harris and Mr. Pettinato were aware of Mr. Keys's bias. For example, in an advertisement on Mr. Keys's website, Mr. Pettinato endorsed Mr. Keys, saying: "Both Mr. Keys and his staff have assisted me as well as my firm in resolving an untold number of large multi-million dollar losses to an amicable resolution and settlement to the policyholders' benefit and satisfaction." And a profile on Merlin's website reported that Mr. Keys "had dedicated his professional life to being a voice for policyholders in property insurance claims." In this profile, Mr. Keys stated: "I was taught to always handle a claim as if my momma was the insured."

In sum, the district court did not abuse its discretion in finding that Mr. Harris and Mr. Pettinato had violated the disclosure order.

C. Waiver 
Mr. Harris and Mr. Pettinato contend that Auto-Owners waived its objection to the sufficiency of the disclosures by failing to object despite knowledge of Mr. Keys's relationship with Merlin and past expressions of bias toward policyholders. We disagree. Auto-Owners had some knowledge about Mr. Keys's bias but did not know much of what had been withheld. Without full knowledge of the undisclosed information, Auto-Owners did not waive its right to seek sanctions for nondisclosure.

IV. The district court reasonably interpreted the scope of its sanctions order.

In sanctioning the two attorneys, the court invoked 28 U.S.C. $\S 1927$. Under $\S 1927$, an attorney "who so multiplies the proceedings in any case unreasonably and vexatiously may be required by the court to satisfy personally the excess costs, expenses, and attorneys' fees reasonably incurred because of such conduct." Applying this statute in the sanctions order, the court found that Mr. Harris and Mr. Pettinato had unreasonably prolonged the proceedings:

I note that Section 1927 indicates a purpose to compensate victims of abusive litigation practices, not to deter and punish offenders. With this purpose in mind, I reject AutoOwners' request for fees for proceedings in this Court that relate to conducting the appraisal process and conducting the appraisal process itself because Auto-Owners would have incurred these fees regardless of Harris' and Pettinato's misconduct. I grant the request, however, as to Auto-Owners' investigation into George Keys and its objections to his participation in the appraisal, as this work would not have taken place in the absence of Harris' and Pettinato's misconduct. The award shall be assessed against Harris and Pettinato jointly and severally.

Mr. Harris and Mr. Pettinato challenge the scope of this order. They concede that the award covered Auto-Owners' objection to Mr. Keys $(\$ 186,705.50)$ and investigation of Mr. Keys $(\$ 33,805)$. But the attorneys disagree with the inclusion of attorneys' fees for

- Auto-Owners' preparation of the motion for sanctions $(\$ 51,309.50)$,

- Auto-Owners' preparation of the application for attorneys' fees and expenses $(\$ 16,960.50)$, and

- Auto-Owners' other related work $(\$ 61,662.50)$.

According to Mr. Harris and Mr. Pettinato, these activities fell outside of the initial sanctions order. We disagree.

In setting attorneys' fees following the sanctions order, the district court explained:

Thus, viewed properly in its context, my award encompasses any fees incurred as a result of Harris' and Pettinato's misconduct. The fees requested by Auto-Owners for work on the third amended petition, the reservation of rights letter, and other matters described in the detailed billing records would not have been incurred but for Harris' and Pettinato's misconduct. I therefore conclude they are within the scope of the award. 
We give deference to the district court's interpretation of its own order.

With such deference, we conclude that the district court reasonably interpreted its prior sanctions order. The sanctions order had noted that $\S 1927$ was designed "to compensate victims of abusive litigation practices." In light of this purpose, the court interpreted its sanctions order against Mr. Harris and Mr. Pettinato as encompassing all of the attorneys' fees and expenses resulting from violation of the disclosure order. This interpretation was reasonable.

The sanctions order expressly included the investigation of and objection to Mr. Keys. But the district court could reasonably interpret the sanctions order to go beyond the investigation and objection. If Mr. Harris and Mr. Pettinato had not violated the disclosure order, Auto-Owners would not have had to move for sanctions, seek attorneys' fees and expenses, and complete other work. As a result, the district court could reasonably consider these litigation expenses as the product of the two attorneys' misconduct. In these circumstances, it was reasonable for the district court to conclude that the earlier sanctions order had encompassed attorneys' fees and expenses from the motion for sanctions, application for attorneys' fees and expenses, and related work involving the motion and application.

V. The district court did not deprive the two attorneys of due process.

Alternatively, Mr. Harris and Mr. Pettinato assert a deprivation of due process based on an inability to respond to the district court's inclusion of litigation activities outside of the initial sanctions order. We disagree. Auto-Owners filed an application for attorneys' fees, and Mr. Harris and Mr. Pettinato had an opportunity to respond. In the response, they could have objected to any of the attorneys' fees being sought. This opportunity supplied due process.

VI. The amount of attorneys' fees awarded was reasonable.

Mr. Harris and Mr. Pettinato also argue that the court awarded an unreasonable amount of attorneys' fees. We disagree.

The district court closely reviewed the information in Auto-Owners' request for fees, determining that most of the fee requests were reasonable given

- the circumstances of the case,

- the hourly rates prevailing in the community, and

- the use of billing judgment.

First, the district court concluded that it was reasonable for Auto-Owners' counsel to spend long hours because "Auto-Owners had over $\$ 30$ million at stake" and the issues were complex. This conclusion was reasonable. 
Second, the court considered the local market, the qualifications of the attorneys, and the contentiousness of the litigation. These considerations led the district court to find that the billing rates had been reasonable. In our view, this finding was permissible under the record.

Third, the court considered the use of billing judgment by Auto-Owners' counsel through concessions such as staffing with lower-billing attorneys, declining to charge for all hours worked, and discounting hours worked by paralegals and secretaries. The district court acted reasonably in considering these concessions.

For these three reasons, we conclude that the district court did not abuse its discretion in calculating the amount of the sanction $(\$ 354,350.65)$.

VII. Conclusion

The district court did not err in sanctioning Mr. Harris and Mr. Pettinato. Regardless of the validity of the disclosure order, compliance was required in the absence of an appellate challenge. Mr. Harris and Mr. Pettinato violated the order by failing to disclose information bearing on Mr. Keys's impartiality. In light of this violation, the district court had the discretion to sanction Mr. Harris and Mr. Pettinato and set a reasonable amount. We therefore affirm the assessment of sanctions.

\section{Questions:}

1. Why was it improper for Harris and Pettinato not to disclose their previous relationship with Keys?

2. Could Harris and Pettinato have hired Keys as their expert, if they made the proper disclosures?

\section{Further Reading:}

- Benjamin Edwards, The Professional Prospectus: A Call for Effective Professional Disclosure, W\&L L. Rev. (forthcoming)

\section{Further Listening:}

- Benjamin Edwards on Improving the Market for Professional Services, Ipse Dixit, March 19,2019 


\section{3: Attorney Misconduct}

Walking the line, you were a marksman. Told me that law, like wine, is ageless. Public defender, you had to admit, you wanted the love of a sex offender. ${ }^{94}$

In addition to their disciplinary authority under Federal Rule of Civil Procedure 11 and Model Rule of Professional Conduct 3.1, courts have the "inherent authority" to regulate the conduct of attorneys and punish attorney misconduct. This inherent authority is recognized by both state and federal courts, and is not derived from any particular state or rule. Rather, it is a function of the need for courts to "manage their own affairs." As the Supreme Court observed in Chambers v. Nasco, Inc., 501 U.S. 32 (1991):

It has long been understood that certain implied powers must necessarily result to our Courts of justice from the nature of their institution, powers which cannot be dispensed with in a Court, because they are necessary to the exercise of all others. For this reason, Courts of justice are universally acknowledged to be vested, by their very creation, with power to impose silence, respect, and decorum, in their presence, and submission to their lawful mandates. These powers are governed not by rule or statute but by the control necessarily vested in courts to manage their own affairs so as to achieve the orderly and expeditious disposition of cases.

The inherent authority of a court is non-exclusive of any statutes or rules that prohibit the same or similar conduct, and courts may use their inherent authority to punish conduct that would fall outside the scope of otherwise applicable statutes of rules. Among other things, courts can use their inherent authority to punish attorneys for conduct that is abusive, vexatious or in bad faith. For example, as the Supreme Court observed in Chambers:

A court may assess attorney's fees when a party has acted in bad faith, vexatiously, wantonly, or for oppressive reasons. In this regard, if a court finds that fraud has been practiced upon it, or that the very temple of justice has been defiled, it may assess attorney's fees against the responsible party, as it may when a party shows bad faith by delaying or disrupting the litigation or by hampering enforcement of a court order. The imposition of sanctions in this instance transcends a court's equitable power concerning relations between the parties and reaches a court's inherent power to police itself, thus serving the dual purpose of vindicating judicial authority without resort to the more drastic sanctions available for contempt of court and making the prevailing party whole for expenses caused by his opponent's obstinacy.

\section{The Inherent Authority of the Court}

${ }^{94}$ Blondie, X Offender, Blondie (1976). 


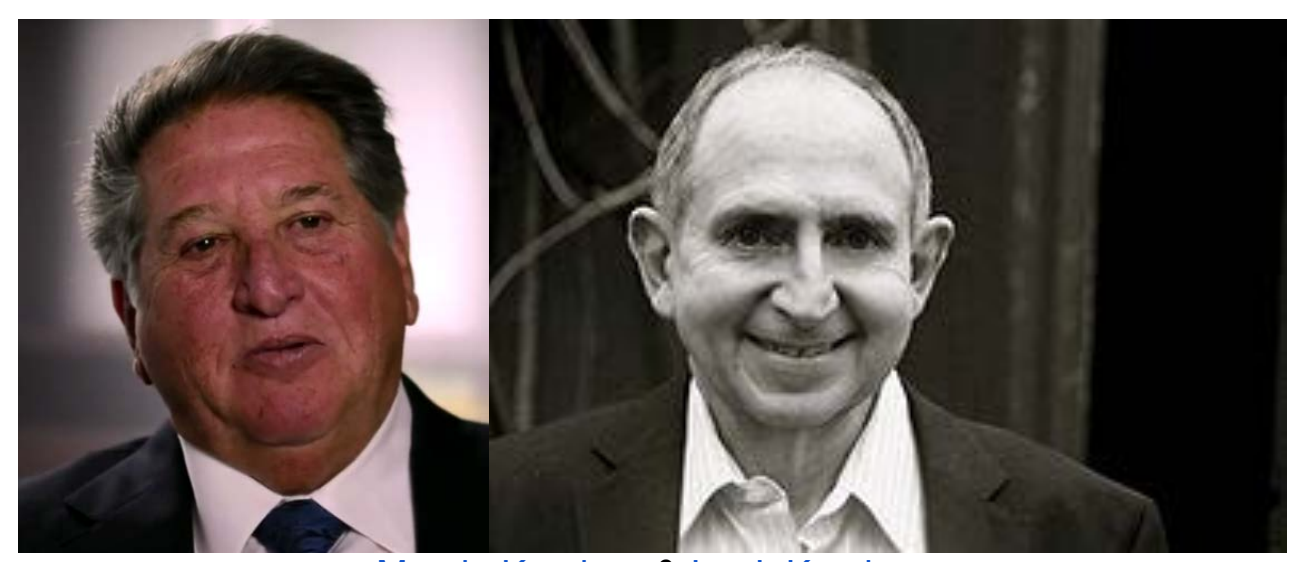

Marvin Kurzban \& Ira J. Kurzban

Lee v. American Eagle Airlines, Inc., 93 F. Supp. 2d 1322 (S.D. Fla. 2000)

MIDDLEBROOKS, District Judge.

Summary: Marvin and Ira Kurzban represented Anthony Lee in an employment discrimination action against American Eagle Airlines, alleging racial discrimination. The found for Lee on his hostile work environment claim and awarded him $\$ 300,000$ in compensatory damages and $\$ 650,000$ in punitive damages, but denied Lee's claim for termination on account of his race. The Kurzbans filed motion seeking $\$ 1,611,910.50$ in attorney's fees and costs. The district court criticized their conduct during the trial, and relied on its inherent authority to award only $\$ 312,324.63$ in attorney's fees and costs. In addition, it reported their conduct to the Florida Bar.

This Cause came before the Court upon Plaintiff's Amended Verified Motion for Attorney's Fees and Costs.

\section{Introduction}

"Let's kick some ass," Marvin Kurzban said loudly to his client, Anthony Lee, and his co-counsel, Ira Kurzban. I had taken the bench, and Court was in session. Opposing counsel and their client representatives were seated across the aisle. The jury was waiting to be called into the courtroom. Mr. Kurzban's comment was suited more to a locker room than a courtroom of the United States, and the conduct of Plaintiff's counsel that followed disrupted the adversary system and interfered with the resolution of a civil dispute.

The trial of this case lasted approximately fourteen days. The jury found that American Eagle Airlines had subjected Mr. Lee to a racially hostile work environment. As compensation, the jury awarded Mr. Lee $\$ 300,000$. In addition, the jury awarded Mr. Lee $\$ 650,000$ in punitive damages. The jury denied Mr. Lee's other claim, finding that Mr. Lee had not been terminated because of his race. This motion seeking attorney's fees and costs followed. 
As the prevailing party in a Title VII action, the Plaintiff now seeks $\$ 1,611,910.50$ in attorney's fees. This request presents the question of whether unprofessional and disruptive conduct of counsel which prolongs the proceedings and creates animosity which interferes with the resolution of a cause can be considered in determining an award of attorney's fees.

In their post-trial motions, counsel for the parties filed opposing affidavits concerning additional misconduct that was not directly observed by the Court. Since these affidavits presented vastly different versions of events, an evidentiary hearing was held; counsel and other witnesses testified.

These issues have been distasteful and time consuming. There is a great temptation to simply move on and ignore the issue. It is unpleasant to hear lawyers accusing each other of lies and misrepresentations. Unprofessionalism on the part of lawyers is a distraction and takes time away from other pending cases; it also embroils the Court in charges and counter charges. However, the functioning of our adversary system depends upon being able to rely upon what a lawyer says. So, confronted by affidavits of counsel that were directly contradictory, I decided to hear testimony and make credibility findings. These findings are based upon direct observations by the Court, the transcript of the trial, and the evidentiary hearing.

In addition, we contacted the Florida Bar to determine whether counsel had been the subject of complaints regarding unprofessional conduct. The Florida Bar forwarded a record of a previous complaint by a state court judge concerning the conduct of Marvin Kurzban. In response to that complaint, and immediately before the trial in this cause, the Florida Bar had directed Mr.

Kurzban to attend an ethics class and pay a fine.

\section{Findings of Fact Pertaining to Misconduct by Counsel}

Discovery in this case was rancorous from the beginning. As is often the case, counsel for both sides contributed to the lack of civility. The tone of depositions was harsh, witnesses were treated with discourtesy, and discovery disputes were abundant. The transcripts of the depositions in this case are weighted down with bitter exchanges between the lawyers.

Testimony at the evidentiary hearing reflected that this uncivil conduct also continued during conversations between counsel. The testimony of a young lawyer formerly with the Defendant's counsel's law firm was particularly poignant. This lawyer testified that during telephone conversations with Ira Kurzban, she was hung up on, told that she had only been assigned to work on the case because she was African-American, and wrongly accused of misrepresentations. She testified that her experience with opposing counsel in this case was a factor in her decision to leave her litigation practice.

This testimony was not only powerful and credible, but it also reflects the corrosive impact this type of unprofessional behavior can have upon the bar itself. A litigation practice is stressful and often exhausting. Unprofessional litigation tactics affect everyone exposed to such behavior and the ripple effect of incivility is spread throughout the bar. 
The trial began. Testimony at the evidentiary hearing reveals that Mr. Kurzban's "Let's kick some ass" comment was not an aberration. A client representative of the Defendant, a lawyer for American Airlines, testified that she and others were subjected to a barrage of comments out of the hearing of the Court and jury which she likened to trash talk at a sporting event. Local counsel for the Defendant was called a "Second Rate Loser" by Marvin Kurzban. She testified that each day as court began, Marvin Kurzban would say, "Let the pounding begin." In front of defense counsel's client, Mr. Kurzban would ask, "How are you going to feel when I take all of your client's money?" When walking out of the courtroom, Marvin Kurzban would exclaim, "Yuppies out of the way."

Other than Mr. Kurzban's opening comment, I was unaware of this conduct towards opposing counsel and their client's representatives, although counsel for the Defendants alluded to it during the trial. However, I observed continuing misconduct during the trial itself.

Early in the trial, an episode occurred when defense counsel brought to the Court's attention that after an instruction to a witness not to discuss his testimony during a break in his testimony for lunch, Ira and Marvin Kurzban had approached the witness and had a discussion - with an open deposition transcript in hand. Marvin Kurzban responded, "That's a lie." The Kurzbans then explained that they had the transcript open because they were looking at it, but that they were not talking with the witness about it. Their explanation was that they were talking about where they were going for lunch. I accepted the explanation, but with the observation that it was an exercise of poor judgment. (Tr. 324-325).

Shortly afterward, Marvin Kurzban objected to a question, and I overruled his objection. He continued to argue his point, then he visibly expressed his dismay with the ruling. I asked counsel to approach for a sidebar conference, wherein I advised him that for the third time he had made visible displays of disagreement with rulings by nodding his head or looking upward at the ceiling. I told him to stop that conduct and to cease making speaking objections.

Subsequently, I warned both counsel again; once before the jury, and again at the close of the mornings testimony. Ira Kurzban responded that he was way beyond acrimony with opposing counsel.

After this warning, defense counsel followed the Court's admonition and refused to respond to provocations from opposing counsel. Later than day, Marvin Kurzban interrupted an appropriate cross-examination and requested a sidebar to accuse counsel of intentionally delaying the examination so that he could not reach a witness.

Despite repeated warnings, Plaintiff's counsel continued to address comments to opposing counsel rather than to the Court and interject inappropriate comments before the jury. 
The belligerence of Plaintiff's counsel, particularly Marvin Kurzban, spread like a contagion through the courtroom. On September 22, 1999, I returned to the bench after a luncheon break. Marvin Kurzban wanted to raise a matter prior to the jury's return.

Mr. Kurzban stated:

I am concerned about the record, Your Honor. I went over to the ... Mr. Reporter there, when we took the first break, and asked him about the ability to get a page typed. And instead I ended up having names called at me and a confrontation. I only bring it to the Court's attention because I am concerned about the record being clear. I feel this Court Reporter for whatever reason ... I don't know the gentlemen, never met him before - is either unstable based on his reaction and not competent to be reporting or has some bias.

At the next recess, I asked the Court Reporter what had happened. He indicated that at the break, which was a brief break for him inasmuch as we had a calendar call scheduled during that luncheon break, Marvin Kurzban asked him for a portion of transcript. The reporter responded that he could not produce those pages over the break (because he had to report the calendar call). Marvin Kurzban responded, "What are you here for, just to look pretty?" The Court Reporter responded with an epithet, at which point Marvin Kurzban remarked, "We're not talking about your family." Then Mr. Kurzban said, "I guess money talks," suggesting that since the Defendant was ordering daily copy, the reporter was biased in their favor. At that point, the Court Security Officer intervened.

I required the Court Reporter to apologize for his behavior. Because of the accusation of bias, I arranged for other Court Reporters to cover the remainder of the trial.

I learned that accusations of bias followed any disagreement with positions espoused by Plaintiff's counsel: "There's no question that he's entitled to it, so it's no - if I understand what Your Honor's saying, you don't want it to go in front of the jury for whatever reason." "Your Honor, I know you're angry at me, but I hope you're not taking it out on my client." "In fact, I think that the Court has exhibited extreme bias in this case and your rulings on objections." "Well, Your Honor, I respectfully disagree with you, that's for a court of appeals ultimately to decide, but to put a motive on it I think it exhibits a substantial amount of bias on behalf of Your Honor." "And I concur with what my brother has said. There's been clear animus by this Court to this side." "I've practiced 26 years and l've tried over 50 cases, and I've won multimillion dollar verdicts on more than a dozen cases. I don't need for this Court to allow a witness to have his wife introduced. I can't think of any reason or purpose, other than prejudice, that this Court would allow such an act to occur."

Disturbing behavior by both Marvin Kurzban and Ira Kurzban occurred repeatedly during the trial. When confronted about their conduct, they would deny that which I had just observed and then lash out in a personal attack. For instance, after I overruled an objection made by Ira Kurzban, Marvin Kurzban laughed. Other examples of their conduct following rulings include 
Marvin Kurzban tossing a pen; Ira Kurzban exclaiming, "This is outrageous"; the rolling of eyes; exasperated looks at the ceiling; and flailing of arms. I warned counsel about this behavior.

After the episode of Marvin Kurzban laughing at my ruling, I asked counsel to approach the bench. Marvin Kurzban responded: "I didn't laugh. What I started doing was writing a note, saying to my brother ... I didn't realize I was saying it out loud - we're not trying his case. That's what the objection was, because he's telling about his problems." Ira Kurzban then interjected: "I'd like to add, Your Honor, there's a continuing pattern of conduct we believe shows enormous bias and has turned this trial into a circus-like atmosphere."

Ira Kurzban then listed a litany of complaints about rulings which he stated should result in a mistrial. (When offered a mistrial, the Plaintiff declined.) Defense counsel and the Court Security officer also heard a laugh.

Shortly thereafter, during a discussion between the Court, Marvin Kurzban, and defense counsel about the admissibility of an exhibit a witness had allegedly drawn during a videotaped deposition but which was not on the Plaintiff's exhibit list, Ira Kurzban walked to the video machine and begin playing the videotape of the deposition in front of the jury. I directed that the machine be turned off and we took a fifteen minute break.

After the break, defense counsel raised the issue and requested some sanction. I asked Ira Kurzban for an explanation. He responded:

Mr. Kurzban: Yes, Your Honor. First, Mr. Connor asked me not to tamper with the tape now, because you were going to come out and rule. I assume he didn't have any ex parte communication with you. I'm a little perturbed about the fact that somehow he knew you were coming out to make a ruling, which I was totally unaware.

The Court: I think he knew that I was coming back after a 15 minute break. There has been absolutely no contact between me and Mr. Connor or any other lawyer in this case between the time I left the bench 15 minutes ago and when I returned now. Now, is there some reason why you would make that accusation?

Ira Kurzban: Yes, Your Honor.

The Court: All right. What was it?

Ira Kurzban: Mr. Connor said the Judge is going to come out here, he's going to impose some sanction. That's what Mr. Connor said, Your Honor, you are not here.

I'm simply saying that's what Mr. Connor did. I'm not accusing you of anything. We can have the marshal testify that I should not touch the tape because you were going to impose sanctions.

The Deputy: No, no.

The Court: The marshal is nodding no. Mr. Marshal?

The Deputy: No mention of sanctions was ever made.

Mr. Kurzban then stated that he had put the tape into the machine so that it would be ready if needed and that the tape began playing accidentally. I accepted his explanation but stated: 
If I can't rely on lawyers being able to respect each other and be respected and accept what other people say in the courtroom, this system can't work. It's as important to me as whether or not you have a law degree. I'm beginning to really have a problem with what you are telling me is happening, based on what l'm seeing and what others in the courtroom are seeing. So you all really need to think about that.

During a cross-examination concerning how much time the witness spent on various shifts, Marvin Kurzban held a file towards the witness and asked:

Marvin Kurzban: I have your personnel file (indicating). How many times did you have to work between 1992 and 1994, sir? Do you think it was more than a handful of times?

After an objection, and out of the presence of the jury, I asked Mr. Kurzban for the witness's personnel file. He responded:

Marvin Kuzban: Actually, we do have Mr. Blades's personnel file, when it was produced among all the other personnel files in Miami of the people. I don't know if that box is here or I left it in the office. I think the personnel files that we were given by counsel is in the office.

The Court: So it wasn't in the folder that you picked up and carried to the stand? Marvin Kurzban: No it wasn't, Your Honor.

The Court: You said, :Mr. Blades, we have your personnel file here!" You believe it is permissible to pick up a file from your desk, carry it to the witness stand and tell the witness "Mr. Blades, we have your personnel file," and then begin questioning him? You believe that's appropriate court examination?

Marvin Kurzban: I do, on hostile witnesses; on cross-examination, I believe that I'm entitled to have that witness believe l'm going to question him on something whether or not I have that in my hand or not. Yes, I do.

The Court: I believe, frankly, that it is inappropriate to make a deliberate misrepresentation to a witness or to ask, implying in your questioning something that is not true.

Marvin Kurzban: Neither was I implying something that wasn't true, nor was I making a misrepresentation. The question was about how many times he worked, Your Honor. The question wasn't: In your personnel file it says something. I didn't make any such misrepresentation.

Mr. Kurzban insisted that he had the personnel file back at his office. He was asked to produce it and he responded that he would the following day. The file was never produced.

At the end of the trial, defense counsel Connor approached Ira Kurzban and offered his hand in congratulations. Mr. Kurzban refused to shake his hand. The trial ended much like it had begun. 
At the evidentiary hearing, Plaintiff's counsel were unrepentent, attacking opposing counsel and accepting no responsibility for their own actions. They argued that the perceived misconduct was only a matter of style and the exercise of first amendment rights. In keeping with that "style," Marvin Kurzban ended the hearing with the proclamation that he had called his opponent a loser, but not a second-rate loser because, "I don't rate losers." Mr. Kurzban's testimony reflects that he has no clue about what it means to be a lawyer.

\section{Analysis}

Courts presiding over civil rights actions may, in their discretion, award the prevailing party a "reasonable attorney's fee (including expert fees)" as part of its costs. Although the presiding court has discretion, a prevailing plaintiff is to be awarded attorney's fees "in all but special circumstances." This presumption in favor of awarding attorney's fees is a reflection of Congress' clear intent to "cast the Title VII plaintiff in the role of 'a private attorney general,' vindicating a policy of the highest priority." By awarding prevailing plaintiffs their attorney's fees, the section "makes it easier for a plaintiff of limited means to bring a meritorious suit."

Courts determining attorney's fee awards begin by determining the "lodestar": the product of the number of hours reasonably expended on the litigation and a reasonable hourly rate for the attorney's services. This lodestar may then be adjusted for the results obtained.

\section{The reasonable hourly rate}

"A reasonable hourly rate is the prevailing market rate in the relevant legal community for similar services by lawyers of reasonably comparable skills, experience, and reputation." The party seeking attorney's fees, in this case Mr. Lee, bears the burden of producing "satisfactory evidence that the requested rate is in line with prevailing market rates." To be satisfactory, evidence must consist of "more than the affidavit of the attorney performing the work."

Prior to adoption of the lodestar formula, the so-called "Johnson factors" governed fee awards. Although the lodestar formula has since displaced the "Johnson factors," the Eleventh Circuit has permitted district courts to consider the factors in establishing a reasonable hourly rate. Among those factors is the experience, reputation, and ability of the attorneys and the skill requisite to perform the legal service properly. As explained more fully in the findings of misconduct, the conduct of Ira Kurzban and Marvin Kurzban both during and prior to trial was very troubling. In my estimation, the manner in which a lawyer interacts with opposing counsel and conducts himself before the Court is as indicative of the lawyer's ability and skill as is mastery of the rules of evidence. Upon review of the trial transcripts and the evidence presented during the evidentiary hearing on attorney conduct and based on observations at trial, I find that the conduct of Ira Kurzban and Marvin Kurzban in the litigation of this case fell far below acceptable standards, especially in light of the $\$ 300$ hourly rate the attorneys claim.

Accordingly, I find "special circumstances" justifying a departure from counsels' requested rates: Ira Kurzban shall be awarded $\$ 150$ per hour for his pretrial work and $\$ 0$ for his trial work; Marvin Kurzban's rate for this action is $\$ 0$. 
For further support of the above rate reductions, we rely upon our "inherent power" to sanction attorney misconduct. "It is well-established that "certain implied powers must necessarily result to our Courts of justice from the nature of their institution,' powers 'which cannot be dispensed with in a Court, because they are necessary to the exercise of all others.' For this reason, 'Courts of justice are universally acknowledged to be vested, by their very creation, with power to impose silence, respect, and decorum, in their presence, and submission to their lawful mandates.' These powers are 'governed not by rule or statute but by the control necessarily vested in courts to manage their own affairs so as to achieve the orderly and expeditious disposition of cases."

Among these powers is the contempt sanction, "which a judge must have and exercise in protecting the due and orderly administration of justice and in maintaining the authority and dignity of the court." "The inherent power of a court to manage its affairs necessarily includes the authority to impose reasonable and appropriate sanctions upon errant lawyers practicing before it."

A finding that counsels' conduct "constituted or was tantamount to bad faith" must precede any sanction levied pursuant to a court's inherent powers. The Court of Appeals for the Second Circuit requires that bad faith be shown by (1) "clear evidence" or (2) "harassment or delay or other improper purposes." Where imposed for the purpose of deterring misconduct rather than remedying some prejudice, as here, the District of Columbia Circuit has held that sanctions must be supported by "clear and convincing evidence" of "flagrant or egregious misconduct." Before imposing a severe sanction based on principles of deterrence, a district court must consider whether a lesser sanction is more proportionate to the misconduct.

In this case, we are imposing a lesser sanction. We did not dismiss this case, but rather permitted it to go the jury. Moreover, although counsel were warned during the trial that further disruptive conduct would be a basis for criminal contempt, that sanction was not employed. We have also elected not to deny Plaintiff's fee request altogether, though we are reducing it significantly. Additionally, our sanction is supported by "clear and convincing" evidence of "flagrant or egregious" misconduct demonstrating counsels' "bad faith." In assessing attorney misconduct, the Court had the benefit of an exhaustive evidentiary hearing concerning attorney misconduct and trial transcripts replete with examples of unprofessional behavior. Most significantly, much of the misconduct in this matter occurred before the Court. Plaintiff's counsels' continued misbehavior in the face of repeated verbal reprimands and warnings that the Court intended to revisit counsels' misconduct at a later date demonstrated counsels' "bad faith."

There is precedent for denying a party attorney's fees to which it was otherwise statutorily entitled as a sanction for attorney misconduct. In Litton Sys., Inc. v. American Tel. and Tel. Co., the Second Circuit Court of Appeals affirmed the district court's denial of attorney's fees to a prevailing plaintiff in an antitrust suit. The plaintiff was entitled to its costs and fees under, among other provisions, the Clayton Act. Though the Litton court based its decision on its power 
to sanction disobedience of court orders under Federal Rule of Civil Procedure 37(b), it noted that "given the court's express findings of bad faith, it could also have imposed sanctions on the plaintiff as an exercise of its inherent powers."

In addition, the Court reduces the rates sought by Plaintiff for associate work. Magistrate Judge Barry L. Garber recently found, by order dated May 5,1999 , that $\$ 125$ was a reasonable hourly rate for associates. Magistrate Judge Stephen T. Brown, in a recommendation dated August 17, 1999 , noted that the parties agreed to an hourly rate of $\$ 125$ for associates. Accordingly, the Court finds that $\$ 125$ is the prevailing hourly rate in the Southern District for associate work. Thus, the work of Brian Torres, Raquel Libman, Jed Kurzban, and Florence Zolin shall be billed at a rate of $\$ 125$ per hour. Peter Hoffer, who has eight years of civil rights litigation experience, shall be billed at $\$ 175$.

\section{The number of hours reasonably expended}

Defendant argues that not all of the 3,269.54 hours claimed by Plaintiff were "reasonably expended." Specifically, Defendant contends that Plaintiff claims hours from another case, which are not compensable in this matter, and that Plaintiff did not exercise proper billing judgment.

\section{i. Hours spent on another case}

Defendant points out that although Plaintiff initiated the action before this Court on March 21, 1997, Plaintiff has submitted time records with dates as early as August 1994. Defendant surmises that many of these entries are for work done on other cases and thus are not compensable. Plaintiff replies that the Kurzban firm had begun representing Mr. Lee in 1994, before the firm's formal retention by Mr. Lee and commencement of this action, and that the work underlying these entries was the basis for Plaintiff's hostile environment claim. Initially, Ira Kurzban represents that he advised Mr. Lee and other black mechanics at American Eagle who complained of racism at American Eagle, then Flagship Airlines. Thereafter, Mr. Kurzban assisted Plaintiff in his negotiations with American Eagle and in his claims before the Equal Employment Opportunity Commission.

Kurzban, Kurzban et al. may collect fees for legal services it provided Mr. Lee prior to commencement of this action or its formal retention by Mr. Lee. Defendant does not seem to contest this, but rather asks the Court to strike those hours it claims were clearly not spent on matters related to this case.

We begin by striking those entries, dated prior to the commencement of this action, that appear to relate to motions practice and other matters in a pending lawsuit or which do not seem sufficiently related to this action. These entries add up to 137.15 hours. In addition, the Court reduces by $50 \%$ the remaining hours claimed between August 10, 1994 and January 2, 1997. We find Plaintiff's documentation to be inadequate for purposes of demonstrating that these hours were reasonably expended in the litigation of this matter. While the information gathered 
at this stage was likely helpful in the eventual litigation of Mr. Lee's claims, the information was being gathered for other purposes. Accordingly, the Court is not convinced that all the time claimed, or even most of it, was reasonably expended in the pursuit of Mr. Lee's claims.

ii Billing judgment

Fee applicants must exercise "billing judgment." That means that they must exclude from their fee applications "excessive, redundant, or otherwise unnecessary hours," which are hours "that would be reasonable to bill to a client and therefore to one's adversary irrespective of the skill, reputation or experience of counsel." Defendant maintains that further reductions are warranted based on Plaintiff's counsels' time and record keeping practices. Vague entries, according to Defendant, preclude the Court from determining that hours were reasonably expended, and cannot be cured by Plaintiff's counsel's post hoc, hand-written notes. Defendant also contests counsels' repetitious charges, claims for hours spent by attorneys "getting up to speed," and excessive time spent on certain activities.

While wary of counsels' after-the-fact, clarifying notes, the Court does not ignore the added detail and takes counsel at their word that the additions are supported by reference to red books, pertinent files, and their own memories. The Court is more concerned about the excessive number of hours billed in this case in light of its nature. This case involved racial harassment endured by a single plaintiff at a single site of employment. Although this matter was hotly contested, due in large part to overzealousness on both sides, the $\$ 1,611,910.50$ in fees sought by Plaintiff's counsel based on 3,269.54 hours is clearly excessive. This view is supported by a review of recent awards in employment discrimination cases in the Southern District, which the Court may consider under Johnson. This case was not so much more lengthy or complex than these cases to justify such a grossly disproportionate award. Indeed, Judge Hurley, following a eight-day trial, awarded $\$ 191,524.75$ in attorneys' fees. The award followed a jury verdict in favor of the plaintiff on her sexually hostile work environment and retaliation claims.

To account for the excessive number of hours claimed in this case, we reduce Plaintiff's counsels' hours by $40 \%$ across-the-board. In addition, the Court reduces by one-third Ira Kurzban's non-contemporaneous October 8, 1998 entry, allotting 30 hours to the reading of "all new 11 th Circuit cases on employment discrimination related to case" over the past six months.

\section{The lodestar figure}

\section{i. Reasonable hours}

For the period August 10, 1994 to January 2, 1997, after deleting hours unrelated to this litigation, the Court recognizes 106.4 hours. We then reduce that figure by $50 \%$, as explained above, for Plaintiff's failure to establish that those hours were spent on matters sufficiently related to this litigation, leaving 53.2 hours. All but one of these hours was billed to Brian Torres or Raquel Libman; the other hour was billed to Ira Kurzban. For the period January 2, 1997 to 
September 14,1999 , the date the trial began, we recognize the following hours: $1,879.85$ hours for Ira Kurzban; 682.24 hours for Raquel Libman; 669.2 hours for Peter Hoffer; 28.6 hours for Jed Kurzban; and 12 hours for Florence Zolin. Finally, for the trial period, we credit 81.7 hours to Jed Kurzban.

Next the Court cuts counsels' hours by $40 \%$ across-the-board for the period January 2, 1997 through trial, having found, upon review of counsels' billing records and other employment discrimination cases in the District, counsels' claimed hours to be excessive:

- Ira Kurzban: $1,879.85 \times .6=1,127.91$ hours

- Raquel Libman: $682.24 \times .6=409.34$ hours

- Peter Hoffer: $669.2 \times .6=401.52$ hours

- Jed Kurzban: $(28.6+81.7) \times .6=66.18$ hours

- Florence Zolin: $12 \times .6=7.2$ hours

ii. Multiplied by the reasonable hourly rates

$\begin{array}{ll}\text { Associates: } & 534.92[13] \times \$ 125=\$ 66,865 \\ \text { Peter Hoffer: } & 401.52 \times \$ 175=\$ 70,266 \\ \text { Ira Kurzban: } & 1,128.91[14] \times \$ 150=\$ 169,336.50 \\ \text { Final lodestar: } & \$ 306,467.50\end{array}$

4. The results obtained

As noted above, the lodestar may then be adjusted for the results obtained. This factor is particularly important where, as here, Plaintiff is deemed "prevailing" even though he succeeded on only one of his claims for relief.

The Court finds that as in many civil rights cases, Plaintiff's claims involve a common core of facts and related legal theories. Accordingly, the Court does not treat Plaintiff's suit as a series of discrete claims, readily separated for purposes of apportioning hours between prevailing and non-prevailing claims. Rather, the Court focuses on the overall results achieved by Plaintiff in relation to the hours reasonably expended by Plaintiff's counsel on the litigation. Having done this, the Court finds that Plaintiff achieved only limited success, rendering the product of the hours reasonably expended on the litigation as a whole and the reasonable hourly rates an excessive fee recovery. While Plaintiff's recovery on his hostile environment claim was significant, he was unable to convince the jury that he had been discharged based on his race. Moreover, the Court dismissed on summary judgment Plaintiff's claims for intentional and negligent infliction of emotional distress, as well as his state civil rights claims. At trial, the Court granted Defendant's Motion for Judgment as a Matter of Law on Plaintiff's claims of negligent training, retention, and supervision. Even though Plaintiff's claims were "interrelated, nonfrivolous, and raised in good faith," we may reduce the lodestar to account for his limited success. 
For guidance in reducing the lodestar, we turn to Bohen v. City of E. Chicago, a case involving similar facts: plaintiff prevailed on her sexual harassment claim, but failed on her discriminatory discharge claim. Judge Easterbrook, sitting by designation, reduced the plaintiff's fees to account for her limited success, but did so only by $10 \%$ across-the-board. He noted that the same witnesses dealt with both aspects of the case and that since the claimed harassment was extensive, it would have been necessary to examine the plaintiff's whole period of employment even without the discharge claim. Noting that at least some time was spent solely on the discharge claim, though he could not say precisely how much, Judge Easterbrook concluded that the plaintiff's counsel would have spent about $90 \%$ of the time it did had there been no discharge claim. The same reasoning applies here. However, the Court awards Plaintiff $80 \%$ of the lodestar, estimating that $20 \%$ of Plaintiff's counsels' time was devoted exclusively to the discharge claim. Specifically, the Court finds that significant time was spent by Plaintiff examining Defendant's alleged early release program, which was only tangentially related to the hostile environment claim.

Final lodestar figure adjusted for results obtained: $\$ 306,467.50 \times .8=\$ 245,174$

\section{Costs}

The Court recognizes that the traditional limits on what costs may be taxed,do not apply to requests submitted under $\S 1988$ and that the Eleventh Circuit traditionally takes a liberal approach when reimbursing attorney expenses. However, Plaintiff still bears the burden of submitting a request for expenses that would enable the Court to determine what expenses were incurred and whether Plaintiff is entitled to them. Plaintiff's entries for photocopy, telephone, and fax charges are wholly devoid of explanation. The Court has no way of knowing whether the rates paid for the photocopies were reasonable or even whether these expenses were related to this action. Therefore, the Court will not tax these costs or others that lack description. Moreover, the Court finds that the costs incurred prior to commencement of the action are not taxable.

Having deleted expenses associated with the above-described entries, we tax $\$ 67,150.63$ as costs.

\section{Conclusion}

As I considered this issue, I reflected upon a letter recently received from a trial lawyer following a discussion on civility and professionalism with the Miami Chapter of the American Board of Trial Advocates. This lawyer stated:

It seems to me that the courts are basically facing this issue as one of education. Hence we have seminars, guidelines and articles from both that state and federal bench explaining what lawyers should do to be civil and professional to each other. However, I do not think that problem is that lawyers do not know how to act in a civil manner. Rather, I think some lawyers will simply do that with which they can get away. 
Special masters, grievance committees and educational seminars are not as effective as a sanction for uncivil behavior.

I know our federal court is quite busy and that the time it takes to consider uncivil behavior may have to be taken from some other pending case. However, I would submit that eliminating uncivil behavior not only helps that case, but every other case in which that lawyer is involved. Moreover, as the word spreads as to the price to be paid for unprofessionalism, other lawyers and other cases will be implicated.

I believe that this reduction in attorney fees is an appropriate response to the conduct by Plaintiff's counsel in this case, but I am not convinced it will deter future misconduct. I frankly considered denying fees altogether but while I have reviewed many of the depositions, I did not observe everything that happened during the pretrial phase of the case. The reduction in attorneys' fees based upon misconduct of counsel is therefore approximately $\$ 358,423.20$.

For the foregoing reasons, it is hereby ORDERED AND ADJUDGED that Plaintiff's Amended Verified Motion for Attorney's Fees and Costs is GRANTED. Based on the foregoing we award Plaintiff $\$ 312,324.63$ in fees and costs.

Furthermore, because of the misconduct of counsel which occurred in this case, a copy of this order shall be sent to the Florida Bar and the Peer Review Committee for the Southern District of Florida for any action deemed appropriate.

\section{Questions:}

1. This article from the New York Post provides some additional information about the case and the judge. Marvin Kurzban and Ira J. Kurzban were partners in a Florida law firm. Marvin Kurzban was disciplined by the Florida Bar for his conduct in this action. In 2019, another disciplinary complaint was filed against him, for violating an evidentiary ruling and insulting the judge and opposing counsel. He petitioned for disciplinary revocation without leave for readmission, and is currently disbarred in Florida. Ira Kurzban is still practicing, teaches immigration law at the University of Miami School of Law as an adjunct professor, and is the author of Kurzban's Immigration Law Sourcebook.

2. Was the court justified in criticizing the conduct of Marvin and Ira Kurzban? Does it matter that they won? Does it matter that the jury imposed substantial punitive damages on the defendant?

3. Was the court justified in reducing the attorney's fees and costs award? If so, did it go too far or not far enough? Could the court have denied attorney's fees and costs altogether?

\section{Limitations on Inherent Authority}




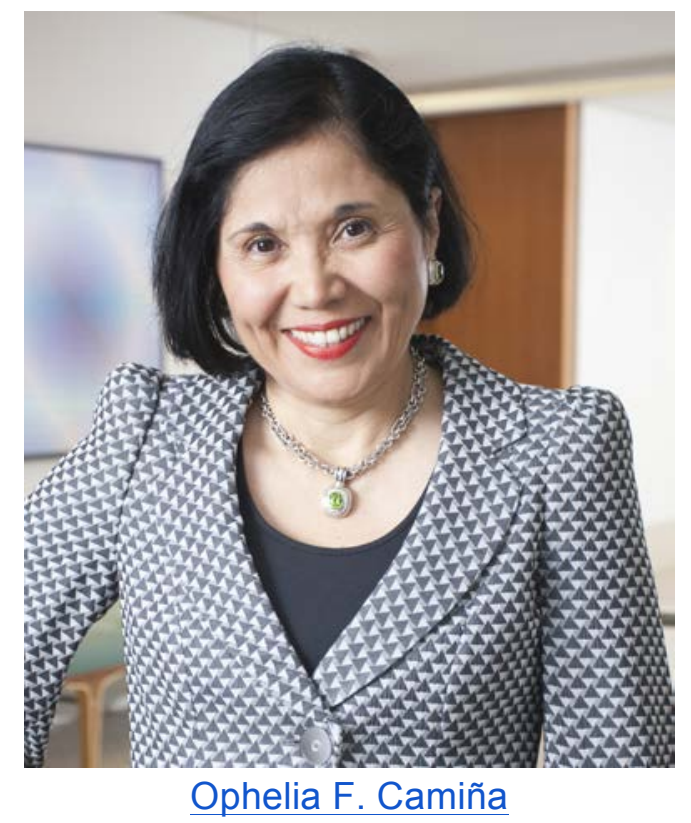

Positive Software Solutions v. New Century Mortg., 619 F. 3d 458 (5th Cir. 2010)

Summary: Positive Software filed an infringement action against New Century, which was represented by Camiña. The district court sent the action to arbitration, then vacated the award, because the arbitrator failed to disclose a previous relationship with Camiña. The circuit court reversed and remanded, at which point New Century declared bankruptcy, and the parties settled. As part of the settlement, New Century assigned its attorney-client privilege and work product rights to Positive Software, which moved for sanctions against Camiña, based on her actions in the arbitration. The district court exercised its inherent authority and imposed a $\$ 10,000$ sanction for acting in bad faith, but the circuit court reversed, holding that actions in arbitration are outside the inherent authority of the court.

JERRY E. SMITH, Circuit Judge:

Ophelia Camiña appeals the district court's imposition of sanctions for her conduct during arbitration. Because that court lacked inherent authority to impose those sanctions, we reverse and remand.

I.

In 2003, Positive Software Solutions, Inc., sued New Century Mortgage Corporation for allegedly infringing telemarketing software licensed to New Century. Ophelia Camiña, a partner at Susman Godfrey LLP, appeared as attorney for New Century. Over Positive Software's objection, the district court ordered the case to arbitration in accordance with the parties' contract. 
During arbitration, Camiña advised New Century on various discovery matters. In September 2004, the district court vacated the award because the arbitrator had failed to disclose his previous professional relationship with Camiña. This court reversed the vacatur and remanded.

After remand, New Century declared bankruptcy. In the course of the bankruptcy proceedings, Positive Software settled its claims against New Century, and the case was administratively closed. Under the settlement, New Century waived and assigned to Positive Software its attorney-client and work-product rights. The district court granted Positive Software's demand that Susman Godfrey LLP turn over its files for use by Positive Software in pursuing sanctions.

In March 2008, Positive Software moved for sanctions against Camiña, Barry Barnett, and Susman Godfrey LLP under Federal Rule of Civil Procedure 37, 28 U.S.C. $§ 1927$, and the court's inherent authority. In February 2009, using its purported inherent authority, the court sanctioned Camiña $\$ 10,000$, representing a portion of Positive Software's attorneys' fees. Camiña appeals the sanction.

III.

Camiña claims that the district court lacked inherent authority to impose sanctions for her conduct during arbitration. In the alternative, she argues that the court employed the wrong standard of proof in finding that she acted in bad faith, and that the sanctions were not supported by the evidence. Because the court lacked inherent authority to sanction Camiña for her actions during arbitration, we need not address her alternative claims.

A.

A district court has the inherent authority to impose sanctions "in order to control the litigation before it." The court may also use that power to sanction conduct, if it is "in direct defiance of the sanctioning court," or constitutes "disobedience to the orders of the Judiciary," Inherent power, however, "may be exercised only if essential to preserve the authority of the court."

In Maxxam, we confirmed the limited reach of the court's inherent authority. There the FDIC sued Charles Hurwitz, alleging that he was responsible for the failure of a savings and loan association. The FDIC also encouraged the Office of Thrift Supervision to pursue similar claims in an administrative proceeding. The FDIC moved that the district court stay its case pending completion of the OTS proceeding. When the district court denied that motion, the FDIC continued to support the administrative action. Invoking its inherent powers, the court sanctioned the FDIC for Hurwitz's expenses in defending the OTS action. We reversed part of those sanctions on the ground that the inherent power does not extend to collateral proceedings that "do not threaten the court's own judicial authority or proceedings." Inherent authority "is not a broad reservoir of power, ready at an imperial hand, but a limited source; an implied power squeezed from the need to make the court function." 
Here the district court distinguished Maxxam, positing that arbitration is not a collateral proceeding but instead an "annex" to litigation. It reasoned that because the court ordered the parties to arbitrate, it retained the authority to impose sanctions for conduct committed in arbitration. That approach is puzzling. To begin with, arbitration is not an annex to litigation, but an alternative method for dispute resolution. Treating arbitration as if it were an appendage to adjudication is a mistake that would undermine the very purpose of arbitration - "the provision of a relatively quick, efficient and informal means of private dispute settlement." Parties agree to arbitration to avoid litigation; they voluntarily surrender judicial remedies in favor of an extrajudicial process.

Furthermore, the notion that the court's inherent authority turns on whether the arbitration was "court-ordered" is untenable. Positive Software claims that the district court retained significant supervisory authority by virtue of ordering the parties to arbitrate. When asked, in oral argument, whether the court would have had inherent authority to sanction Camiña if the parties had chosen to enter arbitration at the outset, Positive Software's counsel candidly stated, "of course not - that's Maxxam." Positive Software's distinction, then, would allow trial courts to oversee arbitrations in which one party had to be compelled to arbitrate but not those in which both parties complied with their arbitration agreement. Such a significant and perverse asymmetry cannot be justified, and Positive Software's efforts to distinguish this case from Maxxam are unavailing.

In an attempt to rescue the sanctions order, Positive Software additionally claims that the sanctions are based on Camiña's direct defiance of the preliminary injunction and protective order. That assertion, however, is belied by the court's own explicit explanation that the sanctioned conduct "took place in connection with the arbitration, not in connection with discovery under the Court's supervision." In other words, the court imposed sanctions not on account of any direct violation of a court order, but only because it found that Camiña had exhibited four particular instances of bad faith during arbitration.

Positive Software's argument, therefore, fails according to the court's own findings. Because Camiña's conduct was neither before the district court nor in direct defiance of its orders, the conduct is beyond the reach of the court's inherent authority to sanction.

B.

Not only are the sanctions at odds with our caselaw on inherent authority, but they also are in serious tension with the Federal Arbitration Act. Under the FAA, the district court has the authority to determine (1) whether arbitration should be compelled, and (2) whether an arbitration award should be confirmed, vacated, or modified. Beyond those narrowly defined procedural powers, the court has no authority to interfere with an arbitration proceeding. Because both parties agree that their contract gave the arbitrator authority to sanction Camiña for bad-faith conduct, the FAA counsels against the district court's assigning itself that task. 
Positive Software cites LaPrade v. Kidder Peabody \& Co., to resolve the apparent tension between the sanction order and the FAA. In LaPrade, the district court stayed an action brought by Linda LaPrade against her former employer because the dispute was covered by a valid arbitration agreement. While the arbitration was pending, LaPrade's attorney went into state court and obtained an ex parte order staying the arbitration without informing that court of the district court's previous order. On the employer's motion, the district court lifted the state court's stay and imposed sanctions against LaPrade's attorneys under 28 U.S.C. $\S 1927$ for their "vexatious and dilatory tactics." On appeal, the District of Columbia Circuit upheld the sanctions, concluding that the FAA did not divest the district court of jurisdiction to enter the sanctions order.

LaPrade, however, does not support the district court's exercise of inherent power against Camiña. First, LaPrade held only that the FAA does not affect the district court's jurisdiction over a case stayed pending arbitration. But jurisdiction alone does not create the inherent power to sanction arbitration conduct. That power must be grounded in some threat to the court's authority or its ability to function and must not be contrary to statute. Unlike the court in LaPrade, which involved sanctions under a specific statutory provision, the district court here relied only on its inherent authority, which, as noted, was not up to the task.

Furthermore, it is misleading to suggest that LaPrade's attorneys were sanctioned for conduct in arbitration. Instead, the court imposed sanctions for the direct violation of its order. In staying the federal suit, the court mandated that LaPrade seek redress of her employment-related grievances only through arbitration. By obtaining a stay of arbitration in state court, her attorneys disregarded that order, thereby posing a threat to the federal district court's authority. That conduct might have been analogous to what happened here if Camiña's sanctions had rested on her violation of the preliminary injunction or the protective order. But as already discussed, the district court found no such violation.

C.

Finally, and perhaps most importantly, the sanctions order threatens unduly to inflate the judiciary's role in arbitration. The FAA provides for minimal judicial involvement in resolving an arbitrable dispute; the court is limited to only a few narrowly defined, largely procedural tasks. But by using its power to sanction, a court could seize control over substantive aspects of arbitration. The court would, in effect, become a roving commission to supervise a private method of dispute resolution and exert authority that is reserved, by statute, caselaw, and longstanding practice, to the arbitrator. That supervision is inconsistent with the scope of inherent authority and with federal arbitration policy, which aims to prevent courts from delaying the resolution of disputes through alternative means.

In response, Positive Software claims that expansion of district court authority is necessary here, because Positive Software did not discover some of Camiña's alleged misdeeds until after the case had been settled and administratively closed. Positive Software argues that without the district court's assertion of inherent authority, there would have been no means to redress 
Camiña's supposed wrongdoing. That argument, however, ignores at least two other procedures that were available to Positive Software.

First, it could have asked the American Arbitration Association to re-open the proceedings so it could request sanctions from the arbitrator. Second, it could have relied on the grievance process. In fact, it did: Its counsel filed a grievance against Camiña, which was dismissed as lacking just cause. Contrary to Positive Software's contentions, then, there was no particular need for the district court to expand its inherent authority to prevent misdeeds from falling through the cracks.

IV.

In sum, the district court lacked inherent authority to sanction Camiña for her conduct during arbitration. That conduct was neither before the district court nor in direct defiance of its orders. If inherent authority were expanded to cover Camiña's conduct, there would be nothing to prevent courts from inserting themselves into the thicket of arbitrable issues - precisely where they do not belong. Such an expansion would also threaten the integrity of federal arbitration law in the name of filling a gap that does not exist. We therefore REVERSE the sanctions ${ }^{95}$ and REMAND for any further proceedings that may be needed.

\section{Questions:}

1. Why did the circuit court hold that Camiña's conduct was outside the scope of the district court's inherent authority? Why didn't it matter that the district court had sent the action to arbitration?

2. The district court had the authority to review at least some aspects of the arbitration. Why didn't that place Camiña's conduct during the arbitration within the scope of its inherent authority?

3. Notably, New Century was a subsidiary of New Century Financial Corporation, a real estate investment trust, and one of the largest issuers of subprime mortgages. When New Century filed for bankruptcy in 2007 , it signaled the beginning of the subprime mortgage crisis.

\section{Candor to the Court}

\footnotetext{
${ }^{95}$ We do not condone Camiña's complained-of actions as they are alleged to have occurred. The clerk is directed to send a copy of this opinion to the Office of the General Counsel of the State Bar of Texas. We are mindful that the State Bar declined to act on this matter in response to Positive Software's request, and we express no view on whether the State Bar should consider this matter further or, if it does, on what action it should take. We opine only that the federal courts are without power to issue sanctions under these particular facts.
} 


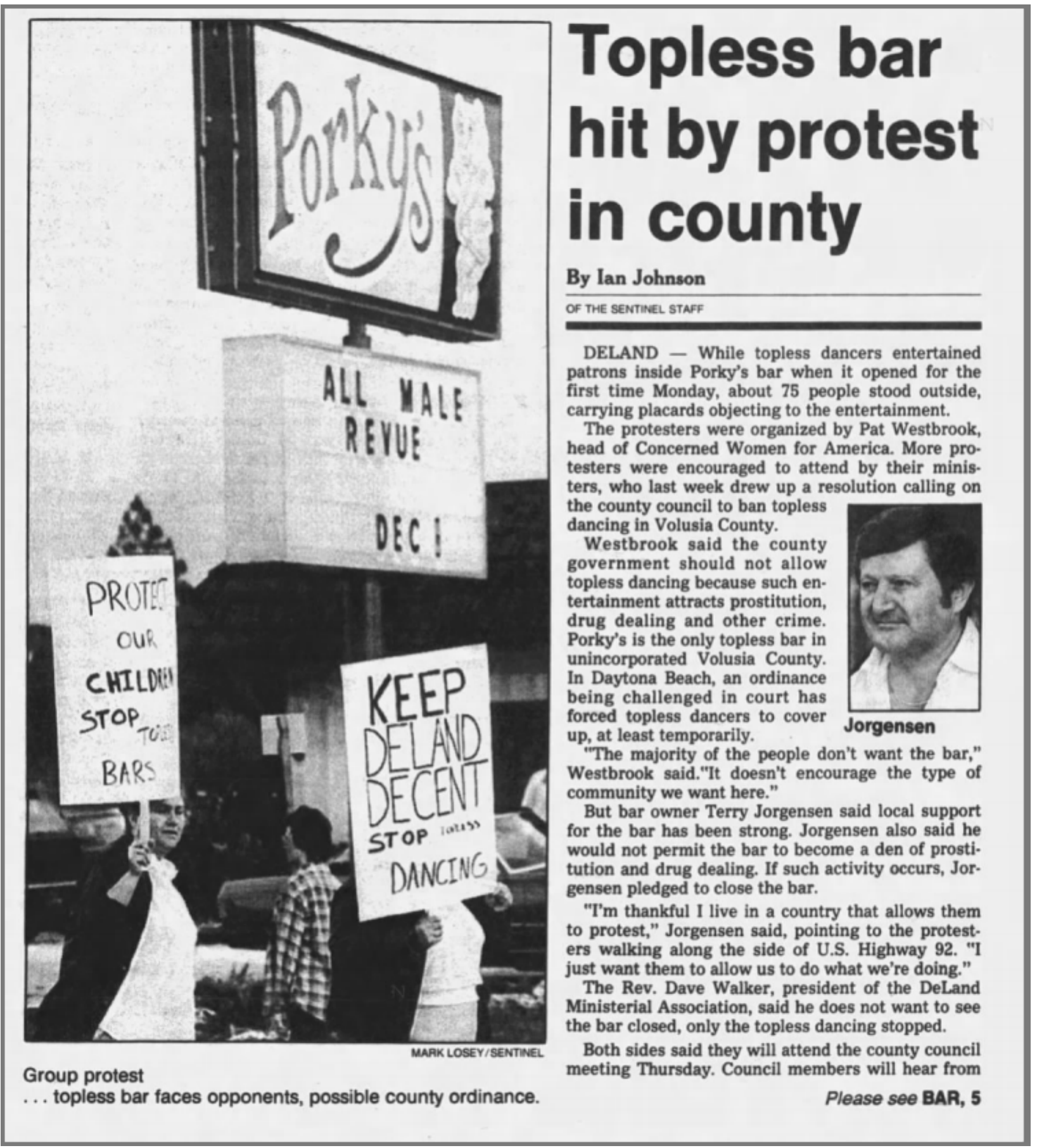

The Orlando Sentinel (Orlando, Florida), Tues., Dec. 3, 1985, at 45 


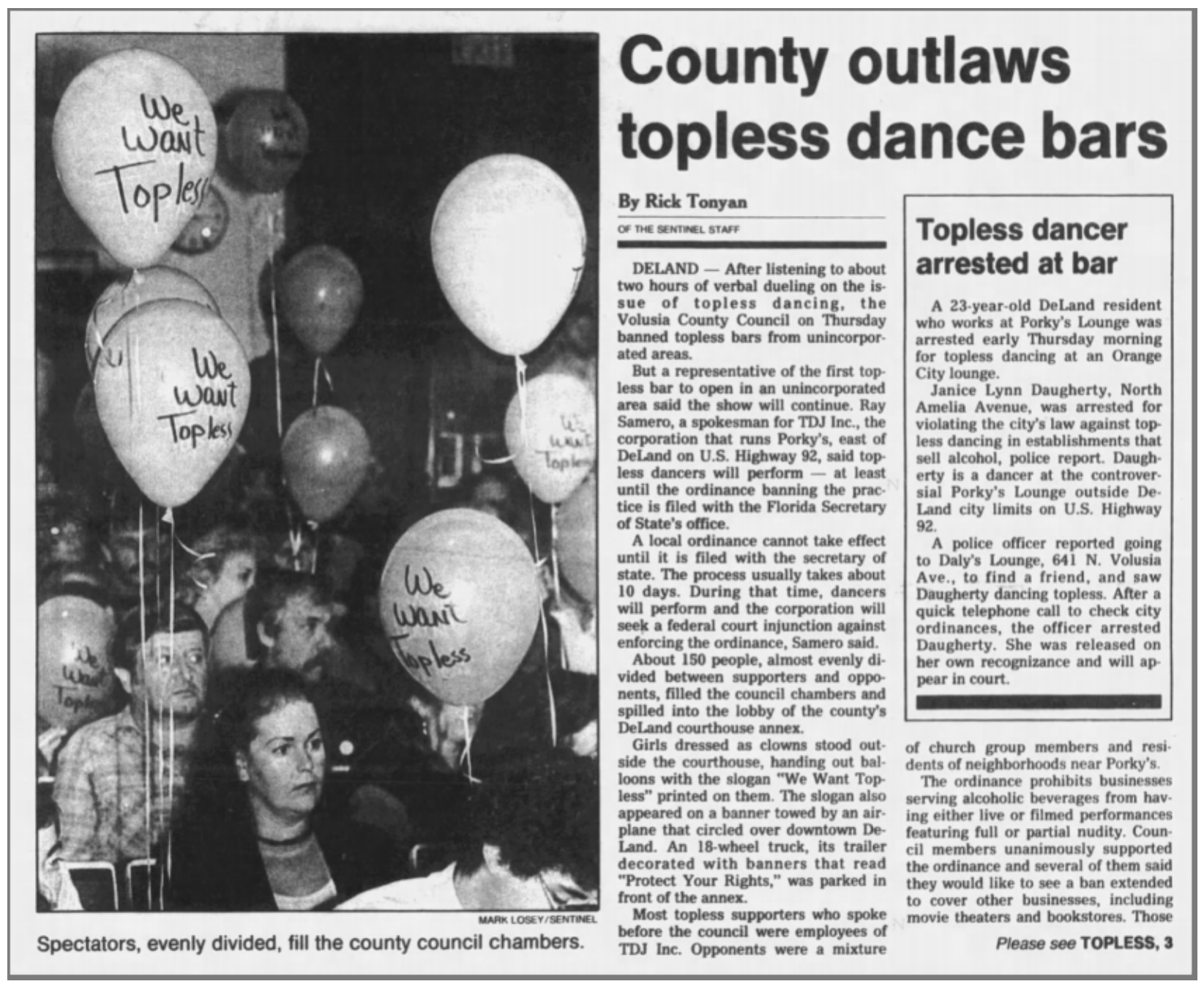

The Orlando Sentinel (Orlando, Florida), Fri., Jan. 10, 1986, at 149

\section{Jorgenson v. Volusia County, 846 F. 2d 1350 (11th Cir. 1988)}

Summary: Porky's was a topless bar outside of DeLand, Florida. When Volusia County passed an ordinance prohibiting topless bars, Porky's challenged the constitutionality of the ordinance, represented by Latinsky and Fendt. The standard of review of the ordinance depended on whether Florida had delegated its powers under the 21st Amendment to counties and municipalities. In City of Daytona Beach v. Del Percio, the Florida Supreme Court held that it had, but Latinsky and Fendt argued that it hadn't, and did not cite Del Percio. The district court sanctioned them under Rule 11 for intentionally failing to cite controlling adverse precedent and the circuit court affirmed.

\section{PER CURIAM:}

The appellants, attorneys Eric Latinsky and Fred Fendt, were sanctioned by the district court pursuant to Fed. R. Civ. P. 11 for failing to cite adverse, controlling precedent in a memorandum filed in support of an application for a temporary restraining order and a preliminary injunction. In 
the appellants' initial appeal to this court, the case was remanded to the district court because the court had failed to notify the attorneys in advance that it was considering sanctions, and did not give them an opportunity to respond. On remand, the district court reaffirmed the imposition of sanctions, and the attorneys appeal. We affirm.

Appellants filed an application in the district court for a temporary restraining order and a preliminary injunction on behalf of their clients, who own and operate a lounge known as "Porky's." In support of the application, appellants filed a memorandum of law which challenged the validity of a Volusia County ordinance prohibiting nude or semi-nude entertainment in commercial establishments at which alcoholic beverages are offered for sale or consumption. The memorandum failed to discuss or cite two clearly relevant cases: City of Daytona Beach v. Del Percio and New York State Liquor Authority v. Bellanca. We find that this failure supports the imposition of Rule 11 sanctions in the circumstances of this case.

The field of law concerning the regulation of the sale and consumption of alcohol in connection with nude entertainment is a narrow and somewhat specialized field. Prior to the opinion of the Supreme Court of Florida in Del Percio, the critical question of whether the state of Florida had delegated its powers under the Twenty-First Amendment to counties and municipalities had gone unanswered. In some circles, that decision was long-awaited. If the state had delegated the authority, local ordinances regulating the sale or consumption of alcohol would be entitled to a presumption in favor of their validity which is conferred by the Twenty-First Amendment. If the state had not delegated the authority, the ordinances would be subject to the stricter review applicable to exercises of the general police power.

The question regarding Florida's delegation of its powers under the Twenty-First Amendment was answered by the Supreme court of Florida in Del Percio, a case in which one of the appellants, Latinsky, participated. The court held that the powers had been delegated. Less than one year later, on or about January 13, 1986, Latinsky and an associate brought the instant suit seeking a declaration that a similar ordinance was unconstitutional and requesting a temporary restraining order and a preliminary injunction. In their presentation to the court, the appellants cited a number of cases describing the limits on the exercise of the general police power. However, they did not advise the court in any way that Del Percio had been decided, despite the fact that $D e l$ Percio required that the validity of the ordinance be judged in light of powers retained under the Twenty-First Amendment rather than the general police power.

The appellants purported to describe the law to the district court in the hope that the description would guide and inform the court's decision. With apparently studied care, however, they withheld the fact that the long-awaited decision by the Supreme Court of Florida had been handed down. This will not do. The appellants are not redeemed by the fact that opposing counsel subsequently cited the controlling precedent. The appellants had a duty to refrain from affirmatively misleading the court as to the state of the law. They were not relieved of this duty by the possibility that opposing counsel might find and cite the controlling precedent, particularly where, as here, a temporary restraining order might have been issued ex parte. 
In this court, appellants argue that the cases were not cited because they are not controlling. We certainly acknowledge that attorneys are legitimately entitled to press their own interpretations of precedent, including interpretations which render particular cases inapplicable. It is clear, however, that appellants' attempts to show that Del Percio and Bellanca are not controlling are simply post hoc efforts to evade the imposition of sanctions. Neither the original complaint nor the memorandum of law filed by appellants in the district court reflect or support the arguments they now raise. Indeed, it is likely that the arguments were not raised previously because they are completely without merit. In the circumstances of this case, the imposition of Rule 11 sanctions by the district court was warranted. The judgment of the district court is affirmed.

\section{Questions:}

1. You can read newspaper articles about Porky's here and here. After the court's ruling in 1986, the bar changed to a "bottle club," where patrons purchased alcohol elsewhere and mixed their own drinks, in order to avoid the ordinance, but soon closed. You can read a newspaper article about the disciplinary case against Latinsky and Fendt case here. The district court accused them of "reprehensible" conduct and imposed a $\$ 500$ fine. Do you think that is adequate?

2. Model Rule 3.3(a)(2) provides: "A lawyer shall not knowingly fail to disclose to the tribunal legal authority in the controlling jurisdiction known to the lawyer to be directly adverse to the position of the client and not disclosed by opposing counsel." Latinsky and Fendt argued that the action challenging the ordinance was in federal court, so the decision of the Florida Supreme Court was not controlling. Should that have excused their failure to cite it? What if the district court had to independently determine whether Florida had delegated its authority? 


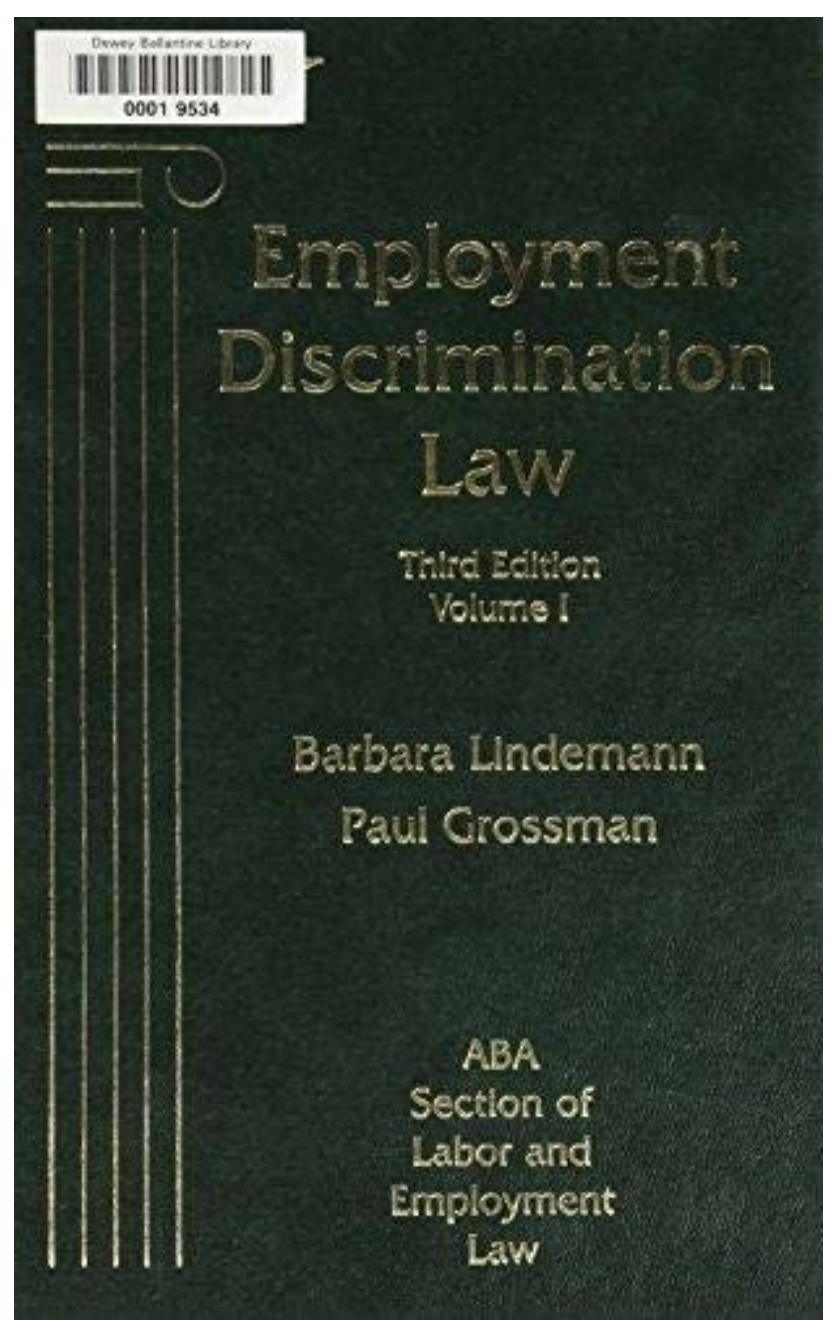

Board of Ethics \& Conduct v. Lane, 642 N.W.2d 296 (lowa 2002)

Summary: Lane represented Sicard in an employment discrimination action. Among other things he filed a post-trial brief, the entire contents of which were plagiarized from a treatise. Lane won the trial, and submitted a bill for attorney's fees, requesting $\$ 16,000$ for 80 hours drafting the post-trial brief. When the court requested documentation of the drafting of the brief, Lane eventually submitted a list of 200 sources, from which the court discovered his plagiarism. The court sanctioned Lane's conduct and suspended his license for 6 months.

STREIT, Justice.

An lowa attorney passed someone else's writing as his own and claimed he spent almost two weeks writing that which he used. The lowa Supreme Court Board of Professional Ethics and Conduct filed a complaint with our Grievance Commission against respondent, William J. Lane, alleging he violated several ethical rules and recommended we suspend Lane's license to 
practice law for three months. We agree with the Commission's findings of misconduct but suspend Lane's license for six months.

\section{Background Facts and Proceedings}

After the conclusion of a trial in federal court in which Daniel Sicard claimed a violation of the Americans with Disabilities Act, attorney Lane submitted a post-trial brief to the court. The legal portion of the brief was in great part plagiarized from a treatise written by Barbara Lindemann and Paul Grossman. Lane later applied to the court for attorney fees. Among other charges, Lane requested compensation for eighty hours of work spent to prepare the questioned brief. Charging $\$ 200$ per hour, Lane asked for $\$ 16,000$ to write the brief that was largely copied from an uncredited source. In total, Lane requested $\$ 104,127$ in attorney fees plus $\$ 13,363.29$ in costs for his representation of Sicard.

On May 5, 1998, there was a hearing on Lane's attorney fee application. The United States magistrate judge stated it did not appear to him that Lane wrote the legal portions of the brief. Lane responded, "I borrowed liberally from other sources. Yes, your Honor." The court noted,

Because of the consistency of style and the sequence of footnotes, the court assumes that the brief is from a particular source. If the source is a published treatise, it can simply be identified by name, author, and publisher.

To address this suspicion, the judge ordered Lane to explain or identify the sources cited in his brief within ten days. At the end of the ten days, Lane did nothing to comply with the court's order. On June 4, 1998, a member of the judge's staff asked Lane if he intended to respond to the order. Only days later, a fire at Lane's home destroyed many of his files and records in the Sicard matter. In July 1998, Lane closed his office, but continued to practice out of his home.

Four months passed and Lane still did not respond to the judge's order. On September 30, 1998 , the judge entered an order awarding Lane $\$ 20,000$ in fees in the Sicard case. The judge stated "there were many serious problems with plaintiff's fees and cost claim." The court was particularly concerned because Lane did not support his contention he was entitled to receive compensation at the rate of $\$ 200$ per hour for his services. Lane also requested $\$ 9000$ as compensation for the time he spent preparing his bill. The judge stated Lane requested $\$ 16,000$ for the lifted brief but failed to comply with the court's order to "disclose the sources from which counsel 'borrowed liberally."' Lane also requested compensation for fifty-nine hours of legal research preceding the trial. The court concluded

It is not reasonable to bill 59 hours of legal research in the two weeks prior to trial. If counsel spent this amount for time performing research, it is further evidence that he does not possess the skill and experience of those who charge $\$ 200$ per hour.

The court further explained its reduction of the attorney fees awarded by citing to Lane's charges of $\$ 5.00$ per telephone call, $\$ 1.00$ per page of facsimile transmissions, $\$ 191$ for long 
distance transmission, and $\$ .50$ per photocopy. Finally, the court stated Lane did not cite authority for the ability to charge for estimated pretrial travel expenses. Lane did not appeal the $\$ 20,000$ award of attorney fees.

On October 30, 1998, Lane filed a compliance with the judge's order to document his sources but the judge was not made aware of the compliance until March 1999. When the judge read Lane's compliance he did not notice any reference to the primary source of the legal portion of Lane's brief. Lane's compliance constituted four pages of single-spaced lists of authorities. Among them was the Grossman treatise. However, no particular attention was drawn to this source. Consequently, the judge undertook his own investigation and discovered Lane took the legal portion of his brief verbatim from the Grossman treatise.

This complaint also involves Lane's representation in two separate and unrelated bankruptcy cases. The Ethics Board charged Lane with, among other violations, neglect of clients' legal matters, withdrawal from employment without taking reasonable steps to avoid prejudice to his clients and without promptly refunding unearned fees, and failure to seek the lawful objectives of his clients. The Commission found, and we agree, the Ethics Board failed to satisfy its burden to prove Lane violated any ethical rules in representing his clients in the bankruptcy matters. Therefore, we will only address the charges relevant to the Sicard case.

\section{Complaint}

The Ethics Board alleges violations of DR 1-102(A)(1), (3), (4), (5), and (6). This rule provides in part, a lawyer shall not:

- Violate a disciplinary rule;

- Engage in illegal conduct involving moral turpitude;

- Engage in conduct involving dishonesty, fraud, deceit or misrepresentation;

- Engage in conduct that is prejudicial to the administration of justice; and

- Engage in any other conduct that adversely reflects on the fitness to practice law.

The Ethics Board also charges Lane with a violation of DR 2-106(A) which states, "a lawyer shall not enter into an agreement for, charge, or collect an illegal or clearly excessive fee." The Commission found Lane violated DR 1-102(A)(1), (3), (4), (5), and (6) and DR 2-106(A) by his handling of the Sicard case.

\section{Ethical Violations}

Lane plagiarized from a treatise and submitted his plagiarized work to the court as his own. This plagiarism constituted, among other things, a misrepresentation to the court. An attorney may not engage in conduct involving dishonesty, fraud, deceit, or misrepresentation. This issue is akin to the matter of ghost-writing attorneys who "author pleadings and necessarily guide the course of the litigation with unseen hand." In this situation, an attorney authors court documents for a pro se litigant who, in turn, submits the court document as his or her own writing. This practice is widely condemned as unethical and a "deliberate evasion of the responsibilities 
imposed on attorneys." Just as ghost writing constitutes a misrepresentation on the court, so does plagiarism of the type we have before us.

Plagiarism itself is unethical. "Plagiarism, the adoption of the work of others as one's own, does involve an element of deceit, which reflects on an individual's honesty." Use of "appropriated material cannot go undisciplined, especially because honesty is so fundamental to the functioning of the legal profession." Undoubtedly, Lane's plagiarism reflects poorly on both his professional ethics and judgment.

It was not difficult to find similarity between Lane's post-trial brief and the Grossman treatise. The legal argument of Lane's post-trial brief consisted of eighteen pages of plagiarized material, including both text and footnotes, from the treatise. In copying this material, Lane cherry-picked the relevant portions and renumbered the footnotes to reflect the altered text. Examination of Lane's brief does not reveal any independent labor or thought in the legal argument.

On the first occasion plagiarism became an issue, Lane appeared to be forthcoming with the court and admitted "he borrowed liberally from other sources." It also appears Lane attempted to identify the source of his writing before the court but was unable to recall the exact title of the treatise. Lane later had the chance to identify his source to the court, but when he responded to the court's order, he failed to specifically draw the court's attention to the Grossman treatise. Instead, Lane buried the title within a list of over 200 other sources. Though a technical compliance with the court's order, Lane's continued lack of candor indicates he hoped, by concealing the treatise among 200 other titles, the judge would not recognize the extent of Lane's plagiarism.

We do recognize Lane's personal circumstances shortly after the time of the court's order were not ideal. Lane's home was nearly destroyed by the fire forcing him and his family to live in a motel for two months. However, this does not excuse his failure to comply with the court's order in a timely fashion. We will not excuse the seriousness of passing off another's work as one's own. We find the record shows Lane knowingly plagiarized and intended to deceive the court.

Equally troubling is Lane's application for attorney fees. Lane copied the entire portion of his legal argument out of a book and then claimed it took him eighty hours to write the brief containing the copied material. He requested attorney fees for this work at the rate of $\$ 200$ per hour. Other than Lane's assertions that perhaps he works less efficiently than other lawyers, there is little in the record to indicate Lane actually spent this amount of time writing the brief. Because he plagiarized the entire legal argument, the chances are remote that it took Lane eighty hours to write the argument. Rather, the facts show Lane stole all eighteen pages of his legal argument from a single source. Then to justify his request for attorney fees for the eighty hours it took to "write" the brief, Lane submitted a list of over 200 legal sources to the court. In doing so, Lane attempted to have the court believe he researched and relied on each of these sources in writing the brief. These circumstances only support the conclusion Lane endeavored to deceive the court. 
The Ethics Board argues Lane's plagiarism was part of a larger scheme to defraud the court by means of inflated time and expense billings. When Lane requested compensation for time he did not spend working on the case, he violated the professional rule forbidding a lawyer from entering into an agreement for, charging, or collecting an illegal or clearly excessive fee. Even after the plagiarism issue arose, Lane continued to assert he was entitled to receive $\$ 200$ for the eighty hours it took him to copy the material in his brief. He did not at any time admit that it did not take, nor could it have taken him that long to simply copy his legal argument out of a treatise. Charging such a clearly excessive bill brings Lane's integrity into question and the entire legal profession into disrepute.

It is important to note that Lane's request for attorney fees in this case is not similar to cases where the attorney is simply not awarded the fee requested. Lane relies on one particular case in which the district court reduced the attorney's fee application of over $\$ 171,000$ to $\$ 95,000$. The dispute in Lynch involved the attorney's expenditure of time, effort, and money in representing her client. There, the trial court properly considered several factors in reducing the award of attorney fees. These factors included: the time necessarily spent; the difficulty of handling and importance of the issues; the responsibility assumed and results obtained; the standing and experience of the attorney in the profession; and the customary charges for similar service. In Lynch, there was no suggestion of impropriety or intent to deceive the court on the part of the attorney who submitted the fee application. Moreover, the record contained no evidence to contradict the evidence supporting the fee application.

In many cases a fee application may not necessarily be a precise measure of the time an attorney spent on a particular case. Ethics concerns are not unavoidably raised where the court reduces the attorney fee award merely reflecting considerations that do not bring into question the attorney's honesty or integrity in submitting the fee application. On the other hand, although ethics is not a matter of degree of misstatement-any knowing misstatement to the court being unethical-the nature and depth of Lane's misrepresentation speaks of knowing deception.

The record before us amply supports the conclusion Lane's conduct rises to the level of intent to deceive. Action based in the hopes of deceiving the court are not the same as those arising from simple negligence or even recklessness. A lawyer who knowingly submits a fee application to the court and thereby attempts to misrepresent the amount of time he or she spent working on a case has committed serious ethical violations. Accordingly, we will not treat all of the cases the same. When the fee application involves culpable conduct, the seriousness of the offense will be considered in fashioning the appropriate sanction. We conclude the record supports the Commission's findings that Lane charged a clearly excessive fee in the Sicard case.

\section{Discipline}

In determining the proper sanction, we consider the particular facts and circumstances of each case. Among the factors we give weight to are the need for deterrence, protection of the public, maintenance of the reputation of the Bar as a whole, and the violator's fitness to continue to practice law. We also consider any aggravating or mitigating circumstances. 
One such aggravating circumstance is a lawyer's prior disciplinary history. Lane has once before faced attorney disciplinary proceedings. In 1997, the Commission sanctioned Lane for failing to respond to an inquiry. He was publicly reprimanded for conduct prejudicial to the administration of justice and conduct adversely reflecting on his fitness to practice law.

A mitigating factor to consider is Lane's recognition of some wrongdoing. Lane filed "Respondent's Statement" with this court. Although not evidence, we will treat this statement as a supplemental brief. Lane stated,

I can accept that my behavior was the result of bad judgment, ignorance, even stupidity or carelessness, or sloppiness, or any number of things, such as laziness, negligence, arrogance, indolence, pettiness, or just plain old incompetence.

Lane asserted he did not intend to deceive the court and cited his reputation for honesty. In support of this contention, several character witnesses testified on Lane's behalf at the hearing before the Commission. Despite Lane's statements to the court, he still does not appear to comprehend the wrongfulness of his actions. In requesting excessive and unreasonable attorney fees for a brief he did not write, Lane was not negligent, or even reckless. Rather, more seriously, he intended to deceive. Lane's purported acknowledgment of misconduct fails to recognize the full extent of his wrongdoing.

Mitigating factors alone do not overcome our responsibility to the public and to the legal profession. Though Lane offered evidence of difficult personal circumstances, this does not excuse his unethical conduct. Taking all of the above factors into consideration, we conclude in cases of this type, fairness and justice require discipline be imposed to deter future misconduct, protect the public, and maintain the reputation of the Bar as a whole. Lane's excessive billing for writing a largely plagiarized brief cannot go undisciplined. Honesty is fundamental to the functioning of the legal profession, and Lane's conduct in this case has compromised that honesty. Moreover, Lane has jeopardized the integrity of the Bar and the public's trust in the legal profession. We conclude a six-month license suspension is warranted. We therefore suspend Lane's license to practice law in the State of lowa, with no possibility of reinstatement for a period of six months from the date of the filing of this opinion. Upon application for reinstatement, Lane shall have the burden to prove he has not practiced law during the period of suspension and that he meets the requirements of lowa Court Rule 35.13. Any hearing on application for reinstatement shall be at least sixty days after the filing of such application.

\section{Questions:}

1. Did the court sanction Lane for plagiarizing the contents of the brief, billing for hours he didn't work, or lack of candor to the court?

2. The court stated that "plagiarism itself is unethical." Do you agree? Does it depend on the context? The court relied on cases involving law students who plagiarized in coursework. Is that an appropriate comparison? 
3. Lane's plagiarized brief was apparently effective, as he won the case. As Lane's client, would you have been upset to learn that he plagiarized the brief, if he only billed you for the number of hours he actually spent drafting the brief? Should the court have censured Lane for plagiarism, if he had only billed for the number of hours he actually spent drafting the brief?

4. Why did Lane plagiarize the treatise rather than quoting it? Would citing the treatise have made Lane's argument weaker or stronger?

\section{Further Reading:}

- Brian L. Frye, Plagiarism is Not a Crime, 54 Duq. L. Rev. 133 (2016) 


\section{4: Client Perjury}

If the truth will hurt someone you love, tell a lie. ${ }^{96}$

Under the Model Rule of Professional Conduct 3.3, attorneys may not permit their clients to testify falsely or introduce false evidence. And under Model Rule 4.1, attorneys may be required to withdraw from representation, if they knows that their client has or will introduce false evidence. As the Restatement of the Law Governing Lawyers § 120 observes, "A lawyer may not knowingly counsel or assist a witness to testify falsely or otherwise to offer false evidence."

What should attorneys do, if they know that their client or a witness has or will introduce false evidence? In many cases, they can simply refuse to introduce the evidence in question. If their client plans to lie, they can refuse to call their client, and they can counsel their client not to lie. If their client does lie, they can ask the client to retract the false evidence. And if the client refuses, the attorney may withdraw from representation. If the false evidence could materially affect the outcome, the attorney must also disclose it to the court.

Criminal cases are more complicated, because criminal defendants have a constitutional right to testify under the Sixth Amendment. Attorneys should still advise criminal defendants not to lie. But if they know that their client intends to lie, some jurisdiction permit the client to testify in narrative form, so long as the attorney does not rely on the perjured testimony.

Some legal scholars, most notably the late Monroe Freedman, argue that an attorney's duty of loyalty to the client must trump the attorney's duty of candor to the court. Accordingly, attorneys should put criminal clients on the stand without notifying the court, even if they know the client will testify falsely. A few scholars argue that attorneys should simply refuse to call their client at all, if they know the client plans to lie.

Each time I was wrong or each time that I lied or somebody made me scared, I would simply report them to Rosemary Woods, and she would make them disappear. ${ }^{97}$

\section{Model Rule 3.3: Candor Toward the Tribunal}

a. A lawyer shall not knowingly:

1. make a false statement of fact or law to a tribunal or fail to correct a false statement of material fact or law previously made to the tribunal by the lawyer;

2. fail to disclose to the tribunal legal authority in the controlling jurisdiction known to the lawyer to be directly adverse to the position of the client and not disclosed by opposing counsel; or

3. offer evidence that the lawyer knows to be false. If a lawyer, the lawyer's client, or a witness called by the lawyer, has offered material evidence and the lawyer

\footnotetext{
96 The Chromatics, Tell a Lie (1956).

${ }^{97}$ Bill Horwitz, If I Had a Friend Like Rosemary Woods, Lies, Lies, Lies (1975).
} 
comes to know of its falsity, the lawyer shall take reasonable remedial measures, including, if necessary, disclosure to the tribunal. A lawyer may refuse to offer evidence, other than the testimony of a defendant in a criminal matter, that the lawyer reasonably believes is false.

b. A lawyer who represents a client in an adjudicative proceeding and who knows that a person intends to engage, is engaging or has engaged in criminal or fraudulent conduct related to the proceeding shall take reasonable remedial measures, including, if necessary, disclosure to the tribunal.

c. The duties stated in paragraphs (a) and (b) continue to the conclusion of the proceeding, and apply even if compliance requires disclosure of information otherwise protected by Rule 1.6.

d. In an ex parte proceeding, a lawyer shall inform the tribunal of all material facts known to the lawyer that will enable the tribunal to make an informed decision, whether or not the facts are adverse.

\section{Model Rule 3.3: Comments}

5. Paragraph $(a)(3)$ requires that the lawyer refuse to offer evidence that the lawyer knows to be false, regardless of the client's wishes. This duty is premised on the lawyer's obligation as an officer of the court to prevent the trier of fact from being misled by false evidence. A lawyer does not violate this Rule if the lawyer offers the evidence for the purpose of establishing its falsity.

6. If a lawyer knows that the client intends to testify falsely or wants the lawyer to introduce false evidence, the lawyer should seek to persuade the client that the evidence should not be offered. If the persuasion is ineffective and the lawyer continues to represent the client, the lawyer must refuse to offer the false evidence. If only a portion of a witness's testimony will be false, the lawyer may call the witness to testify but may not elicit or otherwise permit the witness to present the testimony that the lawyer knows is false.

7. The duties stated in paragraphs (a) and (b) apply to all lawyers, including defense counsel in criminal cases. In some jurisdictions, however, courts have required counsel to present the accused as a witness or to give a narrative statement if the accused so desires, even if counsel knows that the testimony or statement will be false. The obligation of the advocate under the Rules of Professional Conduct is subordinate to such requirements.

8. The prohibition against offering false evidence only applies if the lawyer knows that the evidence is false. A lawyer's reasonable belief that evidence is false does not preclude its presentation to the trier of fact. A lawyer's knowledge that evidence is false, however, can be inferred from the circumstances. Thus, although a lawyer should resolve doubts about the veracity of testimony or other evidence in favor of the client, the lawyer cannot ignore an obvious falsehood.

9. Although paragraph (a)(3) only prohibits a lawyer from offering evidence the lawyer knows to be false, it permits the lawyer to refuse to offer testimony or other proof that the lawyer reasonably believes is false. Offering such proof may reflect adversely on the lawyer's ability to discriminate in the quality of evidence and thus impair the lawyer's 
effectiveness as an advocate. Because of the special protections historically provided criminal defendants, however, this Rule does not permit a lawyer to refuse to offer the testimony of such a client where the lawyer reasonably believes but does not know that the testimony will be false. Unless the lawyer knows the testimony will be false, the lawyer must honor the client's decision to testify.

\section{Model Rule 4.1: Truthfulness in Statements to Others}

In the course of representing a client a lawyer shall not knowingly:

a. make a false statement of material fact or law to a third person; or

b. fail to disclose a material fact to a third person when disclosure is necessary to avoid assisting a criminal or fraudulent act by a client, unless disclosure is prohibited.

\section{Model Rule 4.1: Comments}

Crime or Fraud by Client

1. Under Rule 1.2(d), a lawyer is prohibited from counseling or assisting a client in conduct that the lawyer knows is criminal or fraudulent. Paragraph (b) states a specific application of the principle set forth in Rule 1.2(d) and addresses the situation where a client's crime or fraud takes the form of a lie or misrepresentation. Ordinarily, a lawyer can avoid assisting a client's crime or fraud by withdrawing from the representation. Sometimes it may be necessary for the lawyer to give notice of the fact of withdrawal and to disaffirm an opinion, document, affirmation or the like. In extreme cases, substantive law may require a lawyer to disclose information relating to the representation to avoid being deemed to have assisted the client's crime or fraud. If the lawyer can avoid assisting a client's crime or fraud only by disclosing this information, then under paragraph (b) the lawyer is required to do so, unless the disclosure is prohibited by Rule 1.6 .

\section{Restatement (Third) of the Law Governing Lawyers $\S 120$ (2000): False Testimony or Evidence}

1. A lawyer may not:

a. knowingly counsel or assist a witness to testify falsely or otherwise to offer false evidence;

b. knowingly make a false statement of fact to the tribunal;

c. offer testimony or other evidence as to an issue of fact known by the lawyer to be false.

2. If a lawyer has offered testimony or other evidence as to a material issue of fact and comes to know of its falsity, the lawyer must take reasonable remedial measures and may disclose confidential client information when necessary to take such a measure. 
3. A lawyer may refuse to offer testimony or other evidence that the lawyer reasonably believes is false, even if the lawyer does not know it to be false.

\section{Further Reading:}

- Harry I. Subin, The Lawyer as Superego: Disclosure of Client Confidences to Prevent Harm, 70 lowa L. Rev. 1091 (1985)

- $\mathrm{H}$. Lowell Brown, The Dilemma of Corporate Counsel Faced with Client Misconduct: Disclosure of Client Confidences or Constructive Discharge, 44 Buffalo L. Rev. 777 (1996)

- $\quad$ Thomas L. Shaffer, On Lying for Clients, 71 Notre Dame L. Rev. 195 (1995-1996)

- Richard H. Underwood, Perjury! The Charges and the Defenses, 36 Duq. L. Rev. 715 (1998)

- Barry Adler, The Ethics of Perjury, 71 ABA Journal 76 (November 1985)

- Monroe H. Freedman, Professional Responsibility of the Criminal Defense Lawyer: The Three Hardest Questions, 64 Mich. L. Rev. 1469 (1966)

- Monroe H. Freedman, Getting Honest About Client Perjury, 21 Geo. J. Legal Ethics 133 (2008)

- $\quad$ Ray McKoski, Prospective Perjury by a Criminal Defendant: It's All about the Lawyer, 44 Ariz. St. L.J. 1575 (2012) 


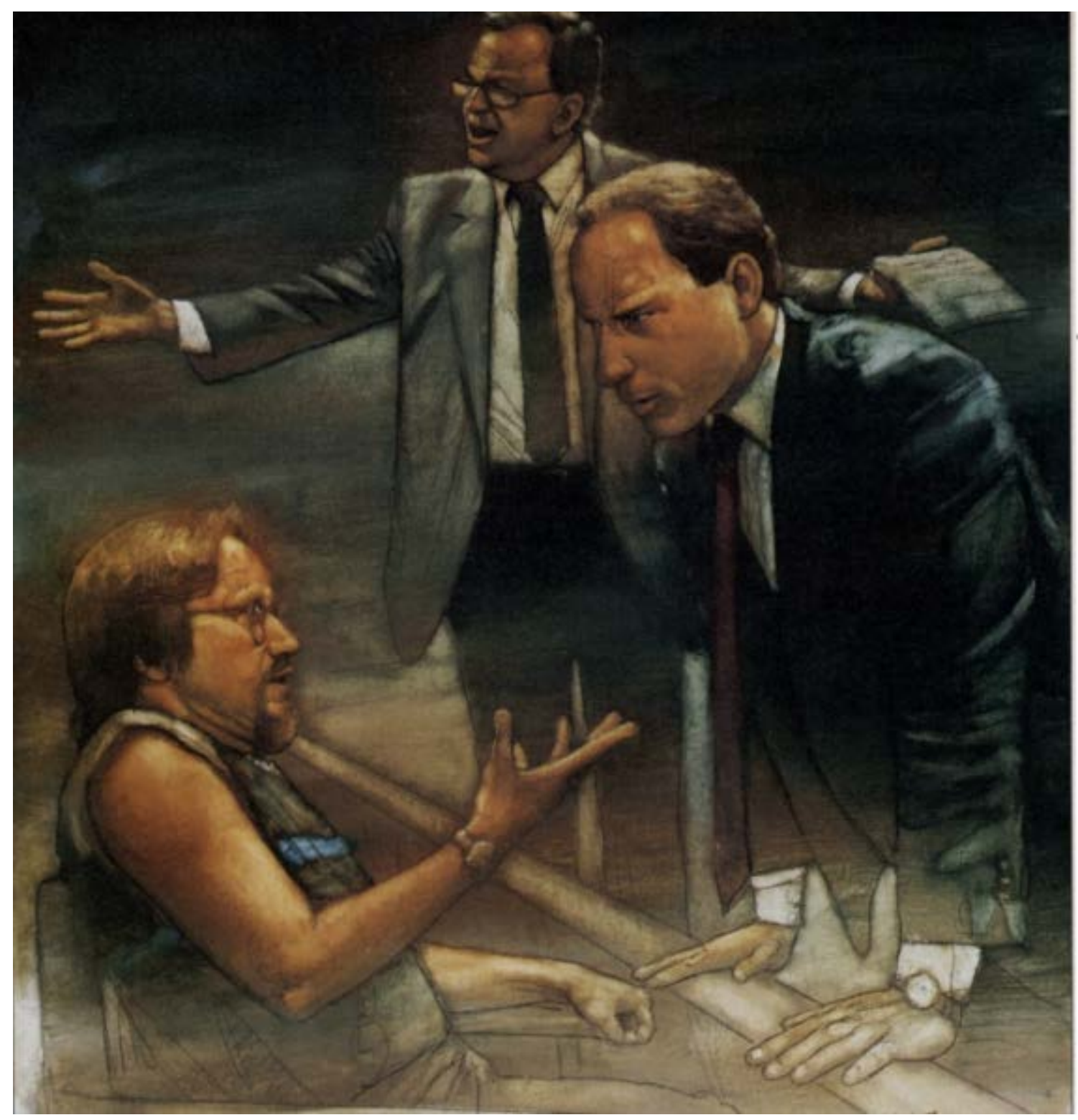

Nix v. Whiteside Courtroom Drawing

Nix v. Whiteside, 475 U.S. 157 (1986)

Summary: Emmanuel Charles Whiteside was charged with the murder of Calvin Love, and was represented by Gary L. Robinson and Donna Paulsen. Whiteside pleaded selfdefense. Initially, he told Robinson that he believed Love had a gun, but had not actually seen one. Later, he told Robinson that he had seen "something metallic." Robinson advised Whiteside that this testimony would be perjury, and that he would inform the court and withdraw from representation if Whiteside committed perjury. Whiteside did not testify that he had seen "something metallic," and was convicted of second-degree murder. The Supreme Court of lowa affirmed the conviction. Whiteside filed a federal habeas petition alleging ineffective assistance of counsel. The district court denied the writ, but the circuit court reversed. The Supreme Court granted certiorari and reversed, 
holding that criminal defendant does not have a right to commit perjury, so Whiteside's right to counsel was not infringed.

We granted certiorari to decide whether the Sixth Amendment right of a criminal defendant to assistance of counsel is violated when an attorney refuses to cooperate with the defendant in presenting perjured testimony at his trial.

Whiteside was convicted of second-degree murder by a jury verdict which was affirmed by the lowa courts. The killing took place on February 8, 1977, in Cedar Rapids, lowa. Whiteside and two others went to one Calvin Love's apartment late that night, seeking marihuana. Love was in bed when Whiteside and his companions arrived; an argument between Whiteside and Love over the marihuana ensued. At one point, Love directed his girlfriend to get his "piece," and at another point got up, then returned to his bed. According to Whiteside's testimony, Love then started to reach under his pillow and moved toward Whiteside. Whiteside stabbed Love in the chest, inflicting a fatal wound.

Whiteside was charged with murder, and when counsel was appointed he objected to the lawyer initially appointed, claiming that he felt uncomfortable with a lawyer who had formerly been a prosecutor. Gary L. Robinson was then appointed and immediately began an investigation. Whiteside gave him a statement that he had stabbed Love as the latter "was pulling a pistol from underneath the pillow on the bed." Upon questioning by Robinson, however, Whiteside indicated that he had not actually seen a gun, but that he was convinced that Love had a gun. No pistol was found on the premises; shortly after the police search following the stabbing, which had revealed no weapon, the victim's family had removed all of the victim's possessions from the apartment. Robinson interviewed Whiteside's companions who were present during the stabbing, and none had seen a gun during the incident. Robinson advised Whiteside that the existence of a gun was not necessary to establish the claim of self-defense, and that only a reasonable belief that the victim had a gun nearby was necessary even though no gun was actually present.

Until shortly before trial, Whiteside consistently stated to Robinson that he had not actually seen a gun, but that he was convinced that Love had a gun in his hand. About a week before trial, during preparation for direct examination, Whiteside for the first time told Robinson and his associate Donna Paulsen that he had seen something "metallic" in Love's hand. When asked about this, Whiteside responded:

In Howard Cook's case there was a gun. If I don't say I saw a gun, I'm dead.

Robinson told Whiteside that such testimony would be perjury and repeated that it was not necessary to prove that a gun was available but only that Whiteside reasonably believed that he was in danger. On Whiteside's insisting that he would testify that he saw "something metallic" Robinson told him, according to Robinson's testimony: 
We could not allow him to testify falsely because that would be perjury, and as officers of the court we would be suborning perjury if we allowed him to do it. I advised him that if he did do that it would be my duty to advise the Court of what he was doing and that I felt he was committing perjury; also, that I probably would be allowed to attempt to impeach that particular testimony.

Robinson also indicated he would seek to withdraw from the representation if Whiteside insisted on committing perjury.

Whiteside testified in his own defense at trial and stated that he "knew" that Love had a gun and that he believed Love was reaching for a gun and he had acted swiftly in self-defense. On cross-examination, he admitted that he had not actually seen a gun in Love's hand. Robinson presented evidence that Love had been seen with a sawed-off shotgun on other occasions, that the police search of the apartment may have been careless, and that the victim's family had removed everything from the apartment shortly after the crime. Robinson presented this evidence to show a basis for Whiteside's asserted fear that Love had a gun.

The jury returned a verdict of second-degree murder, and Whiteside moved for a new trial, claiming that he had been deprived of a fair trial by Robinson's admonitions not to state that he saw a gun or "something metallic." The trial court held a hearing, heard testimony by Whiteside and Robinson, and denied the motion. The trial court made specific findings that the facts were as related by Robinson.

The Supreme Court of lowa affirmed respondent's conviction. That court held that the right to have counsel present all appropriate defenses does not extend to using perjury, and that an attorney's duty to a client does not extend to assisting a client in committing perjury. Relying on the lowa Code of Professional Responsibility for Lawyers, which expressly prohibits an attorney from using perjured testimony, and the lowa Code, which criminalizes subornation of perjury, the lowa court concluded that not only were Robinson's actions permissible, but were required. The court commended "both Mr. Robinson and Ms. Paulsen for the high ethical manner in which this matter was handled."

Whiteside then petitioned for a writ of habeas corpus in the United States District Court for the Southern District of lowa. In that petition Whiteside alleged that he had been denied effective assistance of counsel and of his right to present a defense by Robinson's refusal to allow him to testify as he had proposed. The District Court denied the writ. Accepting the state trial court's factual finding that Whiteside's intended testimony would have been perjurious, it concluded that there could be no grounds for habeas relief since there is no constitutional right to present a perjured defense.

The United States Court of Appeals for the Eighth Circuit reversed and directed that the writ of habeas corpus be granted. The Court of Appeals accepted the findings of the trial judge, affirmed by the lowa Supreme Court, that trial counsel believed with good cause that Whiteside would testify falsely and acknowledged that under Harris $v$. New York, a criminal defendant's 
privilege to testify in his own behalf does not include a right to commit perjury. Nevertheless, the court reasoned that an intent to commit perjury, communicated to counsel, does not alter a defendant's right to effective assistance of counsel and that Robinson's admonition to Whiteside that he would inform the court of Whiteside's perjury constituted a threat to violate the attorney's duty to preserve client confidences. According to the Court of Appeals, this threatened violation of client confidences breached the standards of effective representation set down in Strickland v. Washington. The court also concluded that Strickland's prejudice requirement was satisfied by an implication of prejudice from the conflict between Robinson's duty of loyalty to his client and his ethical duties. A petition for rehearing en banc was denied. We granted certiorari and we reverse.

\section{A}

The right of an accused to testify in his defense is of relatively recent origin. Until the latter part of the preceding century, criminal defendants in this country, as at common law, were considered to be disqualified from giving sworn testimony at their own trial by reason of their interest as a party to the case. lowa was among the states that adhered to this rule of disqualification.

By the end of the 19th century, however, the disqualification was finally abolished by statute in most states and in the federal courts. Although this Court has never explicitly held that a criminal defendant has a due process right to testify in his own behalf, cases in several Circuits have so held, and the right has long been assumed. We have also suggested that such a right exists as a corollary to the Fifth Amendment privilege against compelled testimony.

B.

We turn next to the question presented: the definition of the range of "reasonable professional" responses to a criminal defendant client who informs counsel that he will perjure himself on the stand. We must determine whether, in this setting, Robinson's conduct fell within the wide range of professional responses to threatened client perjury acceptable under the Sixth Amendment. In Strickland, we recognized counsel's duty of loyalty and his "overarching duty to advocate the defendant's cause." Plainly, that duty is limited to legitimate, lawful conduct compatible with the very nature of a trial as a search for truth. Although counsel must take all reasonable lawful means to attain the objectives of the client, counsel is precluded from taking steps or in any way assisting the client in presenting false evidence or otherwise violating the law. This principle has consistently been recognized in most unequivocal terms by expositors of the norms of professional conduct since the first Canons of Professional Ethics were adopted by the American Bar Association in 1908. The 1908 Canon 32 provided:

No client, corporate or individual, however powerful, nor any cause, civil or political, however important, is entitled to receive nor should any lawyer render any service or advice involving disloyalty to the law whose ministers we are, or disrespect of the judicial office, which we are bound to uphold, or corruption of any person or persons exercising 
a public office or private trust, or deception or betrayal of the public. He must observe and advise his client to observe the statute law.

Of course, this Canon did no more than articulate centuries of accepted standards of conduct. Similarly, Canon 37, adopted in 1928, explicitly acknowledges as an exception to the attorney's duty of confidentiality a client's announced intention to commit a crime:

The announced intention of a client to commit a crime is not included within the confidences which the attorney is bound to respect.

These principles have been carried through to contemporary codifications of an attorney's professional responsibility. Disciplinary Rule 7-102 of the Model Code of Professional Responsibility (1980), entitled "Representing a Client Within the Bounds of the Law," provides:

(A) In his representation of a client, a lawyer shall not:

(4) Knowingly use perjured testimony or false evidence.

(7) Counsel or assist his client in conduct that the lawyer knows to be illegal or fraudulent.

This provision has been adopted by lowa, and is binding on all lawyers who appear in its courts.

The more recent Model Rules of Professional Conduct (1983) similarly admonish attorneys to obey all laws in the course of representing a client:

RULE 1.2 Scope of Representation

(d) A lawyer shall not counsel a client to engage, or assist a client, in conduct that the lawyer knows is criminal or fraudulent.

Both the Model Code of Professional Responsibility and the Model Rules of Professional Conduct also adopt the specific exception from the attorney-client privilege for disclosure of perjury that his client intends to commit or has committed. Indeed, both the Model Code and the Model Rules do not merely authorize disclosure by counsel of client perjury; they require such disclosure.

These standards confirm that the legal profession has accepted that an attorney's ethical duty to advance the interests of his client is limited by an equally solemn duty to comply with the law and standards of professional conduct; it specifically ensures that the client may not use false evidence. This special duty of an attorney to prevent and disclose frauds upon the court derives from the recognition that perjury is as much a crime as tampering with witnesses or jurors by way of promises and threats, and undermines the administration of justice. The offense of perjury was a crime recognized at common law, and has been made a felony in most states by statute, including lowa. An attorney who aids false testimony by questioning a witness when perjurious responses can be anticipated risks prosecution for subornation of perjury. 
It is universally agreed that at a minimum the attorney's first duty when confronted with a proposal for perjurious testimony is to attempt to dissuade the client from the unlawful course of conduct. Withdrawal of counsel when this situation arises at trial gives rise to many difficult questions including possible mistrial and claims of double jeopardy.

The essence of the brief amicus of the American Bar Association reviewing practices long accepted by ethical lawyers is that under no circumstance may a lawyer either advocate or passively tolerate a client's giving false testimony. This, of course, is consistent with the governance of trial conduct in what we have long called "a search for truth." The suggestion sometimes made that "a lawyer must believe his client, not judge him" in no sense means a lawyer can honorably be a party to or in any way give aid to presenting known perjury.

Considering Robinson's representation of respondent in light of these accepted norms of professional conduct, we discern no failure to adhere to reasonable professional standards that would in any sense make out a deprivation of the Sixth Amendment right to counsel. Whether Robinson's conduct is seen as a successful attempt to dissuade his client from committing the crime of perjury, or whether seen as a "threat" to withdraw from representation and disclose the illegal scheme, Robinson's representation of Whiteside falls well within accepted standards of professional conduct and the range of reasonable professional conduct acceptable under Strickland.

The Court of Appeals assumed for the purpose of the decision that Whiteside would have given false testimony had counsel not intervened; its opinion denying a rehearing en banc states:

We presume that appellant would have testified falsely. Counsel's actions prevented Whiteside from testifying falsely. We hold that counsel's action deprived appellant of due process and effective assistance of counsel. Counsel's actions also impermissibly compromised appellant's right to testify in his own defense by conditioning continued representation by counsel and confidentiality upon appellant's restricted testimony.

While purporting to follow lowa's highest court "on all questions of state law," the Court of Appeals reached its conclusions on the basis of federal constitutional due process and right to counsel.

The Court of Appeals' holding that Robinson's "action deprived Whiteside of due process and effective assistance of counsel" is not supported by the record since Robinson's action, at most, deprived Whiteside of his contemplated perjury. Nothing counsel did in any way undermined Whiteside's claim that he believed the victim was reaching for a gun. Similarly, the record gives no support for holding that Robinson's action "also impermissibly compromised Whiteside's right to testify in his own defense by conditioning continued representation and confidentiality upon Whiteside's restricted testimony." The record in fact shows the contrary: (a) that Whiteside did testify, and (b) he was "restricted" or restrained only from testifying falsely and was aided by Robinson in developing the basis for the fear that Love was reaching for a gun. Robinson divulged no client communications until he was compelled to do so in response to Whiteside's 
post-trial challenge to the quality of his performance. We see this as a case in which the attorney successfully dissuaded the client from committing the crime of perjury.

Paradoxically, even while accepting the conclusion of the lowa trial court that Whiteside's proposed testimony would have been a criminal act, the Court of Appeals held that Robinson's efforts to persuade Whiteside not to commit that crime were improper, first, as forcing an impermissible choice between the right to counsel and the right to testify; and, second, as compromising client confidences because of Robinson's threat to disclose the contemplated perjury. Whatever the scope of a constitutional right to testify, it is elementary that such a right does not extend to testifying falsely. In Harris v. New York, we assumed the right of an accused to testify "in his own defense, or to refuse to do so" and went on to hold:

That privilege cannot be construed to include the right to commit perjury. Having voluntarily taken the stand, petitioner was under an obligation to speak truthfully.

In Harris we held the defendant could be impeached by prior contrary statements which had been ruled inadmissible under Miranda v. Arizona. Harris and other cases make it crystal clear that there is no right whatever -- constitutional or otherwise -- for a defendant to use false evidence.

The paucity of authority on the subject of any such "right" may be explained by the fact that such a notion has never been responsibly advanced; the right to counsel includes no right to have a lawyer who will cooperate with planned perjury. A lawyer who would so cooperate would be at risk of prosecution for suborning perjury, and disciplinary proceedings, including suspension or disbarment.

Robinson's admonitions to his client can in no sense be said to have forced respondent into an impermissible choice between his right to counsel and his right to testify as he proposed for there was no permissible choice to testify falsely. For defense counsel to take steps to persuade a criminal defendant to testify truthfully, or to withdraw, deprives the defendant of neither his right to counsel nor the right to testify truthfully. In United States $v$. Havens, we made clear that "when defendants testify, they must testify truthfully or suffer the consequences." When an accused proposes to resort to perjury or to produce false evidence, one consequence is the risk of withdrawal of counsel.

On this record, the accused enjoyed continued representation within the bounds of reasonable professional conduct and did in fact exercise his right to testify; at most he was denied the right to have the assistance of counsel in the presentation of false testimony. Similarly, we can discern no breach of professional duty in Robinson's admonition to respondent that he would disclose respondent's perjury to the court. The crime of perjury in this setting is indistinguishable in substance from the crime of threatening or tampering with a witness or a juror. A defendant who informed his counsel that he was arranging to bribe or threaten witnesses or members of the jury would have no "right" to insist on counsel's assistance or silence. Counsel would not be limited to advising against that conduct. An attorney's duty of confidentiality, which totally covers 
the client's admission of guilt, does not extend to a client's announced plans to engage in future criminal conduct. In short, the responsibility of an ethical lawyer, as an officer of the court and a key component of a system of justice, dedicated to a search for truth, is essentially the same whether the client announces an intention to bribe or threaten witnesses or jurors or to commit or procure perjury. No system of justice worthy of the name can tolerate a lesser standard.

The rule adopted by the Court of Appeals, which seemingly would require an attorney to remain silent while his client committed perjury, is wholly incompatible with the established standards of ethical conduct and the laws of lowa and contrary to professional standards promulgated by that State. The position advocated by petitioner, on the contrary, is wholly consistent with the lowa standards of professional conduct and law, with the overwhelming majority of courts, and with codes of professional ethics. Since there has been no breach of any recognized professional duty, it follows that there can be no deprivation of the right to assistance of counsel under the Strickland standard.

\section{Conclusion}

Whiteside's attorney treated Whiteside's proposed perjury in accord with professional standards, and since Whiteside's truthful testimony could not have prejudiced the result of his trial, the Court of Appeals was in error to direct the issuance of a writ of habeas corpus and must be reversed.

JUSTICE BRENNAN, concurring in the judgment.

This Court has no constitutional authority to establish rules of ethical conduct for lawyers practicing in the state courts. Nor does the Court enjoy any statutory grant of jurisdiction over legal ethics.

Accordingly, it is not surprising that the Court emphasizes that it "must be careful not to narrow the wide range of conduct acceptable under the Sixth Amendment so restrictively as to constitutionalize particular standards of professional conduct and thereby intrude into the state's proper authority to define and apply the standards of professional conduct applicable to those it admits to practice in its courts." I read this as saying in another way that the Court cannot tell the States or the lawyers in the States how to behave in their courts, unless and until federal rights are violated.

Unfortunately, the Court seems unable to resist the temptation of sharing with the legal community its vision of ethical conduct. But let there be no mistake: the Court's essay regarding what constitutes the correct response to a criminal client's suggestion that he will perjure himself is pure discourse without force of law. As JUSTICE BLACKMUN observes, that issue is a thorny one, but it is not an issue presented by this case. Lawyers, judges, bar associations, students, and others should understand that the problem has not now been "decided." 
I join JUSTICE BLACKMUN's concurrence because I agree that respondent has failed to prove the kind of prejudice necessary to make out a claim under Strickland $v$. Washington.

JUSTICE BLACKMUN, with whom JUSTICE BRENNAN, JUSTICE MARSHALL, and JUSTICE STEVENS join, concurring in the judgment.

How a defense attorney ought to act when faced with a client who intends to commit perjury at trial has long been a controversial issue. But I do not believe that a federal habeas corpus case challenging a state criminal conviction is an appropriate vehicle for attempting to resolve this thorny problem. When a defendant argues that he was denied effective assistance of counsel because his lawyer dissuaded him from committing perjury, the only question properly presented to this Court is whether the lawyer's actions deprived the defendant of the fair trial which the Sixth Amendment is meant to guarantee. Since I believe that the respondent in this case suffered no injury justifying federal habeas relief, I concur in the Court's judgment.

On February 7, 1977, Emmanual Charles Whiteside stabbed Calvin Love to death. At trial, Whiteside claimed self-defense. On direct examination, he testified that Love's bedroom, where the stabbing had occurred, was "very much dark, and that he had stabbed Love during an argument because he believed that Love was about to attack him with a weapon:

Q. Did you think that Calvin had a gun?

A. Most definitely I thought that.

Q. Why did you think that?

A. Because of Calvin's reputation, his brother's reputation, because of the prior conversation that Calvin and I had, I didn't have no other choice but to think he had a gun. And when he told his girlfriend to give him his piece, I couldn't retreat.

Whiteside's testimony was consistent with that of other witnesses who testified that the room was dark, and that Love had asked his girlfriend to get his "piece" (which they all believed referred to a weapon). No gun, however, was ever found.

Whiteside, who had been charged with first-degree murder, was convicted of second-degree murder, and sentenced to 40 years' imprisonment. He moved for a new trial, contending that his court-appointed attorneys, Gary Robinson and Donna Paulsen, had improperly coerced his testimony. Whiteside now claimed that he had seen a gun, but had been prevented from testifying to this fact.

At an evidentiary hearing on this motion, Whiteside testified that he had told Robinson at their first meeting that he had seen a weapon in Love's hand. Some weeks later, Robinson informed Whiteside that the weapon could not be found and, according to Whiteside, told him to say only that he thought he had seen a gun, rather than that he in fact had seen one. Whiteside "got the 
impression at one time that maybe if I didn't go along with - with what was happening, that it was no gun being involved, maybe that he will pull out of my trial."

Robinson's testimony contradicted Whiteside's. According to Robinson, Whiteside did not initially claim to have seen a gun, but rather claimed only that he was convinced Love had had one. Roughly a week before the trial, however, in the course of reviewing Whiteside's testimony, Whiteside "made reference to seeing something 'metallic' I don't think he ever did say a gun":

And at the end Donna asked him about that, because that was the first time it had ever been mentioned either to her or to myself. His response to that was, "in Howard Cook's case there was a gun. If I don't say I saw a gun, I'm dead." I explained to him at that time that it was not necessary that the gun be physically present for self-defense, one; two, that to say that would be perjury on his part because he had never at any time indicated that there was a gun; three, that we could not allow him to do that; four, I advised him that if he did do that it would be my duty to advise the Court of what he was doing; also, that I probably would be allowed to attempt to impeach that particular testimony. I told him that there was no need for him to lie about what had happened, that he had a good and valid defense on the facts as he had related them to us, and we felt we could present a good self-defense case on the facts he had stated to us.

Robinson acknowledged that Whiteside's claim of self-defense would have been stronger had the gun been found, but explained that at trial "we tried to create a gun," through testimony from people who had seen Love carrying a gun on other occasions, through a stipulation that Love had been convicted of possession of a weapon, and through suggestions made during crossexamination of the State's witnesses that the initial police search had been too cursory to discover the weapon and that Love's girlfriend had removed it from the apartment prior to a second, more thorough, search.

The trial court rejected Whiteside's motion for a new trial, "finding the facts to be as testified to by Ms. Paulsen and Mr. Robinson." The lowa Supreme Court affirmed.

Whiteside then sought federal habeas relief in the United States District Court for the Southern District of lowa. The parties agreed to rest on the record made in the state-court proceedings. Chief Judge Stuart held that the trial judge's factual finding that Whiteside would have committed perjury had he testified at trial actually to having seen a gun was fairly supported by the record and thus entitled to a presumption of correctness. Since Whiteside had no constitutional right to perjure himself, he had been denied neither a fair trial nor effective assistance of counsel.

The Court of Appeals for the Eighth Circuit reversed. The court recognized that the issue before it was not whether Robinson had behaved ethically, ${ }^{98}$ but rather whether Whiteside had been

${ }^{98}$ The court stated:

That question is governed solely by the lowa Code of Professional Responsibility, as it was in effect at the time of the trial in this case, and as it has been authoritatively interpreted by the 
deprived of effective assistance of counsel. In the Court of Appeals' view, Robinson had breached the obligations of confidentiality and zealous advocacy imposed on defense counsel by the Sixth Amendment. In addition, the Court of Appeals concluded that Robinson's actions impermissibly compromised Whiteside's constitutional right to testify in his own behalf by conditioning continued representation and confidentiality on Whiteside's limiting his testimony.

The court recognized that, under Strickland $v$. Washington, a defendant must normally demonstrate both that his attorney's behavior was professionally unreasonable and that he was prejudiced by his attorney's unprofessional behavior. But it noted that Strickland $v$. Washington had recognized a "limited" presumption of prejudice when counsel is burdened by an actual conflict of interest that adversely affects his performance. Here, Whiteside had shown that Robinson's obligations under the lowa Code of Professional Responsibility conflicted with his client's wishes, and his threat to testify against Whiteside had adversely affected Whiteside by "undermining the fundamental trust between lawyer and client" necessary for effective representation.

Petitioner's motion for rehearing en banc was denied by a vote of 5 to 4 . In dissent, Judge John R. Gibson, joined by Judges Ross, Fagg, and Bowman, argued that Whiteside had failed to show cognizable prejudice. Cuyler v. Sullivan was inapposite, both because finding a conflict of interest required making the untenable assumption that Whiteside possessed the right to testify falsely and because Robinson's threat had had no adverse effect on the trial since Whiteside testified fully in his defense. Moreover, the result of the proceeding should not have been different had Whiteside been permitted to testify as he wished.

A separate dissent by Judge Fagg, joined by Judges Ross, John R. Gibson, and Bowman, addressed the performance prong of Strickland. Robinson's admonition to Whiteside to testify truthfully simply could not be viewed as creating a conflict of interest; Robinson presented a full and zealous defense at trial; and, although Robinson's warning to Whiteside may have been "strident," he had communicated with his client in a manner the client understood.

The District Court found that the trial judge's statement that "I find the facts to be as testified to by Ms. Paulsen and Mr. Robinson" was a factual finding that Whiteside "would have perjured himself if he had testified at trial that he actually saw a gun in his victim's hand." This factual finding by the state court is entitled to a presumption of correctness, which Whiteside has not overcome.

Supreme Court of lowa. The Supreme Court of lowa is the last word on all questions of state law, and the Code of Professional Responsibility is a species of state law.

Thus, the court declined to address the question whether Robinson's actions were either compelled or condoned by lowa law. 
Respondent has never attempted to rebut the presumption by claiming that the factfinding procedure employed by lowa in considering new trial motions in any sense deprived him of a full and fair hearing or failed to provide a sufficient basis for denying his motion. Although respondent's argument to this Court in large part assumes that the precluded testimony would have been false, he contends, first, that the record does not fairly support the conclusion that he intended to perjure himself because he claimed in his first written statement that Love had been pulling a pistol from under a pillow at the time of the stabbing, and, second, that whether Robinson had sufficient knowledge to conclude he was going to commit perjury was a mixed question of law and fact to which the presumption of correctness does not apply.

Neither contention overcomes the presumption of correctness due the state court's finding. First, the trial judge's implicit decision not to credit the written statement is fairly supported by Robinson's testimony that the written statement had not been prepared by Whiteside alone and that, from the time of their initial meeting until the week before trial, Whiteside never again claimed to have seen a gun. Second, the finding properly accorded a presumption of correctness by the courts below was that Whiteside's "proposed testimony would have been deliberately untruthful." The lower courts did not purport to presume the correctness of the lowa Supreme Court's holding concerning the mixed question respondent identifies — whether Robinson's response to Whiteside's proposed testimony deprived Whiteside of effective representation.

\section{B}

The Court approaches this case as if the performance-and-prejudice standard requires us in every case to determine "the perimeters of the range of reasonable professional assistance, but Strickland $v$. Washington explicitly contemplates a different course:
Although we have discussed the performance component of an ineffectiveness claim prior to the prejudice component, there is no reason for a court deciding an ineffective assistance claim to approach the inquiry in the same order or even to address both components of the inquiry if the defendant makes an insufficient showing on one. In particular, a court need not determine whether counsel's performance was deficient before examining the prejudice suffered by the defendant as a result of the alleged deficiencies. If it is easier to dispose of an ineffectiveness claim on the ground of lack of sufficient prejudice, which we expect will often be so, that course should be followed.

In this case, respondent has failed to show any legally cognizable prejudice. Nor, as is discussed below, is this a case in which prejudice should be presumed.

The touchstone of a claim of prejudice is an allegation that counsel's behavior did something "to deprive the defendant of a fair trial, a trial whose result is reliable." The only effect Robinson's threat had on Whiteside's trial is that Whiteside did not testify, falsely, that he saw a gun in Love's hand. Thus, this Court must ask whether its confidence in the outcome of Whiteside's 
trial is in any way undermined by the knowledge that he refrained from presenting false testimony.

This Court long ago noted: "All perjured relevant testimony is at war with justice, since it may produce a judgment not resting on truth. Therefore it cannot be denied that it tends to defeat the sole ultimate objective of a trial." When the Court has been faced with a claim by a defendant concerning prosecutorial use of such evidence, it has "consistently held that a conviction obtained by the knowing use of perjured testimony is fundamentally unfair, and must be set aside if there is any reasonable likelihood that the false testimony could have affected the judgment of the jury." Similarly, the Court has viewed a defendant's use of such testimony as so antithetical to our system of justice that it has permitted the prosecution to introduce otherwise inadmissible evidence to combat it. The proposition that presenting false evidence could contribute to (or that withholding such evidence could detract from) the reliability of a criminal trial is simply untenable.

It is no doubt true that juries sometimes have acquitted defendants who should have been convicted, and sometimes have based their decisions to acquit on the testimony of defendants who lied on the witness stand. It is also true that the Double Jeopardy Clause bars the reprosecution of such acquitted defendants, although on occasion they can be prosecuted for perjury. But the privilege every criminal defendant has to testify in his own defense "cannot be construed to include the right to commit perjury." To the extent that Whiteside's claim rests on the assertion that he would have been acquitted had he been able to testify falsely, Whiteside claims a right the law simply does not recognize. "A defendant has no entitlement to the luck of a lawless decisionmaker, even if a lawless decision cannot be reviewed." Since Whiteside was deprived of neither a fair trial nor any of the specific constitutional rights designed to guarantee a fair trial, he has suffered no prejudice.

The Court of Appeals erred in concluding that prejudice should have been presumed. Strickland $v$. Washington found such a presumption appropriate in a case where an attorney labored under "an actual conflict of interest that adversely affected his performance." In this case, however, no actual conflict existed. I have already discussed why Whiteside had no right to Robinson's help in presenting perjured testimony. Moreover, Whiteside has identified no right to insist that Robinson keep confidential a plan to commit perjury. The prior cases where this Court has reversed convictions involved conflicts that infringed a defendant's legitimate interest in vigorous protection of his constitutional rights. Here, Whiteside had no legitimate interest that conflicted with Robinson's obligations not to suborn perjury and to adhere to the lowa Code of Professional Responsibility.

In addition, the lawyer's interest in not presenting perjured testimony was entirely consistent with Whiteside's best interest. If Whiteside had lied on the stand, he would have risked a future perjury prosecution. Moreover, his testimony would have been contradicted by the testimony of other eyewitnesses and by the fact that no gun was ever found. In light of that impeachment, the jury might have concluded that Whiteside lied as well about his lack of premeditation and thus might have convicted him of first-degree murder. And if the judge believed that Whiteside had 
lied, he could have taken Whiteside's perjury into account in setting the sentence. In the face of these dangers, an attorney could reasonably conclude that dissuading his client from committing perjury was in the client's best interest and comported with standards of professional responsibility. In short, Whiteside failed to show the kind of conflict that poses a danger to the values of zealous and loyal representation embodied in the Sixth Amendment. A presumption of prejudice is therefore unwarranted.

C

In light of respondent's failure to show any cognizable prejudice, I see no need to "grade counsel's performance." The only federal issue in this case is whether Robinson's behavior deprived Whiteside of the effective assistance of counsel; it is not whether Robinson's behavior conformed to any particular code of legal ethics.

Whether an attorney's response to what he sees as a client's plan to commit perjury violates a defendant's Sixth Amendment rights may depend on many factors: how certain the attorney is that the proposed testimony is false, the stage of the proceedings at which the attorney discovers the plan, or the ways in which the attorney may be able to dissuade his client, to name just three. The complex interaction of factors, which is likely to vary from case to case, makes inappropriate a blanket rule that defense attorneys must reveal, or threaten to reveal, a client's anticipated perjury to the court. Except in the rarest of cases, attorneys who adopt "the role of the judge or jury to determine the facts," pose a danger of depriving their clients of the zealous and loyal advocacy required by the Sixth Amendment.

I therefore am troubled by the Court's implicit adoption of a set of standards of professional responsibility for attorneys in state criminal proceedings. The States, of course, do have a compelling interest in the integrity of their criminal trials that can justify regulating the length to which an attorney may go in seeking his client's acquittal. But the American Bar Association's implicit suggestion in its brief amicus curiae that the Court find that the Association's Model Rules of Professional Conduct should govern an attorney's responsibilities is addressed to the wrong audience. It is for the States to decide how attorneys should conduct themselves in state criminal proceedings, and this Court's responsibility extends only to ensuring that the restrictions a State enacts do not infringe a defendant's federal constitutional rights. Thus, I would follow the suggestion made in the joint brief amici curiae filed by 37 States at the certiorari stage that we allow the States to maintain their "differing approaches" to a complex ethical question. The signal merit of asking first whether a defendant has shown any adverse prejudicial effect before inquiring into his attorney's performance is that it avoids unnecessary federal interference in a State's regulation of its bar. Because I conclude that the respondent in this case failed to show such an effect, I join the Court's judgment that he is not entitled to federal habeas relief.

JUSTICE STEVENS, concurring in the judgment. 
Justice Holmes taught us that a word is but the skin of a living thought. A "fact" may also have a life of its own. From the perspective of an appellate judge, after a case has been tried and the evidence has been sifted by another judge, a particular fact may be as clear and certain as a piece of crystal or a small diamond. A trial lawyer, however, must often deal with mixtures of sand and clay. Even a pebble that seems clear enough at first glance may take on a different hue in a handful of gravel.

As we view this case, it appears perfectly clear that respondent intended to commit perjury, that his lawyer knew it, and that the lawyer had a duty - both to the court and to his client, for perjured testimony can ruin an otherwise meritorious case - to take extreme measures to prevent the perjury from occurring. The lawyer was successful and, from our unanimous and remote perspective, it is now pellucidly clear that the client suffered no "legally cognizable prejudice."

Nevertheless, beneath the surface of this case there are areas of uncertainty that cannot be resolved today. A lawyer's certainty that a change in his client's recollection is a harbinger of intended perjury - as well as judicial review of such apparent certainty - should be tempered by the realization that, after reflection, the most honest witness may recall (or sincerely believe he recalls) details that he previously overlooked. Similarly, the post-trial review of a lawyer's pretrial threat to expose perjury that had not yet been committed — and, indeed, may have been prevented by the threat - is by no means the same as review of the way in which such a threat may actually have been carried out. Thus, one can be convinced - as I am - that this lawyer's actions were a proper way to provide his client with effective representation without confronting the much more difficult questions of what a lawyer must, should, or may do after his client has given testimony that the lawyer does not believe. The answer to such questions may well be colored by the particular circumstances attending the actual event and its aftermath.

Because JUSTICE BLACKMUN has preserved such questions for another day, and because I do not understand him to imply any adverse criticism of this lawyer's representation of his client, I join his opinion concurring in the judgment.

\section{Questions:}

1. Why did the majority conclude that Whiteside was planning to commit perjury? Is it possible that he recollected something new about the incident? Is it appropriate to rely on the trial court's finding of fact about what Whiteside saw?

2. Why do the concurring justices disagree with the majority opinion? How do they think attorneys should evaluate the truthfulness of client testimony?

People v. DePallo, 754 N.E.2d 751 (NY 2001)

Summary: Michael DePallo was charged with the murder of an elderly man. Initially, DePallo told his attorney that he had participated in the murder, but then insisted on testifying that he had been at home the entire night. In an ex parte meeting, DePallo's 
attorney informed the court that his client was planning to commit perjury. The court permitted DePallo to testify in a narrative form, and his attorney did not use his testimony in summation. DePallo was convicted and appealed. The Appellate Division and Court of Appeals affirmed, holding that DePallo had no right to commit perjury, and his attorney's disclosure to the court did not violate attorney-client confidentiality.

WESLEY, J.

This case calls upon us to clarify a defense attorney's responsibilities when confronted with the dilemma that a client intends to commit perjury.

Defendant and his accomplices executed a calculated attack on a 71-year-old man, ransacking his home, stabbing him repeatedly with a knife and scissors, and finally bludgeoning him to death with a shovel. Defendant's blood was found at the scene and on the victim's clothing. Defendant's fingerprint was also discovered in the home and, upon arrest, he made several incriminating statements placing him at the scene of the crime. Defendant also insisted on making a statement during pre-trial proceedings in which he admitted that he had forced one of his accomplices to participate in the crime under threat of death.

At trial, defense counsel noted at a sidebar that he had advised defendant that he did not have to testify and should not testify, but if he did, he should do so truthfully. Defendant confirmed counsel's statements to the court but insisted on testifying. Defense counsel elicited defendant's direct testimony in narrative form. Defendant testified that he was home the entire evening of the crime, and that his contrary statements to the police were induced by promises that he could return home. During the prosecutor's cross-examination, defense counsel made numerous objections.

After both sides rested, defense counsel addressed the court in Chambers, outside the presence of defendant and the prosecutor. Counsel stated:

Prior to the defendant's testimony, I informed the Court that the defendant was going to take the witness stand, and that he had previously told me he was involved in this homicide. Although I did not get into details with him, I don't know exactly what his involvement was, but he had stated to me that he was there that night, he had gotten at least that far.

Knowing that, I told the defendant I cannot participate in any kind of perjury, and you really shouldn't perjure yourself. But, he, you know, dealing with him is kind of difficult and he was insistent upon taking the stand. He never told me what he was going to say, but I knew it was not going to be the truth, at least to the extent of him denying participation.

The court then noted that counsel had complied with the procedures for such circumstances as outlined in People v. Salquerro. During summations, defense counsel did not refer to 
defendant's trial testimony. Defendant was convicted of two counts of second degree murder, two counts of first degree robbery, two counts of first degree burglary, and one count of second degree robbery. The Appellate Division affirmed, rejecting defendant's claims that he was denied effective assistance of counsel when his attorney disclosed the perjured testimony to the court and that the ex parte conference was a material stage of trial. A Judge of this Court granted leave to appeal, and we now affirm.

The ethical dilemma presented by this case is not new. Defense attorneys have confronted the problem of client perjury since the latter part of the 19th century when the disqualification of criminal defendants to testify in their own defense was abolished by statute in federal courts and in most states, including New York in 1869. A lawyer with a perjurious client must contend with competing considerations-duties of zealous advocacy, confidentiality and loyalty to the client on the one hand, and a responsibility to the courts and our truth-seeking system of justice on the other. Courts, bar associations and commentators have struggled to define the most appropriate role for counsel caught in such situations.

Notwithstanding these ethical concerns, a defendant's right to testify at trial does not include a right to commit perjury, and the Sixth Amendment right to the assistance of counsel does not compel counsel to assist or participate in the presentation of perjured testimony. In light of these limitations, an attorney's duty to zealously represent a client is circumscribed by an "equally solemn duty to comply with the law and standards of professional conduct to prevent and disclose frauds upon the court." The United States Supreme Court has noted that counsel must first attempt to persuade the client not to pursue the unlawful course of conduct. If unsuccessful, withdrawal from representation may be an appropriate response, but when confronted with the problem during trial, as here, an "attorney's revelation of his client's perjury to the court is a professionally responsible and acceptable response."

This approach is consistent with the ethical obligations of attorneys under New York's Code of Professional Responsibility. DR 7-102 expressly prohibits an attorney, under penalty of sanctions, from knowingly using perjured testimony or false evidence; knowingly making a false statement of fact; participating in the creation or preservation of evidence when the attorney knows, or it is obvious, that the evidence is false; counseling or assisting the client in conduct the lawyer knows to be illegal or fraudulent; and knowingly engaging in other illegal conduct. Additionally, DR 7-102(b)(1) mandates that "a lawyer who receives information clearly establishing that the client has, in the course of the representation, perpetrated a fraud upon a tribunal shall promptly call upon the client to rectify the same, and if the client refuses or is unable to do so, the lawyer shall reveal the fraud to the affected tribunal, except when the information is protected as a confidence or secret."

In accordance with these responsibilities, defense counsel first sought to dissuade defendant from testifying falsely, and indeed from testifying at all. Defendant insisted on proceeding to give the perjured testimony and, thereafter, counsel properly notified the court. 
The intent to commit a crime is not a protected confidence or secret, Moreover, in this case defense counsel did not reveal the substance of any client confidence as defendant had already admitted at a pre-trial hearing that he had forced one of his accomplices to participate in the crime under threat of death.

Finally, defendant contends that his counsel should have sought to withdraw from the case. However, substitution of counsel would do little to resolve the problem and might, in fact, have facilitated any fraud defendant wished to perpetrate upon the court. We agree with Salquerro that withdrawal of counsel could present other unsatisfactory scenarios which ultimately could lead to introduction of the perjured testimony in any event or further delay the proceedings.

In this case, defendant was allowed to present his testimony in narrative form to the jury. The remainder of defense counsel's representation throughout the trial was more than competent. The lawyer's actions properly balanced the duties he owed to his client and to the court and criminal justice system; "since there has been no breach of any recognized professional duty, it follows that there can be no deprivation of the right to assistance of counsel."

We also reject defendant's contention that his right to be present during a material stage of trial was violated by his absence from the ex parte communication between the court and his attorney. Although a defendant has a constitutional and statutory right to be present at all material stages of a trial, and at ancillary proceedings when he or she may have something valuable to contribute or when presence would have a substantial effect on a defendant's ability to defend against the charges, this right does not extend to circumstances involving matters of law or procedure that have no potential for meaningful input from a defendant.

The purpose of this ancillary proceeding was simply to place on the record matters which had already occurred regarding defendant's perjury and his attorney's response. The conference memorialized counsel's dilemma for appellate review and possible analysis of counsel's professional ethical obligations. Thus, defendant's presence was not mandated; it had no bearing on his ability to defend against the charges or on the outcome of this jury trial. The situation here is akin to People v. Keen. In Keen, we held that the defendant had no right to be present at two ex parte conferences held at defense counsel's behest which involved discussions regarding the testimony and anticipated perjury of a key witness-matters which we characterized as simply procedural.

In sum, because the subject matter of the ex parte communication here was merely procedural, and there was no hearing or other factual inquiry beyond that which had transpired earlier in the proceedings, defendant had no right to be present.

Accordingly, the order of the Appellate Division should be affirmed.

\section{Questions:}


1. The New York Times reported on this murder here. Michael DePallo and his two friends were 15-16 years old and living in a foster-care group home on Staten Island, when they broke into the home of 71 year old Gus Ferrera and murdered him. How should an attorney evaluate the truthfulness of a teenager's testimony?

2. Should DePallo's attorney have disclosed his belief that DePallo planned to commit perjury? Would nondisclosure have affected the outcome? Should the attorney have prevented DePallo from testifying? Could it have improved the outcome?

\section{Knowledge of Falsehood}

Oh don't you lie to me, because it makes me mad, and l'll get evil as a man can be. ${ }^{99}$

Attorneys are obligated to prevent or cure client perjury only if they "actually know" that their client probably will commit perjury or has committed perjury. Under Model Rule 3.3, a "reasonable belief" of perjury does not constitute actual knowledge. And in general, courts have adopted very high standards for "actual knowledge" of perjury.

All courts require a knowledge of perjury based on specific, actual facts, rather than a mere belief. The fact that a client's account is internally inconsistent, has changed over time, or conflicts with other evidence is insufficient to create a knowledge of perjury. Defendants may even present testimony that appears to be manifestly incredible or absurd, so long as it is not demonstrably perjury.

However, different courts have adopted different interpretations of the "actual knowledge" test. Some courts require a "firm factual basis that the testimony will be false." Others require either "good cause to believe the defendant's proposed testimony would be deliberately untruthful" or a good faith determination of falsehood "based on objective circumstances firmly rooted in fact."

Some courts have even rejected the "actual knowledge" test entirely. Illinois gives attorneys "great discretion" in determining whether their clients will commit perjury. Some jurisdictions require that counsel possess proof of perjury beyond a reasonable doubt. And others require "compelling support" for the expectation of perjury.

I was taught to never tell a lie, to look you in the eye and tell it like it is. Always thought that you would be the same. It's such a shame that's not the way it is. ${ }^{100}$

State v. Hischke, 639 N.W.2d 6 (lowa 2002)

Summary: The police found marijuana in Hischke's jacket pocket and charged him with possession. Bishop represented Hischke. Initially, Hischke told Bishop the marijuana was his, but when he learned that a third possession offense would cause an enhanced

\footnotetext{
99 Hudson "Tampa Red" Whitaker, Don't You Lie to Me (1940).

100 Joan Jett and the Blackhearts, Little Liar, Up Your Alley (1988).
} 
sentence, he denied ownership. Bishop informed the court that Hischke planned to commit perjury, and the court prohibited Hischke from testifying about the ownership of the marijuana. Hischke was convicted and appealed, claiming ineffective assistance of counsel. The lowa Supreme Court affirmed, holding that Hischke had no right to commit perjury, and Bishop acted reasonably under the circumstances. The concurrence argued that criminal defense attorneys should never inform the court that their client intends to commit perjury.

STREIT, Justice.

Mark Hischke made an eleventh-hour decision to deny possession of marijuana after previously admitting to the police and his lawyer the marijuana belonged to him. Hischke's trial counsel, John Bishop, informed the court Hischke intended to commit perjury. After a jury trial, the court convicted Hischke of possession of marijuana. Hischke appeals contending he was denied effective assistance of counsel when his trial lawyer alerted the court to his "personal belief" Hischke planned to present perjured testimony. Because we find Bishop had good cause to believe Hischke's proposed testimony would be deliberately untruthful, we affirm.

\section{Facts}

On December 5, 1999, Waterloo police officers executed an arrest warrant on Eric Twesme at his apartment. When the officers arrived, Twesme and Mark Hischke were present in the apartment. Twesme answered the door and permitted the officers to enter. In the apartment, the officers saw syringes, spoons, and cotton. The officers asked Hischke to wait in the hallway where he consented to a search of his person. The officer discovered a syringe in Hischke's shirt pocket. Before going to the police station, Twesme asked the officers for a jacket. One of the officers saw a leather jacket in the apartment draped over the back of the chair where Hischke had been sitting. The officer asked Twesme if the jacket was his and Twesme said it did not belong to him. Hischke admitted ownership of the jacket but said he was not responsible for anything in the pockets. During a consent search, the police officer found a small bag of marijuana in the jacket.

Mark Hischke was charged with possession of marijuana. On the day the trial was scheduled to begin, Hischke's attorney, John Bishop, moved to withdraw from the case. Bishop stated his client initially claimed ownership of the marijuana but shortly before the trial Hischke denied ownership. Bishop explained to the court,

It's my personal belief that Mr. Hischke's original statements to me that the marijuana was his was the truth, and if Mr. Hischke requires me to present evidence otherwise I think I would be presenting perjured testimony, and so I don't feel I can ethically be permitted to do that. But Mr. Hischke wishes to present that defense and that's, I guess, the dilemma we have here. 
The district court informed Hischke he would not be permitted to testify as to the ownership of the marijuana. Hischke declined to testify and the jury found him guilty as charged.

On appeal, Hischke contends he was denied effective assistance of counsel when Bishop informed the court he believed his client was going to present perjured testimony. Hischke argues it is not sufficient for an attorney to merely "believe" a client intends to commit perjury. Hischke asks us to adopt a standard that requires an attorney to have "actual knowledge" the client's testimony will be false. Hischke argues prejudice should be presumed.

The State contends an attorney need only have a "firm factual basis" for believing a client plans to lie before taking any measures designed to prevent such perjury. The State argues Bishop satisfied this standard.

\section{Ineffective Assistance of Counsel}

To prevail on a claim of ineffective assistance of counsel, Hischke must demonstrate both ineffective assistance and prejudice. Both elements must be proven by a preponderance of the evidence. If a claim lacks one of the elements of an ineffective assistance of counsel claim, it is not necessary for us to address the other element.

Hischke must first prove Bishop's performance was not within the normal range of competence. We measure the attorney's performance by standards of reasonableness consistent with "prevailing professional norms." We begin our analysis with the presumption Bishop performed competently. Claims of ineffective assistance of counsel are more likely to be found where counsel lacked diligence as opposed to the exercise of judgment.

Bishop believed his client planned on committing perjury. Trial counsel may not knowingly present perjured testimony. When counsel knows a client has committed perjury or plans on doing so, counsel may reveal the perjury to the court. On this appeal, we must determine whether Bishop performed competently and reasonably in deciding to inform the court his client intended to present perjured testimony.

The central issue before us is what standard of knowledge is required before a lawyer may inform the court of his or her client's plan to commit perjury. There are several factors to consider in making this determination: (1) how certain counsel was the proposed testimony was false; (2) at what stage of the proceedings counsel discovered the plan; and (3) the ways in which the attorney may be able to dissuade his or her client from committing perjury.

Other jurisdictions have addressed the standard to be applied when a lawyer informs the court his or her client intends to commit perjury. Some courts require a lawyer to have knowledge "beyond a reasonable doubt" before disclosing to the court the belief a client is planning on committing perjury. Other courts have adopted the "firm factual basis" standard. Another court requires a "good faith determination" by counsel the defendant will commit perjury when he 
testifies. Certain other courts require counsel to engage in an independent investigation of the facts before determining the defendant's anticipated testimony will constitute perjury.

We have not addressed this particular issue in lowa since 1978. At that time, we addressed this issue within the context of a case with factual circumstances very similar to the case before us. In Whiteside, the lawyer relied on the defendant's pronouncement shortly before trial that was inconsistent with his story during the initial phases of the proceedings. In asserting self-defense the defendant initially claimed he "thought" the victim had a gun but he did not actually see the gun. Then, before trial, the defendant told counsel he intended to testify he did see a gun because without such testimony he was "dead." We concluded a lawyer is required to be convinced with good cause to believe the defendant's proposed testimony would be deliberately untruthful. Moreover, the lawyer was not required to conduct an independent investigation of the facts before determining his client planned to commit perjury. We reaffirm our holding in Whiteside.

We now turn to the facts before us to determine whether Hischke was denied effective assistance when Bishop alerted the court to Hischke's plan to testify falsely. These are the relevant facts as they occurred before Hischke's change in story. Immediately before Hischke's arrest, he told the police officers he owned the leather jacket but was not responsible for anything inside the pockets. This statement indicates Hischke was aware the officers would find something illegal in the jacket. Consistent with Hischke's declaration of ownership, Twesme told the police officers the leather jacket did not belong to him. Hischke then wore the leather jacket to the police station. During his initial contact with Bishop, Hischke stated the jacket belonged to him.

Shortly before the trial was scheduled to begin, Hischke learned of the enhanced sentence that would accompany his third conviction on a charge of possession of marijuana. At this time Hischke changed his testimony and told Bishop the jacket did not belong to him. Hischke claims he had only been taking "the rap" for his friend Twesme but would no longer do so because of the enhanced punishment Hischke faced. This statement is questionable because of its lateness.

In addition to the facts above, other factors contributed to Bishop's objectively reasonable basis for believing Hischke intended to commit perjury. The police officers found a syringe in Hischke's shirt pocket when they patted him down outside of the apartment. Hischke was visiting a friend who had an outstanding warrant for selling morphine and who lives in an apartment openly littered with drug paraphernalia. As stated above, this was not Hischke's first brush with the law. He has two prior marijuana convictions.

Given these facts, we find Bishop performed competently and reasonably in deciding to inform the court of Hischke's recent change in testimony. Bishop's belief was reasonable under these circumstances. He did not merely suspect or guess Hischke would commit perjury. The facts do not support a finding it was simply Bishop's "gut-level belief" Hischke planned to commit perjury. Moreover, his decision to act on this personal belief is entirely consistent with "prevailing 
professional norms." Bishop was "convinced with good cause to believe defendant's proposed testimony would be deliberately untruthful." Further, it was not necessary for Bishop to conduct an independent investigation of the facts.

We decline to adopt the standard of "actual knowledge" suggested by Hischke. Such a standard would be virtually impossible to satisfy unless the lawyer had a direct confession from his or her client or personally witnessed the event in question. Consequently, the standard of actual knowledge would eviscerate the rules of professional responsibility forbidding a lawyer from presenting perjured testimony.

In finding Bishop's performance was within the normal range of competence we are not stating Bishop was required to take the particular course of action he chose to pursue. This has not been presented to us. We recognize when counsel is faced with the situation of client perjury, he or she has competing interests at stake. Counsel must contend with duties of zealous advocacy, confidentiality, and loyalty to the client. On the other hand, these interests are counter-balanced by duties of accountability to the courts and justice. In order to accommodate these competing interests, there are various appropriate options a lawyer may choose among to decide how to handle such a situation.

\section{Conclusion}

We conclude Hischke's trial counsel acted reasonably when he informed the court his client intended to commit perjury. Hischke satisfied the requisite standard that a lawyer must be "convinced with good cause to believe the defendant's proposed testimony would be deliberately untruthful." Because we find Hischke was not denied effective assistance of counsel, we do not address whether Hischke has demonstrated prejudice. We affirm.

CARTER, Justice (concurring specially).

I concur in affirming defendant's conviction.

This case vividly illustrates the difficulty in determining whether a lawyer has a sufficiently convincing reason to believe a client is about to commit perjury. I have no disagreement with the test, which the opinion of the court employs for making such determinations consistent with the lawyer's ethical obligation. Nor do I question the conclusion of defendant's counsel in the present case in the face of that test. The decision could have gone either way on these facts.

This case does not discuss, because the issue is not raised, whether the action that defendant's counsel took upon becoming convinced of the impending perjury was proper. I am convinced that it was not. My disagreement with defense counsel's action flows from a belief that it is never proper for counsel to advise the court that counsel believes a client will testify falsely. Such conduct will inevitably damage the client's case beyond repair. 
Counsel who reach the conclusion that a client is about to testify falsely should first attempt to dissuade the client from giving the offending testimony. If unsuccessful, counsel should attempt a quiet withdrawal from the representation. The reasons set forth in the application to withdraw should only identify the existence of an unspecified attorney-client disagreement that might compromise the attorney's ethical responsibilities. At no time should the matter of impending perjury be disclosed. If the attempt to withdraw fails, then counsel should proceed with the case and conduct any questioning of the witness so as not to invite the suspected perjury. If the suspected perjury nonetheless occurs, counsel should make no reference of it in arguing the case to the trier of fact. I believe that if a lawyer proceeds in this manner, he or she may fully satisfy the lawyer's ethical obligation to prevent perjury without the necessity of advising the court as to the client's intent to testify falsely.

\section{Questions:}

1. Is it possible that Hischke's proposed testimony was truthful? Did his attorney actually know it was false?

2. What standard should criminal defense attorneys adopt in determining whether their client will commit or has committed perjury?

\section{Further Reading:}

- Ellen Henak, When the Interests of Self, Clients, and Colleagues Collide: The Ethics of Ineffective Assistance of Counsel Claims, 33 Am. J. Trial Adv. 347 (2009) 


\section{5: Alternative Dispute Resolution}

You never give me your money. You only give me your funny paper. And in the middle of negotiations, you break down. ${ }^{101}$

Attorneys have a duty to inform their clients about all of the options available to them. Accordingly, in relation to potential civil litigation, attorneys must inform their clients about alternative dispute resolution mechanisms, when available and appropriate under the circumstances. Among other things, attorneys should advise their clients about the possibility of negotiating a settlement, entering mediation, or pursuing arbitration.

The overwhelming majority of civil actions never go to trial. While settlement rates depend on the jurisdiction, about $95 \%$ of civil actions end in a settlement. More often than not, settlement produces a better outcome for all parties. Litigation is expensive, time-consuming, and risky. It can result in a large award, or it can result in nothing. Settlement allows the parties to arrive at a compromise that reflects their mutual assessment of the value of the claims and the likelihood of success.

In addition, settlements can be more flexible than litigation, allowing the parties to negotiate an outcome that litigation could not produce. Of course, there are limits on negotiation and settlement. For example, the parties cannot agree on an illegal settlement. And settlement requires a meeting of the minds, which may not always be possible, especially if the parties have different assessments of the value of the claims and the likelihood of success.

Mediation is a form of negotiation that involves a neutral third-party mediator, who helps the parties reach a resolution. Mediators typically do not decide the outcome of the mediation. But in some cases, they may give the parties their own assessment of the value of the claims and their likelihood of success. The mediator's third-party opinion may help the parties reach a meeting of the minds and settle.

Arbitration resembles mediation, in that it involves a neutral third-party arbitrator. But unlike in mediation, the arbitrator typically provides a binding decision on the merits. Parties must agree to arbitration and agree to be bound by the arbitrator's decision. While judicial review of the arbitrator's decision is possible in some circumstances, it is very deferential, in order to preserve the finality of the arbitration. Typically, judicial review of an arbitrator's decision is limited to arbitrator bias and misconduct. Even a manifest error of law is usually not grounds for review.

Notably, parties can agree to arbitration in advance, and it is an increasingly common feature of many contracts. Many people worry that these arbitration agreements result in people unwittingly signing away their right to litigate. Some states have resisted enforcing arbitration agreements, but those state laws are often preempted by the Federal Arbitration Act.

\section{Model Rule 4.1: Comments}

\section{Misrepresentation}

1. A lawyer is required to be truthful when dealing with others on a client's behalf, but generally has no affirmative duty to inform an opposing party of relevant facts. A misrepresentation can occur if the lawyer incorporates or affirms a statement of another

${ }^{101}$ Paul McCartney, You Never Give Me Your Money, Abbey Road (1969). 
person that the lawyer knows is false. Misrepresentations can also occur by partially true but misleading statements or omissions that are the equivalent of affirmative false statements. For dishonest conduct that does not amount to a false statement or for misrepresentations by a lawyer other than in the course of representing a client, see Rule 8.4.

Statements of Fact

2. This Rule refers to statements of fact. Whether a particular statement should be regarded as one of fact can depend on the circumstances. Under generally accepted conventions in negotiation, certain types of statements ordinarily are not taken as statements of material fact. Estimates of price or value placed on the subject of a transaction and a party's intentions as to an acceptable settlement of a claim are ordinarily in this category, and so is the existence of an undisclosed principal except where nondisclosure of the principal would constitute fraud. Lawyers should be mindful of their obligations under applicable law to avoid criminal and tortious misrepresentation.

\title{
Kentucky Bar Ass’n v. Geisler, 938 S.W.2d 578 (Ky. 1997)
}

\begin{abstract}
Summary: Milton McNealy was injured by a car in Louisville, Kentucky. Maria Geisler represented McNealy in an action against the driver. Defendant's counsel Kevin Ford asked to depose McNealy, but Geisler postponed because he was too sick. When McNealy died, Geisler contacted Ford and told him her client wanted to settle, but didn't tell him McNealy was dead. Geisler and Ford agreed on a settlement, which McNealy's son signed, and Ford learned McNealy was dead. Ford paid the settlement, but filed a bar complaint against Geisler for failing to disclose McNealy's death. The Kentucky Supreme Court held that attorneys must notify opposing counsel if their client dies and reprimanded Geisler.
\end{abstract}

The Board of Governors of the Kentucky Bar Association, as a result of charges instigated against respondent, Maria T. Geisler of Louisville, found her guilty of violating SCR 3.130-4.1 by failing to divulge the fact of her client's death to opposing counsel prior to entering into and consummating settlement negotiations. Neither the KBA nor the respondent requested review of this case. However, this Court, on its own motion, elected to review the question of whether the respondent's actions were within the scope of SCR 3.130-4.1.

The critical facts in the present case involve respondent's filing of a civil action on behalf of Milton F. McNealy for injuries he sustained when he was struck by an automobile while walking along a street in Louisville, Kentucky on November 26, 1993. Subsequent to the filing of the initial complaint, defendant's counsel, P. Kevin Ford, filed a notice to take the deposition of McNealy. Respondent contacted Ford and told him that McNealy was physically unable to give a deposition since he was in very poor health. Consequently, the deposition of McNealy was never taken.

McNealy died on January 26, 1995. Shortly thereafter respondent contacted Ford and stated that her client wanted to settle the case and asked him to forward an offer of a settlement. After an exchange of offers and counter-offers, a settlement was reached on February 9, 1995. On February 23, 1995, McNealy's son, Joe, was duly appointed as the administrator of his father's estate. Ford eventually forwarded the settlement documents along with a settlement check to respondent on March 13, 1995. On March 22, 1995, Ford received back the settlement documents which had been executed by Joe. Upon receipt of the signed documents, Ford 
learned for the first time of McNealy's death. Ford took no further action to bring the court's attention to the settlement documents that were signed by the Administrator, but instead, sent the agreed order of dismissal to the circuit court which was signed and entered by the court. No appeal was taken.

Thereafter, Ford filed a bar complaint against respondent on May 5, 1995 due to her failure to advise Ford that her client, McNealy, had passed away during the settlement negotiation period of January 26, 1995 through February 9, 1995. The chair of the inquiry tribunal of the KBA charged respondent with violating SCR 3.130-4.1 for failing to divulge the fact of her client's death to opposing counsel prior to entering into and consummating settlement negotiations. After submission to the Board of Governors, the Board determined that respondent was guilty of the charge and recommended to this Court that it issue a private reprimand and a public opinion against an unnamed attorney for the benefit of other members of the KBA.

In its recommendation to this Court, the KBA noted that there is no KBA Ethics Opinion on point with this matter and no Kentucky case law dealing directly with this issue. However, the American Bar Association Standing Committee on Ethics and Professional Responsibility hereinafter ABA, squarely addressed this issue when it issued Formal Opinion 95-397 entitled, "Duty to Disclose Death of Client."

Deciding that counsel has the duty to disclose the death of her client to opposing counsel and to the court when the counsel next communicates with either, the ABA specifically stated in its opinion:

When a lawyer's client dies in the midst of the settlement negotiations of a pending lawsuit in which the client was the claimant, the lawyer has a duty to inform opposing counsel and the Court in the lawyer's first communications with either after the lawyer has learned of the fact.

The ABA's opinion further addressed the question of whether an attorney even has authority to act when her client dies. The opinion determined that prior to death, a lawyer acts on behalf of an identified client. When the death occurs, however, the lawyer ceases to represent that identified client. The ABA maintained that any subsequent communication to opposing counsel with respect to the matter would be the equivalent of a knowing, affirmative misrepresentation should the lawyer fail to disclose the fact that she no longer represents the previously identified client.

Basically, the ABA determined that a lawyer must inform her adversary of the death of her client in her first communication with the adversary after she has learned of that fact. Likewise, the lawyer must also inform her adversary, in the same communication, that the personal representative, if one has been appointed, of her former client is accepting the outstanding settlement offer. Thus, the ABA concluded that a failure to disclose the death of a client is tantamount to making a false statement of material fact within the meaning of Model Rule 4.1(a).

Respondent argues that the ABA's opinion should not apply to her as it was issued on September 18, 1995, many months after the relevant facts in this disciplinary proceeding. She further maintains that ABA Opinion 95-397 is subject to conflicting conclusions and, thus, should not be followed. 
Relying on the additional comments to SCR 3.130-4.1, respondent contends that she did have a duty to disclose "facts" or "evidence." Respondent asserts, however, that an attorney is typically not required to affirmatively reveal evidence that is unknown and potentially helpful to the adverse party. Respondent further maintains that McNealy's death had no significant bearing on the ultimate settlement that was achieved, and that Ford did not oppose the settlement even after it was revealed that McNealy was dead. Finally, respondent contends that Ford knew McNealy had been in poor health and that McNealy's death was a matter of public record reported in the daily newspaper. Respondent argues that she felt she had an ethical duty not to volunteer information about her client's passing. Thus, respondent maintains that it was Ford's own fault to have mistakenly believed that McNealy was alive at the time the settlement was negotiated, because if Ford had wanted to know whether McNealy was dead, all he had to do was ask respondent about it.

Kentucky's SCR 3.130-4.1 specifically provides: "In the course of representing a client a lawyer shall not knowingly make a false statement of material fact or law to a third person." This Court recently considered the application of that rule in Mitchell v. Kentucky Bar Assoc. That case involved a public administrator of an estate who admitted that he had lied to two heirs by falsely stating that an action to determine ownership of some property had been filed, when in fact, no such action had been taken. The respondent in Mitchell, after offering extensive mitigating evidence, including the fact that the heirs' interest had not been impaired, received a public reprimand.

Moreover, in Virzi v. Grand Trunk Warehouse \& Cold Storage Co., the federal district court, relying on Model Rule 4.1 held that a plaintiff's attorney had a duty to disclose the death of her client. The circumstances in that case are strikingly similar to the case at bar in that:

Here, plaintiff's attorney did not make a false statement regarding the death of the plaintiff. He was never placed in a position to do so because during the two weeks of settlement negotiations defendants' attorney never thought to ask if plaintiff was still alive. Instead, in hopes of inducing settlement, plaintiff's attorney chose not to disclose plaintiff's death.

Ultimately, the Virzi court came down on the side of disclosure stating:

This Court feels that candor and honesty necessarily require disclosure of such a significant fact as the death of one's client. Opposing counsel does not have to deal with his adversary as he would deal in the marketplace. Standards of ethics require greater honesty, greater candor, and greater disclosure, even though it might not be in the interest of the client or his estate.

Thus, we hold that the respondent's failure to disclose her client's death to opposing counsel amounted to an affirmative misrepresentation in violation of our SCR 3.130-4.1. While the comments to SCR 3.130-4.1 do indicate that there is no duty to disclose "relevant facts," those same comments go on to state that:

A misrepresentation can occur if the lawyer incorporates or affirms a statement of another person that the lawyer knows is false. Misrepresentations can also occur by failure to act.

Consequently, respondent cannot reasonably argue that her failure to reveal this critical piece of information constituted ethical conduct within the framework of SCR 3.130-4.1. 
Furthermore, respondent's argument that the burden of correcting the mistaken belief that her client was alive should be placed on Ford, is incorrect. Attorneys in circumstances similar to those at bar operate under a reasonable assumption that the other attorney's client, whether a legal fiction or in actual flesh, actually exists and, consequently, that opposing counsel has authority to act on their behalf. Here, respondent obtained authority to act on the behalf of Joe, the administrator, but not McNealy, once he passed away. Basically, when the offer was made after McNealy's death, respondent had no authority to act on his behalf. Despite this fact, respondent proceeded to settle the case under the guise that she still had the authority to do so on behalf of McNealy. Her letters to Ford clearly imply this. Accordingly, this Court cannot go so far as to say that such conduct was ethical under the circumstances and within SCR 3.130-4.1.

It should be noted, that this Court fails to understand why guidelines are needed for an attorney to understand that when their client dies, they are under an obligation to tell opposing counsel such information. This seems to be a matter of common ethics and just plain sense. However, because attorneys such as respondent cannot discern such matters and require written guidelines so as to figure out their ethical convictions, this Court adopts the ruling of ABA Opinion 95-397.

Thus, upon our careful review of the record, we find that the evidence does not support the recommendation of the KBA and consequently we adopt the following order.

\section{IT IS HEREBY ORDERED:}

That respondent, Maria T. Geisler, be, and hereby is, publicly reprimanded for failing to notify her opposing counsel that her client had died during settlement negotiations. The respondent is further ordered to pay the costs of this action pursuant to SCR 3.450.

JOHNSTONE, J., dissents and would concur with the recommendation of the Board of Governors by issuing a private reprimand against an unnamed attorney.

\section{Questions:}

1. Why would it be material to Ford and Ford's client whether McNealy was alive at the time of the settlement? Is it possible that it could have affected their decision whether to settle or the amount of the settlement?

2. The court assumes that Geisler should have known that she had a duty to disclose McNealy's death. Do you agree? Could she have reasonably believed that she had a duty to McNealy's estate not to disclose?

ABA Standing Committee on Ethics and Professional Responsibility, Formal Opinion 06439, Lawyer's Obligation of Truthfulness When Representing a Client in Negotiation: Application to Caucused Mediation (April 12, 2006)

Under Model Rule 4.1, in the context of a negotiation, including a caucused mediation, a lawyer representing a client may not make a false statement of material fact to a third person.

However, statements regarding a party's negotiating goals or its willingness to compromise, as well as statements that can fairly be characterized as negotiation "puffing," ordinarily are not considered "false statements of material fact" within the meaning of the Model Rules. 
In this opinion, we discuss the obligation of a lawyer to be truthful when making statements on behalf of clients in negotiations, including the specialized form of negotiation known as caucused mediation.

It is not unusual in a negotiation for a party, directly or through counsel, to make a statement in the course of communicating its position that is less than entirely forthcoming. For example, parties to a settlement negotiation often understate their willingness to make concessions to resolve the dispute. A plaintiff might insist that it will not agree to resolve a dispute for less than $\$ 200$, when, in reality, it is willing to accept as little as $\$ 150$ to put an end to the matter. Similarly, a defendant manufacturer in patent infringement litigation might repeatedly reject the plaintiffs demand that a license be part of any settlement agreement, when in reality, the manufacturer has no genuine interest in the patented product and, once a new patent is issued, intends to introduce a new product that will render the old one obsolete. In the criminal law context, a prosecutor might not reveal an ultimate willingness to grant immunity as part of a cooperation agreement in order to retain influence over the witness.

A party in a negotiation also might exaggerate or emphasize the strengths, and minimize or deemphasize the weaknesses, of its factual or legal position. A buyer of products or services, for example, might overstate its confidence in the availability of alternate sources of supply to reduce the appearance of dependence upon the supplier with which it is negotiating. Such remarks, often characterized as "posturing" or "puffing," are statements upon which parties to a negotiation ordinarily would not be expected justifiably to rely, and must be distinguished from false statements of material fact. An example of a false statement of material fact would be a lawyer representing an employer in labor negotiations stating to union lawyers that adding a particular employee benefit will cost the company an additional $\$ 100$ per employee, when the lawyer knows that it actually will cost only $\$ 20$ per employee. Similarly, it cannot be considered "posturing" for a lawyer representing a defendant to declare that documentary evidence will be submitted at trial in support of a defense when the lawyer knows that such documents do not exist or will be inadmissible. In the same vein, neither a prosecutor nor a criminal defense lawyer can tell the other party during a plea negotiation that they are aware of an eyewitness to the alleged crime when that is not the case.

\section{Applicable Provision of the Model Rules}

The issues addressed herein are governed by Rule 4.1(a). That rule prohibits a lawyer, "In the course of representing a client," from knowingly making "a false statement of material fact or law to a third person." As to what constitutes a "statement of fact," Comment [2] to Rule 4.1 provides additional explanation:

This Rule refers to statements of fact. Whether a particular statement should be regarded as one of fact can depend on the circumstances. Under generally accepted conventions in negotiation, certain types of statements ordinarily are not taken as statements of material fact. Estimates of price or value placed on the subject of a transaction and a party's intentions as to an acceptable settlement of a claim are ordinarily in this category, and so is the existence of an undisclosed principal except where nondisclosure of the principal would constitute bud. Lawyers should be mindful of their obligations under applicable law to avoid criminal and tortious misrepresentation.

Truthfulness in Negotiation 
It has been suggested by some commentators that lawyers must act honestly and in good faith and should not accept results that are unconscionably unfair, even when they would be to the advantage of the lawyer's own client. Others have embraced the position that deception is inherent in the negotiation process and that a zealous advocate should take advantage of every opportunity to advance the cause of the client through such tactics within the bounds of the law. Still others have suggested that lawyers should strive to balance the apparent need to be less than wholly forthcoming in negotiation against the desirability of adhering to personal ethical and moral standards. Rule 4.1(a) applies only to statements of material fact that the lawyer knows to be false, and thus does not cover false statements that are made unknowingly, that concern immaterial matters, or that relate to neither fact nor law. Various proposals also have been advanced to change the applicable ethics rules, either by amending Rule 4.1 and its Comments, or by extending Rule 3.3 to negotiation, or by creating a parallel set of ethics rules for negotiating lawyers.

Although this Committee has not addressed the precise question posed herein, we previously have opined on issues relating to lawyer candor in negotiations. For example, we stated in Formal Opinion 93-370 that, although a lawyer may in some circumstances ethically decline to answer a judge's questions concerning the limits of the lawyer's settlement authority in a civil matter; the lawyer is not justified in lying or engaging in misrepresentations in response to such an inquiry. We observed that:

While a certain amount of posturing or puffery in settlement negotiations may be an acceptable convention between opposing counsel, a party's actual bottom line or the settlement authority given to a lawyer is a material fact. A deliberate misrepresentation or lie to a judge in pretrial negotiations would be improper under Rule 4.1. Model Rule $8.4(\mathrm{c})$ also prohibits a lawyer from engaging in conduct involving dishonesty fraud, deceit, or misrepresentation, and Rule 3.3 provides that a lawyer shall not knowingly make a false statement of material fact or law to a tribunal. The proper response by a lawyer to improper questions from a judge is to decline to answer, not to lie or misrepresent.

Similarly, in Formal Opinion 94-387, we expressed the view that a lawyer representing a claimant in a negotiation has no obligation to inform the other party that the statute of limitations has run on the client's claim, but cannot make any affirmative misrepresentations about the facts. In contrast, we stated in Formal Opinion 95-397 that a lawyer engaged in settlement negotiations of a pending personal injury lawsuit in which the client was the plaintiff cannot conceal the client's death, and must promptly notify opposing counsel and the court of that fact. Underlying this conclusion was the concept that the death of the client was a material fact, and that any continued communication with opposing counsel or the court would constitute an implicit misrepresentation that the client still was alive. Such a misrepresentation would be prohibited under Rule 4.1 and, with respect to the court, Rule 3.3. Opinions of the few state and local ethics committees that have addressed these issues are to the same effect.

False statements of material fact by lawyers in negotiation, as well as implicit misrepresentations created by a lawyer's failure to make truthful statements, have in some cases also led to professional discipline. For example, in reliance on Formal Opinion 95-397, a Kentucky lawyer was disciplined under Rule 4.1 for settling a personal injury case without disclosing that her client had died. Similarly, in a situation raising issues like those presented in Formal Opinion 93-370, a New York lawyer was disciplined for stating to opposing counsel that, to the best of his knowledge, his client's insurance coverage was limited to $\$ 200,000$, when documents in his files showed that the client had $\$ 1,000,000$ in coverage. Affirmative 
misrepresentations by lawyers in negotiation also have been the basis for the imposition of litigation sanctions, and the setting aside of settlement agreements, as well as civil lawsuits against the lawyers themselves.

In contrast, statements regarding negotiating goals or willingness to compromise, whether in the civil or criminal context, ordinarily are not considered statements of material fact within the meaning of the Rules. Thus, a lawyer may downplay a client's willingness to compromise, or present a client's bargaining position without disclosing the client's "bottom line" position, in an effort to reach a more favorable resolution. Of the same nature are overstatements or understatements of the strengths or weaknesses of a client's position in litigation or otherwise, or expressions of opinion as to the value or worth of the subject matter of the negotiation. Such statements generally are not considered material facts subject to Rule 4.1

Application of the Governing Principles to Caucused Mediation

Having delineated the requisite standard of truthfulness for a lawyer engaged in the negotiation process, we proceed to consider whether a different standard should apply to a lawyer representing a client in a caucused mediation.

Mediation is a consensual process in which a neutral third party, without any power to impose a resolution, works with the disputants to help them reach agreement as to some or all of the issues in controversy. Mediators assist the parties by attempting to fashion creative and integrative solutions to their problems. In the most basic form of mediation, a neutral individual meets with all of the parties simultaneously and attempts to moderate and direct their discussions and negotiations. Whatever is communicated to the mediator by a party or its counsel is heard by all other participants in the mediation. In contrast, the mediator in a caucused mediation meets privately with the parties, either individually or in aligned groups. These caucuses are confidential, and the flow of information among the parties and their counsel is controlled by the mediator subject to the agreement of the respective parties.

It has been argued that lawyers involved in caucused mediation should be held to a more exacting standard of truthfulness because a neutral is involved. The theory underlying this position is that, as in a game of "telephone," the accuracy of communication deteriorates on successive transmissions between individuals, and those distortions tend to become magnified on continued retransmission. Mediators, in turn, may from time to time reframe information as part of their efforts to achieve a resolution of the dispute. To address this phenomenon, which has been called "deception synergy," proponents of this view suggest that greater accuracy is required in statements made by the parties and their counsel in a caucused mediation than is required in face-to-face negotiations.

It has also been asserted that, to the contrary, less attention need be paid to the accuracy of information being communicated in a mediation - particularly in a caucused mediation precisely because consensual deception is intrinsic to the process. Information is imparted in confidence to the mediator, who controls the flow of information between the parties in terms of the content of the communications as well as how and when in the process it is conveyed.

Supporters of this view argue that this dynamic creates a constant and agreed upon environment of imperfect information that ultimately helps the mediator assist the parties in resolving their disputes.

Whatever the validity may be of these competing viewpoints, the ethical principles governing lawyer truthfulness do not permit a distinction to be drawn between the caucused mediation 
context and other negotiation settings. The Model Rules do not require a higher standard of truthfulness in any particular negotiation contexts. Except for Rule 3.3, which is applicable only to statements before a "tribunal," the ethical prohibitions against lawyer misrepresentations apply equally in all environments. Nor is a lower standard of truthfulness warranted because of the consensual nature of mediation. Parties otherwise protected against lawyer misrepresentation by Rule 4.1 are not permitted to waive that protection, whether explicitly through informed consent, or implicitly by agreeing to engage in a process in which it is somehow "understood that false statements will be made. Thus, the same standards that apply to lawyers engaged in negotiations must apply to them in the context of caucused mediation.

We emphasize that, whether in a direct negotiation or in a caucused mediation, care must be taken by the lawyer to ensure that communications regarding the client's position, which otherwise would not be considered statements "of fact," are not conveyed in language that converts them, even inadvertently, into false factual representations. For example, even though a client's Board of Directors has authorized a higher settlement figure, a lawyer may state in a negotiation that the client does not wish to settle for more than $\$ 50$. However, it would not be permissible for the lawyer to state that the Board of Directors had formally disapproved any settlement in excess of $\$ 50$, when authority had in fact been granted to settle for a higher sum.

\section{Conclusion}

Under Model Rule 4.1, in the context of a negotiation, including a caucused mediation, a lawyer representing a party may not make a false statement of material fact to a third person. However, statements regarding a party's negotiating goals or its willingness to compromise, as well as statements that can fairly be characterized as negotiation "puffing," are ordinarily not considered "false statements of material fact" within the meaning of the Model Rules.

In re Fee, 898 P.2d 975 (Ariz. 1995)

ZLAKET, Justice.

Respondents' client gave birth to a severely brain-damaged boy. In 1987, after unsuccessfully seeking representation from three other attorneys, she retained respondents on a $40 \%$ contingent fee. They filed a medical malpractice suit against the State of Arizona and Pima County on behalf of both mother and son. The child's claim was dismissed, as was a pending conservatorship, after the trial court determined that Pizano ex rel. Walker v. Mart precluded all but the mother's action for losses and expenses relating to the boy's condition.

The medical negligence claim was admittedly weak. Respondents' success in developing a colorable racketeering theory, however, prompted negotiations. After an unproductive initial settlement conference, a second was scheduled for January 21, 1991, the day before trial. On Friday the 18th, the defense offered a structured settlement consisting of a cash lump sum followed by periodic payments. This proposal designated a separate amount for attorneys' fees. After consulting an annuities expert, respondents and their client decided that her needs would likely be greater than those contemplated by the offer.

The following Monday at 3:30 P.M., the parties, attorneys, and annuities experts met with the settlement judge. In a private conference with respondents' group, the judge brought up the latest proposal. This prompted a discussion about the "common defense tactic" of making separate offers of attorneys' fees. Respondents and the judge agreed that such a move frequently had the effect of "driving a wedge" between a plaintiff's lawyer and his or her client by 
causing fees to become a source of discomfort, disagreement, and potential conflict. ${ }^{102}$ Despite his recognition of this strategy, however, and respondents' argument that the reasonableness of their fee was an issue for the trial court at the conclusion of the case, the settlement judge indicated that, in his opinion, the contingent fee being charged here was excessive. Testimony before the disciplinary hearing committee shows that the relationship between the court and respondents deteriorated from that point and became progressively antagonistic over this issue. The judge allegedly raised his voice and cursed at respondents. He threatened that if the case did not settle, he would advise the trial judge the failure was because of respondents' greed. All of these statements were made in the presence of the client.

Respondents asserted at the disciplinary hearing that during these negotiations they spoke with their client about the insufficiency of the attorneys' fees being offered by the defense. They claimed that she authorized them to demand more money for the care of her son, thereby possibly securing an increase in fees as well. Although he was not technically a party to these proceedings, the record shows that the son's interests were important to all participants, particularly the court. Consequently, following respondents' pleas, the judge agreed to seek more money from the defendants.

Late in the day, the settlement judge called both sides into the courtroom to discuss a new offer, consisting of $\$ 175,000$ in cash, annuities for both mother and son, $\$ 400,000$ in attorneys' fees, and $\$ 55,000$ in costs. According to the judge, this offer was higher than the previous one because of respondents' representations that the client needed, among other things, better housing and "specially equipped transportation" for her son, as well as additional funds for his possible future surgeries.

After conferring briefly, respondents met privately with the client and proposed that she pay them an additional $\$ 85,000$ in attorney's fees from her share of the cash proceeds. ${ }^{103}$ During this discussion, the judge approached the trio and asked if they needed his help. Respondent Fee testified that he felt pressured by the judge's presence and told him, "I don't want you here." Fee also told the client that she should not allow herself to feel coerced by her attorneys or the judge and that she could refuse the offer or take additional time to consider it.

After repeatedly advising the client of her right to seek independent advice and obtaining numerous assurances from her that she was satisfied with the arrangement, Fee prepared a handwritten agreement concerning the additional fees. This document included a "confidentiality provision," which the committee found was for the client's protection and "to maintain the confidential nature of the settlement conference."

The three then returned to the courtroom where respondents informed their annuities expert about the new agreement. They asked the expert to review the proposed settlement with the client one final time to ensure that the available funds would be sufficient to meet her needs and that the overall agreement was fair. After meeting for approximately ten minutes outside respondents' presence, the expert became satisfied that the client understood and agreed to the

\footnotetext{
102 Indeed, the defense here has since acknowledged that this was its purpose in making a separate offer of fees.

${ }^{103}$ Respondents testified that according to their calculations at the time, receipt of these additional funds would have left them with a total fee amounting to only $34 \%$ of the structured package's present value. We have calculated that the final fee percentage was higher than that, but still slightly less than the $40 \%$ originally agreed upon by the client. In any event, neither the committee nor the commission found that the fee charged was excessive.
} 
terms. The client then signed the additional fee agreement and returned to the judge's chambers with her attorneys.

Respondent Fee announced that they agreed "in principle" to the settlement. However, when the judge repeated the terms previously discussed, nobody disclosed the existence of the newly-enacted fee agreement. Both the committee and the commission found that respondents, not wanting to upset the settlement and believing it was not this judge's role to determine reasonableness of fees, planned to reveal the separate agreement to the trial judge in connection with the formal approval of attorneys' fees required by Rule 3, Uniform Medical Malpractice Rules. ${ }^{104}$ The lawyers never got the chance to do so.

Ten days after the conference, the client telephoned the settlement judge, informed him of the separate agreement, and asked whether she was required to comply with it. The judge obtained a copy of the agreement, held a hearing during which he removed respondents from the case, appointed pro bono counsel to complete the settlement, and provided for the proceeds to be relayed through the clerk of the court for "proper" distribution. He then initiated these disciplinary proceedings.

The hearing committee found that respondents violated ER 3.3(a)(1) (candor toward a tribunal) and ER 8.4(c) (conduct involving a knowing misrepresentation and causing an adverse or potentially adverse effect on a legal proceeding). It recommended 30 -day suspensions. A majority of the disciplinary commission found an additional violation of ER 8.4(d) (conduct prejudicial to the administration of justice) and recommended 60-day suspensions. The state bar asks this court to disregard both recommendations and impose six-month suspensions.

We agree that respondents breached ER 3.3(a)(1), which states: "A lawyer shall not knowingly make a false statement of material fact or law to a tribunal." The comments to ER 3.3 state that "there are circumstances where failure to make a disclosure is the equivalent of an affirmative misrepresentation." Respondents knowingly failed to disclose the separate agreement to the settlement judge in violation of this rule. At the same time, they engaged in "conduct involving dishonesty, fraud, deceit or misrepresentation" in violation of ER 8.4(c).

There are remarkably few cases applying the rules of professional conduct in a settlement context and none that we find directly on point. The bulk of ethical rules seem to have been designed with litigation scenarios in mind. Nevertheless, the scope of their applicability to settlement discussions has been the subject of frequent scholarly debate.

A few commentators have even gone so far as to question the wisdom of demanding truthfulness in settlement conferences, suggesting that a certain amount of gamesmanship is considered acceptable. As one author notes, "the operational necessities of the bargaining process yield an ethical 'functionalism' that results in the minimal truthfulness and fairness necessary for an agreement." Although this court is by no means naive to the realities of the marketplace, we are unwilling to accept or endorse such a flimsy ethical standard. It is not unreasonable to expect more from members of the bar, and we do.

Early drafts of the Model Rules of Professional Conduct contained a separate section devoted to settlement negotiations. It was, however, deleted from the final version. There also appear to

\footnotetext{
104 The record also shows that, within hours of the conference, respondents discussed what they had done with other practitioners and retired judges, all of whom reportedly agreed that their conduct had been proper.
} 
be few formal guidelines for judicial officers acting as mediators, which may serve to explain their occasional use of inappropriate techniques. 'Because of a 'judicial zeal for settlement,' the increased opportunity for abuse may lead to judges punishing parties and lawyers who fail to cooperate in settlement."

Thus, misguided strategies believed to be endemic to the bargaining process and the lack of clearly-defined roles for settlement judges may, regrettably, combine to create an environment ripe for occurrences such as this. ${ }^{105}$ The commission found that ambiguities in these areas played a significant role in the misconduct at issue. Also contributing were circumstances peculiar to this case. The hour was late, and trial was scheduled to begin the following morning. The judge, although deservedly recognized as a seasoned and fair mediator, became somewhat adversarial on this particular day. He not only allowed defense counsel to "drive a wedge" but may unwittingly have assisted them in doing so. Respondents did not want to lose a favorable settlement for their client. At the same time, they neither wished to permit the defense to dictate the amount of their fees, nor felt comfortable with pressure from the judge to reduce them. Moreover, respondents clearly attempted to ensure that their client fully understood and concurred in the separate agreement. Both the committee and commission specifically found that the modification was fair and that the client understood it. The uncontradicted evidence also suggests that respondents thought they were not obligated to disclose the arrangement to the settlement judge.

Nevertheless, we cannot condone their conduct. In our judgment, respondents should have either disclosed the complete arrangement or politely declined any discussion of fees. Fear that this might have jeopardized the settlement, while understandable, does not excuse their lack of candor with the tribunal. The system cannot function as intended if attorneys, sworn officers of the court, can lie to or mislead judges in the guise of serving their clients. "Zealous advocacy" has limits. It clearly does not justify ethical breaches.

We note that neither the committee nor the commission found any aggravating factors. Both, however, cited numerous mitigating circumstances, including the absence of prior disciplinary records, lack of dishonest or selfish motives, full and free disclosures to the disciplinary authorities, and cooperative attitudes throughout these proceedings. The committee also found that respondents "demonstrated a high level of competence in their representation" of this plaintiff.

Although we adopt the factual findings of both the committee and the commission, we are compelled to agree with the dissenting commissioners that the recommended sanction "exceeds the misconduct." ${ }^{106}$ The goal of discipline is to protect the public, not to punish lawyers. Nothing in the record suggests that respondents pose any threat to the public. Moreover, they already have suffered a considerable penalty by virtue of the extensive negative publicity surrounding this case.

\footnotetext{
${ }^{105}$ Although the conduct of defense counsel is not at issue here, respondents point out that they also were not forthcoming about their ultimate settlement authority when questioned by the judge.

${ }^{106}$ A majority of the commission concluded that suspension was necessary because the additional hearing and the judge's removal of respondents from this case caused "an adverse or potentially adverse effect on the legal proceeding." Both actions, however, were initiated by the offended settlement judge, who believed that respondents had engaged in severe professional, and possibly criminal, misconduct. We also note the absence of any finding that respondents' actions caused 'injury or potential injury to a party to the legal proceeding." Thus, under these specific facts, we disagree that suspension is required.
} 
We wish to discourage the previously-described tactic of "driving a wedge" between lawyer and client in negotiations. Although nothing in our ethical rules expressly prohibits separate offers of attorneys' fees, we agree with the New York City Bar ethics committee that they frequently pose a serious dilemma for lawyers. Quite simply, such offers are often intended to place attorneys in the uncomfortable position where they may be caught between their own need to be compensated for legal services and what might otherwise be in their clients' best interests. We therefore urge judges to carefully scrutinize attempts to employ this practice.

Moreover, although it is certainly not forbidden for a judge to raise the topic of attorneys' fees during settlement discussions, we believe it unwise and unfair to focus on the fees of one party without corresponding inquiry into those of the other. With such a selective approach, the judge may easily overstep his or her bounds. An attorney on the receiving end of this type of treatment should be entitled to some measure of self-protection. We have indicated that a more appropriate reply here was for respondents to have politely but firmly declined to discuss their fees. We concede that, considering the level of tension evident in this conference, such a response may have destroyed any chance of settlement. Nevertheless, a good end does not justify deceitful means.

The dissent deserves a brief response. First, it reaches factual conclusions that are diametrically opposed to those of the committee, the commission, and the majority of this court. Second, in positing "4 things that might have happened" if respondents had later "disclosed their side fee agreement to the trial judge and opposing counsel," the dissent completely ignores the possibility that the trial judge might have approved the fees after reviewing the matter in detail and applying the factors set out in ER 1.5(a). Neither the committee nor the commission concluded that the fees were unfair. Moreover, because the issue has not properly been presented to us and there are no findings made by a trial court, which is where the inquiry properly belongs in the first instance, see Rule 3, Uniform Medical Malpractice Rules, the record contains little information from which we can independently determine the overall reasonableness of the fees.

Additionally, the dissent's criticism of the "terms of respondents' fee agreement" simply has nothing to do with the issues presently before us. We also note that it fails to even mention the fact that, according to both the committee and the commission, the client knowingly and voluntarily entered into the contract.

In conclusion, we hold that respondents violated their duties of candor and truthfulness pursuant to ER 3.3(a)(1) and ER 8.4(c) and censure them for their conduct. We emphasize that a judge acting as mediator is still a judge to whom the ethical duty of candor is owed.

Each respondent is assessed costs in the amount of $\$ 1,922.91$.

CORCORAN, Justice, dissenting:

I respectfully dissent.

I view the facts in this case differently from the majority. The respondents Fee and Montijo lied to the settlement judge so that they would get more money and their client would get less money. It is especially egregious for a lawyer to lie to a judge for the purpose of increasing his own fees at the direct expense of his client. I cannot agree with the committee, the commission, and the majority that respondents lacked dishonest or selfish motives. Res ipsa loquitur. Such conduct warrants at least a suspension and not a mere censure. 
Respondents allege that they intended to reveal their side fee agreement to the trial judge. However, this assertion does not ring true. If respondents had disclosed their side fee agreement to the trial judge and opposing counsel, which would have required admitting that they had lied to the settlement judge, 4 things might have happened: (1) the trial judge could have refused to honor the side agreement; (2) the trial judge could have referred the matter back to the settlement judge who possessed the most information about the case; (3) defendants' attorneys could have sought to enforce the settlement agreement as communicated to the settlement judge; or (4) defendants' attorneys could have sought to withdraw their settlement offer. Any one of these events would have ruined respondents' scheme to collect attorneys' fees in excess of those communicated to the settlement judge. In addition, all parties who became aware of the secret fee agreement would have been required to report respondents' misconduct to the state bar. In fact, when the settlement judge learned of respondents' misconduct, he filed a complaint with the state bar.

I agree with the majority that: (1) "the bulk of ethical rules seem to have been designed with litigation scenarios in mind," and (2) there are "few formal guidelines for judicial officers acting as mediators." That, however, does not excuse the misconduct here. For lawyers dealing with judges, whether they be trial or settlement judges, the guiding rule is never lie to or mislead a judge. Respondents claim that they were lying in order to secure the best settlement agreement for their client. Nonetheless, it is often the case that lawyers who lie for the client will also lie to the client.

I also emphasize that the terms of respondents' fee agreement in conjunction with the secret side agreement would have resulted in respondents receiving an overwhelmingly disproportionate share of the client's up-front cash payment. The client signed three fee agreements dated October 29, 1986, January 29, 1987, and December 19, 1989. Only the last fee agreement addressed the possibility of a structured settlement. It provided that "in the event this case is settled by way of a structured settlement the attorney's fees will be computed on the basis of a percentage of the present value of the settlement. The attorney's fees will be paid out of the initial cash payment(s)." If respondents had successfully recovered $\$ 485,000$ in attorneys' fees payable from the initial cash payment, as contemplated by the side fee agreement, they would have received $84 \%$ of the client's up-front cash recovery (excluding the $\$ 55,000$ designated as costs). Furthermore, by collecting their fees from the up-front cash payment, respondents left the client to bear all the risk that the annuity provider would become insolvent. A less onerous fee agreement is one in which the plaintiff's attorney collects his fees only if, as, and when the plaintiff receives the funds. Under an "if, as, and when received" fee arrangement, respondents would only have been entitled to $40 \%$ of the client's up-front cash recovery, or $\$ 230,000$.

For the above reasons, I agree with the hearing committee, the disciplinary commission, and state bar counsel that respondents Fee and Montijo should be suspended.

\section{Questions:}

1. The parties agreed to a settlement. After the settlement conference, the plaintiff's attorneys privately convinced their client to pay them an additional $\$ 85,000$ from her cash settlement, and did not disclose that additional fee agreement to the judge. The majority suggests that the arrangement was ultimately fair to the client, but the dissent disagrees. What do you think? 
2. Did the client provide informed consent to the additional attorney's fees? Is the problem that the respondents convinced their client to pay them an additional $\$ 85,000$ or that they didn't disclose it to the judge?

3. Do you think the punishment was adequate under the circumstances?

\section{Further Readings:}

- $\quad$ Thomas F. Guernsey, Truthfulness in Negotiation, 17 U. Rich. L. Rev. 99 (1982)

- Geoffrey C. Hazard Jr., The Lawyer's Obligation to be Trustworthy When Dealing with Opposing Parties, 33 S.C. L. Rev. 181 (1981)

- Charles B. Craver, Negotiation Ethics: How to Be Deceptive without Being Dishonest/How to Be Assertive without Being Offensive, 38 S. Tex. L. Rev. 713 (1997)

- Geoffrey M. Peters, The Use of Lies in Negotiation, 48 Ohio St. L.J. 1 (1987)

- Eleanor H. Norton, Bargaining and the Ethic of Process, 64 N.Y.U. L. Rev. 493 (1989)

- Daisy H. Floyd, Can the Judge Do That? - The Need for a Clearer Judicial Role in Settlement, 26 Ariz. St. L.J. 45 (1994) 


\section{Section 7: The Regulation of the Legal Profession}

\section{1: Bar Admission}

It's nice to be liked, but it's better by far to get paid. I know that most of the friends that I have don't really see it that way. But if you can give 'em each one wish, how much do you want to bet they'd wish success for themselves and their friends, and that would include lots of money. ${ }^{107}$

In the United States, admission to the bar and the regulation of attorneys is governed primarily by state law. Specifically, the highest court of each state establishes the standards for admission to the state's bar and the rules of professional responsibility regulating the conduct of the members of the state's bar. Courts uniformly delegate those responsibilities to administrative organizations. Typically, courts delegate admission to the bar to a board of bar examiners and delegate the regulation of the bar to a disciplinary board. But the court always retains the ultimate authority over both admission to the bar and regulation of the bar.

Historically, the practice of law was primarily local. The overwhelming majority of attorneys and law firms practiced law only in one state and were members of only one state bar. But as the practice of law has become increasingly national and international and law firms open offices in multiple states and even foreign countries, the localized regulation of the bar has come into tension with the non-local practice of law. Members of the state bar may have an incentive to discourage non-members from joining their bar or practicing in their state. While the desire to reduce competition is understandable, it can harm the consumers of legal services, by reducing their options and increasing the price.

\section{Admission to the Bar}

Originally, the qualifications for bar membership were quite relaxed. In 18th and 19th centuries, there were few law schools, and few attorneys attended or graduated from them. The majority of attorneys qualified for the bar by apprenticing or "reading law" in a law office. Examination for admission was typically oral and often cursory. But legal education and admission to the bar gradually became more formalized in the 20th century.

Today, most states have adopted similar requirements for admission to the state bar. The overwhelming majority of states require applicants to the state bar to have graduated from a law school accredited by the American Bar Association, passed the state's bar examination and professional responsibility examination, and demonstrated good moral character. But there are exceptions. Some states offer independent accreditation of law schools. Some states still allow applicants to qualify for the bar by "reading law" for prescribed period of time, rather than attending law school. Some states allow the graduates of certain law schools to qualify for the bar without taking a bar exam. And some states do not require a professional responsibility exam. But all states require a showing of good moral character.

${ }^{107}$ Liz Phair, Shitloads of Money, whitechocolatespaceegg (1998). 


\section{Residency Requirements}

Until relatively recently, many states imposed explicit residency requirements for bar membership. This enables the members of the state bar to limit or prevent competition, by preventing attorneys from practicing in multiple states. But in Supreme Court of NH v. Piper, 470 U.S. 274 (1985), the Supreme Court invalidated many of those residency requirements, holding that they violated the Privileges and Immunities Clause of the Constitution, unless a state can show "substantial" reasons for discriminating against nonresidents.

Notably, the federal courts have their own bars. The Supreme Court, each federal circuit and district court, and the District of Columbia, all maintain their own independent federal bars. Their bars have different requirements. District court bars typically requirement membership in the bar of the state in which the district court sits, and circuit courts typically require membership in any state bar. Some have even had residency requirements, but the Supreme Court invalidated those residency requirements in Frazier v. Heebe, 482 U.S. 641 (1987).

An attorney who is not a member of the bar of a court but wishes to represent a client in that court may petition to appear pro hac vice or "for this turn only." The court is not required to grant a motion to appear pro hac vice and each new action requires a separate application. In many jurisdictions, an attorney may appear pro hac vice only if they affiliate with a member of the court's bar as co-counsel. In theory, this requirement ensures compliance with local rules, but it also provides employment to the members of the bar.

\section{Barnard v. Thorstenn, 489 U.S. 546 (1989)}

Summary: The Bar of the District Court of the Virgin Islands has a residency requirement for admission, providing that applicants must have resided in the Virgin Island for one year and intend to continue residing in the Virgin Islands. Thorstenn and DeVos of New York applied for the bar examination, but were rejected for failure to satisfy the residency requirement. The District Court allowed them to take the bar examination, which they passed, but upheld the residency requirement. The Third Circuit reversed, and the Supreme Court affirmed, holding that the District Court provided no substantial or legitimate reason for excluding nonresidents.

\section{JUSTICE KENNEDY delivered the opinion of the Court.}

In order to be admitted to the Bar of the District Court of the Virgin Islands, an otherwise qualified attorney must demonstrate that he or she has resided in the Virgin Islands for at least one year and that, if admitted, the attorney intends to continue to reside and practice in the Virgin Islands. The question before us is whether these residency requirements are lawful. 
Local Rule 56(b) of the District Court of the Virgin Islands provides that before an otherwise qualified attorney is admitted to the Virgin Islands Bar, he must "allege and prove to the satisfaction" of the Committee of Bar Examiners that he has "resided in the Virgin Islands for at least one year immediately preceding his proposed admission to the Virgin Islands Bar," and that, "if admitted to practice, he intends to continue to reside in and to practice law in the Virgin Islands." The rule applies not only to practice before the District Court, but also to practice before the local territorial courts.

Respondents Susan Esposito Thorstenn and Lloyd DeVos are attorneys who are members in good standing of the Bars of the States of New York and New Jersey, and who practice law in New York City. Neither respondent resides in the Virgin Islands. In the spring of 1985, respondents applied to take the Virgin Islands bar examination, but their applications were rejected by the Committee of Bar Examiners because they did not satisfy the residency requirements of Local Rule 56(b). Respondents filed this suit in the District Court against petitioner Geoffrey W. Barnard, the Chairman of the Committee of Bar Examiners, seeking a declaration that the residency requirements of Rule 56(b) violate the Privileges and Immunities Clause of Article IV of the Constitution, as interpreted by our decision in Supreme Court of New Hampshire v. Piper. Respondents also sought to enjoin the enforcement of Rule 56(b) against them.

On June 21, 1985, while reserving a decision on the merits, the District Court ordered that respondents be allowed to take the bar examination. They took the examination and passed. Petitioner Virgin Islands Bar Association intervened, and all parties submitted motions for summary judgment with supporting affidavits. The District Court granted summary judgment for petitioners, concluding that the reasons offered for Rule 56(b)'s residency requirements, grounded in the unique conditions in the Virgin Islands, were substantial enough to justify the discrimination against nonresidents.

While the District Court's decision was pending on appeal in the Third Circuit, we decided Frazier v. Heebe, where we invoked our supervisory power to invalidate certain residency requirements contained in the local rules of the United States District Court for the Eastern District of Louisiana. A divided panel of the Court of Appeals reversed the District Court's judgment for petitioners, concluding that the reasons given for Rule 56(b) were in essence the same as those we rejected in Heebe. The case was reheard en banc, and a majority of the full Court of Appeals agreed with the original panel decision that the residency requirements of Rule 56(b) were invalid under Heebe. The en banc court emphasized that alternative and less restrictive means, short of a residency requirement, were available to the District Court to assure that nonresident bar members would bear professional responsibilities comparable to those imposed on resident attorneys. In view of its determination that Heebe controlled the case, the Court of Appeals did not address respondents' claim under the Privileges and Immunities Clause.

We granted certiorari and now affirm. 
In Heebe, we invoked supervisory power over district courts of the United States to invalidate discriminatory residency requirements for admission to the Bar of the United States District Court for the Eastern District of Louisiana. The Court of Appeals in the case now before us expressed "no doubt" that our supervisory power extends to the bar requirements of the District Court of the Virgin Islands.

Without attempting to define the limits of our supervisory power, we decline to apply it in this case. Both the nature of the District Court of the Virgin Islands and the reach of its residency requirements implicate interests beyond the federal system. As to the former, the District Court, which was given its current form and jurisdiction by Congress in the Revised Organic Act of 1954, is not a United States district court, but an institution with attributes of both a federal and a territorial court. Although it is vested with the jurisdiction of a United States district court, the District Court also has original jurisdiction over certain matters of local law not vested in the local courts of the Virgin Islands, as well as concurrent jurisdiction with the local courts over certain criminal matters. It also serves as an appellate court for decisions rendered by the local courts. In fact, Congress provides in the Revised Organic Act that, for certain purposes, the District Court "shall be considered a court established by local law." The application of Rule 56(b) itself similarly extends beyond practice in the federal system. Unlike the rule in Heebe, which was confined to practice before the United States District Court, Rule 56(b) applies to admission to the Bar of the Virgin Islands, and so governs practice before the territorial courts.

Because these territorial interests are intertwined with the operation of Rule 56, we decline to examine this case as an issue of supervisory power.

III

Respondents also contend that Rule 56(b) violates the Privileges and Immunities Clause of Article IV of the Constitution, which Congress has made applicable to the Virgin Islands in the Revised Organic Act. Petitioners concede that the District Court is an instrumentality of the Government of the Virgin Islands and is subject to the Privileges and Immunities Clause through the Revised Organic Act.

Article IV, § 2, of the Constitution provides that the "Citizens of each State shall be entitled to all Privileges and Immunities of Citizens in the several States." When a challenged restriction deprives nonresidents of a privilege or immunity protected by this Clause, it is invalid unless "(i) there is a substantial reason for the difference in treatment; and (ii) the discrimination practiced against nonresidents bears a substantial relationship to the State's objective." In deciding whether the discrimination bears a substantial relation to the State's objectives, we consider, among other things, whether less restrictive means of regulation are available. 
It is by now well settled that the practice of law is a privilege protected by Article IV, $\S 2$, and that a nonresident who passes a state bar examination and otherwise qualifies for practice has an interest protected by the Clause. We need consider here only whether there are substantial reasons to support treating qualified nonresident attorneys differently, and whether the means chosen by the District Court, total exclusion from the Bar, bear a close or substantial relation to the Territory's legitimate objectives.

Petitioners offer five justifications for the residency requirements of Rule 56(b), which track the reasons recited by the District Court. First, petitioners contend that the geographical isolation of the Virgin Islands, together with irregular airline and telephone service with the mainland United States, will make it difficult for nonresidents to attend court proceedings held with little advance notice. Second, petitioners cite the District Court's finding that the delay caused by trying to accommodate the schedules of nonresident attorneys would increase the massive caseload under which that court suffers. Third, petitioners contend that delays in publication and lack of access to local statutes, regulations, and court opinions will prevent nonresident attorneys from maintaining an adequate level of competence in local law. Fourth, petitioners argue that the Virgin Islands Bar does not have the resources for adequate supervision of a nationwide bar membership. Finally, petitioners exert much energy arguing that the residency requirements of Rule 56(b) are necessary to apply Local Rule 16 in a strict and fair manner. That Rule requires all active members of the Bar to represent indigent criminal defendants on a regular basis. We find none of these justifications sufficient to meet the Virgin Island's burden of demonstrating that the discrimination against nonresidents by Rule $56(\mathrm{~b})$ is warranted by a substantial objective and bears a close or substantial relation to that objective.

The answer to petitioners' first justification, based on the geographical isolation of the Virgin Islands and the unreliable airline and telephone service, is found in Piper. In that case, as here, the Bar argued that "even the most conscientious lawyer residing in a distant State may find himself unable to appear in court for an unscheduled hearing or proceeding." We did not find this a sufficient justification for a residency requirement for two reasons. First, we found it likely that a high percentage of nonresidents who took the trouble to take the state bar examination and to pay the annual dues would reside in a place convenient to New Hampshire. Although that observation is not applicable here, we went on to hold in Piper that, for lawyers who reside a great distance from New Hampshire, the State could protect its interests by requiring the lawyer to retain a local attorney who will be available for unscheduled meetings and hearings. The same solution is available to the Virgin Islands. The exclusion of nonresidents from the bar is not substantially related to the District Court's interest in assuring that counsel will be available on short notice for unscheduled proceedings.

Petitioners' second proffered justification is similar to their first. The District Court found that because of its unusually large and increasing caseload, it could not countenance interruptions caused by nonresident lawyers attempting to reach the Virgin Islands from the mainland, or conflicts with their appearances on the mainland. To the extent this justification reiterates the point we have addressed above, the same response applies. Any burden on the Virgin Islands court system to accommodate travel schedules of nonresidents can be relieved in substantial 
part by requiring nonresidents to associate with local counsel. The large caseload of the Virgin Islands District Court does not alter the analysis. Quite aside from the paradox in citing extreme caseload as the reason to exclude more attorneys, it is clear that a State, or a Territory to which the Privileges and Immunities Clause applies, may not solve the problem of congested court dockets by discriminating against nonresidents. Nor do we see the problem of conflicting court appearances as justifying the exclusion of nonresidents from the bar. The problem is not unique to the Virgin Islands. A court in New Jersey may be inconvenienced to some extent by a request to accommodate the conflicting court appearances of a nonresident attorney in New York. But that does not justify closing the New Jersey Bar to New York residents. Further, the District Court may make appropriate orders for prompt appearances and speedy trials.

Nor are we persuaded by petitioners' claim that the delay in publication of local law requires exclusion of nonresidents because they will be unable to maintain an adequate level of professional competence. As we said in Piper, we will not assume that "a nonresident lawyer any more than a resident - would disserve his clients by failing to familiarize himself with the local law." We can assume that a lawyer who anticipates sufficient practice in the Virgin Islands to justify taking the bar examination and paying the annual dues will inform himself of the laws of the Territory. And although petitioners allege that the most recent legal materials, such as District Court opinions and local statutes and regulations, are not available on a current basis, this does not justify exclusion of nonresidents. If legal materials are not published on a current basis, we do not see how this is more of a problem for nonresidents than residents. All that petitioners allege on this point is that residents can review slip opinions by visiting the offices of the law clerks for the District Court judges. We do not think it either realistic or practical to assume that residents resort to this practice with regularity, or that nonresidents, faced with the occasional need to do so, cannot find some adequate means to review unpublished materials. We note, moreover, that the record discloses that after the initial affidavits were submitted by petitioners in this case, the Virgin Islands Bar Association Committee on Continuing Legal Education began a subscription service for all opinions of the District Court and the territorial courts, available to all members of the bar.In short, we do not think the alleged difficulties in maintaining knowledge of local law can justify the drastic measure of excluding all nonresidents as a class.

Petitioners' fourth contention, that the Virgin Islands Bar Association does not have the resources and personnel for adequate supervision of the ethics of a nationwide bar membership, is not a justification for the discrimination imposed here. Increased bar membership brings increased revenue through dues. Each lawyer admitted to practice in the Virgin Islands pays an initial fee of $\$ 200$ to take the bar examination, annual bar association dues of $\$ 100$, and an annual license fee of $\$ 500$. There is no reason to believe that the additional moneys received from nonresident members will not be adequate to pay for any additional administrative burden. To the extent petitioners fear that the Bar will be unable to monitor the ethical conduct of nonresident practitioners, respondents note that petitioners can, and do, rely on character information compiled by the National Conference of Bar Examiners. In this regard, the monitoring problems faced by the Virgin Islands Bar are no greater than those faced by any mainland State with limited resources. 
The final reason offered by petitioners for Rule 56(b)'s residency requirements is somewhat more substantial, though ultimately unavailing. Under District Court Rule 16, each active member of the Virgin Islands Bar must remain available to accept appointments to appear on behalf of indigent criminal defendants. According to the affidavit of the President of the Virgin Islands Bar Association, each member can expect to receive appointments about four times per year. Once appointed, it is the duty of the lawyer "to communicate with the defendant at his place of incarceration as promptly as possible and not later than five days from the date of the clerk's mailing of the order of appointment." Although the statute does not specifically so provide, the District Court interprets Rule 16 to require that only the appointed attorney may appear on behalf of the criminal defendant. The District Court found that, in light of this individual appearance requirement and the strict time constraints imposed by the Speedy Trial Act, it would be virtually impossible for this system of appointed counsel to work with nonresident attorneys.

In Piper, we recognized that a State can require nonresidents to share in the burden of representing indigent criminal defendants as a condition for practice before the Bar. That, however, is not quite what is at issue here. The question in this case is whether bar admission can be denied to a nonresident because at times it may not be feasible for him to appear personally to represent his share of indigent defendants. We determine that this requirement is too heavy a burden on the privileges of nonresidents and bears no substantial relation to the District Court's objective. Petitioners offer no persuasive reason why the strong interests in securing representation for indigent criminal defendants cannot be protected by allowing an appointed nonresident attorney to substitute a colleague in the event he is unable to attend a particular appearance. Further, contrary to the District Court's characterization of the personal appearance requirement as a hard and fast rule, we must assume that in some circumstances it would in fact be detrimental to the goal of competent representation for criminal defendants to require the appointed attorney, whether a resident or nonresident, to appear personally. For instance, where the bar member is an expert in trusts and estates, but has no prior experience in criminal procedure, it would seem counterproductive to the interests that Rule 16 is designed to serve to require the appointed attorney to make an individual appearance. The text of Rule 16 appears to recognize as much in its explicit provision that, where the interests of justice so require, the District Court may substitute one appointed counsel for another.

Petitioners' only effort to explain why this seemingly more sensible and less intrusive alternative would not work is to predict that resident attorneys would not be willing to make the additional appearances required where nonresidents are unavailable. Such speculation, however, is insufficient to justify discrimination against nonresidents. As respondents point out, if handling indigent criminal cases is a requirement of admission to the Bar, a nonresident knows that he must either appear himself or arrange with a resident lawyer to handle the case when he is unavailable. If the nonresident fails to make all arrangements necessary to protect the rights of the defendant, the District Court may take appropriate action. This possibility does not, however, justify a blanket exclusion of nonresidents. 
In sum, we hold that petitioners neither advance a substantial reason for the exclusion of nonresidents from the Bar, nor demonstrate that discrimination against nonresidents bears a close or substantial relation to the legitimate objectives of the court's Rule. When the Privileges and Immunities Clause was made part of our Constitution, commercial and legal exchange between the distant States of the Union was at least as unsophisticated as that which exists today between the Virgin Islands and the mainland United States. Nevertheless, our Founders, in their wisdom, thought it important to our sense of nationhood that each State be required to make a genuine effort to treat nonresidents on an equal basis with residents. By extending the Privileges and Immunities Clause to the Virgin Islands, Congress has made the same decision with respect to that Territory.

The residency requirements of Rule 56(b) violate the Privileges and Immunities Clause, as extended to the Virgin Islands. Accordingly, the judgment of the Court of Appeals is affirmed.

CHIEF JUSTICE REHNQUIST, with whom JUSTICE WHITE and JUSTICE O'CONNOR join, dissenting.

In Supreme Court of New Hampshire v. Piper, the Court held that a rule of the New Hampshire Supreme Court which limited bar admission to state residents violated the Privileges and Immunities Clause. Today the Court extends the reasoning of Piper to invalidate a Virgin Islands rule limiting bar admission to attorneys who demonstrate that they have resided in the Virgin Islands for at least one year and will, if admitted, continue to reside and practice there. I agree that the durational residency requirement is invalid under our prior cases dealing with the "right" of interstate travel. But I cannot agree with the Court's conclusion that the simple residency requirement is invalid under the Privileges and Immunities Clause. Accepting Piper's view of the Privileges and Immunities Clause, I think the unique circumstances of legal practice in the Virgin Islands, as compared to the mainland States, could justify upholding this simple residency requirement even under that view. Because the record reveals the existence of genuine factual disputes about the nature of these circumstances and their relationship to the challenged residency requirement, I would reverse the judgment below and remand for trial on those issues.

\section{Questions:}

1. The majority held that the District Court Bar's residency requirement was unconstitutional because it demonstrated neither a substantial reason for discriminating against nonresidents, nor a substantial relationship to any legitimate purpose. The dissent argued that the might be a legitimate purpose for the restriction. Do any of the reasons provided by the District Court Bar seem legitimate to you?

2. Are residency restrictions ever legitimate? When and why should a state bar be able to limit the membership of non-resident attorneys, if ever? What standard should courts apply in evaluating residency requirements? 
3. Could requirements for state bar membership that do not explicitly require residency effectively discriminate against out-of-state attorneys? When are such requirements legitimate, if ever? How should courts review those requirements, if at all?

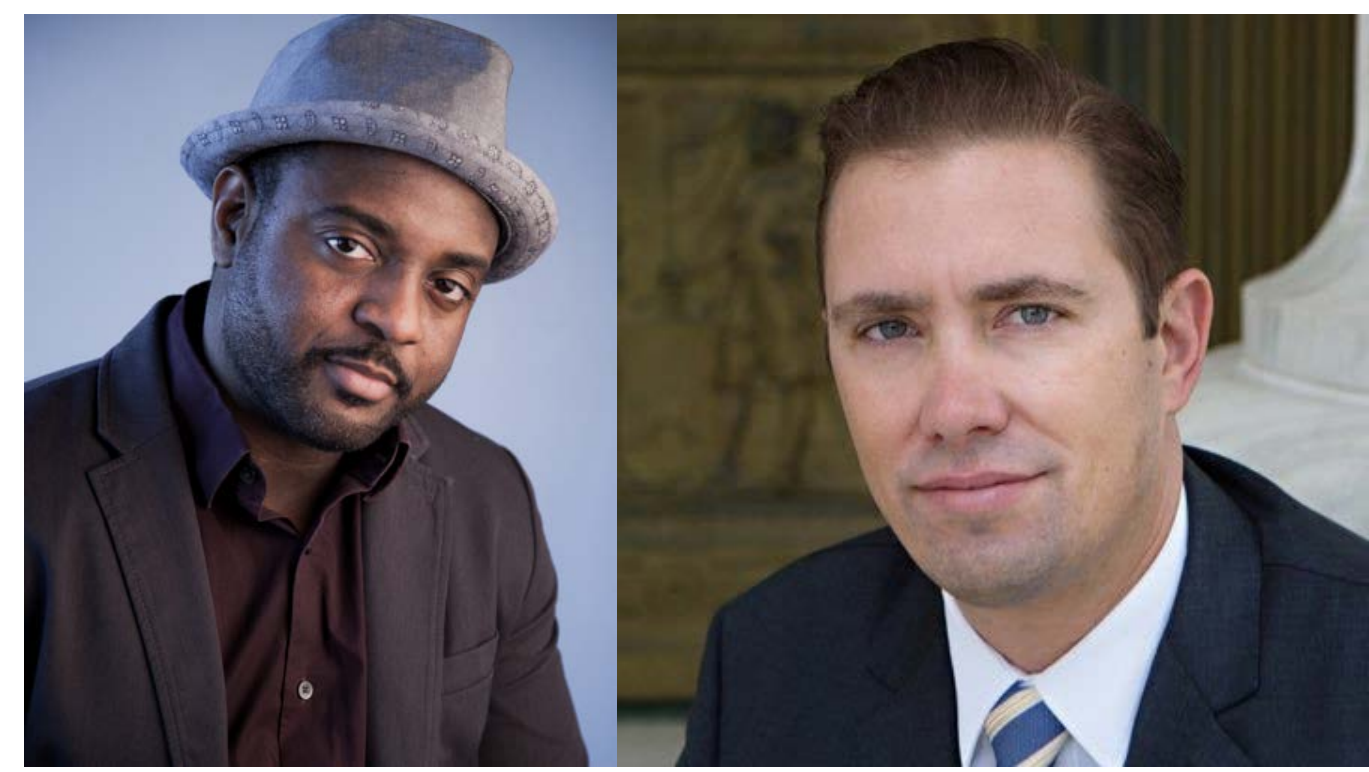

Reginald Dwayne Betts \& Shon Hopwood

\section{Character and Fitness}

All states limit bar admission to candidates of "good moral character," but the contours of the requirement can vary widely from state to state and examiner to examiner. The substance of the good moral character requirement are vague - perhaps deliberately vague? - but typically include honestly, respect for the law, and respect for the rights of others. Typically, applicants are rejected for failing to satisfy the requirement on the basis of failure to disclose material facts on the bar exam application, criminal conduct or convictions, and fraudulent or dishonest behavior.

In theory, applicants who have engaged in past disqualifying conduct may qualify for admission by proving their rehabilitation. But historically, many bar examiners have rejected applicants based on criminal convictions, irrespective of any evidence of rehabilitation. In recent years, this tendency has begun to change. Among other things, the Washington Bar Association approved the admission of Shon Hopwood, who pled guilty to bank robbery in 1998 and served 10 years in federal prison, where he taught himself the law and drafted a successful petition for certiorati to the Supreme Court for one of his fellow inmates, in Fellers v. United States, 540 U.S. 519 (2004). After his release from prison, Hopwood graduated from the University of Washington School of Law and clerked on the D.C. Circuit. He is currently an Associate Professor of Law at Georgetown University Law Center. You can read more about Hopwood's story in his book Law Man: My Story of Robbing Banks, Winning Supreme Court Cases, and Finding Redemption (2012). 
In 1996, when he was 16 years old, Reginald Dwayne Betts participated in a carjacking. He was convicted and served 8 years in prison, where he finish high school and began writing poetry. Betts was released from prison in 2005 , and immediately enrolled in community college. Two years later he received a full scholarship from the University of Maryland. After graduating, he received a poetry fellowship from Harvard's Radcliffe Institute for Advanced Study, before enrolling in Yale Law School. After graduation, he passed the Connecticut bar examination, but was initially denied admission to the Connecticut bar because of his criminal record. On appeal, the Connecticut Bar Examining Committee reversed itself and granted Betts's application for admission. He is currently completing a Ph.D. in Law at Yale and plans to become a law professor.

Other formerly incarcerated people have also rehabilitated themselves and become lawyers, including Cleodis Floyd, Allan P. Haber, and Tarra Simmons. Jarrett M. Adams was wrongfully convicted of sexual assault at 17 and served 10 years in prison before he was exonerated. He graduated from the Loyola University Chicago School of Law and is currently practicing law in Chicago.

Other formerly incarcerated people have graduated from law school, but been denied bar admission for poor moral character, based on their conviction. Bruce Reilly pled guilty to second-degree murder in 1993, when he was 20, and served 12 years in prison, where he became a jailhouse lawyer. Upon release, he applied to 30 law schools before being admitted at Tulane Law School. But after graduation, the bar refused to admit him, based on his conviction. Similarly, Guy Hamilton-Smith pled guilty to possession of child pornography in 2006, when he was 22, and was placed on the Kentucky Sex Offender Registry. He graduated from the University of Kentucky College of Law, but was denied admission to the Kentucky bar, based on his conviction and registration status. He is currently a legal fellow at the Mitchell-Hamline School of Law Sex Offense Litigation and Policy Resource Center.

\section{Questions:}

1. When should state bar associations be permitted to refuse admission based on an applicant's moral character? What factors should they be permitted to consider in evaluating an applicant's moral character?

2. Should state bar associations be permitted to refuse admission based on criminal convictions, if the applicant has shown compelling evidence of rehabilitation?

3. Why do state bar examiners refuse admission to applicants with criminal records who have demonstrated compelling evidence of rehabilitation? Are they trying to protect the integrity of the profession, or the appearance of the integrity of the profession?

4. Courts routinely readmit attorneys who have been disbarred for crimes like tax evasion and defrauding their clients. Should state bar associations evaluate applications for readmission more or less strictly than initial applications for admission? 


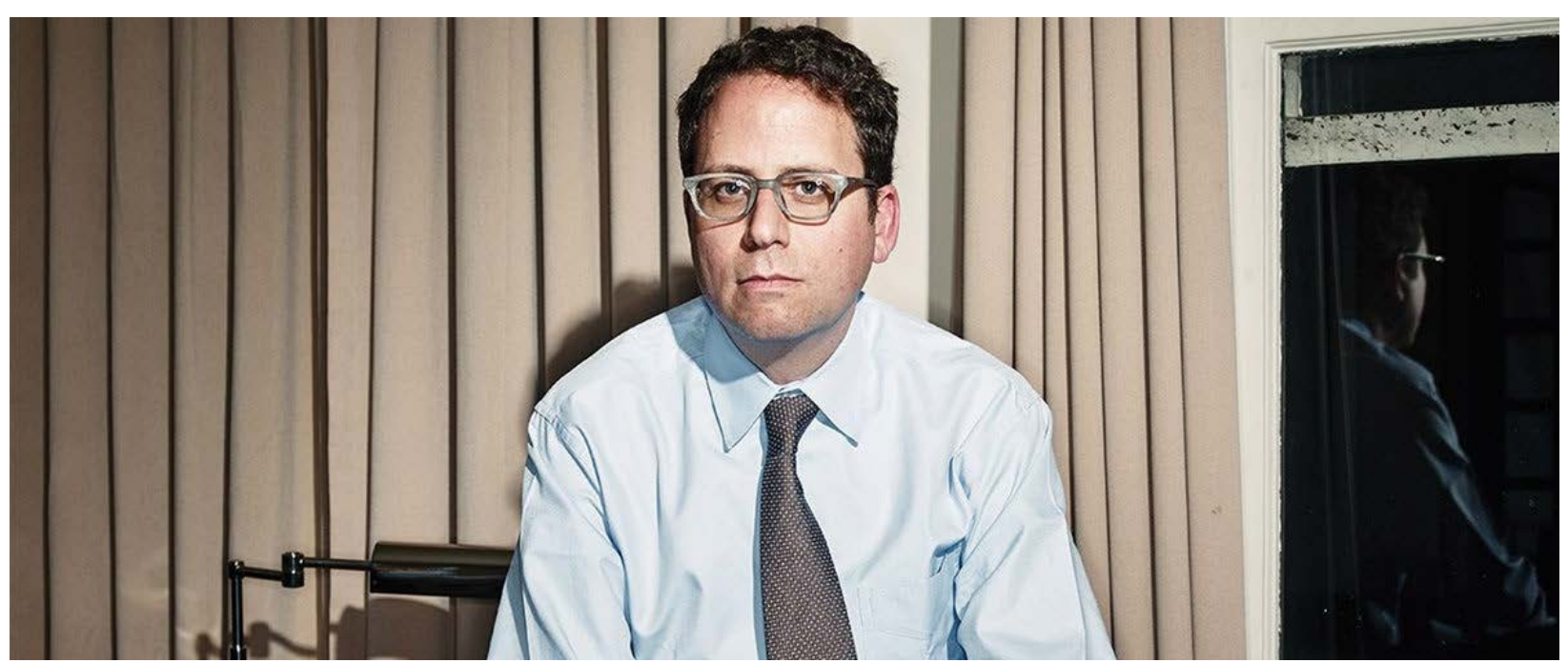

Stephen Randall Glass (2014)

In re Glass, 316 P. 3d 1199 (Cal. 2014)

Summary: Stephen Glass was a journalist for several national magazines, including the New Republic. Between 1996 and 1998, he wrote dozens of articles that consisted in part or whole of fabrications. He also fabricated evidence to substantiate his reporting. At the same time, he was a student at Georgetown University Law Center. After graduation, he applied for membership in the New York bar, but his application was rejected for poor moral character. In 2006, he applied for membership in the California bar. The State Bar Court ultimately recommended admission, but the California Supreme Court reversed, based on poor moral character.

Stephen Randall Glass made himself infamous as a dishonest journalist by fabricating material for more than 40 articles for The New Republic magazine and other publications. He also carefully fabricated supporting materials to delude The New Republic's fact checkers. The articles appeared between June 1996 and May 1998, and included falsehoods that reflected negatively on individuals, political groups, and ethnic minorities. During the same period, starting in September 1997, he was also an evening law student at Georgetown University's law school. Glass made every effort to avoid detection once suspicions were aroused, lobbied strenuously to keep his job at The New Republic, and, in the aftermath of his exposure, did not fully cooperate with the publications to identify his fabrications.

Glass applied to become a member of the New York bar in 2002, but withdrew his application after he was informally notified in 2004 that his moral character application would be rejected. In the New York bar application materials, he exaggerated his cooperation with the journals that had published his work and failed to supply a complete list of the fabricated articles that had injured others.

Glass passed the California Bar examination in 2006 and filed an application for determination of moral character in 2007. It was not until the California State Bar moral character proceedings 
that Glass reviewed all of his articles, as well as the editorials The New Republic and other journals published to identify his fabrications, and ultimately identified fabrications that he previously had denied or failed to disclose. In the California proceedings, Glass was not forthright in acknowledging the defects in his New York bar application.

At the 2010 State Bar Court hearing resulting in the decision under review, Glass presented many character witnesses and introduced evidence regarding his lengthy course of psychotherapy, along with his own testimony and other evidence. Many of his efforts from the time of his exposure in 1998 until the 2010 hearing, however, seem to have been directed primarily at advancing his own well-being rather than returning something to the community. His evidence did not establish that he engaged in truly exemplary conduct over an extended period. We conclude that on this record he has not sustained his heavy burden of demonstrating rehabilitation and fitness for the practice of law.

\section{FACTS}

\section{A. Committee of Bar Examiners's evidence}

Stephen Glass was born in September 1972, in a suburb of Chicago, Illinois. After early success as a journalist in college and a developing interest in the law, in 1994 Glass was admitted to New York University School of Law but deferred his intended legal training to accept a position in Washington, D.C., with Policy Review magazine.

In September 1995 Glass accepted a position at The New Republic magazine. In early June 1996 he began fabricating material for publication. The fabrications continued and became bolder and more comprehensive until he was exposed and fired in May 1998.

Glass's fabrications began when an article entitled The Hall Monitor was published containing a fabricated quotation from an unnamed source disparaging United States Representative Pete Hoekstra for behaving in Congress like an elementary school "super hall monitor." He started by fabricating quotations or sources, and ended by publishing wholesale fictions. He testified that "all but a handful" of the 42 articles he published in The New Republic contained fabrications or were entirely fabricated. He also routinely prepared elaborate reporter's notes and supporting materials to give the false impression to the magazine's fact checkers that he had done all the background work for each article and that his informants had spoken words he falsely attributed to them.

Glass testified at the State Bar Court hearing that he "wrote nasty, mean-spirited, horrible" things about people: "My articles hurt, and they were cruel." He testified that the fabrications gave him "A-plus" stories that afforded him status in staff meetings and also gave particular enjoyment to his colleagues. He said: "Overwhelmingly, what everyone remembers about my pieces are the fake things." 
A notable 1996 article was entitled Taxis and the Meaning of Work. It was Glass's first cover article and one he viewed as "key" to his successful period of writing for The New Republic. Its theme was that Americans, and in particular, African-Americans, were no longer willing to work hard or to take on employment they consider menial. The article falsely recounted as factual supposed encounters between Glass and three entirely fabricated characters, one a limousine driver, one a taxicab driver, and one a criminal. The limousine driver was depicted as an African-American man who had driven a cab at one time, but now drove a limousine instead because he was "sick of those curry people" and found that limousines attracted beautiful women, or, in the purported words of the driver, gave him "the woo quotient." The author went on to say that he had been permitted to ride along for journalistic purposes with a taxi driver of Middle Eastern descent. The article recounted that the driver stopped for a young AfricanAmerican passenger-"the type of fare Imran would normally refuse" but felt he had to accept because of nearby police observation. The article describes the pounding music audible from the young fare's headphones, and claims that as they neared his destination, the young AfricanAmerican man threatened the driver with a knife, hurled coarse abuse at him, and took his wallet. According to the article: “'These things happen,' Imran said coldly on the drive back downtown. 'I give them whatever they want. I just want my life."

Spring Breakdown, published in March 1997, was another example of Glass's fabrications. The theme of the article was that young, conservative Republicans had given up on electoral politics and had turned to drugs and sex. Glass invented a fictional group of male college students attending the Conservative Political Action Conference. To convey the young men's view that conservatives had lost their direction, he attributed to one of them the comment that conservatives were "like a guy who has to pee lost in the desert, searching for a tree." Glass described the young men using marijuana for an hour, then embarking on a search for a young woman to humiliate. The plan was "to choose the ugliest and loneliest they can find," a person the young men described as "a real heifer, the fatter the better, bad acne," for a few of them to lure to their hotel room and persuade to undress. At that point, the remaining men would emerge from under the bed, shout "we're beaching. Whale spotted!" and photograph the woman. After turning to a discussion of asserted losses in popularity experienced by the conservative movement, the article went on to recount the execution of the plot described above. It asserted that a woman in fact emerged from the young men's room unclothed and in tears, while the perpetrators congratulated each other. The article went on: "This repellent scene was only a little beyond the norm of the conference. A wash of despair and alcohol and brutishness hung over the whole thing." More examples of drug use ensued, along with examples of shameless sexual behavior. All of this was fabricated.

In another article, entitled Deliverance, published in November 1996, Glass recounted receiving unsatisfactory service from a named computer company, and claimed that his complaints to a telephone customer service representative were met with an anti-Semitic slur. In truth, no such slur ever was uttered. Glass also wrote a letter to the president of the company, repeating the accusation, and sent a copy to the Anti-Defamation League. 
Glass also engaged in fabrications in freelance articles published by other magazines. An example was Prophets and Losses, an article published in Harper's Magazine in February 1998, at which time Glass was also a law student. In that article, Glass represented that he had worked for a telephone psychic service for a time, and recounted fabricated conversations with management, represented as mercenary and either stupid or cynical, and also fabricated conversations with callers, who were depicted as ignorant and desperate. In one case a caller, a fabricated character to whom Glass had attributed an African-American dialect, could not be persuaded to use his money to feed and clothe his seven children by five different mothers instead of buying VCRs and calling telephone psychics for advice on lottery numbers. The article was almost entirely a fabrication. Glass explained at the hearing that his intent was to expose "how the telephone psychic industry preys on minorities. It uses minority celebrities to advertise and shows that are watched predominantly by minorities to lure them into paying insane amounts of money. I was angry about that, and I wanted to attack that, and I used terrible, horrible stereotypes to create, essentially, straw men to knock down."

In another example, Glass wrote an article entitled The Vernon Question for George magazine. The lengthy article, published in April 1998, concerned Vernon Jordan, an advisor to then President Clinton during the then emerging Monica Lewinsky scandal. In two paragraphs, Glass used nonexistent sources to describe Jordan's supposed reputation as a "boor" and attributed various fictitious statements to "political operatives," "socialites," "political hostesses" and officials. These persons assertedly stated that Jordan was well known for sexually explicit comments, unwanted sexual advances, and crude stares, and added that he was known in their circles as "Vern the Worm" or "Pussyman," and that young women needed protection against him. Another paragraph attributed to a fictional "watchdog" group contained certain claims about Jordan's asserted conflicts of interest and questionable corporate ethics along with statements attributed to fictional "senior officials" at companies on whose boards Jordan sat, saying that Jordan is "totally unaware of the issues" but "we get what we want, access, and he gets what he wants, cash." These were all fabrications.

Charles Lane, who was the editor of The New Republic at the time of Glass's exposure, testified for the Committee of Bar Examiners that he had received an early complaint about Glass concerning an article entitled Boys on the Bus, depicting the actor Alec Baldwin and his brother as silly celebrities whose efforts during a bus tour to campaign on the issue of campaign finance reform were based on ignorance. A representative of Baldwin's disputed the assertion in the article that the actor had been giving out autographs during the bus tour, but Glass repudiated the accusation in print in The New Republic. It was not until Glass prepared his application to the California State Bar that he acknowledged that this article contained fabricated evidence to the effect that interest in the bus tour came from movie fans seeking autographs and referred to a fabricated person who opined that Baldwin lacked real understanding of campaign finance reform.

Although at the time, the Boys on the Bus incident seemingly was resolved in Glass's favor, Lane's suspicions were aroused in May 1998 when a journalist employed by Forbes Digital Tool telephoned to warn him that factual assertions in Glass's recent article for The New Republic 
magazine, Hack Heaven, did not seem to be true. The article had described a teenager hacking a California software company and extorting money to stop the intrusion. The article described a convention in Bethesda, Maryland, where some of the events occurred, and when Lane challenged Glass, the latter journeyed with Lane to Bethesda, purporting to identify the building where the convention had been held. A person working in the building denied such a convention had occurred, and Lane became persuaded that Glass was lying. Lane pressed Glass about the factual basis for the article, and although Glass was evasive, he insisted the article was accurate. Glass spent the night at home fabricating what he would assert were his reporter's notes from interviews, fake business cards, a voicemail box, a website, and newsletters. He also induced his brother to impersonate a source.

Upon their return to the office from Bethesda, Glass lobbied the executive editor and others to intervene on his behalf with Lane, urging that he was being treated unfairly. Lane, now suspecting that other fabrications may have occurred, wanted to fire him, but in response to the lobbying, suspended him. The next day, a Saturday, Lane was surprised to discover Glass at the office. Thinking Glass had been told not to return, Lane suspected he had altered his computer files. He confronted Glass with evidence that Glass had used his brother as a false source in the Hack Heaven piece. Ultimately, during this exchange Glass admitted the article was fabricated, and Lane fired him. Lane found on Glass's desk a letter Glass had written to his landlord, falsely stating he had been transferred by The New Republic to New York and needed his security deposit refunded. Lane also found the letter Glass had written to the chief executive of Gateway computers, again stating the falsehood that a customer service employee had used an anti-Semitic slur against Glass.

Lane reviewed all of Glass's articles over the course of the following three or four weeks. He received a letter from Glass apologizing and saying he had instructed his lawyers to cooperate with The New Republic. Lane compiled a summary of the material in Glass's articles that he found suspicious and submitted the summary to Glass's counsel, who it was agreed would stipulate to those findings of Lane's that Glass believed to be correct. At the time, Lane concluded that 27 of the 42 articles Glass had written for the magazine contained fabrications, and Lane wrote two editorial articles informing the magazine's readership to this effect.

Lane was very surprised to learn for the first time in the California State Bar proceeding that there were four articles Glass identified in his California Bar application as fabrications that he, Lane, had not even suspected were flawed. Lane was also surprised that four of the articles he had identified to Glass's counsel as suspicious, but which Glass had declined to stipulate contained fabrications, were now admitted in the California State Bar application to involve fabrications-including the disturbing Taxis and the Meaning of Work, along with Deliverance, with its false claim of anti-Semitism, and Boys on the Bus, which had involved the magazine in a dispute over authenticity even before Glass's exposure.

Lane testified that he thought Glass had perpetrated an elaborate hoax on readers and was engaged in a con game, not journalism. He testified that Glass's case had been highlighted at the Newseum, a Washington, D.C., museum of journalism, as one of the worst examples of 
misconduct in journalistic history. Lane noted that The New Republic was put to the expense of hiring a private investigator to analyze Glass's articles and incurred legal fees in the tens of thousands of dollars. He testified that Glass had not offered him reimbursement for the magazine's expenses, nor did he offer to refund any portion of the salary he had been paid. Lane added that the fabrications hurt the magazine's reputation, relationships between employees, and of course hurt those maligned in the articles. Lane was not mollified by a letter of apology he received from Glass in August 2003, around the time Glass's novel, The Fabulist, was published. Lane considered the letter fawning. Lane considered Glass "flagrantly incapable of producing honest journalism," and concluded that his record of systematic deception and lack of thorough confession made him unemployable as a journalist.

Richard Bradley, who was Washington affairs editor for George magazine and Glass's editor for his freelance articles for that magazine, testified on behalf of the Committee. Bradley stated that when he learned of the scandal involving Glass at The New Republic, he investigated the background for the three freelance articles Glass had published, as well as a fourth article that Glass had submitted and that was being edited. On investigation, the article on Vernon Jordan "blew apart like a dandelion in a strong wind." Assertions in the other articles were difficult to substantiate. When, within a week of learning there were problems with Glass's work, Bradley contacted Glass for help in identifying problems in the articles, Glass responded that he was psychologically incapable of doing so and that he was suicidal, and hung up. The magazine published an editorial indicating that significant portions of the Vernon Jordan article appeared to be false, and that the fabrications were woven into reliable reporting so that it was difficult to distinguish them. Glass never contacted Bradley to tell him what was true or false in his articles in George magazine, nor was Bradley contacted by Glass's lawyer. (Glass did send a letter of apology to the magazine's editor-in-chief.) Bradley believed that Glass had discredited journalism, contributing to the misconception that journalists are "craven and dishonest." Bradley commented that Glass's articles "caricatured and mocked their subjects and I felt that the perceptions promoted by Glass's fabrications, in these examples of African-American people and conservatives, could not be corrected as easily as a factual mistake could be." Because he would not be credible, Bradley would not hire Glass as a journalist.

Joseph Landau, who later became a law professor at Fordham University Law School, was a fact checker at The New Republic while Glass worked there. He testified that Glass had a superior reputation for accuracy among fact checkers because his notes were so thorough and he was apparently so forthcoming, but he tended to push the fact-checking process to the last minute so that it was rushed and could not be done face-to-face. At times Glass could not verify certain facts but would promise Landau to telephone the source. Glass would soon return with confirmation and updated material, a process that reaffirmed the witness's sense that the fact checking was working. Landau had trusted him. Landau received a letter of apology from Glass in the summer of 2004 , some six years after Glass had been exposed, and found it to be general and vague.

Louis Miller, a lawyer and chairperson of the board of D.A.R.E., testified that Glass published falsehoods in articles in The New Republic in March 1997 and Rolling Stone in March 1998 that 
impaired the organization's reputation, because the articles claimed D.A.R.E. was ineffective. According to Miller, the articles contained fabricated "evidence" that the organization had engaged in a widespread campaign of heavyhanded and even violent criminal tactics to counter academic and journalistic criticism of the program. D.A.R.E. sued Glass for libel and settled after Glass agreed the challenged information was fabricated, issued a retraction, and paid the organization's legal expenses of between $\$ 25,000$ and $\$ 50,000$. D.A.R.E. did not receive a letter of apology from Glass before it filed suit. D.A.R.E. sued Rolling Stone for defamation but lost on the ground that D.A.R.E. had failed to establish actual malice.

Glass graduated from law school in 2000 , when he also took and passed the New York bar examination. He applied to become a member of the New York bar in 2002. After an evidentiary hearing before a subcommittee of a committee on character and fitness, and pursuant to apparent custom, in September 2004, a representative of that committee informed Glass informally that his application would be rejected, so he withdrew it. The record does not disclose the reason for the tentative decision.

In his application to the New York bar, Glass described his misconduct and firing. His application and supporting materials included only 20 articles containing fabrications. Glass wrote that he had apologized to the editor of The New Republic, saying, "I also worked with all three magazines (referring to The New Republic, Harper's, and George magazines) and other publications where I had written freelance articles to identify which facts were true and which were false in all of my stories, so they could publish clarifications for their readers."

At the hearing, Lane challenged the quoted statement as untrue. Lane believed that Glass had failed to come forward to actively assist The New Republic in identifying his fabrications, and instead had placed the entire burden of identifying his errors on Lane. Lane testified: "Well, he didn't work with us. The effort we went through, over the course of nearly a month, to investigate all those stories would have been unnecessary if he had worked with us, and simply come forward and laid bare everything that was untrue in his stories. Instead, he sought legal counsel and, in effect, clammed up. When I read the statement that he's laid out in this proceeding, I discovered that, even to this day, he has not-or had not-come clean about everything. So I'm a little amazed to see that he was representing to somebody that he worked with The New Republic to separate fact from fiction in his articles. That was definitely not my experience."

\section{B. Applicant's evidence}

According to Glass, during his childhood and young adulthood his parents exerted extremely intense and cruel pressure upon him to succeed academically and socially. Glass felt that The New Republic offered an extremely competitive atmosphere and that his journalistic efforts there failed to make a mark sufficient to ensure his retention after his year term had elapsed. It was after a visit to the family home, when his parents berated him for his apparent failure even in what they considered the worthless career of journalism, that he began fabricating material for publication. He also fabricated reporter's notes and supporting materials for his articles. His aim was to impress his parents and colleagues. 
Once he was fired from The New Republic, Glass was distraught, suicidal, and unable to focus, almost immediately entering therapy. He nonetheless hired counsel whom he directed to "work with The New Republic." Glass testified that he believed that The New Republic wanted to conduct its own investigation because it did not trust him and testified that "I came to understand that they were going to provide me with a list of fabricated articles, and that I was to affirm whether or not the article was fabricated that they showed me or that they listed." He had fabricated more than The New Republic had discovered in its investigation, although he testified that due to his distress he did not realize this when he reviewed the list or later when he glanced at The New Republic's editorials listing his fabrications. Four of his articles containing fabrications were not on the list and he had erroneously denied there were fabrications in four articles that were on the list, including Boys on the Bus, Deliverance, and Taxis and the Meaning of Work. He did not read the editorials-incomplete, as it turned out-that Lane published listing his fabricated articles. In fact, he closely read those articles for the first time when the California State Bar asked him to list all of his fabricated articles. Glass testified that he had "no information" indicating that his lawyers had failed to convey information to The New Republic.

Glass did well in law school. Within a few days of his firing, he rescheduled an exam and within a week, managed to earn a B-plus grade on an exam. He explained, however, that this was a poor grade for him.

Members of Georgetown University's law school faculty testified on his behalf at the hearing. Professor Susan Bloch telephoned him when the scandal first broke and asked if he needed someone to talk to. She appointed him as her research assistant, praising him as one of the brightest and best workers she ever had encountered. She found him to be honest and developed complete trust in him. She recommended him for a judicial internship during law school and a clerkship after graduation. Bloch maintained friendly contact with Glass over the years, including after he moved to California, and testified on his behalf when Glass applied for admission to the New York bar. She testified that she believed Glass had learned from his wrongdoing, that the trauma of his exposure would keep him from ever repeating such behavior, and that she had never observed any dishonesty on his part. She did not read his fabricated articles but was generally aware of their content.

Professor Stephen Cohen, also of the Georgetown law school, testified that Glass took full responsibility for his misconduct. They became friends and Glass was a welcome visitor with Cohen's family. Cohen believed Glass would be honest and ethical as an attorney; in sum, he believed Glass to be fully rehabilitated. Cohen deemed it "presumptuous" and "offensive" when counsel for the Committee of Bar Examiners asked him whether the Georgetown law school application should be read to have required Glass to notify the school that the journalistic honors he listed in his application may have been based in part on fabricated journalism.

In 2001, at the end of his clerkship, Glass moved to New York to be with his girlfriend, and underwent psychoanalysis on a four-day-a-week basis. In June 2001 Glass entered into a 
contract to write a novel based on his experiences at The New Republic, testifying that his psychiatrists advised him that it would be therapeutic to write the book, which he hoped would serve as a warning to young journalists. He was paid an advance of $\$ 175,000$ and sold subsidiary rights for $\$ 15,000$. He wrote the novel, The Fabulist, and appeared on the television program 60 Minutes in May 2003 (just prior to the date of publication) to discuss his experiences. He claimed that it was not his intent to use the appearance to sell his book, but rather to offer a public apology.

During his residence in New York, and mostly between 2001 and 2004, Glass also undertook to handwrite approximately 100 letters of apology to journalists affected by his fabrications, as well as to the persons who were injured by his articles. He also spoke at a journalism forum at George Washington University in 2003, where he was loudly berated by other journalists. He spoke at a journalism class at Columbia and to a civics organization for high school students. In addition, he worked at a senior center on a regular basis for approximately one year in New York.

Concerning the questions that had arisen about the accuracy of his New York bar application, specifically his assertion that he had "worked with" the affected magazines "to identify which facts were true and which were false in all [his] stories, so they could publish clarifications," Glass testified that perhaps he should have written that he "offered to work with all three magazines," or in fact, that he "offered to work through counsel," but added that he did not intend to make any misrepresentation or exaggeration. He testified that he assumed his lawyer had contacted George magazine, as Glass had instructed him to do, and that he did not prepare a list of fabrications for George magazine. He explained that he attached to his New York bar application the editorials The New Republic had published incompletely listing his fabrications, but he did not read them, or at least did not read them carefully at that time. He also attached the notice that George magazine had published about his work-an article that did not refer to two of his three articles for George that contained fabrications. He reviewed these carefully for the first time in preparation for the California State Bar hearing.

When asked at the hearing in the present matter whether it would be accurate to say that he offered to work with The New Republic to identify which facts were true and which were false in all of his stories, he answered, "I believe that was my intention at the time, yes, and I believe I tried to do that." He explained that what he meant by this was that he asked his counsel to offer to go through the articles to identify fabrications, and then a "joint defense agreement was entered into, proposed by The New Republic, and we entered into a joint defense agreement that constructed this system."

Similarly, Glass explained, he did not actually undertake any work with Harper's Magazine to identify what was true and what was false in his articles, but "offered to work with them, or asked counsel to offer." He did not "have a memory of asking" his attorney whether counsel had contacted Harper's. When asked whether, when he prepared his New York bar application, he noticed or was troubled by the absence of any article from Harper's about his fabrications, he testified that he still assumed counsel had offered to exchange information or to enter into an 
agreement with Harper's. When pressed on his failure to confirm counsel's contact with Harper's, he testified: "I confirmed-well in my head I asked counsel to do something and he didn't tell me otherwise, I believed it to have occurred."

Concerning his decision to list only 20 articles containing fabrications in his New York bar application materials, Glass emphasized that he had not been asked for a complete list of articles containing fabrications, but rather in a telephone conversation, an employee of the committee on character and fitness asked for "a list of articles that contained a statement about a real person or real entity, as opposed to a fake person or a fake entity, that reflected something negative upon that real person or real entity." He wrote a letter to that committee memorializing this telephone conversation, saying he had been asked to list instances in which his fabrications "had a harmful impact on real persons. In response, I've gone back through all of my articles to identify those in which potentially harmful false statements were made about actual persons and actual organizations," and also warning that there might be inadvertent omissions. He did not list Deliverance, Boys on the Bus, or an article concerning Ted Turner entitled Gift of the Magnate, although these contained fabrications. He explained at the California hearing that the customer service agent to whom he attributed the anti-Semitic slur in Deliverance was a "made-up character," and so, he insisted, the article did not harm a real person. When pressed, he admitted that the article could have caused harm to the customer service agent the company determined had assisted him, and to the company.

Similarly, he did not include the Boys on the Bus article in his New York bar materials because the person to whom he attributed the statement that Alec Baldwin did not know much about campaign finance reform was fake, and he had created some "fake fans." When asked whether the article harmed Alec Baldwin, a real person, he responded that "Alec Baldwin, truth be told, did not know much about campaign finance reform." When pressed, he conceded that there was a potential for injury to Baldwin.

Glass testified that he moved to California in the fall of 2004. He was hired by the Carpenter, Zuckerman and Rowley law firm as a law clerk. The firm has many homeless clients, and in addition to the legal work he does on their cases, he has helped them with their personal problems, even with regard to matters of personal hygiene.

Originally Glass undertook volunteer work in Los Angeles, but because his law firm encouraged him to stop taking time off during the workday, he arranged to work extra hours for deserving clients on matters for which his firm had no expectation of collecting fees.

California Attorney Paul Zuckerman testified that he decided to give Glass a chance as a law clerk. After initially assigning Glass minor projects and exercising close oversight, Zuckerman became convinced that Glass was one of the best employees in the firm, with a fine intellect, a good work ethic, and reliable commitment to honesty. Glass exhibited great compassion, assisting at a personal level with difficult clients and helping to find resources and social services for some of the firm's many homeless clients. Other lawyers who had worked for or with the firm confirmed Zuckerman's view of Glass as an employee who conducted excellent 
legal research, was assiduous and hyperscrupulous about honesty, and stopped to think about ethical issues.

Also offered in support of Glass's application were affidavits that had been submitted in support of his New York bar application from the judges for whom Glass had worked during and immediately after completing law school. Both found him highly competent and honest at that time. Additional declarations from attorneys and friends that had been submitted with the New York bar application were offered in support.

Dr. Richard Friedman, a psychiatrist, testified that he had treated Glass since 2005, and believed he had developed good judgment, scrupulous honesty, and the ability to handle difficult situations well. Dr. Friedman reported that he would be astonished if Glass committed misconduct as he had in the past, both because of the growth of character and moral sense the doctor had observed, but also because of a strong instinct to protect himself from the traumatic results of his prior misconduct. He reported that Glass had no sociopathic personality traits.

Dr. Richard Rosenthal, a psychiatrist and psychoanalyst who is known for treating gamblers and those with impulse control disorders, was approached by Glass's attorney in 2005. Rosenthal had an evaluative as well as therapeutic relationship with Glass that began in 2005 and continued with meetings once or twice a month until the time of the hearing.

Dr. Rosenthal identified Glass's underlying psychological issues as a need for approval, a need to impress others, and a need for attention, and pointed also to Glass's fear of inadequacy, rejection, and abandonment. Rosenthal testified that when they met in 2005, Glass needed to overcome enormous shame and learn to forgive himself. Through therapy, Glass learned to be realistic about family issues and to set boundaries. Rosenthal believed that Glass had grown up in a family that exerted tremendous pressure on him to succeed yet always made him feel like a failure. In Rosenthal's opinion, Glass was rehabilitated, meaning that he was extremely conscientious and honest, avoided the appearance of impropriety, had reasonable goals and expectations, had gained empathy and tolerance, and would not allow himself to be overwhelmed by stress. The doctor saw no evidence that Glass was a sociopath.

Glass himself described his therapy, which had commenced very shortly after his exposure and continued to the time of the 2010 hearing, that is, for 12 years. Through therapy he had learned to separate his feelings about his family from the work environment and to "set boundaries within my family." He testified that he believed the most important thing he could do to make amends was to change himself.

Martin Peretz, who owned and managed The New Republic at the time of the fabrications, testified on Glass's behalf and had developed a charitable view of his misconduct by the time of the California State Bar hearing. He blamed himself and, even more, the magazine's editors for encouraging Glass to write zany, shocking articles and for failing to recognize the improbability of some of Glass's stories. He found the harm of the scandal to the magazine to be minimal. He had renewed social contact with Glass in the past few years and believed that Glass had been 
harshly treated. He would not rule out hiring Glass again as a journalist. He explained that in his experience as a professor "the most brilliant students plagiarize," complaining to the Committee's counsel, "I actually find your pursuing him an act of stalking."

Additional character witnesses included Melanie Thernstrom, a journalist, memoirist, and friend who testified that she had known Glass for more than a decade because she was a close friend of his girlfriend, Julie Hilden. Her initial skepticism about him dissolved soon after she met him and she believed he had become kind, generous, loyal, responsible, empathetic and above all, honest. Thernstrom witnessed Glass during the period he wrote letters of apology and said that each letter required considerable work and caused him anguish. She found him to be very sorry for the deceptions, and believed that he had taken responsibility for his past acts and would never deceive again. She had observed that Glass was intelligent, hardworking, and empathetic with clients who were injured. She thought the Committee was "picking on" irrelevant issuesthat is, the exact number of Glass's deceptive articles and whether or when he had disclosed them all. She believed the Committee's position was "sophistic." In her view, it was enough that he had admitted his misconduct and apologized for it, and she believed that there was no current, ongoing damage from his fabricated articles because Glass's work had been entirely discredited.

Lawrence Berger, a friend, testified on Glass's behalf, saying that Glass immediately told him about the scandal when they met. He testified that Glass is especially committed to being a good person now, being remarkably ethical and a devoted friend. According to Berger, Glass's efforts during the period he wrote the letters of apology were never perfunctory.

Julie Hilden, a freelance lawyer and aspiring scriptwriter and Glass's longtime live-in girlfriend, also testified on his behalf. He took good care of her during a prolonged, serious illness, even though she lived in New York and he was completing law school and doing his clerkship in Washington, D.C., at the time. She testified that he immediately demonstrated that he was very serious about being completely honest in every detail, and honesty is still an overriding concern. She observed the great effort he put into writing letters of apology during a prolonged period between 2002 and 2004. She explained that he takes a personal interest in clients, works very hard for them, and accepts their telephone calls at all hours, including nights and weekends.

\section{California State Bar proceedings}

Glass took and passed the California Bar examination in 2006 and in July 2007 filed an application for determination of moral character as part of his bar application. The Committee of Bar Examiners denied the application, but on Glass's request a moral character hearing was conducted in the State Bar Court in April and May of 2010.

The State Bar Court's hearing judge found that Glass had established good moral character. The Committee sought review. The State Bar Court Review Department independently reviewed the record, and a majority of the three-judge panel agreed with the hearing judge that Glass had established good moral character. 
The Review Department majority acknowledged that Glass's misconduct had been "appalling" and "egregious," but believed that Glass had satisfied his "heavy burden of proof" and established his rehabilitation. The majority stated that Glass's burden of proof as a first-time applicant was "substantially less rigorous" than it would have been for an attorney seeking reinstatement after disbarment. Moreover, the majority declared, its "task here is not to dwell on his past misdeeds, but to determine his present moral fitness." It added that because the "policy of the state favors admission of applicants who have achieved reformation," the majority resolved any reasonable doubt concerning Glass's rehabilitation in his favor and "gave him the benefit of any conflicting but equally reasonable inferences flowing from the evidence." The majority concluded that "cumulatively, Glass's legal employment history, community service, character witnesses, progress in therapy, remorse and acceptance of responsibility" provided a more accurate picture of his moral character than his misconduct of many years ago.

The majority acknowledged that Glass had not fully identified his fabrications until the California Bar proceedings, but observed that Glass had not asked the bar to excuse that failure. The majority also expressed some concern regarding Glass's New York bar application, observing that he had "mischaracterized the degree to which he cooperated with the magazines to identify the fabricated articles." On the other hand, in the majority's view, Glass's careful review of his prior articles in connection with the California State Bar proceedings indicated that he had fully acknowledged his wrongdoing, an "essential step towards rehabilitation." In addition, the majority concluded that Glass had left it to his attorneys to work with the magazines because of his emotional turmoil, and "the State Bar did not prove whether Glass's attorney failed to 'work with' some of the publishers and neither did Glass establish that his attorney had completed the task as requested."

The majority commented upon Glass's excellent reputation with law professors and judicial employers, and observed that Glass's rehabilitation seemed to have occurred over a number of years. The majority recounted the course of Glass's therapy and his therapists' testimony on his behalf in support of the view that he was rehabilitated. The majority further referred to Glass's community service in New York and commented that his work commitments rendered him unable to continue non-work-related community service in Los Angeles, where he had resided since 2004.

The majority placed great emphasis on Glass's character witnesses, saying: "We afford great weight to Glass's character witnesses, who were community leaders, employers, judges, and attorneys, and all of whom spoke with the utmost confidence in Glass's good moral character and rehabilitation."

The majority declined to believe restitution was required of Glass. "We consider his present character in light of his previous moral shortcomings citation, and we are at a loss to understand how monetary restitution would mitigate the reputational harm that Glass had caused." The majority found more significant evidence that he has made amends both to the journalistic 
community in his public admissions concerning his fabrications and to his victims in the letters he sent them.

The majority concluded that "even those who have committed serious, indeed egregious, misconduct, are capable of overcoming their past misdeeds" and that persons who had reformed should be rewarded with an opportunity to serve as lawyers.

The Review Department panel's dissenting opinion concluded that Glass had not proven full rehabilitation, pointing to his "staggering" two-year period of "multi-layered, complex and harmful course of public dishonesty." The dissenting judge found especially troubling Glass's omissions and misstatements in his application to the New York bar. "To gain admission to practice law in New York, Glass understated the number of articles he had fabricated and exaggerated his efforts to help the magazines identify those articles. At a time when he should have been scrupulously honest, he presented an inaccurate application because it benefitted him-the same behavior as his earlier misconduct." The dissenting opinion concluded: "Given the magnitude of his misconduct and his subsequent misrepresentations on his New York bar application, Glass has not shown proof of reform by a lengthy period of exemplary conduct which 'we could with confidence lay before the world' to justify his admission."

\section{DISCUSSION}

\section{A. Applicable Law}

(1) To be qualified to practice law in this state, a person must be of good moral character. Good moral character includes "qualities of honesty, fairness, candor, trustworthiness, observance of fiduciary responsibility, respect for and obedience to the law, and respect for the rights of others and the judicial process." "Persons of good character do not commit acts or crimes involving moral turpitude-a concept that embraces a wide range of deceitful and depraved behavior." A lawyer's good moral character is essential for the protection of clients and for the proper functioning of the judicial system itself.

(2) When the applicant has presented evidence that is sufficient to establish a prima facie case of his or her good moral character, the burden shifts to the State Bar to rebut that case with evidence of poor moral character. Once the State Bar has presented evidence of moral turpitude, the burden "falls squarely upon the applicant to demonstrate his or her rehabilitation."

Of particular significance for the present case is the principle that "the more serious the misconduct and the bad character evidence, the stronger the applicant's showing of rehabilitation must be." "Cases authorizing admission on the basis of rehabilitation commonly involve a substantial period of exemplary conduct following the applicant's misdeeds." Moreover, "truly exemplary" conduct ordinarily includes service to the community.

(3) We independently weigh the evidence that was before the State Bar Court, recognizing that the applicant bears the burden of establishing good moral character. We ask whether the 
applicant is fit to practice law, paying particular attention to acts of moral turpitude and prior misconduct that bears particularly upon fitness to practice law.

In reviewing moral fitness findings made by the State Bar, we accord significant weight to the State Bar Court hearing judge's findings of fact to the extent they are based on witness demeanor and credibility. Although "the moral character determinations of the Committee and the State Bar Court play an integral role in the admissions decision, and both bear substantial weight within their respective spheres," we are not bound by the determinations of the Committee or the State Bar Court. Rather, we "independently examine and weigh the evidence" to decide whether the applicant is qualified for admission.

(4) Contrary to the Review Department majority's view that Glass's burden was significantly lighter than it would be for an attorney seeking readmission because he was a first-time applicant, in many respects the difference between admission and disciplinary proceedings is "more apparent than real." "Because both admission and disciplinary proceedings concern fitness to practice law as evidenced by acts of moral turpitude, this court routinely consults its disciplinary cases in deciding whether applicants for admission possess, at the outset, the requisite moral character." At both admission and disciplinary proceedings, "the common issue is whether the applicant for admission or the attorney sought to be disciplined 'is a fit and proper person to be permitted to practice law, and that usually turns upon whether he has committed or is likely to continue to commit acts of moral turpitude," particularly misconduct that bears upon the applicant's fitness to practice law.

"However, unlike in disciplinary proceedings, where the State Bar must show that an already admitted attorney is unfit to practice law and deserves professional sanction, the burden rests upon the candidate for admission to prove his own moral fitness."

\section{B. Analysis}

(5) The Review Department majority believed it was reasonable to draw all inferences in favor of Glass, failing to be constrained by our discussion in Gossage, as we shall explain. Although an applicant ordinarily receives the benefit of the doubt as to "conflicting, equally reasonable inferences" concerning moral fitness, the State Bar Court majority failed to recognize that this rule does not materially assist applicants who have engaged in serious misconduct. This is because "where serious or criminal misconduct is involved, positive inferences about the applicant's moral character are more difficult to draw, and negative character inferences are stronger and more reasonable." When there have been very serious acts of moral turpitude, we must be convinced that the applicant "is no longer the same person who behaved so poorly in the past," and will find moral fitness "only if he or she has since behaved in exemplary fashion over a meaningful period of time."

Applying the Gossage standard in this case of egregious malfeasance, we begin our own independent review of the record with a focus on Glass's many acts of dishonesty and professional misconduct, and then ask whether he has established a compelling showing of 
rehabilitation and truly exemplary conduct over an extended period that would suffice to demonstrate his fitness for the practice of law.

Glass's conduct as a journalist exhibited moral turpitude sustained over an extended period. As the Review Department dissent emphasized, he engaged in "fraud of staggering proportions" and he "used his exceptional writing skills to publicly and falsely malign people and organizations for actions they did not do and faults they did not have." As the dissent further commented, for two years he "engaged in a multi-layered, complex and harmful course of public dishonesty." Glass's journalistic dishonesty was not a single lapse of judgment, which we have sometimes excused, but involved significant deceit sustained unremittingly for a period of years. Glass's deceit also was motivated by professional ambition, betrayed a vicious, mean spirit and a complete lack of compassion for others, along with arrogance and prejudice against various ethnic groups. In all these respects, his misconduct bore directly on his character in matters that are critical to the practice of law.

Glass not only spent two years producing damaging articles containing or entirely made up of fabrications, thereby deluding the public, maligning individuals, and disparaging ethnic minorities, he also routinely expended considerable efforts to fabricate background materials to dupe the fact checkers assigned to vet his work. When exposure threatened, he redoubled his efforts to hide his misconduct, going so far as to create a phony website and business cards and to recruit his brother to pose as a source. In addition, to retain his position, he engaged in a spirited campaign among the leadership at The New Republic to characterize Lane's obviously well-founded concerns as unfair and to retain his position.

Glass's conduct during this two-year period violated ethical strictures governing his profession. Believing that "public enlightenment is the forerunner of justice and the foundation of democracy," the Code of Ethics of the Society of Professional Journalists provides that "the duty of the journalist is to further those ends by seeking truth and providing a fair and comprehensive account of events and issues, striving to serve the public with thoroughness and honesty.

Deliberate distortion is never permissible." Glass's behavior fell so far short of this standard that Lane recounted seeing Glass featured in an exhibit in the Newseum, a Washington, D.C., museum dedicated to journalism, as embodying one of the worst episodes of deceit in journalistic history.

Glass's misconduct was also reprehensible because it took place while he was pursuing a law degree and license to practice law, when the importance of honesty should have gained new meaning and significance for him.

Moreover, Glass's lack of integrity and forthrightness continued beyond the time he was engaged in journalism. Once he was exposed, Glass's response was to protect himself, not to freely and fully admit and catalogue all of his fabrications. He never fully cooperated with his employers to clarify the record, failed to carefully review the editorials they published to describe the fabrications to their readership, made misrepresentations to The New Republic regarding some of his work during the period he purported to be cooperating with that magazine, and 
indeed some of his fabrications did not come to light until the California State Bar proceedings. He refused to speak to his editor at George magazine when the latter called to ask for help in identifying fabrications in the articles Glass wrote for that magazine.

(6) The record also discloses instances of dishonesty and disingenuousness occurring after Glass's exposure, up to and including the State Bar evidentiary hearing in 2010. In the New York bar proceedings that ended in 2004 , as even the State Bar Court majority acknowledged, he made misrepresentations concerning his cooperation with The New Republic and other publications and efforts to aid them identify all of his fabrications. He also submitted an incomplete list of articles that injured others. We have previously said about omissions on bar applications: "Whether it is caused by intentional concealment, reckless disregard for the truth, or an unreasonable refusal to perceive the need for disclosure, such an omission is itself strong evidence that the applicant lacks the 'integrity' and/or 'intellectual discernment' required to be an attorney."

Our review of the record indicates hypocrisy and evasiveness in Glass's testimony at the California State Bar hearing, as well. We find it particularly disturbing that at the hearing Glass persisted in claiming that he had made a good faith effort to work with the magazines that published his works. He went through many verbal twists and turns at the hearing to avoid acknowledging the obvious fact that in his New York bar application he exaggerated his level of assistance to the magazines that had published his fabrications, and that he omitted from his New York bar list of fabrications some that actually could have injured real persons. He also testified that he told his lawyer to work with Harper's Magazine to identify his fabrications, yet evaded questions concerning whether his lawyer had done so, while insisting that he took responsibility for an inferred failure to follow what obviously were significant instructions. He asserted that he had been too distraught to recognize that the list of fabrications The New Republic gave his lawyer was incomplete-or that in his response he had denied that articles including the egregious Taxis and the Meaning of Work were in fact fabricated-while acknowledging that within a few days of his firing he made arrangements to reschedule a final examination for the end of the exam period and did well on the exam he took within a week of his exposure. Indeed, despite his many statements concerning taking personal responsibility, and contrary to what he suggested in his New York bar application, it was not until the California Bar proceedings that he shouldered the responsibility of reviewing the editorials his employers published disclosing his fabrications, thus failing to ensure that all his very public lies had been corrected publically and in a timely manner. He has "not acted with the "high degree of frankness and truthfulness' and the 'high standard of integrity' required by this process."

(7) Honesty is absolutely fundamental in the practice of law; without it, "the profession is worse than valueless in the place it holds in the administration of justice." "Manifest dishonesty provides a reasonable basis for the conclusion that the applicant or attorney cannot be relied upon to fulfill the moral obligations incumbent upon members of the legal profession." As the dissent in the Review Department pointed out, "if Glass were to fabricate evidence in legal matters as readily and effectively as he falsified material for magazine articles, the harm to the public and profession would be immeasurable." 
We also observe that instead of directing his efforts at serving others in the community, much of Glass's energy since the end of his journalistic career seems to have been directed at advancing his own career and financial and emotional well-being.

(8) As Justice Kennard did in her concurring opinion in Kwasnik, we do well to repeat Justice Felix Frankfurter's "eloquent description" of the moral character required of lawyers: "It is a fair characterization of the lawyer's responsibility in our society that he or she stands "as a shield" in defense of right and to ward off wrong. From a profession charged with such responsibilities there must be exacted those qualities of truth-speaking, of a high sense of honor, of granite discretion, of the strictest observance of fiduciary responsibility, that have, throughout the centuries, been compendiously described as "moral character."

(9) As for Glass's case for admission, although he points to his youth at the time of his employment as a journalist and an asserted period of rehabilitation of 12 years (measured between the time he was fired and the hearing in the State Bar Court), we have outlined instances of dishonesty and disingenuousness persisting throughout that period, including at the California State Bar evidentiary hearing. In addition, Glass's behavior was under the scrutiny of first the New York bar from 2002 to 2004, and then the California Bar from 2007 to 2010, reducing the probative value of the evidence of his good conduct during those periods. "Good conduct generally is expected from someone who has applied for admission with, and whose character is under scrutiny by, the State Bar."

(10) The Review Department majority relied heavily on the testimony of Glass's character witnesses, but the testimony of character witnesses will not suffice by itself to establish rehabilitation. Moreover, stressing that Glass's reputation as a journalist had been exploded and that so many years had passed, some of the character witnesses did not sufficiently focus on the seriousness of the misconduct, incorrectly viewing it as of little current significance despite its lingering impact on its victims and on public perceptions concerning issues of race and politics. They also did not take into account, as we do, that the misconduct reflected poorly on the particular commitment to honesty that Glass might have been expected to have had as a law student. For these reasons we believe the Review Department majority accorded too much probative value to the testimony of Glass's character witnesses.

(11) Glass emphasized the remorse he expressed through his letters to victims, and characterized his novel and his appearance on 60 Minutes as efforts to make amends. Remorse does not establish rehabilitation, however, and in any event, the weight of this evidence is diminished because the letters were not written near the time of his misconduct and exposure, when they might have been most meaningful to the victims, but rather seemed timed to coincide with his effort to become a member of the New York bar. The novel served Glass's own purposes, producing notoriety and a fee of $\$ 175,000$, and the appearance on 60 Minutes was timed to coincide with the release of the novel. Glass did not offer any restitution to Lane or Bradley. It was not until approximately 2008 that he made an offer to the then friendly Peretzwho roundly disclaimed any interest in restitution-to repay his salary. This offer was made after 
Glass applied to the California Bar and was another oddly belated and, we believe, disingenuous effort at making his victims whole.

The record of Glass's therapy does not represent "truly exemplary conduct in the sense of returning something to the community." To be sure, through therapy he seems to have gained a deep understanding of the psychological sources of his misconduct, as well as tools to help him avoid succumbing to the same pressures again. His treating psychiatrists are plainly highly competent and well regarded in their field, and they are convinced that he has no remaining psychological flaws tending to cause him to act dishonestly. Glass believed that he could best make amends by changing himself. But his 12 years of therapy primarily conferred a personal benefit on Glass himself.

(12) Glass points to the pro bono legal work he does for clients of his firm as evidence of sustained efforts on behalf of the community, but we observe that pro bono work is not truly exemplary for attorneys, but rather is expected of them.

(13) Glass and the witnesses who supported his application stress his talent in the law and his commitment to the profession, and they argue that he has already paid a high enough price for his misdeeds to warrant admission to the bar. They emphasize his personal redemption, but we must recall that what is at stake is not compassion for Glass, who wishes to advance from being a supervised law clerk to enjoying a license to engage in the practice of law on an independent basis. Given our duty to protect the public and maintain the integrity and high standards of the profession, our focus is on the applicant's moral fitness to practice law. On this record, the applicant failed to carry his heavy burden of establishing his rehabilitation and current fitness.

\section{CONCLUSION}

For the foregoing reasons, we reject the State Bar Court majority's recommendation and decline to admit Glass to the practice of law.

\section{Questions:}

1. Stephen Randall Glass (1972-) is currently working at a Beverly Hills law firm as a paralegal. He was the subject of the motion picture Shattered Glass (2003). Excellent journalistic accounts of the Glass affair are available from Vanity Fair, Forbes, The Los Angeles Times, and The New Republic. The New Republic's original corrections are available here and here. Links to several of Glass's fabricated articles are available on his Wikipedia page.

2. Did the court provide a fair assessment of Glass's fitness to practice law? Do you agree with the court's conclusion that he failed to rehabilitate himself? Do you agree with the courts assessment of his disclosures in his applications for bar membership in New York and California?

3. The court described Glass's fabrications as acts of moral turpitude. "Moral turpitude" is generally defined as "an act or behavior that gravely violates the sentiment or accepted 
standard of the community." More specifically, the California Supreme Court has observed, "The concept of moral turpitude escapes precise definition. Moral turpitude has been described as an act of baseness, vileness or depravity in the private and social duties which a man owes to his fellowmen, or to society in general, contrary to the accepted and customary rule of right and duty between man and man. It has been described as any crime or misconduct without excuse or any dishonest or immoral act. The meaning and test is the same whether the dishonest or immoral act is a felony, misdemeanor, or no crime at all." Chadwick v. State Bar, 776 P.2d 240 (Cal. 1989). Is this a helpful definition? Do you agree with the court that Glass committed acts of moral turpitude?

4. Was the problem with Glass's articles the fabrications, the content, or both? If Glass had not fabricated any of the facts reported in the articles, would they reflect on his moral character?

5. Was it proper for the court to reverse the State Bar Court's assessment of Glass's rehabilitation, moral character, and fitness to practice?

6. What standard of proof did the court apply to Glass's claim of rehabilitation? Was it higher, lower, or the same as the standard applied to attorneys applying for readmission? What standard should courts apply to new applicants for bar admission, as opposed to applicants for readmission?

7. Many prominent people testified in favor of Glass and his rehabilitation, including some of the people he directly harmed. Should that count in his favor? How seriously did the court take their testimony?

8. If the court granted Glass's application for admission to practice, do you think it is likely that he would engage in fraudulent or misleading conduct? 


\section{2: Advertising}

Call me on the line. Call me, call me any, anytime. Call me, I'll arrive. You can call me any day or night. Call me. ${ }^{108}$

Attorneys are "professionals" and the bar is a "professional organization." But how, if at all, should the professional status of attorneys affect their commercial behavior? Attorneys have fiduciary duties to their clients and professional duties as officers of the court. But do they have professional duties of decorum to the public as a whole? And how should the bar regulate the commercial activities of attorneys? When do professional norms justify regulation? And in whose interests should the bar regulate the commercial activities of attorneys: the public or its members?

\section{Advertising}

In the 19th century, attorneys regularly advertised their services in newspapers and magazines. Among other things, patent attorneys solicited patent applications from inventors nationwide. But in the early 20th century, state bar associations began to frown on advertising. And in 1908, Canon 27 of the American Bar Association's original Canons of Professional Ethics explicitly discouraged advertisement and solicitation as "unprofessional."

Gradually, the "ethical principles" motivating Canon 27 were refined by state and national bar associations to provide increasingly detailed norms governing what kinds of attorney advertising were permissible, from signage on a law office, to attorney directories, to business card and letterhead design. With the exception of patent and trademark attorneys and proctors in admiralty, most attorneys could not even publicly claim a specific area of practice.

Unsurprisingly, these limitations on attorney advertising were observed substantially in the breach. State bar associations were hard-pressed to enforce them and enterprising attorneys were wont to avoid them. Pressure for relaxation of the norms gradually mounted, but did not come to a head until 1977, when the Supreme Court finally weighed in.

\section{Model Rule 7.1: Communications Concerning a Lawyer's Services}

\section{Information About Legal Services}

A lawyer shall not make a false or misleading communication about the lawyer or the lawyer's services. A communication is false or misleading if it contains a material misrepresentation of fact or law, or omits a fact necessary to make the statement considered as a whole not materially misleading.

Model Rule 7.1: Comments

${ }^{108}$ Blondie, Call Me (1980). 
1. This Rule governs all communications about a lawyer's services, including advertising. Whatever means are used to make known a lawyer's services, statements about them must be truthful.

2. Misleading truthful statements are prohibited by this Rule. A truthful statement is misleading if it omits a fact necessary to make the lawyer's communication considered as a whole not materially misleading. A truthful statement is misleading if a substantial likelihood exists that it will lead a reasonable person to formulate a specific conclusion about the lawyer or the lawyer's services for which there is no reasonable factual foundation. A truthful statement is also misleading if presented in a way that creates a substantial likelihood that a reasonable person would believe the lawyer's communication requires that person to take further action when, in fact, no action is required.

3. A communication that truthfully reports a lawyer's achievements on behalf of clients or former clients may be misleading if presented so as to lead a reasonable person to form an unjustified expectation that the same results could be obtained for other clients in similar matters without reference to the specific factual and legal circumstances of each client's case. Similarly, an unsubstantiated claim about a lawyer's or law firm's services or fees, or an unsubstantiated comparison of the lawyer's or law firm's services or fees with those of other lawyers or law firms, may be misleading if presented with such specificity as would lead a reasonable person to conclude that the comparison or claim can be substantiated. The inclusion of an appropriate disclaimer or qualifying language may preclude a finding that a statement is likely to create unjustified expectations or otherwise mislead the public.

\section{Model Rule 7.2: Communications Concerning a Lawyer's Services: Specific Rules}

a. A lawyer may communicate information regarding the lawyer's services through any media.

b. A lawyer shall not compensate, give or promise anything of value to a person for recommending the lawyer's services except that a lawyer may:

1. pay the reasonable costs of advertisements or communications permitted by this Rule

c. A lawyer shall not state or imply that a lawyer is certified as a specialist in a particular field of law, unless:

1. the lawyer has been certified as a specialist by an organization that has been approved by an appropriate authority of the state or the District of Columbia or a

U.S. Territory or that has been accredited by the American Bar Association; and

2. the name of the certifying organization is clearly identified in the communication.

d. Any communication made under this Rule must include the name and contact information of at least one lawyer or law firm responsible for its content.

Model Rule 7.2: Comments 
1. This Rule permits public dissemination of information concerning a lawyer's or law firm's name, address, email address, website, and telephone number; the kinds of services the lawyer will undertake; the basis on which the lawyer's fees are determined, including prices for specific services and payment and credit arrangements; a lawyer's foreign language ability; names of references and, with their consent, names of clients regularly represented; and other information that might invite the attention of those seeking legal assistance.

9. Paragraph (c) of this Rule permits a lawyer to communicate that the lawyer does or does not practice in particular areas of law. A lawyer is generally permitted to state that the lawyer "concentrates in" or is a "specialist," practices a "specialty," or "specializes in" particular fields based on the lawyer's experience, specialized training or education, but such communications are subject to the "false and misleading" standard applied in Rule 7.1 to communications concerning a lawyer's services. 


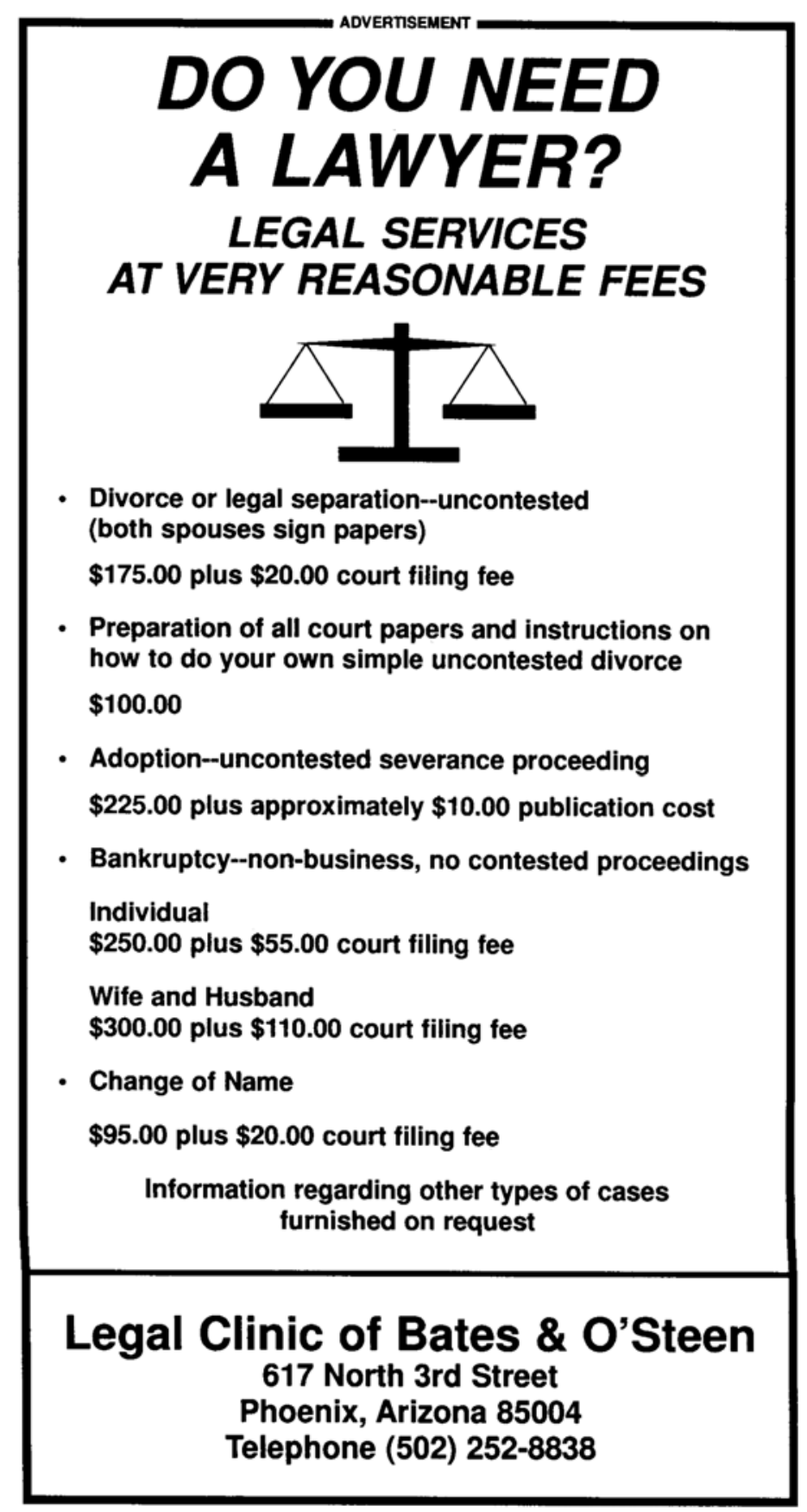

\section{Bates v. State Bar of Ariz., 433 U.S. 350 (1977)}

Summary: Bates and O'Steen were members of the Arizona bar. In 1974, they opened a law office in Phoenix, and published a newspaper advertisement, offering basic legal services at fixed rates. The Arizona bar rules prohibited advertisements, and the Arizona Supreme Court ultimately censured Bates and O'Steen. The Supreme Court reversed, holding that the Arizona bar rule violated the 1st Amendment, because it unreasonably 
prohibited the dissemination of truthful information to the public. The dissent argued that the 1 st Amendment should not prohibit the regulation of attorney advertising.

MR. JUSTICE BLACKMUN delivered the opinion of the Court.

As part of its regulation of the Arizona Bar, the Supreme Court of that State has imposed and enforces a disciplinary rule that restricts advertising by attorneys. This case presents two issues: whether $\S \S 1$ and 2 of the Sherman Act, 15 U. S. C. $\S \S 1$ and 2, forbid such state regulation, and whether the operation of the rule violates the First Amendment, made applicable to the States through the Fourteenth.

I

Appellants John R. Bates and Van O'Steen are attorneys licensed to practice law in the State of Arizona. As such, they are members of the appellee, the State Bar of Arizona. After admission to the bar in 1972, appellants worked as attorneys with the Maricopa County Legal Aid Society.

In March 1974, appellants left the Society and opened a law office, which they call a "legal clinic," in Phoenix. Their aim was to provide legal services at modest fees to persons of moderate income who did not qualify for governmental legal aid. In order to achieve this end, they would accept only routine matters, such as uncontested divorces, uncontested adoptions, simple personal bankruptcies, and changes of name, for which costs could be kept down by extensive use of paralegals, automatic typewriting equipment, and standardized forms and office procedures. More complicated cases, such as contested divorces, would not be accepted. Because appellants set their prices so as to have a relatively low return on each case they handled, they depended on substantial volume.

After conducting their practice in this manner for two years, appellants concluded that their practice and clinical concept could not survive unless the availability of legal services at low cost was advertised and, in particular, fees were advertised. Consequently, in order to generate the necessary flow of business, that is, "to attract clients," appellants on February 22, 1976, placed an advertisement in the Arizona Republic, a daily newspaper of general circulation in the Phoenix metropolitan area. As may be seen, the advertisement stated that appellants were offering "legal services at very reasonable fees," and listed their fees for certain services.

Appellants concede that the advertisement constituted a clear violation of Disciplinary Rule 2101(B). The disciplinary rule provides in part:

(B) A lawyer shall not publicize himself, or his partner, or associate, or any other lawyer affiliated with him or his firm, as a lawyer through newspaper or magazine advertisements, radio or television announcements, display advertisements in the city or telephone directories or other means of commercial publicity, nor shall he authorize or permit others to do so in his behalf.

Upon the filing of a complaint initiated by the president of the State Bar, a hearing was held before a three member Special Local Administrative Committee. Although the committee took the position that it could not consider an attack on the validity of the rule, it allowed the parties to develop a record on which such a challenge could be based. The committee recommended that each of the appellants be suspended from the practice of law for not less than six months. Upon further review by the Board of Governors of the State Bar, the Board recommended only a oneweek suspension for each appellant, the weeks to run consecutively. 
Appellants then sought review in the Supreme Court of Arizona, arguing, among other things, that the disciplinary rule violated $\S \S 1$ and 2 of the Sherman Act because of its tendency to limit competition, and that the rule infringed their First Amendment rights. The court rejected both claims. The plurality may have viewed with some skepticism the claim that a restraint on advertising might have an adverse effect on competition. But, even if the rule might otherwise violate the Act, the plurality concluded that the regulation was exempt from Sherman Act attack because the rule "is an activity of the State of Arizona acting as sovereign." The regulation thus was held to be shielded from the Sherman Act by the state-action exemption.

Turning to the First Amendment issue, the plurality noted that restrictions on professional advertising have survived constitutional challenge in the past. Although recognizing that Virginia Pharmacy Board v. Virginia Consumer Council and Bigelow v. Virginia held that commercial speech was entitled to certain protection under the First Amendment, the plurality focused on passages in those opinions acknowledging that special considerations might bear on the advertising of professional services by lawyers. The plurality apparently was of the view that the older decisions dealing with professional advertising survived these recent cases unscathed, and held that Disciplinary Rule 2-101(B) passed First Amendment muster. Because the court, in agreement with the Board of Governors, felt that appellants' advertising "was done in good faith to test the constitutionality of DR 2-101(B)," it reduced the sanction to censure only.

Of particular interest here is the opinion of Mr. Justice Holohan in dissent. In his view, the case should have been framed in terms of "the right of the public as consumers and citizens to know about the activities of the legal profession," rather than as one involving merely the regulation of a profession. Observed in this light, he felt that the rule performed a substantial disservice to the public:

Obviously the information of what lawyers charge is important for private economic decisions by those in need of legal services. Such information is also helpful, perhaps indispensable, to the formation of an intelligent opinion by the public on how well the legal system is working and whether it should be regulated or even altered. The rule at issue prevents access to such information by the public.

Although the dissenter acknowledged that some types of advertising might cause confusion and deception, he felt that the remedy was to ban that form, rather than all advertising. Thus, despite his "personal dislike of the concept of advertising by attorneys," he found the ban unconstitutional.

\section{The Sherman Act}

We conclude that the Arizona Supreme Court's determination that appellants' Sherman Act claim is barred by the Parker $v$. Brown exemption must be affirmed.

III The First Amendment

\section{B}

The issue presently before us is a narrow one. First, we need not address the peculiar problems associated with advertising claims relating to the quality of legal services. Such claims probably are not susceptible of precise measurement or verification and, under some circumstances, might well be deceptive or misleading to the public, or even false. Appellee does not suggest, 
nor do we perceive, that appellants' advertisement contained claims, extravagant or otherwise, as to the quality of services. Accordingly, we leave that issue for another day. Second, we also need not resolve the problems associated with in-person solicitation of clients-at the hospital room or the accident site, or in any other situation that breeds undue influence-by attorneys or their agents or "runners." Activity of that kind might well pose dangers of overreaching and misrepresentation not encountered in newspaper announcement advertising. Hence, this issue also is not before us. Third, we note that appellee's criticism of advertising by attorneys does not apply with much force to some of the basic factual content of advertising: information as to the attorney's name, address, and telephone number, office hours, and the like. The American Bar Association itself has a provision in its current Code of Professional Responsibility that would allow the disclosure of such information, and more, in the classified section of the telephone directory. We recognize, however, that an advertising diet limited to such spartan fare would provide scant nourishment.

The heart of the dispute before us today is whether lawyers also may constitutionally advertise the prices at which certain routine services will be performed. Numerous justifications are proffered for the restriction of such price advertising. We consider each in turn:

1. The Adverse Effect on Professionalism. Appellee places particular emphasis on the adverse effects that it feels price advertising will have on the legal profession. The key to professionalism, it is argued, is the sense of pride that involvement in the discipline generates. It is claimed that price advertising will bring about commercialization, which will undermine the attorney's sense of dignity and self-worth. The hustle of the marketplace will adversely affect the profession's service orientation, and irreparably damage the delicate balance between the lawyer's need to earn and his obligation selflessly to serve. Advertising is also said to erode the client's trust in his attorney: Once the client perceives that the lawyer is motivated by profit, his confidence that the attorney is acting out of a commitment to the client's welfare is jeopardized. And advertising is said to tarnish the dignified public image of the profession.

We recognize, of course, and commend the spirit of public service with which the profession of law is practiced and to which it is dedicated. The present Members of this Court, licensed attorneys all, could not feel otherwise. And we would have reason to pause if we felt that our decision today would undercut that spirit. But we find the postulated connection between advertising and the erosion of true professionalism to be severely strained. At its core, the argument presumes that attorneys must conceal from themselves and from their clients the reallife fact that lawyers earn their livelihood at the bar. We suspect that few attorneys engage in such self-deception. And rare is the client, moreover, even one of modest means, who enlists the aid of an attorney with the expectation that his services will be rendered free of charge. In fact, the American Bar Association advises that an attorney should reach "a clear agreement with his client as to the basis of the fee charges to be made," and that this is to be done "as soon as feasible after a lawyer has been employed." If the commercial basis of the relationship is to be promptly disclosed on ethical grounds, once the client is in the office, it seems inconsistent to condemn the candid revelation of the same information before he arrives at that office.

Moreover, the assertion that advertising will diminish the attorney's reputation in the community is open to question. Bankers and engineers advertise, and yet these professions are not regarded as undignified. In fact, it has been suggested that the failure of lawyers to advertise creates public disillusionment with the profession. The absence of advertising may be seen to reflect the profession's failure to reach out and serve the community: Studies reveal that many persons do not obtain counsel even when they perceive a need because of the feared price of 
services or because of an inability to locate a competent attorney. Indeed, cynicism with regard to the profession may be created by the fact that it long has publicly eschewed advertising, while condoning the actions of the attorney who structures his social or civic associations so as to provide contacts with potential clients.

It appears that the ban on advertising originated as a rule of etiquette and not as a rule of ethics. Early lawyers in Great Britain viewed the law as a form of public service, rather than as a means of earning a living, and they looked down on "trade" as unseemly. Eventually, the attitude toward advertising fostered by this view evolved into an aspect of the ethics of the profession. But habit and tradition are not in themselves an adequate answer to a constitutional challenge. In this day, we do not belittle the person who earns his living by the strength of his arm or the force of his mind. Since the belief that lawyers are somehow "above" trade has become an anachronism, the historical foundation for the advertising restraint has crumbled.

2. The Inherently Misleading Nature of Attorney Advertising. It is argued that advertising of legal services inevitably will be misleading (a) because such services are so individualized with regard to content and quality as to prevent informed comparison on the basis of an advertisement, (b) because the consumer of legal services is unable to determine in advance just what services he needs, and (c) because advertising by attorneys will highlight irrelevant factors and fail to show the relevant factor of skill.

We are not persuaded that restrained professional advertising by lawyers inevitably will be misleading. Although many services performed by attorneys are indeed unique, it is doubtful that any attorney would or could advertise fixed prices for services of that type. The only services that lend themselves to advertising are the routine ones: the uncontested divorce, the simple adoption, the uncontested personal bankruptcy, the change of name, and the like-the very services advertised by appellants. Although the precise service demanded in each task may vary slightly, and although legal services are not fungible, these facts do not make advertising misleading so long as the attorney does the necessary work the advertised price. The argument that legal services are so unique that fixed rates cannot meaningfully be established is refuted by the record in this case: The appellee State Bar itself sponsors a Legal Services Program in which the participating attorneys agree to perform services like those advertised by the appellants at standardized rates. Indeed, until the decision of this Court in Goldfarb v. Virginia State Bar, the Maricopa County Bar Association apparently had a schedule of suggested minimum fees for standard legal tasks. We thus find of little force the assertion that advertising is misleading because of an inherent lack of standardization in legal services.

The second component of the argument-that advertising ignores the diagnostic role-fares little better. It is unlikely that many people go to an attorney merely to ascertain if they have a clean bill of legal health. Rather, attorneys are likely to be employed to perform specific tasks. Although the client may not know the detail involved in performing the task, he no doubt is able to identify the service he desires at the level of generality to which advertising lends itself.

The third component is not without merit: Advertising does not provide a complete foundation on which to select an attorney. But it seems peculiar to deny the consumer, on the ground that the information is incomplete, at least some of the relevant information needed to reach an informed decision. The alternative - the prohibition of advertising - serves only to restrict the information that flows to consumers. Moreover, the argument assumes that the public is not sophisticated enough to realize the limitations of advertising, and that the public is better kept in ignorance than trusted with correct but incomplete information. We suspect the argument rests on an underestimation of the public. In any event, we view as dubious any justification that is based on 
the benefits of public ignorance. Although, of course, the bar retains the power to correct omissions that have the effect of presenting an inaccurate picture, the preferred remedy is more disclosure, rather than less. If the naivete of the public will cause advertising by attorneys to be misleading, then it is the bar's role to assure that the populace is sufficiently informed as to enable it to place advertising in its proper perspective.

3. The Adverse Effect on the Administration of Justice. Advertising is said to have the undesirable effect of stirring up litigation. The judicial machinery is designed to serve those who feel sufficiently aggrieved to bring forward their claims. Advertising, it is argued, serves to encourage the assertion of legal rights in the courts, thereby undesirably unsettling societal repose. There is even a suggestion of barratry.

But advertising by attorneys is not an unmitigated source of harm to the administration of justice. It may offer great benefits. Although advertising might increase the use of the judicial machinery, we cannot accept the notion that it is always better for a person to suffer a wrong silently than to redress it by legal action. As the bar acknowledges, "the middle $70 \%$ of our population is not being reached or served adequately by the legal profession." Among the reasons for this underutilization is fear of the cost, and an inability to locate a suitable lawyer. Advertising can help to solve this acknowledged problem: Advertising is the traditional mechanism in a free-market economy for a supplier to inform a potential purchaser of the availability and terms of exchange. The disciplinary rule at issue likely has served to burden access to legal services, particularly for the not-quite-poor and the unknowledgeable. A rule allowing restrained advertising would be in accord with the bar's obligation to "facilitate the process of intelligent selection of lawyers, and to assist in making legal services fully available."

4. The Undesirable Economic Effects of Advertising. It is claimed that advertising will increase the overhead costs of the profession, and that these costs then will be passed along to consumers in the form of increased fees. Moreover, it is claimed that the additional cost of practice will create a substantial entry barrier, deterring or preventing young attorneys from penetrating the market and entrenching the position of the bar's established members.

These two arguments seem dubious at best. Neither distinguishes lawyers from others, and neither appears relevant to the First Amendment. The ban on advertising serves to increase the difficulty of discovering the lowest cost seller of acceptable ability. As a result, to this extent attorneys are isolated from competition, and the incentive to price competitively is reduced. Although it is true that the effect of advertising on the price of services has not been demonstrated, there is revealing evidence with regard to products; where consumers have the benefit of price advertising, retail prices often are dramatically lower than they would be without advertising. It is entirely possible that advertising will serve to reduce, not advance, the cost of legal services to the consumer.

The entry-barrier argument is equally unpersuasive. In the absence of advertising, an attorney must rely on his contacts with the community to generate a flow of business. In view of the time necessary to develop such contacts, the ban in fact serves to perpetuate the market position of established attorneys. Consideration of entry-barrier problems would urge that advertising be allowed so as to aid the new competitor in penetrating the market.

5. The Adverse Effect of Advertising on the Quality of Service. It is argued that the attorney may advertise a given "package" of service at a set price, and will be inclined to provide, by indiscriminate use, the standard package regardless of whether it fits the client's needs. 
Restraints on advertising, however, are an ineffective way of deterring shoddy work. An attorney who is inclined to cut quality will do so regardless of the rule on advertising. And the advertisement of a standardized fee does not necessarily mean that the services offered are undesirably standardized. Indeed, the assertion that an attorney who advertises a standard fee will cut quality is substantially undermined by the fixed-fee schedule of appellee's own prepaid Legal Services Program. Even if advertising leads to the creation of "legal clinics" like that of appellants' - clinics that emphasize standardized procedures for routine problems—it is possible that such clinics will improve service by reducing the likelihood of error.

6. The Difficulties of Enforcement. Finally, it is argued that the wholesale restriction is justified by the problems of enforcement if any other course is taken. Because the public lacks sophistication in legal matters, it may be particularly susceptible to misleading or deceptive advertising by lawyers. After-the-fact action by the consumer lured by such advertising may not provide a realistic restraint because of the inability of the layman to assess whether the service he has received meets professional standards. Thus, the vigilance of a regulatory agency will be required. But because of the numerous purveyors of services, the overseeing of advertising will be burdensome.

It is at least somewhat incongruous for the opponents of advertising to extol the virtues and altruism of the legal profession at one point, and, at another, to assert that its members will seize the opportunity to mislead and distort. We suspect that, with advertising, most lawyers will behave as they always have: They will abide by their solemn oaths to uphold the integrity and honor of their profession and of the legal system. For every attorney who overreaches through advertising, there will be thousands of others who will be candid and honest and straightforward. And, of course, it will be in the latter's interest, as in other cases of misconduct at the bar, to assist in weeding out those few who abuse their trust.

In sum, we are not persuaded that any of the proffered justifications rise to the level of an acceptable reason for the suppression of all advertising by attorneys.

\section{IV}

In holding that advertising by attorneys may not be subjected to blanket suppression, and that the advertisement at issue is protected, we, of course, do not hold that advertising by attorneys may not be regulated in any way. We mention some of the clearly permissible limitations on advertising not foreclosed by our holding.

Advertising that is false, deceptive, or misleading of course is subject to restraint. Since the advertiser knows his product and has a commercial interest in its dissemination, we have little worry that regulation to assure truthfulness will discourage protected speech. And any concern that strict requirements for truthfulness will undesirably inhibit spontaneity seems inapplicable because commercial speech generally is calculated. Indeed, the public and private benefits from commercial speech derive from confidence in its accuracy and reliability. Thus, the leeway for untruthful or misleading expression that has been allowed in other contexts has little force in the commercial arena. In fact, because the public lacks sophistication concerning legal services, misstatements that might be overlooked or deemed unimportant in other advertising may be found quite inappropriate in legal advertising. For example, advertising claims as to the quality of services-a matter we do not address today-are not susceptible of measurement or verification; accordingly, such claims may be so likely to be misleading as to warrant restriction. Similar objections might justify restraints on in-person solicitation. We do not foreclose the possibility that some limited supplementation, by way of warning or disclaimer or the like, might 
be required of even an advertisement of the kind ruled upon today so as to assure that the consumer is not misled. In sum, we recognize that many of the problems in defining the boundary between deceptive and nondeceptive advertising remain to be resolved, and we expect that the bar will have a special role to play in assuring that advertising by attorneys flows both freely and cleanly.

The constitutional issue in this case is only whether the State may prevent the publication in a newspaper of appellants' truthful advertisement concerning the availability and terms of routine legal services. We rule simply that the flow of such information may not be restrained, and we therefore hold the present application of the disciplinary rule against appellants to be violative of the First Amendment.

MR. JUSTICE POWELL, with whom MR. JUSTICE STEWART joins, concurring in part and dissenting in part.

I cannot join the Court's holding that under the First Amendment "truthful" newspaper advertising of a lawyer's prices for "routine legal services" may not be restrained. Although the Court appears to note some reservations, it is clear that within undefined limits today's decision will effect profound changes in the practice of law, viewed for centuries as a learned profession. The supervisory power of the courts over members of the bar, as officers of the courts, and the authority of the respective States to oversee the regulation of the profession have been weakened. Although the Court's opinion professes to be framed narrowly, and its reach is subject to future clarification, the holding is explicit and expansive with respect to the advertising of undefined "routine legal services." In my view, this result is neither required by the First Amendment, nor in the public interest.

It has long been thought that price advertising of legal services inevitably will be misleading because such services are individualized with respect to content and quality and because the lay consumer of legal services usually does not know in advance the precise nature and scope of the services he requires. Although the Court finds some force in this reasoning and recognizes that "many services performed by attorneys are indeed unique," its first answer is the optimistic expression of hope that few lawyers "would or could advertise fixed prices for services of that type." But the Court's basic response in view of the acknowledged potential for deceptive advertising of "unique" services is to divide the immense range of the professional product of lawyers into two categories: "unique" and "routine." The only insight afforded by the opinion as to how one draws this line is the finding that services similar to those in appellants' advertisement are routine: "the uncontested divorce, the simple adoption, the uncontested personal bankruptcy, the change of name, and the like." What the phrase "the like" embraces is not indicated. But the advertising of such services must, in the Court's words, flow "both freely and cleanly."

Even the briefest reflection on the tasks for which lawyers are trained and the variation among the services they perform should caution against facile assumptions that legal services can be classified into the routine and the unique. In most situations it is impossible-both for the client and the lawyer - to identify with reasonable accuracy in advance the nature and scope of problems that may be encountered even when handling a matter that at the outset seems 
routine. Neither quantitative nor qualitative measurement of the service actually needed is likely to be feasible in advance.

This definitional problem is well illustrated by appellants' advertised willingness to obtain uncontested divorces for $\$ 195$ each. A potential client can be grievously misled if he reads the advertised service as embracing all of his possible needs. A host of problems are implicated by divorce. They include alimony; support and maintenance for children; child custody; visitation rights; interests in life insurance, community property, tax refunds, and tax liabilities; and the disposition of other property rights. The processing of court papers-apparently the only service appellants provide for \$100-is usually the most straightforward and least demanding aspect of the lawyer's responsibility in a divorce case. More important from the viewpoint of the client is the diagnostic and advisory function: the pursuit of relevant inquiries of which the client would otherwise be unaware, and advice with respect to alternative arrangements that might prevent irreparable dissolution of the marriage or otherwise resolve the client's problem. Although those professional functions are not included within appellants' packaged routine divorce, they frequently fall within the concept of "advice" with which the lay person properly is concerned when he or she seeks legal counsel. The average lay person simply has no feeling for which services are included in the packaged divorce, and thus no capacity to judge the nature of the advertised product. As a result, the type of advertisement before us inescapably will mislead many who respond to it. In the end, it will promote distrust of lawyers and disrespect for our own system of justice.

The advertising of specified services at a fixed price is not the only infirmity of the advertisement at issue. Appellants also assert that these services are offered at "very reasonable fees." That Court finds this to be an accurate statement since the advertised fee fell at the lower end of the range of customary charges. But the fee customarily charged in the locality for similar services has never been considered the sole determinant of the reasonableness of a fee. This is because reasonableness reflects both the quantity and quality of the service. A $\$ 195$ fee may be reasonable for one divorce and unreasonable for another; and a $\$ 195$ fee may be reasonable when charged by an experienced divorce lawyer and unreasonable when charged by a recent law school graduate. For reasons that are not readily apparent, the Court today discards the more discriminating approach which the profession long has used to judge the reasonableness of a fee, and substitutes an approach based on market averages. Whether a fee is "very reasonable" is a matter of opinion, and not a matter of verifiable fact as the Court suggests. One unfortunate result of today's decision is that lawyers may feel free to use a wide variety of adjectives - such as "fair," "moderate," "low-cost," or "lowest in town"-to describe the bargain they offer to the public.

\section{B}

Even if one were to accept the view that some legal services are sufficiently routine to minimize the possibility of deception, there nonetheless remains a serious enforcement problem. The Court does recognize some problems. It notes that misstatements that may be immaterial in "other advertising may be found quite inappropriate in legal advertising" precisely because "the public lacks sophistication concerning legal services." It also recognizes that "advertising claims as to the quality of services are not susceptible of measurement or verification" and therefore "may be so likely to be misleading as to warrant restriction." After recognizing that problems remain in defining the boundary between deceptive and nondeceptive advertising, the Court then observes that the bar may be expected to have "a special role to play in assuring that advertising by attorneys flows both freely and cleanly." 
The Court seriously understates the difficulties, and overestimates the capabilities of the bar-or indeed of any agency public or private-to assure with a reasonable degree of effectiveness that price advertising can at the same time be both unrestrained and truthful. There are some 400,000 lawyers in this country. They have been licensed by the States, and the organized bars within the States-operating under codes approved by the highest courts acting pursuant to statutory authority - have had the primary responsibility for assuring compliance with professional ethics and standards. The traditional means have been disciplinary proceedings conducted initially by voluntary bar committees subject to judicial review. In view of the sheer size of the profession, the existence of a multiplicity of jurisdictions, and the problems inherent in the maintenance of ethical standards even of a profession with established traditions, the problem of disciplinary enforcement in this country has proved to be extremely difficult.

The Court's almost casual assumption that its authorization of price advertising can be policed effectively by the bar reflects a striking underappreciation of the nature and magnitude of the disciplinary problem. The very reasons that tend to make price advertising of services inherently deceptive make its policing wholly impractical. With respect to commercial advertising, MR. JUSTICE STEWART, concurring in Virginia Pharmacy, noted that since "the factual claims contained in commercial price or product advertisements relate to tangible goods or services, they may be tested empirically and corrected to reflect the truth." But there simply is no way to test "empirically" the claims made in appellants' advertisement of legal services. There are serious difficulties in determining whether the advertised services fall within the Court's undefined category of "routine services"; whether they are described accurately and understandably; and whether appellants' claim as to reasonableness of the fees is accurate. These are not factual questions for which there are "truthful" answers; in most instances, the answers would turn on relatively subjective judgments as to which there could be wide differences of opinion. These difficulties with appellants' advertisement will inhere in any comparable price advertisement of specific legal services. Even if public agencies were established to oversee professional price advertising, adequate protection of the public from deception, and of ethical lawyers from unfair competition, could prove to be a wholly intractable problem.

The Court emphasizes the need for information that will assist persons desiring legal services to choose lawyers. Under our economic system, advertising is the most commonly used and useful means of providing information as to goods and other services, but it generally has not been used with respect to legal and certain other professional services. Until today, controlling weight has been given to the danger that general advertising of such services too often would tend to mislead rather than inform. Moreover, there has been the further concern that the characteristics of the legal profession thought beneficial to society-a code of professional ethics, an imbued sense of professional and public responsibility, a tradition of self-discipline, and duties as officers of the courts-would suffer if the restraints on advertising were significantly diluted.

Pressures toward some relaxation of the proscription against general advertising have gained force in recent years with the increased recognition of the difficulty that low- and middle-income citizens experience in finding counsel willing to serve at reasonable prices. The seriousness of this problem has not been overlooked by the organized bar.

The Court observes, and I agree, that there is nothing inherently misleading in the advertisement of the cost of an initial consultation. Indeed, I would not limit the fee information 
to the initial conference. Although the skill and experience of lawyers vary so widely as to negate any equivalence between hours of service by different lawyers, variations in quality of service by duly licensed lawyers are inevitable. Lawyers operate, at least for the purpose of internal control and accounting, on the basis of specified hourly rates, and upon request-or in an appropriate case-most lawyers are willing to undertake employment at such rates. The advertisement of these rates, in an appropriate medium, duly designated, would not necessarily be misleading if this fee information also made clear that the total charge for the representation would depend on the number of hours devoted to the client's problem-a variable difficult to predict. Where the price content of the advertisement is limited to the finite item of rate per hour devoted to the client's problem, the likelihood of deceiving or misleading is considerably less than when specific services are advertised at a fixed price.

III

Although I disagree strongly with the Court's holding as to price advertisements of undefinedand I believe undefinable-routine legal services, there are reservations in its opinion worthy of emphasis since they may serve to narrow its ultimate reach. First, the Court notes that it has not addressed "the peculiar problems associated with advertising claims relating to the quality of legal services." There are inherent questions of quality in almost any type of price advertising by lawyers, and I do not view appellants' advertisement as entirely free from quality implications. Nevertheless the Court's reservation in this respect could be a limiting factor.

Second, the Court notes that there may be reasonable restrictions on the time, place, and manner of commercial price advertising. In my view, such restrictions should have a significantly broader reach with respect to professional services than as to standardized products. This Court long has recognized the important state interests in the regulation of professional advertising. And as to lawyers, the Court recently has noted that "the interest of the States in regulating lawyers is especially great since lawyers are essential to the primary governmental function of administering justice, and have historically been "officers of the courts." Although the opinion today finds these interests insufficient to justify prohibition of all price advertising, the state interests recognized in these cases should be weighed carefully in any future consideration of time, place, and manner restrictions.

Finally, the Court's opinion does not "foreclose the possibility that some limited supplementation, by way of warning or disclaimer or the like, might be required of even an advertisement of the kind ruled upon today so as to assure that the consumer is not misled." I view this as at least some recognition of the potential for deception inherent in fixed-price advertising of specific legal services. This recognition, though ambiguous in light of other statements in the opinion, may be viewed as encouragement to those who believe-as I dothat if we are to have price advertisement of legal services, the public interest will require the most particularized regulation.

\section{IV}

The area into which the Court now ventures has, until today, largely been left to self-regulation by the profession within the framework of canons or standards of conduct prescribed by the respective States and enforced where necessary by the courts. The problem of bringing clients and lawyers together on a mutually fair basis, consistent with the public interest, is as old as the profession itself. It is one of considerable complexity, especially in view of the constantly evolving nature of the need for legal services. The problem has not been resolved with complete satisfaction despite diligent and thoughtful efforts by the organized bar and others over a period 
of many years, and there is no reason to believe that today's best answers will be responsive to future needs.

I am apprehensive, despite the Court's expressed intent to proceed cautiously, that today's holding will be viewed by tens of thousands of lawyers as an invitation-by the public-spirited and the selfish lawyers alike-to engage in competitive advertising on an escalating basis. Some lawyers may gain temporary advantages; others will suffer from the economic power of stronger lawyers, or by the subtle deceit of less scrupulous lawyers. Some members of the public may benefit marginally, but the risk is that many others will be victimized by simplistic price advertising of professional services "almost infinite in variety and nature." Until today, in the long history of the legal profession, it was not thought that this risk of public deception was required by the marginal First Amendment interests asserted by the Court.

MR. JUSTICE REHNQUIST, dissenting in part.

I continue to believe that the First Amendment speech provision, long regarded by this Court as a sanctuary for expressions of public importance or intellectual interest, is demeaned by invocation to protect advertisements of goods and services. I would hold quite simply that the appellants' advertisement, however truthful or reasonable it may be, is not the sort of expression that the Amendment was adopted to protect.

\section{Questions:}

1. What is the objection to attorney advertising? Is the concern that it will harm the public, harm the profession, or both?

2. The majority opinion considers the objections to attorney advertising, which include harming the profession, misleading the public, encouraging litigation, increasing the cost of legal services, lowering the quality of legal services, and unenforceability, and finds all of them wanting. Do you agree?

3. The dissent argues that attorney advertising will mislead the public, and that state bar associations can adopt reforms in a slower and more measured fashion, which will be better for the profession. Do you agree with its concerns? 


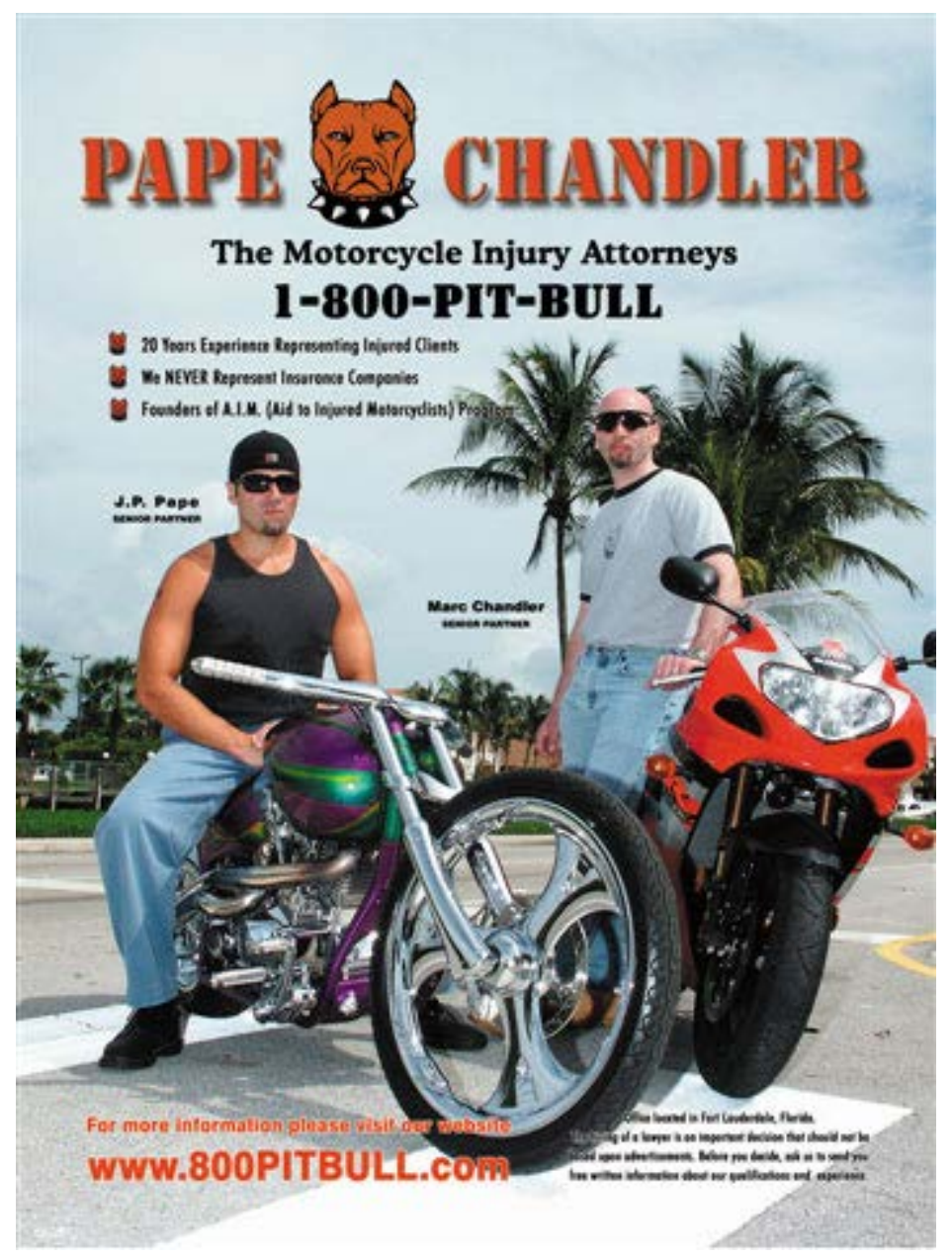

The Florida Bar v. Pape, 918 So.2d 240 (Fla. 2005)

Summary: Pape and Chandler advertised their law firm on television, using an image of a pitbull and the the telephone number 1-800-PIT-BULL. The Florida Bar filed a complaint against them, alleging that their advertisement improperly described the quality of their services and used irrelevant and misleading elements. The referee found no violation, concluding that the advertisement described qualities of the attorneys, not their services, and that the pitbull element was informational. The Florida Supreme Court disagreed, holding that the pitbull motif made claims about the quality of their services, was not informational, and was in poor taste, and therefore was not protected by the $1 \mathrm{st}$ Amendment.

\section{PARIENTE, C.J.}

In this case we impose discipline on two attorneys for their use of television advertising devices that violate the Rules of Professional Conduct. These devices, which invoke the breed of dog known as the pit bull, demean all lawyers and thereby harm both the legal profession and the public's trust and confidence in our system of justice.

We conclude that attorneys Pape and Chandler violated the Rules Regulating the Florida Bar by using the image of a pit bull and displaying the term "pit bull" as part of their firm's phone 
number in their commercial. Further, because the use of an image of a pit bull and the phrase "pit bull" in the firm's advertisement and logo does not assist the public in ensuring that an informed decision is made prior to the selection of the attorney, we conclude that the First Amendment does not prevent this Court from sanctioning the attorneys based on the rule violations. We determine that the appropriate sanctions for the attorneys' misconduct are public reprimands and required attendance at the Florida Bar Advertising Workshop.

\section{BACKGROUND AND PROCEDURAL HISTORY}

On January 12, 2004, The Florida Bar filed complaints against the attorneys, alleging that their law firm's television advertisement was an improper communication concerning the services provided, in violation of the Rules of Professional Conduct. The advertisement included a logo that featured an image of a pit bull wearing a spiked collar and prominently displayed the firm's phone number, 1-800-PIT-BULL. The Bar asserted that this advertisement violated the 2004 version of Rules Regulating the Florida Bar 4-7.2(b)(3) and 4-7.2(b)(4), which state:

(3) Descriptive Statements. A lawyer shall not make statements describing or characterizing the quality of the lawyer's services in advertisements and written communications; provided that this provision shall not apply to information furnished to a prospective client at that person's request or to information supplied to existing clients. (4) Prohibited Visual and Verbal Portrayals. Visual or verbal descriptions, depictions, or portrayals of persons, things, or events must be objectively relevant to the selection of an attorney and shall not be deceptive, misleading, or manipulative.

The referee found that the attorneys did not violate rule 4-7.2(b)(3), relying on the distinction that the logo and telephone number "describe qualities of the respondent attorneys" but do not describe or characterize "the quality of the lawyer services." The referee also rejected the Bar's assertion that the ad violated rule 4-7.2(b)(4). After noting that pit bulls are perceived as "loyal, persistent, tenacious, and aggressive," the referee found these qualities

objectively relevant to the selection of an attorney as they are informational, because these are qualities that a consuming public would want in a trial lawyer and the ad is not improperly manipulative. The advertisement is tastefully done, the logo is not unduly conspicuous in its replacement of an ampersand between respondents' names atop the TV screen, and the large print 1-800 number is an effective mnemonic device tailored to maximize responses from potential clients.

The referee also concluded that the ad was protected speech and therefore that an interpretation of rules to prohibit the ad would render the rules unconstitutional as applied.

\section{ANALYSIS}

\section{A. Violation of Attorney Advertising Rules}

As a preliminary matter, the pit bull logo and 1-800-PIT-BULL telephone number in the ad by the attorneys do not comport with the general criteria for permissible attorney advertisements set forth in the comments to section 4-7 of the Rules of Professional Conduct. The rules contained in section 4-7 are designed to permit lawyer advertisements that provide objective information about the cost of legal services, the experience and qualifications of the lawyer and law firm, and the types of cases the lawyer handles. The comment to rule 4-7.1 provides that "a lawyer's advertisement should provide only useful, factual information presented in a nonsensational 
manner. Advertisements using slogans fail to meet these standards and diminish public confidence in the legal system." The television commercial at issue here uses both a sensationalistic image and a slogan, contrary to the purpose of section 4-7.

More specifically, the attorneys' ad violated rule 4-7.2(b)(3), which prohibits the use of statements describing or characterizing the quality of the lawyer's services. In Florida Bar $v$. Lange, we approved the referee's finding that an advertisement that stated "When the Best is Simply Essential" violated the predecessor provision to rule 4-7.2(b)(3) because it was selflaudatory and purported to describe the quality of the lawyer's services. In this case, the simultaneous display of the pit bull logo and the 1-800-PIT-BULL phone number conveys both the characteristics of the attorneys and the quality of the services they purport to provide. At the very least, the printed words and the image of a pitbull in the television commercial could certainly be perceived by prospective clients as characterizing the quality of the lawyers' services.

On this question we disagree with the referee, who distinguished the "quality of the lawyer's services" from the qualities (i.e., traits or characteristics) of the lawyer. We conclude that this is an artificial distinction which unduly limits the scope of the rule by interpreting "quality of the lawyer's services" in the narrowest sense. From the perspective of a prospective client unfamiliar with the legal system and in need of counsel, a lawyer's character and personality traits are indistinguishable from the quality of the services that the lawyer provides. A courteous lawyer can be expected to be well mannered in court, a hard-working lawyer well prepared, and a "pit bull" lawyer vicious to the opposition. In the attorneys' advertisement, the pit bull image appears in place of an ampersand between the attorneys' names, and the ad includes the use of the words "pit bull" in the attorneys' telephone number in large capital letters. The combined effect of these devices is to lead a reasonable consumer to conclude that the attorneys are advertising themselves as providers of "pit bull"-style representation. We consider this a characterization of the quality of the lawyers' services in violation of rule 4-7.2(b)(3).

We also conclude that the ad violates rule 4-7.2(b)(4), which requires that visual or verbal depictions be "objectively relevant" to the selection of an attorney, and prohibits depictions that are "deceptive, misleading, or manipulative." The comment to this rule explains that it

prohibits visual or verbal descriptions, depictions, or portrayals in any advertisement which create suspense, or contain exaggerations or appeals to the emotions, call for legal services, or create consumer problems through characterization and dialogue ending with the lawyer solving the problem. Illustrations permitted are informational and not misleading, and are therefore permissible. As an example, a drawing of a fist, to suggest the lawyer's ability to achieve results, would be barred. Examples of permissible illustrations would include a graphic rendering of the scales of justice to indicate that the advertising attorney practices law, a picture of the lawyer, or a map of the office location.

The logo of the pit bull wearing a spiked collar and the prominent display of the phone number 1-800-PIT-BULL are more manipulative and misleading than a drawing of a fist. These advertising devices would suggest to many persons not only that the lawyers can achieve results but also that they engage in a combative style of advocacy. The suggestion is inherently deceptive because there is no way to measure whether the attorneys in fact conduct themselves like pit bulls so as to ascertain whether this logo and phone number convey accurate information. 
In addition, the image of a pit bull and the on-screen display of the words "PIT-BULL" as part of the firm's phone number are not objectively relevant to the selection of an attorney. The referee found that the qualities of a pit bull as depicted by the logo are loyalty, persistence, tenacity, and aggressiveness. We consider this a charitable set of associations that ignores the darker side of the qualities often also associated with pit bulls: malevolence, viciousness, and unpredictability. Further, although some may associate pit bulls with loyalty to their owners, ${ }^{109}$ the manner in which the pit bull is depicted in the attorneys' ad in this case certainly does not emphasize this association. The dog, which is wearing a spiked collar, directly faces the viewer and is shown alone, with no indication that it is fulfilling its traditional role as "man's best friend."

Pit bulls have a reputation for vicious behavior that is borne of experience. According to a study published in the Journal of the American Veterinary Medical Association in 2000, pit bulls caused the greatest number of dog-bite-related fatalities between 1979 and 1998. The dangerousness of pit bulls has also been recognized in a number of court decisions.

In State v. Peters, the Third District Court of Appeal upheld a City of North Miami ordinance imposing substantial insurance, registration, and confinement obligations on owners of pit bulls. The City of North Miami ordinance contained findings that pit bulls have a greater propensity to bite humans than all other breeds, are extremely aggressive towards other animals, and have a natural tendency to refuse to terminate an attack once it has begun. The current Miami-Dade County ordinance provides that it is illegal to own a pit bull.

This Court would not condone an advertisement that stated that a lawyer will get results through combative and vicious tactics that will maim, scar, or harm the opposing party, conduct that would violate our Rules of Professional Conduct. Yet this is precisely the type of unethical and unprofessional conduct that is conveyed by the image of a pit bull and the display of the 1-800PIT-BULL phone number. We construe the prohibitions on advertising statements that characterize the quality of lawyer services and depictions that are false or misleading to prohibit a lawyer from advertising his or her services by suggesting behavior, conduct, or tactics that are contrary to our Rules of Professional Conduct.

Further, we reject the referee's finding that the use of the words "pit bull" in the phone number is merely a mnemonic device to help potential clients remember the attorneys' number. Phrasebased phone numbers are memorable because of the images and associations they evoke. The "1-800-PIT-BULL" phone number sticks in the memory precisely because of the image of the pit bull also featured in the ad, the association of pit bulls with the characteristics discussed herein, and the "go for the jugular" style of advocacy that some persons attribute to lawyers. In short, this is a manipulative and misleading use of what would otherwise be content-neutral information to create a nefarious association.

Indeed, permitting this type of advertisement would make a mockery of our dedication to promoting public trust and confidence in our system of justice. Prohibiting advertisements such as the one in this case is one step we can take to maintain the dignity of lawyers, as well as the integrity of, and public confidence in, the legal system. Were we to approve the referee's finding, images of sharks, wolves, crocodiles, and piranhas could follow. For the good of the legal profession and the justice system, and consistent with our Rules of Professional Conduct, this

${ }^{109}$ Even the perception of loyalty may be unwarranted. In June, a twelve-year old boy was mauled to death in San Francisco by his family's two pit bulls. That same month a Bay Area woman suffered severe injuries in an attack by her nine-year-old pit bull. A St. Louis man was killed in May by his two pit bulls that had "no apparent history of aggression and were described as well-kept." 
type of non-factual advertising cannot be permitted. We therefore conclude that the 1-800-PITBULL ad aired by the attorneys violates rules 4-7.2(b)(3) and 4-7.2(b)(4).

\section{B. First Amendment Protection of Lawyer Advertising}

We also disagree with the referee's conclusion that the application of rules 4-7.2(b)(3) and 47.2(b)(4) to prohibit this advertisement violates the First Amendment. Lawyer advertising enjoys First Amendment protection only to the extent that it provides accurate factual information that can be objectively verified. This thread runs throughout the pertinent United State Supreme Court precedent.

The seminal lawyer advertising case is Bates $v$. State Bar of Arizona, which involved the advertising of fees for low cost legal services. In Bates, the Supreme Court held generally that attorney advertising "may not be subjected to blanket suppression," and more specifically that attorneys have the constitutional right to advertise their availability and fees for performing routine services. The cost of legal services, the Supreme Court concluded, would be "relevant information needed to reach an informed decision."

After Bates, in R.M.J. the Supreme Court considered a Missouri rule that restricted lawyer advertising to newspapers, periodicals, and the yellow pages, and limited the content of these advertisements to ten categories of information (name, address and telephone number, areas of practice, date and place of birth, schools attended, foreign language ability, office hours, fee for an initial consultation, availability of a schedule of fees, credit arrangements, and the fixed fee charged for specified "routine" services). Even the manner of listing areas of practice was restricted to a prescribed nomenclature. In violation of the state restrictions, the lawyer advertised areas of practice that did not use the prescribed terminology, listed the states in which the lawyer was licensed, specified that he was admitted to practice before the United States Supreme Court, and did not restrict the recipients of announcement cards to lawyers, clients, former clients, personal friends, and relatives.

Writing for a unanimous Court, Justice Powell summarized the commercial speech doctrine in the context of advertising for professional services:

Truthful advertising related to lawful activities is entitled to the protections of the First Amendment. But when the particular content or method of the advertising suggests that it is inherently misleading or when experience has proved that in fact such advertising is subject to abuse, the States may impose appropriate restrictions. Misleading advertising may be prohibited entirely. But the States may not place an absolute prohibition on certain types of potentially misleading information, e.g., a listing of areas of practice, if the information also may be presented in a way that is not deceptive.

In holding the Missouri restrictions per se invalid as applied to the lawyer, the Supreme Court concluded that the state had no substantial interest in prohibiting a lawyer from identifying the jurisdictions in which he or she was licensed to practice. The Court noted that this "is factual and highly relevant information." Although the Court found the lawyer's listing in large capital letters that he was a member of the Bar of the Supreme Court of the United States to be "somewhat more troubling" and in "bad taste," this alone could not be prohibited without a finding by the Missouri Supreme Court that "such a statement could be misleading to the general public unfamiliar with the requirements of admission to the Bar of this Court." 
In Zauderer, the Supreme Court addressed whether a state could discipline a lawyer who ran newspaper advertisements containing nondeceptive illustrations and legal advice. One advertisement published the lawyer's willingness to represent women injured from the use of the Dalkon Shield intrauterine device. The parties had stipulated that the advertisement was entirely accurate.

In holding that the lawyer could not be disciplined on the basis of the content of his advertisement, the Supreme Court observed that the advertisement did not promise results or suggest any special expertise but merely conveyed that the lawyer was representing women in Dalkon Shield litigation and was willing to represent other women with similar claims. Turning to the lawyer's use of an illustration of the Dalkon Shield, the Court first held that illustrations are entitled to the same First Amendment protection as that afforded to verbal commercial speech. The Court then concluded that "because the illustration for which appellant was disciplined is an accurate representation of the Dalkon Shield and has no features that are likely to deceive, mislead, or confuse the reader, the burden is on the State to present a substantial governmental interest justifying the restriction."

The most recent United States Supreme Court decision to address restrictions on the content of lawyer advertising involved an attorney who held himself out as certified by the National Board of Trial Advocacy. The state supreme court had concluded that the claim of NBTA certification was "misleading because it tacitly attests to the qualifications of petitioner as a civil trial advocate." The state court had not addressed "whether NBTA certification constituted reliable, verifiable evidence of petitioner's experience as a civil trial advocate." After applauding the development of state and national certification programs, a plurality of the Supreme Court concluded that the facts as to NBTA certification were "true and verifiable." The plurality pointed out the important "distinction between statements of opinion or quality and statements of objective facts that may support an inference of quality." A majority of the Court concluded that the letterhead was not actually or inherently misleading, and thus that the attorney could not be prohibited from holding himself out as a civil trial specialist certified by the NBTA.

The pit bull logo and "1-800-PIT-BULL" phone number are in marked contrast to the illustration of the Dalkon Shield intrauterine device at issue in Zauderer, which the United States Supreme Court found to be "an accurate representation and have no features that are likely to deceive, mislead, or confuse the reader." The Dalkon Shield illustration informed the public that the lawyer represented clients in cases involving this device. The "pit bull" commercial produced by the attorneys in this case contains no indication that they specialize in either dog bite cases generally or in litigation arising from attacks by pit bulls specifically. Consequently, the logo and phone number do not convey objectively relevant information about the attorneys' practice. Instead, the image and words "pit bull" are intended to convey an image about the nature of the lawyers' litigation tactics. We conclude that an advertising device that connotes combativeness and viciousness without providing accurate and objectively verifiable factual information falls outside the protections of the First Amendment.

\section{CONCLUSION}

We disapprove the referee's finding that the television commercial at issue is constitutionally protected speech that does not violate our attorney advertising rules. We find John Robert Pape and Marc Andrew Chandler guilty of violating the Rules Regulating the Florida Bar. We order that each attorney receive a public reprimand, which shall be administered by the Board of Governors of The Florida Bar upon proper notice to appear. We also direct Pape and Chandler 
to attend and complete the Florida Bar Advertising Workshop within six months of the date of this opinion.

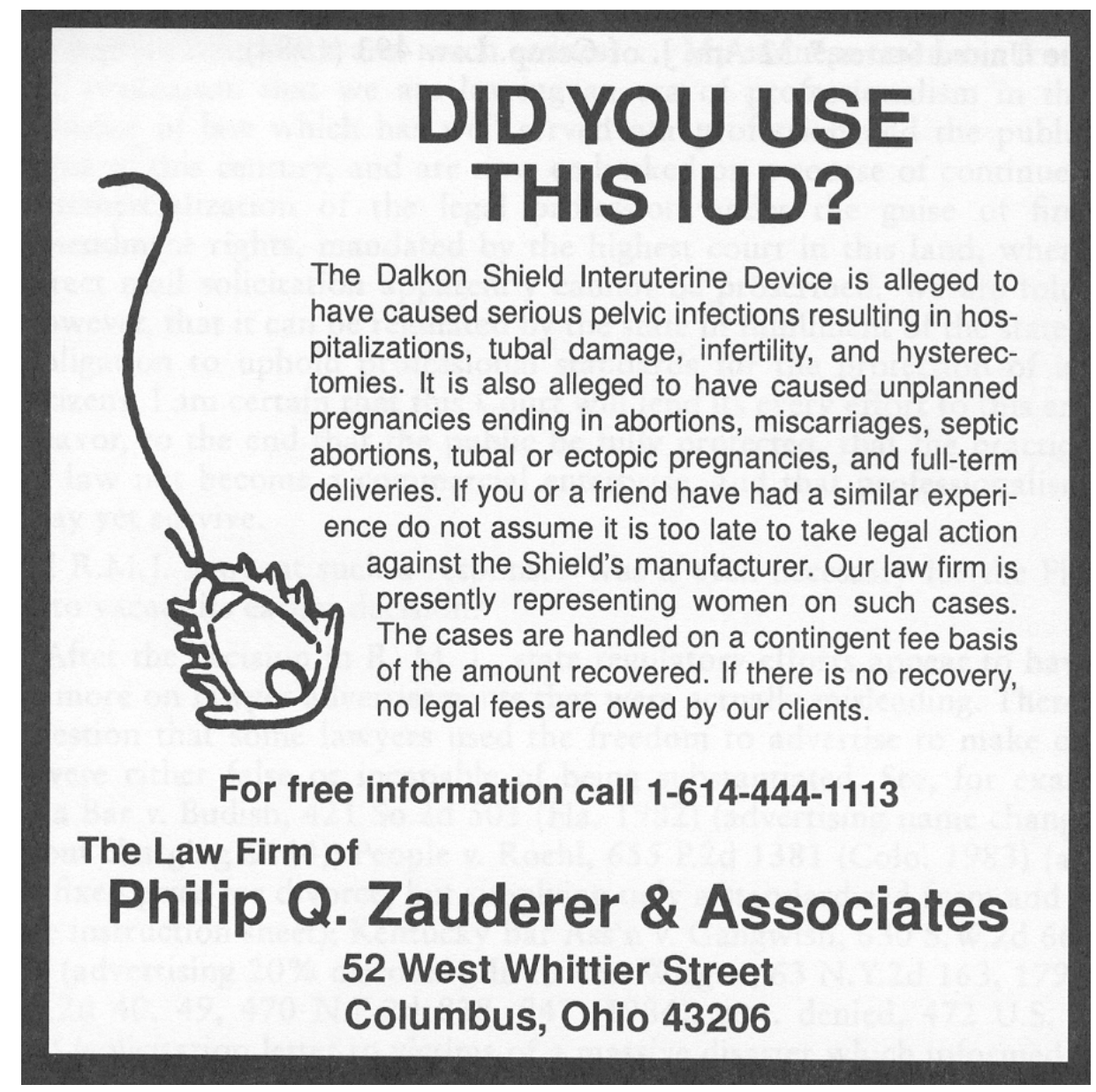

\section{Questions:}

1. This disciplinary action prompted a great deal of discussion, much of it critical of the Florida Supreme Court's decision. You can read more about the case in Legal Affairs, the Sun-Sentinel, the Florida Bar News, and the Broward-Palm Beach New Times, among other places.

2. You can watch the television advertisements for Pape \& Chandler here and here. Do you find them misleading? Do you find them in poor taste? Do you think the Florida Bar and the Florida Supreme Court objected to the advertisements primarily because they made misleading claims about the quality of the legal services provided, because they found the advertisements in poor taste, or because the advertisements criticize other attorneys?

3. Are the Pape \& Chandler advertisements primarily claims about the quality of the legal services they provide or an effort to establish a brand identity for their legal practice? Should attorneys be permitted to use branding to promote their businesses?

4. The oldest and largest law firms in the United States rely on the recognition and goodwill associated with their firm names to communicate quality to the consumers of legal services. Should newer and smaller law firms also be required to rely only on their firm names or should they be permitted to pursue other branding strategies? If branding is 
permissible, should state bars limit what kinds of branding are permissible? Are limitations on law firm branding consistent with the First Amendment?

5. In Matal v. Tam, 137 S.Ct. 1744 (2017), the Supreme Court held that the Trademark Office's refusal to register a trademark on the ground that the mark was disparaging violated the First Amendment. Can state-imposed limits on law firm branding survive Tam?

6. Kentucky attorney Darryl Isaacs refers to himself as "The Hammer" and is well-known for his advertisements, which feature him in parodies of popular television shows and movies like Captain America, Game of Thrones, and Transformers. You can watch the commercials on his website. Is this branding and advertising consistent with the Florida Supreme Court's decision in Pape? Do you find them misleading? Do you find them distasteful? Should the Kentucky Bar be able to prohibit branding and advertisement of this kind?

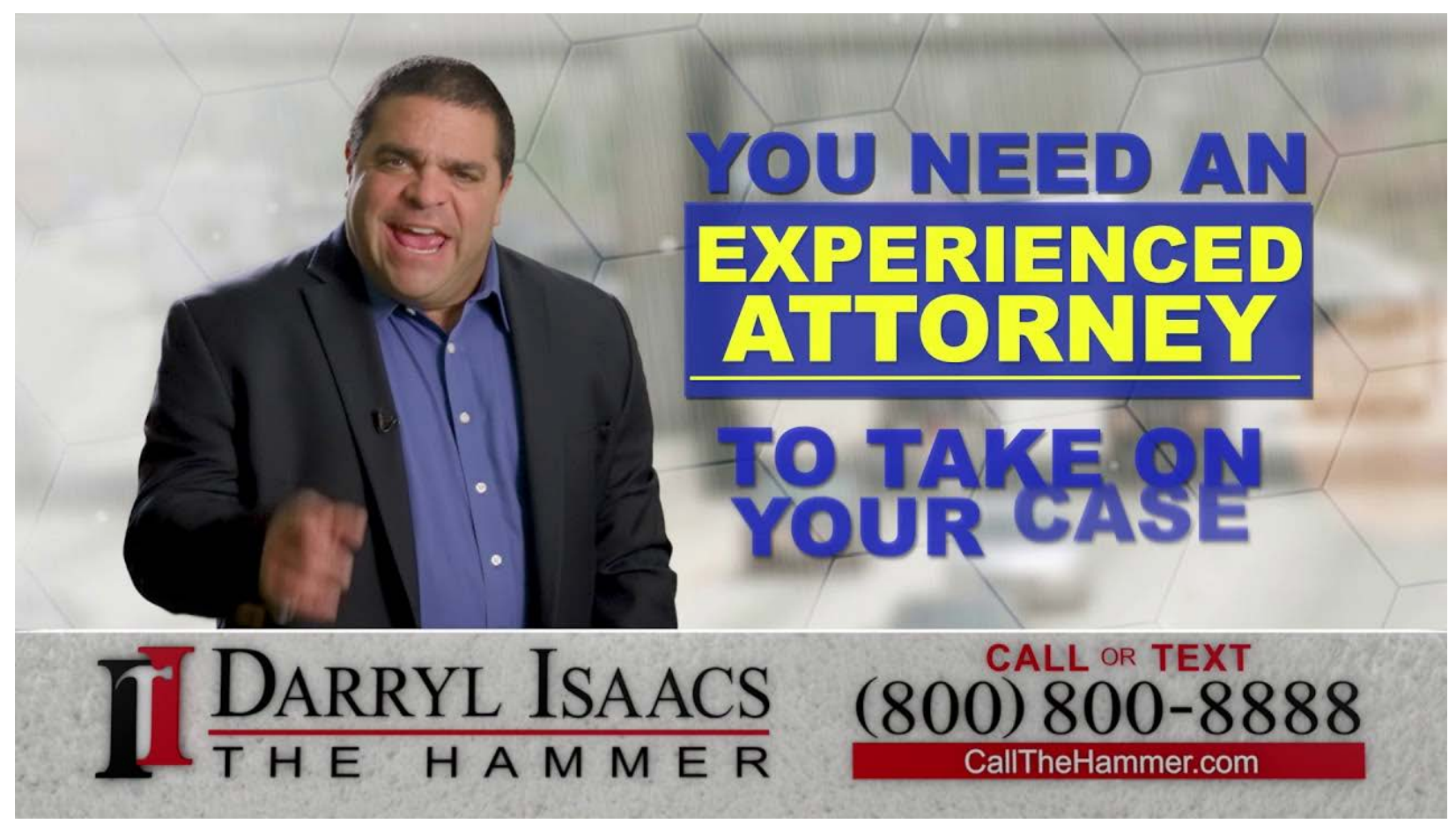




\section{3: Solicitation}

Sweet cream ladies, forward march, the world owes you a living. Sweet cream ladies, do your part, think of what you're giving, to the lost and lonely people of the night. ${ }^{110}$

In addition to prohibiting advertising, bar associations historically also prohibited attorneys from "soliciting" clients, or approaching potential clients directly, rather than as members of the general public. For example, Canon 28 of the 1908 ABA Canons of Professional Ethics specifically proscribed attorneys from volunteering legal advice to a stranger or seeking out injured parties in the hope of providing legal advice.

Indeed, bar associations typically monitored and punished solicitation considerably more aggressively than advertisement. The stated objection to solicitation was the concern that unscrupulous attorneys might take advantage of unsophisticated members of the public, who lacked the capacity to evaluate the quality of their legal services or the fairness of their fees. Of course, the bar associations were also dominated by successful attorneys at large firms, who tended to represent corporate defendants, rather than injured plaintiffs.

\section{Model Rule 7.3: Solicitation of Clients}

a. "Solicitation" or "solicit" denotes a communication initiated by or on behalf of a lawyer or law firm that is directed to a specific person the lawyer knows or reasonably should know needs legal services in a particular matter and that offers to provide, or reasonably can be understood as offering to provide, legal services for that matter.

b. A lawyer shall not solicit professional employment by live person-to-person contact when a significant motive for the lawyer's doing so is the lawyer's or law firm's pecuniary gain, unless the contact is with a:

1. Lawyer;

2. person who has a family, close personal, or prior business or professional relationship with the lawyer or law firm; or

3. person who routinely uses for business purposes the type of legal services offered by the lawyer.

c. A lawyer shall not solicit professional employment even when not otherwise prohibited by paragraph (b), if:

1. the target of the solicitation has made known to the lawyer a desire not to be solicited by the lawyer; or

2. the solicitation involves coercion, duress or harassment.

d. This Rule does not prohibit communications authorized by law or ordered by a court or other tribunal.

\section{Model Rule 7.3: Comments}

1. Paragraph (b) prohibits a lawyer from soliciting professional employment by live personto-person contact when a significant motive for the lawyer's doing so is the lawyer's or the law firm's pecuniary gain. A lawyer's communication is not a solicitation if it is directed to the general public, such as through a billboard, an Internet banner advertisement, a website or a television commercial, or if it is in response to a request for information or is automatically generated in response to electronic searches.

110 The Box Tops, Sweet Cream Ladies Forward March, Dimensions (1969). 
2. "Live person-to-person contact" means in-person, face-to-face, live telephone and other real-time visual or auditory person-to-person communications where the person is subject to a direct personal encounter without time for reflection. Such person-to-person contact does not include chat rooms, text messages or other written communications that recipients may easily disregard. A potential for overreaching exists when a lawyer, seeking pecuniary gain, solicits a person known to be in need of legal services. This form of contact subjects a person to the private importuning of the trained advocate in a direct interpersonal encounter. The person, who may already feel overwhelmed by the circumstances giving rise to the need for legal services, may find it difficult to fully evaluate all available alternatives with reasoned judgment and appropriate self interest in the face of the lawyer's presence and insistence upon an immediate response. The situation is fraught with the possibility of undue influence, intimidation, and overreaching.

8. Communications authorized by law or ordered by a court or tribunal include a notice to potential members of a class in class action litigation.

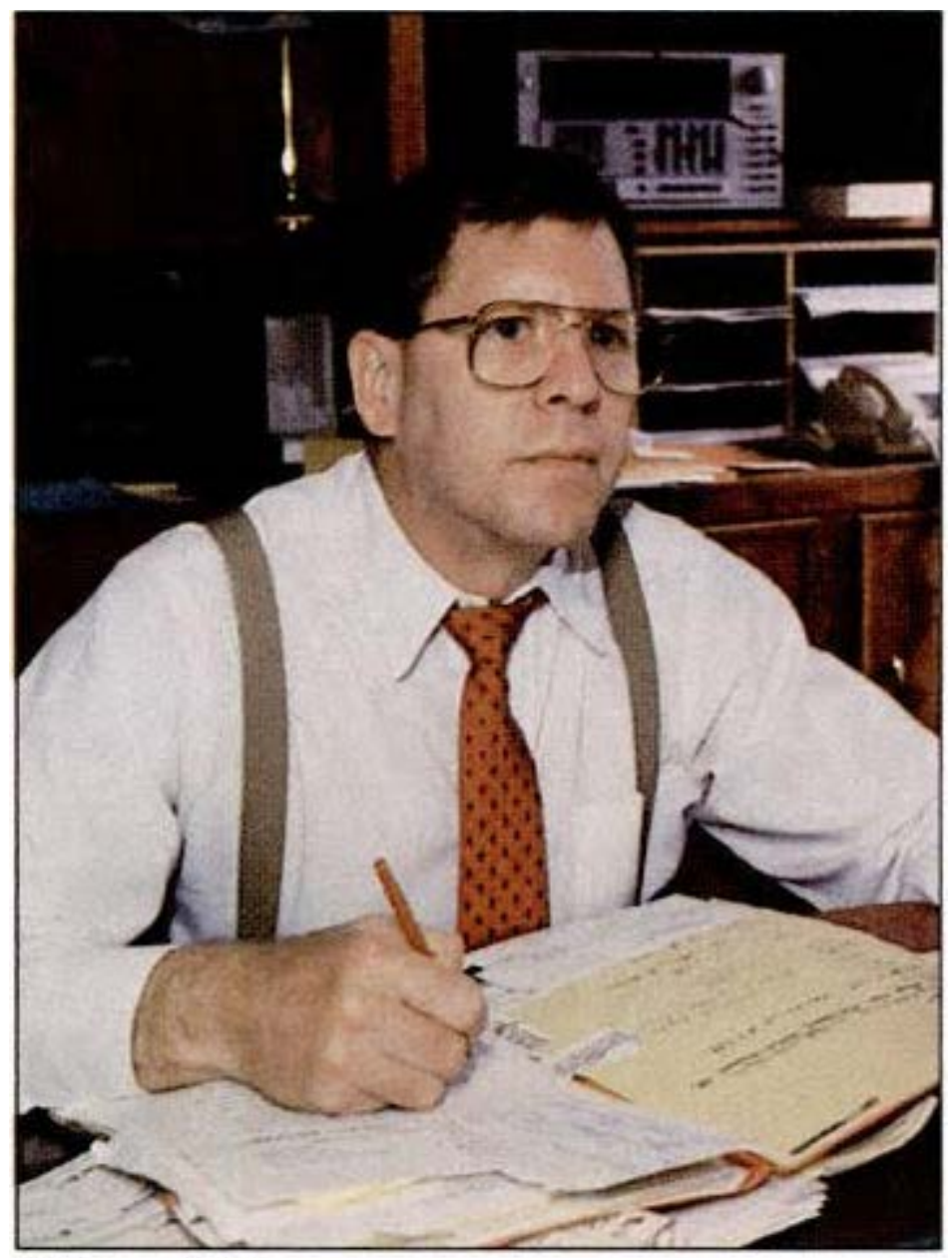

Richard Shapero

Shapero v. Kentucky Bar Assn., 486 U.S. 466 (1988)

Summary: Shapero submitted wanted to send a letter advertising his legal services to people with foreclosure actions filed against them. The Kentucky Supreme Court held that Model Rule of Professional Conduct 7.3 prohibited direct mail solicitation. The 
Supreme Court reversed, holding that a direct mail solicitation was no different from an advertisement, and was protected by the 1st Amendment. The dissent argued that the court had gone too far in limiting regulation of attorney advertising and solicitation, and that advertising would harm the profession.

JUSTICE BRENNAN announced the judgment of the Court and delivered the opinion of the Court as to Parts I and II and an opinion as to Part III in which JUSTICE MARSHALL, JUSTICE BLACKMUN, and JUSTICE KENNEDY join.

This case presents the issue whether a State may, consistent with the First and Fourteenth Amendments, categorically prohibit lawyers from soliciting legal business for pecuniary gain by sending truthful and nondeceptive letters to potential clients known to face particular legal problems.

In 1985, petitioner, a member of Kentucky's integrated Bar Association, applied to the Kentucky Attorneys Advertising Commission for approval of a letter that he proposed to send "to potential clients who have had a foreclosure suit filed against them." The proposed letter read as follows:

It has come to my attention that your home is being foreclosed on. If this is true, you may be about to lose your home. Federal law may allow you to keep your home by ORDERING your creditor to STOP and give you more time to pay them.

You may call my office anytime from 8:30 a. m. to 5:00 p. m. for FREE information on how you can keep your home.

Call NOW, don't wait. It may surprise you what I may be able to do for you. Just call and tell me that you got this letter. Remember it is FREE, there is NO charge for calling.

The Commission did not find the letter false or misleading. Nevertheless, it declined to approve petitioner's proposal on the ground that a then-existing Kentucky Supreme Court Rule prohibited the mailing or delivery of written advertisements "precipitated by a specific event or occurrence involving or relating to the addressee or addressees as distinct from the general public." The Commission registered its view that Rule 3.135(5)(b)(i)'s ban on targeted, directmail advertising violated the First Amendment - specifically the principles enunciated in Zauderer - and recommended that the Kentucky Supreme Court amend its Rules. Pursuing the Commission's suggestion, petitioner petitioned the Committee on Legal Ethics of the Kentucky Bar Association for an advisory opinion as to the Rule's validity. Like the Commission, the Ethics Committee, in an opinion formally adopted by the Board of Governors of the Bar Association, did not find the proposed letter false or misleading, but nonetheless upheld Rule $3.135(5)(b)$ (i) on the ground that it was consistent with Rule 7.3 of the American Bar Association's Model Rules of Professional Conduct.

On review of the Ethics Committee's advisory opinion, the Kentucky Supreme Court felt "compelled by the decision in Zauderer to order Rule 3.135(5)(b)(i) deleted," and replaced it with the ABA's Rule 7.3.

The court did not specify either the precise infirmity in Rule 3.135(5)(b)(i) or how Rule 7.3 cured it. Rule 7.3, like its predecessor, prohibits targeted, direct-mail solicitation by lawyers for pecuniary gain, without a particularized finding that the solicitation is false or misleading. We granted certiorari to resolve whether such a blanket prohibition is consistent with the First Amendment and now reverse. 
Lawyer advertising is in the category of constitutionally protected commercial speech. The First Amendment principles governing state regulation of lawyer solicitations for pecuniary gain are by now familiar: "Commercial speech that is not false or deceptive and does not concern unlawful activities may be restricted only in the service of a substantial governmental interest, and only through means that directly advance that interest." Since state regulation of commercial speech "may extend only as far as the interest it serves," state rules that are designed to prevent the "potential for deception and confusion may be no broader than reasonably necessary to prevent the" perceived evil.

Our lawyer advertising cases have never distinguished among various modes of written advertising to the general public. Thus, Ohio could no more prevent Zauderer from massmailing to a general population his offer to represent women injured by the Dalkon Shield than it could prohibit his publication of the advertisement in local newspapers. Similarly, if petitioner's letter is neither false nor deceptive, Kentucky could not constitutionally prohibit him from sending at large an identical letter opening with the query, "Is your home being foreclosed on?," rather than his observation to the targeted individuals that "It has come to my attention that your home is being foreclosed on." The drafters of Rule 7.3 apparently appreciated as much, for the Rule exempts from the ban "letters addressed or advertising circulars distributed generally to persons who are so situated that they might in general find such services useful."

The court below disapproved petitioner's proposed letter solely because it targeted only persons who were "known to need the legal services" offered in his letter, rather than the broader group of persons "so situated that they might in general find such services useful." Generally, unless the advertiser is inept, the latter group would include members of the former. The only reason to disseminate an advertisement of particular legal services among those persons who are "so situated that they might in general find such services useful" is to reach individuals who actually "need legal services of the kind provided and advertised by the lawyer." But the First Amendment does not permit a ban on certain speech merely because it is more efficient; the State may not constitutionally ban a particular letter on the theory that to mail it only to those whom it would most interest is somehow inherently objectionable.

The court below did not rely on any such theory. Rather, it concluded that the State's blanket ban on all targeted, direct-mail solicitation was permissible because of the "serious potential for abuse inherent in direct solicitation by lawyers of potential clients known to need specific legal services." The court observed:

Such solicitation subjects the prospective client to pressure from a trained lawyer in a direct personal way. It is entirely possible that the potential client may feel overwhelmed by the basic situation which caused the need for the specific legal services and may have seriously impaired capacity for good judgment, sound reason and a natural protective self-interest. Such a condition is full of the possibility of undue influence, overreaching and intimidation.

Of course, a particular potential client will feel equally "overwhelmed" by his legal troubles and will have the same "impaired capacity for good judgment" regardless of whether a lawyer mails him an untargeted letter or exposes him to a newspaper advertisement - concededly constitutionally protected activities — or instead mails a targeted letter. The relevant inquiry is not whether there exist potential clients whose "condition" makes them susceptible to undue 
influence, but whether the mode of communication poses a serious danger that lawyers will exploit any such susceptibility.

In assessing the potential for overreaching and undue influence, the mode of communication makes all the difference. Our decision in Ohralik that a State could categorically ban all inperson solicitation turned on two factors. First was our characterization of face-to-face solicitation as "a practice rife with possibilities for overreaching, invasion of privacy, the exercise of undue influence, and outright fraud." Second, "unique difficulties" would frustrate any attempt at state regulation of in-person solicitation short of an absolute ban because such solicitation is "not visible or otherwise open to public scrutiny." Targeted, direct-mail solicitation is distinguishable from the in-person solicitation in each respect.

Like print advertising, petitioner's letter — and targeted, direct-mail solicitation generally "poses much less risk of overreaching or undue influence" than does in-person solicitation. Neither mode of written communication involves "the coercive force of the personal presence of a trained advocate" or the "pressure on the potential client for an immediate yes-or-no answer to the offer of representation." Unlike the potential client with a badgering advocate breathing down his neck, the recipient of a letter and the "reader of an advertisement can effectively avoid further bombardment of his sensibilities simply by averting his eyes." A letter, like a printed advertisement (but unlike a lawyer), can readily be put in a drawer to be considered later, ignored, or discarded. In short, both types of written solicitation "convey information about legal services by means that are more conducive to reflection and the exercise of choice on the part of the consumer than is personal solicitation by an attorney." Nor does a targeted letter invade the recipient's privacy any more than does a substantively identical letter mailed at large. The invasion, if any, occurs when the lawyer discovers the recipient's legal affairs, not when he confronts the recipient with the discovery.

Admittedly, a letter that is personalized (not merely targeted) to the recipient presents an increased risk of deception, intentional or inadvertent. It could, in certain circumstances, lead the recipient to overestimate the lawyer's familiarity with the case or could implicitly suggest that the recipient's legal problem is more dire than it really is. Similarly, an inaccurately targeted letter could lead the recipient to believe she has a legal problem that she does not actually have or, worse yet, could offer erroneous legal advice.

But merely because targeted, direct-mail solicitation presents lawyers with opportunities for isolated abuses or mistakes does not justify a total ban on that mode of protected commercial speech. The State can regulate such abuses and minimize mistakes through far less restrictive and more precise means, the most obvious of which is to require the lawyer to file any solicitation letter with a state agency, giving the State ample opportunity to supervise mailings and penalize actual abuses. The "regulatory difficulties" that are "unique" to in-person lawyer solicitation - solicitation that is "not visible or otherwise open to public scrutiny" and for which it is "difficult or impossible to obtain reliable proof of what actually took place" - do not apply to written solicitations. The court below offered no basis for its "belief that submission of a blank form letter to the Advertising Commission does not provide a suitable protection to the public from overreaching, intimidation or misleading private targeted mail solicitation." Its concerns were presumably those expressed by the ABA House of Delegates in its comment to Rule 7.3:

State lawyer discipline agencies struggle for resources to investigate specific complaints, much less for those necessary to screen lawyers' mail solicitation material. Even if they could examine such materials, agency staff members are unlikely to know anything 
about the lawyer or about the prospective client's underlying problem. Without such knowledge they cannot determine whether the lawyer's representations are misleading.

The record before us furnishes no evidence that scrutiny of targeted solicitation letters will be appreciably more burdensome or less reliable than scrutiny of advertisements. As a general matter, evaluating a targeted advertisement does not require specific information about the recipient's identity and legal problems any more than evaluating a newspaper advertisement requires like information about all readers. If the targeted letter specifies facts that relate to particular recipients, the reviewing agency has innumerable options to minimize mistakes. It might, for example, require the lawyer to prove the truth of the fact stated; it could require the lawyer to explain briefly how he or she discovered the fact and verified its accuracy; or it could require the letter to bear a label identifying it as an advertisement, or directing the recipient how to report inaccurate or misleading letters. To be sure, a state agency or bar association that reviews solicitation letters might have more work than one that does not. But "our recent decisions involving commercial speech have been grounded in the faith that the free flow of commercial information is valuable enough to justify imposing on would-be regulators the costs of distinguishing the truthful from the false, the helpful from the misleading, and the harmless from the harmful."

III

The validity of Rule 7.3 does not turn on whether petitioner's letter itself exhibited any of the evils at which Rule 7.3 was directed. Since, however, the First Amendment overbreadth doctrine does not apply to professional advertising, we address respondent's contentions that petitioner's letter is particularly overreaching, and therefore unworthy of First Amendment protection. In that regard, respondent identifies two features of the letter before us that, in its view, coalesce to convert the proposed letter into "high pressure solicitation, overbearing solicitation," which is not protected. First, respondent asserts that the letter's liberal use of underscored, uppercase letters "fairly shouts at the recipient that he should employ Shapero." Second, respondent objects that the letter contains assertions that "state no affirmative or objective fact," but constitute "pure salesman puffery, enticement for the unsophisticated, which commits Shapero to nothing."

The pitch or style of a letter's type and its inclusion of subjective predictions of client satisfaction might catch the recipient's attention more than would a bland statement of purely objective facts in small type. But a truthful and non-deceptive letter, no matter how big its type and how much it speculates can never "shout at the recipient" or "grasp him by the lapels," as can a lawyer engaging in face-to-face solicitation. The letter simply presents no comparable risk of overreaching. And so long as the First Amendment protects the right to solicit legal business, the State may claim no substantial interest in restricting truthful and nondeceptive lawyer solicitations to those least likely to be read by the recipient. Moreover, the First Amendment limits the State's authority to dictate what information an attorney may convey in soliciting legal business. "The States may not place an absolute prohibition on certain types of potentially misleading information if the information may also be presented in a way that is not deceptive," unless the State "asserts a substantial interest" that such a restriction would directly advance. Nor may a State impose a more particularized restriction without a similar showing. Aside from the interests that we have already rejected, respondent offers none.

To be sure, a letter may be misleading if it unduly emphasizes trivial or "relatively uninformative facts," or offers overblown assurances of client satisfaction. Respondent does not argue before us that petitioner's letter was misleading in those respects. Nor does respondent contend that 
the letter is false or misleading in any other respect. Of course, respondent is free to raise, and the Kentucky courts are free to consider, any such argument on remand.

The judgment of the Supreme Court of Kentucky is reversed, and the case is remanded for further proceedings not inconsistent with this opinion.

JUSTICE O'CONNOR, with whom THE CHIEF JUSTICE and JUSTICE SCALIA join, dissenting.

I agree with the Court that the reasoning in Zauderer supports the conclusion reached today. That decision, however, was itself the culmination of a line of cases built on defective premises and flawed reasoning. As today's decision illustrates, the Court has been unable or unwilling to restrain the logic of the underlying analysis within reasonable bounds. The resulting interference with important and valid public policies is so destructive that I believe the analytical framework itself should now be reexamined.

Zauderer held that the First Amendment was violated by a state rule that forbade attorneys to solicit or accept employment through advertisements containing information or advice regarding a specific legal problem. I dissented from this holding because I believed that our precedents permitted, and good judgment required, that we give greater deference to the State's legitimate efforts to regulate advertising by their attorneys. Emphasizing the important differences between professional services and standardized consumer products, I concluded that unsolicited legal advice was not analogous to the free samples that are often used to promote sales in other contexts. First, the quality of legal services is typically more difficult for most laypersons to evaluate, and the consequences of a mistaken evaluation of the "free sample" may be much more serious. For that reason, the practice of offering unsolicited legal advice as a means of enticing potential clients into a professional relationship is much more likely to be misleading than superficially similar practices in the sale of ordinary consumer goods. Second, and more important, an attorney has an obligation to provide clients with complete and disinterested advice. The advice contained in unsolicited "free samples" is likely to be colored by the lawyer's own interest in drumming up business, a result that is sure to undermine the professional standards that States have a substantial interest in maintaining.

The roots of the error in our attorney advertising cases are a defective analogy between professional services and standardized consumer products and a correspondingly inappropriate skepticism about the States' justifications for their regulations.

Even if I agreed that this Court should take upon itself the task of deciding what forms of attorney advertising are in the public interest, I would not agree with what it has done. The best arguments in favor of rules permitting attorneys to advertise are founded in elementary economic principles. Restrictions on truthful advertising, which artificially interfere with the ability of suppliers to transmit price information to consumers, presumably reduce the efficiency of the mechanisms of supply and demand. Other factors being equal, this should cause or enable suppliers (in this case attorneys) to maintain a price/quality ratio in some of their services that is higher than would otherwise prevail. Although one could probably not test this hypothesis empirically, it is inherently plausible. Nor is it implausible to imagine that one effect of restrictions on lawyer advertising, and perhaps sometimes an intended effect, is to enable 
attorneys to charge their clients more for some services (of a given quality) than they would be able to charge absent the restrictions.

Assuming, arguendo, that the removal of advertising restrictions should lead in the short run to increased efficiency in the provision of legal services, I would not agree that we can safely assume the same effect in the long run. The economic argument against these restrictions ignores the delicate role they may play in preserving the norms of the legal profession. While it may be difficult to defend this role with precise economic logic, I believe there is a powerful argument in favor of restricting lawyer advertising and that this argument is at the very least not easily refuted by economic analysis.

One distinguishing feature of any profession, unlike other occupations that may be equally respectable, is that membership entails an ethical obligation to temper one's selfish pursuit of economic success by adhering to standards of conduct that could not be enforced either by legal fiat or through the discipline of the market. There are sound reasons to continue pursuing the goal that is implicit in the traditional view of professional life. Both the special privileges incident to membership in the profession and the advantages those privileges give in the necessary task of earning a living are means to a goal that transcends the accumulation of wealth. That goal is public service, which in the legal profession can take a variety of familiar forms. This view of the legal profession need not be rooted in romanticism or self-serving sanctimony, though of course it can be. Rather, special ethical standards for lawyers are properly understood as an appropriate means of restraining lawyers in the exercise of the unique power that they inevitably wield in a political system like ours.

It is worth recalling why lawyers are regulated at all, or to a greater degree than most other occupations, and why history is littered with failed attempts to extinguish lawyers as a special class. Operating a legal system that is both reasonably efficient and tolerably fair cannot be accomplished, at least under modern social conditions, without a trained and specialized body of experts. This training is one element of what we mean when we refer to the law as a "learned profession." Such knowledge by its nature cannot be made generally available, and it therefore confers the power and the temptation to manipulate the system of justice for one's own ends. Such manipulation can occur in at least two obvious ways. One results from overly zealous representation of the client's interests; abuse of the discovery process is one example whose causes and effects (if not its cure) is apparent. The second, and for present purposes the more relevant, problem is abuse of the client for the lawyer's benefit. Precisely because lawyers must be provided with expertise that is both esoteric and extremely powerful, it would be unrealistic to demand that clients bargain for their services in the same arm's-length manner that may be appropriate when buying an automobile or choosing a dry cleaner. Like physicians, lawyers are subjected to heightened ethical demands on their conduct towards those they serve. These demands are needed because market forces, and the ordinary legal prohibitions against force and fraud, are simply insufficient to protect the consumers of their necessary services from the peculiar power of the specialized knowledge that these professionals possess.

Imbuing the legal profession with the necessary ethical standards is a task that involves a constant struggle with the relentless natural force of economic self-interest. It cannot be accomplished directly by legal rules, and it certainly will not succeed if sermonizing is the strongest tool that may be employed. Tradition and experiment have suggested a number of formal and informal mechanisms, none of which is adequate by itself and many of which may serve to reduce competition (in the narrow economic sense) among members of the profession. A few examples include the great efforts made during this century to improve the quality and breadth of the legal education that is required for admission to the bar; the concomitant attempt 
to cultivate a subclass of genuine scholars within the profession; the development of bar associations that aspire to be more than trade groups; strict disciplinary rules about conflicts of interest and client abandonment; and promotion of the expectation that an attorney's history of voluntary public service is a relevant factor in selecting judicial candidates.

Restrictions on advertising and solicitation by lawyers properly and significantly serve the same goal. Such restrictions act as a concrete, day-to-day reminder to the practicing attorney of why it is improper for any member of this profession to regard it as a trade or occupation like any other. There is no guarantee, of course, that the restrictions will always have the desired effect, and they are surely not a sufficient means to their proper goal. Given their inevitable anticompetitive effects, moreover, they should not be thoughtlessly retained or insulated from skeptical criticism. Appropriate modifications have been made in the light of reason and experience, and other changes may be suggested in the future.

In my judgment, however, fairly severe constraints on attorney advertising can continue to play an important role in preserving the legal profession as a genuine profession. Whatever may be the exactly appropriate scope of these restrictions at a given time and place, this Court's recent decisions reflect a myopic belief that "consumers," and thus our Nation, will benefit from a constitutional theory that refuses to recognize either the essence of professionalism or its fragile and necessary foundations. In one way or another, time will uncover the folly of this approach. I can only hope that the Court will recognize the danger before it is too late to effect a worthwhile cure.

\section{Questions:}

1. Richard D. Shapero died at his home in Louisville, Kentucky on December 31, 2006, at 63. According to his obituary, "Richard was an attorney and Pin Ball Wizard. Richard's U.S. Supreme Court Case, Shapero vs. Kentucky Bar Association established laws regarding lawyer advertising in the United States." His colleagues also remembered him fondly, "As we were pondering our past and setting goals for our future, Richard D. Shapero died yesterday at age 63. He will always be remembered for taking the Kentucky Bar Association to the United States Supreme Court, which resulted in a significant opinion striking down bar restrictions on lawyer advertising. A gutsy guy, lightyears ahead of his time, he enjoyed the business side of law much more than the actual practice of law. His forte was bringing in P.I. cases and then farming them out to other attorneys. His trademark, long before other lawfirms thought of tag lines or trademarks, was 'I Know The Experts.' His early TV ads made traditional lawyers cringe, but he spoke a language lay people understood and they hired him."

2. The majority found a direct mail solicitation indistinguishable from an advertisement to the public. Do you agree? Is it reasonable to be more concerned about solicitation of potential clients who appear to need legal assistance than advertisements directed at the general public? Or perhaps we should encourage attorneys to offer legal services to potential clients who are most in need of them?

3. The dissent argues that advertisements and solicitation are debasing the profession and its ethical standards. Have its concerns borne fruit?

\section{Further Reading:}

- David O. Stewart \& Scott Nelson, Hawking Legal Services, ABA Journal, August 1, 1988 , at 44 
Florida Bar v. Went For It, Inc., 515 U.S. 618 (1995)

Justice O'Connor delivered the opinion of the Court.

Rules of the Florida Bar prohibit personal injury lawyers from sending targeted direct-mail solicitations to victims and their relatives for 30 days following an accident or disaster. This case asks us to consider whether such Rules violate the First and Fourteenth Amendments of the Constitution. We hold that in the circumstances presented here, they do not.

In 1989, the Florida Bar completed a 2-year study of the effects of lawyer advertising on public opinion. After conducting hearings, commissioning surveys, and reviewing extensive public commentary, the Bar determined that several changes to its advertising rules were in order. In late 1990, the Florida Supreme Court adopted the Bar's proposed amendments with some modifications. Two of these amendments are at issue in this case. Rule 4-7.4(b)(1) provides that "a lawyer shall not send, or knowingly permit to be sent, a written communication to a prospective client for the purpose of obtaining professional employment if: $(A)$ the written communication concerns an action for personal injury or wrongful death or otherwise relates to an accident or disaster involving the person to whom the communication is addressed or a relative of that person, unless the accident or disaster occurred more than 30 days prior to the mailing of the communication." Rule 4-7.8(a) states that "a lawyer shall not accept referrals from a lawyer referral service unless the service: (1) engages in no communication with the public and in no direct contact with prospective clients in a manner that would violate the Rules of Professional Conduct if the communication or contact were made by the lawyer." Together, these Rules create a brief 30-day blackout period after an accident during which lawyers may not, directly or indirectly, single out accident victims or their relatives in order to solicit their business.

In March 1992, G. Stewart McHenry and his wholly owned lawyer referral service, Went For It, Inc., filed this action for declaratory and injunctive relief in the United States District Court for the Middle District of Florida challenging Rules 4-7.4(b)(1) and 4-7.8(a) as violative of the First and Fourteenth Amendments to the Constitution. McHenry alleged that he routinely sent targeted solicitations to accident victims or their survivors within 30 days after accidents and that he wished to continue doing so in the future. Went For It, Inc., represented that it wished to contact accident victims or their survivors within 30 days of accidents and to refer potential clients to participating Florida lawyers. In October 1992, McHenry was disbarred for reasons unrelated to this suit. Another Florida lawyer, John T. Blakely, was substituted in his stead.

The District Court referred the parties' competing summary judgment motions to a Magistrate Judge, who concluded that the Bar had substantial government interests, predicated on a concern for professionalism, both in protecting the personal privacy and tranquility of recent accident victims and their relatives and in ensuring that these individuals do not fall prey to undue influence or overreaching. Citing the Bar's extensive study, the Magistrate Judge found 
that the Rules directly serve those interests and sweep no further than reasonably necessary. The Magistrate recommended that the District Court grant the Bar's motion for summary judgment on the ground that the Rules pass constitutional muster.

The District Court rejected the Magistrate Judge's report and recommendations and entered summary judgment for the plaintiffs, relying on Bates v. State Bar of Ariz. and subsequent cases. The Eleventh Circuit affirmed on similar grounds. The panel noted, in its conclusion, that it was "disturbed that Bates and its progeny require the decision" that it reached. We granted certiorari, and now reverse.

II

A

Nearly two decades of cases have built upon the foundation laid by Bates. It is now well established that lawyer advertising is commercial speech and, as such, is accorded a measure of First Amendment protection. Such First Amendment protection, of course, is not absolute. We have always been careful to distinguish commercial speech from speech at the First Amendment's core. "Commercial speech enjoys a limited measure of protection, commensurate with its subordinate position in the scale of First Amendment values, and is subject to modes of regulation that might be impermissible in the realm of noncommercial expression." We have observed that "to require a parity of constitutional protection for commercial and noncommercial speech alike could invite dilution, simply by a leveling process, of the force of the Amendment's guarantee with respect to the latter kind of speech."

Mindful of these concerns, we engage in "intermediate" scrutiny of restrictions on commercial speech, analyzing them under the framework set forth in Central Hudson. Under Central Hudson, the government may freely regulate commercial speech that concerns unlawful activity or is misleading. Commercial speech that falls into neither of those categories, like the advertising at issue here, may be regulated if the government satisfies a test consisting of three related prongs: First, the government must assert a substantial interest in support of its regulation; second, the government must demonstrate that the restriction on commercial speech directly and materially advances that interest; and third, the regulation must be "narrowly drawn."

B

The Bar asserts that it has a substantial interest in protecting the privacy and tranquility of personal injury victims and their loved ones against intrusive, unsolicited contact by lawyers. This interest obviously factors into the Bar's paramount (and repeatedly professed) objective of curbing activities that "negatively affect the administration of justice." Because direct-mail solicitations in the wake of accidents are perceived by the public as intrusive, the Bar argues, the reputation of the legal profession in the eyes of Floridians has suffered commensurately. The regulation, then, is an effort to protect the flagging reputations of Florida lawyers by preventing them from engaging in conduct that, the Bar maintains, "is universally regarded as 
deplorable and beneath common decency because of its intrusion upon the special vulnerability and private grief of victims or their families."

We have little trouble crediting the Bar's interest as substantial. On various occasions we have accepted the proposition that "States have a compelling interest in the practice of professions within their boundaries, and as part of their power to protect the public health, safety, and other valid interests they have broad power to establish standards for licensing practitioners and regulating the practice of professions." Our precedents also leave no room for doubt that "the protection of potential clients' privacy is a substantial state interest." In other contexts, we have consistently recognized that "the State's interest in protecting the well-being, tranquility, and privacy of the home is certainly of the highest order in a free and civilized society." Indeed, we have noted that "a special benefit of the privacy all citizens enjoy within their own walls, which the State may legislate to protect, is an ability to avoid intrusions."

Under Central Hudson's second prong, the State must demonstrate that the challenged regulation "advances the Government's interest in a direct and material way." That burden, we have explained, "is not satisfied by mere speculation or conjecture; rather, a governmental body seeking to sustain a restriction on commercial speech must demonstrate that the harms it recites are real and that its restriction will in fact alleviate them to a material degree."

The Bar submitted a 106-page summary of its 2-year study of lawyer advertising and solicitation to the District Court. That summary contains data-both statistical and anecdotal-supporting the Bar's contentions that the Florida public views direct-mail solicitations in the immediate wake of accidents as an intrusion on privacy that reflects poorly upon the profession. As of June 1989, lawyers mailed 700,000 direct solicitations in Florida annually, $40 \%$ of which were aimed at accident victims or their survivors. A survey of Florida adults commissioned by the Bar indicated that Floridians "have negative feelings about those attorneys who use direct mail advertising." Fifty-four percent of the general population surveyed said that contacting persons concerning accidents or similar events is a violation of privacy. A random sampling of persons who received direct-mail advertising from lawyers in 1987 revealed that $45 \%$ believed that directmail solicitation is "designed to take advantage of gullible or unstable people"; $34 \%$ found such tactics "annoying or irritating"; $26 \%$ found it "an invasion of your privacy"; and $24 \%$ reported that it "made you angry." Significantly, $27 \%$ of direct-mail recipients reported that their regard for the legal profession and for the judicial process as a whole was "lower" as a result of receiving the direct mail.

The anecdotal record mustered by the Bar is noteworthy for its breadth and detail. With titles like "Scavenger Lawyers" and "Solicitors Out of Bounds," newspaper editorial pages in Florida have burgeoned with criticism of Florida lawyers who send targeted direct mail to victims shortly after accidents. The study summary also includes page upon page of excerpts from complaints of direct-mail recipients. For example, a Florida citizen described how he was "appalled and angered by the brazen attempt" of a law firm to solicit him by letter shortly after he was injured and his fiancee was killed in an auto accident. Another found it "despicable and inexcusable" that a Pensacola lawyer wrote to his mother three days after his father's funeral. Another 
described how she was "astounded" and then "very angry" when she received a solicitation following a minor accident. Still another described as "beyond comprehension" a letter his nephew's family received the day of the nephew's funeral. One citizen wrote, "I consider the unsolicited contact from you after my child's accident to be of the rankest form of ambulance chasing and in incredibly poor taste. I cannot begin to express with my limited vocabulary the utter contempt in which I hold you and your kind."

In light of this showing - which respondents at no time refuted, save by the conclusory assertion that the Rule lacked "any factual basis"-we conclude that the Bar has satisfied the second prong of the Central Hudson test. In dissent, Justice Kennedy complains that we have before us few indications of the sample size or selection procedures employed by Magid Associates (a nationally renowned consulting firm) and no copies of the actual surveys employed. As stated, we believe the evidence adduced by the Bar is sufficient. In any event, we do not read our case law to require that empirical data come to us accompanied by a surfeit of background information. Indeed, in other First Amendment contexts, we have permitted litigants to justify speech restrictions by reference to studies and anecdotes pertaining to different locales altogether, or even, in a case applying strict scrutiny, to justify restrictions based solely on history, consensus, and "simple common sense." After scouring the record, we are satisfied that the ban on directmail solicitation in the immediate aftermath of accidents targets a concrete, nonspeculative harm.

In reaching a contrary conclusion, the Court of Appeals determined that this case was governed squarely by Shapero. Making no mention of the Bar's study, the court concluded that "a targeted letter does not invade the recipient's privacy any more than does a substantively identical letter mailed at large. The invasion, if any, occurs when the lawyer discovers the recipient's legal affairs, not when he confronts the recipient with the discovery." In many cases, the Court of Appeals explained, "this invasion of privacy will involve no more than reading the newspaper."

While some of Shapero's language might be read to support the Court of Appeals' interpretation, Shapero differs in several fundamental respects from the case before us. First and foremost, Shapero's treatment of privacy was casual. Contrary to the dissent's suggestions, the State in Shapero did not seek to justify its regulation as a measure undertaken to prevent lawyers' invasions of privacy interests. Rather, the State focused exclusively on the special dangers of overreaching inhering in targeted solicitations. Second, in contrast to this case, Shapero dealt with a broad ban on all direct-mail solicitations, whatever the time frame and whoever the recipient. Finally, the State in Shapero assembled no evidence attempting to demonstrate any actual harm caused by targeted direct mail. The Court rejected the State's effort to justify a prophylactic ban on the basis of blanket, untested assertions of undue influence and overreaching. Because the State did not make a privacy-based argument at all, its empirical showing on that issue was similarly infirm.

We find the Court's perfunctory treatment of privacy in Shapero to be of little utility in assessing this ban on targeted solicitation of victims in the immediate aftermath of accidents. While it is undoubtedly true that many people find the image of lawyers sifting through accident and police 
reports in pursuit of prospective clients unpalatable and invasive, this case targets a different kind of intrusion. The Bar has argued, and the record reflects, that a principal purpose of the ban is "protecting the personal privacy and tranquility of Florida's citizens from crass commercial intrusion by attorneys upon their personal grief in times of trauma." The intrusion targeted by the Bar's regulation stems not from the fact that a lawyer has learned about an accident or disaster, but from the lawyer's confrontation of victims or relatives with such information, while wounds are still open, in order to solicit their business. In this respect, an untargeted letter mailed to society at large is different in kind from a targeted solicitation; the untargeted letter involves no willful or knowing affront to or invasion of the tranquility of bereaved or injured individuals and simply does not cause the same kind of reputational harm to the profession unearthed by the Bar's study.

The purpose of the 30-day targeted direct-mail ban is to forestall the outrage and irritation with the state-licensed legal profession that the practice of direct solicitation only days after accidents has engendered. The Bar is concerned not with citizens' "offense" in the abstract, but with the demonstrable detrimental effects that such "offense" has on the profession it regulates. Moreover, the harm posited by the Bar is as much a function of simple receipt of targeted solicitations within days of accidents as it is a function of the letters' contents. Throwing the letter away shortly after opening it may minimize the latter intrusion, but it does little to combat the former.

Passing to Central Hudson's third prong, we examine the relationship between the Bar's interests and the means chosen to serve them. With respect to this prong, the differences between commercial speech and noncommercial speech are manifest. The "least restrictive means" test has no role in the commercial speech context. "What our decisions require," instead, "is a fit between the legislature's ends and the means chosen to accomplish those ends, a fit that is not necessarily perfect, but reasonable; that represents not necessarily the single best disposition but one whose scope is in proportion to the interest served, that employs not necessarily the least restrictive means, but a means narrowly tailored to achieve the desired objective." Of course, we do not equate this test with the less rigorous obstacles of rational basis review; in Cincinnati v. Discovery, for example, we observed that the existence of "numerous and obvious less-burdensome alternatives to the restriction on commercial speech is certainly a relevant consideration in determining whether the fit between ends and means is reasonable."

Respondents levy a great deal of criticism, at the scope of the Bar's restriction on targeted mail. "By prohibiting written communications to all people, whatever their state of mind," respondents charge, the Rule "keeps useful information from those accident victims who are ready, willing and able to utilize a lawyer's advice." This criticism may be parsed into two components. First, the Rule does not distinguish between victims in terms of the severity of their injuries. According to respondents, the Rule is unconstitutionally overinclusive insofar as it bans targeted mailings even to citizens whose injuries or grief are relatively minor. Second, the Rule may prevent citizens from learning about their legal options, particularly at a time when other actorsopposing counsel and insurance adjusters-may be clamoring for victims' attentions. Any 
benefit arising from the Bar's regulation, respondents implicitly contend, is outweighed by these costs.

We are not persuaded by respondents' allegations of constitutional infirmity. We find little deficiency in the ban's failure to distinguish among injured Floridians by the severity of their pain or the intensity of their grief. Indeed, it is hard to imagine the contours of a regulation that might satisfy respondents on this score. Rather than drawing difficult lines on the basis that some injuries are "severe" and some situations appropriate (and others, presumably, inappropriate) for grief, anger, or emotion, the Bar has crafted a ban applicable to all postaccident or disaster solicitations for a brief 30-day period. Unlike respondents, we do not see "numerous and obvious less-burdensome alternatives" to Florida's short temporal ban. The Bar's rule is reasonably well tailored to its stated objective of eliminating targeted mailings whose type and timing are a source of distress to Floridians, distress that has caused many of them to lose respect for the legal profession.

Respondents' second point would have force if the Bar's Rule were not limited to a brief period and if there were not many other ways for injured Floridians to learn about the availability of legal representation during that time. Our lawyer advertising cases have afforded lawyers a great deal of leeway to devise innovative ways to attract new business. Florida permits lawyers to advertise on prime-time television and radio as well as in newspapers and other media. They may rent space on billboards. They may send untargeted letters to the general population, or to discrete segments thereof. There are, of course, pages upon pages devoted to lawyers in the Yellow Pages of Florida telephone directories. These listings are organized alphabetically and by area of specialty. These ample alternative channels for receipt of information about the availability of legal representation during the 30-day period following accidents may explain why, despite the ample evidence, testimony, and commentary submitted by those favoring (as well as opposing) unrestricted direct-mail solicitation, respondents have not pointed to-and we have not independently found-a single example of an individual case in which immediate solicitation helped to avoid, or failure to solicit within 30 days brought about, the harms that concern the dissent. In fact, the record contains considerable empirical survey information suggesting that Floridians have little difficulty finding a lawyer when they need one. Finding no basis to question the commonsense conclusion that the many alternative channels for communicating necessary information about attorneys are sufficient, we see no defect in Florida's regulation.

III

Speech by professionals obviously has many dimensions. There are circumstances in which we will accord speech by attorneys on public issues and matters of legal representation the strongest protection our Constitution has to offer. This case, however, concerns pure commercial advertising, for which we have always reserved a lesser degree of protection under the First Amendment. Particularly because the standards and conduct of state-licensed lawyers have traditionally been subject to extensive regulation by the States, it is all the more appropriate that we limit our scrutiny of state regulations to a level commensurate with the "subordinate position" of commercial speech in the scale of First Amendment values. 
We believe that the Bar's 30-day restriction on targeted direct-mail solicitation of accident victims and their relatives withstands scrutiny under the three-pronged Central Hudson test that we have devised for this context. The Bar has substantial interest both in protecting injured Floridians from invasive conduct by lawyers and in preventing the erosion of confidence in the profession that such repeated invasions have engendered. The Bar's proffered study, unrebutted by respondents below, provides evidence indicating that the harms it targets are far from illusory. The palliative devised by the Bar to address these harms is narrow both in scope and in duration. The Constitution, in our view, requires nothing more.

Justice Kennedy, with whom Justice Stevens, Justice Souter, and Justice Ginsburg join, dissenting.

Attorneys who communicate their willingness to assist potential clients are engaged in speech protected by the First and Fourteenth Amendments. The Court today undercuts this guarantee in an important class of cases and unsettles leading First Amendment precedents, at the expense of those victims most in need of legal assistance. With all respect for the Court, in my view its solicitude for the privacy of victims and its concern for our profession are misplaced and self-defeating, even upon the Court's own premises.

I take it to be uncontroverted that when an accident results in death or injury, it is often urgent at once to investigate the occurrence, identify witnesses, and preserve evidence. Vital interests in speech and expression are, therefore, at stake when by law an attorney cannot direct a letter to the victim or the family explaining this simple fact and offering competent legal assistance. Meanwhile, represented and better informed parties, or parties who have been solicited in ways more sophisticated and indirect, may be at work. Indeed, these parties, either themselves or by their attorneys, investigators, and adjusters, are free to contact the unrepresented persons to gather evidence or offer settlement. This scheme makes little sense. As is often true when the law makes little sense, it is not first principles but their interpretation and application that have gone awry.

Although I agree with the Court that the case can be resolved by following the three-part inquiry we have identified to assess restrictions on commercial speech, a preliminary observation is in order. Speech has the capacity to convey complex substance, yielding various insights and interpretations depending upon the identity of the listener or the reader and the context of its transmission. It would oversimplify to say that what we consider here is commercial speech and nothing more, for in many instances the banned communications may be vital to the recipients' right to petition the courts for redress of grievances. The complex nature of expression is one reason why even so-called commercial speech has become an essential part of the public discourse the First Amendment secures. If our commercial speech rules are to control this case, then, it is imperative to apply them with exacting care and fidelity to our precedents, for what is at stake is the suppression of information and knowledge that transcends the financial selfinterests of the speaker. 
As the Court notes, the first of the Central Hudson factors to be considered is whether the interest the State pursues in enacting the speech restriction is a substantial one. The State says two different interests meet this standard. The first is the interest "in protecting the personal privacy and tranquility" of the victim and his or her family. As the Court notes, that interest has recognition in our decisions as a general matter; but it does not follow that the privacy interest in the cases the majority cites is applicable here. The problem the Court confronts, and cannot overcome, is our recent decision in Shapero. In assessing the importance of the interest in that solicitation case, we made an explicit distinction between direct, in-person solicitations and direct-mail solicitations. Shapero, like this case, involved a direct-mail solicitation, and there the State recited its fears of "overreaching and undue influence." We found, however, no such dangers presented by direct-mail advertising. We reasoned that "a letter, like a printed advertisement (but unlike a lawyer), can readily be put in a drawer to be considered later, ignored, or discarded. We pointed out that "the relevant inquiry is not whether there exist potential clients whose 'condition' makes them susceptible to undue influence, but whether the mode of communication poses a serious danger that lawyers will exploit any such susceptibility." In assessing the substantiality of the evils to be prevented, we concluded that "the mode of communication makes all the difference." The direct mail in Shapero did not present the justification for regulation of speech presented in Ohralik.

To avoid the controlling effect of Shapero in the case before us, the Court seeks to declare that a different privacy interest is implicated. As it sees the matter, the substantial concern is that victims or their families will be offended by receiving a solicitation during their grief and trauma. But we do not allow restrictions on speech to be justified on the ground that the expression might offend the listener. On the contrary, we have said that these "are classically not justifications validating the suppression of expression protected by the First Amendment." And in Zauderer, where we struck down a ban on attorney advertising, we held that "the mere possibility that some members of the population might find advertising offensive cannot justify suppressing it. The same must hold true for advertising that some members of the bar might find beneath their dignity."

We have applied this principle to direct-mail cases as well as with respect to general advertising, noting that the right to use the mails is protected by the First Amendment. In Bolger, we held that a statute designed to "shield recipients of mail from materials that they are likely to find offensive" furthered an interest of "little weight," noting that "we have consistently held that the fact that protected speech may be offensive to some does not justify its suppression." It is only where an audience is captive that we will assure its protection from some offensive speech. Outside that context, "we have never held that the Government itself can shut off the flow of mailings to protect those recipients who might potentially be offended." The occupants of a household receiving mailings are not a captive audience, and the asserted interest in preventing their offense should be no more controlling here than in our prior cases. All the recipient of objectionable mailings need do is to take "the short, though regular, journey from mail box to trash can." As we have observed, this is "an acceptable burden, at least so far as the 
Constitution is concerned." If these cases forbidding restrictions on speech that might be offensive are to be overruled, the Court should say so.

In the face of these difficulties of logic and precedent, the State and the opinion of the Court turn to a second interest: protecting the reputation and dignity of the legal profession. The argument is, it seems fair to say, that all are demeaned by the crass behavior of a few. The argument takes a further step in the amicus brief filed by the Association of Trial Lawyers of America. There it is said that disrespect for the profession from this sort of solicitation (but presumably from no other sort of solicitation) results in lower jury verdicts. In a sense, of course, these arguments are circular. While disrespect will arise from an unethical or improper practice, the majority begs a most critical question by assuming that direct-mail solicitations constitute such a practice. The fact is, however, that direct solicitation may serve vital purposes and promote the administration of justice, and to the extent the bar seeks to protect lawyers' reputations by preventing them from engaging in speech some deem offensive, the State is doing nothing more (as amicus the Association of Trial Lawyers of America is at least candid enough to admit) than manipulating the public's opinion by suppressing speech that informs us how the legal system works. The disrespect argument thus proceeds from the very assumption it tries to prove, which is to say that solicitations within 30 days serve no legitimate purpose. This, of course, is censorship pure and simple; and censorship is antithetical to the first principles of free expression.

Even were the interests asserted substantial, the regulation here fails the second part of the Central Hudson test, which requires that the dangers the State seeks to eliminate be real and that a speech restriction or ban advance that asserted state interest in a direct and material way. The burden of demonstrating the reality of the asserted harm rests on the State. Slight evidence in this regard does not mean there is sufficient evidence to support the claims. Here, what the State has offered falls well short of demonstrating that the harms it is trying to redress are real, let alone that the regulation directly and materially advances the State's interests. The parties and the Court have used the term "Summary of Record" to describe a document prepared by the Florida Bar (Bar), one of the adverse parties, and submitted to the District Court in this case. This document includes no actual surveys, few indications of sample size or selection procedures, no explanations of methodology, and no discussion of excluded results. There is no description of the statistical universe or scientific framework that permits any productive use of the information the so-called Summary of Record contains. The majority describes this anecdotal matter as "noteworthy for its breadth and detail," but when examined, it is noteworthy for its incompetence. The selective synopses of unvalidated studies deal, for the most part, with television advertising and phone book listings, and not direct-mail solicitations. Although there may be issues common to various kinds of attorney advertising and solicitation, it is not clear what would follow from that limited premise, unless the Court means by its decision to call into question all forms of attorney advertising. The most generous reading of this document permits identification of 34 pages on which direct-mail solicitation is arguably discussed. Of these, only two are even a synopsis of a study of the attitudes of Floridians 
towards such solicitations. The bulk of the remaining pages include comments by lawyers about direct mail (some of them favorable), excerpts from citizen complaints about such solicitation, and a few excerpts from newspaper articles on the topic. Our cases require something more than a few pages of self-serving and unsupported statements by the State to demonstrate that a regulation directly and materially advances the elimination of a real harm when the State seeks to suppress truthful and nondeceptive speech.

It is telling that the essential thrust of all the material adduced to justify the State's interest is devoted to the reputational concerns of the Bar. It is not at all clear that this regulation advances the interest of protecting persons who are suffering trauma and grief, and we are cited to no material in the record for that claim. Indeed, when asked at oral argument what a "typical injured plaintiff gets in the mail," the Bar's lawyer replied: "That's not in the record, and I don't know the answer to that question." Having declared that the privacy interest is one both substantial and served by the regulation, the Court ought not to be excused from justifying its conclusion.

The insufficiency of the regulation to advance the State's interest is reinforced by the third inquiry necessary in this analysis. Were it appropriate to reach the third part of the Central Hudson test, it would be clear that the relationship between the Bar's interests and the means chosen to serve them is not a reasonable fit. The Bar's rule creates a flat ban that prohibits far more speech than necessary to serve the purported state interest. Even assuming that interest were legitimate, there is a wild disproportion between the harm supposed and the speech ban enforced. It is a disproportion the Court does not bother to discuss, but our speech jurisprudence requires that it do so.

To begin with, the ban applies with respect to all accidental injuries, whatever their gravity. The Court's purported justification for the excess of regulation in this respect is the difficulty of drawing lines between severe and less serious injuries, but making such distinctions is not important in this analysis. Even were it significant, the Court's assertion is unconvincing. After all, the criminal law routinely distinguishes degrees of bodily harm, and if that delineation is permissible and workable in the criminal context, it should not be "hard to imagine the contours of a regulation" that satisfies the reasonable fit requirement.

There is, moreover, simply no justification for assuming that in all or most cases an attorney's advice would be unwelcome or unnecessary when the survivors or the victim must at once begin assessing their legal and financial position in a rational manner. With regard to lesser injuries, there is little chance that for any period, much less 30 days, the victims will become distraught upon hearing from an attorney. It is, in fact, more likely a real risk that some victims might think no attorney will be interested enough to help them. It is at this precise time that sound legal advice may be necessary and most urgent.

Even as to more serious injuries, the State's argument fails, since it must be conceded that prompt legal representation is essential where death or injury results from accidents. The only 
seeming justification for the State's restriction is the one the Court itself offers, which is that attorneys can and do resort to other ways of communicating important legal information to potential clients. Quite aside from the latent protectionism for the established bar that the argument discloses, it fails for the more fundamental reason that it concedes the necessity for the very representation the attorneys solicit and the State seeks to ban. The accident victims who are prejudiced to vindicate the State's purported desire for more dignity in the legal profession will be the very persons who most need legal advice, for they are the victims who, because they lack education, linguistic ability, or familiarity with the legal system, are unable to seek out legal services.

The reasonableness of the State's chosen methods for redressing perceived evils can be evaluated, in part, by a commonsense consideration of other possible means of regulation that have not been tried. Here, the Court neglects the fact that this problem is largely self-policing: Potential clients will not hire lawyers who offend them. And even if a person enters into a contract with an attorney and later regrets it, Florida, like some other States, allows clients to rescind certain contracts with attorneys within a stated time after they are executed. The State's restriction deprives accident victims of information which may be critical to their right to make a claim for compensation for injuries. The telephone book and general advertisements may serve this purpose in part; but the direct solicitation ban will fall on those who most need legal representation: for those with minor injuries, the victims too ill informed to know an attorney may be interested in their cases; for those with serious injuries, the victims too ill informed to know that time is of the essence if counsel is to assemble evidence and warn them not to enter into settlement negotiations or evidentiary discussions with investigators for opposing parties. One survey reports that over a recent 5 -year period, $68 \%$ of the American population consulted a lawyer. The use of modern communication methods in a timely way is essential if clients who make up this vast demand are to be advised and informed of all of their choices and rights in selecting an attorney. The very fact that some 280,000 direct-mail solicitations are sent to accident victims and their survivors in Florida each year is some indication of the efficacy of this device. Nothing in the Court's opinion demonstrates that these efforts do not serve some beneficial role. A solicitation letter is not a contract. Nothing in the record shows that these communications do not at the least serve the purpose of informing the prospective client that he or she has a number of different attorneys from whom to choose, so that the decision to select counsel, after an interview with one or more interested attorneys, can be deliberate and informed. And if these communications reveal the social costs of the tort system as a whole, then efforts can be directed to reforming the operation of that system, not to suppressing information about how the system works. The Court's approach, however, does not seem to be the proper way to begin elevating the honor of the profession.

\section{IV}

It is most ironic that, for the first time since Bates $v$. State Bar of Arizona, the Court now orders a major retreat from the constitutional guarantees for commercial speech in order to shield its own profession from public criticism. Obscuring the financial aspect of the legal profession from public discussion through direct-mail solicitation, at the expense of the least sophisticated 
members of society, is not a laudable constitutional goal. There is no authority for the proposition that the Constitution permits the State to promote the public image of the legal profession by suppressing information about the profession's business aspects. If public respect for the profession erodes because solicitation distorts the idea of the law as most lawyers see it, it must be remembered that real progress begins with more rational speech, not less. I agree that if this amounts to mere "sermonizing," the attempt may be futile. The guiding principle, however, is that full and rational discussion furthers sound regulation and necessary reform. The image of the profession cannot be enhanced without improving the substance of its practice. The objective of the profession is to ensure that "the ethical standards of lawyers are linked to the service and protection of clients."

Today's opinion is a serious departure, not only from our prior decisions involving attorney advertising, but also from the principles that govern the transmission of commercial speech. The Court's opinion reflects a new-found and illegitimate confidence that it, along with the Supreme Court of Florida, knows what is best for the Bar and its clients. Self-assurance has always been the hallmark of a censor. That is why under the First Amendment the public, not the State, has the right and the power to decide what ideas and information are deserving of their adherence. "The general rule is that the speaker and the audience, not the government, assess the value of the information presented." By validating Florida's rule, today's majority is complicit in the Bar's censorship. For these reasons, I dissent from the opinion of the Court and from its judgment.

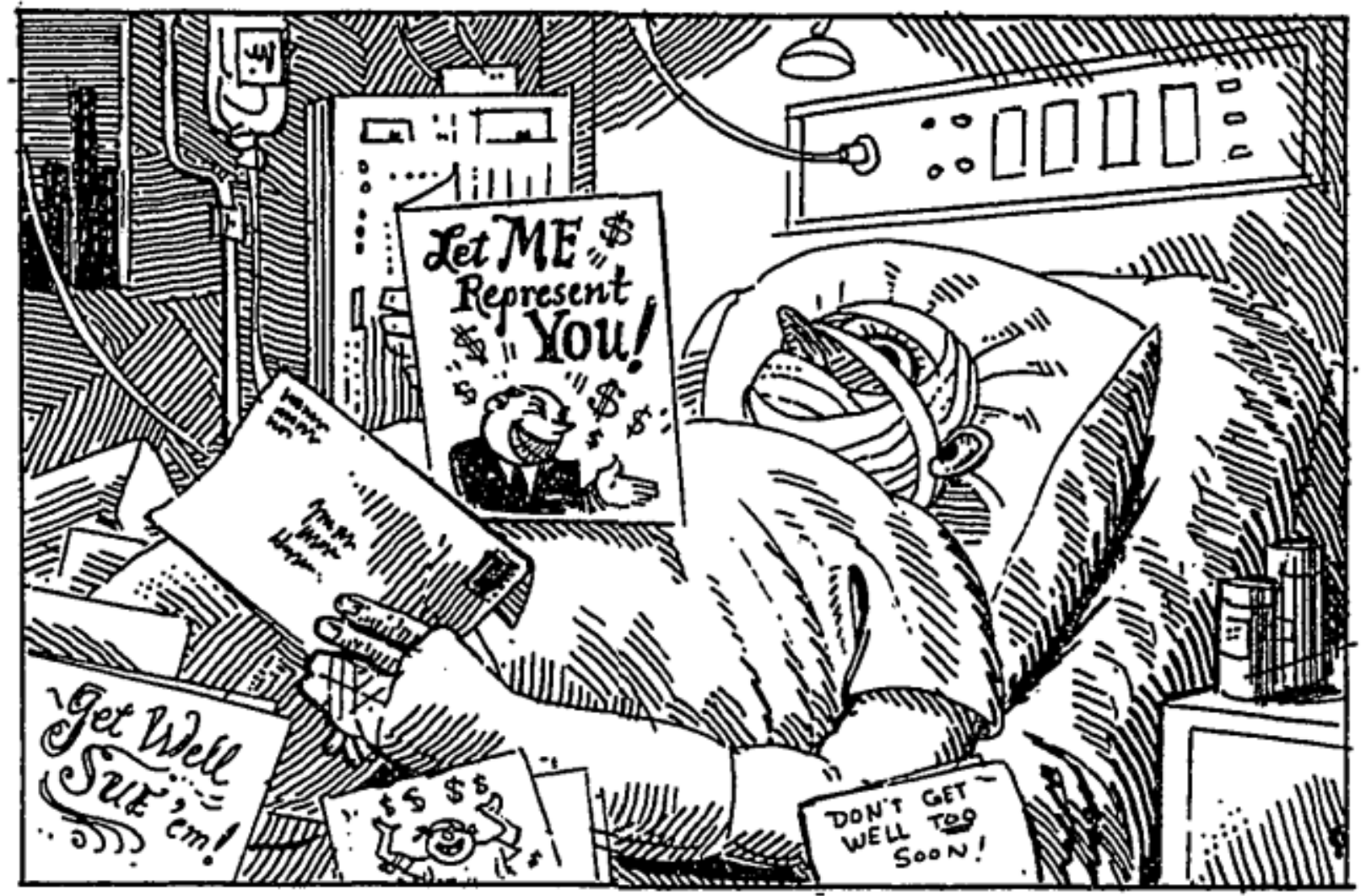

Illustrations by Elliott Banfield 
Illustration for Linda Greenhouse, In the longtime war over lawyer advertising, the latest shot leaves as many wounds as ever, New York Times, June 23, 1995, at A23

\section{Questions:}

1. G. Stewart McHenry was disbarred in 1992 for masturbating in front of one female client and fondling another. He was also disciplined by the bar in 1985 and 1988, for brandishing a gun in his office, hitting a paralegal with a file and refusing to pay her when she quit, improperly withdrawing funds from his client trust account, and drunk driving, among other things.

2. Opponents of bar association rules limiting attorney advertisements and solicitation argue that the rules are motivated by the fear of increased competition and intended to protect the interests of established attorneys. Supporters of those rules argue that they reflect philosophical principles, including an aversion to "ambulance chasing." Which argument do you find more compelling? Can both be true?

3. Justice O'Connor's majority opinion relied on empirical evidence submitted by the bar showing that attorney solicitations sent to people after they or a family member suffered an injury caused harm and were unwanted. Justice Kennedy's dissent questioned the credibility of the empirical evidence and argued that attorney solicitations could help consumers, who didn't realize they had a potential claim or didn't know who to contact. Did you find O'Connor's empirical claims convincing? Do you think they provided adequate evidence of harm to overcome Justice Kennedy's 1st Amendment objections? 


\section{Lawyers' soliciting tactics draw scorn at Bar hearing}

\section{BY MARY DOLAN}

Times Staff Writter

TAMPA - Kenneth Addison was barely a year old when he received his first letter from a lawyer.

Kenneth and his mother, Cecelia Addison, had been in a minor automobile accident, and the lawyer had gotten hold of the accident report.

The lawyer, G. Stewart McHenry, is one of eight lawyers who each week stop by the Tampa Police Department or Hillsborough County Sheriff's Office to pick up copies of hundreds of accident reports.

Their practice concerns the Florida Bar Association, which is examining the methods lawyers use to advertise their services. The Bar relaxed its rules Jan. 1 to permit solicitation by mail after the U.S. Supreme Court ruled that such mailings are a form of advertisement. Some area lawyers say the practice gives their profession a sleazy image and they want the rules tightened.

"It's not a profession anymore. It's like a bunch of sharks in the water," said Michael C. Addison, a Tampa lawyer and Kenneth's father

Michael Addison spoke against the practice of mailing letters to accident victims Tuesday at a meeting of a Florida Bar committee studying lawyer solicitation. Stephen N. Zack, chairman of the committee, said the group will recommend to the Bar whether certain advertising practices by lawyers should be curtailed or forbidden.

Most of the lawyers who spoke at the hearing were opposed to direct mail solicitation.

Oddly, one of them routinely picks up hundreds of accident reports at the police department.

"I am violently opposed to any type of direct mail solicitation," said Edward C. Rood.

Asked afterward why he orders copies of accident reports from Tampa police, Rood said he sends the accident victims letters warning them that they will receive letters from other attorneys and to check their backgrounds. Nowhere in the letters does he suggest that the accident victim call his office, although his telephone number and address are printed on each letter, he said.

Rood also said he did not consider the letters solicitation.

Asked if he considered such letters solicitation,
Zack, the committee chairman, said: "I'd consider that any time a lawyer is putting his or her name in front of a person that it could be solicitation."

Another lawyer who routinely gets accident reports, Barry Caskey, said he does not solicit clients by mail, but gives the reports to other lawyers, with whom he has a "referral arrangement." He would not name the lawyers.

Lawyers are charged from 5 cents to 50 cents a page for the copies. Their bills for police copies last month ranged from $\$ 813$ to $\$ 1,626$.

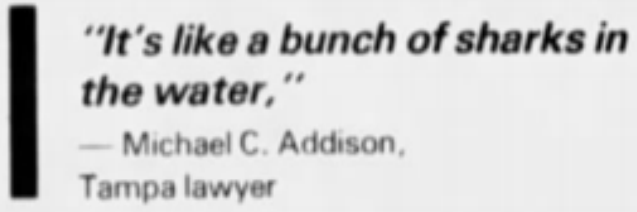

Spokesmen for the Police Department and Sheriff's Office said lawyers have been requesting copies of all serious traffic accident reports for the past few months.

Other lawyers receiving copies of accident reports are: Lillian Joyce, Clay B. Rood, Michael H. Otis and D. Russell Stahl, Bob Joyce and a company called Investigative Enterprises.

All are members of the Florida Bar, said Janice Rowland, administrative secretary to staff counsel.

Only McHenry has a record of violations with the Bar. In 1985, the Florida Supreme Court issued a public reprimand against him for violating disciplinary rules of the Bar, she said.

Rowland said McHenry violated rules that govern the conduct of attorneys, including knowingly engaging in illegal conduct. She could not provide details of the incident.

Rood, the son of Tampa lawyer Edward B. Rood, was found innocent last December of charges that he advised several of his clients to lie under oath.

Spokesmen for the Pinellas County Sheriff's Office and the St. Petersburg Police Department said they knew of of no lawyers coming in to look at accident reports but that it could be happening without them knowing about it.

- Staft writers Kimberly D. Kleman and William Fox contributed to this report.

Tampa Bay Times (St. Petersburg, Florida), Wed., Oct. 7, 1987, at 24 


\section{The Powerful Self-Marketing Of Personal Injury Lawyers}

Children who never come when called will grow up to be doctors.

Children who come before they're called will grow up to be lawyers.

- From the Nolo News, a

quarterly newspaper in California devoted to lawyerly affairs, quoted by Lakeland Ledger columnist Lonnie Brown.

O Sept. 24, the day the Bucs beat the Saints, Emmett C. Lee, Jr., was involved in a collision. As Lee drove from Tampa Stadium, a driver ran a stop sign. Occupants were shaken but $\mathrm{OK}$.

Within 48 hours, Lee, who is Tampa's port director, was inundated with stimulating mail.

"I was sorry to learn of your recent accident," wrote Sherman M. Brod.

"The Public Records of Hillsbor. ough County, Florida, indicate that you were involved in an accident through no fault of your own on the above referenced date," wrote G. Stewart McHenry.

"It is with great remorse and sympathy that I am writing to you and your family after the trauma of having been involved in an automobile accident on the above date through no fault of your own," wrote Anthony P. Prieto.

These are the opening pitches of hungry lawyers. As you may have deduced, barristers who would never dream of joining an ambulance chase apparently think nothing of engaging in a paper chase.

But keep reading. There's more to this story than just lawyers hoist with their own petard. Constitutional rights are at stake. And a lawyers' reform effort. To top it off, a question of crime and punishment.

But first, let us take a last look at the missives aimed at Lee.

Robert T. Joyce of Joyce \& Reyes strikes a consumerist tone: "As a victim of an accident you should be aware that there are numerous benefits you may be entitled to."

Sherman M. Brod is helpful: "Please call me for a free consultation with no obligation to you. No appointment is necessary. If you are confined to a bed or have difficulty getting around, someone may come to your home."

Anthony P. Prieto goes for the scare: "Our experienced staff is ready to protect your rights! Do not expect the Insurance Company of the negligent driver to offer you a fair settlement, because they will not."

G. Stewart McHenry strives to make one point crystal clear:

"IF I DO NOT WIN, YOU DO NOT PAY ANYTHING!"

There are photos, too. Presumably so prospective clients can get a look at them, partners Earle Moffitt and Bob Vessel include in their brochure snapshots of themselves, dedicated and industrious. Caption: "We know what it takes to get you the money you deserve - quickly."

What do these letters tell us? According to the Florida Bar's Board of Governors, hard-sell, self-promotional solicitation is conduct unbefitting a lawyer. Earlier this year, the board proposed to restrict distasteful ads. Testimonials from celebrities and former clients: banned. Dramatization of accidents: banned. Background music: banned. Direct-mail advertising targeted to accident victims: banned.

To fight back, a group of dissident lawyers formed an organization, Citlzens Against Censorship. The American Civil Liberties Union joined the slugging match. So did a Ralph Naderaffiliated watchdog. Public Citizen Litigation Group.

This past summer, the Board of Governors approved the reform package anyway, and the matter would seem to be, if not closed, at least of interest only to lawyers working in the field of personal injury.

But part of the reform package found its way into state law. As of Oct. 1, lawyers may no longer do what the lawyers did who wrote to Emmett Lee. They may not pick up the names of accident victims from police blotters and use them as leads.

Let us ignore, for the moment, the constitutional quandary created when government can publish a public document, but prevent a citizen from writing to a person named in that document. Let us concern ourselves with the letter of the law. (This is crucial because: What do you get when you cross an attorney with the Godfather? Answer: An offer you can't understand.)

The mail-solicitation ban was accomplished via an amendment to Chapter 316 of the Florida Statutes. Language has been inserted: "Acci. dent reports shall not be used for solicitation purposes."

What happens to the lawyer who does solicit from accident reports? Statute 316.655 states: "A violation of any of the provisions of this chapter ... shall be deemed an infraction, as de. fined in Section 318.13(3)."

On to $318.13(3)$. There, we find that an infraction means a "noncriminal violation which is not punishable by incarceration and for which there is no right to a trial by jury or a right to court-appointed counsel." Which brings us to .14, which spells out penalties for noncriminal traffic infractions. Traffic infractions? So the lawyer who writes letters of solicitation gets a traffic ticket? Points on his record?

Does the mail-solicitation ban suggest it is possible to have a crime without a punishment? Is the new law unconstitutional? Unenforceable? Stly? Only a lawyer knows for sure. So ask one. Quick - before he asks you.

The Tampa Tribune (Tampa, Florida), Tues., Oct 31, 1989, at 8 


\section{4: Prosecutorial Misconduct}

Is a dream a lie if it don't come true, or is it something worse $?^{111}$

Prosecutors are responsible for enforcing criminal law. Indeed, for better or worse, prosecutors probably have the most important role in our modern criminal justice system. Among many other things, prosecutors decide who to charge with crimes, which crimes to charge, and whether to offer a plea bargain. And they exercise immense discretion in all of those areas.

In practice, prosecutors play a much more important role in the administration of criminal justice than judges, because only about $3 \%$ of criminal prosecutions go to trial. The overwhelming majority of criminal defendants plead guilty, and the prosecutors determine what sentence the defendant will receive, with limited oversight from the judge. And prosecutors strongly encourage defendants to plead guilty, rather than go to trial. If a defendant refuses to plead guilty, prosecutors typically charge aggressively and request the longest possible sentence.

At least in theory, the paramount duty of the prosecutor is to seek justice, not a conviction. As Justice Sutherland observed in Berger v. United States, 295 U.S. 78 (1935), a prosecutor

is the representative not of an ordinary party to a controversy, but of a sovereignty whose obligation to govern impartially is as compelling as its obligation to govern at all; and whose interest, therefore, in a criminal prosecution is not that it shall win a case, but that justice shall be done. As such, he is in a peculiar and very definite sense the servant of the law, the twofold aim of which is that guilt shall not escape or innocence suffer. He may prosecute with earnestness and vigor - indeed, he should do so. But, while he may strike hard blows, he is not at liberty to strike foul ones. It is as much his duty to refrain from improper methods calculated to produce a wrongful conviction as it is to use every legitimate means to bring about a just one.

Accordingly, prosecutors should never employ improper means, even to achieve results they believe to be just. They should always be candid with the court and the defense, and should never suppress exculpatory evidence or make improper statements. As Justice Jackson observed:

The qualities of a good prosecutor are as elusive and as impossible to define as those which make a gentleman. And those who need to be told would not understand it anyway. A sensitiveness to fair play and sportsmanship is perhaps the best protection against the abuse of power, and the citizens safety lies in the prosecutor who tempers zeal with human kindness, who seeks truth and not victims, who serves the law and not factional purposes, and who approaches his task with humility.

${ }^{111}$ Bruce Springsteen, The River, The River (1980). 
The American Bar Association has described the duties of a prosecutor in Model Rule of Professional Responsibility 3.8 and in a separate set of model rules governing the prosecution function. Most jurisdiction have adopted some version of these rules. But their effectiveness is limited by the discretion and immunity of prosecutors. For one thing, it is often difficult or impossible to know when prosecutors have violated their professional duties. Even if they have, they are usually protected by absolute immunity. And historically, courts have been reluctant to impose meaningful sanctions on prosecutors, even for egregious misconduct.

\section{Prosecution Function Standard 3-1.2: The Function of the Prosecutor}

a. The office of prosecutor is charged with responsibility for prosecutions in its jurisdiction.

b. The prosecutor is an administrator of justice, an advocate, and an officer of the court; the prosecutor must exercise sound discretion in the performance of his or her functions.

c. The duty of the prosecutor is to seek justice, not merely to convict.

d. It is an important function of the prosecutor to seek to reform and improve the administration of criminal justice. When inadequacies or injustices in the substantive or procedural law come to the prosecutor's attention, he or she should stimulate efforts for remedial action.

e. It is the duty of the prosecutor to know and be guided by the standards of professional conduct as defined by applicable professional traditions, ethical codes, and law in the prosecutor's jurisdiction. The prosecutor should make use of the guidance afforded by an advisory council.

\section{Model Rule 3.8: Special Responsibilities of a Prosecutor}

The prosecutor in a criminal case shall:

a. refrain from prosecuting a charge that the prosecutor knows is not supported by probable cause;

b. make reasonable efforts to assure that the accused has been advised of the right to, and the procedure for obtaining, counsel and has been given reasonable opportunity to obtain counsel;

c. not seek to obtain from an unrepresented accused a waiver of important pretrial rights, such as the right to a preliminary hearing;

d. make timely disclosure to the defense of all evidence or information known to the prosecutor that tends to negate the guilt of the accused or mitigates the offense, and, in connection with sentencing, disclose to the defense and to the tribunal all unprivileged mitigating information known to the prosecutor, except when the prosecutor is relieved of this responsibility by a protective order of the tribunal;

e. not subpoena a lawyer in a grand jury or other criminal proceeding to present evidence about a past or present client unless the prosecutor reasonably believes:

1. the information sought is not protected from disclosure by any applicable privilege; 
2. the evidence sought is essential to the successful completion of an ongoing investigation or prosecution; and

3. there is no other feasible alternative to obtain the information;

f. except for statements that are necessary to inform the public of the nature and extent of the prosecutor's action and that serve a legitimate law enforcement purpose, refrain from making extrajudicial comments that have a substantial likelihood of heightening public condemnation of the accused and exercise reasonable care to prevent investigators, law enforcement personnel, employees or other persons assisting or associated with the prosecutor in a criminal case from making an extrajudicial statement that the prosecutor would be prohibited from making under Rule 3.6 or this Rule.

g. When a prosecutor knows of new, credible and material evidence creating a reasonable likelihood that a convicted defendant did not commit an offense of which the defendant was convicted, the prosecutor shall:

1. promptly disclose that evidence to an appropriate court or authority, and

2. if the conviction was obtained in the prosecutor's jurisdiction,

i. promptly disclose that evidence to the defendant unless a court authorizes delay, and

ii. undertake further investigation, or make reasonable efforts to cause an investigation, to determine whether the defendant was convicted of an offense that the defendant did not commit.

h. When a prosecutor knows of clear and convincing evidence establishing that a defendant in the prosecutor's jurisdiction was convicted of an offense that the defendant did not commit, the prosecutor shall seek to remedy the conviction.

\section{Model Rule 3.8: Comments}

1. A prosecutor has the responsibility of a minister of justice and not simply that of an advocate. This responsibility carries with it specific obligations to see that the defendant is accorded procedural justice, that guilt is decided upon the basis of sufficient evidence, and that special precautions are taken to prevent and to rectify the conviction of innocent persons. The extent of mandated remedial action is a matter of debate and varies in different jurisdictions. Many jurisdictions have adopted the ABA Standards of Criminal Justice Relating to the Prosecution Function, which are the product of prolonged and careful deliberation by lawyers experienced in both criminal prosecution and defense. Competent representation of the sovereignty may require a prosecutor to undertake some procedural and remedial measures as a matter of obligation. Applicable law may require other measures by the prosecutor and knowing disregard of those obligations or a systematic abuse of prosecutorial discretion could constitute a violation of Rule 8.4.

7. When a prosecutor knows of new, credible and material evidence creating a reasonable likelihood that a person outside the prosecutor's jurisdiction was convicted of a crime that the person did not commit, paragraph (g) requires prompt disclosure to the court or other appropriate authority, such as the chief prosecutor of the jurisdiction where the conviction occurred. If the conviction was obtained in the prosecutor's jurisdiction, paragraph $(\mathrm{g})$ requires the prosecutor to examine the evidence and undertake further 
investigation to determine whether the defendant is in fact innocent or make reasonable efforts to cause another appropriate authority to undertake the necessary investigation, and to promptly disclose the evidence to the court and, absent court-authorized delay, to the defendant. Consistent with the objectives of Rules 4.2 and 4.3, disclosure to a represented defendant must be made through the defendant's counsel, and, in the case of an unrepresented defendant, would ordinarily be accompanied by a request to a court for the appointment of counsel to assist the defendant in taking such legal measures as may be appropriate.

8. Under paragraph (h), once the prosecutor knows of clear and convincing evidence that the defendant was convicted of an offense that the defendant did not commit, the prosecutor must seek to remedy the conviction. Necessary steps may include disclosure of the evidence to the defendant, requesting that the court appoint counsel for an unrepresented indigent defendant and, where appropriate, notifying the court that the prosecutor has knowledge that the defendant did not commit the offense of which the defendant was convicted.

9. A prosecutor's independent judgment, made in good faith, that the new evidence is not of such nature as to trigger the obligations of sections $(\mathrm{g})$ and $(\mathrm{h})$, though subsequently determined to have been erroneous, does not constitute a violation of this Rule. 


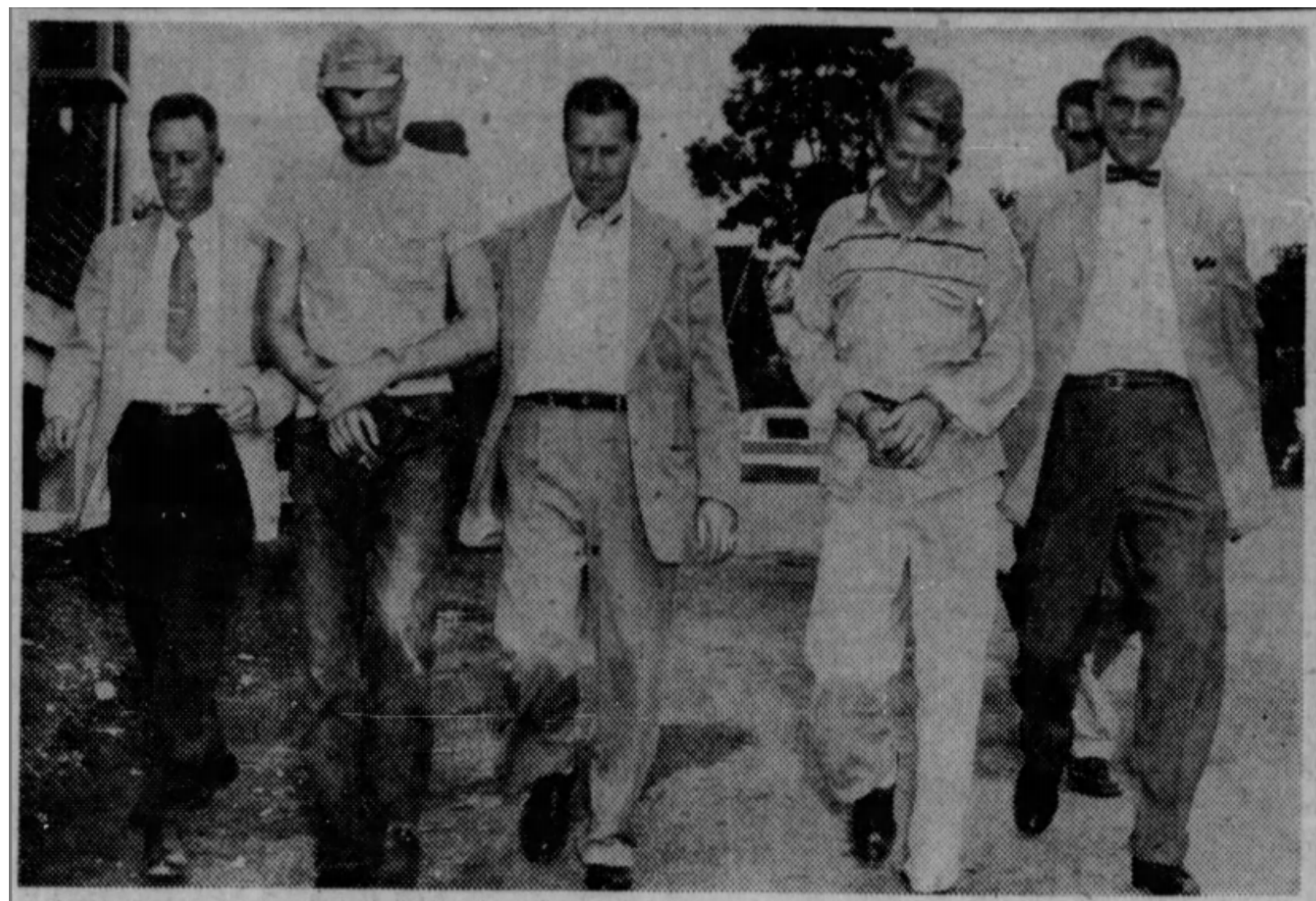

ACCUSED OF MURDER-Charles D. Boblit, 24, and John L. Brady, 25, charged by Anne Arundel county police with the murder of William Brooks on June 27, leave the Fermdale Police Station today after further questioning. Left to right are Cpl. Richard S. Disney, Boblit, Cpl. Bernard Kiessling, Brady, Sgt. Maxwell Frye (partially obscure) and Sgt. Edward Praley. Brady allegedly confessed to the bludgeon-murder in Cuba last week and told police there where he and a companion, allegedly Boblit, had tossed Brooks's body out of a car on a lonely county road. Both men are being held in the jail at Annapolis.

The Evening Sun (Baltimore, Maryland), July 10, 1958, at 28

Brady v. Maryland, 373 U.S. 83 (1963)

Summary: John Leo Brady and Charles Donald Boblit were charged with the murder of William Brooks and tried separately. Brady confessed to participating in the murder, but claimed that Boblit actually killed Brooks. The prosecutor suppressed a confession in which Boblit admitted killing Brooks, and Brady was sentenced to death. The Supreme Court reversed Brady's sentence, holding that the Due Process Clause of the 14th Amendment requires prosecutors to disclose all exculpatory evidence.

Opinion of the Court by MR. JUSTICE DOUGLAS, announced by MR. JUSTICE BRENNAN.

Petitioner and a companion, Boblit, were found guilty of murder in the first degree and were sentenced to death, their convictions being affirmed by the Court of Appeals of Maryland. Their trials were separate, petitioner being tried first. At his trial Brady took the stand and admitted his 
participation in the crime, but he claimed that Boblit did the actual killing. And, in his summation to the jury, Brady's counsel conceded that Brady was guilty of murder in the first degree, asking only that the jury return that verdict "without capital punishment." Prior to the trial petitioner's counsel had requested the prosecution to allow him to examine Boblit's extrajudicial statements. Several of those statements were shown to him; but one dated July 9, 1958, in which Boblit admitted the actual homicide, was withheld by the prosecution and did not come to petitioner's notice until after he had been tried, convicted, and sentenced, and after his conviction had been affirmed.

Petitioner moved the trial court for a new trial based on the newly discovered evidence that had been suppressed by the prosecution. Petitioner's appeal from a denial of that motion was dismissed by the Court of Appeals without prejudice to relief under the Maryland Post Conviction Procedure Act. The petition for post-conviction relief was dismissed by the trial court; and on appeal the Court of Appeals held that suppression of the evidence by the prosecution denied petitioner due process of law and remanded the case for a retrial of the question of punishment, not the question of guilt. The case is here on certiorari.

The crime in question was murder committed in the perpetration of a robbery. Punishment for that crime in Maryland is life imprisonment or death, the jury being empowered to restrict the punishment to life by addition of the words "without capital punishment." In Maryland, by reason of the state constitution, the jury in a criminal case are "the Judges of Law, as well as of fact." The question presented is whether petitioner was denied a federal right when the Court of Appeals restricted the new trial to the question of punishment.

We agree with the Court of Appeals that suppression of this confession was a violation of the Due Process Clause of the Fourteenth Amendment.

This ruling is an extension of Mooney $v$. Holohan, where the Court ruled on what nondisclosure by a prosecutor violates due process:

It is a requirement that cannot be deemed to be satisfied by mere notice and hearing if a State has contrived a conviction through the pretense of a trial which in truth is but used as a means of depriving a defendant of liberty through a deliberate deception of court and jury by the presentation of testimony known to be perjured. Such a contrivance by a State to procure the conviction and imprisonment of a defendant is as inconsistent with the rudimentary demands of justice as is the obtaining of a like result by intimidation.

In Pyle v. Kansas, we phrased the rule in broader terms:

Petitioner's papers are inexpertly drawn, but they do set forth allegations that his imprisonment resulted from perjured testimony, knowingly used by the State authorities to obtain his conviction, and from the deliberate suppression by those same authorities of evidence favorable to him. These allegations sufficiently charge a deprivation of rights 
guaranteed by the Federal Constitution, and, if proven, would entitle petitioner to release from his present custody.

The Third Circuit in the Baldi case construed that statement in Pyle v. Kansas to mean that the "suppression of evidence favorable" to the accused was itself sufficient to amount to a denial of due process. In Napue v. Illinois, we extended the test formulated in Mooney v. Holohan when we said: "The same result obtains when the State, although not soliciting false evidence, allows it to go uncorrected when it appears."

We now hold that the suppression by the prosecution of evidence favorable to an accused upon request violates due process where the evidence is material either to guilt or to punishment, irrespective of the good faith or bad faith of the prosecution.

The principle of Mooney $v$. Holohan is not punishment of society for misdeeds of a prosecutor but avoidance of an unfair trial to the accused. Society wins not only when the guilty are convicted but when criminal trials are fair; our system of the administration of justice suffers when any accused is treated unfairly. An inscription on the walls of the Department of Justice states the proposition candidly for the federal domain: "The United States wins its point whenever justice is done its citizens in the courts." ${ }^{112}$ A prosecution that withholds evidence on demand of an accused which, if made available, would tend to exculpate him or reduce the penalty helps shape a trial that bears heavily on the defendant. That casts the prosecutor in the role of an architect of a proceeding that does not comport with standards of justice, even though, as in the present case, his action is not "the result of guile."

\section{Questions:}

1. The story behind Brady $v$. Maryland is peculiar and sad. A thorough narrative account is available here. Essentially, in 1958, John Leo Brady and his friend Charles Donald Boblit decided to rob a bank, because Brady was in love with Boblit's married sister Nancy, and had promised her $\$ 35,000$. They needed a getaway car, so they tried to steal one from Brady's friend William Brooks, a disabled factory worker. The plan was to kidnap Brooks and release him after the bank robbery, but in the heat of the moment, Boblit strangled him. They split the $\$ 255.30$ in Brooks wallet, and Brady fled to Cuba. In the meantime, the police soon found Brooks's body and went looking for Brady and Boblit. They arrested Boblit, who took them to the body, and accused Brady of the murder. Brady turned himself in at the United States Embassy and was extradited back to

112 Judge Simon E. Sobeloff when Solicitor General put the idea as follows in an address before the Judicial Conference of the Fourth Circuit on June 29, 1954:

The Solicitor General is not a neutral, he is an advocate; but an advocate for a client whose business is not merely to prevail in the instant case. My client's chief business is not to achieve victory but to establish justice. We are constantly reminded of the now classic words penned by one of my illustrious predecessors, Frederick William Lehmann, that the Government wins its point when justice is done in its courts. 
Maryland. Both Brady and Boblit confessed and were charged with first-degree murder. The only question was who actually killed Brooks. Boblit gave five confessions. In the first four, he accused Brady of the murder. But in the fifth, he admitted that he was the murderer. Brady and Boblit were tried separately, and the prosecutor in Brady's case suppressed Boblit's fifth confession. Brady was sentenced to death, but Brady $v$. Maryland overturned the sentence, on the basis of the suppressed fifth confession. Afterward, Maryland had to resentence Brady, but never did. In 1974, the Governor of Maryland granted Brady clemency and he was paroled. He lived a quiet life, and died in 2009.

2. Brady's attorney, E. Clinton Bamberger, Jr., was a Baltimore corporate lawyer who represented criminal defendants pro bono. In 1965, he quit his firm and became the first director of the the Office of Economic Opportunity Legal Services Program, which became the Legal Services Corporation. You can read Bamberger's account here and find a history of the Legal Services Corporation here.

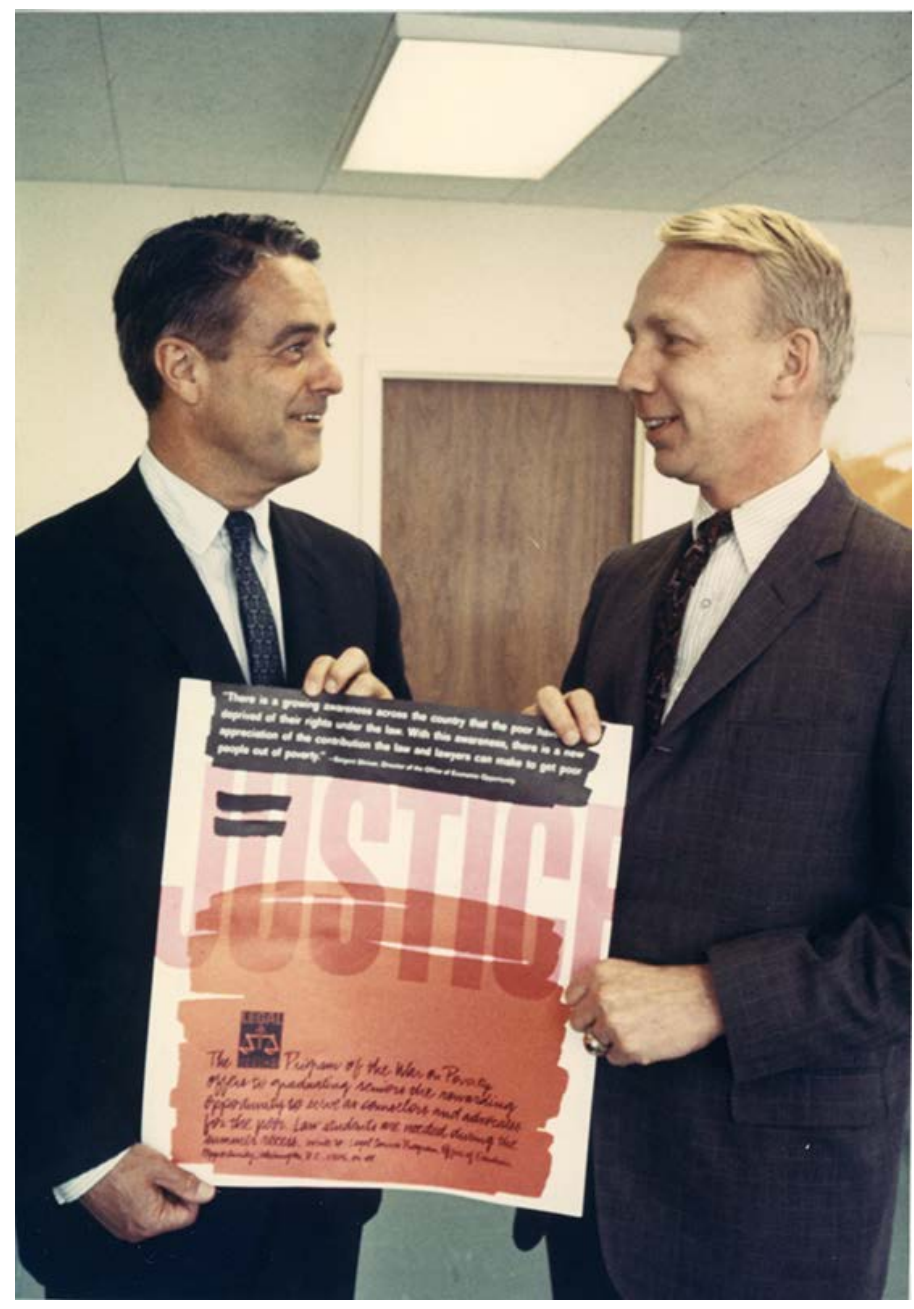

Sargent Shriver \& Clint Bamberger (1966)

Taylor v. Kavanagh, 640 F. 2d 450 (2d Cir. 1981) 
Summary: In 1974, Rodney Taylor was arrested and indicted for burglary, and in 1975 he was arrested again for burglary. Assistant District Attorney Michael Kavanagh told Taylor the grand jury had returned an indictment on the 1975 charge, so Taylor pleaded guilty to both charges, in exchange for Kavanagh's promise not to recommend a sentence. But Taylor later tried to withdraw his plea, because he was never indicted on the 1975 charge and Kavanagh withdrew his promise. The trial court denied Taylor's motion, Kavanagh recommended the maximum sentence, and the court imposed a 6 year sentence. The appellate court reversed and remanded for resentencing because Kavanagh failed to honor his promise, but Taylor received the same sentence. Accordingly, Taylor filed a § 1983 action against Kavanagh. The district court granted Kavanagh's motion for judgment on the pleadings and the circuit court affirmed, holding that he was protected by absolute immunity.

IRVING R. KAUFMAN, Circuit Judge:

Plaintiff Rodney Taylor, pro se, instituted this action against Michael Kavanagh, an Assistant District Attorney for Ulster County, New York. Claiming that Kavanagh lied to him during plea negotiations and violated the terms of the negotiated plea agreement, Taylor seeks to set aside a criminal conviction resulting from his guilty plea. He also requests compensatory and punitive damages amounting to $\$ 5.5$ million.

I.

Taylor was arrested in Kingston, New York, in October 1974, and on December 20, 1974, he was indicted and charged with third degree burglary and attempted grand larceny. He was taken into custody again on August 14, 1975, and charged with third degree burglary and criminal possession of a controlled substance in the seventh degree.

On June 9, 1976, Taylor, represented by counsel, pleaded guilty in the Ulster County Court to the third degree burglary charge contained in the December 1974 indictment. This plea was in full satisfaction of the charges resulting from both the October 1974 and the August 1975 arrests, although no indictment concerning the events of August 1975 had ever been returned. The court was advised that Taylor and Assistant District Attorney Kavanagh had agreed that no recommendation or statement would be made relating to the sentence to be imposed.

On June 7,1977 , Taylor moved in the state court to vacate his guilty plea, claiming that 1) during plea negotiations and at the time he entered his plea, the Assistant District Attorney had misrepresented to him and the court that a grand jury had returned an indictment on the charges relating to the August 1975 arrest; and 2) Kavanagh had indicated he would not abide by his promise not to recommend any sentence. This motion was denied.

At the sentencing proceeding in February 1978, Kavanagh made a lengthy and detailed statement concerning Taylor's prior criminal record and recommended that he receive the maximum punishment. The court then sentenced Taylor to an indeterminate term of six years, 
with a minimum term of two years. Taylor appealed the judgment of conviction, but the Appellate Division affirmed, ordering, however, that Taylor be resentenced. The court stated that although the misrepresentation by the prosecutor concerning the existence of the second indictment was harmless error, resentencing was necessary because the prosecutor failed to honor his promise. Taylor eventually was resentenced to the same term he had previously received.

Taylor filed the instant action in October 1978, claiming he was induced to plead guilty by the Assistant District Attorney's misrepresentations concerning the alleged second indictment. $\mathrm{He}$ also asserted that he should be awarded damages for Kavanagh's breach of the plea bargain.

The defendant moved for judgment on the pleadings, which Judge Griesa granted in July 1980. He reasoned that because a prosecutor does not have custody over a convicted prisoner, Kavanagh was not a proper defendant in the suit to set aside Taylor's conviction. Extending the doctrine of absolute immunity to a prosecutor's plea bargaining activities. Judge Griesa also held that Kavanagh was immune from liability, and dismissed the action. We affirm.

II.

We note at the outset that when a prisoner is challenging his imprisonment in state facilities, his sole federal remedy is a writ of habeas corpus. Taylor followed this approach in September 1979, seeking a writ in the United States District Court for the Northern District of New York. Judge Port dismissed the petition and denied a certificate of probable cause. Taylor did not appeal this order. Accordingly, we hold that he cannot raise this request to be set free in the instant civil rights action.

Taylor's damages claim also fails because the Assistant District Attorney's conduct in the plea bargaining negotiations and the sentencing proceeding in state court is protected by the doctrine of absolute prosecutorial immunity. Imbler v. Pachtman, 424 U.S. 409 (1976). Imbler provided the basis for the development of a functional approach to the immunity question. The Court held that absolute immunity from $\S 1983$ liability exists for those prosecutorial activities "intimately associated with the judicial phase of the criminal process." These protected "quasijudicial" activities include the initiation of a prosecution and the presentation of the Government's case.

Absolute protection does not extend, however, to a prosecutor's investigative or administrative acts. Accordingly, we have recognized that where prosecutors act in this capacity, only the qualified "good faith" immunity that protects, for example, police officers, is available.

The task of determining whether a particular activity is better characterized as "quasi-judicial" and subject to absolute immunity, or "investigative" and subject to only qualified "good faith" immunity requires more than the mechanical application of labels. An examination of the functional nature of prosecutorial behavior, rather than the status of the person performing the act, is determinative. Thus, a prosecutor is insulated from liability where his actions directly 
concern the pre-trial or trial phases of a case. For example, the swearing of warrants to insure a witness's attendance at trial, the falsification of evidence and the coercion of witnesses, or the failure to drop charges until immediately before trial, have been held to be prosecutorial activities for which absolute immunity applies. Similarly, because a prosecutor is acting as an advocate in a judicial proceeding, the solicitation and subornation of perjured testimony, the withholding of evidence, or the introduction of illegally-seized evidence at trial does not create liability in damages. The rationale for this approach is sound, for these protected activities, while deplorable, involve decisions of judgment affecting the course of a prosecution. The efficient, and just, performance of the prosecutorial function would be chilled if Government attorneys were forced to worry that their choice of trial strategy and tactics could subject them to monetary liability, or at best, the inconvenience of proving a "good faith" defense to a § 1983 action.

In contrast, activities in which a prosecutor engages that are independent of prosecution are not protected by the doctrine of absolute immunity. For example, only a "good faith" immunity is available where a prosecutor testifies falsely as a witness, distributes extraneous statements to the press designed to harm a suspect's reputation, or participates in an illegal search that violates a suspect's Fourth Amendment rights.

Decisions to engage in conduct of this character are not directly related to the delicate judgments prosecutors must make concerning the development of the Government's case. The "investigatory" and "administrative" work involved in testifying before a grand jury, accumulating evidence, and disseminating information to the press is analogous to the tasks performed by the police, and therefore only the same qualified "good faith" immunity is available.

This functional approach requires us to evaluate plea bargaining in light of the general purpose of the absolute immunity doctrine. Judge Griesa properly recognized that the purpose of the doctrine "is to insure that a prosecutor will perform his difficult function with complete vigor and independence, undeterred by the spectre of liability for damages with respect to his activities." Learned Hand has told us that the doctrine we apply today supports the just administration of the criminal law, for we all would suffer if prosecutors "who try to do their duty were subject to the constant dread of retaliation." The threat of $\S 1983$ liability would inhibit prosecutors from exercising independent judgment and would divert their attention from the immediate matters at hand.

III.

We are satisfied that a prosecutor's activities in the plea bargaining context merit the protection of absolute immunity. The plea negotiation is an "essential component" of our system of criminal justice. It is at this stage that the prosecutor evaluates the evidence before him, determines the strength of the Government's case, and considers the societal interest in disposing of the case by a negotiated guilty plea. The effective negotiation of guilty pleas would be severely chilled if a prosecutor were constantly concerned with the possibility of ruinous personal liability for judgments and decisions made at this critical stage of the criminal process. 
Moreover, reference to the type of harm suffered from the alleged misconduct during a plea negotiation demonstrates that defendant Kavanagh should be afforded absolute immunity in this case. We recently noted that there can be no monetary liability for injuries related solely to the prosecution itself. Thus, if as a result of prosecutorial misconduct, a defendant is compelled to face prosecution, or to suffer imprisonment or pretrial detention, the harm cannot be redressed via a $\S 1983$ civil rights suit. But, where the alleged harm is inflicted independently from the prosecution - for example, the damage to reputation caused by a prosecutor's dissemination of false information to the press or the violation of Fourth Amendment privacy rights resulting from a prosecutor's authorization of an illegal search - the prosecutor cannot rely on the blanket protection of absolute immunity. In this case, the only harm caused by Kavanagh's purported misrepresentations and his failure to abide by a promise was imprisonment, an injury for which the Imbler doctrine of immunity protects the prosecutor.

Finally, we note that by extending the doctrine of absolute immunity to a prosecutor's plea bargaining activities, we do not condone Kavanagh's alleged misconduct. Prosecutorial abuses can and should be remedied at the trial and appellate levels, as well as by state and federal post-conviction collateral procedures. Relief for misconduct committed during a plea negotiation includes the setting aside of the plea or ordering specific performance of the agreement. ${ }^{113}$ In this case, Taylor raised vigorous objections to Kavanagh's conduct in state court. He also employed the federal habeas corpus procedure, without success. His failure to prevail in both the state and federal forums cannot justify the creation of another remedy, one which would impose a tremendous burden on society by severely undercutting prosecutorial independence and morale.

\section{Questions:}

1. The New York Times reported on Taylor v. Kavanagh here.

2. In Imbler v. Pachtman, the Supreme Court held that prosecutors are protected by absolute immunity from tort liability under $\S 1983$ for the exercise of their prosecutorial powers. Accordingly, even manifest abuse of those powers cannot create tort liability for the prosecutor or the government, although it can be the basis for discipline. The Supreme Court held that absolute immunity is necessary in order to protect prosecutorial independence. Do you agree?

${ }^{113}$ Prosecutors are also subject to professional discipline for their misconduct. 


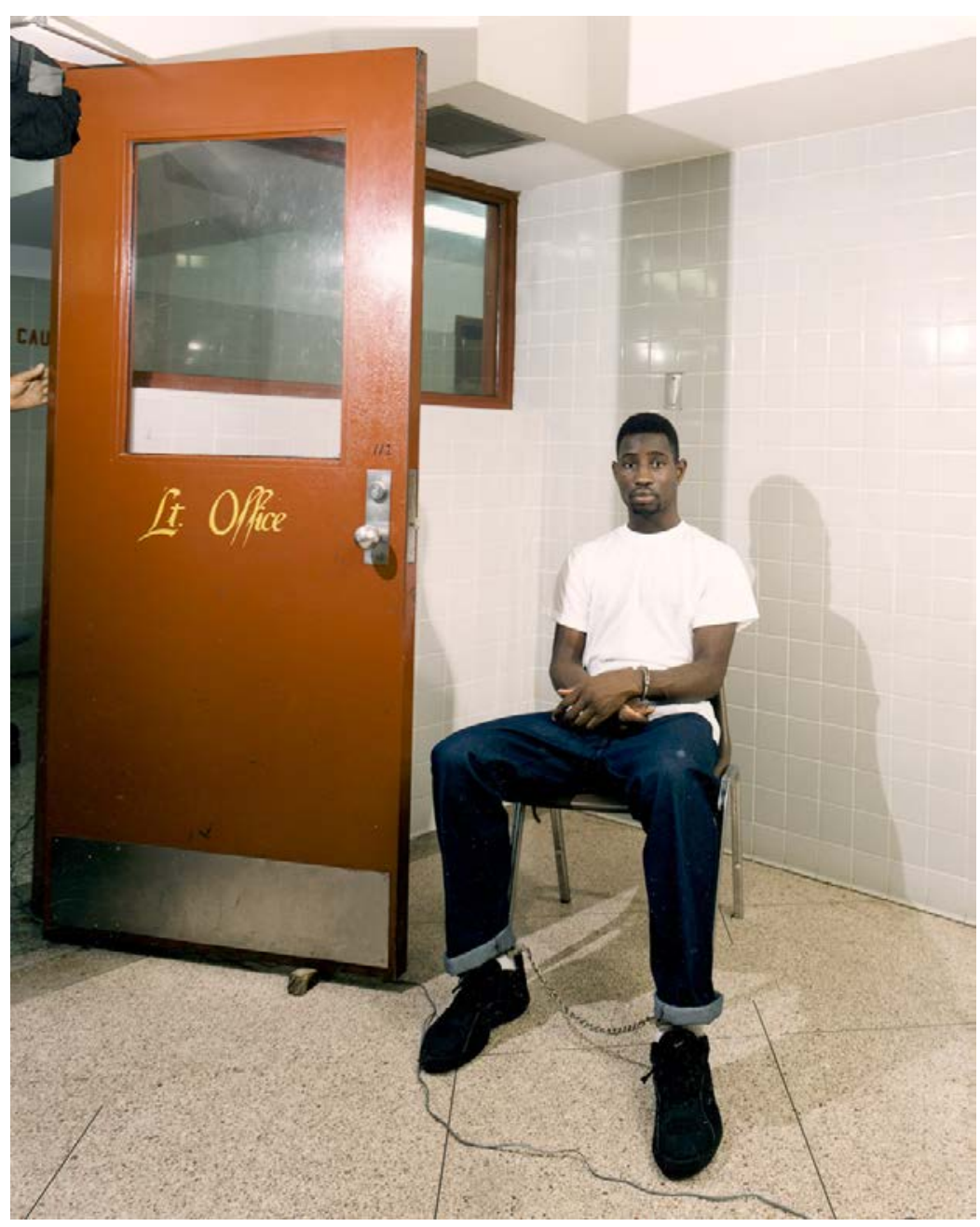

Shareef Cousin ( 1999)

In re Jordan, 913 So. 2d 775 (La. 2005)

Summary: Shareef Cousin was convicted of the murder of Michael Gerardi and sentenced to death, based on the eyewitness testimony of Connie Babin. However, prosecutor Roger Jordan suppressed Babin's testimony that she was not wearing contact lenses during the murder. Cousin was exonerated and the Office of Disciplinary Counsel pursued charges against Jordan. The Louisiana Supreme Court eventually concluded that Jordan had violated Rule 3.8(d) and imposed a three-month suspension, deferred.

TRAYLOR, J.

This attorney disciplinary matter arises from formal charges filed by the Office of Disciplinary Counsel against respondent, Roger W. Jordan, Jr., a former Orleans Parish prosecutor.

UNDERLYING FACTS AND PROCEDURAL HISTORY 
On April 22, 2003, the ODC filed one count of formal charges against respondent, alleging that he violated Rules $3.8(\mathrm{~d})^{114}$ and $8.4(\mathrm{a})^{115}$ of the Rules of Professional Conduct by failing to timely disclose to the defense evidence tending to negate the guilt of the accused or mitigate the offense. The formal charges against respondent arise from the capital prosecution of Shareef Cousin and respondent's undisputed failure to turn over an eyewitness's statement to the defense.

\section{FACTS AND PROCEDURAL HISTORY OF STATE V. COUSIN:}

Before addressing the merits of the case, it is necessary to discuss, in some detail, the underlying facts and procedural history of Shareef Cousin's criminal case.

On March 2, 1995, Michael Gerardi was shot at point-blank range during an armed robbery attempt outside the Port of Call restaurant in New Orleans. Connie Ann Babin, Mr. Gerardi's date that evening and the only eyewitness to the murder, gave three separate statements to the New Orleans Police Department during the homicide investigation. When questioned on the night of the murder, a "visibly shaken" Ms. Babin told the police that she "did not get a good look at the perpetrators and probably could not identify them." In the second statement, which was tape recorded by police at Ms. Babin's home on March 5, 1995, three days after the murder, Ms. Babin was asked by a New Orleans Police Department detective whether she could "describe the person who did the shooting, his clothing?" In response, Ms. Babin said that she remembered the shooter was wearing an oversized denim jacket. She continued:

I don't know, it was dark and I did not have my contacts nor my glasses so I'm coming at this at a disadvantage. I ... you know you could see outlines and shapes and things that stick out, but er ... the socks, I remember the colorful socks, because he kept drawing my attention to it when he kept fidgeting at his ankle area.

Ms. Babin went on to describe the shooter's hair and to say that the shooter was in his late teens and five feet seven or eight inches tall. After providing this description, Ms. Babin stated:

As he looked to me ... I keep getting this vision of a young man with, with an older man's face ... er I don't know that if this is coming ... er somewhere, or if I really did see this person ... if this is just coming from my imagination or what, but I ... every time I go over

${ }^{114}$ Rule 3.8 of the Rules of Professional Conduct provides in pertinent part as follows:

The prosecutor in a criminal case shall:

(d) Make timely disclosure to the defense of all evidence or information known to the prosecutor that tends to negate the guilt of the accused or mitigates the offense, except when the prosecutor is relieved of this responsibility by a protective order of the tribunal.

${ }^{115}$ Rule 8.4 of the Rules of Professional Conduct provides, in pertinent part: It is professional misconduct for a lawyer to:

(a) Violate or attempt to violate the Rules of Professional Conduct, knowingly assist or induce another to do so, or do so through the acts of another. 
it and close my eyes er ... I remember thinking that he had an older man's face or a young body, on a young person ... how I visualize that, I don't know.

On March 25, 1995, three weeks after the murder, Ms. Babin viewed a photographic lineup presented by the police and positively identified sixteen-year old Shareef Cousin as the shooter. Mr. Cousin was arrested a short time later and indicted for the first degree murder of Mr. Gerardi.

In the summer of 1995, the criminal case was assigned to respondent, then an assistant district attorney in Orleans Parish. When respondent was first assigned the case, he recalls that there were three identification witnesses. However, Ms. Babin was the only witness to positively identify Mr. Cousin.

In preparing for trial, respondent interviewed Ms. Babin. She informed him that she is nearsighted and only needs her contacts or glasses for nighttime driving, but not to see at close distances. Considering this information, respondent unilaterally determined that the absence of contacts or glasses on the night of the murder did not affect Ms. Babin's identification of Mr. Cousin as the shooter.

Respondent testified at his disciplinary hearing that he believed Ms. Babin's second statement provided significant additional details that tended to corroborate her identification of Mr. Cousin, especially the observation of the killer as having "an old man's face" on "a young person's body." Respondent therefore concluded that, in his judgment, Ms. Babin's second statement was not material exculpatory evidence to which the defense would be entitled under Brady v. Maryland. Accordingly, he did not produce that statement to Mr. Cousin's attorneys in response to their motion for the production of exculpatory evidence. Respondent has never maintained that he was unaware of his obligation as a prosecutor to disclose exculpatory evidence pursuant to Brady.

Prior to the trial, Mr. Cousin's defense team filed a motion to suppress Ms. Babin's identification of Mr. Cousin. Ms. Babin testified at the suppression hearing, and, in response to questions by respondent, explained the manner by which she came to identify Mr. Cousin in the photographic lineup conducted by the NOPD. On cross-examination, Mr. Cousin's attorney questioned Ms. Babin as to whether she had given a description of the perpetrator to the police "when they questioned you about this case." Ms. Babin testified she described the perpetrator as youthful, slim, slightly shorter than Mr. Gerardi, with short cropped hair and a very distinctive "unusual" or "evil-looking" face. Mr. Cousin's attorney also asked whether Ms. Babin told the police "about any characteristics that you felt were outstanding." Ms. Babin said that she could only recall stating "that he had an older-looking face on a younger body." While Mr. Cousin's attorney attempted to discover whether or not Ms. Babin had given any additional descriptions to anyone else prior to the photographic lineup, respondent objected, and the question was rephrased. Eventually, Mr. Cousin's attorney questioned Ms. Babin as to whether she had provided any additional statements to the police other than the night of the murder and the photographic lineup. Ms. Babin testified that her description had been consistent throughout. Thus, the only 
way that the defense could have known about Statement 2 would have been disclosure by respondent.

Ms. Babin testified at trial and repeated her positive identification of Mr. Cousin. Mr. Cousin was convicted of first degree murder. The same jury subsequently sentenced him to death in a bifurcated penalty phase.

Several days after the completion of the guilt phase of the trial but before the penalty phase, a copy of Statement 2 was delivered anonymously to defense counsel. On appeal, the defense raised as error respondent's failure to produce Statement 2 prior to trial. This Court did not reach that issue. Instead, a unanimous Court reversed Mr. Cousin's conviction and death sentence based on the erroneous admission of a witness' testimony as impeachment evidence and respondent's improper use of that evidence in closing argument. Nevertheless, the Court commented in footnotes that Ms. Babin's second statement was "obviously" exculpatory, material to the issue of guilt, and "clearly" should have been produced to the defense under Brady and Kyles v. Whitley.

Following this court's decision in Cousin, the Orleans Parish District Attorney's Office elected not to retry Mr. Cousin for the murder of Michael Gerardi.

\section{DISCIPLINARY PROCEEDINGS}

\section{DISCIPLINARY COMPLAINT}

In May 1998, Mr. Cousin and his sister, Tonya Cropper, filed a complaint against respondent with the ODC, alleging, among other things, that respondent wrongfully suppressed Brady evidence by failing to disclose Ms. Babin's second statement. In his July 1998 response to the complaint, respondent asserted his belief that the witness's statement at issue was more inculpatory than exculpatory, and his determination that disclosure of the statement was not required by Brady. Respondent reiterated this assertion in his sworn statement taken by the ODC on June 16, 1999.

Following its investigation, the ODC dismissed the complaint against respondent. Ms. Cropper appealed the dismissal, but the hearing committee found that the ODC did not abuse its discretion in dismissing the complaint. Subsequently, the disciplinary board remanded the matter to the ODC with instructions to file formal charges against respondent.

\section{FORMAL HEARING}

The hearing committee conducted a formal hearing on the charges. ODC called several witnesses in its case in chief, including respondent, Shareef Cousin's defense attorney, and the complainant, Tonya Cropper. Respondent presented character testimony from several members of the bench and bar. 
Hearing Committee Recommendation

In a split decision, the chair and the public member of the committee found that the ODC did not prove a violation of Rules 3.8(d) and 8.4(a) as charged, and recommended that the formal charges against respondent be dismissed. In a nineteen page report, the majority found respondent's testimony credible regarding the nature of the Brady material. The committee acknowledged that respondent was in possession of the statement yet failed to disclose the second statement to the defense. However, the committee found no violation of Rule 3.8, as the committee determined that respondent reasonably believed that Ms. Babin's statement was inculpatory rather than exculpatory. The committee concluded that the defense was aware of the second statement and that it did not believe that the prosecution had an obligation "to help out the defense" by providing the statement. Based on these factual determinations, the majority of the committee concluded that respondent did not violate the Rules of Professional Conduct.

The lawyer member of the committee dissented, noting her objection to the majority's interpretation of a prosecutor's duty under Brady. She commented that she did not believe that the prosecutor has the discretion to determine whether to disclose exculpatory evidence to the defense. Rather, she interpreted Brady as imposing an affirmative duty on the prosecutor to disclose material exculpatory evidence, irrespective of whether a request was made by the defense.

The ODC filed an objection to the hearing committee's report and recommendation.

\section{Ruling of the Disciplinary Board}

The disciplinary board determined that respondent technically violated the Rules of Professional Conduct, but found that no discipline was appropriate and dismissed the formal charges against respondent. While the board adopted the hearing committee's factual findings, it rejected the committee's legal conclusions and application of the Rules of Professional Conduct. The board determined that the committee erred in its finding that respondent did not violate either Brady or Rule 3.8(d) when he failed to produce Ms. Babin's second statement. The board concluded that respondent was ethically bound to voluntarily disclose Statement 2, which tended to negate the guilt of the accused by calling into question Ms. Babin's positive identification of Cousin as the perpetrator of the crime. By failing to do so, respondent violated Rule 3.8(d).

The board found no aggravating factors present in this case, but found "numerous and weighty" mitigating factors, including the absence of a prior disciplinary record, absence of a dishonest or selfish motive, full and free disclosure to the disciplinary board and a cooperative attitude toward the proceedings, character and reputation, and remorse. The board concluded:

While the board finds that respondent's actions constitute a technical violation of the Rules of Professional Conduct, considering all of the factors, particularly respondent's good faith and lack of intent, the lack of any actual injury, respondent's excellent reputation among judges and colleagues and his unblemished disciplinary record, and 
considering the purpose of lawyer discipline, the board finds that no formal discipline is warranted.

Based on this reasoning, the formal charges against respondent were dismissed.

The ODC sought review of the board's ruling in this Court. We ordered the parties to submit briefs addressing the issue of whether the record supports the disciplinary board's report. After reviewing the briefs filed by both parties, we docketed the matter for oral argument.

\section{DISCUSSION}

In our system of justice, we entrust vast discretion to a prosecutor. Because a prosecutor is given such great power and discretion, he is also charged with a high ethical standard. A prosecutor stands as the representative of the people of the State of Louisiana. He is entrusted with upholding the integrity of the criminal justice system by ensuring that justice is served for both the victims of crimes and the accused. "Society wins not only when the guilty are convicted but when criminal trials are fair; our system of the administration of justice suffers when any accused is treated unfairly." The actions, or inactions in this case, of the prosecutor are paramount to a fair administration of justice; and the people of this state must have confidence in a prosecutor's integrity in performing his duty to disclose exculpatory evidence in order for the system to be just. Any intentional deviation from the principle of the fair administration of justice will be dealt with harshly by this Court.

This is a case of first impression in the State of Louisiana. Never before have we been confronted with the issue of disciplining a prosecutor for failing to disclose "evidence or information known to the prosecutor that tends to negate the guilt of the accused or mitigates the offense, and, in connection with sentencing, disclose to the defense and to the tribunal all unprivileged mitigating information known to the prosecutor." The language of Rule 3.8(d) is recognizably similar to the prosecutor's duty set forth in Brady and its progeny. Moreover, the Louisiana Code of Criminal Procedure likewise imposes a corresponding statutory duty on a prosecutor to disclose exculpatory evidence to the defendant.

The duty of a prosecutor to disclose exculpatory evidence is embedded in the principle that a criminal defendant is deprived of a fair trial when the state withholds exculpatory evidence that is material to guilt or punishment. The state's failure to disclose material evidence favorable to a criminal defendant implicates more than the defendant's discovery rights; the prosecutor has an affirmative duty to disclose such evidence under the Fourteenth Amendment's Due Process Clause. Failure to reveal this evidence implicates the defendant's right to a fair trial.

Whether the questioned evidence is material under Brady has been explained by this Court in Marshall:

The issue is whether the exculpatory evidence is material under the Brady-Bagley-Kyles line of cases. Evidence is material only if it is reasonably probable that the result of the 
proceeding would have been different had the evidence been disclosed to the defense. A reasonable probability is one which is sufficient to undermine confidence in the outcome. This Court must provide a cumulative evaluation of the suppressed evidence, keeping in mind that Marshall does not have to show that, with the addition of the suppressed evidence, his trial would have resulted in acquittal or that there would be an insufficiency of the evidence to support a conviction. Marshall need only show that "disclosure of the suppressed evidence to competent counsel would have made a different result reasonably probable."

During his testimony before the hearing committee, respondent testified that he did not believe Ms. Babin's second statement was material and did not qualify as the type of evidence to be disclosed under Brady. Specifically, respondent stated that he thought the evidence was inculpatory rather than exculpatory as Ms. Babin recounted specific details regarding the defendant's clothing and colorful socks. While the definition of materiality set forth in Kyles and its progeny may be seen as leaving a prosecutor with a degree of discretion, it does not.

Exculpatory evidence includes evidence which impeaches the testimony of a witness whose credibility or reliability may determine guilt or innocence. Additionally, United States $v$. Bagley reiterates the principle that there is no distinction between exculpatory evidence and impeachment evidence under Brady. Clearly, Ms. Babin's second statement negates her ability to positively identify the defendant in a lineup. The statement should have been disclosed to the defense. As we noted in our decision overruling Mr. Cousin's conviction, citing Justice Souter's eloquent statement in Kyles, a prosecutor anxious about "tacking too close to the wind will disclose a favorable piece of evidence" and "will resolve doubtful questions in favor of disclosure." Respondent failed to produce evidence which was clearly exculpatory and should have resolved this issue in favor of disclosure.

Accordingly, we agree with the factual findings of the disciplinary board that respondent violated Rule 3.8(d) by failing to disclose the second statement of Ms. Babin to the defendant.

\section{SANCTIONS}

In considering the issue of sanctions, we are mindful that disciplinary proceedings are designed to maintain high standards of conduct, protect the public, preserve the integrity of the profession, and deter future misconduct. The discipline to be imposed depends upon the facts of each case and the seriousness of the offenses involved, considered in light of any aggravating and mitigating circumstances. Thus, we must consider the facts as they are presented herein in deciding the type of discipline to impose on respondent.

The violation of Rule 3.8(d) by a prosecutor raises a great deal of concern to this Court. Rule 3.8 (d) exists to ensure that the integrity of the prosecutorial arm of our criminal justice system is maintained. Moreover, prosecutors are in a unique position from other members of the bar as they are immune from civil liability under Imbler $v$. Pachtman. Neither are they realistically subject to criminal sanctions. Our research reveals only one instance in which a judge held a 
prosecutor in contempt of court for failing to disclose evidence. Thus, absent consequences being imposed by this Court under its authority over disciplinary matters, prosecutors face no realistic consequences for Brady violations.

In deciding the appropriate sanction, we begin our analysis with Supreme Court Rule XIX, § 10(C), which sets forth the following considerations in imposing discipline:

1. Whether the lawyer has violated a duty owed to a client, to the public, to the legal system, or to the profession;

2. Whether the lawyer acted intentionally, knowingly, or negligently;

3. The amount of the actual or potential injury caused by the lawyer's misconduct; and

4. The existence of any aggravating or mitigating factors.

By withholding material exculpatory evidence from a criminal defendant, respondent violated a duty owed to the public. As a prosecutor, respondent is charged with a high ethical standard and may not carelessly skirt his obligation. Although neither Brady nor Rule 3.8 incorporates a mental element, Rule XIX, §10(C) does. Based on the testimony of respondent and the character evidence discussed below, we find that respondent knowingly withheld Brady evidence. ${ }^{116}$ As to the element regarding actual injury, this Court reversed Shareef Cousin's conviction on other grounds and granted him a new trial. However, this Court's actions in reversing the conviction does not vitiate the potential injury to the criminal justice system, or to Cousin, caused by respondent's actions, and warrants serious consideration and discipline by this Court.

As to the issue of aggravating and mitigating factors, we find the only aggravating factor present in this case is respondent's substantial experience as a prosecutor. However, on the issue of mitigation, we find a host of factors present. Specifically, we find the absence of any prior disciplinary record, absence of a dishonest motive, full and free disclosure to the board, a cooperative attitude towards the proceedings, and good character and reputation in the legal community.

As stated above, the issue of discipline against a prosecutor for his violation of Rule 3.8 is res nova in the State of Louisiana. While this Court has the benefit of Rule XIX considerations, we have no prior case law on the issue. However, Louisiana is not the first jurisdiction to address the issue of a prosecutor's failure to disclose evidence to a defendant. Our brethren in North Carolina, Kansas, South Carolina, Ohio and lowa have imposed discipline against an attorney who fails to disclose evidence pursuant to Brady. Thus, we find some guidance in their decisions. The sanctions imposed in other jurisdictions range from public reprimand or censure to a six-month suspension from the practice of law. Based upon the facts of this case, we conclude the appropriate baseline sanction for respondent's misconduct is a three-month

${ }^{116}$ The ABA's Standards for Imposing Lawyer Sanctions, defines "knowledge" as: The conscious awareness of the nature or attendant circumstances of the conduct but without the conscious objective or purpose to accomplish a particular result. 
suspension from the practice of law. However, in light of the mitigating factors, we will defer this suspension in its entirety, subject to the condition that any misconduct during a one-year period following the finality of this judgment may be grounds for making the deferred suspension executory, or imposing additional discipline, as appropriate.

JOHNSON, J. concurs in part, dissents in part, for the reasons that follow.

I concur in the majority's opinion that respondent knowingly withheld Brady evidence, that respondent's experience as a prosecutor was an aggravating factor, that the Court's actions in reversing defendant's conviction failed to invalidate the potential injury to the criminal justice system, or to defendant, and that respondent's behavior warrants discipline by this Court. However, because of the actual injury caused by respondent's prosecutorial misconduct, I dissent from the majority's conclusion that respondent's suspension should be deferred.

As cited in the majority opinion, Louisiana Supreme Court Rule XIX, § 10(c) sets forth four factors to be considered when imposing lawyer discipline. The third factor in this analysis is the "amount of the actual or potential injury caused by the lawyer's misconduct." Regarding actual injury, the majority opinion states that "this Court reversed Shareef Cousin's conviction on other grounds and granted him a new trial." Thus, the majority opinion adopts the reasoning, stated explicitly by the disciplinary board in the lower proceedings, that no injury resulted from respondent's conduct since the defendant's conviction was reversed. Although reversal of defendant's sentence of death by lethal injection amends the wrongful sentence, it fails to negate the actual injury caused by respondent's misconduct.

Pursuant to Louisiana Supreme Court Rule XIX, § 10(c), this court has held that an attorney caused an actual injury because the attorney's failure to pay a client's medical bill resulted in a negative report to a credit agency. In another matter, we determined that an attorney caused an actual injury when he abandoned his legal practice and failed to return a $\$ 750$ fee to a client and delayed the client's legal proceedings. In my view, the taking of a liberty interest is an even greater injury. As one legal commentator noted, "liberty is absolute and the loss of it is the greatest of all human injustices." Indeed, how can we ignore the injury caused by the wrongful taking of freedom, or the despair that inevitably follows as a defendant sits on death row and prepares for execution by lethal injection. "The execution of a legally and factually innocent person would be a constitutionally intolerable event," wrote Justice Sandra Day O'Connor in Herrera v. Collins. It is noteworthy that Shareef Cousin faced this predicament at the age of sixteen. The United States Supreme Court has since determined that execution of individuals who were under the age of 18 at the time of their capital crimes is unconstitutional.

Wrongful conviction constitutes an actual injury. Moreover, the United States Supreme Court has held that a wrongful conviction "has continuing collateral consequences." Michael Anthony Williams, who was recently freed from Angola State Penitentiary after serving 24 years for a crime he did not commit, and who, like Shareef Cousin, was convicted at the age of sixteen, described his time in prison as "a living hell." He stated that "a lot of terrible things happened to me while I was in there." Williams confessed that when he was younger, he was sexually 
abused "while guards turned their backs." Persons wrongfully convicted lose time during incarceration that cannot be retrieved. Furthermore, inmates, generally, leave prison with no savings, dismal employment prospects, and oftentimes medical and mental issues. Wrongful conviction can also cause significant stress on family relationships including the financial pressure that may have been created by legal fees associated with the wrongful conviction.

In the present case, disciplinary charges were filed against respondent by Shareef Cousin and his sister, Tonya Cropper. Tonya Cropper's testimony at the Hearing Committee describes the emotional turmoil that the Cousin family endured as a result of defendant's wrongful conviction. ${ }^{117}$

In 1976, the United States Supreme Court held that individual prosecutors have absolute immunity under common law tort claims as well as section 1983 suits. This court adopted the

${ }^{117}$ Cropper now resides in Boston, Massachusetts but at the time of the conviction and sentencing, she resided in Plano, Texas. During the trial Cropper drove from Plano and stayed through the duration of the trial. Cropper testified that after the conviction and sentencing she was numbed by the whole procedure. She couldn't believe that her brother was going to die. During this time her family was bitter with the justice system; they still hold resentment towards the courts.

Cropper said that Roger Jordan's insistence on the guilt of her brother infuriated her. On the Geraldo talk show, it was Jordan's face that represented her brother's conviction and death sentence. Even after the dismissal of the charges, she stated that Jordan continued to insist on the guilt of her brother.

Cropper expressed how she was too angry, hurt, and confused to testify during the penalty phase of the trial. She told how her brother had an outburst of emotion in court during Jordan's closing statement. The same emotional fury flowed through her veins. After the denial of a new trial, she, her four sisters, and her mother had an emotional, tear-filled prayer with Cousin before he was sent to Angola State Penitentiary. As he was taken away from his family, Cousin cried for the first time since the ordeal began.

She tells how she hated to see her brother in jail, and how she had only visited him once since he was initially arrested for the murder. She spent a lot of time dwelling on the fact that her brother was going to die of lethal injection. She finally decided to subject herself to seeing her brother behind bars.

Cropper goes on to tell of the travel accommodations that had to be made so the whole family would have an opportunity to see her brother in jail. She drove eight hours from Texas to pick her sisters and mom up; none of them had a car. The family would then travel two and a half hours to Angola. After the visit she would transport her family back to New Orleans. She would then rest for several hours and then drive back to Texas. This was all in one day. She made the trip faithfully every month until Cousin was removed from death row. Her daughter also had to endure seeing her uncle in jail. She never wanted her child to think her uncle was a murderer.

She felt Jordan had no regard for her family or for her brothers rights because her brother was arrested for four separate counts of armed robbery. She believes Jordan thought no one cared about her brother and he could do anything to win at all cost, regardless of her brother's due process rights. Her brother believed his attorney who told him that the robbery plea bargain was in his best interest because the judge was going to try him (and sentence him) on each count separately, and he would have to serve two times the sentence he is currently serving if found guilty of those robberies separately. Cropper did not understand why Jordan seemed to feel that her brother's life was so disposable.

Cropper explained that an injustice has been done not only to the Cousin family but also to the victim, Gerardi's, family because that family has no closure in the death of their son. 
Imbler court's reasoning in Knapper v. Connick, when we determined that "prosecutors are entitled to absolute immunity for conduct within the course and scope of their prosecutorial functions." Thus, prosecutors have absolute immunity even in instances, such as the present case, where the prosecutor suppressed exculpatory information. However, the Imbler decision also identifies the legal community's responsibility for maintaining the integrity of prosecutors and deterring prosecutors from violating standards of the legal profession. The court concluded that "a prosecutor stands perhaps unique, among officials whose acts could deprive persons of constitutional rights, in his amenability to professional discipline by an association of his peers." Therefore, our function in dispensing disciplinary action is critical both for upholding the highest ethical and professional standards among prosecutors and ensuring fundamental fairness for defendants. As expressed by the Honorable Calvin Johnson of Orleans Parish Criminal Court, in a letter contained in the record to then Orleans Parish District Attorney Harry Connick, Rule 3.8 was established to ensure professional responsibility among lawyers as well as to guarantee the constitutional due process rights of criminal defendants. ${ }^{118}$

In determining whether respondent caused an actual injury pursuant to Louisiana's Supreme Court Rule XIX, $\S 10(\mathrm{c})$, our focus should be on the unnecessary and unlawful suffering of the wrongfully convicted as a result of the prosecutorial misconduct, not just the reversal of the wrongfully imposed sentence. Because, in my view, loss of a liberty interest is more valuable than financial loss or injury to one's credit, I would impose an actual period of suspension.

118 In addition to the actual injury caused by respondent's violation of Rule 3.8, there are other allegations of misconduct cited in the complaint, though no formal charges were brought by the Office of Disciplinary Counsel. Specifically, during testimony at a motion for new trial, it was alleged that Jordan's co-counsel, Assistant District Attorney Byron Berry, may have removed several of defendant's alibi witnesses from outside the courtroom to the District Attorney's office. Later, when the time came for those witnesses to be called, respondent failed to tell defense counsel where the witnesses were.

Furthermore, there are some concerns with defendant's guilty pleas to armed robbery. Cousin was arrested and charged with First Degree Murder on March 27, 1995. This is the arrest for the instant matter. The next day, March 28, 1995, Cousin was arrested and charged with four counts of armed robbery. Cousin pled guilty to the armed robberies before he was found guilty of murder, but after he had been arrested and charged with the crime.

Cousin later petitioned this Court to grant supervisory writs and order post-conviction relief for the judgments entered against him in the armed robbery cases. In his writ application, Cousin argued that his guilty plea had been involuntary since he was never advised of the consequences of his plea. He claimed that he had not been apprised that his guilty plea would be used against him as four aggravating factors in the penalty phase of his capital trial. Additionally, he argued that he was not told that his guilty plea would prevent him from testifying in his capital trial, as the "prior" convictions would be used to impeach him if he got on the stand. This court denied defendant's application for writ of certiorari. J. Johnson dissented, stating that she was "not convinced that Cousin understood the consequences of his guilty pleas." 


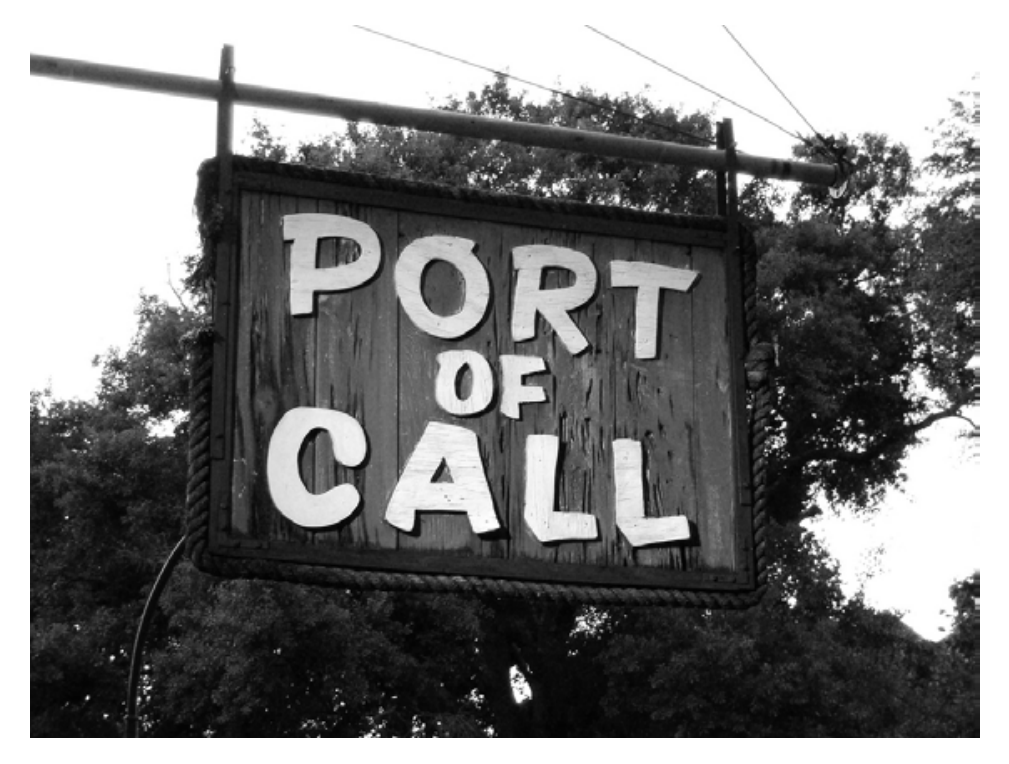

\section{Questions:}

1. On May 2, 1995, at about 10:20 P.M., Michael Gerardi and Connie Babin left the Port of Call restaurant in the French Quarter of New Orleans. While they were walking to Gerardi's truck, three men followed them, and one of the men shot and killed Gerardi. Shortly afterward, the New Orleans police arrested James Rowell on nine counts of armed robbery. In exchange for reduced charges, Rowell provided information to the police. Among other things, he claimed that Shareef Cousin had bragged about killing Gerardi. The police arrested Cousin, and Babin eventually identified him as the killer. In fact, Cousin was playing basketball when Gerardi was killed. The basketball game was videotaped, and a clock showed that it ended at about 10:00 P.M., after which coach Eric White drove Cousin and three other players home. At trial, Jordan not only suppressed Babin's testimony that she was not wearing contact lenses during the murder, but also altered recorded statements made by White in order to suppress the videotape of the basketball game and prevented the other basketball players from testifying. On January 25, 1996, Cousin was convicted of first-degree murder and sentenced to death. The Louisiana Supreme Court reversed Cousins's murder conviction and death sentence in 1998. State v. Cousin, 710 So. $2 d 1065$ (La. 1998). But Cousin had also pleaded guilty to four counts of armed robbery, and was not released from prison until 2005. Cousins told his story in CNN, NPR, and TIME, among other publications. You can watch a short video of Cousins describing his experiences here. After his release from prison, Cousins began working for Stephen Bright at the Southern Center for Human Rights in Atlanta. Unfortunately, Cousins applied for credit cards in Bright's name and charged $\$ 42,000$. In 2008 , he pleaded guilty to identity theft and credit card fraud and served three years in prison. He currently lives in New Orleans and is active in criminal justice reform advocacy.

2. The New York Times reported on the Orleans Parish District Attorney Office's long history of prosecutorial misconduct here. The Huffington Post reported on prosecutorial misconduct in New Orleans and elsewhere here. 
3. In assessing Jordan's culpability, the Louisiana Supreme Court found only one aggravating factor and many mitigating factors. How would you assess Jordan's culpability?

4. The Louisiana Supreme Court sanctioned Jordan by imposing a three-month suspension, deferred. The dissent argued that the suspension should not be deferred. What sanction would you have imposed, if any?

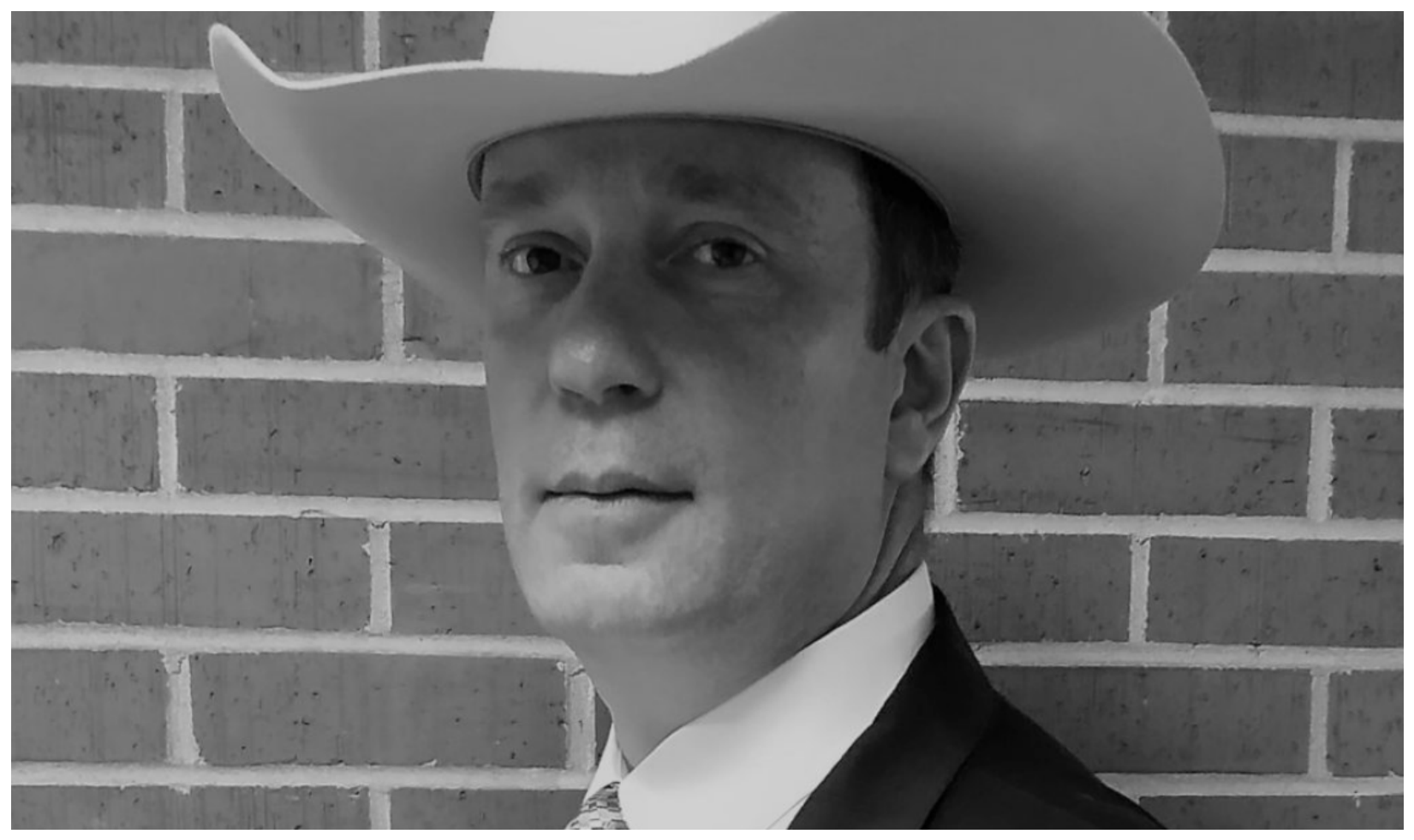

Eric Hillman (2014)

\section{Hillman v. Nueces County (Tex. 2019)}

Summary: Eric Hillman was an assistant district attorney in Nueces County, Texas. In 2014, he prosecuted a defendant for intoxicated assault and leaving the scene of an accident. In the course of investigating the case, Hillman interviewed a witness who stated the defendant was not intoxicated. The police report did not identify the witness, so Hillman informed his supervisor that he needed to disclose the witness to the defense, but his supervisor told him not to disclose. Hillman consulted with the State Bar Ethics Hotline and the Texas Center for Legal Ethics. Both told him to disclose, so he did, and he was fired. Hillman filed a wrongful termination action against Nueces County, but the trial court granted the county's motion to dismiss and the appeals court affirmed. The Texas Supreme Court also affirmed, holding that sovereign immunity barred Hillman's action.

JEFFREY S. BOYD, Justice. 
A former assistant district attorney filed this suit alleging that the county wrongfully terminated his employment because he refused his supervisor's order to withhold exculpatory evidence from a criminal defendant. The trial court dismissed the suit for lack of jurisdiction, and the court of appeals affirmed. Because we agree with those courts that governmental immunity bars the suit, we also affirm.

\section{Background}

Eric Hillman served as an assistant district attorney in Nueces County for two years. While preparing to prosecute a defendant charged with intoxicated assault and leaving the scene of an accident, Hillman discovered and interviewed a witness who said she was with the defendant the night of the incident and he was not intoxicated. Because the police report did not identify this witness, Hillman told his supervisor that he needed to disclose the witness to the defendant's attorney. The supervisor disagreed and instructed Hillman not to disclose the witness. Believing that he was legally required to disclose the witness, Hillman called the State Bar Ethics Hotline and the Texas Center for Legal Ethics for advice. Both told him he should disclose the information.

Three days before the defendant's trial, the victim confirmed to Hillman that the witness had been present at the scene. Hillman relayed this information to his supervisor and informed her that he had decided to disclose the witness to the defense attorney. On the day of trial, Hillman was fired for "failing to follow instructions." He alleges he was fired solely for refusing to withhold exculpatory evidence.

Hillman sued the County, the District Attorney's Office, and then-District Attorney Mark Skurka, in his official capacity, seeking actual damages for lost wages and benefits, mental anguish, pain and suffering, and loss of earning capacity, and exemplary damages. The County moved to dismiss on the ground that governmental immunity bars Hillman's claims. The trial court agreed and dismissed the case, and the court of appeals affirmed.

\section{II.Governmental Immunity}

Sovereign immunity—usually called governmental immunity when referring to political subdivisions-protects governmental entities against suits and legal liabilities. The County pleaded immunity from both suit and liability in this case, but only immunity from suit implicates the courts' jurisdiction. Because the trial court dismissed this case for lack of jurisdiction, we focus here solely on governmental immunity from suit. Because Hillman filed suit seeking money damages against a county and its department and official, governmental immunity bars this suit unless immunity has been waived.

Like every court of appeals that has addressed the issue, the court of appeals concluded here that governmental immunity applies to Hillman's wrongful-termination claim and has not been waived. Presenting three alternative grounds for reversal, Hillman argues that (1) this Court abrogated or waived the County's immunity from this type of suit in Sabine Pilot Service, Inc. $v$. 
Hauck, in which we recognized a cause of action for wrongful termination of an at-will employee for refusal to perform an illegal act, (2) the Texas legislature waived the County's immunity through the Michael Morton Act, or (3) we should abrogate or waive the County's immunity from such suits today. Although Hillman and his supporting amici bolster these grounds with serious and important policy concerns, we ultimately find the grounds themselves unconvincing.

\section{A. Sabine Pilot}

Texas-"steadfastly an at-will employment state"-generally permits both employers and employees to terminate their relationship at any time for any reason unless they contractually agree otherwise. The law recognizes, however, a number of exceptions to this rule. One "very narrow exception to the employment-at-will doctrine," which we adopted in Sabine Pilot, prohibits employers from terminating at-will employees "for the sole reason that the employee refused to perform an illegal act." An employer who terminates an employee solely for that reason is liable to the employee for all resulting "reasonable tort damages, including punitive damages."

Sabine Pilot involved claims against a private-sector employer, and this Court's very brief opinion never mentioned the duties or obligations of government employers. Noting that the Court did not expressly limit the exception to private employers or declare it inapplicable to government employers, Hillman argues that Sabine Pilot prohibits all employers-government as well as private-from terminating at-will employees solely for refusing to perform an illegal act. This argument reads too much into Sabine Pilot. Nothing in that opinion indicates anything regarding government employers. Because we simply did not consider or address whether the exception applies to government employers in Sabine Pilot, it provides no controlling principle on that issue here.

Hillman suggests that even if Sabine Pilot did not resolve the issue, we can and should clarify today that the Sabine Pilot exception applies to government employers. We have no problem holding that the exception applies to all Texas employers, in the sense that they all have a common-law-tort duty not to terminate at-will employees solely because the employee refuses to perform an illegal act. But holding that the Sabine Pilot exception applies to government employers does not help Hillman. Hillman's problem is not that the duty does not apply to government employers, but that immunity bars any suit for a government employer's breach of that duty.

Governmental immunity protects all governmental entities against suits and liabilities for their governmental actions, even when acting as employers. The legislature has provided a limited waiver of that immunity for certain tort and breach-of-contract actions. These statutes do not create tort or contractual duties or impose them on governmental entities. Those common-law duties preexist the statutes and apply to governmental entities as to anyone else, but immunity bars suits for breach of those duties. 
Instead of creating or imposing duties, the statutes waive the immunity that would otherwise protect the government, removing the barrier that precludes suits or liability for breach of those preexisting common-law duties. So although we can say that the common-law-tort duty we recognized in Sabine Pilot applies to all Texas employers, Hillman still cannot pursue this suit for the County's alleged breach of that duty unless the legislature has waived the County's governmental immunity. Because Sabine Pilot did not involve a governmental defendant and did not address governmental immunity or its waiver, it does not support Hillman's argument that the trial court had jurisdiction over his claim.

\section{B. The Michael Morton Act}

More than fifty-five years ago, the United States Supreme Court held that the Constitution's dueprocess clause prohibits criminal prosecutors from suppressing material evidence that is "favorable to an accused." Just over five years ago, the Texas legislature statutorily addressed "Brady violations" by passing the Michael Morton Act. The Michael Morton Act expressly requires prosecutors to

disclose to the defendant any exculpatory, impeachment, or mitigating document, item, or information in the possession, custody, or control of the state that tends to negate the guilt of the defendant or would tend to reduce the punishment for the offense charged.

Prosecutors must disclose such information whenever they discover it, whether "before, during, or after trial."

Hillman contends that the Michael Morton Act required him to disclose the witness's information in the case he was prosecuting, so the County wrongfully terminated him for refusing to perform an illegal act. But even accepting these assertions as true, the issue here is not whether Hillman has pleaded a valid Sabine Pilot claim, but whether the Act waives the County's governmental immunity against that claim.

To waive governmental immunity, a statute must use "clear and unambiguous language" expressing that intent. When deciding whether a statute clearly and unambiguously waives governmental immunity, we

1. consider "whether the statutory provisions, even if not a model of clarity, waive immunity without doubt";

2. resolve any "ambiguity as to waiver in favor of retaining immunity";

3. generally find waiver "if the Legislature requires that the governmental entity be joined in a lawsuit even though the entity would otherwise be immune from suit";

4. consider whether the legislature "provided an objective limitation on the governmental entity's potential liability"; and

5. consider "whether the statutory provisions would serve any purpose absent a waiver of immunity." 
Like the Sabine Pilot opinion, the Michael Morton Act does not address governmental immunity or waiver at all. None of its language waives immunity "without doubt" or even creates any ambiguity on the point. The Act does not require that the government be joined in any lawsuit or impose any limitation on the government's potential liability in such a suit. Implicating only the fifth consideration, Hillman argues that the Act necessarily must waive the County's immunity from his wrongful-termination suit because the Act's sole purpose is to require prosecutors to disclose exculpatory evidence. He contends that the Act would be "illusory" unless it waives immunity from Sabine Pilot claims, and finding no waiver "would defeat the sole purpose for passing the Michael Morton Act in the first place." As Hillman puts it, "A law making it a crime for a prosecutor to withhold evidence from the defense, but at the same time allowing the prosecutor's supervisor to fire him for refusing to do so is nonsensical and cannot possibly be what the legislature intended when it enacted the Michael Morton Act."

These arguments read too much into the Michael Morton Act. The Act serves obvious purposes separate and apart from addressing any wrongful-termination issues. It codifies and "supplements" prosecutors' constitutional obligations under Brady. It requires production of several items that "previously were not discoverable" in criminal cases, including "written witness statements, written communications between the State and its agents, and work product." And violations of the Act may constitute grounds for reversing a conviction.

Of course, the legislature could always do more to ensure that prosecutors disclose exculpatory information. Presumably, at least, prosecutors would be more likely to disclose such information if the Act authorized civil-damages suits-and waived immunity for such suits-against those who violate its requirements or who terminate subordinates who refuse to violate them. Whether countervailing policy concerns outweigh such benefits, however, "is the very essence of legislative choice." And the mere fact that a statute prohibits a government official from engaging in particular conduct does not establish that the statute also waives governmental immunity whenever a government employer terminates an employee for refusing to engage in that conduct. If that were true, every statutory prohibition would waive immunity from wrongfultermination claims.

Nothing in the Michael Morton Act indicates a legislative intent to waive governmental immunity from a wrongful-termination suit under Sabine Pilot. No explicit language or even ambiguous language indicates such an intent. We hold that the Michael Morton Act does not waive the County's governmental immunity from this suit.

\section{Judicial Abrogation of Immunity}

Alternatively, Hillman urges us to abolish the "ancient and antiquated" doctrine of governmental immunity altogether, or at least modify it to allow for Sabine Pilot claims against governmental entities. He notes that sovereign immunity developed and exists as a common-law doctrine, and "it remains the judiciary's responsibility to define the boundaries of the common-law doctrine and to determine under what circumstances sovereign immunity exists in the first instance." But 
in fulfilling that responsibility, we must respect both our precedent and our limitations under the constitutional separation of powers.

Having existed for more than six hundred years, the governmental-immunity doctrine is "an established principle of jurisprudence in all civilized nations." We first recognized it as a principle of Texas law more than 170 years ago. Although the justifications for its existence have evolved through the years, we have steadfastly retained it in modern times precisely because it shields "the public from the costs and consequences of improvident actions of their governments," and ensures that the taxes the public pays are used "for their intended purposes."

We are not blind to the truism that, "just as immunity is inherent to sovereignty, unfairness is inherent to immunity." But as the Court's majority explained in that case, we resolve that concern by deferring to the legislature, as the policy-making branch of government, "to decide whether and to what extent that immunity should be waived." As important as Hillman's and his supporting amici's policy concerns may be, they do not justify discarding these fundamental principles of Texas law.

We in no way discount the serious policy concerns that Hillman, his supporting amici, and today's concurring opinion express. Governmental immunity from Sabine Pilot claims eliminates one means by which the law could ensure that prosecutors disclose exculpatory evidence as Brady and the Michael Morton Act require. As the amici note, the Act has enjoyed broad, bipartisan support in the legislature, the public, and the press, and the legislature has further strengthened the Act in more recent legislative sessions. But to hold that governmental immunity does not apply to Sabine Pilot claims, we must trespass across the boundary between defining immunity's scope (a judicial task) and waiving it (a legislative task). The distinction between scope and waiver is "a fine one," and we must "be very hesitant to declare immunity nonexistent in any particular case," lest we use our authority to define the scope as "a ruse for avoiding the Legislature."

As we have repeatedly confirmed, "it is the Legislature's sole province to waive or abrogate sovereign immunity." That the legislature has recently revised the Michael Morton Act to strengthen its protections illustrates its continuing awareness of the Act and its importance, as well as its willingness to take steps to improve it. Whether waiving immunity from Sabine Pilot claims should be the next step in that process is up to the legislature, and we must defer to it to "protect its policymaking function."

\section{Conclusion}

"Sovereign immunity from suit defeats a trial court's subject matter jurisdiction." When, as here, a claim falls within the realm of governmental immunity, courts have no jurisdiction to hear the case unless immunity has been waived. We hold that neither Sabine Pilot nor the Michael Morton Act waives the County's governmental immunity from Hillman's wrongful-termination claim, and we defer to the legislature to decide whether such a waiver would be appropriate as 
a matter of public policy. We affirm the trial court's judgment granting the County's plea to the jurisdiction and dismissing the case.

Justice GUZMAN, joined by JUSTICE LEHRMANN and JUSTICE DEVINE, concurring.

No tyranny is more cruel than the one practiced in the shadow of the laws and under color of justice. ${ }^{119}$

Imagine being accused, charged, and convicted of bludgeoning your spouse to death. You are innocent but sentenced to life in prison, effectively orphaning your only child. Over the next 24 years, you wage an uphill battle to prove your innocence, eventually discovering that the prosecution held the keys to your jail cell before you ever set foot in it. Eyewitness testimony pointing the finger at someone else and DNA evidence that was never tested would have exculpated you if the prosecutor had not secreted the evidence from those who were constitutionally charged with defending you. Ultimately exonerated after nearly a quarter century in confinement, you walk free. The prosecutor-now a judge-is found in contempt of court for suppressing this evidence. Small comfort. Justice delayed is justice denied. But more than that, justice delayed is life denied.

While you were locked away for a crime you did not commit, you were denied your unalienable rights of life, liberty, and the pursuit of happiness. You lost your constitutional right to parent your child. To have his love and companionship. To shape who he is and how he became that way. Instead, your beautiful toddler is now a man struggling to reconnect with a person he doesn't know, can't remember as a parent, and spent years thinking was a vicious monster. And worse, the actual perpetrator of this heinous crime continued to walk the streets. Free to kill again.

Alas, this is not a hypothetical. This is the true story of Michael Morton. Husband. Father. Supermarket manager. An ordinary Texan whose young wife fell victim to a stranger's brutality. And while Morton languished in jail, another young wife-Debra Baker-paid the ultimate price at the hands of the same killer, leaving yet another young child motherless. Foreseeable victims of overzealous prosecution.

Unfortunately, this is not an isolated incident. Official misconduct has been a factor in more than half of the nationally reported exonerations since 1989-nearly four score of which have occurred in Texas. Wrongful convictions are anathema to our constitution. And suppression of evidence is anathema to the duty of a prosecutor to seek justice. Concealment of exculpatory evidence undermines the integrity of our criminal justice system, which is of vital importance to every one of us: "Society wins not only when the guilty are convicted but when criminal trials are fair. The administration of justice suffers when any accused is treated unfairly."

${ }^{119}$ Charles de Secondat, Baron de Montesquieu, Considerations on the Causes of the Greatness of the Romans and Their Decline 130 (David Lowenthal trans., Hackett Pub. Co., 1999) (1965). 
The tragic story of Michael Morton and Debra Baker compelled the Legislature to take affirmative steps to prevent wrongful convictions due to prosecutorial misconduct. In the legislative session following Morton's exoneration, the Texas Legislature unanimously passed the Michael Morton Act. The Morton Act extends, but has not altered, prosecutors' longstanding obligation under Brady to disclose exculpatory evidence in the prosecution's possession. Before the Morton Act, prosecutors had a constitutional duty under Brady to disclose all evidence that might exonerate the defendant, but the defense had very limited pretrial discovery rights. Under the Morton Act, if the defense requests discovery, the prosecution is under a statutory duty to continually disclose exculpatory, mitigating, or impeachment evidence. The Act is an important legislative step towards ensuring Brady compliance and bolstering the integrity of the criminal justice system.

As this case sadly demonstrates, however, unacceptable gaps remain. When one good man refuses to stay silent, refuses to "just follow orders," and refuses to do the wrong thing under the misguided belief that it's for the greater good, he should not lose his job. While Hillman might have had a viable ultra vires claim, had he chosen to pursue one, the limited remedies available under that theory are manifestly inadequate to ensure accountability in matters of the highest constitutional dimension. The law must-but currently does not-afford a remedy that advances the Legislature's calculated efforts to secure our constitutional guarantees.

Injustice anywhere is a threat to justice everywhere. ${ }^{120}$

In 2013, Eric Hillman, an assistant district attorney in Nueces County, was assigned to prosecute David Sims for intoxication assault and leaving the scene of an accident. Hillman performed a diligent independent investigation and located a witness who was not listed in the police report. The witness told Hillman she was with Sims the entire evening, he had only consumed two alcoholic beverages, and he was not intoxicated when the accident occurred.

Hillman immediately informed his supervisor that a new witness with exculpatory testimony had been located and he would be releasing that information to Sims's defense counsel. The supervisor demanded Hillman withhold the information, assuring him it was proper to do so.

Unconvinced, Hillman conducted an independent investigation of his ethical obligations, consulting with both the Texas Center for Legal Ethics and the State Bar of Texas Ethics Hotline. Both admonished him to disclose the information to defense counsel. Hillman therefore reported to his supervisor that he intended to turn over the evidence to the defense because withholding it would be unethical. According to Hillman, his supervisor responded, "Eric, you need to decide if you want to be a prosecutor or a defense attorney." A week after Hillman announced his intention to disclose the information, former District Attorney Mark Skurka summarily terminated Hillman's employment for refusing to "follow instructions."

${ }^{120}$ Martin Luther King, Jr., Letter from Birmingham Jail (Apr. 16, 1963). 
Hillman sued the County, District Attorney Skurka, and the District Attorney's Office for wrongful termination, but his case was dismissed on a plea to the jurisdiction.

I concur in today's judgment and join in much of the Court's reasoning. The gravamen of this case is governmental immunity: whether the County is immune from a wrongful-termination suit alleging a prosecutor was fired because he insisted on doing what the law requires. Under our immunity jurisprudence, this case is fairly straightforward, and the Court's analysis is sound. First, we did not abrogate governmental immunity in Sabine Pilot. The employer in that case was not a governmental entity, so the issue of governmental immunity was not before us and cannot be inferred sub silentio. Second, immunity has not been waived. We defer to the Legislature to waive immunity, and I agree with the Court that the Morton Act contains no such waiver because no "clear and unambiguous language" expresses that intent. Third, we should not abrogate immunity here. Although we have the power to abrogate immunity, we have rarely done so, and even then we limited it to offset claims rather than allowing unlimited recovery of monetary damages. Sanctioning the recovery of monetary damages-without any legislatively considered limitations like those in the Texas Tort Claims Act-would have significant public-fisc implications that raise separation-of-powers concerns. Finally, though Hillman arguably has a viable ultra vires claim, he has disclaimed any intent to assert one. Accordingly, I agree with the Court that the County is immune from suit in this case and that remand is not appropriate. I write separately, however, to highlight a lacuna in the legislative scheme that neuters the Legislature's efforts to forestall prosecutorial misconduct that could lead to wrongful convictions.

If impunity is not demolished, all efforts to bring an end to corruption are in vain. ${ }^{121}$

Taking Hillman's account as true, he was fired for endeavoring to fulfill constitutional and statutory obligations imposed on all prosecutors. By any measure of law and morality in a civilized country, that is wrongful termination. Those we entrust to pursue justice should not be put to the Hobson's choice of earning a living or doing the right thing. Cloaking governmental employers with absolute immunity in such circumstances erodes public confidence in the criminal justice system and undermines concerted legislative efforts to reform that system. By and large, prosecutors are honorable public servants committed to fairness in the administration of justice, but when unlawful practices are tolerated, encouraged, or rewarded with career advantages, others may be enticed to cross the line or may be cowed by consequences visited on those who resist. It's fair to assume that the Legislature did not envision such a consequence when enacting the Morton Act without adopting measures to ensure prosecutors could comply with the Act without losing their jobs. In light of the underbelly this case exposes, it would be appropriate for the Legislature to do so now.

${ }^{121}$ Rigoberta Menchú Tum, The Plague of Corruption: Overcoming Impunity and Injustice, in GLOBAL CORRUPTION REPORT 2001, at 155 (Robin Hodess, Jessie Banfield \& Toby Wolfe eds., Transparency Int'l 2001). 
Both Brady and the Morton Act obligate prosecutors to disclose certain types of evidence to the defense as a function of due process and to stave off wrongful convictions by thwarting pernicious prosecutorial practices. Wrongful convictions, as numerous studies have shown, come at a significant cost to our society. Financial burdens on the taxpayers accumulate through "an appeal, an appellate reversal, a retrial, investigational efforts to trace the real offender, possible civil lawsuits, and compensatory payments." While we can calculate economic losses from wrongful convictions-for example, the state has paid more than $\$ 93$ million in compensation to 101 men and women who were wrongfully sent to prison over the past 25 years-the true cost is immeasurable. There is simply no way to restore lost time, no reset button that erases the financial and emotional consequences to the wrongfully incarcerated and their families.

On the other side of the coin, for every innocent person that sits in jail, a criminal roams free. Free to commit more crimes. If DNA-exoneration cases are any kind of indicator, the societal consequences of convicting the wrong person-however it happens-are devastating. For example, out of 325 DNA-exoneration cases from 1989 to 2014,68 of the true perpetrators later committed an additional 142 violent crimes-including 77 rapes, 34 homicides, and 31 other violent crimes.

With such grave consequences, the best defense is a good offense. The Morton Act is a strong foundation, but more is required to ensure that those wielding power use it as the founders intended. Prosecutors are on the forefront of avoiding wrongful convictions and ameliorating the ensuing societal costs. Based on data compiled by the National Registry of Exonerations, official misconduct ranks second among the top five factors contributing to exonerations, leading to over half of the 2,401 (and counting) exonerations since 1989. The most common type of official misconduct involves concealing exculpatory evidence.

While multiple external forces are aimed at ensuring accountability for misconduct-including professional discipline, potential criminal charges, and loss of elected office-this case epitomizes the limits of existing accountability measures. Research shows professional discipline and criminal charges are rarely imposed for prosecutorial misconduct. Even in the rare instances when misconduct is uncovered, it usually does not surface until after an innocent person has stayed in prison for years, presenting time-based challenges to any investigation or prosecution of wrongdoing. The possibility of some adverse consequence in some future public election has even less force as a deterrent and, more importantly, does absolutely nothing to alleviate irreparable harm resulting from the wrong.

Brady violations are difficult to uncover because, by definition, they involve concealment of evidence in the prosecution's exclusive possession and control. Indeed, exposure of Brady violations generally requires the prosecution's own admission, some "chance discovery" by the defense team, or "dumb luck." The most effective way to combat prosecutorial misconduct is to provide a disincentive extrinsic to an individual prosecutor's own moral compass. "Ironically, the only one who can act as a check on the prosecution is the prosecution itself." This case places the internal dynamics within the prosecutor's office under a microscope. Although many district 
attorney's offices have implemented internal guidance or best practices, when the pressure to withhold evidence comes from the top, internal guidelines are at best a window dressing. Under circumstances like those alleged here, it is imperative that honest prosecutors not be punished.

Absent legislative action, the best someone in Hillman's position could hope for is to seek prospective equitable relief under an ultra vires theory. An ultra vires claim can be brought against a state official if the officer "acted without legal authority." Although a district attorney has discretion to fire subordinates, one could argue there is no discretion to undertake such an action if it "conflicts with the law." If Hillman had not opposed consideration of his claims under an ultra vires theory, I would remand in the interest of justice to allow him to pursue that claim.

However, as a policy matter, I am dubious that a remedy limited to prospective equitable relief is strong enough to deter the egregious conduct alleged here. To be effective, the remedy must be proportional to the wrong. To my mind, the threat of other consequences, including monetary relief, would provide the external pressure required to motivate vigilance and self-policing. The Legislature is better suited, and constitutionally constituted, to weigh the policy interests that bear on whether to waive immunity (and to what extent), but as to that matter, this case makes painfully clear that what's past is prologue.

\section{Questions:}

1. Hillman was the first prosecutor represented by the Innocence Project, in recognition of his commitment to doing justice. Hillman's action was also covered by the ABA Journal, the Houston Chronicle, the Austin Statesman, the Associated Press, and the San Francisco Chronicle, among others. You can watch a video of the oral argument in Hillman v. Nueces County (2018) here.

2. Do you agree with the court's conclusion that sovereign immunity bars Hillman's action? Should the court have construed sovereign immunity differently? Should Hillman have a claim against Skurka? Would absolute prosecutorial immunity bar any such claim? Should it?

3. Under the circumstances, what should Hillman have done? Did he have any other options?

\section{Further Reading:}

- Bennett L. Gershman, The Prosecutor's Duty of Silence, 79 Alb. L. Rev. 1183 (2016)

\section{Further Viewing \& Listening:}

- Last Week Tonight With John Oliver: Prosecutors (2018)

- Carissa Byrne Hessick on the Myth of Common Law Crimes, Ipse Dixit, January 9, 2019

- Rachel Barkow on Criminal Justice Reform, February 4, 2019

- Maybell Romero on Profit-Driven Prosecution, February 28, 2019 


\section{5: Judicial Recusal \& Misconduct}

Good morning Judge, why do you look so mean? Sorry Mr. Judge, what can the charges be? If there's been trouble I will plead not guilty. It must be someone else, you know it can't be me. ${ }^{122}$

"If I had me job to pick out," said Mr. Dooley, "I'd be a judge. I've looked over all th' others an' that's th' on'y wan that suits. I have th' judicyal timperamint. I hate wurruk."123

Judges must be neutral and impartial at all times. Or at least, they must appear to be neutral and impartial. Accordingly, judicial conduct is regulated by a congeries of constitutional, statutory, and administrative rules intended to ensure neutrality and impartiality.

Among other things, due process requires judges to recuse themselves to avoid conflicts of interest, and may require disqualification if a judge fails to recuse. Federal law prohibits judges from accepting or soliciting bribes. ${ }^{124}$ But it also requires judges to recuse themselves whenever their impartiality could reasonably be questioned. ${ }^{125}$ The Judicial Conduct and Disability Act of 1980 authorizes complaints alleging that a federal judge "has engaged in conduct prejudicial to the effective and expeditious administration of the business of the courts" or "is unable to discharge all the duties of office by reason of mental or physical disability." ${ }^{126}$ And the Rules for Judicial-Conduct and Judicial-Disability Proceedings govern misconduct and disability proceedings against federal judges under the Act. ${ }^{127}$ States may have similar statutory and administrative provisions.

Finally, federal and state judicial codes of conduct comprehensively regulate judges. In 1924, the ABA first created and approved its Canons of Judicial Conduct, which were revised in 1972, 1990, and 2007. The ABA canons are currently titled the Model Code of Judicial Conduct, and consist of both aspirational principles and specific rules intended to realize those principles. The federal judiciary has adopted the Code of Conduct for United States Judges, which includes the ethical canons that apply to federal judges and provides guidance on their performance of official duties and engagement in a variety of outside activities. Most states also have judicial commissions, which are empowered to investigate violations of judicial ethics.

\section{Judicial Recusal}

Stop eatin' that fudge, cause here comes the judge. Don't nobody buzz, cause here comes the judge. Judge Shorty is presidin' today, and he don't take no stuff from nobody, no kind of way. ${ }^{128}$

\footnotetext{
122 Wynonie Harris, Good Morning Judge (1952).

${ }^{123}$ Finley Peter Dunne, Observations by Mr. Dooley (1902).

12418 U.S.C. $\$ 203(a)(1)(B)$.

12528 U.S.C. $\$ 455$.

12628 U.S. Code $\S \S 351-64$.

127 Guide to Judiciary Policy, Vol. 2: Ethics and Judicial Conduct, Pt. E: Judicial Conduct and Disability Act and Related Materials, Ch. 3: Rules for Judicial-Conduct and Judicial-Disability Proceedings.

${ }^{128}$ Shorty Long, Here Comes the Judge (1968).
} 


\section{Model Code of Judicial Conduct: Canon 1}

A judge shall uphold and promote the independence, integrity, and impartiality of the judiciary, and shall avoid impropriety and the appearance of impropriety.

\section{Model Rule 1.2: Promoting Confidence in the Judiciary}

A judge shall act at all times in a manner that promotes public confidence in the independence, integrity, and impartiality of the judiciary, and shall avoid impropriety and the appearance of impropriety.

\section{Model Rule 1.2: Comments}

1. Public confidence in the judiciary is eroded by improper conduct and conduct that creates the appearance of impropriety. This principle applies to both the professional and personal conduct of a judge.

2. A judge should expect to be the subject of public scrutiny that might be viewed as burdensome if applied to other citizens, and must accept the restrictions imposed by the Code.

3. Conduct that compromises or appears to compromise the independence, integrity, and impartiality of a judge undermines public confidence in the judiciary. Because it is not practicable to list all such conduct, the Rule is necessarily cast in general terms.

5. Actual improprieties include violations of law, court rules or provisions of this Code. The test for appearance of impropriety is whether the conduct would create in reasonable minds a perception that the judge violated this Code or engaged in other conduct that reflects adversely on the judge's honesty, impartiality, temperament, or fitness to serve as a judge. 


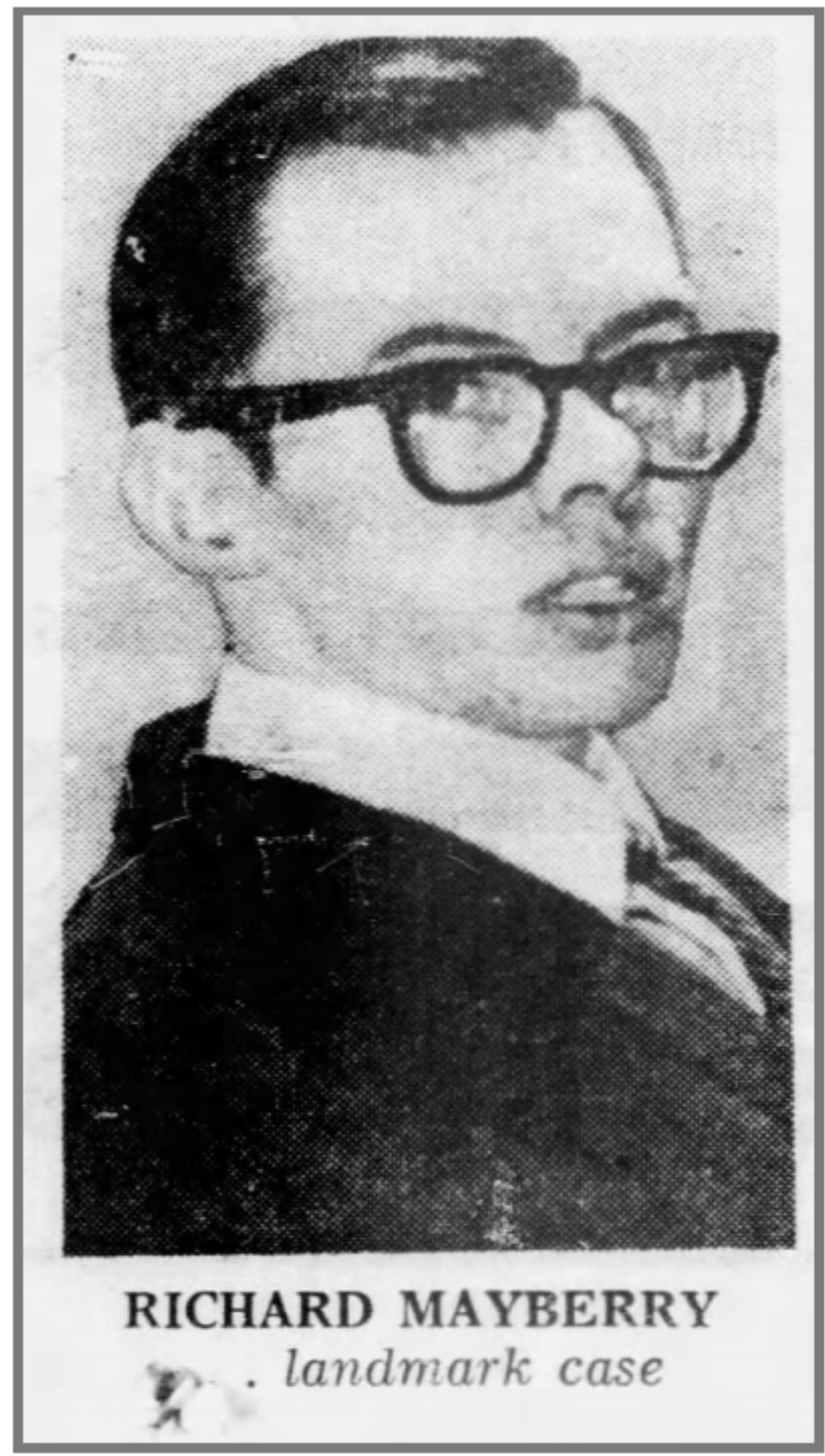

The Philadelphia Inquirer, Jan. 11, 1972, at 1

Mayberry v. Pennsylvania, 400 U.S. 455 (1971)

Summary: Mayberry and two co-defendants were tried in state court for an attempted prison break. They were appointed counsel, but represented by Mayberry. During the trial, Mayberry repeatedly insulted the judge and questioned his impartiality. The jury 
found the defendants guilty, but before imposing the sentence, the judge pronounced Mayberry guilty of 11 counts of criminal contempt, and sentenced him to 11 to 22 years. The Supreme Court of Pennsylvania affirmed the contempt charges, but the Supreme Court granted Mayberry's pro se petition for certiorari and reversed, holding that due process entitles a defendant in a criminal contempt proceeding to a trial before a different judge.

MR. JUSTICE DOUGLAS delivered the opinion of the Court.

Petitioner and two codefendants were tried in a state court for prison breach and holding hostages in a penal institution. While they had appointed counsel as advisers, they represented themselves. The trial ended with a jury verdict of guilty of both charges on the 21st day, which was a Friday. The defendants were brought in for sentencing on the following Monday. Before imposing sentence on the verdicts the judge pronounced them guilty of criminal contempt. He found that petitioner had committed one or more contempts on 11 of the 21 days of trial and sentenced him to not less than one nor more than two years for each of the 11 contempts or a total of 11 to 22 years.

The Supreme Court of Pennsylvania affirmed by a divided vote. The case is here on a petition for writ of certiorari.

Petitioner's conduct at the trial comes as a shock to those raised in the Western tradition that considers a courtroom a hallowed place of quiet dignity as far removed as possible from the emotions of the street.

On the first day of the trial petitioner came to the sidebar to make suggestions and obtain rulings on trial procedures. Petitioner said: "It seems like the court has the intentions of railroading us" and moved to disqualify the judge. The motion was denied. Petitioner's other motions, including his request that the deputy sheriffs in the courtroom be dressed as civilians, were also denied. Then came the following colloquy:

Mr. Mayberry: I would like to have a fair trial of this case and like to be granted a fair trial under the Sixth Amendment.

The Court: You will get a fair trial.

Mr. Mayberry: It doesn't appear that I am going to get one the way you are overruling all our motions and that, and being like a hatchet man for the State.

The Court: This side bar is over.

Mr. Mayberry: Wait a minute, Your Honor.

The Court: It is over.

Mr. Mayberry: You dirty sonofabitch."

The second episode took place on the eighth day of the trial. A co-defendant was crossexamining a prison guard and the court sustained objections to certain questions: 
Mr. Codispoti: Are you trying to protect the prison authorities, Your Honor? Is that your reason?

The Court: You are out of order, Mr. Codispoti. I don't want any outbursts like that again. This is a court of justice. You don't know how to ask questions.

Mr. Mayberry: Possibly Your Honor doesn't know how to rule on them.

The Court: You keep quiet.

Mr. Mayberry: You ought to be Gilbert and Sullivan the way you sustain the district attorney every time he objects to the questions.

The Court: Are you through? When your time comes you can ask questions and not make speeches.

The next charge stemmed from the examination of an inmate about a riot in prison in which petitioner apparently was implicated. There were many questions asked and many objections sustained. At one point the following outburst occurred:

Mr. Mayberry: Now, I'm going to produce my defense in this case and not be railroaded into any life sentence by any dirty, tyrannical old dog like yourself.

The Court: You may proceed with your questioning, Mr. Mayberry.

The fourth charge grew out of an examination of another defense witness:

By Mr. Mayberry:

Q. I ask you, Mr. Nardi, is that area, the handball court, is it open to any prisoner who wants to play handball, who cares to go to that area to play handball?

A. Yes.

Q. Did you understand the prior question when I asked you if it was freely open and accessible area?

The Court: He answered your question. Let's go on.

Mr. Mayberry: I am asking him now if he understands...

The Court: He answered it. Now, let's go on.

Mr. Mayberry: I ask Your Honor to keep your mouth shut while I'm questioning my own witness. Will you do that for me?

The Court: I wish you would do the same. Proceed with your questioning.

The fifth charge relates to a protest which the defendants made that at the end of each trial day they were denied access to their legal documents-a condition which the trial judge shortly remedied. The following ensued:

Mr. Mayberry: You're a judge first. What are you working for? The prison authorities, you bum?

Mr. Livingston: I have a motion pending before Your Honor.

The Court: I would suggest...

Mr. Mayberry: Go to hell. I don't give a good God damn what you suggest, you stumbling dog. 
Meanwhile one defendant told the judge if he did not get access to his papers at night he'd "blow your head off." Another defendant said he would not sit still and be "kowtowed and be railroaded into a life imprisonment." Then the following transpired:

Mr. Mayberry: You started all this bullshit in the beginning.

The Court: You keep quiet.

Mr. Mayberry: Wait a minute.

The Court: You keep quiet.

Mr. Mayberry: I am my own counsel.

The Court: You keep quiet.

Mr. Mayberry. Are you going to gag me?

The Court: Take these prisoners out of here. We will take a ten minute recess, members of the jury.

The sixth episode happened when two of the defendants wanted to have some time to talk to a witness whom they had called. The two of them had had a heated exchange with the judge when the following happened:

Mr. Mayberry: Just one moment, Your Honor.

The Court: This is not your witness, Mr. Mayberry. Keep quiet.

Mr. Mayberry: Oh, yes, he is my witness, too. He is my witness, also. Now, we are at the penitentiary and in seclusion. We can't talk to any of our witnesses prior to putting them on the stand like the District Attorney obviously has the opportunity, and as he obviously made use of the opportunity to talk to his witnesses. Now...

The Court: Now, I have ruled, Mr. Mayberry.

Mr. Mayberry: I don't care what you ruled. That is unimportant. The fact is...

The Court: You will remain quiet, sir, and finish the examination of this witness.

Mr. Mayberry: No, I won't be quiet while you try to deny me the right to a fair trial. The only way I will be quiet is if you have me gagged. Now, if you want to do that, that is up to you; but in the meantime I am going to say what I have to say. Now, we have the right to speak to our witnesses prior to putting them on the stand. This is an accepted fact of law. It is nothing new or unusual. Now, you are going to try to force us to have our witness testify to facts that he has only a hazy recollection of that happened back in 1965. Now, I believe we have the right to confer with our witness prior to putting him on the stand.

The Court: Are you finished?

Mr. Mayberry: I am finished.

The Court: Proceed with your examination.

The seventh charge grew out of an examination of a codefendant by petitioner. The following outburst took place:

By Mr. Mayberry: 
Q. No. Don't state a conclusion because Gilbert is going to object and Sullivan will sustain. Give me facts. What leads you to say that?

Later petitioner said:

Mr. Mayberry: My witness isn't being in an inquisition, you know. This isn't the Spanish Inquisition.

Following other exchanges with the court, petitioner said:

Mr. Mayberry: Now, just what do you call proper? I have asked questions, numerous questions and everyone you said is improper. I have asked questions that my adviser has given me, and I have repeated these questions verbatim as they came out of my adviser's mouth, and you said they are improper. Now just what do you consider proper? The Court: I am not here to educate you, Mr. Mayberry.

Mr. Mayberry: No. I know you are not. But you're not here to railroad me into no life bit, either.

Mr. Codispoti: To protect the record...

The Court: Do you have any other questions to ask this witness?

Mr. Mayberry: You need to have some kind of psychiatric treatment, I think. You're some kind of a nut. I know you're trying to do a good job for that Warden Maroney back there, but let's keep it looking decent anyway, you know. Don't make it so obvious, Your Honor.

A codefendant was removed from the courtroom and when he returned petitioner asked for a severance.

Mr. Mayberry: I have to ask for a severance.

The Court: I have heard that before. It is denied again. Let's go on.

(Exception noted.)

Mr. Mayberry: This is the craziest trial I have ever seen.

The Court: You may call your next witness, Mr. Mayberry.

Petitioner wanted to call witnesses from the penitentiary whose names had not been submitted earlier and for whom no subpoenas were issued. The court restricted the witnesses to the list of those subpoenaed:

Mr. Mayberry: Before I get to that I wish to have a ruling, and I don't care if it is contempt or whatever you want to call it, but I want a ruling for the record that I am being denied these witnesses that I asked for months before this trial ever began.

The ninth charge arose out of a ruling by the court on a question concerning the availability of tools to prisoners in their cells. 
The Court: I have ruled on that, Mr. Mayberry. Now proceed with your questioning, and don't argue.

Mr. Mayberry: You're arguing. I'm not arguing, not arguing with fools.

The court near the end of the trial had petitioner ejected from the courtroom several times. The contempt charge was phrased as follows by the court:

On December 7, 1966, you have created a despicable scene in refusing to continue calling your witnesses and in creating such consternation and uproar as to cause a termination of the trial.

As the court prepared to charge the jury, petitioner said:

Before Your Honor begins the charge to the jury defendant Mayberry wishes to place his objection on the record to the charge and to the whole proceedings from now on, and he wishes to make it known to the Court now that he has no intention of remaining silent while the Court charges the jury, and that he is going to continually object to the charge of the Court to the jury throughout the entire charge, and he is not going to remain silent. $\mathrm{He}$ is going to disrupt the proceedings verbally throughout the entire charge of the Court, and also he is going to be objecting to being forced to terminate his defense before he was finished.

The court thereupon had petitioner removed from the courtroom and later returned gagged. But petitioner caused such a commotion under gag that the court had him removed to an adjacent room where a loudspeaker system made the courtroom proceedings audible. The court phrased this contempt charge as follows:

On December 9, 1966, you have constantly, boisterously, and insolently interrupted the Court during its attempts to charge the jury, thereby creating an atmosphere of utter confusion and chaos.

These brazen efforts to denounce, insult, and slander the court and to paralyze the trial are at war with the concept of justice under law. Laymen, foolishly trying to defend themselves, may understandably create awkward and embarrassing scenes. Yet that is not the character of the record revealed here. We have here downright insults of a trial judge, and tactics taken from street brawls and transported to the courtroom. This is conduct not "befitting an American courtroom," and criminal contempt is one appropriate remedy.

As these separate acts or outbursts took place, the arsenal of authority described in Allen was available to the trial judge to keep order in the courtroom. He could, with propriety, have instantly acted, holding petitioner in contempt, or excluding him from the courtroom, or otherwise insulating his vulgarity from the courtroom. The Court noted in Sacher v. United States, that, while instant action may be taken against a lawyer who is guilty of contempt, to 
pronounce him guilty of contempt is "not unlikely to prejudice his client." Those considerations are not pertinent here where petitioner undertook to represent himself. In Sacher the trial judge waited until the end of the trial to impose punishment for contempt, the Court saying:

If we were to hold that summary punishment can be imposed only instantly upon the event, it would be an incentive to pronounce, while smarting under the irritation of the contemptuous act, what should be a well-considered judgment. We think it less likely that unfair condemnation of counsel will occur if the more deliberate course be permitted.

Generalizations are difficult. Instant treatment of contempt where lawyers are involved may greatly prejudice their clients but it may be the only wise course where others are involved. Moreover, we do not say that the more vicious the attack on the judge the less qualified he is to act. A judge cannot be driven out of a case. Where, however, he does not act the instant the contempt is committed, but waits until the end of the trial, on balance, it is generally wise where the marks of the unseemly conduct have left personal stings to ask a fellow judge to take his place. What Chief Justice Taft said in Cooke v. United States is relevant here:

The power of contempt which a judge must have and exercise in protecting the due and orderly administration of justice and in maintaining the authority and dignity of the court is most important and indispensable. But its exercise is a delicate one and care is needed to avoid arbitrary or oppressive conclusions. This rule of caution is more mandatory where the contempt charged has in it the element of personal criticism or attack upon the judge. The judge must banish the slightest personal impulse to reprisal, but he should not bend backward and injure the authority of the court by too great leniency. The substitution of another judge would avoid either tendency but it is not always possible. Of course where acts of contempt are palpably aggravated by a personal attack upon the judge in order to drive the judge out of the case for ulterior reasons, the scheme should not be permitted to succeed. But attempts of this kind are rare. All of such cases, however, present difficult questions for the judge. All we can say upon the whole matter is that where conditions do not make it impracticable, or where the delay may not injure public or private right, a judge called upon to act in a case of contempt by personal attack upon him, may, without flinching from his duty, properly ask that one of his fellow judges take his place.

We conclude that that course should have been followed here, as marked personal feelings were present on both sides.

Whether the trial be federal or state, the concern of due process is with the fair administration of justice. At times a judge has not been the image of "the impersonal authority of law," but has become so "personally embroiled" with a lawyer in the trial as to make the judge unfit to sit in judgment on the contempt charge. 
"The vital point is that in sitting in judgment on such a misbehaving lawyer the judge should not himself give vent to personal spleen or respond to a personal grievance. These are subtle matters, for they concern the ingredients of what constitutes justice. Therefore, justice must satisfy the appearance of justice."

Offutt does not fit this case, for the state judge in the instant controversy was not an activist seeking combat. Rather, he was the target of petitioner's insolence. Yet a judge, vilified as was this Pennsylvania judge, necessarily becomes embroiled in a running, bitter controversy. No one so cruelly slandered is likely to maintain that calm detachment necessary for fair adjudication. In re Murchison was a case where a judge acted under state law as a one-man grand jury and later tried witnesses for contempt who refused to answer questions propounded by the "judge-grand jury." We held that since the judge who sat as a one-man grand jury was part of the accusatory process he "cannot be, in the very nature of things, wholly disinterested in the conviction or acquittal of those accused." "Fair trials are too important a part of our free society to let prosecuting judges be trial judges of the charges they prefer."

It is, of course, not every attack on a judge that disqualifies him from sitting. In Ungar v. Sarafite, we ruled that a lawyer's challenge, though "disruptive, recalcitrant and disagreeable commentary," was still not "an insulting attack upon the integrity of the judge carrying such potential for bias as to require disqualification." Many of the words leveled at the judge in the instant case were highly personal aspersions, even "fighting words"-_"dirty sonofabitch," "dirty tyrannical old dog," "stumbling dog," and "fool." He was charged with running a Spanish Inquisition and told to "Go to hell" and "Keep your mouth shut." Insults of that kind are apt to strike "at the most vulnerable and human qualities of a judge's temperament."

Our conclusion is that by reason of the Due Process Clause of the Fourteenth Amendment a defendant in criminal contempt proceedings should be given a public trial before a judge other than the one reviled by the contemnor. In the present case that requirement can be satisfied only if the judgment of contempt is vacated so that on remand another judge, not bearing the sting of these slanderous remarks and having the impersonal authority of the law, sits in judgment on the conduct of petitioner as shown by the record. 


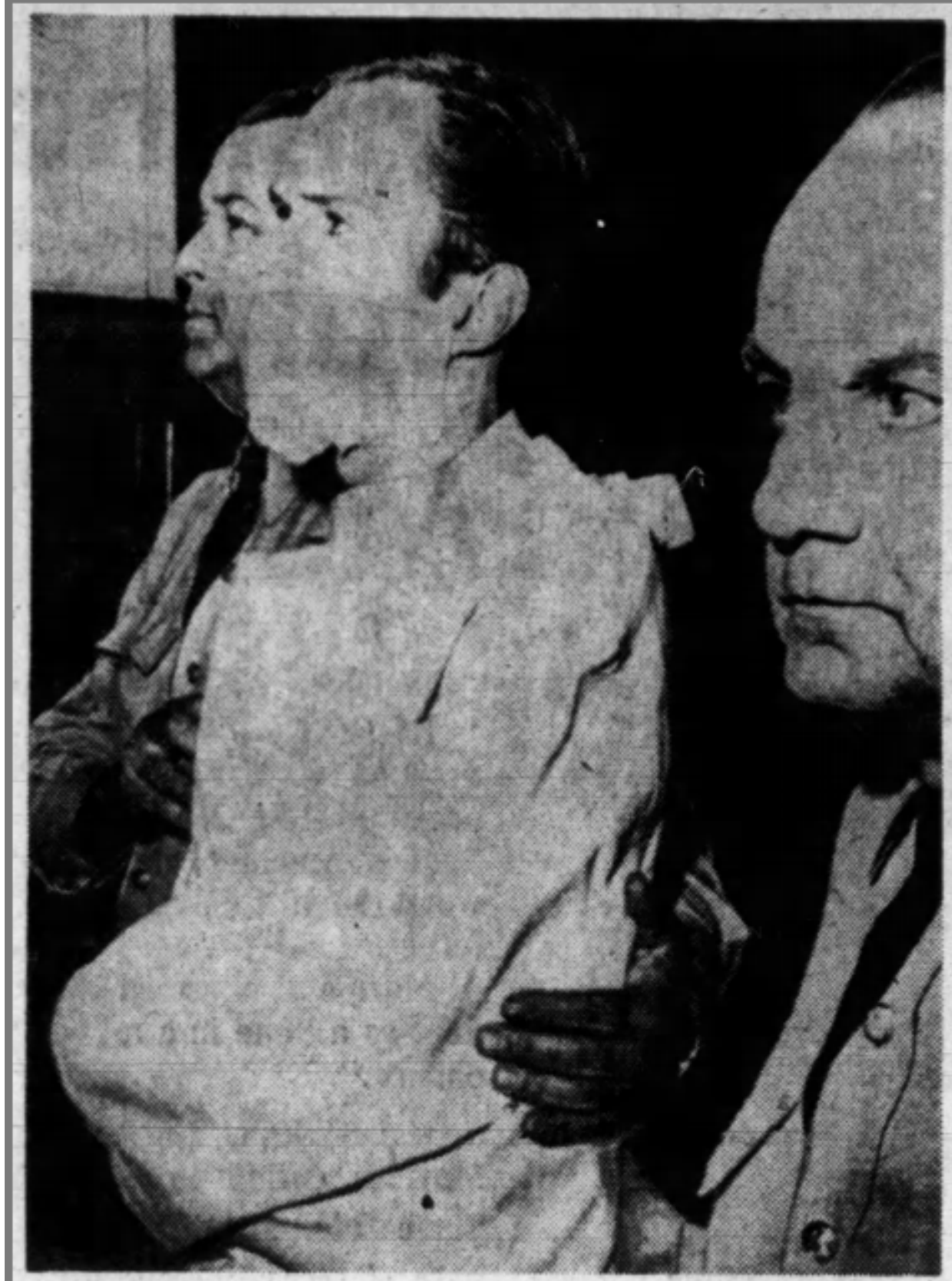

CONVICT GOES TO COURT IN STRAITJACKET Richard Mayberry restrained after outburst.-(AP)

Oakland Tribune, Dec. 10, 1966, at 2

\section{Questions:}

1. On June 27, 1965, Richard O.J. Mayberry, Dominick Codispopi, and Herbert Langes tried to escape from Western State Penitentiary in Pittsburgh, Pennsylvania. Mayberry was originally convicted of armed robbery in 1957, and was serving 3.5 to 10 years for a 
previous escape attempt in 1961. Mayberry, Codispoti, and Langes armed themselves with zip guns and homemade bombs, and took two guards hostage in the prison hospital. They surrendered after 90 minutes, when the state police bombarded them with tear gas, and released their hostages unharmed. Mayberry's hand was injured when one of the bombs exploded while he was throwing it. Mayberry became a legendary "jailhouse lawyer." Two of his petitions for certiorari were accepted by the Supreme Court, and several of the actions he filed led to significant prison reform. Today, Mayberry is still incarcerated in the Pennsylvania State Correctional Institution at Huntingdon.

2. Why did the Court hold that due process required the judge to recuse himself from deciding the criminal contempt charges? Did Mayberry receive any due process on those charges?

3. Mayberry, Codispoti, and Langes were all charged with contempt. On remand, all three were convicted of criminal contempt of court in non-jury trials, and sentenced to multiple consecutive terms, amounting to about 3 years. The Pennsylvania Supreme Court affirmed, but the Supreme Court granted certiorari and reversed, holding that criminal defendants in a contempt proceeding are entitled to a jury trial if the cumulative sentence could exceed 6 months. Codispoti v. Pennsylvania, 418 U.S. 506 (1974).

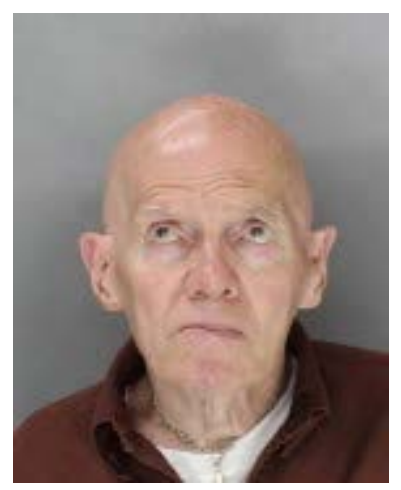

Richard Mayberry (2018) 


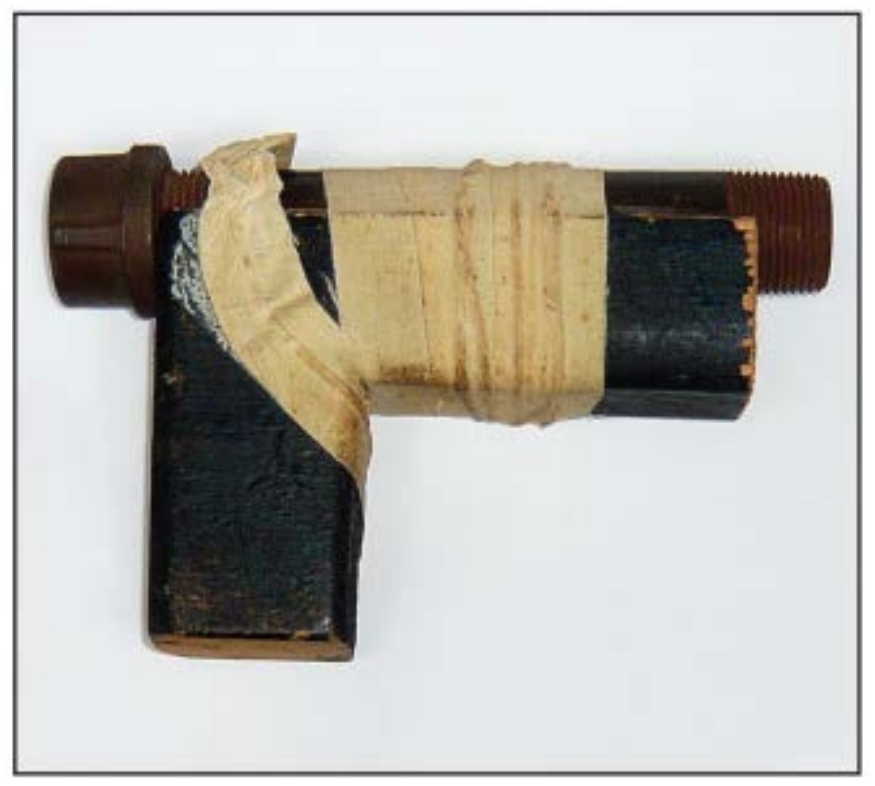

Zip gun used in prison escape attempt

\section{Further Reading:}

- Steven R. Jenkins, Mayberry v. Pennsylvania: Due Process Limitation in Summary Punishments for Contempt of Court, 25 Sw L.J. 805 (1971)

- Contempt: Mayberry v. Pennsylvania, 400 U.S. 455 (1971), 62 J. Crim. L. Criminology \& Police Sci. 525 (1971)

Caperton v. A.T. Massey Coal Co., Inc., 556 U.S. 868 (2009)

Summary: In 2002, Caperton won a business tort action against Massey and Blankenship, and received a $\$ 50$ million damages award, which Massey and Blankenship appealed. In the meantime, Benjamin ran for a seat on the Supreme Court of Appeals of West Virginia. Blankenship spent about \$3 million campaigning for Benjamin. When Benjamin won, Caperton filed a motion to disqualify Benjamin from the appeal, which Benjamin denied. The Supreme Court of Appeals granted the appeal and reversed. Benjamin also declined to recuse on rehearing, and the court once again reversed. The Supreme Court granted certiorari and reversed, holding that due process requires recusal when the facts create an objective appearance of impropriety. The dissent argued that the standard adopted by the majority was arbitrary and unworkable.

Justice KENNEDY delivered the opinion of the Court.

In this case the Supreme Court of Appeals of West Virginia reversed a trial court judgment, which had entered a jury verdict of $\$ 50$ million. Five justices heard the case, and the vote to reverse was 3 to 2. The question presented is whether the Due Process Clause of the Fourteenth Amendment was violated when one of the justices in the majority denied a recusal motion. The basis for the motion was that the justice had received campaign contributions in an 
extraordinary amount from, and through the efforts of, the board chairman and principal officer of the corporation found liable for the damages.

Under our precedents there are objective standards that require recusal when "the probability of actual bias on the part of the judge or decisionmaker is too high to be constitutionally tolerable." Applying those precedents, we find that, in all the circumstances of this case, due process requires recusal.

In August 2002 a West Virginia jury returned a verdict that found respondents A.T. Massey Coal Co. and its affiliates liable for fraudulent misrepresentation, concealment, and tortious interference with existing contractual relations. The jury awarded petitioners Hugh Caperton, Harman Development Corp., Harman Mining Corp., and Sovereign Coal Sales the sum of $\$ 50$ million in compensatory and punitive damages.

In June 2004 the state trial court denied Massey's post-trial motions challenging the verdict and the damages award, finding that Massey "intentionally acted in utter disregard of Caperton's rights and ultimately destroyed Caperton's businesses because, after conducting cost-benefit analyses, Massey concluded it was in its financial interest to do so." In March 2005 the trial court denied Massey's motion for judgment as a matter of law.

Don Blankenship is Massey's chairman, chief executive officer, and president. After the verdict but before the appeal, West Virginia held its 2004 judicial elections. Knowing the Supreme Court of Appeals of West Virginia would consider the appeal in the case, Blankenship decided to support an attorney who sought to replace Justice McGraw. Justice McGraw was a candidate for reelection to that court. The attorney who sought to replace him was Brent Benjamin.

In addition to contributing the $\$ 1,000$ statutory maximum to Benjamin's campaign committee, Blankenship donated almost $\$ 2.5$ million to "And For The Sake Of The Kids." The $\S 527$ organization opposed McGraw and supported Benjamin. Blankenship's donations accounted for more than two-thirds of the total funds it raised. This was not all. Blankenship spent, in addition, just over $\$ 500,000$ on independent expenditures-for direct mailings and letters soliciting donations as well as television and newspaper advertisements—-to support Brent Benjamin."

To provide some perspective, Blankenship's $\$ 3$ million in contributions were more than the total amount spent by all other Benjamin supporters and three times the amount spent by Benjamin's own committee. Caperton contends that Blankenship spent \$1 million more than the total amount spent by the campaign committees of both candidates combined.

Benjamin won. He received 382,036 votes (53.3\%), and McGraw received 334,301 votes $(46.7 \%)$. 
In October 2005, before Massey filed its petition for appeal in West Virginia's highest court, Caperton moved to disqualify now-Justice Benjamin under the Due Process Clause and the West Virginia Code of Judicial Conduct, based on the conflict caused by Blankenship's campaign involvement. Justice Benjamin denied the motion in April 2006. He indicated that he "carefully considered the bases and accompanying exhibits proffered by the movants." But he found "no objective information to show that this Justice has a bias for or against any litigant, that this Justice has prejudged the matters which comprise this litigation, or that this Justice will be anything but fair and impartial." In December 2006 Massey filed its petition for appeal to challenge the adverse jury verdict. The West Virginia Supreme Court of Appeals granted review.

In November 2007 that court reversed the $\$ 50$ million verdict against Massey. The majority opinion, authored by then-Chief Justice Davis and joined by Justices Benjamin and Maynard, found that "Massey's conduct warranted the type of judgment rendered in this case." It reversed, nevertheless, based on two independent grounds - first, that a forum-selection clause contained in a contract to which Massey was not a party barred the suit in West Virginia, and, second, that res judicata barred the suit due to an out-of-state judgment to which Massey was not a party. Justice Starcher dissented, stating that the "majority's opinion is morally and legally wrong." Justice Albright also dissented, accusing the majority of "misapplying the law and introducing sweeping 'new law' into our jurisprudence that may well come back to haunt us."

Caperton sought rehearing, and the parties moved for disqualification of three of the five justices who decided the appeal. Photos had surfaced of Justice Maynard vacationing with Blankenship in the French Riviera while the case was pending. Justice Maynard granted Caperton's recusal motion. On the other side Justice Starcher granted Massey's recusal motion, apparently based on his public criticism of Blankenship's role in the 2004 elections. In his recusal memorandum Justice Starcher urged Justice Benjamin to recuse himself as well. He noted that "Blankenship's bestowal of his personal wealth, political tactics, and 'friendship' have created a cancer in the affairs of this Court." Justice Benjamin declined Justice Starcher's suggestion and denied Caperton's recusal motion.

The court granted rehearing. Justice Benjamin, now in the capacity of acting chief justice, selected Judges Cookman and Fox to replace the recused justices. Caperton moved a third time for disqualification, arguing that Justice Benjamin had failed to apply the correct standard under West Virginia law - i.e., whether "a reasonable and prudent person, knowing these objective facts, would harbor doubts about Justice Benjamin's ability to be fair and impartial." Caperton also included the results of a public opinion poll, which indicated that over $67 \%$ of West Virginians doubted Justice Benjamin would be fair and impartial. Justice Benjamin again refused to withdraw, noting that the "push poll" was "neither credible nor sufficiently reliable to serve as the basis for an elected judge's disqualification."

In April 2008 a divided court again reversed the jury verdict, and again it was a 3-to-2 decision. Justice Davis filed a modified version of her prior opinion, repeating the two earlier holdings. She was joined by Justice Benjamin and Judge Fox. Justice Albright, joined by Judge Cookman, dissented: "Not only is the majority opinion unsupported by the facts and existing 
case law, but it is also fundamentally unfair. Sadly, justice was neither honored nor served by the majority." The dissent also noted "genuine due process implications arising under federal law" with respect to Justice Benjamin's failure to recuse himself.

Four months later - a month after the petition for writ of certiorari was filed in this Court Justice Benjamin filed a concurring opinion. He defended the merits of the majority opinion as well as his decision not to recuse. He rejected Caperton's challenge to his participation in the case under both the Due Process Clause and West Virginia law. Justice Benjamin reiterated that he had no "'direct, personal, substantial, pecuniary interest' in this case." Adopting "a standard merely of 'appearances," he concluded, "seems little more than an invitation to subject West Virginia's justice system to the vagaries of the day - a framework in which predictability and stability yield to supposition, innuendo, half-truths, and partisan manipulations."

We granted certiorari.

It is axiomatic that "a fair trial in a fair tribunal is a basic requirement of due process." As the Court has recognized, however, "most matters relating to judicial disqualification do not rise to a constitutional level." The early and leading case on the subject is Tumey v. Ohio (1927). There, the Court stated that "matters of kinship, personal bias, state policy, remoteness of interest, would seem generally to be matters merely of legislative discretion."

The Tumey Court concluded that the Due Process Clause incorporated the common-law rule that a judge must recuse himself when he has "a direct, personal, substantial, pecuniary interest" in a case. This rule reflects the maxim that "no man is allowed to be a judge in his own cause; because his interest would certainly bias his judgment, and, not improbably, corrupt his integrity." Under this rule, "disqualification for bias or prejudice was not permitted"; those matters were left to statutes and judicial codes. Personal bias or prejudice "alone would not be sufficient basis for imposing a constitutional requirement under the Due Process Clause."

As new problems have emerged that were not discussed at common law, however, the Court has identified additional instances which, as an objective matter, require recusal. These are circumstances "in which experience teaches that the probability of actual bias on the part of the judge or decisionmaker is too high to be constitutionally tolerable." To place the present case in proper context, two instances where the Court has required recusal merit further discussion.

\section{A}

The first involved the emergence of local tribunals where a judge had a financial interest in the outcome of a case, although the interest was less than what would have been considered personal or direct at common law. 
This was the problem addressed in Tumey. There, the mayor of a village had the authority to sit as a judge (with no jury) to try those accused of violating a state law prohibiting the possession of alcoholic beverages. Inherent in this structure were two potential conflicts. First, the mayor received a salary supplement for performing judicial duties, and the funds for that compensation derived from the fines assessed in a case. No fines were assessed upon acquittal. The mayorjudge thus received a salary supplement only if he convicted the defendant. Second, sums from the criminal fines were deposited to the village's general treasury fund for village improvements and repairs.

The Court held that the Due Process Clause required disqualification "both because of the mayor-judge's direct pecuniary interest in the outcome, and because of his official motive to convict and to graduate the fine to help the financial needs of the village." It so held despite observing that "there are doubtless mayors who would not allow such a consideration as $\$ 12$ costs in each case to affect their judgment in it." The Court articulated the controlling principle:

Every procedure which would offer a possible temptation to the average man as a judge to forget the burden of proof required to convict the defendant, or which might lead him not to hold the balance nice, clear and true between the State and the accused, denies the latter due process of law.

The Court was thus concerned with more than the traditional common-law prohibition on direct pecuniary interest. It was also concerned with a more general concept of interests that tempt adjudicators to disregard neutrality.

This concern with conflicts resulting from financial incentives was elaborated in Ward $v$. Monroeville (1972), which invalidated a conviction in another mayor's court. In Monroeville, unlike in Tumey, the mayor received no money; instead, the fines the mayor assessed went to the town's general fisc. The Court held that "the fact that the mayor in Tumey shared directly in the fees and costs did not define the limits of the principle." The principle, instead, turned on the "possible temptation" the mayor might face; the mayor's "executive responsibilities for village finances may make him partisan to maintain the high level of contribution to those finances from the mayor's court." As the Court reiterated in another case that Term, "the judge's financial stake need not be as direct or positive as it appeared to be in Tumey."

The Court in Lavoie further clarified the reach of the Due Process Clause regarding a judge's financial interest in a case. There, a justice had cast the deciding vote on the Alabama Supreme Court to uphold a punitive damages award against an insurance company for bad-faith refusal to pay a claim. At the time of his vote, the justice was the lead plaintiff in a nearly identical lawsuit pending in Alabama's lower courts. His deciding vote, this Court surmised, "undoubtedly 'raised the stakes'” for the insurance defendant in the justice's suit.

The Court stressed that it was "not required to decide whether in fact the justice was influenced." The proper constitutional inquiry is "whether sitting on the case then before the Supreme Court of Alabama "would offer a possible temptation to the average judge to lead him 
not to hold the balance nice, clear and true." The Court underscored that "what degree or kind of interest is sufficient to disqualify a judge from sitting cannot be defined with precision." In the Court's view, however, it was important that the test have an objective component.

The Lavoie Court proceeded to distinguish the state-court justice's particular interest in the case, which required recusal, from interests that were not a constitutional concern. For instance, "while the other justices might conceivably have had a slight pecuniary interest" due to their potential membership in a class-action suit against their own insurance companies, that interest is "too remote and insubstantial to violate the constitutional constraints."

B

The second instance requiring recusal that was not discussed at common law emerged in the criminal contempt context, where a judge had no pecuniary interest in the case but was challenged because of a conflict arising from his participation in an earlier proceeding. This Court characterized that first proceeding (perhaps pejoratively) as a "one-man grand jury."

In that first proceeding, and as provided by state law, a judge examined witnesses to determine whether criminal charges should be brought. The judge called the two petitioners before him. One petitioner answered questions, but the judge found him untruthful and charged him with perjury. The second declined to answer on the ground that he did not have counsel with him, as state law seemed to permit. The judge charged him with contempt. The judge proceeded to try and convict both petitioners.

This Court set aside the convictions on grounds that the judge had a conflict of interest at the trial stage because of his earlier participation followed by his decision to charge them. The Due Process Clause required disqualification. The Court recited the general rule that "no man can be a judge in his own case," adding that "no man is permitted to try cases where he has an interest in the outcome." It noted that the disqualifying criteria "cannot be defined with precision.

Circumstances and relationships must be considered." These circumstances and the prior relationship required recusal: "Having been a part of the one-man grand jury process a judge cannot be, in the very nature of things, wholly disinterested in the conviction or acquittal of those accused." That is because "as a practical matter it is difficult if not impossible for a judge to free himself from the influence of what took place in his 'grand-jury' secret session."

The Murchison Court was careful to distinguish the circumstances and the relationship from those where the Constitution would not require recusal. It noted that the single-judge grand jury is "more a part of the accusatory process than an ordinary lay grand juror," and that "adjudication by a trial judge of a contempt committed in a judge's presence in open court cannot be likened to the proceedings here." The judge's prior relationship with the defendant, as well as the information acquired from the prior proceeding, was of critical import.

Following Murchison the Court held in Mayberry v. Pennsylvania (1971), "that by reason of the Due Process Clause of the Fourteenth Amendment a defendant in criminal contempt 
proceedings should be given a public trial before a judge other than the one reviled by the contemnor." The Court reiterated that this rule rests on the relationship between the judge and the defendant: "A judge, vilified as was this Pennsylvania judge, necessarily becomes embroiled in a running, bitter controversy. No one so cruelly slandered is likely to maintain that calm detachment necessary for fair adjudication."

Again, the Court considered the specific circumstances presented by the case. It noted that "not every attack on a judge disqualifies him from sitting." The Court distinguished the case from Ungar v. Sarafite (1964), in which the Court had "ruled that a lawyer's challenge, though 'disruptive, recalcitrant and disagreeable commentary,' was still not 'an insulting attack upon the integrity of the judge carrying such potential for bias as to require disqualification." The inquiry is an objective one. The Court asks not whether the judge is actually, subjectively biased, but whether the average judge in his position is "likely" to be neutral, or whether there is an unconstitutional "potential for bias."

III

Based on the principles described in these cases we turn to the issue before us. This problem arises in the context of judicial elections, a framework not presented in the precedents we have reviewed and discussed.

Caperton contends that Blankenship's pivotal role in getting Justice Benjamin elected created a constitutionally intolerable probability of actual bias. Though not a bribe or criminal influence, Justice Benjamin would nevertheless feel a debt of gratitude to Blankenship for his extraordinary efforts to get him elected. That temptation, Caperton claims, is as strong and inherent in human nature as was the conflict the Court confronted in Tumey and Monroeville when a mayor-judge (or the city) benefited financially from a defendant's conviction, as well as the conflict identified in Murchison and Mayberry when a judge was the object of a defendant's contempt.

Justice Benjamin was careful to address the recusal motions and explain his reasons why, on his view of the controlling standard, disqualification was not in order. In four separate opinions issued during the course of the appeal, he explained why no actual bias had been established. He found no basis for recusal because Caperton failed to provide "objective evidence" or "objective information," but merely "subjective belief" of bias. Nor could anyone "point to any actual conduct or activity on his part which could be termed 'improper." In other words, based on the facts presented by Caperton, Justice Benjamin conducted a probing search into his actual motives and inclinations; and he found none to be improper. We do not question his subjective findings of impartiality and propriety. Nor do we determine whether there was actual bias.

Following accepted principles of our legal tradition respecting the proper performance of judicial functions, judges often inquire into their subjective motives and purposes in the ordinary course of deciding a case. This does not mean the inquiry is a simple one. "The work of deciding cases goes on every day in hundreds of courts throughout the land. Any judge, one might suppose, 
would find it easy to describe the process which he had followed a thousand times and more. Nothing could be farther from the truth."

The judge inquires into reasons that seem to be leading to a particular result. Precedent and stare decisis and the text and purpose of the law and the Constitution; logic and scholarship and experience and common sense; and fairness and disinterest and neutrality are among the factors at work. To bring coherence to the process, and to seek respect for the resulting judgment, judges often explain the reasons for their conclusions and rulings. There are instances when the introspection that often attends this process may reveal that what the judge had assumed to be a proper, controlling factor is not the real one at work. If the judge discovers that some personal bias or improper consideration seems to be the actuating cause of the decision or to be an influence so difficult to dispel that there is a real possibility of undermining neutrality, the judge may think it necessary to consider withdrawing from the case.

The difficulties of inquiring into actual bias, and the fact that the inquiry is often a private one, simply underscore the need for objective rules. Otherwise there may be no adequate protection against a judge who simply misreads or misapprehends the real motives at work in deciding the case. The judge's own inquiry into actual bias, then, is not one that the law can easily superintend or review, though actual bias, if disclosed, no doubt would be grounds for appropriate relief. In lieu of exclusive reliance on that personal inquiry, or on appellate review of the judge's determination respecting actual bias, the Due Process Clause has been implemented by objective standards that do not require proof of actual bias. In defining these standards the Court has asked whether, "under a realistic appraisal of psychological tendencies and human weakness," the interest "poses such a risk of actual bias or prejudgment that the practice must be forbidden if the guarantee of due process is to be adequately implemented."

We turn to the influence at issue in this case. Not every campaign contribution by a litigant or attorney creates a probability of bias that requires a judge's recusal, but this is an exceptional case. We conclude that there is a serious risk of actual bias - based on objective and reasonable perceptions - when a person with a personal stake in a particular case had a significant and disproportionate influence in placing the judge on the case by raising funds or directing the judge's election campaign when the case was pending or imminent. The inquiry centers on the contribution's relative size in comparison to the total amount of money contributed to the campaign, the total amount spent in the election, and the apparent effect such contribution had on the outcome of the election.

Applying this principle, we conclude that Blankenship's campaign efforts had a significant and disproportionate influence in placing Justice Benjamin on the case. Blankenship contributed some $\$ 3$ million to unseat the incumbent and replace him with Benjamin. His contributions eclipsed the total amount spent by all other Benjamin supporters and exceeded by $300 \%$ the amount spent by Benjamin's campaign committee. Caperton claims Blankenship spent \$1 million more than the total amount spent by the campaign committees of both candidates combined. 
Massey responds that Blankenship's support, while significant, did not cause Benjamin's victory. In the end the people of West Virginia elected him, and they did so based on many reasons other than Blankenship's efforts. Massey points out that every major state newspaper, but one, endorsed Benjamin. It also contends that then-Justice McGraw cost himself the election by giving a speech during the campaign, a speech the opposition seized upon for its own advantage.

Justice Benjamin raised similar arguments. He asserted that "the outcome of the 2004 election was due primarily to his own campaign's message," as well as McGraw's "devastating" speech in which he "made a number of controversial claims which became a matter of statewide discussion in the media, on the internet, and elsewhere."

Whether Blankenship's campaign contributions were a necessary and sufficient cause of Benjamin's victory is not the proper inquiry. Much like determining whether a judge is actually biased, proving what ultimately drives the electorate to choose a particular candidate is a difficult endeavor, not likely to lend itself to a certain conclusion. This is particularly true where, as here, there is no procedure for judicial factfinding and the sole trier of fact is the one accused of bias. Due process requires an objective inquiry into whether the contributor's influence on the election under all the circumstances "would offer a possible temptation to the average judge to lead him not to hold the balance nice, clear and true." In an election decided by fewer than 50,000 votes $(382,036$ to 334,301$)$, Blankenship's campaign contributions - in comparison to the total amount contributed to the campaign, as well as the total amount spent in the election - had a significant and disproportionate influence on the electoral outcome. And the risk that Blankenship's influence engendered actual bias is sufficiently substantial that it "must be forbidden if the guarantee of due process is to be adequately implemented."

The temporal relationship between the campaign contributions, the justice's election, and the pendency of the case is also critical. It was reasonably foreseeable, when the campaign contributions were made, that the pending case would be before the newly elected justice. The $\$ 50$ million adverse jury verdict had been entered before the election, and the Supreme Court of Appeals was the next step once the state trial court dealt with post-trial motions. So it became at once apparent that, absent recusal, Justice Benjamin would review a judgment that cost his biggest donor's company $\$ 50$ million. Although there is no allegation of a quid pro quo agreement, the fact remains that Blankenship's extraordinary contributions were made at a time when he had a vested stake in the outcome. Just as no man is allowed to be a judge in his own cause, similar fears of bias can arise when - without the consent of the other parties - a man chooses the judge in his own cause. And applying this principle to the judicial election process, there was here a serious, objective risk of actual bias that required Justice Benjamin's recusal.

Justice Benjamin did undertake an extensive search for actual bias. But, as we have indicated, that is just one step in the judicial process; objective standards may also require recusal whether or not actual bias exists or can be proved. Due process "may sometimes bar trial by judges who have no actual bias and who would do their very best to weigh the scales of justice equally between contending parties." The failure to consider objective standards requiring 
recusal is not consistent with the imperatives of due process. We find that Blankenship's significant and disproportionate influence - coupled with the temporal relationship between the election and the pending case - "offers a possible temptation to the average judge to lead him not to hold the balance nice, clear and true." On these extreme facts the probability of actual bias rises to an unconstitutional level.

\section{IV}

Our decision today addresses an extraordinary situation where the Constitution requires recusal. Massey and its amici predict that various adverse consequences will follow from recognizing a constitutional violation here - ranging from a flood of recusal motions to unnecessary interference with judicial elections. We disagree. The facts now before us are extreme by any measure. The parties point to no other instance involving judicial campaign contributions that presents a potential for bias comparable to the circumstances in this case.

It is true that extreme cases often test the bounds of established legal principles, and sometimes no administrable standard may be available to address the perceived wrong. But it is also true that extreme cases are more likely to cross constitutional limits, requiring this Court's intervention and formulation of objective standards. This is particularly true when due process is violated.

This Court's recusal cases are illustrative. In each case the Court dealt with extreme facts that created an unconstitutional probability of bias that "cannot be defined with precision." Yet the Court articulated an objective standard to protect the parties' basic right to a fair trial in a fair tribunal. The Court was careful to distinguish the extreme facts of the cases before it from those interests that would not rise to a constitutional level. In this case we do nothing more than what the Court has done before.

As such, it is worth noting the effects, or lack thereof, of the Court's prior decisions. Even though the standards announced in those cases raised questions similar to those that might be asked after our decision today, the Court was not flooded with Monroeville or Murchison motions. That is perhaps due in part to the extreme facts those standards sought to address. Courts proved quite capable of applying the standards to less extreme situations.

One must also take into account the judicial reforms the States have implemented to eliminate even the appearance of partiality. Almost every State — West Virginia included — has adopted the American Bar Association's objective standard: "A judge shall avoid impropriety and the appearance of impropriety." The ABA Model Code's test for appearance of impropriety is "whether the conduct would create in reasonable minds a perception that the judge's ability to carry out judicial responsibilities with integrity, impartiality and competence is impaired."

The West Virginia Code of Judicial Conduct also requires a judge to "disqualify himself or herself in a proceeding in which the judge's impartiality might reasonably be questioned." Under Canon $3 E(1)$, "the question of disqualification focuses on whether an objective assessment of 
the judge's conduct produces a reasonable question about impartiality, not on the judge's subjective perception of the ability to act fairly." Indeed, some States require recusal based on campaign contributions similar to those in this case.

These codes of conduct serve to maintain the integrity of the judiciary and the rule of law. The Conference of the Chief Justices has underscored that the codes are "the principal safeguard against judicial campaign abuses" that threaten to imperil "public confidence in the fairness and integrity of the nation's elected judges." This is a vital state interest:

Courts, in our system, elaborate principles of law in the course of resolving disputes. The power and the prerogative of a court to perform this function rest, in the end, upon the respect accorded to its judgments. The citizen's respect for judgments depends in turn upon the issuing court's absolute probity. Judicial integrity is, in consequence, a state interest of the highest order.

It is for this reason that States may choose to "adopt recusal standards more rigorous than due process requires."

"The Due Process Clause demarks only the outer boundaries of judicial disqualifications. Congress and the states, of course, remain free to impose more rigorous standards for judicial disqualification than those we find mandated here today." Because the codes of judicial conduct provide more protection than due process requires, most disputes over disqualification will be resolved without resort to the Constitution. Application of the constitutional standard implicated in this case will thus be confined to rare instances.

The judgment of the Supreme Court of Appeals of West Virginia is reversed, and the case is remanded for further proceedings not inconsistent with this opinion.

Chief Justice ROBERTS, with whom Justice SCALIA, Justice THOMAS, and Justice ALITO join, dissenting.

I, of course, share the majority's sincere concerns about the need to maintain a fair, independent, and impartial judiciary - and one that appears to be such. But I fear that the Court's decision will undermine rather than promote these values.

Until today, we have recognized exactly two situations in which the Federal Due Process Clause requires disqualification of a judge: when the judge has a financial interest in the outcome of the case, and when the judge is trying a defendant for certain criminal contempts. Vaguer notions of bias or the appearance of bias were never a basis for disqualification, either at common law or under our constitutional precedents. Those issues were instead addressed by legislation or court rules.

Today, however, the Court enlists the Due Process Clause to overturn a judge's failure to recuse because of a "probability of bias." Unlike the established grounds for disqualification, a 
"probability of bias" cannot be defined in any limited way. The Court's new "rule" provides no guidance to judges and litigants about when recusal will be constitutionally required. This will inevitably lead to an increase in allegations that judges are biased, however groundless those charges may be. The end result will do far more to erode public confidence in judicial impartiality than an isolated failure to recuse in a particular case.

\section{I}

There is a "presumption of honesty and integrity in those serving as adjudicators." All judges take an oath to uphold the Constitution and apply the law impartially, and we trust that they will live up to this promise. We have thus identified only two situations in which the Due Process Clause requires disqualification of a judge: when the judge has a financial interest in the outcome of the case, and when the judge is presiding over certain types of criminal contempt proceedings.

It is well established that a judge may not preside over a case in which he has a "direct, personal, substantial, pecuniary interest." This principle is relatively straightforward, and largely tracks the longstanding common-law rule regarding judicial recusal. For example, a defendant's due process rights are violated when he is tried before a judge who is "paid for his service only when he convicts the defendant."

It may also violate due process when a judge presides over a criminal contempt case that resulted from the defendant's hostility towards the judge. In Mayberry, the defendant directed a steady stream of expletives and ad hominem attacks at the judge throughout the trial. When that defendant was subsequently charged with criminal contempt, we concluded that he "should be given a public trial before a judge other than the one reviled by the contemnor."

Our decisions in this area have also emphasized when the Due Process Clause does not require recusal:

All questions of judicial qualification may not involve constitutional validity. Thus matters of kinship, personal bias, state policy, remoteness of interest, would seem generally to be matters merely of legislative discretion.

Subject to the two well-established exceptions described above, questions of judicial recusal are regulated by "common law, statute, or the professional standards of the bench and bar."

In any given case, there are a number of factors that could give rise to a "probability" or "appearance" of bias: friendship with a party or lawyer, prior employment experience, membership in clubs or associations, prior speeches and writings, religious affiliation, and countless other considerations. We have never held that the Due Process Clause requires recusal for any of these reasons, even though they could be viewed as presenting a "probability of bias." Many state statutes require recusal based on a probability or appearance of bias, but "that alone would not be sufficient basis for imposing a constitutional requirement under the Due 
Process Clause." States are, of course, free to adopt broader recusal rules than the Constitution requires - and every State has - but these developments are not continuously incorporated into the Due Process Clause.

II

In departing from this clear line between when recusal is constitutionally required and when it is not, the majority repeatedly emphasizes the need for an "objective" standard. The majority's analysis is "objective" in that it does not inquire into Justice Benjamin's motives or decisionmaking process. But the standard the majority articulates - "probability of bias" — fails to provide clear, workable guidance for future cases. At the most basic level, it is unclear whether the new probability of bias standard is somehow limited to financial support in judicial elections, or applies to judicial recusal questions more generally.

But there are other fundamental questions as well. With little help from the majority, courts will now have to determine:

1. How much money is too much money? What level of contribution or expenditure gives rise to a "probability of bias"?

2. How do we determine whether a given expenditure is "disproportionate"? Disproportionate to what?

3. Are independent, non-coordinated expenditures treated the same as direct contributions to a candidate's campaign? What about contributions to independent outside groups supporting a candidate?

4. Does it matter whether the litigant has contributed to other candidates or made large expenditures in connection with other elections?

5. Does the amount at issue in the case matter? What if this case were an employment dispute with only $\$ 10,000$ at stake? What if the plaintiffs only sought non-monetary relief such as an injunction or declaratory judgment?

6. Does the analysis change depending on whether the judge whose disqualification is sought sits on a trial court, appeals court, or state supreme court?

7. How long does the probability of bias last? Does the probability of bias diminish over time as the election recedes? Does it matter whether the judge plans to run for reelection?

8. What if the "disproportionately" large expenditure is made by an industry association, trade union, physicians' group, or the plaintiffs' bar? Must the judge recuse in all cases that affect the association's interests? Must the judge recuse in all cases in which a party or lawyer is a member of that group? Does it matter how much the litigant contributed to the association?

9. What if the case involves a social or ideological issue rather than a financial one? Must a judge recuse from cases involving, say, abortion rights if he has received "disproportionate" support from individuals who feel strongly about either side of that issue? If the supporter wants to help elect judges who are "tough on crime," must the judge recuse in all criminal cases? 
10. What if the candidate draws "disproportionate" support from a particular racial, religious, ethnic, or other group, and the case involves an issue of particular importance to that group?

11. What if the supporter is not a party to the pending or imminent case, but his interests will be affected by the decision? Does the Court's analysis apply if the supporter "chooses the judge" not in his case, but in someone else's?

12. What if the case implicates a regulatory issue that is of great importance to the party making the expenditures, even though he has no direct financial interest in the outcome (e.g., a facial challenge to an agency rulemaking or a suit seeking to limit an agency's jurisdiction)?

13. Must the judge's vote be outcome determinative in order for his non-recusal to constitute a due process violation?

14. Does the due process analysis consider the underlying merits of the suit? Does it matter whether the decision is clearly right (or wrong) as a matter of state law?

15. What if a lower court decision in favor of the supporter is affirmed on the merits on appeal, by a panel with no "debt of gratitude" to the supporter? Does that "moot" the due process claim?

16. What if the judge voted against the supporter in many other cases?

17. What if the judge disagrees with the supporter's message or tactics? What if the judge expressly disclaims the support of this person?

18. Should we assume that elected judges feel a "debt of hostility" towards major opponents of their candidacies? Must the judge recuse in cases involving individuals or groups who spent large amounts of money trying unsuccessfully to defeat him?

19. If there is independent review of a judge's recusal decision, e.g., by a panel of other judges, does this completely foreclose a due process claim?

20. Does a debt of gratitude for endorsements by newspapers, interest groups, politicians, or celebrities also give rise to a constitutionally unacceptable probability of bias? How would we measure whether such support is disproportionate?

21. Does close personal friendship between a judge and a party or lawyer now give rise to a probability of bias?

22. Does it matter whether the campaign expenditures come from a party or the party's attorney? If from a lawyer, must the judge recuse in every case involving that attorney?

23. Does what is unconstitutional vary from State to State? What if particular States have a history of expensive judicial elections?

24. Under the majority's "objective" test, do we analyze the due process issue through the lens of a reasonable person, a reasonable lawyer, or a reasonable judge?

25. What role does causation play in this analysis? The Court sends conflicting signals on this point. The majority asserts that "whether Blankenship's campaign contributions were a necessary and sufficient cause of Benjamin's victory is not the proper inquiry." But elsewhere in the opinion, the majority considers "the apparent effect such contribution had on the outcome of the election," and whether the litigant has been able to "choose the judge in his own cause." If causation is a pertinent factor, how do we know whether the contribution or expenditure had any effect on the outcome of the election? What if 
the judge won in a landslide? What if the judge won primarily because of his opponent's missteps?

26. Is the due process analysis less probing for incumbent judges - who typically have a great advantage in elections - than for challengers?

27. How final must the pending case be with respect to the contributor's interest? What if, for example, the only issue on appeal is whether the court should certify a class of plaintiffs? Is recusal required just as if the issue in the pending case were ultimate liability?

28. Which cases are implicated by this doctrine? Must the case be pending at the time of the election? Reasonably likely to be brought? What about an important but unanticipated case filed shortly after the election?

29. When do we impute a probability of bias from one party to another? Does a contribution from a corporation get imputed to its executives, and vice-versa? Does a contribution or expenditure by one family member get imputed to other family members?

30. What if the election is nonpartisan? What if the election is just a yes-or-no vote about whether to retain an incumbent?

31. What type of support is disqualifying? What if the supporter's expenditures are used to fund voter registration or get-out-the-vote efforts rather than television advertisements?

32. Are contributions or expenditures in connection with a primary aggregated with those in the general election? What if the contributor supported a different candidate in the primary? Does that dilute the debt of gratitude?

33. What procedures must be followed to challenge a state judge's failure to recuse? May Caperton claims only be raised on direct review? Or may such claims also be brought in federal district court under 42 U.S.C. $\S 1983$, which allows a person deprived of a federal right by a state official to sue for damages? If $\S 1983$ claims are available, who are the proper defendants? The judge? The whole court? The clerk of court?

34. What about state-court cases that are already closed? Can the losing parties in those cases now seek collateral relief in federal district court under $\S 1983$ ? What statutes of limitation should be applied to such suits?

35. What is the proper remedy? After a successful Caperton motion, must the parties start from scratch before the lower courts? Is any part of the lower court judgment retained?

36. Does a litigant waive his due process claim if he waits until after decision to raise it? Or would the claim only be ripe after decision, when the judge's actions or vote suggest a probability of bias?

37. Are the parties entitled to discovery with respect to the judge's recusal decision?

38. If a judge erroneously fails to recuse, do we apply harmless-error review?

39. Does the judge get to respond to the allegation that he is probably biased, or is his reputation solely in the hands of the parties to the case?

40. What if the parties settle a Caperton claim as part of a broader settlement of the case? Does that leave the judge with no way to salvage his reputation?

These are only a few uncertainties that quickly come to mind. Judges and litigants will surely encounter others when they are forced to, or wish to, apply the majority's decision in different circumstances. Today's opinion requires state and federal judges simultaneously to act as 
political scientists (why did candidate $X$ win the election?), economists (was the financial support disproportionate?), and psychologists (is there likely to be a debt of gratitude?).

The Court's inability to formulate a "judicially discernible and manageable standard" strongly counsels against the recognition of a novel constitutional right. The need to consider these and countless other questions helps explain why the common law and this Court's constitutional jurisprudence have never required disqualification on such vague grounds as "probability" or "appearance" of bias.

III

A

To its credit, the Court seems to recognize that the inherently boundless nature of its new rule poses a problem. But the majority's only answer is that the present case is an "extreme" one, so there is no need to worry about other cases. The Court repeats this point over and over.

But this is just so much whistling past the graveyard. Claims that have little chance of success are nonetheless frequently filed. The success rate for certiorari petitions before this Court is approximately $1.1 \%$, and yet the previous Term some 8,241 were filed. Every one of the "Caperton motions" or appeals or $\S 1983$ actions will claim that the judge is biased, or probably biased, bringing the judge and the judicial system into disrepute. And all future litigants will assert that their case is really the most extreme thus far.

Extreme cases often test the bounds of established legal principles. There is a cost to yielding to the desire to correct the extreme case, rather than adhering to the legal principle. That cost has been demonstrated so often that it is captured in a legal aphorism: "Hard cases make bad law."

Consider the cautionary tale of our decisions in United States v. Halper and Hudson v. United States. Historically, we have held that the Double Jeopardy Clause only applies to criminal penalties, not civil ones. But in Halper, the Court held that a civil penalty could violate the Clause if it were "overwhelmingly disproportionate to the damages the defendant has caused" and resulted in a "clear injustice." We acknowledged that this inquiry would not be an "exact pursuit," but the Court assured litigants that it was only announcing "a rule for the rare case, the case such as the one before us."

Just eight years later, we granted certiorari in Hudson "because of concerns about the wide variety of novel double jeopardy claims spawned in the wake of Halper." The novel claim that we had recognized in Halper turned out not to be so "rare" after all, and the test we adopted in that case - "overwhelmingly disproportionate" — had "proved unworkable." We thus abandoned the Halper rule, ruing our "ill considered" "deviation from longstanding double jeopardy principles." 
The déjà vu is enough to make one swoon. Today, the majority again departs from a clear, longstanding constitutional rule to accommodate an "extreme" case involving "grossly disproportionate" amounts of money. I believe we will come to regret this decision as well, when courts are forced to deal with a wide variety of Caperton motions, each claiming the title of "most extreme" or "most disproportionate."

\section{B}

And why is the Court so convinced that this is an extreme case? It is true that Don Blankenship spent a large amount of money in connection with this election. But this point cannot be emphasized strongly enough: Other than a $\$ 1,000$ direct contribution from Blankenship, Justice Benjamin and his campaign had no control over how this money was spent. Campaigns go to great lengths to develop precise messages and strategies. An insensitive or ham-handed ad campaign by an independent third party might distort the campaign's message or cause a backlash against the candidate, even though the candidate was not responsible for the ads. The majority repeatedly characterizes Blankenship's spending as "contributions" or "campaign contributions," but it is more accurate to refer to them as "independent expenditures." Blankenship only "contributed" $\$ 1,000$ to the Benjamin campaign.

Moreover, Blankenship's independent expenditures do not appear "grossly disproportionate" compared to other such expenditures in this very election. "And for the Sake of the Kids" - an independent group that received approximately two-thirds of its funding from Blankenship spent $\$ 3,623,500$ in connection with the election. But large independent expenditures were also made in support of Justice Benjamin's opponent. "Consumers for Justice" — an independent group that received large contributions from the plaintiffs' bar - spent approximately $\$ 2$ million in this race. And Blankenship has made large expenditures in connection with several previous West Virginia elections, which undercuts any notion that his involvement in this election was "intended to influence the outcome" of particular pending litigation.

It is also far from clear that Blankenship's expenditures affected the outcome of this election. Justice Benjamin won by a comfortable 7-point margin (53.3\% to $46.7 \%$ ). Many observers believed that Justice Benjamin's opponent doomed his candidacy by giving a well-publicized speech that made several curious allegations; this speech was described in the local media as "deeply disturbing" and worse. Justice Benjamin's opponent also refused to give interviews or participate in debates. All but one of the major West Virginia newspapers endorsed Justice Benjamin. Justice Benjamin just might have won because the voters of West Virginia thought he would be a better judge than his opponent. Unlike the majority, I cannot say with any degree of certainty that Blankenship "chose the judge in his own cause." I would give the voters of West Virginia more credit than that.

It is an old cliché, but sometimes the cure is worse than the disease. I am sure there are cases where a "probability of bias" should lead the prudent judge to step aside, but the judge fails to do so. Maybe this is one of them. But I believe that opening the door to recusal claims under the Due Process Clause, for an amorphous "probability of bias," will itself bring our judicial system 
into undeserved disrepute, and diminish the confidence of the American people in the fairness and integrity of their courts. I hope I am wrong.

Justice SCALIA, dissenting.

The principal purpose of this Court's exercise of its certiorari jurisdiction is to clarify the law. As THE CHIEF JUSTICE's dissent makes painfully clear, the principal consequence of today's decision is to create vast uncertainty with respect to a point of law that can be raised in all litigated cases in (at least) those 39 States that elect their judges. This course was urged upon us on grounds that it would preserve the public's confidence in the judicial system.

The decision will have the opposite effect. What above all else is eroding public confidence in the Nation's judicial system is the perception that litigation is just a game, that the party with the most resourceful lawyer can play it to win, that our seemingly interminable legal proceedings are wonderfully self-perpetuating but incapable of delivering real-world justice. The Court's opinion will reinforce that perception, adding to the vast arsenal of lawyerly gambits what will come to be known as the Caperton claim. The facts relevant to adjudicating it will have to be litigated - and likewise the law governing it, which will be indeterminate for years to come, if not forever. Many billable hours will be spent in poring through volumes of campaign finance reports, and many more in contesting nonrecusal decisions through every available means.

A Talmudic maxim instructs with respect to the Scripture: "Turn it over, and turn it over, for all is therein." Divinely inspired text may contain the answers to all earthly questions, but the Due Process Clause most assuredly does not. The Court today continues its quixotic quest to right all wrongs and repair all imperfections through the Constitution. Alas, the quest cannot succeed - which is why some wrongs and imperfections have been called nonjusticiable. In the best of all possible worlds, should judges sometimes recuse even where the clear commands of our prior due process law do not require it? Undoubtedly. The relevant question, however, is whether we do more good than harm by seeking to correct this imperfection through expansion of our constitutional mandate in a manner ungoverned by any discernable rule. The answer is obvious.

\section{Questions:}

1. You can watch some of the television advertisements that Don Blankenship and "And For the Sake of the Kids" ran opposing Justice Warren McGraw here, here, here, here, here, here, here, here, and here. In 2009, the Supreme Court of Appeals of West Virginia reheard the appeal, with Justice Benjamin recused, and once again overturned the lower court verdict, holding 4-1 that the contract required Caperton to file his action in Virginia. Caperton refiled his action in Virginia, where it is still pending. The

2. On April 5, 2010, an explosion at Massey's Upper Big Branch mine killed 29 miners. In the wake of the disaster, Blankenship resigned as CEO of Massey. On December 6 , 2011, Mine Safety and Health Administration concluded that flagrant safety violations contributed to a coal dust explosion, and imposed \$10.8 million in penalties on Massey. 
Blankenship was indicted on criminal charges, convicted of misdemeanor conspiracy to violate federal mine safety standards, and sentenced to one year in prison. Caperton's action against Massey and the Upper Big Branch disaster were widely reported, including in the New York Times, the Daily Beast, Mother Jones, and elsewhere.

3. After his release from prison, Blankenship became a Republican candidate for the United States Senate in West Virginia in 2018, but lost in the primary. You can see one of his campaign ads, in which he refers to Senate Majority Leader Mitch McConnell as "Cocaine Mitch" and makes other questionable comments here. When Blankenship lost, the McConnell campaign tweeted the following image.

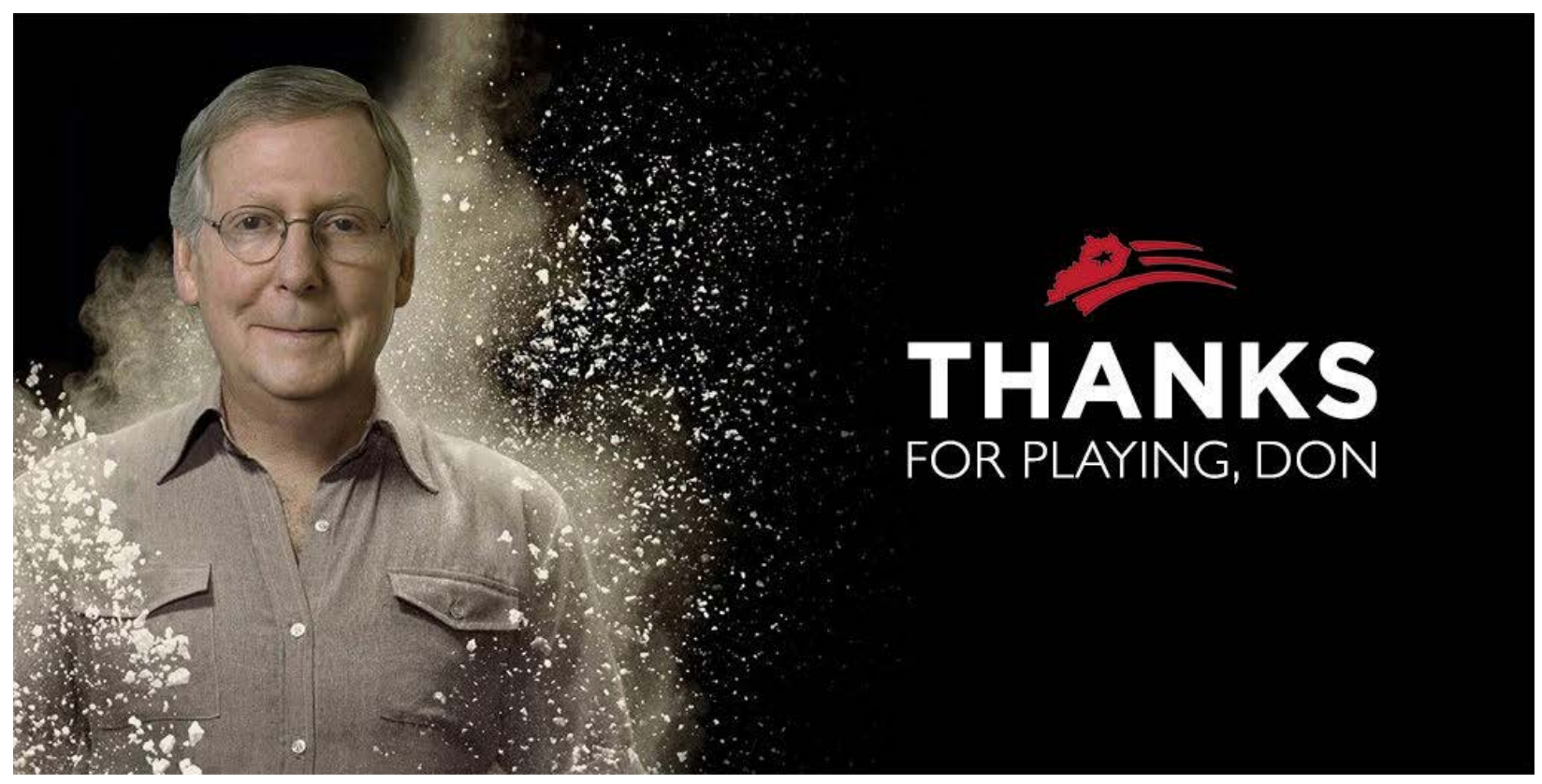

4. In Caperton v. Massey, Justice Kennedy's majority opinion held that due process requires recusal when the facts present a "serious, objective risk of actual bias." The Roberts and Scalia dissents argued that the standard adopted by the majority is meaningless and unworkable, and would erode public confidence in the judiciary. Which argument do you find more compelling?

\section{Further Reading:}

- Charles Gardner Geyh, Judicial Disqualification: An Analysis of Federal Law, Federal Judicial Center (2010)

- John P. Frank, Disqualification of Judges, 56 Yale L.J. 605 (1947)

- Hearing on Examining the State of Judicial Recusals after Caperton v. A.T. Massey, Hearing before the Subcomm. on Courts and Competition Policy of the H. Comm. on the Judiciary, 111th Cong. (2009)

- Bruce A. Green, Fear of the Unknown: Judicial Ethics after Caperton, 60 Syracuse L. Rev. 229 (2010) 
- Jeffrey W. Stempel, Playing Forty Questions: Responding to Justice Roberts' Concerns in Caperton and Some Tentative Answers About Operationalizing Judicial Recusal and Due Process, 39 Southwestern L. Rev. 1 (2009)

- Pamela S. Karlan, Electing Judges, Judging Elections, and the Lessons of Caperton, 123 Harv. L. Rev. 80 (2009)

- Kenneth L. Karst, Caperton's Amici, 33 Seattle U. L. Rev. 633 (2010)

- Ronald D. Rotunda, Judicial Disqualification in the Aftermath of Caperton v. A.T. Massey Coal Co., 60 Syracuse L. Rev. 247 (2010)

- Jed H. Shugerman, In Defense of Appearances: What Caperton v. Massey Should Have Said, 59 DePaul L. Rev. 529 (2010)

\section{Judicial Misconduct}

Order, now my court is in session, will you please stand? First, allow me to introduce myself, my name is Judge Hundredyears. Some people call me Judge Dread. Now, I have come here to whoop you, to try all you rudeboys for shooting black people. In my court only we talk, cause I'm vexed, and I am the rudeboy today. ${ }^{129}$

\section{Model Code of Judicial Conduct: Canon 2}

A judge shall perform the duties of judicial office impartially, competently, and diligently.

Model Rule 2.3: Bias, Prejudice, and Harassment

A. A judge shall perform the duties of judicial office, including administrative duties, without bias or prejudice.

B. A judge shall not, in the performance of judicial duties, by words or conduct manifest bias or prejudice, or engage in harassment, including but not limited to bias, prejudice, or harassment based upon race, sex, gender, religion, national origin, ethnicity, disability, age, sexual orientation, marital status, socioeconomic status, or political affiliation, and shall not permit court staff, court officials, or others subject to the judge's direction and control to do so.

C. A judge shall require lawyers in proceedings before the court to refrain from manifesting bias or prejudice, or engaging in harassment, based upon attributes including but not limited to race, sex, gender, religion, national origin, ethnicity, disability, age, sexual orientation, marital status, socioeconomic status, or political affiliation, against parties, witnesses, lawyers, or others.

D. The restrictions of paragraphs $(B)$ and $(C)$ do not preclude judges or lawyers from making legitimate reference to the listed factors, or similar factors, when they are relevant to an issue in a proceeding.

${ }^{129}$ Prince Buster (Cecil Bustamente Campbell / Muhammed Yusef Ali), Judge Dread (1967). 


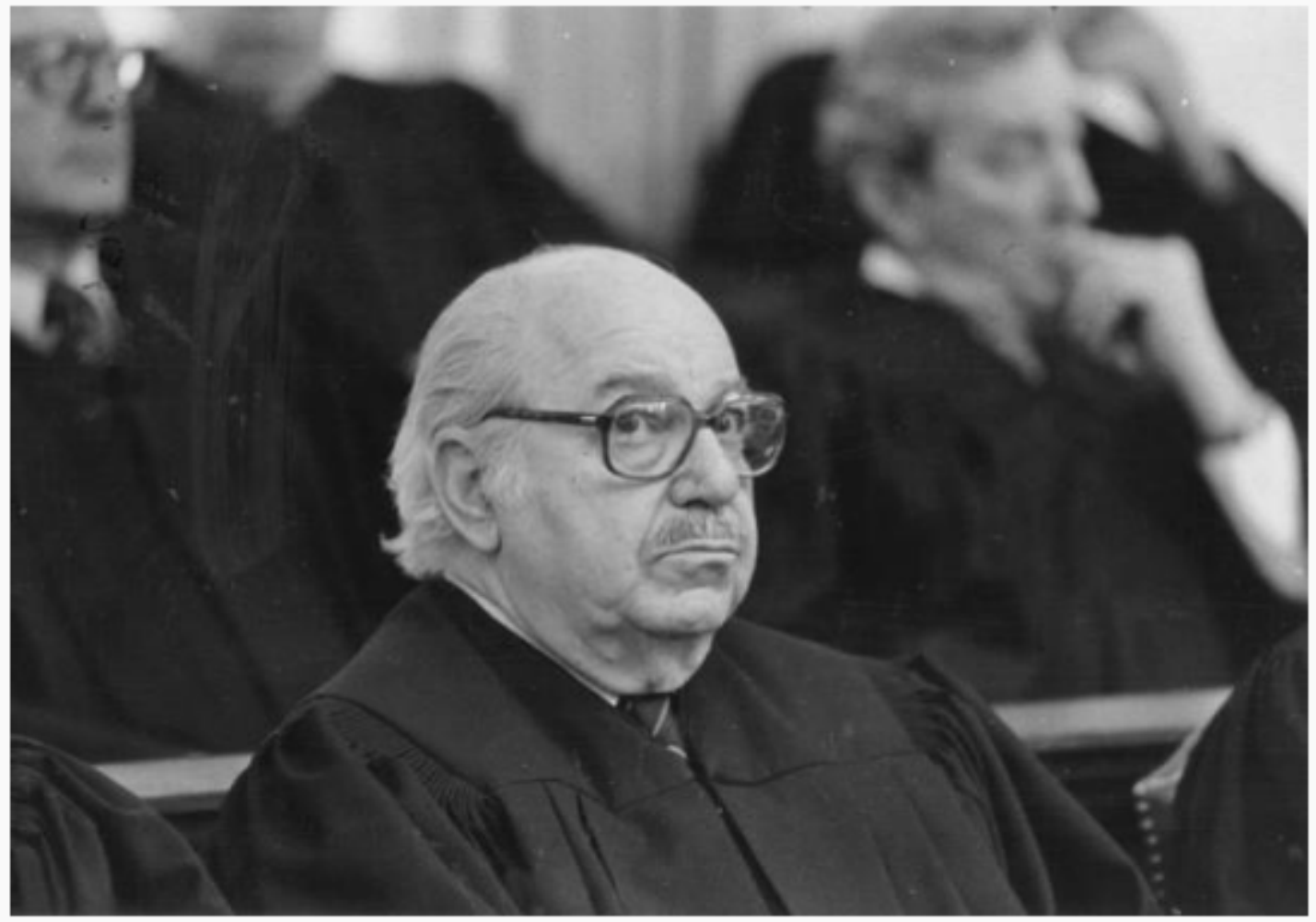

Judge Alvin D. Lichtenstein (1984)

In re Inquiry Concerning Lichtenstein, 685 P. 2d 204 (Colo. 1984)

Summary: Burns shot and killed his wife when he learned she was planning to leave him, and pleaded guilty to second-degree murder. At the sentencing hearing, Judge Lichtenstein observed, among other things, that Burns's mental state was affected by "highly provoking acts on the part of the victim," and imposed a two-year work release sentence. The Commission on Judicial Discipline found misconduct and recommended a public reprimand. The Colorado Supreme Court rejected the recommendation and dismissed the complaint.

\section{PER CURIAM.}

Pursuant to Article VI, Section 23(3)(e) of the Colorado Constitution, the Commission on Judicial Discipline certified the record of these proceedings to this court and recommended that a public reprimand be issued to District Judge Alvin D. Lichtenstein because he violated Canon $2 A$ of the Colorado Code of Judicial Conduct. Having reviewed the record of the proceedings, we conclude that the conduct of Judge Lichtenstein did not violate Canon 2A of the Code. We therefore reject the Commission's recommendation of a public reprimand and return the case to the Commission with directions to dismiss the complaint.

I. 
On December 5, 1983, a formal complaint was filed with the Commission, alleging that on June 22, 1983, while serving as a district judge in the Denver District Court and presiding over a criminal action, Judge Lichtenstein made remarks during a sentencing hearing which "undermined public confidence in the integrity and impartiality of the judiciary" and "tended to bring the judiciary into disrepute" in violation of Canon $2 \mathrm{~A}$ of the Code. ${ }^{130}$ The facts are not in dispute. Judge Lichtenstein was appointed a district judge of the Second Judicial District on January 4, 1978. In November 1980 he was elected to serve a six year term and is currently serving that term of office. During the events in question he was assigned to the criminal division of the Denver District Court. As part of his judicial responsibilities, Judge Lichtenstein heard various motions in the case of People v. Clarence Burns, in which Burns was charged with the first degree murder of his wife on August 15, 1982. During the pendency of the case, the defendant filed a motion to suppress a confession, which was heard by Judge Lichtenstein on April 4, 1983. Various witnesses testified at the suppression hearing, including a clinical psychologist who described the defendant's condition on August 15, the day of the shooting, as one of severe and suicidal depression resulting from the fact that he and his wife had separated earlier in the month. The judge granted the motion, ruling that the defendant's state of depression preexisted and continued after his arrest and "caused a cognitive impairment which prevented the Defendant from understanding his Miranda rights and from intelligently waiving them." Thereafter, a plea agreement was reached between the defendant and the district attorney's office and, on May 2, 1983, the defendant entered a plea of guilty to second degree murder in exchange for a dismissal of the first degree murder charge. The defendant's guilty plea was accepted, and the case was continued for a sentencing hearing on June 22, 1983.

During the sentencing hearing the judge received the stipulated testimony of one witness, considered the testimony of five additional witnesses, reviewed the videotaped deposition of the defendant's and victim's fifteen-year-old son, and considered the statements of counsel. Judge Lichtenstein began his remarks by stating that he had thoroughly reviewed the presentence report and had considered the matters presented by both sides during the sentencing hearing. Noting that Colorado case law required him to state on the record the reasons for the imposition of a sentence, the judge proceeded to describe the various degrees of homicide, the presumptive sentence of eight to twelve years for second degree murder, the statutory provision authorizing a sentence outside the presumptive range for extraordinary mitigating or aggravating circumstances, and concluded that extraordinary mitigating circumstances existed in this case. After stating that he was incorporating the specific findings of fact which he had previously made in ruling on the defendant's motion to suppress, the judge found that the defendant's capacity to appreciate the wrongfulness of his conduct was significantly impaired by a state of severe depression arising from his inability to understand why his wife had left him.

\footnotetext{
${ }^{130}$ After the formal complaint was filed and during the preliminary investigation of this matter by the Commission, other complaints were filed alleging that Judge Lichtenstein exhibited a bias in favor of criminal defendants, particularly those who allegedly committed crimes against women, and that he had a bias against women. These charges were investigated by the Commission and found to be without substance or merit. We therefore limit our consideration to the sentencing remarks made by Judge Lichtenstein.
} 
The judge then made the following remarks which formed the basis of the formal complaint filed against him:

The Court finds that this mental state, his mental and emotional condition, combined with the sudden heat of passion caused by a series of highly provoking acts on the part of the victim of leaving him without any warning; in fact, based on the testimony that the Court has heard, in a sense deceiving him as to her intentions by being extremely loving and caring up to and through the morning that she left the family home with the full intention of obtaining a divorce and proceeding with a separation from him without even giving him any knowledge of her whereabouts or that of their son, the Court finds that this affected the Defendant sufficiently so that it excited an irresistible passion as it would in any reasonable person under the circumstances and, consequently, would warrant a sentence under the extraordinary mitigating terms of the statute.

The judge imposed a sentence of four years plus one year of parole, suspended the sentence, and ordered the defendant to undergo supervision by the Probation Department under various conditions including a two-year work release sentence to the county jail and the successful completion of a program of psychotherapy. ${ }^{131}$ The sentencing comments of the judge and the four-year suspended sentence generated extensive publicity. The formal complaint was thereafter filed with the Commission.

The Commission found that Judge Lichtenstein's sentencing remarks "did not convey his intended meaning, and, as a direct result, the public questioned his impartiality on the bench and his ability and willingness to faithfully adhere to the law." The Commission concluded that, although not constituting willful misconduct, the judge's remarks nonetheless violated Canon $2 \mathrm{~A}$ by bringing the judiciary into disrepute and undermining public confidence in the integrity and impartiality of the judiciary. The Commission, with three members dissenting, recommended a public reprimand.

II.

Because we have not previously addressed the matter of judicial discipline under Article VI, Section 23 of the Colorado Constitution, we take this occasion to delineate the constitutional basis of our responsibility in this matter. Article VI, Section 23(3), which became effective on July 1, 1983, states in pertinent part:

\footnotetext{
${ }^{131}$ After the sentencing hearing, the judge on June 28, 1983, sua sponte, vacated the suspended sentence and imposed a sentence of four years imprisonment plus one year of parole. Thereafter, the defendant and the district attorney filed original proceedings in this court directed to the June 22 and June 28 sentences. The defendant requested that the sentence of June 28 be vacated and that the original sentence of June 22 be reinstated. The district attorney, on the other hand, requested that both sentences be vacated and that the district judge be directed to impose a sentence within the aggravated range or at least a sentence within the presumptive range for second degree murder. We held that the sentence of June 22 was an illegal sentence and remanded the case for resentencing.
} 
(d) A justice or judge of any court of record of this state, in accordance with the procedure set forth in this subsection (3), may be removed or disciplined for willful misconduct in office, willful or persistent failure to perform his duties, intemperance, or violation of any canon of the Colorado code of judicial conduct, or he may be retired for disability interfering with the performance of his duties which is, or is likely to become, of a permanent character.

(e) The commission may, after such investigation as it deems necessary, order informal remedial action; order a formal hearing to be held before it concerning the removal, retirement, suspension, censure, reprimand, or other discipline of a justice or a judge; or request the supreme court to appoint three special masters, who shall be justices or judges of courts of record, to hear and take evidence in any such matter and to report thereon to the commission. After a formal hearing or after considering the record and report of the masters, if the commission finds good cause therefor, it may take informal remedial action, or it may recommend to the supreme court the removal, retirement, suspension, censure, reprimand, or discipline, as the case may be, of the justice or judge. The commission may also recommend that the costs of its investigation and hearing be assessed against such justice or judge.

(f) Following receipt of a recommendation from the commission, the supreme court shall review the record of the proceedings on the law and facts and in its discretion may permit the introduction of additional evidence and shall order removal, retirement, suspension, censure, reprimand, or discipline, as it finds just and proper, or wholly reject the recommendation. Upon an order for retirement, the justice or judge shall thereby be retired with the same rights and privileges as if he retired pursuant to statute. Upon an order for removal, the justice or judge shall thereby be removed from office, and his salary shall cease from the date of such order. On the entry of an order for retirement or for removal of a judge, his office shall be deemed vacant.

(g) Prior to the filing of a recommendation to the supreme court by the commission against any justice or judge, all papers filed with and proceedings before the commission on judicial discipline or masters appointed by the supreme court, pursuant to this subsection (3), shall be confidential, and the filing of papers with and the giving of testimony before the commission or the masters shall be privileged; but no other publication of such papers or proceedings shall be privileged in any action for defamation; except that the record filed by the commission in the supreme court continues privileged and a writing which was privileged prior to its filing with the commission or the masters does not lose such privilege by such filing.

III.

Canon $2 \mathrm{~A}$ of the Code states that "a judge should respect and comply with the law and should conduct himself at all times in a manner that promotes public confidence in the integrity and impartiality of the judiciary." This canon includes within its scope statements made by a judge 
during judicial proceedings. Judicial misconduct creating the need for discipline may thus arise from the same source as judicial conduct that is within the scope of appellate review. The former seeks to prevent potential prejudice to the judicial system itself, while the latter seeks to correct erroneous legal rulings prejudicial to a particular party.

The question of whether Judge Lichtenstein's remarks were violative of Canon 2A must be evaluated in the context of the entire sentencing hearing. Section 18-1-105(7), which was applicable to the sentencing hearing in issue, requires a judge in imposing a sentence outside the presumptive range to "make specific findings on the record of the case, detailing the specific extraordinary circumstances which constitute the reasons for varying from the presumptive sentence." Judge Lichtenstein's remarks were made in an effort to place on record the extraordinary mitigating circumstances that he believed justified a sentence below the presumptive sentence of eight to twelve years applicable to second degree murder. The judge was attempting to describe how the victim's conduct, as perceived and interpreted by the defendant, brought about an emotional state in the defendant similar to the "irresistible passion" required for voluntary manslaughter. Although the sentencing comments contain some phraseology which, when read in isolation, might have offended the sensibilities of others, the full context of the sentencing hearing indicates that the choice of words was no more than an awkwardly executed effort to place on record the confused and highly emotional state of the defendant at the time of the killing, which, in the judge's opinion, constituted a mitigating circumstance justifying a sentence below the presumptive range. The judge's comments were not intended to be disrespectful of the law, the victim, or anyone else; nor do they reasonably lend themselves to such a connotation in the full context of the hearing. We thus conclude that the judge's remarks were not such as to bring the judiciary into disrepute or to undermine public confidence in the integrity or impartiality of the judicial system within the intendment of Canon $2 \mathrm{~A}$.

The recommendation of the Commission for a public reprimand is rejected and the case is returned to the Commission with directions to dismiss the formal complaint.

\section{Questions:}

1. On August 15, 1982, Clarence Burns shot and killed his estranged wife Patricia Ann Burns. Burns saw Patricia Ann's car parked near her parents' house, and climbed into the trunk. Eventually, she drove their son Darren to her new apartment. When they arrived, Burns emerged from the trunk and followed them into the apartment. An argument ensued, and Burns shot Patricia Ann five times in the face, killing her. Lichtenstein's comments provoked considerable outrage and were widely reported, including in the New York Times. Burns was eventually sentenced to 10 years in prison, and served 6. You can watch a short video about the case here. After the misconduct investigation, Lichtenstein requested and received a transfer to civil court. However, he continued to hear criminal cases on occasion, and made some other controversial decisions. In 2000, the Colorado Criminal Defense Bar established the Alvin D. 
Lichtenstein Award "for remarkable accomplishments over a lifetime of distinguished service."

2. Was the objection to Lichtenstein's conduct the sentence he imposed, his explanation of the sentence, or both? Should judges be censured for imposing lenient sentences?

3. The Colorado Supreme Court rejected the Commission's recommendation to reprimand Lichtenstein. Do you agree with its decision? Why or why not?

\section{Further Reading:}

- Cynthia Gray, The Line Between Legal Error and Judicial Misconduct: Balancing Judicial Independence and Accountability, 32 Hofstra L. Rev. 1245 (2004) 


\section{Section 8: Justifying the Rules of Professional Responsibility}

\section{1: Theories of Legal Ethics}

Me and Franky laughing and drinking, nothing feels better than blood on blood. Taking turns dancing with Maria, as the band played, "Night of the Johnstown Flood." I catch him when he's straying, like any brother would. Man turns his back on his family, he just ain't no good. ${ }^{132}$

In one form or another, lawyers have existed since time immemorial. The very formation of a system for dispensing justice seems to summon forth the need for advocates to represent those requesting it. And as long as lawyers have existed, we have debated the ethics of lawyering. On the one hand, we believe that people are entitled to zealous representation by counsel, in order to ensure that their rights and interests are respected. But on the other, we question the ethics of a profession that exists in order to set aside the morals of society in favor of a client.

While philosophers have long struggled with legal ethics, the jurisprudential study of legal ethics is still in its infancy. The following excepts provide an eclectic selection of perspectives on modern philosophical legal ethics, beginning with a historical survey, and continuing with representative examples from canonical works.

\section{David Luban \& W. Bradley Wendel, Philosophical Legal Ethics: An Affectionate History,} 30 Georgetown Journal of Legal Ethics 337 (2017)

We identify two "waves" of theoretical legal ethics scholarship, one that views the profession through the lens of moral philosophy, and a later wave that criticizes the moral philosophy orientation and approaches the profession through political philosophy. Roughly (but only roughly), the first wave focuses on the individual lawyer as a moral agent, and addresses the moral tension between ethical life and the lawyer's role morality. The second wave focuses instead on legal representation as a political institution within a pluralist democracy, and links legal ethics to the requirements necessary for the profession to help sustain pluralist institutions. Chronologically, the first wave began in the 1970s and the second wave in the 2000s-but this too is very rough: the two schools of thought overlap in time more than the "two waves" metaphor suggests.

\section{The First Wave: Legal Ethics as a Problem of Moral Philosophy}

The first wave of scholarship and reflection grew out of the larger social and political ferment in the 1960s and 1970s. This was the time of the civil rights movement, the time of Martin Luther King Jr. and Malcolm $X$ and the struggle for racial equality. It was also the beginning of the modern feminist movement. Importantly, it was also the time of the Vietnam War and the antiwar movement. To a great many people, young and old but mostly young, the Vietnam War proved, once and for all, the moral bankruptcy of American Cold War liberalism, with its slow

${ }^{132}$ Bruce Springsteen, Highway Patrolman, Nebraska (1982). 
progress on equality at home and its aggressive interventions abroad. That led to powerful political mistrust of the Establishment. This was also the era of the counter-culture. Notably, the counter-culture rebelled against conformism and careerism, which they thought were souldeadening. Institutions became suspect, and that included legal institutions. Individual conscience, according to this world-view, must always trump institutional demands.

The widespread attitude of all these movements, both the political and the cultural, was therefore anti-authoritarian and intensely moralistic. Looking back, we can say that perhaps the movements lacked a political vision-like many social movements, they knew what they were against without knowing exactly what they were for. No doubt the movements were also too moralistic and too self-righteous. The fact remains that in this time of turmoil, an anti-authority stance seemed to many people like the bare minimum that human decency required.

The law schools were hardly immune to these larger currents in U.S. society. The New Left in the legal academy was active by the mid-1970s, and in 1977 the Conference on Critical Legal Studies held its first organizational meetings. Critical Legal Studies aimed at a radical critique of legal institutions based on the fundamentally moral ground that the law had become an enemy of an authentic and empathetic community.

\section{The Critique of the "Standard Neutral Partisanship Conception}

Notably, two of the founding scholars of theoretical legal ethics identified with the left social movements of the time. In 1975, Richard Wasserstrom published a paper, titled "Lawyers as Professionals: Some Moral Issues," that launched philosophical legal ethics. Wasserstrom worried that the lawyer's role "renders the lawyer at best systematically amoral and at worst more than occasionally immoral in his or her dealings with the rest of mankind," and he questioned whether one-sided loyalty to clients can be reconciled with the universalism inherent in the moral point of view. Remember that Kant claimed that every human being, indeed every rational being, must be treated as an end in him- or herself, not merely a means to your own end. By contrast, the lawyer's job is to treat the client as an end in himself, but nobody else.

Three years later, William Simon, a young law professor associated with Critical Legal Studies, published a brilliant 100-page article, titled "The Ideology of Advocacy." It was a fierce critique of traditional advocacy ethics. He began by providing the first precise definition of what has been called the "neutral partisanship" model or the "standard conception" of legal ethics. The standard conception, which was the target of much of the critical attention by philosophers in the emerging legal ethics scholarship, generally lists three principles: (1) partisanship (zealously pursuing the client's lawful interests); (2) neutrality (not taking sides regarding the moral merits of the client's ends); and (3) nonaccountability (being exempt from moral criticism for having helped another act immorally). Simon reviewed the main positions in U.S. legal thought that tried to justify the standard conception - legal realism, legal process theory, and the defense of client autonomy - and argued that none of them succeeds. Furthermore, he warned that by surrounding the law with a fog of technicality and mystique that only legal experts can 
understand, lawyers alienate their clients from the law. They substitute their own definitions of client problems for the subjective experiences of the client. In place of professionalized advocacy, Simon proposed a kind of deprofessionalization, where the lawyer's personal moral convictions would play a central role in determining how far to go on the client's behalf.

There followed a veritable flood of writing on the themes that Wasserstrom, Simon, and a handful of others introduced. This was what we call the "First Wave" of legal ethics scholarship. It felt like a time of discovery - a time in which real intellectual progress was being made on some of the deepest questions in moral and legal philosophy. Instead of asking abstract conceptual questions, scholars were looking at the working lives of lawyers, and that seemed like exactly the right direction to go. It still seems that way. Stanford law professor Deborah L. Rhode, another influential First Wave scholar, combined theory and sophisticated multidisciplinary analysis of regulatory issues such as the bar's moral character requirement and its prohibition on unauthorized practice. Moreover, she gave attention to the necessary institutional aspects of the emerging field, such as casebooks, professional centers, and mentoring junior scholars. Rhode and Carrie Menkel-Meadow were also among the first theorists to bring an explicitly feminist perspective to legal ethics. Harvard law professor David Wilkins situated legal ethics within American legal thought more generally, including the law and economics, legal process, and, importantly, legal realist traditions. Wilkins also raised crucial questions about the connections between race and role - asking, for example, whether a black lawyer could, as a moral matter, represent the Ku Klux Klan.

Also during the First Wave of scholarship, religiously affiliated scholars, most prominently Thomas Shaffer, asked about how specifically Christian lawyers should act within their role. (Scholars writing from the Jewish tradition have posed similar questions.) A Christian lawyer may wonder, for example, whether it is possible to be a lawyer without being involved in the fallenness of all human institutions, including the law.

\section{Defenders of a (More or Less) Standard Conception}

Not everyone in the First Wave of philosophical legal ethics was a critic of the standard conception. Traditional advocacy also had its defenders. A first, and deeply original, defense was offered by Charles Fried, who coined the striking metaphor of the "Lawyer as Friend." Fried argued that a lawyer is like a special-purpose friend of the client. Morality allows us to favor our friends over other people, as long as we don't violate the rights of third parties. Relationships with certain individuals - paradigmatically, family and friends - become important, constitutive aspects of a person's life. It follows that morality permits us to favor the interests of those with whom we are in particularly close, personal relationships over the more abstract commitment to the well-being of humanity as a whole. As the client's friend, the lawyer adopts the client's interests as his own, for adopting your friend's interests as your own is part of the classical definition of friendship. Furthermore, because the lawyer works within a legal system, she is not directly responsible for damaging outcomes the system produces - "the wrong is wholly institutional," in Fried's words. It is not a personal wrongdoing by the lawyer. As the saying goes, "don't hate the player - hate the game." 
In response, Fried's critics argued that he drew the wrong conclusion from his "lawyer as friend" analogy. One pointed out that if you adopt your friend's interests as your own, that makes you morally responsible for them. Simon went even further in criticizing Fried. Emphasizing that normally the lawyer takes money for becoming the client's friend, Simon complained that Fried had given the classical definition not of friendship, but of prostitution. Dauer and Leff believe that Fried's conception of friendship - adopting the friend's interests as your own - captures only a thin slice of what friendship is about, and the result is that "a lawyer is like a friend because, for Professor Fried, a friend is like a lawyer." Despite these critiques, many lawyers today continue to see the attraction of Fried's vision, because it corresponds with an authentic experience of representing clients.

A second powerful defense of the standard conception emphasizes that lawyers enhance their clients' autonomy before the law. An autonomous person chooses her own ends. The lawyer's role is to assist clients in doing what they have every right to do: pursue their ends to the limit set by the law, even if the lawyer thinks the client's ends are reprehensible. Assisting clients this way is an essential job in a rule of law regime, because the law is opaque and hard for laypeople to understand. All the lawyer is doing is helping clients do what they have autonomously chosen to do, and which the law permits them to do. That is clearly a good thing and a noble calling.

The late Monroe Freedman gave the autonomy argument a distinctive grounding in the American Constitution, which may have limited the influence of his work internationally, but which resonates powerfully with lawyers, particularly the criminal defense bar. For Freedman, the criminal defender's all-in ethic of adversarial zeal on behalf of the client is grounded in the Fifth Amendment right to due process and the Sixth Amendment right to counsel - and, ultimately, the individual's autonomy rights against state force that these doctrines embody. In his famous paper on the "three hardest questions" for criminal defense lawyers, Freedman argued that the duties owed to clients - confidentiality and competent representation - should have priority over the duty of candor to the tribunal. Lawyers, therefore, should permit clients to testify perjuriously. This position was so scandalous that then D.C. Circuit Court of Appeals Chief Judge Warren Burger, along with two other federal judges, actually filed disciplinary grievances against him. But Freedman never wavered from the view that, if a lawyer's obligations are in conflict, then the duty to protect her clients should take precedence.

The First Wave highlighted a third defense of the standard conception, which has its origins in the adversarial structure of adjudication. Adversary argument seems like the best way to find the truth, and partisan advocacy seems like the best way to defend the individual's rights - or so the argument goes. The search for truth and the defense of rights are social goods of enormous importance. If partisan advocates are essential instruments for finding truth and defending rights, shouldn't that be enough to justify the lawyer's role?

The problem with the adversary system excuse is that it is only as good as the adversary system, which is an imperfect truth-seeker and rights-defender. Adversarial argument works 
best when lawyers are arguing issues of law, not issues of fact. When judges decide questions of law, hearing both sides of the questions argued in their most forceful form will almost certainly help the judges decide more intelligently. In purely legal arguments there are no confidences or secrets to conceal and no witnesses to impeach - there is a relatively pure dialectic of arguments carried on in the open.

It is different when lawyers argue about factual matters. There, the advocate's job is to protect the client's secrets and cast doubt on the other side's evidence - even if the advocate knows that the truth lies with the other side. Does a system with that design feature do a good job of finding truth? There are reasons to doubt that it does.

To summarize the First Wave of theoretical scholarship in four sentences, it holds:

1. Legal ethics is not only a matter of legal doctrine; at its most basic level, it is a subject in moral philosophy.

2. The principal question it must answer is how to reconcile the lawyer's professional role morality with "ordinary" or "common" morality, when they seemingly conflict.

3. The role morality centrally involves a "standard" conception, according to which lawyers must zealously advance the client's lawful ends, while maintaining moral neutrality toward those ends and the lawful means used to pursue them - and, furthermore, that lawyers are morally unaccountable for any "collateral damage" they inflict in their representation.

4. The arguments about role morality circle around the moral importance of the clientlawyer relationship, the value of client autonomy, and the moral significance of the adversary system.

\section{The Second Wave: From Moral to Political Philosophy}

Second Wave accounts begin with the political purpose of the legal system in a pluralist society. By a pluralist society, we mean a society of people with many different, sometimes competing, moral and religious beliefs. Concrete decisions must be made about a wide range of matters of importance to the community, yet citizens of that community disagree about what constitutes a good life, what ends are worth pursuing, and what facts bear on the resolution of these controversies. Such a society faces what Rawls calls the burdens of judgment. If pluralism means anything, it is that rational people's judgments, even about very basic matters, cannot be expected to agree - hence the "burden" that judgment carries, namely that reason and rationality do not yield unique right answers on contested moral and political questions.

Of course, a lawyer has a right to refuse a client on moral grounds. But refusal should be an exceptional event. Otherwise, lawyers are imposing their own moral views on their clients, and when they do that they are dishonoring the pluralism of society - the very same pluralism that democratic legal systems exist to preserve. Preserving pluralism provides a powerful reason for a lawyer not to engage in moral deliberation about the client's ends or the lawful means used to 
pursue it. In the language of legal theory, it is an "exclusionary reason" - a second-order reason not to engage in first-order moral deliberation.

Less theoretically, respecting the institutional settlement is what practicing lawyers believe they are doing. Lawyers and practically-minded legal scholars have sometimes expressed annoyance at what they take to be philosophers' broad-brush condemnation of advocacy as morally unjustified. One of the motivations behind Second Wave legal ethics scholarship was to take seriously the possibility that lawyers may be fully justified in doing what they do, even when it "looks nasty," and then try to work out a philosophical explanation of how that could be the case.

These are the fundamental arguments of the Second Wave of philosophical legal ethics, in three sentences:

1. Legal ethics is a subject in political philosophy, not moral philosophy.

2. The political function of legal institutions is to resolve disputes in a pluralist society.

3. And that requires lawyers to abstain from moral judgment about their clients, understand their role of serving as agents of their clients, and follow the positive legal obligations in the code of ethics.

These thinkers are very different from each other. And they do not all defend traditional advocacy. Wendel, in particular, argues that the fundamental value lawyers must serve is fidelity to law, not fidelity to clients' goals. This is particularly important when we turn from the lawyer's role as courtroom advocate to the role of confidential advisor. As an advisor, the lawyer's duty is to give the client a candid, objective opinion about the law, even if it is not what the client wants to hear. Of course we know that business clients often want opinion letters from their lawyers telling them they can do whatever it is they want to do; but the lawyer must be faithful to the law even if it means the client cannot do the deal.

Markovits shares the political premises of Wendel's argument, including the view that law has "a distinctively political kind of authority" over citizens, which derives from the capacity of the law to sustain a stable framework for collective government, notwithstanding the incompatible interests, and plurality of reasonable moral commitments, of individuals. But Markovits places considerable additional emphasis on participation by citizens in the processes of democratic self-government, an affective sense of solidarity with other members of the political community, shared ownership of political outcomes, and the transformative potential of political engagement.

Markovits argues that the primary lawyerly virtue is what he calls "negative capability." This concept, which he borrows from the poet John Keats, suggests openness to others and the setting aside of one's preconceptions. One might object that the world needs "negatively capable" lawyers like a hole in the head, if negative capability means pushing their own judgment out of the way. 


\section{Second Wave Responses to the Moralist Challenge}

One area of concern with Second Wave arguments is the extent to which they seem to require lawyers to abstain from moral deliberation, for the sake of preserving the institutional settlement of our pluralist society. This is an issue about which the two co-authors disagree, and we think our disagreement is symptomatic of the difference between First Wave and Second Wave theoretical legal ethics - the difference, as we have explained, between treating legal ethics as a subject within moral philosophy rather than political philosophy. The former approach, recall, asks whether, as a moral matter, a good lawyer can be a good person even when representing morally disagreeable ends in morally disagreeable ways. Luban is skeptical that the answer is yes, and proposes an alternative - "moral activism" - in which the lawyer leaves her moral judgment switch in the "on" position and engages actively with the client on issues of ends and means. The latter points to the importance of lawyers to a legal system that knits together a pluralist society, and argues that lawyers must suspend moral judgment of their clients' ends and the lawful means needed to pursue them.

The argument for the moralist position is straightforward: fundamentally, our moral agency is always with us; it is inescapable. It is part of the human condition. Therefore an advocate can never ignore the damage her representation inflicts on innocent others. Human solidarity demands no less. Can any reason for side-stepping moral deliberation be truly exclusionary?

One response is that, no, there is no reason that would be truly exclusionary, but the bar for opting out of the requirements of a role can be set at a high level. On one influential conception of role morality, the occupants of a social role may opt out if the best way to serve the ends of the role is to do something that is not permitted by the constitutive rules of the role.

A second possible Second Wave response to the moralistic challenge is that First Wave moralists simply have no plausible moral psychology to back up the exacting demands they place on lawyers. You cannot lead a professional life in a constant state of moral arousal, any more than a physician can practice emergency room medicine in a constant state of sympathetic anguish for the patients. The traits of character the moralists call for are not functional, realistic, or desirable. They would make a lawyer a misfit in the teamwork-based setting of a law firm, and constant moral evaluation of client ends and means assumes cognitive capacities and moral virtue at an unrealistic level.

Another possibility for dealing with the alarms and torments brought upon others by the law, with which both of us have some sympathy, is to emphasize that public ethics deals with a world characterized by the necessity of compromise. Dilemmas in political life, of which the practice of law is a part, are sometimes incapable of resolution without a sense that there is something disagreeable, even wrongful, about the resolution, even though the conclusion may be justified.

\section{Questions:}


1. Luban and Wendel describe different theories of legal ethics that arose at different points in time. Which of those theories do you find most convincing and why?

2. Did the theories advanced in this article affect the practice of law and the application of the rules of professional responsibility? Can you identify any ways in which theories of legal ethics may have affected how lawyers argued cases, judges decided cases, or organizations regulated lawyers?

\section{Further Listening:}

- W. Bradley Wendel on the History of Philosophical Legal Ethics, Ipse Dixit, January 23, 2019

\section{Legal Ethics According to the Legal Profession}

Boswell: "But what do you think of supporting a cause which you know to be bad?" Johnson: "Sir, you do not know it to be good or bad till the Judge determines it."133

\section{Louis D. Brandeis, The Opportunity in the Law (1905)}

The ethical question which laymen most frequently ask about the legal profession is this: How can a lawyer take a case which he does not believe in? The profession is regarded as necessarily somewhat immoral, because its members are supposed to be habitually taking cases of that character. As a practical matter, the lawyer is not often harassed by this problem; partly because he is apt to believe, at the time, in most of the cases that he actually tries; and partly because he either abandons or settles a large number of those he does not believe in. But the lawyer recognizes that in trying a case his prime duty is to present his side to the tribunal fairly and as well as he can, relying upon his adversary to present the other side fairly and as well as he can. Since the lawyers on the two sides are usually reasonably well matched, the judge or jury may ordinarily be trusted to make such a decision as justice demands.

But when lawyers act upon the same principle in supporting the attempts of their private clients to secure or to oppose legislation, a very different condition is presented. In the first place, the counsel selected to represent important private interests possesses usually ability of a high order, while the public is often inadequately represented or wholly unrepresented. Great unfairness to the public is apt to result from this fact. Many bills pass in our legislatures which would not have become law, if the public interest had been fairly represented; and many good bills are defeated which if supported by able lawyers would have been enacted. Lawyers have, as a rule, failed to consider this distinction between practice in courts involving only private interests, and practice before the legislature or city council involving public interests. Some men of high professional standing have even endeavored to justify their course in advocating professionally legislation which in their character as citizens they would have voted against.

133 James Boswell, Life of Johnson (1791). 
Furthermore, lawyers of high standing have often failed to apply in connection with professional work before the legislature or city council a rule of ethics which they would deem imperative in practice before the court. Lawyers who would indignantly retire from a court case in the justice of which they believed, if they had reason to think that a juror had been bribed or a witness had been suborned by their client, are content to serve their client by honest arguments before a legislative committee, although they have as great reason to believe that their client has bribed members of the legislature or corrupted public opinion. This confusion of ethical ideas is an important reason why the Bar does not now hold the position which it formerly did as a brake upon democracy, and which I believe it must take again if the serious questions now before us are to be properly solved.

Here, consequently, is the great opportunity in the law. The next generation must witness a continuing and ever-increasing contest between those who have and those who have not. The people's thought will take shape in action; and it lies with us, with you to whom in part the future belongs, to say on what lines the action is to be expressed; whether it is to be expressed wisely and temperately, or wildly and intemperately; whether it is to be expressed on lines of evolution or on lines of revolution. Nothing can better fit you for taking part in the solution of these problems, than the study and preeminently the practice of law. Those of you who feel drawn to that profession may rest assured that you will find in it an opportunity for usefulness which is probably unequalled. There is a call upon the legal profession to do a great work for this country.

Woodrow Wilson, The Lawyer and the Community, 192 N. Am. Rev. 604 (1910)

Lawyers are not a mere body of expert business advisers in the field of civil law or a mere body of expert advocates for those who get entangled in the meshes of the criminal law. They are servants of the public, of the State itself. They are under bonds to serve the general interest, the integrity and enlightenment of law itself, in the advice they give individuals. It is their duty also to advise those who make the laws?to advise them in the general interest, with a view to the amelioration of every undesirable condition that the law can reach, the removal of every obstacle to progress and fair dealing that the law can remove, the lightening of every burden the law can lift and the righting of every wrong the law can rectify. The services of the lawyer are indispensable not only in the application of the accepted processes of the law, the interpretation of existing rules in the daily operations of life and business. His services are indispensable also in keeping and in making the law clear with regard to responsibility, to organization, to liability and, above all, to the relation of private rights to the public interest.

Whatever may be the cause, it is evident that he now regards himself as the counsel of individuals exclusively and not of communities. He may plead the new organization of politics, which seems to exclude all counsel except that of party success and personal control; he may argue that public questions have changed, have drifted away from his field, and that his advice is no longer asked; but, whatever his explanation or excuse, the fact is the same. He does not play the part he used to play. He does not show the spirit in affairs he used to show. He does not do what he ought to do. 


\section{Tom C. Clark, Teaching Professional Ethics, 12 San Diego L. Rev. 249 (1975)}

Traditionally, the organized bar has prided itself upon being a profession, based upon the wellaccepted view that the primacy of service over profit is the criterion which distinguishes a profession from a business. Now, though, strong voices have begun to challenge the bar's complacent view of itself. For example, in a recent speech to a joint luncheon of the American Judicature Society and the National Conference of Bar Presidents, Senator John V. Tunney of California criticized what he perceived as the bar's over-emphasis on pecuniary return and declared that "the profession is kidding itself if it views Watergate as the flaw in an otherwise heroic tapestry of public service."

In scholarly articles as well as in the popular press, lawyers are being condemned as valueless technicians who are more concerned with the tactical than with the ethical, and the blame for this general erosion in integrity is being attributed to the failure of the profession to discipline itself. Most of that criticism centers around enforcement of our canons of ethics-the tools by which the bar polices itself and the goals by which we judge ourselves. It is charged that our Code of Professional Responsibility does not in fact protect either the public or the recipients of professional services, but rather safeguards only the interests of an entrenched segment of the profession. Many would agree with Professor Waltz's comment that: "By regulating ourselves and brooking no lay interference in the process, we too often avoid disciplining even the most venal and inept among us."

There is no doubt in my mind that the present state of our disciplinary machinery is deplorable and that we must perfect the professional system of disciplining and weeding out judges and lawyers who are inept, lazy, corrupt or dishonest. Happily, the organized bar has finally begun to move in this direction, but this is an effort which has a crucial prerequisite, the same prerequisite that Senator Ervin alluded to in his Honolulu speech: integrity. Unless the bar is uniformly imbued with that spirit of honesty and decency and unless it is inspired to insist upon the exercise of the highest ideals in the day-to-day practice of law, then no disciplinary system can be effective and no code of professional conduct will be anything more than a hypocritical farce.

\section{Warren E. Burger, The Role of the Law School in the Teaching of Legal Ethics and Professional Responsibility, 29 Clev. St. L. Rev. 377 (1980)}

To become a lawyer is to be more than being available as a "hired gun" or a "legal mechanic." To be sure, one of our great tasks is to be effective advocates. The history of our profession is rich with accounts of lawyers who risked careers by asserting their independence in opposition to the government or to popular attitudes. Andrew Hamilton did that in defending John Peter Zenger; John Adams did that when he defended the soldiers accused of what history calls the "Boston Massacre;" that is what Luther Martin and others did when they defended Aaron Burr in his trial for treason. Defending their clients, these men advanced the liberties of all. An independent judiciary alone is not enough; it must be supported by a strong, independent, courageous and competent bar. This is an imperative for a free people. 
But lawyers are not "licensed" to promote conflict; they must be more than skilled legal technicians. We should be that, but in a larger sense, we must be legal architects, engineers, builders, and from time to time, inventors as well. We have served, and must continue to see our role, as problem-solvers, harmonizers, and peacemakers, the healers - not the promoters of conflict. Lawyers must reconcile and stabilize, for a democracy often functions best by compromise. For hundreds of years England and the United States have been able largely to avoid internecine conflict, vigilantism, and collective violence because lawyers have served as the indispensable "brokers" of social progress, providing the lubricant for acceptable resolution of controversies and for gradual change and evolution of the law. It bears repeating that we must see ourselves more clearly in the function of healers rather than as promoters of litigation.

Our profession carries public and ethical burdens with its privileges. Daniel Webster spoke of justice as "the greatest interest of man on earth." As a profession with a monopoly over the performance of certain services, we have special obligations to the consumers of justice to be energetic and imaginative in producing the best quality of justice at the lowest possible costs for those who use it, and with a minimum of delay. It was in these respects that my late colleague, Charles Fahy, hoped that we would think of a lawyer and the law as forces for moral good, "as a civilization of its own, enhancing the whole of our civilization."

\section{Questions:}

1. How do Brandeis, Wilson, Clark, and Burger define legal ethics? Do they provide a basis for determining whether an action is ethical?

2. How would you describe the ethical theories advanced by Brandeis, Wilson, Clark, and Burger in relation to the categories advanced by Luban and Wendel?

\section{The First Wave of Legal Ethics: Moral Theories}

Richard Wasserstrom, Lawyers as Professionals: Some Moral Issues, 5 Hum. Rts. 1 (1975)

Conventional wisdom has it that where the attorney-client relationship exists, the point of view of the attorney is properly different - and appreciably so - from that which would be appropriate in the absence of the attorney-client relationship. For where the attorney-client relationship exists, it is often appropriate and many times even obligatory for the attorney to do things that, all other things being equal, an ordinary person need not, and should not do. What is characteristic of this role of a lawyer is the lawyer's required indifference to a wide variety of ends and consequences that in other contexts would be of undeniable moral significance. Once a lawyer represents a client, the lawyer has a duty to make his or her expertise fully available in the realization of the end sought by the client, irrespective, for the most part, of the moral worth to which the end will be put or the character of the client who seeks to utilize it. Provided that the end sought is not illegal, the lawyer is, in essence, an amoral technician whose peculiar skills and knowledge in respect to the law are available to those with whom the relationship of client is 
established. The question, as I have indicated, is whether this particular and pervasive feature of professionalism is itself justifiable. At a minimum, I do not think any of the typical, simple answers will suffice.

One such answer focuses upon and generalizes from the criminal defense lawyer. For what is probably the most familiar aspect of this role-differentiated character of the lawyer's activity is that of the defense of a client charged with a crime. The received view within the profession (and to a lesser degree within the society at large) is that having once agreed to represent the client, the lawyer is under an obligation to do his or her best to defend that person at trial, irrespective, for instance, even of the lawyer's belief in the client's innocence. There are limits, of course, to what constitutes a defense: a lawyer cannot bribe or intimidate witnesses to increase the likelihood of securing an acquittal. And there are legitimate questions, in close cases, about how those limits are to be delineated. But, however these matters get resolved, it is at least clear that it is thought both appropriate and obligatory for the attorney to put on as vigorous and persuasive a defense of a client believed to be guilty as would have been mounted by the lawyer thoroughly convinced of the client's innocence. I suspect that many persons find this an attractive and admirable feature of the life of a legal professional. I know that often I do. The justifications are varied and, as I shall argue below, probably convincing.

But part of the difficulty is that the irrelevance of the guilt or innocence of an accused client by no means exhausts the altered perspective of the lawyer's conscience, even in criminal cases. For in the course of defending an accused, an attorney may have, as a part of his or her duty of representation, the obligation to invoke procedures and practices which are themselves morally objectionable and of which the lawyer in other contexts might thoroughly disapprove. And these situations, I think, are somewhat less comfortable to confront.

Nor, it is important to point out, is this peculiar, strikingly amoral behavior limited to the lawyer involved with the workings of the criminal law. Most clients come to lawyers to get the lawyers to help them do things that they could not easily do without the assistance provided by the lawyer's special competence. And in each case, the role-differentiated character of the lawyer's way of being tends to render irrelevant what would otherwise be morally relevant considerations.

The lawyer need not of course agree to represent the client (and that is equally true for the unpopular client accused of a heinous crime), but there is nothing wrong with representing a client whose aims and purposes are quite immoral. And having agreed to do so, the lawyer is required to provide the best possible assistance, without regard to his or her disapproval of the objective that is sought. The lesson, on this view, is clear. The job of the lawyer, so the argument typically concludes, is not to approve or disapprove of the character of his or her client, the cause for which the client seeks the lawyer's assistance, or the avenues provided by the law to achieve that which the client wants to accomplish. The lawyer's task is, instead, to provide that competence which the client lacks and the lawyer, as professional, possesses. In this way, the lawyer as professional comes to inhabit a simplified universe which is strikingly amoral - 
which regards as morally irrelevant any number of factors which nonprofessional citizens might take to be important, if not decisive, in their everyday lives. And the difficulty I have with all of this is that the arguments for such a way of life seem to be not quite so convincing to me as they do to many lawyers. I am, that is, at best uncertain that it is a good thing for lawyers to be so professional-for them to embrace so completely this role-differentiated way of approaching matters.

More specifically, if it is correct that this is the perspective of lawyers in particular and professionals in general, is it right that this should be their perspective? Is it right that the lawyer should be able so easily to put to one side otherwise difficult problems with the answer: but these are not and cannot be my concern as a lawyer? What do we gain and what do we lose from having a social universe in which there are professionals such as lawyers, who, as such, inhabit a universe of the sort I have been trying to describe?

William H. Simon, The Ideology of Advocacy: Procedural Justice and Professional Ethics, 1978 Wis. L. Rev. 29 (1978)

Conventional morality frowns at the ethics of advocacy. Public opinion disapproves of what it considers the lawyer's most characteristic activities. Popular culture can reconcile itself to him only by pretending that all his clients are virtuous. The lawyer's response takes the form of a dialectic of cynicism and naivete. On one hand, he sees his more degrading activities as licensed by a fundamental amorality lying beneath conventional morality. On the other hand, he sees his more heartening ones as serving an institutional justice higher than conventional morality. The two moods divide the profession as a whole, and the division can sometimes be seen in the professional lives of individual lawyers, as, for instance, when they turn from their paid efforts on behalf of what they admit to be private interests to their donated services on behalf of what they claim to be the public good.

The formal, articulate expression of the lawyer's response is the "Ideology of Advocacy." The purpose of the Ideology of Advocacy is to rationalize the most salient aspect of the lawyer's peculiar ethical orientation: his explicit refusal to be bound by personal and social norms which he considers binding on others. The most elaborate expressions of the Ideology of Advocacy occur in officially promulgated rules of ethics, in doctrinal writings on legal ethics, the attorneyclient evidentiary privilege, and the constitutional right to counsel, and in writings on the legal profession.

Although this literature is voluminous, it is barren of any fundamental questioning of the ethical premises of legal professionalism. The profession has never been inclined to join issue on any but the most superficial level with the lay critique of these premises, and it presently seems less disposed toward reexamination of them than ever.

Of course, there is a growing body of writing addressed to the profession which is critical of the conduct of lawyers and professional organizations. Yet, most of these discussions take place within the framework of the Ideology of Advocacy and do not involve criticism of its premises. 
The more prominent of these discussions have been of two types. First, doctrinal writings on legal ethics and judicial procedure often take the form of a debate between the partisans of a "battle" model and the partisans of a "truth" model of adjudication. These writings criticize certain kinds of conduct by lawyers as inconsistent with one or the other of these models. Yet, almost all of the distinctive ethical views of lawyers can be rationalized in terms of one or the other of the models, and the differences between them are greatly exaggerated in the debate. Both models accept the basic principles of the Ideology of Advocacy and are primarily concerned with defending those principles.

Second, there is a substantial body of sociology and social criticism which focuses on the legal profession. Some of this literature argues that lawyers compromise their clients' interests in order to advance their own interests. Other studies focus on an elite within the profession and argue that the elite has used professional ethics and organization to achieve prestige and economic privilege at the expense of the less powerful members of the profession and of the lower classes generally. Studies which emphasize the exploitation of clients explicitly accept the Ideology of Advocacy and criticize lawyers for failing to live up to it. Although studies which emphasize elite domination purport to criticize legal ethics and professionalism, they do not deal with the basic principles expressed by the Ideology of Advocacy. Instead, they focus on principles such as restrictions on membership in the profession and prohibitions on advertising and solicitation. Such studies are concerned less with the nature of legal services than with their distribution. In suggesting that the increased availability of legal services allegedly inhibited by professional ethics and organization would be desirable, these writings often rely on the Ideology of Advocacy. It is notable that writing from both perspectives often calls for reforms which would enlarge the size and power of the profession.

Although the three versions of the Ideology of Advocacy all defend the same core of basic principles, each is based on different attitudes and commitments, and each describes and recommends a somewhat different style of law practice. Although all three versions exert influence today, each originated in a distinct historical situation and attained its greatest influence at a different time. The influence of the three versions has also varied significantly among different strata of the profession and in different areas of law practice.

At the base of each version of the Ideology of Advocacy is an appeal to an aspect of the fundamental value of individuality: autonomy, responsibility, dignity. Yet, in each instance, the practices and attitudes of professional advocacy subvert the norms of individuality in the interest of a repressive conception of social stability. The essay will argue that to take the value of individuality seriously would require the abandonment of the Ideology of Advocacy and of legal professionalism. Indeed, it will also suggest that respect for the value of law itself may require the repudiation of legal professionalism.

\section{Deborah L. Rhode, Ethical Perspectives on Legal Practice, 37 Stan. L. Rev. 589 (1985)}

A more ethically reflective form of legal practice will require different ideological foundations. Lawyers must assume personal moral responsibility for the consequences of their professional 
actions. At its most fundamental level, such a redefinition abandons Durkheim's faith in the ability of insular occupational communities to generate adequate normative visions. Given the tendency of parochial interests to skew ethical judgment, the justification for conduct must be tested by conventional techniques of moral reasoning. The rationale for professional action cannot depend on a reflexive retreat to role, which denies the need for reflection at the very point when reflection becomes most essential. To be convincing, professional judgments must withstand scrutiny by individuals seeking consistent, disinterested, and generalizable foundations for conduct. Counsel should no longer categorically deflect responsibility to some governmental or private agent acting in a presumptively ideal regulatory system. Rather, attorneys must confront the consequences of their decisions against a realistic social backdrop, in which wealth, power, and information are unevenly distributed, and democratic, adversarial, and market processes function imperfectly.

This reformulation of role in no sense contemplates that lawyers will become personally accountable for every adverse consequence that flows from client representation or collegial relationships. Under conventional ethical theories, moral responsibility depends on a variety of factors, including the significance of harm and the agent's degree of involvement, knowledge, and capacity to .affect action. Nor does it follow that counsel must endorse a client's every objective or course of conduct before providing representation. Whether particular forms of assistance are defensible depends not only on the specific acts involved but also on their social and economic contexts, and on the principles at issue.

What distinguishes this framework is the insistence on an ethical predicate - on an attempt to justify systematically the consequences of professional action. That clients may have a "legal right" to engage in certain conduct or to invoke a particular procedure is conclusive neither of their moral right, nor of the appropriateness of counsel's aid. Lawyers cannot simply retreat to role in the face of larger normative questions. To cite only the most obvious example, attorneys who delay safety standards they would privately endorse, or who knowingly assist the distribution of products with significant undisclosed risks, are implicated in the human suffering that may result. So too, in more common circumstances, counsel cannot continually resolve doubts in favor of those with a history of revising reality, misplacing discoverable documents, or operating on the fringes of fraud. In effect, the attorney can no longer avoid responsibility for allowing client interests to trump all competing concerns.

Nor is the maxim "judge not" an adequate response to collegial misconduct. Participation in a common enterprise entails some accountability for the practices it tolerates and the values it engenders. Attorneys who blink at over-billing, misrepresentation, or procedural belligerence thereby legitimate forms of professional acculturation that are debilitating for practitioners as well as litigants. To argue for individual assumption of responsibility, however, only begins analysis. The more difficult issue, which remains a highly contextual determination, is what that responsibility entails. Relevant factors include not only the magnitude and likelihood of potential harm and the attorney's capacity to affect it, but also the personal and social costs that corrective action would impose. Among those costs, the possible loss of client or collegial trust is entitled to weight. In some instances, an individual's dependency, or a lawyer's limited 
leverage and access to information, may make suspension of judgment the only practicable course.

So too, some limits to self-sacrifice demand recognition. To suggest that individuals are morally obligated to respond to every harmful consequence that they could potentially influence would impose paralyzing burdens. Conventional ethical theories do not posit that all humanity should live as Trappist monks, devote every discretionary dollar to famine relief, or pontificate at every possible opportunity. Without some concept of supererogation, some "cut off for heroism," no significant realm of individual autonomy would survive. If it is to provide useful normative guidance, a reformulation of professional role must remain sensitive to normal human capacities for altruism, as well as the psychological and economic pressures of legal practice.

Yet while professional ideology need not mandate canonization, neither should it legitimate abdication. For lawyers to do for profit what they would deplore as decisionmakers cannot be justified simply by recourse to role. Under some circumstances, an attorney may be more able or inclined to make principled judgments than other individuals involved in the process.

Depending on the context, the only acceptable course may be a refusal to aid, or an affirmative attempt to prevent asocial conduct.

Such contexts cannot, of course, be identified in the abstract. Yet to concede that decisionmaking will necessarily prove situational is not to embrace a totally relativist perspective. Given the heterogeneity of the American legal profession, collective adherence to some codified standards remains essential. Deference to established precepts such as honesty, fair dealing, or procedural civility is a necessary means of minimizing temptation and keeping normative ambiguity within reasonable bounds. Exhaustive evaluation of every act would yield a numbing moral perplexity. Given the inevitable human tendency to skew ethical assessments in expedient directions, an a priori commitment to certain principles remains appropriate. What is critical, however, is that those precepts be themselves morally defensible in a world of regulatory imperfections and gross socioeconomic disparities. By that standard, as earlier discussion suggests, one cannot convincingly generate a principle that all clients are entitled to either unqualified confidentiality or the maximum neutral partisanship they can afford.

That is by no means to imply that systematic reflection will yield determinate resolutions, or to overlook the limitations of moral methodology noted earlier. But this concession need not invite paralysis. There may be no uncontrovertible answers, but there are better and worse ways of thinking about the questions. Thus, the attempt must be to create more channels within which serious normative dialogue can occur. Individuals must have ongoing occasions to confront ethical issues, to test their perceptions openly, and to raise concerns about client or collegial practices without professional risk. For that purpose, far more is needed than bar association advisory opinions or law firm conflict-of-interest committees. Rather, the profession must fashion structures within and across employing institutions that can encourage collective support and a sense of responsibility for normative concerns.

Thomas Shaffer, The Legal Ethics of Radical Individualism, 65 Tex. L. Rev. 963 (1987) 
Paternalism, in most writing on the professions, is a bad word. But pater (father) is not a bad word. The Hebraic religious tradition chose and retains the word, if only as metaphor, to describe God, despite the difficulty of a theology of patriarchy. The description approximates with a family metaphor the understanding of the Hebrew prophets that the God of Israel is a God with feelings - the "divine pathos," as Abraham Joshua Heschel called it. God's pathos means that He feels as a father feels; the prophetic response to God is thus sympathy. Father, consequently, is not a bad word; it cannot be. Writers on professionalism erred in thinking otherwise.

It is not a moral condemnation of standards of professional conduct, then, to call them "fatherly" (paternalistic); nor would it be a moral condemnation to call them "motherly" (maternalistic) or even parent-like (parentalistic). If we take our theological metaphors seriously, to analogize behavior to the parental is to fit it to our traditions. The retreat from parental metaphors in modern writing on professionalism is subject to two criticisms. First, the analysis has not proceeded deeply enough; writing on professionalism has been duped into announcing a moral principle when it should have been concerned with description - truthfulness - in the comparison of a professional person and a parent, and of the virtues of good parents and the failures of bad parents. Writing on professionalism should describe the moral reasons that we use family metaphors, in theology and in professional life and it then should turn those reasons into doctrine. Second, the condemnation of paternalism (parentalism) in modern writing on ethics in the professions is the product of the lonely-individual doctrine in philosophical ethics, and of the philosophical distinction between fact and value, particularly in its disposition to turn the parental metaphor into a moral principle.

Radical individualism is the philosophy of an adolescent who wishes he had no parents. The school of moral philosophy that posits a parentless moral agent duped us into accepting an untruthful description of the world. I notice that untruthful description in The Case of the Unwanted Will, when legal-ethics commentators describe the woman making the will as a radical individual rather than as a wife, a mother, and a member of a family. The alternative is to understand enough about oneself and one's client to know that family words describe more than a set of social roles that a woman puts on as she might put on a hat.

The argument I make here is an argument from the Hebraic religious tradition. In Judaism, the family is not merely fundamental; it is ordained. God dealt with the family; He made a covenant with it. Israel is a family of families. This "master story" has innumerable implications, some obvious and some subtle, for Hebraic norms on sex, raising children, business and property, and inheritance. These implications turn on the moral teaching that a person alone is not complete; as the Midrash says, "He who lives without a wife lives without blessing, without life, without joy, without help, without good, and without peace."

In Christianity, marriage is, in the Hebraic ethics of Jesus, so fundamental that it is sinful to dissolve it. St. Paul's metaphors equate family and church, and speak of the church as the body of Christ. The early Christian church was a patriarchy that tried to be open to notions of equality 
and partnership within the metaphor of family. That aspiration was fundamentally Judaic: "Unity is a task, to endure means to be one."

There are two ways to take account of the religious tradition in American legal ethics. One way is to note that the cultural deposits of most American lawyers include the religious tradition. Failing to take account of the tradition therefore is failing to be truthful. As Peter Berger put it, "The very least that a knowledge of religious traditions has to offer is a catalogue of heresies for possible home use." That is, the religious tradition, when we are conscious of it, helps to keep us from repeating obvious moral mistakes and, more profoundly, it influences our behavior when we are not conscious of it. Berger thought that these influences were appropriate: "In everyday life it is just as important that some things can silently be taken for granted as that some things are reaffirmed in so many words." In that sense, law-office behavior probably rests on religious tradition in an ordinary and everyday way. The risk in Berger's reassurance, as Robert Bellah and his colleagues recently demonstrated, is that we will lose or distort influences that we do not bring into the light and make sense of. The work of bringing moral influences into the light and making sense of them is the purpose of the discipline of ethics.

\section{Charles Fried, The Lawyer as Friend: The Moral Foundations of the Lawyer-Client}

Relation, 85 Yale L.J. (1976)

In this essay I will consider the moral status of the traditional conception of the professional. The two criticisms of this traditional conception, if left unanswered, will not put the lawyer in jail, but they will leave him without a moral basis for his acts. The real question is whether, in the face of these two criticisms, a decent and morally sensitive person can conduct himself according to the traditional conception of professional loyalty and still believe that what he is doing is morally worthwhile.

It might be said that anyone whose conscience is so tender that he cannot fulfill the prescribed obligations of a professional should not undertake those obligations. He should not allow his moral scruples to operate as a trap for those who are told by the law that they may expect something more. But of course this suggestion merely pushes the inquiry back a step. We must ask then not how a decent lawyer may behave, but whether a decent, ethical person can ever be a lawyer. Are the assurances implicit in assuming the role of lawyer such that an honorable person would not give them and thus would not enter the profession? And, indeed, this is a general point about an argument from obligation: It may be that the internal logic of a particular obligation demands certain forms of conduct (e.g., honor among thieves), but the question remains whether it is just and moral to contract such obligations.

I will argue in this essay that it is not only legally but also morally right that a lawyer adopt as his dominant purpose the furthering of his client's interests-that it is right that a professional put the interests of his client above some idea, however valid, of the collective interest. I maintain that the traditional conception of the professional role expresses a morally valid conception of human conduct and human relationships, that one who acts according to that conception is to that extent a good person. Indeed, it is my view that, far from being a mere creature of positive 
law, the traditional conception is so far mandated by moral right that any advanced legal system which did not sanction this conception would be unjust.

The general problem raised by the two criticisms is this: How can it be that it is not only permissible, but indeed morally right, to favor the interests of a particular person in a way which we can be fairly sure is either harmful to another particular individual or not maximally conducive to the welfare of society as a whole?

The resolution of this problem is aided, I think, if set in a larger perspective. Charles Curtis made the perspicacious remark that a lawyer may be privileged to lie for his client in a way that one might lie to save one's friends or close relatives. I do not want to underwrite the notion that it is justifiable to lie even in those situations, but there is a great deal to the point that in those relations - friendship, kinship - we recognize an authorization to take the interests of particular concrete persons more seriously and to give them priority over the interests of the wider collectivity. One who provides an expensive education for his own children surely cannot be blamed because he does not use these resources to alleviate famine or to save lives in some distant land. Nor does he blame himself. Indeed, our intuition that an individual is authorized to prefer identified persons standing close to him over the abstract interests of humanity finds its sharpest expression in our sense that an individual is entitled to act with something less than impartiality to that person who stands closest to him - the person that he is. There is such a thing as selfishness to be sure, yet no reasonable morality asks us to look upon ourselves as merely plausible candidates for the distribution of the attention and resources which we command, plausible candidates whose entitlement to our own concern is no greater in principle than that of any other human being. Such a doctrine may seem edifying, but on reflection it strikes us as merely fanatical.

This suggests an interesting way to look at the situation of the lawyer. As a professional person one has a special care for the interests of those accepted as clients, just as his friends, his family, and he himself have a very general claim to his special concern. But I concede this does no more than widen the problem. It merely shows that in claiming this authorization to have a special care for my clients I am doing something which I do in other contexts as well.

\section{The Second Wave of Legal Ethics: Political Theories}

Monroe H. Freedman, A Critique of Philosophizing About Lawyers' Ethics, 25 Geo. J. Legal Ethics 91 (2012)

In the world of real lawyers and real clients, "role differentiation" refers to a fiduciary relationship in which the lawyer promises to take all reasonable and lawful means to attain the objectives of the client. This promise is an inescapable part of any meaningful moral analysis. Also, lawyers function under ethical rules, many of which reflect ordinary morality, and violation of those rules can result in serious professional sanctions and malpractice liability. Those rules and that potential responsibility should not be ignored in proposals for radical changes in how lawyers serve their clients. In addition, lawyers in the United States are subject to a constitutionalized 
adversary system, which defines and limits their professional responsibilities in fundamental respects. When moral philosophers ignore these practical concerns, they produce articles and books that have no significance in the world of real lawyers and real clients. As Chief Justice Roberts recently observed: "What the academy is doing is largely of no use or interest to people who actually practice law."

Structural engineers do not debate whether using skyhook cables that drop magically from the sky would be a better way of building bridges than the present suspension method. Nor do they publish reply articles about how air traffic would have to be rerouted to avoid the non-existent sky hook cables. In a similar sense, philosophical theorizing about lawyers' ethics, based upon unrealistic facts and the omission of critical authorities, is irrelevant to the real-life concerns of lawyers and is a waste of scholarly effort.

My point is not that the rules of lawyers' ethics do not demand serious reform from a moral perspective. On the contrary, more practical moral criticism is badly needed. One of the reasons for my impatience with the work of the philosophical ethicists is that their moral sensitivity and keen intellects could be used to bring about much needed improvement in the ethics and practice of lawyers and judges.

Finally, despite the ongoing need for reform of ethical rules and practices, I resent the irresponsible charge that the practice of law is inherently immoral or amoral. For more than half a century I have served as an associate, partner, supervisor, co-counsel, consultant, and mentor alongside countless lawyers who, like me, have found the practice of law to be an exhilarating, gratifying, and essentially moral profession of serving the dignity and autonomy of our fellow citizens and of maintaining the ideals of our constitutional democracy. This moral role of service to others, and to our society, would not be possible if lawyers were to view their relationship with their clients with a patronizing attitude of moral arrogance.

\section{Susan P. Koniak, Through the Looking Glass of Ethics and the Wrong with Rights We} Find There, 9 Geo. J. Legal Ethics 1 (1995)

When we try to control the definition of rights by relying on our laws of obligation, we seem ridiculous, as if we were advocating that the tail wag the dog. The ethical obligations of lawyers, whether they be those articulated by the courts in ethics rules or enforced by the courts in tort actions, are simply too weak to drive the definition of right. The idea that a constitutional right should be contoured to reinforce the obligations set forth in secondary (obligation) law, like the rules of legal ethics, seems absurd and is rejected easily both by the Supreme Court in Strickland and by the federal courts deciding whether due process has been satisfied in a class action proceeding through the provision of adequate representation.

Rights law is not only strong enough to overshadow obligation law, it is strong enough to stop obligation law altogether. The right having been satisfied, making state action appropriate, it seems at once unseemly and unnecessary to question whether obligations have been met. This 
attitude accounts for the legal obstacles that prevent tort actions and the absence of disciplinary proceedings in both the class action and the criminal defense context.

Unlike tax law, tort law or other sources of legal obligation in our normative world, ethics is not merely a source of obligation but the place where obligation is understood as dignifying and ennobling. Our normative structure thus allows for the possibility that obligation can be understood as something more akin to a blessing than a burden. But the fact that this idea is so central to ethics may account for the secondary status that ethics occupies in our world, culturally and legally. The idea basic to ethics - dignifying and ennobling obligation - is an idea adrift in an alien universe. It does not resonate with our basic normative structures and, thus, we cannot quite take the enterprise seriously. Our thought tends to get stuck in this circle: if the obligation were meant to be mandatory or binding in some strong sense, it would be legal; on the other hand, if the obligation were designed to be ennobling, it would not be a legal obligation, which we understand to be a burden visited on us by the state, not a gift.

\section{Katherine R. Kruse, Fortress in the Sand: The Plural Values of Client-Centered} Representation, 12 Clinical L. Rev. 501 (2006)

Legal obligations in our world are not worthy of the name of ethics. By making that move we make ethics not just something more than law, more ennobling, but something also much less, less compelling. Ultimately, we conceive of ethics in terms of rights. We have the right to be ethical or not, which in terms of an ethic makes no sense at all. The inconsistency in our world between law and ennobling obligation is apparent when we start speaking of legal ethics, which claims to be both law and ethics, both mandatory and dignifying. It claims to occupy a place in our normative world that seems like it cannot exist, a place where rain falls up instead of down.

Despite these problems, courts sometimes, however reluctantly, take the responsibilities of lawyers seriously, although not often and never with the passion that courts speak of rights. Blinded by rights rhetoric in the case of vulnerable clients, courts are easily persuaded that their job is done, that obligation will somehow take care of itself, that the petty matter of lawyer obligation cannot dictate the outcome of the struggle between individual and state or even be allowed to speak after the outcome of that struggle has been determined. That is how we get looking glass ethics.

The solution is not to get rid of the rights the law provides these vulnerable clients. In our world, with its understanding of rights, such a move would signal precisely the wrong thing. The answer is to understand that rights are not a substitute for obligations, to reinstate the tort remedies, to enliven the disciplinary process, and to express commitment to obligations by using them to contour rights. For any of this to happen, we first need to realize how nonsensical a law our rights jurisprudence has created. It is a law that imposes fewer obligations where the need is greatest, that guarantees the least protection for the most vulnerable of clients. That end is inconsistent with what we set out to do when we confer a right and, thus, the result may be critiqued from within the rights framework itself. 
An internal critique is, however, not enough. The inherent weakness of rights theory is an important and pervasive problem, not only in the little corner of concern that has served as the vehicle for this discussion, but also everywhere where basic needs remain unmet. For all those who believe that a just society provides more than freedom, the inherent weakness of rights theory presents a formidable obstacle to achieving justice. To address this weakness, we need more than an internal critique. We need a serious jurisprudence of obligation.

Ethics, legal ethics and judicial ethics in particular, is the natural starting point for such an effort. In legal and judicial ethics we find the possibility of dignifying obligations that are enforceable as law. Adrift in a legal world obsessed with rights, these areas of study have long been and remain the step-children of American legal thought. They are considered soft, secondary subjects not worthy of the attention of our most serious scholars. They are law that is not quite law because how could dignifying obligation be mandatory like law? And ethics that is not quite ethics because how could mandatory obligation like law be worthy of the name of ethics? These subjects posit a possibility not found elsewhere in law, a possible normative understanding we need to nurture and explore, not ignore or mock. By treating legal obligations that dignify as important features in our jurisprudential vision, we may not only be able to walk back through the looking glass. We may be able to bring with us new possibilities of achieving a more just world.

Alice Woolley \& W. Bradley Wendel, Legal Ethics and Moral Character, 23 Geo. J.L. Ethics 1065 (2010)

The most familiar debate in legal ethics involves a critique of theories, such as those of Fried, Simon, and Luban, in terms of their attractiveness as maxims of action. Simon's act prescriptions, for example, can be critiqued on the basis that they require a reasoning style that is at odds with the expectations of clients, and may result in the disregarding of client interests if they happen not to coincide with the discretionary judgment of the lawyer in question. Moreover, the act prescriptions of Simon's theory give insufficient weight to the procedural norms and ideals which justice arguably constitutes. His theory is relentlessly focused on substantive justice. This position leaves little room to recognize the possibility that what we call justice, and what we as lawyers should aim for, is what results from the procedures of the legal system and is not a concept that identifiably exists outside of those procedures and constraints. On the other hand, Fried's act prescriptions can be critiqued on the basis that they result in the perpetuation of distributive injustices, simply cementing existing social disparities. The critiques offered from a dispositional or psychological perspective are, however, of a different nature. The point here is not to ask whether the acts prescribed, if accomplished, would be desirable. But is to ask whether the type of lawyer who would be able to accomplish those acts in a given case is the type of lawyer we would want to have across every case, across the totality of the legal system as a whole. Further, it is to ask whether, even if desirable, the type of lawyer posited is realistic. Simon and Luban, for example, rely on lawyers to be relentlessly focused on justice or morality. This may be how we think lawyers should be, but is it the equivalent of wanting basketball players who are 12 feet tall? 
Each theory faces some uncomfortable questions when analyzed in this way. For Simon, the major challenge for his theory is that the maverick nature of Simon's lawyer has an obvious maladaptive version. In its (perhaps) best conception, it may simply make the lawyer more like a critic or academic and less like an advocate. In its worst conception it turns the lawyer into the equivalent of a whistleblower. As sociological studies of whistleblowers show, the maladaptive version of Simon's lawyer is not the "hysterical malcontent" of stereotypes, but someone for whom individuality is a defining fact of life. The "unassimilated individual" is not necessarily the best building block for a stable and functional organizational culture. Research by business ethicists and social psychologists shows that organizational cultures may be much more important, as a determinant of behavior, than the personal characteristics of individuals within the organization. Individuals are susceptible to biases and other cognitive failings, which predictably cause certain kinds of dysfunctions within organizations. Organizational cultures can be designed to blunt the impact of some of these psychological processes. Assuming that it is possible to reform the cultures of law firms, government offices, and in-house legal departments, the last thing one would want in a lawyer is a disposition to regard established rules and procedures as optional guidelines, to be disregarded whenever the lawyer believed justice or morality would be better served. The whole point of rules and procedures is to supplant individual decision-making, presumably because we have reason to believe that following the procedures will do better in the long run, as compared with relying on the judgment of individuals.

In addition, it is not obvious that adopting the personality of the whistleblower or outlier is something that people can do as an act of choice or will. Being willing to question and stand outside the institutional, cultural, and personal structures within which you work may require exceptional fearlessness as to the consequences of your actions, a willingness to fight instead of conciliate those with whom one spends a great deal of time, and a preference for autonomy in judgment over relationships with others. Particularly given the social stigmatization suffered by many whistleblowers, it is unlikely that most individuals within an organization would want to be mavericks. It seems odd to ground a general theory of ethical lawyering, intended to be applicable to all lawyers, on a complex of personal characteristics that occurs only infrequently in the form of exceptionally courageous and individualistic people.

This critique is similarly applicable to Luban's lawyer. As noted, discourses of morality are highly disfavored in legal practice. The ability to swim upstream against those norms either requires an agility in negotiating human relations, which may not be realistic to expect across the population as a whole, or an unwillingness to "go along and get along" which may be undesirable and dysfunctional in institutions which are generally good rather than generally corrupt. Luban worries a great deal about the possibility of organizations socializing individuals into acquiescing in great evils - what may be called the Eichmann problem. In response, he emphasizes relying on personal moral tripwires. Lawyers should establish in advance lines they will not cross, and be willing to walk away from a situation that seems to be pushing them to cross these lines. The experimental evidence showing how easily individuals may be socialized into corruption is both what pushes Luban to recommend this all-or-nothing solution and the grounds for criticizing his 
reliance on integrity as a way of ensuring ethical conduct by lawyers. If organizations are indeed such a powerful socializing force, then it would appear futile to regulate organizational wrongdoing by insisting on right conduct by individuals. Instead, it would be more effective to regulate organizations directly to ensure that they maintain healthy ethical cultures.

Yet another issue for Luban is his reliance on possession of moral character. This is where the critique of social psychology and the observation of the relationship between conduct and circumstances has the most bite. While psychological personality has, as noted, some ability to withstand the situationality critique, moral character has relatively little. Moral character seems neither identifiable nor predictive of conduct. That is to say, managers of an organization might do well to try to select employees on the basis of "Big Five" personality characteristics such as agreeableness, stability, or conscientiousness. It would be less helpful, and possibly even counterproductive, to choose on the basis of perceptions that a candidate is honest or loyal. One must consider the possibility of committing the fundamental attribution error, and confusing responses to situational pressures with cross-situationally stable moral dispositions.

For Fried the issues are different, and relate to the problem of the maladaptive version of the morally skeptical lawyer, who loses her moral compass altogether, pursuing victory for her client at any cost. Fried's ideal of being a special purpose friend is attractive on its face, but does not carry over completely to the lawyering context. As many of Fried's critics have pointed out, friends are not privileged to do nasty things for each other merely because they are friends. Moreover, lawyers sometimes treat their clients in ways they would never treat their friends - for example, refusing to help a client once he runs out of money. Indeed, some lawyers learn to be hired guns rather than friends. An obviously extreme version of this is the New Jersey lawyer who (allegedly) arranged for the murder of witnesses to secure acquittal for his clients on the basis of "no witnesses, no case." This is not to suggest that every lawyer who embraces zealous advocacy so loses his moral bearings as to view murder as an acceptable litigation strategy, but is to suggest the fine li that exists between reserving moral judgment and losing the capacity for it. Critics of Fried's metaphor complain that he drained the morally attractive features out of friendship in order to make it work as an analogy for representing clients. By doing that, he made it difficult to find anything of real moral value in the lawyer-client relationship. Thus, as Postema suggests, a lawyer feels torn between her personal moral commitments and the requirements of role, and thus begins to identify with a stance of detachment from all normatively significant commitments.

\section{Questions:}

1. How do these different theories of legal ethics conceptualize the attorney "role morality" differently?

2. Reflecting on the different subjects discussed in this casebook, do you think any of these concepts of legal ethics influenced the way lawyers and judges acted?

3. How might adopting one of these theories of legal ethics affect legal decisionmaking? 
When peace, like a river, attendeth my way, when sorrows like sea billows roll; whatever my lot, thou hast taught me to say, it is well, it is well with my soul. ${ }^{134}$

${ }^{134}$ Horatio G. Spafford, It Is Well with My Soul (1873). 